\title{
Photonuclear Data - Abstract Sheets
} $1955-1982$

Volume [X (Nickal - Galium)

\section{US DEPARTMENT OF COMMMEF.CE}

Natmral Zureat! of Standaros

Nistonal Vheasuremen: Laboratcry

Cer:er ior Risiaicn Resajich

Galtiersburg. MD 20899

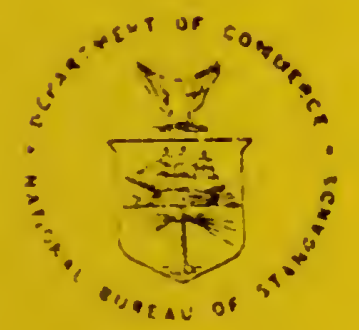

11.S. DEDARTMENT OF COMMERCE

NaTIONAL ELUEALI OF STANOARDS 


$$
\infty
$$


NBSIR 83-2742

PHOTONUCLEAR DATA - ABSTRACT SHEETS

$1955-1982$

VOLUME IX (NICKEL - GALLIUM)

E. G. Fuller, Henry Gerstenberg

U.S. DEPARTMENT OF COMMERCE

National Bureau of Standards

National Measurement Laboratory

Center for Radiation Research

Gaithersburg, MD 20899

August 1985

U.S. DEPARTMENT OF COMMERCE, Malcolm Baldrige, Secretary NATIONAL BUREAU OF STANDARDS, Ernest Ambler, Director 


\section{TABLE OF COIVEY!TS}

Table of Contents................. . . i

Introduction. . . . . . . . . . . . . . . 1

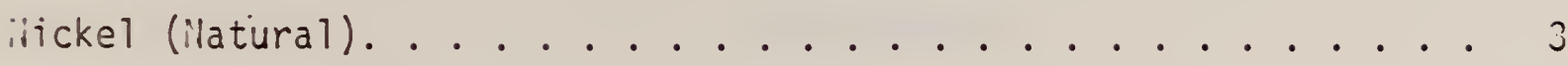

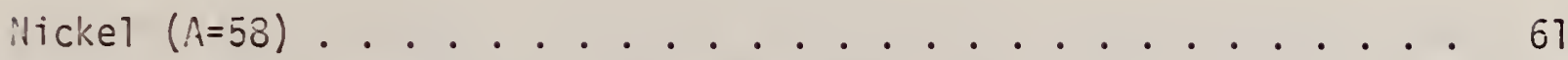

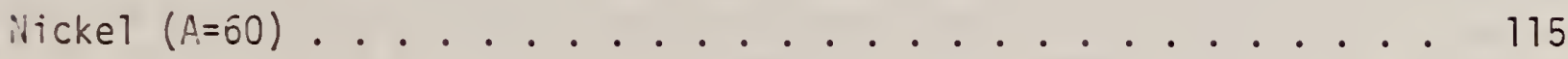

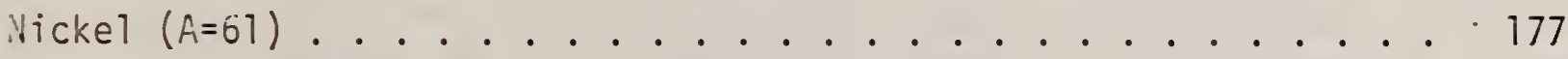

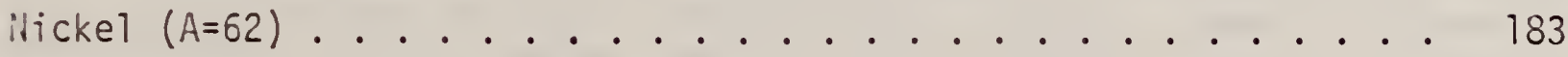

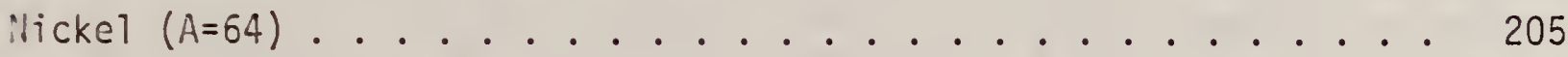

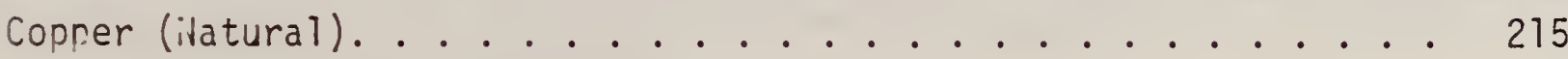

Copper $(A=59)$. . . . . . . . . . . . . 325

Copper $(A=60)$. . . . . . . . . . . . . . . 329

Copper $(A=61) \ldots . . \ldots 333$

Copper $(A=[3)$. . . . . . . . . . . . 337

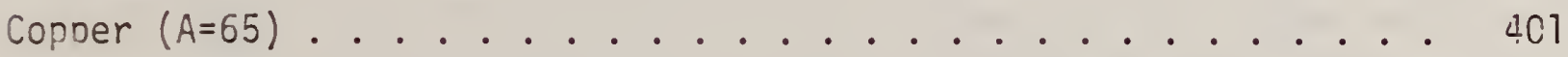

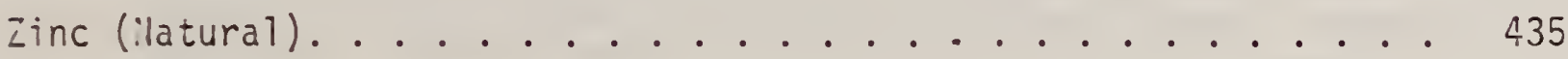

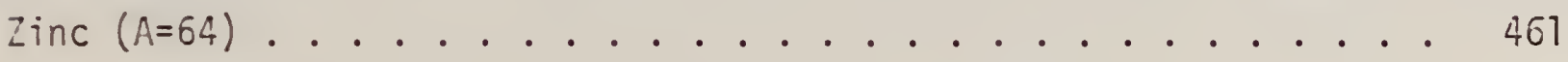

$\operatorname{Zinc}(A=66)$.......................... 507

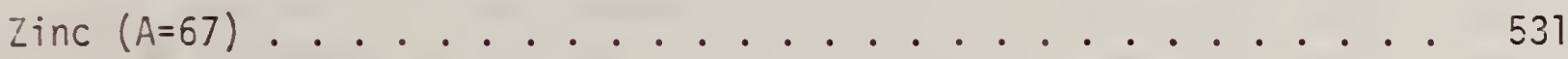

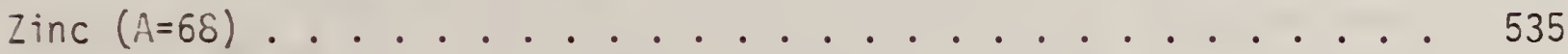

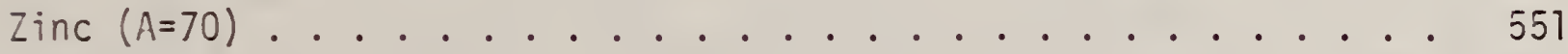

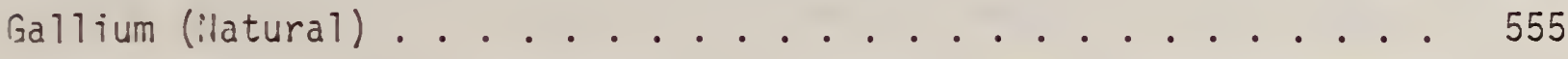

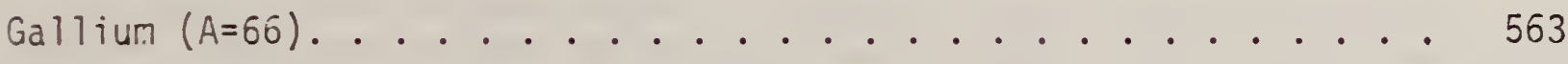

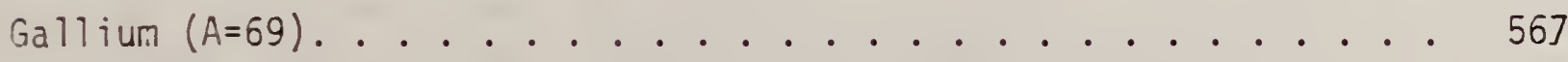

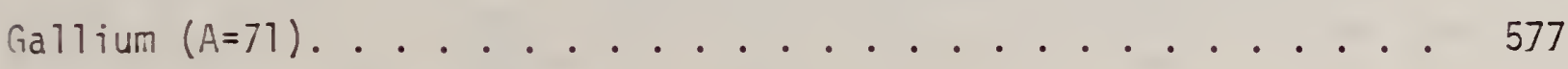

Definitions of Abbreviations and Symbols. . . . . . . . . 585 


\section{Introduction}

As used in connection with this collection of data-abstract sheets, the term photonuclear data is taken to mean any data leading to information on the electromagnetic matrix element between the ground state and excitedstates of a given nuclide. The most common types of reactions included in this compilation are: $\left(e, e^{\prime}\right),(\gamma, \gamma)$, $\left(\gamma, \gamma^{\prime}\right),(\gamma, n),(\gamma, p)$, etc. as well as ground-state particle capture reactions, e.g. $\left(\alpha, y_{0}\right)$. Two reactions which fit the matrix element criterion are not included in the compilation because of their rather special nature. These are heavy particle Coulomb excitation and the thermal neutron capture reaction $\left(n, \gamma_{0}\right)$. While the energy region of particular interest extends from 0 to $150 \mathrm{MeV}$, papers are indexed which report measurements in the region from $150 \mathrm{MeV}$ to $4 \mathrm{GeV}$. Most of the experiments listed are concerned with the excitation energy range from 8 to $30 \mathrm{MeV}$, the region of the photonuclear giant resonance.

The hierarchical grouping of the photonuclear data-abstract sheets within the file is by: 1. Target Element, 2. Target Isotope, and 3. by the Bibliographic ReferenceCode assigned to the paper from which the data on the sheet were abstracted. In this file, colored pages are used to mark the beginning and end of the sheets for each chemical element. A brief historical sketch of the element is given on the divider sheet marking the start of each section; the information for this sketch was derived from references such as the Encyclopaedia Britannica. In those cases where the sheets for a given element make up a major part of a volume, colored pages are also used to delineate sections pertaining to the individual isotopes of the element. Each of the sections of the file, as delineated by two colored divider sheets, represents a 27 year history of the study of electromagnetic interactions in either a specific nuclide or a specifc element.

The data-abstract sheets are filed under the element and/or isotope in which the ground-state electromagnetic transition takes place. For example, the abstract sheet for a total neutron yield measurement for a naturally occurring copper sample would appear in the elemental section of the copper file. On the other hand, a measurement of the ${ }^{62} \mathrm{Cu} 9.73$ minute positron activity produced in the same sample by photons with energies below the three-neutron separation energy for $65 \mathrm{Cu}$ ( $28.68 \mathrm{MeV}$ ) would be filed with the sheets for $63 \mathrm{Cu}$. Similarly a measurement of the ground-state neutron capture cross section in $12 \mathrm{C}$ would be filed under $13 \mathrm{C}$ while the corresponding ground-state alpha-particle capture cross section would be filed under 160 .

At the end of this volume there is a master list of the abbreviations that have been used in the index section of the abstract sheets. The listings are those used in the final published index, Photonuclear Data Index, 1973-1981, NBSIR 82-2543, issued in August 1982 by the U.S. Department of Commerce, National Bureau of Standards, Washington, DC 20234. In some cases two notations are entered for the same quantity. The second entry is the abbreviation that was used in one or more of the earlier published editions of the index. 


\section{IITCLEL}

$z=28$

An alloy of nickel called packfong was used by the Chinese long before the metal was known in Europe. A heavy, reddish brown ore, of ten found covered with green spots or stains, was used in Germany to color glass green; the miners called the sibstance Kupfernickel meaning copper demon. The ore resembled copper in color but yielded a brittle unfamiliar product that caused the copper miners considerable trouble.

Axel Fredrik Cronstedt was the first to discover nickel; he worked as a metallurgist in the Swedish Bureau of Mines. In 1751 Cronstedt was investigating a new mineral from the cobolt mines and placed a piece of iron in an acid solution of the ore expecting to see a copper deposit on it. To his great surprise, he was unable to secure a deposit of and kindthe ore nicolite contaired no copper. Futher work yielded the metal. After studying the physical, chemical and magnetic properties of the metal, he announced in the Memoirs of the Stockholm Academiy that he had discovered a new metal. 
Ref. Z. Dlouhý, V. Petržilka, M. Rozkoŭ

Czech. I. Phys. 2, 193 (1955)

Menod Li $(p, \gamma)$ source; nuclear emulsions; G-M counter; $C u 63(\gamma, n)$ reaction;

flux calibration

\begin{tabular}{c|c|c} 
Elem. Sym. & A & $z$ \\
Ni & & 28 \\
\hline $\begin{array}{c}\text { Ref. No. Dl } \\
\text { N5 }\end{array}$ & EGF
\end{tabular}

\begin{tabular}{|c|c|c|c|c|c|c|}
\hline Reaction & $E$ or $J E$ & $E_{0}$ & $\Gamma$ & $\int \sigma d E$ & $J \pi$ & Notes \\
\hline $\mathrm{Ni}(\gamma, \mathrm{p})$ & 17.6 & & - & & & $\begin{array}{l}\text { Monitor in terms of counts on G-M } \\
\text { counter which had Deen calibrated in } \\
\text { terms of } \mathrm{Cu}^{65}(\gamma, \mathrm{n}) \mathrm{Cu}^{62} \text { (absolute } \\
\text { counting and effective } \sigma \text { I.i }=7.75 \\
\mathrm{X} 10^{-26} \pm 15 \% \mathrm{~cm}^{2} \text { given by Shimigu: } \\
\text { Mem of Un. Kyoto } 25,19+(1949) \text { ) } \\
\text { Plates used to detect protons } \\
\text { Li } \sigma=8 \pm 4 \times 10^{-25} \mathrm{~cm}^{2}\end{array}$ \\
\hline
\end{tabular}
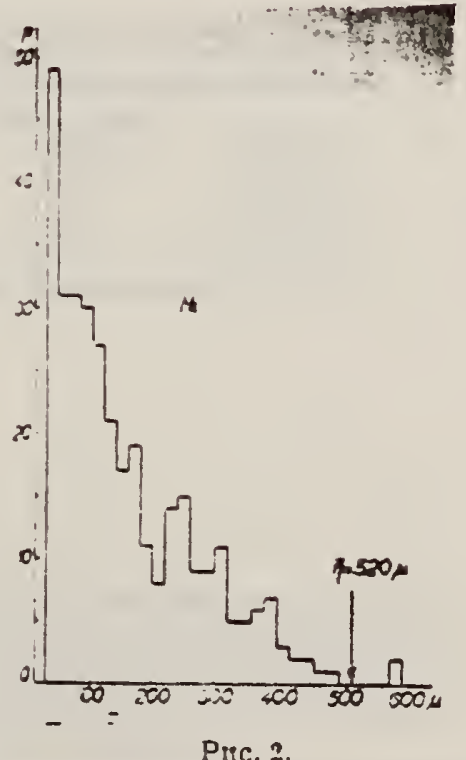

Pric. 2. 
Synchrotron; ZnS counter; ion chamber

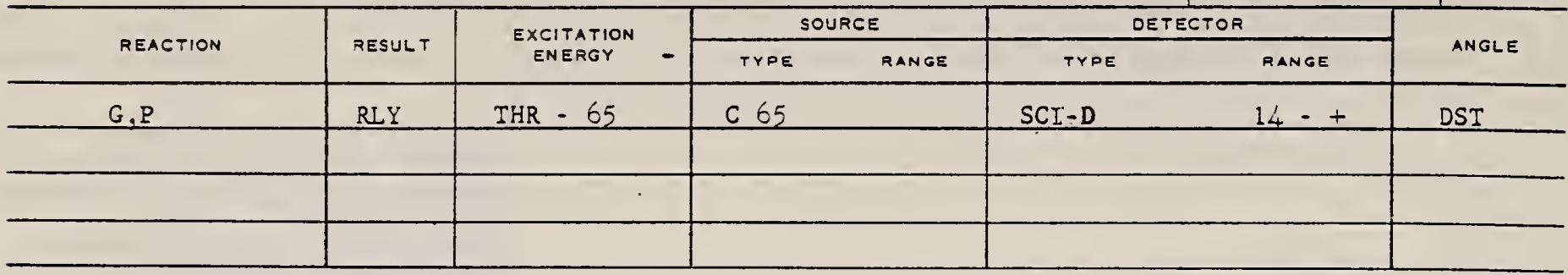

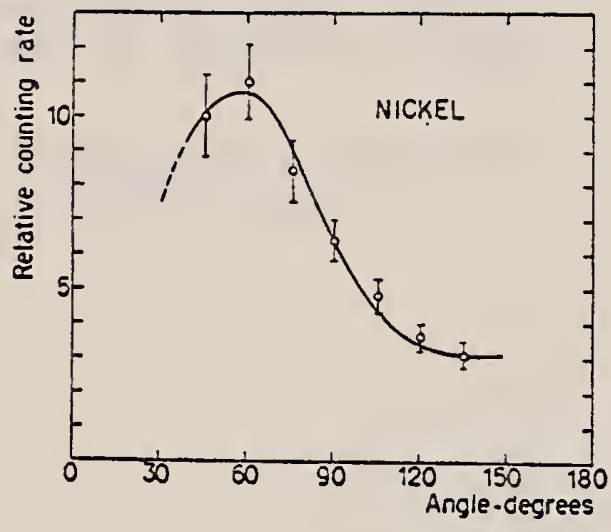

FIG. 5. The angular distributions of protons with an energy above $14 \mathrm{Mev}$.

TABLE I. Target thickness and the constants $a$ and $b$ in the angular distribution curve $a+(\sin \theta+b \sin \theta \cos \theta)^{3}$

\begin{tabular}{lccc}
\hline Element & $\begin{array}{c}\text { Tarzet thickness } \\
\mathrm{mg} / \mathrm{cm}^{2}\end{array}$ & $a$ & $b$ \\
\hline Carbon & 182 & 0.32 & 0.80 \\
Aluminum & 274 & 0.58 & 1.35 \\
Jickel & 352 & 0.94 & 1.45 \\
Molybdenum & 295 & 0.62 & 2.00 \\
\hline
\end{tabular}

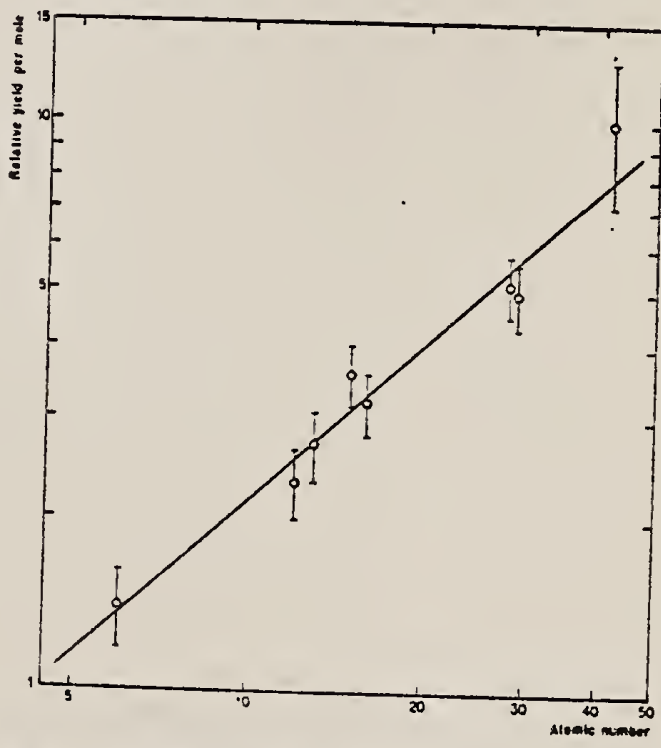

FIG. 10. The relative yield per mole for protons above $14 \mathrm{Me}$ as a function of the atomic number. 
Rei. E.G. Fuller, E. Hayward

Phys. Rev. 101, 692 (1956)

Method Betatron; photon scattering; NaI spectrometer

\begin{tabular}{|c|c|c} 
Elem. Sym. & A & $z$ \\
Ni & & 28 \\
\hline $\begin{aligned} \text { Ref. No. } \\
56 \text { Fu 1 }\end{aligned}$ & NVB \\
\hline
\end{tabular}

\begin{tabular}{|c|c|c|c|c|c|c|}
\hline Reaction & $E$ or $J E$ & $E_{0}$ & $\Gamma$ & $\int \sigma d E$ & $\mathrm{~J} \pi$ & Noces \\
\hline $\mathrm{si}(\gamma, \gamma)$ & $\begin{array}{c}\text { Bremss. } \\
4-40\end{array}$ & & & & & $\begin{array}{l}\text { Detector at } 120^{\circ} \text {. } \\
\text { Cross sections given here are } 13 \% \text { too } \\
\text { high due to erroneous cos } 3 \text { factor in } \\
\text { denominator of Eq. } 5 \text {. [See footnote } \\
8 \text { in Phys. Rev. } 106,993(1957)] \text {. }\end{array}$ \\
\hline
\end{tabular}

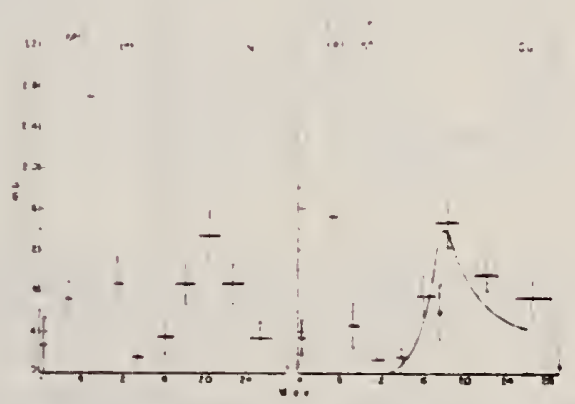

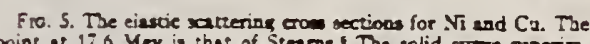
poine at $17.6 \mathrm{Mev}$ is that of Stearas." The solid curve superim. posed of the CI lats is the scatteriag cros section caicuizied irom the dispersuon reintion by subsurutung for $\sigma_{0}(E)$ in Eq. (7) the ' r) cross section' mulcipied by the zatio of the intal prticle neld to the neutwon yield. The ooen circles on the verical use idicale the mingurude of the Thomson crose section for $Z$ iree protons scalleing cobereasly. 
Ref. W.H. Hartley, W.E. Stephens, E.J. Winhold

Phys. Rev. 104, 178 (1956)

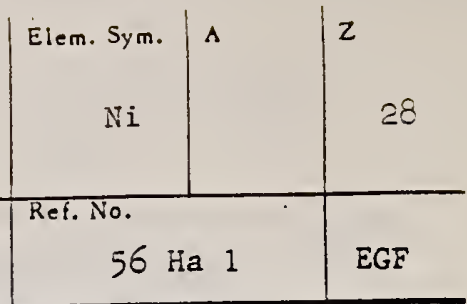

Ii $(p, \gamma)$ source, $480 \mathrm{kev}$ protons.

$56 \mathrm{Ha} 1$

Notes

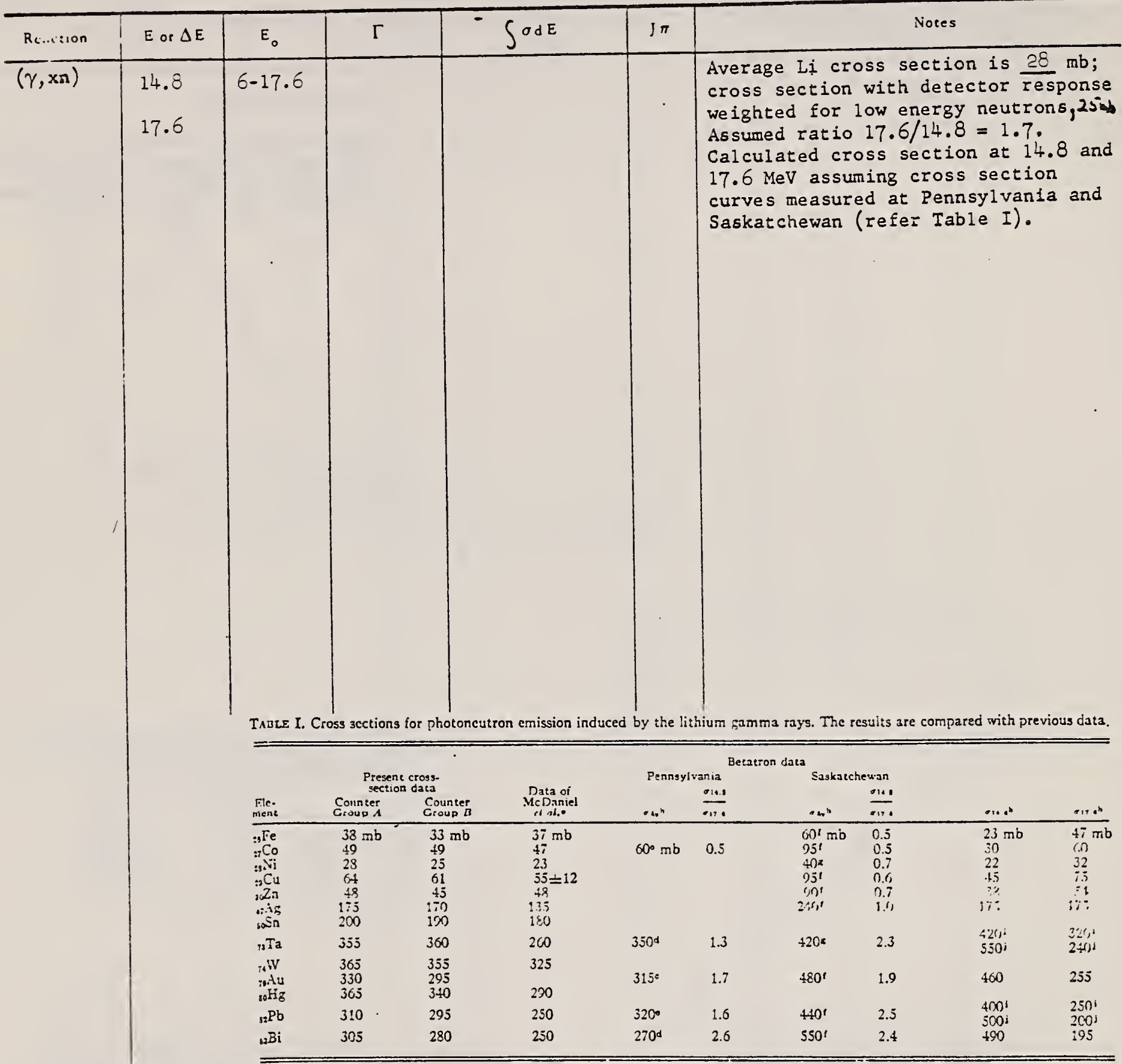

- See reference 3.

iverage of $14 . \dot{3}$ - and $17.6-\mathrm{Mev}$ cross sections weighted with relative intensitles of the lithlum gamma-ray lines.

R. Yiathans. Ph.D. thesis. University of Pennsylvania, 1954 (un published).

J. Halpern (private communication).

1 See reierence 23.

Srnarate crosg sections at 14.8 and 17.6 Mev as obtained imm Grnup $A$ data and 14.8/17.6 betatron cross-section ratios.

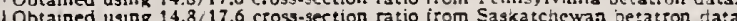


Ref. E. Lejkin, R. Osokina, B. Ratner

玉1 Suovo Cimento 2 Suppl. 1, 105 (1956)

Mechod $30.5 \mathrm{MeV}$ Bremss. synchrotron; emulsions; ion chamber monitor

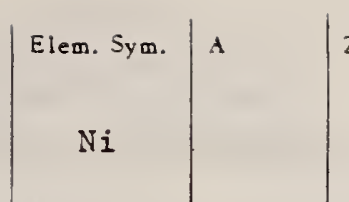

$i^{*}$ 28

\section{Wethod 30.5 YeV Bremss. symchrotron; emulsions; ion chamer monitor}

Ref. No.

56 Le 1

EGF

\begin{tabular}{l|c|c|c|c|c|c}
\hline Reaction & $E$ or $\Delta E$ & $E_{0}$ & $\Gamma^{-}$ & $\int \sigma d E$ & $j \pi$ & Nores \\
\hline$(\gamma, p)$ & Bremss. & & & & & Assuming shape for $\sigma(\gamma, p)[$ Ha]pern and
\end{tabular}

21.5

25.5

28.0

24.0

Mann, Phys. Rev. 83, 370 (1951)] gives peak $\sigma(\gamma, p)=9.0 \times 10-26 \mathrm{~cm}^{2} \pm 30 \%$. At $E_{\gamma}=25.5 \mathrm{MeV}$ ratio of proton. yields $\mathrm{Ni} / \mathrm{Cu}=1.76 \pm 10 \%$.

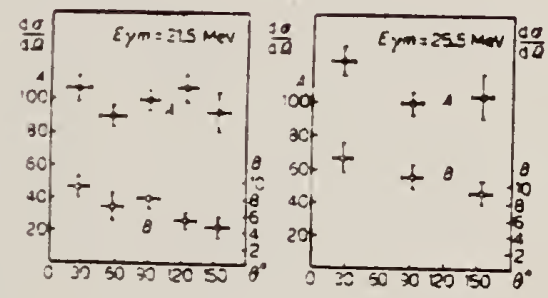

Figure 7: Angular distribution oz photoprotons from nickel. do/d relative cross section: $A$, for $e_{p}$ $\geq 3 \mathrm{MeV}$ protons; $\mathrm{B}$, for $e_{p} \geq 10 \mathrm{MeV}$ protons. The cross section for the angle $\theta=90^{\circ}$ is taken equal 100 . 


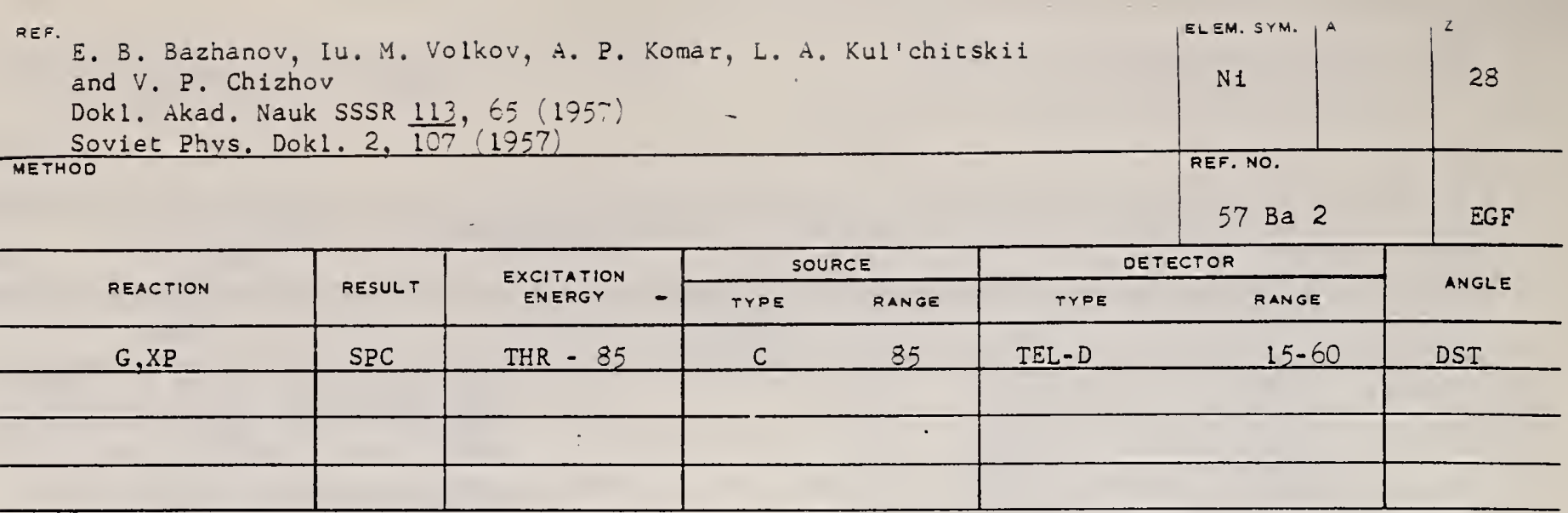

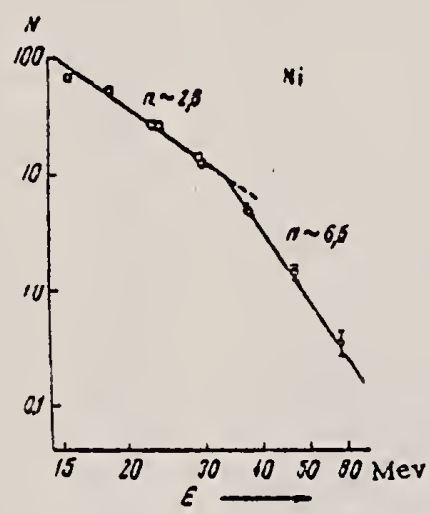

Fig. 1. Energy distribution of photoprotons from Ni. The vertical axis gives the number of protons in a $1 \mathrm{Mev}$ interval per monitor unit, plotted in arbitrary units. Only the statistical errors are indicated.

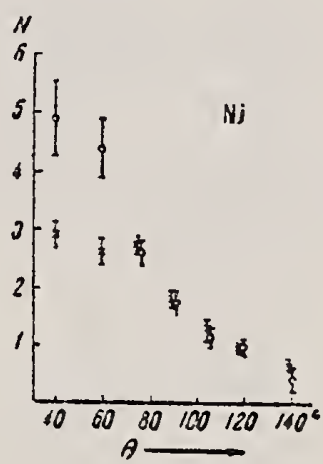

Fig. 3. Angular distibutions of photoprotons from Ni. T..e crosses represent 20-33 Mcv protons; die open carcles represent 33-65 Mev protons. The errors aie statistical. 
REF. E. Bobard, G. Boulegue, and P. Chanson

Compt. Rend. 24, 1761 (1957)

$-$

\begin{tabular}{|c|c|c|c|c|c|c|c|}
\hline WETMOD & & & $\cdot$ & & & $\begin{array}{l}\text { REF. NO. } \\
57 \text { BO } 1\end{array}$ & $E G F$ \\
\hline \multirow[b]{2}{*}{ REACTION } & \multirow[b]{2}{*}{ RESULT } & \multirow{2}{*}{$\begin{array}{l}\text { EXCITATION } \\
\text { ENERGY }\end{array}$} & \multicolumn{2}{|c|}{ SOURCE } & \multicolumn{2}{|c|}{ DETECTOR } & \multirow[b]{2}{*}{ ANGLE } \\
\hline & & & TYPE & RANGE & TYPE & RANGE & \\
\hline$G, A$ & SPC & THR -30 & $\mathrm{C}$ & 31 & EMU-D & $5-15$ & DST \\
\hline & & & & & & & \\
\hline & & & & & & & \\
\hline & & & & & & & \\
\hline
\end{tabular}

Yield per milligram per roentgen Cu 0.36 , Ni 0.99 , Al 1.15 for $30.5 \mathrm{MeV}$ bremstrahlung.

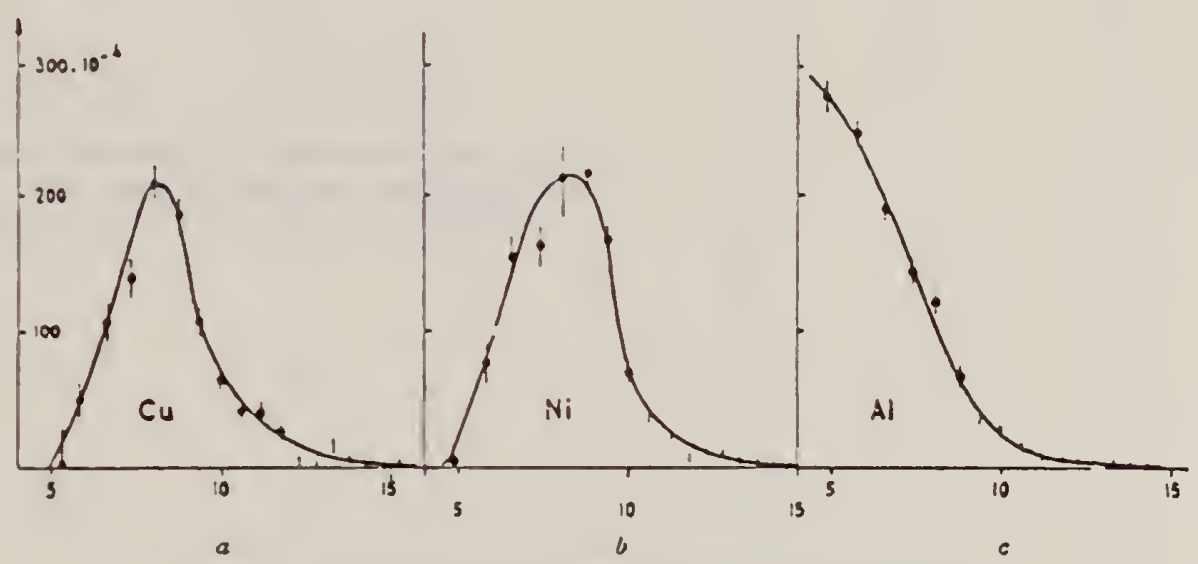

Fig. 2. - Xomble de particules a,ingister:idian/Röntgen/intervalle de i MeV. 
Ref. B.M. Spicer, E.G. Muirhead, G.G. Shute Australian J. Phys. 10, 217 (1957)

\begin{tabular}{l|l|l} 
& Ni & 28 \\
\hline Method $17.5 \mathrm{MeV}$ Bremss.; proton yield; angular distribution; emulsion & $\begin{array}{r}\text { Ref. No. } \\
57 \text { Sp } 1\end{array}$ & EGF \\
\hline
\end{tabular}

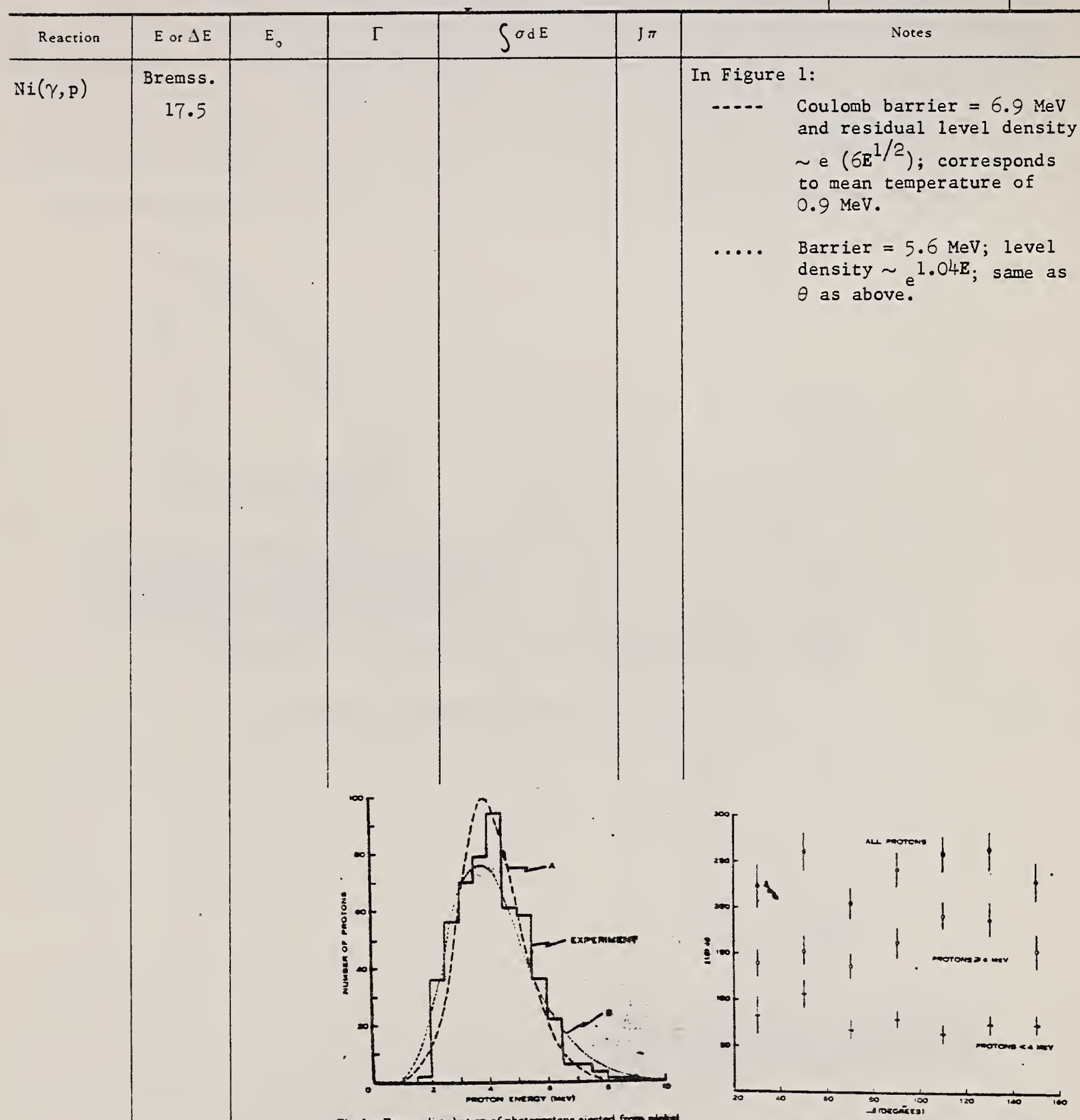

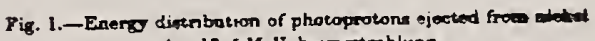
by $17.5 \mathrm{MoV}$ bremertrahluas.

Fig. 2.-Anguier distnbution of photoprotosi from alckel. 
E. B. Bazhanov, Iu. M. Volkov, and L. A. Kul'Chitskii

J. Exptl. Theoret. Phys. (USSR) 35, 322 (195

Soviet Phvs. JEIP $35,224(1958)$

\begin{tabular}{|c|c|c|c|c|c|c|c|}
\hline \multirow{2}{*}{ REACTION } & \multirow{2}{*}{ RESULT } & \multirow{2}{*}{$\begin{array}{c}\text { EXCITATION } \\
\text { ETERGY }\end{array}$} & \multicolumn{2}{|c|}{ SOURCE } & \multicolumn{2}{|c|}{ OETECTOR } & \multirow{2}{*}{ ANGLE } \\
\hline & & & TYPE & RANGE & TYPE & RANGE & \\
\hline$G, X P$ & SPC & THR - 85 & C & 85 & TEL-D & $13-40$ & DST \\
\hline & & & & & & & \\
\hline & & & & & & & \\
\hline & & & & & & & \\
\hline
\end{tabular}
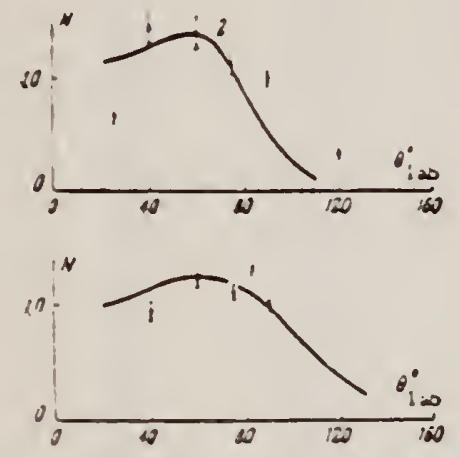

FIG. 4. Angular cistribuisons of pinotoprotons from vi. The solid curves atve the sesulis of calculation. Oniy statisical errors are shown. i) $\vec{E}_{p}=(3.7-21.5 ; 2) E_{p}=21.5-33.3$ iiev. 
Ref. M.E. Toms, J. McElhinney

Phys. Rev. 111, 561 (1958)
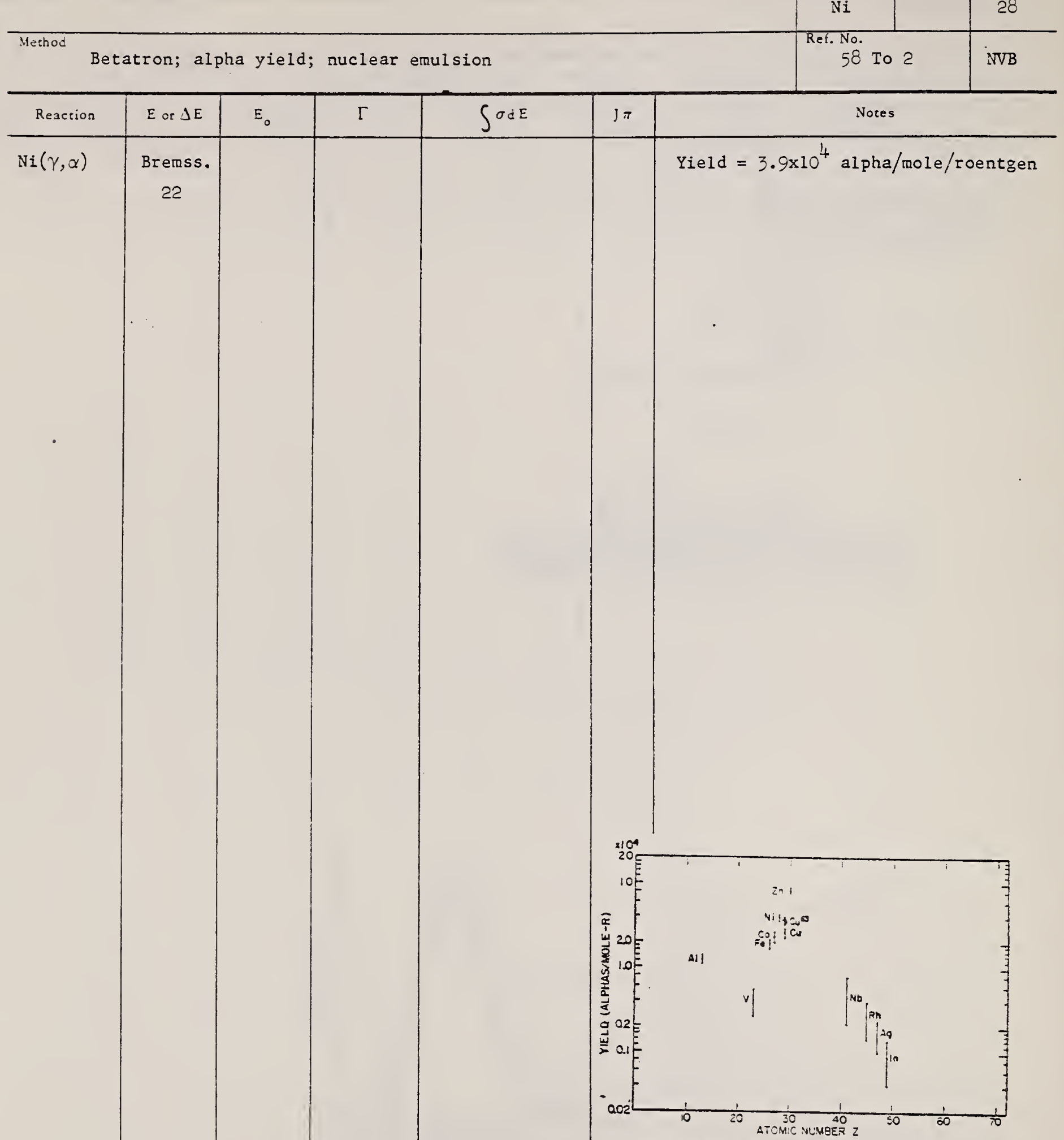

FIG. 8. Photo-alpha yields plotted agäinst atomic numbers for the expusures of the survey. 
Ret. V.?. Chiziov

Zhur. Essp. i Teoret. Fiz. 38, 809_(1960)

Soviet Phys. JETP 11, 587 (1960)

SO MeV Bremsstrablung; scint1llator counter telescopo

\begin{tabular}{|c|c|c|}
\hline $\begin{array}{c}\text { Elem. Sym. } \\
\mathrm{Ni}\end{array}$ & A & $\begin{array}{l}z \\
28\end{array}$ \\
\hline $\begin{array}{r}\text { Ret. No. } \\
60 \mathrm{ch}\end{array}$ & & $\mathrm{J}$ HसH \\
\hline
\end{tabular}

\begin{tabular}{|c|c|c|c|c|c|c|}
\hline Reaction & $E$ or $\Delta E$ & $E_{0}$ & $\Gamma^{-}$ & $\int \sigma d \varepsilon$ & $3 \pi$ & Notes \\
\hline $\begin{array}{l}\mathrm{Ni}(\gamma, \mathrm{p}) \\
\mathrm{Ni}(\gamma, \mathrm{d}) \\
\mathrm{Ni}(\gamma, \mathrm{r})\end{array}$ & & & & & & $\begin{array}{c}\text { Energy Range of particles detected: } \\
B_{d}-15.5-30 \mathrm{MeV} \\
B_{p}-15.5-30 \mathrm{MeV} \\
E_{t}-17-30 \mathrm{MeV}\end{array}$ \\
\hline
\end{tabular}

Ratios:

$$
\left.\begin{array}{l}
\sigma(\gamma, \mathrm{d}) / \sigma(\gamma, \mathrm{p}) \\
\sigma(\gamma, \mathrm{t}) / \dot{(}(\gamma, \mathrm{d})
\end{array}\right\} \text { at } \theta=90^{\circ}
$$

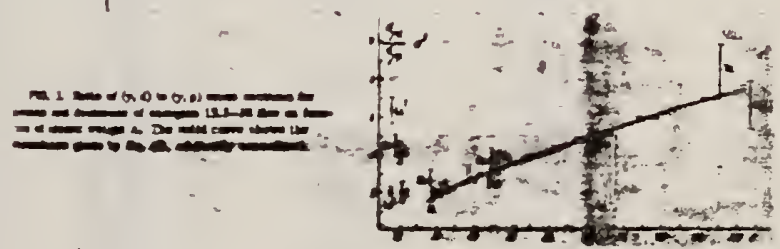

TABLE I

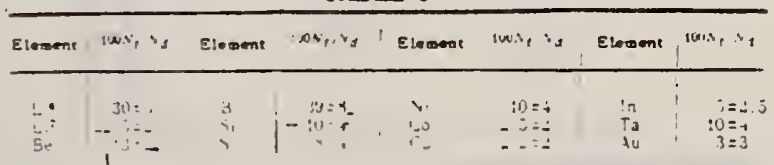




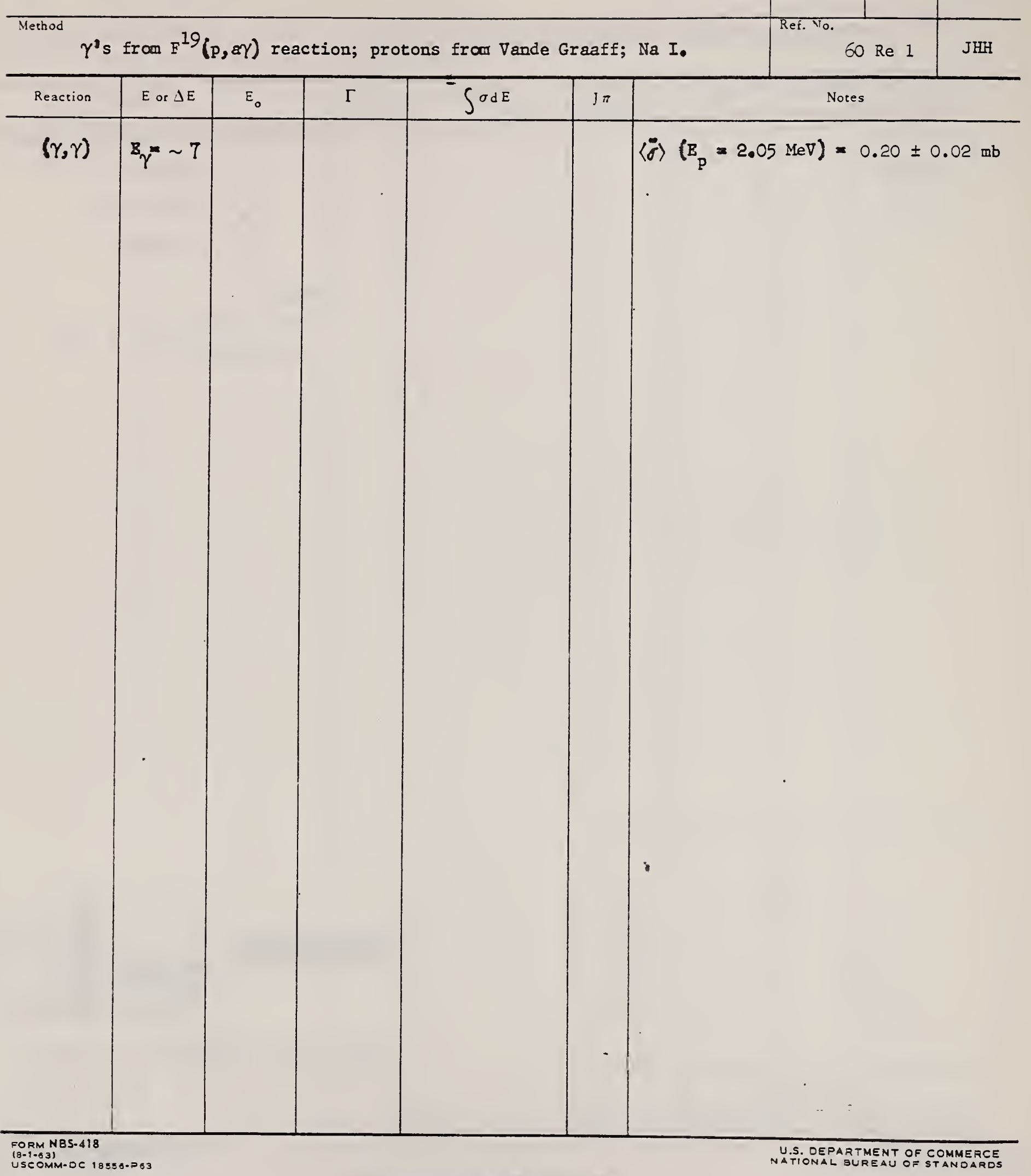


A.G. Bäker, R.G. McNeill

aii. J. Phys. 29, 1158 (ic, :

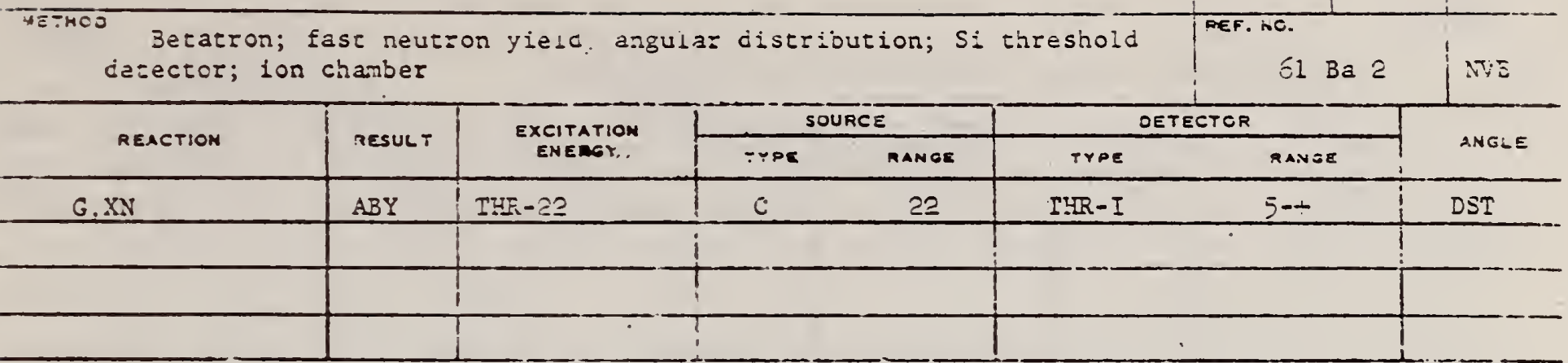

\section{In Tabie 4:}

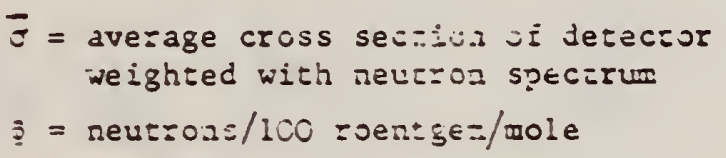

\begin{tabular}{|c|c|c|c|c|c|c|}
\hline$\stackrel{1}{1}$ & $\because 1$ & $\begin{array}{ll}111 \\
a_{1}\end{array}$ & IV & $\begin{array}{c}V \\
(\bar{\sigma} \phi) \times 10^{00}\end{array}$ & $\begin{array}{c}V_{i} \\
\phi_{\text {moul }}(22 \mathrm{~s} 3 \times) \times 10^{0}\end{array}$ & 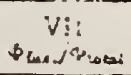 \\
\hline $\begin{array}{l}\text { Varadium } \\
\text { Chronium } \\
\text { Manganee } \\
\text { Iren } \\
\text { Cobale } \\
\text { Nickel } \\
\text { Copper } \\
\text { Arsenic } \\
\text { Rubidium } \\
\text { Serontium } \\
\text { Yetrium } \\
\text { Silver } \\
\text { Cadmium } \\
\text { lodine } \\
\text { Barium } \\
\text { Lanthanum } \\
\text { Cerium } \\
\text { Dysprosium } \\
\text { Tantalum } \\
\text { Tucgsien } \\
\text { Mercury } \\
\text { Lead } \\
\text { Bisnuth } \\
\text { Thorium } \\
\text { Uranium }\end{array}$ & 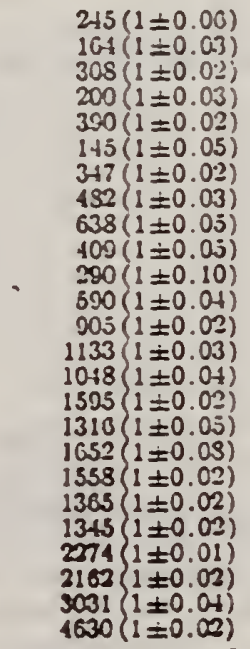 & $\begin{array}{l}0.01 \pm 0.08 \\
0.04 \pm 0.04 \\
0.07 \pm 0.03 \\
0.05=0.04 \\
0.08 \pm 0.03 \\
0.07 \pm 0.07 \\
0.05=0.03 \\
0.11=0.01 \\
0.13=0.06 \\
0.10 \pm 0.06 \\
0.08 \pm 0.12 \\
0.10=0.06 \\
0.02 \pm 0.0 \% \\
0.01=0.04 \\
0.10=0.06 \\
0.02=0.03 \\
0.05 \pm 0.06 \\
0.04 \pm 0.10 \\
0.04 \pm 0.03 \\
-0.07 \pm 0.03 \\
0.04 \pm 0.03 \\
0.02 \pm 0.02 \\
0.05 \pm 0.03 \\
0.06 \pm 0.05 \\
0.05 \pm 0.03\end{array}$ & 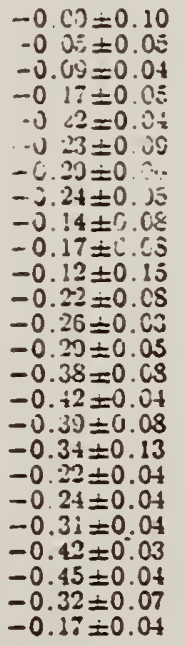 & 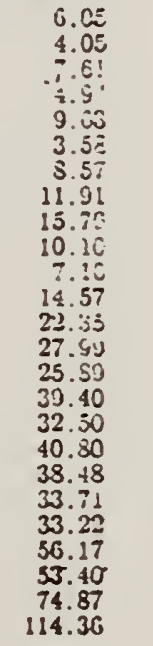 & $\begin{array}{l}0.21 \\
0.17 \\
0.25 \\
0.18 \\
0.26 \\
0.12 \\
0.30 \\
0.33 \\
\\
0.87 \\
\therefore .42 \\
1.04 \\
2.30 \\
2.72 \\
3.36 \\
.\end{array}$ & $\begin{array}{l}0.12 \\
0.16 \\
0.12 \\
0.11 \\
0.15 \\
0.12 \\
0.12 \\
c .15 \\
0.07 \\
0.08 \\
0.15 \\
0.08 \\
0.08 \\
0.06\end{array}$ \\
\hline
\end{tabular}

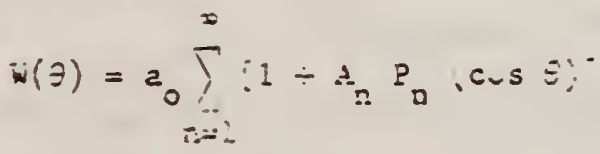

TABLE!V

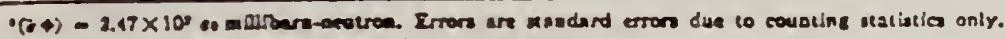


REF.

M. Masuda

J. Phys. Soc. 16, 1801 (1961)

Betatron; proton angular distribution; 2 nS scintillator

\begin{tabular}{|c|c|c|c|c|c|c|c|}
\hline \multirow{2}{*}{ REACTION } & \multirow{2}{*}{ RESULT } & \multirow{2}{*}{$\begin{array}{c}\text { EXCITATION } \\
\text { ENERGY }\end{array}$} & \multicolumn{2}{|c|}{ SOURCE } & \multicolumn{2}{|c|}{ DETECTOR } & \multirow{2}{*}{ ANGLE } \\
\hline & & & Trpe & RANGE & TYPE & RANGE & \\
\hline$G, X P$ & $R \phi x$ & $8-21$ & C & 18,21 & $S C I-I$ & $1-10$ & DST \\
\hline & & & & & & & \\
\hline & & & & & & & \\
\hline & & & & & & & \\
\hline
\end{tabular}

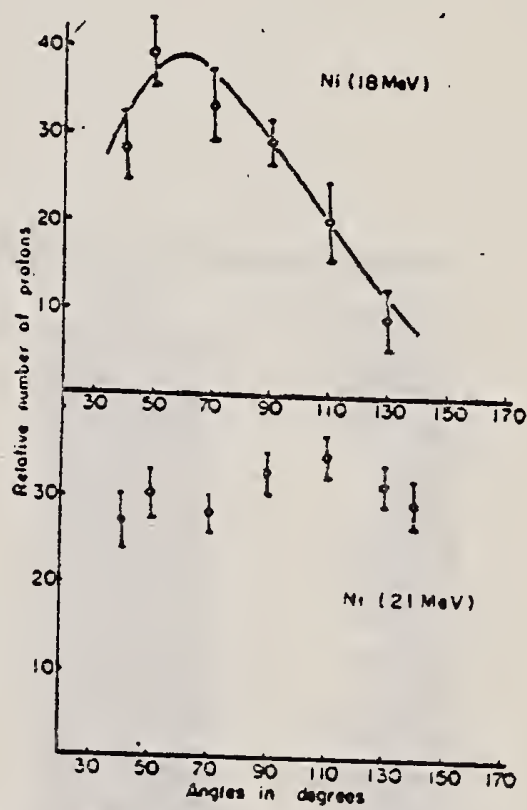

Fig. 7. Angular distribution of photo-protons from aickel. The results of the least aquare io tit the experimental plots with $18 \mathrm{MeV}$ bremastrain. lung are iescribed with the form,

$1+6.0 \sin ^{2} \alpha(1+0.87 \cos 0)^{2}$. 


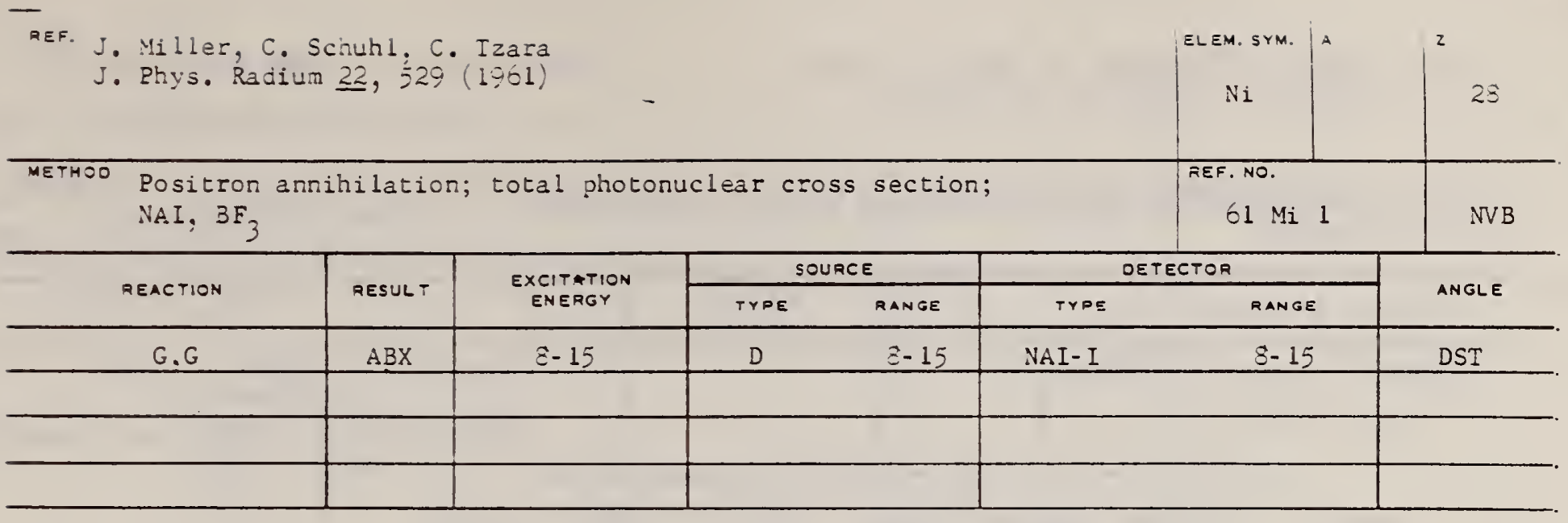
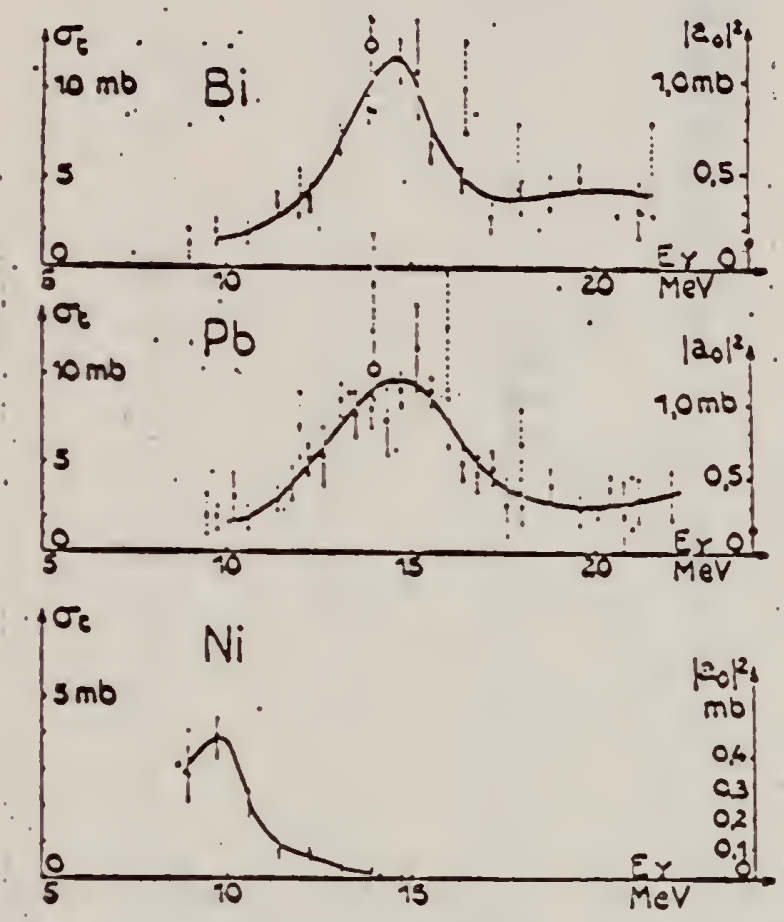

716. 8. - Section emcace totale do diriusion clastique et modulo au carté de l'amplitudo de difiusion vers l'avonh Ces do Ni, Pb of $3 i$.

Carcles vides : module au carrd cies implitudes de diffusion absorptive culculces a partor des sicier.s unewces $\sigma(y, n) \div 2 \sigma\left(y, 2 r_{0}\right) \div e(\because, n p)-\ldots$ iscule lis picmicre rástion intervient vers 114 lievi.

Cercles pleirs : limitrs $\left(\%, e^{3} /, W^{2}\right)^{2}$ de la section arreace

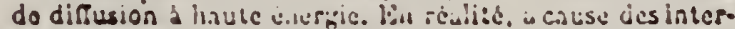
actions mesoniriturs de's nuclions el do l'incertitudo sur - la limile a hau:e ineräie do la diTusion, il vaudraitmieux parler do la section ciricace do dirtusion vers l'avans au dela de la risonance gusnic e: avant le souil pholoméso nique; on peut montice quo l'axpression

$$
\left(2 e^{2} / .4 c^{2}\right)^{\prime}(1+0.3 x)^{2}
$$

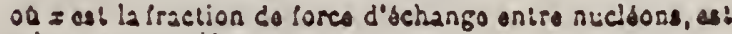
mieux approprice.

En pointilles : idsultate do Fulicr ot ilayward. 
Ref. T. Tohei, M. Sugawara, S. Mori, M. Kimura

J. Phys. Soc. Japan 16́, 1657 (1961)

Method $25 \mathrm{MeV}$ betatran; photon scattering; NaI(Tl) spectrometer; ion chamber.

\begin{tabular}{|c|c|c|c|c|c|c|}
\hline Reaction & $E$ or $\Delta E$ & $E_{0}$ & $\Gamma$ & $\int \sigma d E$ & $\mathrm{~J} \pi$ & Notes \\
\hline $\mathrm{Ni}(\gamma, \gamma)$ & $\begin{array}{l}\text { Bremss. } \\
5-12 \\
\text { Table II }\end{array}$ & 9.8 & & & & $\begin{array}{l}\text { Detector at } 120^{\circ} \\
\text { Table II from J. Phys. Soc. Japan } 18 \text {, } \\
\text { 17-22 (1963) }\end{array}$ \\
\hline
\end{tabular}

Table II. The summary of the cross sections and the threshold energies.

\begin{tabular}{|c|c|c|c|c|c|c|}
\hline Element & $E_{\max }(\mathrm{MeV})$ & $\underset{(\mathrm{MeV})}{E_{\ln }(T, p)}$ & $\begin{array}{c}E_{\mathrm{Ln}}(r, n) \\
(\mathrm{MeV})\end{array}$ & $\frac{\sigma(r, r)}{\sigma_{p d}(r, r)}$ & $\frac{\sigma(\gamma, p)}{\sigma_{p s}(\gamma, r)}$ & $\frac{\sigma(\tau, n)}{\sigma_{p 0}(\gamma, n)}$ \\
\hline Al & 8.3 & 8.27 & 13.07 & 0.04 & 0.02 & \\
\hline$s$ & 8.5 & 8.8 & 15.07 & 0.02 & 0.06 & \\
\hline $\mathrm{Si}$ & 12.0 & 11.59 & 17.18 & 0.12 & 0.05 & \\
\hline $\mathrm{K}$ & 7.0 & 6.39 & 13.09 & 0.04 & 0.07 & \\
\hline $\mathrm{Ca}$ & 8.0 & 8.34 & 15.73 & 0.05 & 0.07 & \\
\hline $\begin{array}{r}\mathrm{Ni} 58 \\
60\end{array}$ & 9.8 & $\begin{array}{l}7.91 \\
9.53\end{array}$ & $\begin{array}{l}11.93 \\
11.39\end{array}$ & 0.09 & 0.15 & \\
\hline $\begin{array}{r}\text { Cu63 } \\
65\end{array}$ & 7.5 & $\begin{array}{l}6.12 \\
7.46\end{array}$ & $\begin{array}{r}10.83 \\
9.92\end{array}$ & 0.07 & 0.11 & \\
\hline $\mathrm{Cd}$ & 7.5 & $\sim 9.5$ & $\sim 9.3$ & 0.18 & & 0.50 \\
\hline Sn & 7.5 & $\sim 9.8$ & $\sim 9.2$ & 0.75 & & 0.63 \\
\hline $\mathrm{Pb}$ & 7.2 & $\sim 7.5$ & $\sim 7.5$ & 1.00 & & 1.00 \\
\hline $\mathrm{Bi}$ & 8.0 & 3.7 & 7.4 & 1.00 & & 1.00 \\
\hline
\end{tabular}

Table II. The correction of the energy scale.

\section{Energy in Ref. 1}

4.0 MeV

6.0

8.0

10.0

12.0

14.0

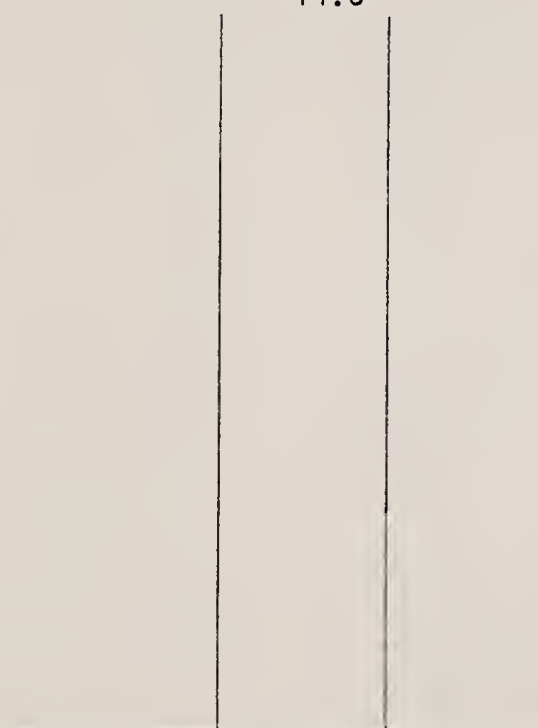

Should be read

$$
\begin{array}{r}
3.3 \mathrm{MeV} \\
5.5 \\
7.7 \\
9.9 \\
12.1 \\
11.3
\end{array}
$$

Keterences

1) E. G. Fuller and E. Hayward: Phys. Rev. 101 (1956) 692.

2) see E. Segre: Experimental Nuclear Physics, vol. 1, p. 346.

3) J. S. Levin and n? Hughes: Phys. Rev. 101 (1956) $132 s$.

4) K. Reibel and A. K. Mann: Phys. Rev. 118 (1960) 701.

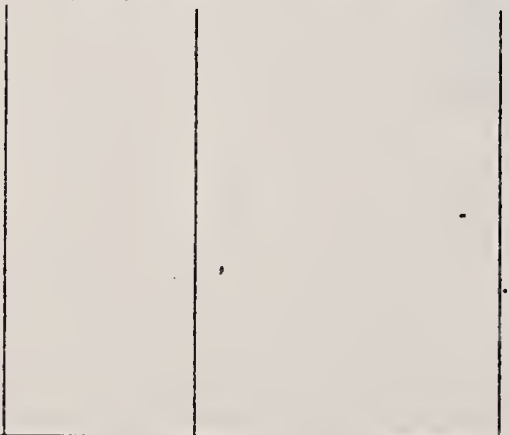

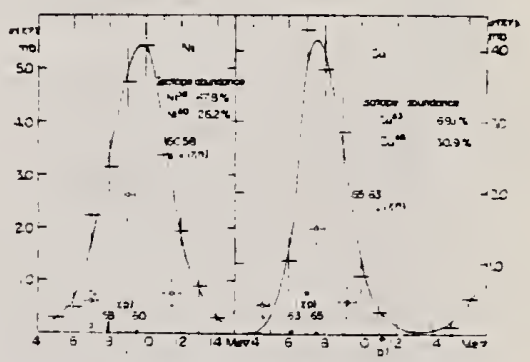

Fig. 7. The elastic scattering cross sections of photons. .. - - data from Fuller and Hay. ward ${ }^{1}$. Z: data from the experiment using the monochromatic $y$-rays 1 .

(a): $\sigma(r, \tau)$ by $\mathrm{Ni}$. The arrows indicate the positions of the $(i, p)$ and $(i, \pi)$ thresbold energies of $\mathrm{Nis}$ and $\mathrm{Niso}$.

b):,$(, ;, y)$ by $\mathrm{Cu}$. The arrows indicate the positions of $i, p \mid$ and $i, n 1$ threshold energies of $\mathrm{Cu}^{63}$ and $\mathrm{Cu}^{\mathrm{b} s}$. 
Rer. G.Ben-David (Davis); B. Huebschmann

Phys.Letters 3,87 (1962)

\begin{tabular}{c|l|r} 
Elem. Sym. & A & $z$ \\
Ni & & 28
\end{tabular}

\begin{tabular}{|c|c|c|}
\hline Method $(n, \gamma)$ reaction - NaI $(T 1)$ & $\begin{array}{l}\text { Ref. No. } \\
\text { 62Be2 }\end{array}$ & $\beta G$ \\
\hline
\end{tabular}

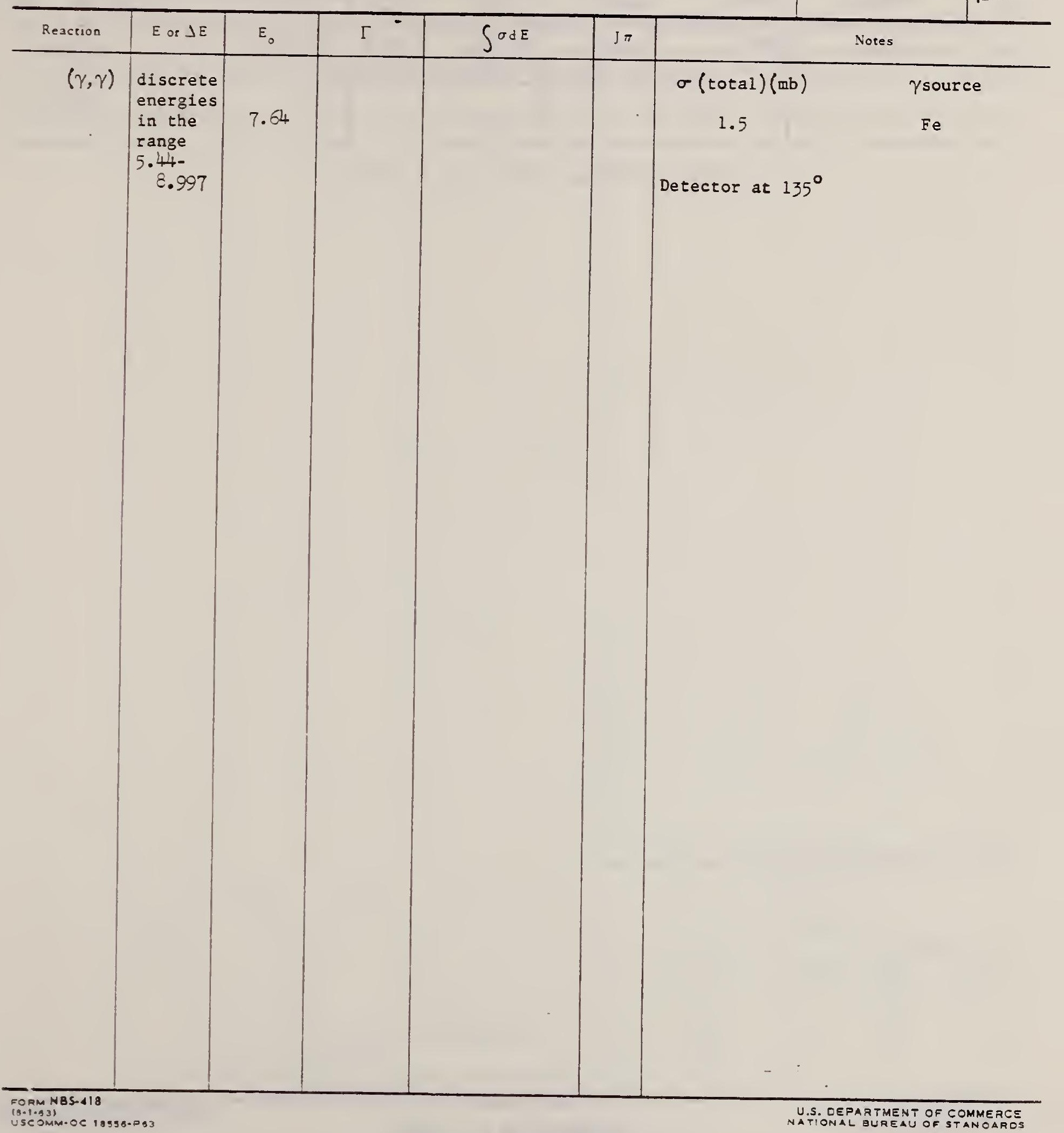


W. Sebaoun

J. Phys. Radium 23, 989 (1962)

ELEM. SYM. |A

J. Phys. Radium 23, 989 (1962)

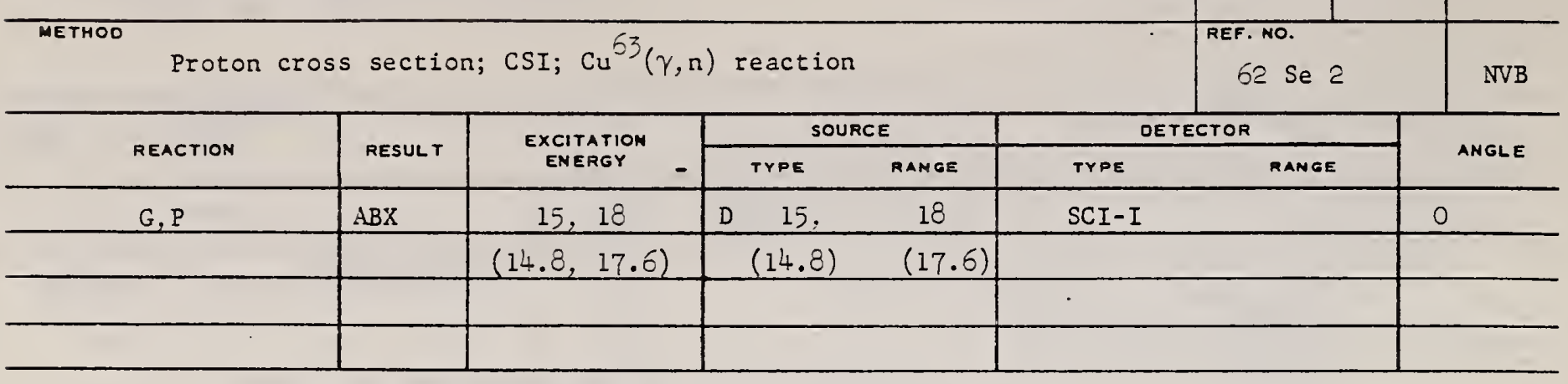

$\sigma=43 \pm 5 \mathrm{mb}$, assuming $\sigma\left[\mathrm{cu}^{63}(\gamma, \mathrm{n})\right]=82 \pm 8 \mathrm{mb}$. 
Rei. M. Kregar, B. Povh

Nuclear Phys. $4 \vec{z}, 170(196 \vec{j})$

Erratum in Nuclear Phys. $47,528(196 \overline{3})$

Method Betatron; $\alpha$ yields; spectra; solid state detectors; NBS chamber monitor.

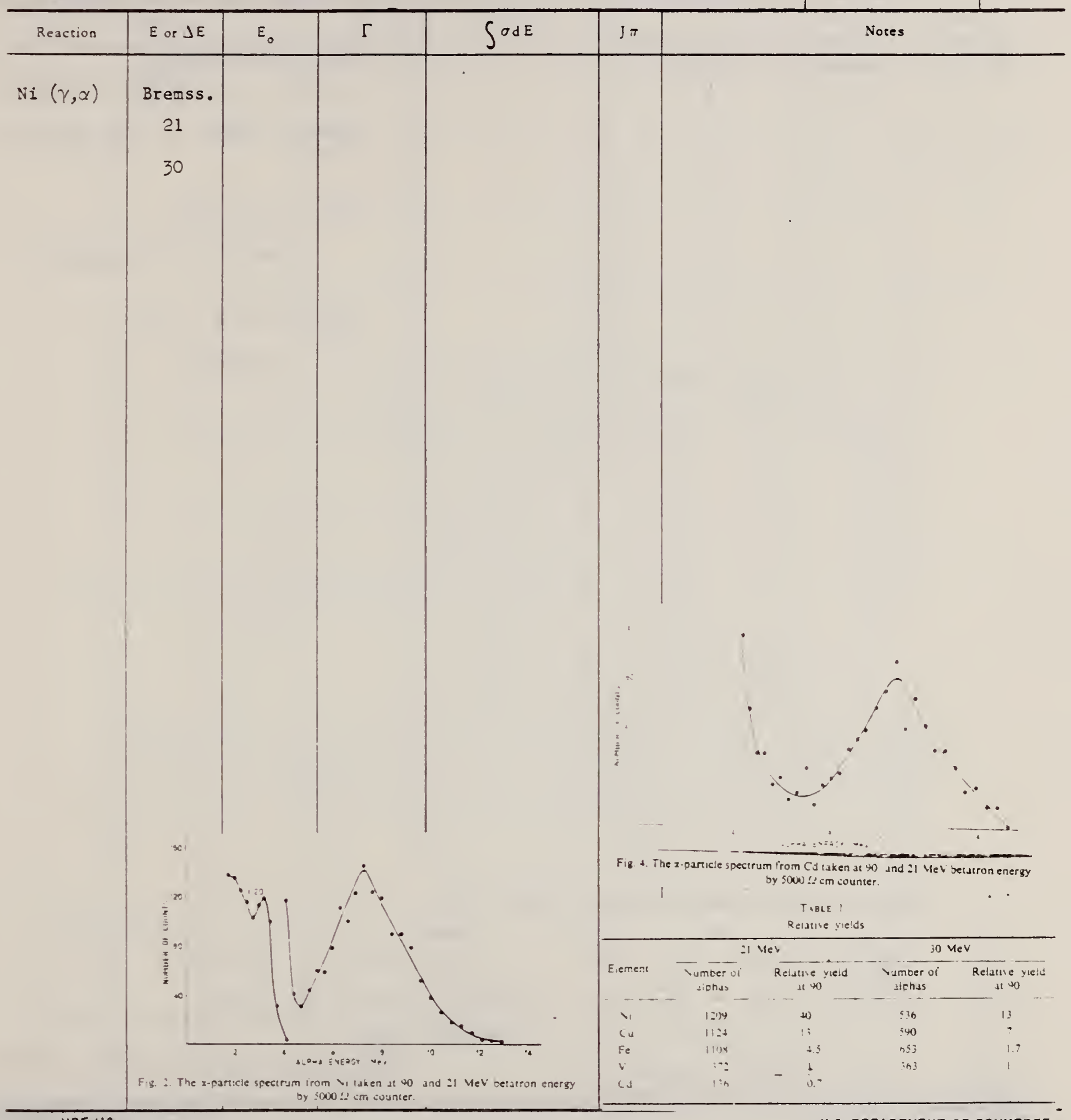


Ref. O.M.M. Mitchell, K.G. McNeill

Can. J. Phys. 41,871 (1963)

Method Betatron; proton yield; angular distribution; scintillator; ion chamber.

\begin{tabular}{|c|c|l}
$\begin{array}{c}\text { Elem. Sym. } \\
\text { Ni }\end{array}$ & Z & 28 \\
\hline $\begin{array}{c}\text { Ref. No. } \\
63 \text { Mi } 5\end{array}$ & NVB \\
\hline
\end{tabular}

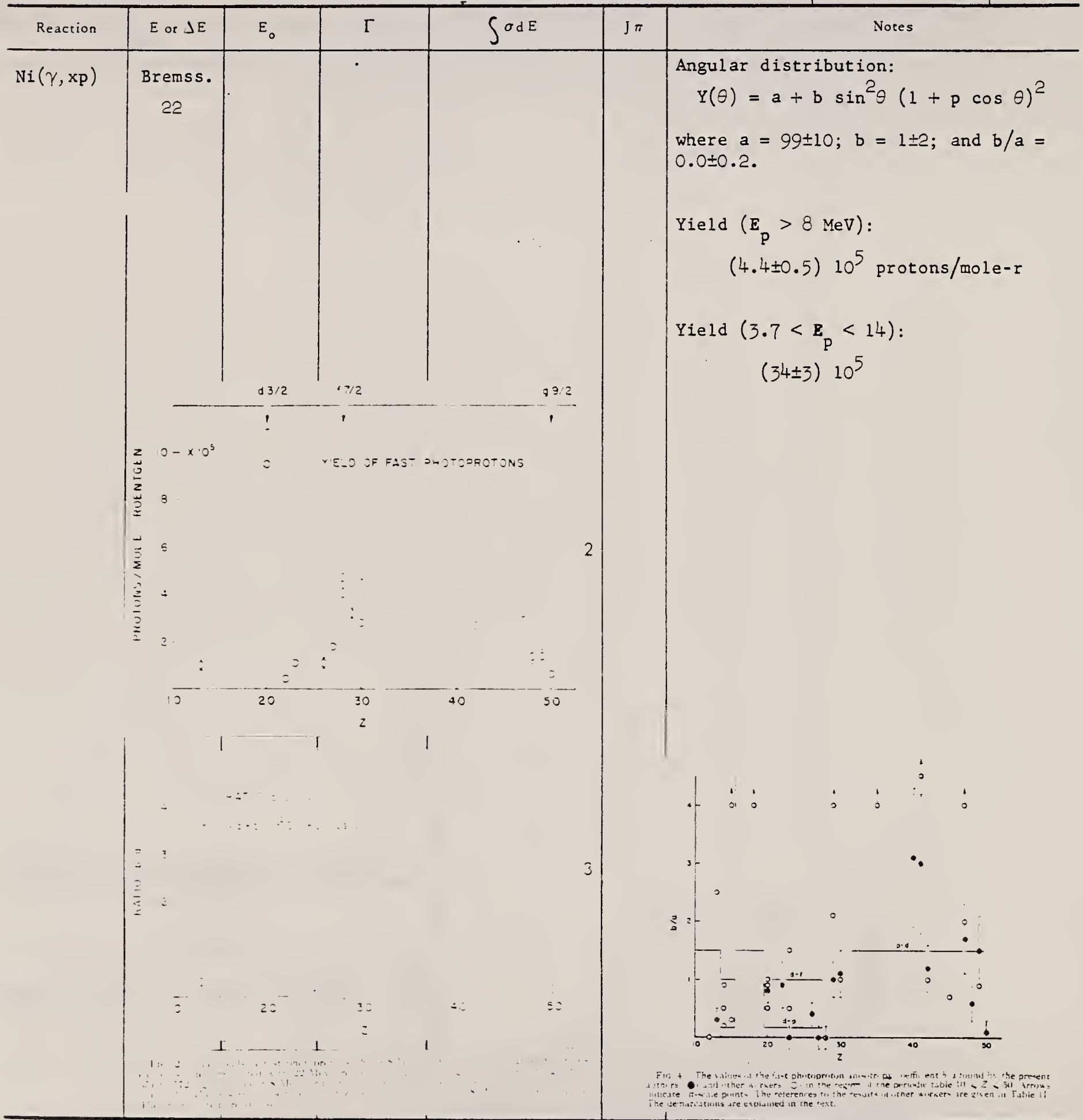


Ret. M. Yananouchi

J. Phys. Soc. Japan 18, 638 (1963)

\begin{tabular}{l||r|l|l} 
& $\begin{array}{r}\text { Elem. Sym. } \\
\text { Ni }\end{array}$ & Z & 28 \\
\hline lear emulsion & $\begin{array}{r}\text { Ref. No. } \\
63 \mathrm{Ya} \mathrm{2}\end{array}$ & NVB \\
\hline
\end{tabular}

\begin{tabular}{|c|c|c|c|c|c|c|}
\hline Reacrioo & $E$ or $\Delta E$ & $E_{0}$ & $\Gamma$ & $\int \sigma d E$ & $\mathrm{~J} \pi$ & Notes \\
\hline$N i(\gamma, d)$ & $\begin{array}{c}\text { Bremss. } \\
25.5\end{array}$ & & & & & Detectors at $90^{\circ}$. \\
\hline
\end{tabular}

Table l. Ratios of the yield of photodeuterons to that of photoprotons.

Element

Angle of observation

Number of events examined

- - - - -

Number of photodeuterons

estimated

Yield ratio

- Y
$\mathrm{Ni}$

$90^{\circ}$

$\overline{161}$

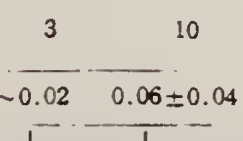

$\frac{3}{0.02}-\frac{10}{0.06 \pm 0.04}$
$\mathrm{Cu}$

$126^{\circ}$

171

7

$0.04=0.02$
Sn

$24^{\circ}, 90^{\circ}$

and $126^{\circ}$

$-\frac{126}{-1}$

99

4

$-\frac{274}{36}$


B. Arad (Huebschmann), G. Ben-David (Davis). I. Pelah, $Y$. Schlesinger

Phys. Rev. 133, BE84-700 (1964)

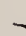

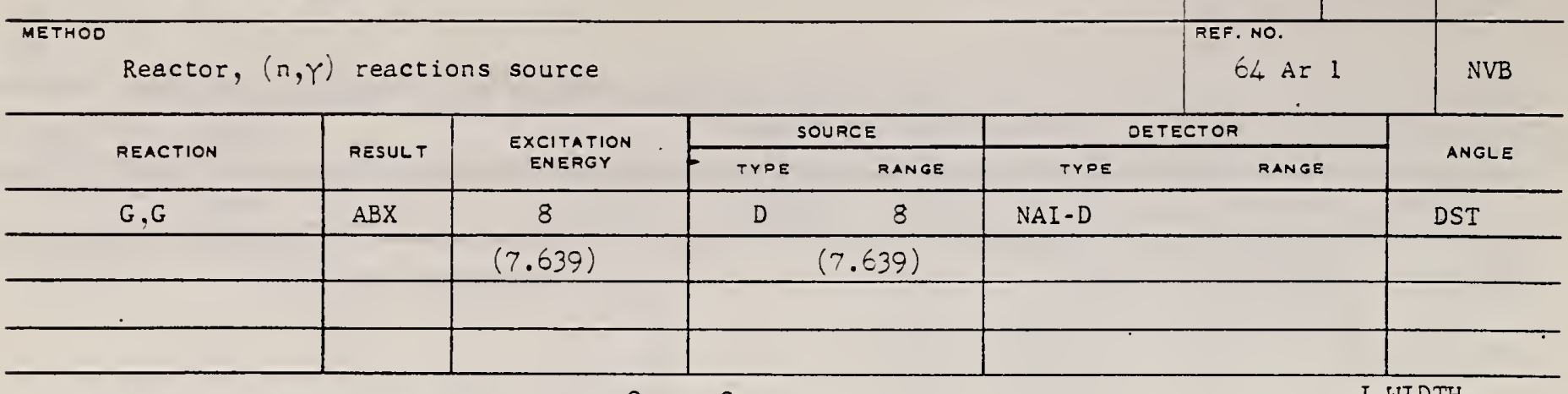

Angular correlation measurement at $90^{\circ}, 135^{\circ}$

gives $\frac{W\left(135^{\circ}\right)}{W\left(90^{\circ}\right)}=1.7=0.1$, indicating $\mathrm{J}=1$.

Level width $\Gamma_{0}=\left(3.28-0.50^{+0.70}\right) / \mathrm{s} \mathrm{MeV}$, where $\omega=$ fractional isotopic abundance.

TABLE III. Effective cross sections.

\begin{tabular}{|c|c|c|c|c|c|c|}
\hline$\gamma$ source & $\begin{array}{l}\text { Energy } \\
(\mathrm{MeV})\end{array}$ & Element & Protons & Neutrons & $\begin{array}{l}\left\langle\sigma_{77}\right\rangle \\
(\mathrm{mb})\end{array}$ & Notes \\
\hline $\begin{array}{l}\mathrm{Hg} \\
\mathrm{Cl} \\
\mathrm{V} \\
\mathrm{Co} \\
\mathrm{Co} \\
\mathrm{Al} \\
\mathrm{Cl} \\
\mathrm{Ti} \\
\mathrm{Cu} \\
\mathrm{Ti} \\
\mathrm{Co} \\
\mathrm{Hin} \\
\mathrm{Fe} \\
\mathrm{V} \\
\mathrm{Hg} \\
\mathrm{Fe} \\
\mathrm{Fe} \\
\mathrm{Cr} \\
\mathrm{Cr} \\
\mathrm{Ni}\end{array}$ & $\begin{array}{l}.44 \\
6.12 \\
6.508 \\
6.690 \\
6.867 \\
6.98 \\
6.98 \\
6.996 \\
7.01 \\
7.149 \\
7.201 \\
7.261 \\
7.285 \\
7.305 \\
7.32 \\
7.639 \\
7.639 \\
8.499 \\
8.881 \\
8.997\end{array}$ & 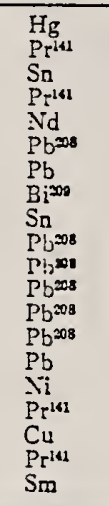 & $\begin{array}{l}80 \\
59 \\
50 \\
59 \\
60 \\
82 \\
82 \\
83 \\
50 \\
82 \\
82 \\
82 \\
82 \\
82 \\
82 \\
28 \\
59 \\
29 \\
59 \\
62\end{array}$ & $\begin{array}{l}116,118,119,120,121,122,124 \\
82 \\
62,64-70,72 \\
82 \\
82,83,84,85,86,88 \\
126 \\
124,125,126 \\
126 \\
62,64-70,72 \\
126 \\
126 \\
126 \\
126 \\
126 \\
124,125,126 \\
30,32,34,36 \\
82 \\
34,36 \\
82 \\
82,85-88,90,92\end{array}$ & $\begin{array}{c}128 \\
103 \\
14 \\
2.7 \\
22 \\
2900 \\
346 \\
1560 \\
1000 \\
1000 \\
25 \\
25 \\
4100 \\
12.5 \\
5500 \\
10.5 \\
10 \\
24.4 \\
9.3 \\
2.8\end{array}$ & $\begin{array}{l}a \\
a \\
a \\
b \\
a \\
b \\
b \\
b \\
a \\
a \\
c \\
c \\
d \\
d\end{array}$ \\
\hline
\end{tabular}

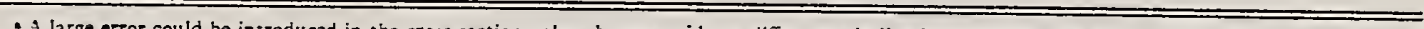
- A large error could be introduced in the cross-section values because of large differences in line intensities quoted by Bartholomew and Higgs and by
Groshev et al. (Ref. 6$\rangle$. because of the low counting rate, thick scatterers were used, which will introduce a systematic error in estimating ( $\sigma_{\mathrm{r}}$ ) for resonanceg having a high
nuclear cross section.

- The cross section was evaluated assuming the gamma intensity to be 0.02 photons per 100 captured reutrons (see text)

2031 (1962) 6 zives the 7.639 line of iron capture gamma rays as a single line. However, a recent paper by Fieoiger, Kand. and Segel [Phys. Rev. 125. difference oi $14 \mathrm{keV}$, thereiore, there is no possibility of deciding wilch line 13 responsiole ior the MeV. The present experiment cannot resolve an energy 
G. Baciu, A. Bonazzola, B. Minetti, C. Molino, L. Pasqualini and G. Piragino

Rev. Roum. Phys. 9, 977 (1964)

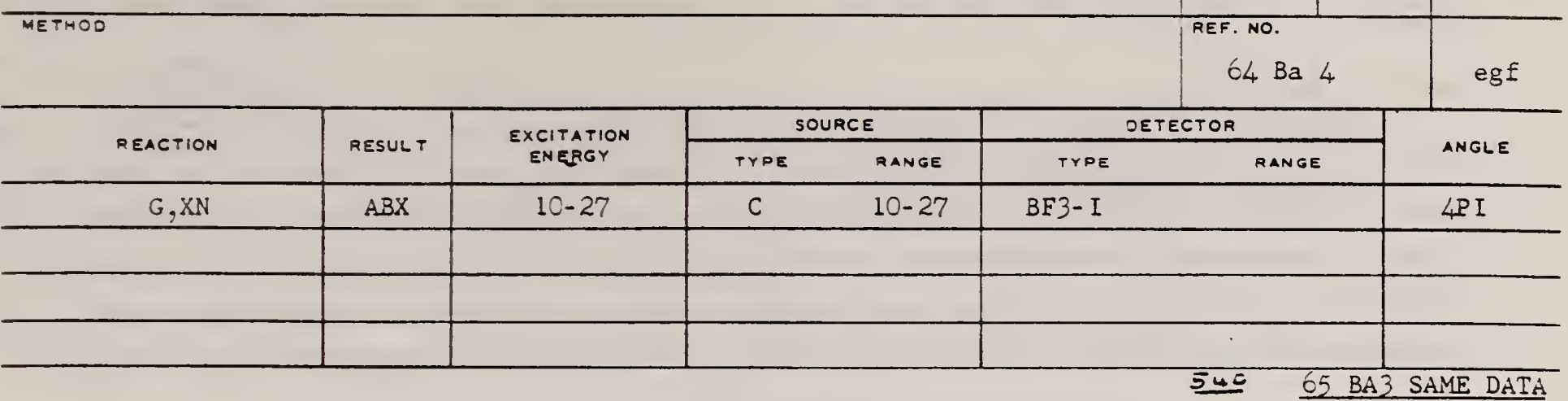

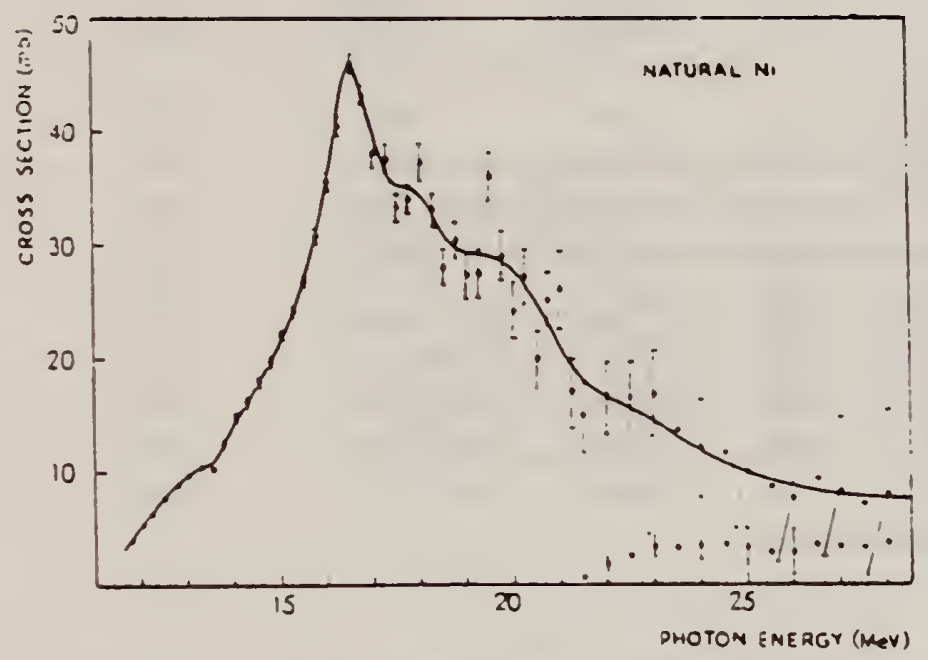

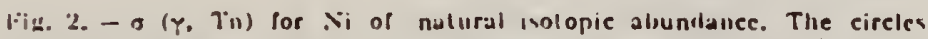
repuresent lise values for $\sigma$ (Y. 2n) culculated ( $\mathrm{nor} a=6.5 \mathrm{MeV}-2$ ) in the alproxilusalinn of the equality of I hresholds for the reaction $\sigma(\gamma, n)$ and $\sigma(Y, 2, i)$ for Nion and Nim. 


\begin{tabular}{|c|c|c|c|c|c|c|c|}
\hline \multicolumn{6}{|c|}{$\begin{array}{l}\text { G. Baciu, C. Molino, B. Minetti, L. Pasqualini, G. Piragino } \\
\text { Stud. Cercetari Fiz. 16, } 903(1964)\end{array}$} & $\mid$\begin{tabular}{c|} 
ELEM. SYM. \\
$\mathrm{Ni}$
\end{tabular} & 28 \\
\hline \multicolumn{6}{|l|}{ METHOD } & $\begin{array}{l}\text { REF. NO. } \\
64 \mathrm{Ba} 5\end{array}$ & egf \\
\hline \multirow{2}{*}{ REACTION } & \multirow[b]{2}{*}{ RESULT } & \multirow{2}{*}{$\begin{array}{l}\text { EXCITATION } \\
\text { ENERGY }\end{array}$} & \multicolumn{2}{|c|}{ SOURCE } & \multicolumn{2}{|c|}{ OETECTOR } & \multirow{2}{*}{ ANGLE } \\
\hline & & & TYPE & RANGE & TYPE & RANGE & \\
\hline$G, X N$ & $A B X$ & $12-28$ & & $12-28$ & \multicolumn{2}{|l|}{ BE3-I } & $4 \mathrm{PI}$ \\
\hline \multicolumn{8}{|l|}{. } \\
\hline & & & & & & & \\
\hline & & & & & & & \\
\hline
\end{tabular}

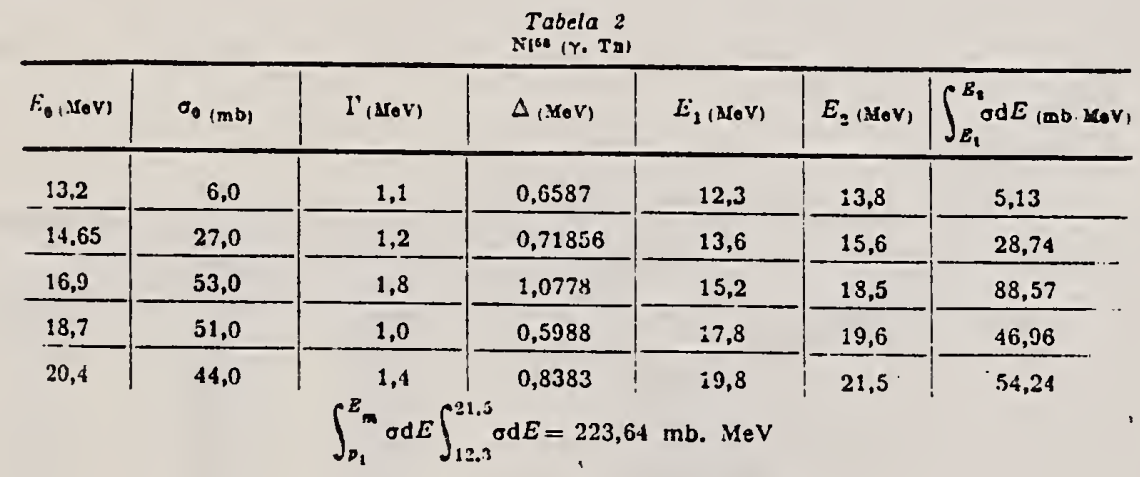

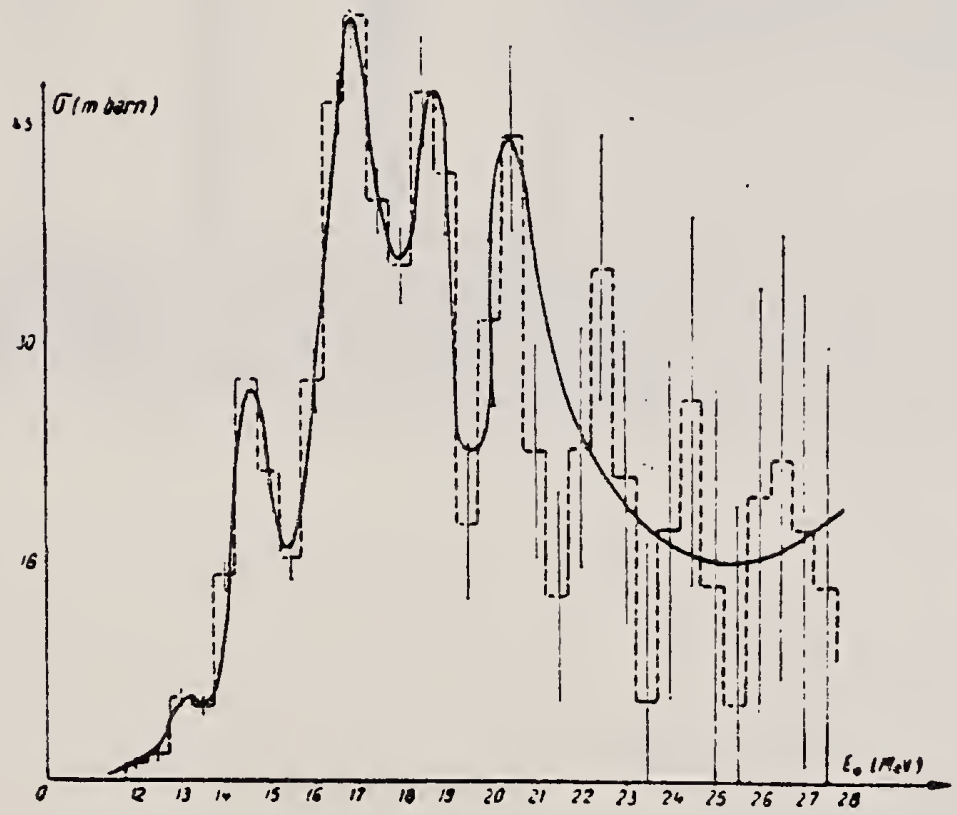

Fig. 2 


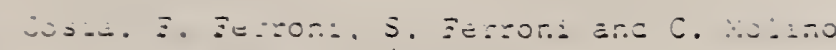

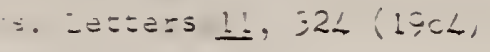

$-$

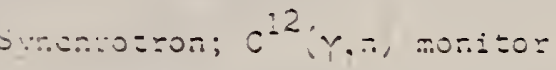

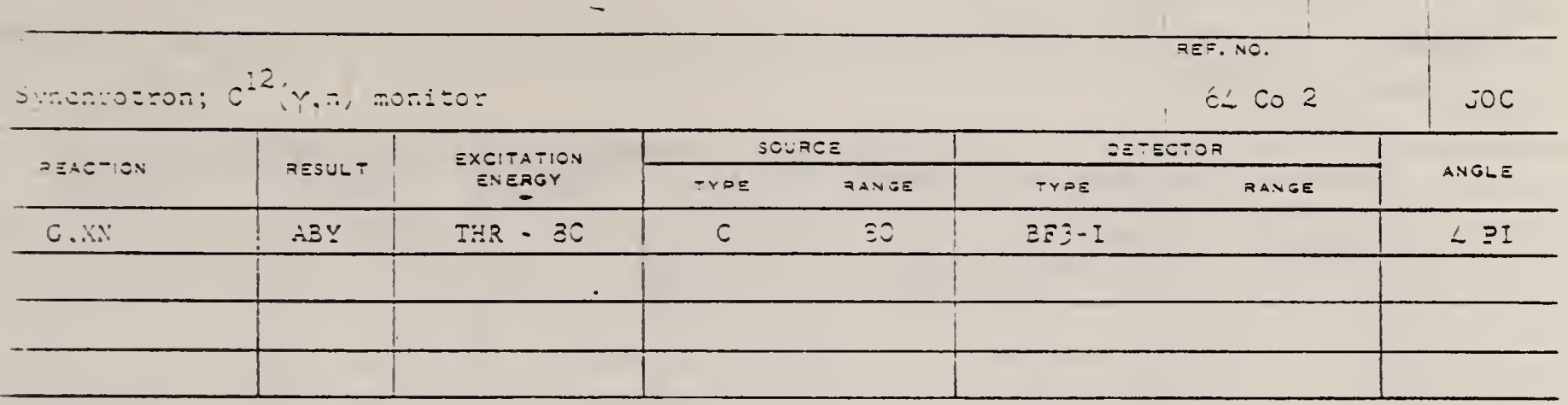

Iab:e:

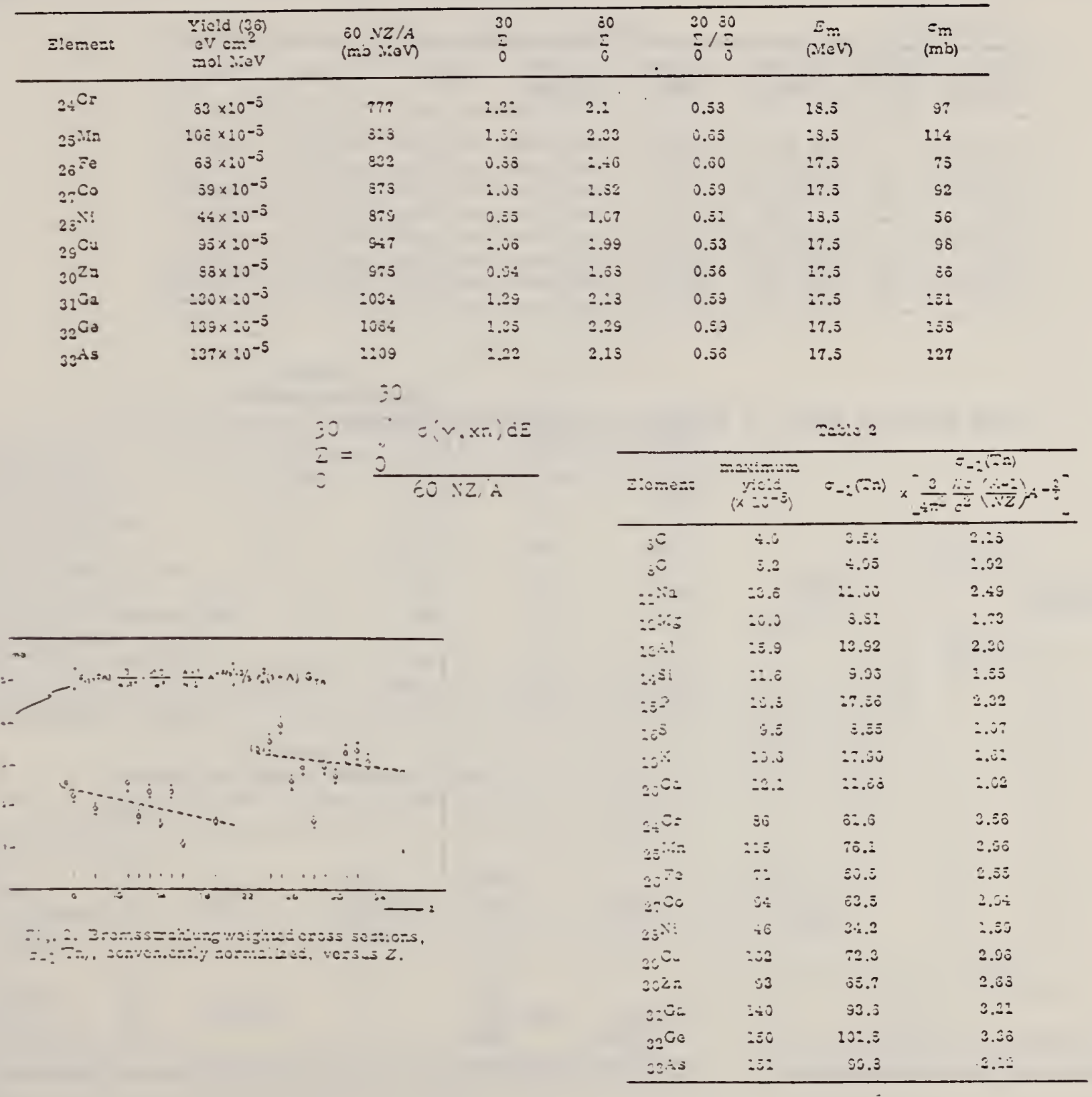


REF.

M. Giannini, P. Oliva, D. Prosperi and S. Sciuti

Nuovo Cimento 34,1116 (1964)

$F e(n, Y)$

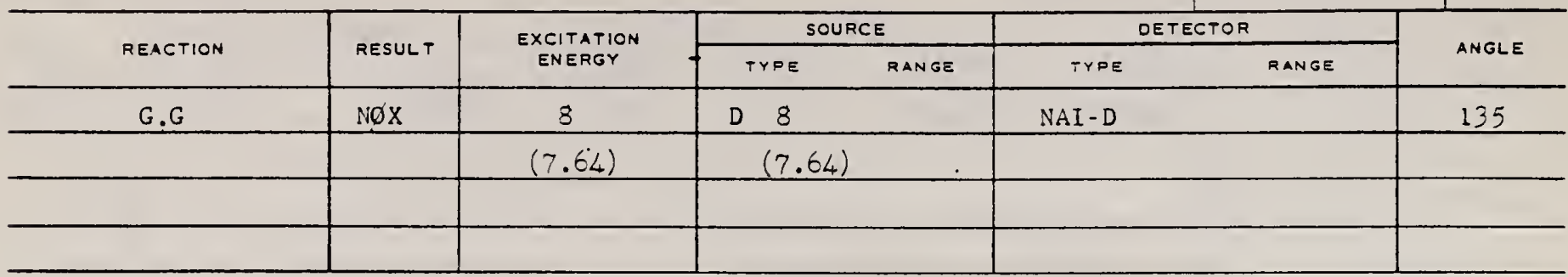

TABLE I.

\begin{tabular}{|c|c|c|c|c|c|c|c|}
\hline $\begin{array}{l}\text { Source- } \\
\text { scatterer }\end{array}$ & $\begin{array}{c}\text { Energy } \\
(\mathrm{MeV})\end{array}$ & $\begin{array}{c}\left\langle\sigma_{r,}(300)\right\rangle \\
(\text { Barn })\end{array}$ & $\begin{array}{l}\bar{\sigma}_{r a}(300) \\
\text { (Barz) }\end{array}$ & $\frac{\left\langle\sigma_{r s}(100)\right\rangle}{\left\langle\sigma_{r s}(300)\right\rangle}$ & $\Gamma_{\text {Yo }} / \Gamma$ & $\Gamma_{\gamma_{0}}(\theta \mathrm{V})$ & $\delta(\theta V)$ \\
\hline${ }^{67} \mathrm{Fe}-{ }^{208} \mathrm{~Pb}$ & 7.28 & $5.62 \pm 0.15$ & $17.5 \pm 1.5$ & $1.004 \div 0.006$ & $0.84 \pm 0.08$ & $0.73 \pm 0.05$ & $4.8 \pm 0.3$ \\
\hline${ }^{67} \mathrm{Fe} \cdot{ }^{(82)} \mathrm{Ni}$ & 7.64 & $0.375 \pm 0.006$ & 55 & $0.338 \pm 0.011$ & $0.71 \doteq 0.07$ & $0.15 \div 0.02$ & $11.0 \pm 0.5$ \\
\hline${ }^{37} \mathrm{Fe}-(116) \mathrm{Cd}$ & 7.64 & $0.287 \pm 0.006$ & $4.1=1.8$ & $1.116 \doteq 0.015$ & $0.11 \pm 0.06$ & $0.22 \pm 0.02$ & $\$ 1$ \\
\hline${ }^{28} \mathrm{Al}-200 \mathrm{~Pb}$ & 6.98 & $1.29 \pm 0.06$ & $22.1 \div 2.7$ । & $1.002 \pm 0.012$ & $0.30 \pm 0.07$ & $0.86=0.10$ & $11.5 \div 2.5$ \\
\hline
\end{tabular}

Cross sections based on assumed $1+\cos ^{2} \theta$ distribution. 
J. A. Scheer, K. Schlupmarn und F. Triancafyllidis

Nucl. 'Phys. 26, $113-116(1904)$

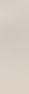

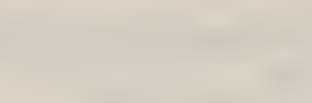

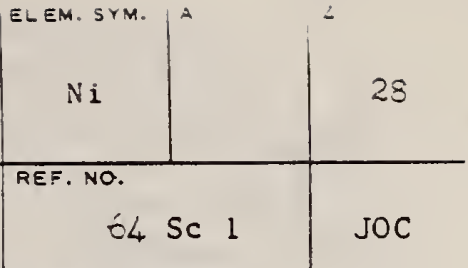

Betatron

ANGLE

\begin{tabular}{|c|c|c|c|c|c|c|c|}
\hline \multirow{2}{*}{ REACTION } & \multirow{2}{*}{ RESULT T } & \multirow{2}{*}{$\begin{array}{c}\text { EXCITATION } \\
\text { EN TRGY }\end{array}$} & \multicolumn{2}{|c|}{ SOURCE } & \multicolumn{2}{|c|}{ DETECTOR } & \multirow{2}{*}{ ANGLE } \\
\hline & & & TYPE & RANGE & TYPE & RANGE & \\
\hline \multirow[t]{2}{*}{ G.A } & SPC & THR - 33 & C & 33 & $S C D$ & $4-13$ & ao \\
\hline & & & & & & $=$ & $=$ \\
\hline & & & & & & & \\
\hline & & & & & & & \\
\hline
\end{tabular}

ABS YIELD

TAgeLLE 1

MeBdaten und Ergebnisse

\begin{tabular}{|c|c|c|c|c|}
\hline & $\mathrm{Ti}$ & $\mathrm{Ni}$ & $\mathrm{Cu}$ & $\mathrm{Nb}$ \\
\hline Targetdicke $\left(\mathrm{mg} / \mathrm{cm}^{\mathrm{s}}\right)$ & 2.08 & 1.52 & 9.90 & 8.87 \\
\hline Bestrahlungsdauer (b) & 52.5 & 55.5 & 18.0 & 84.5 \\
\hline $\begin{array}{l}\text { Registrierte Teilchenanzahl } \\
\left(4 \leq E_{3} \leqq 12.6 \mathrm{MeV}\right)\end{array}$ & 1861 & 2376 & 2333 & 1987 \\
\hline $\begin{array}{l}\text { Lage des Maximums } E_{\text {max }} \text { der } \\
\text { Energieverteilung ( } \mathrm{MeV} \text { ) }\end{array}$ & 6.4 & 8.2 & 8.5 & 11 \\
\hline Halbwernsbreite des Maxumums (MeV) & 2.3 & 2.8 & 4.0 & 3.5 \\
\hline $\begin{array}{l}\text { Mittlerer Energieveriust } \\
\text { im Target bei } E_{3}=E_{\max }(\mathrm{MeV}) \\
\text { Ausbeute in } \mu \mathrm{b} / \mathrm{MeV} \bullet)\end{array}$ & $\begin{array}{c}0.4 \\
22 \pm 3.5\end{array}$ & $\begin{array}{c}0.25 \\
45=7\end{array}$ & $\begin{array}{c}1.7 \\
23 \pm 3.5\end{array}$ & $\begin{array}{c}1.1 \\
5.5 \pm 0.8\end{array}$ \\
\hline
\end{tabular}

-) V/gl. Beroerkung ") in Tabelle 2

TABRU: 2

Vergleich der Esgebousse verschiedener Autoren

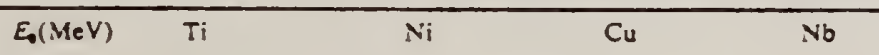

Ausbeure $\left(10^{2} \times N_{3} / \mathrm{Mol}\right.$. P)

Boulegue 31

Diese Arbeit \&) 32.

2.5

$48 \pm 7$

58.7

$98=15$

50.8

Toms und MeElhianey 21.5

39.4

$50=7.5$

$12=1.8$

Relarice Ausbeure

Boultrue 3

Kregar und Povb 30

Diese Arbeit 325

Toms und McElhianey 21.5

$$
0.49 \pm 0.08
$$

-) Die Fehlerangaben beunhalten auch die Unsicherbeit in der Absoluteichung der Intensilát des y-Straniea.

b) Dieser Wiert wurde aus aur 14 beobachteten Erelgnissen bestimmt.

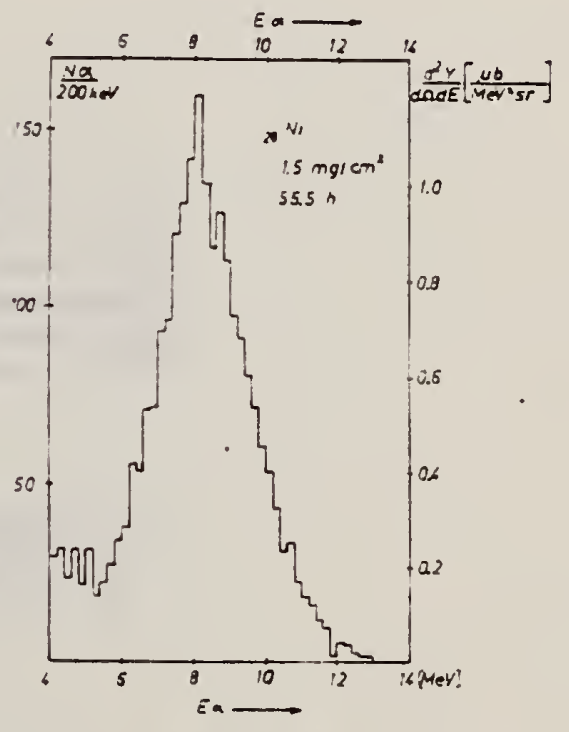

Abb. 1. Die erbaltenen Energie-Spektren der Photoalphateilchen aus $\mathrm{Ti}, \mathrm{Ni}, \mathrm{Cu}$ und $\mathrm{Nb}$. 
G. Baciu, G. C. Bonazzola, B. Minetti, C. Molino, L. Pasqualini and $G$. Piragino

Nuclear Phys. 67,178 (1965)

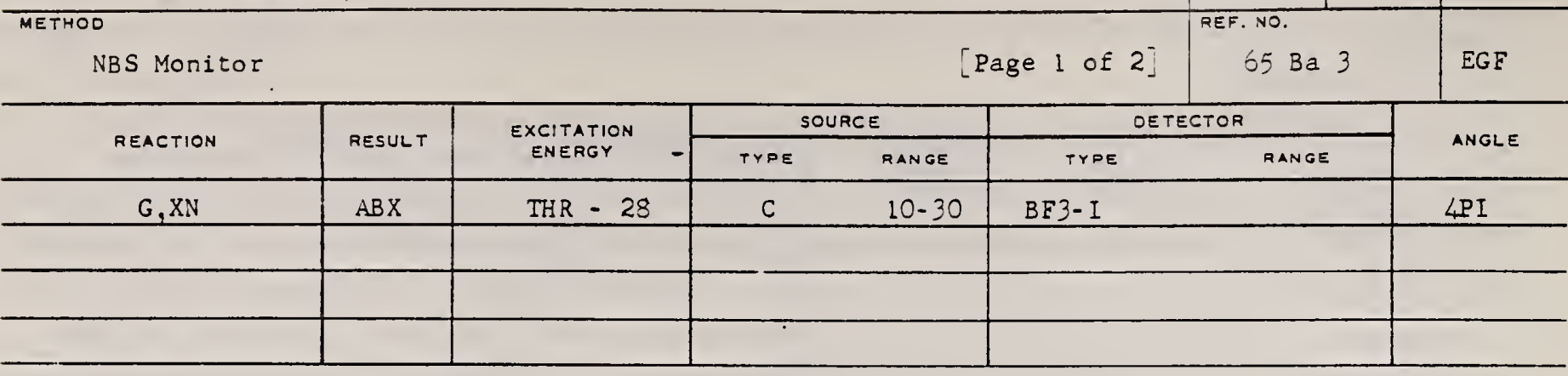

TABLR 2

Cross sections for $\mathrm{Co}, \mathrm{Ni}, \mathrm{Cu}$ and $\mathrm{Ga}$

\begin{tabular}{|c|c|c|c|c|c|}
\hline & $\underset{(\mathrm{Me}}{E_{\mathrm{m}}}$ & & $\begin{array}{l}\sigma_{m} \\
(m b)\end{array}$ & $\int_{0}^{x} \sigma(E) \mathrm{d} E(\mathrm{mb} \cdot \mathrm{MeV})$ & Ref. \\
\hline $\mathrm{Co}^{\prime \prime}$ & $\begin{array}{l}16.9 \\
16.75 \\
17.5 \\
16.5 \\
16.5\end{array}$ & $\begin{array}{l}19 \\
19 \\
19\end{array}$ & $\begin{array}{rr}130 & \\
110 & 103 \\
68 & \\
82 & 80 \\
72 & 74\end{array}$ & $\begin{array}{l}750(24) \\
709(25) \\
725 \pm 72(28) \\
701 \pm 91(29) \\
657 \pm 89(28) \\
537 \pm 34(24) \\
445 \pm 48(24)\end{array}$ & $\begin{array}{l}\text { ) } \\
\text { ) } \\
\text { 13) } \\
\text { this work } \\
\text { this work } \\
\text { ") }\end{array}$ \\
\hline $\mathrm{Ni}$ & $\begin{array}{l}16.5 \\
16.5\end{array}$ & & $\begin{array}{l}50 \\
46 \pm 1\end{array}$ & $\begin{array}{l}340(24) \\
313 \pm 48(28) \\
276 \pm 25(24)\end{array}$ & $\begin{array}{l}\text { 11) } \\
\text { this work } \\
\text { this work }\end{array}$ \\
\hline $\mathrm{Ni}^{30}$ & $\begin{array}{l}18.5 \\
\\
20.5 \\
19.0\end{array}$ & & $\begin{array}{l}60 \\
30 \\
21 \\
32\end{array}$ & $\begin{array}{l}330(24) \\
180(24) \\
160(24) \\
220 \pm 30(32)\end{array}$ & $\begin{array}{r}12) \\
\text { 16) } \\
13) \\
14)\end{array}$ \\
\hline $\mathrm{Ni}{ }^{\infty}$ & 16.5 & & 85 & $440( \pm 20 \%)(24)$ & b) \\
\hline $\mathrm{Cu}$ & $\begin{array}{l}19.5 \\
17.2 \\
17 \\
16.75 \\
17.0\end{array}$ & & $\begin{array}{l}120 \\
126 \\
90 \\
71 \pm 7 \\
86 \pm 2\end{array}$ & $\begin{array}{l}870(20) \\
904(27) \\
930(27) \\
450 \pm 15(19,6) \\
745 \pm 74(28) \\
733 \pm 105(28) \\
451 \pm 18(20)\end{array}$ & $\begin{array}{l}\text { ") } \\
\text { 13) } \\
\text { 1s) } \\
\text { 1") } \\
\text { 19) } \\
\text { this work } \\
\text { this work }\end{array}$ \\
\hline Ga & 16.5 & & $115 \pm 3$ & $947 \pm 98(28)$ & this work \\
\hline
\end{tabular}

$\sigma_{\mathrm{m}}$ is the peak value of the cioss section, $E_{\mathrm{m}}$ is the peak energy and $\int_{0}^{x} \sigma(E) d E$ is the integrated cross section. The upper limit of the integration is indicated in parentheses.

-) Value obtained subtracting the $(\gamma, 2 n)$ reaction contribution from the $\sigma\left(\gamma, T_{n}\right)$.

b) Value obtained by subtracting the $\mathrm{Ni}^{30}(y, n) \mathrm{Ni}^{\text {" }}$ reaction contribution from the $\sigma\left(\gamma, \mathrm{T}_{\mathrm{a}}\right)$ for natural aickel corrected for the $(\gamma, 2 n)$ reaction contribution.

11) J. Goldenberz and L. Katz, Can. J. Phys. 32 (1954) 49

12) L. Katz and A. G. W. Cameron. Can. J. Phyo. 29 (1951) 518

13) J. P. Roalswing, R. N. H. Haslam and D. J. McKenzie, Can. J. Phys. 37 (1959) 607

14) J. H. Carver, and W. Tuchinetz, Proc. Phys. Soc. 73 (1959) 585 
G. Baciu, G. C. Bonazzola, B. Minetti, C. Molino, L. Pasqualini and $G$. Piragino

Nuclear Phys.

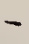

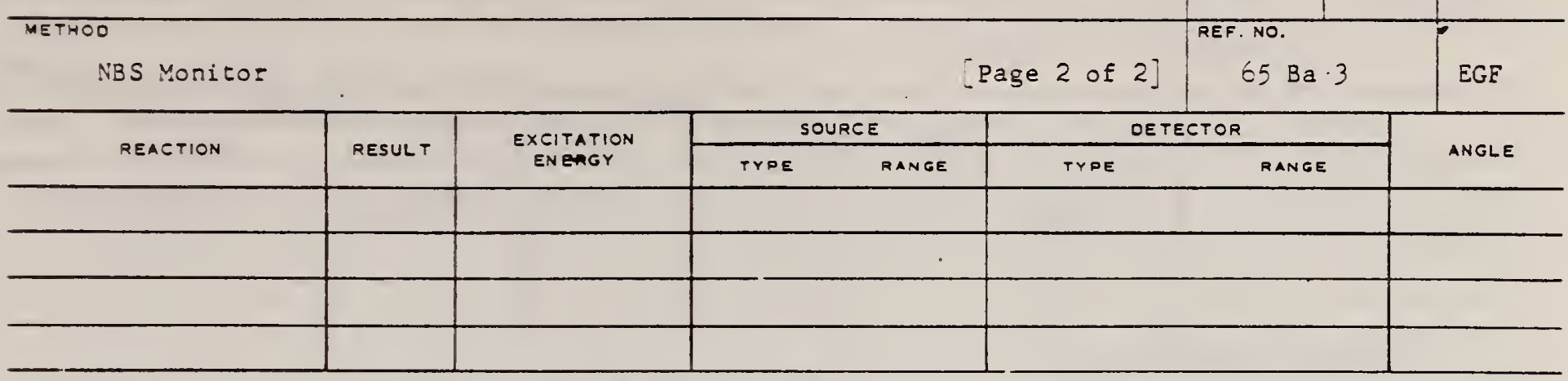

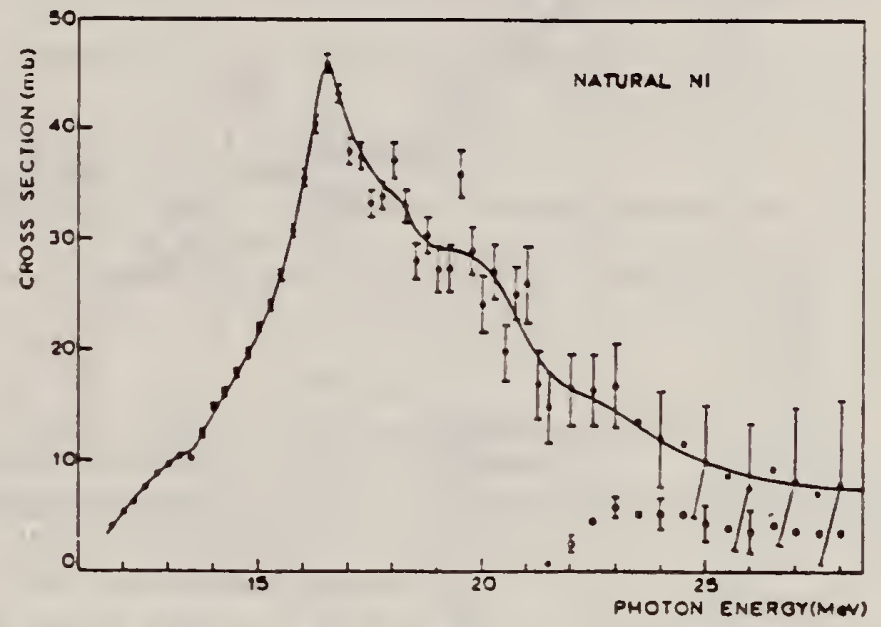

Fig. 2. The solid line represents the average of data poines of the total cross section $\sigma(\gamma, T n)$ for natural aickel. The open circles represent the $\sigma(\gamma, 2 n)$ calculated by taking $a=6.5 \mathrm{MeV}^{-1}$ and assuming that the $(y, \mathrm{a})$ and $(\gamma, 2 \mathrm{n})$ reaction threshold bave tho seme values for $\mathrm{Ni}^{\text {so }}$ and $\mathrm{Ni \omega}$. 
REF.

M. Giannini, P. Oliva, D. Prosperi and S. Sciuti

Nuclear Phys. $65,344(1965)$

Source: n-capture $Y^{\prime}$ s from Fe.

65 Gi 1

\begin{tabular}{|c|c|c|c|c|c|c|c|}
\hline \multirow[b]{2}{*}{ REACTION } & \multirow{2}{*}{ RESULT } & \multirow{2}{*}{$\begin{array}{l}\text { EXCITATION } \\
\text { ENERGY }\end{array}$} & \multicolumn{2}{|c|}{ SOURCE } & \multicolumn{2}{|c|}{ DETECTOR } & \multirow{2}{*}{ ANGLE } \\
\hline & & & TYPE & RANGE & TYPE & RANGE & \\
\hline$G, G$ & RLY & 8 & $\mathrm{D}$ & 8 & $\mathrm{NAI}-\mathrm{D}$ & 8 & 135 \\
\hline & & & & & - & & \\
\hline & & & & & & & \\
\hline & & & & & & & \\
\hline
\end{tabular}

Inelastic branching ratio

$I\left(E_{Y}=5.59\right) \approx 0.47 I(7.64)$

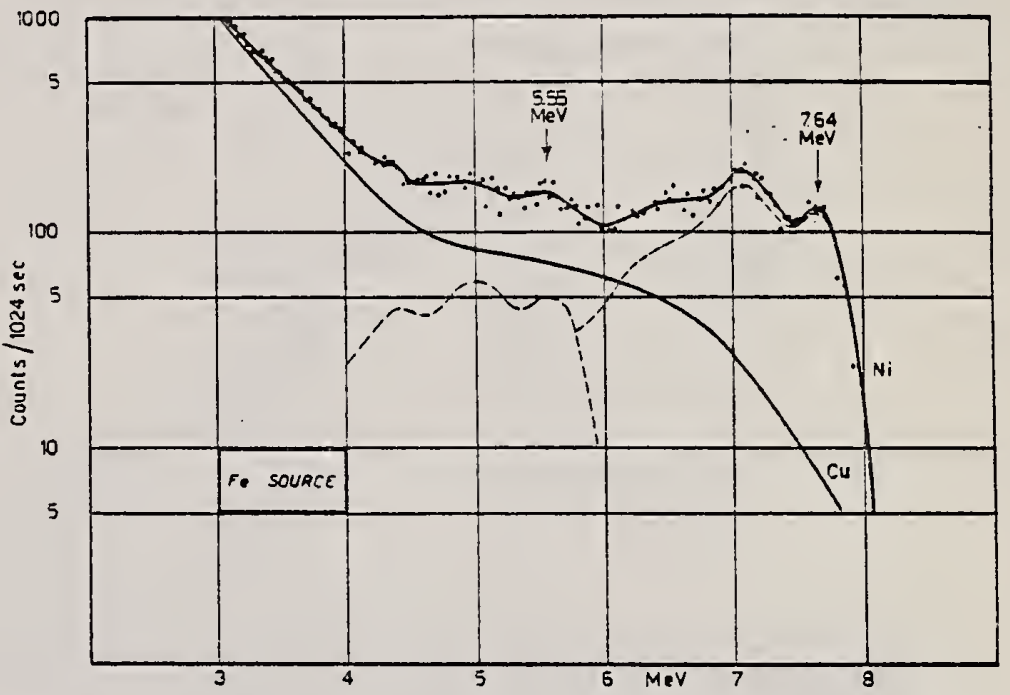

Fig. 3. Spectra of $\gamma$-rays scattered by $\mathrm{Ni}$ and $\mathrm{Cu}$ targets.

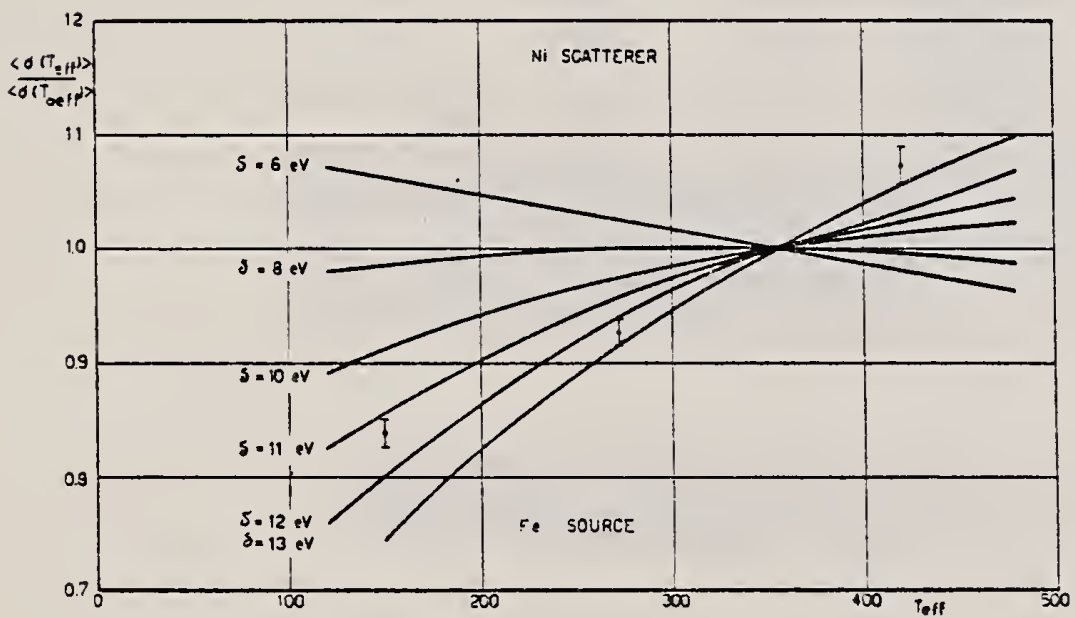

Fig. 7. Fe-Ni resonance. 
REF.

J.M. Nyckoff, B. Ziegler, H.W. Koch, and R. Uhilg

Phys. Rev. 137, B576́-94 (1965)

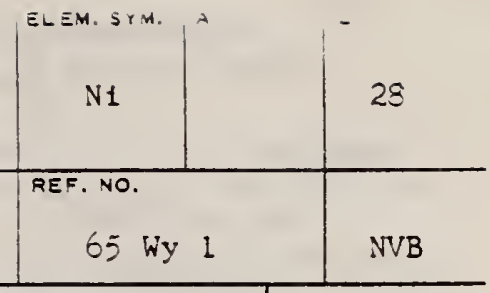

Synchrotron; ion chamber monitor

\begin{tabular}{|c|c|c|c|c|c|c|c|}
\hline \multirow{2}{*}{ REACTION } & \multirow{2}{*}{ RESULT } & \multirow{2}{*}{$\begin{array}{l}\text { EXCITATION } \\
\text { ENETGY }\end{array}$} & \multicolumn{2}{|c|}{ SOURCE } & \multicolumn{2}{|c|}{ DETECTOR } & \multirow{2}{*}{ ANGLE } \\
\hline & & & TYPE & RANGE & TYPE & RANGE & \\
\hline G.MU-I & $A B X$ & 10.35 & C & 90 & $S C I-D$ & & $4 P I$ \\
\hline & & & & & & & \\
\hline & & & & & & & \\
\hline
\end{tabular}

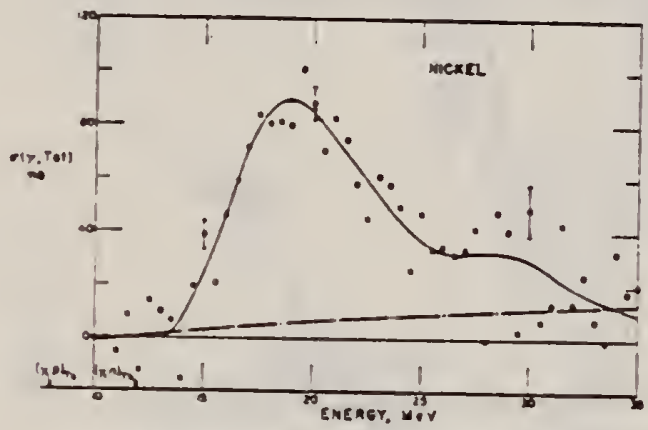

Fic. 25. Nickel totai pbotonuclear cross section.

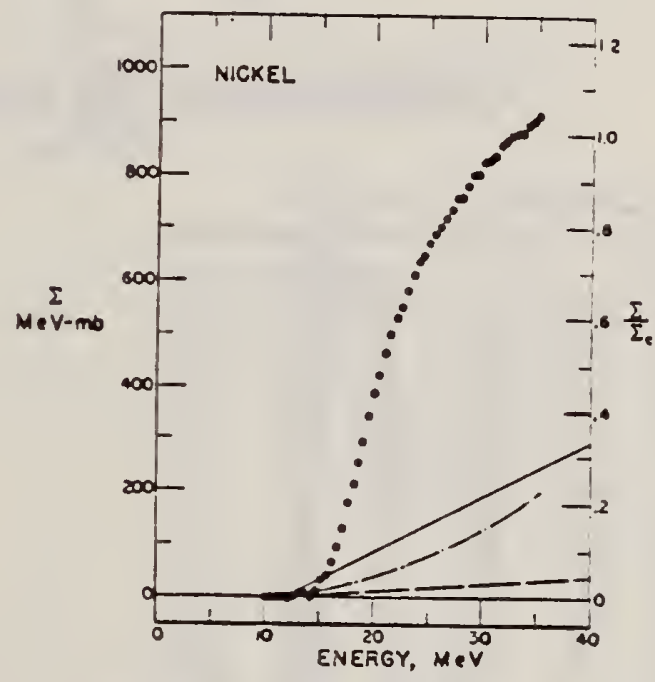

Fic. 26. Nickel totai photonuclear cross section integrated over energy. 
REF.

I. Bergqvist, B. Lundberg, L. Nilsson and N. Starfelt Phys. Letters $19,670(1966)$

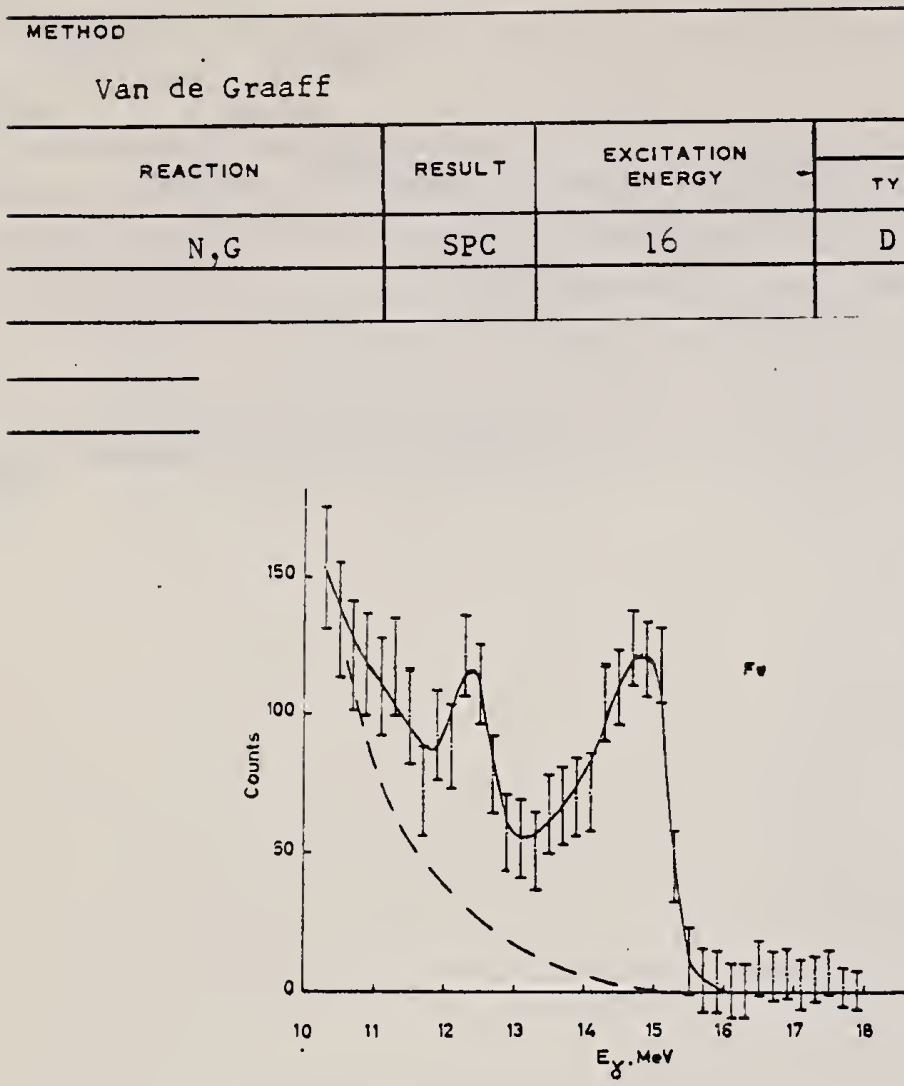

\begin{tabular}{|c|c|c|c|}
\hline SOURCE & & & \\
\hline RANGE & TYPE & RANGE & ANGLE \\
\hline 7 & NAI-D & $8-18$ & \\
\hline
\end{tabular}
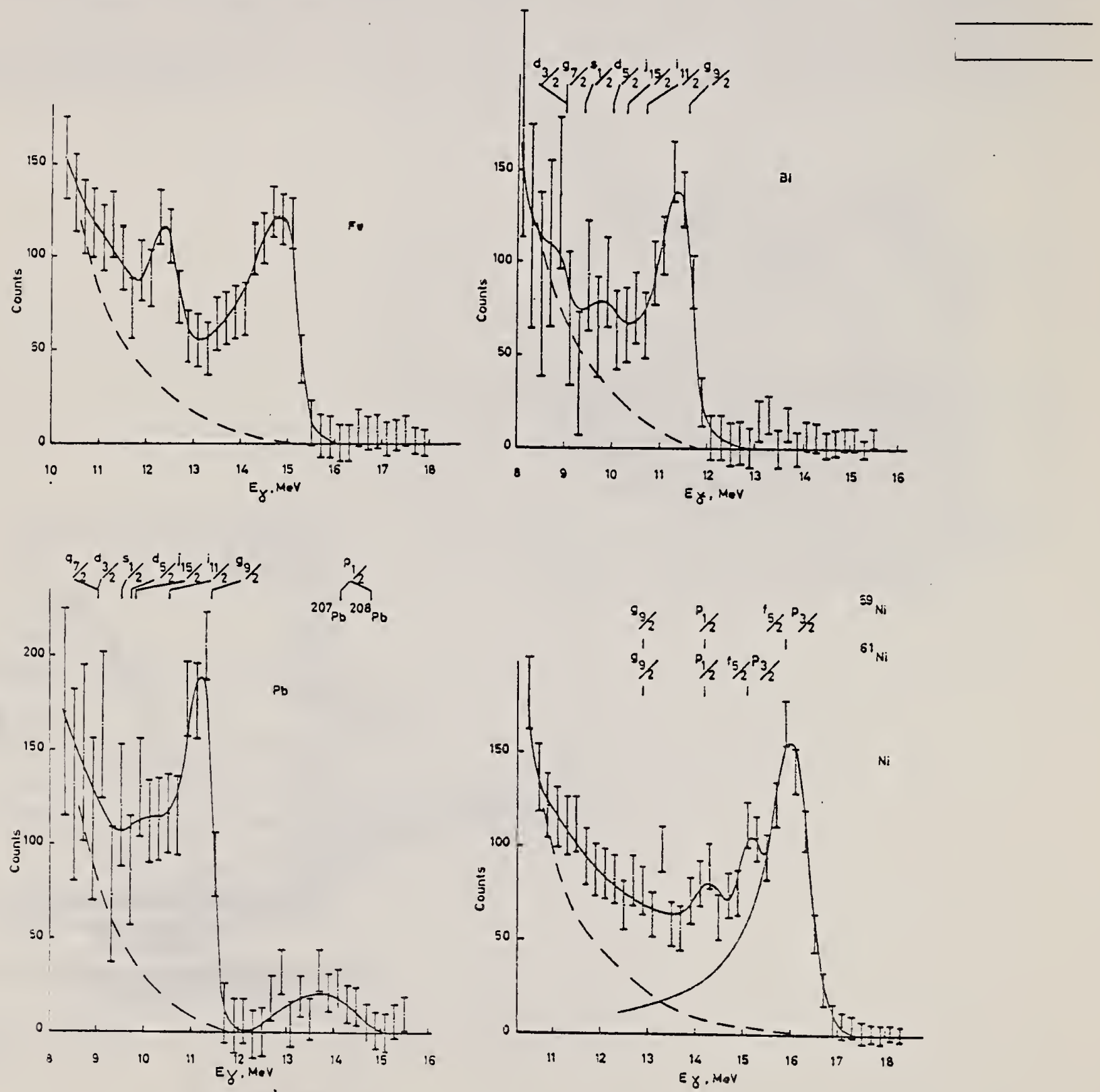

Fig. 1. Gamma-ray spectra emitted in the capture of $7.4 \mathrm{MeV}$ neutrons. The dashed line is the spectrum calculated for the decay of a compound nucleus. The dot-dashed line is the response function of the gamma-ray spectrometer for $16.0 \mathrm{MeV} \gamma$ rays. Single-particle states as determined from (d,p) reactions are shown. 
ReF. G. Ben-David, B. Arad, J. Baldeman, and Y. Schlesinger Phys. Rev. 1L6, 3852 (1966)

Nuclear Resonance Scattering using N,G reactions.

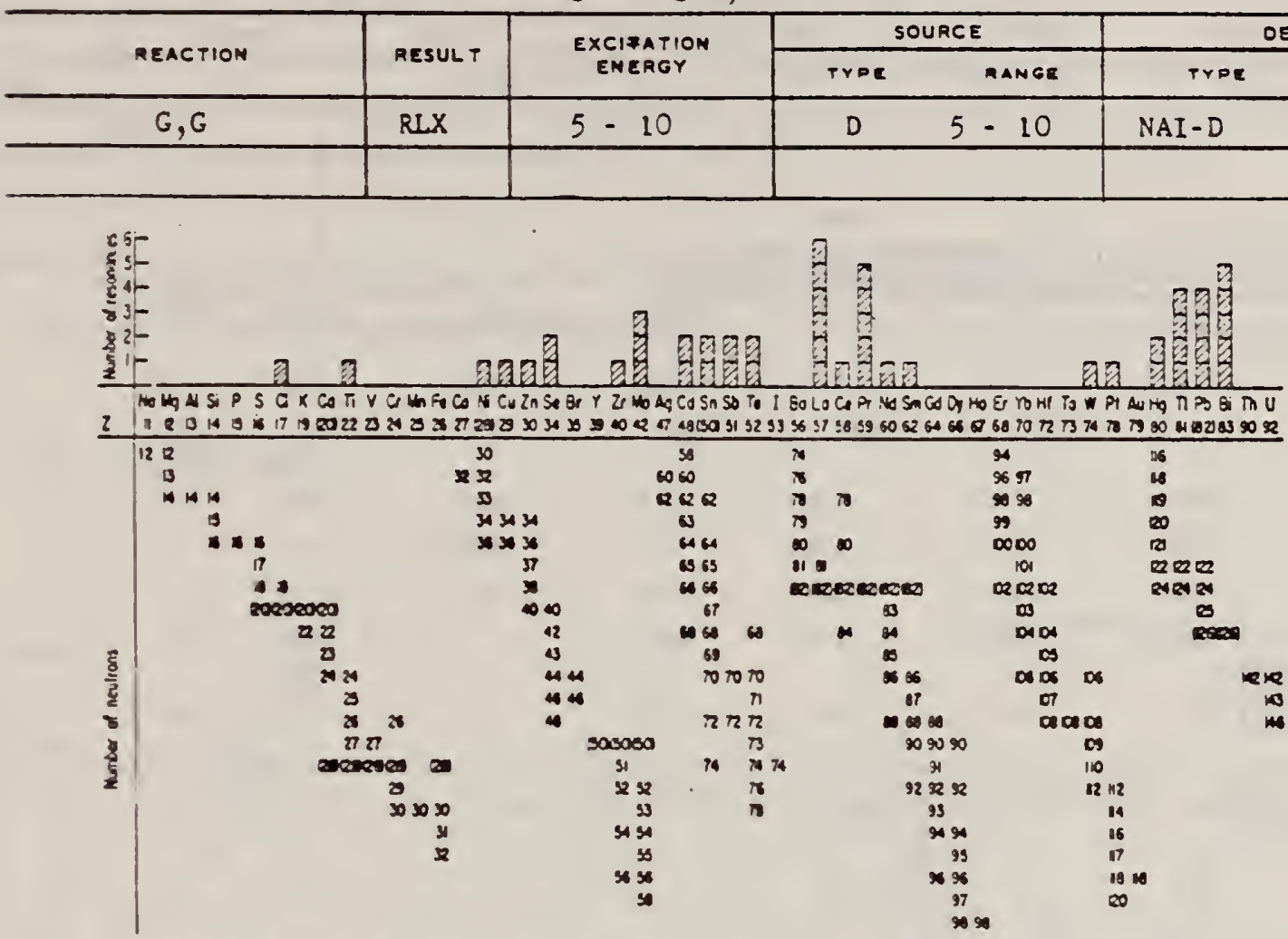

Fic. 3. Histogram of distribution of observed resonances among the different targets. The atomic number is given directiy beneatb the chemical symbol followed by the neutron numbers of the asturaly occurring isotopes. Magic numbers are shown in brackets.

TAвLE III. List of effective cross sections.

\begin{tabular}{|c|c|c|c|c|c|c|c|}
\hline Scatterer & $\begin{array}{l}\text { Energy } \\
\text { (MeV) }\end{array}$ & Comme & $(m b)$ & Scatterer & $\begin{array}{l}\text { Energy } \\
\text { (MeV) }\end{array}$ & $\begin{array}{l}\text { Garmm } \\
\text { cource }\end{array}$ & $\stackrel{1}{(m b)}$ \\
\hline 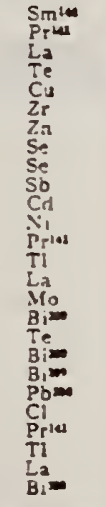 & $\begin{array}{l}8.207 \\
8.811 \\
8.532 \\
8.532 \\
3.499 \\
8.496 \\
9.119 \\
7.817 \\
7.36 \\
7.67 \\
7.54 \\
7.64 \\
7.64 \\
7.64 \\
7.634 \\
7.034 \\
7.634 \\
7.523 \\
7.416 \\
7.300 \\
7.285 \\
7.285 \\
7.185 \\
7.16 \\
7.15 \\
7.149\end{array}$ & $\begin{array}{l}\mathrm{Ni} \\
\mathrm{Cr} \\
\mathrm{Ni} \\
\mathrm{ii} \\
\mathrm{Cr} \\
\mathrm{Se} \\
\mathrm{Ni} \\
\mathrm{Ni} \\
\mathrm{K} \\
\mathrm{V} \\
\mathrm{Fe} \\
\mathrm{Fe} \\
\mathrm{Fe} \\
\mathrm{Ge} \\
\mathrm{Cu} \\
\mathrm{Cu} \\
\mathrm{Cu} \\
\mathrm{Ni} \\
\mathrm{Se} \\
\mathrm{Ag} \\
\mathrm{Fe} \\
\mathrm{Fe} \\
\mathrm{Se} \\
\mathrm{Cu} \\
\mathrm{Mn} \\
\mathrm{Ti}\end{array}$ & $\begin{array}{r}100 \\
9 \\
6 \\
30 \\
24 \\
3050 \\
13 \\
50 \\
20 \\
70 \\
400 \\
70 \\
120 \\
3700 \\
7 \\
11 \\
4 \\
664 \\
100 \\
800 \\
4100 \\
34 \\
80 \\
120 \\
50 \\
2000\end{array}$ & 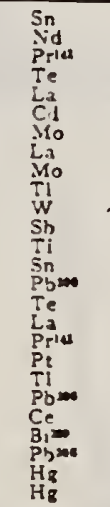 & $\begin{array}{l}7.01 \\
6.867 \\
6.867 \\
6.7 \\
6.54 \\
6.474 \\
6.44 \\
6.113 \\
6.113 \\
6.413 \\
6.3 \\
6.31 \\
6.31 \\
6.27 \\
6.15 \\
5.8 \\
6.12 \\
6.12 \\
5.79 \\
5.99 \\
5.2 \\
5.646 \\
5.646 \\
5.53 \\
5.44 \\
4.903\end{array}$ & 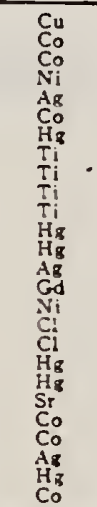 & $\begin{array}{c}110 \\
30 \\
3 \\
\ldots \\
12 \\
110 \\
256 \\
72 \\
10 \\
25 \\
\ldots .6 \\
60 \\
20 \\
75 \\
\ldots 1 \\
\ldots 15 \\
35 \\
110 \\
40=0 \\
54 \\
\ldots 7 \\
17 \\
55 \\
70 \\
754 \\
385\end{array}$ \\
\hline
\end{tabular}

- Hish-enerzy component of a comple opectrum.

- A broal scattered spectrum vich no observable deak structure.

- There are actualy itwo lines of energies 7.647 and $8.633 \mathrm{MeV}$ having equal incensities in the iron capture gamma spectrum. The cross section deciding xhich line is resoonsibie for each resonance.

in on Te. mirs on Te.

1 May be indiastic componeat from 7.538 leved is Te

- The relative lise intentes in this cae are due to Grouber and co-workers.

i No line is knowe for the source at this eners. 


\begin{tabular}{|c|c|c|c|c|c|c|c|}
\hline $\begin{array}{l}\text { METHOD } \\
\text { Betatron }\end{array}$ & & & & & & $\begin{array}{r}\text { REF. NO. } \\
66 \text { Ho } 3\end{array}$ & JDM \\
\hline \multirow[b]{2}{*}{ REACTION } & \multirow[b]{2}{*}{ RESULT } & \multirow{2}{*}{$\begin{array}{l}\text { EXCITATION } \\
\text { ENERGY }\end{array}$} & & & \multicolumn{2}{|c|}{ DETECTOR } & \multirow{2}{*}{ ANGLE } \\
\hline & & & TYPE & RANGE & TYPE & RANGE & \\
\hline$G, A$ & SPC & THR- 31 & C & 31 & SCD-D & $3-14$ & 130 \\
\hline
\end{tabular}

TABLE 1

Experimental data and results

\begin{tabular}{|c|c|c|c|c|c|c|c|}
\hline Element & $\mathbf{M g}$ & Al & $\mathbf{s}$ & $\mathrm{Ni}$ & $\mathrm{Cu}$ & $\mathrm{Zn}$ & Error $(\%)$ \\
\hline target thickness $\left(\mathrm{mg}^{\prime} \mathrm{cm}^{2}\right)$ & $0.8 !$ & 1.54 & 0.80 & .2 .50 & 2.68 & 3.00 & $5 \bullet$ \\
\hline dose $(r)$ & 6190 & 25400 & 23200 & $3880^{-}$ & 5840 & 4220 & 10 \\
\hline $\begin{array}{l}\text { yield absolute }\left(10^{s} / \mathrm{mole} \cdot \mathrm{r}\right) \\
\text { for } E_{\mathrm{m}}>3.16 \mathrm{MeV}\end{array}$ & 0.61 & 0.93 & 1.46 & 1.65 & 0.92 & 2.42 & $11 *$ \\
\hline yield relative to $\mathrm{Ni}$ & 0.36 & 0.56 & 0.88 & 1 & 0.55 & 1.43 & 54) \\
\hline$Y_{Y, 2} / Y_{Y, \operatorname{lot}}(\%)$ & 9.6 & 11.4 & 12.4 & 7.0 & 3.2 & b) & \\
\hline nuclear temp. $\theta(\mathrm{MeV})$ & 1.43 & 1.48 & 1.46 & 1.04 & & 0.91 & 10 \\
\hline $\begin{array}{l}\text { level density parameter a } \\
\left(\mathrm{MeV}^{-1}\right)\end{array}$ & 5.1 & 4.8 & 4.9 & 8.6 & & 10.8 & 10 \\
\hline
\end{tabular}

2) For $\mathrm{S}$, the error of the target thickness has been $10 \%$ of the absolute yield $14 \%$ and of the relative yield $10 \%$.

b) For $Z_{n} \sigma_{y, t o t}$ is not known.
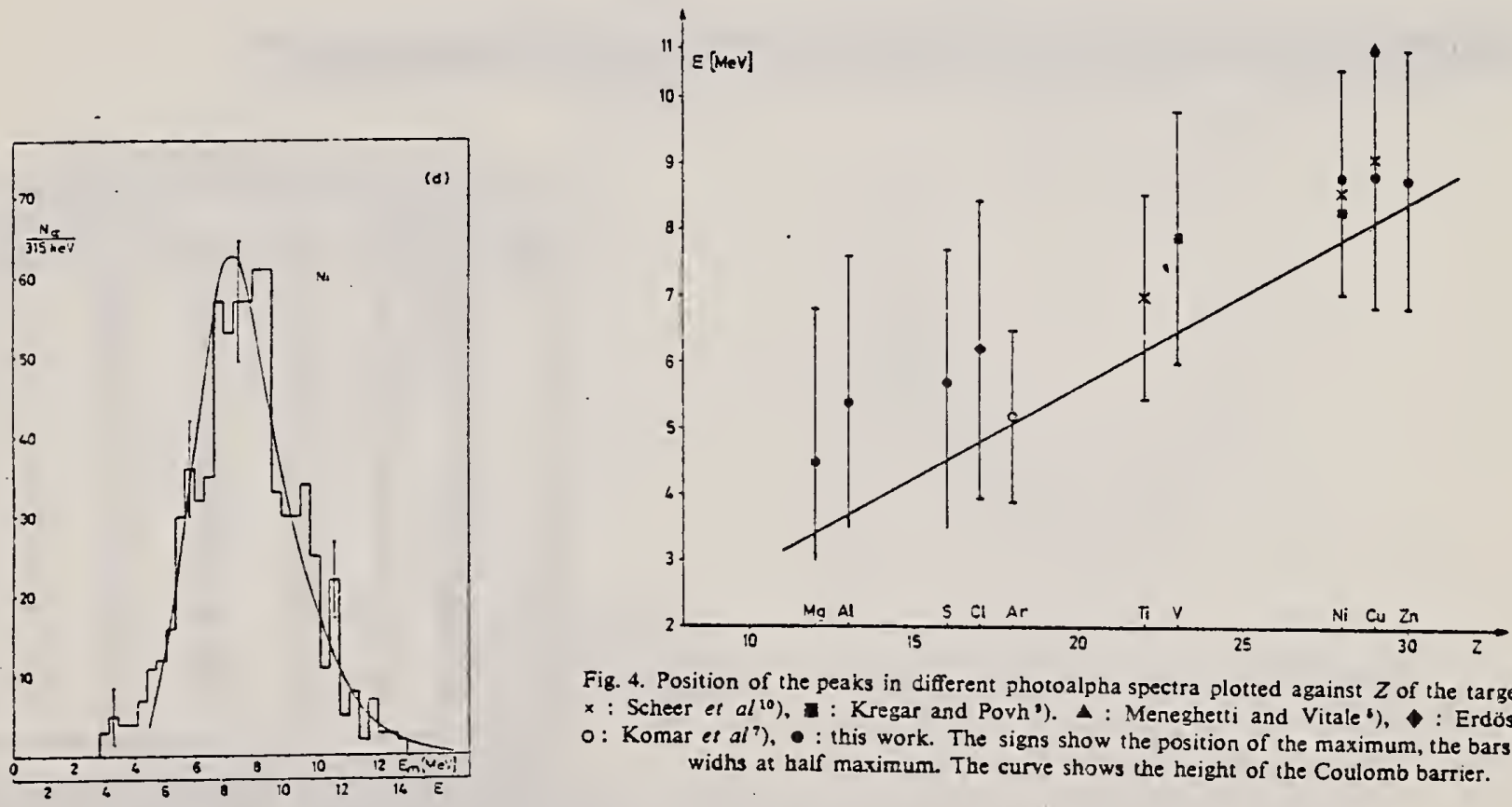

Fig. 4. Position of the peaks in different photoalpha spectra plotted against $Z$ of the target nuclei. $x$ : Scheer et $\left.a l^{10}\right)$, : : Kregar and Povh'). $\Delta$ : Meneghetti and Vitale $\left.{ }^{\prime}\right)$, : Erdös et al $\left.{ }^{1}\right)$, 0 : Komar ef $\left.a l^{7}\right)$, : this work. The signs show the position of the maximum, the bars give the widhs at half maximum. The curve shows the height of the Coulomb barrier.

Fig. 3d-e. Photozlpha spectra of $\mathrm{Ni}$ and $\mathrm{Zn}$. Notations as in fig. 3a-c.

Fig. 3f. Statistisal plot of the measured spectea. The straight lines ate dratin to give the best fit. 


\begin{tabular}{c|c|c}
\hline REACTION & RESULT & $\begin{array}{c}\text { EXCITATTO } \\
\text { ENERGY }\end{array}$ \\
\hline$G, N$ & ABY & THR-22 \\
\hline & & \\
\hline & & \\
\hline
\end{tabular}

YIELO AT EO = $22 \mathrm{M} \bullet V$

${ }^{20}$ si $(n, p)$ ACTIVATION BY PHOTONEUTRONS
Fic. 3. The yields of fast photoneutrons from various elements as measured in the present work and by Baker. The present results have been normalized to Baker's measurements for lead.
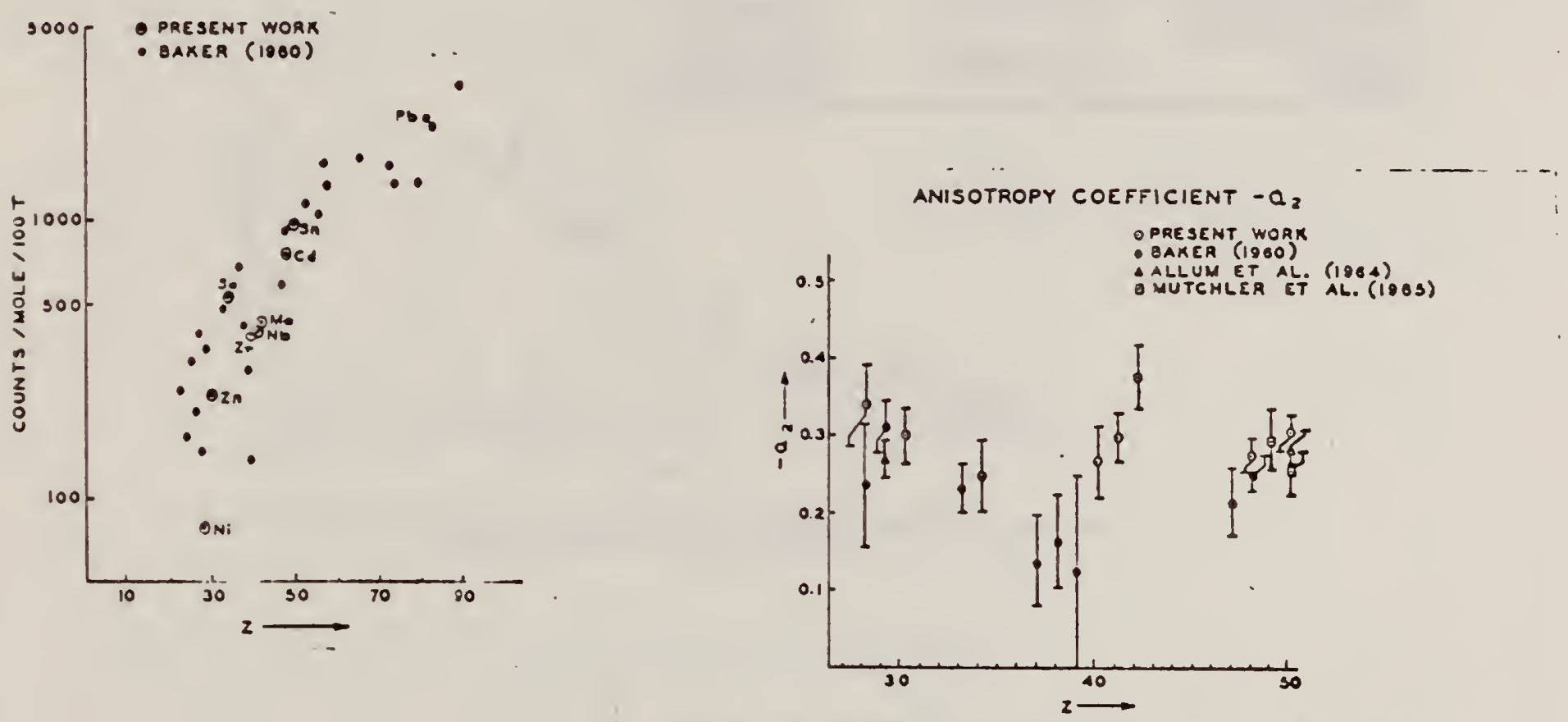

FIc. 2. The arisotropy coefficients $a_{2}$ in the formula $W(\theta)-c_{0}\left(1+a_{1} P_{1}+a_{9} P_{2}\right)$, obtained in the present work, and those obtained by other worken in the same part of the Periadic Table.

TABLE I

\begin{tabular}{|c|c|c|c|}
\hline Element & $\infty_{0}$ & $a_{1}$ & $a_{1}$ \\
\hline $\begin{array}{l}\text { Nickel } \\
\text { Zinc } \\
\text { Sclenium } \\
\text { Zirconium } \\
\text { Niobium } \\
\text { Molbdenum } \\
\text { Cadmium } \\
\text { Tin } \\
\text { Lead }\end{array}$ & $\begin{array}{r}77(1.0 \pm 0.05) \\
236(1.0 \pm 0.04) \\
325(1.0 \pm 0.05) \\
350(1.0 \pm 0.05) \\
392(1.0 \pm 0.03) \\
110(1.0 \pm 0.03) \\
755(1.0 \pm 0.02) \\
9.25(1.0 \pm 0.02) \\
2274(4.0 \pm 0.02)\end{array}$ & $\begin{array}{l}0.14=0.04 \\
0.06 \pm 0.03 \\
0.10 \pm 0.04 \\
0.03 \pm 0.04 \\
0.04 \pm 0.02 \\
0.0 .5 \pm 0.03 \\
0.05 \pm 0.01 \\
0.05 \pm 0.02 \\
0.06 \pm 0.02\end{array}$ & $\begin{array}{l}-0.3 \cdot 1=0.06 \\
-0.30 \pm 0.04 \\
-0.25 \pm 0.05 \\
-0.27 \pm 0.05 \\
-0.30 \pm 0.03 \\
-0.41 \pm 0.04 \\
-0.28 \pm 0.02 \\
-0.30 \pm 0.02 \\
-0.48 \pm 0.02\end{array}$ \\
\hline
\end{tabular}

that oblainel by Bak-r and MeNetli (1901) and is the yield pes 
PEF.

P. Kneisel, A. Goldmann and H. V. Buttlar

Z. Physik 199, $440(1967)$

\begin{tabular}{|c|c|c|c|c|c|c|c|}
\hline $\begin{array}{l}\text { METHOD } \\
\text { LinaC }\end{array}$ & & . & & & & $\begin{array}{l}\text { REF. NO. } \\
67 \mathrm{Kn} 1\end{array}$ & JDM \\
\hline \multirow[b]{2}{*}{ REACTION } & \multirow{2}{*}{ RESULT } & \multirow{2}{*}{$\begin{array}{c}\text { EXCITATION } \\
\text { ENERGY }\end{array}$} & \multicolumn{2}{|c|}{ SOURCE } & \multicolumn{2}{|c|}{ DETECTOR } & \multirow{2}{*}{ ANGLE } \\
\hline & & & TYPE & RANGE & TYPE & RANGE & \\
\hline \multirow[t]{2}{*}{$\mathrm{G}, \mathrm{T}$} & RLY & THR- 49 & C & 36,49 & \multicolumn{2}{|l|}{$\mathrm{ACT}-\mathrm{I}$} & $4 P I$ \\
\hline & & & & & \multicolumn{2}{|l|}{. } & \\
\hline & & & & & & & \\
\hline & & & & & & & \\
\hline
\end{tabular}

Tabelle. Zusammenstellung der Meßergebnisse

\begin{tabular}{l|l|l}
\hline & $E_{m}=36,2 \mathrm{MeV}$ & $E_{m}=49,2 \mathrm{MeV}$ \\
\hline$Y[\mathrm{Ni}(\gamma, t)] / Y\left[C(\gamma, n) C^{11}\right]$ & $(2,2 \pm 0,2) \cdot 10^{-3}$ & $(4,6 \pm 0,4) 10^{-3}$ \\
$Y[\operatorname{Pd}(\gamma, t)] Y\left[C(\gamma, n) C^{11}\right]$ & - & $(6,1 \pm 1,0) 10^{-3}$ \\
$\sigma_{y}[\mathrm{Ni}(\gamma, t)]$ & $(4,0 \pm 0,4) \mu b \mathrm{barn}$ & $(10,5 \pm 1,0) \mu \mathrm{bam}$ \\
$\sigma_{y}[\operatorname{Pd}(\gamma, t)]$ & - & $(13,8 \pm 2,3) \mu \mathrm{barn}$ \\
\hline
\end{tabular}


S. Costa, C. Manfredotti, L. Pasqualini, F. Ferrero Nuovo Cimento 54B, 344 (1968)

\begin{tabular}{|c|c|c|}
\hline SLEM. SYM. & A & 2 \\
\hline $\mathrm{Ni}$ & & 28 \\
\hline REF. NO. & & \\
\hline $68 \mathrm{Co}$ & 3 & egf \\
\hline
\end{tabular}

\begin{tabular}{|c|c|c|c|c|c|c|c|}
\hline \multirow{2}{*}{ DEACTION } & \multirow{2}{*}{ FESULT } & \multirow{2}{*}{$\begin{array}{c}\text { EXCITATION } \\
\text { ENERGY }\end{array}$} & \multicolumn{2}{|c|}{ SOURCE } & \multicolumn{2}{|c|}{ OETECTOR } & \multirow{2}{*}{ ANGLE } \\
\hline & & & TYOE & RANGE & TYPE & FANGE & \\
\hline$G, x N$ & $A B X$ & $11-34$ & C & $11-34$ & $B F 3-I$ & & $4 \mathrm{PI}$ \\
\hline \multicolumn{8}{|l|}{. } \\
\hline & & & & & & & \\
\hline & & & & & & & \\
\hline
\end{tabular}

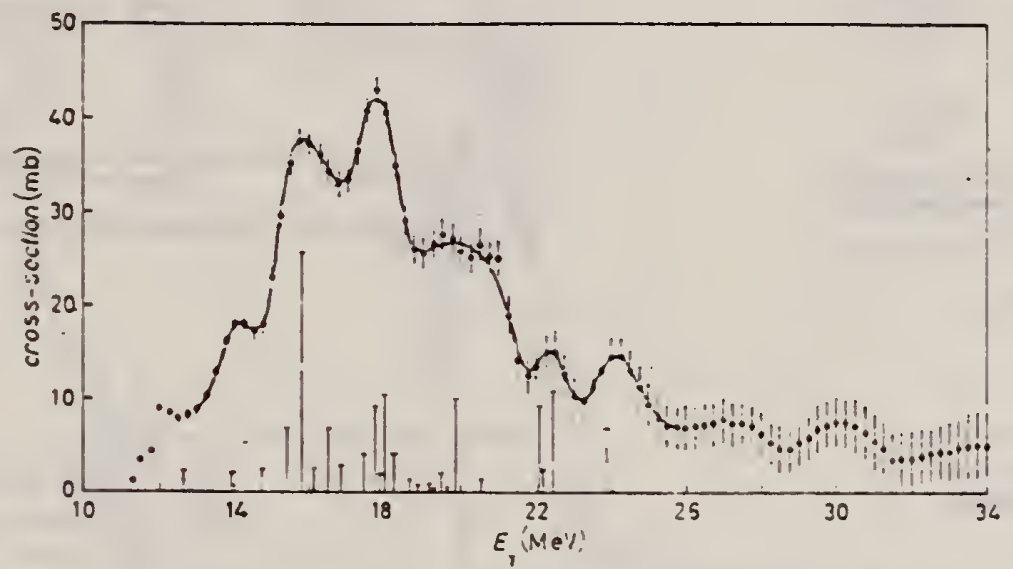

Fis. 1. - Experimental photnneutron crossection in natural Ni. The rertlenl bars represcnt the dipole etrengtbe predicted by the iheory (sec text). 
$68 \mathrm{Fi} 1$

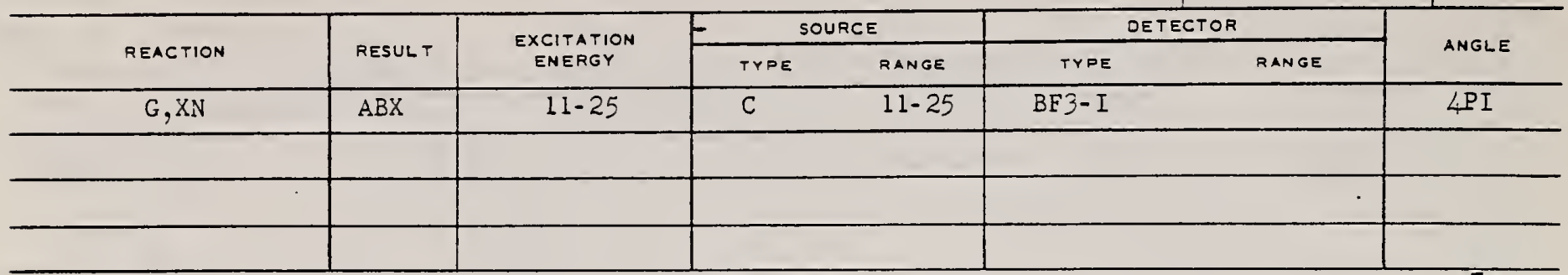

TABLZ II. Results.

\begin{tabular}{|c|c|c|c|}
\hline$\sigma_{m}(m b)$ & $\begin{array}{l}\text { Nickel [witho } \\
E_{m}(\mathrm{MeV})\end{array}$ & $\begin{array}{l}\text { out }(\gamma, 2 n) \text { correction] } \\
\sigma_{10 \mathrm{t}}(\mathrm{MeV} \mathrm{mb})\end{array}$ & Reference \\
\hline \multirow[t]{2}{*}{$\begin{array}{l}41.9 \pm 0.4 \\
46 \pm 1\end{array}$} & $\begin{array}{l}15.9 \\
16.5\end{array}$ & $\begin{array}{l}291.1 \pm 11(24)^{2} \\
276 \pm 25(24)^{2}\end{array}$ & $\begin{array}{c}\text { This work } \\
15\end{array}$ \\
\hline & Silver [with & $(\gamma, 2 n)$ correction ] & \\
\hline $\begin{array}{l}181 \pm 1 \\
240 \pm 17\end{array}$ & $\begin{array}{l}16.3 \\
16.0\end{array}$ & $\begin{array}{l}1254(24) a . b \\
1600(21)^{a . b}\end{array}$ & $\begin{array}{c}\text { This work } \\
16^{\circ}\end{array}$ \\
\hline
\end{tabular}

- The numbers in parenthesis are the upper limits of integration for

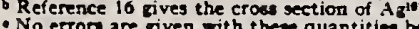

作 the neutron muleidleity cortection.

14 D. B. Thomson, Phys. Rev. 129, 1649 (1963).
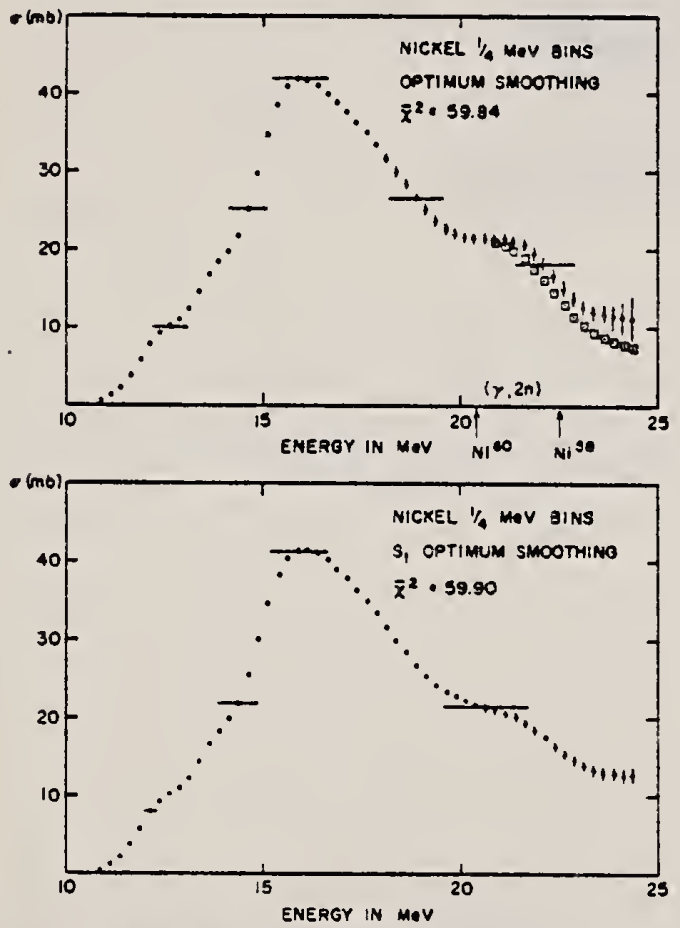

Fic. 1. Least-structure solutions for natural nickel. Upper curve: optimum smoothing using $S:[\mathrm{Eq}$. (3b)]; lower curve; optimum smoothing using $S_{\uparrow}[\mathrm{Eq}$. (3a) $]$.
TABLE III. Integrated partial cross sections up to $24 \mathrm{MeV}$ for the natural nickel, $\mathrm{Ni}^{\text {is }}$ and $\mathrm{Ni}^{\text {to }}$

\begin{tabular}{|c|c|c|c|c|}
\hline & 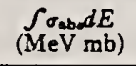 & $\begin{array}{l}f_{\sigma}(\gamma, n) d E \\
\left(\mathrm{MeV}_{\mathrm{mb}}\right)\end{array}$ & $\begin{array}{c}\mathcal{S}_{\sigma}(\gamma, p) d E \\
(\mathrm{MeV} \mathrm{mb})\end{array}$ & $\begin{array}{l}\mathcal{S}_{\sigma}(\gamma, \beta) d E / \\
\mathcal{S}_{\sigma}(\gamma, \boldsymbol{n}) d E\end{array}$ \\
\hline $\begin{array}{l}\text { Natural } \\
\mathrm{Ni}^{20} \\
\mathrm{Ni}^{* 0}\end{array}$ & $650^{\circ}$ & $\begin{array}{l}290 \\
180^{b} \\
570\end{array}$ & $\begin{array}{l}360 \\
440^{\circ} \\
160\end{array}$ & $\begin{array}{l}1.2 \\
2.4 \\
0.28\end{array}$ \\
\hline
\end{tabular}

- Taken from Ref. 18. Taken from Ref. 21.

" J. H. Carver and W. Turchinetz. Proc. Phys. Soc. (London) 73,585 (1959).
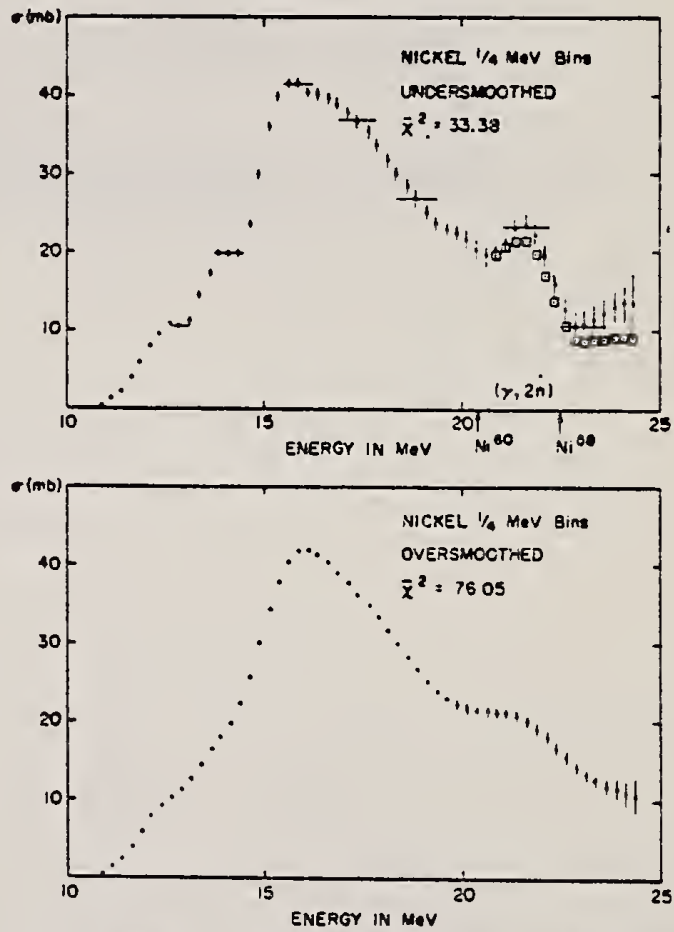

FrG. 2. Least-structure soiutions for natural nickel. Upper curve: undersmoothed solution, $x^{2}=33.38$; lower curve: oversmoothed solution, $x^{2}=76.05$. 


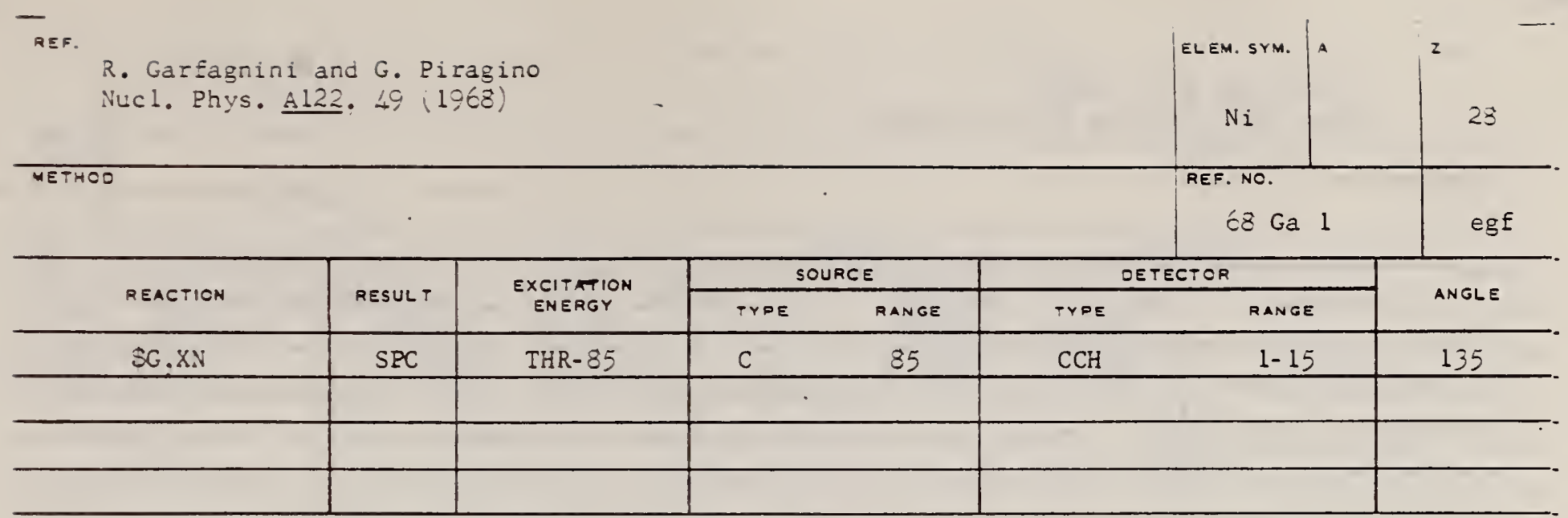
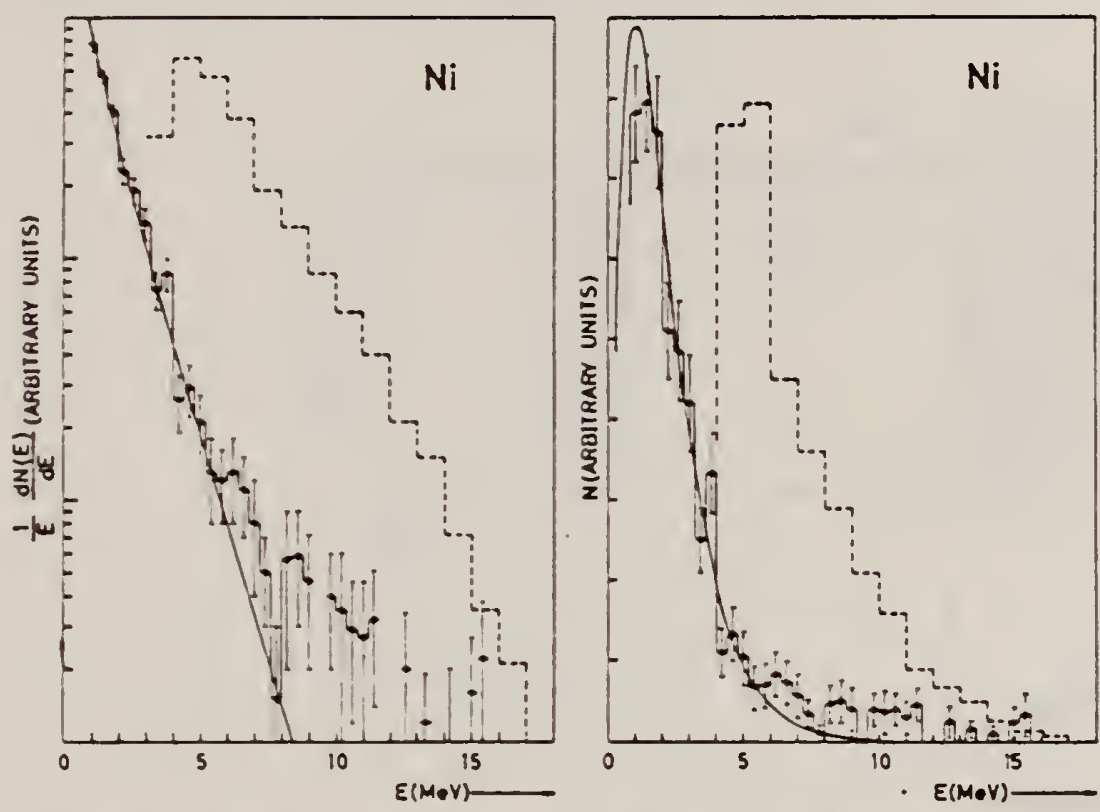

Fig. 6. Esergy spectrum of photoneutrons from natural nickel compared with the spectrum of photoneutrons tor $E_{\mathrm{gng}}=28 \mathrm{MeV}$ of ref. 2 ) (dashed histogram) and with the evaporation-model prediction (full line). The normalization used is described in the text.

${ }^{23}$ E. Lejkin, R. Osokina and B. Ratner, Nuovo Cim. Suppl. 2, 105 (196́).
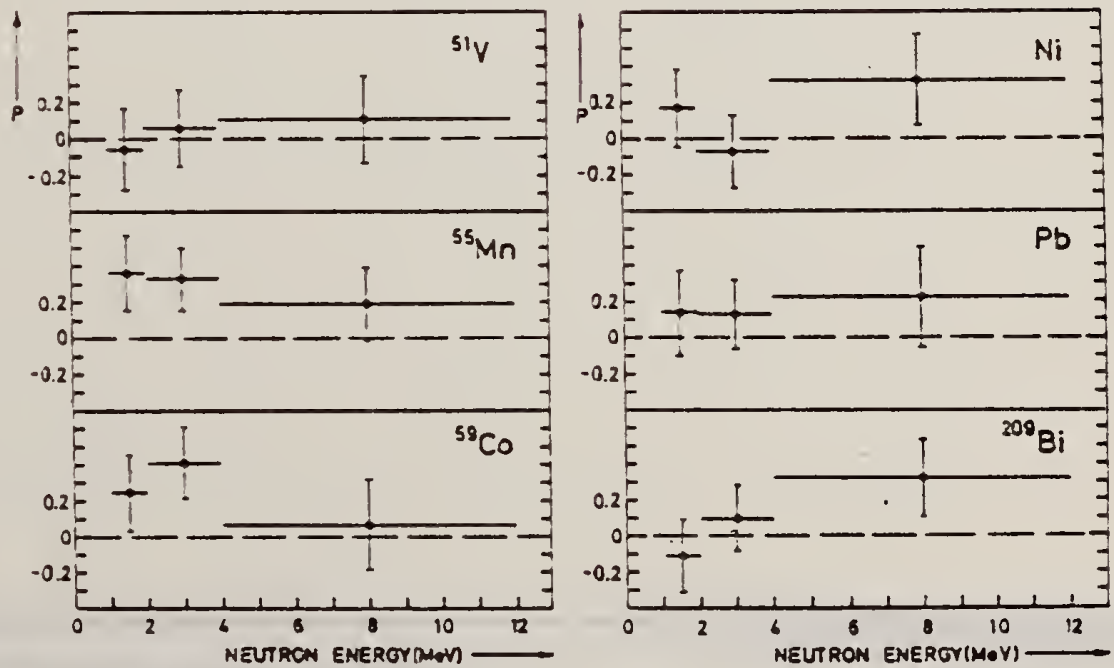

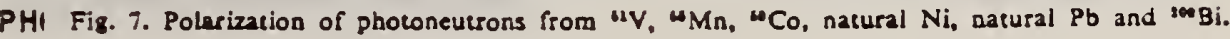


REF.

K. Min and T. A. White

Phys. Rev. Letters 21, 1200 (1968)

\begin{tabular}{c|c|c} 
ELEM. SYM. & A & 2 \\
Ni & & 28 \\
\hline REF. NO. & egf \\
\hline
\end{tabular}

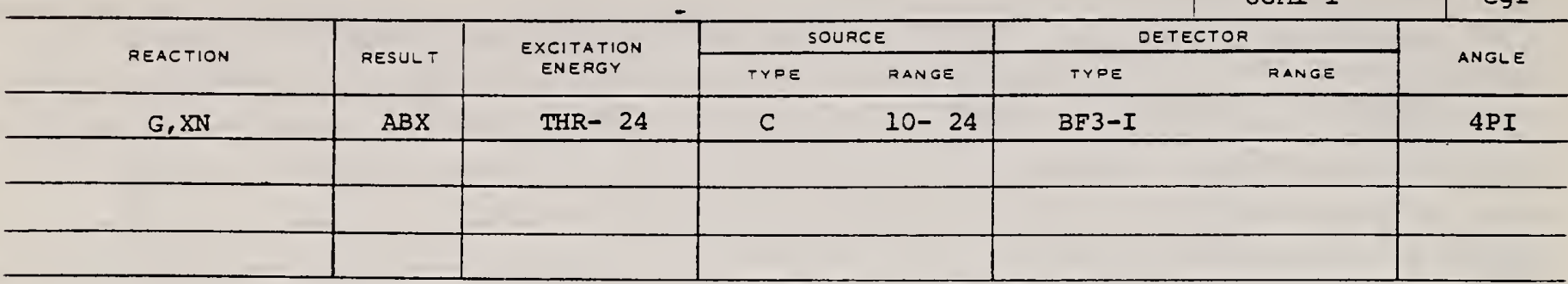

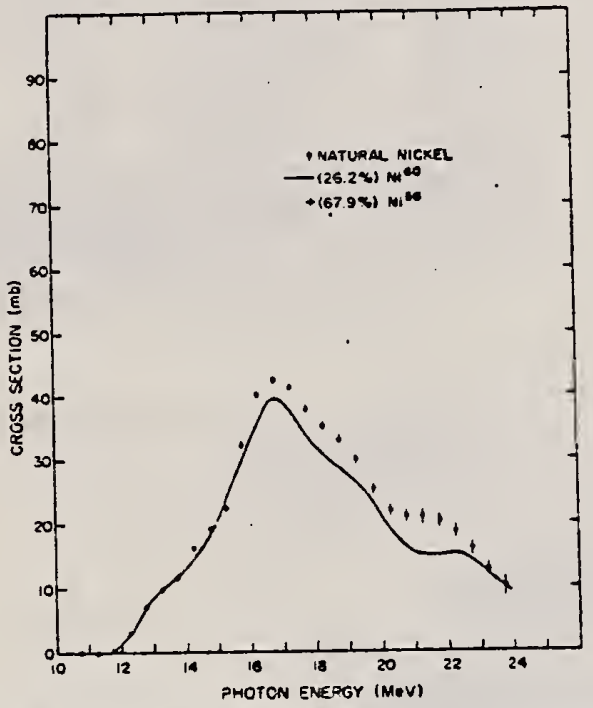

FIG. 2. Photoneutron cross section of natural nickel and the sum of $\mathrm{Ni}^{60}$ and $\mathrm{Ni}^{58}$ contributions. 
R. Cesareo, M. Giamini. P. Oliva, D. Prosperi and M. C. Ramorino Nuc1. Phys. A132, 512 (190́9)

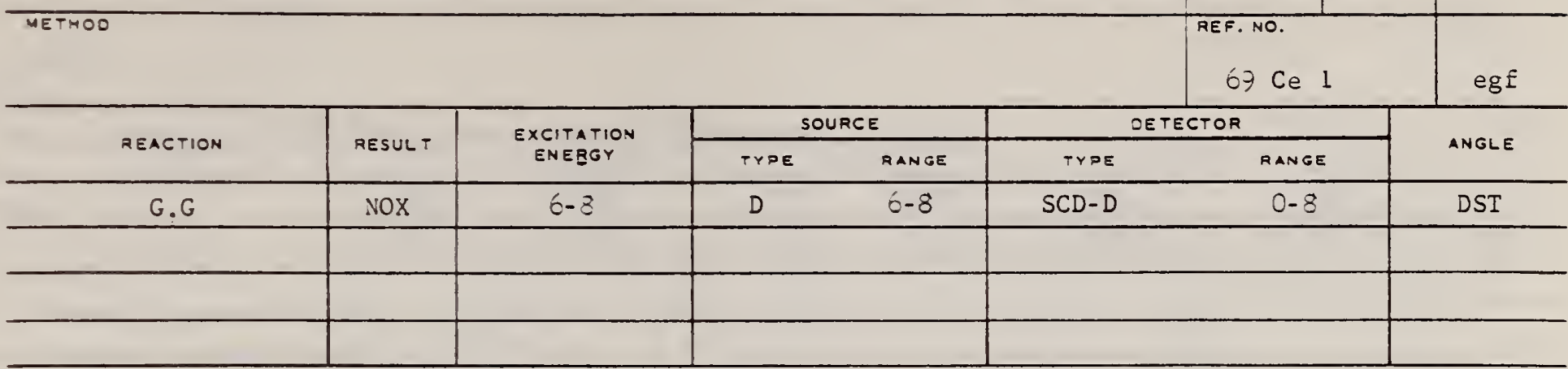

TABLE' 5

Energies and relative intensities of elastic and inelastic $\%$ transitions scattered from $\mathrm{Ni}$

\begin{tabular}{|c|c|c|c|c|}
\hline$E_{-,}($heV $)$ & $I_{y}(\mathrm{rel})$ & $\left.\left.I_{y}(\mathrm{rel})\right)^{\prime}\right)$ & $E_{y}(n, y)$ fe $\left.{ }^{\circ}\right)$ & $\left.t_{y}(n, y)_{F e}{ }^{0}\right)$ \\
\hline $\begin{array}{l}\therefore 60-6=2 \\
6266=4\end{array}$ & $\begin{array}{r}21.0=0.6 \\
3.0=0.5\end{array}$ & $23=8$ & $\begin{array}{l}\text { inel. trans. } \\
\text { elastuc trans. } \\
E_{\gamma}\left(n, y_{\mathrm{fc}}=6269 \pm 8^{\circ}\right)\end{array}$ & 3.5 \\
\hline $\begin{array}{l}6470=4 \\
6977=4\end{array}$ & $\begin{array}{l}5.2=0.5 \\
3.5 \pm 0.8\end{array}$ & $3=2$ & & \\
\hline 7646 & $73.8=6.0$ & $69=8$ & $\begin{array}{l}\text { elastic trans. } \\
E_{\gamma}\left(n_{0} ;\right)_{\mathrm{Fe}}=76+6=1^{\circ} \text { ) }\end{array}$ & 32 \\
\hline
\end{tabular}

•) Rei. ${ }^{\circ}$.

-, Rei."', 
R. Garfagnini, G. Piragino \& A. Zanini

Atti Accad. Naz. Lincei, Rend.

C1. Sc1. Fis. Mat. Natur. 47, 33 (1969)

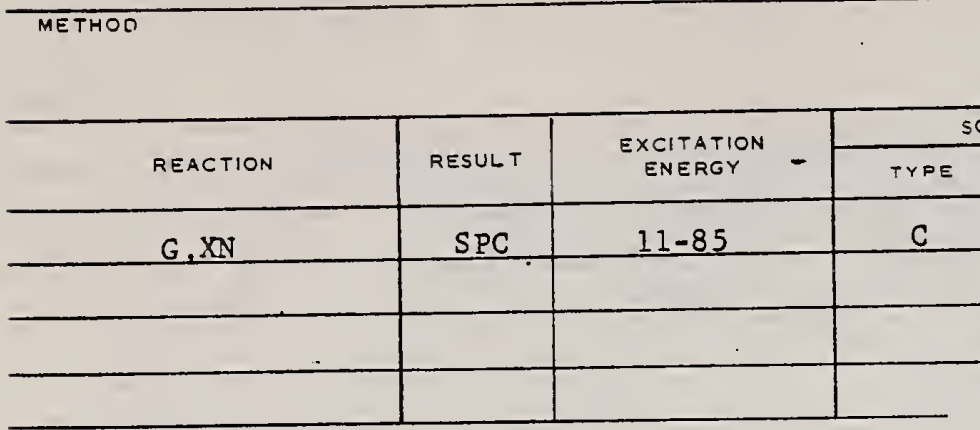
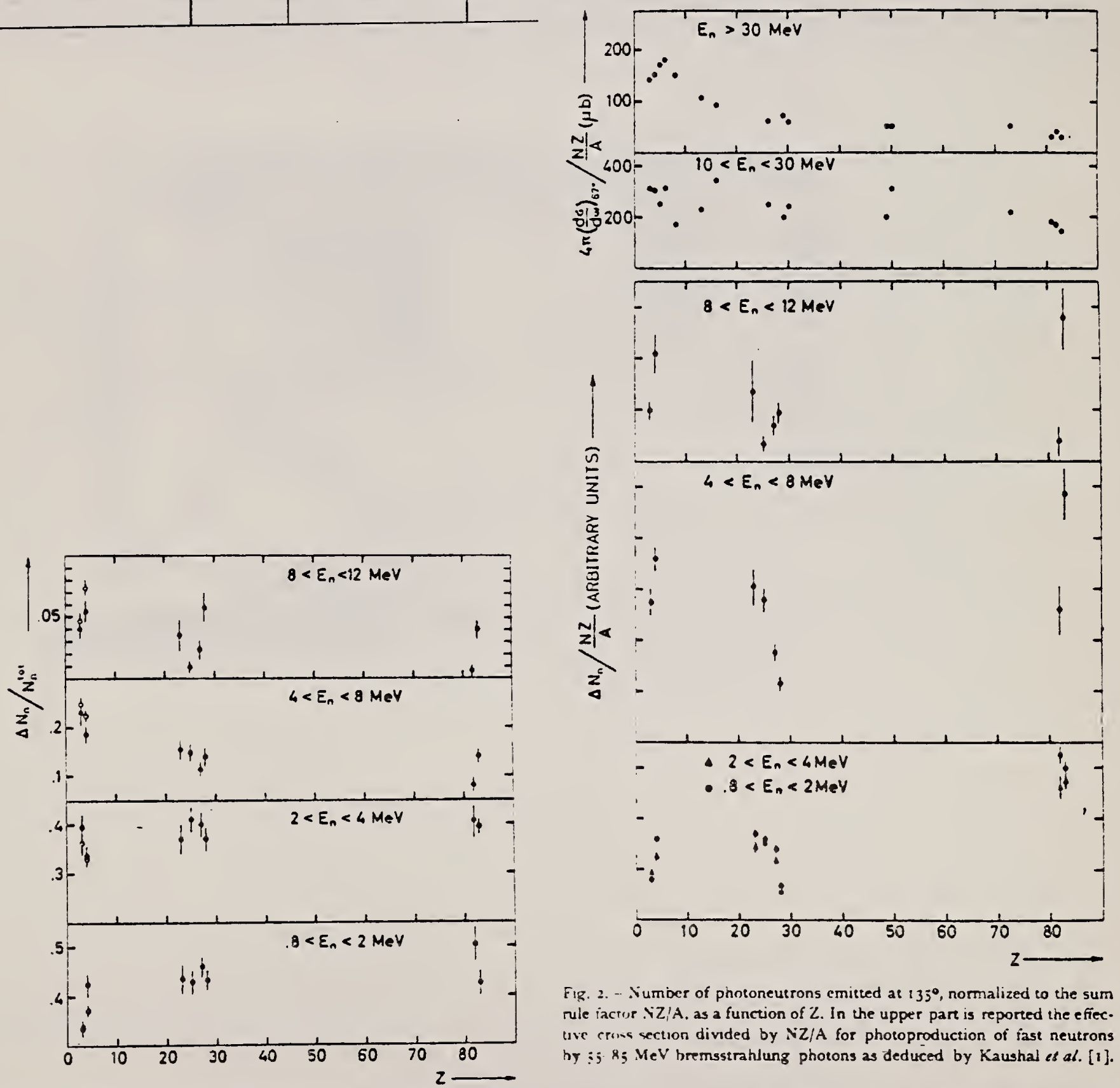

Fig. 2. - . Number of photoneutrons emitted at $133^{\circ}$, normalized to the sum rule iactis . $Y Z / A$, as a function of $Z$. In the upper part is reported the effec. tive crins section divided by NZ/A for photoproduction of fast neutrons hy $: 5.85 \mathrm{MeV}$ bremsstrahlung photons as deduced by Kaushal et al. [1].

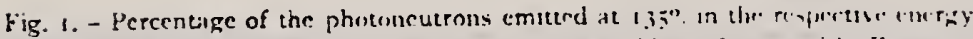
interval as a function of $\%$. by a $y$ - ray brems-tribiling beam with Fymax - -

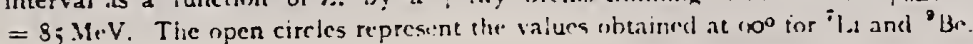

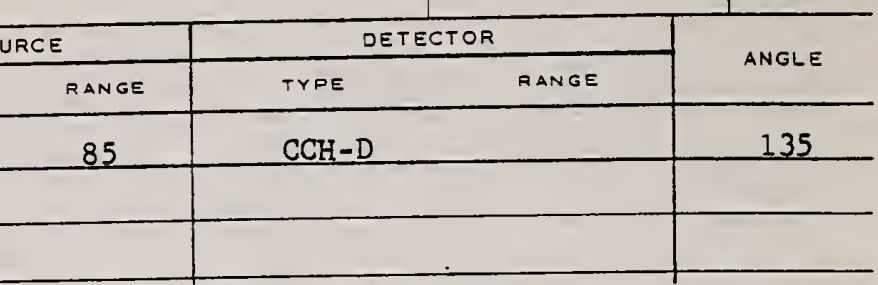


Yu. P. Antuf'ev, V. L. Agranovich, V. G. Ganenko, V. S. Kuz'menko, I. I. Miroshnichenko, and P. V. Sorokin

Yad. Fiz. 12, 11+3 (1970); Sov. J. Nucl. Phys. 12, 627 (1971)

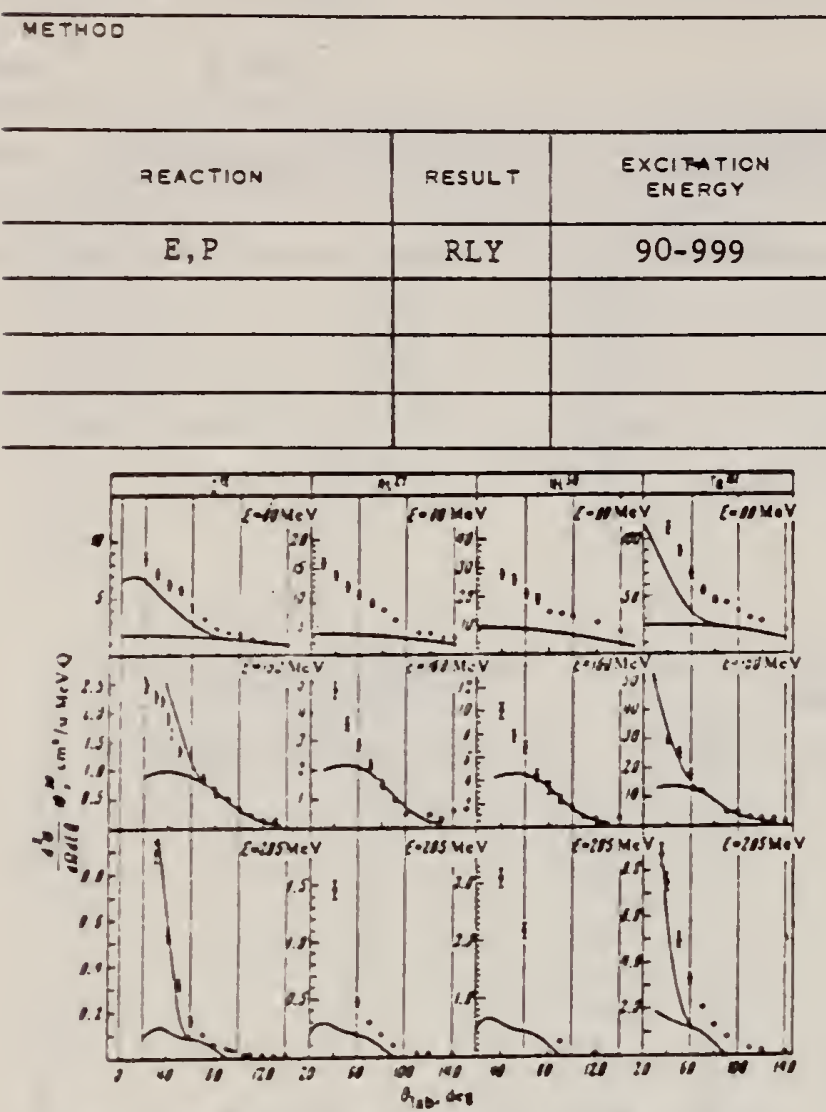

FIC. 1. Angular distnbutions of protons with enerzees of $80,160$. and $285 \mathrm{MeV}$ produced from $\mathrm{C}^{12}, \mathrm{Al}^{2 ?}, \mathrm{~N}_{1}$. and $\mathrm{TI}^{121}$ nuclel by pho cons with maximum energy $1140 \mathrm{MeV}$. Only the statisucal errors are shown.

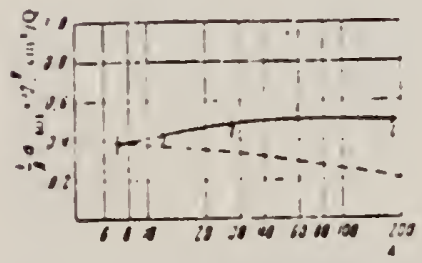

FIG. 3

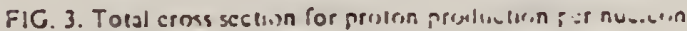

$E_{\text {max }}=11: 0 \mathrm{McV}$. : swad curve-lucury tro... ref ii.

11.K. S. Kölbig and B. Margolis, Nucl. Phys. B6, 85 (1968). 
REF.

T. Methasiri and S. A. E. Johansson

Nucl. Phys. Aló7, 97 (1971)

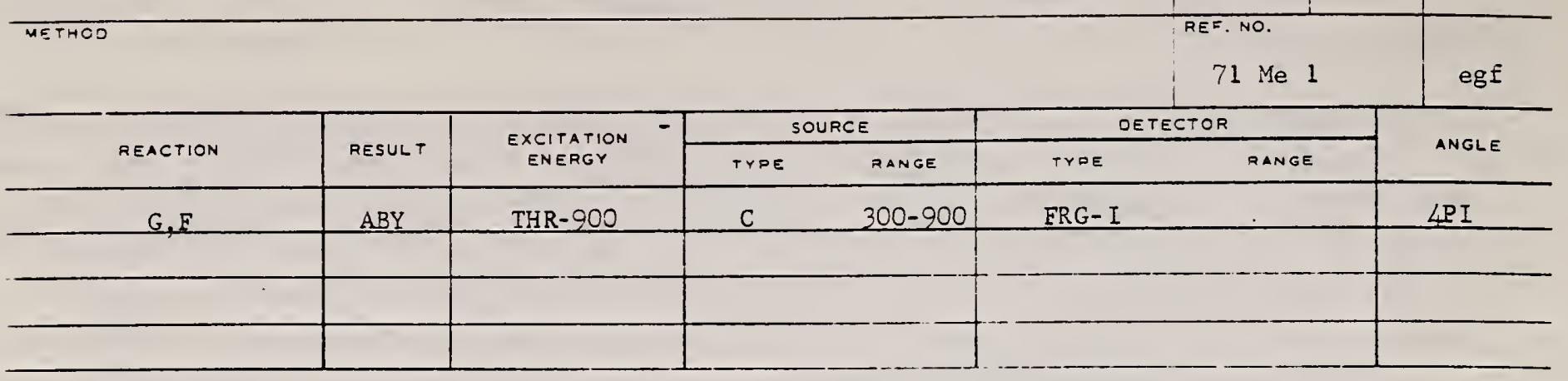

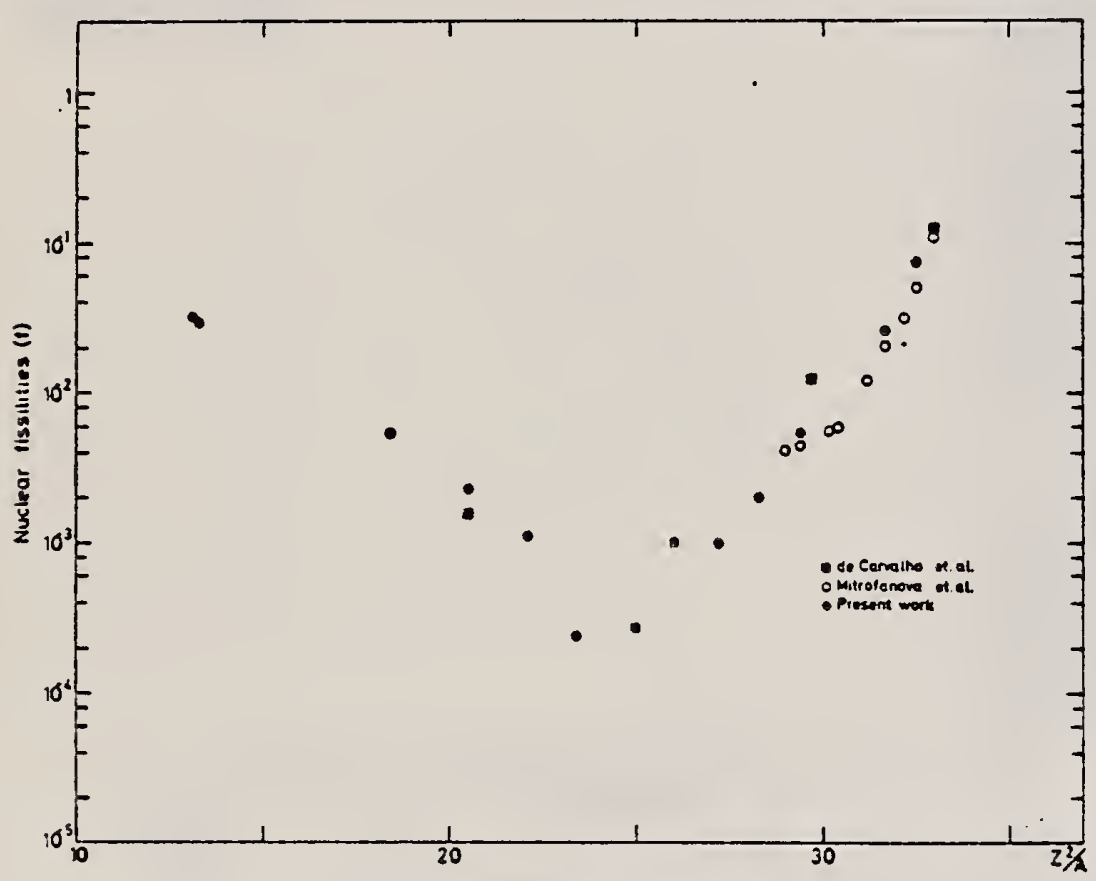

Fig. 2. Nuclear fissilities as a function of $Z^{2} / A$.

TABL 1

The constant fission sross scctions above the threshold

\begin{tabular}{cccc}
\hline Element & $\sigma_{\mathrm{f}}\left(\mathrm{cm}^{2}\right)$ & Element & $\sigma_{\mathrm{f}}\left(\mathrm{cm}^{2}\right)$ \\
\hline $\mathrm{Pb}$ & $(5.0 \pm 0.2) \times 10^{-29}$ & $\mathrm{La}$ & $(1.1 \pm 0.1) \times 10^{-39}$ \\
$\mathrm{Au}$ & $(1.7 \pm 0.1) \times 10^{-27}$ & $\mathrm{Sn}$ & $(4.3 \pm 1.1) \times 10^{-29}$ \\
$\mathrm{Ta}$ & $(3.3 \pm 0.2) \times 10^{-21}$ & $\mathrm{Az}$ & $(8.4 \pm 2.0) \times 10^{-39}$ \\
$\mathrm{Yb}$ & $(1.2 \pm 0.2) \times 10^{-23}$ & $\mathrm{Mo}$ & $(1.7 \pm 0.4) \times 10^{-21}$ \\
$\mathrm{Ho}$ & $(5.5 \pm 0.3) \times 10^{-23}$ & $\mathrm{Cu}$ & $(6.6 \pm 1.2) \times 10^{-21}$ \\
$\mathrm{Gd}$ & $(5.3 \pm 0.8) \times 10^{-29}$ & $\mathrm{Ni}$ & $(5.8 \pm 0.1) \times 10^{-30}$ \\
$\mathrm{Nd}$ & $(1.3 \pm 0.2) \times 10^{-29}$ & & \\
\hline
\end{tabular}




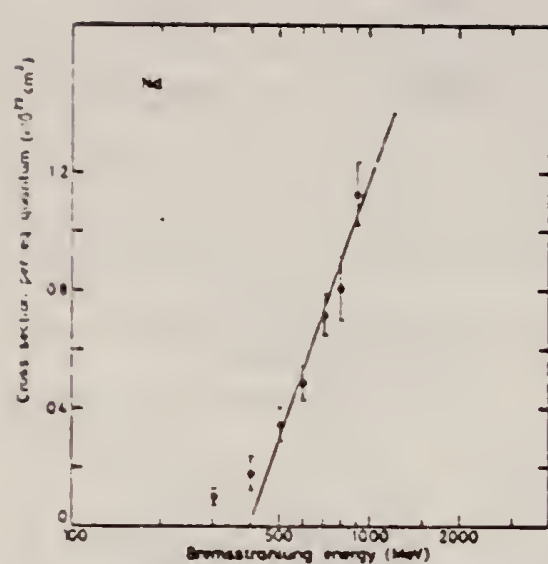

(8)
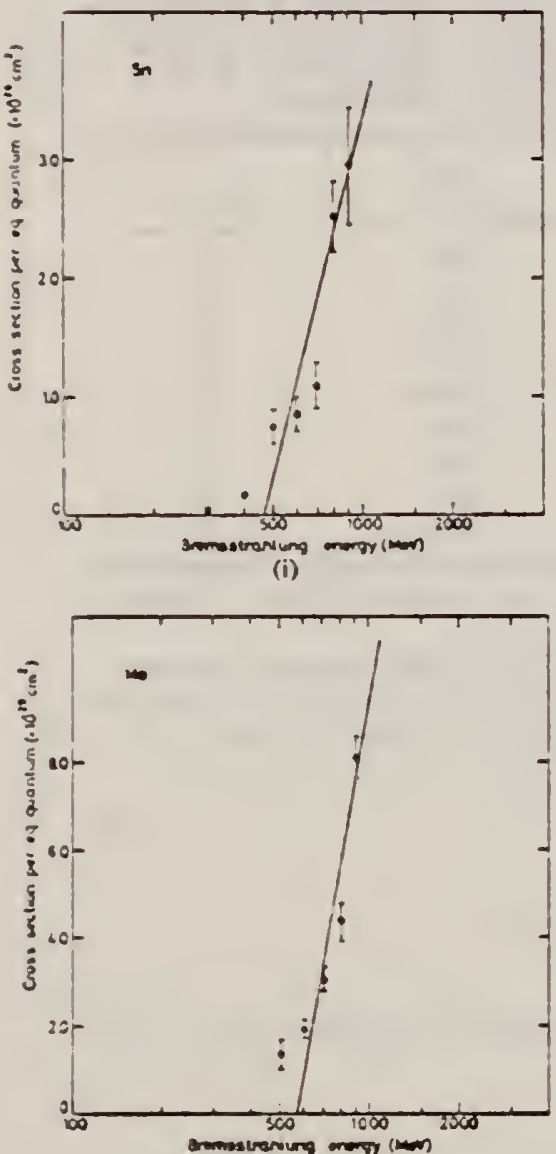

(c)

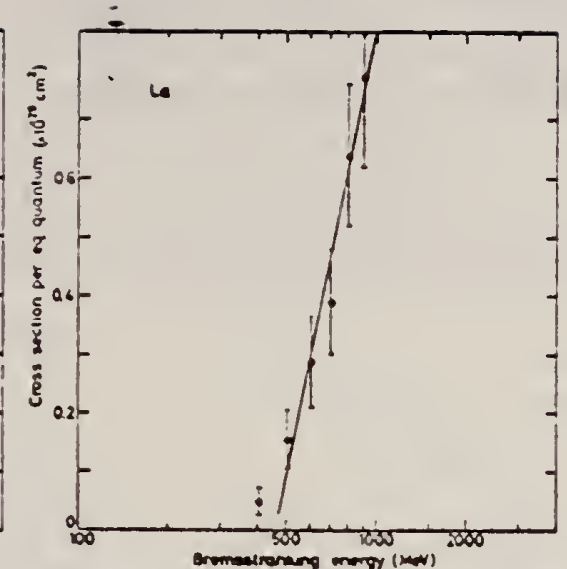

(h)
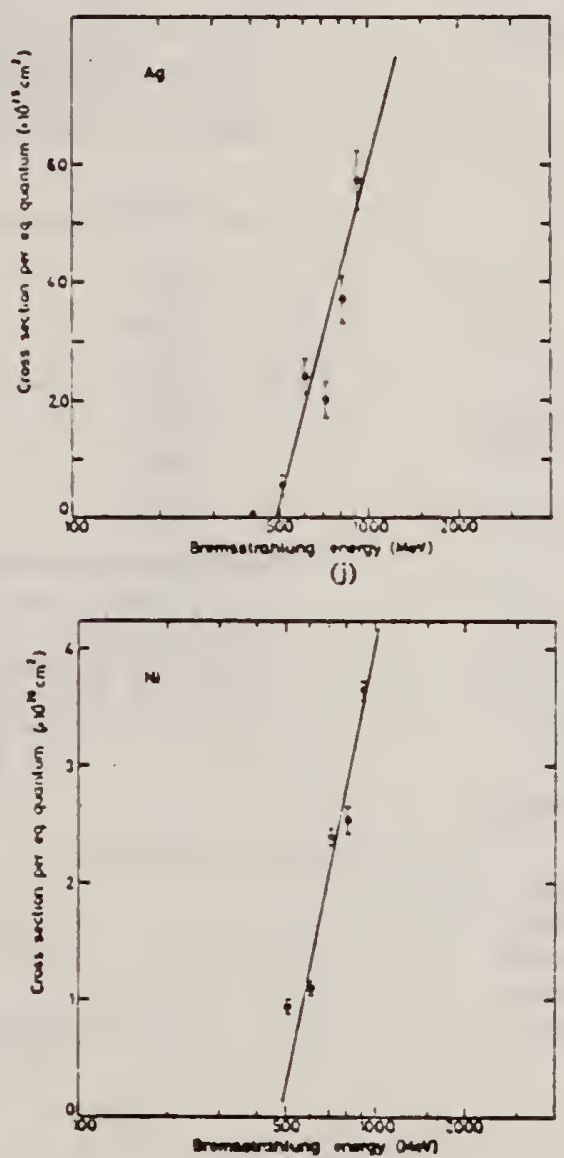

(1)

F1g. 1. Cross sections per equivalent quantum $\sigma_{q}(\vec{E})$ as a function of $\log \vec{E}$. 
E. J. Moniz, I. Sick, R. R. Whitney, J. R. Eicenec, R. G. Kephart and W. P. Trower

Phys. Rev. Letters 26, 445 (1971)

71 Mo 3

\begin{tabular}{|c|c|c|c|c|c|c|c|}
\hline \multirow[b]{2}{*}{ REACTION } & \multirow{2}{*}{ RESULT } & \multirow{2}{*}{$\begin{array}{l}\text { EXCITATION } \\
\text { ENERGY }\end{array}$} & \multicolumn{2}{|c|}{ SOURCE } & \multicolumn{2}{|c|}{ OETECTOR } & \multirow{2}{*}{ ANGLE } \\
\hline & & & TYPE & RANGE & TYPE & RANGE & \\
\hline$E, E /$ & $A B X$ & $0-240$ & $D$ & 500 & $M A G=D$ & & 60 \\
\hline & & & & & & & \\
\hline & & & & & & & \\
\hline
\end{tabular}

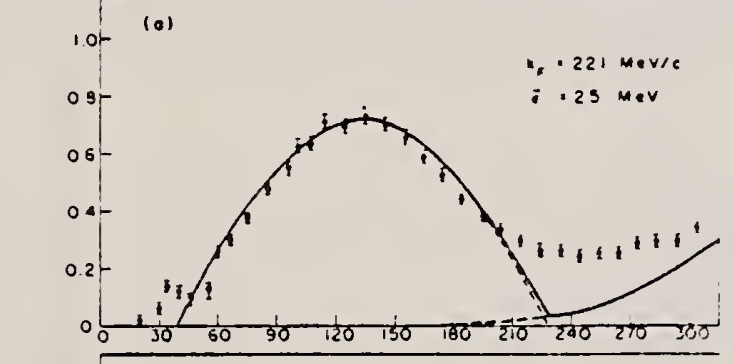

(b)

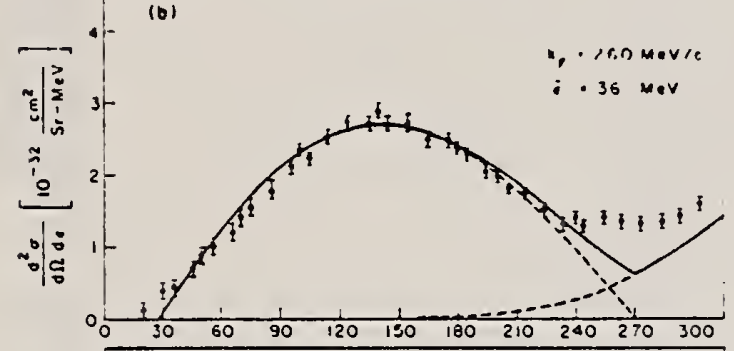

(c)

R. $263 \mathrm{NeV/C}$

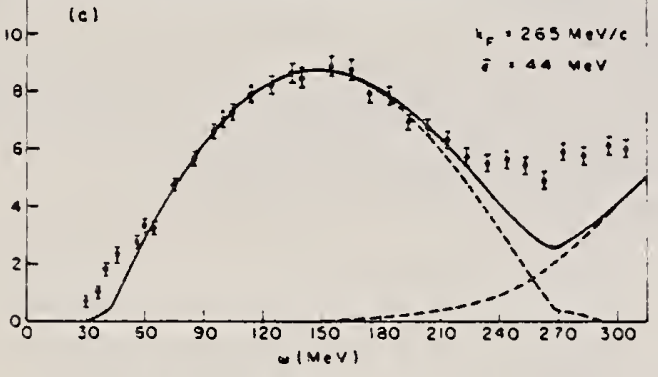

Fig. 1. Cross sections $d^{2} \sigma / d \Omega d \epsilon$ versus electron energy loss $\omega=\epsilon_{1}-\epsilon_{2}$ for inelastic scattering of 500$\mathrm{MeV}$ electrons at $60^{\circ}$ from (a) carbon, (b) nickel, and (c) lead. Solid lines are the results of the Fermi-gas calculation with the nuclear parameters indicated on the figure.

Talilo I. Nuelear Ferml momentum $t_{F}$ and aver:uso

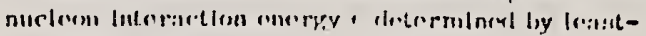

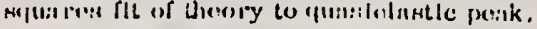

\begin{tabular}{lcc}
\hline Nucleus & $\begin{array}{c}k_{\bar{F}} \\
(\mathrm{MeV} / \mathrm{c})^{a}\end{array}$ & $\begin{array}{c}\bar{\epsilon} \\
(\mathrm{MeV})^{\mathrm{b}}\end{array}$ \\
\hline${ }_{3} \mathrm{Li}^{6}$ & 169 & 17 \\
${ }_{6} \mathrm{C}^{12}$ & 221 & 25 \\
${ }_{12} \mathrm{Mrg}^{24}$ & 235 & 32 \\
${ }_{20} \mathrm{Ca}^{40}$ & 251 & 28 \\
${ }_{28} \mathrm{Ni}^{58.7}$ & 260 & 36 \\
${ }_{39} \mathrm{Y}^{39}$ & 254 & 39 \\
${ }_{50} \mathrm{Sr}^{119.7}$ & 260 & 42 \\
${ }_{73} \mathrm{Ta}^{181}$ & 265 & 42 \\
${ }_{92} \mathrm{~Pb}^{208}$ & 265 & 44 \\
\hline \hline
\end{tabular}

${ }^{3}$ The fitting uncertainty in these numbers is approximately $\pm 5 \mathrm{MeV} / c$.

The fitting uncertainty in these numbers is approximately $\neq 3 \mathrm{MeV}$. Simple estimates for $\bar{\epsilon}$ give numbers in reasonable agreement with those in the table. 
N. A. Keller and D. B. McConnell

Can. J. Thys. 50, 1554 (1972)

\begin{tabular}{|c|c|c|c|c|c|c|c|}
\hline METHOD & & & & & & $\begin{array}{l}\text { REF. NO. } \\
72 \mathrm{Ke} 4\end{array}$ & hmg \\
\hline \multirow{2}{*}{ REACTION } & \multirow{2}{*}{ RESULT } & \multirow{2}{*}{$\begin{array}{l}\text { EXCITATION } \\
\text { ENERGY }\end{array}$} & \multicolumn{2}{|c|}{ SOURCE } & \multicolumn{2}{|c|}{ DETECTOR } & \multirow{2}{*}{ ANGLE } \\
\hline & & & TyPE & RANGE & TYPE & RANGE & \\
\hline$G, A$ & RLY & $6-32$ & $C$ & 32 & $S C D-D$ & & DST \\
\hline & & & & & & & \\
\hline & & & & & & & \\
\hline & & & & & & & \\
\hline
\end{tabular}

Tame 3 Observed angular distribution paramelers for $32 \mathrm{MeV}$ electron energy

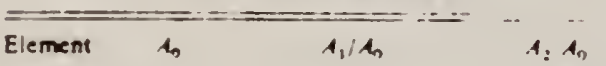

\begin{tabular}{|c|c|c|c|}
\hline met & An & $A_{1} / A_{h}$ & A: $A_{n}$ \\
\hline$T_{1}$ & $703 \pm 0.15$ & $0.073 \pm 0.052$ & $-0 \quad \Sigma \times n=0.073$ \\
\hline$v$ & $2.58 \pm 006$ & $0037=0.042$ & $-01: 5=0$ \\
\hline $\mathrm{Fe}$ & $1022 \pm 0.30$ & $0.006 \pm 0.043$ & $-033 \pm 0072$ \\
\hline Co & $6.80 \pm 0.20$ & $0.022=0.048$ & $-0016=0077$ \\
\hline $\mathrm{Ni}$ & $15.95 \pm 0.49$ & $0.051 \pm 0.048$ & $-0213=0074$ \\
\hline Cu & $8.37 \pm 0.28$ & $0076=0056$ & $-0035=0081$ \\
\hline Zn & $17.87 \pm 0.61$ & $0.004 \pm 0.045$ & $-0270=0.073$ \\
\hline$A_{\mathbf{E}}$ & $0.39 \pm 0.01$ & $0119 \pm 0.049$ & $-0.097 \geq 0074$ \\
\hline
\end{tabular}
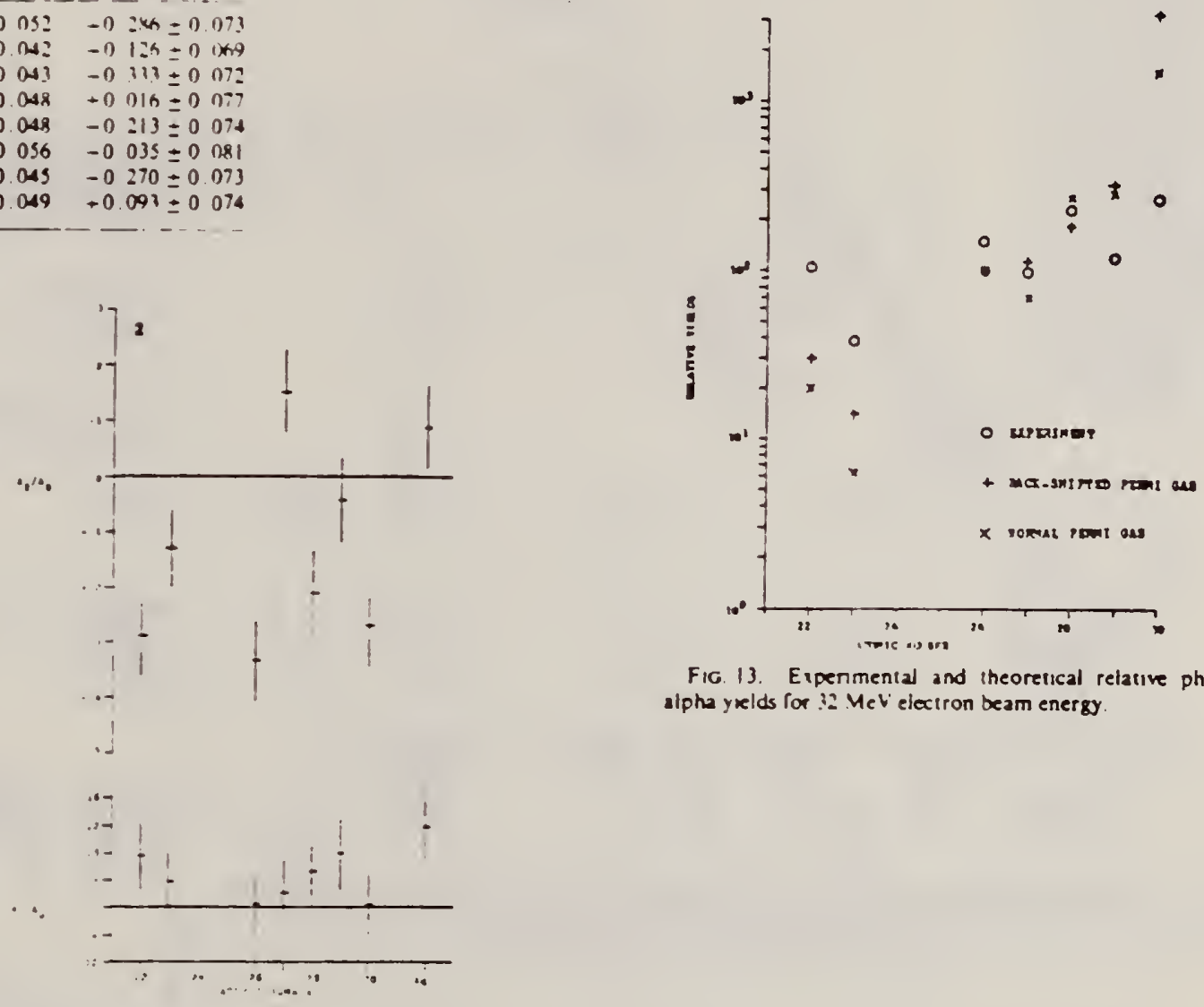

Fic. 13. Eipenmental and theoretical relative photoalpha yelds for $: 2 \mathrm{MeV}$ electron beam energy.

Fic : Angular distributions for $32 \mathrm{MeV}$ eiectron energy 
R.F. Barrett, J.R. Birkelund, B.J. Thomas, K.S. Lam, and H.H. Thies Nucl. Phys. A210, 355 (1973)

$73 \mathrm{Ba} 20$

\begin{tabular}{|c|c|c|c|c|c|c|c|}
\hline \multirow{2}{*}{ REACTION } & \multirow{2}{*}{ RESULT } & \multirow{2}{*}{$\begin{array}{l}\text { EXCITATION } \\
\text { ENERGY - }\end{array}$} & \multicolumn{2}{|c|}{ SOURCE } & \multicolumn{2}{|c|}{ DETECTOR } & \multirow{2}{*}{ ANGLE } \\
\hline & & & TYPE & RANOE & TYFE & RANGE & \\
\hline $\mathrm{G}, \mathrm{N}$ & NOX & THR- 27 & $C$ & $10-27$ & BFP $-I$ & & 4PI \\
\hline & & & & & & & \\
\hline & & & & & & & \\
\hline & & & & & & & \\
\hline
\end{tabular}

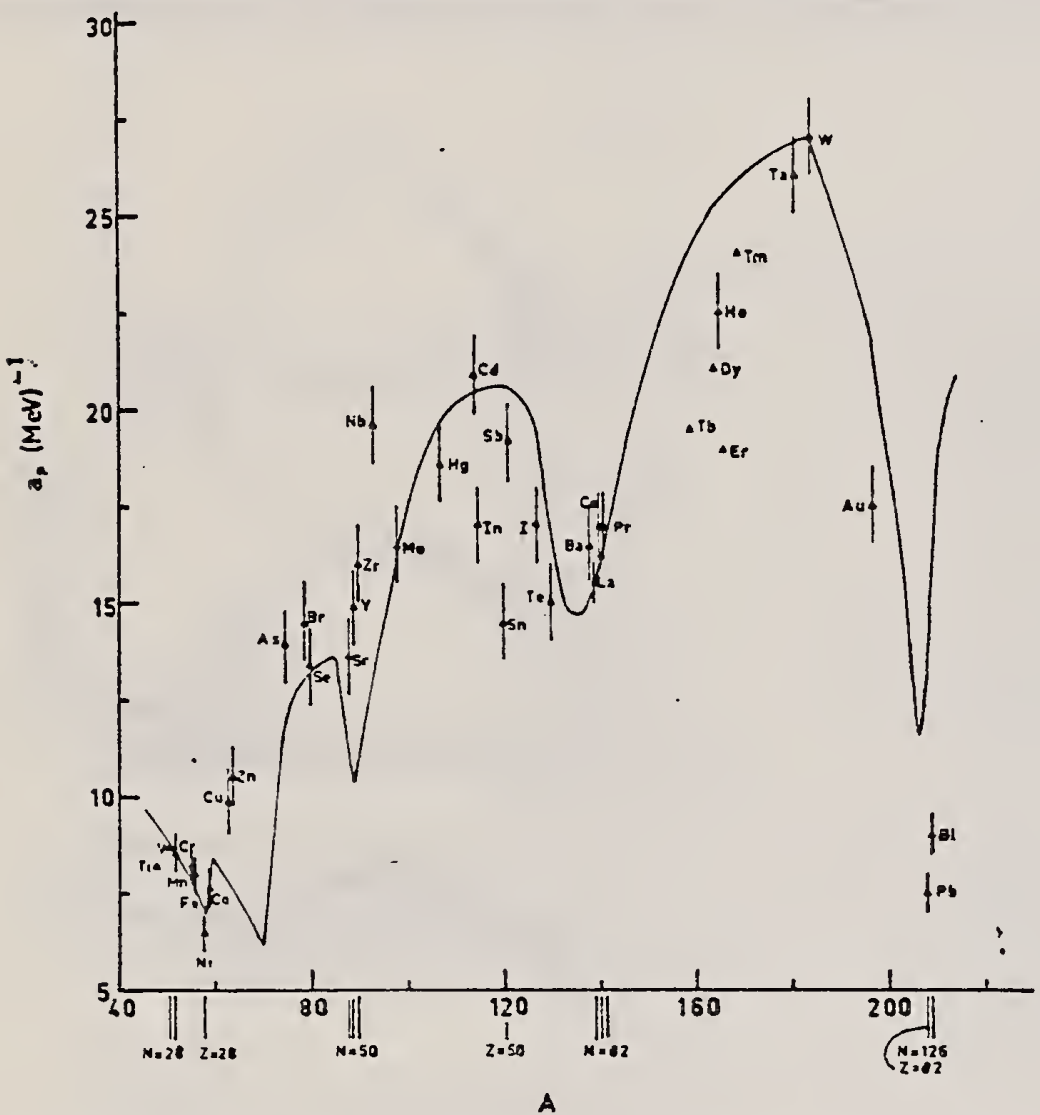

Fig. 12. Experimental values of the level density parameter $a_{3}$ (Fermi gas formula plus pairing correction) versus atomic number $A$. The continuous curve is a leasi-squares fit to the data of a theoretical calculation from Newton ${ }^{13}$ ).

1

H. Baba and S. Baba, Japan Atomic Energy Research Institute report JAERI-1183 (1969).

2

H. Baba, Nucl. Phys. Al59, 625 (1970).

15

T.D. Newton, Can. J. Phys. 34, 804 (1956).

(over)

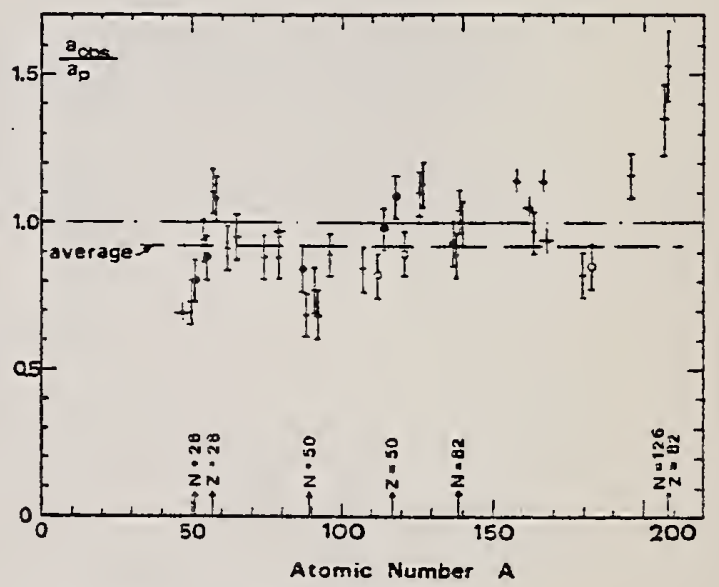

Fig. 15. Ratio $a_{\text {obs }} a_{0}$ versus atomic number $A$. Here $a_{\text {ob }}$ is the level density parameter taken from the neutron resonance work of refs. ${ }^{1.2}$ ), and $a_{p}$ is the level density parameter derived from the present $(\gamma, n)$ work. Filled circles represent points where nuclei in the neutron resonance and in the $(\gamma, n)$ experiment were the same. Open circles represeat points where the respective nuclei were approximately matched. Triangles represent points which are based on measurement of neutron mean energies at two bremsstrahlung energies only. 

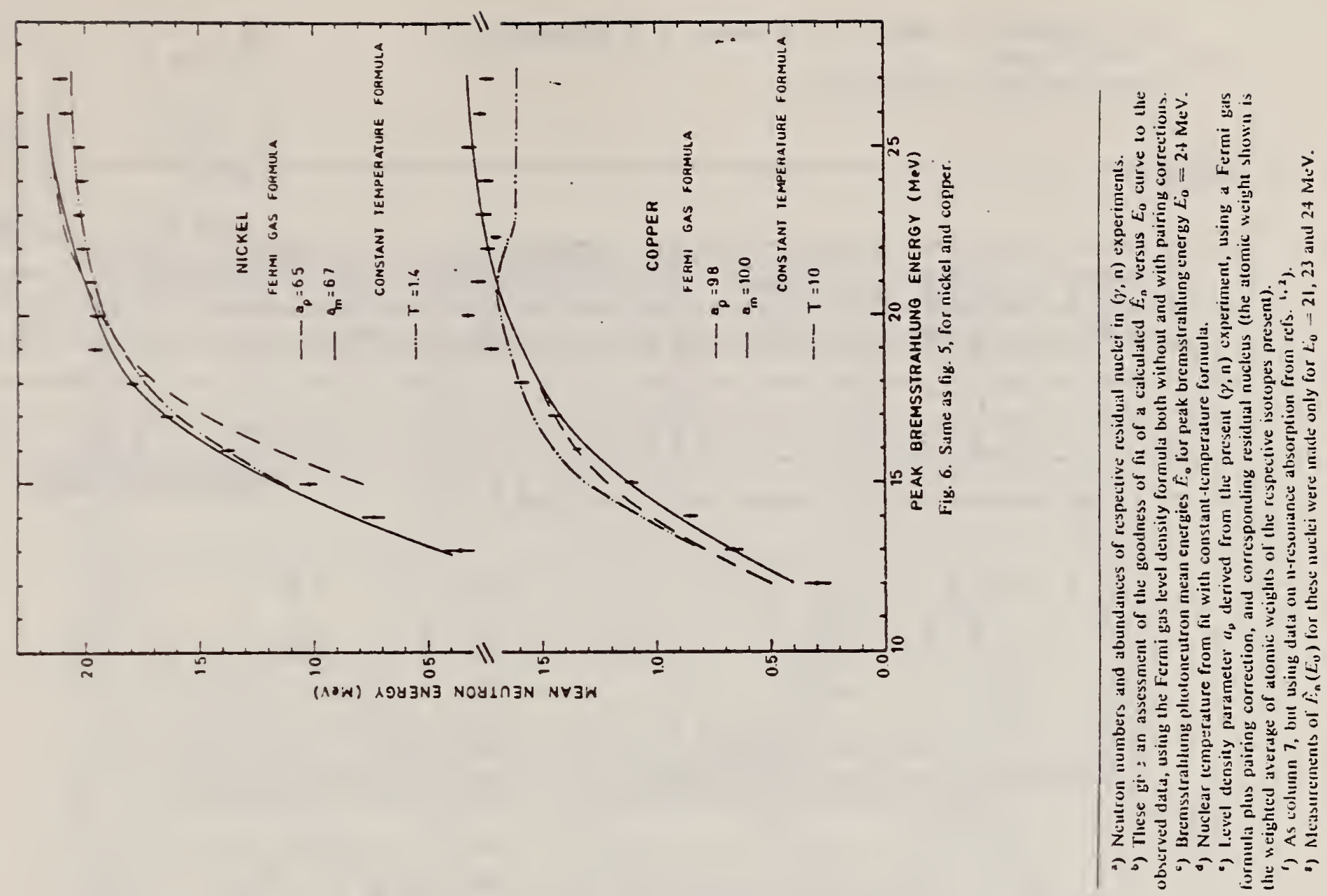

\begin{tabular}{|c|c|c|c|c|c|c|c|c|c|c|c|c|c|}
\hline 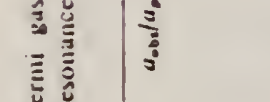 & $\begin{array}{l}2 \\
0 \\
0\end{array}$ & $\stackrel{5}{0}$ & of & å & $\begin{array}{l}x \\
0 \\
0\end{array}$ & $\stackrel{\circ}{\circ}$ & $\stackrel{0}{=}$ & जa & å & $\begin{array}{l}\infty \\
\substack{\infty \\
0}\end{array}$ & â & $\stackrel{\infty}{\infty}$ & ل्री \\
\hline 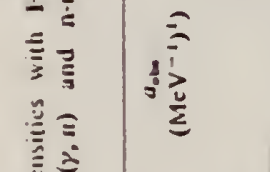 & $\frac{7}{\frac{1}{3}}$ & $\begin{array}{l}3 \\
\vdots \\
\vdots \\
\vdots \\
0\end{array}$ & $\begin{array}{l}0 \\
\vdots \\
\vdots \\
0 \\
0 \\
0\end{array}$ & 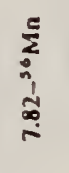 & $\begin{array}{l}\frac{0}{n} \\
n_{1} \\
\vdots \\
\dot{n}\end{array}$ & $\begin{array}{l}: \\
\vdots \\
\vdots \\
\infty\end{array}$ & $\begin{array}{l}\bar{z} \\
\vdots \\
\vdots \\
\frac{\alpha}{i} \\
i\end{array}$ & $\begin{array}{l}\bar{u} \\
\vdots \\
\vdots \\
\infty \\
\infty\end{array}$ & $\begin{array}{l}5 \\
\vdots \\
\vdots \\
\vdots \\
\stackrel{5}{0}\end{array}$ & 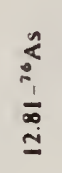 & 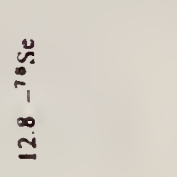 & 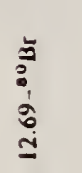 & $\begin{array}{l}\dot{5} \\
\vdots \\
\vdots \\
\vdots\end{array}$ \\
\hline 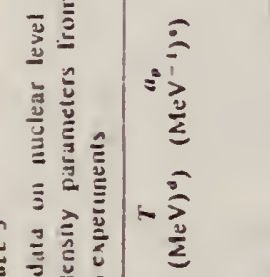 & $\frac{i}{i}$ & $\frac{b_{0}}{b_{1}}$ & 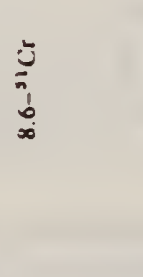 & $\begin{array}{l}\sum_{2} \\
\vdots \\
\dot{n} \\
\dot{1} \\
\infty\end{array}$ & 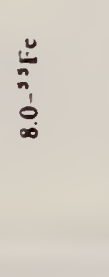 & $\begin{array}{l}0 \\
\vdots \\
\vdots \\
\vdots \\
i\end{array}$ & 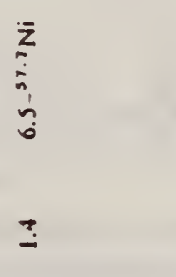 & $\begin{array}{l}\vec{U} \\
\vdots \\
0 \\
0 \\
0\end{array}$ & $\begin{array}{l}\vdots \\
\vdots \\
\vdots \\
\dot{a} \\
\varrho\end{array}$ & $\begin{array}{l}\hat{k} \\
\vdots \\
\vdots \\
\underline{i}\end{array}$ & 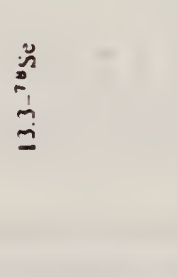 & 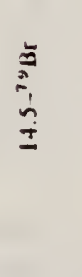 & $\begin{array}{l}: \\
\vdots \\
\vdots \\
0 \\
= \\
=\end{array}$ \\
\hline 言言言 & $\underline{2}$ & $\stackrel{2}{-}$ & 唡 & $\bar{i}$ & $\stackrel{2}{2}$ & $\dddot{i}$ & $\underset{i}{J}$ & $\stackrel{2}{=}$ & $\underset{-}{\square}$ & $\stackrel{T}{\Xi}$ & $\stackrel{\mathrm{m}}{\mathrm{g}}$ & $\Xi$ & $\bar{m}$ \\
\hline 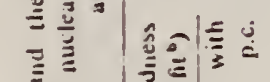 & & & 0 & 0 & 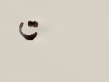 & - & & $=$ & L & - & & $\stackrel{2}{>}$ & ט \\
\hline 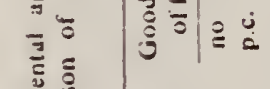 & & & $=$ & $\stackrel{\dot{3}}{>}$ & $=$ & 2 & $\stackrel{3}{>}$ & $\stackrel{\doteqdot}{>}$ & 4 & $\stackrel{5}{>}$ & & $\stackrel{2}{>}$ & 4 \\
\hline$z \overline{\bar{g}}$ & 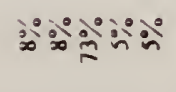 & 字 & 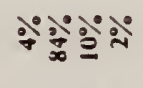 & $\stackrel{\grave{3}}{\underline{s}}$ & ดेฏूें & 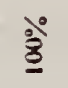 & 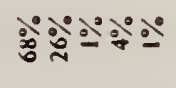 & ํํำ & & @̊̀े & 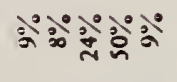 & ڤัహे & อ̊ํํ요 \\
\hline 产 & สิส & $\approx$ & 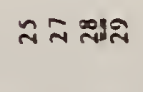 & 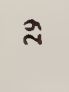 & 추 సิำ & $\bar{m}$ & $\approx \approx \approx \approx \sim ⿻ 冂 𠃍 𠃌$ & $m \approx$ & $\tilde{m} \approx \bar{m}=$ & $\overline{7}$ & $テ ゙ テ \overline{7}$ & $\approx 2$ & $7 \%$ \\
\hline 䇋 & $\Xi$ & $\bar{j}$ & u & $\bar{\Sigma}$ & ü & 8 & 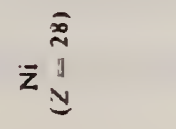 & $\vec{U}$ & $\overline{\mathbf{N}}$ & $\hat{\varepsilon}$ & $\hat{\dot{y}}$ & $\Xi$ & $\check{n}$ \\
\hline
\end{tabular}


R.R. Whitney, I. Sick, J.R. Ficenec, R.D. Kephart, and REF. W. P. Trower

Phys. Rev. C9, 2230 (1974)

\begin{tabular}{|c|c|c|c|c|c|c|c|}
\hline METHOO & & - & & & & $\begin{array}{l}\text { REF. NO. } \\
74 \text { th } 3\end{array}$ & hing \\
\hline \multirow{2}{*}{ REACTION } & \multirow{2}{*}{ RESULT } & \multirow{2}{*}{$\begin{array}{l}\text { EXCITATION } \\
\text { ENERGY }\end{array}$} & \multicolumn{2}{|c|}{ SOUNCE } & \multicolumn{2}{|c|}{ OETECTOR } & \multirow{2}{*}{ ANGLE } \\
\hline & & & TrPe & MANGe & TYPE & RANGE & \\
\hline$E, E /$ & $A B X$ & $0-300$ & $D$ & 500 & MAG-D & & 60 \\
\hline \multicolumn{8}{|c|}{.$\quad}$. \\
\hline & & & & & & & \\
\hline & & & & & & & \\
\hline
\end{tabular}

See further analysis of this data in reference $79 \mathrm{Zil}$

QUASIZIASTIC SCAT

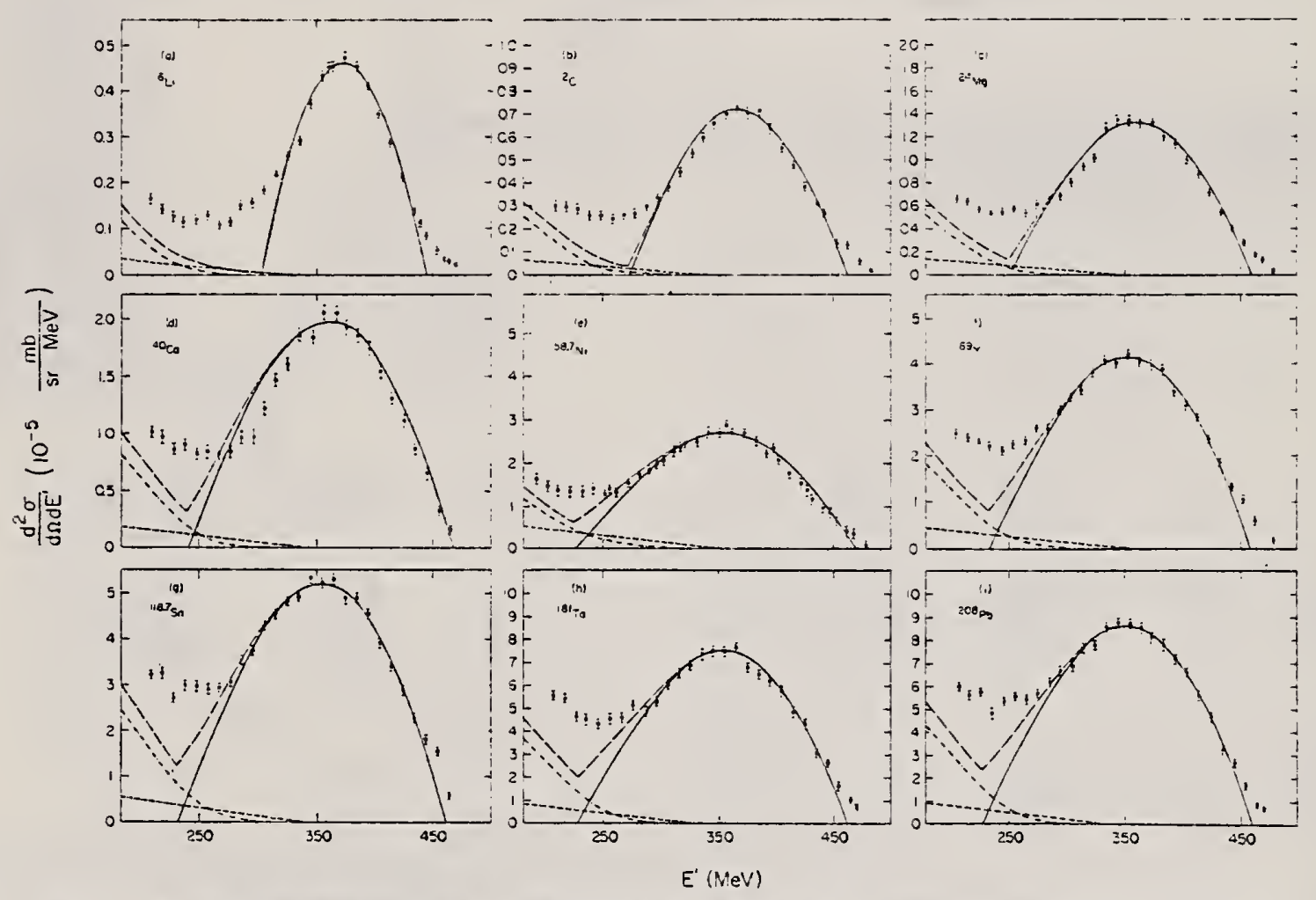

FIG. 1. The measured quasielastic peaks; the errors on the data points do not include an over-all $3 \%$ normalization uncertaing. The solid curve is a fit by the Fermi-gas model which yieided $k_{p}$ (in $\mathrm{MeV} / c$ ) and $\bar{\epsilon}$ (in $\mathrm{MeV}$ ) as follows: (a) ${ }^{6} \mathrm{Ll}(169,17)$; (b) ${ }^{12} \mathrm{C}(221,25)$; (c) ${ }^{2} \mathrm{MIg}(235,32)$; (d) ${ }^{40} \mathrm{Ca}(249,33)$; (e) ${ }^{58.7} \mathrm{Ni}(260,36)$; (I) ${ }^{89} \mathrm{Y}(254,39)$; (g) ${ }^{1: 8 .} \mathrm{Sm}(250,42)$; (h) ${ }^{181} \mathrm{Ta}(265,42)$; (i) ${ }^{208} \mathrm{~Pb}(265,44)$. The fitting uncertainty in $k_{F}$ is $\pm 5 \mathrm{MeV} / \mathrm{c}$ and in $\bar{\epsilon}$ it is \pm 3

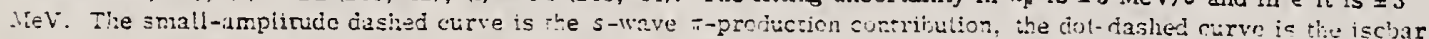
excitation, and the large-amplitude diashed curve is the total result. 


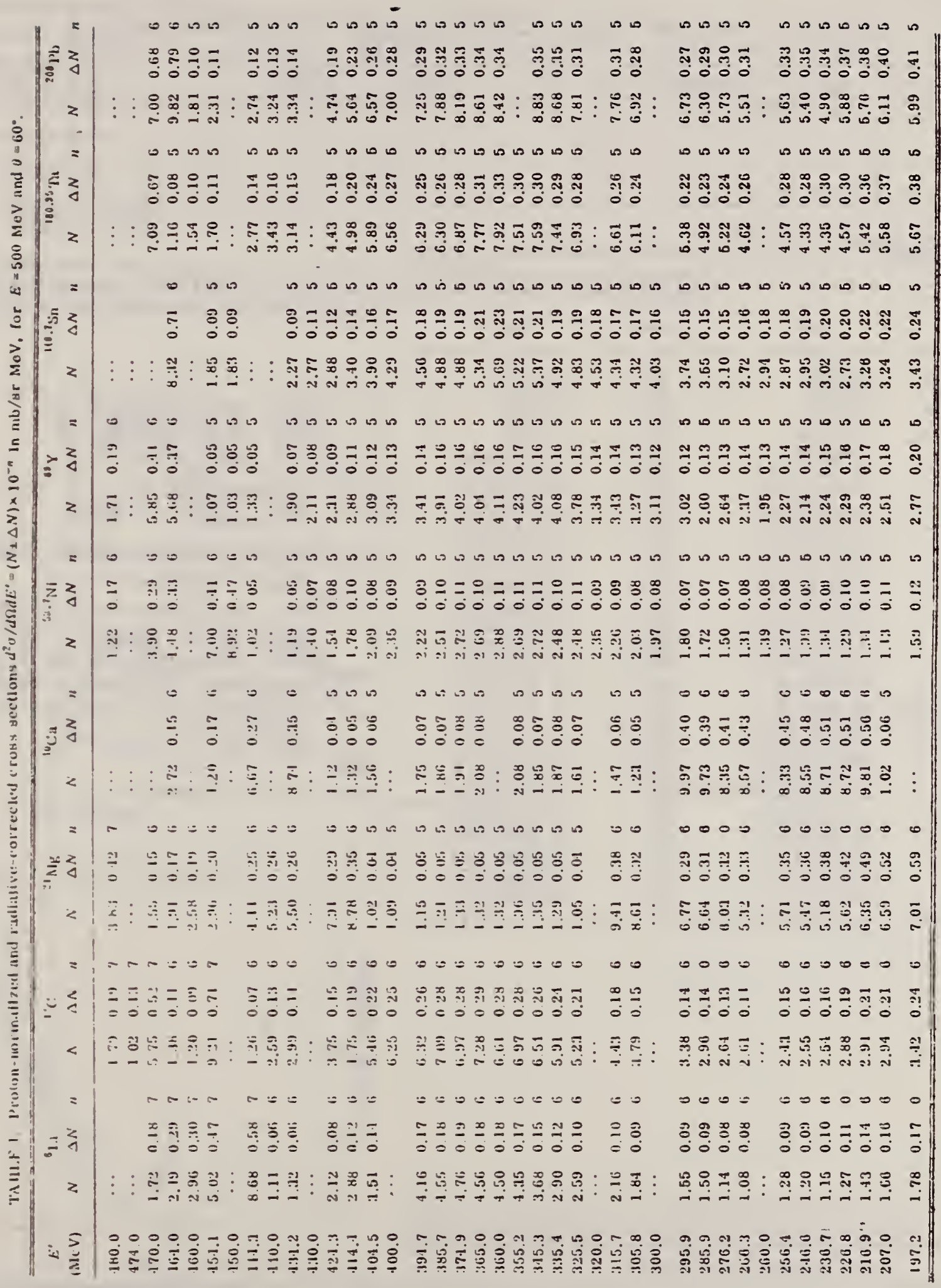


V. Emma, S. Lo Nigro, C. Milone

Nucl. Phys. A257, 438 (1976)

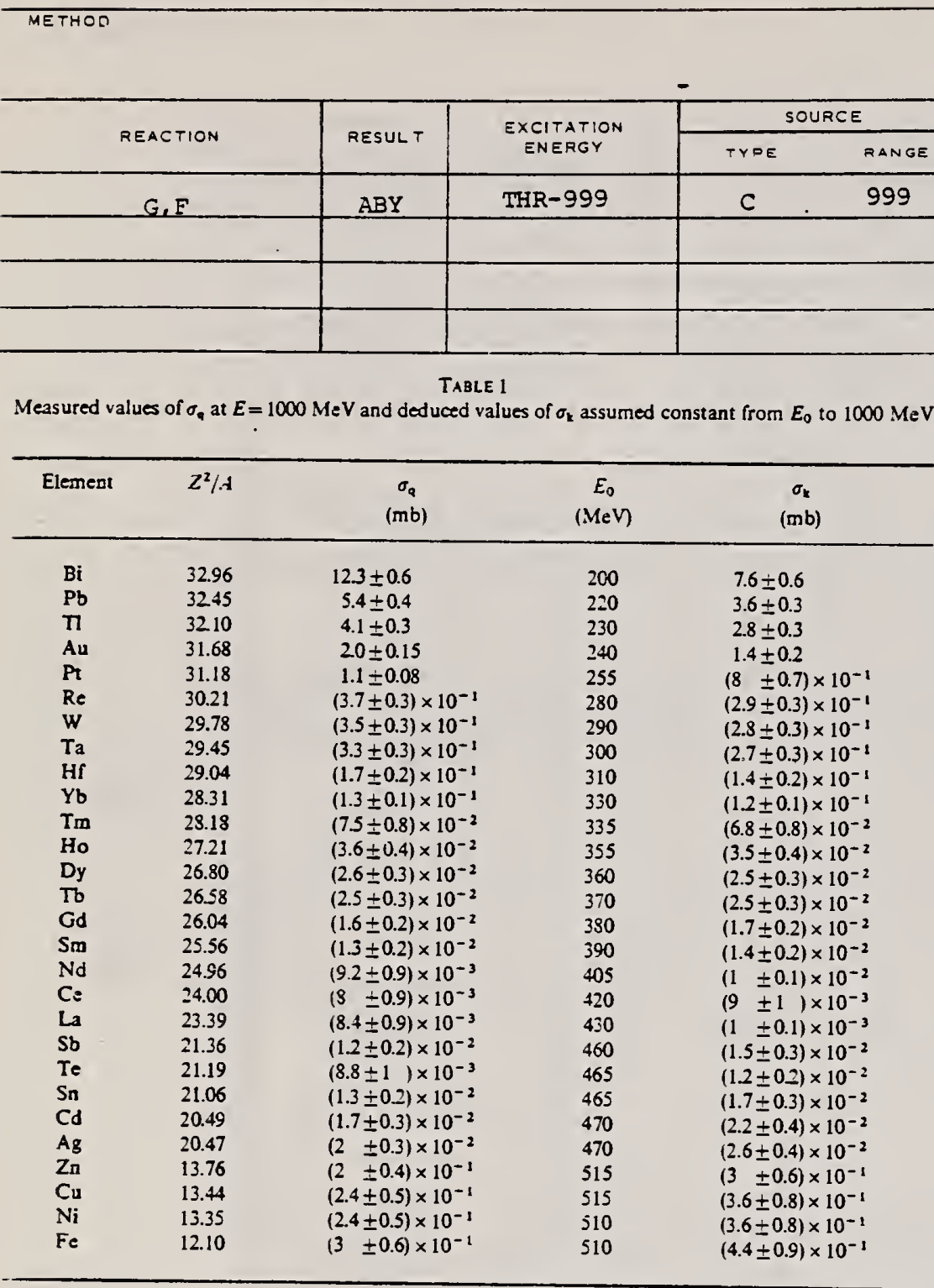

Fig. 2. Nuclear fissilities as a function of $Z^{2} / A$. Experimental points: solid circles represent our data; squares, the data from ref. 4 ); open circls. the data from ref. ${ }^{7}$; and crosses, the data from $(p, n)$ experiments ${ }^{20}$ ). The straight line is the best lit calculated from our data for $Z^{2} / A>26$. The dashed curve is the curve VT calculated by $\mathrm{Nix}$ and Sassi ${ }^{12}$ ).

4.V. Mitrofanova et al. Sov. J. Nucl. Phys. 6 , \$12 (\$968).

7 T. Methasiri et al., Nucl. Phys. A167, 97 (1971).

12 J.R. Nix et al., Nucl. Phys. 81,61 (1966).

20 N.A. Perifilov et al., JETP (Sov. Phys.) 14, 623 (1962); Proc. Symp. on the physics \& chemistry of fission, Salzburg 1965, vol. 2 (IAEA) Vienna, $1965, ? .283$.

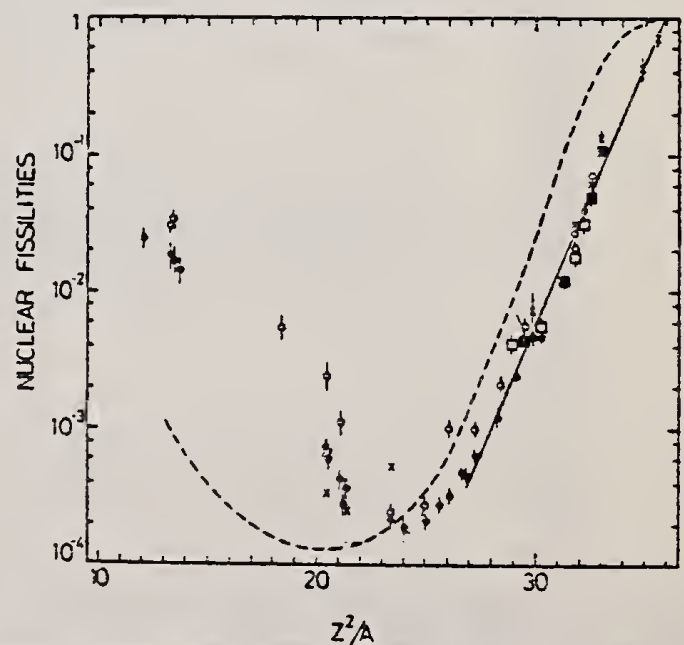


V.G. Vlasenko, V.A. Gol'dshtein, A.V. Mitrofanova, V.I. Noga,

Yu.N. Ranuuk, V.I. Startsevi P.V. Sorokin, Yu.N. Telegin

Yad. Fiz. 23, 504 (1976)

Sov. J. Nucl. Phys. 23, 265 (1976)

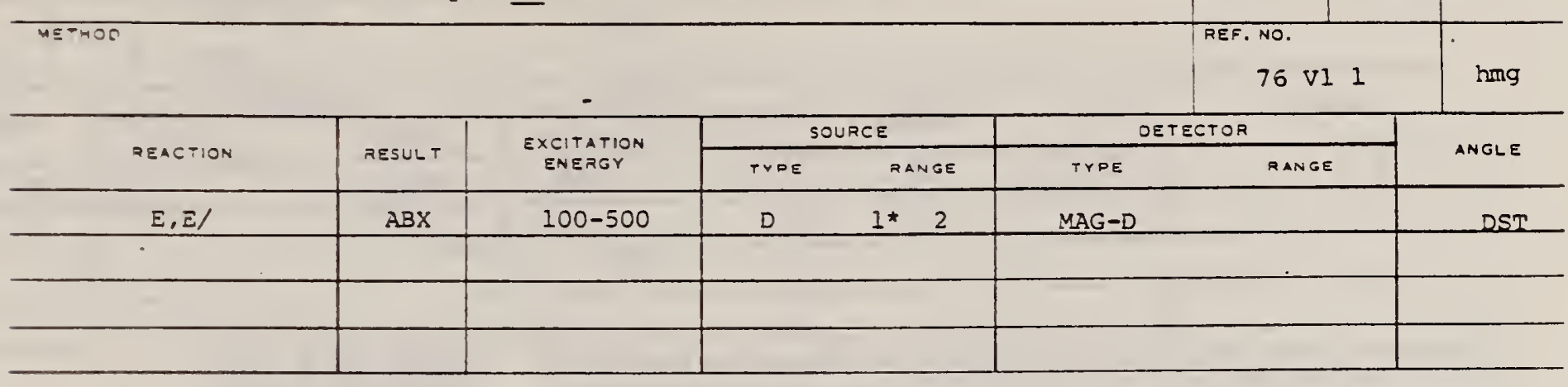

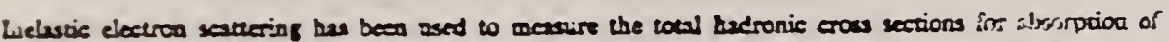

${ }^{*}$ E IN GEV $, 1.2,1.36$

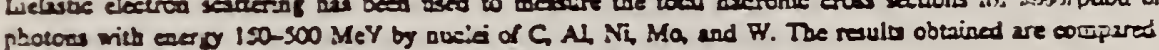
vitb ealculations anried out in the impulse approciranoion.

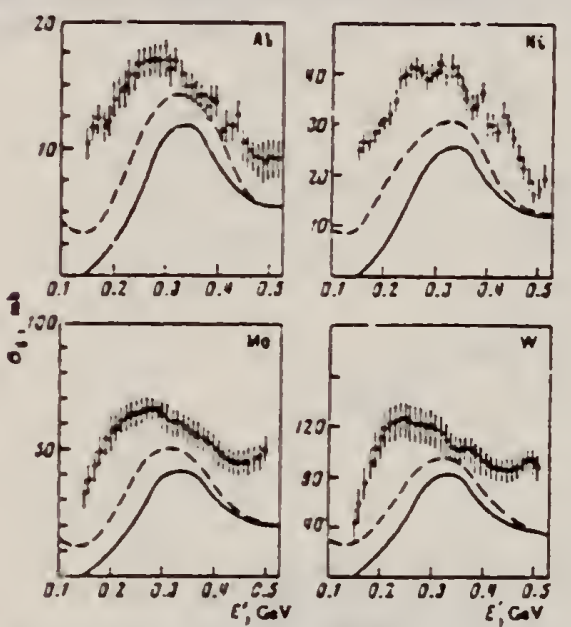

FIG. 5. Total badroalc cross sections for absorptoo of ptowos by melel.

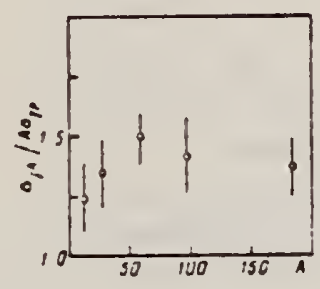

FIG. 6. The ratto $\sigma_{y N} / A \sigma_{p}$, as a fucction of $A$ for $k=0.32 \mathrm{GeV}$. 
Rer. A.G. Flowers, D. Branford, J. C. McGeorge, A. C. Shotter, P. Thorley

C. H. Zimmerman, R. O. Owens, J. S. Pringle

Phys. Rev. Lett. 43 , 323 (1979)

METHO

\begin{tabular}{|c|c|c|c|c|c|c|c|}
\hline \multirow{2}{*}{ REACTION } & \multirow{2}{*}{ RESULT } & \multirow{2}{*}{$\begin{array}{l}\text { EXCITATION } \\
\text { ENERGY }\end{array}$} & \multicolumn{2}{|c|}{ SOURCE } & \multicolumn{2}{|c|}{ DETECTOR } & \multirow{2}{*}{ ANGLE } \\
\hline & & & TYPE & RANGE & TYPE & pange & \\
\hline$E, A$ & SPC & UKN & $D$ & 120 & MAG-D & & DST \\
\hline & & & & & & & \\
\hline & & & & & & & \\
\hline
\end{tabular}

This paper presents energy spectra of $\alpha$ particles emitted following the bombardrcent of ${ }^{27} \mathrm{Al},{ }^{n a t} \mathrm{Ni},{ }^{92} \mathrm{MO},{ }^{94} \mathrm{MO}$, and ${ }^{197} \mathrm{Au}$ with $120-\mathrm{MeV}$ electrons, together with $\alpha$-particle

PREEQUILIB A EMISS angular distributions from ${ }^{197} \mathrm{Au}$ and $" \mathrm{at} \mathrm{Ni}$ for $E_{\alpha}=30$ and $50 \mathrm{MeV}$. The data are compared with preequilibrium exciton-model and statistical-model calculations. It is concluded that few-step processes are domicant in the production of $\alpha$ particles with energies above $20 \mathrm{MeV}$.

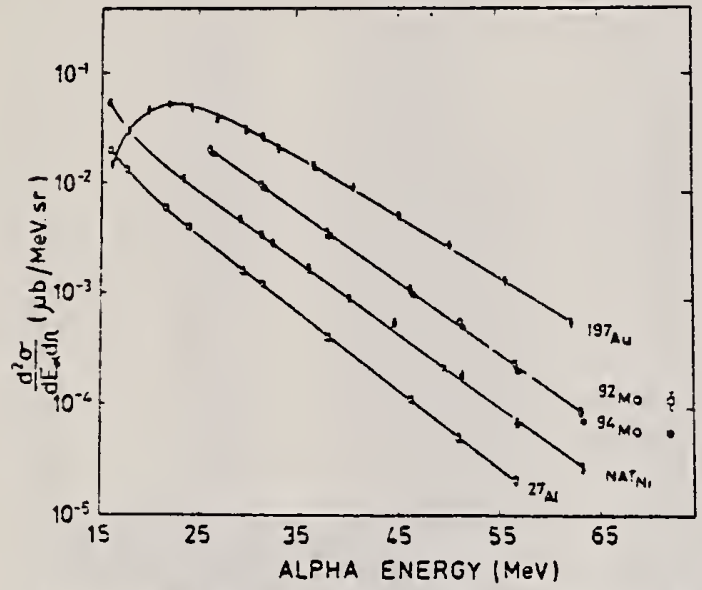

FIG. 1. $\alpha$-particle eqergy spectra at $\theta_{\alpha}=30^{\circ}$, for $E_{8}$ $=120 \mathrm{MeV}$. Errors stown are the sum of statistical and systematic contributious. Tite solid lines are a guide to the eye.

TABLE I. Temperatures corresponding to the preequilibrium component of the $(e, \alpha)$ reaction, derived from energy spect ra at $\theta_{\alpha}=30^{\circ}$ for $E_{\alpha}=120 \mathrm{MeV}$.

\begin{tabular}{cc}
\hline \hline Target & Temperature ${ }^{2}(\mathrm{MeV})$ \\
\hline${ }^{29} \mathrm{Al}$ & 5.3 \\
${ }^{02} \mathrm{Ni}$ & 5.5 \\
${ }^{88} \mathrm{ZD}$ & 5.4 \\
${ }^{82} \mathrm{Mo}$ & 5.6 \\
${ }^{94} \mathrm{Mo}$ & 5.4 \\
${ }^{19} \mathrm{Al}$ & 6.1 \\
\hline
\end{tabular}

Error is $\pm 0.2 \mathrm{MleV}$.

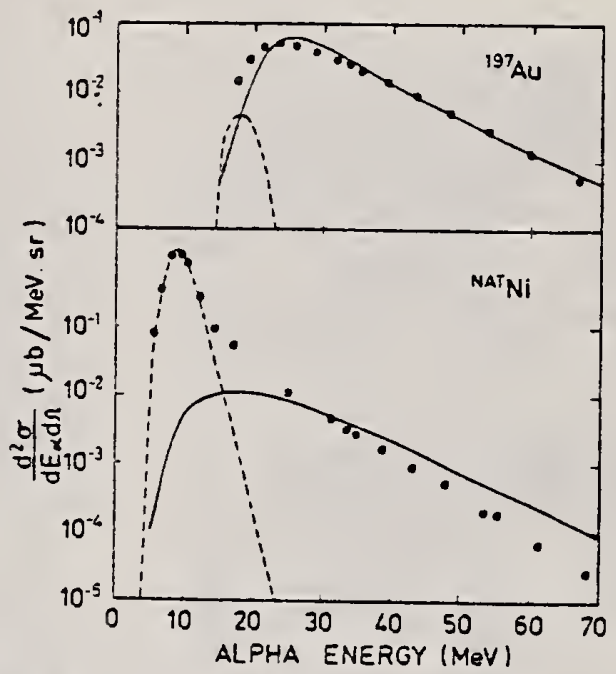

FIG. 2. $\alpha$-particle energy spectra at $\theta_{\alpha}=30^{\circ}$, for $E_{\alpha}$ $=120 \mathrm{MeV}$. The solid circles are experimental polats. The solid lines are the results of preequilibrium exciton-model calculations and the dashed lines are the results of statistical calcuiations neglecting photon absorption above $E_{y}=33 \mathrm{MleV}$.
FORM MBS- 418
(AEV. $7.1<-184$ )

USCOMM-N SS-OC
PHOTONUCLEAR OATA SHEET (over)

hg




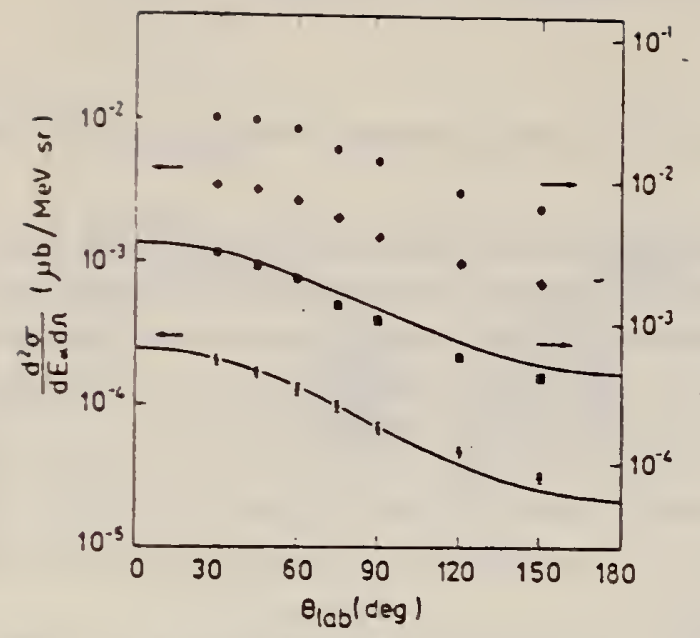

FIG. 3. Q-particle angular distributions at $E_{i}=120$ $\mathrm{MeV}$ for ${ }^{197} \mathrm{Au}$ (sbown as circles for $E_{\alpha}=30 \mathrm{MeV}$ and squares for $E_{\alpha}=50 \mathrm{MeV}$ ) and aril (showa as dlamonds for $E_{\alpha}=30 \mathrm{MeV}$ and stars for $E_{\alpha}=50 \mathrm{MeV}$ ). The solld Llees are the result of simple kinematic calculations described in the text. The sum of statistical and systematc errors is shown where it exceeds the size of the polats. 
ReF. J.C. McGeorge, A.G. Flowers, D. Branford, C.H. Zimmerman, R.O. Owens, J. Phys. G: Nucl. Phys. $\underline{6}$, L133 (1980)...

80 Mc 6

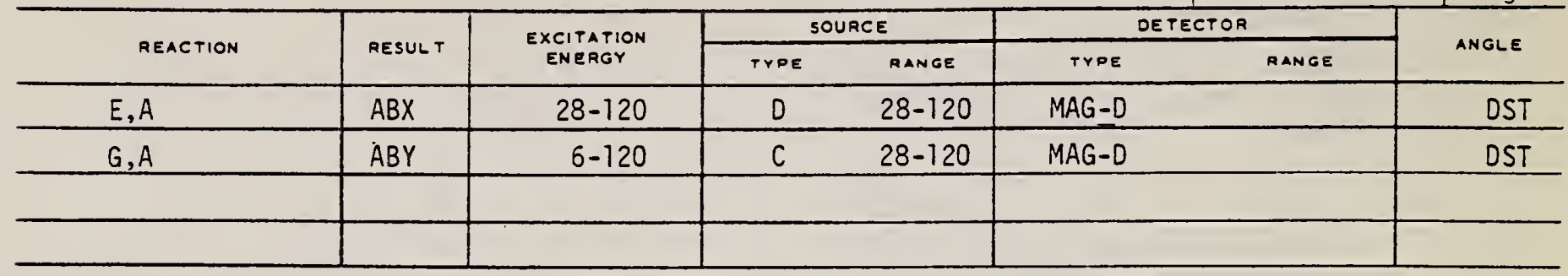

Abstract. New data on electron- and bremsstrahlung-induced $8 \mathrm{MeV}$ x-particle emission from $\mathrm{Ni}$ are shown to be consistent with statistical decay of the excited nucleus. This result is in marked disagreement with a recent analysis of a similar experiment but ir. good agreement with $\left(\alpha, \alpha^{\prime} x\right)$ coincidence experiments.

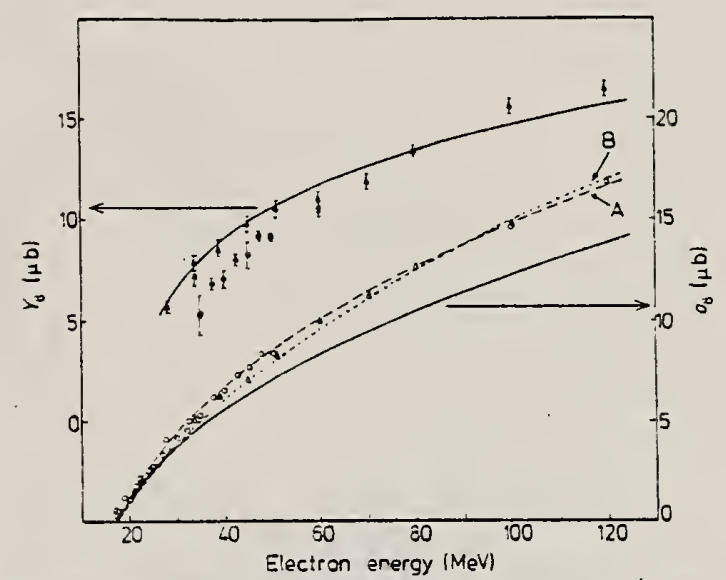

Figure 1. Excitation functions for electron- (open symbols) and bremsstrahlung- (closed symbols) induced yields of $7.5-8.5 \mathrm{MeV} \propto$ particles from natural nickel. Statistical uncertainties are shown or are smaller than the size of the symbols ; the systematic uncertainties are $\leqslant 7 \%$. The triangles show the present data and the circles represent the equivalent data derived from the results of Wolynec et al (1979) normalised to the present radiator thickness of $0.169 \mathrm{~g} \mathrm{~cm}^{-2}$. The full curves result from folding the bremsstrahlung and $\mathrm{E}$ ! virtual photon spectra with the $(;, z)$ cross section of figure 2 . The broken curve $A$ is the result of multiplying the EI-only calculation by a factor of $1 \cdot 2$, while the broken curve $B$ is the result of including a $10 \%$ EWSR E2 contribution. 
IIICIEL

$z=28$

iiI

$A=58$ 
Ref. J.P. Roalsvig, R.N.H. Haslam, D.J. McKenzie Can. J. Phys. 37, 607 (1959)

Method $24 \mathrm{MeV}$ betatron; neutron yield; proportional flow counter; I chamber

Elem. Sym.

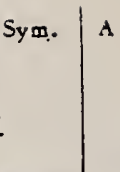

Ref. No.

59 Ro 2

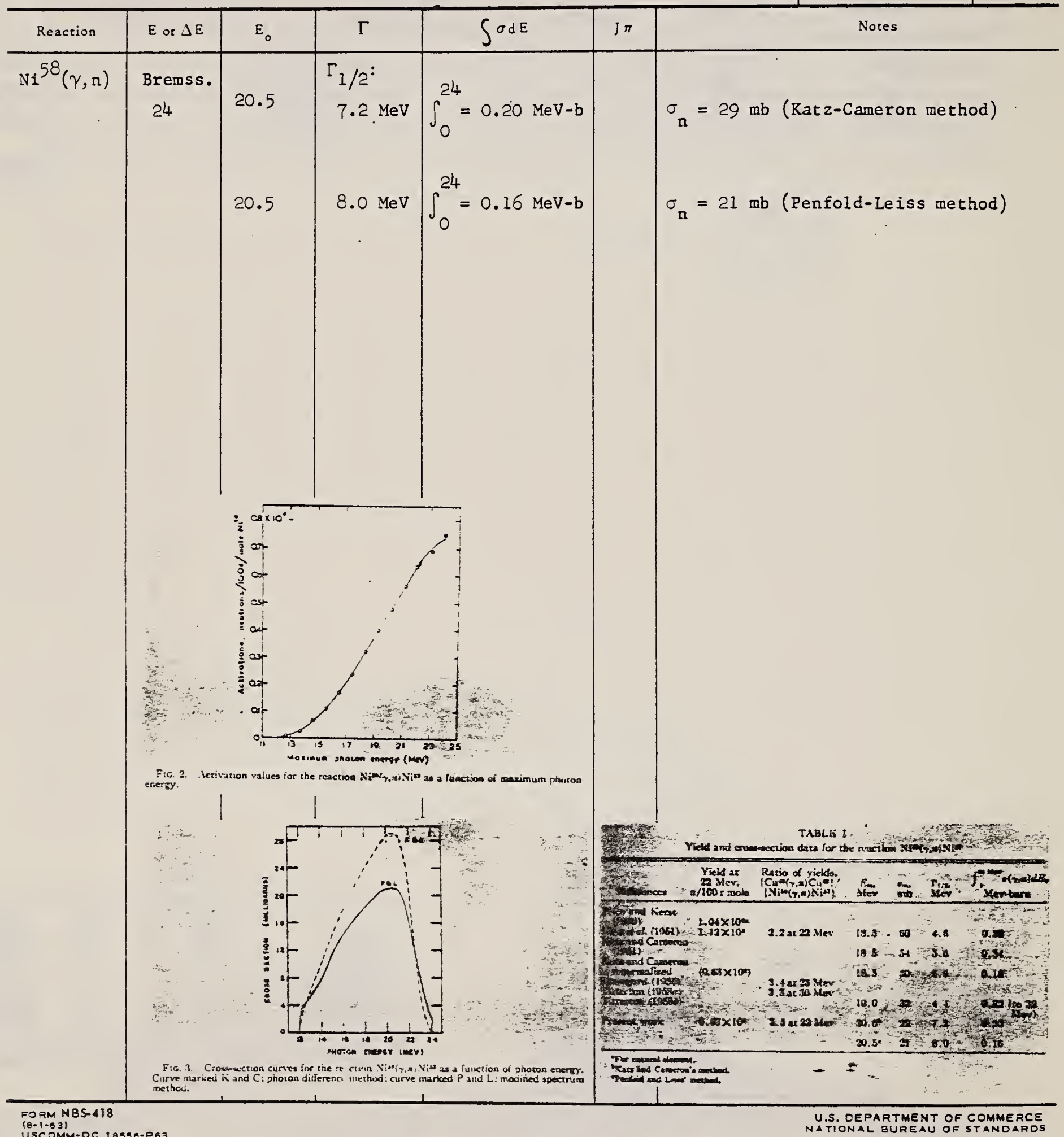


Re:. H. Cranne11, R. Helm, H. Kenda11, J. Oeser, M. Yearian Phys. Rev. 123, 923 (1961)

\begin{tabular}{ll|l}
\hline Method Linac; Cerenkov counter telescope & Ret
\end{tabular}

\begin{tabular}{|c|l|l} 
Elem. Sym. & A & Z \\
Ni & 58 & 28 \\
\hline $\begin{array}{c}\text { Ref. No. } \\
61 \text { Cr } 1\end{array}$ & JHH \\
\hline
\end{tabular}

\begin{tabular}{|c|c|c|c|c|c|c|}
\hline Reaction & $E$ or $\triangle E$ & $E_{0}$ & $\Gamma$ & $\int \sigma d E$ & $\mathrm{~J} \pi$ & Notes \\
\hline$\left(e^{-}, e^{-1}\right)$ & 183 & $\begin{array}{l}1.45 \\
2.50 \\
3.20 \\
3.51 \\
4.50 \\
7.55\end{array}$ & & & $\begin{array}{l}2^{+} \\
4^{+} \\
2^{+} \\
4^{+} \\
3^{+}\end{array}$ & 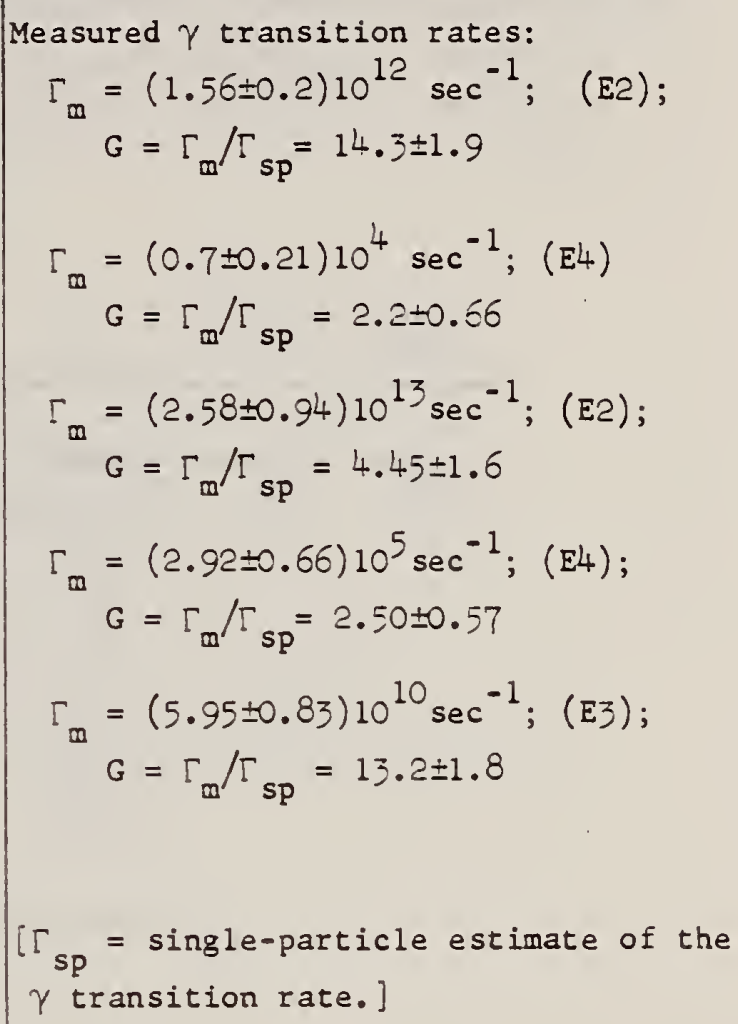 \\
\hline
\end{tabular}

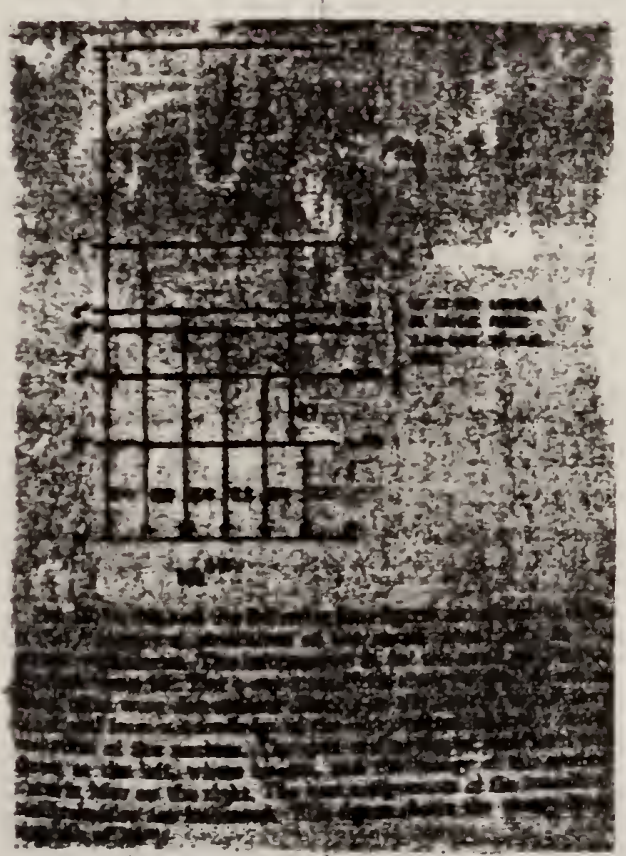

Fits $R_{0}=1.20$ fermi except for 4.50 $\mathrm{MeV}$ level ( 1.11 fermi).

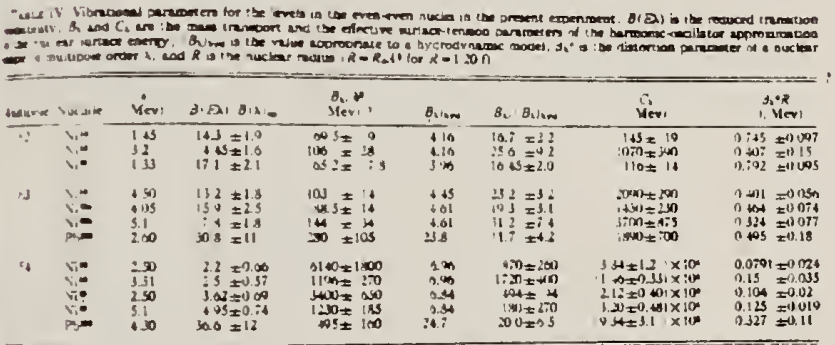
-

Ref 15: Data on the decay schemes are taken principally from Nuclear Data Sheets National Academy of Sciences - National Reseach Council (U.S. Government Printing Office, Washington, D.C. 1959)

Ref 37: Crut, Sweetman, Wall - Nuclear Phys. 17, $655(1960)$. 


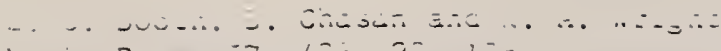

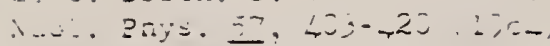

Van de Graaff; resonance fluorescence

ćs 50 :

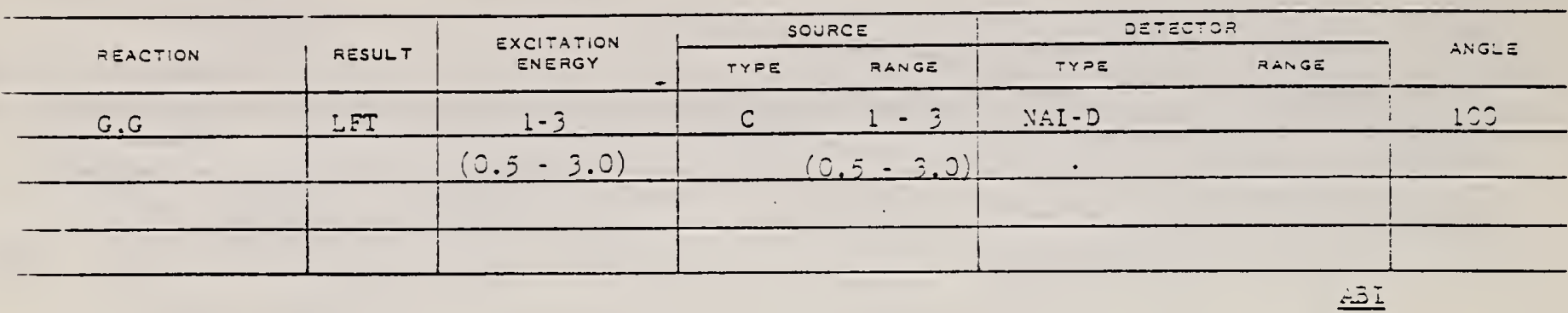

Table 1

Cascs of ojserved resonance finoziszence

\begin{tabular}{|c|c|c|c|c|c|c|c|}
\hline $\begin{array}{l}\text { Nucleus } \\
\text { multipol. }\end{array}$ & $\begin{array}{l}\text { Siate } \\
\text { (MifV) }\end{array}$ & Spin & $\Gamma_{0} i \Gamma$ & $\begin{array}{c}T\left(g * \Gamma_{0}^{3} / \Gamma^{2}\right)^{-1} \\
(\mathrm{scc})\end{array}$ & $\begin{array}{c}\text { Mean ifictniz } T \\
\text { BCW } \\
\text { (sec) }\end{array}$ & 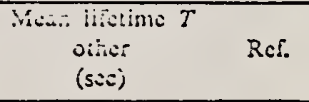 & $\begin{array}{l}\Gamma_{0 /} F_{W} \\
3 C W\end{array}$ \\
\hline $\mathrm{Ni}^{33}$ & 0.00 & $0^{-}$ & & & & & \\
\hline$E 2{ }^{2} j$ & 1.45 & $2^{-}$ & 1 & $19 \doteq 6 \times 10^{-14}$ & $62 \pm 20 \times 10^{-14}$ & & 16 \\
\hline
\end{tabular}




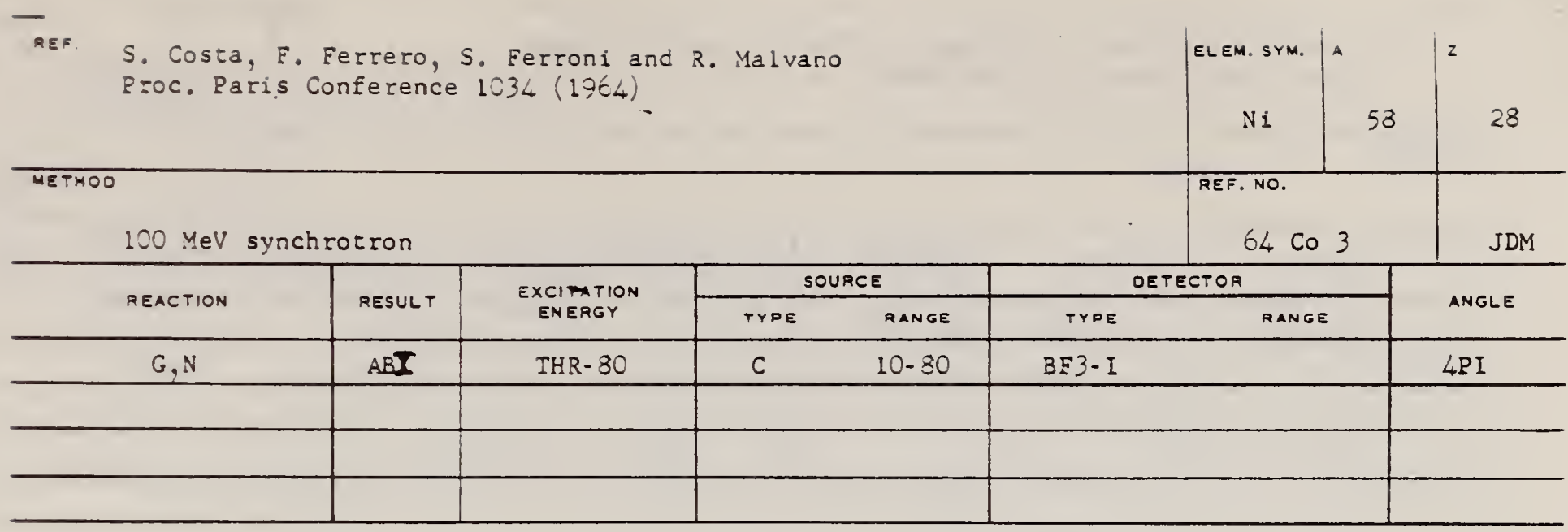

TABLB

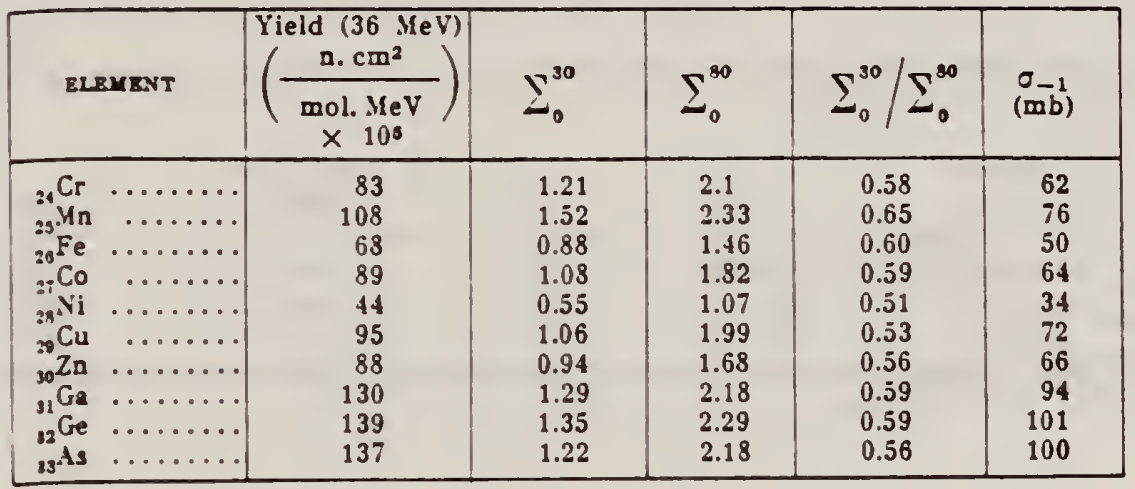

$\Gamma^{*}=\frac{A}{60 \mathrm{NZ}} \int^{\mathrm{b}} \sigma(E) \mathrm{d} E$ is the integrated cross section measured in units of the classical dipole $60 \mathrm{NZ} / \mathrm{Amb}$. MeV. 
M. Masuda, M. Kondo, S. Takeda, M. Okumura, and J. Ookuma

J. Phys. Soc. Japan 19,2339 (1964)

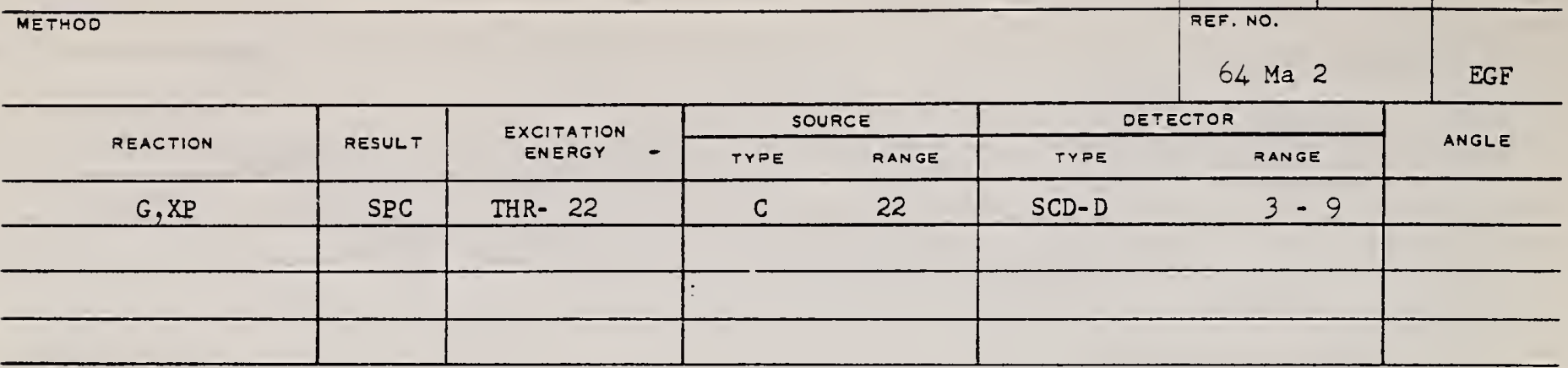

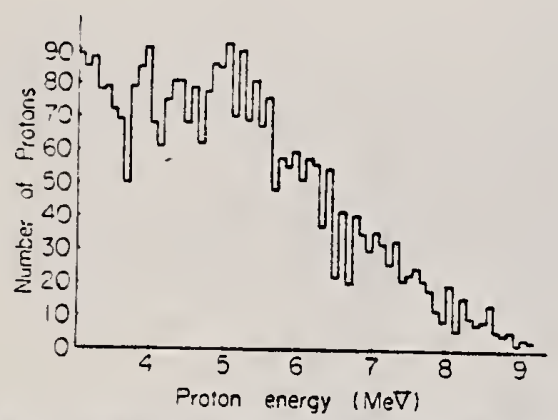

Fig. 2. Energy spectrum of emitted protons from nickel foil Irradiated by $22 \mathrm{MeV}$ brems-strahlung. 


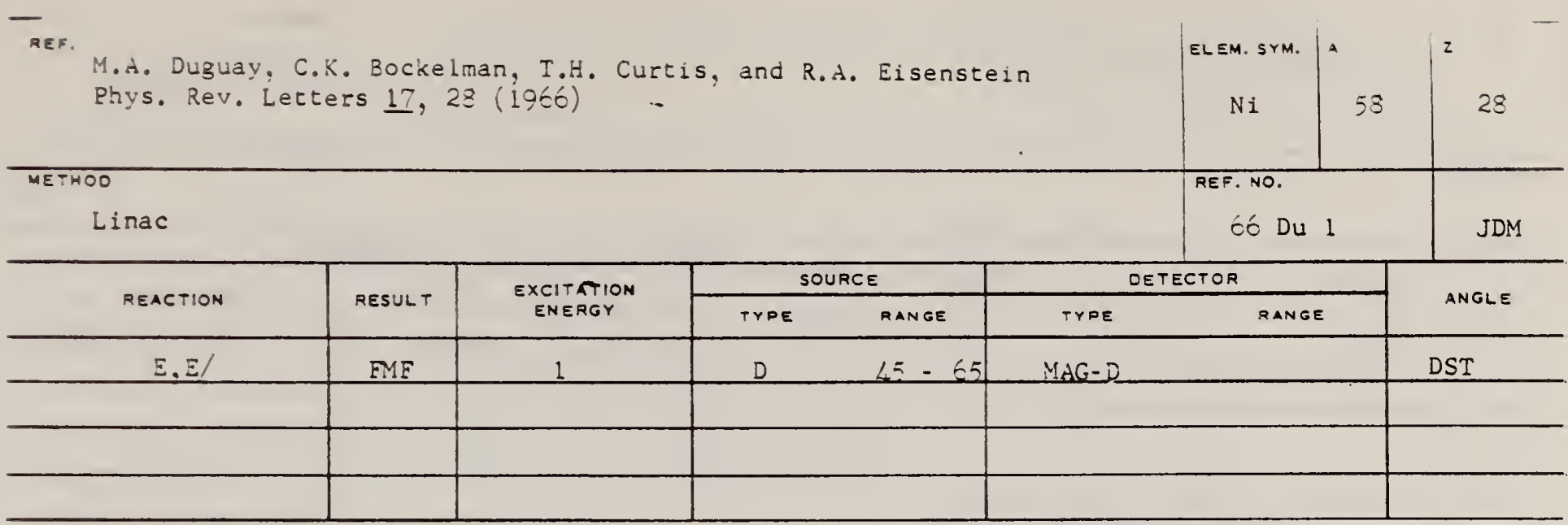

Table :. Recuced transition probabilities $B(E 2)$ and transition radii $R_{t r}$ for the first excited states of the even $\mathrm{Ni}$ isotopes.

\begin{tabular}{|c|c|c|c|c|c|}
\hline \multirow[b]{2}{*}{ Isotope } & \multirow[b]{2}{*}{$\begin{array}{l}\text { Level ener } B \mathbf{~} \\
\quad \text { (MeV) }\end{array}$} & \multicolumn{3}{|c|}{$\begin{array}{c}B\left(E 2,0^{+}-2^{+}\right) \\
\left(e^{2} F^{-1}\right)\end{array}$} & \multirow[b]{2}{*}{$\mathbb{R}_{(\bar{F})}$} \\
\hline & & $J^{\pi}$ & Ref. 12 & $\begin{array}{l}\text { Present } \\
\text { work }\end{array}$ & \\
\hline. $\mathrm{xi}^{38}$ & 1.452 & $2^{-}$ & $720 \times 10 \%$ & $620=14 \%$ & $5.35=10 \%$ \\
\hline $\mathrm{Ni}^{60}$ & 1.332 & $2^{+}$ & $910=9 \%$ & $776=12 \%$ & $5.23=12 \%$ \\
\hline $\mathrm{Ni}^{62}$ & 1.172 & $2^{+}$ & $830 \pm 9 \%$ & $770=12 \%$ & $5.23=10 \%$ \\
\hline
\end{tabular}


M. A. Duguay, C. K. Bockelman, T. H. Curtis and R. A. Eisenstein

Phys. Rev. 102, $1259(1967)$

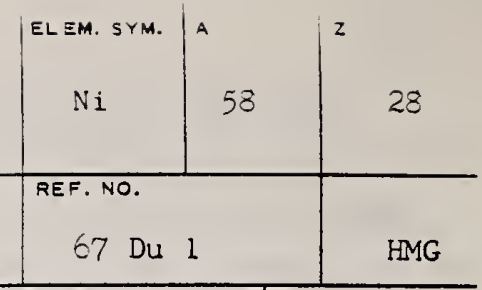

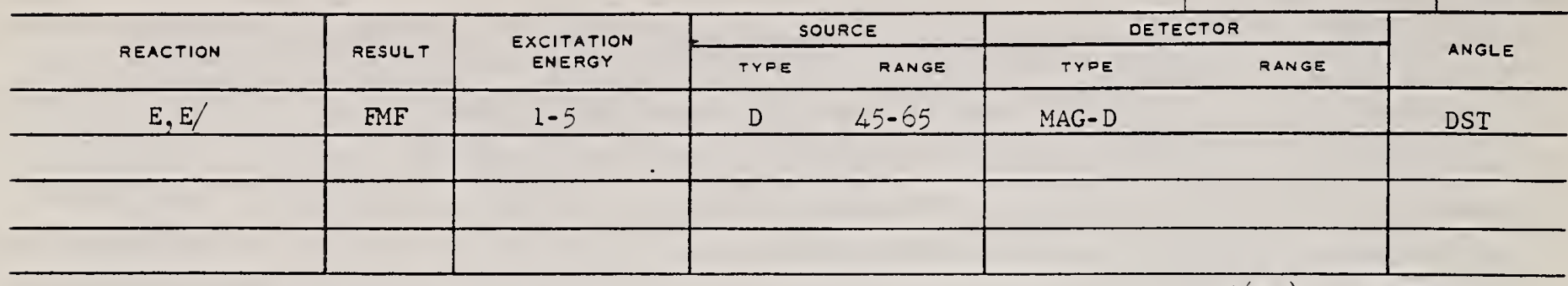

TABLE II. Reduced radiative transition probabilities

$B(E L)$, SEP ISOTPS and transition radii.

\begin{tabular}{|c|c|c|c|c|c|}
\hline \multicolumn{6}{|c|}{ E2 Transitlonso } \\
\hline & $\begin{array}{l}\text { Excitation } \\
\text { energy } \\
\text { (MeV) }\end{array}$ & $\begin{array}{l}B\left(E 2,0^{+} \rightarrow 2^{+}\right) \\
\left(C^{1} F^{\prime}\right)\end{array}$ & $\frac{B\left(B 2,0^{+} \rightarrow 2^{+}\right)}{B\left(B 2,0^{+} \rightarrow 2^{+}\right)_{0+\infty}}$ & $\beta_{1}$ & $\begin{array}{l}R_{1,} \\
\text { (F) }\end{array}$ \\
\hline $\begin{array}{l}\text { Nin } \\
\text { Nim } \\
\text { Nin }\end{array}$ & $\begin{array}{l}1.452 \\
3.034 \\
3.26 \\
1.330 \\
1.172\end{array}$ & $\begin{array}{l}657 \pm 11 \\
83 \pm 3 \\
153 \pm 15 \\
845 \pm 9 \\
877 \pm 11\end{array}$ & $\begin{array}{r}10 \\
1 \\
2 \\
12 \\
12\end{array}$ & $\begin{array}{l}0.177 \pm 0.003 \\
0.063 \pm 0.002 \\
0.035=0.008 \\
0.197 \pm 0.002 \\
0.197 \pm 0.001\end{array}$ & $\begin{array}{l}5.51 \\
5.51 \\
5.51 \\
5.55 \\
5.59\end{array}$ \\
\hline \multicolumn{6}{|c|}{ E3 Tranwitionse } \\
\hline & $\begin{array}{l}\text { Excilation } \\
\text { energy } \\
\text { (MeV) }\end{array}$ & $\underset{\left.\left(e^{2} F\right)^{1}\right)}{B\left(E 3.0^{+}\right)}$ & $\frac{B\left(E 3,0^{+} \rightarrow 3^{-}\right)}{B\left(E 3,0^{+} \rightarrow 3^{-}\right)_{10}}$ & $\theta_{3}$ & $\begin{array}{l}\boldsymbol{R}_{\mathrm{tr}} \\
(\mathbf{F})\end{array}$ \\
\hline $\begin{array}{l}\overline{N i s 0} \\
\text { Niw } \\
\text { Nin }\end{array}$ & $\begin{array}{l}4.480 \\
4.038 \\
3.75\end{array}$ & $\begin{array}{l}18600 \pm 520 \\
28100 \pm 640 \\
20100 \pm 540\end{array}$ & $\begin{array}{l}13 \\
19 \\
13\end{array}$ & $\begin{array}{l}0.203 \neq 0.005 \\
0.241 \pm 0.006 \\
0.197 \pm 0.005\end{array}$ & $\begin{array}{l}6.05 \\
6.09 \\
6.11\end{array}$ \\
\hline
\end{tabular}

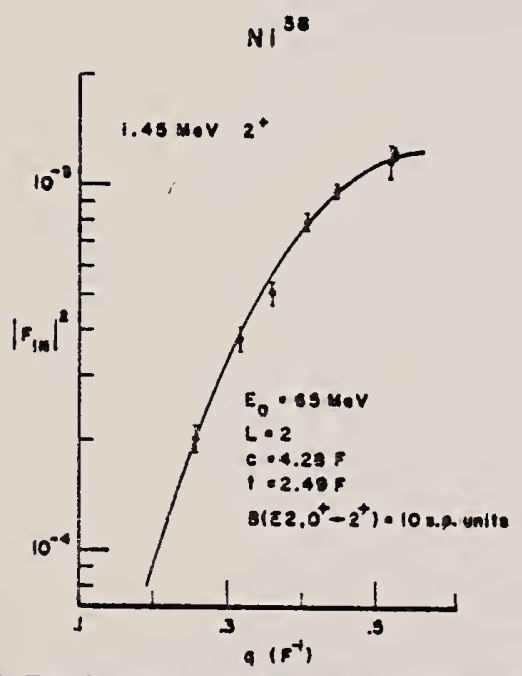

Fig. 19. The theoretical and experimental $\left|F_{\text {to }}\right|^{2}$ vergus $q$ for the $\mathrm{Ni}^{4} 1.45-\mathrm{MeV} 2^{+}$state. The solid curve is the $\left|F_{\text {in }}\right|^{3} \mathrm{calculated}$ by Code GBgow using the strict hydrodynamic model $\left(c_{\mathrm{a}}=c\right.$; $\left.h_{m}=6\right)$. The best fit to the data is obtained by a lesst-squares andyais.

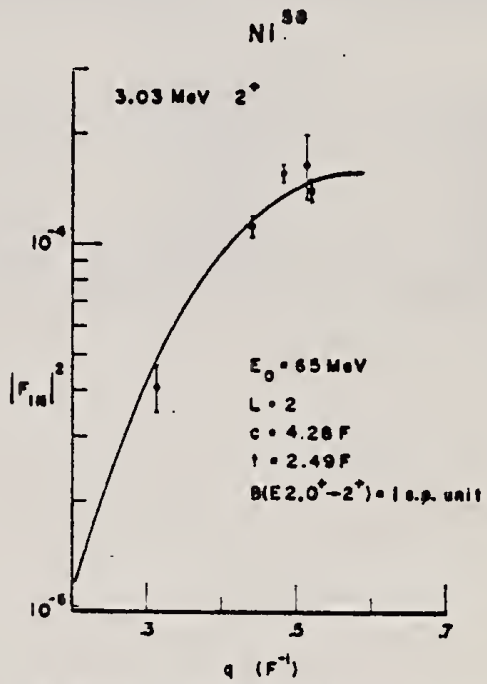

Fic. 20. The theoretical and experimental $\left|F_{\text {ta }}\right|^{2}$ versus $q$ for the $\mathrm{Nis} 3.03-\mathrm{MeV} 2^{+}$state. culated by Code GBROW using the strict hydrodynamic model $\left(c_{\mathrm{tr}}=c ; h_{\mathrm{r}}=t\right)$. The best fit to the data is obtained by a leastsquares analysis.
FORM NBS- 418

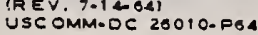

- 
M. A. Duguay, C. K. Bockelnan, I. H. Curtis and R. A. Eisenstein Phys. Rev. 10;. 12:0 (106́)

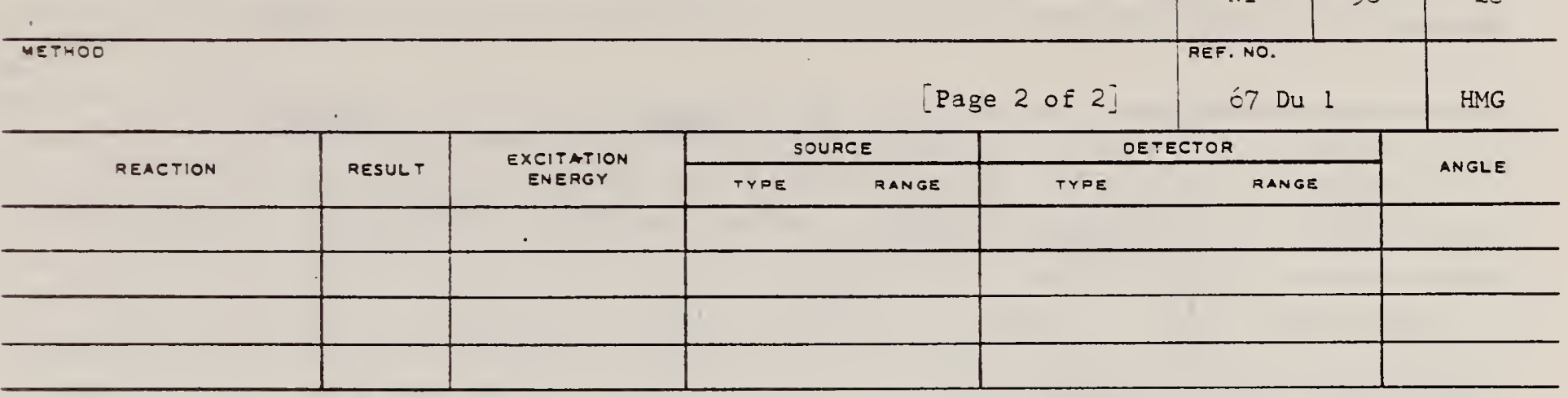

$\mathrm{NI}^{\text {BO }}$

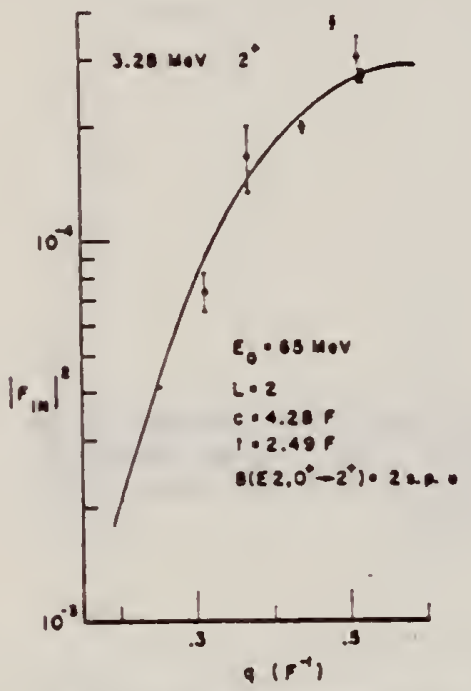

Fic. 21. The theoretical and experimental $\left|F_{i}\right|^{\prime}$ versus $q$ for the $\mathrm{Ni}^{2} 3.26-\mathrm{MeV} 2^{+}$state. The solid curve is the $\left|F_{\text {t }}\right|^{\prime}$ calculated by code $C B 20$ using the surice bydrodynamic model ( $c u=c$; $h_{1}=1$ ). The besi fit to the data is obtained by a least-squases andipin the $4 .+8-\mathrm{MeV} 3^{-}$state. The solid curve is the $\left(a_{r}=c ; h_{r}=b\right)$. The best fit to the data is obtained by a least. squares andysis.

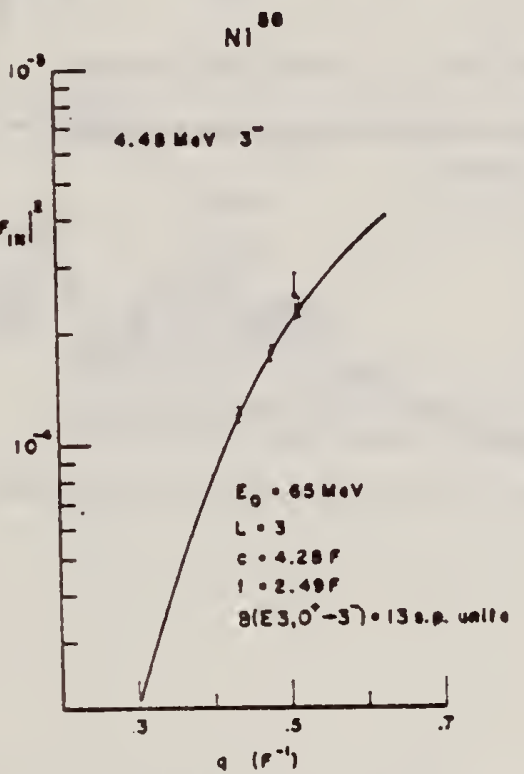




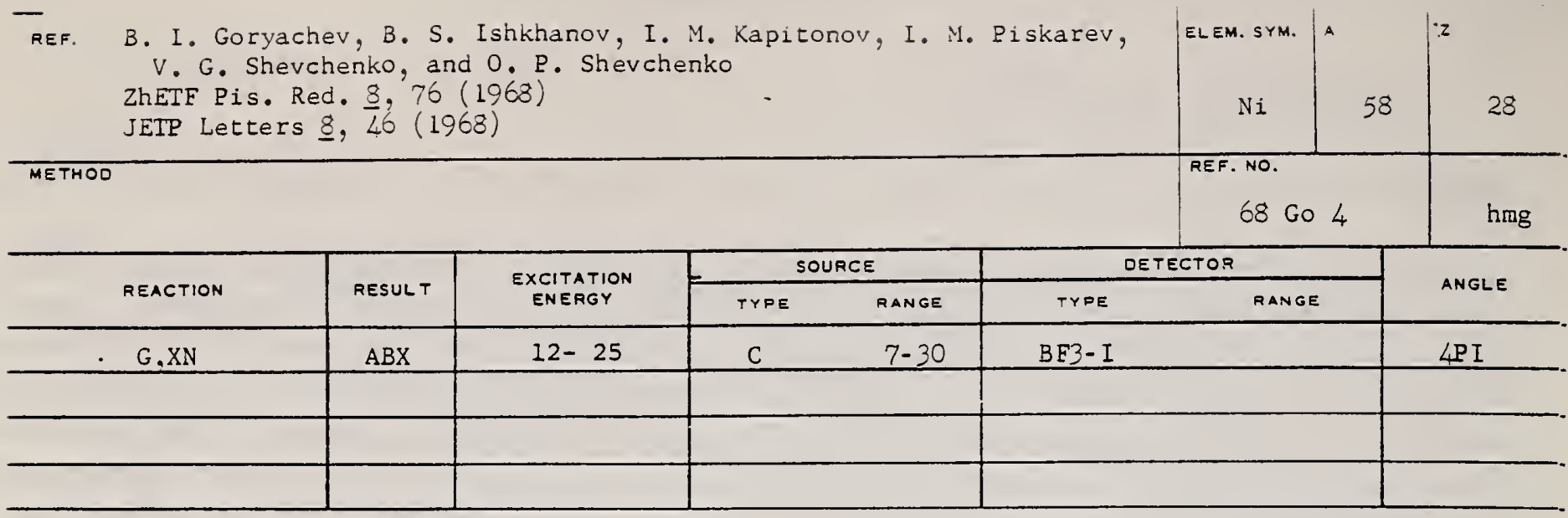

$\sigma_{\text {int }}(30 \mathrm{MeV})=380 \pm 30 \mathrm{MeV}-\mathrm{mb}$.

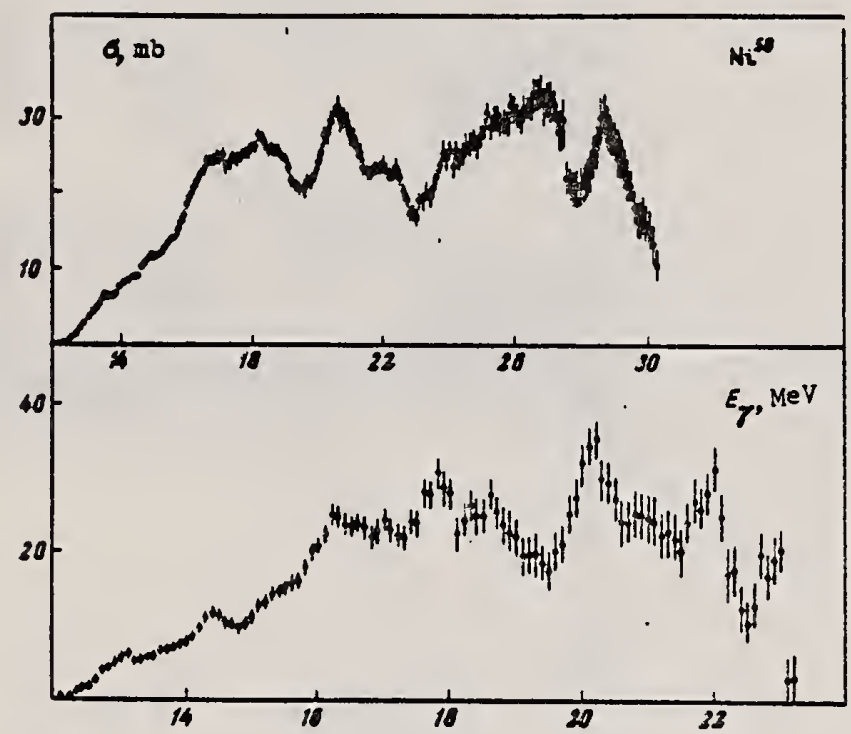

Fig. 1. Effective cross section of the reaction $\mathrm{Ni}^{58}(Y, \mathrm{~T})$. Upper flgure analysis in steps of $1 \mathrm{MeV}$, lower - in steps of $0.5 \mathrm{MeV}$. 


\begin{tabular}{|c|c|c|c|c|c|c|c|}
\hline \multirow{2}{*}{ REACTION } & \multirow{2}{*}{ RESULT } & \multirow{2}{*}{$\begin{array}{c}\text { EXCITATION } \\
\text { ENERGY }\end{array}$} & \multicolumn{2}{|c|}{ SOURCE } & \multicolumn{2}{|c|}{ OETECTOR } & \multirow{2}{*}{ ANGLE } \\
\hline & & & TYPE & RANGE & TYPE & RANGE & \\
\hline G. XV & $A B X$ & $12-24$ & C & $10-25$ & $B E^{3}-I$ & & $\angle P I$ \\
\hline & & & & & & & \\
\hline
\end{tabular}

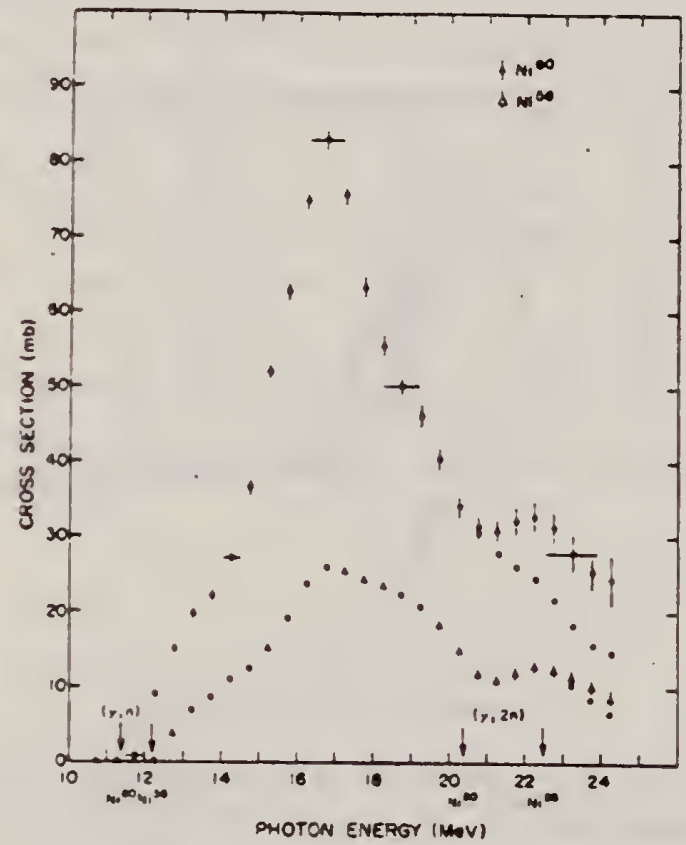

Table I. Integrated $(\gamma, x)$ crass sections up to 25 MeV.

\begin{tabular}{cc}
\hline Isotope & $\begin{array}{c}\text { Integrated cross section } \\
\text { (MeV mb) }\end{array}$ \\
\hline $\mathrm{Ni}^{50}$ & $185 \pm 3$ \\
$\mathrm{Ni}^{60}$ & $482 \pm 12$ \\
Natural nickel & $283 \pm 6$ \\
$(0.262) \mathrm{Ni} i^{60}+(0.679) \mathrm{Ni}$ & $252 \pm 4$ \\
Ratio of integrated cross section, $\mathrm{Ni}^{60} / \mathrm{Ni}^{5 \mathrm{a}}=2.6$ \\
\hline
\end{tabular}

FIG. 1. Photoneutron cross sections of $\mathrm{Ni}^{* 0}$ and $\mathrm{Ni}^{40}$. The corrected values for $(\gamma, 2 \pi)$ process are shown by circles. 
nef. V. D. Afanas'ev, N. G. Afanas'ev, I. S. Gul'karov, G. A. Savitskii, V. M. Khvastunov, N. G. Shevchenko and A. A. Khomich

Yad. Fiz. 10, 33 (1969)

Sov. J. Nucl. Phys. 10, 18 (1970)

69 Af 1

\begin{tabular}{|c|c|c|c|c|c|c|c|}
\hline \multirow{2}{*}{ REACTION } & \multirow{2}{*}{ RESULT } & \multirow{2}{*}{$\begin{array}{l}\text { EXCITATION } \\
\text { ENERGY }\end{array}$} & \multicolumn{2}{|c|}{ SOURCE } & \multicolumn{2}{|c|}{ OETECTOR } & \multirow{2}{*}{ ANGLE } \\
\hline & & & TYPE & RANGE & TYDE & RANGE & \\
\hline$E, E /$ & FMF & 1,4 & D & 150,225 & MAG-D & & DST \\
\hline & & & & & & & \\
\hline & & & & & - & & \\
\hline & & & & & & & \\
\hline
\end{tabular}

$1,4=1.45,4.45 \mathrm{MEV}$
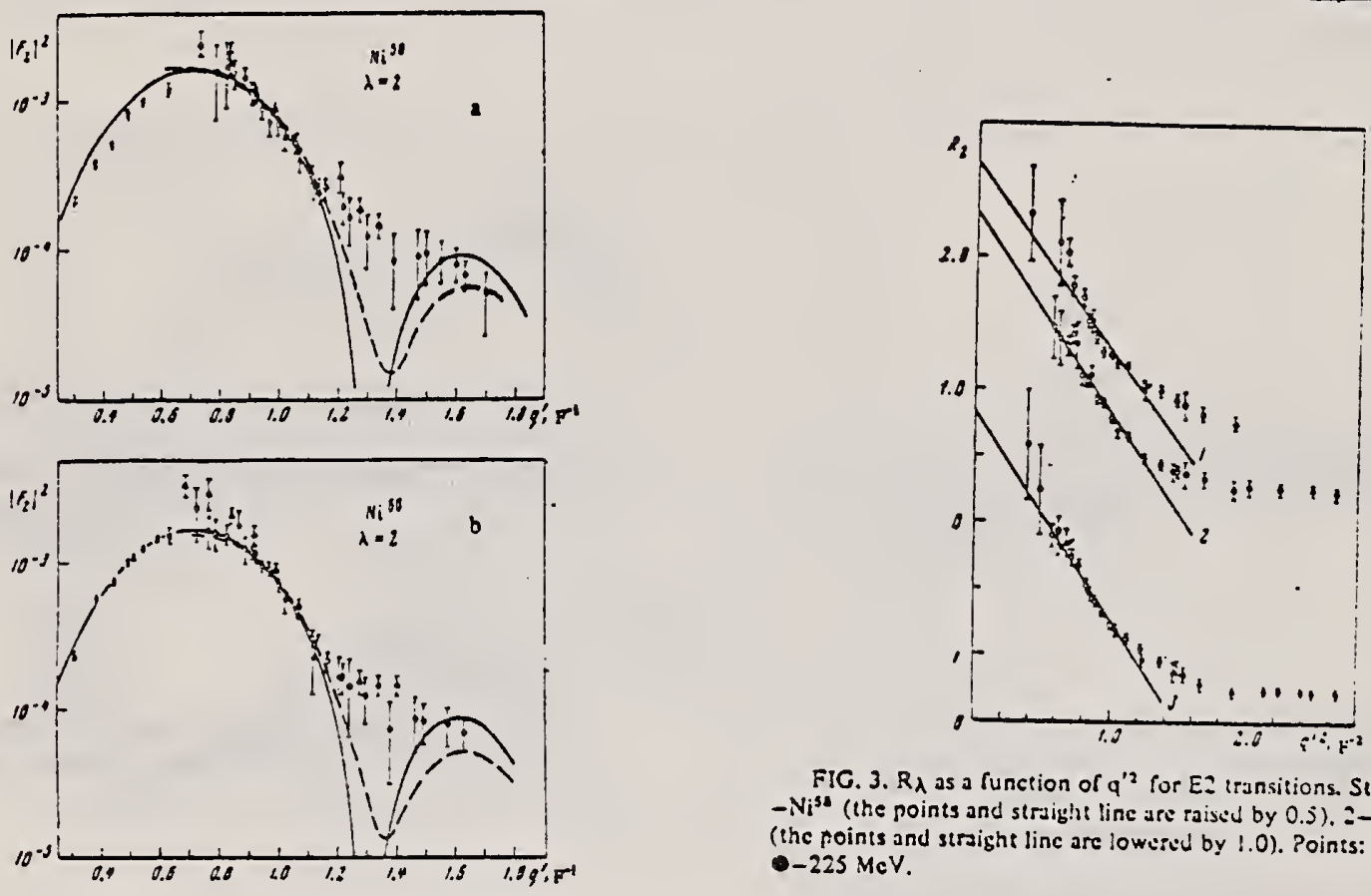

FIC. 3. $R_{\lambda}$ as a function of $q^{\prime 2}$ for $E 2$ transitions. Straight :inus: 1-

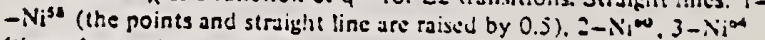
(the foints and straght line are lowsicd by 1.0 ). Points: $0-150$ Mit.

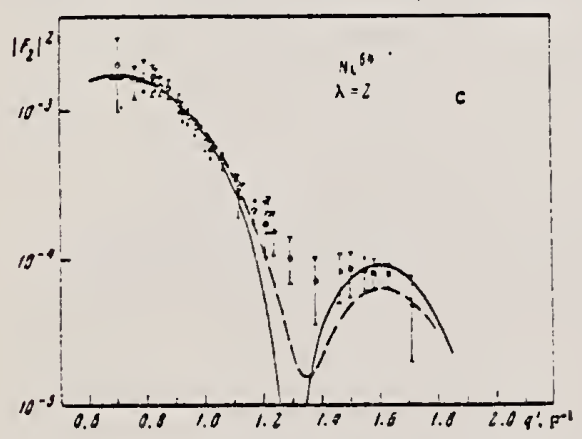

FIG. 2. Form factors for $E 2$ transitions in nickel isotopes: a $-\mathrm{Ni}^{\text {s4, }}$, $b-\mathrm{Ni}^{\infty}, \mathrm{c}-\mathrm{Ni} \mathrm{i}^{\text {* }}$. Solid eurves-Heim's model, dashed curves-high-energy approximation. Points: 0,0 -our data for 150 and $225 \mathrm{MeV}, \triangle-S t a n-$ ford data $(9), X$-Yale data $\left({ }^{\circ}\right)$.

Table I. Reduced probabilities of quadrupole transitions in the isotopes $\mathrm{Nt}^{59,90,01}$

\begin{tabular}{|c|c|c|c|c|c|c|c|c|c|c|c|}
\hline \multirow{3}{*}{$\begin{array}{l}\text { 1so. } \\
\text { topope }\end{array}$} & \multirow{3}{*}{$\underset{M e V}{\pi .}$} & \multirow[b]{3}{*}{ je } & \multicolumn{4}{|c|}{$\left.\nabla(R), p^{\prime}\right)$} & \multirow[b]{3}{*}{$\sigma_{1}$} & \multirow{2}{*}{\multicolumn{2}{|c|}{ Theory }} & \multirow{2}{*}{\multicolumn{2}{|c|}{$\begin{array}{l}\text { Dace of other } \\
\text { zuctiors }\end{array}$}} \\
\hline & & & & 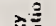 & $\equiv$ & & & & & & \\
\hline & & & 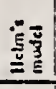 & $\begin{array}{l}3 \\
0 \\
\end{array}$ & 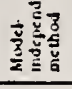 & 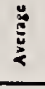 & & $\Xi$ & $\Xi$ & $\frac{\bar{E}}{6}$ & 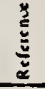 \\
\hline$N_{1} \infty$ & 1.45 & $=$ & 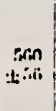 & $\begin{array}{l}.54 \\
.11 \\
4: 11\end{array}$ & 519 & $\operatorname{sis}$ & $x, 4$ & 210 & $2 n 0$ & 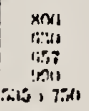 & 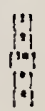 \\
\hline Nim & 1.27 & $2^{4}$ & ${ }_{1}^{m M n}$ & $\begin{array}{r}m_{2}=2 \\
+4011\end{array}$ & ancin & ก.? & $9 . n$ & xin & Aen & 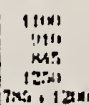 & 紧 \\
\hline$N_{1} \omega$ & 1.32 & 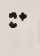 & $\begin{array}{l}a^{s}+1 \\
=0,\end{array}$ & $\begin{array}{l}8 \times 1 \\
\pm 53\end{array}$ & $\begin{array}{l}\sin \\
=5 s\end{array}$ & 050 & 9.8 & 1430 & ano & 370 & in \\
\hline
\end{tabular}


Table W. Reduced probabi'itles of octupole transitions in the isotopes $\mathrm{Ni}^{30,00, \mathrm{~N}}$

\begin{tabular}{|c|c|c|c|c|c|c|c|c|}
\hline \multirow{2}{*}{ isotops } & \multirow{2}{*}{$E_{\text {E. }}^{E}$} & \multirow{2}{*}{20} & \multicolumn{3}{|c|}{$J(E), e^{2} F^{4}$} & \multirow{2}{*}{$c_{2}$} & \multicolumn{2}{|c|}{$\begin{array}{l}\text { Dats of other } \\
\text { suthors }\end{array}$} \\
\hline & & & $\begin{array}{l}\text { Helmi, } \\
\text { model }\end{array}$ & $\begin{array}{l}\text { Mode:- } \\
\text { independent } \\
\text { meinod }\end{array}$ & Averaso & & $\Delta(\varepsilon)$ & Reference \\
\hline$v_{i} \omega^{\infty}$ & 4.45 & $3^{-}$ & $\begin{array}{r}13800 \\
=1450\end{array}$ & $\begin{array}{r}13030 \\
. \pm 780\end{array}$ & 13100 & $\begin{array}{r}10 \\
-\quad\end{array}$ & $\begin{array}{l}18600 \\
27 \mathrm{~mm} \\
14600\end{array}$ & {$\left[\begin{array}{l}10 ! \\
i \neq j \\
i=1\end{array}\right]$} \\
\hline$Y$ & 4.04 & 3- & $\begin{aligned} & 133 m \\
= & 1800\end{aligned}$ & $\begin{array}{l}13910 \\
=230\end{array}$ & 13000 & ๑ & $\begin{array}{l}\text { בn: } \\
35 \mathrm{mn} \\
19100\end{array}$ & $\mid$ \\
\hline$Y_{1} \omega$ & 3.53 & 5 & $\begin{aligned} & 1500 \\
\pm & 1800\end{aligned}$ & $\begin{aligned} & 17000 \\
= & 1400\end{aligned}$ & 16500 & 9.4 & & \\
\hline
\end{tabular}

Table $W$. Transition radit and parameters of the vibraclonal mode! of the nucleus for $\Sigma 2$ and $\Sigma 3$ transitions in $\mathrm{Ni}^{30,30,04}$

\begin{tabular}{|c|c|c|c|c|c|c|c|}
\hline \multirow[b]{2}{*}{ trotepe } & \multirow[b]{2}{*}{$I_{1}-I_{1}$} & \multicolumn{2}{|c|}{ REvas } & \multirow[b]{2}{*}{$\boldsymbol{\lambda u} \cdot v$} & \multirow{2}{*}{$\begin{array}{c}\begin{array}{c}3 \lambda_{0} \\
M e V-x e c\end{array} \\
N^{2}\end{array}$} & \multirow{2}{*}{$\frac{B \lambda}{\left(B \nu_{t} \cdot d .\right.}$} & \multirow[b]{2}{*}{$n_{2}^{\prime}$} \\
\hline & & $\begin{array}{l}\text { Ous } \\
\text { result }\end{array}$ & {$[-1$} & & & & \\
\hline \multirow[b]{2}{*}{ 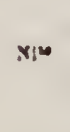 } & 202 & $\begin{array}{r}4.35 \\
+0.21\end{array}$ & 5.51 & $\begin{array}{r}173 \\
\pm 19\end{array}$ & $\begin{array}{r}12 \\
=9\end{array}$ & $\begin{array}{r}20.0 \\
=2.2\end{array}$ & $\begin{aligned} & 0.11 \mathrm{~s} \\
= & 0.0 \mathrm{~m}\end{aligned}$ \\
\hline & $0-3$ & $\begin{array}{r}3.13 \\
\pm 0.11\end{array}$ & 3.03 & $\begin{array}{l}1 \leq 2 n \\
\pm 134\end{array}$ & $\begin{array}{r}17 \\
=8\end{array}$ & $\begin{array}{r}17 \\
=2\end{array}$ & $\begin{aligned} & 0.1 n ! \\
= & 0.006\end{aligned}$ \\
\hline \multirow{2}{*}{$Y i \infty$} & $a \rightarrow 2$ & $\begin{array}{r}6.92 \\
\pm 0.15\end{array}$ & 3.53 & $\begin{array}{r}15.3 \\
\pm: 7\end{array}$ & $\begin{array}{r}36 \\
=9\end{array}$ & $\begin{array}{l}=0 \\
=2.2\end{array}$ & $\begin{aligned} & 0.148 \\
= & 0.0 .8\end{aligned}$ \\
\hline & $0 \rightarrow 3$ & $\begin{array}{r}5.21 \\
\pm 0.10\end{array}$ & 6.69 & $\begin{array}{r}1500 \\
=130\end{array}$ & $\begin{array}{l}92 \\
=3\end{array}$ & $\begin{array}{l}13.5 \\
=1.6\end{array}$ & $\begin{aligned} & 0.099 \\
= & 0.095\end{aligned}$ \\
\hline \multirow{2}{*}{$Y_{1}=$} & $a-2$ & $\begin{aligned} & 4.99 \\
= & 0.15\end{aligned}$ & - & $\begin{array}{r}135 \\
\pm 16\end{array}$ & $\begin{array}{r}13 \\
=9\end{array}$ & $\begin{array}{r}17.3 \\
\pm 1.5\end{array}$ & $\begin{array}{r}0.1(\mathrm{~s}) \\
\pm 0.18 \mathrm{~m}\end{array}$ \\
\hline & $a-3$ & $\begin{aligned} & 3.21 \\
= & 0.11\end{aligned}$ & - & $\begin{array}{r}1160 \\
=130\end{array}$ & $=12$ & $\begin{array}{r}17.1 \\
\pm 2.2\end{array}$ & $\begin{aligned} & 0 . \ln : \\
= & 0.410\end{aligned}$ \\
\hline
\end{tabular}

(B)h.d. is the axcliaison parametef of una nucleus, obtained with a hydrody. uimical model.

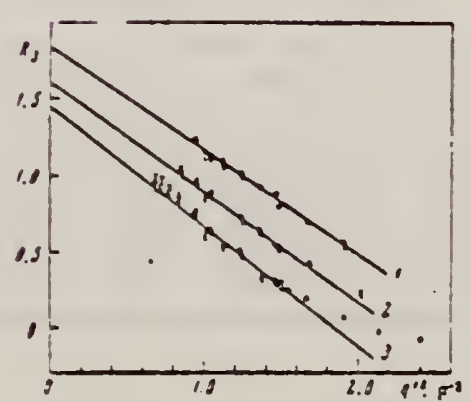

FIC. S. Analysis of E3 transitions by the mode!-independent mechod. Sersight ines: $1-N^{31}$ (the da:a and straight line have been raised by 0.5 ) $=-N_{1}^{\infty}, 3-N_{i} i^{\text {se }}$ (the cata and siraighe line have been lowered by 0.5 ).

Polis: $0-150, \mathrm{MeV}, 0-225 \mathrm{MeV}$.

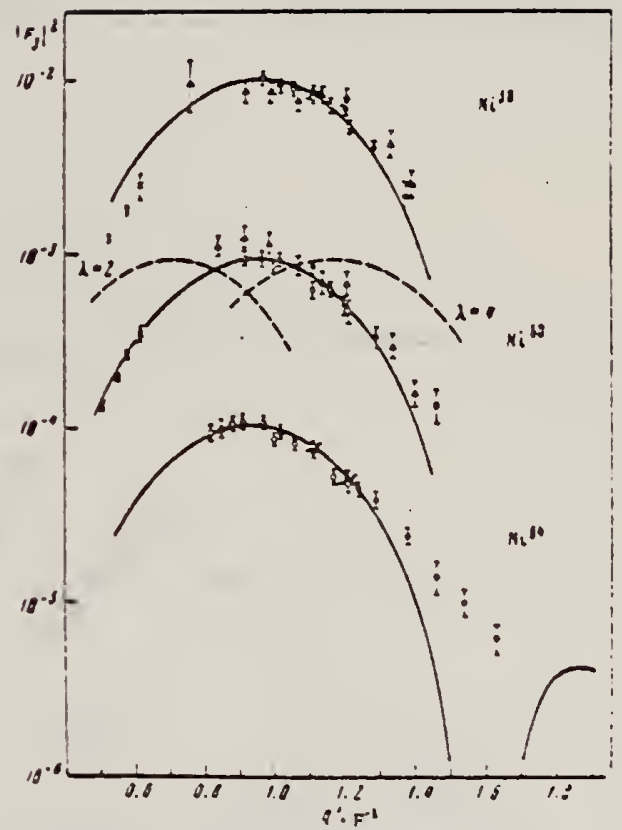

FIC. 4. Form factors for E3 transitions in the isotones. $\mathrm{Ni}^{93}$ (the ex.

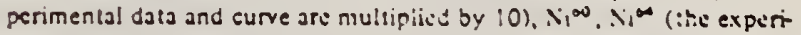
menta! data and curve are divided by 10 ). The solid surves represint the form factor calculated by Heln's modit with $\lambda=3$. and ihd dished curves the form factor caicuiated by the sume motel for $\lambda=$ : and $\lambda=4$. Poinis: $O$ and $O$-our data for 150 and $2: 5 \mathrm{MeV}, \Delta-$ Sianiond data [", $\mathrm{X}-Y \mathrm{Yle}$ data $\{10 \%$. 
REF. B.I. Goryachev, B.S. Ishkhanov, I.M. Kapitorov, I.M. Piskarev, V.G. Shevchenko, and O.P. Shevchenko

Yad. Fiz. 10, 252 (1969)

Sov. J. Nucl. Phys. 11,141 (1970)

69 Go 2

\begin{tabular}{|c|c|c|c|c|c|c|c|}
\hline \multirow{2}{*}{ REACTION } & \multirow{2}{*}{ RESUL T } & \multirow{2}{*}{$\begin{array}{l}\text { EXCITATION - } \\
\text { ENERGY }\end{array}$} & \multicolumn{2}{|c|}{ SOURCE } & \multicolumn{2}{|c|}{ DETECTOR } & \multirow{2}{*}{ ANGLE } \\
\hline & & & TYDE & RANGE & TYDE & RANGE & \\
\hline \multirow[t]{2}{*}{$G, X N$} & $A B X$ & $12-30$ & $C$ & $12-30$ & BF3-I & & $4 \mathrm{PI}$ \\
\hline & & $(12.2-30)$ & & & & & \\
\hline & & & & & & & \\
\hline & & & & & & & \\
\hline
\end{tabular}

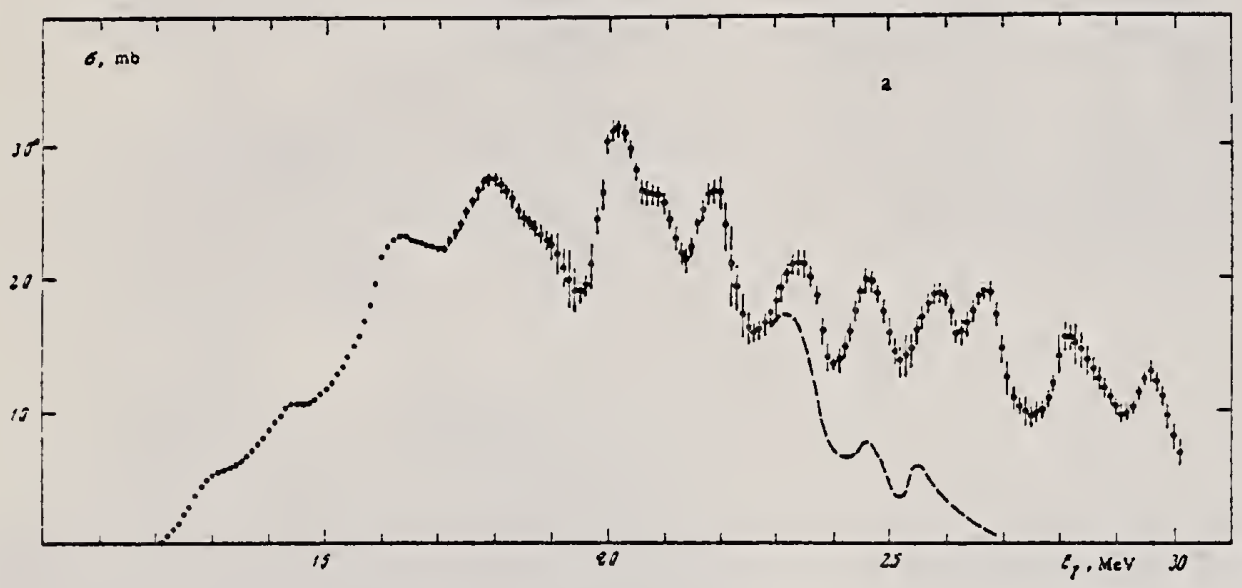

$\int^{30} \sigma \mathrm{dE}=310 \pm 30 \mathrm{MeV} \mathrm{mb}$

FIG. 1. Cross section of the photoneutron reaction for $\mathrm{Ni}^{\text {ss }}$ (a) and. $\mathrm{Ni}^{60}(\mathrm{~b})$. The dasined line shows the cross sestion of the reaction $(\gamma, n)$ above the threshold of two-neutron emission, obtained from our data on the basis of the statistical theory. 
I. S. Gul'karov, N. G. Afanas'ev, V. M. Khvastunov, N. G. Shevchenko,

V. D. Afanas'ev, G. A. Savitskii, A. A. Khomich

Yad. Fiz. 2, 478 (1969)

sov. I. vicle Phvs, $0,274(1060)$. (1)

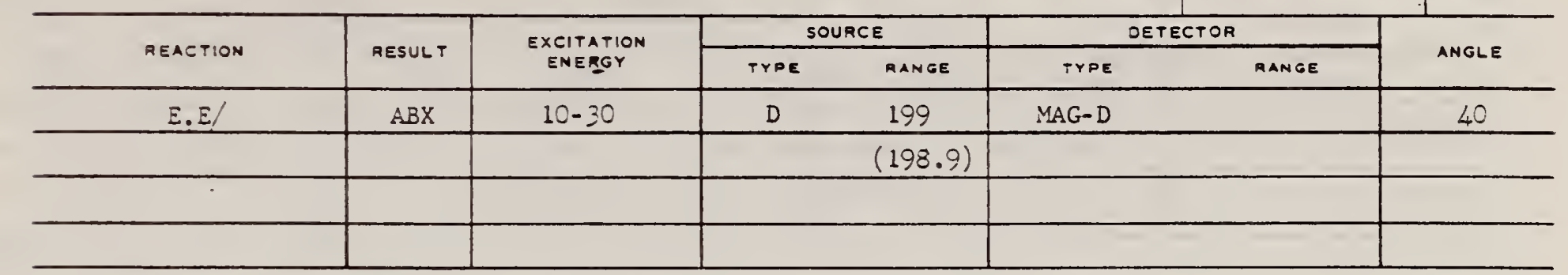

See paper for sumary of other data.

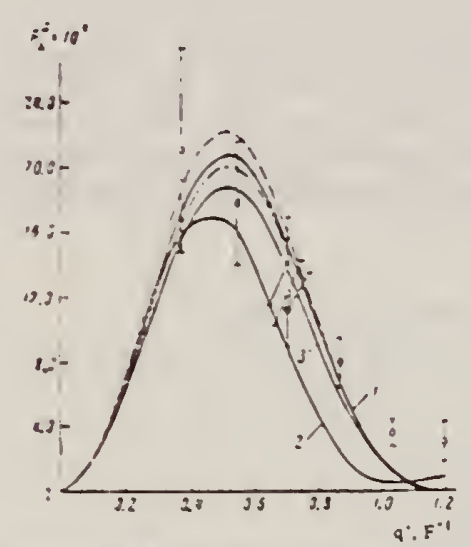

FIG. 2. Giantresonance form factor as a function of momentum

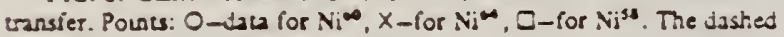
eirre, eurve I, and the dotdash curve were calculated from formula ( $(\Omega)$ for the nucles $\mathrm{Ni}^{3 s}$ is respectuvely, with $\mathrm{k}=19 \mathrm{MeV}$. Curve 3 wass alculated from the same formula for $\mathrm{Ni}^{\circ}$ with $k=21 \mathrm{MeV}$. Curve 2 is a calculation according to the Coldhaber-Teller collective model.

Table I Absolute differential cross sections for iselastic scattering of electrons with excitation of the giart resonarce in aickel isotopes

\begin{tabular}{|c|c|c|c|c|c|c|}
\hline Mucions & 0.4 & E. W. V & a $F^{-1}$ & $9 \cdot F^{1}$ & $\cos 1 \Omega_{0} \mathrm{~cm}^{2} / \mathrm{m}$ & $r^{3}(x)$ \\
\hline 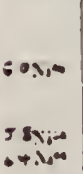 & 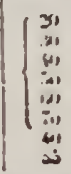 & 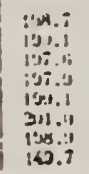 & 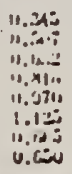 & 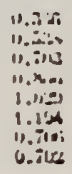 & 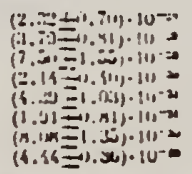 & 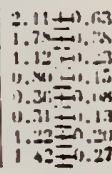 \\
\hline
\end{tabular}

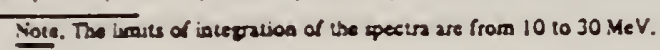

FMF

\begin{tabular}{|c|c|c|} 
ELEM. SYM. & \multirow{2}{*}{58} & 28 \\
\hline $\begin{array}{c}\text { REF. NO. } \\
69 \mathrm{Gu} 1\end{array}$ & $\mathrm{hmg}$ \\
\hline
\end{tabular}
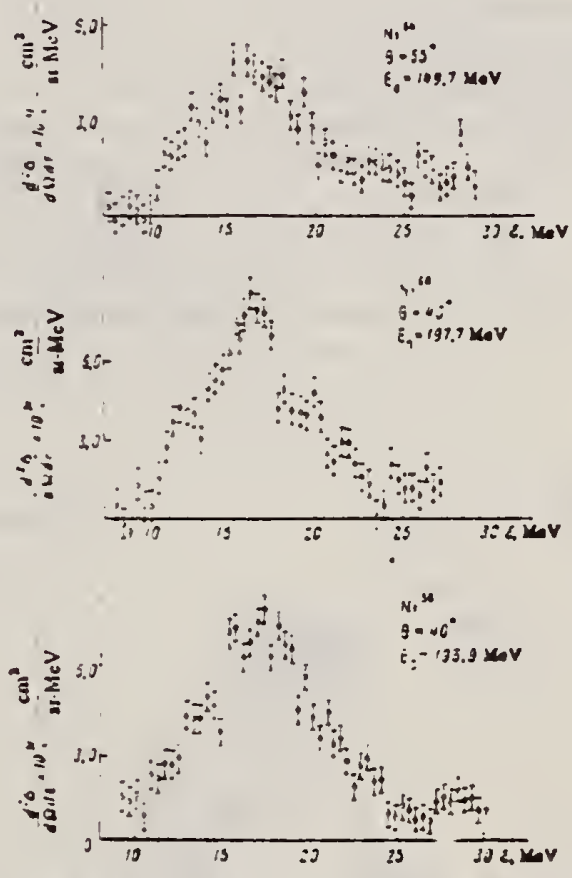

FIG. 3. Energy spectrz of electrons inelastically xattered by the isoloper $\mathrm{Nimi}$ is so. All threo spectra were mensured at the same value of momentum transex. 
D. G. Owen, E. G. Muirhead, B. M. Spicer

Contributions Montreal Conference 349 (19,69)

69 Ow 1

egf

\begin{tabular}{|c|c|c|c|c|c|c|c|}
\hline \multirow[b]{2}{*}{ REACTION } & \multirow[b]{2}{*}{ RESULT } & \multirow{2}{*}{$\begin{array}{l}\text { EXCITATION } \\
\text { ENERGY }\end{array}$} & \multicolumn{2}{|c|}{ SOURCE } & \multicolumn{2}{|c|}{ OETECTOR } & \multirow{2}{*}{ ANGLE } \\
\hline & & & TYPE & RANGE & TYPE & RANGE & \\
\hline $\mathrm{G}, \mathrm{XN}$ & $A B X$ & $12-25$ & $\mathrm{C}$ & $12-25$ & $B F 3-I$ & & $4 \mathrm{PI}$ \\
\hline & & & & & & & \\
\hline & & & & & & & \\
\hline & & & & & & & \\
\hline
\end{tabular}

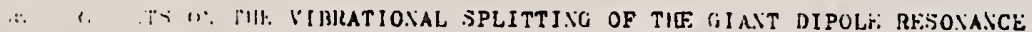

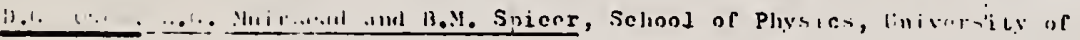

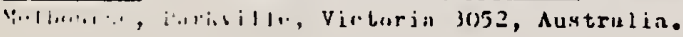

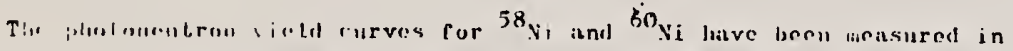

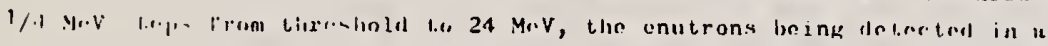

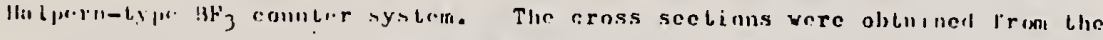
yinbl curves hy the lesiss-pentold mulirix thversion method. A rorrection,

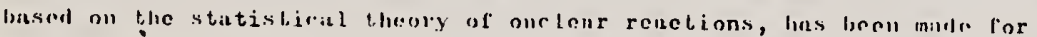
multiple neutron emission. The drr: vert eross sections ure hown in figures 1 and 2.

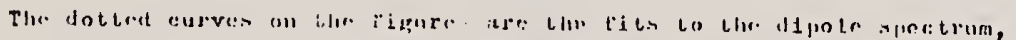

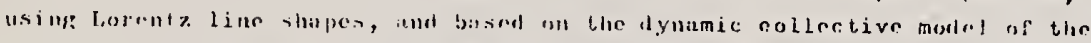

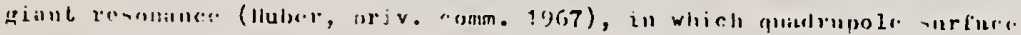

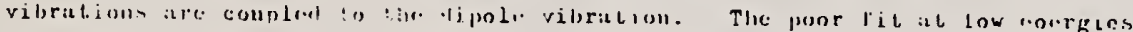
is attributed to oegles: of single particle effects.

Also shown in ligure 1 in the re-ult of the collestiw enrelations

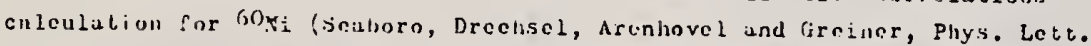
$23(1966) 576)$. ilere the surfiace viorations are coupled to particle-lode dipoin states, not just the dipoic state. This ealculation for the closed-subsictl nueleus $60 \mathrm{Ni}$ yields the result shown in the full eurve of figure 1. The agrenment with experiment is very mucil improved, indiearing the importinoer of includin! single particlo effects.

The imilazity of low corrgy spectra for $58 \mathrm{Ni}_{\mathrm{i}}$ and $60 \mathrm{Ni}$, coupleif with the fact that the same single particle states are filled in the ground itate, leads to thr expectation that the giant resonance structure will b. aimilar for the we isotoper. This is in fact observed.

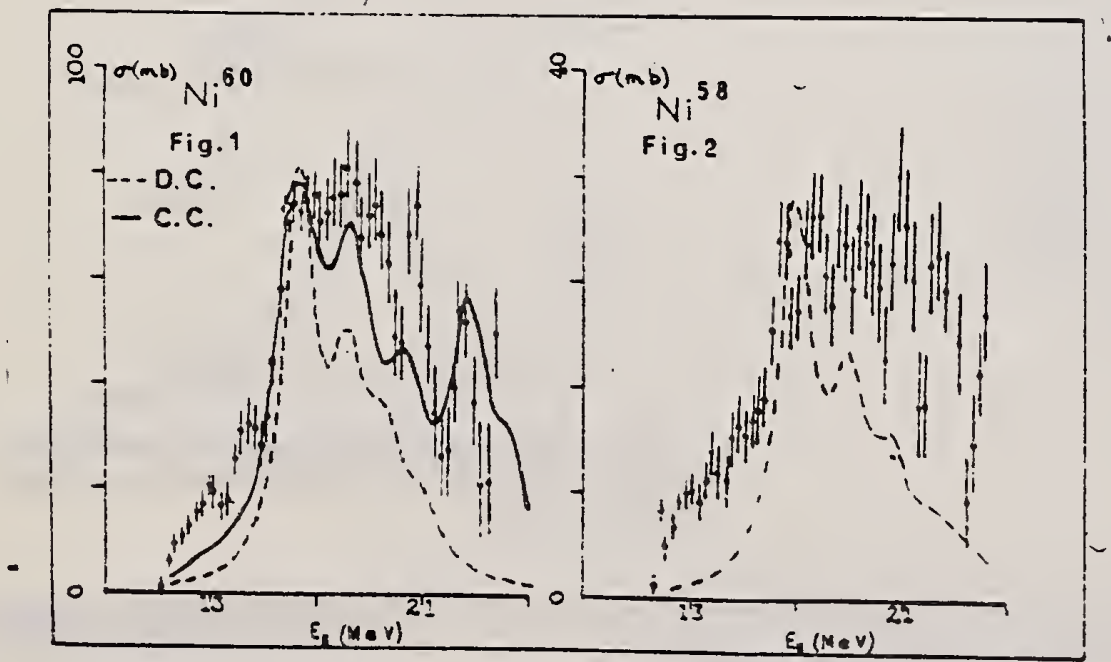


To Is 4

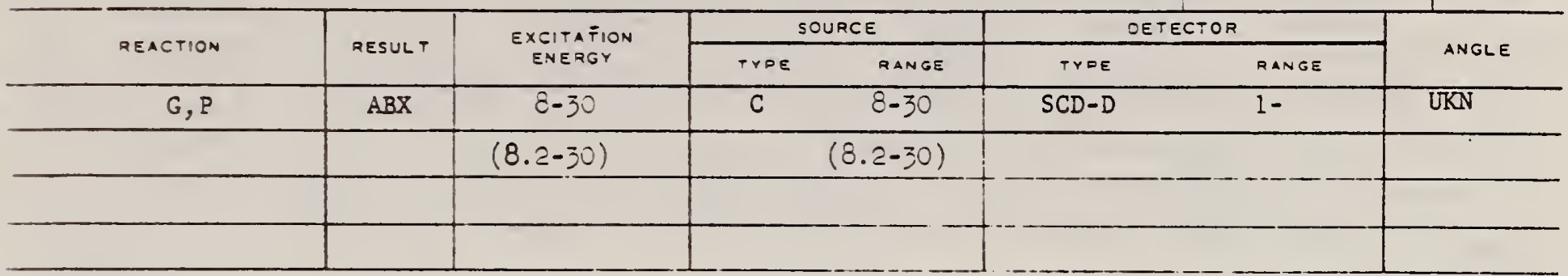

We measured the photoproton cross sections for the nuclel $\mathrm{Cr}^{32}, \mathrm{N1}^{30}$, and $\mathrm{N1}^{10}$ from the threshold to $30 \mathrm{NeV}$. We registered protons with energy larger than $1 \mathrm{MeV}$. A number of maxima were obtalned in the cross sections. The values of the integral cross sections for $\mathrm{Cr}^{52}, \mathrm{N1}^{30}$, and $\mathrm{Ni}^{80}$ are equal respectively to 240,570, and $320 \mathrm{MeV}-\mathrm{mb}$. The anomalously large cross section for the production of photoprotons for $\mathrm{Ni}^{30}$, and also the shilt of the centers of gravity of the photoproton cross sections towards tigher excitation energies relative to the photoneutron cross sections in the case of $\mathrm{Cr}^{52}$ ard $\mathrm{Ni}^{30}$, can be attributed to the influence of aralog states.

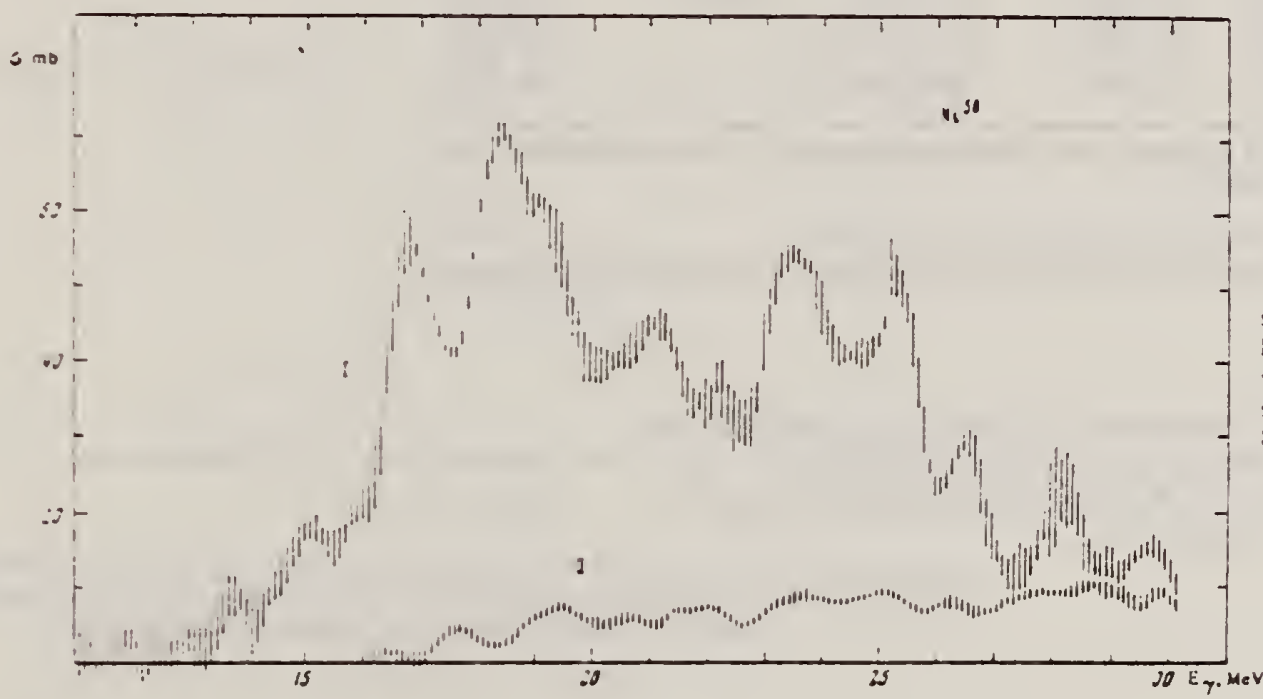

PROB 90 DEGREES

$743+$
FIG. 2. Photoproton cross sections for $\mathrm{Ni}^{\text {so }}$ Cross section I has been obtained for protons with $E_{p}>1 \mathrm{MeV}$ and the cross section 11 ior protons with $E_{p}>$ $8 . \mathrm{MeV}$.

Integral characteristics of the photoproton cross sections

$\sigma_{p}$, of the photoneutron cross sections $\sigma_{n}$, and of the total absorption cross sections $\sigma_{3}=c_{n}+c_{p}$

\begin{tabular}{|c|c|c|c|c|c|c|c|}
\hline 立 & 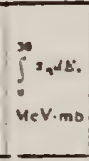 & 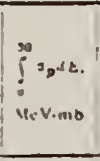 & 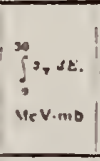 & $\begin{array}{l}\text { SNCSz:Al. } \\
\text { Notumn }\end{array}$ & $\prod_{i}^{n} e_{\nu}, \eta_{i}= \pm$ & 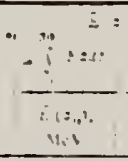 & 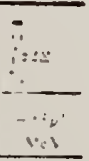 \\
\hline & $\begin{array}{l}-50=3 w \\
310=w 0\end{array}$ & & 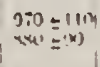 & 䔶 & 政 & \begin{tabular}{l}
$\because: \cdots !$ \\
\hdashline$: 1:$
\end{tabular} & 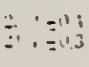 \\
\hline & $18: 0-2)$ & ( (i) $=3$ & rill $=$ tin & \$1וי4 & 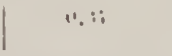 & 1 $\quad *=13 ;$ & $\therefore \Delta-$ \\
\hline
\end{tabular}

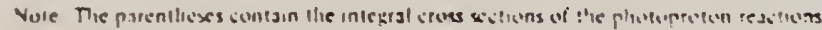
for protuns will enerey !: $>$ X liev 


\begin{tabular}{|c|c|c|c|c|c|c|c|}
\hline \multirow[b]{2}{*}{ REACTION } & \multirow[b]{2}{*}{ RESUL T } & \multirow{2}{*}{$\begin{array}{l}\text { EXCITATION } \\
\text { ENERGY }\end{array}$} & \multicolumn{2}{|c|}{ SOURCE } & \multicolumn{2}{|c|}{ DETECTOR } & \multirow{2}{*}{ ANGLE } \\
\hline & & & TYPE & RANGE & TYDE & RANGE & \\
\hline \multirow[t]{2}{*}{$\mathrm{G}, \mathrm{G}$} & LFT & $1-4$ & C & 4 & SCD-D & $1-5$ & DST \\
\hline & & $(4.1)$ & & & & & \\
\hline & & & & & & & \\
\hline & & & & & & & \\
\hline
\end{tabular}

TABu 1

The direct results of the resonance scattering experiments on ${ }^{\text {a }} \mathrm{Ni}$ described in this paper are listed in the fourth column

\begin{tabular}{|c|c|c|c|c|c|c|}
\hline \multirow[b]{2}{*}{$\begin{array}{c}E_{\text {lewd }} \\
(\mathrm{MeV})\end{array}$} & \multirow[t]{2}{*}{$I^{\prime \prime}$} & \multirow[t]{2}{*}{$\Gamma_{\mathrm{o}} / \Gamma$} & \multirow{2}{*}{$\begin{array}{c}\Gamma_{0}^{2} / \Gamma \text { (meV) } \\
\text { res. scatt. }\end{array}$} & \multicolumn{3}{|c|}{ Total width $\Gamma$ (meV) } \\
\hline & & & & res. scatt. & $\begin{array}{l}\text { inelastic } \\
\text { elec. scatt. }\end{array}$ & $\begin{array}{l}\text { Doppler } \\
\left.\text { shirt }{ }^{4}\right)\end{array}$ \\
\hline 1.453 & $2^{+}$ & $\left(.00^{2}\right)$ & $0.67 \pm 0.06$ & $0.67 \pm 0.06$ & $0.69 \pm 0.10$ & $0.72 \pm 0.09$ \\
\hline 3.038 & $2^{+}$ & $0.41=$ & $1.56 \pm 0.34$ & $9.3 \pm 2.3$ & $8.4 \pm 1.3$ & $11.5 \pm 1.6$ \\
\hline 3.263 & $2^{+}$ & $\left.0.62^{\circ}\right)$ & $5.3 \pm 0.8$ & $13.8 \pm 2.2$ & $14.7 \pm 2.2$ & $18.3 \pm 26$ \\
\hline 3.593 & $l^{( \pm)}$ & $0.69 \%$ & $4.6 \pm 0.8$ & $9.7 \pm 2.1$ & & $13.7 \pm 3.5$ \\
\hline 3.898 & $2^{+}$ & $\left.0.22^{\circ}\right)$ & $2.1 \pm 0.9$ & $43 \pm 19$ & & $19.9 \pm 2.4$ \\
\hline 4.108 & $2^{+}$ & $\left.0.50^{\circ}\right)$ & $1.0 \pm 0.6$ & $4.0 \pm 2.5$ & & $7.0 \pm 1.1$ \\
\hline
\end{tabular}

To arrive at the widths listed in column S, the branching ratios given in the third column were used.

1) Taken from table 4 of ref. ${ }^{4}$ ).

b) See ref. ${ }^{3}$ ).

c) Average of the two branching ratios listed in table 3 of ref. ${ }^{3}$ ).

d) To simplify the tabulation, the asymmetrical errors given in ref. ${ }^{3}$ ) were replaced by symmetrical errors.

$\left.{ }^{3}\right)$ M.C. Bertin, N. Benczer-Koller, G.G. Seaman and J.R. MacDonald, Phys. Rev. 183 (1969) 964.

$\left.{ }^{4}\right)$ D.M. Van Patter, R.N. Horoshko and H.L. Scott, Nucl.Phys. A.137 (1969) 353. 
D. G. Ower. E. G. Muirhead, and B. M. Spicer

Vucl. Phys. A1 $120,523(1970)$

70 Ow 1

egf

\begin{tabular}{|c|c|c|c|c|c|c|c|}
\hline \multirow{2}{*}{ REACTION } & \multirow{2}{*}{ RESULT } & \multirow{2}{*}{$\begin{array}{l}\text { EXCITATION } \\
\text { ENERGY }\end{array}$} & \multicolumn{2}{|c|}{ SOURCE } & \multicolumn{2}{|c|}{ DETECTOR } & \multirow{2}{*}{ ANGLE } \\
\hline & & & TYPE & TANGE & TYPE & RANGE & \\
\hline G.XN & $A B X$ & $11-24$ & $\mathrm{C}$ & $10-24$ & BF $3-I$ & & $\angle P I$ \\
\hline & & & \multicolumn{2}{|c|}{ ? } & & & \\
\hline & & & & & & & \\
\hline & & & & & & & \\
\hline
\end{tabular}

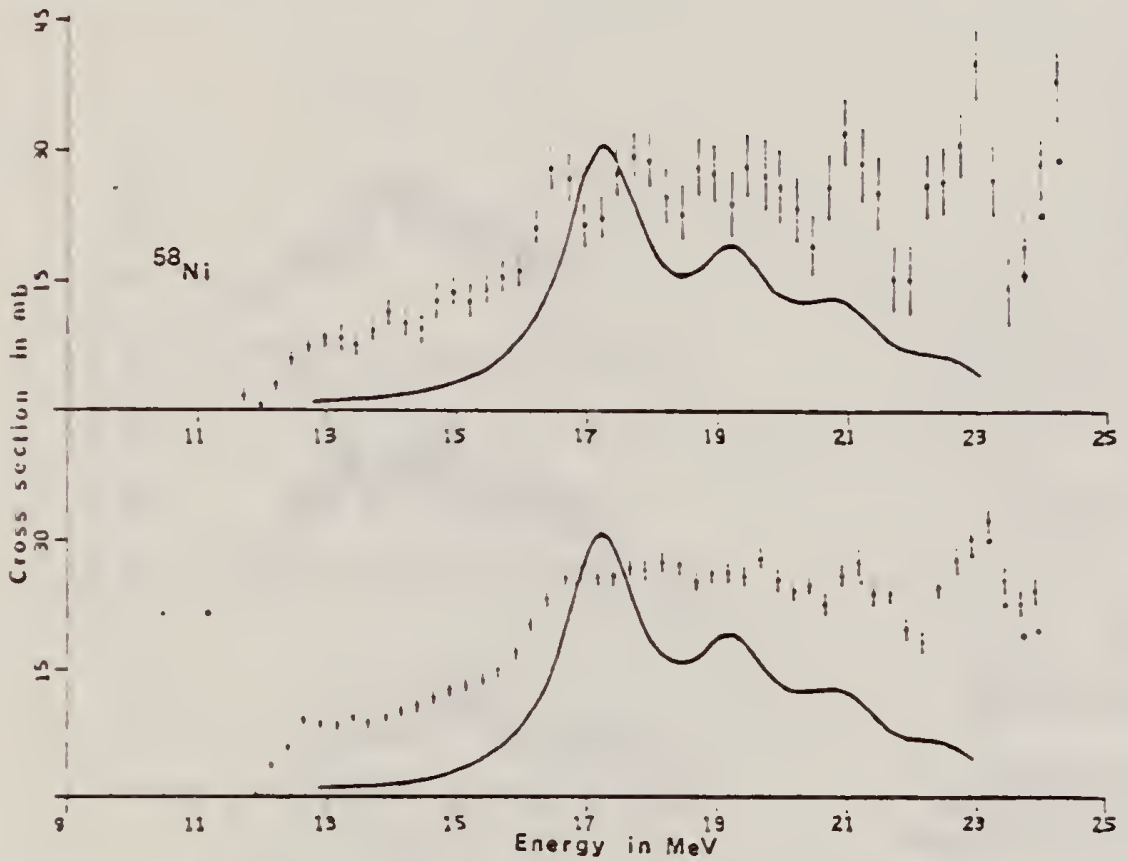

Fig. 2. The " $\mathrm{Mi}(\%, x \mathrm{n})$ cross sec:ion analysed in (top) 0.5 and (bottom) $1.0 \mathrm{MeV}$ bins. The errors shown represent the total experimental uncerainty ior eaca point. The continuous curve is the shape of the "Ni photo-absorption cross section prediered by Hüber '0.).

3 M. G. Huber, private comminication (1967). 
Yu. P. Antuf ev, V.L. Agranovich, V.B. Ganenko, V.S. Kuz menko, I.I. Miroshnichenko, and P.V. Sorokin

Yad. Fiz. 14, 898 (1971)

Sov. J. Nucl. Phys. 14, 502 (1972)

\begin{tabular}{|c|c|c|}
\hline \multirow{2}{*}{$\begin{array}{c}E L \equiv M . S Y M . \\
N \pm\end{array}$} & A & $z$ \\
\hline & 58 & 28 \\
\hline \multicolumn{2}{|l|}{ REF. NO. } & \\
\hline $71 \mathrm{~A}$ & 2 & hmg \\
\hline
\end{tabular}

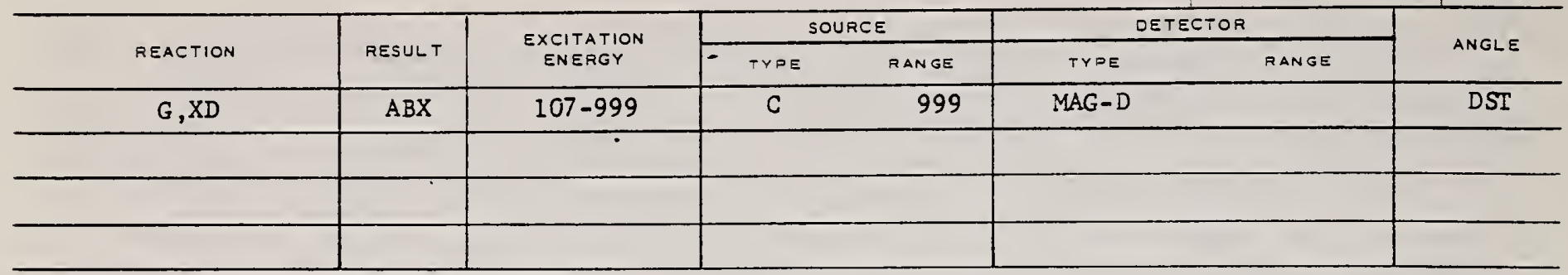

$999=1.14 \mathrm{GEV}$
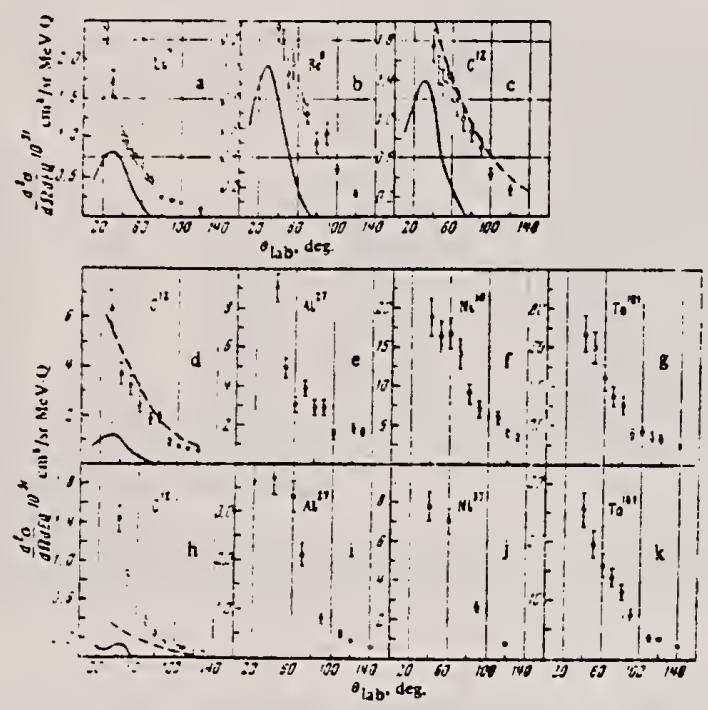

FIG. 1 . Anquiar distributions of deuterons in $(\gamma, d)$ reactions in nuslet for $E_{0}=620 \mathrm{MeV}(a-c)$ and $E_{0}=1140 \mathrm{MeV}(d-k)$. The statistiil errors are shown. a-g-angular distributions of deuterons with energies of $90 \mathrm{MeV}, \mathrm{h}-\mathrm{k}$-with energy $160 \mathrm{MeV}$. 
K. Shoda, M. Sugawara, T. Saito, H. Miyase, A. Suzuki, S. Oikawa, and J. Uegaki

Picns-72, 321 Sendai

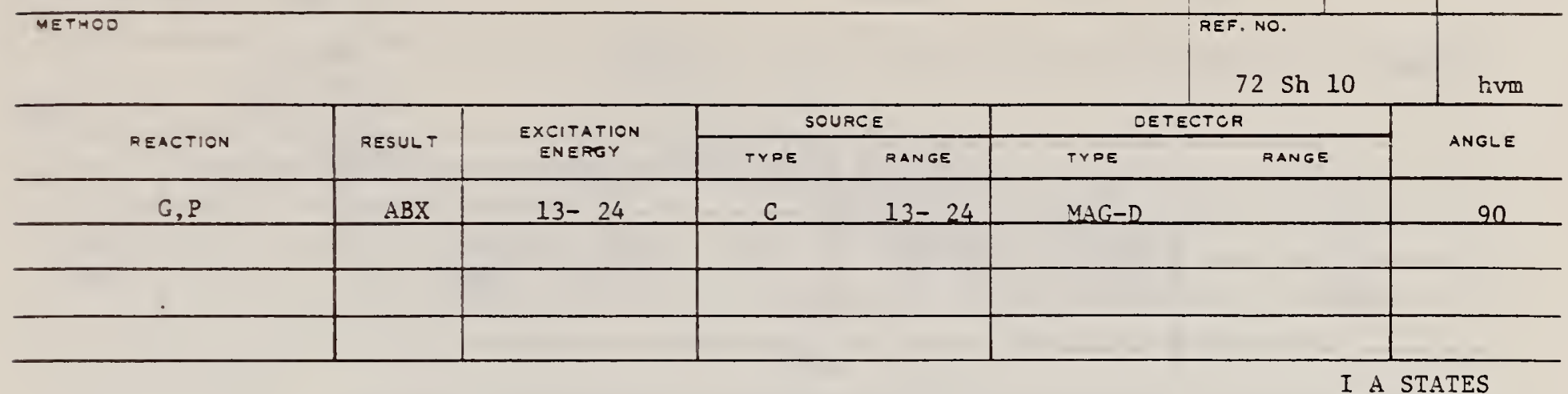

I A STATES

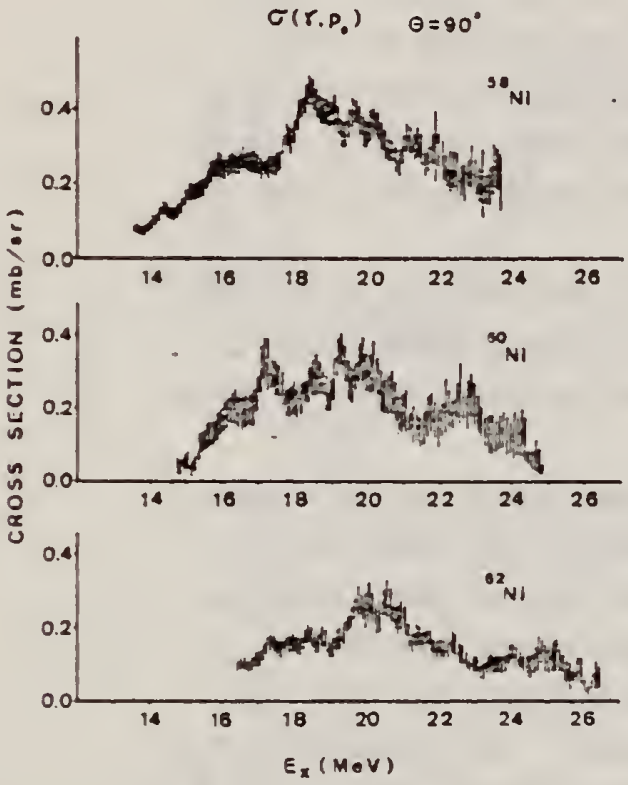

F18. 10 The $\left(Y, P_{0}\right)$ cross sections of $X_{1}$ 1sotopes obcalned from proton spectra by the $\left(e, e^{\prime} p\right)$ reaction. 
REF. S. C. Fultz, R.A. Alvarez, B.L. Berman, and P. Meyer PICNS-73, Vol. I, p. 549 Asilomar

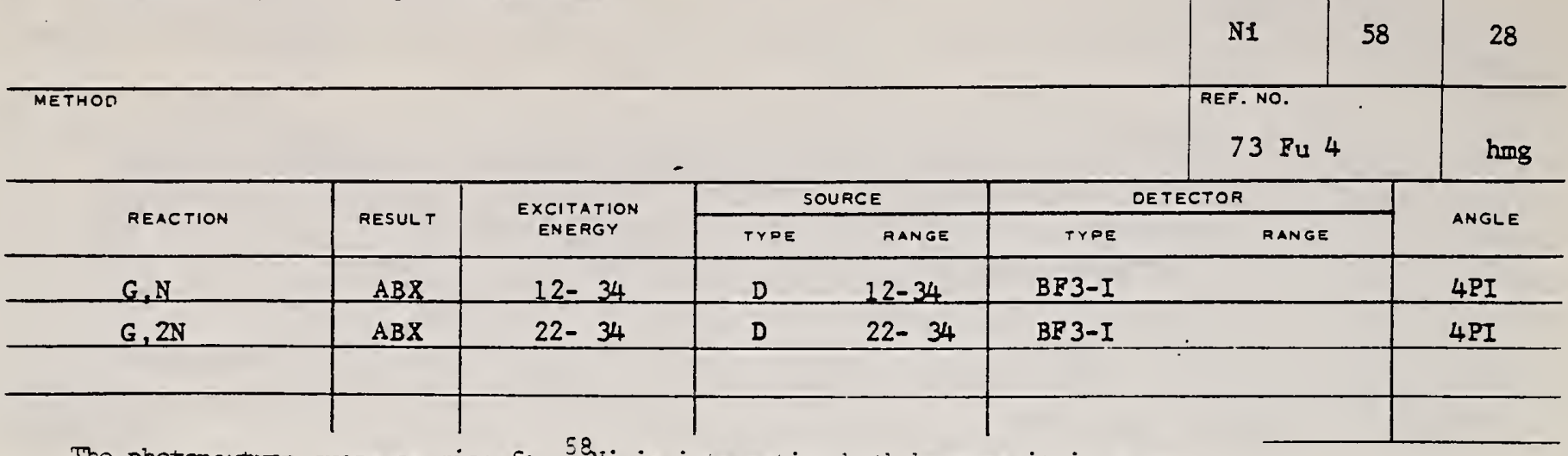

The photoneutron cross section for $5 \mathrm{~g}_{\mathrm{ii}}$ is irteresting toth tecause it is anomalously small and because much structure has been obsermed in previous experiments. 1-4 We have measured the cross sections, with rather high resolution, for the first time with nearly monoenergetic photons from in-flight anninilation of positrons from the new Livemore electron-positron linac. The experinental method employed was similan to that used in a number of earlier experiments ${ }^{5}$ by the Livermore group. The ${ }^{58}$ Ni content of the target sample was $99.89 \%$. The photon enersy resolution varied smoothly from about $50 \mathrm{keV}$ at $10 \mathrm{MeV}$ to axproximately $90 \mathrm{keV}$ at $35 \mathrm{MeV}$.

The experimental results are shown in Fig. 1. The error bars shown are statistical only. In addition there are several sources of systematic uncertainty which could introduce an overally erron of up to about $10 \%$ in the region of the giant resonance peak, and perhaps $40 \%$ at $35 \mathrm{MeV}$.

The total photoneutron cross section reaches a peak of about $25 \mathrm{mb}$ in the neigibon hood of $18 \mathrm{MeV}$, and exhibits considerable structure which persists well above $20 \mathrm{Mel}$. Our data are generally in good arreement with the magnitude of the peak cross sections obtained in previous experiments ${ }^{2-4}$ but disagree on the details of the coserved structure. The $(\gamma, 2 \pi)$ cross section, which has been measured here for the first tine, is small (generallv $\leqslant I \mathrm{mb}$ ) and appears to varish by about $33 \mathrm{MeV}$. The integrated total photoneutron cross section, up to $33.5 \mathrm{MeV}$, is $286 \mathrm{MeV}-\mathrm{mb}$, while the integrated $(\gamma, 2 \mathrm{n})$ cross section is $7.7 \mathrm{MeV}-\mathrm{mb}$.

The distribution of strength in the cross section, up to $25 \mathrm{MeV}$, is in good qualitative agreement with particle-hole calculations of the $\mathrm{E}$ transition strengths; ${ }^{6}$ however, considerable cross section appears to lie above the region of the calculated dipole strength. Comparison of our data with those of Carven and Turcininetz ${ }^{1}$ implies that most of the high-energy cross section resuits from the $(y, p n)$ reaction.

t Work performed under the auspices of the U. S. Atomic Energy Commission.

* Deceased

I J. H. Carver and W. Turchinetz, Proc. Phys. Soc. (Icncion) 73, 585 (1959).

2 K. Min and T. A. White, Phys. Rev. Letters 2I, 1200. (1958).

3 B. I. Goryachev, B. S. Ishkhanov, I. M. Kapitonov, I. M. Piskarev, V. G. Shevehenko, and O. P. Shevchenko, Sov. J. Nucl. Fhysics 11, I4I (1970) [Yad.Fiz. 10, 252 (1969)].

4 D. G. Owen, E. G. Muimead, and B. M. Spicen, Vucl. Phys. Alu0, 523 (1970).

5 B. L. Berman, J. T. Caldwell, R. R. Harrey, M. A. Kelly, R. L. Bramblett, and S. C. FuItz, Fnys. Rev. 162, 1098 (1967).

6 Y. Tanaka, Pros. Theor. Fhys. 46, 787 (1971). 

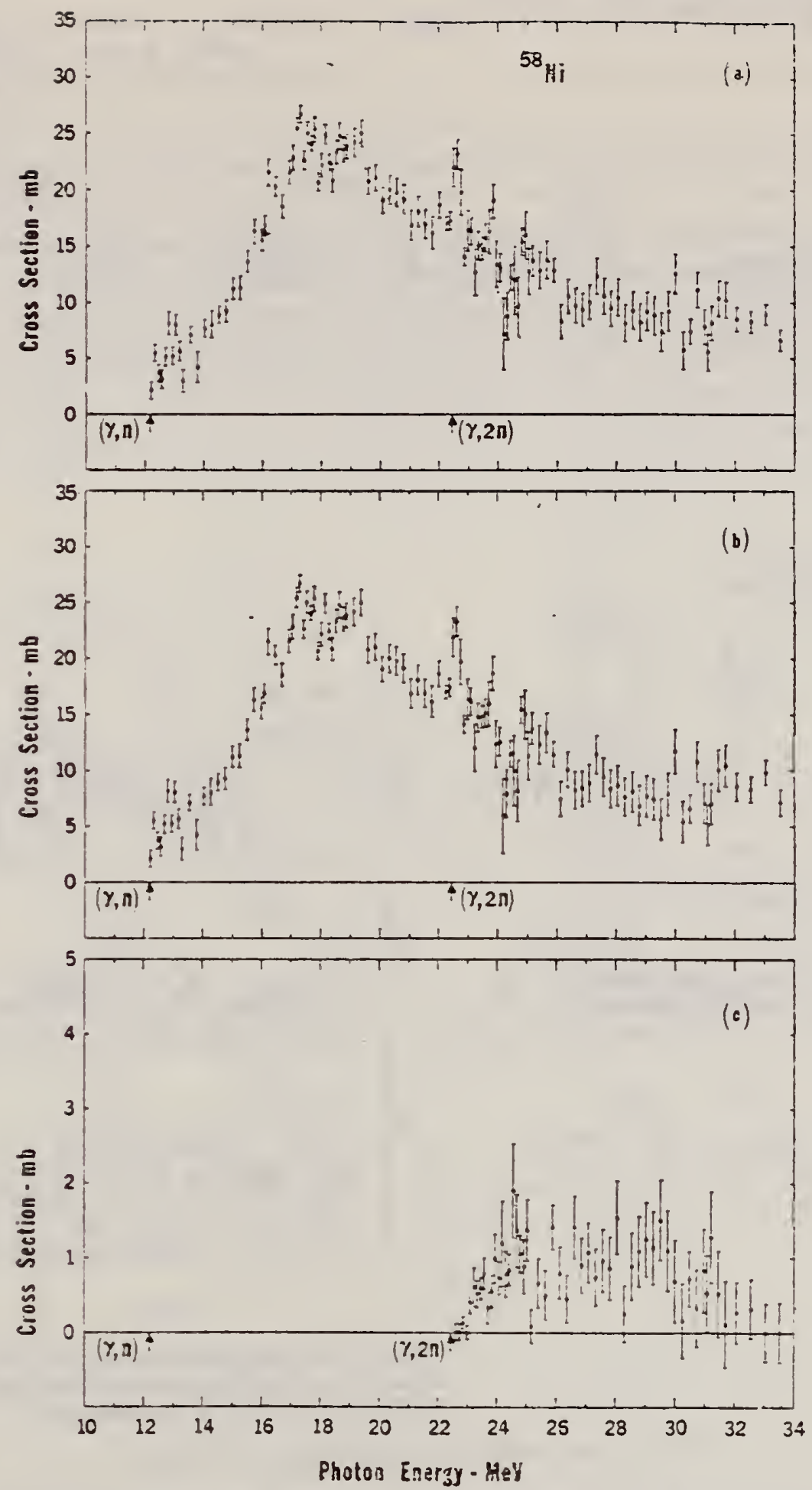

Figire 1. Fhotoneutron cross sections of 5 a.ti. Thresholds are indicated by amowi.

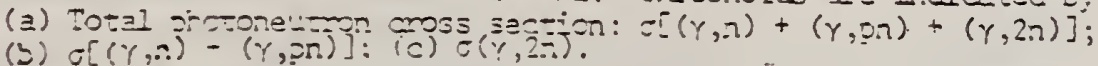


K. Itoh, M Oyamada, and Y. Torlzuka

Phys. Rev. C7, 458 (1973)

\begin{tabular}{|c|c|c|c|c|c|c|c|}
\hline METHOO & & & & & & $\begin{array}{l}\text { REF. NO. } \\
73 \text { It } 1\end{array}$ & hing \\
\hline \multirow{2}{*}{ REACTION } & \multirow{2}{*}{ RESUL T } & \multirow{2}{*}{$\begin{array}{l}\text { EXCITATION } \\
\text { ENERGY }\end{array}$} & \multicolumn{2}{|c|}{ SOURCE } & \multicolumn{2}{|c|}{ DETECTOR } & \multirow{2}{*}{ ANGLE } \\
\hline & & & TYPE & RANGE & TYPE & RANGE & \\
\hline$B, 8 /$ & FMR & $0-7$ & $D$ & 183,250 & \multicolumn{2}{|l|}{ MAG-D } & 82 \\
\hline & & & & & & & \\
\hline & & & & & & & \\
\hline & & & & & & & \\
\hline
\end{tabular}

See 69To3.

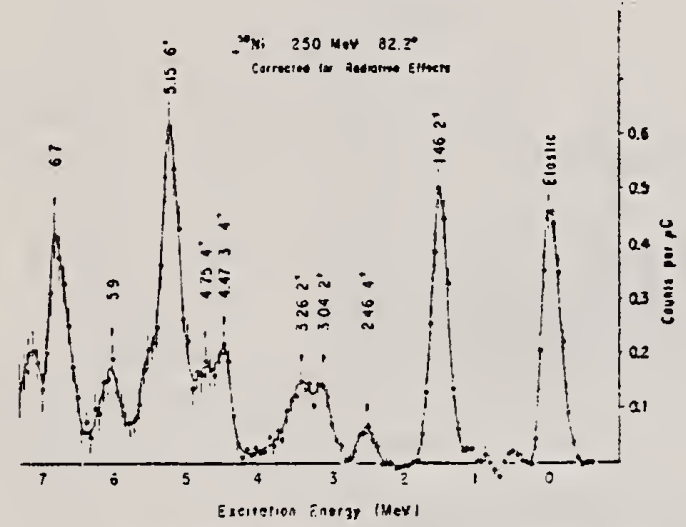

FIG. 1. The spectrum of ${ }^{58} \mathrm{Ni}$ for inelastic electron gcattering obtained at $250 \mathrm{MeV}$ and $322^{\circ}$ indicates a prominent peak at $5.15 \mathrm{MreV}$.

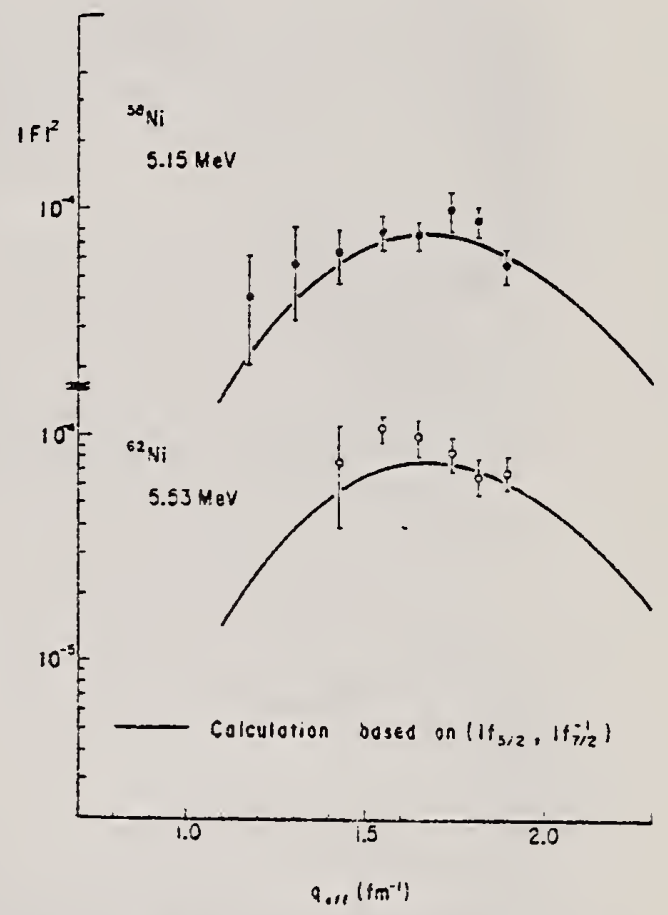

- FTG. 2. The experimental form fictors for the $\sigma^{+}$ ctates compared with the theoreticsl form fictors cslculated for the $\left(1 f_{6 / 2}, 1 f_{7 / 2}^{-1}\right)$ configuration. 
H. Myase, S. Olkawa, A. Suzuki, J. Uegaki, T. Saito,

Y. Sugawara, and $K$. Shoda

PICrS-73, Vol. I, p. 553 Asilomar

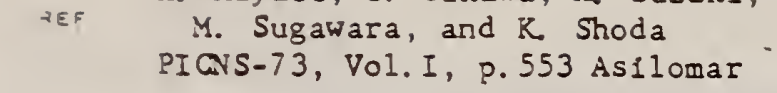

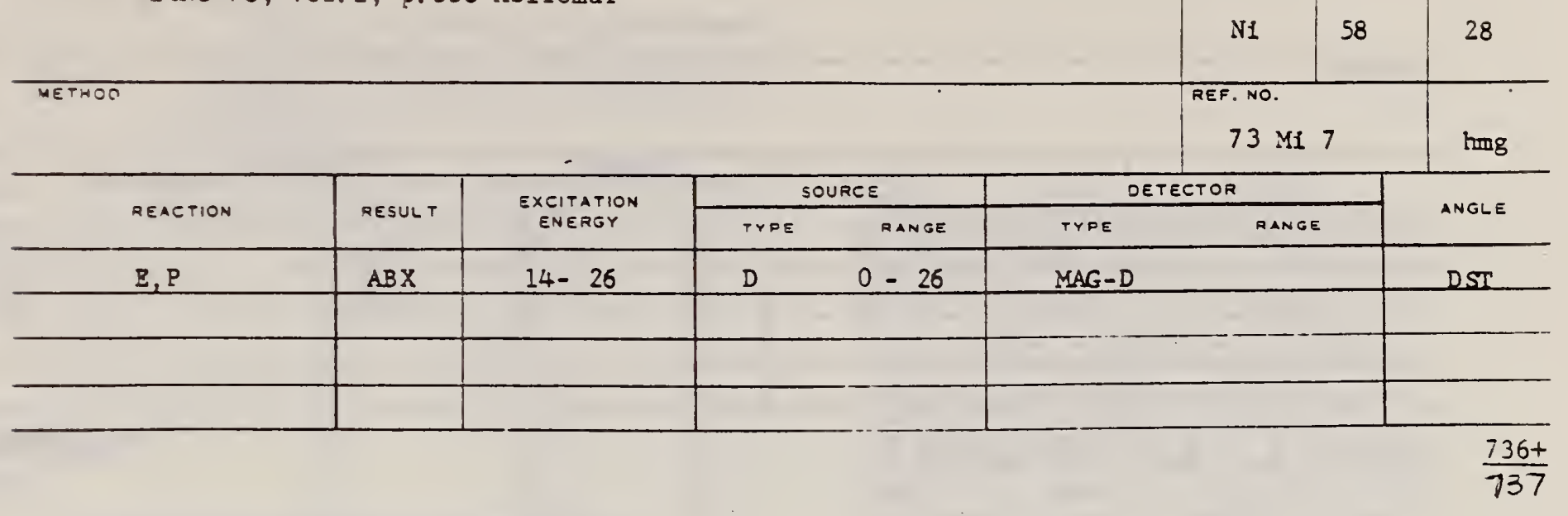

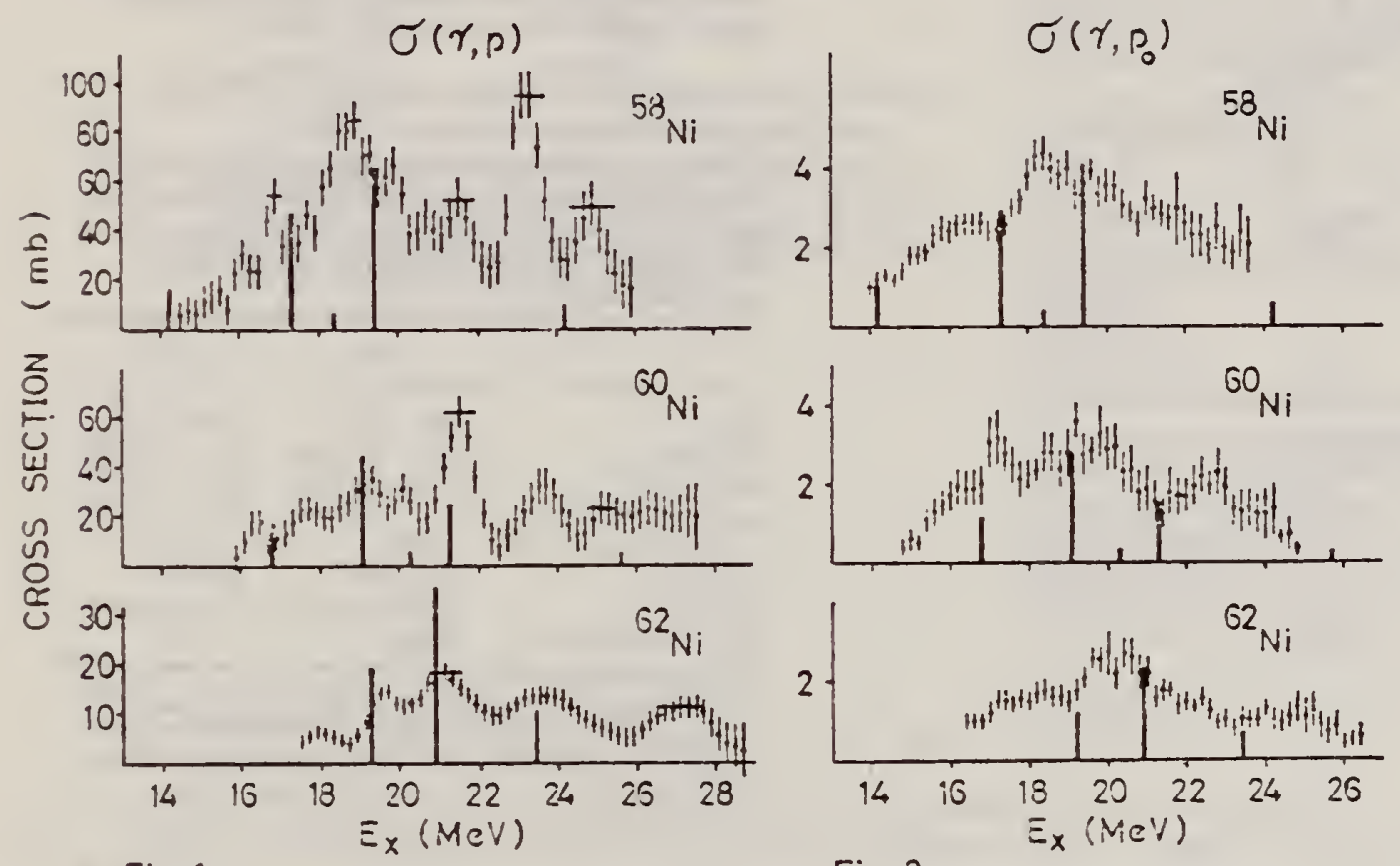

Fig. 1

Fig. 2

Table 1 Experimental anc theoretical results

\begin{tabular}{|c|c|c|c|c|c|c|}
\hline Nucleus & $I_{0}$ & $\int_{(m b-Y e v)} \sigma_{a}^{3)}$ & $\int_{(a b-Y e v)} \sigma_{p}$ & $\int_{(=b-i ! e v)} \sigma_{n}+\int \sigma_{p}$ & $\frac{\int \sigma_{p}}{\int \sigma^{n}+\int \sigma_{p}}$ & $\frac{\left|c_{>}\right|^{2}}{\left|c_{<}\right|^{2}+\left|c_{>}\right|^{2}}$ \\
\hline${ }^{58}{ }_{\mathrm{Ni}}$ & 1 & $310 \pm 30$ & $480 \pm 100$ & $790 \div 130$ & 0.61 & 0.45 \\
\hline${ }^{60} \mathrm{NI}:$ & 2 & $620 \div 50$ & $210 \pm 50$ & $830 \pm 130$ & 0.25 & 0.27 \\
\hline${ }^{62} \mathrm{N1}$ & 3 & & $110 \pm 25$ & & & 0.17 \\
\hline
\end{tabular}




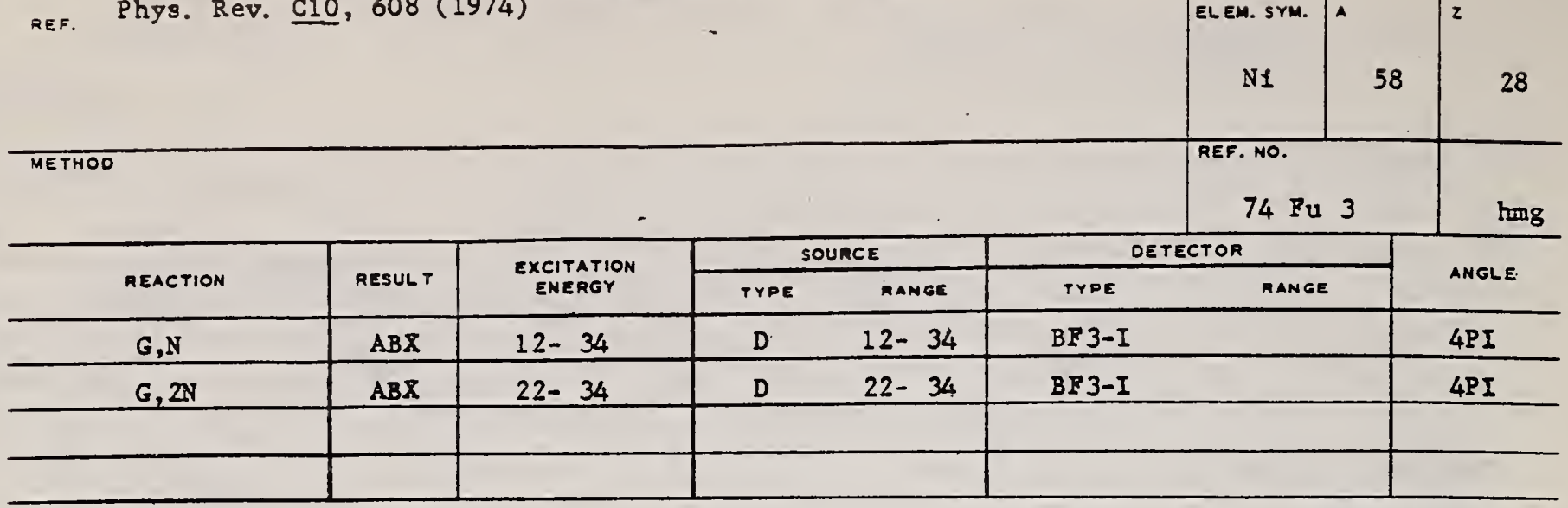
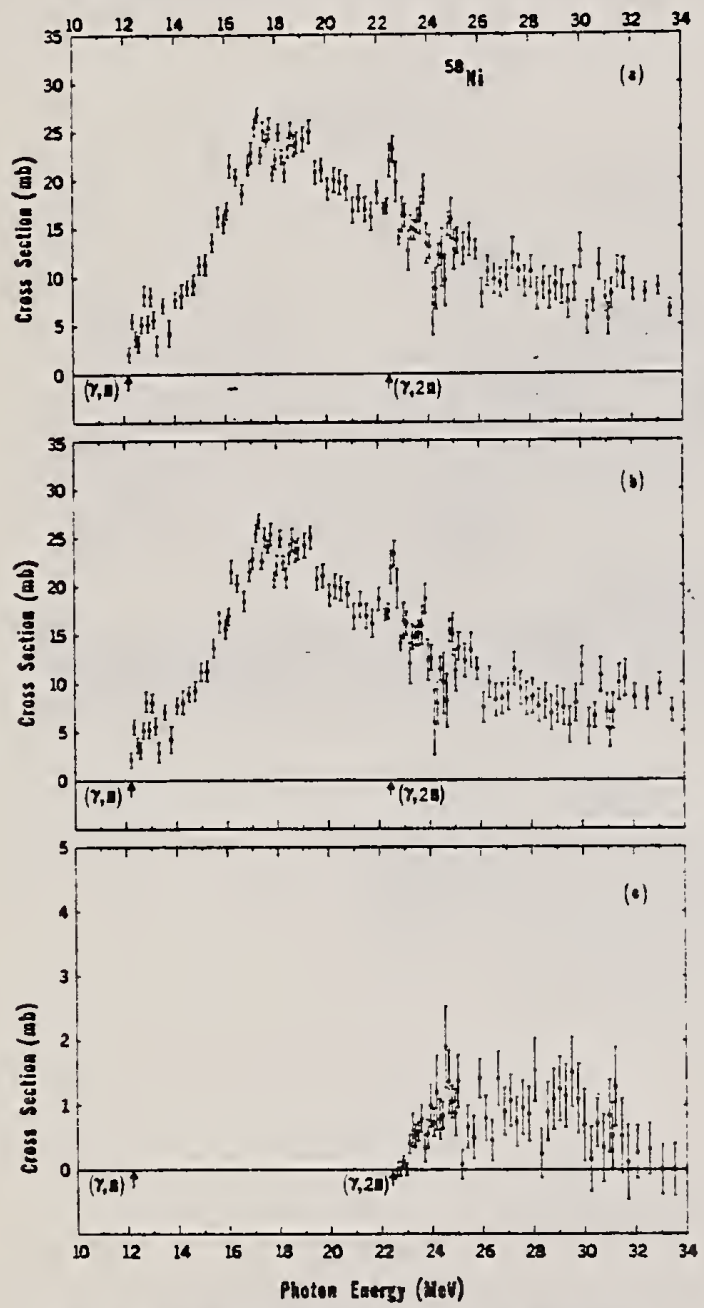

FIG. 2. Measured photoneutron cross sections for ${ }^{58} \mathrm{Ni}$ : (a) $\sigma(\gamma, S \pi)$ (see Ref. 17); (b) $\sigma[(\gamma, n)+(\gamma, p \pi)]$; (c) $\sigma(\gamma, 2 n)$.
SEP ISOTOPES

$.522+$

TABLE II. Integrated photoneutron cross sections and related quantites from the data of the present experiment. The deffnitions used in this table are

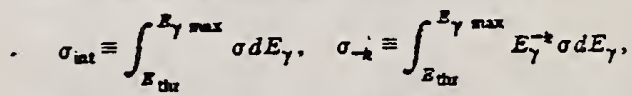

where $E_{\text {tir }}$ is the threshold energy (see Table D) and $E_{\gamma}$ is the photon energy; the quantity $(\gamma, S n)$ is defined in Ref. 17. Errors on the integrated cross sections are dominated by the systematic errors as discussed in Sec. III of the text.

\begin{tabular}{|c|c|c|c|c|}
\hline \multirow[b]{2}{*}{$E_{y \max }$} & \multicolumn{2}{|c|}{${ }^{53} \mathrm{Ni}$} & \multicolumn{2}{|r|}{${ }^{60} \mathrm{NI}$} \\
\hline & 33.5 & $\mathrm{MeV}$ & 33.5 & $\mathrm{MeV}$ \\
\hline$\sigma_{i n e}(\gamma, S n)$ & 286 & $3 \mathrm{leV} \mathrm{mb}$ & 704 & $\mathrm{MeV} \mathrm{mb}$ \\
\hline$\sigma_{i n t}(\gamma, 2 n)$ & 7.65 & $\mathrm{MeV} m b$ & 72.2 & $\mathrm{MeV} \mathrm{mb}$ \\
\hline$\sigma_{\operatorname{inz}}[(\gamma, n)+(\gamma, p n)\}^{2}$ & 278 & $\mathrm{MieV} \mathrm{mb}$ & 632 & $\mathrm{MeV} \mathrm{mb}$ \\
\hline$\sigma_{\mathrm{int}}(\gamma, 2 n) / \sigma_{\mathrm{int}}\left(\gamma, S_{n}\right)$ & 0.027 & & $\cdot 0.10$ & \\
\hline$\sigma_{-1}(\gamma, S n)$ & 13.5 & $\mathrm{mb}$ & 35.6 & $\mathrm{mb}$ \\
\hline$\sigma_{-2}\left(\gamma, S_{n}\right)$ & 0.700 & $\mathrm{mb} \mathrm{MeV}^{-1}$ & 1.90 & $0 \mathrm{mb} \mathrm{MeV}$ \\
\hline$\sigma_{\text {tot }}(\gamma, S n) / 60(N Z / A)$ & 0.329 & & & \\
\hline
\end{tabular}

a This quantity was obtained by subtracting $\sigma_{\text {int }}(y, 2 \pi)$ from $\sigma_{\operatorname{mi}}\left(\gamma, S_{n}\right)$; direct integration of the single-photoneutron crass sections gave the same values to within $0.5 \%$.

TABIE IV. Comparison of integrated total photoneutron cross sections $\sigma_{\text {int }}\left(\gamma, S_{n}\right)$ with those from previous experiments.

\begin{tabular}{|c|c|c|c|}
\hline Reference & $E_{\gamma \max }(\mathrm{MeV})$ & ${ }_{(\mathrm{MeV} \mathrm{mb})}$ & ${ }_{(\mathrm{MeV}}^{60 \mathrm{mb}}$ \\
\hline This expertment & 30 & 256 & 643 \\
\hline Ref. 6 (Moscow) & 30 & 310 & 620 \\
\hline This experinent & 25 & 204 & 537 \\
\hline Ref. 5 (Virginfa) & 25 & 185 & 482 \\
\hline
\end{tabular}

(over) 
TABLE EI. Energies (AeV) at which peaks appear in be $\left(\gamma, S_{r}\right)$ cross sections of ${ }^{58} \mathrm{NI}$ and ${ }^{60} \mathrm{~N} 1$. The energies listed are those at wich peaks or shoulders exist in the cross section. Actual resonance exergies might be slightly different.

\begin{tabular}{ccc}
\hline Peak No. & ${ }^{2} \mathrm{NI}$ & ${ }^{\mathrm{N}} \mathrm{NI}$ \\
\hline 1 & 12.3 & 12.6 \\
2 & 12.8 & 13.7 \\
3 & 13.1 & 14.4 \\
4 & 13.6 & 15.1 \\
5 & 14.2 & 15.5 \\
6 & 15.7 & 16.3 \\
7 & 16.3 & 17.0 \\
8 & 17.3 & 17.7 \\
9 & 17.7 & 18.8 \\
10 & 18.2 & 19.6 \\
11 & 18.6 & 21.2 \\
12 & 19.3 & 22.1 \\
13 & 22.6 & 24.5 \\
14 & 23.3 & \\
15 & 24.9 & \\
16 & 25.7 & \\
\hline
\end{tabular}

- Re have 1acluded in the tabulations only the more well-defized peaks (or sboulders). In addition there aro 206sible broad peaks at approximately 20.7, 27.8, and $30.9 \mathrm{MeV}$ is ${ }^{50} \mathrm{Ni}$, and at $23.5,26.1,27.5$, and $30.3 \mathrm{MeV}$ is $9 \mathrm{N1}$, but the data are not sufficlently detailed to make a pore de:initive judgmeat about these.
TABLE V. Integrated total photon absorption cross sectlous and related quantities from the combined data of the preseat experimeat and Ref. 7 . The $(\gamma, X p)$ cross sections of Ref. 7 have been used rather than those of Ref. 8 because the former extend over a wider energy range: in their mutually inclusive energy range (see Flgs. 5 and 6$)$ the integrated cross sectons from the two $(\gamma, X p)$ measurements agree to within $2 \%$ for ${ }^{58} \mathrm{Nl}$ and $10 \%$ for ${ }^{60} \mathrm{Yl}$, the values derived from the data of Ref. 8 being the larger in both cases. The total photon absorpton cross section $\sigma(\gamma$, total) is as sumed to be equal to $\sigma(\gamma, S n)+\sigma(\gamma, X p)$; that is the photon scatterting cross sectlon is assumed to be negligible and double counting, owing to the presence of $\sigma(\%, p r)$ in both $\sigma\left(\gamma, S_{\pi}\right)$ and $\sigma(\gamma, X p)$, Is ignored. The latter effect is reasonably compensated for, however (see footnote 3 ).

\begin{tabular}{|c|c|c|c|c|}
\hline \multirow[b]{2}{*}{$E_{\gamma \operatorname{mex}}$} & \multicolumn{2}{|r|}{${ }^{58} \times 1$} & \multicolumn{2}{|r|}{${ }^{80} \mathrm{NI}$} \\
\hline & 33.5 & $\mathrm{MeV}^{\mathbf{2}}$ & 33.5 & $\mathrm{MeV}^{2}$ \\
\hline$\sigma_{\text {int }}(\gamma, \operatorname{total})$ & 850 & $\mathrm{MeV}$ mb & 1025 & $\mathrm{MeVmb}$ \\
\hline$\sigma_{-1}(\gamma$, total $)$ & 41.3 & $\pi b$ & 48.7 & $\mathrm{mb}$ \\
\hline$\sigma_{-2}(\gamma$, total $)$ & 2.09 & $\mathrm{mb} . \mathrm{IeV}^{-1}$ & 2.62 & $\mathrm{mb} \mathrm{MeV} \mathrm{M}^{-1}$ \\
\hline $\begin{array}{c}\sigma_{\ln t}(\gamma, \text { total }) / \\
(60 N Z / A)\end{array}$ & 0.98 & & 1.10 & \\
\hline$\sigma_{-1}(\gamma$, total $) / A^{4 / 3}$ & 0.18 & & 0.21 & \\
\hline$\sigma_{-2}(\gamma, \omega t a l) / A^{5 / 3}$ & 0.00 & 264 & 0.00 & 286 \\
\hline
\end{tabular}

2 The $(\gamma, X p)$ data extend only to $30.1 \mathrm{MeV}$ for ${ }^{58} \mathrm{N1}$ and $30.5 \mathrm{MeV}$ for ${ }^{60} \mathrm{Nl}$; above these energies re have used the $(\gamma, S r)$ cross section only. Since much of the bigbenergy cross sectlon probably comes from the $(\gamma, p r)$ process, the error introduced is probabiy small and might very well compensate for the double counting of the $(\gamma, p n)$ cross section below $30 \mathrm{MeV}$.

5

K. Min and I.A. White, Phys. Rev. Lett. 21, 1200 (1968).

6

B.I. Goryachev, B.S. Ishkhanov, I.M. Kapitonov, I.M. Piskarev, V.G. Shevchenko, and O.P. Shevchenko, Yad. Fiz. 10, 252 (1969); Sov. J. Nucl. Phys. 11, 141 (1970). 7

B.S. Ishikhanov, I.M. Kapitonov, I.M. Piskarev, V.G. Shevchenko, and O.P. Shevchenko, Yad. Fiz. 11,485 (1970); Sov. J. Nucl. Phys. 11, 272 (1970).

8)K. Shoda, private communication; see also H. Miyase, S. Oikawa, A. Suzuki, J. Uegaki, T. Saito, M. Sugawara, and K. Shoda, in Proceedings of the International Conference on Photonuclear Reactions and Applications, Asilomar, March, 1973, ed. by B.L. Berman (Lawrence Livermore Laboratory, Livermore, 1973), p.553.

17

In our reaction notation we have essentially adopted the convention used by E.G. Fuller, H.M. Gerstenberg, H. Vander Molen, and T.C. Dunn (NBS SP-380, 1973) wherein ( $Y, S n$ ) represents the sum of all neutron-producing reactions, ( $Y, X p)$ denotes total proton yield, etc. We use $(\gamma, p n)$ to represent either the $(\gamma, n p)$ or $(\gamma, p n)$ reaction since experimentally the two are indistinguishable. 
REF. V. V. Varlamov, V. S. Ishkhanov, I. M. Kapitonov, Zh. I. Kocharova, I. K. Pevtsova, I. M. Piskarev, and 0 . P. Shevchenko

Yad. Fiz. 21, 457 (1975); Sov. J. Nucl. Phys. 21, 239 (1975)

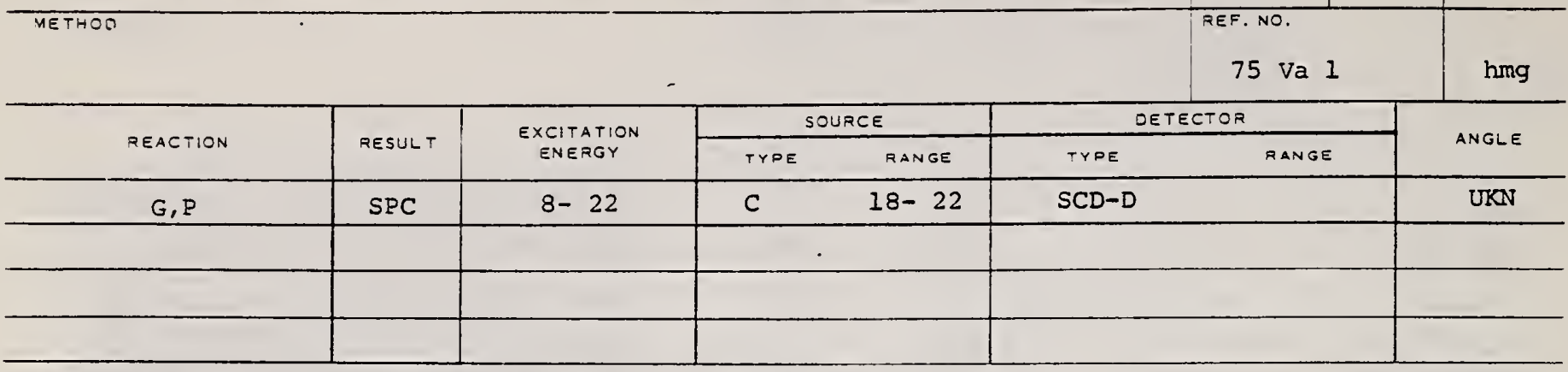

Photoproton spectra have been measured for five different values of bremsstrahlung end-point energy with

the purpose of investigating the decay characteristics of giant dipole resonance states in the nucleus ${ }^{\text {so }} \mathrm{Ni}$.
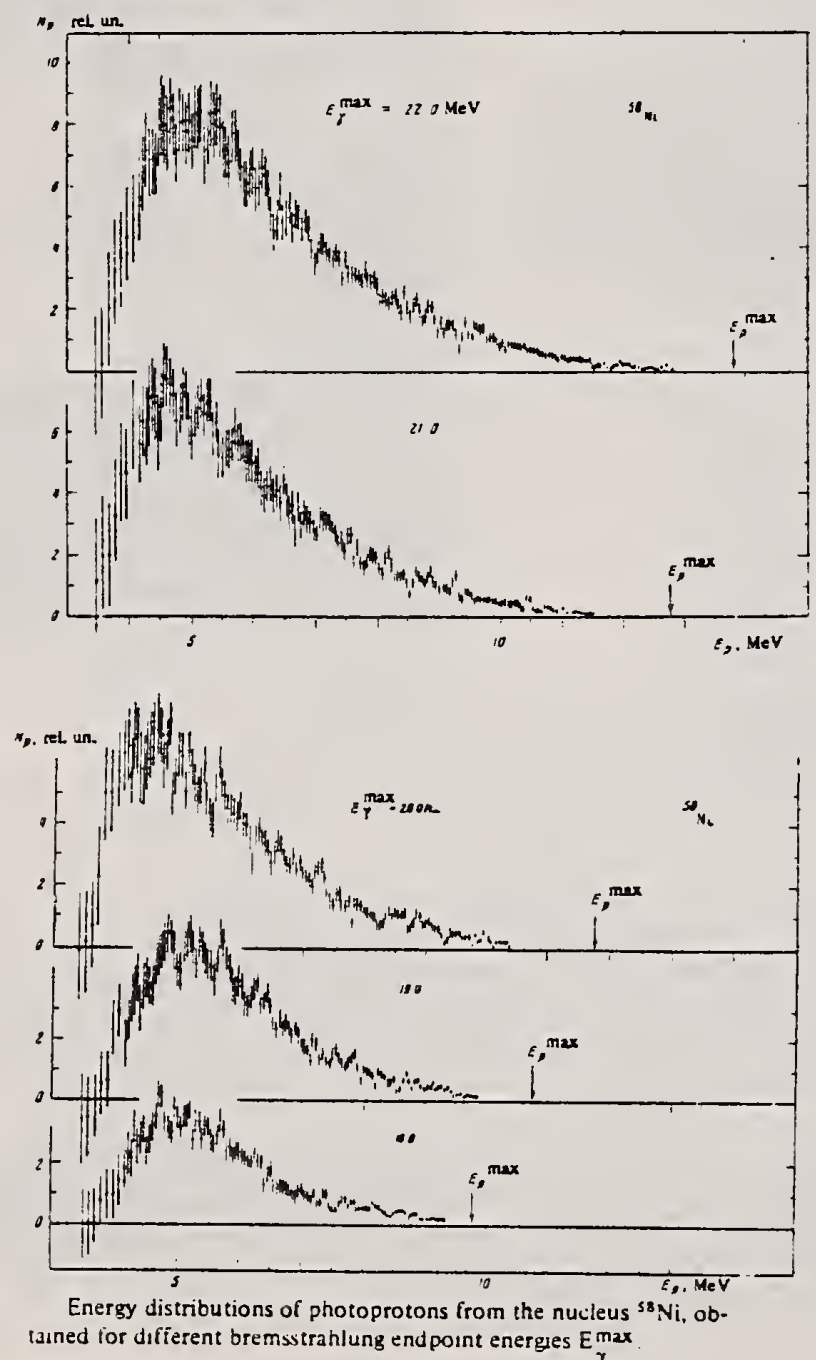


\begin{tabular}{|c|c|c|} 
ELEM. SYM. & A & 2 \\
$\mathrm{Ni}$ & 58 & 28 \\
\hline $\begin{array}{l}\text { REF. NO. } \\
75 \text { We } 4\end{array}$ & egf \\
\hline
\end{tabular}

\begin{tabular}{|c|c|c|c|c|c|c|c|}
\hline \multirow{2}{*}{ REACTION } & \multirow{2}{*}{ RESUL T } & \multirow{2}{*}{$\begin{array}{l}\text { EXCITATION } \\
\text { ENERGY }\end{array}$} & \multicolumn{2}{|c|}{ SOURCE } & \multicolumn{2}{|c|}{ DETECTOR } & \multirow{2}{*}{ ANGLE } \\
\hline & & & TYPE & RANGE & TYPE & RANGE & \\
\hline$G, P$ & $A B X$ & 18 & $\mathrm{D}$ & 18 & $S C D-D$ & & 90 \\
\hline & & & & & & & \\
\hline & & & & & . & & \\
\hline
\end{tabular}

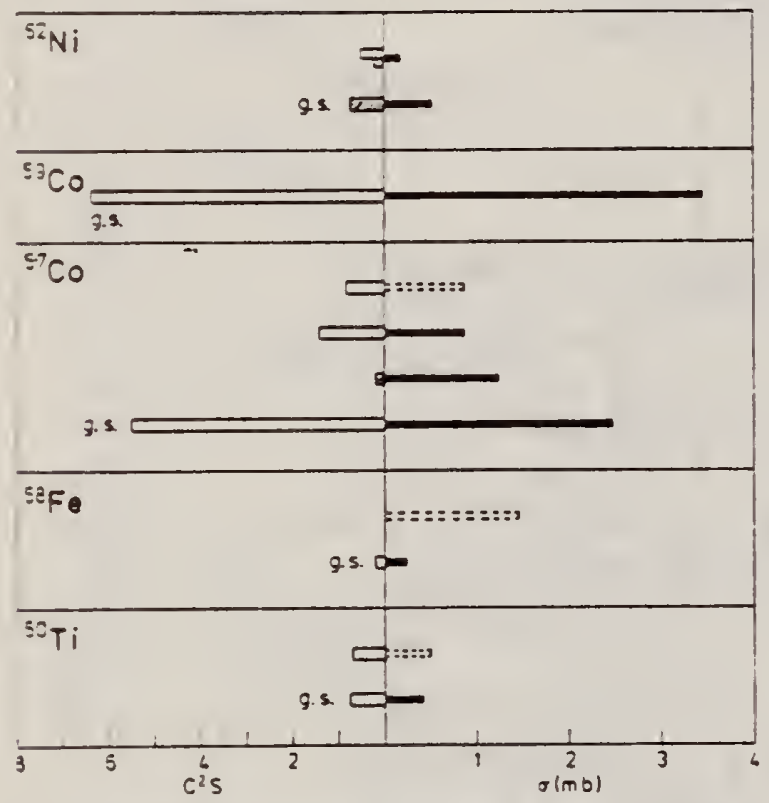

Fiz. 5. Correlation between the spectroscopic factors and the crosssections measured in this work. Open staples indicate $\ell,=3$ pick-up dit $d$ cross hatched staples $l,=1$ pick-up. Dashed staples indicate that the cross section is uncertasn due to the suberaction of a large back. ground
Table :

\begin{tabular}{|c|c|c|c|}
\hline \multirow{2}{*}{$\begin{array}{l}\text { Daughter } \\
\text { nucleus }\end{array}$} & \multicolumn{2}{|l|}{ Level } & \multirow{2}{*}{$\begin{array}{l}\sigma^{2} \\
(m b)\end{array}$} \\
\hline & $(\mathrm{MeV})$ & $J^{*}$ & \\
\hline${ }^{4+} \mathrm{C}_{3}$ & $\begin{array}{l}0 \\
1.16\end{array}$ & $0^{-}$ & $\begin{array}{l}\leqq 0.2^{n} \\
\leqq 0.5^{\circ}\end{array}$ \\
\hline 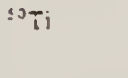 & $\begin{array}{l}0 \\
2.68\end{array}$ & $0^{-}$ & $\begin{array}{c}0.41 \\
(0.5)^{5}\end{array}=0.05$ \\
\hline${ }^{9} \mathrm{Fe}$ & $\begin{array}{l}0 \\
3.24 ?\end{array}$ & $\begin{array}{l}0= \\
0 * ?\end{array}$ & $\begin{array}{l}0.23 \\
(1.5)^{c}\end{array}$ \\
\hline$\because{ }^{-C o}$ & $\begin{array}{l}0 \\
1.76 \\
1.90 \\
2.31\end{array}$ & $\begin{array}{l}7: 2- \\
3 / 2- \\
7: 2- \\
72-\end{array}$ & $\begin{array}{l}2.5 \pm 0.2^{4} \\
1.2 \pm 0.3 \\
0.9 \pm 0.2 \\
(0.9)^{6}\end{array}$ \\
\hline$\because C 0$ & 0 & $7 / 2-$ & $3.5 \pm 0.8$ \\
\hline$\because \mathrm{Yi}$ & $\begin{array}{l}0 \\
1.18\end{array}$ & $\begin{array}{l}0 * \\
2- \\
\end{array}$ & $\begin{array}{l}0.51 \pm 0.09 \\
0.2 \pm 0.1\end{array}$ \\
\hline
\end{tabular}

- The quoted errors are only those due to counting statistics.

- Conĩdenze leviel $95 \%$.

- Cncertain because of large background.

$\sigma=2.4$ mo from [43].

43. Mivase, ب.. Oikiza, S., Suztki, A. Uegaki, J, Saito, T. Suzzawara, $M_{-}$Stuoda K. The photoproton reactions of Ni-isotopes In: Proc. Ine. Cosf. Photonuclear Reactions and Applicatic os Vol. I. p. 553. Livermore. USA 1973 (see Ref. 13) 
REF. I. A. Grishaev, N. I. Lapin, G. D. Pugachev

Yad. Fiz. 24, 335 (1976)

Sov. J. Nucl. Phys. 24, 175 (1976)

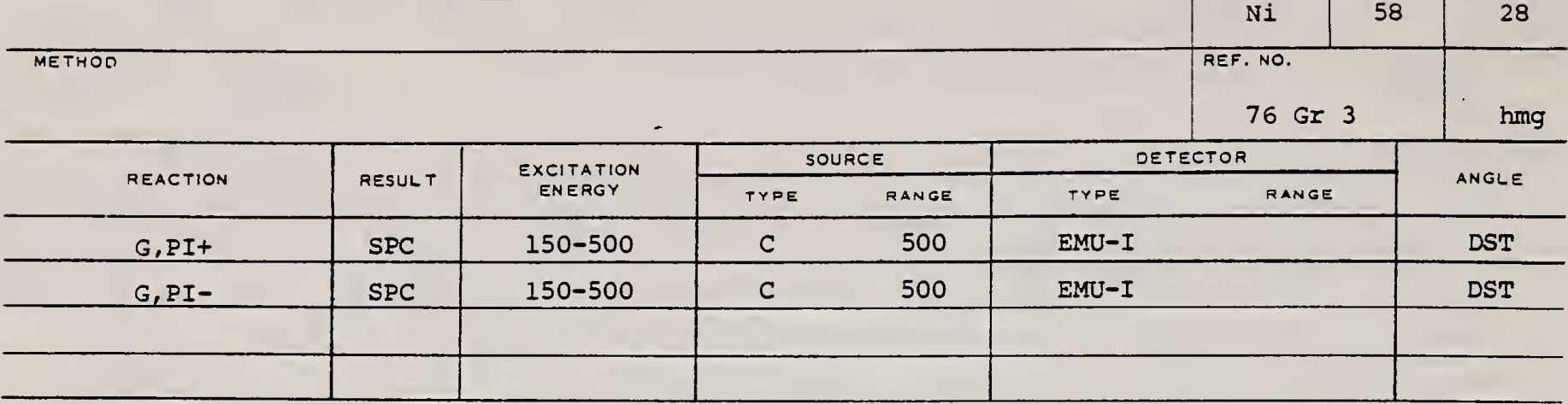

The energy spectra of charged photopions from ${ }^{54} \mathrm{Fe},{ }^{56} \mathrm{Fe}$ and ${ }^{36} \mathrm{Ni}$ targets irradiated with bremsstratulung of maximum energy $500 \mathrm{MeV}$ have been measured at photopion-emission angles of $30,60,90,120$, and $150^{\circ}$ in the lab system over the kinetic-energy range from 15 to $80 \mathrm{MeV}$. Isotope effects are found in the $\pi^{-}$yields at 30,60 , and 90 . At all angles and energies, the $\pi^{+}$yields are the same for all three targets within the experimental error.

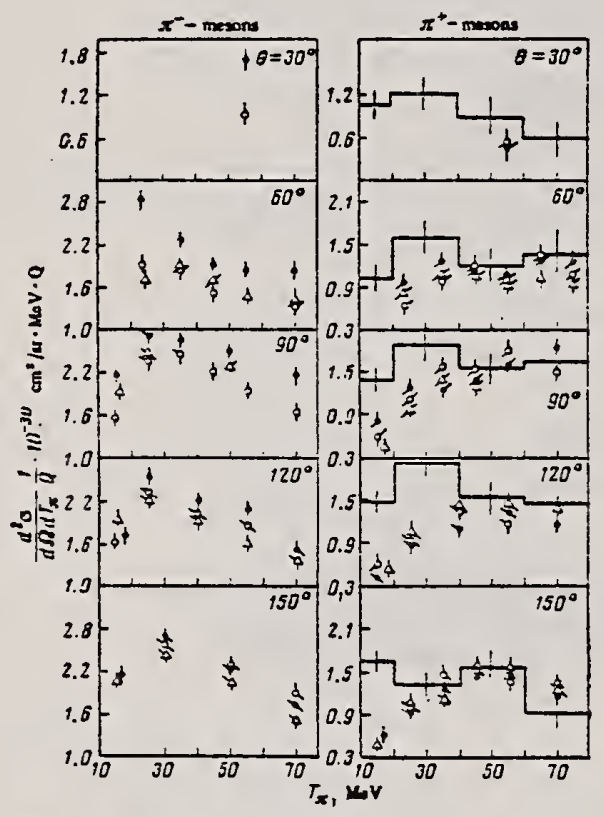

FIG. 1. Energy speckra of charged photopions from ${ }^{54} \mathrm{Fe}$,

${ }^{56} \mathrm{Fe}$, and ${ }^{58} \mathrm{Ni}$ targets lopen circles, black circles, and triangles, respectively) at $E_{0}=500 \mathrm{MeV}$. The error bars reprosent statistical errors. The histograms on the $x^{2}$-meson plots represeat the results of cascado-model calculations for ${ }^{56} \mathrm{Fe}$. 


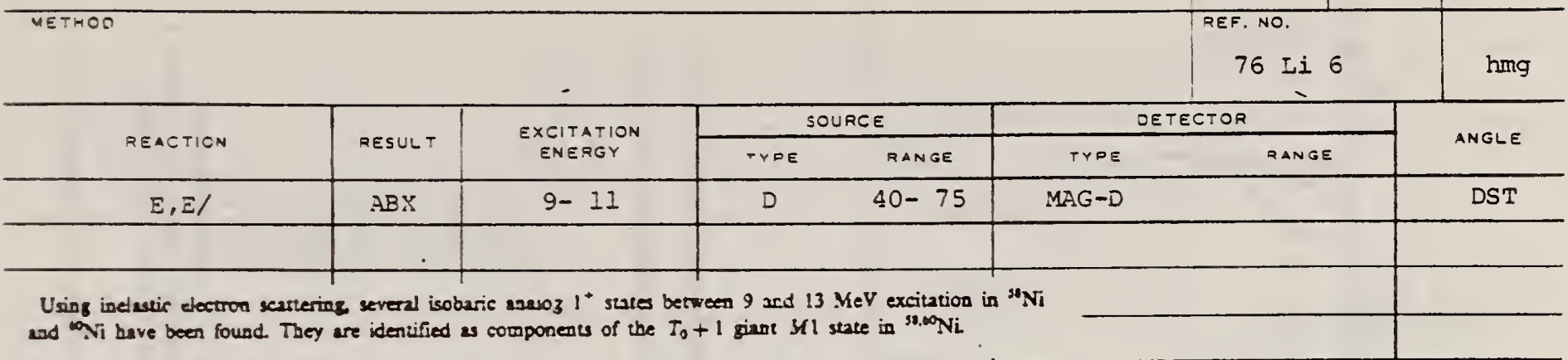

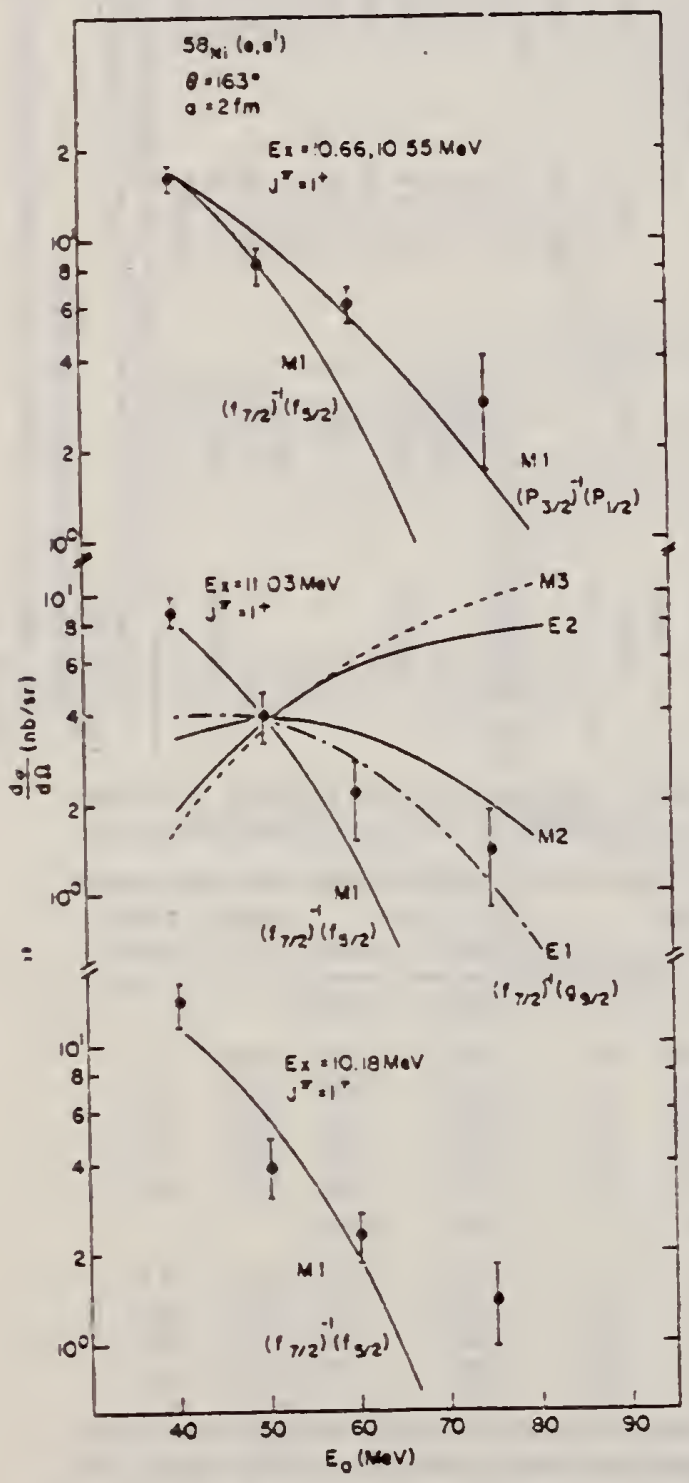

FTG. 7. Comparison of measured cross section with DWBA predictlors plotted as a function of $E_{0}$ for states $E_{x} \geqslant 10$ Siev.

\section{MI STATES}

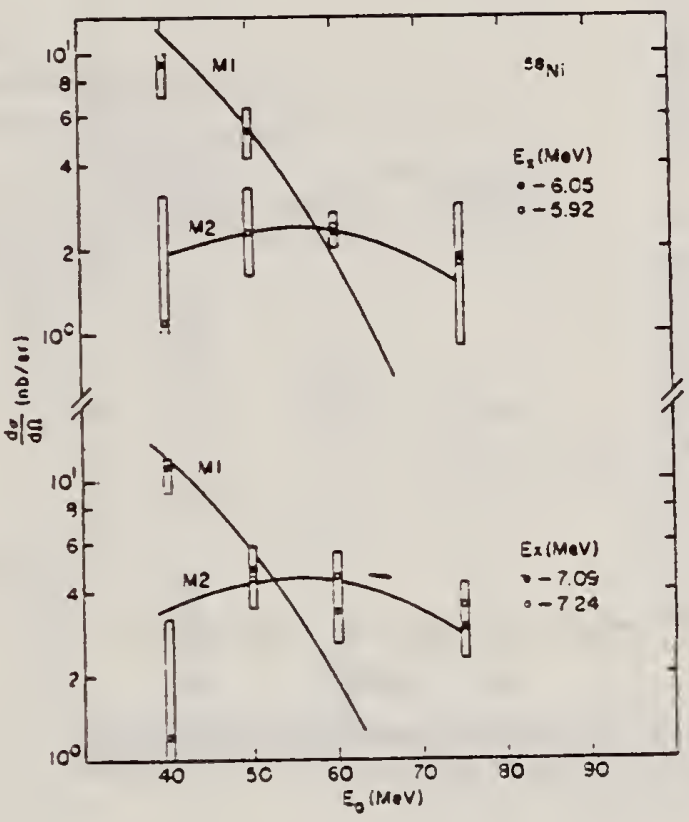

FIG. 9. Decomposition of the differential cross section at $\theta=160^{\circ}$ for the partially resolved $E_{x}=5.92$ and $6.05 \mathrm{MeV}$ and $E_{x}=7.09$ and $7.24 \mathrm{MeV}$ states as a furcthon of $E_{0}$, the incident electron bombarding eneray. The data are shown compared to MI and .VI2 DVBBA calculaHors. 


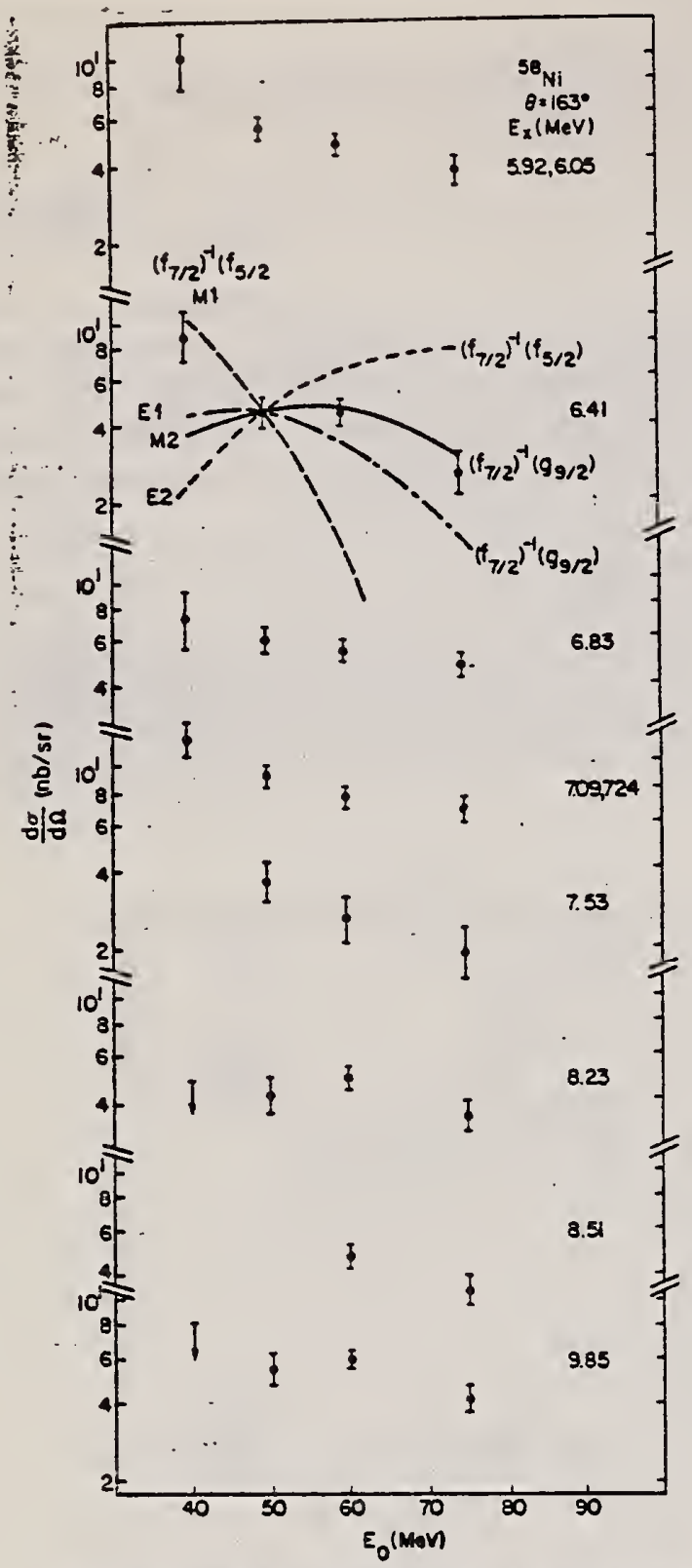

FIG. 8. Comparison of measured cross section with DWBA predictions platted 28 a function of $E_{0}$ for states in the range $9.8 \geqslant E_{z} \geqslant 5.50 \mathrm{MeV}$.
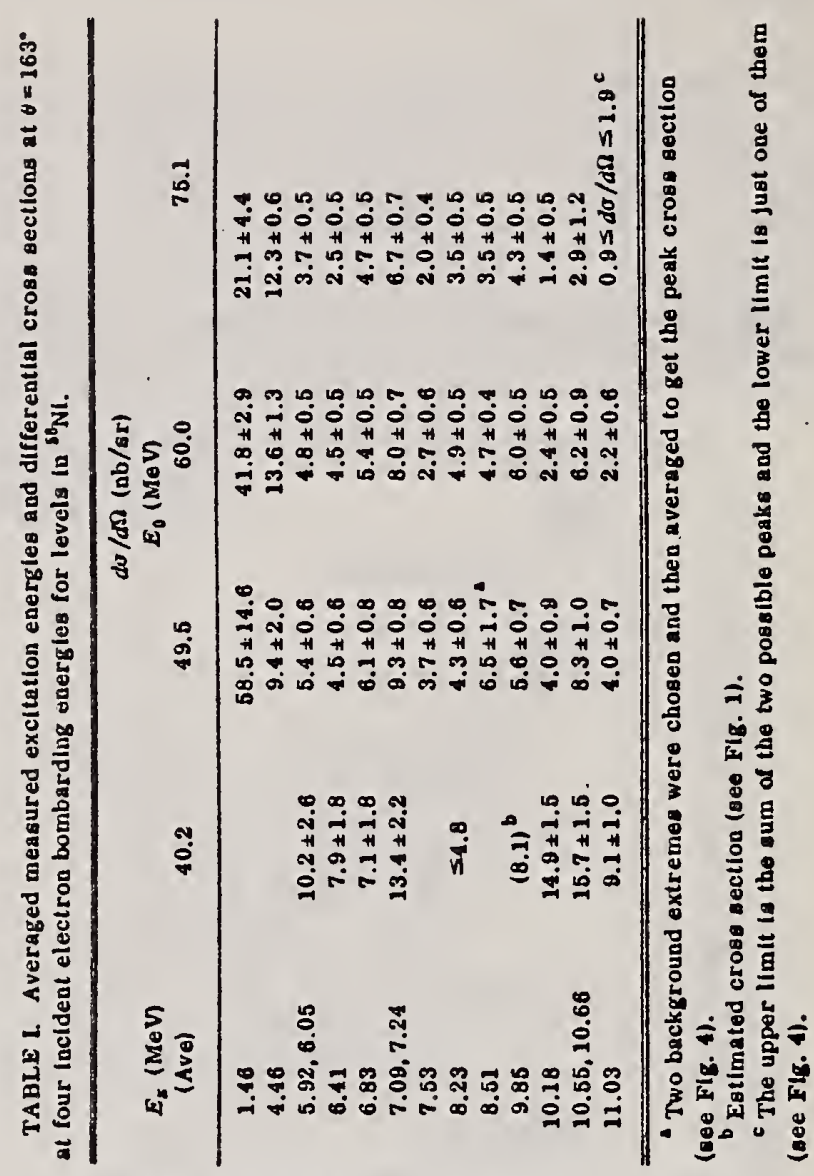

TABLE II. Measured excitation enerzies, J sasignments, and reduced $M$ transition probabllities for lorels in ${ }^{50,00} \mathrm{NL}$.

\begin{tabular}{|c|c|c|c|c|c|}
\hline $\begin{array}{c}E_{x}(\mathrm{MeV}) \\
\operatorname{Exp}^{2}\end{array}$ & $j$ & $\begin{array}{l}E_{x}(M \\
\text { Predicted }^{b}\end{array}$ & $\begin{array}{l}\text { V } \\
\text { Pareat }\end{array}$ & $\begin{array}{l}B(M) d \\
\left(\mu_{N}\right)^{2}\end{array}$ & $\begin{array}{l}\Gamma(M) \\
(\mathrm{eV})^{d}\end{array}$ \\
\hline${ }^{58} \mathrm{NI}$ & & ${ }^{38} \mathrm{NI}$ & ${ }^{58} \mathrm{Co}$ & & \\
\hline 9.85 & $\cdot\left(1^{+}\right)$ & 9.87 & 1.05 & $(0.32)^{e}$ & $(3.4)^{\circ}$ \\
\hline 10.18 & $1^{+}$ & 10.25 & 1.43 & 0.59 & 7.2 \\
\hline 10.55 & $1^{*}$ & 10.55 & 1.73 & 0.21 & 3.0 \\
\hline 10.66 & 1 & 10.68 & 1.86 & 0.41 & 5.7 \\
\hline 11.03 & $1^{*}$ & 11.06 & 2.24 & 0.36 & 5.6 \\
\hline${ }^{\infty} \mathrm{NI}$ & & ${ }^{80} \mathrm{NI}$ & ${ }^{\infty} \mathrm{Co}$ & & \\
\hline 11.9 & $1^{+}$ & 11.87 & 0.74 & 0.46 & 8.9 \\
\hline 12.3 & $1^{*}$ & 12.34 & 1.21 & 0.26 & 5.6 \\
\hline 13.1 & $(1+)$ & 13.11 & 1.98 & $\leq 0.06$ & $\leq 1.5$ \\
\hline 13.4 & $\left(1^{+}\right)$ & 13.35 & 2.22 & $\leq 0.06$ & $\leq 1.6$ \\
\hline 13.3 & $\left(1^{*}\right)$ & 13.84 & 2.71 & $\leq 0.06$ & $\leq 1.8$ \\
\hline
\end{tabular}

Eaergy uncertafoty is $\pm 0.04 \mathrm{MeV}$ in ${ }^{50} \mathrm{NI}$ and $\pm 0.1 \mathrm{MeV}$ Ln ${ }^{\circ} \mathrm{Ni}$.

To get predicted energy in ${ }^{58} \mathrm{Ni}$ add 8.82 -MeV to excitation energies in ${ }^{58} \mathrm{Co}$ and for ${ }^{60} \mathrm{NI}$ add $11.13 \mathrm{MeV}$.

${ }^{c} M M$ atreagth uncertainty is estimated to be about

d $\Gamma(M)=0.0115 E_{x}^{3} B(M)$.

- Tentative An Ideatificatioa (see tert). 
3.S. Ishkhanov, I.M. Kapitonov, V.G. Shevchenko, V.I. Shvedunov and V.V. Varlamov

ilucl. Phys. A283, 307 (1977)

\begin{tabular}{l} 
Nucl. Phys. A283, 307 (1977) \\
\hline \\
\hline
\end{tabular}

TAgLE 3

The proton decay probabilities in the various cinansels

\begin{tabular}{|c|c|c|c|c|c|c|}
\hline \multirow{2}{*}{\multicolumn{2}{|c|}{ Initial states (MeV) }} & \multicolumn{5}{|c|}{ Final scates (MeV) } \\
\hline & & $\alpha(15,1)$ & $\approx 1.5$ & $33\left(1 d_{3 / 2}^{-1}\right)$ & $6.2\left(2 s_{1 / 2}^{-1}\right)$ & $9.6\left(1 d_{3 / 2}^{-1}\right)$ \\
\hline $38 \mathrm{Ni}$ & $\begin{array}{l}11.0-16.0 \\
16.8 \\
18.4 \\
19.1 \\
21.0 \\
23.3 \\
25.2 \\
25.5 \\
27.3\end{array}$ & $\begin{array}{r}10 \\
5 \\
5 \\
.\end{array}$ & $\begin{array}{r}100 \\
10 \\
20 \\
20 \\
10\end{array}$ & $\begin{array}{l}80 \\
75 \\
35 \\
20 \\
10\end{array}$ & $\begin{array}{l}50 \\
70 \\
30\end{array}$ & $\begin{array}{l}60 \\
x \\
x \\
x\end{array}$ \\
\hline${ }^{\circ} \mathrm{Ni}$ & $\begin{array}{l}11.0-16.0 \\
16.4 \\
18.6 \\
20.4 \\
23.3 \\
35.3,26.6 .\end{array}$ & $\begin{array}{r}20 \\
20 \\
5 \\
5\end{array}$ & $\begin{array}{r}x 100 \\
10 \\
10 \\
5 \\
5\end{array}$ & $\begin{array}{l}70 \\
70 \\
40 \\
10\end{array}$ & $\begin{array}{l}50 \\
50 \\
\times\end{array}$ & 30 \\
\hline
\end{tabular}


REF.

J. Mougey, M. Bernheim, A. Bussiere, A. Gillebert, Phan Xuan Ho, M. Priou, D. Royer, I. Sick, G. J. Wagner Nucl. Phys. A262, 461 (1976)

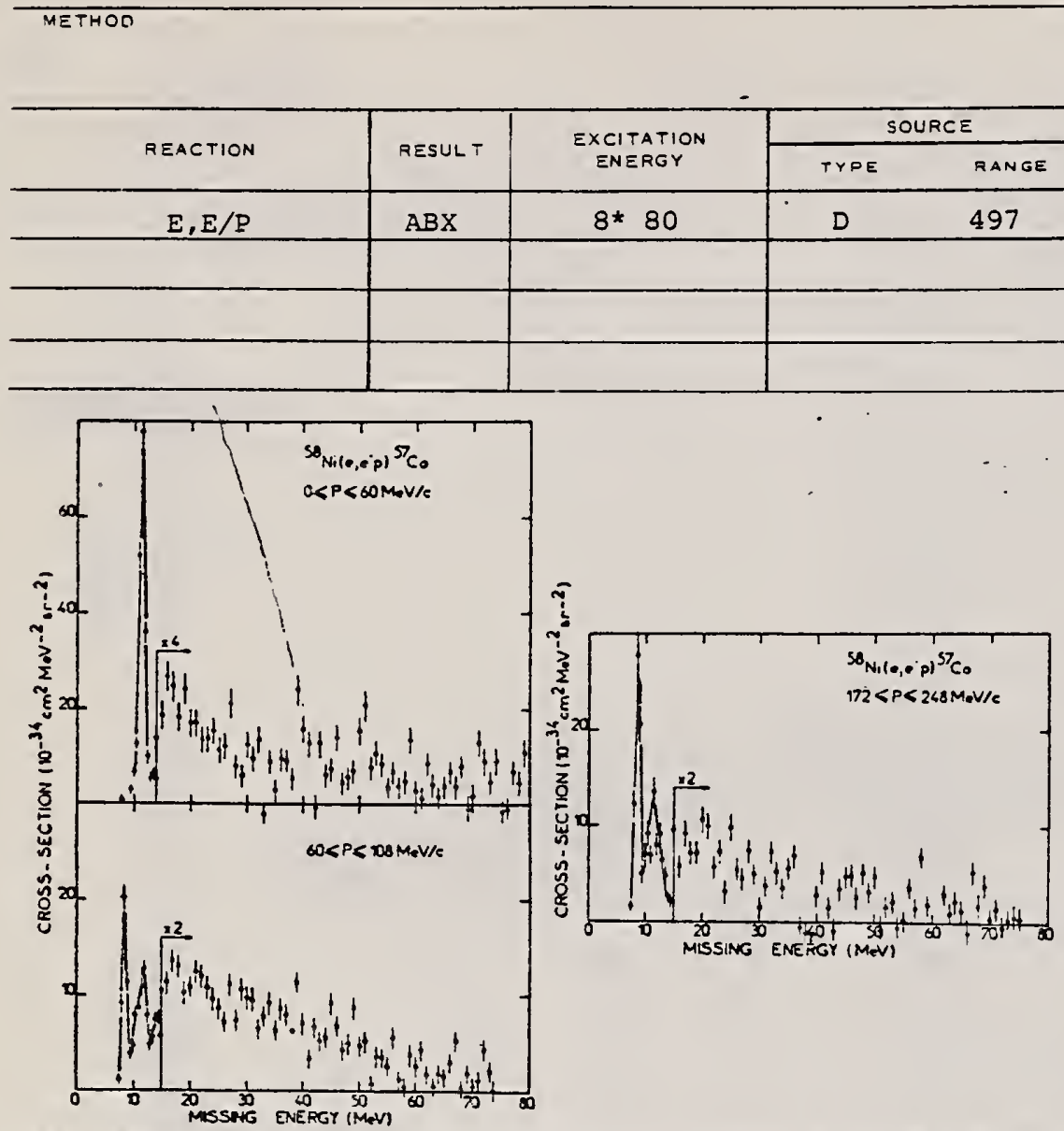

Fig. 15. Missing energy spectra from ${ }^{88} \mathrm{Ni}\left(e, e^{\prime} p\right)$; (a) $0 \leqq P \leqq 60 \mathrm{MeV} / c$, (b) $60 \leqq P \leqq 108 \mathrm{MeV} / c$ and (c) $172 \leqq P \leqq 248 \mathrm{MeV} / c$.

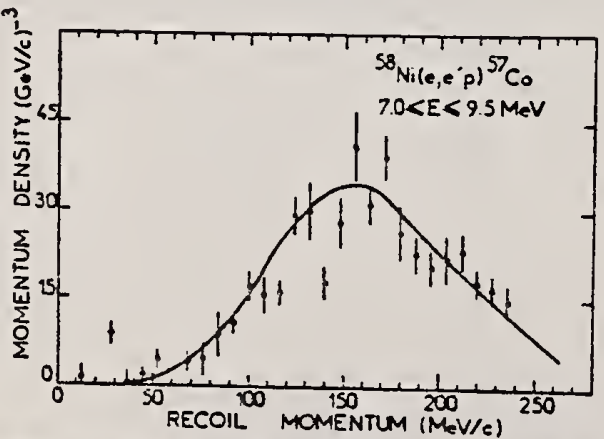

Fig. 16. Momentum distribution from ${ }^{58} \mathrm{Ni}\left(e, e^{\prime} p\right)$ for $7 \leqq E \leqq 9.5 \mathrm{MeV}$. The solid lire represents the DWLA calculation. 
R. h. Lindgren, J.3. Franz, W.J. Gerace, R.S. Hicks, A. Hotta,

D. Huse, G.A. Peterson, R.C. York, C.F. Williamson and

S. Kowalski

Phys. Rev. Lett. $41 ; 1705$ (1978)

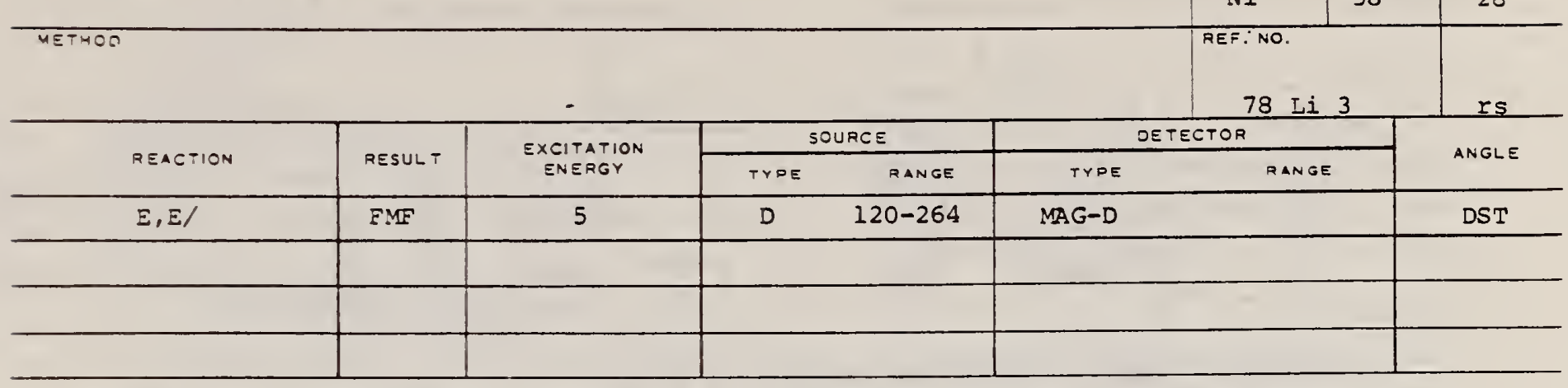

Transverse $(E 6)$ and longitudioal $(C 6)$ cross sections for the excitation of the $J^{\pi}=6^{*}$. $E_{s}=5.125 \mathrm{MeV}$ state in ${ }^{58} \mathrm{Ni}$ were measured by means of loelastic electron scattering. The deduced isoscalar component of the particle-bole wave function is found to be two orders of magnitude greater in amplitude than the isovector. This implies that the particle-bole isospin is relatively pure $T=0$ and is not significantly mixed with $\tau=1$.

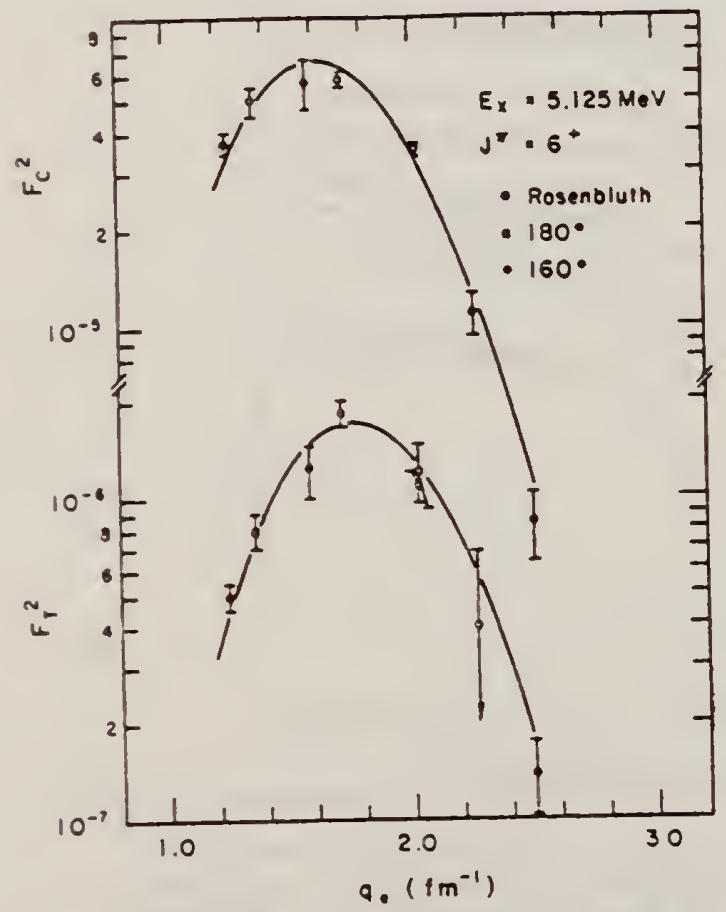

TABIE I. A tabulation of our measured cross secthon for the 5.125-MleV state for varlous energles and angles that were used to deduce the transverse and longitudinal form factors.

\begin{tabular}{ccccc}
\hline $\begin{array}{c}E_{0} \\
(\mathrm{MeV})\end{array}$ & $\begin{array}{c}\theta \\
(\mathrm{deg})\end{array}$ & $\begin{array}{c}q \\
\left(\mathrm{fm}^{-1}\right)\end{array}$ & $\begin{array}{c}q . \\
\left(\mathrm{fm}^{-1}\right)\end{array}$ & $\begin{array}{c}d \sigma / d \Omega \\
(\mathrm{nb} / \mathrm{s} r)\end{array}$ \\
\hline 189.6 & 120 & 1.64 & 1.71 & $3.41 \pm 0.11$ \\
228.1 & 120 & 1.97 & 2.04 & $1.35 \pm 0.03$ \\
251.1 & 120 & 2.17 & 2.24 & $0.40 \pm 0.04$ \\
120.4 & 160 & 1.17 & 1.25 & $0.41 \pm 0.04$ \\
131.1 & 160 & 1.28 & 1.36 & $0.60 \pm 0.11$ \\
153.2 & 160 & 1.50 & 1.58 & $0.64 \pm 0.03$ \\
167.0 & 160 & 1.64 & 1.72 & $0.57 \pm 0.02$ \\
200.4 & 160 & 1.97 & 2.05 & $0.92 \pm 0.07$ \\
221.5 & 160 & 2.18 & 2.26 & $0.067 \pm 0.008$ \\
242.6 & 160 & 2.39 & 2.47 & $0.017 \pm 0.003$ \\
131.1 & 180 & 1.30 & 1.38 & $0.20 \pm 0.02$ \\
195.2 & 180 & 1.95 & 2.03 & $0.13 \pm 0.02$ \\
\hline \hline
\end{tabular}

FIG. 2. The extracted transverse and longitudinal form factors compared with calculations described in text. 
ref. K. Masumoto, T. Kato, N. Suzuki

Nucl. Inst. Meth. 157, 567 (1978)

\begin{tabular}{|c|c|c}
$\begin{array}{c}\text { ELEM. SYM. } \\
\mathrm{Ni}\end{array}$ & A & $\mathrm{z}$ \\
\hline $\begin{array}{c}\text { REF. NO. } \\
78 \mathrm{Ma}\end{array}$ & 28 \\
\hline
\end{tabular}

\begin{tabular}{|c|c|c|c|c|c|c|c|}
\hline \multirow{2}{*}{ REACTION } & \multirow{2}{*}{ RESULT } & \multirow{2}{*}{$\begin{array}{l}\text { EXCITATION } \\
\text { ENERGY }\end{array}$} & \multicolumn{2}{|c|}{ SOURCE } & \multicolumn{2}{|c|}{ DETECTOR } & \multirow{2}{*}{ ANGLE } \\
\hline & & & TYPE & RANGE & TYPE & RANGE & \\
\hline$G, N$ & $A B Y$ & $12-68$ & $\mathrm{C}$ & $30-68$ & $A C T-I$ & & $4 P I$ \\
\hline G, PN & $\overline{A B Y}$ & $20-68$ & $\bar{C}$ & $30-68$ & AET - I & & 4PI \\
\hline$G, 2 N$ & $A B Y$ & $22-68$ & $\mathrm{C}$ & $30-68$ & $A C T-I$ & & $4 P I$ \\
\hline
\end{tabular}

Analysis is made of reactions interfering with photon activation analysis procedures.

The activation yield curves have been presented for a number of photonuclear reactions in the energy range from 30 to $68 \mathrm{MeV}$, in order to evaluate quantitatively the interferences due to competing reactions in multielement photon activation analysis. The general features of the yields as functions of both target mass number and excitation energy were elucidated from the data obtained, discussion being given on the results in terms of the reaction mechanism.

Simultaneous neutron activation due to appreciable neutron production from the converter and surrounding materials has also been studied, and, finally, the magnitudes of interferences in real multielement analysis were given in the form of their energy dependences.

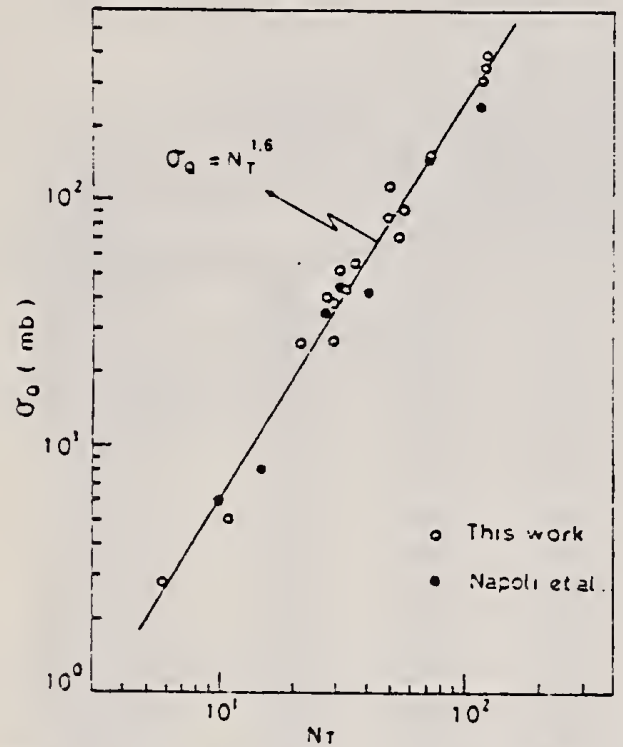

Fig. 2. Yield per equivalent quanta versus turget neutron num. ber.

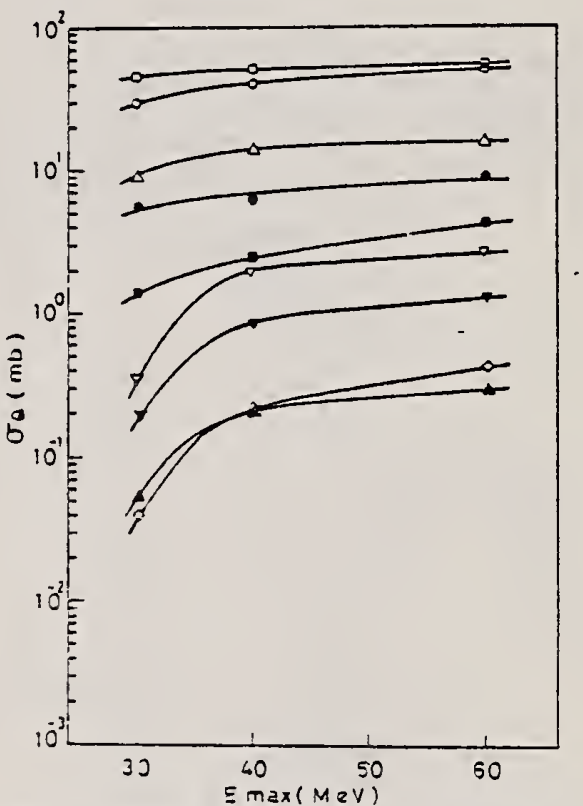

Fig. 6. Acisivation yield curves for the reactions on $\mathrm{Co} . \mathrm{Ni}$ and $\mathrm{Cu}$.

${ }^{54} \mathrm{Co}(\because, n)^{58} \mathrm{Co}, \quad{ }^{59} \mathrm{Co}(\%, 2 n)^{57} \mathrm{Co}, 4{ }^{58} \mathrm{Ni}(\%, n)^{57} \mathrm{Yi}$.

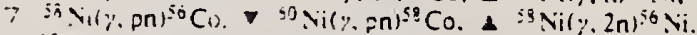

$={ }^{6 j} \mathrm{Cu}(\%, n)^{0+} \mathrm{Cu}$ a $\left.{ }^{0 j} \mathrm{Cu} \%, 2 n\right)^{0} \mathrm{Cu}: \&$ vi $\mathrm{Cu}(\%, m)^{i 3} \mathrm{Co}$.

(over) 


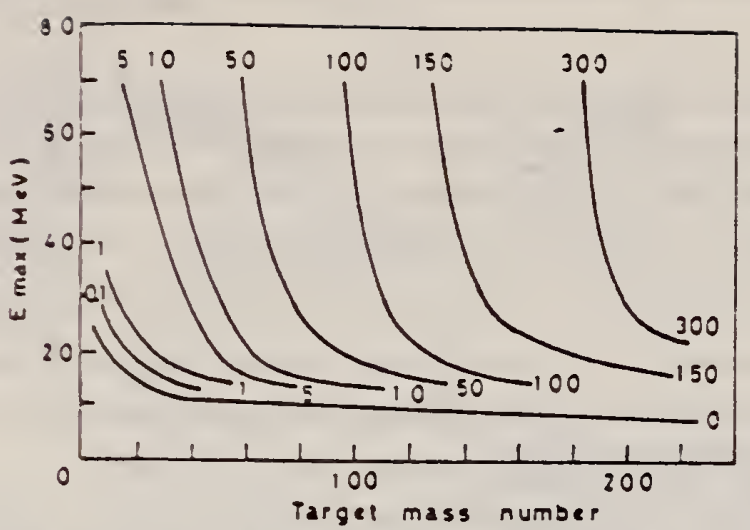

Fig. 9 Yields of the $(\%, n)$ reactions as a function of bremsstrahlun; maximum energy and target mass number. The numerical values in the figure are yields per equivalent quanta in mo.

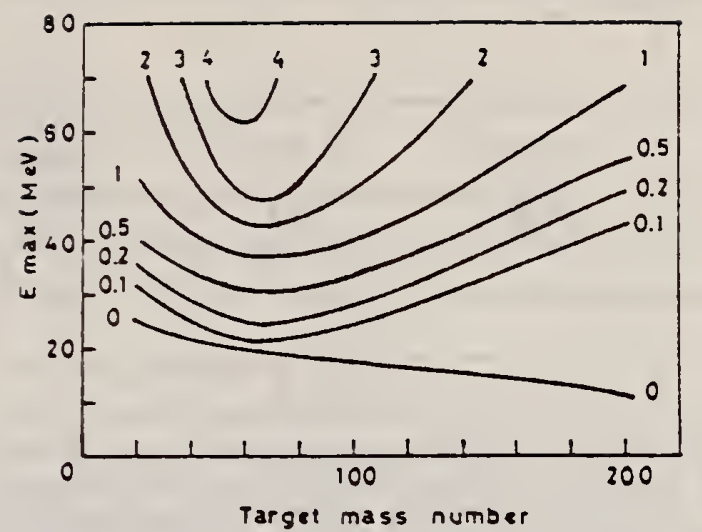

Fig. 11. Yields of the (\%.pn) reactions as a function of brems. strahlung maximum energy and target mass number. The numerical values in the figure are yields per equivalent quanta in $\mathrm{mb}$. 
REF.

L. Meyer-Schutzmeister, R.E. Segel, K. Raghunathan, P.T. Debevec, W.R. Wharton, L.L. Rutledge, and T.R. Ophel

Phys. Rev. C 17, 56 (1978)

78 Me 1

\begin{tabular}{|c|c|c|c|c|c|c|c|}
\hline \multirow{2}{*}{ REACTION } & \multirow{2}{*}{ RESULT } & \multirow{2}{*}{$\begin{array}{l}\text { EXCITATION } \\
\text { ENEROY }\end{array}$} & \multicolumn{2}{|c|}{ SOURCE } & \multicolumn{2}{|c|}{ DETECTOR } & \multirow[b]{2}{*}{ ANGLE } \\
\hline & & & TYPE & RANGE & Troe & RANGE & \\
\hline$\overline{A, G}$ & $A B X$ & $13-19$ & & $7-14$ & $N A I-D$ & & DST \\
\hline & & & & & & & \\
\hline & & & & & & & \\
\hline
\end{tabular}

The reaction ${ }^{54} \mathrm{Fe}\left(a, \gamma_{)}\right)^{8 \mathrm{Ni}}$ has been studied for $7.6 \geq E_{\mathrm{a}} \geq 12.8 \mathrm{MeV}$. Seventeen angular distributions have been measured in this energy region making it possible to separate the $E 2$ strength from the $E 1$ strength. The $E l$ cross section reaches a maximum at about the expected energy. A compact $E 2$ resonance was observed which agres quite well with the one measured by inelastic a scattering, with a peak cross section at about $16 \mathrm{MeV}$ and a width of $-3 \mathrm{MeV}$ (half width at half maximum). The observed $E$ l strength equals $0.9 \%$ of the isospin allowed $E 1$ sum rule. The masured $E 2$ strength, however, equals $4.3 \%$ of the isoscalar E2 sum rule, which is about the same as the fraction of the total E1 strength in ${ }^{38} \mathrm{Ni}$ excited by proton capture. Assuming only statistical processes and applying the Hauser-Feshbach formula to calculate the total $\gamma$ absorption from the measured particle-capture cross sections leads to the conclusion that the $(a, \gamma)$ reaction exciting the isoscalar giant quadrupole resonance and the $(p, \gamma)$ resction exciting the giant dipole resonance must have direct components.

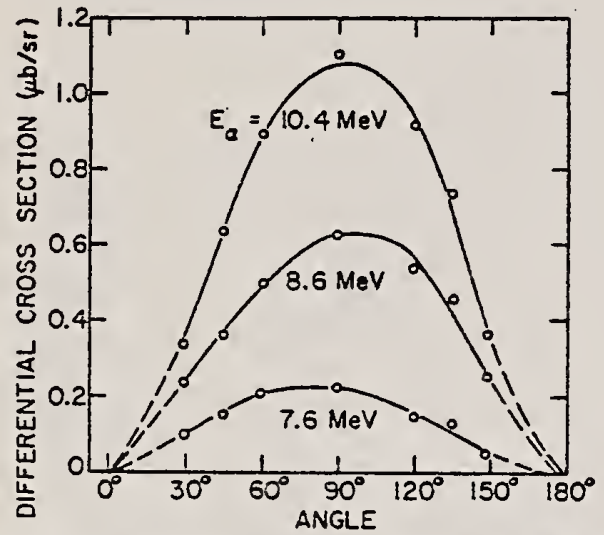

FTG. 2. Angular distributions of the ${ }^{4 A} \mathrm{Fe}(\alpha, \gamma)^{38} \mathrm{Ni}$ re-

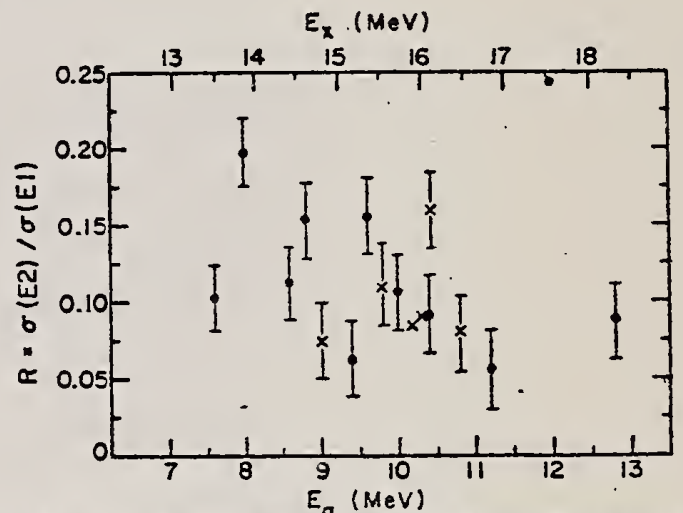

FIG. 3. The ratio $R=\sigma(E 2): \sigma(E 1)$ as function of energy. The estimated error is indicated. Crosses indicato angular distribution measurements with only three angles. action.

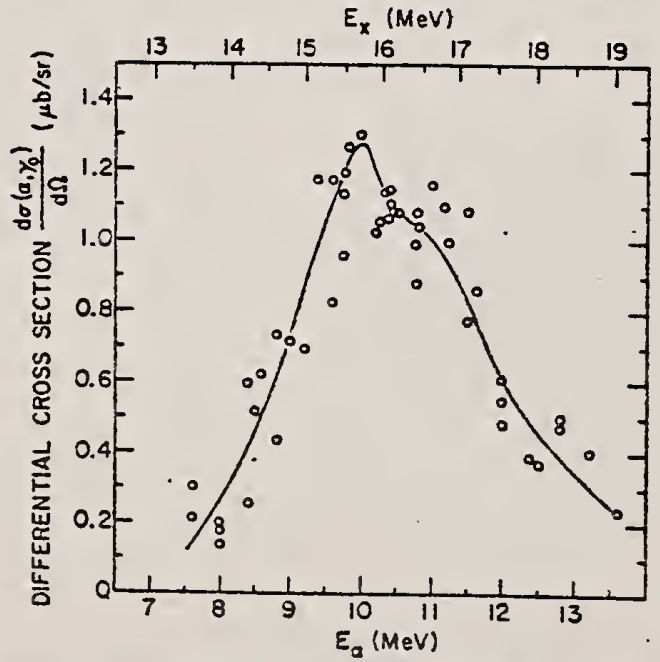

FORM N8S. 418

(REV. 7.14-84)

USCOMM-N $\triangle S-O C$
FIG. 4. Differential cross section of the ${ }^{A} F e\left(\alpha, \gamma_{0}\right)^{58} \mathrm{Ni}$ reaction as function of energy. The measurements have been made at $90^{\circ}$ for the incoming $\alpha$ beam. 


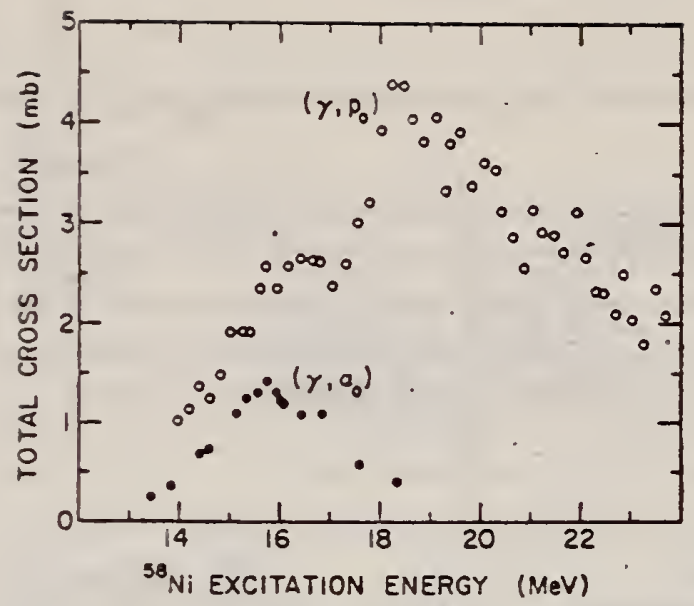

FIG. 7. The cross section of the ${ }^{58} \mathrm{Ni}\left(y_{,}, \alpha_{0}\right)$ is presented as function of the excitaticn energy in ${ }^{58} \mathrm{xi}$. The small contribution of the GQR is subtracted. For comparison the cross scction of the ${ }^{\text {se }} \mathrm{Ni}\left(y, p_{0}\right)$ (see Ref. 6) is shown.

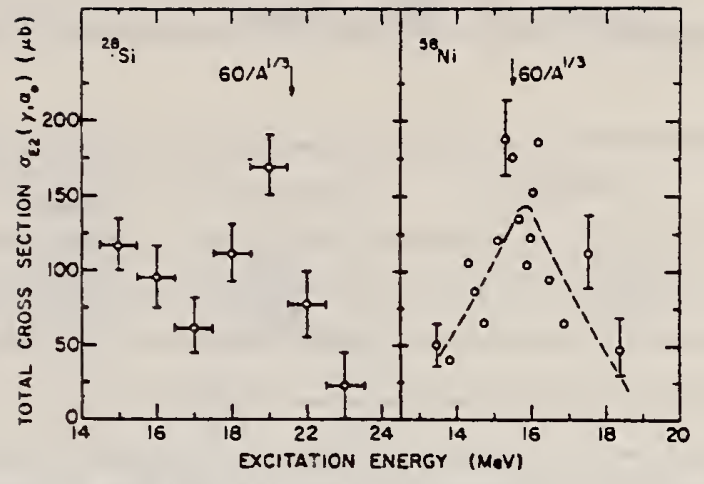

FIG. 8. The cross section of the ${ }^{58} \mathrm{Ni}\left(\gamma, \alpha_{0}\right)$ reaction exciting only the GQR is shown as function of the energy. For comparison an older measurement of the reaction ${ }^{2} \mathrm{Si}\left(x, \alpha_{0}\right)^{24}$.ig (Ref. 7) had been partially reanalyzed for a more detailed extraction of the E2 strength.

TABEL I. Determination of absolute cross sections of the ${ }^{54,38} \mathrm{Fe}\left(\alpha, \gamma_{0}\right)^{58,60} \mathrm{Ni}$ reactions by using the known reactions ${ }^{12} \mathrm{C}\left(p, \gamma_{0}\right)^{13} \mathrm{~N}$ and ${ }^{54} \mathrm{Co}\left(p, \gamma_{0}\right)^{60} \mathrm{Ni}$ for normalization (see text).

\begin{tabular}{|c|c|c|c|c|c|}
\hline \multirow[b]{2}{*}{ Reaction } & \multirow{2}{*}{$\begin{array}{c}E_{a} \\
\text { (iev) }\end{array}$} & \multirow{2}{*}{$\stackrel{\theta}{(\mathrm{deg})}$} & \multirow{2}{*}{$\begin{array}{c}\text { Target } \\
\text { thickness } \\
\left(\mathrm{mg} / \mathrm{cm}^{2}\right)\end{array}$} & \multicolumn{2}{|c|}{$\begin{array}{l}d \sigma / d \Omega(\mu b / s r) \\
\text { normallzed to }\end{array}$} \\
\hline & & & & ${ }^{12} \mathrm{C}\left(p, \gamma_{0}\right)^{13} \mathrm{~N}^{2}$ & ${ }^{59} \mathrm{Co}\left(p, y_{0}\right)^{60} \mathrm{Ni}^{b}$ \\
\hline${ }^{4} \mathrm{Fe}\left(\alpha, \gamma_{0}\right)^{58} \mathrm{\gamma i}$ & 10.0 & 90 & 1.1 & $1.3 \pm 0.2$ & $1.2 \pm 0.2$ \\
\hline${ }^{s i} \mathrm{Ee}\left(\alpha, \gamma_{0}\right){ }^{\mathrm{i}} \mathrm{Ni}$ & 10.0 & 90 & 1.0 & $0.56 \pm 0.15$ & $0.53 \pm 0.15$ \\
\hline
\end{tabular}

Reference 12

Reference 13.

$6_{H}$. Miyase, S. Oikawa, A. Suzuki, J. Uegaki, T. Saito, M. Sugawara, and $K$. Shoda, in Proceedings of the International Conference on Photonuclear Reaction and Applications, Asilomar, March 1973, edited by B.L. Berman (Lawrence Livermore Laboratory, Livermore, 1973), V01. 1, p. 553.

7L. Meyer-Schutzmeister, Z. Vager, R.E. Sege1, and P.P. Singh, Nuc7. Phys. A108, 180 (1968)

${ }^{12}$ F.S. Dietrich, M. Suffert, A.V. Nero, and S.S. Hanna, Phys. Rev. 168,1169 (1968)

13 E.M. Diener, J.F. Amann, P. Paul, and S.L. Blatt, Phys. Rev. C 3, $2303(1971)$ 
nef. Yu.M. Volkov, A.I. Agnat'ev, G.A. Kolomenskii, E.F. Lakovichev, E.D. Makhnovskii, A.V. Nadtochii, V.V. Popov, V.P. Fominenko, V.P. Chizkov JETP Lett. 30,59 (1979)

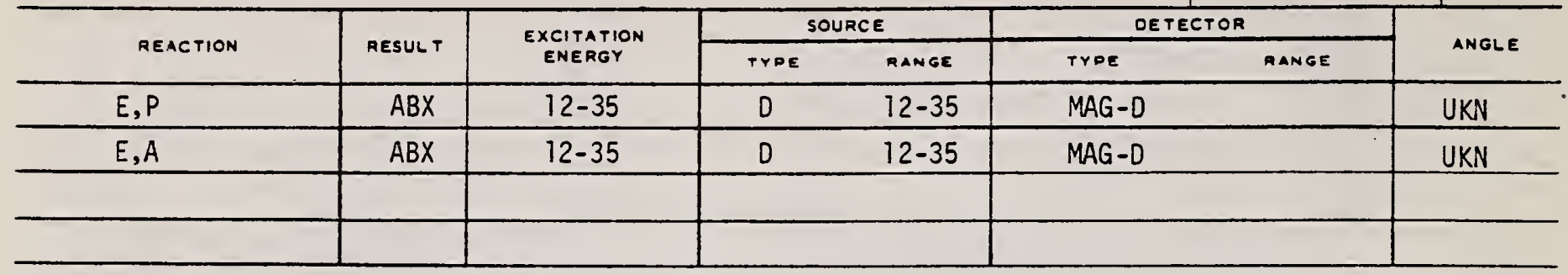

Cross sections have been measured for $\mathrm{Ni}^{58}\left(e, e^{\prime} p\right)$ and $\mathrm{Ni}^{59}\left(e, e^{\prime} \alpha\right)$ reactions.

Virtual photon spectra calculated in the distorted wave Born approximaticn have

VIRT PHOTON ANAL

been used to analyze the experimental results. An elcctric quadrupole $(E 2)$ giant

resonance has been found which decays principally by the emission of $\alpha$-particles.

PACS numbers: $24.30 . \mathrm{Cz}, 25.30 . \mathrm{Cg}, 27.40 .+\mathrm{z}$

TABLE I.

\begin{tabular}{|l|l|l|c|c|c|}
\hline $\begin{array}{c}\mathrm{Ni}^{38}(\gamma, \mathrm{p}) \\
\left.\int_{30}^{0} \sigma E_{\gamma}\right) d E_{y} \\
0\end{array}$ & $\begin{array}{l}\text { multi- } \\
\text { polarity }\end{array}$ & $\begin{array}{c}\omega_{0} \\
\mathrm{MeV}\end{array}$ & $\begin{array}{c}\Gamma \\
\mathrm{MeV}\end{array}$ & $\begin{array}{l}\int \sigma\left(E_{\gamma}\right) d E_{\gamma} \\
\text { MeV-mbarn }\end{array}$ & $\begin{array}{c}S \\
\%\end{array}$ \\
\hline $539 \pm 33$ & $E 1$ & $19.1 \pm 1.0$ & $4.6 \pm 0.4$ & $15.9 \pm 2.3$ & $1.8 \pm 0.3$ \\
$570 \pm 60[4]$ & $E 2$ & $16.0 \pm 1.0$ & $2.5 \pm 0.5$ & $5.4 \pm 1.4$ & $47 \pm 12$ \\
\hline
\end{tabular}



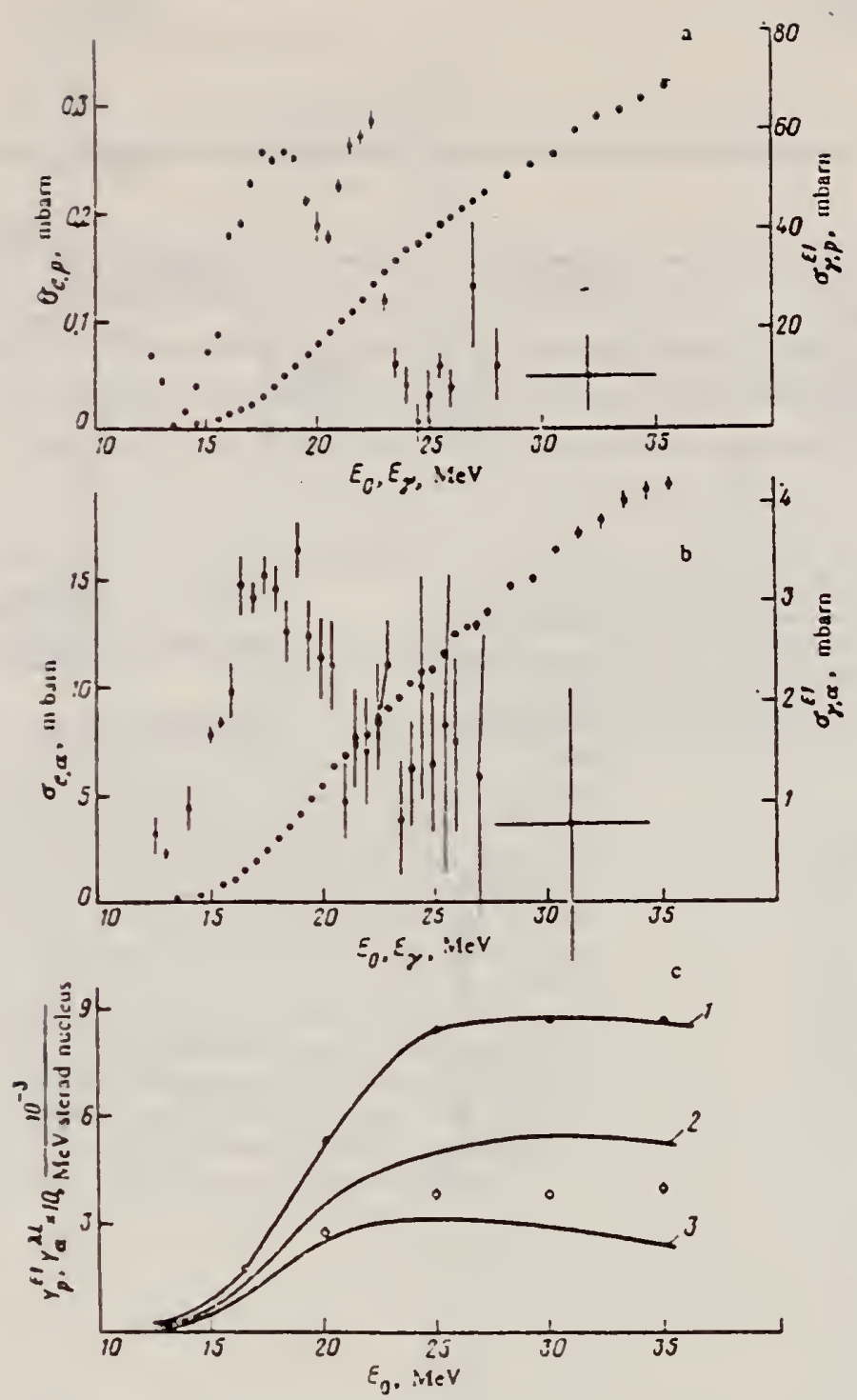

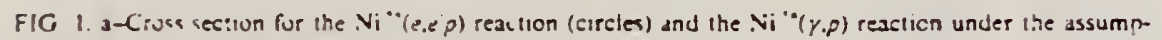

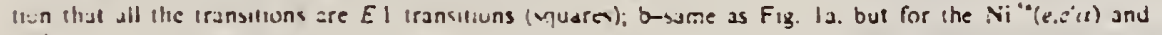

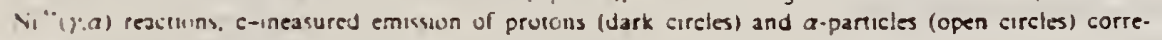
spondingly in the $\mathrm{Ni}^{* *}(\gamma, \rho)$ and $\mathrm{Ni}^{*}(\gamma . a)$ rosctions. Curves 1 and 2 are the erpected emissiun respectively uf protuns and a 1 -particles under the assumption of $E$ I transtions Curve 3 is the same as curve 2. but under the awumpion of $E$ : iransilions. The meisured proton emission is normalized to curve 1 at an arbitrary pant 
Ref. E. Wolynec, W.R. Dodge, E. Hayward

Phys. Rev. Lett. 42,27 (1979)

79 Wo 3

\begin{tabular}{|c|c|c|c|c|c|c|c|}
\hline \multirow{2}{*}{ REACTION } & \multirow{2}{*}{ RESULT } & \multirow{2}{*}{$\begin{array}{c}\text { EXCITATION } \\
\text { ENERGY }\end{array}$} & \multicolumn{2}{|c|}{ SOURCE } & \multicolumn{2}{|c|}{ DETECTOR } & \multirow{2}{*}{ ANGLE } \\
\hline & & & TYPE & RANGE & TYPE & RANGE & \\
\hline$E, X P$ & $A B X$ & $8-50$ & D & $16-50$ & $M A G-D$ & & 4PI \\
\hline$E, X A$ & $A B X$ & $6-50$ & D & $16-50$ & $M A G-D$ & & $4 P I$ \\
\hline
\end{tabular}

The $(\epsilon, p)$ and $(e, \alpha)$ cross sections for targets of ${ }^{58} \mathrm{Ni},{ }^{60} \mathrm{Ni}$, and ${ }^{\mathrm{i}} \mathrm{Ni}$ have been measured in the electron energy range 16-50 MeV. They have been analyzed using the distored-wave Born-approximation $E 1$ and $E 2$ virtual-photon spectra. Protons are emitted primarily following $E 1$ absorption but $\alpha$ emission results from a combination of $E 1$ and $E 2$ absorption. The $E 2$ isoscalar giant resonance decays predominantly by $\alpha$ emission for these auclei.

$(E, X P)$

$(E, X A)$

See also 80 :No 1
TABLE I. Resonance parameters for $\sigma_{y, p}$

\begin{tabular}{ccccc}
\hline \hline Nucleus & $\begin{array}{c}E_{\mathbf{x}} \\
(\mathrm{MeV})\end{array}$ & $\begin{array}{c}\Gamma \\
(\mathrm{MeV})^{\mathrm{a}}\end{array}$ & $\begin{array}{c}\int_{n}^{30} \mathrm{OdE} \\
(\mathrm{MeV} \mathrm{mb})\end{array}$ & $\begin{array}{c}\mathrm{SR}^{n} \\
\left(G_{\mathrm{C}}\right)\end{array}$ \\
\hline${ }^{58} \mathrm{Ni}$ & $19.2 \pm 0.5$ & $6.5 \pm 1.3$ & $738 \pm 40$ & $85 \pm 5$ \\
${ }^{60} \mathrm{Ni}$ & $18.5 \pm 0.5$ & $9.2 \pm 1.8$ & $304=20$ & $34=2$ \\
${ }^{62} \mathrm{Ni}$ & $21.0 \pm 0.5$ & $5.8 \pm 1.0$ & $140 \pm 10$ & $15=1$ \\
\hline \hline
\end{tabular}

${ }^{2} \Gamma$ is the full width at balf maximum.

bSP. stands for sum rule; the $E 1 \mathrm{SR}$ equals $60 \mathrm{NZ} / \mathrm{A}$ $\mathrm{MeV} \mathrm{mb}$.

TABLE II. E1 components in the $(\gamma, \alpha)$ reaction.

\begin{tabular}{lccrc}
\hline Nucleus & $\begin{array}{c}E_{x} \\
(\mathrm{MeV})\end{array}$ & $\begin{array}{c}\Gamma \\
(\mathrm{MeV})^{2}\end{array}$ & $\begin{array}{c}\int^{5} \mathrm{~J} d E \\
(\mathrm{MeV} \mathrm{mb})\end{array}$ & \multicolumn{1}{c}{$\begin{array}{c}\mathrm{SR}^{\mathrm{b}} \\
(\%)\end{array}$} \\
\hline${ }^{58} \mathrm{Ni}$ & $18.3 \pm 0.5$ & $6 \pm 1$ & $15.3=1.3$ & $1.8 \pm 0.2$ \\
${ }^{60} \mathrm{Ni}$ & $21.5 \pm 1.0$ & $6 \pm 1$ & $18.5 \pm 1.4$ & $2.1=0.2$ \\
${ }^{82} \mathrm{Ni}$ & $18.3 \pm 1.0$ & $5 \pm 1$ & $4.8 \pm 0.6$ & $0.5 \pm 0.1$ \\
\hline
\end{tabular}

a $\Gamma$ is the full wicth at half maximum.

${ }^{3} E 1 \mathrm{SR}$ equals $60 \mathrm{NZ} / \mathrm{A} \mathrm{MeV} \mathrm{mb}$.

TABLE IU. E2 components in the $(\gamma, \alpha)$ reaction.

\begin{tabular}{lcccc}
\hline Nucleus & $\begin{array}{c}E_{\mathrm{z}} \\
(\mathrm{MeV})\end{array}$ & $\begin{array}{c}\Gamma \\
(\mathrm{MeV})^{\mathrm{a}}\end{array}$ & $\begin{array}{c}\int \sigma d E \\
\left(\mathrm{MeV}^{\mathrm{mb}}\right)\end{array}$ & $\begin{array}{c}S^{b} \\
(\tau)\end{array}$ \\
\hline${ }^{5{ }^{5} \mathrm{Ni}}$ & $16.5 \pm 0.5$ & $4.2 \pm 1.0$ & $10.4=0.7$ & $56 \pm 4$ \\
${ }^{50} \mathrm{Ni}$ & $16.0 \pm 0.5$ & $3.7 \pm 0.3$ & $6.9=0.4$ & $52=3$ \\
${ }^{52} \mathrm{Ni}$ & $16.8 \pm 0.5$ & $4.5 \pm 1.0$ & $5.1 \neq 0.4$ & $28=2$ \\
\hline
\end{tabular}

${ }^{a} \Gamma$ in the full width at balf maximum.

${ }^{b} E 2$ SR equals $0.22 Z^{2} / A^{1 / 3} \mu \mathrm{b} / \mathrm{MeV}$.

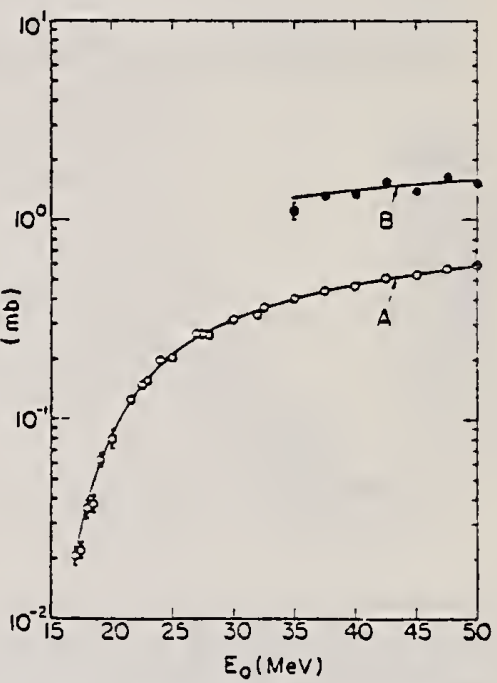

FIG. 2. The cross section for the production of protons, $\sigma_{2, g}\left(E_{0}\right)$, when electrons of total energy $E_{0}$ are lacident on a ${ }^{9 ?} \mathrm{NI}$ target (open circles). The clused circles represeat the yield of protons obtained when a $0.21 \mathrm{i}-\mathrm{g} / \mathrm{cm}^{2} \mathrm{Ta}_{\mathrm{S}}$ sil was plased $\mathrm{i}$ the incident electron beam. Curve $A$ is predict:d using 1.26 times the $(\gamma, \rho)$ cross section of Ref. 5 sloss with the $E 1$ virtual-photon spectra to Eq. (1). Curve $B$ is obtained by taking iato account the radiztor thicingess according to Eq. (2).

(over) 


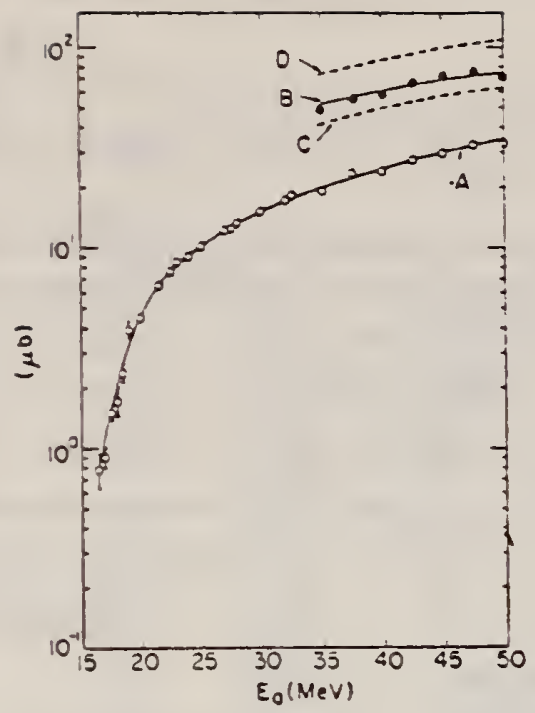

FIG. 3. The measured $\sigma_{\text {a } \alpha}\left(E_{0}\right)$ (opeo circles) for ${ }^{58} \mathrm{Ni}$ as 3 function of total incideat electron energy, $E_{0}$. The closed circles represeat the electrodisiategration plus photodisintegration yield obtained when the $0.217-g / \mathrm{cm}^{2}$ taotalum foll was iaterposed la the iacideat electron beam. Curve $A$ ls the best fit to the data obtained by usiag the $E l$ and $E$ 2 virtual-photon spectra io Eq. (1) aloog with the two resonace liaes whose parameters are given to Tables $\amalg$ and III. Curve $B$ is the correspoodinz result with the radiator in, obtained usiog Eq. (2). Curve $D$ was predlcted usiog the best $E l$ flt to the da:a, 3 22-Miev-wide resocacce. Curve $C$ was predic:ed usieg the best $E 2$ fit to the data. This figure is ic:ended to show that both $E 1$ and $E 2$ compone of $s$ are aecessary to explais the $(c, a)$ cross sectioo. 


\begin{tabular}{c|c|c}
\hline REACTION & RESULT & $\begin{array}{c}\text { EXCITATION } \\
\text { ENERGY }\end{array}$ \\
\hline G,SPI & ABY & THR-999 \\
\hline & & \\
\hline & & \\
\hline
\end{tabular}
REF. NO.

Yield of $(\gamma, n) /(\gamma, p)=2.77 \pm 0.22$

New data are presented on the photodisintegration of the enriched isotopes ${ }^{5 t} \mathrm{Ni}$ and ${ }^{4} \mathrm{Ni}$ under bombardment by photons with maximum energy $4.5 \mathrm{GeV}$. The isotope effect in photonuclear reactions with formation of residual nuclei is investigated. The experimental yield values are compared with theoretical calculations by Rudstam's formula. In the results we observe a systematic shift of the experimental disintegration yields in comparison to the calculated values. An exponenvial dependence is found for the ratios of the yields of the residual nuclei from the "Ni target to the yields of the same nuclei from ${ }^{\mathrm{s}} \mathrm{Ni}$ as a function of the third projection of the isotopic spin of the product nucleus, and an exponential dependence is found for the ratios of the experimental yield values to the theoretical values as a function of the difference of the third projections of the isotopic spins of the target nuclei and the residual nuclei.

PACS numbers: $25.20 .+y, 27.50$. +e

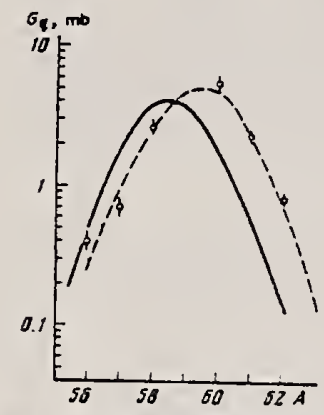

FIG. 1. Distributions of independent yields of Co residual nuclei in mass number. The solid curve is a calculation with Eq. (1), and the dashed curve has been drawn from the experimental points.

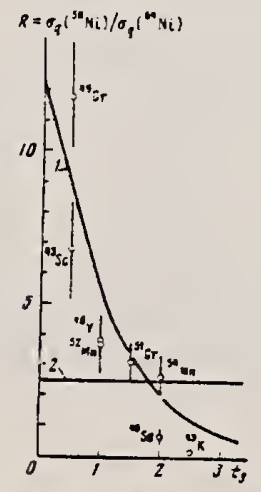

FIG. 3. Ratio of yields of identical residual nuclei from two isotopes of the target nuclei as a function of the third projection of the isotopic spins of the residual nuclei. Curve 1 is the function $15 \exp \left(-t_{3}\right)$, and curve 2 is calculated with Eq. (1).

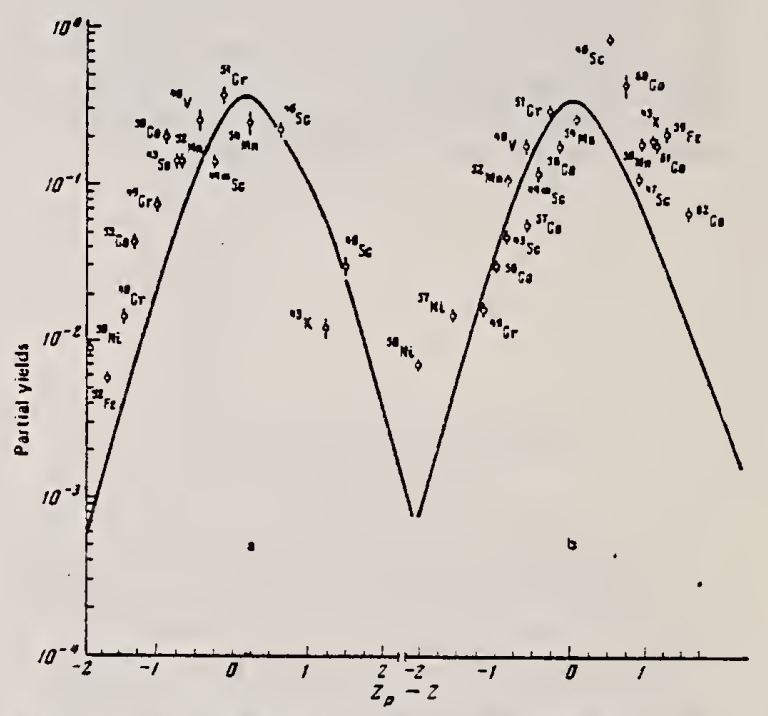

FIG. 2. Charge-dispersion curves of residual nuclei from targets of ${ }^{58} \mathrm{Ni}$ ( a) and ${ }^{54} \mathrm{Ni}(\mathrm{b})$. 


\begin{tabular}{|c|c|c|c|c|c|c|c|c|}
\hline \multirow[b]{2}{*}{ 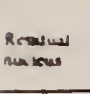 } & \multicolumn{3}{|c|}{$\ldots$} & \multicolumn{3}{|c|}{ Nont arset } & \multirow[b]{2}{*}{$\begin{array}{l}\text { Type } \\
\text { of yeid }\end{array}$} & \multirow[b]{2}{*}{ t, } \\
\hline & o-rexom & 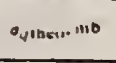 & $\frac{\sigma_{\text {gero }}}{\text { oginou }}$ & $\sigma_{y=x p, m b}$ & Oqinew mb & $\frac{\text { ogeos }}{\text { oqther }}$ & & \\
\hline$\cdot 4 \cdot$, & $10 \times 2 ; 118$ & 11.1.:- & $\therefore$ & & & & 1 & 6 \\
\hline "an & $\therefore .1 i .11 .8$ & $11 \cdot i=$ & \&lli & & & & $c$ & 3.5 \\
\hline$-1,3$ & $\therefore, i=1$ & 1.inzii & LW & - & & 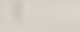 & $t$ & 3 \\
\hline$\cdot \varepsilon_{11}$ & $\because 4-11-i$ & i: & 0. Ki & 11. 1 $1 x_{i}=n 02$ & & & 1 & 2 \\
\hline$\therefore 1 \div$ & $1.11 .+1.1$ & lliiz: & U.1.0i & $i 65 \pm 1$ & 4966 & 9.35 & $c$ & 1.5 \\
\hline iv & u.t. =11.ui & 11. hisis & $13 i$ & R.1 $1 \pm 1,8$ & 1.965 & 6.255 & $c$ & 1 \\
\hline 4 & - & $0.1 \times 1 \times$ & - & $1.7 \pm 0.1$ & 0.2497 & 6.81 & $c$ & 0.5 \\
\hline mi & 1).2.1=0.12 & 1.0971 & 2987 & $1 i \Sigma \pm 1$ & 0.251 & 681 & 1 & 1 \\
\hline vii & 11. $1 .:=0.00$ & (1) & 9.816 & $0.5 \pm 0.03$ & 0.0058 & 13.97 & I & 0 \\
\hline$\cdot F c$ & $|\Delta=1| 2$ & 11.362 & 6.85 & - & - & - & 1 & 3.5 \\
\hline Bic & - & (1), ) & - & $0.13=0.01$ & 10.0283 & 3.52 & 1 & 0 \\
\hline 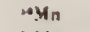 & $1=1315$ & 11. 8975 & 2153 & - & - & - & $c$ & 3 \\
\hline "Yn & $1.020=$ & 1.790 & 0.39 & $3.8 \pm 0.6$ & 5.23 & 0.7307 & 1 & 2 \\
\hline $\begin{array}{l}1: 11, \\
1:-1 / 8\end{array}$ & 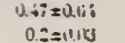 & 03916 & 1.71 & $\left.\begin{array}{l}1.3620 .1 \\
0.85 * 0.07\end{array}\right\}$ & 1.042 & 212 & $c$ & 1 \\
\hline$r^{r}$ & $1.1=11.1$ & 11942 & 1.1677 & . $3.45=0.3$ & 25977 & 1.33 & $c$ & 1.5 \\
\hline$\cdot \mathrm{C}$ & $0.06,3=1 ., 14 \times 6$ & IIIRT & 0.721 & $0.6 i \pm 0.03$ & 0.211 & 3.175 & $c$ & 0.5 \\
\hline$\cdot \mathrm{Cs}$ & - & $0.016 i$ & - & $0.13 \pm 0.01$ & 0.007 & 3.513 & $c$ & 0 \\
\hline$\omega v^{*}$ & 11. $\Sigma=0.04$ & 02933 & 1.524 & $1.7=0.15$ & 0.7516 & 220 & $c$ & 1 \\
\hline use & - & 0.0933 & - & $0.07 \pm 0.02$ & 0.0524 & 1.336 & i & 3 \\
\hline "se & $0.4: 0.03$ & 0.078987 & 1.72 & - & 0.187 & - & $c$ & 25 \\
\hline nse & $\because 31=0,2 y$ & 0.2004 & $4.5 i$ & $0.53 \pm 0.05$ & 0.493 & 1.075 & 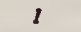 & 2 \\
\hline 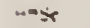 & $0.13: 0.02$ & 0,20000 & - & $0.32=0.03$ & 0.186 & - & 1 & 1 \\
\hline$\omega$ & 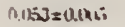 & 0.0631 & $n 8399$ & $0.32 \pm 0.05$ & 0.163 & 224 & $c$ & 0.5 \\
\hline WK & $0.09=0.000$ & 0,0209 & 4308 & 0.011 & 0.015 & 0.24 & 1 & 25 \\
\hline
\end{tabular}

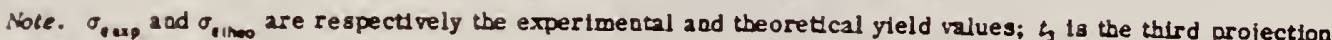
of the tsosplas. 
Phys. Rev. C21, 147 (1980)

.B. Dally, D.H. Dubois, 

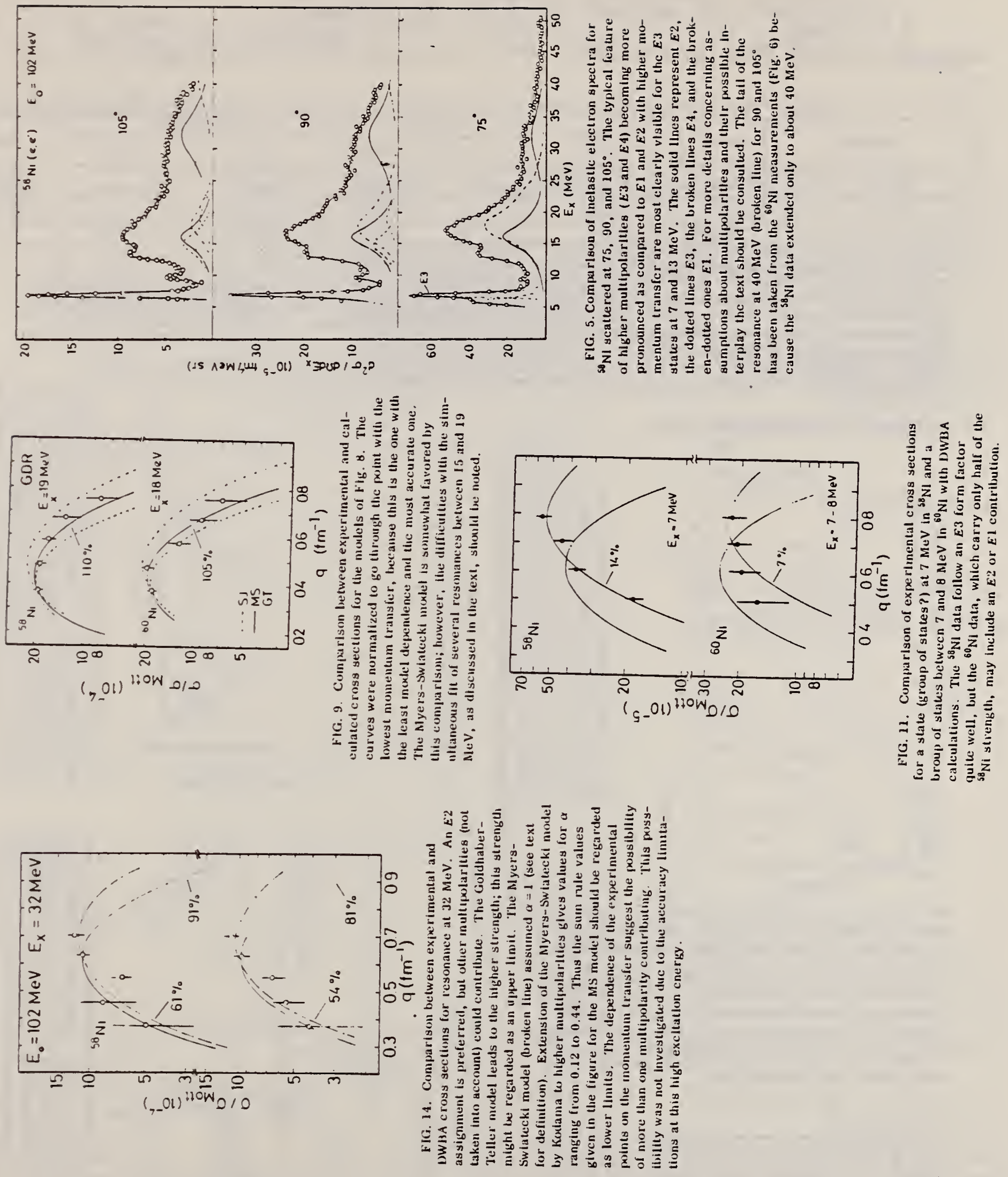
Yu.M. Volkov, A.I. Ignat'ev, G.A. Kolomenskii, E.F. Lakovichev, E.D. Makhnovskii, A.V. Nadtochis, V.V. Popov, V.P. Fominenko, V.P. Chizhov

Sov. J. Nuc] Phys 32, 306 (1980) yad Fiz 32,595 (1980)

\begin{tabular}{|c|c|c|c|c|}
\hline \multirow[b]{2}{*}{ REACTION } & \multirow{2}{*}{ RESUL T } & \multirow{2}{*}{$\begin{array}{l}\text { EXCITATION } \\
\text { ENERGY }\end{array}$} & \multicolumn{2}{|c|}{ SOURCE } \\
\hline & & & TYPE & RANGE \\
\hline$E, P$ & $A B X$ & $8-35$ & C & $12-30$ \\
\hline$E, A$ & $A B X$ & $6-35$ & $C$ & $12-30$ \\
\hline \multicolumn{5}{|c|}{ 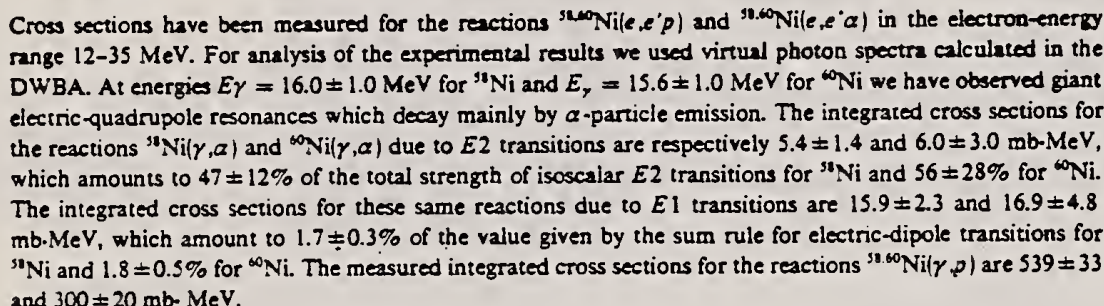 } \\
\hline
\end{tabular}

and $300 \pm 20$ mb. $\mathrm{MeV}$.

PACS numbers: $25.30 . \mathrm{Cg}_{3}, 24.30 . \mathrm{Cz}, 27.40 .+2,27.50 .+e$

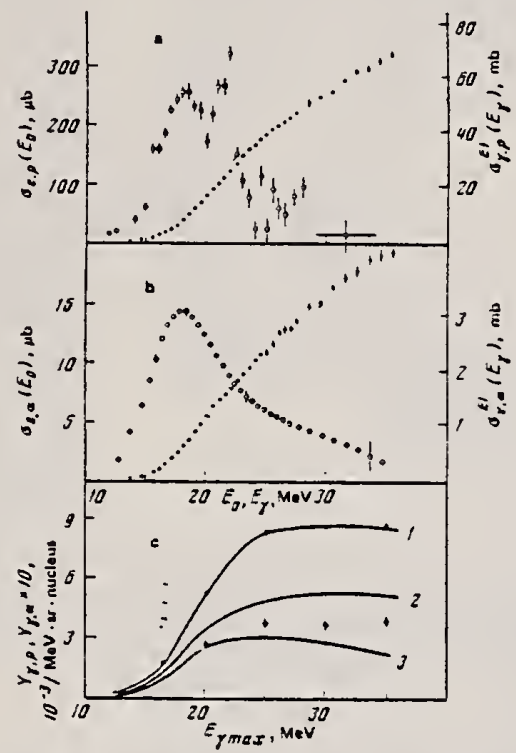



FIG. 2. Cross sections of the reactions ${ }^{58} \mathrm{Ni}\left(e, e^{\prime} p\right)$ (solid points points) and ${ }^{58} \mathrm{Ni}(\gamma, p)$, calculated on the assumption that oaly El transitions are excited (hollow points)-a; b-the same but for the reactions ${ }^{53} \mathrm{Ni}\left(e, e^{\prime} \alpha\right)$ and ${ }^{53} \mathrm{Ni}(\gamma, \alpha) ; c$-measured yields of protons (solid points) and $\alpha$ particles (bollow points) in the reactions ${ }^{58} \mathrm{Ni}(\gamma, p)$ and ${ }^{58} \mathrm{Ni}(\gamma, \alpha)$. Curves 1 and 2 respectively are the expected yields of protons and $\alpha$ particles obtained on the assumption that only $E 1$ transitions are excited; curve 3 is the same as curve 2 but on the assumption that only $E 2$ transitions are excited. The proton yield bas been normallzed to curve 1 at an arbitrary polnt.

TABLE I.

\begin{tabular}{|c|c|c|c|c|c|c|}
\hline \multirow[b]{2}{*}{ Nudeus } & \multirow{2}{*}{ 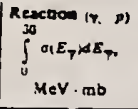 } & \multicolumn{5}{|c|}{$10(1.9)+100000$} \\
\hline & & Multipolanty & $\varepsilon_{R}$, MeV & r. MeV & 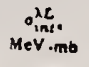 & $5^{2 c} . \%$ \\
\hline${ }^{*} \mathrm{Ni}$ & $\begin{array}{l}539=.33 \\
570 \pm 00114 \mid\end{array}$ & $\frac{E !}{E 2}$ & $\begin{array}{l}19.1 \pm 1.0 \\
16.0 \pm 1.0\end{array}$ & $\begin{array}{l}\{6 \pm 0.5 \\
25=0.5\end{array}$ & $\begin{array}{l}15.9 \pm 2.3 \\
5.4=1.6\end{array}$ & $\begin{array}{l}1.7 \pm 0.3 \\
47 \pm 12\end{array}$ \\
\hline ovi & $300 \pm 20$ & $\begin{array}{ll}\Sigma_{1} \\
\Sigma 2\end{array}$ & $\begin{array}{l}18.0 \pm 1.0 \\
15.6 \times 1.0\end{array}$ & $\begin{array}{l}3.3 \pm 1.0 \\
24 \pm 0.8\end{array}$ & $\begin{array}{l}18.9=18 \\
8.0 \pm 3.0\end{array}$ & $\begin{array}{l}1.8 \pm 0.5 \\
56 \pm 28\end{array}$ \\
\hline
\end{tabular}

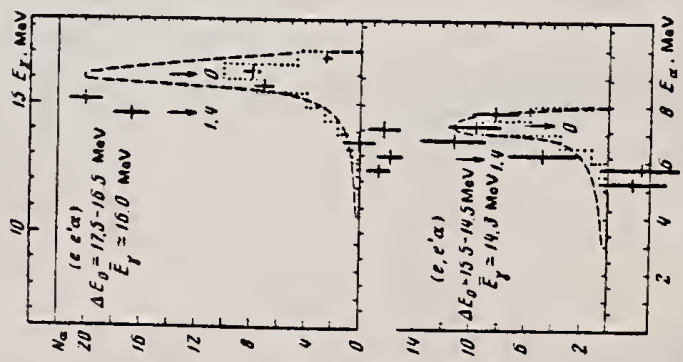

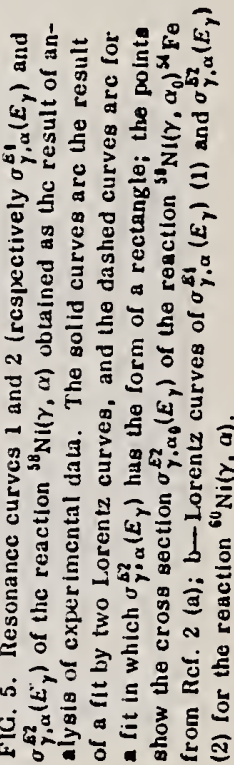

VIRT PHOTON ANALYSIS

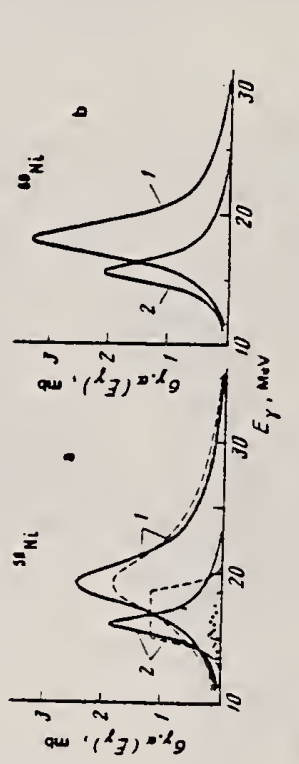

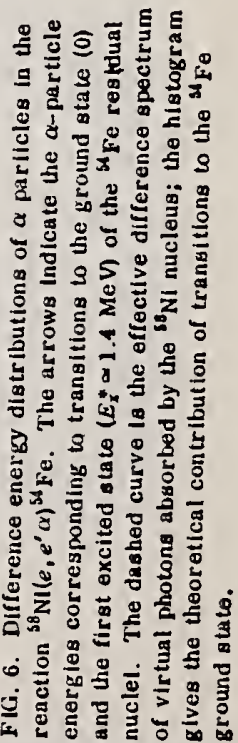


-er. E. Wolynec, W.R. Dodge, R.G. Leicht, E. Hayward

Phys. Rev. C22, 1012 (1980)

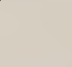

4

$\quad-\cdots+\cdots$ 28 (a)

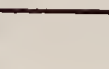

\begin{tabular}{|c|c|c|c|c|}
\hline \multirow{2}{*}{ REACTION } & \multirow{2}{*}{ RESULT } & \multirow{2}{*}{$\begin{array}{l}\text { EXCITATION } \\
\text { ENERGY }\end{array}$} & \multicolumn{2}{|c|}{ SOURCE } \\
\hline & & & TrPE & ๓ \\
\hline$E, X P$ & $A B X$ & $8-50$ & D & 1 \\
\hline$E, X A$ & $A B X$ & $6-50$ & D & 1 \\
\hline \multicolumn{5}{|c|}{$\begin{array}{l}\text { The }(e, q) \text { and }(e, a) \text { cross sections for targets of }{ }^{38} \mathrm{Ni},{ }^{90} \mathrm{Ni} \text {, and }{ }^{62} \mathrm{Ni} \text { have been measured in the } \\
\text { energy range } 16-100 \mathrm{MeV} \text { They have been analyzed using the distorted-wave Born approximation } E \\
E 2 \text { virtual photion spectra. Protons are emitted primarily following } E \text { ! absorption but a-emission } \\
\text { from a combination of } E l \text { and } E 2 \text { absorption. }\end{array}$} \\
\hline \multicolumn{5}{|c|}{ 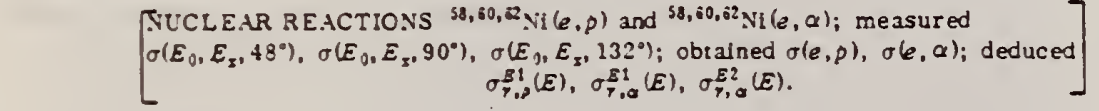 } \\
\hline
\end{tabular}
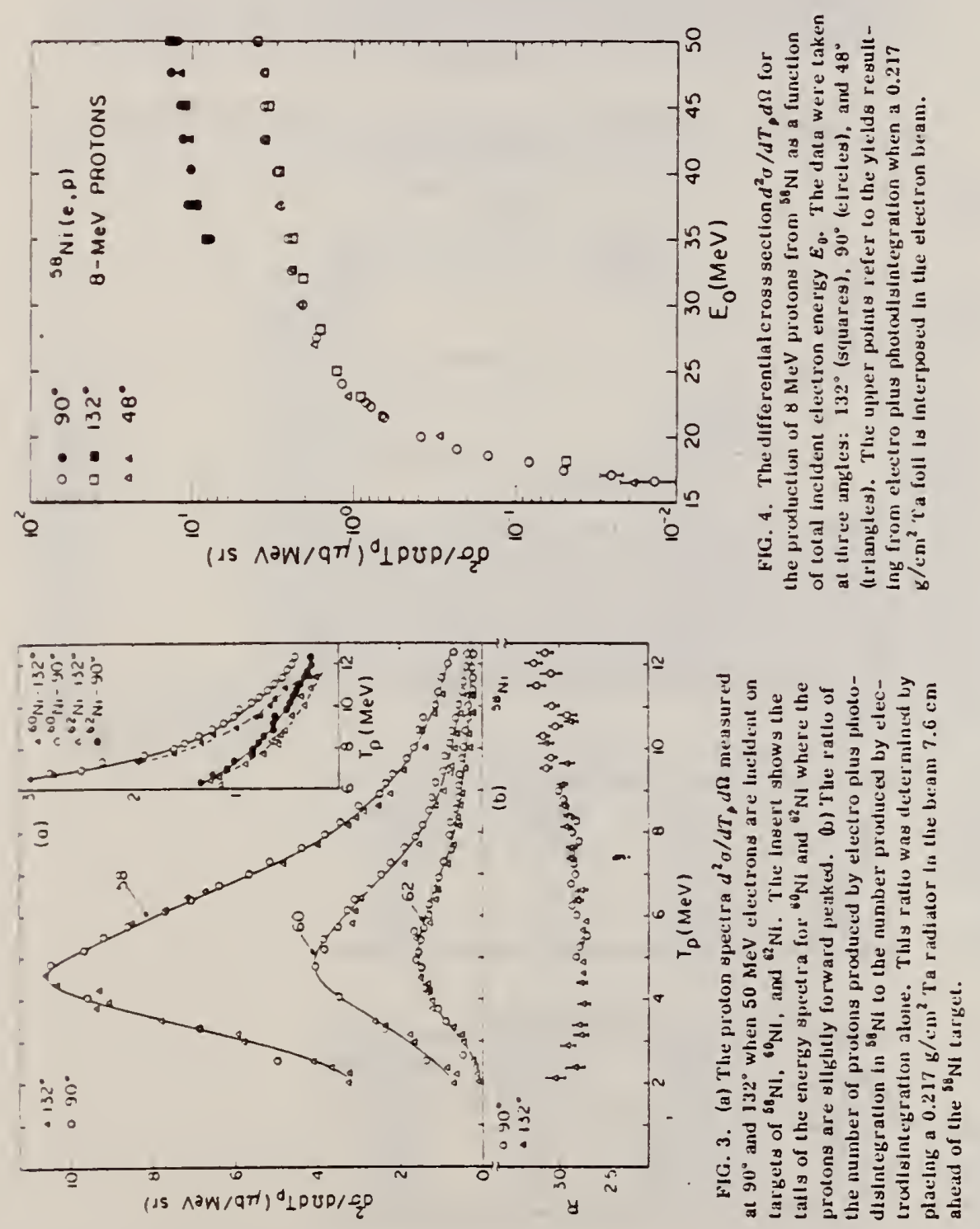

(over)

\section{(E,XP) VIRTUAL PHOTON $G, X P$ \\ $(E, X A)$ VIRTUAL PHOTON $G, X A$}

1. Measurement also made at 100 MeV

2. Assumptions:

For photons: $\frac{d \sigma}{d r}(\theta)=$ constant

For alphas:

$\frac{d \sigma}{d r}(\theta)=\sigma\left(90^{\circ}\right)\left[A\left(E_{0}\right)+B\left(E_{0}\right) \sin ^{2} \theta\right]$

$A\left(E_{0}\right), B\left(E_{0}\right)$ determined empirically

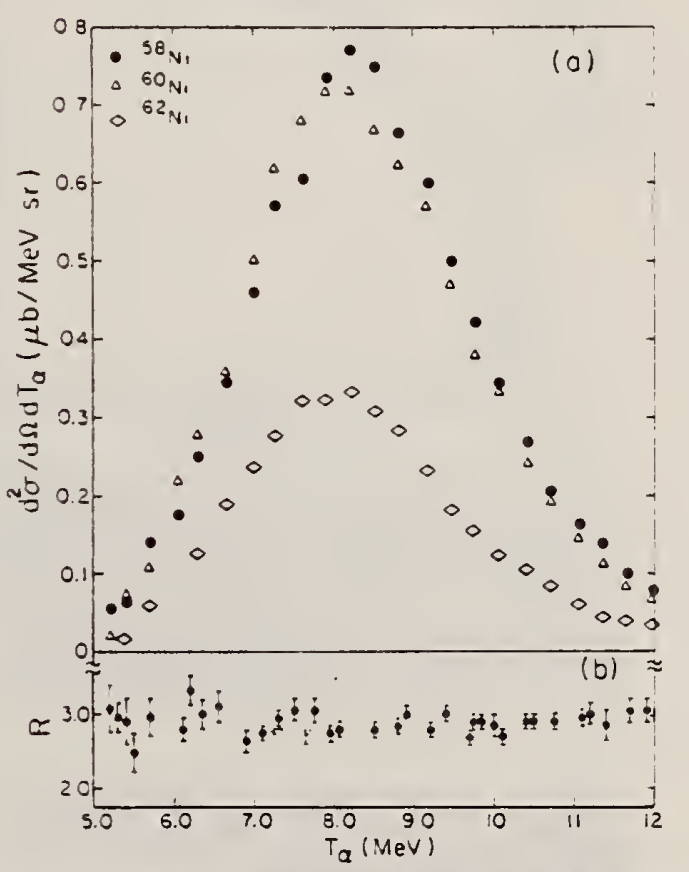

FIG. 2. (a) The $\alpha$ spectra $d^{2} \sigma / d T_{\alpha} d \Omega$ measured at $90^{\circ}$ when $50 \mathrm{MeV}$ electrons are incident on targets of ${ }^{58} \mathrm{Ni}$, ${ }^{69 \mathrm{Ni}}$, and ${ }^{2} \mathrm{Ni}$. (b) The ratio of the number of $\alpha$ particles produced by electro ptus photodisintegration in ${ }^{58} \mathrm{Ni}$ to the number produced by electrodisintegration alone. This ratio was obtained by placing a $0.217 \mathrm{~g} / \mathrm{cm}^{2} \mathrm{Ta}$ radiator in the beam ahead of the ${ }^{58} \mathrm{Ni}$ :arget. 


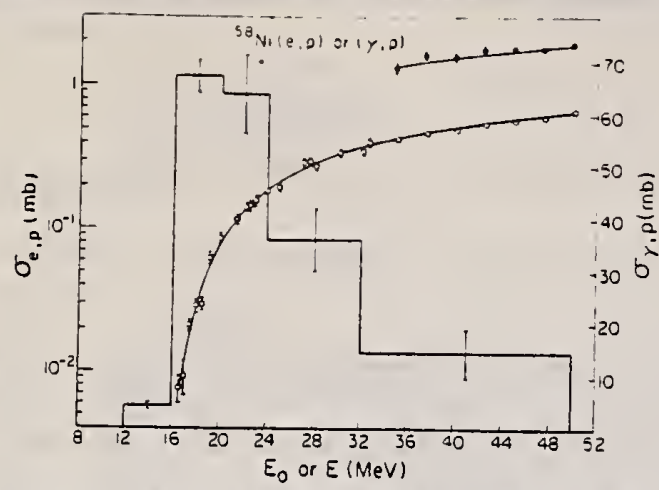

FIG. 5. The cross section (left-hand scale) for the production of protons $\sigma_{\theta, \theta}\left(E_{0}\right)$ when electrons of total energy $E_{0}$ are incident on a ${ }^{58} \mathrm{Ni}$ target (open circles). The closed circles represent the yield of protons obtained when a $0.217 \mathrm{~g} / \mathrm{cm}^{2} \mathrm{Ta}$ foil was interposed in the inciden electron beam. The latter have been corrected for the changes in geometry produced by the multiple scattering of the electrons in the radiator. The lines drawn through the points result from folding the histogram, representing the $(\gamma ; p)$ cross section (right-hand scale), with the $E 1$ virtual photon spectrum in Eq. (1) and using the Davies-Bethe-Maximon cross section in Eq. (2).

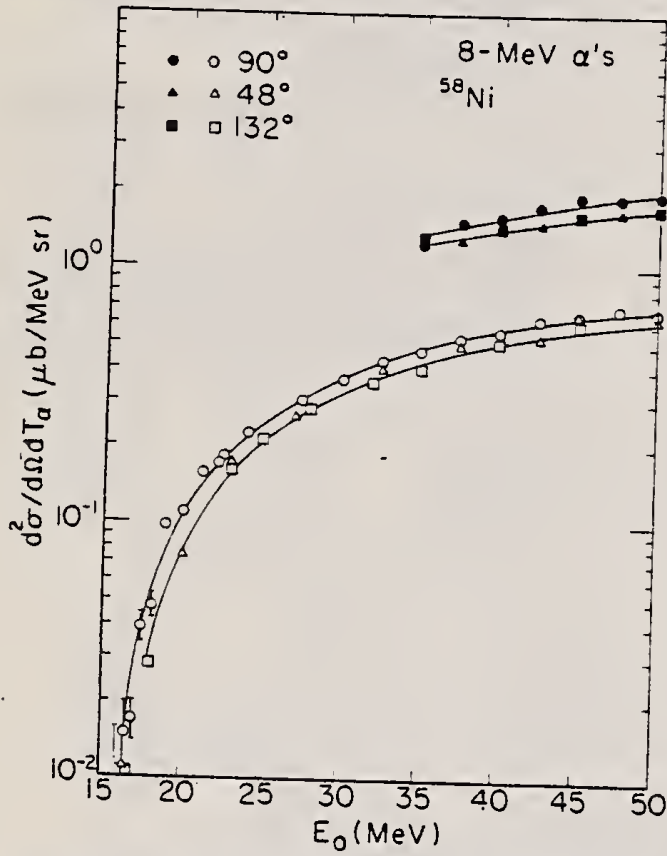

FIG. 9. The differential cross section $d^{2} \sigma / d T_{\alpha} d \Omega$ for the production of $8 \mathrm{MeV} \alpha$ particles from ${ }^{58} \mathrm{Ni}$ as a function of total incident electron energy $E_{0}$. The data were taken at three angles: $90^{\circ}$ (circles), $48^{\circ}$ (triangles), and $132^{\circ}$ (squares). The upper points refer to the yields resulting from electro plus photodisintegration when a $0.217 \mathrm{~g} / \mathrm{cm}^{2}$ tantalum radiator was interposed in the incident electron beam. The curves drawn through the points are merely to guide the eye.

TABLE IV. Percentage of the $E 1$ and $E 2$ sums in the $\alpha$ channel. $E_{1}$ sum: $60 \mathrm{~N} 2 / \mathrm{A} \mathrm{MeV} \mathrm{mb.} \Sigma_{2}$ sum: $0.22 Z^{2} A^{-1 / 3} \mu \mathrm{b} / \mathrm{MeV}$. $E 2$ bin: $14-20 \mathrm{MeV}$. Upper limits of the integrals $=50 \mathrm{MeV}$.

\begin{tabular}{ccccc}
\hline & & \multicolumn{2}{c}{$E 1$} & \multicolumn{2}{c}{$E 2$} \\
Nucleus & Schiff & D-B-M & Schiff & D-B-M \\
\hline${ }^{58} \mathrm{Ni}$ & $4.3 \pm 0.5$ & $6.0 \pm 0.6$ & $24 \pm 3$ & $15 \pm 3$ \\
${ }^{\infty} \mathrm{Ni}$ & $4.4 \pm 0.7$ & $5.4 \pm 0.7$ & $24 \pm 4$ & $15 \pm 4$ \\
${ }^{2} \mathrm{Ni}$ & $2.4 \pm 0.3$ & $2.9 \pm 0.3$ & $10 \pm 2$ & $6 \pm 2$ \\
\hline
\end{tabular}

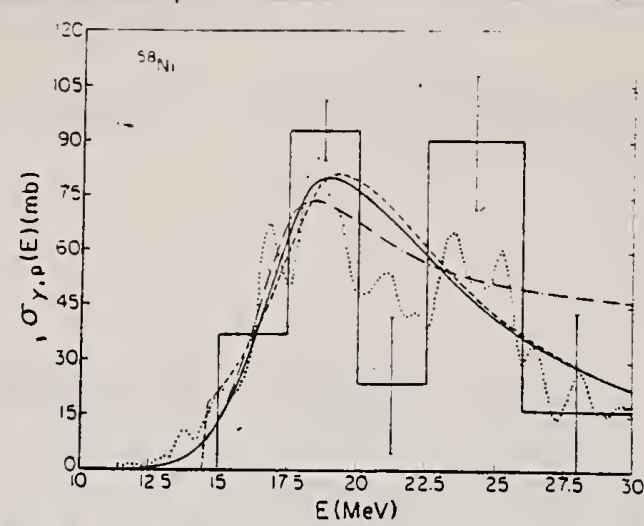

FIG. 6. Various $(\gamma, p)$ cross section shapes that fit the ${ }^{58} \mathrm{Ni}(e, p)$ data when combined with the $E 1$ virtual photon spectrum in Eq. (8). Here only the electrodisintegration dat a below $30 \mathrm{MeV}$ have been used. The dotted curve represents the data of Ref. 17 multiplied by 1.22. The dashed curve is a Lorentz line having a smaller width below the resonance eriery than above and truncated near $15 \mathrm{MeV}$. The solid curve has a Gaussian shape below and a Lorentz shape above the resonance energy. The dot-dashed curve is a Gaussian below the resonance energy and a Lorentz line plus a constant above. The histogram with $2.5 \mathrm{MeV}$ bins roughly reproduces the structure in the measured $(\gamma, p)$ cross section.

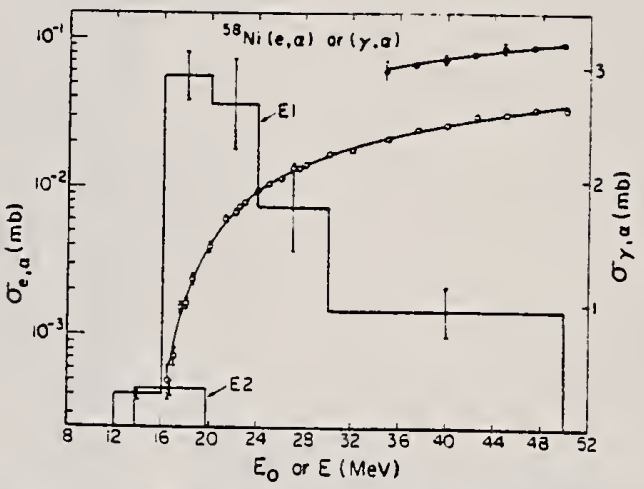

FIG. 11. The ${ }^{5 \mathrm{~N}} \mathrm{Ni}(e, \alpha)$ (open circles) cross section (left-hand scale) corrected yield (closed circles) obtained with radiator in. The curves through the points result from combining the histograms, representis: the $E 1$ and $E 2(\gamma, \alpha)$ cruss sections (right-hand scale), in Eqs. (1) and (2): ith the $E 1$ and $E 2$ virtual photon spectra! and making use of the Davies-Bethe-Maximon cross section.

TABLE V. $\sigma_{e, p}$ at $100 \mathrm{MeV}$.

\begin{tabular}{|c|c|c|c|}
\hline Nucleus & $\begin{array}{c}\sigma_{\text {a, }} \text { (meas) } \\
(\mathrm{mb})\end{array}$ & $\begin{array}{c}\sigma_{\text {eap }}(\mathrm{calc}) \\
(\mathrm{mb})\end{array}$ & $\begin{array}{c}\sigma_{c, p}(\operatorname{corr}) \\
(\mathrm{mb})\end{array}$ \\
\hline${ }^{58} \mathrm{NI}$ & $1.15 \pm 0.02$ & 1.10 & 0.98 \\
\hline${ }^{\infty} \mathrm{NI}$ & $0.50 \pm 0.01$ & 0.47 & 0.42 \\
\hline${ }^{62} \mathrm{Ni}$ & $0.24 \pm 0.01$ & 0.22 & 0.19 \\
\hline
\end{tabular}

TABLE VI. $\sigma_{e . \alpha}$ at $100 \mathrm{MeV}$.

\begin{tabular}{|c|c|c|c|}
\hline Nucleus. & $\begin{array}{c}\sigma_{\theta . \alpha} \text { (meas) } \\
(\mathrm{mb})\end{array}$ & $\begin{array}{c}\sigma_{a, \alpha}(\text { calc }) \\
(\mathrm{mb})\end{array}$ & $\begin{array}{c}\sigma_{\text {e, } \alpha(\operatorname{corr})} \\
(\mathrm{mb})\end{array}$ \\
\hline${ }^{58} \mathrm{NI}$ & $0.069 \pm 0.002$ & 0.084 & 0.063 \\
\hline$\$ \mathrm{Ni}$ & $0.063 \pm 0.002$ & 0.081 & 0.060 \\
\hline${ }^{62} \mathrm{Ni}$ & $0.033 \pm 0.001$ & 0.036 & 0.027 \\
\hline
\end{tabular}


aEF K. Ackermann, K. Bangert, U.E.P. Berg, G. Junghans, R.K.M. Schneider,

R. Stock, K. Wienhard

Nucl. Phys. A372, 1 (1981)

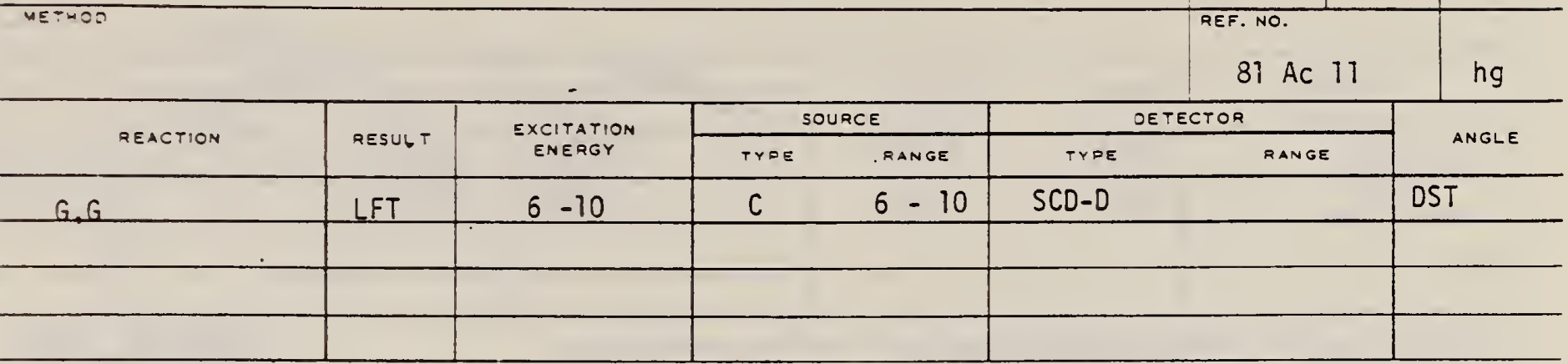

Abstract: Nuclear resonance ntorescence measurements on ${ }^{38} \mathrm{Ni}$ with bremsstrahlung and Ge(Li) detectors were performed :o searth for bound state dipole excitations. Ten fevels with ground stite desay widhs larger than $0.3 \mathrm{eV}$ have been observed in the entrgy region betwcen 6 and $10 \mathrm{MeV}$ for which precise excitation encigics. spins and lifetimes arc reported. The measured transition probabilities are compared with theoretical esumates of El and MI strength in "Ni. Since the

${ }^{3} \mathrm{~N}_{1}(\%, \%)$ cross sections were determined relative to strong transitions in $: 0 \mathrm{~Pb}^{\mathrm{P}}$. the results of a separate $: 08 \mathrm{~Pb}(; . ;)$ measurement are also presenied.

NUCLEAR REACTIONS ${ }^{13} \mathrm{~N}:(\% ;) .208 \mathrm{~Pb}(\% ; i) . E<10 \mathrm{MeV}:$ measured $E_{\mathrm{a}} . \sigma(U)$ : deduced lifetimes. spins. Enriched tarçets.

TABLE 2

Results from the ${ }^{38} \mathrm{Ni}(\%, \eta)$ experiment

\begin{tabular}{|c|c|c|c|c|}
\hline$E_{\text {al }}$ (kel) & $\frac{I\left(90^{\circ}\right)}{I\left(125^{\circ}\right)}$ & $J$ & $\left.r_{0}{ }^{\prime}\right)(e V)$ & $\left.{ }^{b}\right)([s)$ \\
\hline $6030 \pm 3$ & $0.97 \pm 0.31$ & 1 & $0.33 \pm 0.12$ & 199.113 \\
\hline$: 051 \pm 3$ & $0.70 \pm 0.23$ & 1 & $0.69 \div 0.26$ & $0.95=0.93$ \\
\hline $7: 10 \pm 3$ & $1.05 \pm 0.44$ & 1 & $0.49=0.20$ & $1.34 \div 0.93$ \\
\hline $8240 \pm 3$ & $0.66 \pm 0.09$ & 1 & $2.96 \pm 0.46$ & $0.22=0.04$ \\
\hline $8682=3$ & $0.95 \pm 0.26$ & 1 & $1.16 \pm 0.40$ & $0.57=?$ ig \\
\hline $9193 \pm 3$ & $1.20 \pm 0.43$ & 1 & $1.01=0.40$ & $065=0.13$ \\
\hline $9368 \pm 3$ & $0.80 \pm 0.31$ & 1 & $1.26 \pm 0.48$ & $0.52=0.32$ \\
\hline $9557=3$ & $1.38 \pm 0.54$ & 1 & $1.53 \pm 0.51$ & $0.43 \div 0: 9=$ \\
\hline $9670 \pm 3$ & $083 \pm 0.28$ & 1 & $1.91=0.69$ & $0.34+0.19$ \\
\hline $9843 \pm 5$ & $2.84 \pm 1.79$ & $\begin{array}{l}2 \\
1\end{array}$ & $\begin{array}{l}0.38 \pm 0.38 \\
1.79 \pm 0.91\end{array}$ & $\begin{array}{l}0.70 \div 0.70 \\
0.37 \div 0.3 \\
-0.1\end{array}$ \\
\hline
\end{tabular}

-) $\Gamma_{0}, r=1$ assumed.

) $:=h, r$ 
$81 \mathrm{Br} 2$

\begin{tabular}{|c|c|c|c|c|c|c|c|}
\hline \multirow{2}{*}{ REACTION } & \multirow{2}{*}{ RESULT $T$} & \multirow{2}{*}{$\begin{array}{l}\text { EXEITATION } \\
\text { ENERGY }\end{array}$} & \multicolumn{2}{|c|}{ SOURCE } & \multicolumn{2}{|c|}{ DETECTOR } & \multirow{2}{*}{ ANGLE } \\
\hline & & & TYPE & RANGE & TYOE & RANGE & \\
\hline$E, N$ & $A B X$ & 40,80 & D & 40,30 & $A C T-I$ & & $4 \mathrm{PI}$ \\
\hline$G, N$ & $A B Y$ & $12-80$ & $C$ & 40,80 & ACT -I & & $4 \mathrm{PI}$ \\
\hline
\end{tabular}

$\sigma_{a} \sigma$. ratuos. $F$ values and "Ni production rates are measured with 10 and $80 \mathrm{MeV}$ electron beams as a

NI 57 PROD. RATES $\sigma_{a} \sigma_{\text {. ratios. }} F$ values and "Ni production rates are measured with
function of the $Z$ vatue and thickness of bremsstrahlung converters.

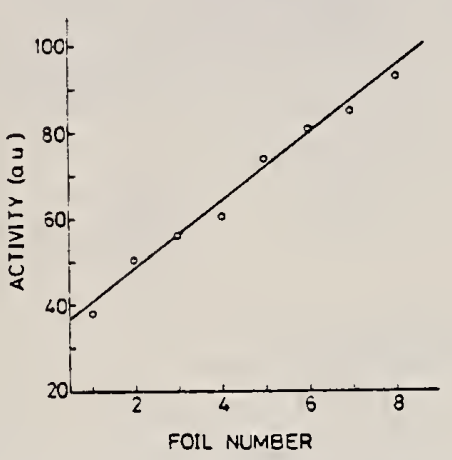

Fig. 1. ${ }^{57} \mathrm{Ni}$ activitles (arbitrary units) of a stuck of $8 \mathrm{Ni}$ fonls irradiated with $80 \mathrm{MeV}$ electrons.

TABLE 1. $F$ values for the ${ }^{58} \mathrm{Ni}^{\left(c, a_{n}\right)^{57} \mathrm{Ni} \text { reaction }}$

\begin{tabular}{|c|c|c|c|c|c|c|}
\hline \multirow{2}{*}{$\begin{array}{c}\text { Radiator } \\
\text { thickness } \\
(\mathrm{mm})\end{array}$} & \multicolumn{6}{|c|}{ Radiator } \\
\hline & $\mathrm{Ni}$ & $\mathrm{Ta}$ & $\mathrm{Pt}$ & $\mathrm{Ni}$ & $\mathrm{Ta}_{\mathrm{a}}$ & $\mathrm{Pl}$ \\
\hline $\begin{array}{l}0.1 \\
0.2 \\
0.6 \\
1.0\end{array}$ & 4.0 & $\begin{array}{l}4.2 \\
3.4\end{array}$ & $\begin{array}{l}3.1 \\
3.4\end{array}$ & 4.8 & 3.2 & $\begin{array}{l}3.6 \\
3.5\end{array}$ \\
\hline Mean & & $6 \pm$ & & & $8.8 \pm$ & \\
\hline
\end{tabular}

- $F$ is a measure for the ratio of activities produced by bremsstrahlung and by electrons. lis definition is given in the text.

\begin{tabular}{cccc}
\hline & $\sigma_{s}(\mathrm{mb})$ & $\sigma_{q}(\mathrm{mb})$ & $\sigma_{q} \sigma_{c}$ \\
\hline$+0 \mathrm{MeV}$ & 0.21 & 8.0 & 38 \\
$80 \mathrm{MeV}$ & $0.28-0.38$ & $13.4-14.0$ & $48-37$ \\
\hline
\end{tabular}

TAale 2. Activities $(\mu \mathrm{Ci})$ of Ni loils $(0.1 \mathrm{~mm})$ after $1 \mathrm{~h}$ irradiation using $50 \mu \mathrm{A}$ electrons

\begin{tabular}{|c|c|c|c|c|c|c|c|}
\hline \multicolumn{8}{|c|}{$\begin{array}{l}\text { (a) EV A. thin conterters, no deftectimy magnet } f=\mathrm{I}^{2} \\
40 \mathrm{MeV} \\
80 \mathrm{MeV}\end{array}$} \\
\hline Converter $(\mathrm{mm})$ & None & $\mathrm{Ni}$ & Tia & $\mathrm{Pi}$ & None $^{b}$ & $-\mathrm{Ni}$ & $T a$ \\
\hline $\begin{array}{l}0.0 \\
0.1 \\
0.2 \\
0.7 \\
1.0\end{array}$ & \multicolumn{2}{|r|}{50} & $\begin{array}{l}40 \\
130\end{array}$ & $\begin{array}{l}20 \\
30\end{array}$ & \multicolumn{3}{|r|}{$80 \quad 10$} \\
\hline \multicolumn{8}{|c|}{ (b) EVA. stundurd conterters } \\
\hline $\begin{array}{l}\text { Thin } \\
15\end{array}$ & \multicolumn{2}{|c|}{$\begin{array}{l}\text { Middle } \\
10\end{array}$} & \multicolumn{2}{|c|}{$\begin{array}{c}\text { Thick } \\
1\end{array}$} & $\begin{array}{l}\text { Thin } \\
55\end{array}$ & $\begin{array}{l}\text { Middle } \\
45\end{array}$ & $\begin{array}{c}\text { Thick } \\
7\end{array}$ \\
\hline \multicolumn{8}{|c|}{$\begin{array}{l}\text { (c) .hEA (LECH-haln). thin W'-conterlers with deflectung magnet } \\
\text { Converter (mm) }\end{array}$} \\
\hline $\begin{array}{l}0.05 \\
0.125 \\
0.25 \\
0.50\end{array}$ & \multicolumn{2}{|c|}{$\begin{array}{l}5^{4} \\
6 \\
7^{d} \\
9^{4}\end{array}$} & & $\begin{array}{l}4 \\
24 \\
14 \\
09\end{array}$ & $\begin{array}{l}12 \\
16 \\
19 \\
26\end{array}$ & & $\begin{array}{l}0.81 \\
0.57 \\
0.37 \\
0.25\end{array}$ \\
\hline
\end{tabular}

" $f$ is the "Ausberute Faktor" it

- No converter uas used. the given activities are mainly produced by the ${ }^{8}$ Nile. $(2) 1^{5} \mathrm{Ni}$ reaction.

"Except for the thin and middle converters used at $80 \mathrm{MeV}$. the converters are thick enough to stop all the electrons.

${ }^{4}$ Calculated. ser text. 

Rer. F.R. Metzger

Phys. Rev. 103, 983 (1956)

Method Radioactive source; photon scattering; NaI spectrometer

Ref. No.

$56 \mathrm{Me} 2$

NVB

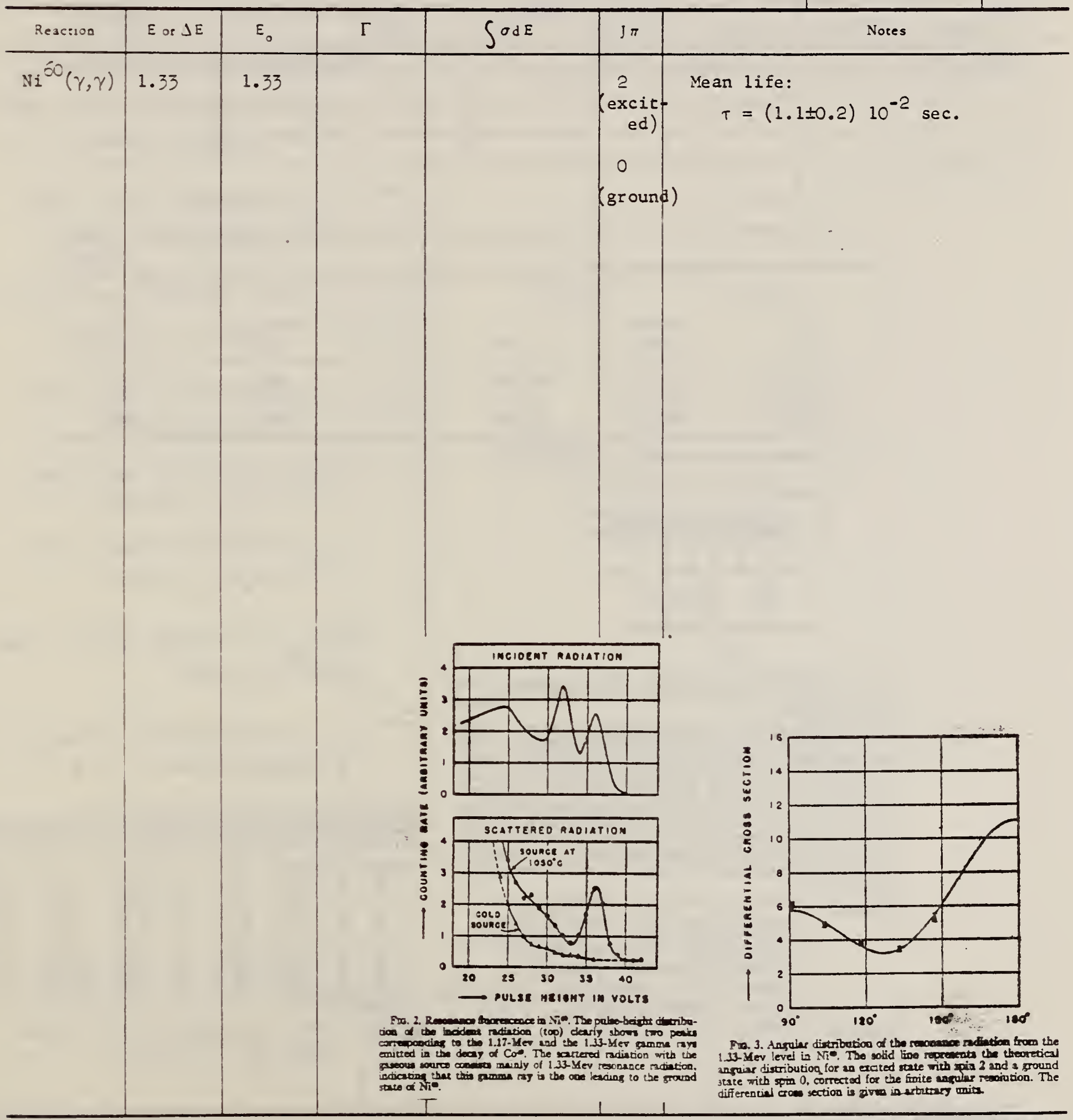


Ref. H. Crannell, R. He 1m, H. Kendall, J. Oeser, M. Yearian Phys. Rev. 123, 923 (1961)

Method. Linac; Cerenkov counter telescope

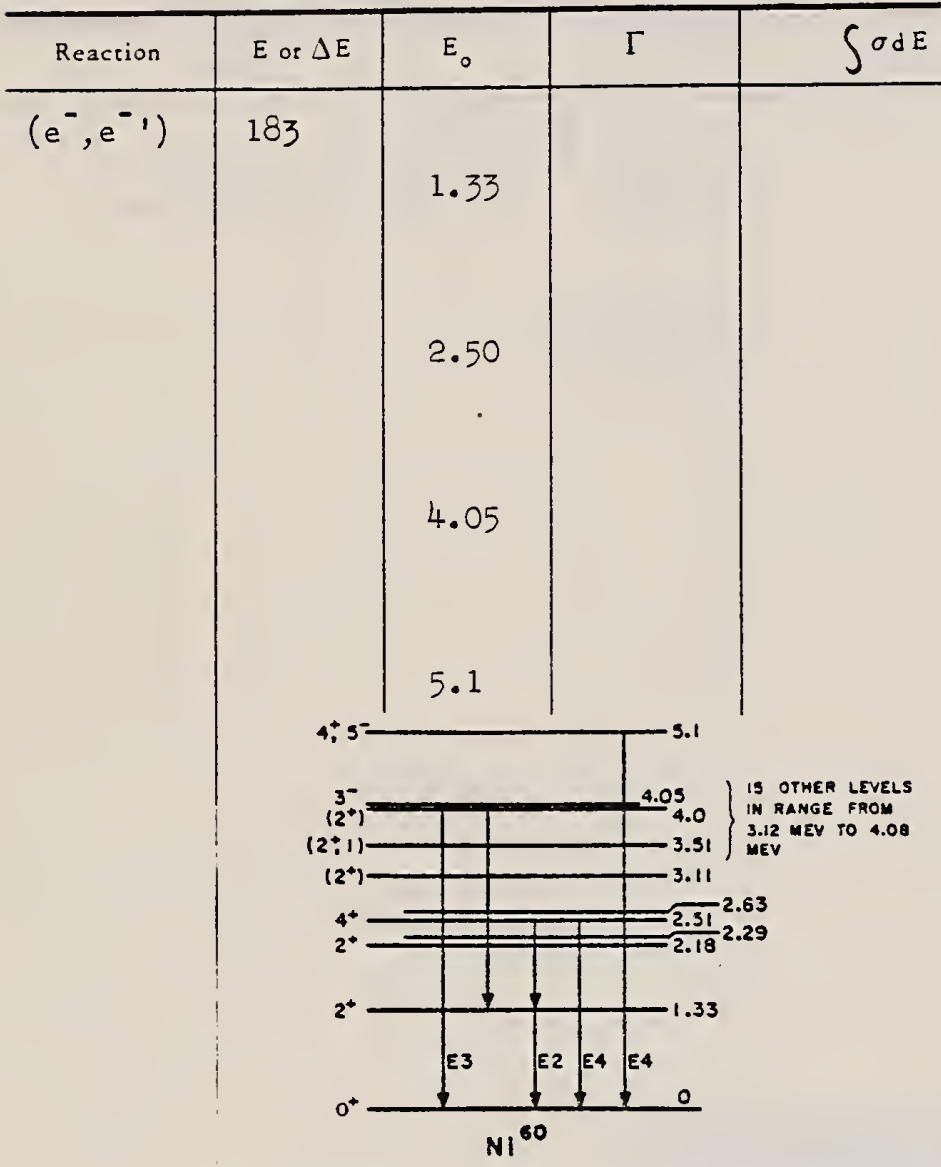

Fic. 15. Energy-level diagram for $\mathrm{Ni}^{\infty 0}$. (See caption for Fig. 13.) A number of leveis have been omitted from the diagram (see reference 16).

Fic. 13. In this and the following four figures are shown portions of the energy-level structures of the nuclei investigated in the present experiment. The iniormation is, for the most part, taken irom reference 15. The $\gamma$-ray transitions shown are those whose decay rates were determined directly in the present experiment or inferted from a knowledge of the $\gamma$-ray branching ratios in deexcitation of the nucleus. The spin and parity of each level are shown at the left, where known, and the energy of the excited states in Mev on the right. The best assignments of the transition nuitipolarities are indicated. This fgure shows the energy-level irlirture of $\mathrm{Ni}^{58}$.

Ref 15: Data on the decay schemes are taken principally from Nuclear Data Sheets, National Academy of Sciences, National Research Council U.S. Government Printing Office, Washington, D.C., 1959)

Ref 16: Mazari et al - Phys. Rev. 107, 365 $(1957)$.

$$
\begin{aligned}
& \mathrm{J} \pi \quad \text { Notes } \\
& \text { Measured } \gamma \text { transition rates, } \Gamma_{\mathrm{m}} \text { : } \\
& 2^{+} \quad \Gamma_{\mathrm{m}}=(1.27 \pm 0.15) 10^{12} \mathrm{sec}^{-1} ; \quad \text { (E2); } \\
& \mathrm{G}=\Gamma_{\mathrm{m}} / \Gamma_{\mathrm{sp}}=17.1 \pm 2.1 \\
& 4^{+} \quad \Gamma_{\mathrm{m}}=(1.3 \pm 0.24) 10^{4} \mathrm{sec}^{-1} ;\left(E_{4}\right) \text {; } \\
& G=\Gamma_{m} / \Gamma_{s p}=3.62 \pm 0.67 \\
& 3^{-} \quad \Gamma_{\mathrm{m}}=(3.64 \pm 5.8) 10^{10} \mathrm{sec}^{-1} ;(\mathrm{E} 3) \text {; } \\
& G=\Gamma_{m} / \Gamma_{s p}=3.62 \pm 0.67 \\
& \Gamma_{\mathrm{m}}=\left(7.7^{8} \pm 2.0\right) 10^{10} \mathrm{sec}^{-1} ;(\mathrm{E} 3) \text {; } \\
& \mathrm{G}=\Gamma_{\mathrm{m}} / \Gamma_{\mathrm{sp}}=7.8 \pm 2.0 \\
& \Gamma_{\mathrm{m}}=(1.58 \pm 0.24) 10^{7} \mathrm{sec}^{-1} ;\left(\mathrm{EL}_{4}\right) \text {; } \\
& \mathrm{G}=\Gamma_{\mathrm{m}} / \Gamma_{\mathrm{sp}}=4.9 \pm 0.73 \\
& \Gamma_{\mathrm{m}}=(4.66 \pm 1.5) 10^{3} \mathrm{sec}^{-1} ;\left(\mathrm{E}_{5}\right) \text {; } \\
& \mathrm{G}=\Gamma_{\mathrm{m}} / \Gamma_{\mathrm{sp}}=27 \cdot 2 \pm 8.7 \\
& \text { Fits } \mathrm{R}_{0}=1.20 \text { fermi except } 5.1 \mathrm{MeV} \\
& \text { level ( } 1.1 \text { fermi). } \\
& {\left[\Gamma_{\text {so }}=\right.\text { single-particle estimate of the }} \\
& \gamma \text { transition rate.] }
\end{aligned}
$$

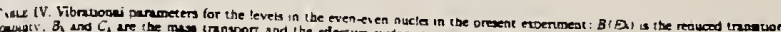

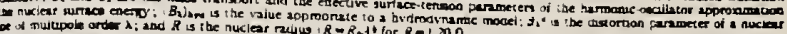

\begin{tabular}{ccccccccc} 
& & & & & \\
\hline
\end{tabular}

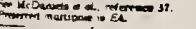

Ref 37: Crut, Sweetman, Wall - Nuclear Phys. 17, 655 (1960). 
R. B. Begzhanov and A. A. Islamov

J. Nucl. Phys. (USSR) 5, $483(1967)$

Sov. J. Nucl. Phys. 2, 339 (1907)

\begin{tabular}{|c|c|c|c|c|c|c|c|}
\hline METHOD & & & & & & $\begin{array}{l}\text { REF. NO. } \\
67 \text { Be } 5\end{array}$ & HMG \\
\hline \multirow[b]{2}{*}{ REACTION } & \multirow[b]{2}{*}{ RESUL T } & \multirow{2}{*}{$\begin{array}{c}\text { EXCITATION } \\
\text { ENERGY }\end{array}$} & \multicolumn{2}{|c|}{ SOURCE } & \multicolumn{2}{|c|}{ DETECTOR } & \multirow{2}{*}{ ANGLE } \\
\hline & & & TYPE & RANGE & TYPE & RANGE & \\
\hline$G, G$ & LFT & 1.0 & $D$ & 1.0 & NAI-D & & 120 \\
\hline & & & . & & & & \\
\hline & & & & & & & \\
\hline
\end{tabular}

$T_{Y}=(9.0 \pm 1.8) \cdot 10^{-13} \mathrm{sec} \cdot 1.33 \mathrm{MeV}$ 
M. A. Duguay, C. K. Bockelman, I. H. Curtis and R. A. Eisenstein

Phys. Rev. 10: $1259(1907)$

\begin{tabular}{|c|c|c} 
ELEM. SYM. & A & $z$ \\
Ni & 60 & 28 \\
\hline $\begin{array}{c}\text { REF. NO. } \\
67 \text { DU 1 }\end{array}$ & HMG \\
\hline
\end{tabular}

\begin{tabular}{|c|c|c|c|c|c|c|c|}
\hline \multirow{2}{*}{ REACTION } & \multirow{2}{*}{ RESULT } & \multirow{2}{*}{$\begin{array}{l}\text { EXCITAFION } \\
\text { ENERGY }\end{array}$} & \multicolumn{2}{|c|}{ SOURCE } & \multicolumn{2}{|c|}{ DETECTOR } & \multirow{2}{*}{ ANGLE } \\
\hline & & & TYPE & RANGE & TYPE & RANGE & \\
\hline$E, E /$ & FME & $1-5$ & $D$ & $45-65$ & $M A G-D$ & & DST \\
\hline & & & & & & & \\
\hline & & & & & & & \\
\hline
\end{tabular}

TABLI II. Reduced radiative transition probabilities

$B(E L)$, SEP ISOTPS and transition radii.

\begin{tabular}{|c|c|c|c|c|c|}
\hline \multicolumn{6}{|c|}{ B2 Traneiltonor } \\
\hline & $\begin{array}{l}\text { Exeivacloo } \\
\text { enersy } \\
\text { (MeVy) }\end{array}$ & $\underset{\left(\in \mathrm{CON}^{\circ}\right)}{B\left(E 2,2^{\circ}\right)}$ & $\frac{B\left(E 2.0^{*} \rightarrow 2^{+}\right)}{B\left(82,0^{*} \rightarrow 22^{+}\right) 00}$ & Bi & $\begin{array}{l}R_{w} \\
\text { (F) }\end{array}$ \\
\hline$\underset{\text { Nim }}{N}$ & $\begin{array}{l}1.452 \\
3.034 \\
3.26 \\
1.330 \\
1.172\end{array}$ & $\begin{array}{l}657 \pm 11 \\
23 \pm 3 \\
153 \pm 15 \\
345 \pm 9 \\
877 \pm 11\end{array}$ & $\begin{array}{r}10 \\
1 \\
\frac{1}{3} \\
12 \\
12\end{array}$ & $\begin{array}{l}0.177 \pm 0.003 \\
0.063 \pm 0.002 \\
0.085 \pm 0.008 \\
0.197 \pm 0.002 \\
0.197 \pm 0.001\end{array}$ & $\begin{array}{l}5.51 \\
5.51 \\
5.51 \\
3.55 \\
3.59\end{array}$ \\
\hline \multicolumn{6}{|c|}{ EJ Trandition } \\
\hline & $\begin{array}{l}\text { Excitation } \\
\text { energy } \\
\text { (MeV) }\end{array}$ & $\left.\left.B(E]_{\left(0^{*}\right.} F^{*}\right)^{-3-}\right)$ & $\frac{B\left(E 3.0^{+}-3-\right)}{B\left(E 3.0^{+} \rightarrow 3-\right)_{00}}$ & s & $\begin{array}{l}R_{\text {ur }} \\
\text { (P) }\end{array}$ \\
\hline 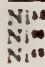 & $\begin{array}{l}4.480 \\
4.038 \\
3.75\end{array}$ & $\begin{array}{l}18600 \pm 530 \\
28100=640 \\
20100 \pm 540\end{array}$ & $\begin{array}{l}13 \\
19 \\
13\end{array}$ & $\begin{array}{l}0.203=0.005 \\
0.241 \pm 0.006 \\
0.197 \pm 0.005\end{array}$ & $\begin{array}{l}6.05 \\
6.09 \\
6.11\end{array}$ \\
\hline
\end{tabular}

- The erroro auoced for $B(E L)$ cosume the llavid drop model for the - The errors quoled for $B(E L)$ ansume the llquid-drop model for the transition charge dengity and are purely rutistical in aature. The estimate $\pm 15 \%$ for bocb $B(E L)$ and $R_{17}$. Sere tert.
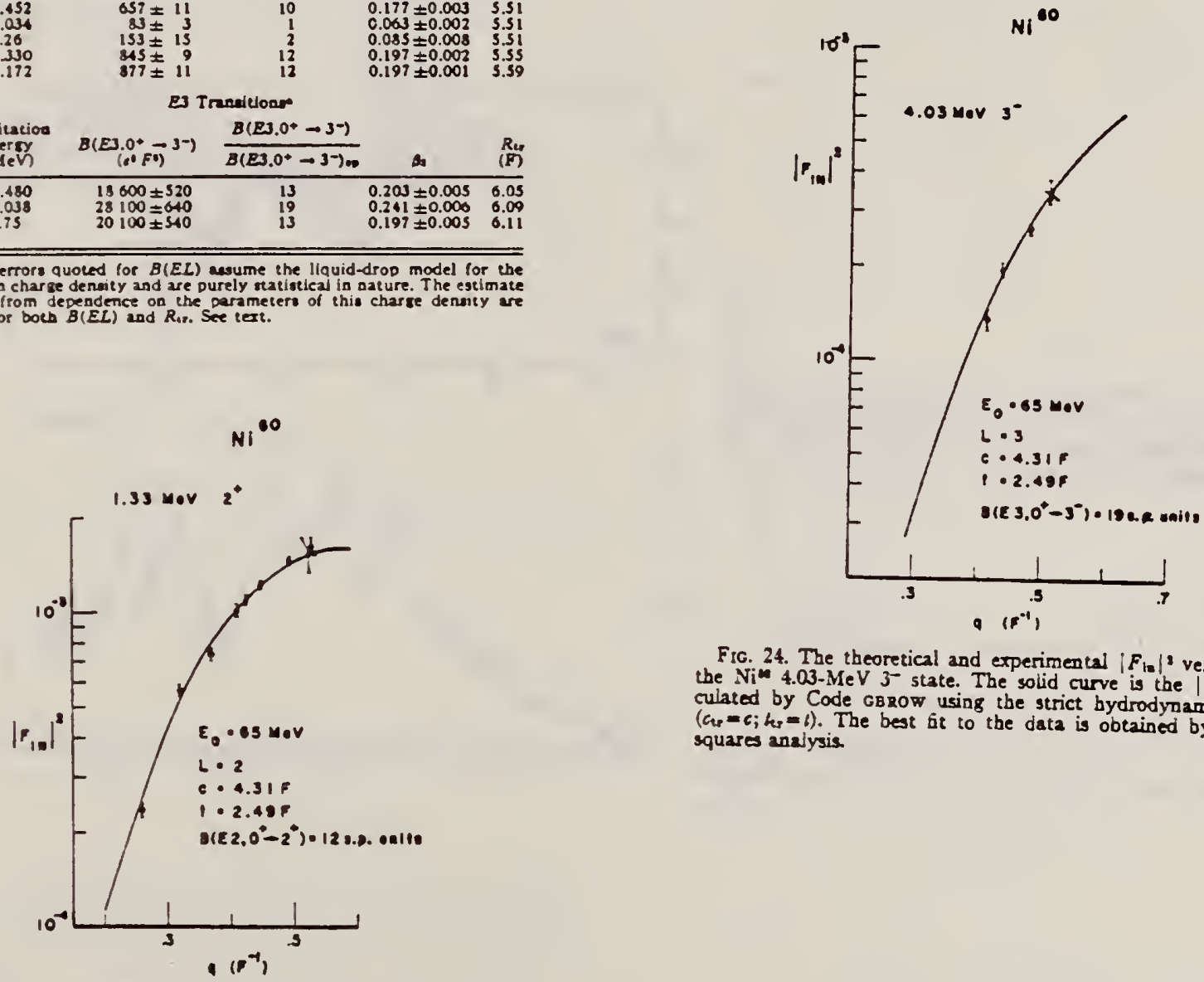

Fic. 24. The theoretical and experimental $\left|F_{10}\right|^{2}$ versus $q$ for the Niw 4.03-MeV $3^{-}$state. The solid curve is the $\left|F_{\text {bi }}\right|^{3} \mathrm{cal}$ culated by Code GBROw using the strict bydrodynamic model $\left(c_{x s}=c ; h_{s}=t\right)$. The best fit to the data is obtained by a leastsquares ansiysis.

Fro. 23. The theoretical and experimental $\left|F_{6}\right|^{2}$ versus $q$ for the Niw $1.33-\mathrm{MeV} 2^{+}$state. The solid curve is the $\left|F_{\text {to }}\right|^{2} \mathrm{Cal}$ culated by Code GBROW using the strict bydrodynemic moded $\left(h_{r}-c ; h_{r}-b\right)$. The best fit to the dats is obtained by a leastsqueres anclyeis. 
Ref. B. I. Goryachev, B. S. Ishkhanov, I. M. Kapitonov, I. M. Piskarev, V. G. Shevchenko, and O.P. Shevchenko ZhETF Pis. Red. 8 , 76 (1968)

JETP Letters $\underline{8}, 46$ (1968)

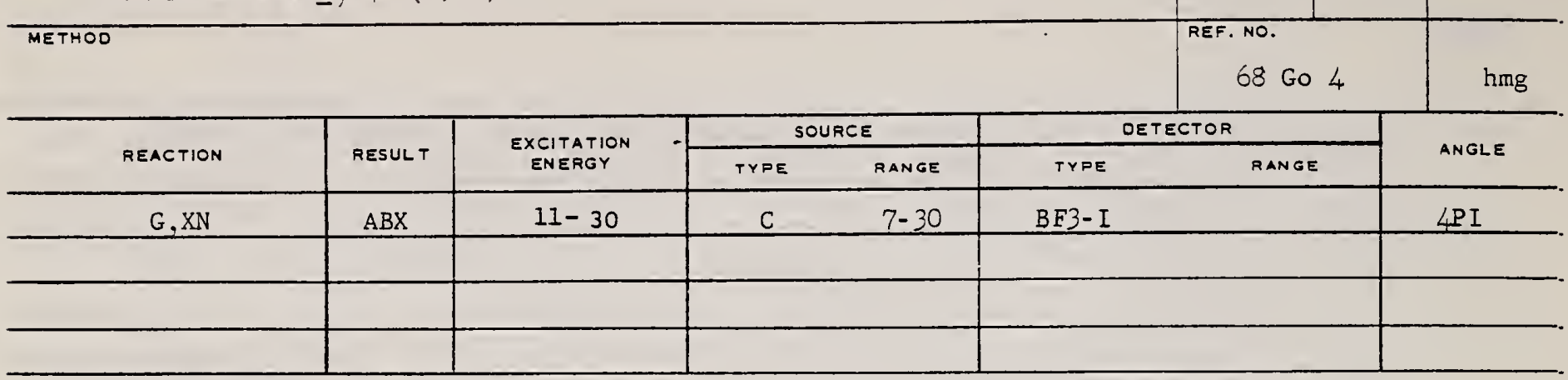

$\sigma_{\text {int }}(30 \mathrm{MeV})=800 \pm 50 \mathrm{MeV}-\mathrm{mb}$

Fig. 2. Effective cross section of the reaction $\mathrm{Ni}^{60}(Y, \mathrm{~T})$. Upper figure analyais in steps of I MeV, lower - in steps of $0.5 \mathrm{MeV}$

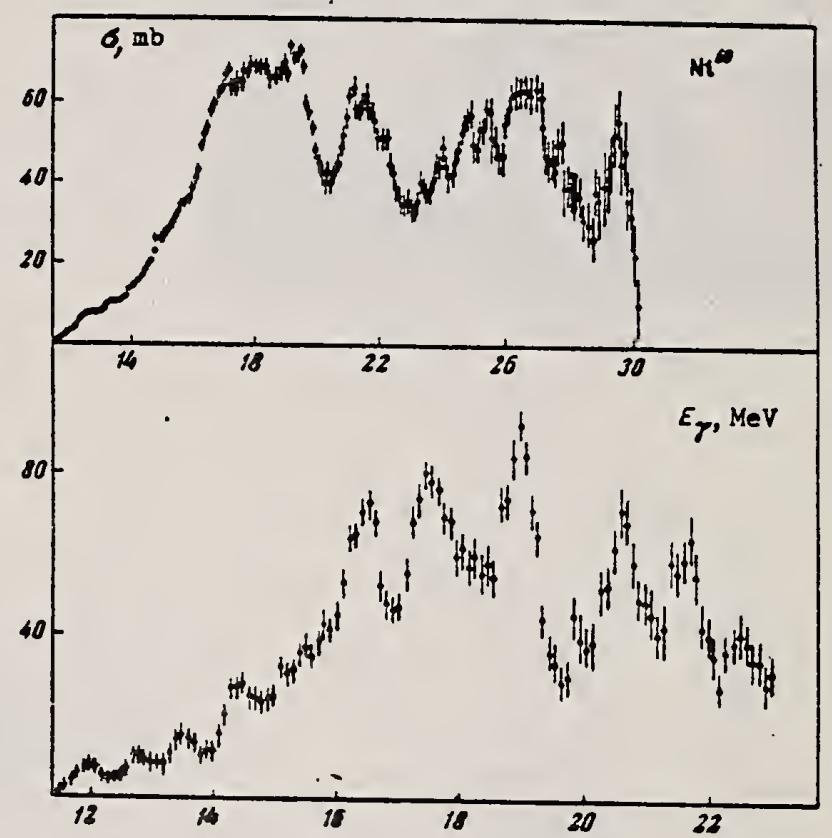




REF. NO.

\begin{tabular}{|c|c|c|c|c|c|c|c|}
\hline \multirow{2}{*}{ REACTION } & \multirow{2}{*}{ RESULT } & \multirow{2}{*}{$\begin{array}{l}\text { EXCITAION } \\
\text { ENERGY }\end{array}$} & \multicolumn{2}{|c|}{ SOURCE } & \multicolumn{2}{|c|}{ DETECTOR } & \multirow{2}{*}{ ANGLE } \\
\hline & & & TYPE & RANGE & TYPE & RANGE & \\
\hline$G, X N$ & $A B X$ & $11-25$ & $C$ & $10-25$ & BF $3-I$ & & $\angle P I$ \\
\hline \\
\hline & & & & & 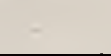 & & \\
\hline & & & & & & & \\
\hline
\end{tabular}

Table I. Integrated $(\gamma, n)$ crass sections up to 25 Mev.

\begin{tabular}{cc}
\hline \hline Isotope & $\begin{array}{c}\text { Integrated cross section } \\
(\mathrm{MeV} \text { mb })\end{array}$ \\
\hline $\mathrm{Ni}^{58}$ & $185 \pm 3$ \\
$\mathrm{Ni}^{80}$ & $482 \pm 12$ \\
Natural nickel & $283 \pm 6$ \\
$(0.262) \mathrm{N1^{60 }}+(0.679) \mathrm{Ni}$ & $252 \pm 4$ \\
Ratio of integrated cross section, $\mathrm{Ni}^{10} / \mathrm{Ni}^{50}=2.6$ \\
\hline
\end{tabular}

FIG. 1. Photoneutron cross sections of $\mathrm{Ni}^{60}$ and $\mathrm{Ni}^{58}$.
The corrected values for $(\gamma, 2 r)$ process are shown by circles.

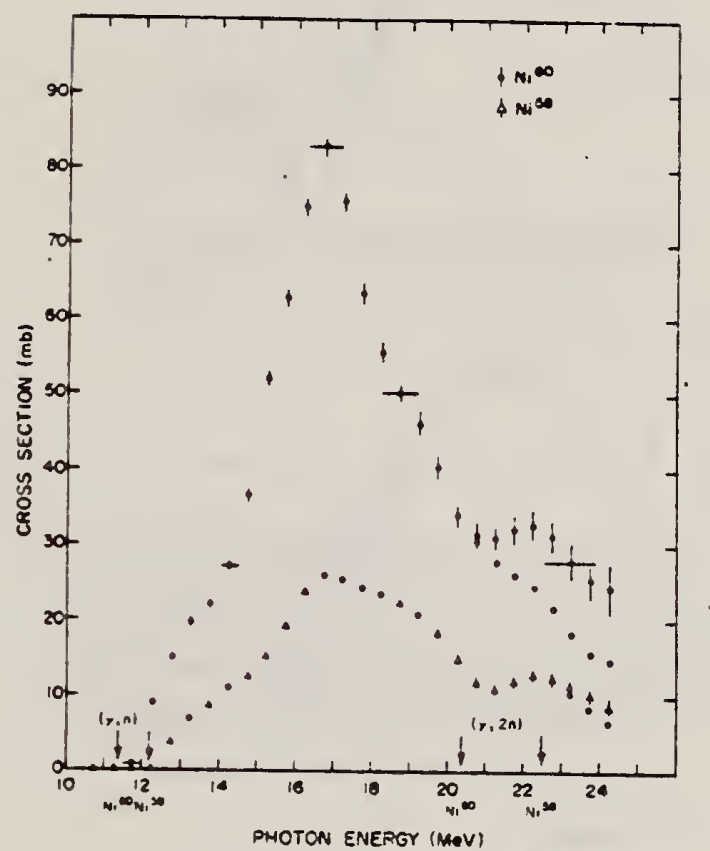


ref. V. D. Afanas'ev, N. G. Afanas'ev, I. S. Gul'karov, G. A. Savitskii, V. M. Khvastunov, N. G. Shevchenko and A. A. Khomich

Yad. Fiz. 10, 33 (1969)

Sov. J. Nucl. Phys. 10, 18 (1970)

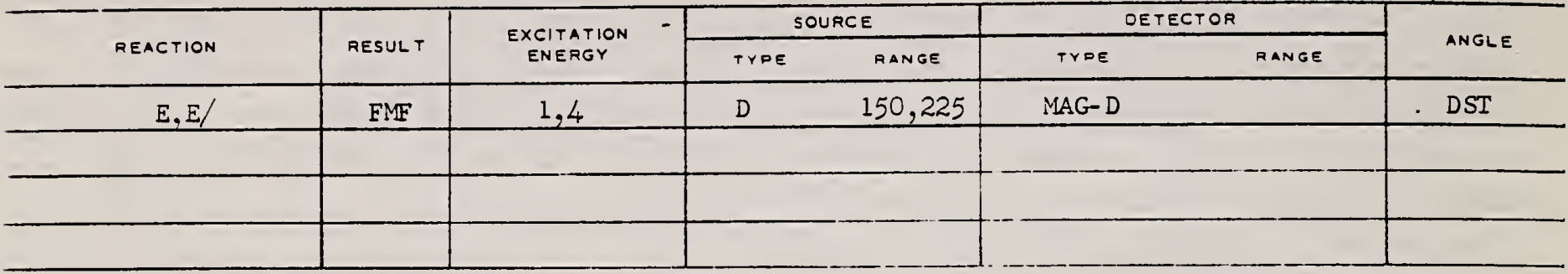

$1,4=1.33,4.04 \mathrm{MEV}$
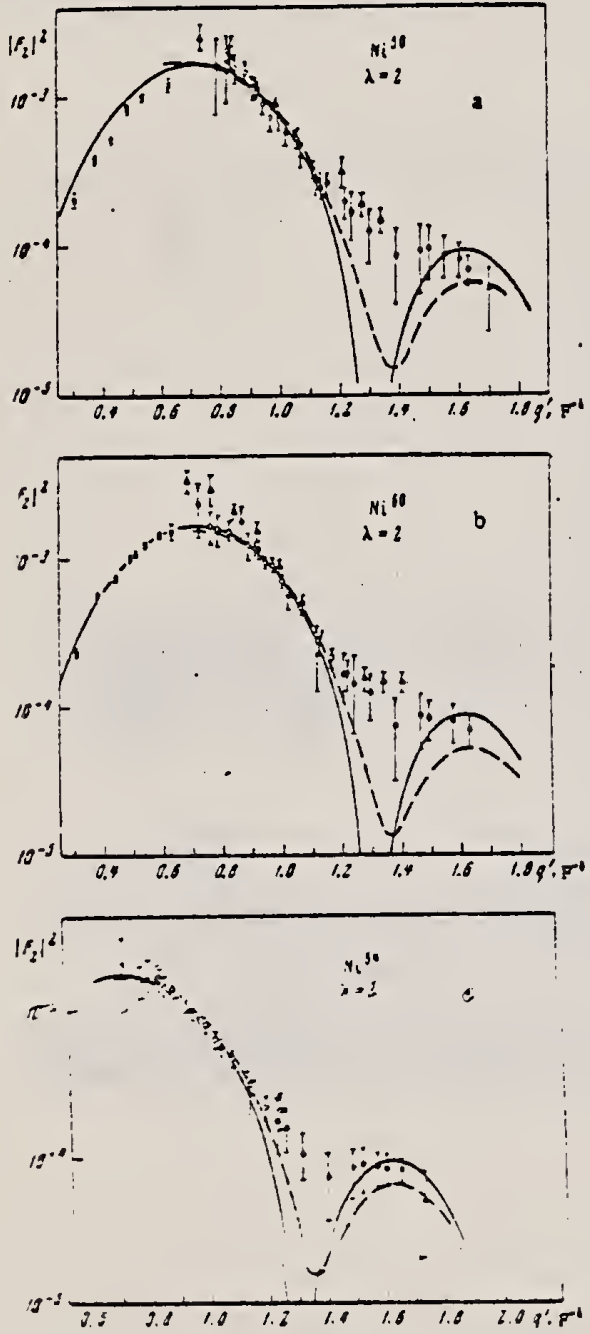

FIC. 2. Form factors for $\mathrm{E} 2$ transitions in nickel isotopes: $2-\mathrm{Ni}_{\mathrm{i}}^{30}$, $b-\mathrm{Ni}^{\infty}, \mathrm{e}-\mathrm{Ni} \mathrm{j}^{*}$. Solid eurves-Helm's model, dashed eurves-high-energy approximation. Points: 0,0 -our data for 150 and $225 \mathrm{McV}, 4-S t a n-$ ford data $["], x$-Yale data $[10 \%$.

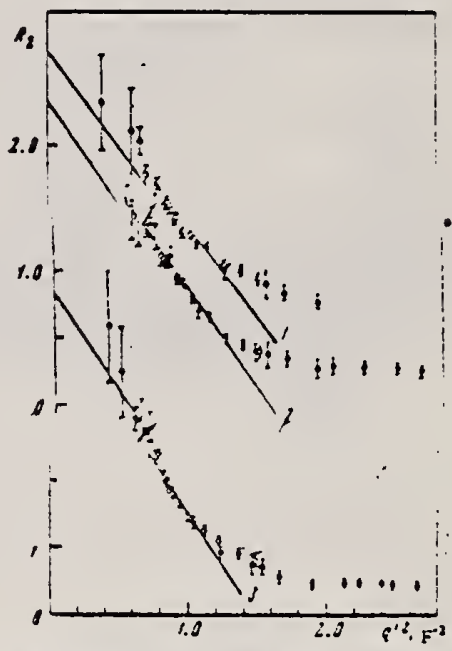

FIG. 3. $R_{\lambda}$ as a function of $q^{\prime 2}$ for E2 transitions. Straighe lines: 1$-\mathrm{Ni}^{3 \mathrm{~s}}$ (the points and straight line are raised by 0.5 ), $=-\mathrm{Ni}^{\infty}, 3-\mathrm{N} \mathrm{j}^{\text {or }}$ (the points and straight line are lowered by 1.0 ). Points: $0-150 \mathrm{MteV}$. $-225 \mathrm{MeV}$.

Table II. Reduced probabilities of quadrupole transitions in the isotopes $\mathrm{Ni}^{80,80,04}$

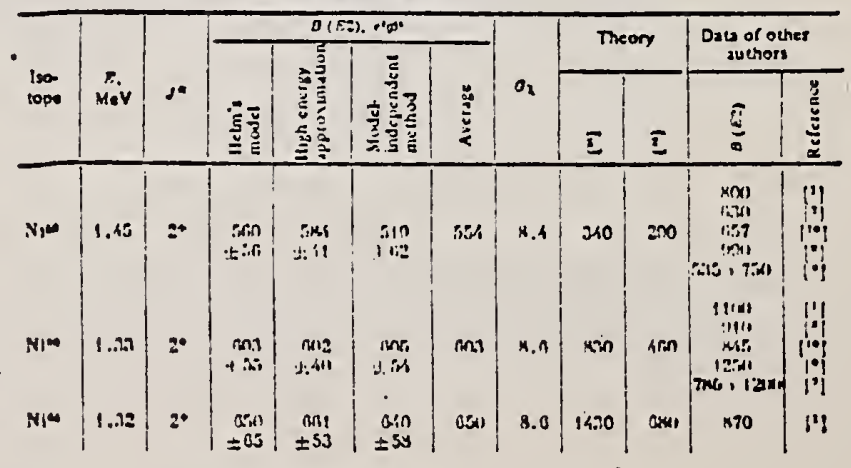


Tabie II. Recuced probabilities of octupole transitions in the isotopes $\mathrm{Ni}^{38,80, \mathrm{en}}$

\begin{tabular}{|c|c|c|c|c|c|c|c|c|}
\hline \multirow{2}{*}{101000} & \multirow{2}{*}{$\begin{array}{c}\varepsilon . \\
M e V\end{array}$} & \multirow{2}{*}{20} & \multicolumn{3}{|c|}{$D(D), e^{2} F^{0}$} & \multirow{2}{*}{$\sigma_{\lambda}$} & \multicolumn{2}{|c|}{$\begin{array}{l}\text { Datu of othes } \\
\text { authors }\end{array}$} \\
\hline & & & $\begin{array}{l}\text { Helm 's } \\
\text { model }\end{array}$ & $\begin{array}{l}\text { Modeb } \\
\text { independent } \\
\text { method }\end{array}$ & Averson & & $D(E)$ & Reference \\
\hline$N_{i}$ & 4.45 & 3 & $\begin{array}{r}13500 \\
\pm 1650\end{array}$ & $\begin{array}{r}13020 \\
=780\end{array}$ & 13100 & $\begin{array}{r}10 \\
-\end{array}$ & $\begin{array}{l}19600 \\
27000 \\
14600\end{array}$ & $\underset{l 01}{\log )}$ \\
\hline$Y: \infty$ & 4.04 & $3^{-}$ & $\begin{aligned} & 133 \mathrm{~m} \\
= & 1300\end{aligned}$ & $\begin{array}{l}13910 \\
=230\end{array}$ & 13600 & 9 & $\begin{array}{l}23100 \\
35 \mathrm{~mm} \\
29100\end{array}$ & (10) \\
\hline $\mathrm{Nim}$ & 3.53 & 5 & $\begin{array}{l}18 \mathrm{~cm} \\
\pm 1360\end{array}$ & $\begin{array}{r}17000 \\
+1100\end{array}$ & 16500 & 9.4 & & \\
\hline
\end{tabular}

Table $W$. Transit:on radii and parameters of the vibrational model of the nucleus for $\Xi 2$ and $E 3$ transitions in $\mathrm{Ni} 58,00,04$

\begin{tabular}{|c|c|c|c|c|c|c|c|}
\hline \multirow[b]{2}{*}{01000} & \multirow[b]{2}{*}{$t_{1}-1_{1}$} & \multicolumn{2}{|c|}{ Rurn? } & \multirow[b]{2}{*}{$\lambda_{0} M_{0} v$} & \multirow{2}{*}{$\frac{\begin{array}{c}9 \lambda . \\
M e V \cdot s e c\end{array}}{\pi}$} & \multirow{2}{*}{$\frac{B_{\lambda}}{\left(B N_{\text {h.d. }}\right.}$} & \multirow[b]{2}{*}{$A_{1}^{\prime}$} \\
\hline & & $\begin{array}{l}\text { Our } \\
\text { result }\end{array}$ & : $\cdots$ & & & & \\
\hline \multirow{3}{*}{ Sim } & $a=2$ & $\begin{array}{r}4.95 \\
\pm 0.21\end{array}$ & 5.51 & $\begin{array}{r}173 \\
\pm 19\end{array}$ & $\begin{array}{r}82 \\
=0\end{array}$ & $\begin{array}{r}20.0 \\
=2.2\end{array}$ & $\begin{array}{r}0.115 \\
=0.0 \mathrm{~m}\end{array}$ \\
\hline & $a-3$ & $\begin{array}{r}5.13 \\
\pm 0.11\end{array}$ & 8.05 & $\begin{aligned} & 5.9 n \\
\pm & 130\end{aligned}$ & $\begin{array}{c}77 \\
=3\end{array}$ & $\begin{array}{r}19 \\
\pm 2\end{array}$ & $\begin{aligned} & 0.1 \mathrm{n} \\
= & 0.006\end{aligned}$ \\
\hline & $a-2$ & $\begin{array}{r}4.92 \\
\pm 0.15\end{array}$ & 3.55 & $\begin{array}{r}153 \\
=17\end{array}$ & $\begin{array}{r}88 \\
\pm 9\end{array}$ & $\begin{array}{l}20 \\
=2.2\end{array}$ & $\begin{array}{r}0.118 \\
=0.015\end{array}$ \\
\hline \multirow[t]{2}{*}{, vime } & $a-3$ & $\begin{array}{r}5.21 \\
=0.10\end{array}$ & 8.03 & 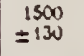 & $\begin{array}{l}92 \\
\pm 8\end{array}$ & $\begin{array}{l}13.5 \\
\pm 1.8\end{array}$ & $\begin{aligned} 0.097 \\
=0 . \text { uns }\end{aligned}$ \\
\hline & $a-2$ & $\begin{array}{r}4.99 \\
=0.13\end{array}$ & - & $\begin{aligned} & 1 / 3 \\
&=16\end{aligned}$ & $\begin{array}{r}23 \\
=9\end{array}$ & $\begin{array}{r}19.3 \\
=1.9\end{array}$ & $\begin{aligned} & 0.15 n \\
= & 0.14 n\end{aligned}$ \\
\hline$N_{0} \infty$ & $a \rightarrow 3$ & $\begin{array}{r}5.34 \\
=0.11\end{array}$ & - & $\begin{array}{r}116 n \\
=130\end{array}$ & $=12$ & $\begin{array}{r}17.8 \\
=2.2\end{array}$ & $\begin{array}{l}0.1 n \pi \\
=0.406\end{array}$ \\
\hline
\end{tabular}

"(B)h.e is the ascillasion parnmeter of the nucleus, oblained with a hydrody. namveal model.

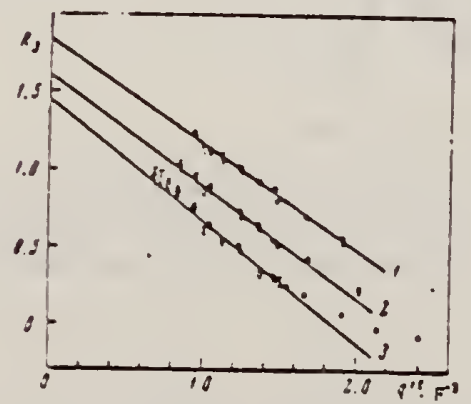

FIC. 5. Analysis of $\ 3$ transitions by the model-independent method. Sersicht lines: $1-\mathrm{Ni}^{3 \mathrm{~s}}$ (the data and straight line have been raised by 0.5 ) :-Nio, $3-\mathrm{Ni}^{\infty}$ (the data and straight line have been lowered by 0.5 ).

Poin:s: $0-150 \mathrm{MeV}, 0-225 \mathrm{MeV}$.

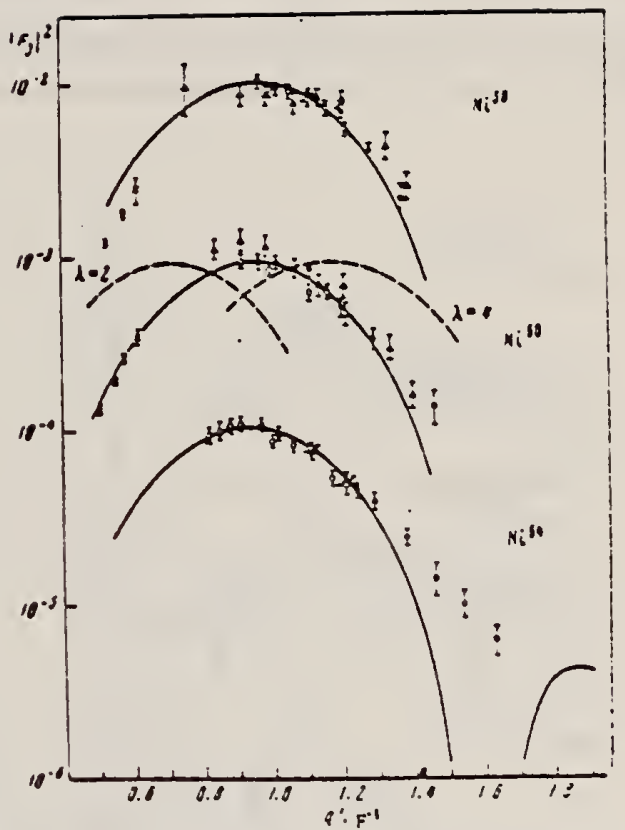

FIC. 4. Form factors for $E 3$ transitions in the isotones $N^{\text {ss }}$ (the experimental data and eurve are nutitiplied by $: 0$ ), $\lambda^{\infty}, \lambda^{\infty}$, (the exper mental data and eurve are divided by 10). The solid eunies sensesint the form facior calculated by Heim's modsi with $\lambda=j$, and the dastivd itives the form factor calculated by :he same model for $\lambda=2$ and $\lambda=4$. Poin:s:

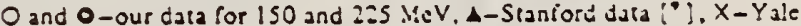
data $(10 \%$. 
REF. B.I. Goryachev, B.'S. Ishkhanov, I.M. Kapitonov, I.M. Piskarev, V.G. Shevchenko, and O.P. Shevchenko Yad. Fiz. 10, 252 (1969)

Sov. J. Nucl. Phys. 11,141 (1970)

69 Go 2

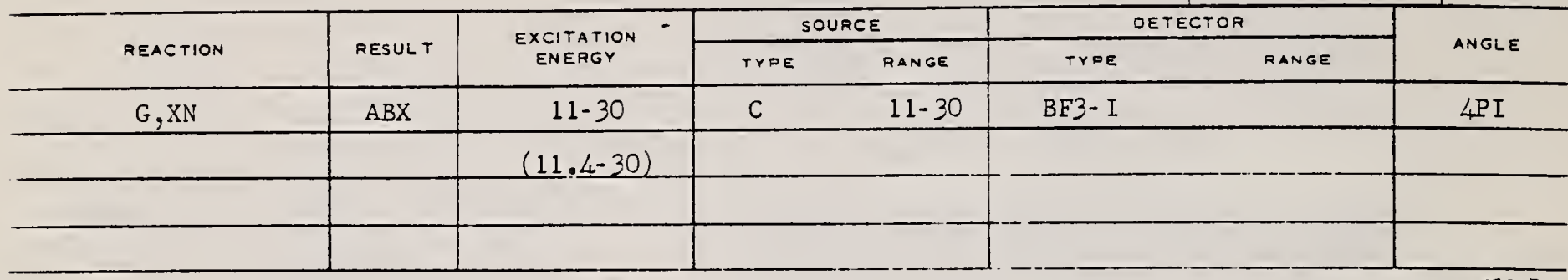

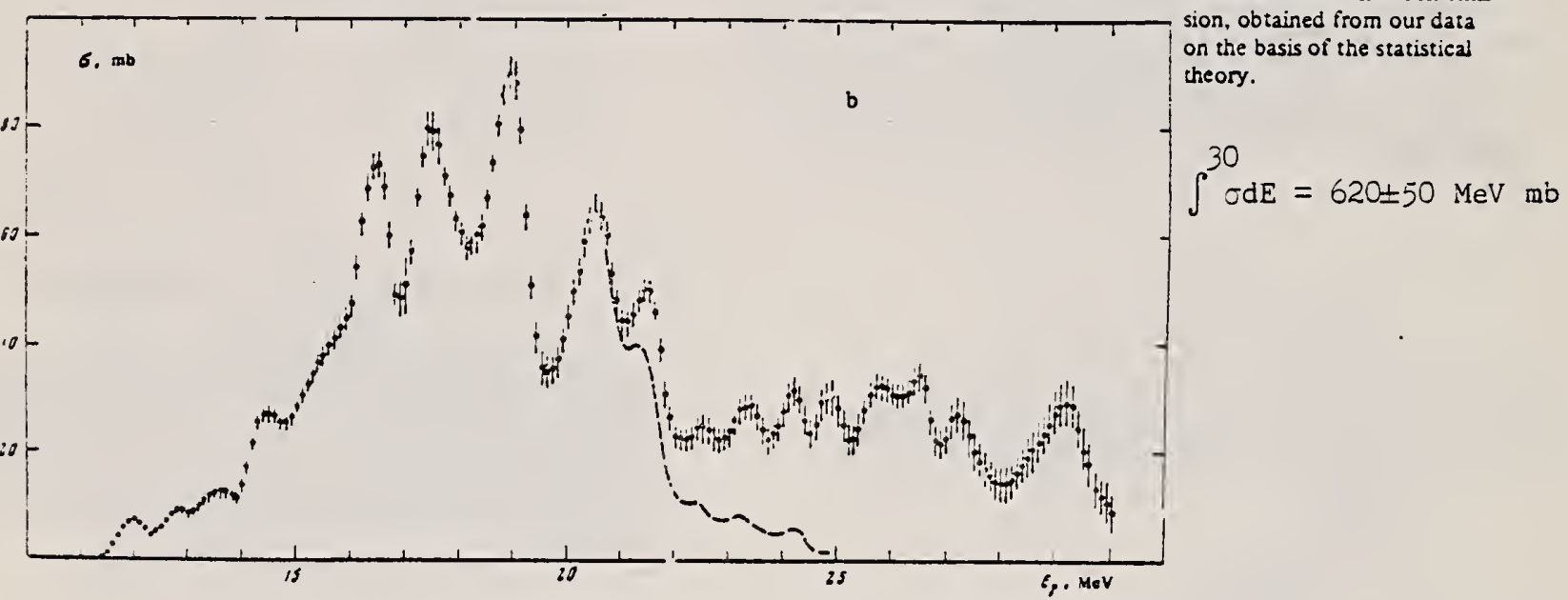

FIG. 1. Cross section of the photoneutron reaction for $\mathrm{Ni}^{58}$ (a) and $\mathrm{Ni}^{60}(\mathrm{~b})$. The dashed line shows the cross section of the reaction $(\gamma, n)$ above the threshold of two-neutson emission, obtained from our data on the basis of the statistical heory. $\int \sigma d E=620 \pm 50 \mathrm{MeV}$ mb 


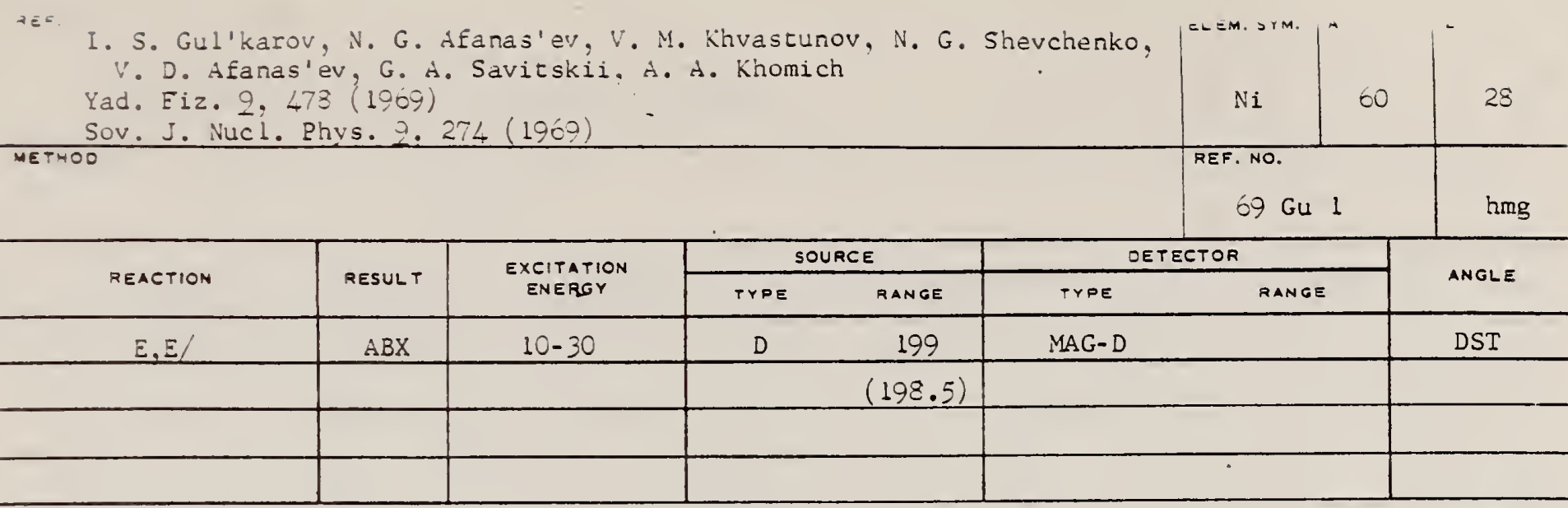

See paper for summary of other data.

FMF

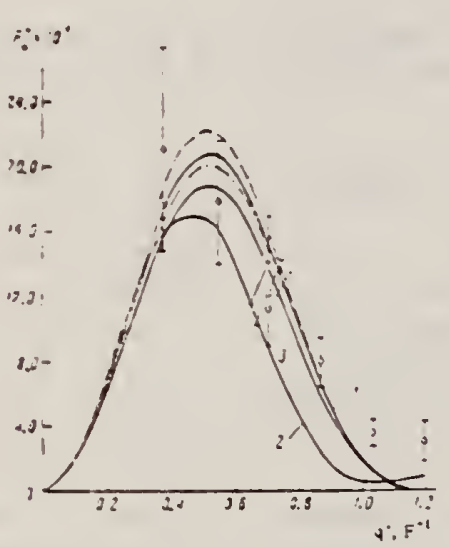

FIC. 2. Giant-resonance form iactor as a furction of momentum trarsier. Pounts: O-data for $\mathrm{Ni}^{\infty}, \mathrm{x}$-ior $\mathrm{Ni}^{64}, \square-$ ior $\mathrm{Ni}^{33}$. The dashed curve, curve I, and the dot-dash cure were olculated irom formula (2) for the nuclei $. \mathrm{vi}^{34}+\mathrm{s}^{\mathrm{s}}$ respectively, with $\mathrm{k}=19 \mathrm{\textrm {NeV }}$. Curve 3 was alestated from the same iomula for $\mathrm{Ni}^{\infty}$ with $k=21 \mathrm{MeV}$. Curve $?$ is a cleulation accordisg to the Coldhaber-Teller collective model.

Tabla I. Absolute differential cross sections for inelastic scattering of electoons witi excitation of the giant resonance in nickel isotopes

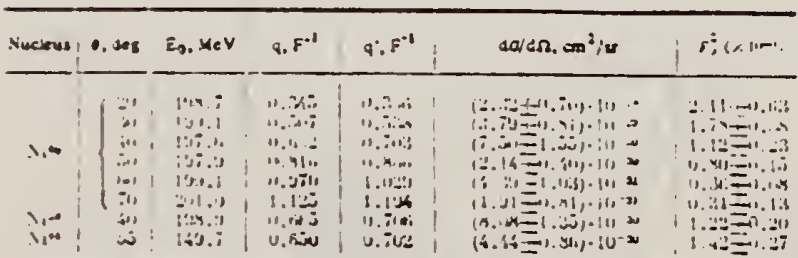

Vole. The limrse of nowgration of the ppectre are from 10 to $30 \mathrm{MeV}$.

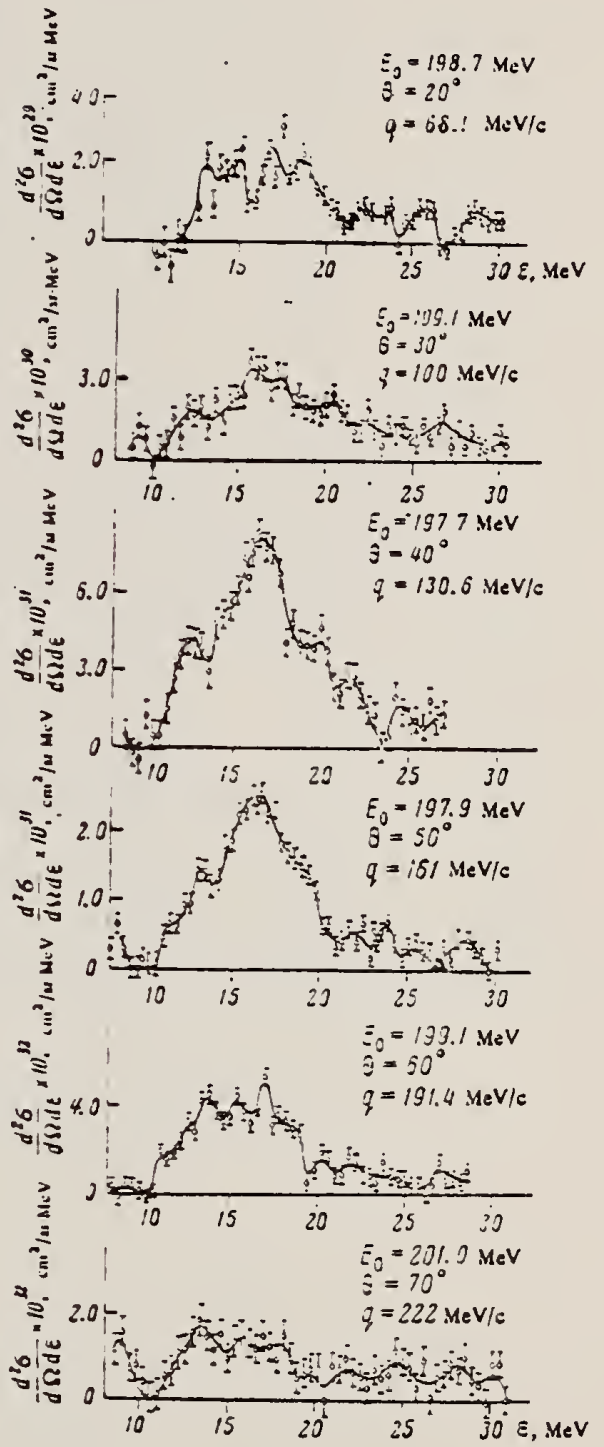

FKC. 1. Energy spectra of electrons inciustically scattered by $\mathrm{Ni}^{60}$ obtained after subtraction of the asdiation tail trom the elastic and inelastic peaks. $\epsilon$ is the excitation energy. The curves tinrough the experimental poisis have been drawn visually.

U.S. DEPARTMENT OF COMMERCE NATIONAL BUREAU OF STANDARDS [over] 

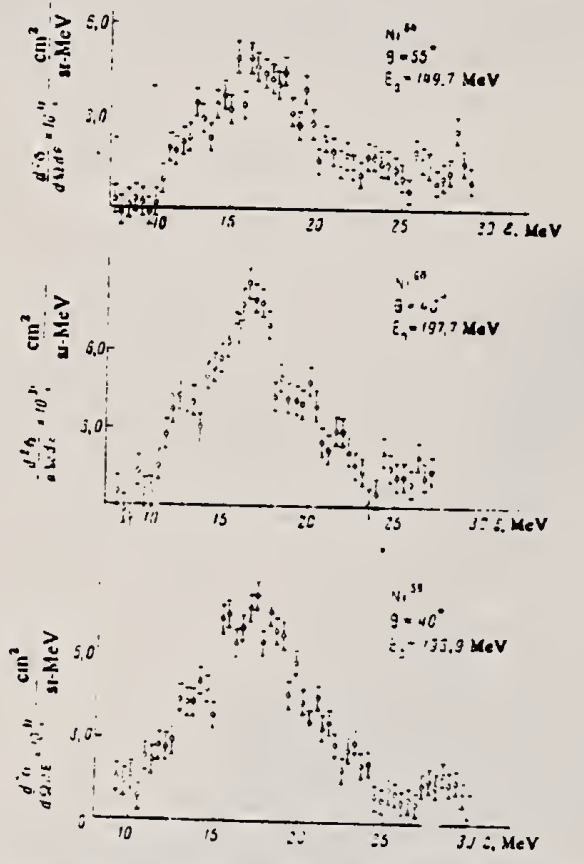

FIG. 3. Energy spectra of electrons inelastically scattered by the isotopes $\mathrm{Ni}^{64,60,58}$. All three spectra were measured at the same value of momentum transfer. 
D. G. Owen, E. G. Muirhead, B. M. Spicer

Contributions Montreal Conference 349 (1969)

\begin{tabular}{|c|c|c|c|c|c|c|c|}
\hline \multirow{2}{*}{ REACTION } & \multirow{2}{*}{ RESULT } & \multirow{2}{*}{$\begin{array}{l}\text { EXCITATION } \\
\text { ENERGY }\end{array}$} & \multicolumn{2}{|c|}{ SOURCE } & \multicolumn{2}{|c|}{ DETECTOR } & \multirow{2}{*}{ ANGLE } \\
\hline & & & TYPE & RANGE & TYPE & RANGE & \\
\hline G.XN & $\mathrm{ABX}$ & $12-25$ & $C$ & $12-25$ & BF3-I & & $4 P I$ \\
\hline & & & & & & & \\
\hline & & & & & & & \\
\hline & & & & & & & \\
\hline
\end{tabular}

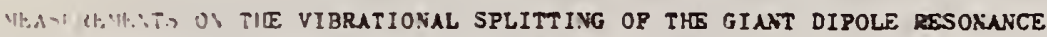

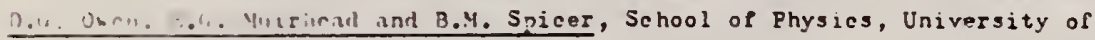
Yollinurne, Parinille, Vietoria 3052 , Australia.

The plinenueutron yicld curves for ${ }^{58} \mathrm{Ni}$ and ${ }^{60} \mathrm{Ni}$ have been measured in $1 / .1 \mathrm{MeV}$ iteps from thresliold to $24 \mathrm{MrV}$, the enutrons being detected in a llalpern-type $B B_{3}$ counter system. The cross sections vere obtained from the yicld curves by the Leiss-Penfold matrix inversion method. A correction, bascl on the statistical theory of nuclear reactions, has been made for multiple neutron emission. The derived cross sections are show in figures 1 and 2 .

Tlie dotend curves on the figures are the fits to the dipole sicecrum, using Lorentz line shapes, and based on the dynamic collective molle of the glant resnnaner (Huber, priv. comm. 1967), in which quadrupole urfis " vibrations are counled to the dipole vibration. Tlie poor fit it low cnirgin: is attributed to neglect of single particle effects.

Also shown in figure $l$ is the result of the collective corrclations calevlarion for 60 Ni (Seaborn, Drechsel, Arenhovel and Greiner, Pliys. Lett. 23 (1966) 576). Here the suriace vibrations are coupled to particic-nole dipole states, not just the dipole state. This calculation for the closed-subshell nucleus ${ }^{60} \mathrm{Ni}$ yiclds the result show in the full curve of figure 1. The agrcement $w$ th experiment is very much improved, indicating the importance of including single particle effects.

The similarity of low energy spectra for $38 \mathrm{Ni}$ and $60 \mathrm{Ni}$, coupled vith the fact that the same single particle states are filled in the ground state, leads to the expectation that the giant resonance structure vill be similar for the two isotopes. This is in pact observed.

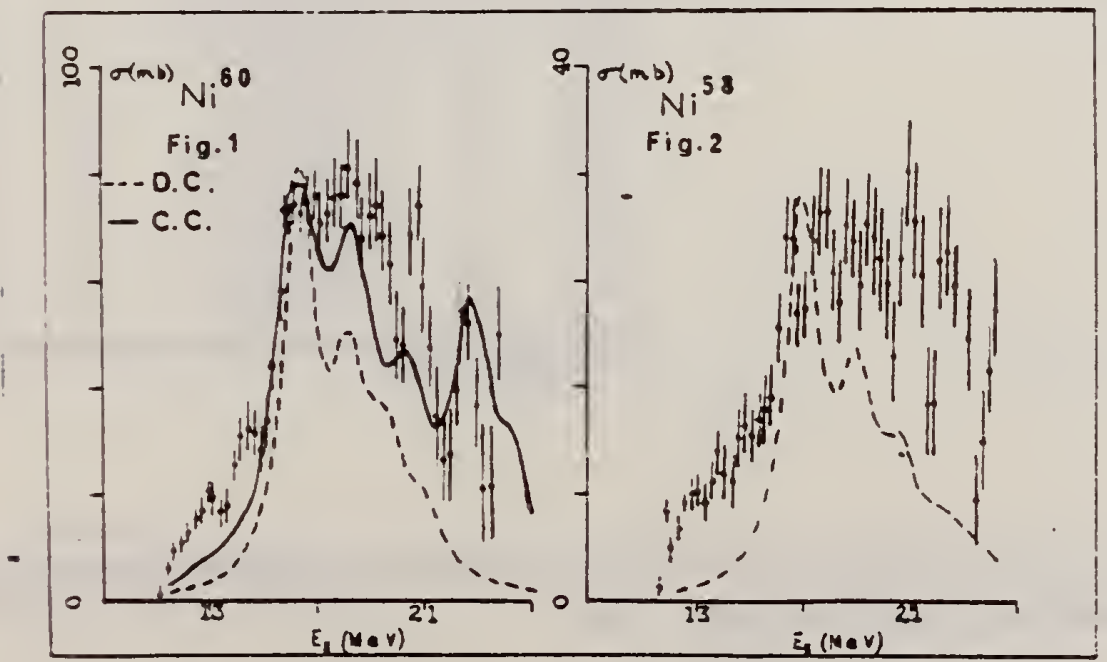


Y. Torizuka, Y. Kojima, M. Oyamada, K. Nakahara, K. Sugiyama,

T. Terasawa, K. Itoh, A. Yamaguchi, and M. Kimura

Phys. Rev. 185, 1499 (1969)

(Page 1 of 3 )

69 To 3

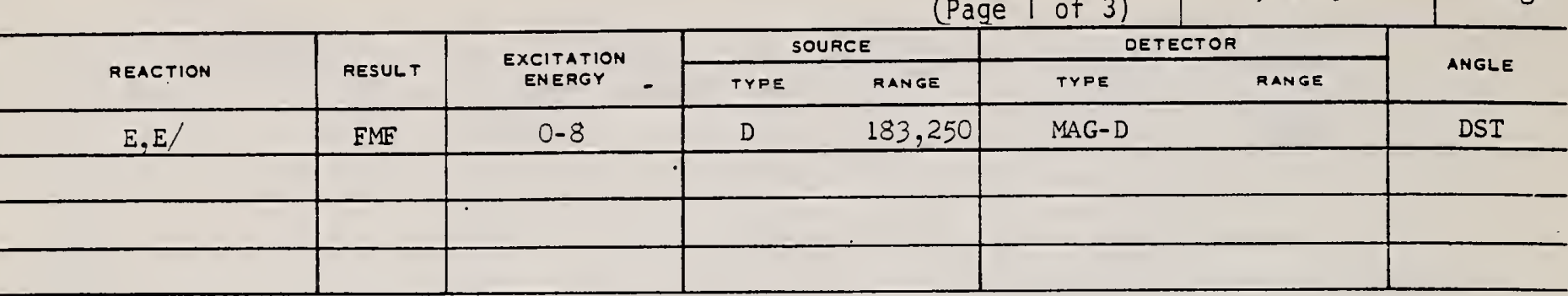

TABLE I. Inelastic form factors for " $\mathrm{Ni}$ at the incident energy of $183 \mathrm{MeV}$.

\begin{tabular}{|c|c|c|c|c|c|c|c|c|}
\hline$\underset{(\text { MeV }}{E}$ & $\mathrm{~J}$ & $35^{\circ}$ & $45^{\circ}$ & $55^{\circ}$ & $\left.\left.10^{4}\right|_{5^{\circ}} 8\right|^{2}$ & $75^{\circ}$ & $85^{\circ}$ & $95^{\circ}$ \\
\hline $\begin{array}{l}1.33 \\
2.16 \\
2.50 \\
3.13 \\
3.67 \\
4.04 \\
4.35 \\
5.05\end{array}$ & $\begin{array}{l}2^{+} \\
2^{+} \\
4^{+} \\
4^{+} \\
4^{+} \\
3^{-} \\
\left(2^{+}, 4^{+}\right) \\
4^{+}, 6^{+}\end{array}$ & $\begin{array}{l}0.18 \pm 0.14 \\
4.25 \pm 0.17 \\
1.18 \pm 0.23\end{array}$ & $\begin{array}{c}19.5 \pm 0.10 \\
0.30 \pm 0.15 \\
0.70 \pm 0.17 \\
0.20 \pm 0.14 \\
0.24 \pm 0.07 \\
8.48 \pm 0.24 \\
1.70=0.34 \\
0.82=0.08\end{array}$ & $\begin{array}{c}14.7 \pm 0.71 \\
0.43 \pm 0.12 \\
1.18 \pm 0.13 \\
0.23 \pm 0.12 \\
0.62 \pm 0.12 \\
10.3 \pm 0.05 \\
1.16 \pm 0.23 \\
1.4 \pm 0.13\end{array}$ & \multirow{2}{*}{$\begin{array}{l}4.16 \pm 0.17 \\
0.023 \pm 0.06 \\
1.35 \pm 0.13 \\
0.37 \pm 0.07 \\
0.69 \pm 0.07 \\
7.97 \pm 0.19 \\
0.90 \pm 0.11 \\
1.91 \pm 0.18 \\
0.22 \pm 0.18 \\
1.35 \pm 0.14 \\
1.25 \pm 0.12 \\
1.21 \pm 0.13\end{array}$} & \multirow{2}{*}{$\begin{array}{l}0.58 \pm 0.11 \\
0.045 \pm 0.03 \\
1.60 \pm 0.28 \\
0.37 \pm 0.08 \\
0.89 \pm 0.19 \\
4.58 \pm 0.32 \\
0.73 \pm 0.13 \\
2.29 \pm 0.24 \\
0.50 \pm 0.24 \\
0.92 \pm 0.14 \\
0.82 \pm 0.13 \\
1.24 \pm 0.16\end{array}$} & \multirow{2}{*}{$\begin{array}{l}0.55 \pm 0.22 \\
0.038 \pm 0.01 \\
1.14 \pm 0.24 \\
0.40 \pm 0.08 \\
1.03 \pm 0.24 \\
2.35 \pm 0.21 \\
0.64 \pm 0.12 \\
2.46 \pm 0.22 \\
1.10 \pm 0.20 \\
0.50 \pm 0.10 \\
0.84 \pm 0.13 \\
0.70 \pm 0.13\end{array}$} & $\begin{array}{l}1.22 \pm 0.13 \\
0.47 \pm 0.12 \\
0.41 \pm 0.12 \\
0.49 \pm 0.12 \\
0.33 \pm 0.09 \\
2.19 \pm 0.21\end{array}$ \\
\hline $\begin{array}{l}6.20 \\
6.85 \\
7.05\end{array}$ & $(2+, 5)$ & $\begin{array}{l}1.29 \pm 0.15 \\
0.83 \pm 0.12 \\
1.04 \pm 0.12\end{array}$ & $\begin{array}{l}1.45 \pm 0.08 \\
1.21 \pm 0.07 \\
1.33 \pm 0.08\end{array}$ & $\begin{array}{l}1.78 \pm 0.17 \\
1.20 \pm 0.15 \\
1.49 \pm 0.14\end{array}$ & & & & $\begin{array}{l}0.44 \pm 0.18 \\
0.78 \pm 0.13 \\
0.53 \pm 0.10\end{array}$ \\
\hline
\end{tabular}

TABLE II. Inelastic form factors for ${ }^{\infty} \mathrm{Ni}$ at the incident energy of $250 \mathrm{MeV}$.

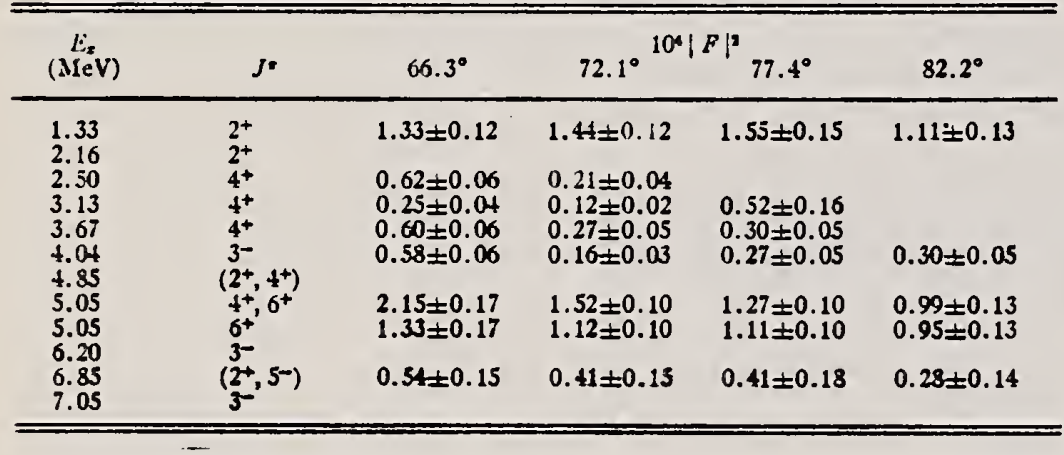

$\underline{B(E L), J-P I}$

TAale III. Summary of spins, parities, and reduced transition probabilities in ${ }^{-N i}$ extracted from present $\left(s, \sigma^{\prime}\right)$ raction.

\begin{tabular}{ccccc}
\hline $\begin{array}{c}E \\
(\mathrm{MeV})\end{array}$ & $J^{+}$ & $B(E L)\left(A F^{2 L}\right)$ & $G\left(B / B_{m}\right)$ & $R(F)$ \\
\hline 1.33 & $2^{+}$ & $(7.66 \pm 0.77) \times 10^{+}$ & 11.0 & 4.73 \\
2.16 & $2^{+}$ & $(1.5 \pm 0.4) \times 10^{3}$ & 0.2 & 4.50 \\
2.50 & $4^{+}$ & $(1.50 \pm 0.30) \times 10^{+}$ & 4.8 & 4.96 \\
3.13 & $4^{+}$ & $(3.09 \pm 0.62) \times 10^{4}$ & 1.0 & 4.73 \\
3.67 & $4^{+}$ & $(5.67 \pm 1.13) \times 10^{4}$ & 1.8 & 4.62 \\
4.04 & $3^{-}$ & $(1.65 \pm 0.25) \times 10^{4}$ & 11.1 & 4.73 \\
4.85 & $\left(2^{+}\right)$ & $(5.0 \pm 1.0) \times 10^{4}$ & 0.7 & 4.73 \\
4.85 & $\left(4^{+}\right)$ & $(4.38 \pm 0.88) \times 10^{4}$ & 1.4 & 4.73 \\
5.05 & $4^{+}$ & $(1.22 \pm 0.24) \times 10^{+}$ & 3.9 & 4.73 \\
5.05 & $6^{+}$ & $(1.54 \pm 0.46) \times 10^{\circ}$ & 11.6 & 4.73 \\
6.20 & $3^{-}$ & $(2.20 \pm 0.33) \times 10^{+}$ & 1.5 & 4.50 \\
6.85 & $\left(2^{+}\right)$ & $(3.88 \pm 0.58) \times 10^{4}$ & 0.5 & 4.73 \\
6.85 & $(5-)$ & $(3.53 \pm 0.88) \times 10^{\circ}$ & 5.5 & 4.96 \\
7.05 & $3^{-}$ & $(2.17 \pm 0.33) \times 10^{\circ}$ & 1.5 & 4.50 \\
\hline \hline
\end{tabular}

is lo enerod to be $0.95 \mathrm{~F}$. 


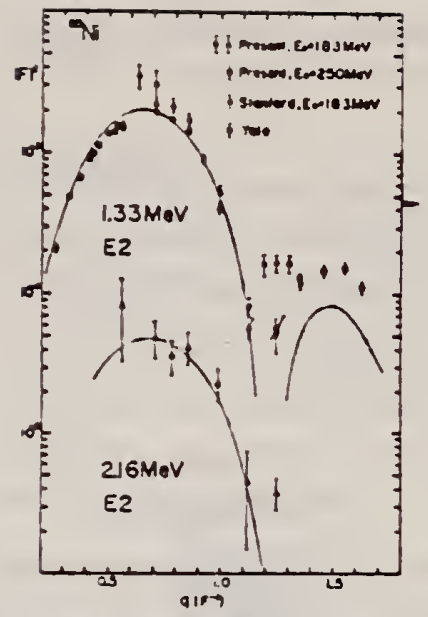

Fic. 5. Experimental $|P|^{3}$ versus $q$ for the 1.33 and $2.16-\mathrm{MeV}$ excitations in $* \mathrm{Ni}$. Solid curves are reproduced using Eq. (2) in the text. The experimental dats of Staniond and Y le for $1.33-\mathrm{MeV}$ level are also plocted for comparisons.

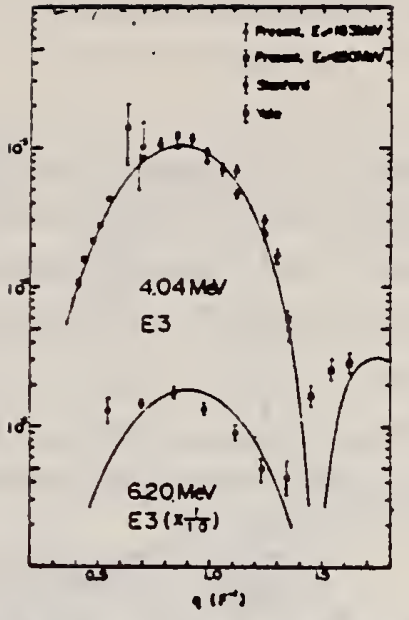

Fo. 6. Experimental $|R|^{2}$ verues $q$ for the 4.04 ad $6.20 \mathrm{MeV}$ excitstione See caption to Fig 5.

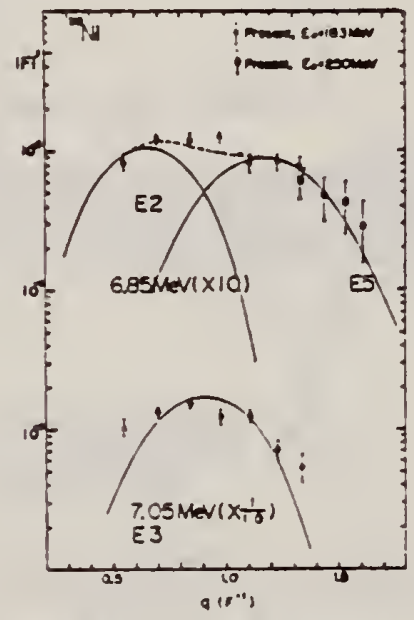

FIG. 7. Experimental $|F|^{2}$ yersus $q$ for the 6.85 and $7.05-\mathrm{MIeV}$ exciucions. The $\mid \vec{F}$ is of $6.85 \mathrm{M} \mathrm{MeV}$ excitation were decomposed tentatively to $E 2$ and $E S$ components uning the theoretical curves predicted by Eq. (2) in the texe

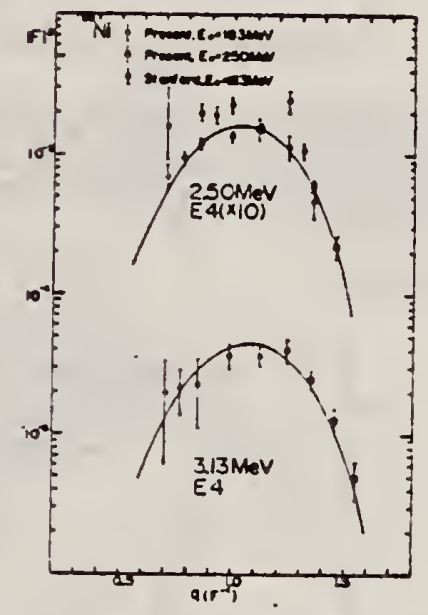

Fic. 8. Experimental $|F|^{2}$ versus $q$ for the $2.50-$ and $3.13 \mathrm{MeV}$ encitetions See caption to Fig. 3. 
Y. Torizuka, Y. Kojima, M. Oyamada, K. Nakahara, K. Sugiyama, T. Terasawa, K. Itoh, A. Yamaguchi, and M. Kimura

Phys. Rev. 185, 1499 (1969)

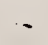

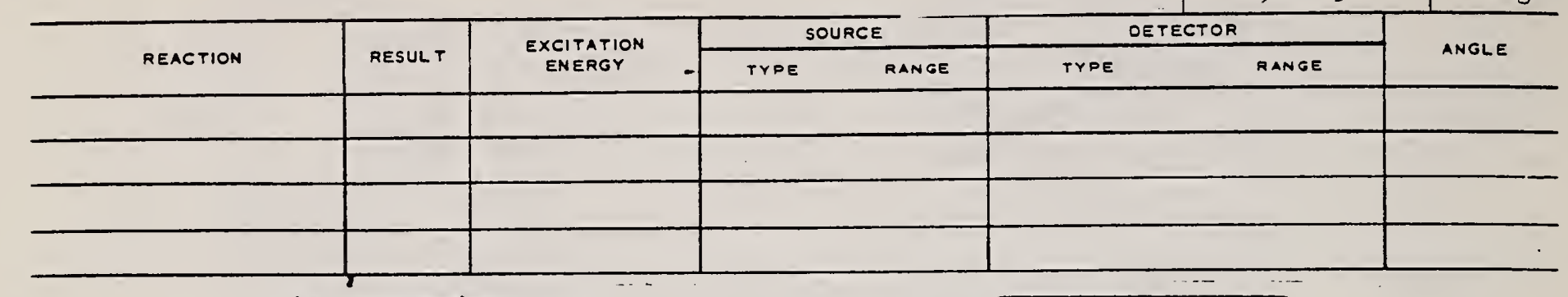

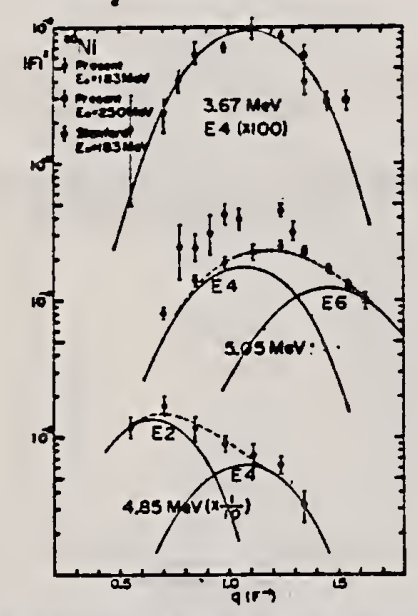

Fic. 9. Experimental $|P| P$ versus $q$ for the $3.67-, 4.85-$, and $3.05-\mathrm{MeV}$ excitations. The $|\nabla|^{2}$ of $5.05 \mathrm{MeV}$ were decomposed to $E A$ and $E 6$ by the belp of theoretical curves of Eq. (2) in the tert The $|F| P^{2}$ of $4.85 \mathrm{NeV}$ are tentatively decomposed to $E 2$ and $B A$ as meotioned above.

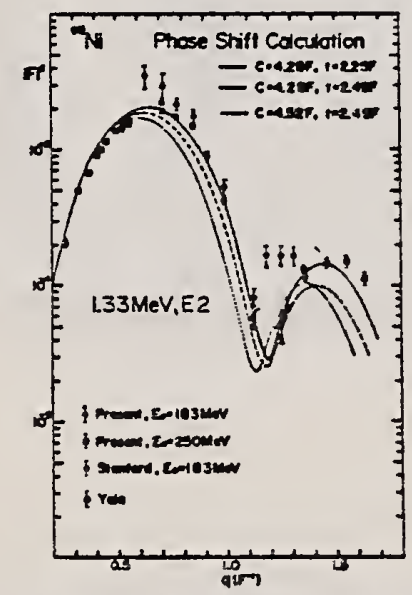

FIG. 11. Theoretical and experimeatul $|P|$ versus $q$ for the 1.33-MeV $\left(2^{+}\right)$state. The theoretical aurves were caiculated by

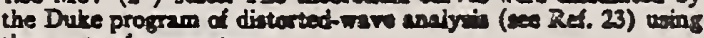
three sect of parameters

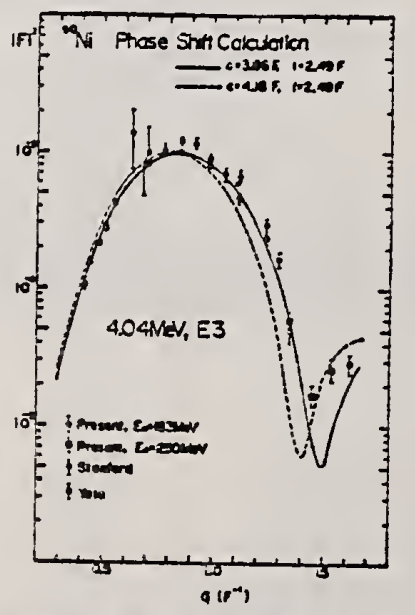

Fso. 12. Theoretical and experimental $|F|^{2}$ versos $q$ for the $4.04 \mathrm{MeV}\left(3^{-}\right)$itale The curves were caloulated by the Duke program. 
B.S. Ishkhanov, I.M. Kapitonov, I.M. Piskarev, V.G. Shevchenko, and O.P. Shevchenko

Yad. Fiz. 11, 485 (1970)

Sov. J. Nucl. Phys. 11, 272 (1970)

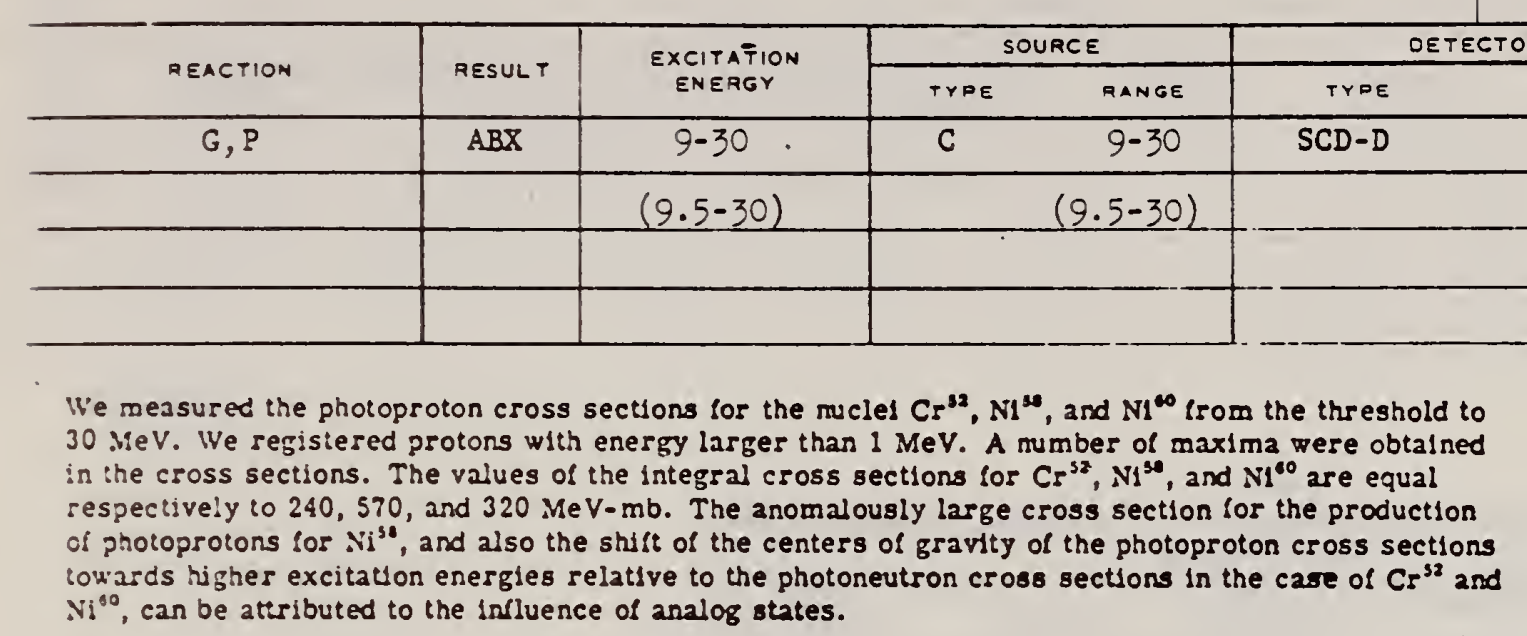

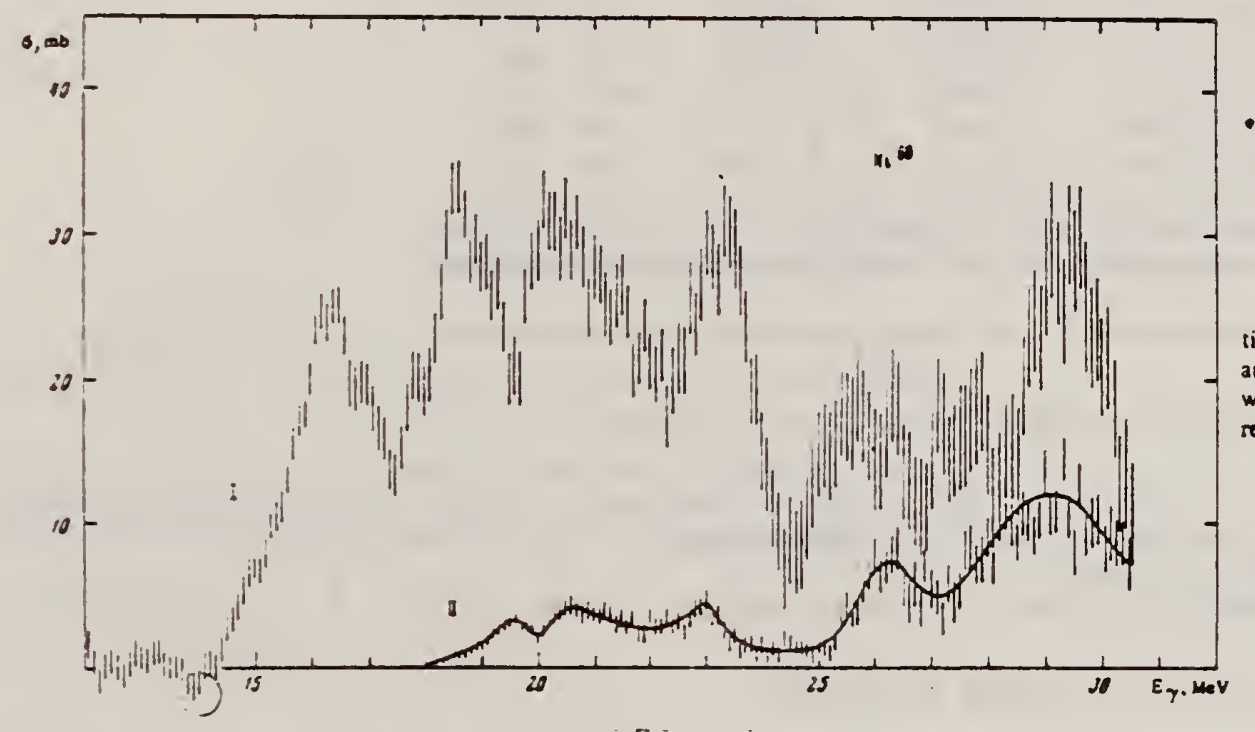

FIC. 3. Photoproton cross sections for $\mathrm{Ni}^{\infty}$. The cross sections I and II were obtained for protons with $E_{p}>1 \mathrm{MeV}$ and $E_{p}>8 \mathrm{MeV}$, respectively.

Integral characteristics of the photoproton cross sections

$\sigma_{p}$, of the photoneutron cross sections $\sigma_{n}$, and of the total absorption cross sections $\sigma_{\gamma}=\sigma_{n}-\sigma_{p}$

\begin{tabular}{|c|c|c|c|c|c|c|}
\hline \multirow{2}{*}{$\frac{\overline{3}}{2}$} & \multirow{2}{*}{$\int_{n e V-m b}^{\infty}$} & \multirow{2}{*}{ 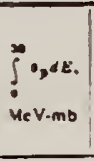 } & \multirow{2}{*}{ 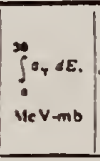 } & \multirow{2}{*}{ Mev-mo } & \multirow{2}{*}{$\vdots_{0,12}^{\infty} \prod_{0}^{\infty}{ }^{4}, \Sigma$} & 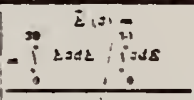 \\
\hline & & & & & & 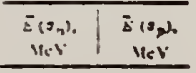 \\
\hline $\mathrm{crot}_{\mathrm{N}}$ & 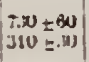 & 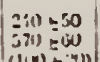 & $\begin{array}{l}970=1101 \\
x \times 2=200\end{array}$ & $\begin{array}{l}5 \pi \\
370\end{array}$ & u. & 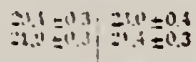 \\
\hline Yim & $020=: 0$ & 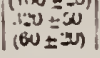 & $360 \pm 100$ & s:5 & 0.11 & $20.7=1.3 \mid=0.0=0,3$ \\
\hline
\end{tabular}

Vole. The paren theses contain the integral cross ections of the photoproton reactions for protons with energ $E_{p}>3 \mathrm{MleV}$. 


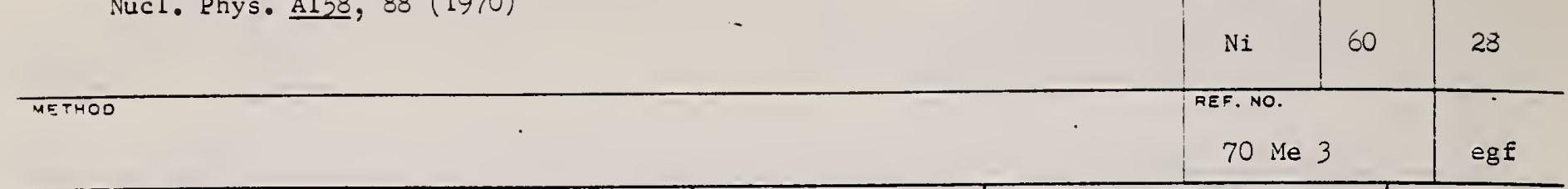

\begin{tabular}{|c|c|c|c|c|c|c|c|}
\hline \multirow[b]{2}{*}{ REACTION } & \multirow{2}{*}{ RESULT } & \multirow{2}{*}{$\begin{array}{l}\text { EXCITATION } \\
\text { ENERGY }\end{array}$} & \multicolumn{2}{|c|}{ SOURCE } & \multicolumn{2}{|c|}{ DETECTOR } & \multirow{2}{*}{ ANGLE } \\
\hline & & & TYPE & RANGE & TYDE & RANGE & \\
\hline \multirow[t]{2}{*}{$G, G$} & $\mathrm{LFT}$ & $1-4$ & C & 4 & $S C D-B$ & $1-5$ & DST \\
\hline & & $(4.1)$ & & & & $(<4.5)$ & \\
\hline & & & & & & & \\
\hline & & & & & & & \\
\hline
\end{tabular}

Thase 3 .

The direct results of the resonance seattering experiments on ${ }^{60} \mathrm{Ni}$ described in this paper are listed in the fourth column

\begin{tabular}{|c|c|c|c|c|c|c|c|}
\hline \multirow{2}{*}{$\frac{\begin{array}{c}E_{\text {lene }} \\
(\mathrm{MeV})\end{array}}{1.333}$} & \multirow{2}{*}{$\frac{17}{2+}$} & \multicolumn{2}{|c|}{$\Gamma_{0} / \Gamma(\%$ error $)$} & \multirow{2}{*}{$\frac{\begin{array}{c}\Gamma_{0}^{2} / \Gamma(\mathrm{meV}) \\
\text { this experiment }\end{array}}{0.61 \pm 0.08}$} & $\begin{array}{c}\Gamma_{0} \\
(\mathrm{meV})\end{array}$ & \multicolumn{2}{|c|}{$\underset{(m e V)}{\Gamma}$} \\
\hline & & 1.00 & $(<1)$ & & $0.61 \pm 0.08$ & & $\left.1 \pm 0.08^{\circ}\right)$ \\
\hline 3.124 & $2^{+}$ & $\left.0.096^{\circ}\right)$ & (5) & $0.07 \pm 0.10$ & $0.8 \pm 1.1$ & 8 & \pm 11 \\
\hline 3.194 & $1^{+}$ & $\left.0.16^{\circ}\right)$ & (4) & $0.63 \pm 0.20$ & $3.9 \pm 1.3$ & 25 & \pm 8 \\
\hline 3.269 & $2^{+}$ & $\left.0.15^{\circ}\right)$ & (8) & $<0.5$ & $<4$ & & $<32$ \\
\hline 4.008 & $2^{+}$ & $0.31 ")$ & (39) & $3.2 \doteq 0.5$ & $10 \pm 4$ & 33 & \pm 19 \\
\hline 4.020 & $1^{+}$ & $0.54 \%$ & (15) & $11.1 \pm 1.5$ & $21 \pm 4$ & 39 & \pm 10 \\
\hline
\end{tabular}

To arrive at the widths listed in columns 5 and 6 , the branching ratios given in the third column were used. The crrors quoted for the partial and total widths include the unccrtainties in these branching ratios.

-) Average of the value reported in ref. ${ }^{7}$ ) and of four values of differcnt groups summarized in tabie 1 of ref. $\left.{ }^{6}\right)$.

") Taken from ref. ").

c) A much more accurate value, $\Gamma=0.63 \doteq 0.01 \mathrm{meV}$, has recently been reported ${ }^{15}$ ).

6)F. Rauch, D.M. Van Patter and P.F. Hinrichsen, Nuc 1. Phys. A124 (1969) 145 .

7) E.J. Hof fman and D.G. Sarantites, Phys. Rev.

181 (1969) 1597 .

T)F.R. Metzger, Nucl.Phys. A148 (1970) 362. 
D. G. Owen, E. G. Muirhead, and B. M. Spicer

Nucl. Phys. AlLO, 523 (1970)

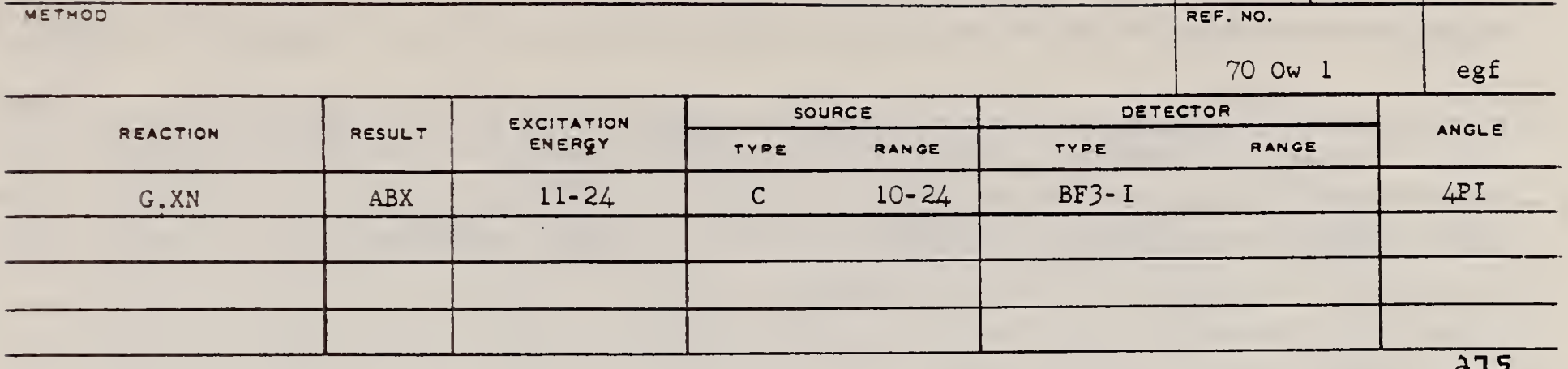

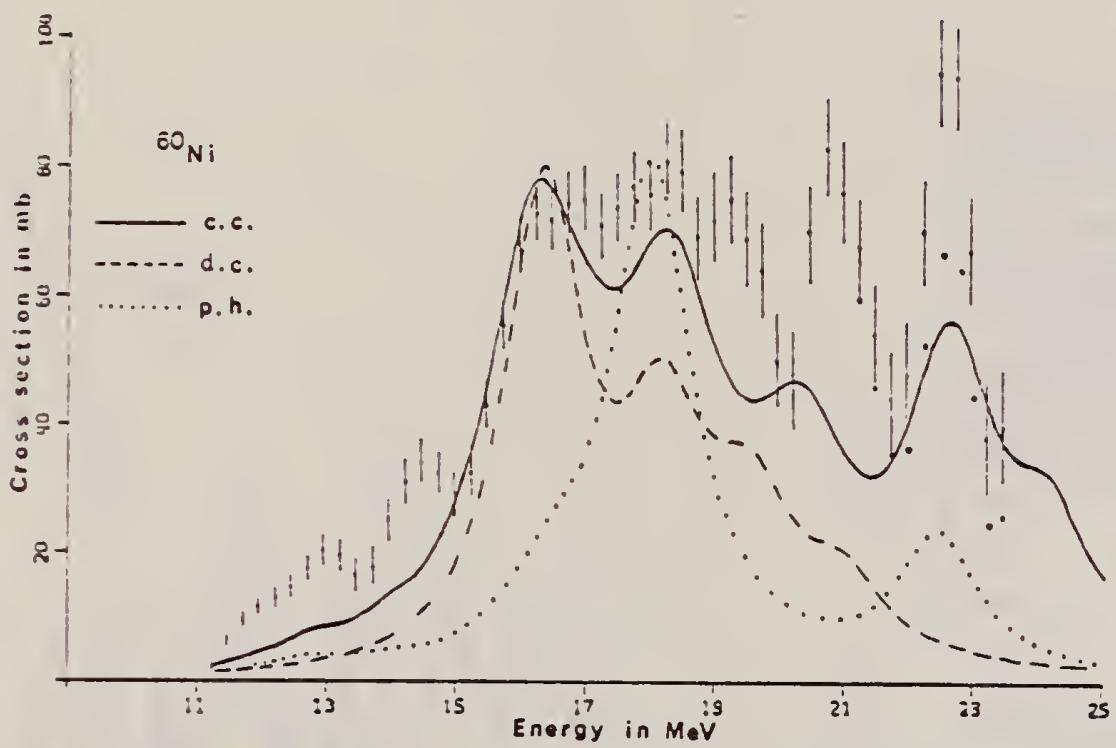

Fig. 3. The ${ }^{60} \mathrm{Ni}(\%, x \mathrm{n})$ experimental cross section is contrasted with the theoretical photo-absorption eross sections predicted by the collective correlations (c.c.) calculation, the dynamic collective model (d.c.) and the particle-hole calculation (p.h.) all as taken from ref. $\left.{ }^{\star}\right)$.

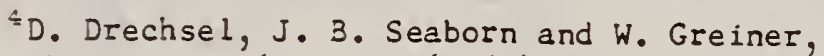
Phys. Rev. 16́2B, 983 (1967). 
REF.

V.G. Tikhonov, V.G. Shevchenko, V.Ya. Galkin et al.

Ser. III. F1z. Astron. 11, 208 (1970)

$70 \mathrm{~T} 12$

\begin{tabular}{|c|c|c|c|c|c|c|c|}
\hline \multirow[b]{2}{*}{ REACTION } & \multirow[b]{2}{*}{ RESULT } & \multirow{2}{*}{$\begin{array}{l}\text { EXCITATION } \\
\text { ENERGY }\end{array}$} & \multicolumn{2}{|c|}{ SOURCE } & \multicolumn{2}{|c|}{ OETECTOR } & \multirow{2}{*}{ ANGLE } \\
\hline & & & TYPE & RANGE & TYPE & RANGE & \\
\hline$G, X N$ & RLY & $12-30$ & C & $12-30$ & BF3-I & & $4 \mathrm{PI}$ \\
\hline & & & & & & & \\
\hline & & & & & & & \\
\hline
\end{tabular}

No data given for ${ }^{51} \mathrm{v},{ }^{59} \mathrm{Co},{ }^{58} \mathrm{~N} 1$.

59772 DETERMINATION OF PHOTONUCLEAR REACTION CROSS SECTIONS. TIkhonor. A. N.; Sherchenko, V. G.; Galkd V. Ya.: (and others). Vesto. Mosk. Uaiv., Ser. III. Fiz. Astron. 11: No. 2, 208-14(Mar-Apr 1970). (In Russian).

An operative system for the automatlc handling of data is described for the determination of photonuclear reaction cross sections with $235-\mathrm{MeV}$ betatron. The system provides for fully automatic processing of experimental data as accumulated in the analyzer all the way to oblaining the cross section of a photonuclear reaction. Bremsstrahlung whlch lo generated at the target of the betatron passes through a collimator and then Impinges on the deslred materlal. The neutrons thus produced aro recorded by a $B F$, detector using a paraffin moderator. The pulses are sent to the memory of a pulse-beight analyzer. The system is illustrated with data from $(Y, n)$ reactlons with the

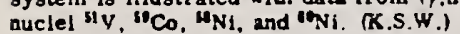

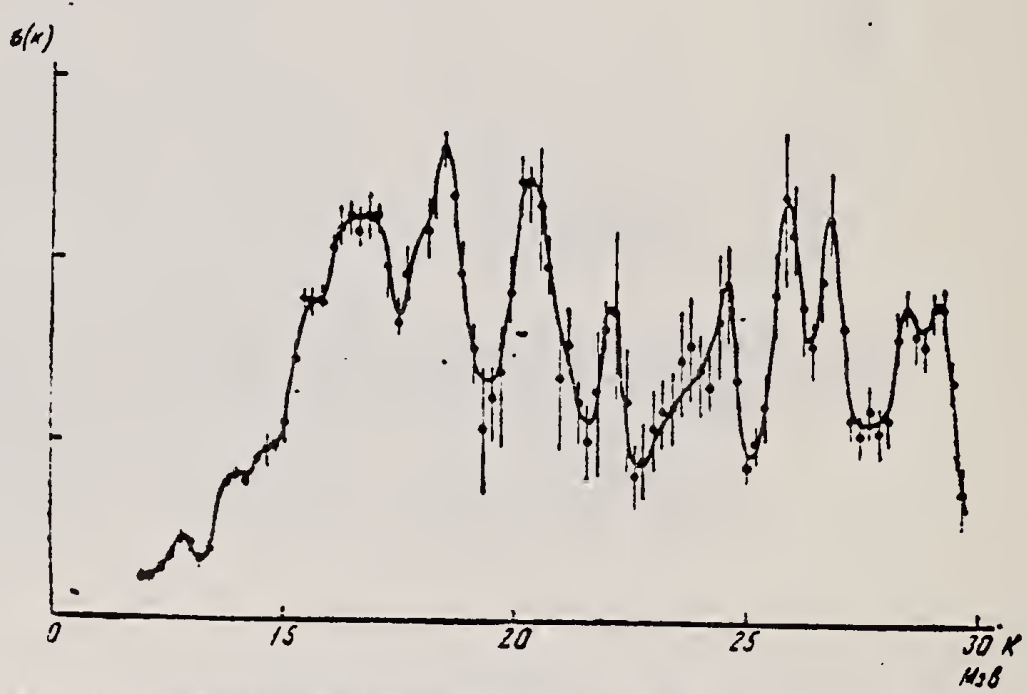

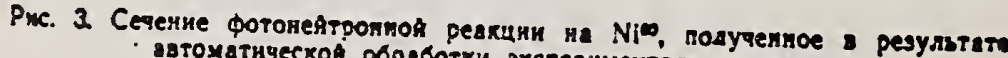
asтоматическон обработхи экспериментальных данних 


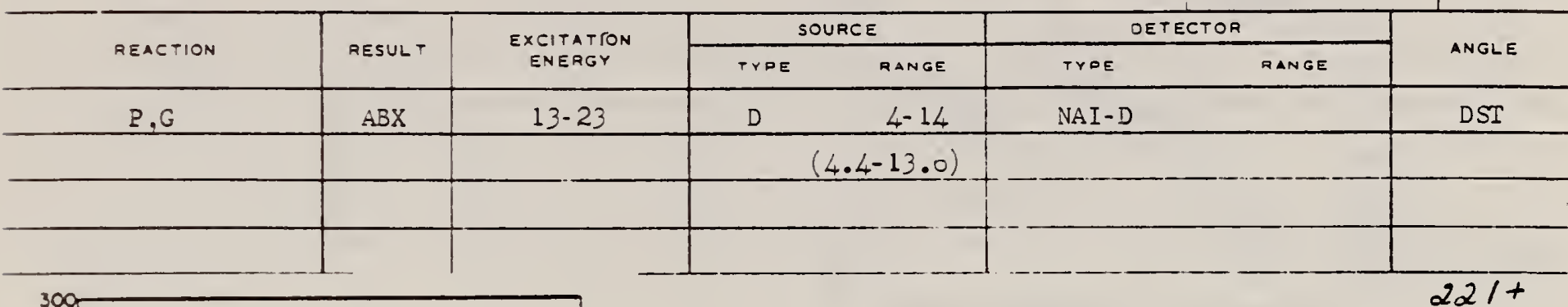
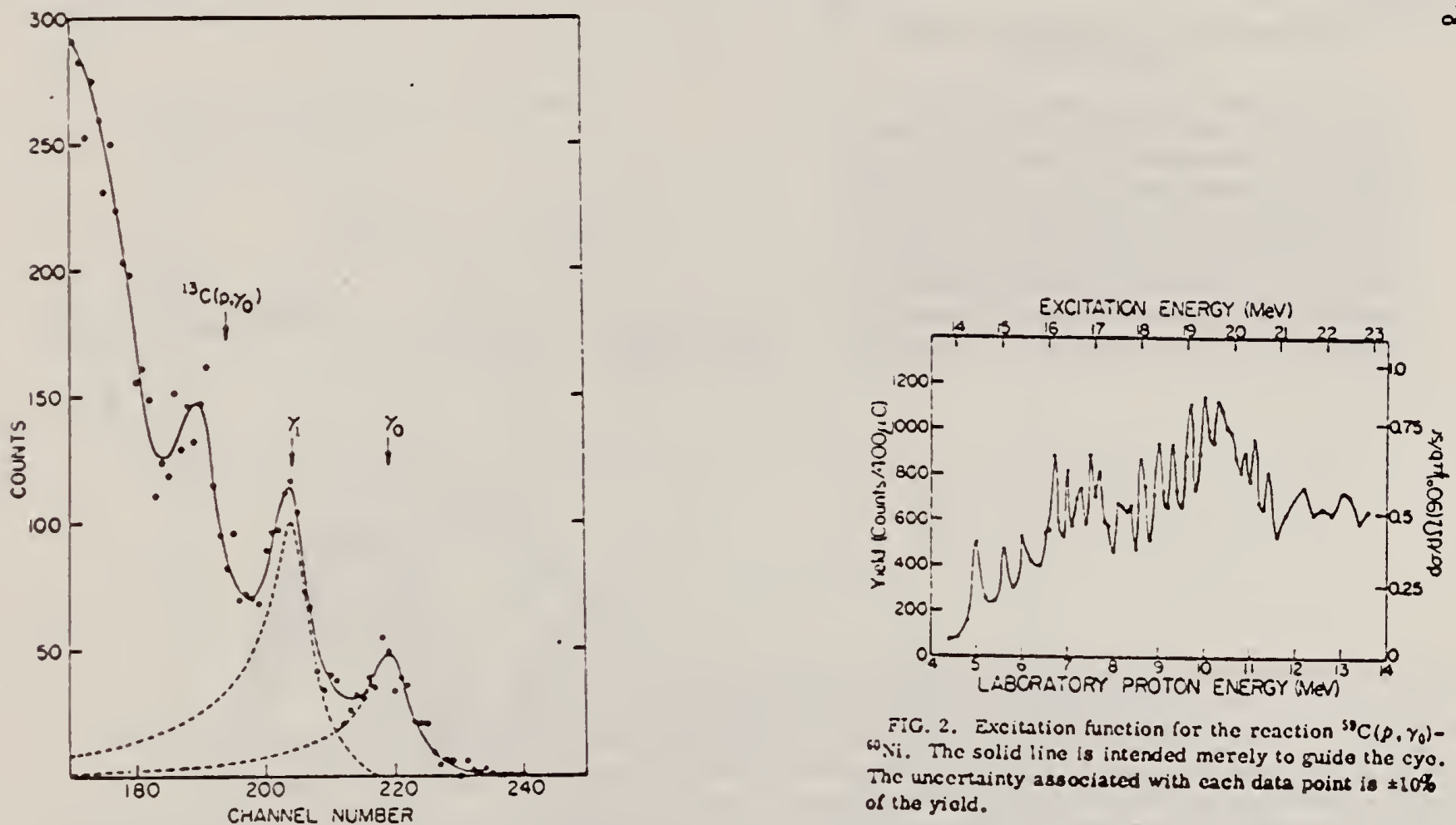

FiG. 2. Excitation function for the reaction ${ }^{31} \mathrm{C}\left(p, \gamma_{0}\right)-$ wiv. The solid line is intended merely to guide the cyo. the uncerazinty associated with each data point is $\pm 10 \%$ of the yiold.

FIC. 1. Sixcerum of high-encery y rays from radiativo calture of protons by "9o. Onlp the riwion of the rulseheighe spectrum which corres;ronds to $E_{y}>13 \mathrm{hicV}$ is shown. The $7.6-3 i c V$ hominardin: encra results in :7.00and $15.67-\mathrm{hicV} y$ rays from the fround-state $\left(y_{j}\right)$ and first-excited-stale $\left(y_{1}\right)$ transitions, icspecively. The next lowcr pak is due to transitions to a group oi hizhcr excited states in Wii. Also indicned is the position at which $y$ rays from the reaction ${ }^{13} \mathrm{C}\left(\rho . Y_{j}\right)^{14} \mathrm{~N}$ would appear. Tho dashed lincs indicate the coneributions from the $\gamma_{\text {, }}$ and $y_{1}$ transitsons oblained by fitsing the data 28 described in the text. 


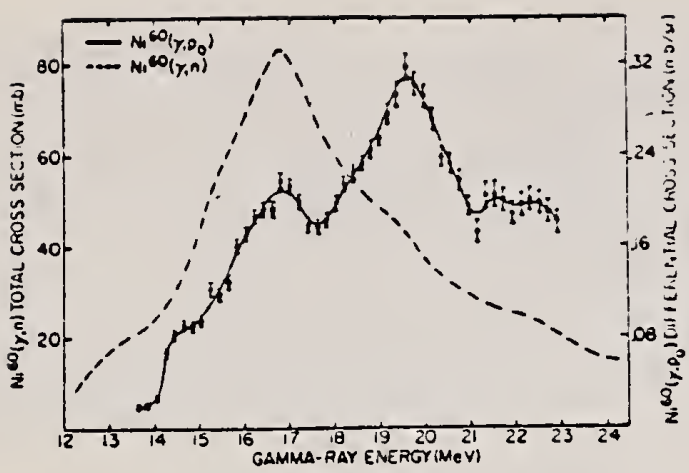

FTC. 3. Excitation functions for the renctions ${ }^{59} \mathrm{Ni}-$ $(\gamma, p)^{59} \mathrm{C}$ at $20^{\circ}$, obtained by detailed balance irom the datz of Fif. 1 averaged over a $600-k c V$ interval, ard ${ }^{80} \mathrm{Ni}(\gamma, n){ }^{s 9} \mathrm{Ni}$ obthined from Ref. 23. Note the cifferent eross-section scales for the two reactions. Above the ${ }^{50} \mathrm{Ni}(\gamma, 2 n)$ threshold. the photoneutron data have been corrected for multiple neutron emission to yicld the ${ }^{60} \mathrm{Ni}(\gamma, n)$ cross section. The indicated error bars were obtained from the averaging procedurc. The solid lise through the "Ni $(y, p)$ data points is drawn to guide the eye.
23 $1200(1968)$.

The rediative-capture reaction ${ }^{19} \mathrm{Co}(y, y)^{60} \mathrm{Ni}$ has hecn sturlicel for proton enerifics from

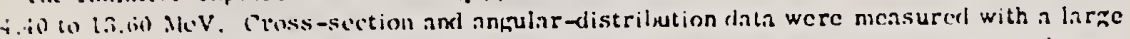

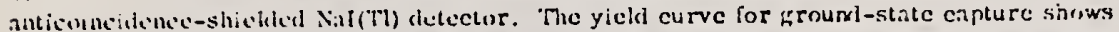
iwo broad penks, at io $\mathrm{Ni}$ excitatious of 16.6 and $19.6 \mathrm{MeV}$ : these are interpreted as the $T_{c}$ and $T$ components of the giant dipole resonance. The results of a detailed calculation isnoring isos;in cifects do not adequatcly explain all of the observations: a simpie : $p-1$ h calculation usin: eigcniunctions of $T$ describes the results quite well. The first-cxcited-state-capture yield curve is similar to the ground-state eurve, shifted in enerfy by $-300 \mathrm{keV}$. The inta subacst that most of the ouserved strength in the giant dipole resonance based on the first excited state of ${ }^{6 h} \mathrm{Ni}$ is concentrated in $2^{-}$states. 
J. W. Lightbody Jr.

Phys. Letters 38B, 475 (1972)

\begin{tabular}{|c|c|c} 
NI & 60 & 28 \\
\hline REF. NO. & egf \\
\hline
\end{tabular}

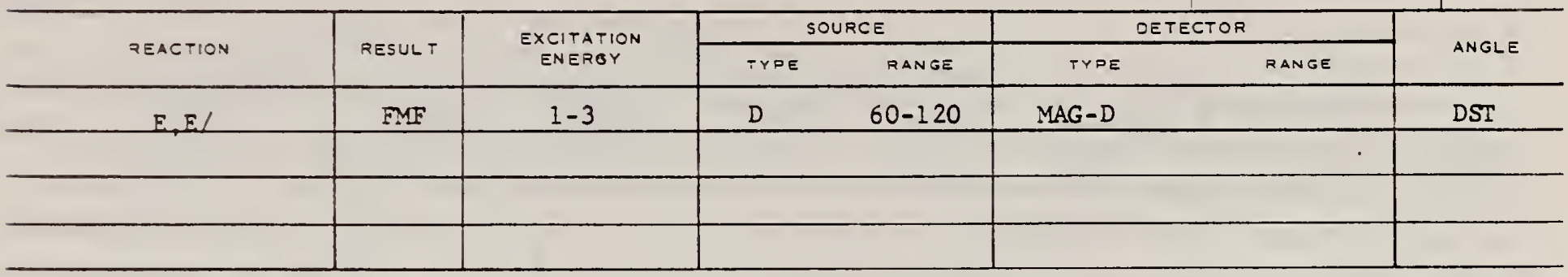

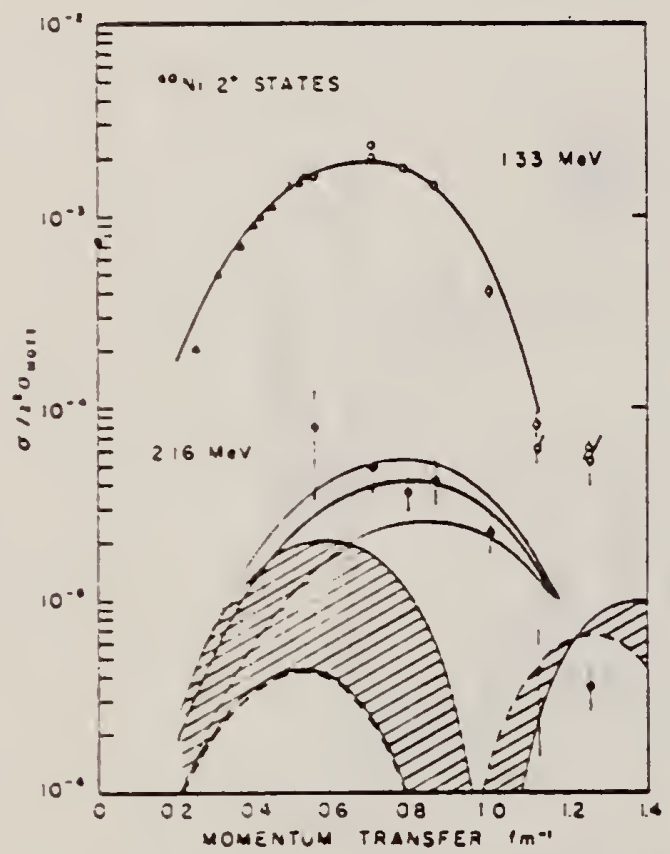

F!z. L. E:ec:ron scat:ering form factors for the lowest 7. 2- siaies in ou $\mathrm{Ni}_{1}$. jolid lines were calculated using a best $\therefore:$ simulture and passe. The dashed line represer:s :ie hasmonic :wo-phonon form factor. The stased and cross-rasched regions ivere determined by is ing acruxizes wrich fit the measured $B R$ for $\$$. - and 0 , respectively. 
K. Shoda, M. Sugawara, T. Saito, H. Miyase, A. Suzuki, S. Oikawa, and $J$. Uegaki

PICNS-72, 321 Sendai

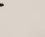

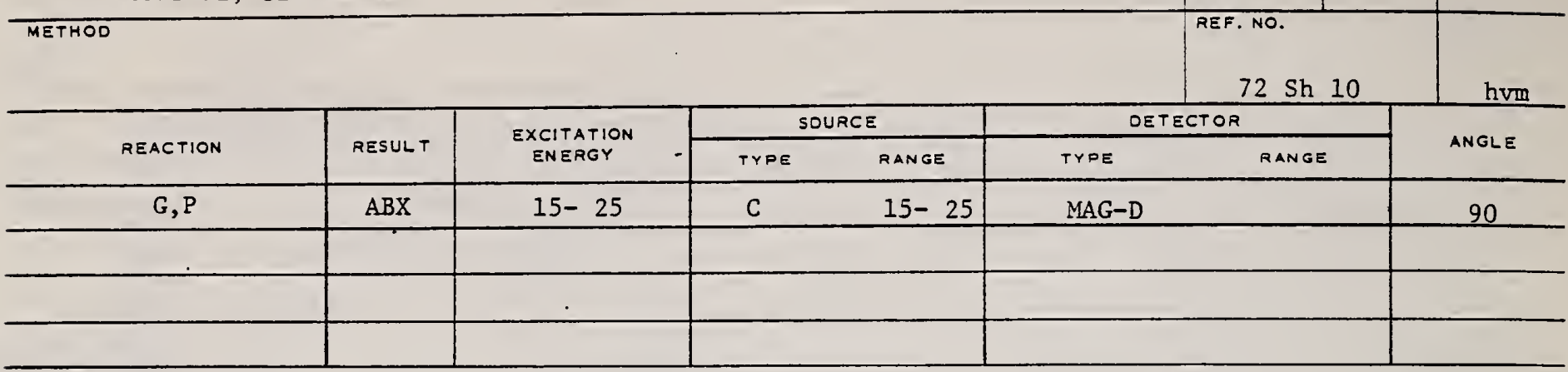

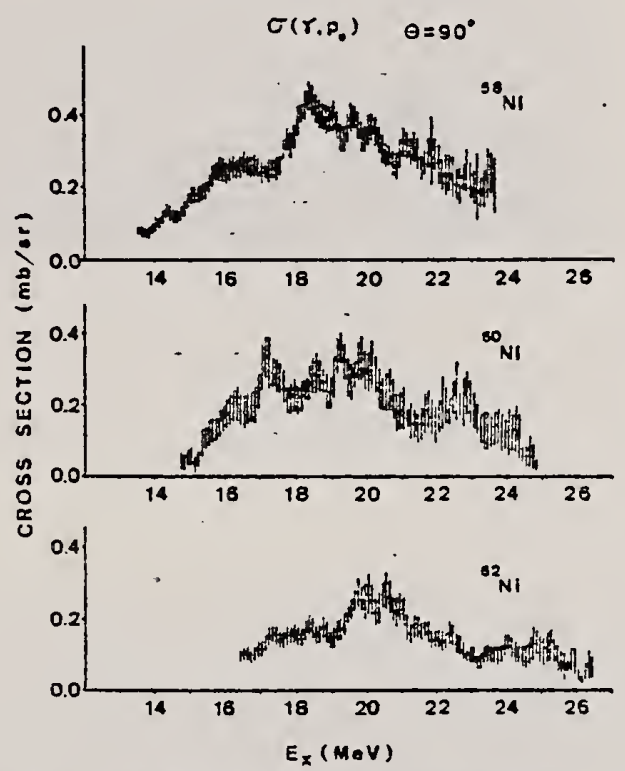

F1g. 10 The $\left(Y, p_{0}\right)$ cross sections of $N 1$ 1sotopes obtalned from proton spectra by the $\left(e, e^{\prime} p\right)$ reaction. 
zef D. Branford, G.S. Boote, R. A. I. Bell, D. C. Welsser, R.C.P. Huang and R.B. Wat son -

PICNS-73, Vol.II, P.943 (1973) Asilomar

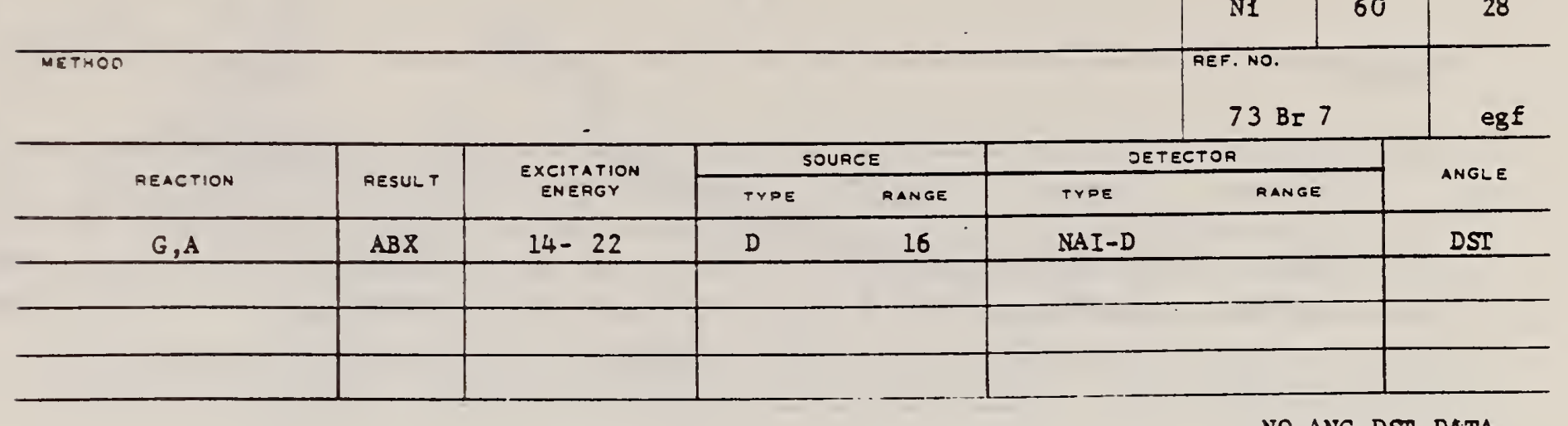

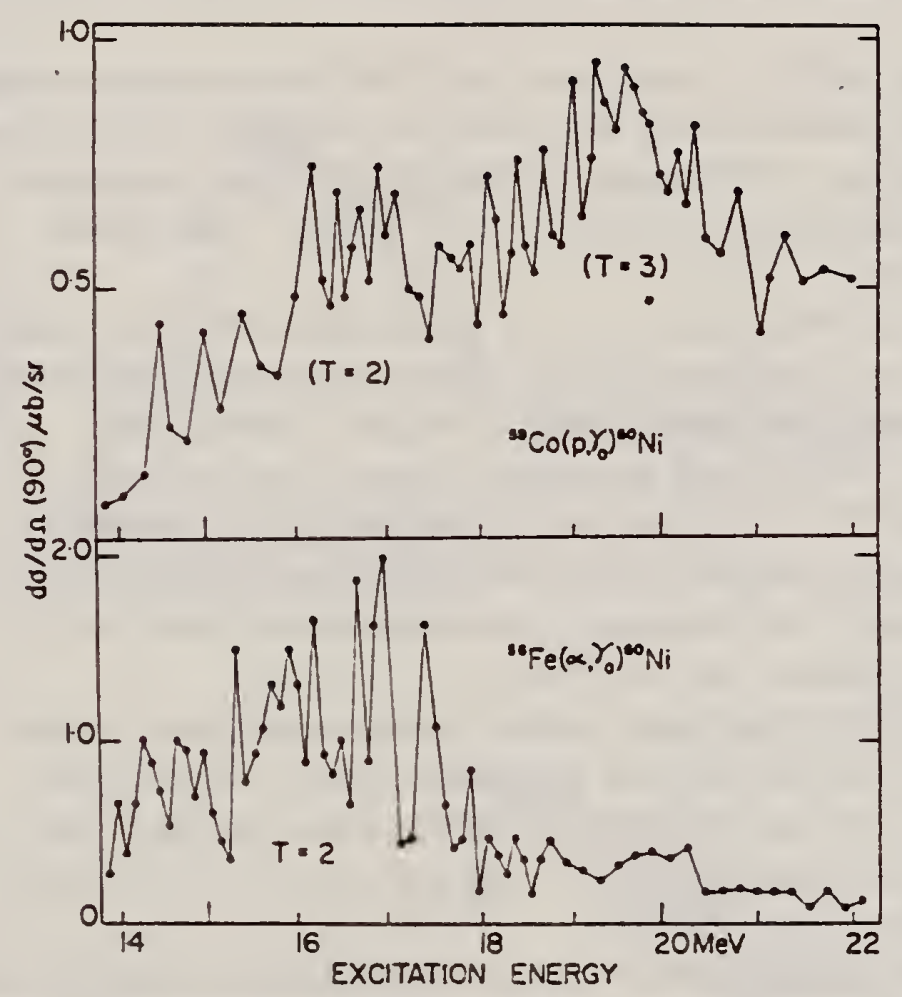

NO ANG DST DATA

Fig. 1. Excitation functions for radiative eapture reactions leading to ${ }^{60} \mathrm{Ni}$ GDR

Table 1. Preliminary Results with Relative Errors; Absolute Errors $=30 \%$

\begin{tabular}{|c|c|c|c|}
\hline Reaction & $\begin{array}{c}\int \sigma\left(\gamma_{0}, \alpha_{0}\right) d E \\
m b . M e V \\
\end{array}$ & $\begin{array}{c}\int \sigma\left(\gamma_{1}, a_{0}\right) \mathrm{dE} \\
\pi b .1 \mathrm{eV} \\
\end{array}$ & $\begin{array}{c}\text { Excitation Energy } \\
\text { ( (eV) }\end{array}$ \\
\hline${ }^{40} \mathrm{Ar}(\alpha, \gamma)^{44} \mathrm{Ca}$ & $1.4 \pm 0.3$ & $0.42 \pm 0.08$ & 15.5 \\
\hline${ }^{48} \mathrm{Ti}(\alpha, y){ }^{52} \mathrm{Cr}$ & $3.0 \pm 0.6$ & $0.48=0.10$ & 17.0 \\
\hline${ }^{56} \mathrm{Fe}(\alpha, y)^{60} \mathrm{Ni}$ & $7.8 \pm 1.5$ & $1.52=0.30$ & 16.0 \\
\hline
\end{tabular}




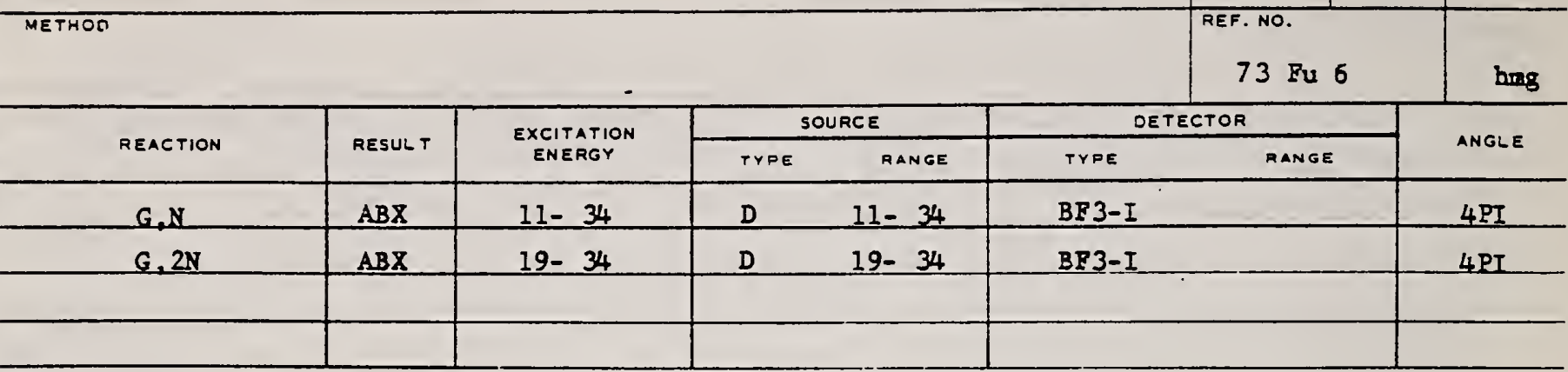

As in the case of ${ }^{58} \mathrm{Ni}^{\mathrm{I}}$ we report, in this paper, the first high-resolution measurement of the ${ }^{60} \mathrm{Ni}$ protoneutron cross sections with nearly monornengetic photons from in-flight annihilation of positrons. The experimental details, including resolution

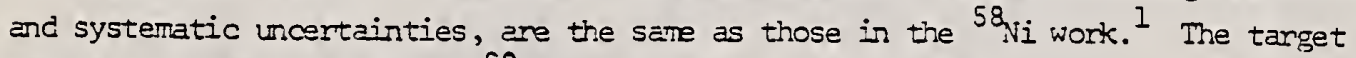
sample enrichment was $39.79 \% 60 \mathrm{Ni}$.

Oun experimental results are shown in Fig. 1. The total photoneutron cross section reaches a peak value of about $75 \mathrm{mb}$ just.above $16 \mathrm{MeV}$. There is some structure evident, superingosed on the general shape of the giant resonance, which is sonewhat less prominent than that observed in $58 \mathrm{Ni}$; it does not agree in detail with the structure observed in previous experiments ${ }^{2-4}$ on ${ }^{60} \mathrm{Ni}$ perfomed with brensstrahling photons. The magnitude of the peak" cross section observed in tivis and previous experiments ${ }^{2-4}$ are in reascrably good agreement, however. The integrated total photoneutron cross section is $705 \mathrm{MeV}-\mathrm{mb}$, ebout 2.5 times as lange as that for ${ }^{58} \mathrm{Ni}$

Unilke the $58_{\mathrm{Ni}}$ case, the $60_{\mathrm{Ni}}(\gamma, 2 \mathrm{n})$ cross section forms a significant fraction of the total in the region above $20 \mathrm{MeV}$, elthcugh it appears to drop to nearly zero at $33 \mathrm{MeV}$. The statistics are sufficiently good that definite structure can be discemed in the cross section. The integrated $(\gamma, 2 n)$ cross section is $73 \mathrm{MeV}-\mathrm{rb}$, alnost an order of magnitude langer than in the $5{ }^{\mathrm{Nj}}$. case.

As in the case of ${ }^{58} \mathrm{Ni}$, the measured cross section is in qualitative agreement, up to about $25 \mathrm{MgV}$, with the distribution of dipole strength calculated by Tanaka. 5 The collective correlations calculation of Seabom, et al $^{6}$ appears to provide some additional cispersion of the dipole strength to higher energies, yet there still appears to be too much experimental cross section above $25 \mathrm{MeV}$ to be explained by the shell-model calculations done this far.

Work performed under the auspices of tha U. S. Atomic Energy Comission.

Deceased

1 S. C. Fultz, R. A. Alvarez, B. L. Berman, P. Meyer: preceding paper.

2 K. Min and T. A. White, Phys. Rev. Letters 21, 1200 (1968).

3 B. I. Goryachev, B. S. Ishkhanov, I. M. Kapitcrov, I. M. Piskarev, V. G. Shevchenko, and O. P. Shevchenko, Sov. J. Nucl. Physics 11, 141 (1970) [Yad. Fiz. 10, 252 (1969)].

4 D. G. Ower, E. G. Muirhead, B. M. Spicer, Nucl. Phys. Alu0, 523 (1970).

5 Y. Tanaka, Prog. Theor. Phys. 46, 787 (1971).

6 J. B. Seabom, D. Drechsel, H. Arenhovel, W. Greiner, Fhys. Lett. 23, 576 (1960). 

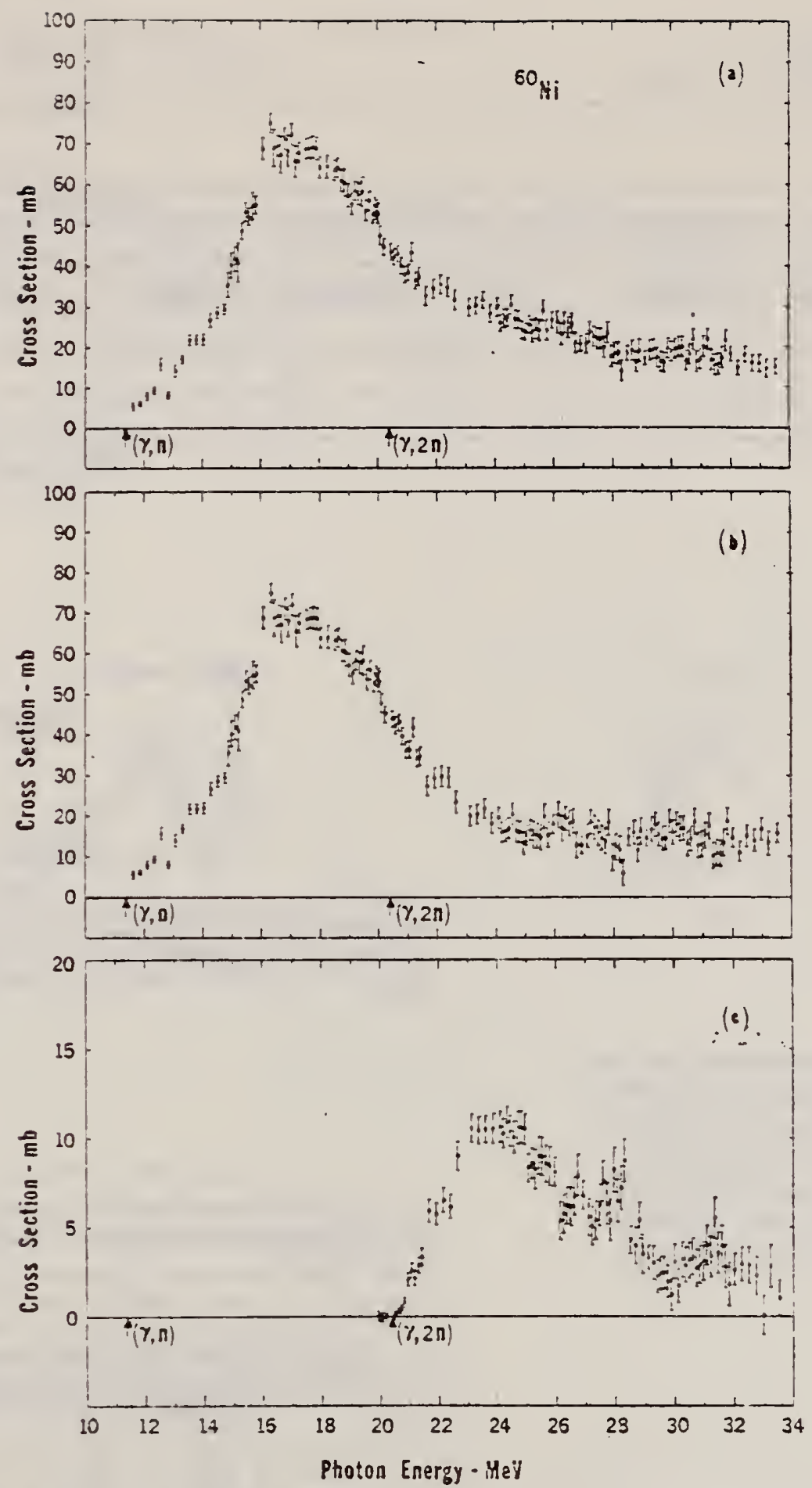

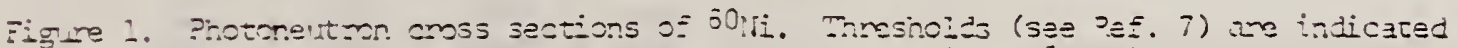

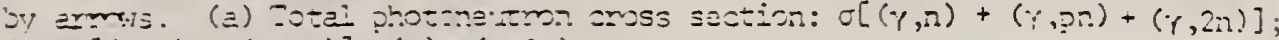
(b) $\sigma[(\gamma, n)+(\gamma, \sigma n)] ;(\Omega) \sigma(\gamma, n)$. 
REF.

I.S. Gul'karov

Yad. Fiz. 18, 519 (1973)

Sov. J. Nucl. Phys. 18,267 (1974)

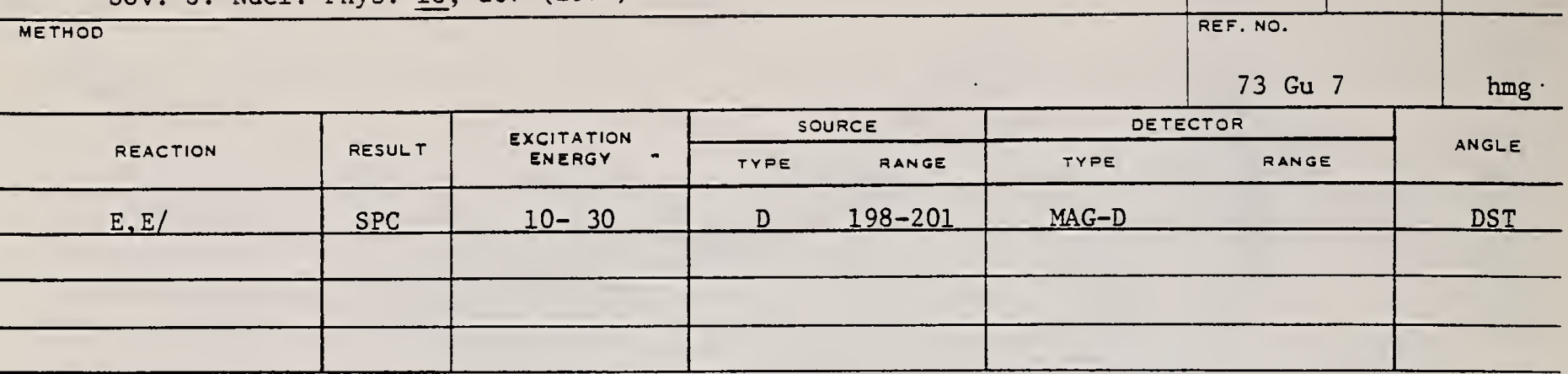

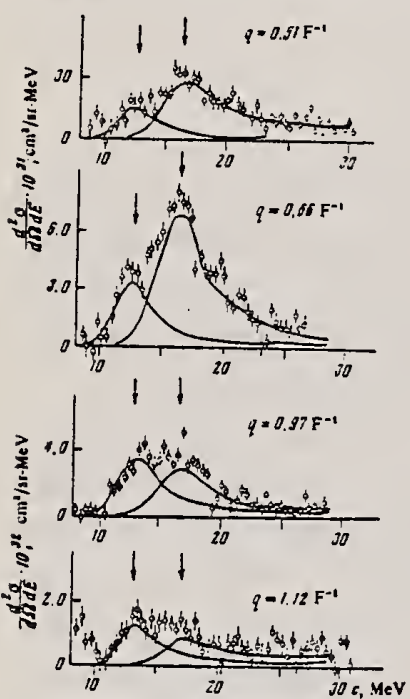

FiG. 1

FIG. 1. Energy spectra of electrons inelastically scattered by $\mathrm{Ni}^{60}$, obtained after subtraction of the radiation tail from the elastic and inelastic peaks. The arrows show the locations of the peaks of the two resonances. With increasing $q$ the contribution from the resonance at $13.0 \pm 0.3 \mathrm{MeV}$ increases, and while that from the $16.2 \pm 0.2 \mathrm{MeV}$ resonance decreases.

FIG. 2. Form factors for the giant $E 1$ and $E 2$ resonances as a function of effective momentum transfer $q^{\prime}$. Points: $-13.0 \pm 0.3 \mathrm{MeV}, 0-16.3$ $\pm 0.2 \mathrm{MeV}$. Curves: 1 -calculation of El resonance form factor in terms of dynamic sollective theory, ${ }^{6}{ }^{\circ}$ 2-in Helm's model, 1713 and 4-the same as 1 and 2 but for the E2 resonance. Curves 1 and 3 have been decreased by $20 \%$ and a factor of 4 , respectively.

TABLE l. Form factors of glant dipole and quadrupols resonances of $\mathrm{Ni}^{60}$

\begin{tabular}{|c|c|c|c|c|}
\hline a, des & $\varepsilon_{m} \mathrm{MeV}$ & $q^{\prime} \cdot F^{-1}$ & $\left.F_{i-1}^{Z}(x) n-n\right)$ & $\hat{F}_{\lambda=3}(x 10-9$ \\
\hline $\begin{array}{l}20 \\
30 \\
40 \\
50 \\
50 \\
70\end{array}$ & $\begin{array}{l}198.7 \\
19 y .1 \\
197.60 \\
197.9 \\
19 y .1 \\
-v 1.0\end{array}$ & $\begin{array}{l}0.366 \\
0.334 \\
0.703 \\
0.865 i \\
1.029 \\
1.19 i\end{array}$ & $\begin{array}{l}1.58=0.64 \\
1.14 \pm 0.12 \\
0.84=0.19 \\
0.5 \pm \pm 0.12 \\
0.17 \pm 0.01 \\
0.12 \pm 0.96\end{array}$ & $\begin{array}{l}0.33=0.27 \\
0.3- \pm 0.10 \\
0.23=0.06 \\
0.23 \pm 0.05 \\
0.19=0.05 \\
0.19=0.10\end{array}$ \\
\hline
\end{tabular}

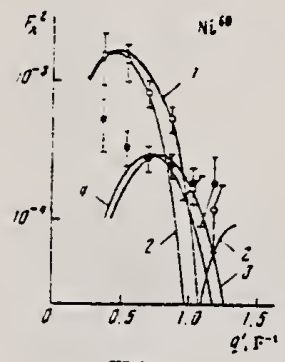

FIG. 2

FMF/13.0,16.3 MEV

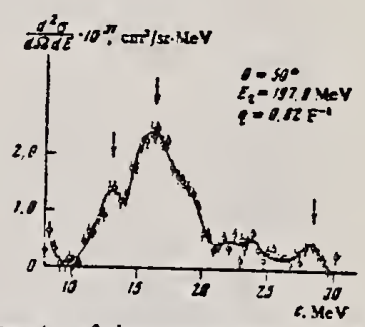

FIG. 3. Energy spectra of electrons scattered by $\mathrm{Ni}^{60}$. The arrows show the locations of the peaks of the E2 (13.0 YeV) and E1 (16.3 $\mathrm{HeV})$ resonances, and also the resonance at excitation energy $28.5 \mathrm{MeV}$ whose nature is unknown. The curve was drawn by eye through the experirental
points.

TABLE II. Entrgy luwtion. half-width, reluced transition pros abitity. $r a d i a t i o n$ width, and enhancement factor of $E I$ and $E ?$ resonances ir.
$\mathrm{Ni}^{60}, \mathrm{Zr}^{\circ 0}$, and $\mathrm{Pb}^{208}$

\begin{tabular}{|c|c|c|c|c|c|c|c|}
\hline Nusteus & $e_{1}, \mathrm{MeV}$ & A. $N=V$ & \multicolumn{2}{|c|}{$r_{1} \mathrm{HeV}$} & $I_{x}, 4=4$ & $\left|\begin{array}{c}\theta\left(E t-J_{1}-d g^{2}\right. \\
\mathrm{e}^{2} F^{2}\end{array}\right|$ & 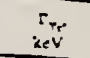 \\
\hline $\mathrm{NiN}$ & $16.3=0 . ?$ & $13,0=0.3$ & \multirow{2}{*}{\multicolumn{2}{|c|}{$\begin{array}{c}4.8 \pm 0.3 \\
4.0 \\
\end{array}$}} & \multirow{2}{*}{$\begin{aligned} i 1 & =0.3 \\
i 3 & =0.6\end{aligned}$} & $120=26$ & $13.1=3.6$ \\
\hline $\begin{array}{l}7 p=0 \\
P_{b}=4\end{array}$ & $\begin{array}{l}16.65 \\
14.1 \\
\end{array}$ & $\begin{array}{r}14.0 \\
-10.7 \\
\end{array}$ & & & & $\begin{array}{l}17.0=5.0 \\
6<.0=8.0\end{array}$ & $\begin{array}{l}27-3=3.9 \\
6,2=8.9\end{array}$ \\
\hline Nucleus & $G$. & \multicolumn{2}{|c|}{$\left.e^{2}=s_{1}-s_{p}\right)$} & \multicolumn{2}{|c|}{$\begin{array}{l}r_{r_{r}} \\
e^{2}\end{array}$} & $c_{2}$ & $\begin{array}{l}\text { Souras } \\
\text { of dau }\end{array}$ \\
\hline $\mathrm{Si}^{\infty}$ & $4.1 \neq 0.8$ & \multicolumn{2}{|c|}{$\begin{array}{l}125 \pm 95 \\
103 \pm 21\end{array}$} & \multicolumn{2}{|c|}{$\begin{array}{l}7.5=1.5 \\
6.2 \pm 1.2\end{array}$} & $\left\{\begin{array}{l}1.8 \pm 0.4 \\
15 \pm 0.3\end{array}\right.$ & $\begin{array}{c}\text { Present } \\
\text { vork }\end{array}$ \\
\hline $\begin{array}{l}\mathrm{Zr} \\
\mathrm{Pb}^{\mathrm{T}}\end{array}$ & $\begin{array}{l}4.4 \pm 1.3 \\
9.4 \pm 1.2\end{array}$ & \multicolumn{2}{|c|}{$\begin{aligned} 990 & =300 \\
2600 & \pm 900\end{aligned}$} & \multicolumn{2}{|c|}{$\begin{array}{l}85.5 \pm 25.9 \\
58.7 \div 20.4\end{array}$} & $8.3 \pm 2.5$ & {$[1]$} \\
\hline
\end{tabular}

Note. The values of (B(E2), $\Gamma_{\gamma_{3}}$, and $G_{2}$ given in the upper line were obtained on the basis of the vibrational modet, and those in the lower line on the besis of Helm's model 
K. Itoh, 1 Oyamada, and $Y$. Torlzuka

Phys. Rev. C7, 458 (1973)

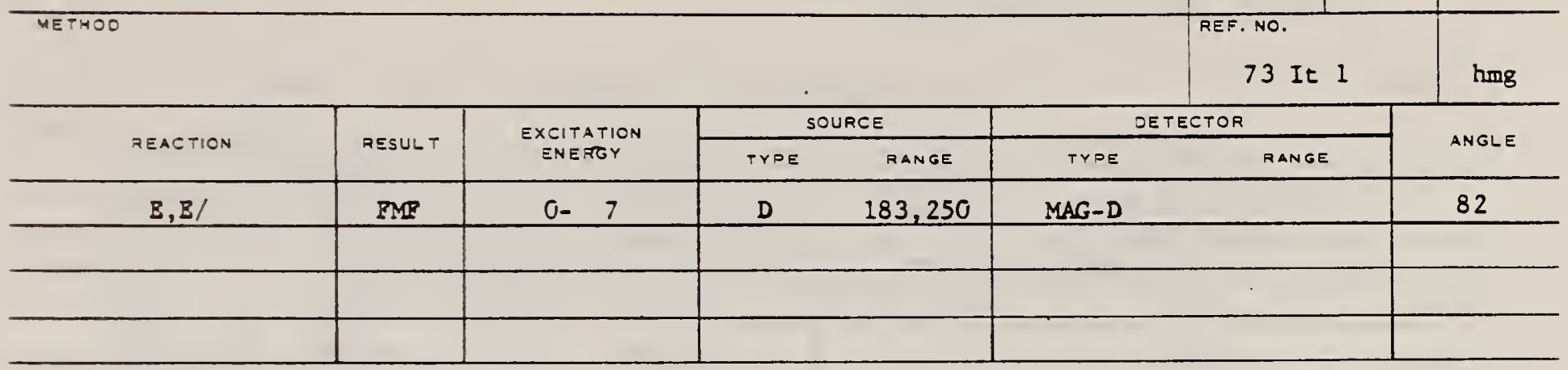

See 09 To 3.

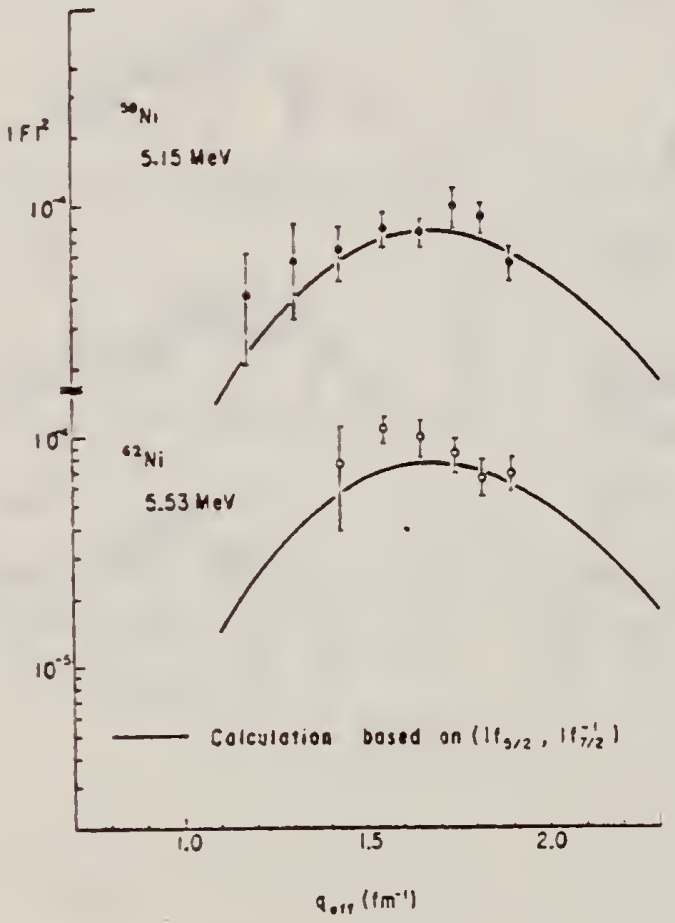

FG. 2. The experimental form factors for the $\sigma$ ratel compared with the theoretical form factors calaulated for the $\left(1 f_{\mathrm{S} / 2}, 1 f_{7 / 2}^{-1}\right)$ configuration. 
ref. H. Miyase, S. Oikawa, A. Suzuk1, J. Uegak1, T. Salto, M. Sugawara, and $K$. Shoda

PICNS-73, Vol. I, P. 553 Astlomar

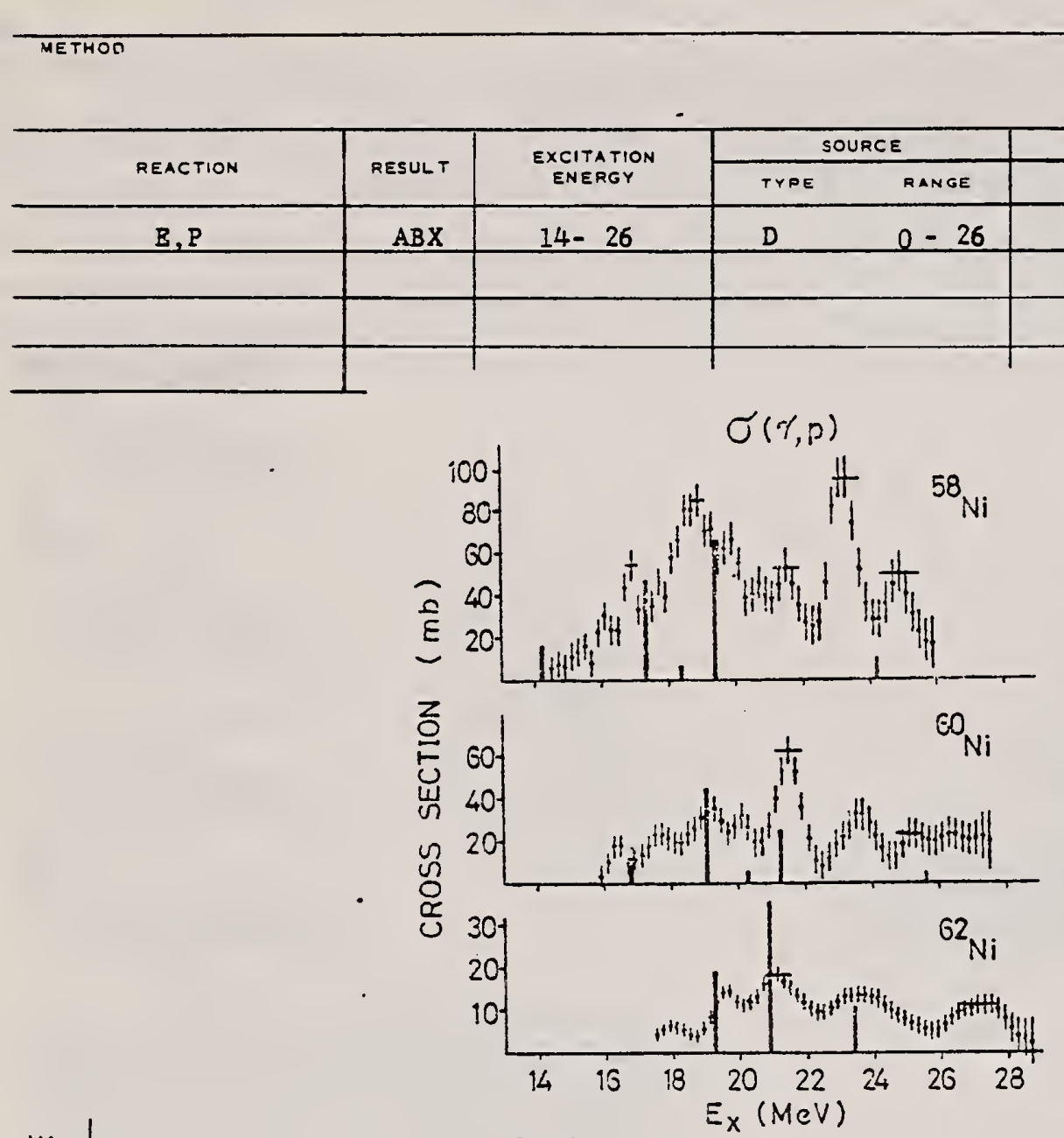

Fig. 1
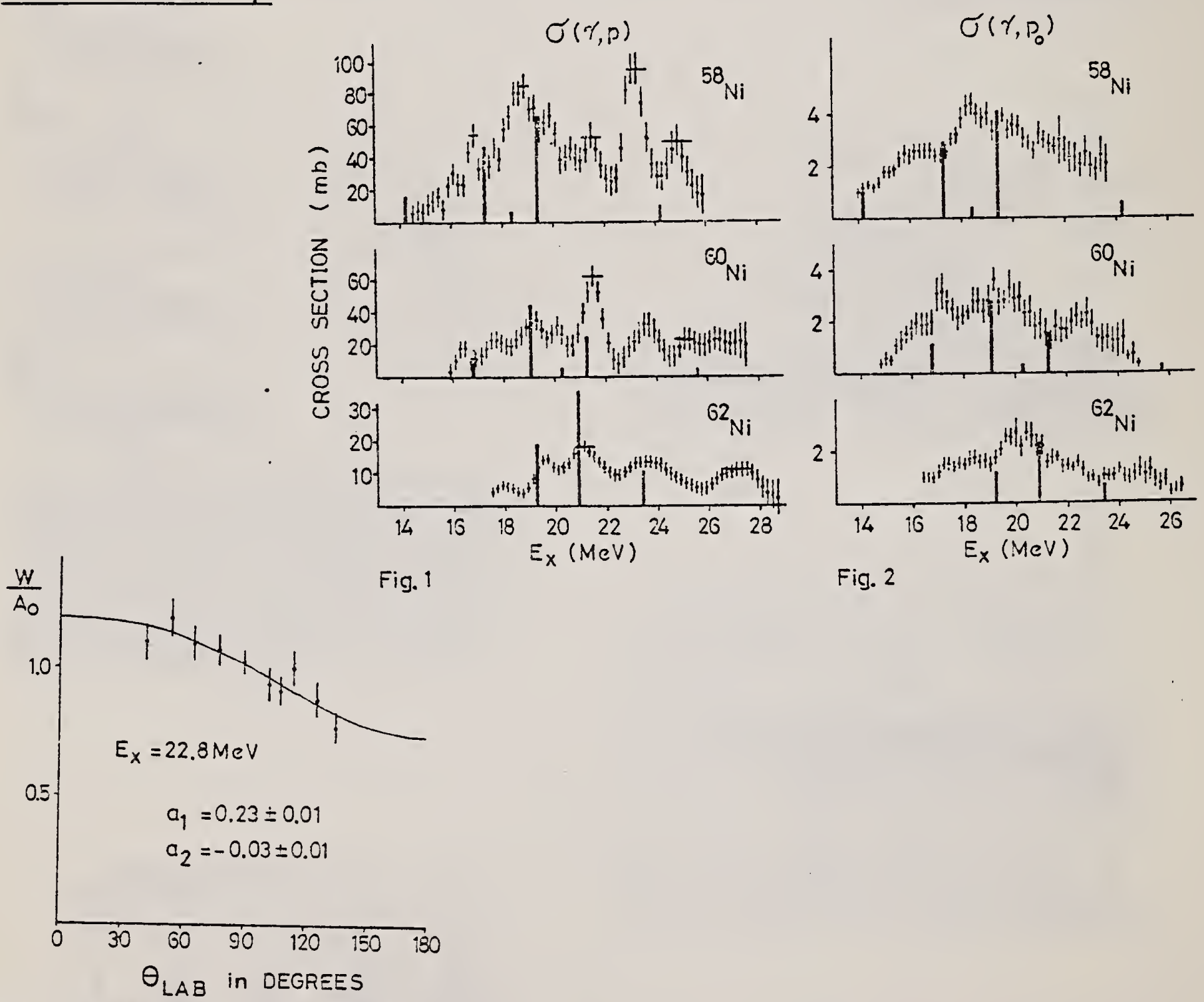

Fig. 3 Angular distribution in $60 \mathrm{Ni}\left(e, e^{\prime} ?_{0}\right)$ at $E_{X}=22.8 \mathrm{MeV}$. The curve is fit obtained with the series $1+a_{1} \mathrm{P}_{1}+a_{2} \mathrm{P}_{2}$. The values of $a_{1}$ and $a_{2}$ are listed in ine fixure. 
Table 1 Experimental and cheoretical results

\begin{tabular}{|c|c|c|c|c|c|c|}
\hline Nucleus & $I_{0}$ & $\int_{(m 0-M e V)} \sigma_{n}^{3)}$ & $\int_{(z b-y e v)} \sigma_{p}$ & $\int_{(m b-i ! e v)} \sigma_{n}+\int \sigma_{p}$ & $\frac{\int \sigma_{p}}{\int \sigma_{n}+\int \sigma_{p}}$ & $\frac{\left|c_{>}\right|^{2}}{\left|c_{<}\right|^{2}+\left|c_{>}\right|^{2}}$ \\
\hline${ }^{58} \mathrm{XI}$ & 1 & $310 \pm 30$ & $480 \pm 100$ & $790 \pm 130$ & 0.61 & 0.45 \\
\hline${ }^{s}{ }_{\text {si }}:$ & 2 & $620 \pm 50$ & $210 \pm 80$ & $830 \pm 130$ & 0.25 & 0.27 \\
\hline $62 \mathrm{vi}$ & 3 & & $110 \pm 25$ & & & 0.17 \\
\hline
\end{tabular}


REF. V. V. Verbinsk1, Hans Weber, and R. E. Sund

Phys. Rev. C8, 1002 (1973)

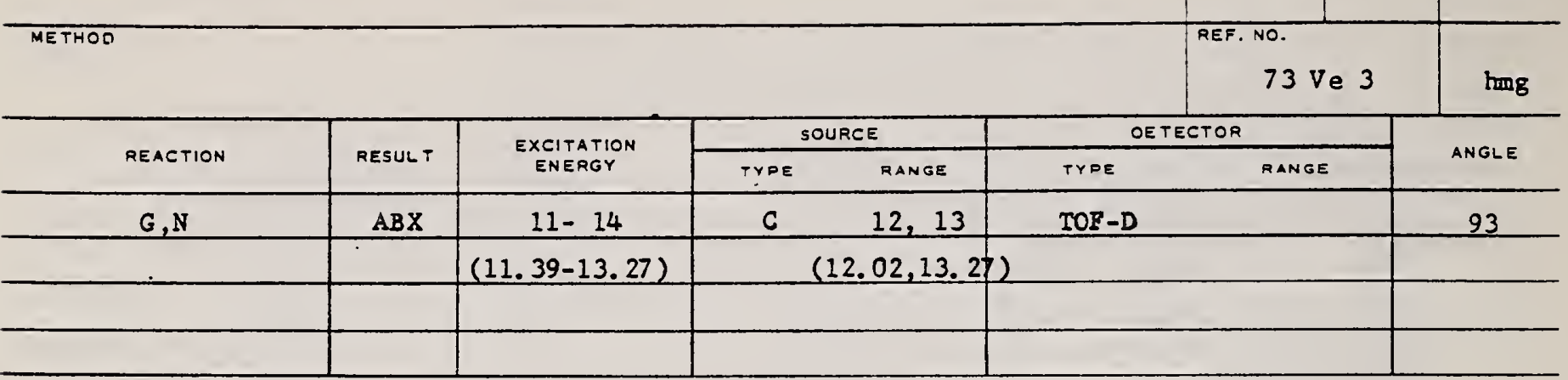

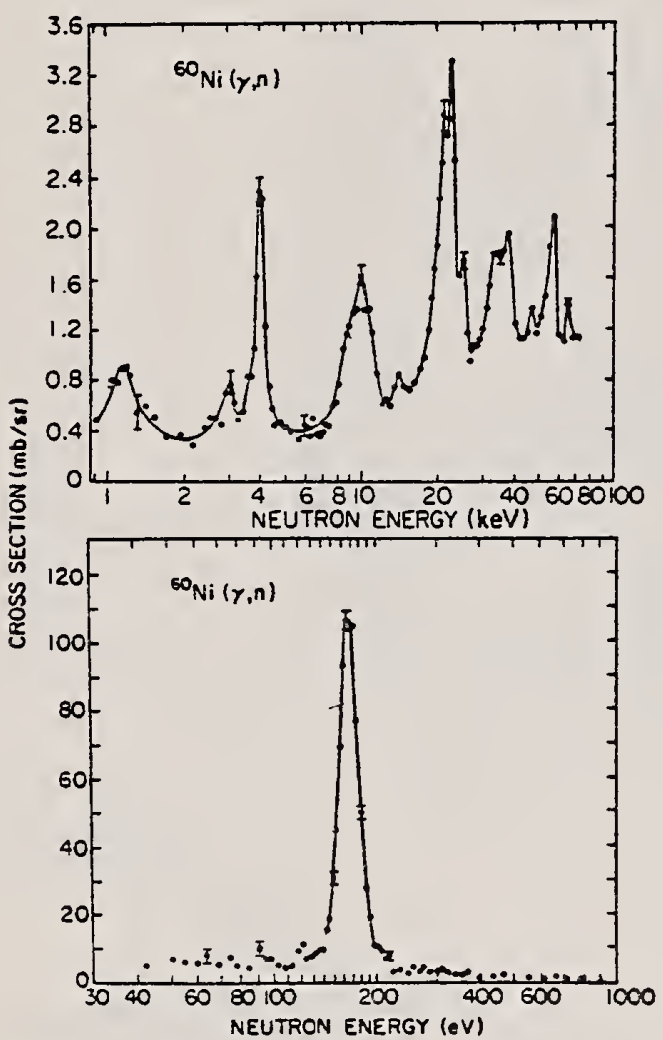

FIG. 2. The $93^{\circ}$ differential threshold photoneutron cross section for ${ }^{\circ} \mathrm{Ni}$ versus the energy of the ematted peutron. Electrons of $13.27-\mathrm{MeV}$ and $3 \%$ resolution were weident on the bremsstrablung converter.

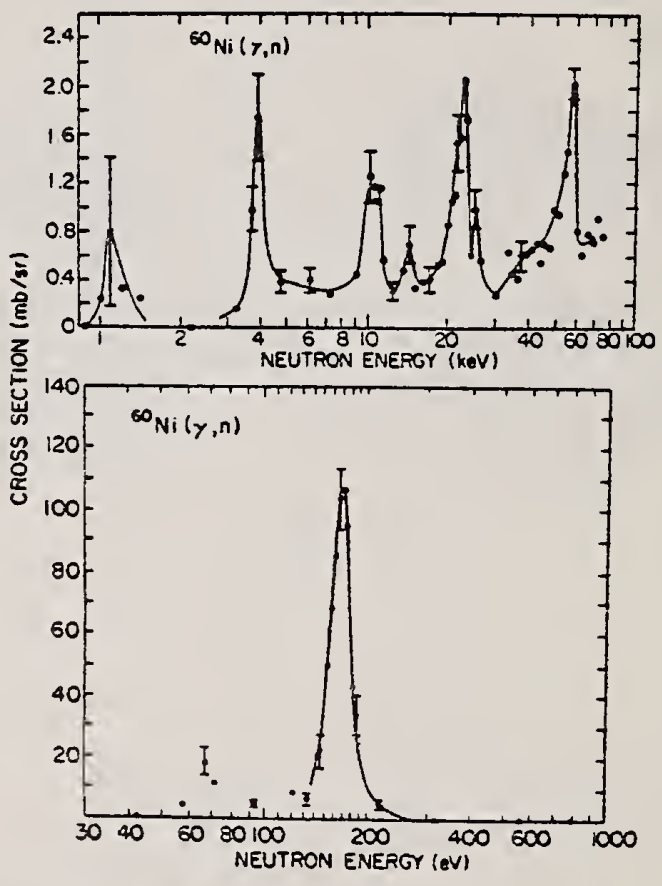

FIG. 3. The $93^{*}$ differential threshold photoneutron cross section for ${ }^{80} \mathrm{Ni}$ versus the energy of the emitted nextron. Electrons of $12.02-\mathrm{MeV}$ and $1 \%$ resolution were tneldent on the bremsstrablung converter. 
TABLE I. Resonance parameters from threshold ${ }^{60} \mathrm{Ni}(\gamma, n)$ data.

\begin{tabular}{|c|c|c|c|c|c|c|}
\hline $\begin{array}{l}\text { Neutron } \\
\text { energy } \\
\text { (kev) }\end{array}$ & $\begin{array}{l}\text { Width at } \\
\text { half maximum } \\
\text { (keV) }\end{array}$ & $\begin{array}{l}\text { Experimental } \\
\text { resolution } \\
\text { (keV) }\end{array}$ & $\begin{array}{c}\text { Ratio of peak area } \\
\text { for } E_{0}=13.27 \mathrm{MeV} \\
\text { to that } \\
\text { for } E_{0}=12.02 \mathrm{MeV}\end{array}$ & $\begin{array}{l}\text { Deexcitation to } \\
\text { ground state (G) } \\
\text { or to excited } \\
\text { states (E) of }{ }^{59} \mathrm{Ni}\end{array}$ & $\begin{array}{l}r \approx \Gamma_{0} \\
(\mathrm{keV})\end{array}$ & $\begin{array}{c}g \Gamma_{y 0} \Gamma_{n} / \Gamma \\
(\mathrm{eV})\end{array}$ \\
\hline 0.168 & 0.025 & 0.0013 & 0.93 & $\mathbf{G}$ & 0.025 & 0.65 \\
\hline $1.15(?)$ & $0.35(?)$ & 0.017 & 0.92 & $?$ & $0.35(?)$ & $0.051(?)$ \\
\hline 3.0 & $\sim 0.30$ & 0.065 & very lasge & $\mathrm{E}(\geq 0.878 \mathrm{MeV})$ & $\sim 0.29$ & \\
\hline 4.0 & 0.36 & 0.094 & 1.01 & G & 0.35 & 0.20 \\
\hline$\sim-9.0$ & 329 & 0.32 & Very large & $\mathrm{E}(\geq 0.878 \mathrm{MeV})$ & & \\
\hline 10.5 & $1.7\}^{2.9}$ & 0.38 & & $G(?)$ & 1.7 & 0.26 \\
\hline 14.2 & $\sim 1.2$ & 0.54 & 1.05 & G & $\sim 1.1$ & 0.065 \\
\hline 21.1 & 3 & $1.0)$ & & $E(?)$ & & \\
\hline 22.8 & 3.4 & $1.1\}$ & 1.5 & $E(0.340 \mathrm{MeV} ?)$ & & \\
\hline 25.5 & $?$ & $1.3)$ & & $?$ & & \\
\hline 33.7 & o & 2.0 & Very large & $E(\geq 0.878 \mathrm{MeV})$ & & \\
\hline 38.1 & 8 & 2.5 & Very large & $E(\geq 0.878 \mathrm{MeV})$ & & \\
\hline $47.5(? ?)$ & $?$ & 3.4 & & $?$ & & \\
\hline 57 & 5.4 & 4.6 & 0.74 & G & & \\
\hline 66 & $?$ & 5.6 & & 3 & & \\
\hline
\end{tabular}


REF.

G. S. Foote, D. Branford, R.A.I. Bell, and R.B. Watson

Nuc1. Phys. A220, 505 (1974)

74 Fo 2

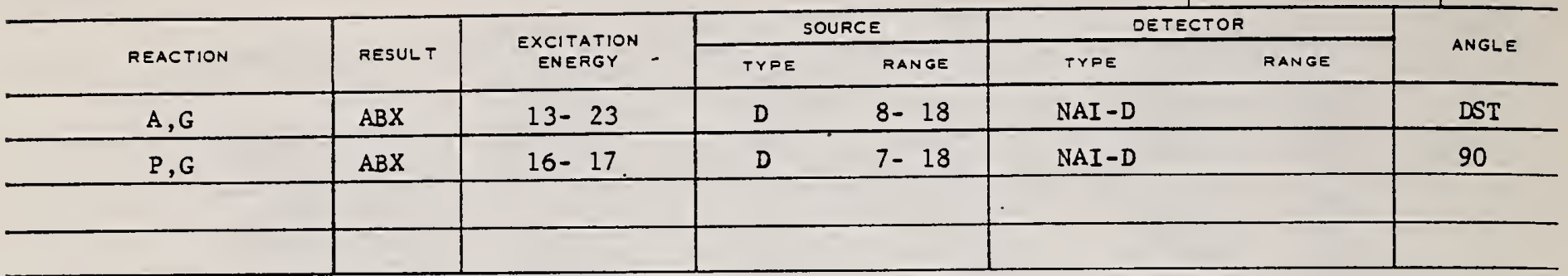

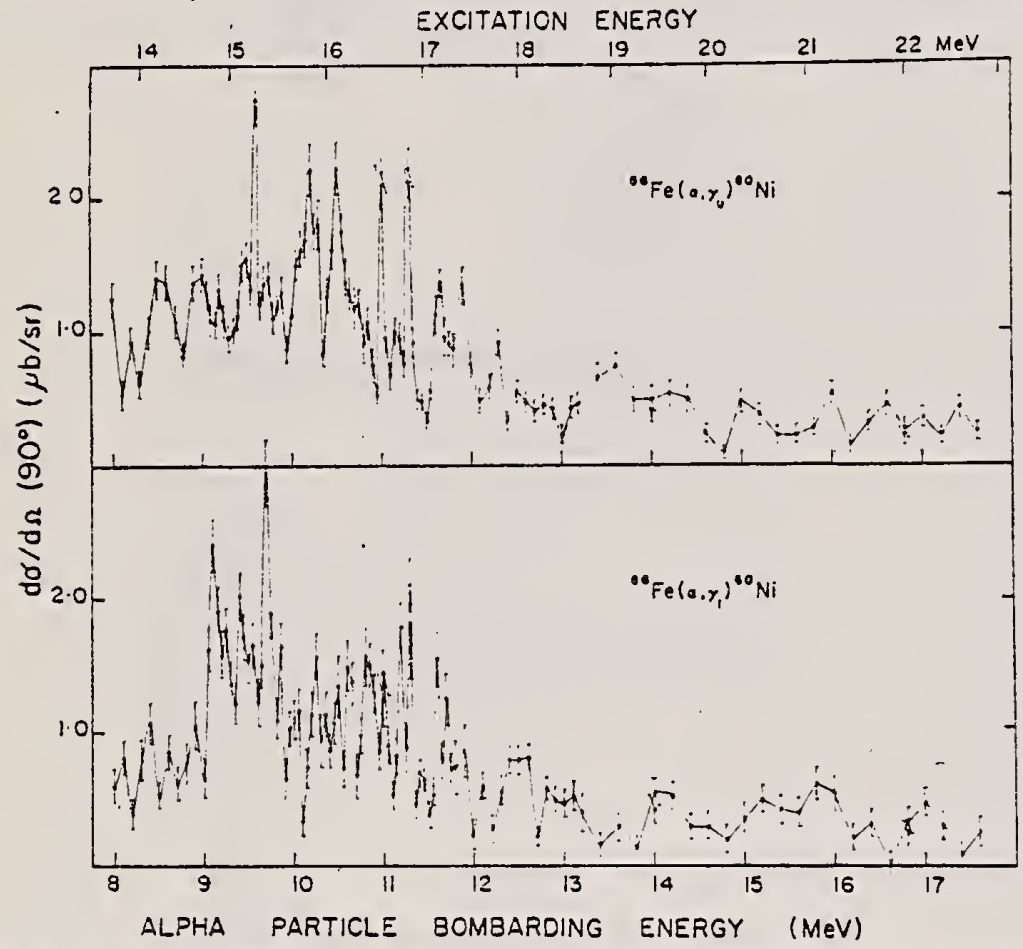

Fig. 2. The absolute differential cross sections for the ${ }^{56} \mathrm{Fe}\left(\alpha, \gamma_{0}\right)^{60} \mathrm{Ni}$ and ${ }^{56} \mathrm{Fe}\left(\alpha, \gamma_{1}\right){ }^{60} \mathrm{Ni}$ reaction at $90^{3}$ to the beam direction as a function of bombarding energy. The error bars represent statistical errors. The errors in the absolute values are $\pm 25 \%$.

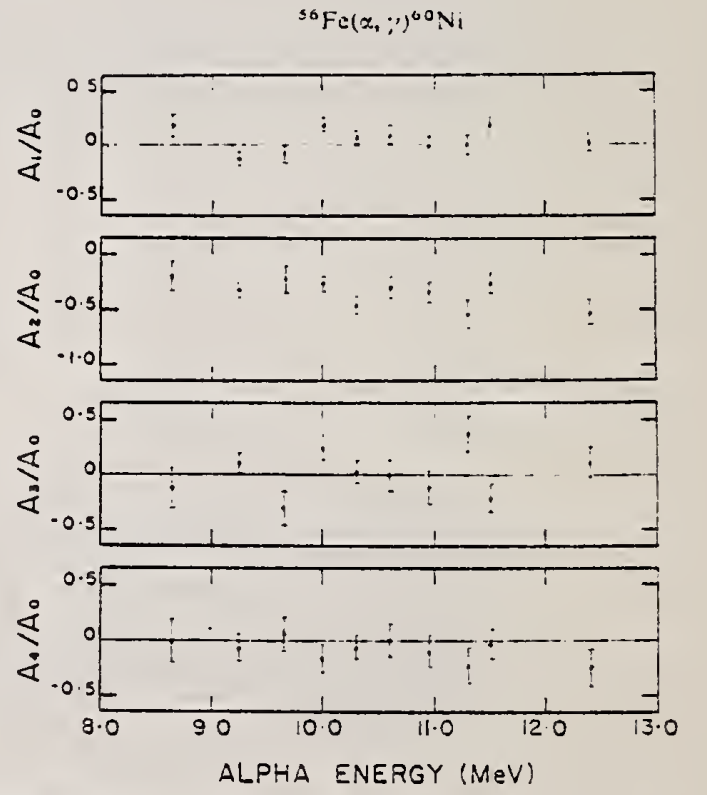

Fig. 7. Normalised Legendre coefficients determined by the method of least squires from the $\gamma_{0}$ angular distributions shown in fig. 5.

(over) 

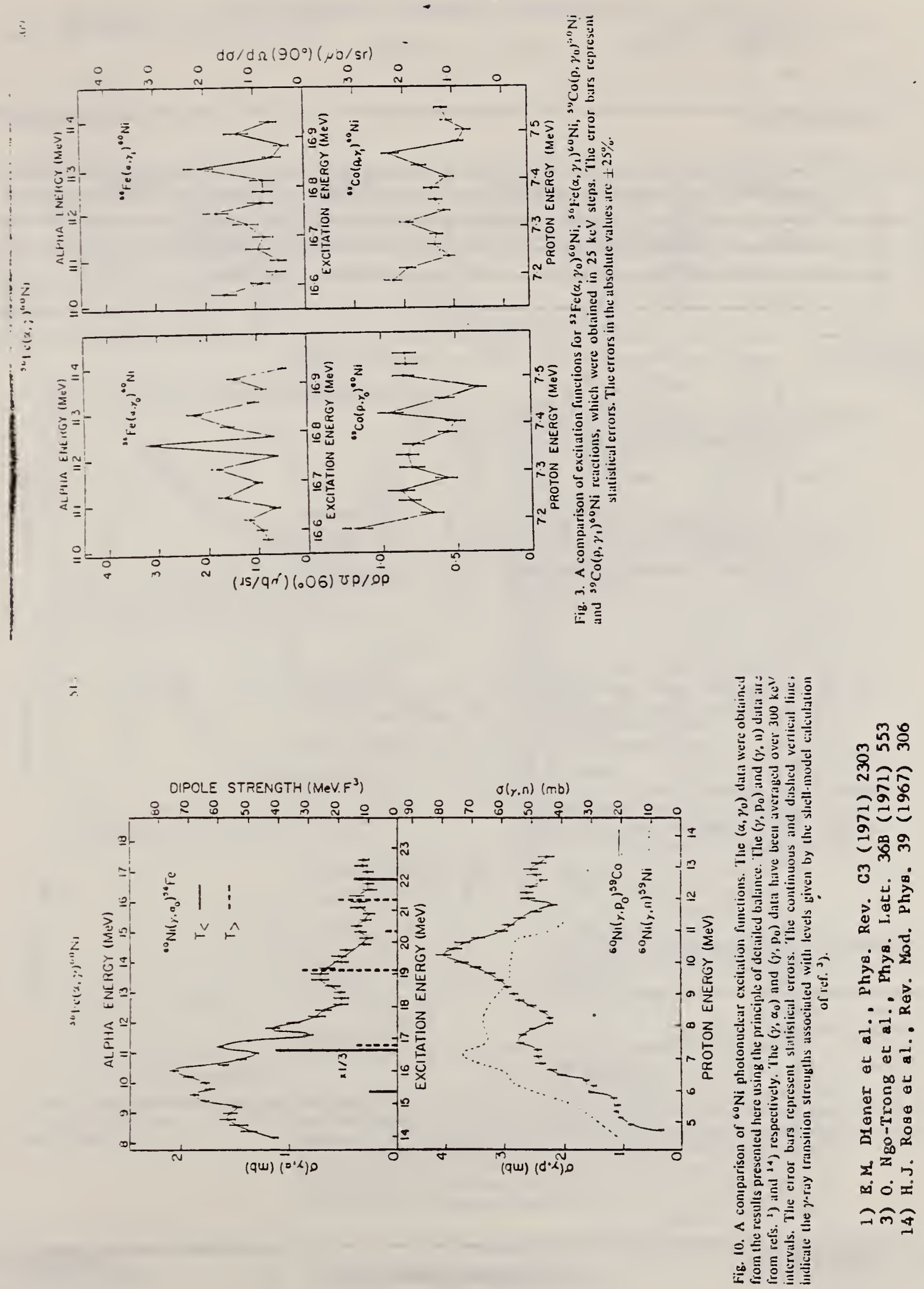
G.S. Foote, D. Branford, D.C. Weisser, N. Shikazono, and

J. Phys. A: Math., Nucl. Gen., I, L4 (1974)

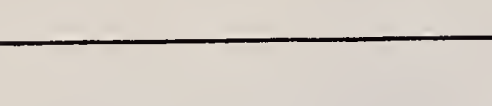

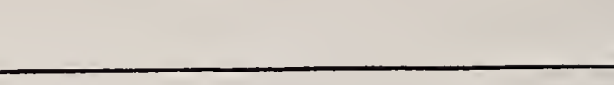

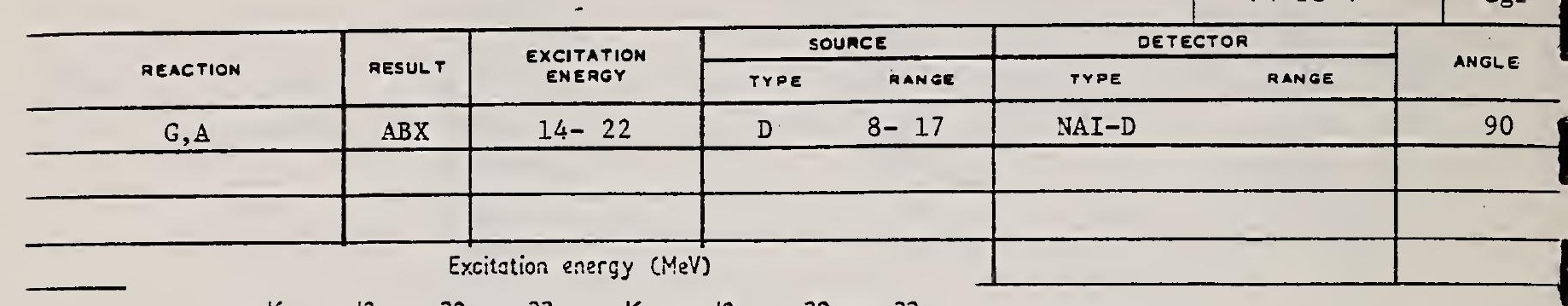

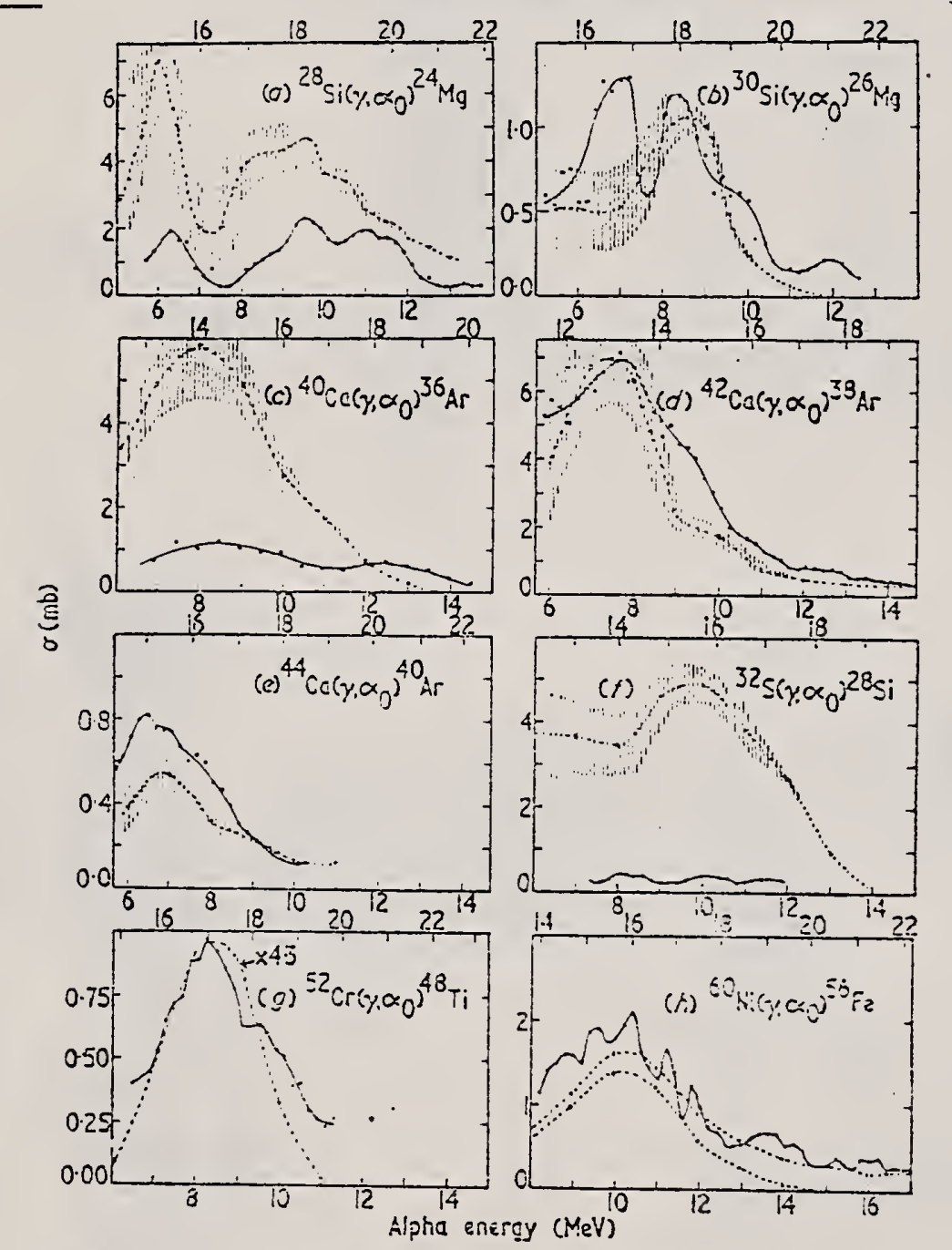

Finure 1. Excitation functions for the $\left(y, x_{0}\right)$ reaction obtained from $\alpha$ capture data using the principle of detailed balance. The data shown in $(a)$ and $(f)$ are from MeyerShutzmeister at al (1968). Those in (b) are from Vatson ef al (1973). The relative experimental errors are approximately $\pm 10 \%$. The absolute crrors are $\pm 25 \%$. The broken curves are the resilts of ealculations (see text). The vertical tines indicate the relative errors due to theertinties in the tetal piotonuclear cross sections ithere they are greater than $\pm 10 \%$. Tle cresses indicate the energies at which transmission coeffcienis were calculated.

\begin{tabular}{|c|l|l} 
ELEM. SYM. & A & z \\
$\mathrm{Ni}$ & 60 &
\end{tabular}

REF. NO.

74 Fo 4

egf 
S.C. Pultz, R.A. Alvarez, B.L. Berman, and P. Meyer

ReF. Phys. Rev. C10, 608 (1974)

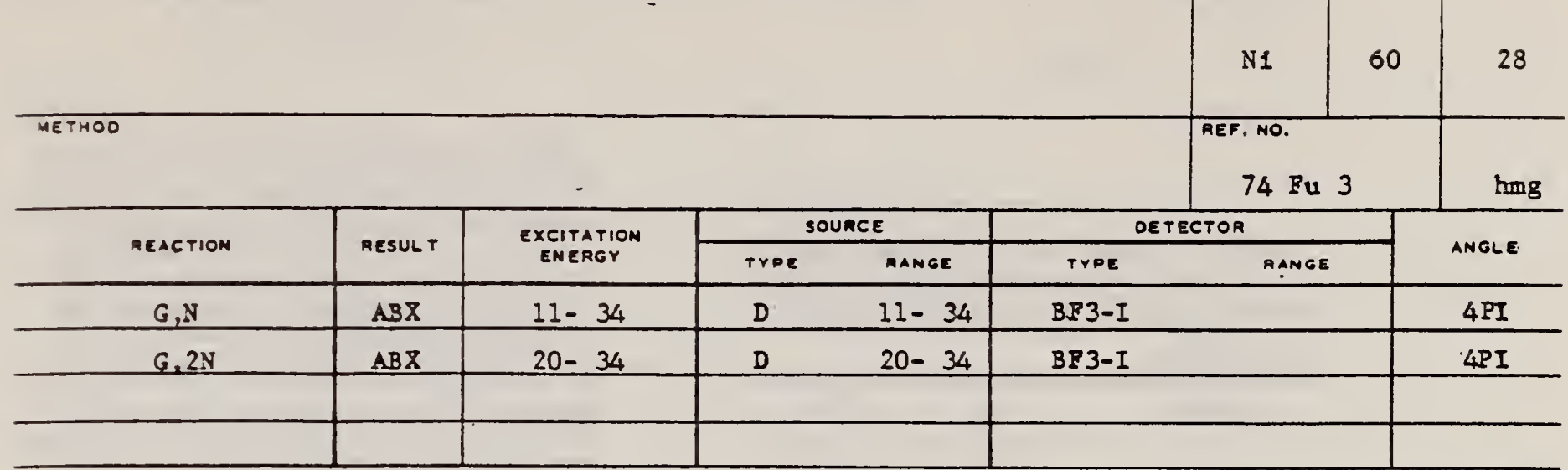
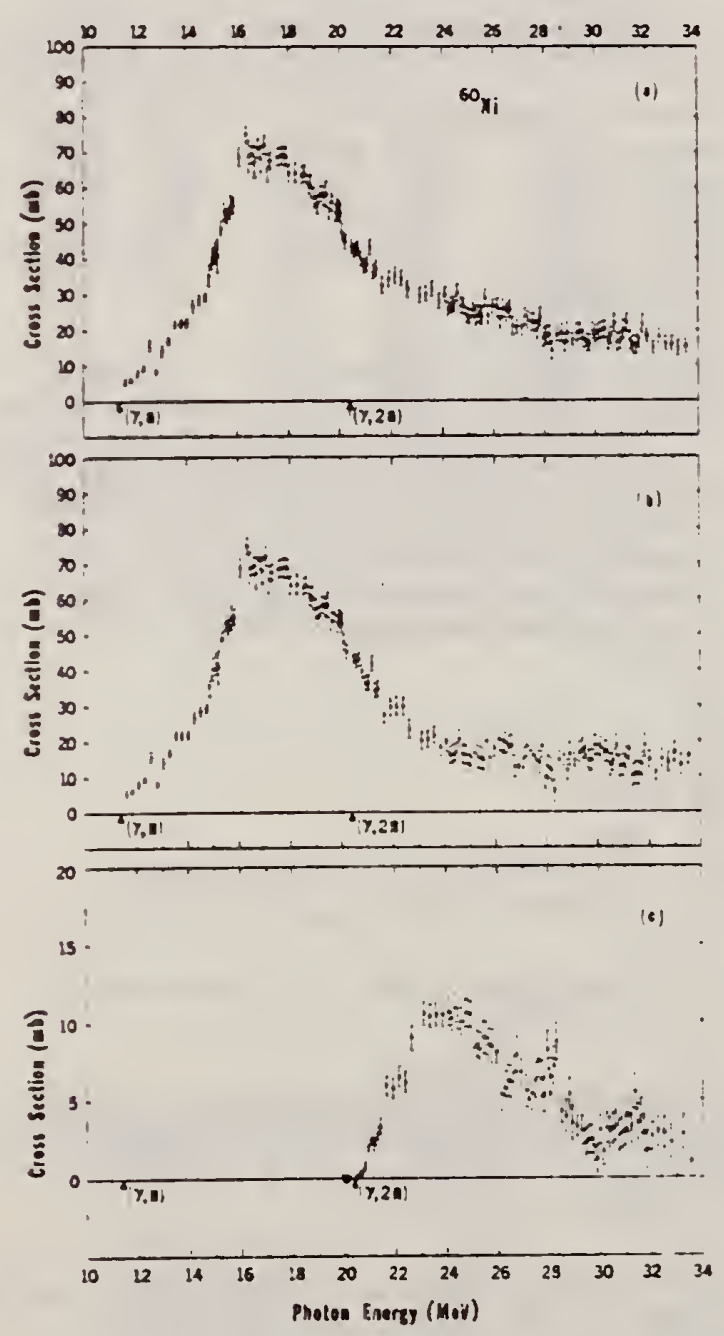

ITG. 3. Measured pbotoneutron cross sections for

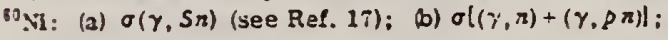
(c) $\sigma(\gamma, 2 n)$.

TABLE N. Comparison of lategrated total photoneutron cross sections $\sigma_{\text {int }}\left(\gamma, S_{n}\right)$ with those from previous experiments.

\begin{tabular}{lccc}
\hline Reference & $E_{y \text { max }}$ (MeV) & $\begin{array}{c}{ }^{58}{ }_{\mathrm{NI}} \\
\text { MeV mb) }\end{array}$ & $\begin{array}{c}{ }^{60} \mathrm{Ni} \\
\text { (MeV mb) }\end{array}$ \\
\hline This experiment & 30 & 256 & 643 \\
Ref. 6 (Moscow) & 30 & 310 & 620 \\
This experineat & 25 & 204 & 537 \\
Ref. 5 (Virginta) & 25 & 185 & 482 \\
\hline
\end{tabular}

(over) 


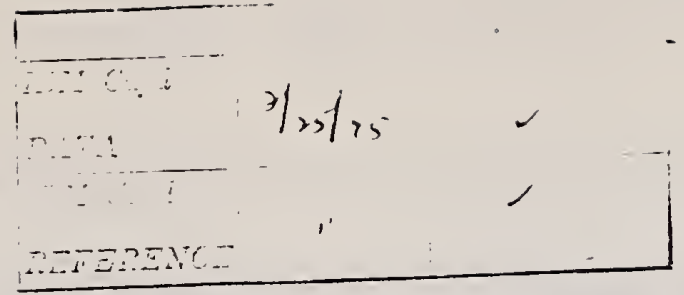

TABLE III. Energles (MtoV) at wilch peaks appear in be $\left(\gamma, S_{n}\right)$ cross sections of ${ }^{58} \mathrm{N1}$ and ${ }^{80} \mathrm{NI}$. The energies jisted are those at wiich peaics or shoulders exist in the cross section. Acrual resonance energies might be sllghtly dufferent.

\begin{tabular}{ccc}
\hline Peak No. & ${ }^{58} \mathrm{Ni}$ & ${ }^{60} \mathrm{Ni}$ \\
\hline 1 & 12.3 & 12.6 \\
2 & 12.8 & 13.7 \\
3 & 13.1 & 14.4 \\
4 & 13.6 & 15.1 \\
5 & 14.2 & 15.5 \\
6 & 15.7 & 16.3 \\
7 & 16.3 & 17.0 \\
8 & 17.3 & 17.7 \\
9 & 17.7 & 18.6 \\
10 & 18.2 & 19.6 \\
11 & 18.6 & 21.2 \\
12 & 19.3 & 22.1 \\
13 & 22.6 & 24.5 \\
14 & 23.8 & \\
15 & 24.9 & \\
16 & 25.7 & \\
\hline
\end{tabular}

- We have included in the tabulations only the more well-defined peaks (or shoulders). In addition there are possible broad peaks at approximately 20.7, 27.8, and $30.9 \mathrm{MeV}$ in ${ }^{58} \mathrm{N1}$, and at 23.5, 26.1, 27.5, and $30.3 \mathrm{MeV}$ In ${ }^{6 \mathrm{XI}}$, but the data are not sufficiently detailed to make a more cefinitive judgment about these.
TABLE V. Integrated total photon absorption cross sections and related quantities from the combined data of the present experiment and Ref. 7 . The $\left(\gamma, X_{p}\right)$ cross sections of Ref. $i$ bave been used rather than those of Ref. 8 because the former extend over a wider energy range: in their mutually inclusive energy range (see Figs. 5 and 6) the integrated cross sectors from the two $(\gamma, X p)$ measurements agree to within $2 \%$ for ${ }^{58} \mathrm{NI}$ and $10 \%$ for ${ }^{60} \mathrm{NI}$, the values derived from the data of Ref. 8 being the larger in both cases. The total photon absorption cross section $\sigma(\gamma$, total $)$ is assumed to be equal to $\sigma(\gamma, S n) \div \sigma(\gamma, X p)$; that is the photon scattering cross section is assumed to be negligible and double counting, owing to the presence of $\sigma(\gamma, p n)$ in both $\sigma(\gamma, S n)$ and $\sigma(\gamma, X p)$, is ignored. The latter effect is reasonably compensated for, however (see footnote a).

\begin{tabular}{|c|c|c|c|c|}
\hline \multirow[b]{2}{*}{$E_{y} \max$} & \multicolumn{2}{|r|}{${ }^{58} \mathrm{N1}$} & \multicolumn{2}{|r|}{${ }^{60} \mathrm{Ni}$} \\
\hline & 33.5 & $\mathrm{MeV}^{*}$ & 33.5 & $\mathrm{MeV}$ \\
\hline$\sigma_{\text {init }}(\gamma$, total $)$ & 850 & $\mathrm{MeVmb}$ & 1025 & $\mathrm{MeV} \mathrm{mb}$ \\
\hline$\sigma_{-1}(\gamma$, total $)$ & 41.3 & $m b$ & 48.7 & $\mathrm{mb}$ \\
\hline$\sigma_{-2}(\gamma$, total $)$ & \multicolumn{2}{|c|}{$2.09 \mathrm{mb} \mathrm{MeV}^{-1}$} & \multicolumn{2}{|c|}{$2.62 \mathrm{mb} \mathrm{MeV}^{-1}$} \\
\hline $\begin{array}{c}\sigma_{\text {int }}(\gamma, \text { total }) / \\
(60 N Z / A)\end{array}$ & \multicolumn{2}{|c|}{0.98} & \multicolumn{2}{|c|}{1.10} \\
\hline$\sigma_{-1}(\gamma$, total $) / A^{1 / 3}$ & \multicolumn{2}{|c|}{0.18} & \multicolumn{2}{|c|}{0.21} \\
\hline$\sigma_{-2}(\gamma$, total $) / A^{5 / 3}$ & \multicolumn{2}{|c|}{0.00264} & \multicolumn{2}{|c|}{0.00286} \\
\hline
\end{tabular}

The $(\gamma, X p)$ data extend only to $30.1 \mathrm{MeV}$ for ${ }^{58} \mathrm{~N} 1$ and $30.5 \mathrm{MeV}$ for ${ }^{60} \mathrm{Ni}$; above these energies we have used the $(\gamma, S n)$ cross section only. Since much of the highenergy cross section probably comes from the $(\gamma, p n)$ process, the error introduced is probably small and might very well compensate for the double counting of the $(\gamma, p n)$ cross section below $30 \mathrm{MeV}$.

${ }^{5}$ K. Min and T.A. White, Phys. Rev. Lett. 21, 1200 (1968). 6

B.I. Goryachev, B.S. Ishkhanov, I.M. Kapitonov, I.M. Piskarev, V.G. Shevchenko, and O.P. Shevchenko, Yad. Fiz. 10, 252 (1969); Sov. J. Nucl. Phys. 11, 141 (1970). 7

B.S. Ishkanov, I.M. Kapitonov, I.M. Piskarev, V.G. Shevchenko, and 0.P. Shevchenko; Yad. Fiz. 11, 485 (1970); Sov. J. Nucl. Phys. 11, 272 (1970). 8

K. Shoda, private communication; see also H. Miyase, S. Oikawa, A. Suzuki, J. Uegaki, T. Saito, M. Sugawara, and K. Shoda, in Proceedings of the International Conference on Photonuclear Reactions and Applications, Asilomar, March, 1973, ed. by B.L. Berman (Lawrence Livermore Laboratory, Livermore, 1973) p.553. 17

In our reaction notation we have essentially adopted the convention used by E.G. Fuller, H.M. Gerstenberg, H. Vander Molen, and T.C. Dunn NBS SP-380, 1973; wherein ( $\gamma, S n)$ represents the sum of all neutron-producing reactions, ( $\gamma$, Xp) denotes total proton yield, etc. We use $(\gamma, p n)$ to represent either the $(\gamma, n p)$ or $(\gamma, p n)$ reaction, since experimentally the two are indistinguishable. 
R. Yen, L. S. Cardman, D. Kalinsky, J. R. Legg,

C. K. Bockelman

Nucl. Phys. A235, 135 (1974)

$\mathrm{Ni}$

60

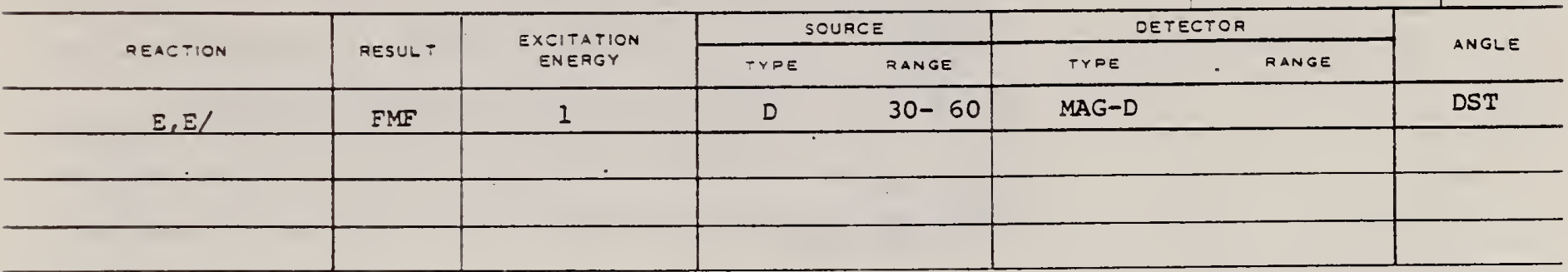

TABLE 2

Experimental data for the ${ }^{60} \mathrm{Ni} 2+(1.332 \mathrm{MeV})$ state

\begin{tabular}{|c|c|c|c|c|c|c|c|c|}
\hline$E_{0}(\mathrm{MeV})$ & $\theta(\operatorname{deg})$ & $q\left(\mathrm{fm}^{-1}\right)$ & $\left|F_{\text {es }}\right|^{2}$ & $10^{2} \times R_{1}$ & $10^{2} \times ! F_{10 i^{2}}$ & $10^{2} \times\left|F_{1 \mathrm{n}}\right|^{2} \mathrm{~N}$ & Error(\%) & $x^{2 / n}$ \\
\hline 59.89 & 110 & 0.492 & 0.225 & 0.675 & 0.167 & 0.167 & 5.2 & $s / 28$ \\
\hline 4247 & 130 & 0.384 & 0.465 & 0.239 & 0.117 & 0.110 & 7.3 & $12 / 29$ \\
\hline 42.45 & 130 & 0.384 & 0.466 & 0.223 & 0.109 & 0.103 & 8.3 & $10 / 28$ \\
\hline 4247 & 110 & 0.347 & 0.564 & 0.154 & 0.0907 & $0.08 \leq 0$ & 6.4 & $16 / 28$ \\
\hline 42.44 & 110 & 0.347 & 0.565 & 0.130 & 0.0764 & 0.0717 & 7.5 & $16 / 28$ \\
\hline 42.53 & 90 & 0.301 & 0.693 & 0.0812 & 0.0564 & 0.0529 & 9.0 & $30 / 27$ \\
\hline 42.46 & 90 & 0.300 & 0.696 & 0.0727 & 0.0522 & 0.0488 & 9.6 & $28 / 29$ \\
\hline 31.67 & 130 & 0.285 & 0.772 & 0.0640 & 0.0509 & 0.0449 & 11.9 & $S / 18$ \\
\hline 42.47 & 70 & 0.243 & 0.846 & 0.0351 & 0.0303 & 0.0284 & 18.3 & $20 / 23$ \\
\hline 42.47 & 70 & 0.243 & 0.846 & 0.0321 & 0.0277 & 0.0260 & 16.6 & $16 / 28$ \\
\hline
\end{tabular}

Ground-state charge distributions parameters ${ }^{21}$ ): $c=4.15=0.017 \mathrm{fm}, t=2.54=0.02 \mathrm{fm}$.

TABLE 4

Results of the best-fits by allowing both $B\left(E 2_{1}^{A}\right)$ and $R_{t r}^{\prime 2 \prime}$ as free parameters

\begin{tabular}{|c|c|c|c|c|c|c|c|c|c|c|}
\hline & \multicolumn{7}{|c|}{ Assumptions } & \multicolumn{3}{|c|}{ Results } \\
\hline & $\bar{z}$ & $R_{\operatorname{mog}}(\mathrm{fm})$ & $a_{-1}$ & $\overline{a_{1}}$ & $\overrightarrow{a_{3}}$ & $a_{4}$ & $a_{3}$ & $B(E 2 \hat{\imath})\left(e^{2} \cdot b^{2}\right)$ & $R_{u}^{(2)}\left(\mathrm{fm}^{2}\right)$ & $x^{2} / n$ \\
\hline $114 \mathrm{Cd}$ & 48 & 4.624 & 1.045 & 0.933 & 1.056 & 1.158 & 1.323 & $0.553=0.018$ & $38.1 \doteq 1.0$ & 1.12 \\
\hline${ }^{60} \mathrm{Ni}$ & 28 & 3.862 & 1.075 & 0.976 & 1.078 & 1.024 & 1.471 & $0.102=0.004$ & $31.9 \doteq 2.0$ & 0.60 \\
\hline${ }^{6} \mathrm{Li}$ & 3 & 2.540 & 1.208 & 0.941 & 1.189 & 1.572 & 2.290 & $(0.218 \doteq 0.008) \times 10^{-2}$ & $17.6 \doteq 1.2$ & 1.05 \\
\hline
\end{tabular}

TABLE 6

Summary of $B\left(E 2_{i}\right)$ values for the ${ }^{60} \mathrm{Ni} 2^{*}(1.332 \mathrm{MeV})$ stat

\begin{tabular}{ccc}
\hline$B(E 2 i)\left(e^{2} \cdot b^{2}\right)$ & $\begin{array}{c}\text { Type of } \\
\text { experiment }\end{array}$ & Ref. \\
\hline $0.087 j \pm 0.0070$ & $\left(e, e^{\prime}\right)$ & $34)$ \\
$0.0938 \pm 0.0020$ & $\left(y_{1} \gamma^{\prime}\right)$ & $36)$ \\
$0.0992 \pm 0.0099$ & $\left(e, e^{\prime}\right)$ & $37)$ \\
$0.0914 \pm 0.0020$ & $C E$ & $38)$ \\
$0.117 \pm 0.009$ & h.p. & $39)$ \\
$0.0845 \pm 0.0009$ & $\left(e, e^{\prime}\right)$ & $40)$ \\
$0.097 \pm 0.008$ & $C E$ & $41)$ \\
\hline
\end{tabular}

(over) 
21 V.M. Khvastunov et al, Yucl. Phys. Al46, 15 (1970).

36) F. R. Metzger, Nuel. Phys. A148 (1970) 362

37) Y. Torizuka,-Y. Kojima, M. Oyamada, K. Nakahara, K. Sugiyama, T. Terasawa, K. Itoh, A. Yamaguchi and M. Kimura, Phys. Rev. 185 (1969) 1499

38) D. Cline, H. S. Gertsman, H. E. Gove, R. M. S. Lesser and J. J. Schwarzz, Nucl. Phys. A133 (1969) 445

39) R. K. Golby, M. D. Goldberg and A. K. Sengupta. Nucl. Phys. A123 (1969) 54

40) M. A. Duguay, C. K. Bockelman, T. H. Curtis and R. A. Eisenstein, Phys. Rev. 171 (1968) 1142

41) P. H. Stelson and L. Grodzins, Nuclear Data, seet. A, vol. 1, no. 1 (Academic Press, New: York, 1965)

54) R. P. Sirghal, S. W. Bram, W. A. Gillespie, A. Johnston, E W. Lees and A. G. Slight, Nuel. Phys. A218 (1974) 189

TABLE 7

Best fits of $R_{4}^{(2)}$ with $B(E 2 \uparrow)$ fixed

\begin{tabular}{lccccccc}
\hline & $R_{t r}^{2}\left(\mathrm{fm}^{2}\right)$ & $\begin{array}{c}\text { Statistical } \\
\text { error }\left(\mathrm{fm}^{2}\right)\end{array}$ & $\begin{array}{c}\text { Systematic } \\
\text { error }\left(\mathrm{fm}^{2}\right)\end{array}$ & $\begin{array}{c}\text { Totid } \\
\text { error }\left(\mathrm{fm}^{2}\right)\end{array}$ & $\chi^{2} / n$ & $\begin{array}{c}B\left(\mathrm{E} \mathrm{R}^{4}\right)\left(\mathrm{e}^{2} \cdot \mathrm{b}^{2}\right) \\
\text { assumed }\end{array}$ \\
\hline${ }^{114} \mathrm{Cd}$ & 35.7 & \pm 0.6 & \pm 0.3 & \pm 0.9 & 1.19 & $0.312 \pm 0.05$ \\
${ }^{60 \mathrm{Ni}}$ & 27.5 & \pm 1.1 & \pm 0.8 & \pm 1.9 & 0.66 & $0.0926 \pm 0.15$ \\
\hline
\end{tabular}


2e₹. V.Ya. Kitaev, A.I. Abramov, A.V. Rogov, and M.G. Yutkin

Izv. Akad. Nauk SSSR, Ser. Fiz. 39,1754 (1975)

Bull. Acad. Sci. USSR Phys. Ser. 39,159 (1975)

\begin{tabular}{|c|c|c}
$\begin{array}{c}\text { ELEM. SYM. } \\
\mathrm{Ni}\end{array}$ & A & $\mathrm{z}$ \\
\hline $\begin{array}{c}\text { REF. NO. } \\
75 \mathrm{Ki} 12\end{array}$ & $\mathrm{hmg}$ \\
\hline
\end{tabular}

\begin{tabular}{|c|c|c|c|c|c|c|c|}
\hline \multirow{2}{*}{ REACTION } & \multirow{2}{*}{ RESULT } & \multirow{2}{*}{$\begin{array}{l}\text { EXCITATION } \\
\text { ENERGY }\end{array}$} & \multicolumn{2}{|c|}{ SOURCE } & \multicolumn{2}{|c|}{ DETECTOR } & \multirow{2}{*}{ ANGLE } \\
\hline & & & TYPE & RANGE & TYPE & RANGE & \\
\hline $\mathrm{G}, \mathrm{N}$ & $A B X$ & $11-13$ & $C$ & $11-13$ & TOF -D & & 78 \\
\hline & & & & & & & \\
\hline & & & & & & & \\
\hline
\end{tabular}

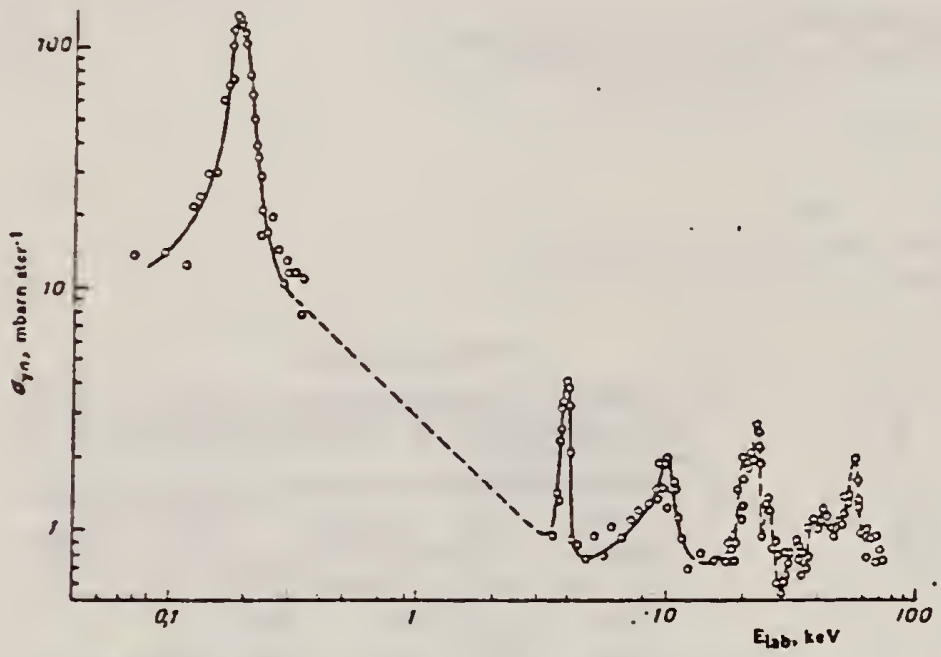

Fig. 1. Measurements of the differential cross sections for the ${ }^{60} \mathrm{Ni}\left(y_{n}\right){ }^{59} \mathrm{Ni}$ reaction at $78^{\circ}$ for $\varepsilon_{\gamma}^{\max }=12.5 \mathrm{MeV}$. Solid line - results of an analysis of experimental data based on the Pade aoproxination of the second kind. Broken line drawn by "eye."

Table 1

Energies of the Resonances in the ${ }^{60} 1 \mathrm{Hi}\left(\gamma_{n}\right){ }^{59} \mathrm{Ni}$ Reaction Near the Threshold

\begin{tabular}{|c|c|c|c|c|c|c|c|c|}
\hline$\underset{k \in V}{E_{l \rightarrow b}^{0}}$ & $E_{k \in v}$ & \begin{tabular}{|l|} 
Final nucle us \\
erannition into \\
sround (z) \\
or Excuted \\
(E) state
\end{tabular} & $\sum_{k \in v}^{0}$ & $E_{\mathrm{kem},}$ & 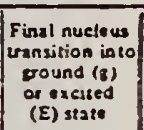 & $\sum_{\mathrm{iab}, 0}^{0}$ & $\begin{array}{l}E_{\mathrm{em} .} \\
\mathrm{kev}\end{array}$ & $\begin{array}{l}\text { Final nucleus } \\
\text { transition into } \\
\text { Eound (8) } \\
\text { or excited } \\
(\varepsilon) \text { state }\end{array}$ \\
\hline $\begin{array}{l}0,198 \\
11 \\
10.8 \\
21,0\end{array}$ & $\begin{array}{c}0.199 \\
4.07 \\
10.6 \\
21.1\end{array}$ & $\begin{array}{l}8 \\
8 \\
8\end{array}$ & $\begin{array}{l}23.0 \\
25.9 \\
33,8\end{array}$ & $\begin{array}{l}23.1 \\
26.0 \\
34.6\end{array}$ & $\begin{array}{l}B \\
E ? \\
E ?\end{array}$ & $\begin{array}{l}39.6 \\
43.3 \\
51\end{array}$ & $\begin{array}{l}39,9 \\
43.7 \\
57,6\end{array}$ & $\begin{array}{l}E ? \\
E ? \\
8\end{array}$ \\
\hline
\end{tabular}

Table 2

Resonance Parameters of ${ }^{60} \mathrm{Ni}$ Levels

\begin{tabular}{|c|c|c|c|}
\hline Elub $_{k=V}^{0}$ & $\begin{array}{c}\sigma_{i .} \\
\text { mbern- } \\
\text {-ster }\end{array}$ & r.eV & $e^{r}{ }^{\Gamma}$ \\
\hline $\begin{array}{c}0,198 \\
4,115 \\
10,59\end{array}$ & $\begin{array}{c}129 \\
5,58 \\
2,0\end{array}$ & $\begin{array}{r}39.7 \\
160 \\
2100\end{array}$ & $\begin{array}{l}1,62 \\
0,284 \\
1,31\end{array}$ \\
\hline
\end{tabular}


76 Li 6

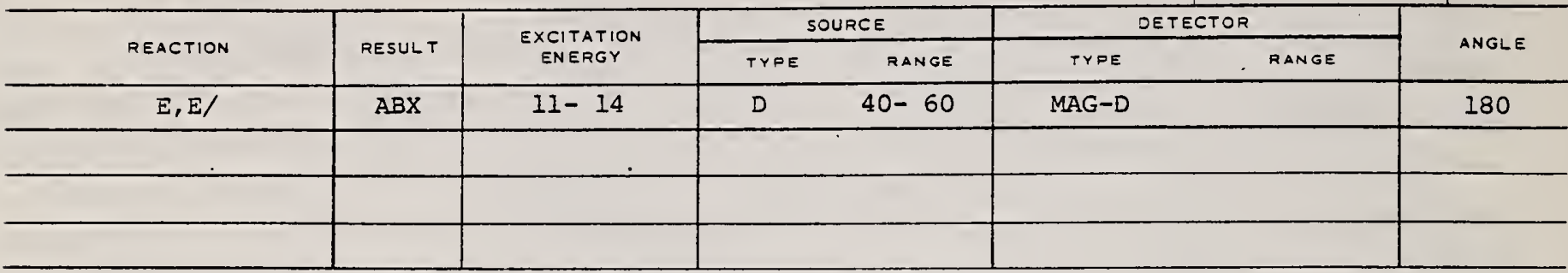

Using inelastic electron seartering, several isobaric anaiog $\mathrm{L}^{+}$states between 9 and $13 \mathrm{MeV}$ excitation in ${ }^{5 /} \mathrm{Ni}$ and "Ni have been found. They are identified as components of the $T_{0}+1$ giant $M 1$ state in ${ }^{30,00} \mathrm{Ni}$.

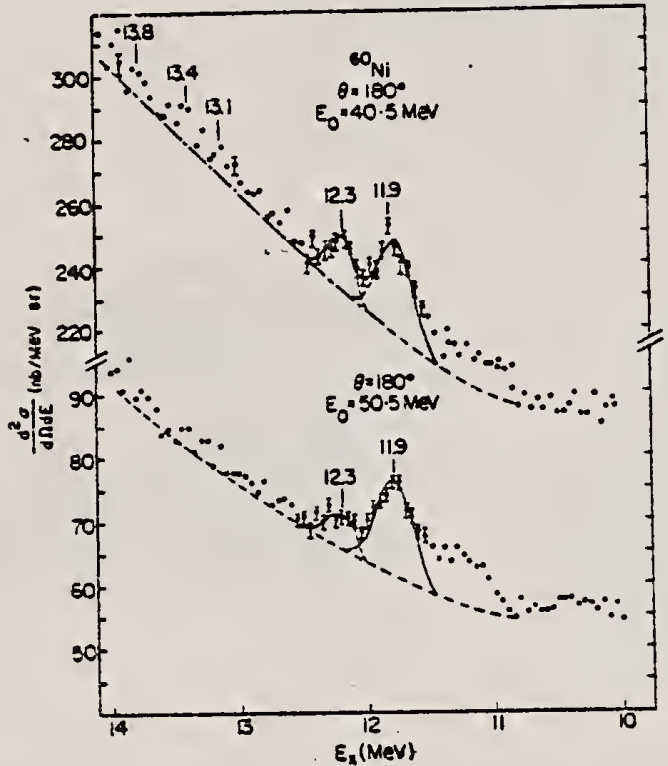

FTG. 5. Portion of spectrum observed at $\theta=180^{\prime \prime}$ from 40.5 and $50.5 \mathrm{MeV}$ electrons incident con $2^{80} \mathrm{Ni}$ target.
TABLE $\pi$. Measured excitatioc energies, $f^{\pi}$ assignments, and reduced $M$ transition probablitites for levels in ${ }^{58,60} \mathrm{NI}$.

\begin{tabular}{|c|c|c|c|c|c|}
\hline \multirow{2}{*}{$\begin{array}{c}E_{x}(\mathrm{MeV}) \\
\operatorname{Exp}^{2}\end{array}$} & \multirow{2}{*}{$J^{\pi}$} & \multicolumn{2}{|c|}{$E_{x}(\mathrm{MeV})$} & \multirow{2}{*}{$\begin{array}{l}B(M I) 6 \\
\left(\mu_{m}^{2}\right)^{C}\end{array}$} & \multirow{2}{*}{$\begin{array}{l}\Gamma(M I) \\
(\mathrm{eV})^{d}\end{array}$} \\
\hline & & Predicted & Parent & & \\
\hline${ }^{58} \mathrm{NI}$ & & ${ }^{58} \mathrm{NI}$ & ${ }^{58} \mathrm{Co}$ & & \\
\hline 9.85 & $\left(1^{+}\right)$ & 9.87 & 1.05 & $(0.32)^{e}$ & $(3.4)^{e}$ \\
\hline 10.18 & $1^{+}$ & 10.25 & 1.43 & 0.59 & 7.2 \\
\hline 10.55 & $1^{+}$ & 10.55 & 1.73 & 0.21 & 3.0 \\
\hline 10.66 & $1^{+}$ & 10.68 & 1.86 & 0.41 & 5.7 \\
\hline 11.03 & $1^{+}$ & 11.06 & 2.21 & 0.36 & 5.6 \\
\hline${ }^{80} \mathrm{NI}$ & & ${ }^{50} \mathrm{NI}$ & ${ }^{50} \mathrm{Co}$ & & \\
\hline 11.9 & $1^{+}$ & 11.87 & 0.74 & 0.46 & 8.9 \\
\hline 12.3 & $1^{*}$ & 12.34 & 1.21 & 0.26 & 5.6 \\
\hline 13.1 & $\left(I^{+}\right)$ & 13.11 & 1.98 & $\leq 0.06$ & $\leq 1.5$ \\
\hline 13.4 & $\left(I^{+}\right)$ & 13.35 & 2.22 & $\leq 0.00$ & $\leq 1.6$ \\
\hline 13.8 & $\left(I^{+}\right)$ & 13.84 & 2.71 & $\leq 0.06$ & $\leq 1.8$ \\
\hline
\end{tabular}

2 Energy uncertainty is $\pm 0.04 \mathrm{MeV}$ in ${ }^{58} \mathrm{NI}$ and $\pm 0.1 \mathrm{MeV}$ ln ${ }^{80} \mathrm{NI}$.

Tu get predicted energy in ${ }^{58} \mathrm{Ni}$ add $8.82 \mathrm{MeV}$ to excitation energles in ${ }^{58} \mathrm{Co}$ and for ${ }^{60} \mathrm{Ni}$ add $11.13 \mathrm{MeV}$.

'MI strength uncertalnty is estimated to be about $\pm 25 \%$ for individual levels.

$\Gamma(M 1)=0.0115 E_{x}^{3} B(M)$.

Tentative $1 / 2$ tdeatification (see texi). 


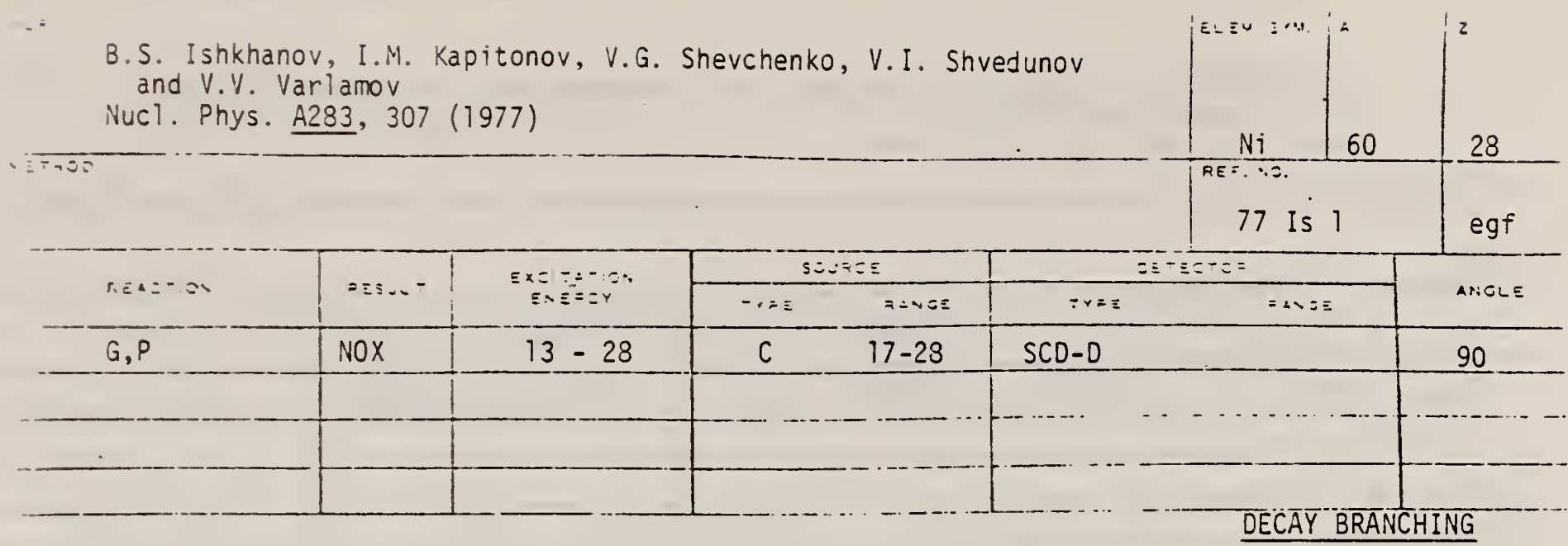

TABLE 3

The proton decay probabilities in the various channels

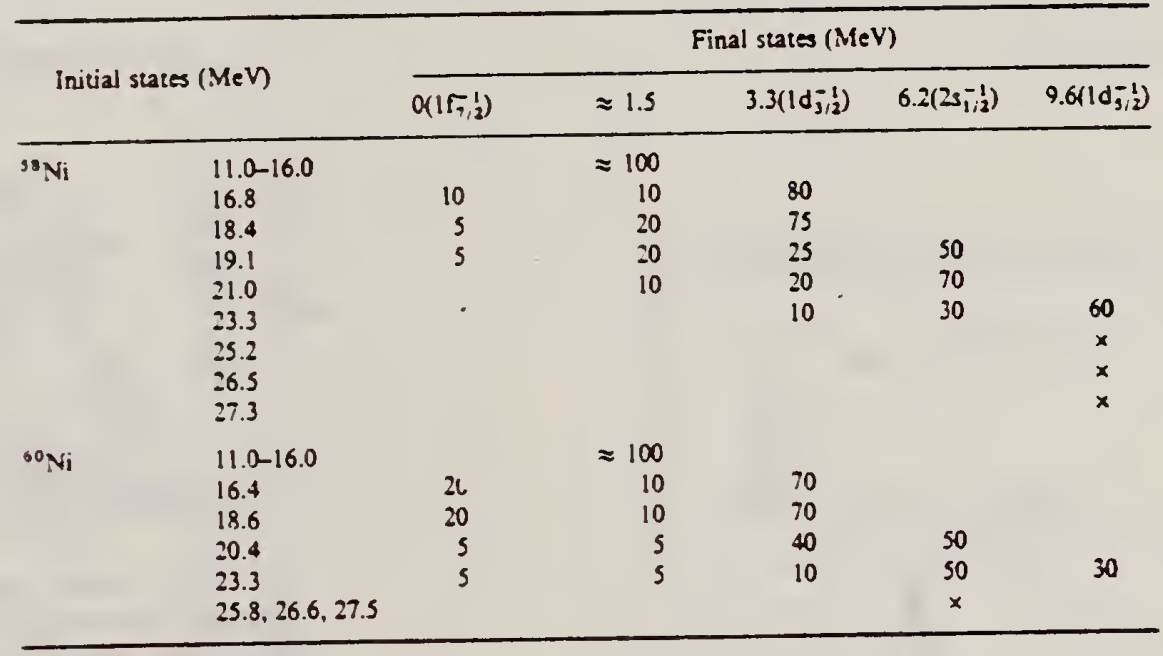


REF. T.J. Bowles, R.J. Holt, H.E. Jackson, R.M. Laszewski, A.M. Nathan, J.R. Specht, and R. Starr

Phys. Rev. Lett. 41,1095 (1978)

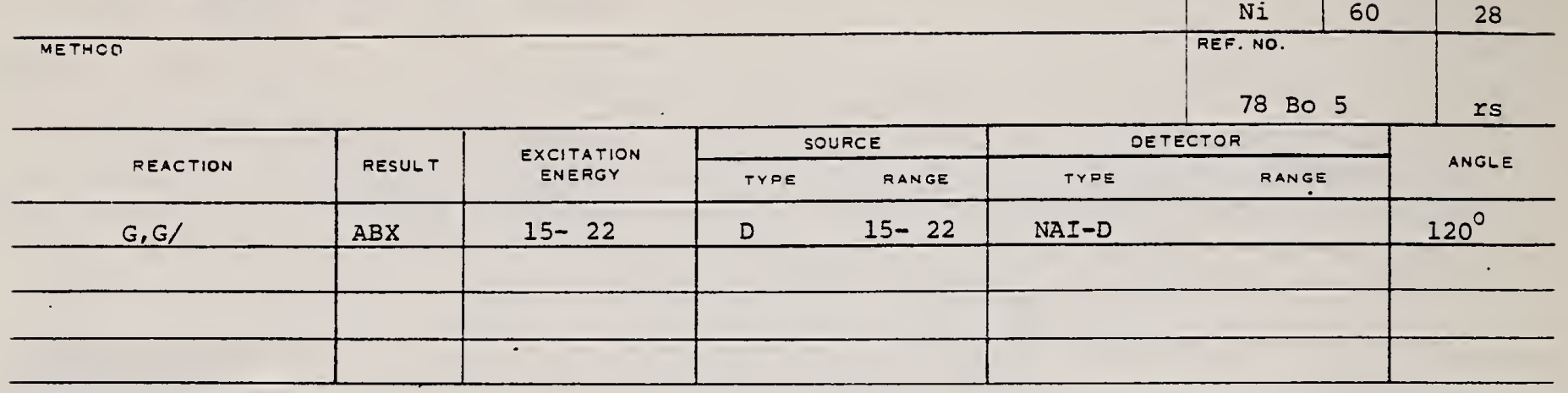

Monoenergetic photons and a high-resolution NaI spectrometer have been used to measure the absolute $120^{\circ}$ scattering cross sections to the ground state and to the first excited state in ${ }^{60} \mathrm{NI}$ for excitations between 15 and $22 \mathrm{MrV}$. The inelastic scattering to the first excited state was found to be about $15 \%$ of the elastic throughout this energy range. Our results do not appear to be in quantitative agreement with the predictions of the dyamic collective model.

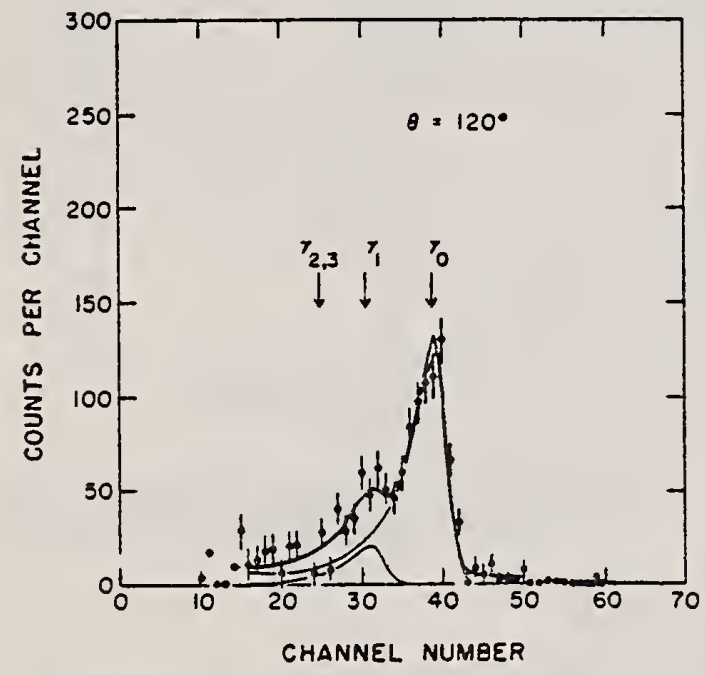

FIG. 2. Seattering spectrum for monoenergetic 19.81$\mathrm{MeV}$ photons incident on ${ }^{80} \mathrm{Nl}$. The fitting procedure by which elastic and inelastic scattering was separated is shown. The shapes of the detector response to monoenergetic photons used in the fit were measured directly by placing the detector in the tagged photon beam.

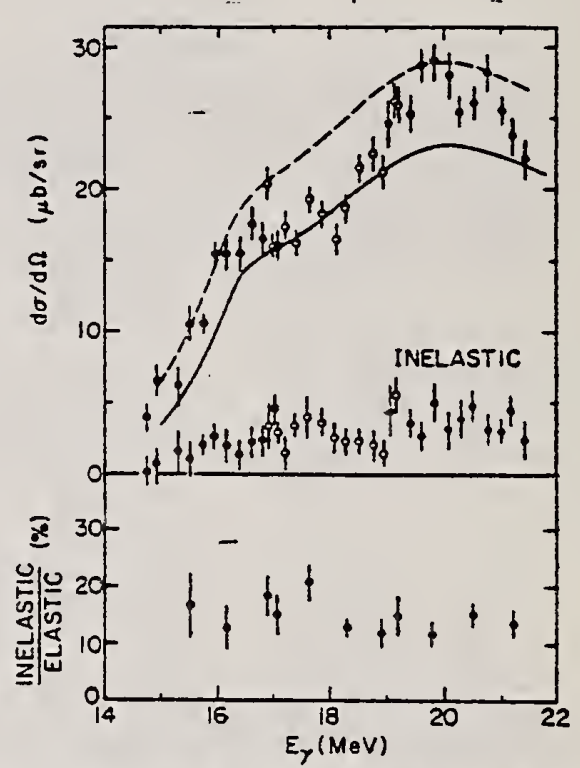

FIG. 3. The cross sections at an angle of $120^{\circ}$ for elastic and inelastic scattering to the first excited state in ${ }^{60} \mathrm{NI}$ are shown at the top. The solld curve shows the elastic cross section predicted by dispersion relations using $\sigma(\gamma, n)$ data for the total absorption cross section. The dashed curve indicates an estimate of the contribution that would come from including ... $\sigma(\gamma, p)$ as well. The ratio of inelastic to elastic scattering is shown below. The open and solid deta points represent the three different energy ranges scanned by the mocochromator. 
A. G. Flowers, A. C. Shotter, J. C. McGeorge and R. 0. Owens

Phys. Rev. Lett. 40, 709 (1978)

$78 \mathrm{FI} 1$

\begin{tabular}{|c|c|c|c|c|c|c|c|}
\hline \multirow{2}{*}{ REACTION } & \multirow{2}{*}{ RESULT } & \multirow{2}{*}{$\begin{array}{l}\text { EXEITATION } \\
\text { ENERGY }\end{array}$} & \multicolumn{2}{|c|}{ SOURCE } & \multicolumn{2}{|c|}{ DETECTOR } & \multirow{2}{*}{ ANGLE } \\
\hline & & & proe & RANGE & Troe & MANGE & \\
\hline \multirow[t]{2}{*}{$E, A$} & SPC & $6-120$ & 0 & $33-120$ & MAG-D & & DST \\
\hline & & & & & & & 10051 \\
\hline & & & & & & & 10052 \\
\hline
\end{tabular}

Alpha-particle eaerzy and angular distributions bave been measured for the reaction 10053

"Nile, ale' $X$ using electrons of energles 33,60 , and $120 \mathrm{MeV}$. Statistical-model calculatlons glve good quantitative agreement in the region of the peak of the $a$ energy spectra. Higher-energy a particles exbibl: a forward-peaked angular distribution and a cross section scveral orders of magnitude above the statistical-model predictlons, indicattag the presence of a direct-resction component.

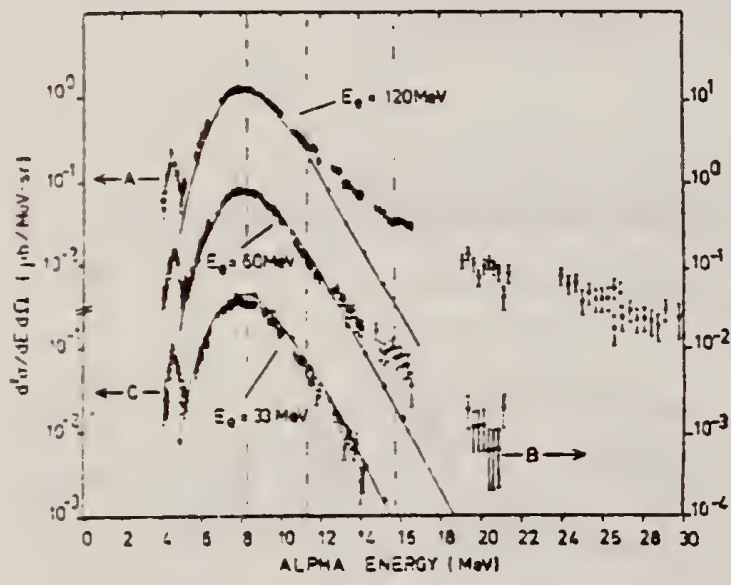

EIG. 1. Alpba-particle ener $\sigma^{5}$ spectra at $\theta_{a}=90^{\circ}$, for $E_{f}=120 \mathrm{MeV}$ (curve $A_{\text {, }}$ 'upper left-haod scale), $E_{0}=60 \mathrm{MeV}$ (curve $B$, right-inand scale), and $E_{a}=33$ SieV icurse C, lower left-iand scale). Errors stotn are sbsolute. The solld lioes are the results of a staitsticai calculaitoa assuming pboton absorptloa below $E_{y}=33 \mathrm{SieV}$. The dasbed lices mark the mean energles at whics angular distributions were taken.

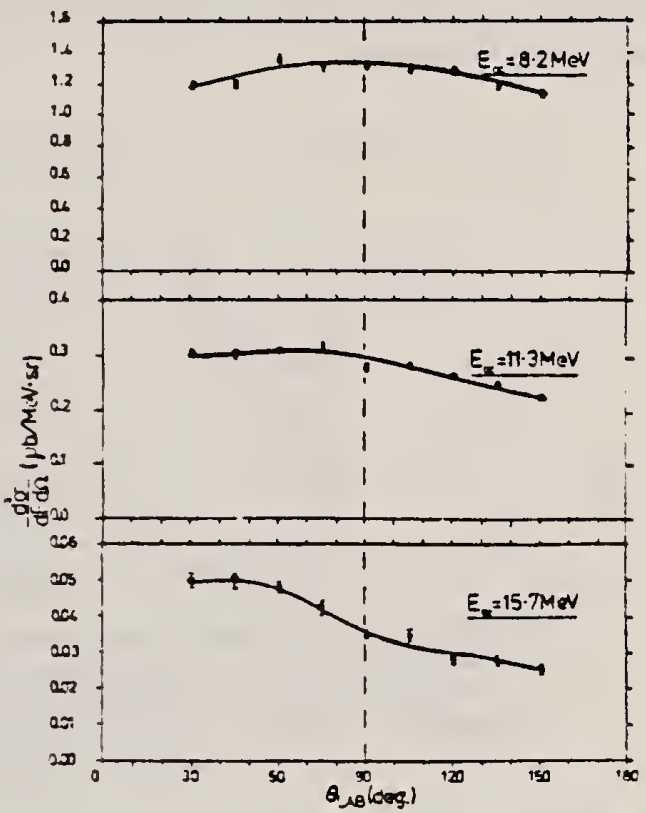

FIG. 2. Aloba-particle angular distribtutons at $E$. $=120 \mathrm{MSV}$ averaged over the a energy ranges 7.7-8.7 Miel, 10.6-11.9 MeV, and 14.8-16.4 MeV. Errors shown are relative. The soltd lines are merely to gulde the eye. 
ref. K. Masumoto, T. Kato, N. Suzuki

Nucl. Inst. Meth. 157,567 (1978)

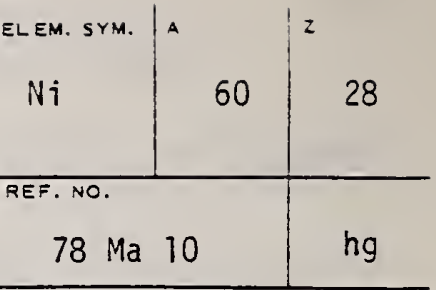

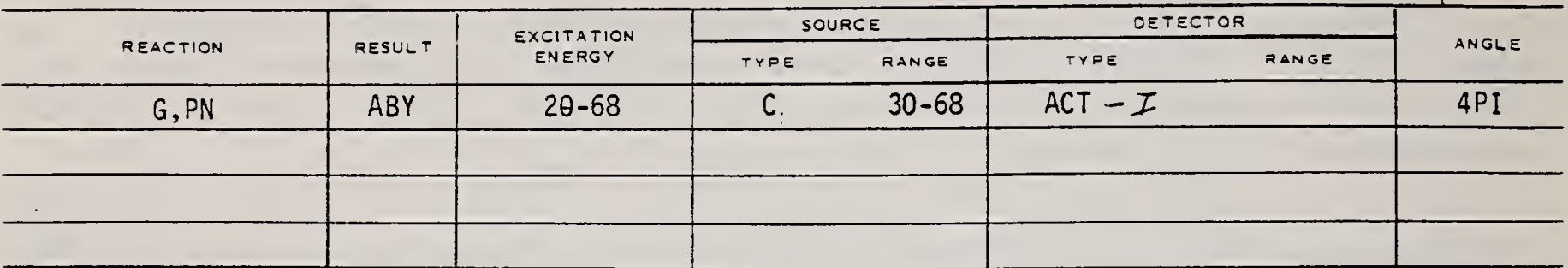

\section{Analysis is made of reactions interfering with} photon activation analysis procedures.

The activation yield curves have been presented for a number of photonuclear reactions in the energy range from 30 to $68 \mathrm{MeV}$, in order to evaluate quantitatively the interferences due to competing reactions in multielement photon activation analysis. The general features of the yields as functions of both target mass number and excitation energy were elucidated from the data obtained, discussion being given on the results in terms of the reaction mechanism.

Simultaneous neutron activation due to appreciable neutron production from the converter and surrounding materials has also been studied, and, finally, the magnitudes of interferences in real multielement analysis were given in the form of their energy dependences.

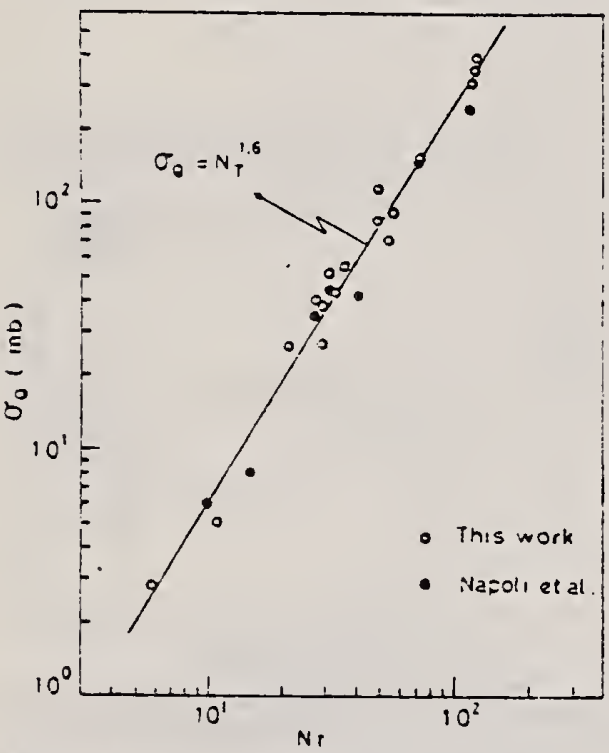

Fig. 2. Yield per equivaient quanta versus target ncutron number.

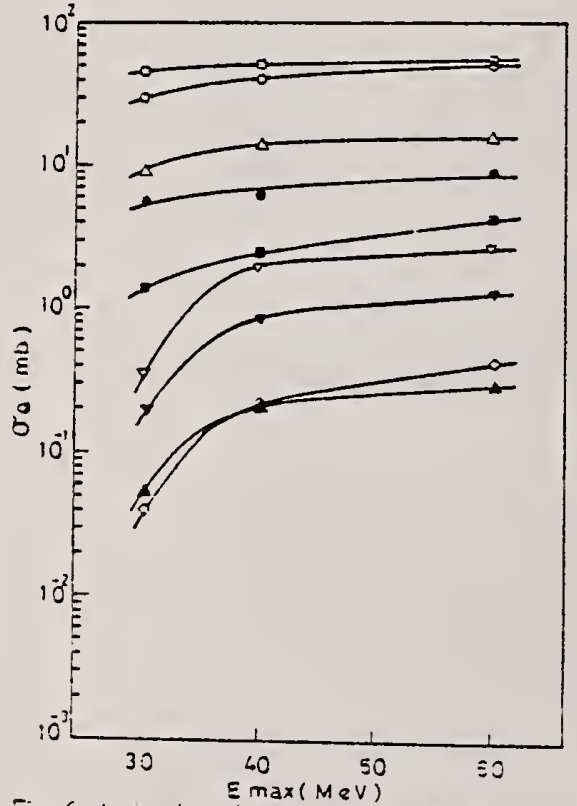

Fig. 6. A:ivation yieid curves for the reactions on $\mathrm{Co}, \mathrm{Ni}$ and $\mathrm{Cu}$.

$\left.2{ }^{59} \mathrm{Cur} \because n\right)^{58} \mathrm{Co}$ - $\left.{ }^{59} \mathrm{Co} \% 2 \mathrm{n}\right)^{57} \mathrm{Co} . \Delta{ }^{58} \mathrm{Ni}(\%, n)^{57} \mathrm{Vi}$

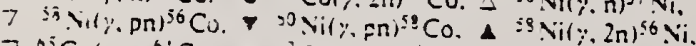

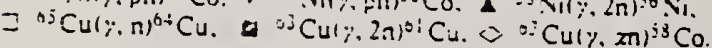


REF. J.D. Turner, C.P. Cameron, N.R. Roberson, H.R. Weller and

D.R. Tilley

Phys. Rev. C 17, 1853 (1978)

78 TU 2

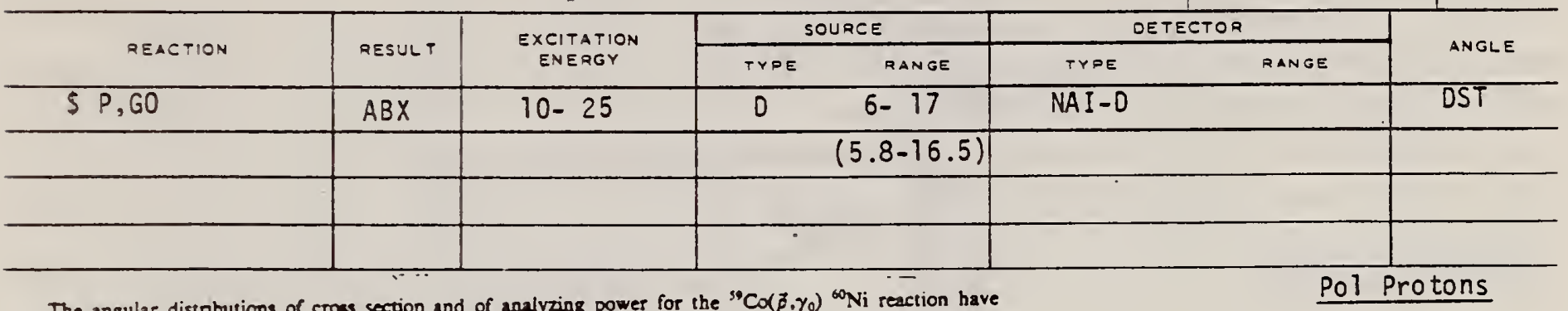

The angular distnbutions of cross section and of analyzing power for the ${ }^{99} \mathrm{Co}\left(\vec{p}, \gamma_{0}\right){ }^{60} \mathrm{Ni}$ reaction have been measured throughout the giant dipole resonance region of $\mathrm{Ni}$. In addition, the 90 yield curve has been measured for $E$, from 5.8 to $16.5 \mathrm{MeV}$. The Jata are analyzed to deduce the amplitudes and phases of the $T$ matrix elements involved. Comparison of the results is made to both the dynamic collective model alculacion of Ligensa and Grenner and to a direct-semidirect model calculation. The direct-semidirect alculation indicates that the reaction proceds predominantly via the radiative capture of $d_{9 / 2}$ protons. isospin splitring is also discussed.

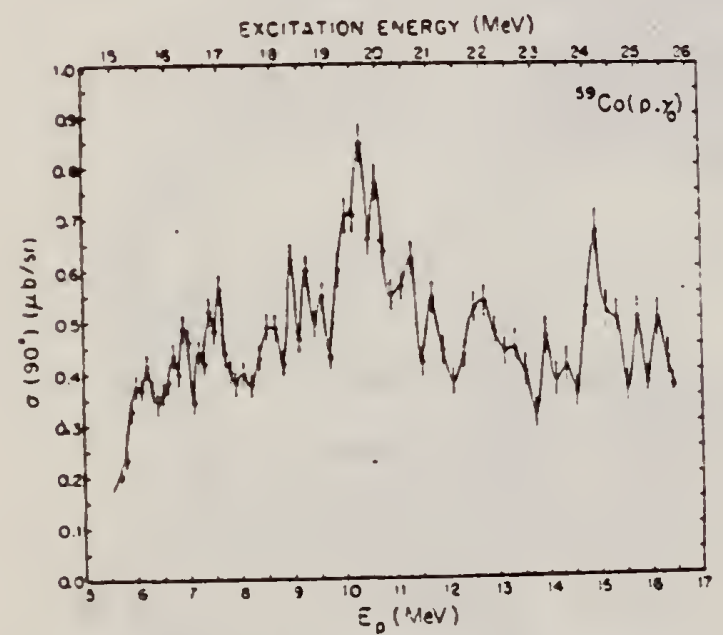

FIG. 2. The $90^{\circ}$ yield curve for the ${ }^{59} \mathrm{Co}\left(p, \gamma_{0}\right){ }^{60} \mathrm{NI}$ reaction. The error bars represent the statistical error associated with the data poirts and the solid curve is a $s$ mooth line drawn through the data points.

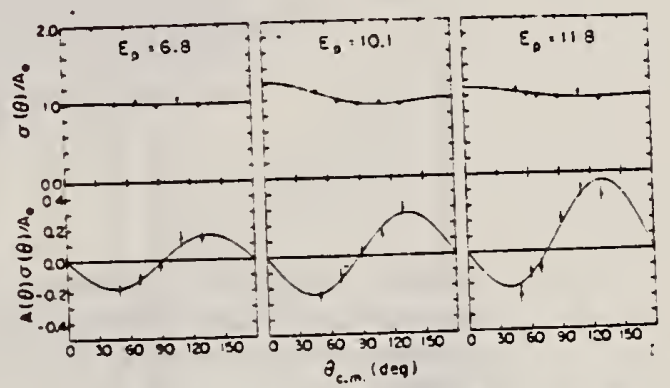

FIG. 3. Typical data at three energies for the quantities $\sigma(\theta) / A_{0}$ and $\sigma(\theta) A(\theta) / A_{0}$. The errors bars represent the statistical errors associated with the data points. The solid curves are the result of fitting the dac as described in the text. 


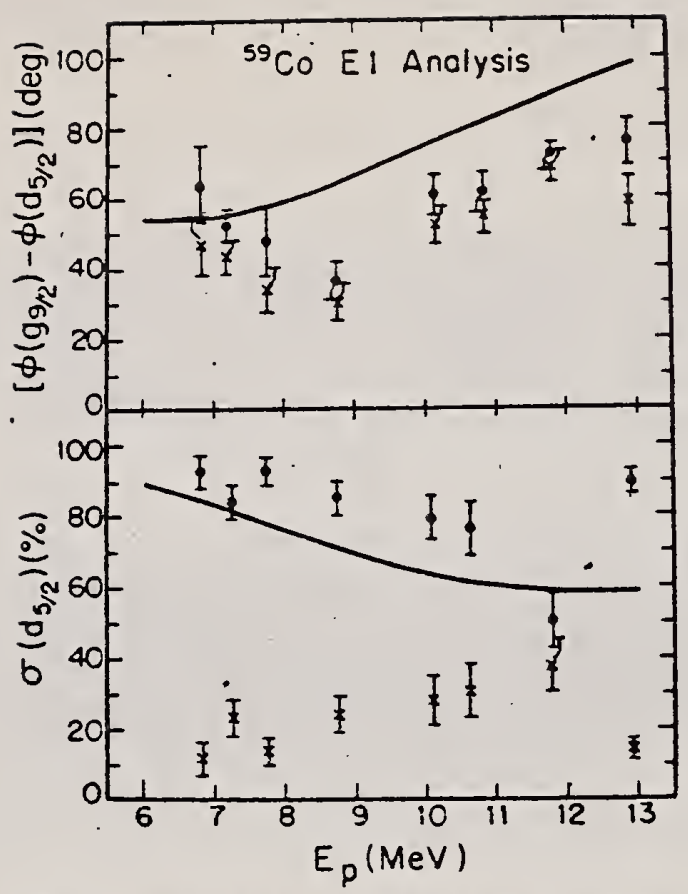

FIG. 5. Comparison of the transition matrix elements extracted from the present data with those from a direct-semidirect reaction model calculation as described in the text. The solid curve shows the results of the calculation. The results are presented as a percentage of the cross section, $\sigma\left(d_{s / 3}\right)+\sigma\left(g_{9 / 2}\right)$, where $\sigma\left(d_{5 / 2}\right)=d_{5 / 2}^{2}$, etc. The error bars represent the statistical errors associated with the data.

TABLE $i$. The $a_{k}$ and $b_{k}$ coefficients obtained from least squares fits to the dat as described in the text. Also presented are the $a_{*}$ coefficients from Ref. 1.

\begin{tabular}{|c|c|c|c|c|c|c|c|c|}
\hline$E$ & (MeV) & $a_{1}$ & $a_{2}$ & $x_{2}$ & $b_{1}$ & $b_{2}$ & $b_{3}$ & $x_{2}$ \\
\hline & $6.70^{2}$ & $0.02 \pm 0.03$ & $0.03 \pm 0.05$ & 1.5 & & & & \\
\hline & 5.80 & $0.01 \pm 0.05$ & $0.01 \pm 0.07$ & 1.8 & $-0.01 \pm 0.03$ & $-0.12 \pm 0.02$ & $0.00 \pm 0.02$ & 0.5 \\
\hline & 7.20 & $0.06 \pm 0.03$ & $0.15 \pm 0.06$ & 0.4 & $0.05 \pm 0.02$ & $-0.15 \pm 0.02$ & $0.04 \pm 0.02$ & 1.3 \\
\hline & $7.55^{\mathrm{a}}$ & $0.08 \pm 0.05$ & $0.16 \pm 0.07$ & 1.5 & & & & \\
\hline & $7.60^{3}$ & $-0.01 \pm 0.02$ & $0.28 \pm 0.03$ & 0.6 & & & & \\
\hline & 7.75 & $0.02 \pm 0.04$ & $0.10 \pm 0.08$ & 6.1 & $0.02 \pm 0.03$ & $-0.10 \pm 0.02$ & $0.01 \pm 0.02$ & 0.1 \\
\hline & 8.75 & $0.05 \pm 0.03$ & $0.26 \pm 0.05$ & 1.5 & $0.04 \pm 0.02$ & $-0.10 \pm 0.02$ & $0.00 \pm 0.02$ & 0.9 \\
\hline & $10.00^{2}$ & $0.22 \div 0.03$ & $0.07 \pm 0.04$ & 1.5 & & & & \\
\hline & 10.10 & $0.11 \neq 0.03$ & $0.12=0.06$ & 0.7 & $0.02 \pm 0.02$ & $-0.17 \pm 0.02$ & $0.01 \pm 0.02$ & 1.1 \\
\hline & 10.60 & $0.11=0.04$ & $0.12 \pm 0.06$ & 0.4 & $0.04=0.02$ & $-0.18 \pm 0.02$ & $-0.01 \pm 0.02$ & 8.1 \\
\hline & 11.30 & $0.06 \div 0.04$ & $0.05 \pm 0.06$ & 1.2 & $0.14 \pm 0.03$ & $-0.23 \pm 0.02$ & $-0.05 \pm 0.02$ & 0.8 \\
\hline & 12.80 & $0.12 \pm 0.03$ & $-0.03 \pm 0.06$ & 2.3 & $0.05 \neq 0.02$ & $-0.24 \pm 0.02$ & $-0.02 \pm 0.02$ & 1.8 \\
\hline
\end{tabular}

a From Ref. 1.

1

E.M. Dlener, J.F. Amann, P. Paul, and S.L. Blatt, Phys. Rev. C 3, 2303 (1971) 
78 We 4

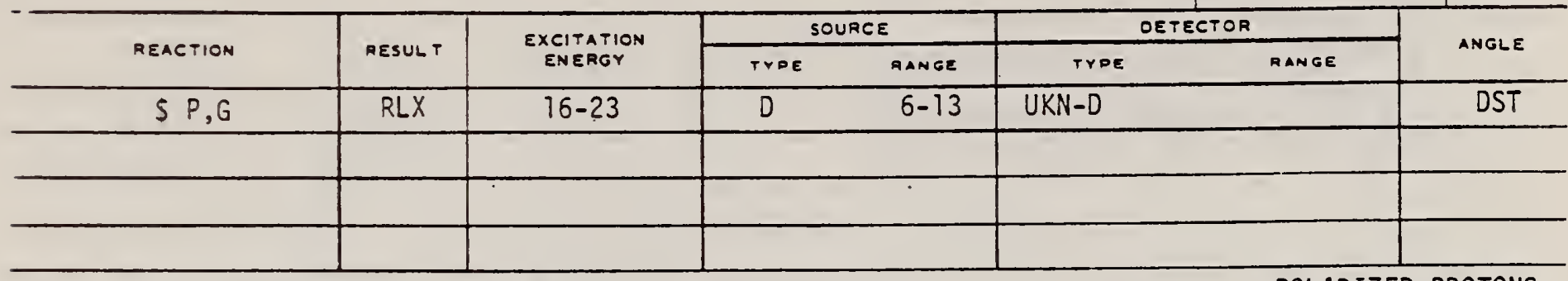

Analysis of data in reference 6 .

Measurements of cross sections and analyziag powers are examined for polarized proton capture on ${ }^{10} \mathrm{C}$,

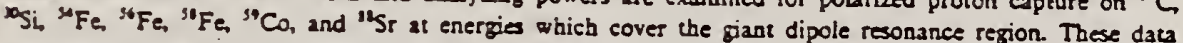
are used to extraet the relative amplitudes and phases of the contributing EI $T$-matrix elements. A typical result exhibits two solutions. Calculation: using the direct (or a direct-semidirect) capture model appear to provide a means for choosing the physical solution

[ItCLEAR REACTIONS: " $\mathrm{C}\left(\vec{p}, \gamma_{l}\right),{ }^{30} \mathrm{SI}\left(\vec{p}, \gamma_{0}\right),{ }^{44} \mathrm{Fe}\left(\vec{p}, \gamma_{0}\right), "{ }^{8} \mathrm{Fe}\left(\vec{p}, \gamma_{0}\right)$, $4 \mathrm{ge}\left(\vec{p}, \gamma_{t}\right),{ }^{3} \mathrm{Co}\left(\vec{p}, \gamma_{0}\right), "{ }_{\mathrm{Sr}}\left(\vec{p}, \gamma_{0}\right)$; measured $\sigma(\theta)$ and $A(\theta)$ over energy regrion of the glaat dipole resonance. Deduced $T$-marrix amplitudes and phases. Corapare results to direct-semidirect model calculations.
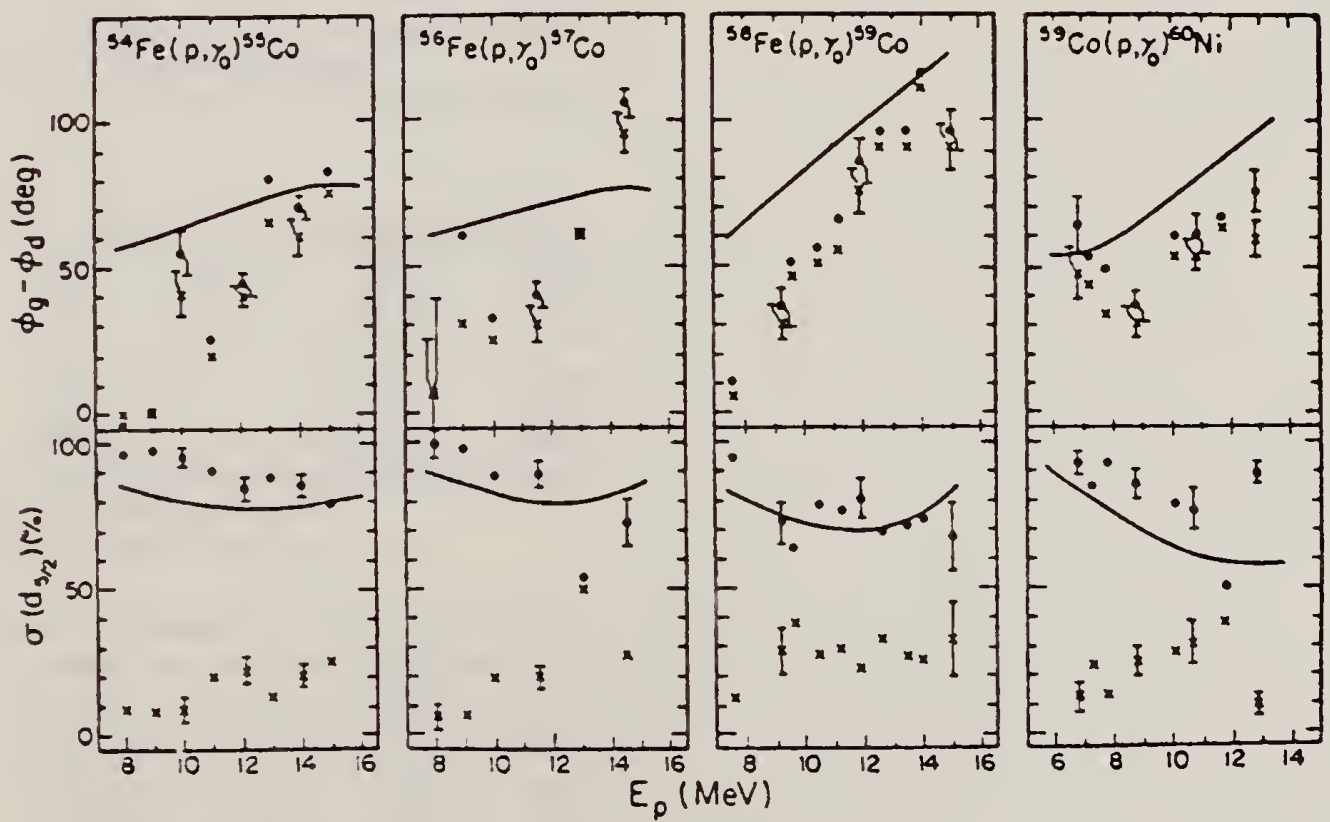

EIG. 2. Same as Ftg. 1 for the target nuclei of ${ }^{94} \mathrm{Fe},{ }^{38} \mathrm{Fe},{ }^{90} \mathrm{Ee}$, and ${ }^{99} \mathrm{Co}$. The remaining cross section is due to the $\delta_{y / 2}$ matrix element.

IT. 1. The two solutioes (dots and $x^{\prime} s$ ) regulting from a pure $E 1$ analysis of the data are shown along with the results of the calculation for target nuclel of ${ }^{14} \mathrm{C},{ }^{18} \mathrm{Sr}$, and ${ }^{30} \mathrm{SI}$. The remalning cross section in the $\mathrm{case}$ of ${ }^{14} \mathrm{C}$ and ${ }^{80} \mathrm{Sr}$ is due to the $s_{1 / 2} \mathrm{matrix}$ element. In the case of ${ }^{30} \mathrm{St}$ it arises from the $p_{v}$, matrix element. The error bars represent typical statistical errors assoclated with the data polnts. The amplitudes are presented in terms of the percentage of the cotal cross section for which they are responsible. The curves represent DSD calculations as described in the text. The dastaed curves In the case of ${ }^{85} \mathrm{Sr}$ were obtained using the optlcal model parameters of Rel. 16 whlle the solid lines were obtalned from the parameters of Ref. 18. 
${ }^{2}$ H. R. Weller, R. A. Blue, N. R. Roberson, D. G. Rickel, S. Maripuu, C. P. Cameron, R. D. Ledford, and D. R. Tilley, Phys. Rev. C 13 , 922 (1976). Note; an error exists in the sign of the phase in this paper. The

quantity $\phi_{3}-\phi_{d}$ should be $\phi_{d}-\phi_{3}$ wherever it appears.)

${ }^{3}$ C. P. Cameron, N. R. Roberson, D. G. Rickel, R. D. Ledford, H. R. Weller, R. A. Blue, and D. R. Tilley, Phys. Rev. C 14, 553 (1976).

'C. P. Cameron, Ph.D. thesis, Duke University, 1976 (unpublished).

${ }^{5} R$. D. Ledford, Ph.D. thesis, Duke University, 1976 (ünpublished).

'J. D. Turuer, C. P. Cameron, N. R. Roberson, H. R. Weller, and D. R. Tilley, Phys. Rev. C 17,1853

(1978). 
Qe: E. Wolynec, W.R. Dodge, E. Hayward

Phys. Rev. Lett. 42,27 (1979)

ETMOO

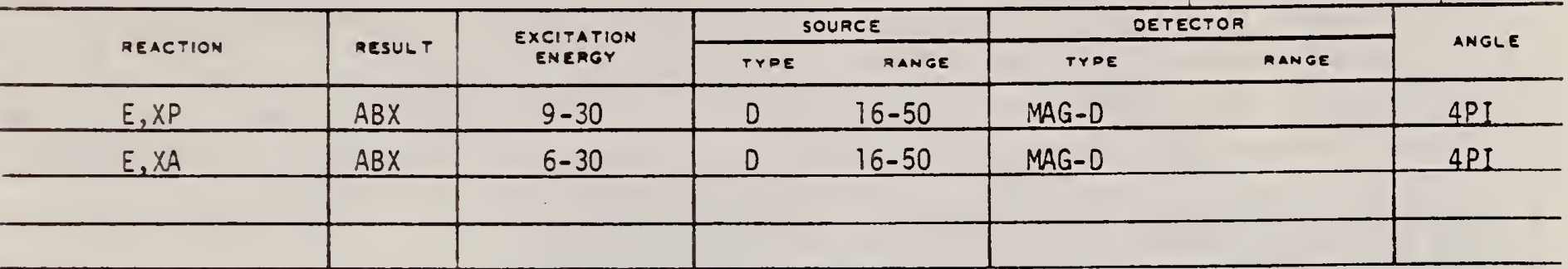

The $(f, p)$ and $(e, a)$ cross sections for targets of ${ }^{59} \mathrm{Ni},{ }^{90} \mathrm{Ni}$, and ${ }^{\mathrm{i} 2} \mathrm{Ni}$ have bee measured in the electron energy range 16-50 MeV. They have been analyzed usins the dis-

(E,XP) VIRTUAL PHOTON $G, X P$ tored-wave Born-approximation $E 1$ and $E 2$ virtual-photon spectra. Protons are emitted primarlly followig $E l$ absorption but $\alpha$ emission results from a combiation of $E l$ and $\Xi 2$ absorction. The $E 2$ isoscalar giant resoannce decays predominanily by $\alpha$ emission for these auclei.

TABLE I. Resonance parameters for $\sigma_{y, 0}$

\begin{tabular}{|c|c|c|c|c|}
\hline Nuclsus & $\begin{array}{c}E_{\mathbf{r}} \\
(\operatorname{Me} V)\end{array}$ & $\frac{\Gamma}{(\mathrm{MeV})^{2}}$ & $\begin{array}{c}\int_{h}^{30} \sigma d E \\
\text { (MeV mb) }\end{array}$ & $\begin{array}{l}S R^{n} \\
\left(C_{c}\right)\end{array}$ \\
\hline${ }^{38} \mathrm{Ni}$ & $19.2=0.5$ & $6.5=1.3$ & $733 \pm 40$ & $3 j \pm 5$ \\
\hline${ }^{50} \mathrm{Xi}$ & $18.5=0.5$ & $9.2=1.3$ & $304=20$ & $34 \pm 2$ \\
\hline$\because \mathrm{Ni}$ & $21.0=0.5$ & $5.3 \pm 1.0$ & $140 \pm 10$ & $15=1$ \\
\hline
\end{tabular}

II the full wicth at balf maximum.

SSR. stands for sum rule; the EI SR equals $60 \mathrm{NZ} / \mathrm{A}$ MeV mb.

T.ABLE II. EI composezts in the $(\gamma, \alpha)$ reac:ion.

\begin{tabular}{|c|c|c|c|c|}
\hline Xucleus & $\frac{E_{\mathrm{z}}}{(\mathrm{MeV})}$ & $\underset{(M e V)^{2}}{\Gamma}$ & $\begin{array}{c}\int_{\sigma j}^{J} d^{\prime} E \\
(\text { MeV mb) }\end{array}$ & $\begin{array}{l}S R^{0} \\
\left(c^{*}\right)\end{array}$ \\
\hline${ }^{53} \mathrm{Ni}$ & $18.3=0.5$ & $6 \pm 1$ & $15.3=1.3$ & $i .3=0.2$ \\
\hline${ }^{30} \times 1$ & $21.5=1.0$ & $6=1$ & $18.5=1.4$ & $2.1=0.2$ \\
\hline E. vi & $13.3=1.0$ & $5 \pm 1$ & $4.3=0.6$ & $0.5=0.1$ \\
\hline
\end{tabular}

Is the full wicth at half maximum.

${ }^{3}$ El SR equals $60 \mathrm{NZ} / \mathrm{A} \mathrm{MeV} \mathrm{mb.}$

TABIE III. E2 components in the $(\gamma, \alpha)$ reaction.

\begin{tabular}{|c|c|c|c|c|}
\hline Nucleus & $\begin{array}{c}E_{\mathrm{x}} \\
(\mathrm{MeV})\end{array}$ & $\underset{(M e V)^{2}}{\Gamma}$ & $\begin{array}{c}\int \sigma d E \\
(\mathrm{MeV} \mathrm{mb})\end{array}$ & $\begin{array}{l}S R^{\circ} \\
\left(P^{\circ}\right)\end{array}$ \\
\hline${ }^{58} \mathrm{yi}$ & $16.5 \pm 0.5$ & $4.2 \pm 1.0$ & $10.4=0.7$ & $56 \pm 4$ \\
\hline 50 Yil & $16.0=0.5$ & $3.7 \pm 0.3$ & $6.9=0.4$ & $52=3$ \\
\hline $5 \mathrm{Yi}$ & $16.3=0.5$ & $4.5 \times 1.0$ & $5.1=0.4$ & $23=2$ \\
\hline
\end{tabular}

I I the sull width at haif maximum.

${ }^{b} E 2$ SR equals $0.22 Z^{2} / A^{1 / 3} \mu \mathrm{b} / \mathrm{MeV}$. 
Ref. R. Pitthan, G.M. Bates, J.S. Beachy, E.B. Dally, D.H. Dubois, J.N. Dyer, S.J. Kowalick, F.R. Buskirk.

Phys. Rev. C21, 147 (1980)

METHOD

\begin{tabular}{|l|l} 
& $\mathrm{Ni}$ \\
\hline. & REF. NO.
\end{tabular}

$80 \mathrm{Pi} 2$

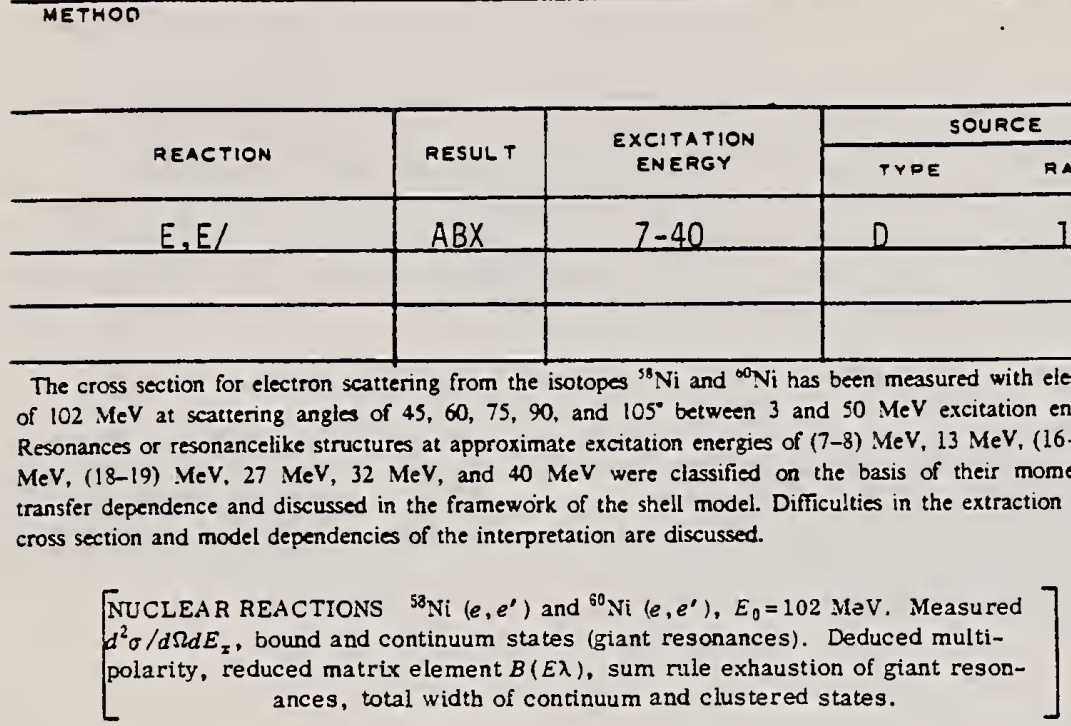

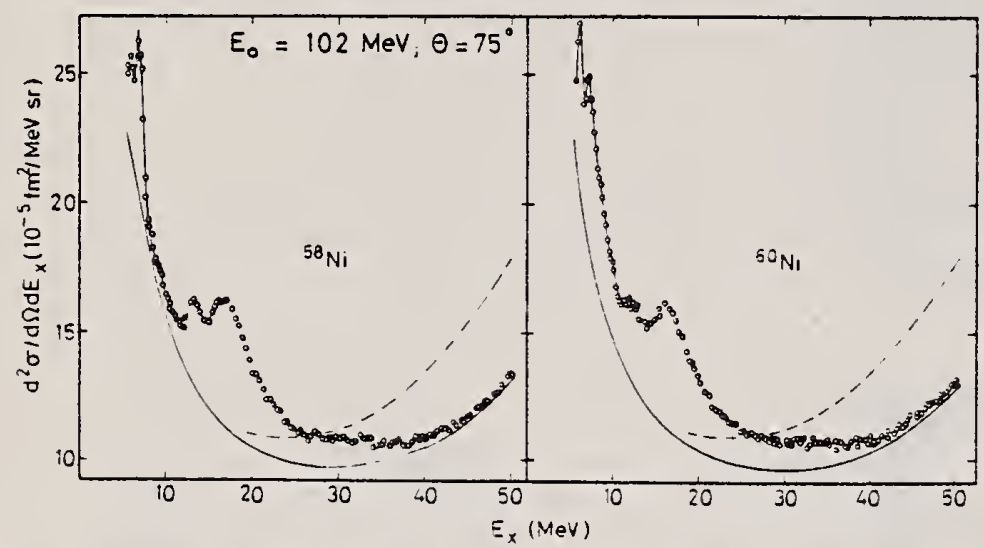

FIG. 4. Comparison of spectra of $102 \mathrm{MeV}$ electrons scactered at $75^{\circ}$ (rom ${ }^{58} \mathrm{Ni}$ and ${ }^{60} \mathrm{Ni}$. The cross section ior ${ }^{30} \mathrm{Ni}$ has been renormalized so that the highest and lowest points in both plots are equal. The spectra were taken with 10 points/MeV but have been reduced for graphical purposes. The broken line is the calculated radiation tail. For demonstration purposes we have subtracted the ghost peak at $3 \mathrm{MeV}$ irom the data for ${ }^{58} \mathrm{Ni}$, but not for ${ }^{\text {i0 }} \mathrm{Ni}$; the difference is clearly visible. Note the suppressed zero.

TABLE III. Strength of $E 1$ components in the present work. The resonance parameters shown were used to approximate the $E 1$ strength distribution for the $x^{2}$ fit. As evident from Fig. 3 , where mainly $E 1$ contributes, the $E 1$ strength function is reasonably well described. The $E 1$ strength extracted from the resonances, corresponding to integration to infinity, adds up to approximately $110 \%$ of the classical $E 1$ sum rule. For ease of comparison, we also give the sum rule strength found by integration from 10 to $30 \mathrm{MeV}, 94=10$ and $87=10 \%$ for ${ }^{53} \mathrm{Ni}$ and ${ }^{60} \mathrm{Ni}$, respectively. The table and Fig. 8 aiso show that the peak strength is shifted to lower excitation energy by going from ${ }^{58} \mathrm{Ni}$ to ${ }^{30} \mathrm{Ni}$. Altinough the gross shift is in agreement with the isospin coupling model ${ }^{1.37}$ we do not think it is a sufficient basis for a claim of observed isospin splitting. The average excitation energy, weighted with the $E 1$ strength function between 10 and 30 MeV, in contrast, remains virtually unchanged.

\begin{tabular}{|c|c|c|c|c|c|c|c|c|c|}
\hline \multirow[b]{2}{*}{$E_{x}(\mathrm{MeV})$} & \multicolumn{3}{|c|}{${ }^{58} \mathrm{Ni}$} & \multirow[b]{2}{*}{$R_{0}{ }^{3}$} & \multicolumn{5}{|c|}{${ }^{60} \mathrm{Ni}$} \\
\hline & $\Gamma(\mathrm{MeV})$ & $B\left(\mathrm{fm}^{2}\right)$ & $R \gamma^{2}$ & & $E_{x}(\mathrm{MeV})$ & $\Gamma(\mathrm{MeV})$ & $B\left(\mathrm{fm}^{2}\right)$ & $R \gamma^{2}$ & $R_{\infty}^{b}$ \\
\hline $16.2=0.3$ & $2.5 \pm 0.5$ & 1.5 & 10.5 & $11 \div 2$ & $16.6=0.4$ & $2.75=0.5$ & 2.5 & 16.5 & $18=4$ \\
\hline $18.3=0.5$ & $4.5=0.5$ & 7.3 & 54 & $62=7$ & $19.5=0.5$ & $6.0=1.0$ & 7.4 & 51 & $63 \div 8$ \\
\hline $22.0=1.0$ & $6.0=1.0$ & 3.3 & 27 & $3 t=3$ & $23.5=1.5$ & $6.0 \pm 1.5$ & 1.9 & 15 & $19 \pm 4$ \\
\hline
\end{tabular}



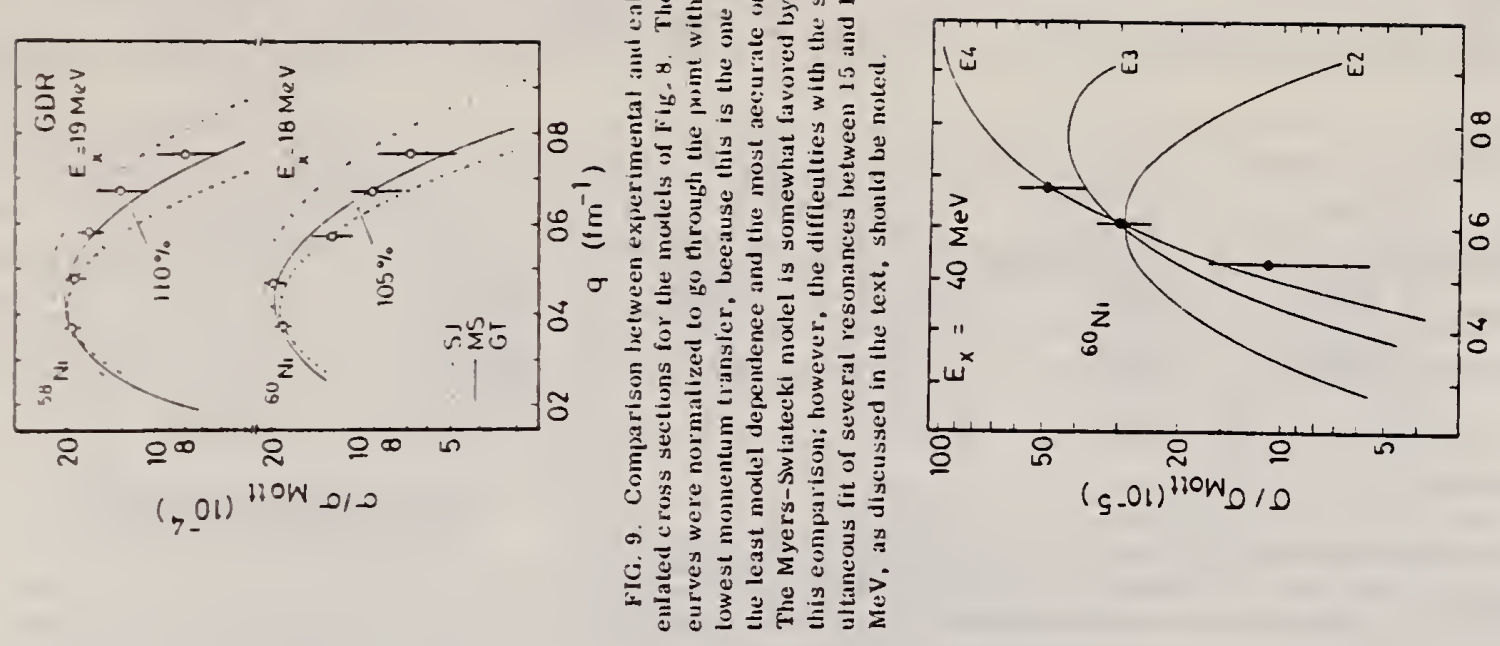

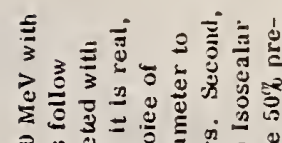

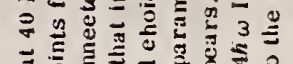

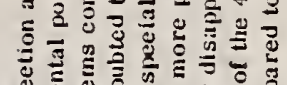
人

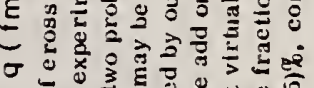

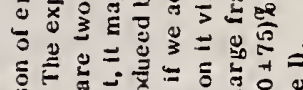

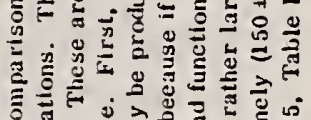
今े

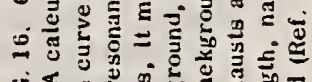

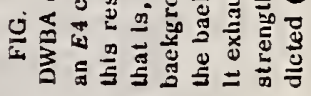
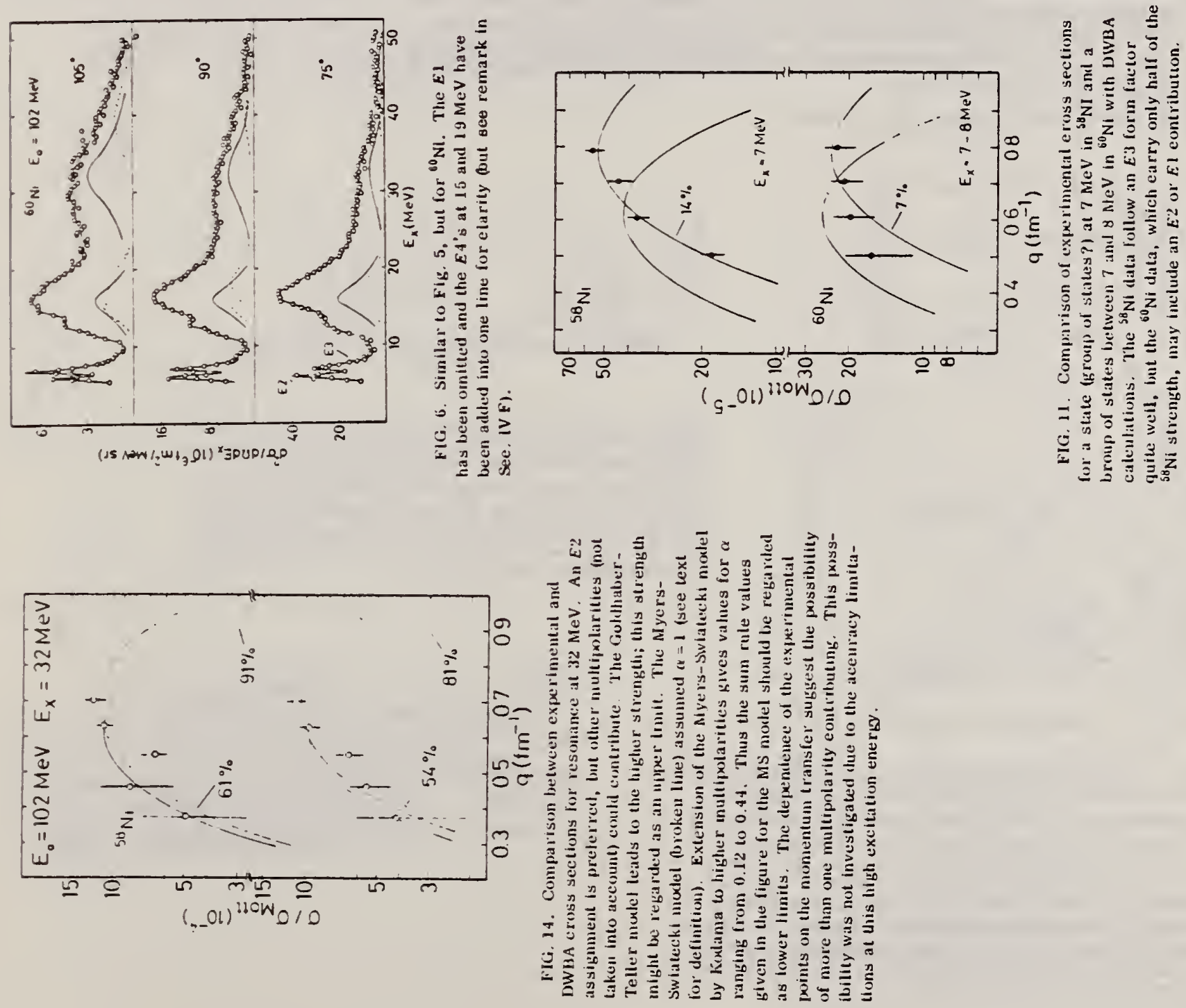
Yu.M. Volkov, A.I. Ignat'ev, G.A. Kolomenskii, E.F. Lakovichev,

E.D. Makhnovski, A.V. Nadtochi i, V.V. Popov, V.P. Fominenko,

V.P. Chizhov

Sov. J. Nucl. Phys. 32, 306 (1980) Yad. Fiz. 32, 595 (1980)

\begin{tabular}{|c|c|c|c|c|c|c|c|}
\hline \multirow{2}{*}{ REACTION } & \multirow{2}{*}{ RESULT } & \multirow{2}{*}{$\begin{array}{l}\text { EXCITATION } \\
\text { ENERGY }\end{array}$} & \multicolumn{2}{|c|}{ SOURCE } & \multicolumn{2}{|c|}{ DETECTOR } & \multirow{2}{*}{ ANGLE } \\
\hline & & & TYPE & RANGE & TYPE & RANGE & \\
\hline$E, P$ & $A B X$ & $9-30$ & $c$ & $12-35$ & $I E L-D$ & & DST \\
\hline$E, A$ & $A B X$ & $6-30$ & $c$ & $12-35$ & $T E L-D$ & & DST \\
\hline
\end{tabular}

Cross sections have been measured for the reactions "Novile, $\left.e^{\prime} \rho\right)$ and ${ }^{\prime \prime} \cdot \mathrm{Ni}\left(e, e^{\prime} \alpha\right)$ in the eiectron-energy VIRT PHOTON ANALYSIS range 12-35 MeV. For analysis of the experimental reulis we used virtual photon spectra calcuiated in the DWBA. At energies $E_{\gamma}=16.0 \pm 1.0 \mathrm{MeV}$ for ${ }^{37} \mathrm{Ni}$ and $E_{7}=15.6 \pm 1.0 \mathrm{MeV}$ for ${ }^{\circ 0} \mathrm{Ni}$ we have observed giant electric-quadnupoie resonances which decay mainly by $\alpha$-particle emission. The integrated cross sections for the reactions ${ }^{3 /} \mathrm{Ni}(\gamma, \alpha)$ and ${ }^{\circ 0} \mathrm{Ni}(\gamma, \alpha)$ due to $E 2$ transitions are respectively $5.4 \pm 1.4$ and $6.0 \pm 3.0 \mathrm{mb} \cdot \mathrm{MeV}$, which amounts to $47 \pm 12 \%$ of the total strength of isoscalar $E 2$ transitions for ${ }^{37} \mathrm{Ni}$ and $56 \pm 28 \%$ for ${ }^{60} \mathrm{Ni}$. The integrated cross sections for these same reactions due to $E l$ transitions are $15.9 \pm 2.3$ and $16.9 \pm 4.8$ mb.MeV, which amount to $1.7 \pm 0.3 \%$ of the value given by the sum rule for electric-dipole transitions for si $\mathrm{Ni}$ and $\mathrm{i} .8 \pm 0.5 \%$ for ${ }^{60} \mathrm{Ni}$. The measured integrated cross sections for the reactions $30.60 \mathrm{Ni}(\gamma, p)$ are $539 \pm 33$ and $300 \pm 20 \mathrm{mb} \cdot \mathrm{MeV}$.

PACS numbers: 25.30.C8, 24.30.Cz, 27.40. $+z, 27.50 .+e$

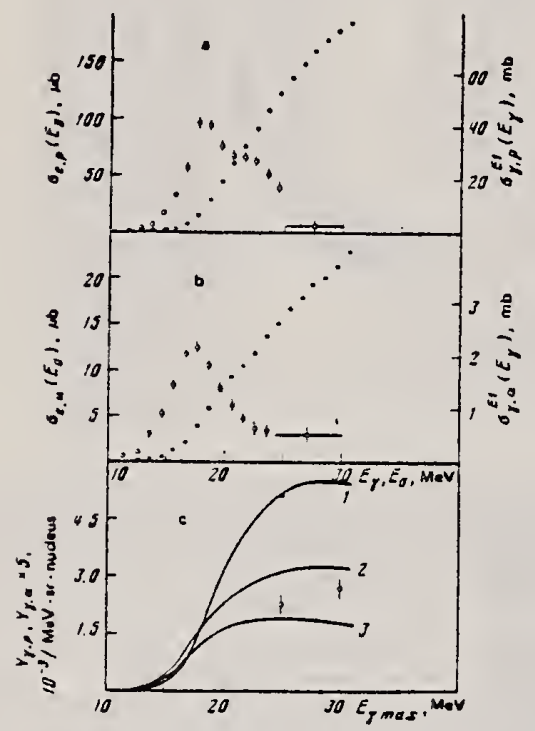

IIG. 3. The same as Fig. 2 but for ${ }^{60} \mathrm{Ni}$ nuclei.

FIG. 2. Cross sections of the reactions ${ }^{38} \mathrm{Ni}\left(e, e^{\prime} p\right.$ ) (solid points points) and ${ }^{58} \mathrm{Ni}(\gamma, p)$, calculated on the assumption that only E1 transitions are excited (hollow points) -a; b- the same but for the reactions ${ }^{58} \mathrm{Ni}\left(e, e^{\prime} \alpha\right)$ and ${ }^{58} \mathrm{Ni}(\gamma, \alpha) ; c-$ measured $y$ ields of protons (solid points) and $\alpha$ particles (hollow points) in the reactions ${ }^{58} \mathrm{Ni}(\gamma, p)$ and ${ }^{58} \mathrm{Ni}(\gamma, \alpha)$. Curves 1 and 2 respectiveiy are the expected yields of protons and $\alpha$ particles obtained on the assumption that only $E 1$ transitions are excited; curve 3 is the same as curve 2 but on the assumption that only E2 transitions are excited. The proton yleid bas been normalized to curve 1 at an arbitrary point.

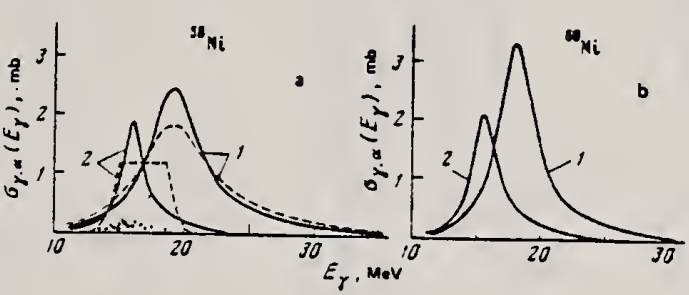

FIG. 5. Resonance curves 1 and 2 (respectively $\sigma_{Y, \alpha}^{\varepsilon_{1}}\left(E_{\gamma}\right)$ and $\sigma_{\gamma, \alpha}^{\mathcal{Z}}\left(E_{\gamma}\right)$ of the reaction ${ }^{53} \mathrm{Ni}(\gamma, \alpha)$ obtained as the resuit of analysis of experimental data. The solid curves are the result of a fit by two Lorentz curves, and the dashed curves are for a fit in which $\sigma_{\gamma}^{\mathbb{2} 2}{ }_{\alpha}\left(E_{\gamma}\right)$ has the form of a rectangle; the points show the cross section $\sigma_{\gamma, \alpha_{0}}^{\sigma_{2}}\left(E_{\gamma}\right)$ of the reaction ${ }^{58} \mathrm{Ni}\left(\gamma, \alpha_{0}\right)^{4} \mathrm{Fe}$ from Ref. 2 (a); b-Lorentz curves of $\sigma_{\gamma, \alpha}^{\varepsilon_{1}}\left(E_{y}\right)(1)$ and $\sigma_{\gamma, \alpha}^{\delta_{0}^{2}}\left(E_{\gamma}\right)$ (2) for the reaction ${ }^{60} \mathrm{Ni}(\gamma, \alpha)$.
TABLE I.

\begin{tabular}{|c|c|c|c|c|c|c|}
\hline \multirow[b]{2}{*}{ Nucleuss } & \multirow{2}{*}{ 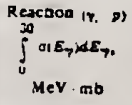 } & \multicolumn{5}{|c|}{ 10 $(7, a)$ reactuon } \\
\hline & & Mulapolarify & $\varepsilon_{R}, \mathrm{MeV}$ & r. MeV & $\begin{array}{c}\sigma_{i n t}^{\lambda C} \\
M e V \cdot m o\end{array}$ & $s^{2 k} . \%$ \\
\hline i & $\begin{array}{l}539=33 \\
530 \pm 001 \text { ('4) }\end{array}$ & $\begin{array}{l}\varepsilon_{1} \\
\varepsilon_{2}\end{array}$ & $\begin{array}{l}19.1=1.0 \\
18.0 \pm 1.0\end{array}$ & $\begin{array}{l}36 \pm 0.4 \\
25=0.5\end{array}$ & $\begin{array}{r}15.9=2.3 \\
S .4 \pm 1.4\end{array}$ & $\begin{array}{l}1.7 \pm 0.3 \\
47 \pm 12\end{array}$ \\
\hline$\omega_{\mathrm{Ni}}$ & $300 \pm 20$ & $\begin{array}{l}E 1 \\
E 2\end{array}$ & $\begin{array}{l}18.0=1.0 \\
15.6 \pm 1.0\end{array}$ & $\begin{array}{l}3.3 \pm 1.0 \\
2.4 \neq 0.8\end{array}$ & $\begin{array}{r}16.9 \pm 68 \\
6.0 \pm 3.0\end{array}$ & $\begin{array}{l}1.3 \pm 0.3 \\
56 \pm 28\end{array}$ \\
\hline
\end{tabular}


ags. E. Wolynec, W.R. Dodge, R.G. Leicht, E. Hayward

Phys. Rev. C22, 1012 (1980)

. Phys. Rev. C22, 1012 (1980)

(n)

METHOO

.

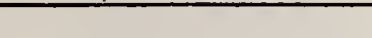

\begin{tabular}{|c|c|c|c|c|c|c|c|}
\hline \multirow{2}{*}{ REACTION } & \multirow{2}{*}{ RESULT } & \multirow{2}{*}{$\begin{array}{l}\text { EXCITATION } \\
\text { ENEAGY }\end{array}$} & \multicolumn{2}{|c|}{ SOURCE } & \multicolumn{2}{|c|}{ DETEETOR } & \multirow{2}{*}{ ANGLE } \\
\hline & & & TYDE & RANGE & TYPE & RANGE & \\
\hline$E, X P$ & $A B X$ & $9-50$ & $D$ & $16-50$ & MAG-D & & DST \\
\hline$E, X A$ & $A B X$ & $6-50$ & $D$ & $16-50$ & MAG-D & & DST \\
\hline
\end{tabular}

The $(e, p)$ and $(e, a)$ cross sectons for targets of ${ }^{19} \mathrm{Ni},{ }^{50} \mathrm{Ni}$, and ${ }^{62} \mathrm{Ni}$ have been measured in the electron energy range $16-100 \mathrm{MeV}$. They have been analyzed using the distorted-wave Bom approximation $E \mathrm{I}$ and $E 2$ virtual photon spectra. Protons are emitted primarily following $E 1$ absorption but a-emission results from a combination of $E I$ and $E 2$ absorption.

NUCLEAR RE.ACTIONS $58,60, \mathrm{EF} \mathrm{Ni}(e, p)$ and $58,60,62 \mathrm{Ni}(e, \alpha)$; measured $\sigma\left(E_{0}, \bar{E}_{x}, 48^{\circ}\right), \sigma\left(E_{0}, E_{5}, 9^{\circ}\right), \sigma\left(E_{0}, E_{x}, 132^{\circ}\right)$; obtained $\sigma(e, p), \sigma(\varepsilon, \alpha) ;$ deduced $\sigma_{Y, \rho}^{\delta !}(E), \sigma_{Y, \alpha}^{E 1}(E), \sigma_{Y, \alpha}^{E^{2}}(E)$.

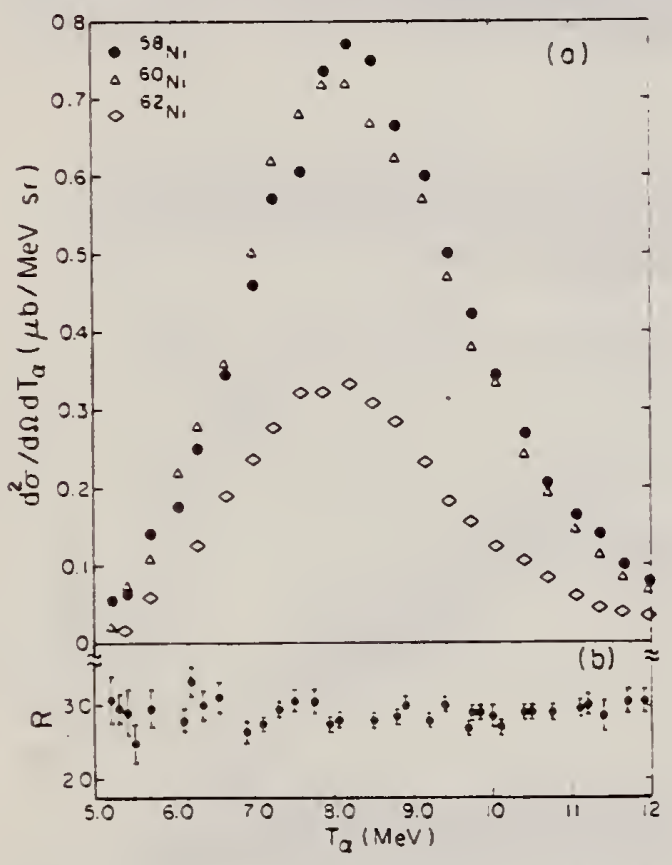

FIG. 2. (a) The $\alpha$ spectra $t^{2} \sigma / d T d \Omega$ measured at $90^{\circ}$ when $50 \mathrm{MeV}$ electrons are incident on targets of ${ }^{58} \mathrm{NI}$. $69 \mathrm{Ni}$, and ${ }^{2} \mathrm{Ni}$. (b) The ratio of the number of $\alpha$ particles produced by electro plus photodisintegration in ${ }^{58} \mathrm{Ni}$ to the number produced by electrodisintegration alone. This ratio was obtained by placing a $0.217 \mathrm{~g} / \mathrm{cm}^{2} \mathrm{Ia}$ radiator in the beam ahead of the ${ }^{58} \mathrm{Ni}$ target.

(over)
$(E, X P) \quad$ VIRTUAL PHOTON $G, X P$

$(E, X A)$ VIRTUAL PHOTON $G, X A$

1. Measurement also made at $100 \mathrm{MeV}$

2. Assumptions:

For photons:

$$
\frac{d \sigma}{d r}(\theta)=\text { constant }
$$

For al phas:

$\frac{d \sigma}{d r}(\theta)=c\left(90^{\circ}\right)\left[A\left(E_{0}\right)+B\left(E_{0}\right) \sin ^{2} \theta\right]$

$A\left(E_{0}\right), B\left(E_{0}\right)$ determined empirically

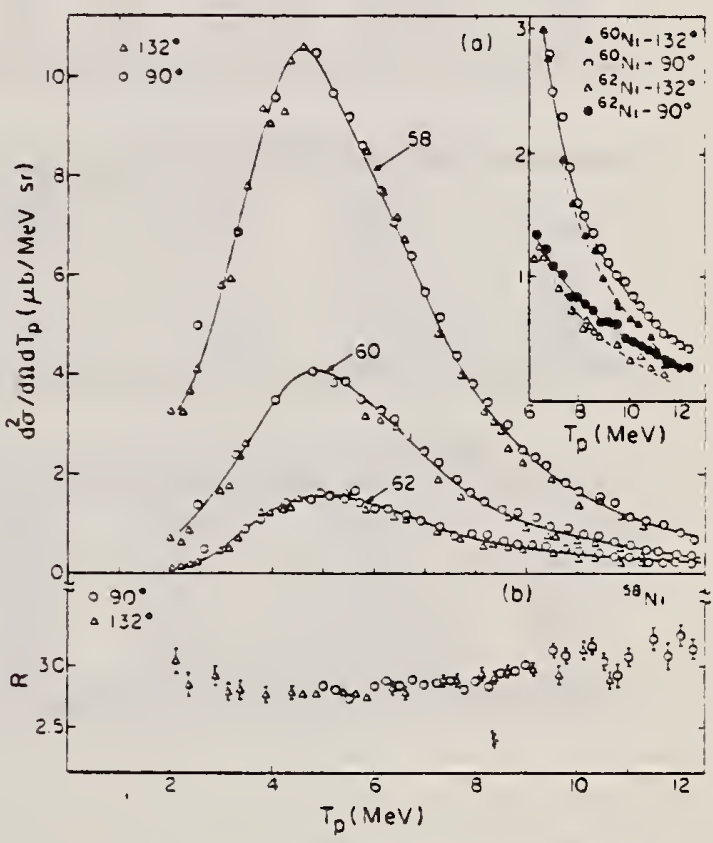

FIG. 3. (a) The proton spectra $d^{2} \sigma / d T, d \Omega$ measured at $90^{\circ}$ and $132^{\circ}$ when $50 \mathrm{MeV}$ electrons are incident on targets of ${ }^{58} \mathrm{Ni},{ }^{89} \mathrm{NI}$, and ${ }^{62} \mathrm{Ni}$. The insert shows the tails of the energy spectra for ${ }^{\text {iq }} \mathrm{Ni}$ and ${ }^{62} \mathrm{Ni}$ where the protons are slightly forward peaked. (b) The ratio of the number of protons produced by electro plus photodisintegration in ${ }^{58} \mathrm{NI}$ to the number produced by electrodisintegration alone. This ratio was determined by placing a $0.217 \mathrm{~g} / \mathrm{cm}^{2} \mathrm{~T}$ a radiator in the beam $7.6 \mathrm{~cm}$ ahead of the ${ }^{58} \mathrm{Ni}$ target. 


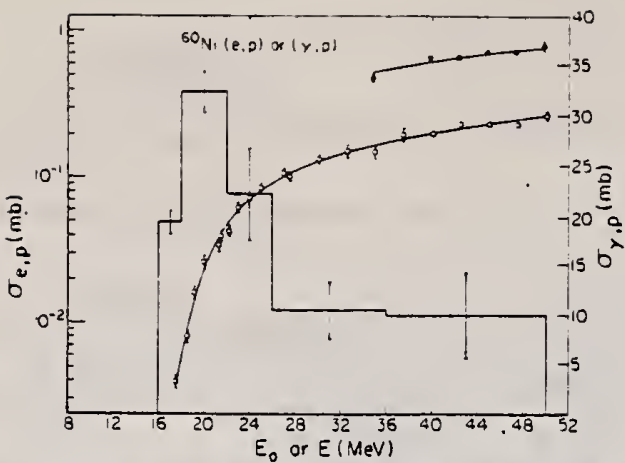

FIG. 7. The cross section (left-hand scale) for the production of protons $\sigma_{\theta, p}\left(E_{0}\right)$ when electrons of total energy $E_{0}$ are incident on a ${ }^{00} \mathrm{Ni}$ target (open circles). The closed circles represent the yield of protons obtained when a $0.217 \mathrm{~g} / \mathrm{cm}^{2} \mathrm{Ta}$ foil was interposed in the incident electron beam. The latter have been corrected for the changes in geometry produced by the multiple scattering of the electrons in the radiator. The lines drawn through the points result from folding the histogram, representing the $(\gamma, p)$ cross section (right-hand scale), with the $E 1$ virtual photon spectrum in Eq. (1) and using the Davies-Bethe-Maximon cross section in Eq. (2).

TABLE IV. Percentage of the $E 1$ and $E 2$ sums in the $\alpha$ channel. El sum: $60 \mathrm{NZ} / \mathrm{A} \mathrm{MeV} \mathrm{mb}$. $\Sigma_{2}$ sum: $0.22 Z^{2} A^{-1 / 3} \mu \mathrm{b} / \mathrm{MeV}$. E2 bin: $14-20 \mathrm{MeV}$. Upper limits of the integrais $=50 \mathrm{MeV}$.

\begin{tabular}{llccr}
\hline \hline Nucleus & Schiff & D-B-M & Schiff & D-B-M \\
\hline${ }^{58} \mathrm{Ni}$ & $4.8 \pm 0.5$ & $6.0 \pm 0.6$ & $24 \pm 3$ & $15 \pm 3$ \\
${ }^{\infty} \mathrm{Ni}$ & $4.4 \pm 0.7$ & $5.4 \pm 0.7$ & $24 \pm 4$ & $15 \pm 4$ \\
${ }^{2} \mathrm{Ni}$ & $2.4 \pm 0.3$ & $2.9 \pm 0.3$ & $10 \pm 2$ & $6 \pm 2$ \\
\hline
\end{tabular}

TABLE V. $\sigma_{e, p}$ at $100 \mathrm{MeV}$.

\begin{tabular}{|c|c|c|c|}
\hline Nucleus & $\begin{array}{c}\sigma_{e . p}(\text { meas }) \\
\text { (mb) }\end{array}$ & $\begin{array}{c}\sigma_{e, p}(\text { calc }) \\
(m b)\end{array}$ & $\begin{array}{c}\sigma_{e, p}(\operatorname{cor} r) \\
(\mathrm{mb})\end{array}$ \\
\hline${ }^{58} \mathrm{Ni}$ & $1.15 \pm 0.02$ & 1.10 & 0.98 \\
\hline$\infty \mathrm{Ni}$ & $0.50 \pm 0.01$ & 0.47 & 0.42 \\
\hline${ }^{62} \mathrm{Ni}$ & $0.24 \pm 0.01$ & 0.22 & 0.19 \\
\hline
\end{tabular}

TABLE VI. $\sigma_{\theta, \alpha}$ at $100 \mathrm{MeV}$.

\begin{tabular}{cccc}
\hline Nucleus & $\begin{array}{c}\sigma_{e, \alpha}(\text { meas }) \\
(\mathrm{mb})\end{array}$ & $\begin{array}{c}\sigma_{e, \alpha} \text { (calc) } \\
(\mathrm{mb})\end{array}$ & $\begin{array}{c}\sigma_{e, \alpha} \text { (corr) } \\
(\mathrm{mb})\end{array}$ \\
\hline${ }^{58} \mathrm{Ni}$ & $0.069 \pm 0.002$ & 0.084 & 0.063 \\
${ }^{\infty 0} \mathrm{Ni}$ & $0.063=0.002$ & 0.081 & 0.060 \\
${ }^{52} \mathrm{Ni}$ & $0.033 \pm 0.001$ & 0.036 & 0.027 \\
\hline
\end{tabular}

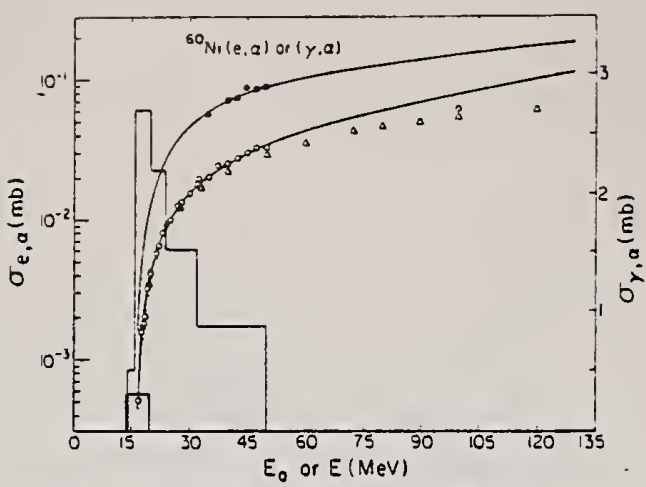

FIG. 12. The measured $\sigma_{e, \alpha}\left(E_{0}\right)$ for ${ }^{60} \mathrm{Ni}$ as a function of total incident electron energy $E_{0}$ (open circles). The full circles represent the electro plus photodisintegration yield obtained when the $0.217 \mathrm{~g} / \mathrm{cm}^{2}$ foll was interposed in the incident electron beam and the triangles show the data of Ref. 25. The smooth curves through the points result from combining the histograms, representing the $E 1$ and $E 2(\gamma, \alpha)$ cross sections (right-hand scale), in Eqs. (1) and (2) with the $E 1$ and $E 2$ virtual photon spectra and making use of the Davies-Bethe-Maximon bremsstrahlung cross section. These integrals have been extended to $130 \mathrm{MeV}$ assuming that the $(\gamma, \alpha)$ cross section is zero above $50 \mathrm{MeV}$. That the measured cross secthons lie below this curve probably stems from the failure of the long wavelength approximation. 
T.J. Bowles, R.J. Holt, H.E. Jackson, R.M. Laszewski, R.D. Mckeown,

A.M. Nathan, J.R. Specht Phys. Rev. C24, 1940 (1981)

ckson,
R.M. Laszewski,

$+$

$+2$

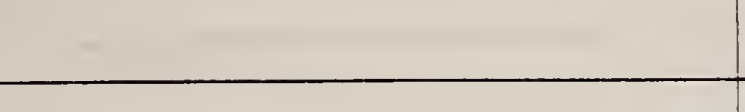

\begin{tabular}{|c|c|c|c|c|c|c|c|}
\hline & & & & & & 1 Bo 5 & hg \\
\hline \multirow[b]{2}{*}{ REACTION } & \multirow{2}{*}{ RESULT } & \multirow{2}{*}{$\begin{array}{l}\text { EXCITATION } \\
\text { ENERGY }\end{array}$} & \multicolumn{2}{|c|}{ SOURCE } & \multicolumn{2}{|c|}{ DETECTOR } & \multirow{2}{*}{ ANGLE } \\
\hline & & & TYDE & RANGE & TYPE & RANGE & \\
\hline$\overline{G, G}$ & $A B X$ & $15-23$ & $\bar{D}$ & $15-23$ & NAI-D & & 120 \\
\hline & & & & & & & \\
\hline & & & & & & & \\
\hline & & & & & & & \\
\hline
\end{tabular}

Quasimonochromatic photons have been used to measure elastic and inelastic photon scatterng cross sections in the giant dipole resonance region of ${ }^{39} \mathrm{Cr}, \mathrm{Fe},{ }^{60} \mathrm{Ni}$, ${ }^{92} \mathrm{MO}$, and ${ }^{\circ} \mathrm{Mo}$ in an experiment in which the elastic and inelastic scattering are resolved. The elastic scattering cross sections show clear evidence for isospin splitting of the giant dipole resonance. The inelastic scattering to low-lying vibrational levels, which is a measure of the coupling between the giant dipole resonance and collective surface vibrations, is in qualitative agreement with the predictions of the dynamic collective model. However, when examined in detail, this model does not provide an adequate description of the scattering data.

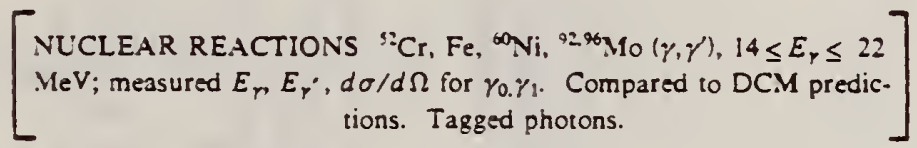

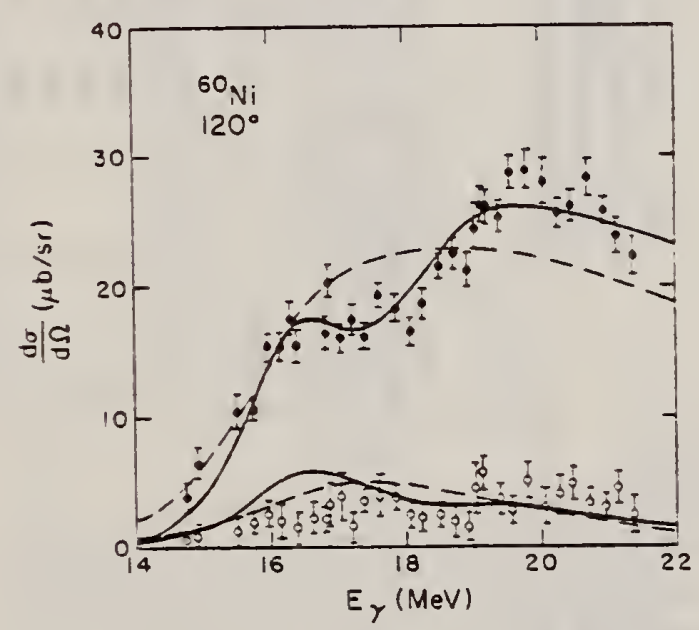

FIG. 6. Elastic (closed circles) and inelastic lopen circles) scattenng cross sections at $\theta=120^{\circ}$ for ${ }^{\circ} \mathrm{Ni}$. The error bars represent statistical uncertainties only. The solid (dashed) lines are DC.M calculations for the elastic and inelastic cross sections including (not including) the effect of isospin splitting.

sorption cross section $\sigma_{r}$ based on application of 
ReF. R.A. Lindgren, M.A. Plum, W.J. Gerace, R.S. Hicks, B. Parker, G.A. Peterson, R. Singha T, C.F. Williamson, X.K. Maruyama, F. Petrovich Phys. Rev. Lett. 47, 1266 (1981)

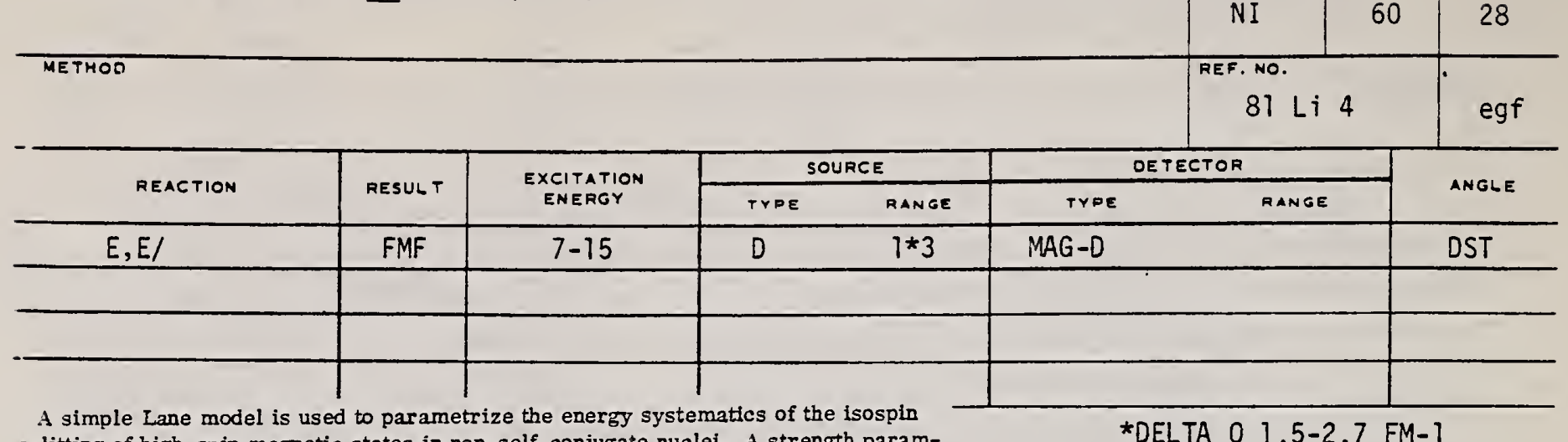

A simple Lane model is used to parametrize the energy systematics of the isospin splitting of high-spin magnetic states in non-self-conjugate auclei. A strength parameter $V_{1}=106 \pm 10 \mathrm{MeV}$ is found.

PACS numbers: $25.30 . \mathrm{Cg}, 21.10 . \mathrm{Dr}, 21.10 . \mathrm{Hw}$

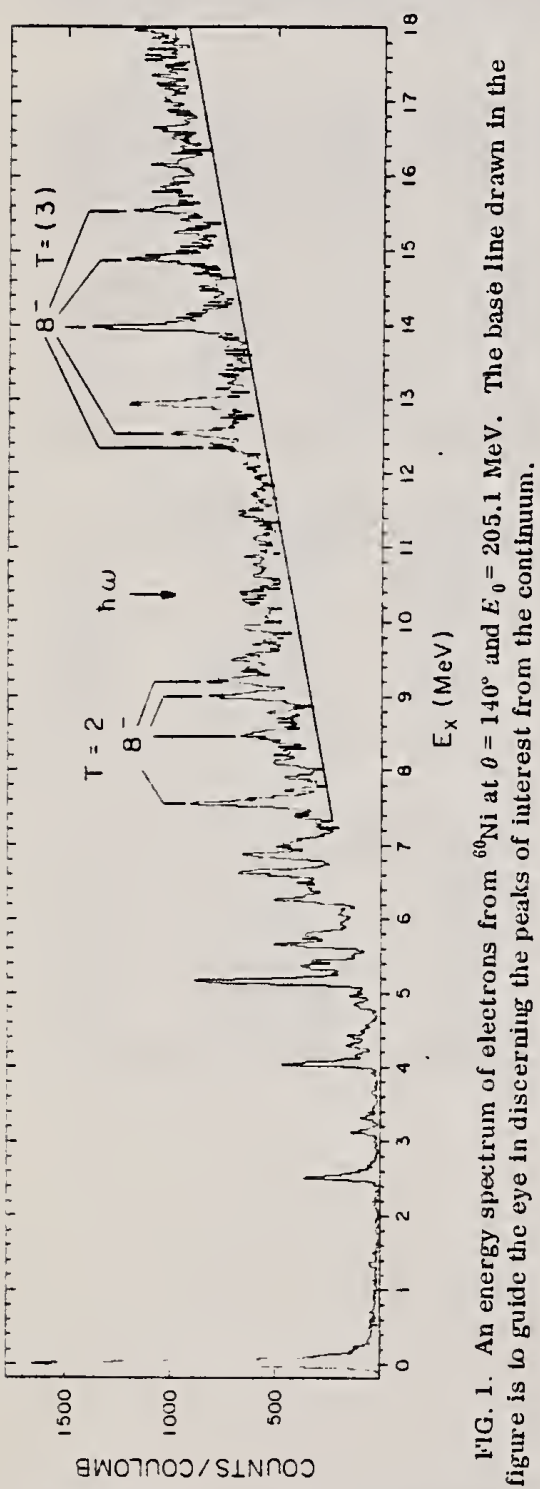

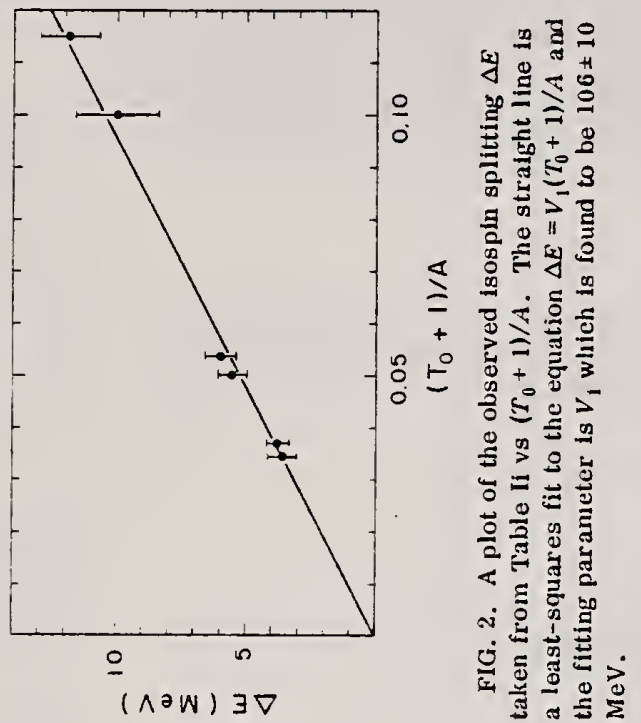

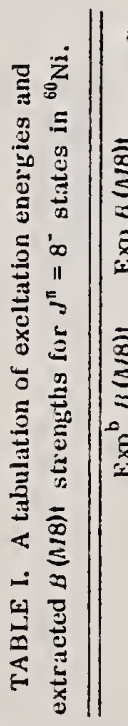

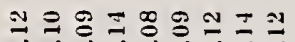

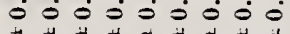
冈ิ

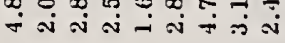
कौ

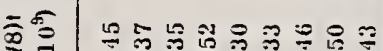
$\sum^{2}$ $\approx \bar{\Xi}$ 产 ப $\dot{0} \dot{0} \dot{0} \ddot{\theta} \ddot{0} \dot{0}$

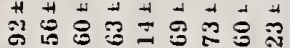
$=2000$ h n n n n $\widehat{3} \overline{3} \widehat{3} \widehat{3}$ $\Rightarrow$ م'

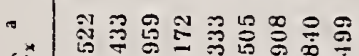

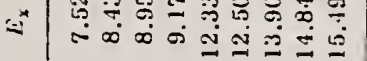

\section{*DELTA Q 1.5-2.7 FM-1}

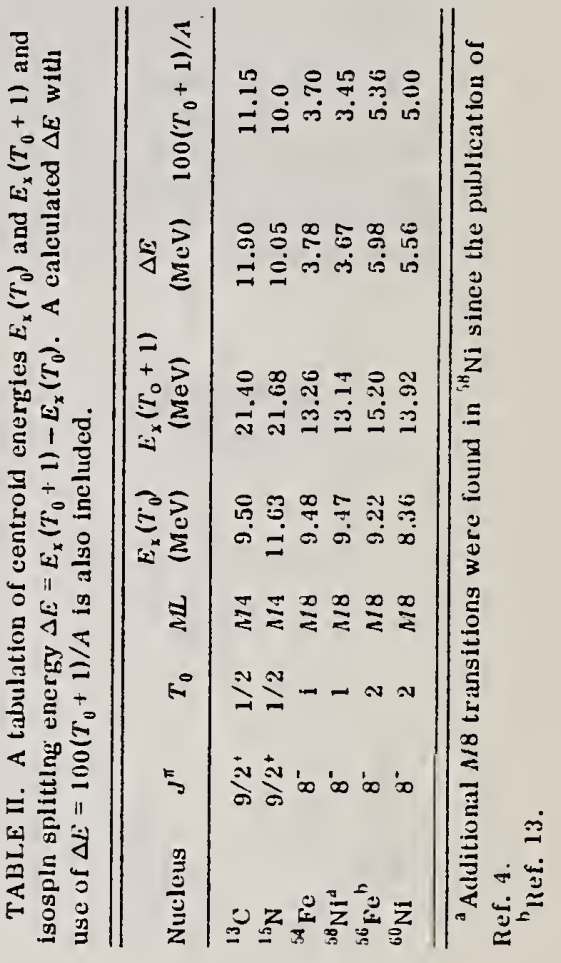


ref. T.J. Bowles, R.J. Holt, H.E. Jackșon, R.D. Mckeown, A.M. Nathan, U.R. Specht

Phys. Rev. Lett. 48,986 (1982)

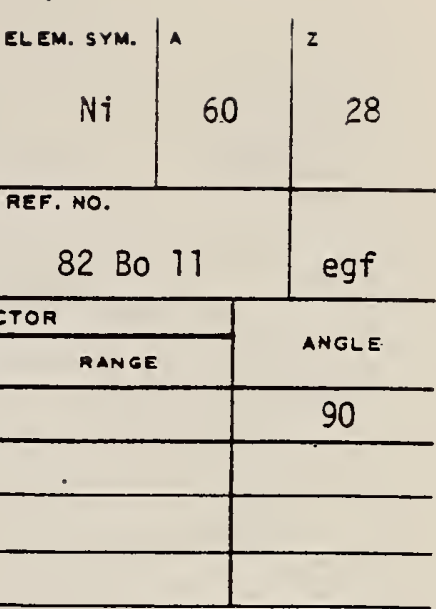

The most stringent test to date of the concept of isospin splitting of the giant dipole resonance in a medium-weight nucleus has been performed by a study of the $\left(\gamma, n_{\gamma},(\gamma\right.$, $p \gamma$. and $(\gamma, \gamma)$ reaction channels for ${ }^{j \theta} \mathrm{Ni}$. The ground-state photoneutron cross section for ${ }^{60} \mathrm{Ni}$ was measured and compared with the already known $(\gamma, p)$ reaction cross section in order to demonstrate isospin splitting. The relative strength and separation of the isospin-dependent components of the resonance were estimated from an analysis of photon scattering data.

P.ACS numbers: $25.20 .+y, 24.30 . C z, 27.50 .+e$

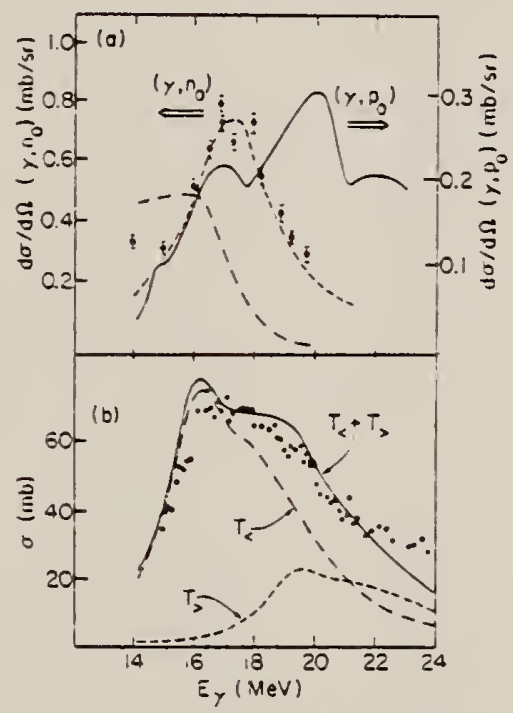

FIG. 1. (a) Ground-state photoneutron (points) and photoproton (solid line) cross sections for ${ }^{20} \mathrm{Ni}$. The data points are the results of the present measurement. The solid line is from Ref. 5. The dashed curve is a Lorentizian of width $3.4 \mathrm{MeV}$ and peak cross section adjusted to it the $\left(\gamma, n_{\alpha}\right)$ data. The dasn-dotted curve is a Hauser-Feshbach statistical calculation of the $(\gamma, n, y$ cross section. (b) Total photoneutron cross sections for ${ }^{60} \mathrm{~N}$ from Ref. 7 (circles) and the calculated photoabsorption cross section $\sigma_{y}$ for ${ }^{j 0} \mathrm{Ni}$ (sol id linel. The dashed and dash-dotted lines are the calculated $T$, and $T$, components, respectively, of $\sigma_{y}$. The calculation was performed in the framework of the dynamic collective model with parameters adjusted to fit the elastic photon scattering data. 



\begin{tabular}{|c|c|c|c|c|c|c|c|}
\hline \multirow{2}{*}{ REACTION } & \multirow{2}{*}{ RESULT } & \multirow{2}{*}{$\begin{array}{l}\text { EXCITATION } \\
\text { ENERGY }\end{array}$} & \multicolumn{2}{|c|}{ SOURCE } & \multicolumn{2}{|c|}{ DETECTOR } & \multirow{2}{*}{ ANGLE } \\
\hline & & & TYPE & RANGE & TYPE & RANGE & \\
\hline \multirow[t]{2}{*}{$G, N$} & RIX & $7-9$ & $C$ & $7-9$ & TOF-D & & DST \\
\hline & & $(7.8-8.9)$ & & $-8.9)$ & & & \\
\hline & & & & & & & \\
\hline & & . & & & & & \\
\hline
\end{tabular}

TABLE VT. Ene rgies and parametcrs for resonances in the reaction ${ }^{61} \mathrm{Ni}(\gamma, \pi)$. The $: 20 \%$ crror in the cerantity $\Gamma_{\gamma} \Gamma_{n} / \Gamma$ for all resonances is duc mainly to the uncertalnty in the absolute nargnalization of the data. The energies given in column 2 are calculated from those of column 1 by applying a correction for recoil cffects. For unassigned levels, column 4 gives $g \Gamma_{p} \Gamma_{n} / \Gamma$.

\begin{tabular}{|c|c|c|c|}
\hline $\begin{array}{c}E_{n}(n, \gamma) \\
\text { Reference } 18 \\
(k e V)\end{array}$ & $\begin{array}{l}E_{q}(\gamma, x) \text { a } \\
\text { Calc. } \\
\text { (kev) }\end{array}$ & $\begin{array}{l}\theta=90^{\circ} \\
\text { Obs. } \\
(k e v)\end{array}$ & $\begin{array}{c}\Gamma_{r r_{1}} \Gamma_{1} / \Gamma \\
(\mathrm{eV})\end{array}$ \\
\hline \multicolumn{4}{|c|}{$J=\frac{t}{2}$} \\
\hline $12.4 i$ & 11.64 & 11.6 & 0.367 \\
\hline 28.64 & 27.00 & $\cdots$ & $\ldots$ \\
\hline$\$ 3.08$ & 40.36 & 40.4 & 0.018 \\
\hline 65.23 & 62.04 & $\cdots$ & ... \\
\hline 86.8 & 82.77 & $\cdots$ & $\ldots$ \\
\hline $98.1 \div 0.7$ & 0.3 .62 & 92.6 & 0.102 \\
\hline $107.8 \div 0.75$ & 10.3 .1 & 102.9 & $0.20 ?$ \\
\hline 156.4 & 149.3 & ... & $\ldots$ \\
\hline $162.1=1.3$ & 155.0 & 154. & $0.16 n$ \\
\hline 186.5 & 179.1 & 179. & 0.052 \\
\hline $198.0 \pm 1.8$ & 190.0 & 192.0 & Total $\frac{0.5 .57}{1.481}$ \\
\hline \multicolumn{4}{|c|}{$J=t^{-}$} \\
\hline .. & $\cdots$ & 12.6 & $0.0 \cdot i n$ \\
\hline $43.4 \pm 0.22$ & 45.0 & 45.0 & $0.16,5$ \\
\hline $56.9 \pm 0.29$ & 54.1 & 53.9 & 0.052 \\
\hline $111.3 \pm 1.0$ & 106.3 & 106.0 & $0 . i 19$ \\
\hline $136.5 \pm 1.4$ & 130.5 & 129.5 & 0.256 \\
\hline $139.6=1.4$ & 133.5 & 132.5 & 0.314 \\
\hline No data & & 141.6 & $0.1+8$ \\
\hline No daca & & 159.0 & Total $\frac{0.216}{1.651}$ \\
\hline \multicolumn{4}{|c|}{$J=\frac{7^{-}}{2}$} \\
\hline $23.3=0.1$ & 22.4 & 22.0 & 0.020 \\
\hline $32.9=0.1$ & 31.1 & 31.0 & 0.018 \\
\hline $51.5 \pm 0.3$ & 48.9 & 48.3 & 0.0 .34 \\
\hline \multicolumn{2}{|c|}{ under strong $s$-wave level } & 62.0 & 0.189 \\
\hline $84.7 \pm 0.6$ & 80.7 & 81.4 & 0.093 \\
\hline $120.6 \pm 11$ & 1152 & 114.8 & 0.205 \\
\hline$\cdots$ & .. & 162.0 & 0.231 \\
\hline$\cdots$ & $\cdots$ & 187.0 & Total $\frac{0.165}{1.067}$ \\
\hline \multicolumn{4}{|c|}{ Unassigned levels } \\
\hline 93.3 & 89.0 & 89.0 & 0.014 \\
\hline$\cdots$ & $\cdots$ & 107.9 & 0.032 \\
\hline No daka & & 175.0 & Total $\frac{0.067}{0.113}$ \\
\hline
\end{tabular}

TABLEV. An:jular momentum assismments for resorances in the reaction ${ }^{51} \mathrm{Ni}(\gamma, n)$.

\begin{tabular}{|c|c|c|c|c|c|}
\hline $\begin{array}{c}E_{n}(\%, \pi) \\
(\text { hell) }\end{array}$ & $\frac{d \sigma\left(90^{\circ}\right) / d \Omega}{d \sigma\left(135^{\circ}\right) / d \Omega}$ & s? & $\begin{array}{c}E_{n}(n, n) \\
\text { (iev) }\end{array}$ & $\frac{d \sigma\left(90^{\circ}\right) / d \Omega}{d \sigma\left(135^{\circ}\right) / d \Omega}$ & $J^{\prime \prime}$ \\
\hline 11.6 & $s$ wave & $\vdots$ & 102.9 & s wave & it \\
\hline 12.6 & $1.25=0.15$ & $\frac{1}{5}$ & 106.0 & $1.05 \pm 0.07$ & $\frac{1-}{2}$ \\
\hline 22.0 & $0.53=0.10$ & 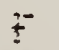 & 114.8 & $0.61 \pm 0.05$ & $\frac{1}{2}$ \\
\hline 31.0 & $0.5 n=0.12$ & 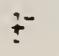 & 129.5 & $0.95 \neq 0.09$ & $\frac{1-}{2}$ \\
\hline 40.4 & $s$ wave & $\stackrel{2}{2}$ & 132.5 & $0.91 \pm 0.08$ & $\left(\frac{1}{2}\right)^{-}$ \\
\hline$\$ 5.0$ & $1.13 \pm 0.07$ & $\div$ & 141.6 & $1.29 \pm 0.19$ & $\frac{10}{2}$ \\
\hline 48.8 & $\begin{array}{l}0.04=0.10 \\
0.49=0.07\end{array}$ & $\frac{1}{2}$ & 154.0 & s wave & $\frac{1}{2}$ \\
\hline 53.9 & $\begin{array}{l}0.97=0.11 \\
1.10=0.12\end{array}$ & 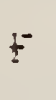 & $\begin{array}{l}159.0 \\
162.0\end{array}$ & $\begin{array}{l}1.24=0.08 \\
0.72=0.06\end{array}$ & $\frac{\frac{1}{2}}{\frac{2}{2}}$ \\
\hline 62.0 & $\begin{array}{l}0.68=0.04 \\
0.30=0.05\end{array}$ & $\frac{1-}{2}$ & $\begin{array}{l}179.0 \\
187\end{array}$ & $\begin{array}{l}s \text { wave } \\
0.62 \pm 0.05\end{array}$ & $\begin{array}{l}\frac{1}{2} \\
\frac{1}{2}\end{array}$ \\
\hline 81.8 & $0.001=0.09$ & $\frac{i-}{2}$ & 192 & 3 wave & $\frac{t}{2}$ \\
\hline 92.5 & s wave & $\dot{2}$ & & & \\
\hline
\end{tabular}




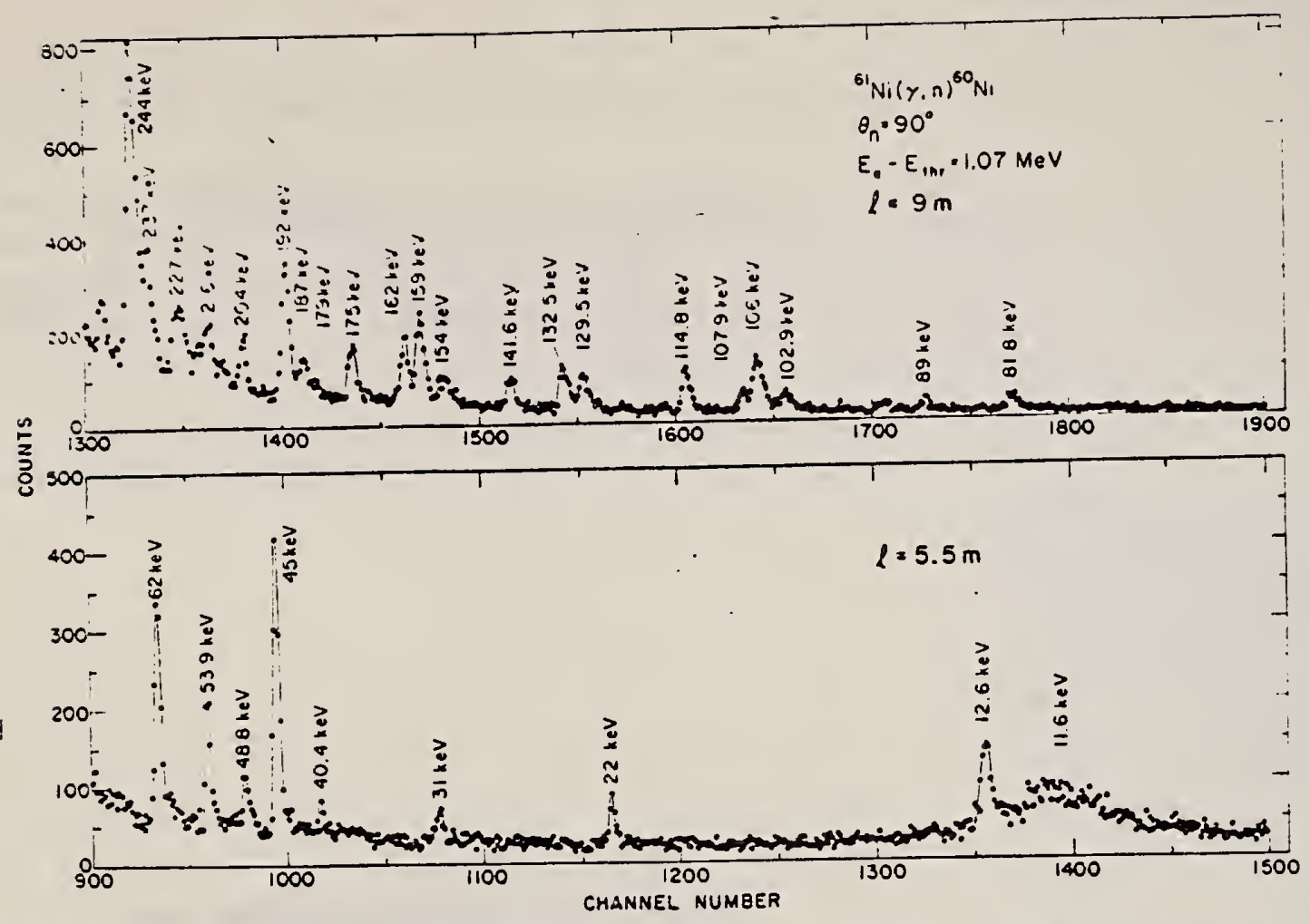

FIG. 7. Photoneutron time-of-alight spectrum for ${ }^{11} \mathrm{NI}(\gamma, n)$. The upper section was taken with a tlight path of $9 \pi$ the lower section with a fight path of $5.5 \mathrm{~m}$.

TABLE VTI. Intcgrated yieids and reduced widths for electric and mametic dipole radiation. Interrated yields are given for all resonances observed, but reduced widths for magnetic dipole transitions are calculatcd only from yields for $p$-wave levels above $100-\mathrm{keV}$ neutron energy (see discussion in Sec. IV). The number of resonance widths used to obtain each $\bar{k}$ is given by $n$. The errors given were caiculated by assuming that the individual $\Gamma_{\gamma}$ 's follow a PorterThomas distribution.

\begin{tabular}{|c|c|c|c|c|c|c|}
\hline Target & $J^{T}$ & $\sum \underset{(\mathrm{eV})}{\sum \Gamma_{r_{0}} \Gamma_{n} / \Gamma}$ & $\sum \underset{(\mathrm{eV})}{\Gamma_{\gamma} \Gamma_{n} / \Gamma}$ & $n$ & $\begin{array}{l}10^{3} \times \text { reduced width } \\
\text { Individual average }\end{array}$ & \\
\hline \multirow[t]{3}{*}{${ }^{55} \mathrm{Cr}$} & $\frac{1}{2}$ & 0.97 & 3.88 & 7 & $k_{B 1}=1.7+1 . j$ & \\
\hline & 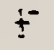 & 1.27 & 5.06 & 6 & $\vec{k}_{n 1}=41$ & $\bar{k}_{n}=28 \pm 15$ \\
\hline & 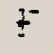 & 0.86 & 1.71 & 10 & $\vec{k}_{n i}=16$ & \\
\hline \multirow[t]{3}{*}{${ }^{57} \mathrm{Fe}$} & $\frac{1+}{2}$ & 0.83 & 1.66 & 8 & $\vec{k}_{E 1}=0.86_{-0}^{* 0.8}$ & \\
\hline & $t^{-}$ & 0.37 & 0.74 & 4 & $\bar{k}_{m}=9$ & $\bar{k}_{m}=10 \pm-j 0$ \\
\hline & $\frac{3-}{2}$ & 0.84 & 0.84 & 3 & $E_{M}=10$ & \\
\hline \multirow[t]{3}{*}{${ }^{61} \mathrm{NI}$} & $\frac{10}{2}$ & 0.37 & 1.48 & 11 & $\bar{k}_{\Sigma 1}=0.96 \pm 0.49$ & \\
\hline & $i$ & 0.41 & 1.65 & 5 & $\bar{k}_{y_{1}}=27$ & $\vec{k}_{m 1}=20 \pm 18$ \\
\hline & $\frac{3-}{2}$ & 0.54 & 1.07 & 3 & $\bar{b}_{m}=12$ & \\
\hline
\end{tabular}


Y. Cauchois, H. Ben Abdelaziz, R. Khérouf, C. Schloesing-Möller

REF. J. Phys. G7, 1539 (1981)

\begin{tabular}{lll|l|l|}
\hline METHOO & REF. \\
\hline
\end{tabular}

REF. NO.

$81 \mathrm{Ca} 2$

hg

\begin{tabular}{|c|c|c|c|c|c|c|c|}
\hline \multirow[b]{2}{*}{ REACTION } & \multirow[b]{2}{*}{ RESULT $T$} & \multirow{2}{*}{$\begin{array}{l}\text { EXCITATION } \\
\text { ENERGY }\end{array}$} & \multicolumn{2}{|c|}{ SOURCE } & \multicolumn{2}{|c|}{ DETECTOR } & \multirow{2}{*}{ ANGLE } \\
\hline & & & TYPE & MANGE & TYPE & RANGE & \\
\hline \multirow[t]{4}{*}{$G, G$} & LFT & 1 & $C$ & $0-2$ & $S C D-D$ & & \\
\hline & & $(1.186)$ & & & & & \\
\hline & & & & & & & \\
\hline & & & & & & & \\
\hline
\end{tabular}

Abstrach Lifetimes of 49 excited states below $1.65 \mathrm{MeV}$ have been measured in ${ }^{4} \mathrm{Mg} .{ }^{27} \mathrm{Al}$.

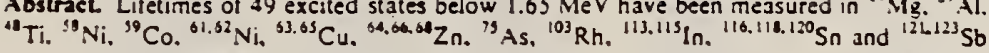
by means of nuclear resonance iuorescence experıments. The levels are excited by bremsstrahlung $x$-ray photons. The self-absorption technique applied to suitable cases provides nuclear absorption cross sections. widths and lifetimes from which the $x$-ray spectral distributions are also obtained. Scattering experiments are performed for all othet cases in order to obtain widths and lifetimes from these $x$-ray photon curves. The Compton eftect in the sample is taken into account. Self-absorption provices $g \Gamma_{0}$ from which $r$ is deduced using adopted $J^{*}$ and $\Gamma_{0} / \Gamma$ values; scatcering provides $u=g\left(\Gamma^{2} / \Gamma\right) b(\theta)$ from which $\Gamma$ is also deduced with $J, r_{0} / \Gamma$ and mixing ratios taken from the literature. Thanks to simultaneous determınation of the r-ray spectra a!l the life:ımes as given by our programs with their statistical errors form an unusually coherent set of values.

NUCLEAR REACTIONS (\% \%). bremsstrahlung excitation: natural 15otopes: ${ }^{24} \mathrm{Mg}$.

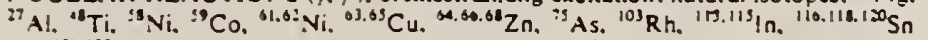
and ${ }^{121.123} \mathrm{Sb}: E=0.5-1.65 \mathrm{MeV}$; measured g $\Gamma_{0}$ or $g\left(\Gamma_{0}^{\dot{\alpha}} / \Gamma\right)(t)(\theta)$ : deduced $T_{1: 2}$. 
Tableau 3. Resultats des mesures des niveaux etudiès par diffusion.

Table 3. Results obtained using the diffusion method.

\begin{tabular}{|c|c|c|c|c|c|c|c|c|c|}
\hline Isotope & Energie (keV) & $J^{2}$ & $J_{0}^{R}$ & $\Gamma_{0} / \Gamma$ & $\dot{0}$ & $\begin{array}{l}u=g\left(\Gamma_{0}^{2} / \Gamma\right) W(\theta) \\
(\mathrm{meV})\end{array}$ & $\begin{array}{l}\tau(\mathrm{ps}) \\
\text { ce travail }\end{array}$ & $\tau_{\mathrm{ref}}(\mathrm{ps})$ & Refërcncest \\
\hline$\therefore \mathrm{Mg}$ & $1368.59(4)$ & $\geq^{*}$ & $0^{-}$ & 1 & E2 & $1,08(13)$ & $1.76(21)$ & $1,98(4)$ & $\begin{array}{l}\text { Endt et van der Leun } \\
\quad(1978)\end{array}$ \\
\hline${ }^{27} \mathrm{Al}$ & $1014.45(3)$ & $!^{*}$ & $\vdots$ & $0.97 !$ & $+0.351(12)$ & $0,186(13)$ & $2.20(16)$ & $2.12(8)$ & $\begin{array}{l}\text { Endt et van der Leun } \\
\qquad(1978)\end{array}$ \\
\hline${ }^{48} \mathrm{Ti}$ & $983.512(3)$ & $2^{*}$ & $0^{*}$ & 1 & E2 & $0.282(23)$ & $6.74(55)$ & $6.1(13)$ & $\operatorname{Bec11}(1978)$ \\
\hline${ }^{58} \mathrm{Ni}$ & $1454,45(15)$ & $2^{*}$ & $0^{*}$ & 1 & E2 & $2,11(26)$ & $0,90(11)$ & $0.92(3)$ & $\begin{array}{l}\text { Kocher el Auble } \\
\text { (1976) }\end{array}$ \\
\hline${ }^{59} \mathrm{Co}$ & $1099.224(25)$ & & $i^{-}$ & 1 & $(E 2)$ & $0.069(8)$ & $4.79(55)$ & $3.17(58)$ & $\operatorname{Kim}(1976)$ \\
\hline${ }^{99} \mathrm{Co}$ & $1458.8(3)$ & & 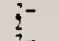 & $0,9 !$ & $(E 2)$ & $0.68(8)$ & $1,17(14)$ & $1.52(16)$ & $\operatorname{Kim}(1976)$ \\
\hline${ }^{59} \mathrm{Co}$ & $1480.9(3)$ & & $\overline{1}$ & 0.8 & $<0.35^{\circ}$ & $1.23(15)$ & $0.254(31)$ & $0.31(3)$ & $\operatorname{Kim}(1976)$ \\
\hline${ }^{31} \mathrm{Ni}$ & $1185.7(6)$ & 6 & $!^{-}$ & $0.77(8)^{\prime}$ & $|0.14|$ & $1.88(49)$ & $0.21(5)$ & $0.16(3)$ & Andreev el al (1974) \\
\hline${ }^{62} \mathrm{Ni}$ & $1172.91(9)$ & $2^{*}$ & $0^{*}$ & 1 & E2 & $0.88(17)$ & $2,15(42)$ & $2.09(3)$ & Halbcrt (1979a) \\
\hline${ }^{63} \mathrm{Cu}$ & $1327,00(7)$ & & $3-$ & 0.84 & (E2) & $1,04(14)$ & $0.84(11)$ & $0,88(4)$ & Auble (1979b) \\
\hline${ }^{63} \mathrm{Cu}$ & $1+12.05(4)$ & & $i^{-}$ & 0,72 & $+0.61(\div-8)$ & $0.260(38)$ & $1,90(28)$ & $1.61(3)$ & Auble (1979b) \\
\hline $\mathrm{Zn}$ & $991.54(7)$ & $2^{*}$ & $0^{*}$ & 1 & E2 & $0,640(54)$ & $2,97(25)$ & $2,60(13)$ & Halbert (1979b) \\
\hline${ }^{63} \mathrm{Cu}$ & $1481,83(5)$ & $:-$ & $\xi^{-}$ & 0.85 & $(E 2)$ & $1,13(19)$ & $0,79(13)$ & $0,49(5)$ & Auble (1975a) \\
\hline $\mathrm{Zn}_{\mathrm{n}}$ & $1039,37(6)$ & $2^{-}$ & $0^{-}$ & 1 & E2 & $0,70(6)$ & $2,71(23)$ & $2,25(15)$ & Auble (1975b) \\
\hline${ }^{6} \mathrm{Zn}$ & $1077,38(5)$ & $2^{*}$ & $0^{*}$ & 1 & E2 & $0,70(6)$ & $2,71(23)$ & $2,34(23)$ & Lewis (1975) \\
\hline${ }^{75}$ As & $572,5(10)$ & & $?^{-}$ & $1^{d}$ & $0.39^{b}$ & $0,236(26)$ & $4.14(46)$ & $3.5(9)$ & Horen et Lcwis (1975) \\
\hline${ }^{73}$ As & $823,0(10)$ & & & $0,86^{\triangleleft}$ & (E2) & $0.214(22)$ & $4,27(43)$ & $3,5(3)$ & Rubinson el al (1967) \\
\hline${ }^{79}$ As & $865.5(10)$ & $i^{+}$ & & $0.83^{d}$ & $-c$ & $0,78(6)$ & $0.863(68)$ & $0,60(12)$ & Celliers el al (1977) \\
\hline${ }_{75}^{73}$ As & $1076,0(10)$ & & & $0,94^{d}$ & $0,38^{d}$ & $1,97(13)$ & $0,287(19)$ & $0,32(7)$ & Celliers el al (1977) \\
\hline${ }^{75} \mathrm{As}$ & $1128,5(10)$ & $2^{*}$ & $i^{-}$ & 1 & $E l^{d}$ & $0,224(24)$ & $1,47(16)$ & - & \\
\hline As & $13 \div 9.0101$ & $1-$ & $2-$ & $0.67^{d}$ & $0.20^{d}$ & $1.01\langle 29\rangle$ & $0,180 \times 32)$ & $0.12(3)$ & Wilsun (1 470$)$ \\
\hline is As & $1370.1 \times !(0)$ & 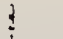 & - & $0.47^{\mathrm{s}}$ & $0.47^{\circ}$ & $0.64(13)$ & $0.218(44)$ & - & \\
\hline${ }^{103} \mathrm{Rh}$ & 803.1121 & $\vdots$ & $!$ & 0.70 & $M 1$ & $1.85(16)$ & $0.174(15)$ & - & Harmatz (1979) \\
\hline${ }^{103} \mathrm{Kh}$ & $1277 .(x) 1$ & 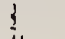 & $!$ & 0.75 & $-0.62(30)^{c}$ & $0.81(4)$ & $0.37(10)$ & $1.3(9)$ & 11:1rmatle(147y) \\
\hline 11111 & $1177(1)$ & 13 & ?* & 1 & $+0.5(2)$ & $9.1(8)$ & $0.086(8)$ & $0.10(6)$ & Tutte et wi $(1976)$ \\
\hline 11311 & $1510(1)$ & $?$ & 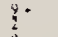 & 0.435 & $-0.5\left(\begin{array}{l}(-1) \\
-2)\end{array}\right.$ & $6.4(y)$ & $0.071(10)$ & $0.11 ! 310$ & Tuttle el $a /(1476)$ \\
\hline 119111 & $1077.7(10)$ & $\xi$ & $\stackrel{9}{4}$ & $0.81^{1}$ & (E2) & $0.159(24)$ & $1.61(24)$ & $1.23(7)$ & Tulle $i: a l(1976)$ \\
\hline $115 \ln$ & 1290.59131 & 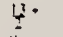 & $\stackrel{?}{?} \cdot$ & $0.98^{1}$ & $(\mathrm{E} 2)$ & $1.31(11)$ & $0.66(6)$ & $0.55(4)$ & Tutile $4 t a /(1976)$ \\
\hline 115111 & $1: 98.78(3)$ & $\frac{u}{2}$ & $?^{-}$ & 0.86 & $-8^{\prime}$ & $0.90(11)$ & $0.50(6)$ & $0.52(20)$ & Tuttle :t $a /(1970)$ \\
\hline $1191 \mathrm{n}$ & 1446.1111 & $? \cdot$ & $?^{\circ}$ & 0.787 & $-0.8^{t}$ & $0.63(9)$ & $0.63(9)$ & $0.4(3)$ & Tuttle et al $(1976)$ \\
\hline $1191 \mathrm{ln}$ & $1+47.2(+1)$ & $(\vdots)$ & $?^{\circ}$ & $<1$ & $(E 2)$ & $1.33(16)$ & $<0.30(4)$ & - & \\
\hline $115 \ln$ & $1607.8(15)$ & $(\vdots-1$ & $\xi^{*}$ & $\leqslant !$ & (E-2) & $1,54(24)$ & $\leqslant 0.26(1)$ & - & \\
\hline${ }^{116} \mathrm{Sn}$ & $1293.54(2)$ & $z^{*}$ & $0^{*}$ & 1 & E2 & $3.58(37)$ & $0.53(6)$ & $0.522(14)$ & Carlson el al (1975) \\
\hline${ }^{118} \mathrm{Sn}$ & $1229.6+(4)$ & $2^{*}$ & $0^{+}$ & 1 & E2 & $2.75(28)$ & $0.69(7)$ & $0.67(2)$ & Cirlson et $a /(1476)$ \\
\hline${ }^{120} \mathrm{Sn}$ & $1171.6(2)$ & $2^{*}$ & $0^{*}$ & 1 & E? & $1.83(16)$ & $1,04(9)$ & $0.91(2)$ & Kocher $(1476)$ \\
\hline${ }^{121} \mathrm{Sb}$ & $1023.5(10)$ & ?* & $\vdots$ & 1 & $|0.57|^{8}$ & $3.69(34)$ & $0.228(2 !)$ & $0.20(7)^{h}$ & Taniura el al $(19-9)$ \\
\hline${ }^{121} \mathrm{Sb}$ & $1105.5(10)$ & $?^{-}$ & $?$ & 0.4 & 一 & $0.47(4)$ & $0,42(4)$ & $\rightarrow$ & \\
\hline${ }^{121} \mathrm{Sb}$ & $1142,5(10)$ & $2^{*}$ & $\xi^{+}$ & 0.6 & $(E 2)$ & $0.85(8)$ & $0,449(40)$ & $0,41(8)^{h}$ & Booth ef af (1973) \\
\hline${ }^{121} \mathrm{Sb}$ & $1381.0(10)$ & $?$ & 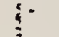 & 1 & $|0.45|^{3}$ & $4.7(5)$ & $0,09 \geq 1101$ & $0.088(14)^{n}$ & Booth et al (1973) \\
\hline${ }^{123} \mathrm{Sb}$ & $10 \div 9,5(10)$ & $i^{*}$ & 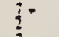 & 1 & $\left.0.57\right|^{\prime}$ & $2,96(27)$ & $0,272(25)$ & $0.26(4)^{n}$ & Booth el al (1973) \\
\hline${ }^{123} \mathrm{Sb}$ & 1056.51101 & $!^{\bullet}$ & $?^{*}$ & 1 & $|0|>! .26^{8}$ & $1,06(4)$ & $0.67(6)$ & $0.72(15)^{3}$ & Buoth et .it (1973) \\
\hline
\end{tabular}

+ References pour !es colonnes 3,4.5.6 et 9 de shaque ligne, sauf indication appelee au bas de ce tableau. Pour les autres junnejes se reporter au texte.

Re'marque. Pour calculer $j^{2}$ quand nous ne disposons que de $B(E 2)$, pour un mẻlange $(E 2)+(M 1)$, nous diduisons $g \Gamma_{0}(E 2) x B(E 2) E_{r}^{s} ;$ en

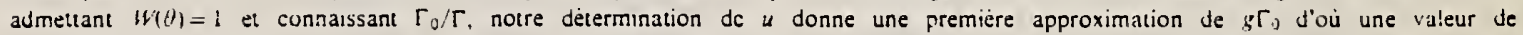
$i^{2}=\left(g \Gamma_{0}(E 2)\right) /\left(g \Gamma_{0}-g \Gamma_{0}(E 2)\right)$ qui permet d'ameliorer $W(\theta)$ et $g \Gamma_{0}$ de proche en proche.

"Swann (1971): "Robinson et al (1967): " $W^{\prime}(\theta)=0.99$ calcule d'apres la formule de Celliers el a/(1977): "Abbundanno et a/(1973): ${ }^{\circ}$ Sayer el al (1472): 'Tuttle et al(1976); "d'apres B(E2) de Barnes et al(1966); "calcule J'apres Booth el al(1973): 'Williams el al (1975): I Dietricli el al (1970). 
$A=62$ 
J.H. Carver, W. Turchinetz

Proc. Phys. Soc. 73, 585 (1959)

METHOD

Synchrotron; proton cross se:tion; radioactivity.

$59 \mathrm{Ca} 4$

NVB

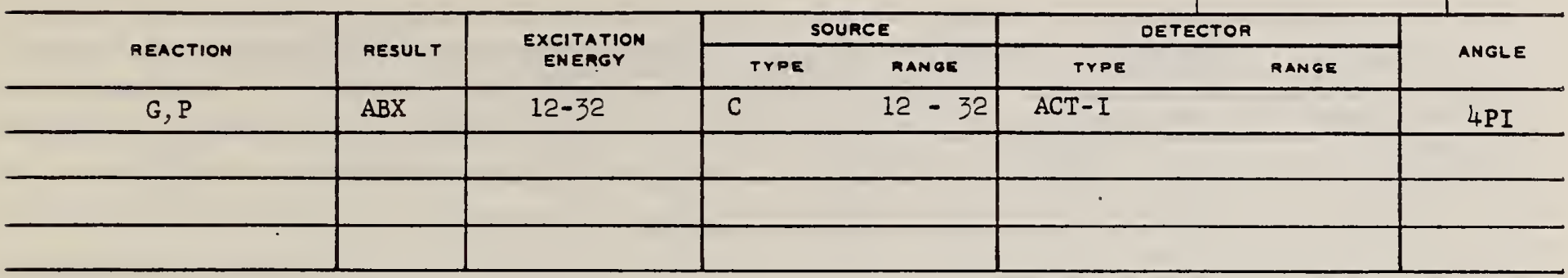

$\sigma_{\max }=0.019 \mathrm{~b}$

$\Gamma \cdot(1 / 2 \sigma \max )=5.2 \mathrm{MeV}$

$\int_{0}^{32} \sigma(\gamma, p) d E=0.13 \pm 0.02 \mathrm{MeV}-\mathrm{b}$

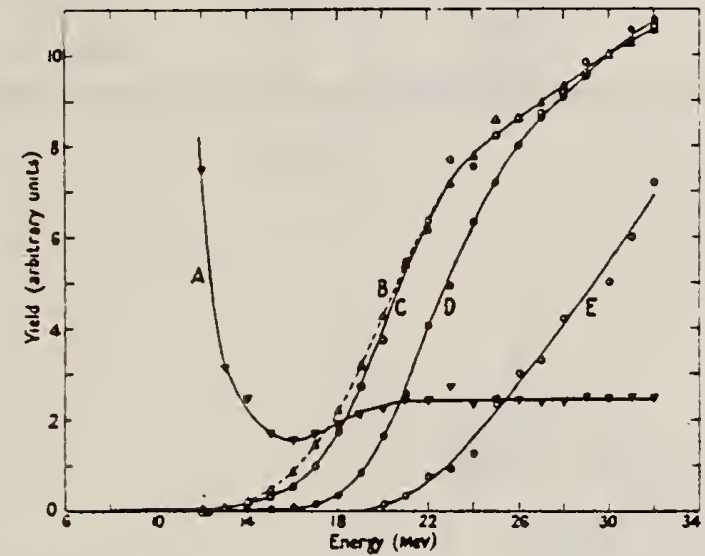

Figure 1. Activation curves for the photodisintegration of nickel: $A,{ }^{30} \mathrm{Ni}(\gamma, \mathrm{p}) /{ }^{\mathrm{s}} \mathrm{Ni}(\gamma, \mathrm{n})$; B, ${ }^{38} \mathrm{Ni}(\gamma, n) ; C,{ }^{38} \mathrm{Ni}(\gamma, p) ; \mathrm{D},{ }^{12} \mathrm{Ni}(\gamma, p) ; E,{ }^{88} \mathrm{Ni}(\gamma, n p+\gamma, 2 \mathrm{n})$. The ordinates for curves $B, C, D, E$ are in arbitrary units, while those for curve $A$ give the ratio absolutely.

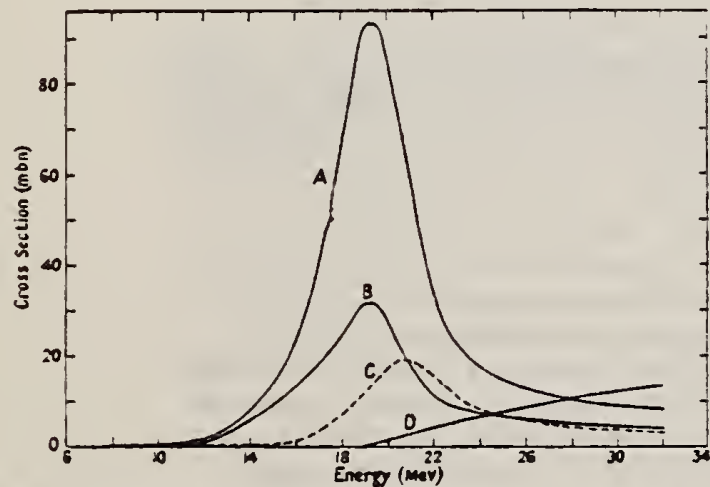

Figure 2. Excitation functions for the photodisintegration of nickel: A, ${ }^{8} \mathrm{Ni}(\gamma, \mathrm{p})$; B, ${ }^{58} \mathrm{Ni}(\gamma, n) ; C,{ }^{02} \mathrm{Ni}(\gamma, p) ; \mathrm{D},{ }^{58} \mathrm{Ni}(\gamma, \mathrm{np}+\gamma, 2 \mathrm{n})$. 
M.A. Duguay, C.K. Bockelman, T.H. Curtis, and R.A. Eisenstein Phys. Rev. Letters 17, 28 (1966)

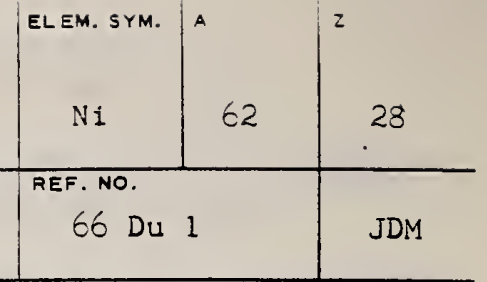

\section{Linac}

\begin{tabular}{|c|c|c|c|c|c|c|c|}
\hline \multirow{2}{*}{ REACTION } & \multirow{2}{*}{ RESUL T } & \multirow{2}{*}{$\begin{array}{l}\text { EXCITATION } \\
\text { ENERGY }\end{array}$} & \multicolumn{2}{|c|}{ SOURCE } & \multicolumn{2}{|c|}{ DETECTOR } & \multirow{2}{*}{ ANGLE } \\
\hline & & & TYPE & RANGE & TYPE & RANGE & \\
\hline$E, E /$ & EME & 1 & $D$ & $45-65$ & MAG-D & & DST \\
\hline & & & & & & & \\
\hline & & & & & & & \\
\hline
\end{tabular}

Table I. Recuced transition probabilities $B(E 2)$ and transition radii $R_{t r}$ for the first excited states of the even $\mathrm{Ni}$ isotopes.

\begin{tabular}{cccccc}
\hline \hline & & \multicolumn{3}{c}{$\begin{array}{c}B\left(E 2,0^{+}-2^{+}\right) \\
\left(e^{2} F^{4}\right)\end{array}$} \\
Isotope & $\begin{array}{c}\text { Level energy } \\
(\mathrm{MeV})\end{array}$ & $J^{\pi}$ & Ref. 12 & $\begin{array}{c}\text { Present } \\
\text { work }\end{array}$ & $\begin{array}{c}R_{\mathrm{tr}} \\
(\mathrm{F})\end{array}$ \\
\hline $\mathrm{Ni}^{58}$ & 1.452 & $2^{+}$ & $720 \pm 10 \%$ & $620 \pm 14 \%$ & $5.35 \pm 10 \%$ \\
$\mathrm{Ni}^{60}$ & 1.332 & $2^{+}$ & $910 \pm 9 \%$ & $776 \pm 12 \%$ & $5.23 \pm 12 \%$ \\
$\mathrm{Ni}^{62}$ & 1.172 & $2^{+}$ & $830 \pm 9 \%$ & $770 \pm 12 \%$ & $5.23 \pm 10 \%$ \\
\hline \hline
\end{tabular}

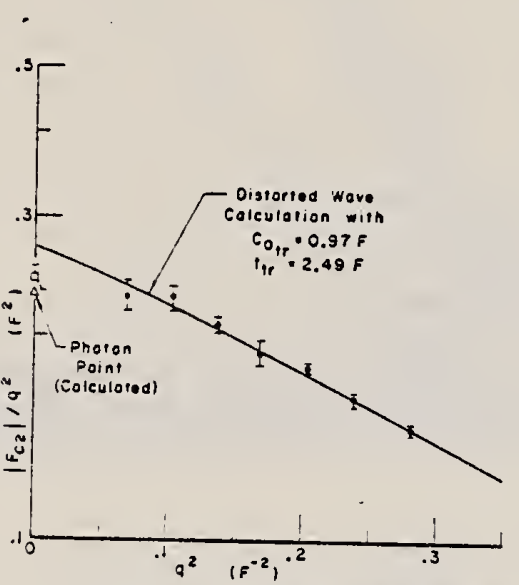

FIG. 1. Form factor for the first excited $\left(2^{+}\right)$state of $\mathrm{Ni}^{62}$, as a function of momentum transfer squared. The solid points represent measured form factcr 3 divided by the square of the momentum transfer plottec logarithmically as a function of the square of the nomentum transfer. The line is a plot of theoretical results using the computer program of Ref. 9 to calculate form factors corresponding to transition charge densities described by the parameters $c_{0} t_{r}$ and $t_{t r}$ [Eq. (3)]. The open triangle at $q=0$ represents the photon point, calculated from Eqs: (2) and (4), using the parameters quoted is the figure. The square represents the results of the Coulomb-excitation experiment of Ref. 12. 
M. A. Duguay, C. K. Bockelman, T. H. Curtis and R. A. Eisenstein

Phys. Rev. 103, $1259(1967)$

\begin{tabular}{|c|c|c} 
ELEM. SYM. & A & $z$ \\
Ni & 02 & 28 \\
REF. NO. & HMG DU 1 & ANGLE \\
\hline RANGE & DST \\
\hline
\end{tabular}

TABLE II. Reduced radiative transition probabilities and transition radii.

\begin{tabular}{|c|c|c|c|c|c|c|c|}
\hline \multirow{2}{*}{ REACTION } & \multirow{2}{*}{ RESULT } & \multirow{2}{*}{$\begin{array}{c}\text { EXCITATTON } \\
\text { ENERGY }\end{array}$} & \multicolumn{2}{|c|}{ SOURCE } & \multicolumn{2}{|c|}{ DETECTOR } & \multirow{2}{*}{ ANGLE } \\
\hline & & & TYPE & RANGE & TYPE & RANGE & \\
\hline E.E/ & EME & $1-5$ & D & $45-65$ & MAG-D & & DST \\
\hline & & & & & & & \\
\hline & & & & & & & \\
\hline
\end{tabular}

\begin{tabular}{|c|c|c|c|c|c|}
\hline \multicolumn{6}{|c|}{ B3 Trancitions } \\
\hline & $\begin{array}{l}\text { Excitation } \\
\text { energy } \\
\text { (MeV) }\end{array}$ & $B\left(E 2,0^{+}-2^{+}\right)$ & $\frac{B\left(B 2.0^{+} \rightarrow 2^{+}\right)}{B\left(B 2,0^{+} \rightarrow 2^{+}\right)=}$ & Ai & $\underset{(F)}{R_{\text {LF }}}$ \\
\hline $\begin{array}{l}\text { Nias } \\
\text { Nio } \\
\text { Nion }\end{array}$ & $\begin{array}{l}1.452 \\
3.034 \\
3.26 \\
1.330 \\
1.172\end{array}$ & $\begin{array}{r}657 \pm 11 \\
83 \neq 3 \\
153=15 \\
945 \pm 9 \\
877 \pm 11\end{array}$ & $\begin{array}{r}10 \\
1 \\
2 \\
12 \\
12\end{array}$ & $\begin{array}{l}0.177 \neq 0.003 \\
0.063 \pm 0.002 \\
0.085 \pm 0.008 \\
0.197 \neq 0.002 \\
0.197 \neq 0.001\end{array}$ & $\begin{array}{l}5.51 \\
5.51 \\
5.51 \\
5.55 \\
5.59\end{array}$ \\
\hline \multicolumn{6}{|c|}{ E3 Transitions } \\
\hline & $\begin{array}{l}\text { Excitation } \\
\text { energy } \\
\text { (MeV) }\end{array}$ & $\underset{\left(c^{+} F\right)^{*}}{B\left(E 3.0^{+}\right)}$ & $\frac{B\left(E 3,0^{+}-3^{-}\right)}{B\left(E 3,0^{\circ}-3^{-}\right)_{00}}$ & Dh & $\begin{array}{l}R_{\text {Lr }} \\
(\boldsymbol{F})\end{array}$ \\
\hline $\begin{array}{l}\text { Sin } \\
\text { Nin } \\
\text { Nin }\end{array}$ & $\begin{array}{l}4.480 \\
4.038 \\
3.75\end{array}$ & $\begin{array}{l}18600=520 \\
28100 \pm 640 \\
20100=540\end{array}$ & $\begin{array}{l}13 \\
19 \\
13\end{array}$ & $\begin{array}{l}0.203=0.005 \\
0.241 \neq 0.006 \\
0.197 \pm 0.005\end{array}$ & $\begin{array}{l}6.05 \\
6.09 \\
6.11\end{array}$ \\
\hline
\end{tabular}
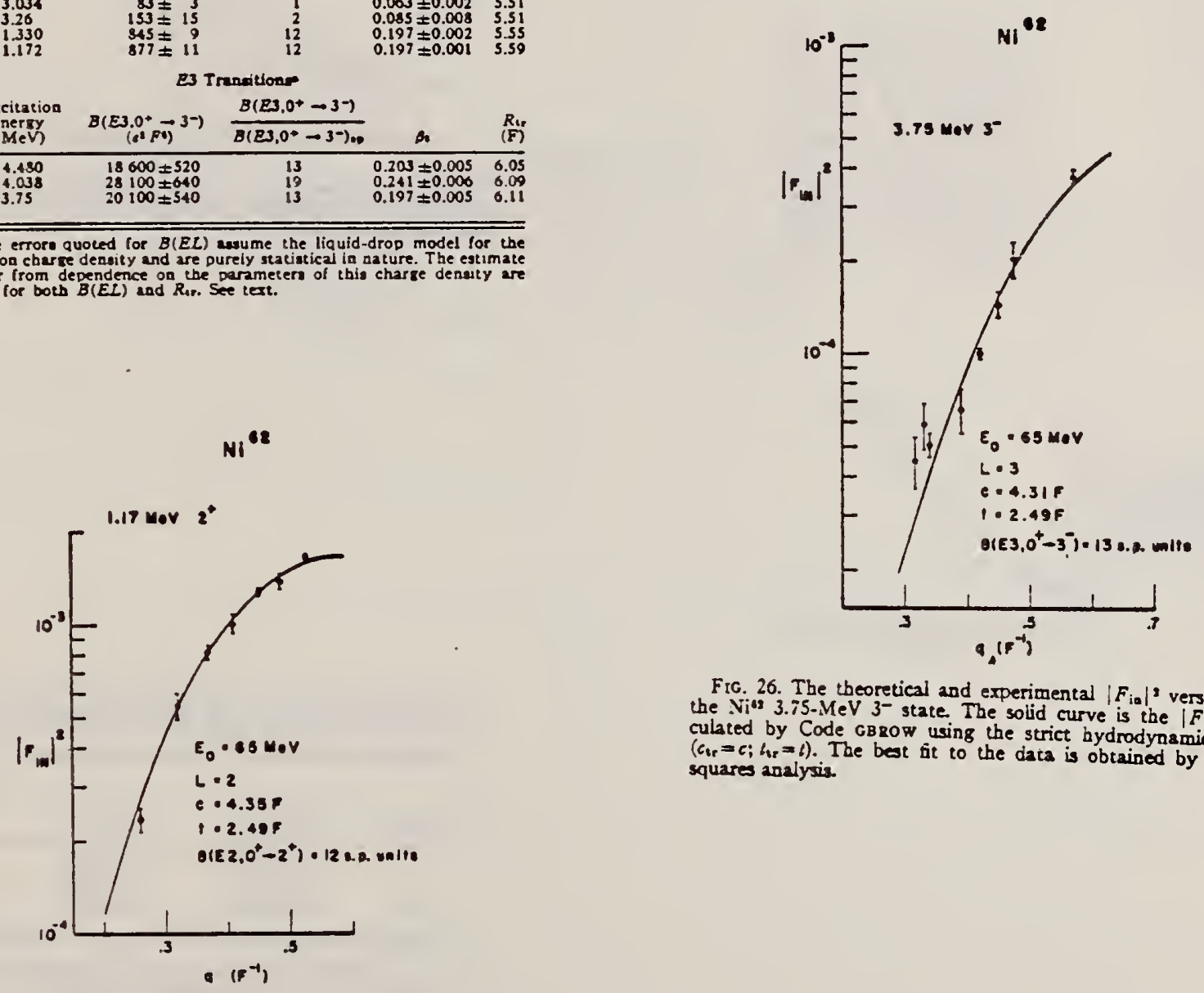

Fic. 26. The theoretical and experimental $\left|F_{\text {ia }}\right|^{2}$ versus $q$ for the $\mathrm{Ni}^{23} 3.75-\mathrm{MeV} 3^{-}$state. The soid curve is the $\left|F_{\mathrm{in}}\right|^{2} \mathrm{cal}$ culated by Code GBOOW using the strict hydrodynamic model $\left(c_{t r}=c ; b_{t r}=t\right)$. The best fit to the data is obtained by a least-
squares analysis.

FIG. 25. The theoretical and experimental $\mid F$ in $\left.\right|^{\prime}$ versus $q$ for the $\mathrm{Vi}^{13} 1.17-\mathrm{MeV} 2^{+}$state. The soid curve is the $\left|F_{\text {la }}\right|^{2} \mathrm{cal}$ culated by Code GBROw using the strict hydrodynamic model $\left(c_{r}=c ; h_{r}=t\right)$. The best fit to the data is obtained by a leastsquares andyeis. 
REF.

G. P. Estes and K. Min

Phys. Rev. 154, 1104 (1967)

REF. NO.

Nuclear resonant scattering

67 Es 1

JDM

\begin{tabular}{|c|c|c|c|c|c|c|c|}
\hline \multirow{2}{*}{ REACTION } & \multirow{2}{*}{ RESULT } & \multirow{2}{*}{$\begin{array}{l}\text { EXCITATION } \\
\text { ENERGY }\end{array}$} & \multicolumn{2}{|c|}{ SOURCE } & \multicolumn{2}{|c|}{ DETECTOR } & \multirow{2}{*}{ ANGLE } \\
\hline & & & TYPE & RANGE & TYPE & RANGE & \\
\hline$G, G /$ & $A B X$ & 8 & $D$ & 8 & NAI - D & & DST \\
\hline & & & & & & & \\
\hline & & & & & & & \\
\hline
\end{tabular}

$$
\begin{aligned}
& \left\langle\left({ }^{d} \sigma_{Y} \cdot d \Omega\right)_{1380}\right\rangle=(16.8 \pm 3.4) \mathrm{mb} / \mathrm{sr} . \\
& \left\langle\sigma_{Y \gamma}\right\rangle=(190 \pm 40) \mathrm{mb} .
\end{aligned}
$$

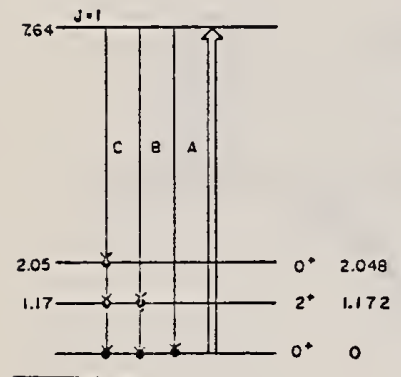

Ftc. 5. Energy levels (MeV) and photon tran. sitions observed in this experiment. The energics on the left and the $J=1$ assignment for the 7.6tMeV level were determined in this experiment. For comparison, the energies and the angular momenta determined in other reactions (Ref. 6) are given on the right.

Fic. 6. Angular distribution of the elastically scattered photons. The solid line is the theoretical curve for $J=1, \quad I V(\theta)=C\left(1+\cos ^{2} \theta\right)$ normalized at $135^{\circ}$.

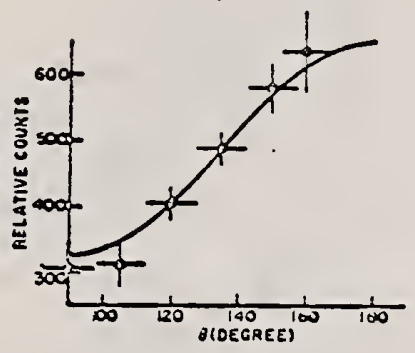

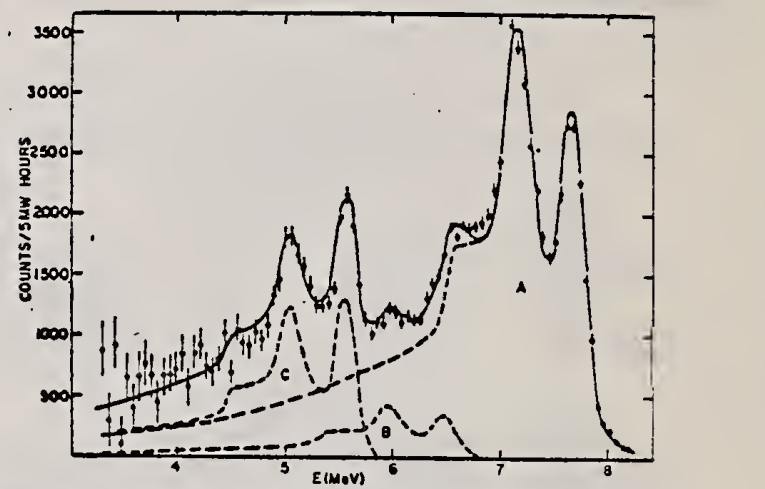

F1c. 2. Decomposition of the scattered-photon spectrum after the background subtraction. The solid line is the sum of the three components $A, B$, and $C$.
TABLE I. Energies and relative intensities of the resonantly scattered photon groups. The third column gives the energies of the lower lying levels populated by the scattered photons.

\begin{tabular}{cccc}
\hline Component & $\begin{array}{c}\text { Energy } E_{i} \\
(\mathrm{MeV})\end{array}$ & $\begin{array}{c}\epsilon_{i}=E_{A}-E_{i} \\
(\mathrm{MeV})\end{array}$ & $\begin{array}{c}\text { Relative } \\
\text { intensity } \\
(\%)\end{array}$ \\
\hline$A$ & $7.64 \pm 0.05$ & $0.00 \pm 0.07$ & $69 \pm 8$ \\
$B$ & $6.77=0.05$ & $1.17 \pm 0.07$ & $8 \pm 2$ \\
$C$ & $5.58 \neq 0.05$ & $2.06 \pm 0.07$ & $23 \pm 8$ \\
\hline
\end{tabular}

5 W. F. Miller and William J. Snow, Argonne National Laboratory Report No. ANL-6318, 1961 (unpublished). 


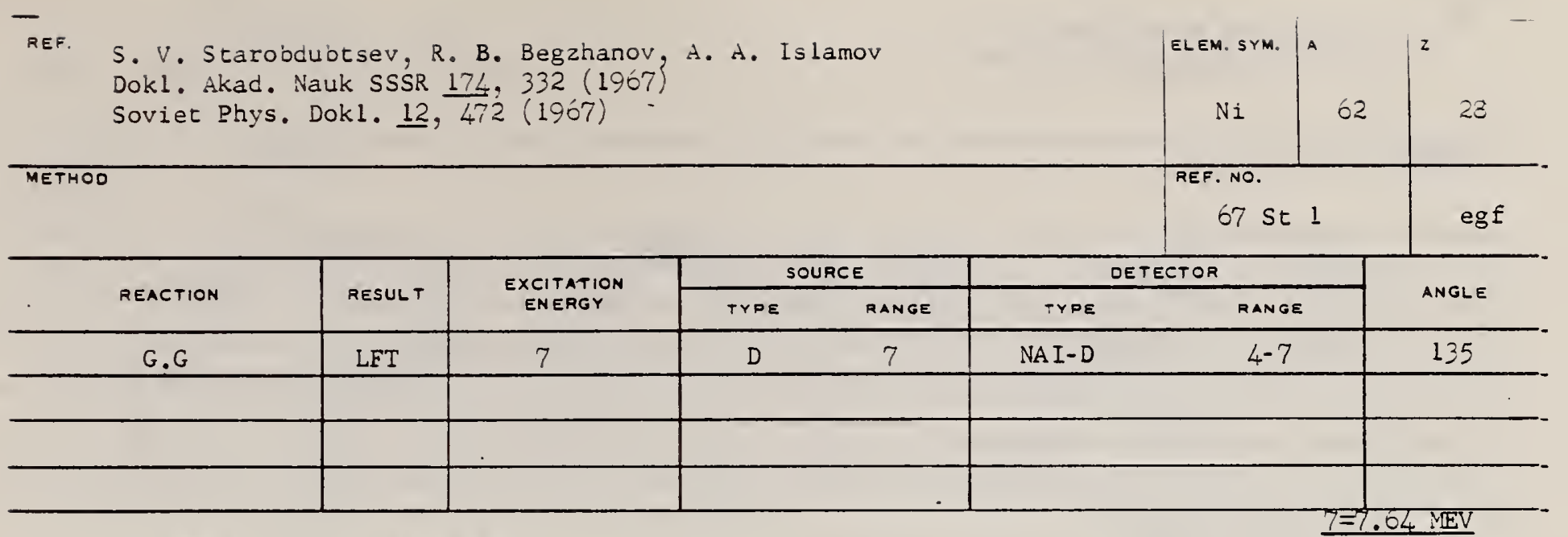

Self-absorption measurement

\begin{tabular}{|c|c|c|c|c|c|c|c|}
\hline Nucleus & $\begin{array}{l}\text { Transi- } \\
\text { eion en- } \\
\text { ergy. MeV }\end{array}$ & $t_{i}-p_{i}$ & $r_{y} \cdot \mathrm{eV}$ & Nucleus & $\begin{array}{l}\text { Traissi- } \\
\text { tion en - } \\
\text { ergy, MeV }\end{array}$ & $r_{i}^{2}-r_{i}^{2}$ & $r_{Y} \in V$ \\
\hline${ }_{20} \mathrm{Ni}_{\mu 4}^{42}$ & $\begin{array}{l}7.174 \\
10.47 \\
5.611 \\
5.34 \\
5.11 \\
4.70\end{array}$ & 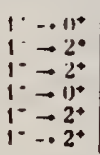 & $\begin{array}{l}1 . n \pm 11.11 \\
11.33 \pm 11.11 \\
1.26 \pm 11.38 \\
11.151 \pm \pm 11.18 \\
11.31 \pm 11.14 \\
2.15 \pm 1.64\end{array}$ & ${ }_{n}^{\infty} \mathrm{Cd}_{\omega 4}^{114}$ & $\begin{array}{l}7.61 \\
7.118 \\
1: 511 \\
5.81 \\
7.28\end{array}$ & 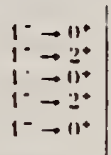 & 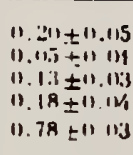 \\
\hline
\end{tabular}




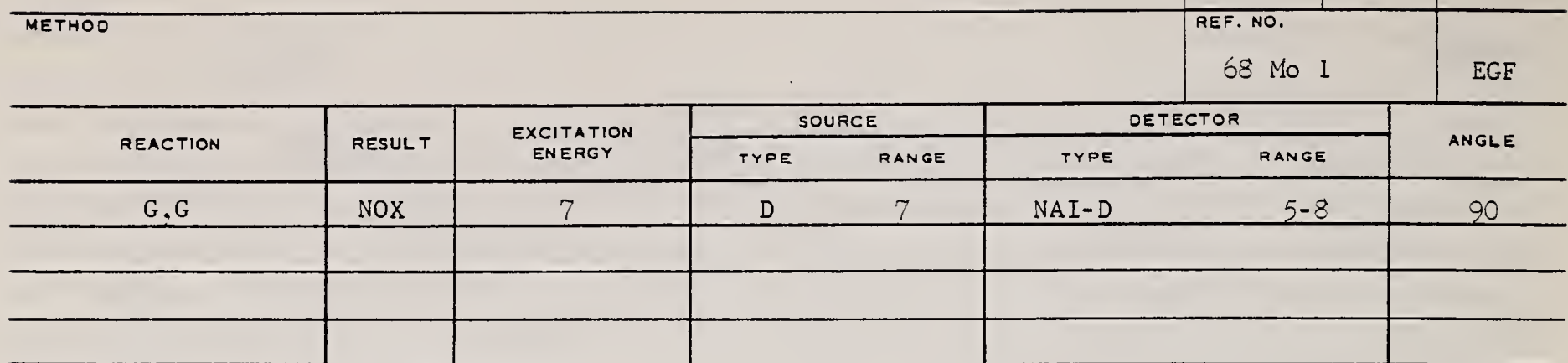

Compton polarimeter.

Table 1

Properties of levele populated by resonance scatlering of Iron capture $\gamma$ rays; $J_{0}$ and $J$ denote the spins of the ground and resonance levels, reapectively.

\begin{tabular}{|c|c|c|c|c|c|c|}
\hline \multirow{2}{*}{$\begin{array}{c}\text { Scattering } \\
\text { I6otope }\end{array}$} & \multirow[t]{2}{*}{$J_{0}$} & \multirow{2}{*}{$\begin{array}{l}\text { Resonance } \\
\text { level (MeV) }\end{array}$} & \multirow{2}{*}{$\begin{array}{c}\text { Resonance } \\
\text { opin }\end{array}$} & \multicolumn{2}{|c|}{$N(90,90) / N(90,0)$} & \multirow{2}{*}{$\begin{array}{l}\text { Trangition } \\
\text { character }\end{array}$} \\
\hline & & & & exp. & caic. & \\
\hline $208 \mathrm{~Pb}$ & $0^{+}$ & 7.279 & 1 & $1.18 \pm 0.03$ & 1.18 & E1 \\
\hline $112 \mathrm{Cd}$ & $0^{+}$ & 7.632 & 1 & $0.87 \pm 0.04$ & 0.855 & MI \\
\hline $141 \mathrm{Pr}$ & $\frac{3}{2}+$ & 7.632 & $\frac{1}{2}$ & $1.03 \pm 0.02$ & 1.03 & EI \\
\hline $62 \mathrm{Nt}$ & $0^{+}$ & 7.646 & 1 & $0.88 \pm 0.04$ & 0.855 & MI \\
\hline $203_{T I}$ & $\frac{1}{2}+$ & 7.646 & $t$ & $1.00 \pm 0.01$ & 1.00 & - \\
\hline
\end{tabular}




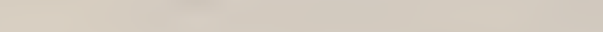

CTION

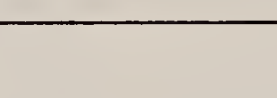

$G, G$

\begin{tabular}{|c|c|}
\hline RESULT & $\begin{array}{c}\text { EXCITATION } \\
\text { ENERGY }\end{array}$ \\
\hline NOX & 7 \\
\hline & . \\
\hline & \\
\hline
\end{tabular}

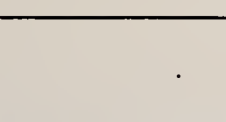

(2)

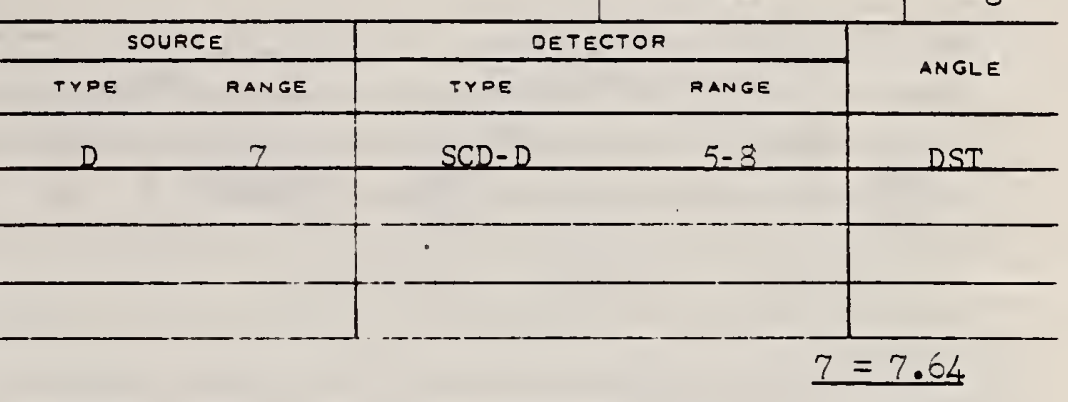

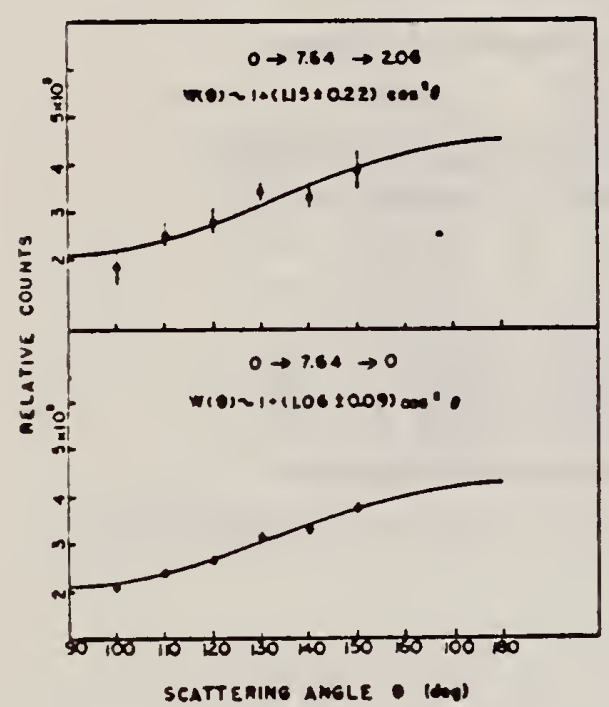

Fir. 9. Angular distributions of resonantly scattered photons in.$i^{\circ}$. The solid lines are the least-equares fit through the date prints.

TABLE II. Summary of angular distribution measurements in Nire.

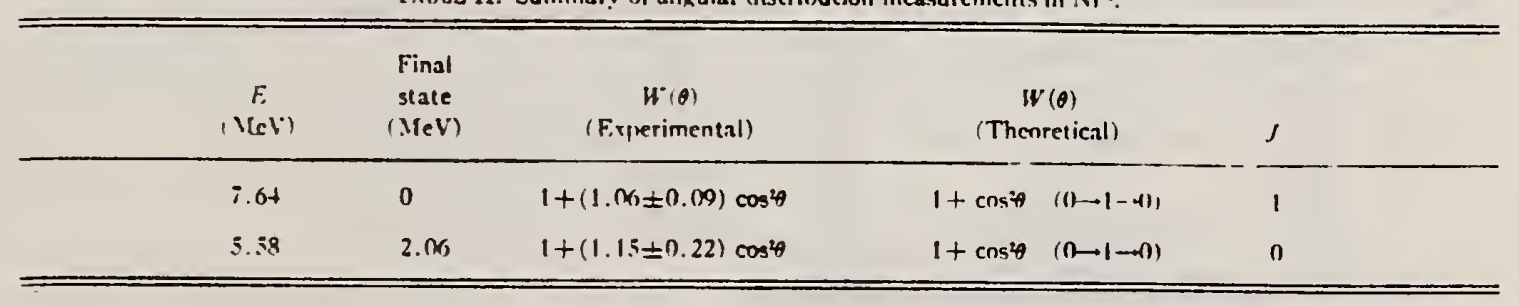


REF. R. Moreh, S. Shlomo, and A. Wolf

Phys. Rev. C2, 1144 (1970)

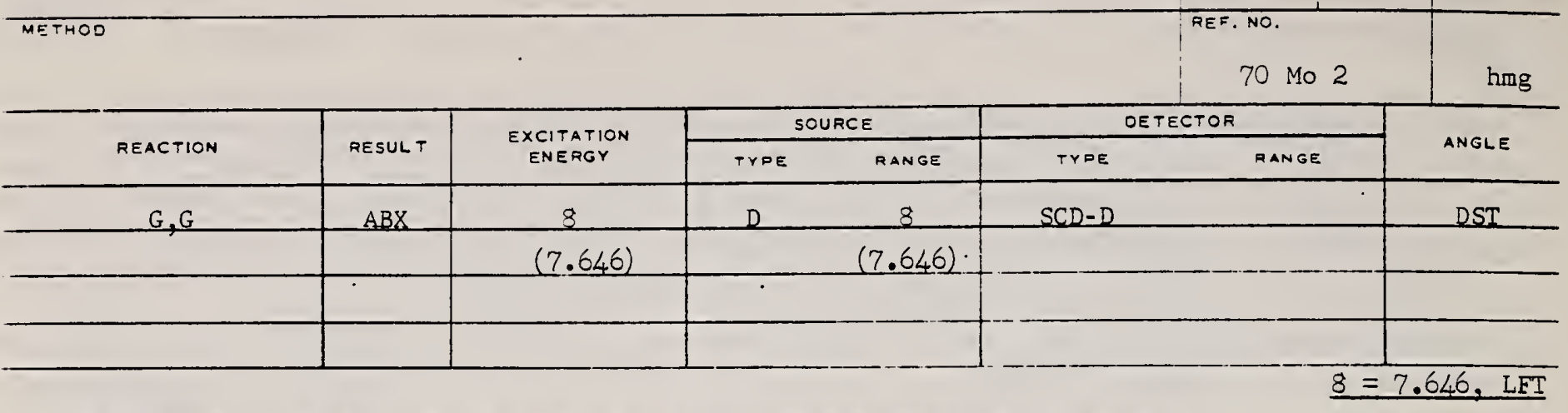

TABIE II. Summary of the results of spins, parities, and total widths of resonance levels excited by $\gamma$ rays obtained from neutron capture in iron. Parities in parantheses are uncertain.

\begin{tabular}{|c|c|c|c|c|c|c|c|}
\hline Isotope & $\begin{array}{l}\text { Energy } \\
\text { (MeV) }\end{array}$ & $\begin{array}{c}\delta=\left|E_{r}-E_{d}\right| \\
(e V)\end{array}$ & $J^{\pi}$ & $J^{\pi}$ & Transition & $\begin{array}{l}\Gamma_{0} / \Gamma_{\gamma} \\
( \pm 8 \%)\end{array}$ & $\begin{array}{c}\Gamma_{y} \\
\left(10^{-3} \mathrm{eV}\right)\end{array}$ \\
\hline${ }^{80} \mathrm{Cr}$ & 8.888 & $18 \pm 1$ & $0^{+}$ & 1 & $\cdots$ & 0.90 & $750 \pm 200$ \\
\hline${ }^{62} \mathrm{Ni}$ & 7.646 & $14 \pm 1$ & $0^{+}$ & $1-$ & E1 & 0.64 & $480 \pm 50$ \\
\hline${ }^{14} \mathrm{Ge}$ & 6.018 & $4.5 \pm 0.5$ & $0^{+}$ & $1=$ & $E 1$ & 0.19 & $120=15$ \\
\hline is As & 7.646 & $7.4 \pm 0.3$ & $3 / 2^{-}$ & $1 / 2^{x+1}$ & $\cdots$ & 0.11 & $360 \pm 100$ \\
\hline${ }^{109} \mathrm{As}$ & 7.632 & $9=1$ & $1 / 2^{-}$ & $3 / 2$ & $\cdots$ & 0.7 & $2=1$ \\
\hline${ }^{112} \mathrm{Cd}$ & 7.632 & $4.8=0.4$ & $0^{+}$ & $1-$ & $E 1$ & 0.55 & $86 \pm 15$ \\
\hline${ }^{129} \mathrm{La}$ & 6.018 & $8.2=0.6$ & $7 / 2^{+}$ & $3 / 2^{-}$ & $E I$ & 0.50 & $51+14$ \\
\hline $11: p_{r}$ & 7.632 & $11.4=0.93$ & $5 / 2^{+}$ & $5 / 2^{+}$ & $M 1$ & 0.46 & $72+i \frac{i 4}{i}$ \\
\hline${ }^{205} \mathrm{Tl}$ & 7.646 & $9.3 \pm 0.3$ & $1 / 2^{+}$ & $\left.1 / x^{\prime}-\right)$ & $\cdots$ & 0.58 & $980 \pm 90$ \\
\hline${ }^{208} \mathrm{~Pb}$ & 7.279 & $7.1 \pm 0.3$ & $0^{+}$ & $1^{+}$ & $M 1$ & 1.00 & $780 \pm 60$ \\
\hline
\end{tabular}

TABIE IV. Effective elastic scattering cross section $\left\langle\sigma_{r}\right\rangle=\sigma_{0}^{\pi}\left(\Gamma_{0} / \Gamma_{\gamma}\right) \Psi\left(x_{0}, t_{0}\right)$, where $\delta, J, \Gamma_{0}, \Gamma_{\gamma}$ were taken from Table III. The temperature of the scatterer was $300^{\circ} \mathrm{K}$, while that of the iron $\gamma$ source was $640^{\circ} \mathrm{K}$.

\begin{tabular}{ccc}
\hline \hline & $\begin{array}{l}\text { Resonance } \\
\text { energy } \\
(\mathrm{MeV})\end{array}$ & $\begin{array}{l}\left\langle\sigma_{r}\right\rangle \\
(\mathrm{mb})\end{array}$ \\
\hline Target & 8.838 & 905 \\
${ }^{50} \mathrm{Cr}$ & 7.646 & 569 \\
${ }^{62} \mathrm{Ni}$ & 6.018 & 61 \\
${ }^{74} \mathrm{Ge}$ & 7.646 & 4.4 \\
${ }^{75} \mathrm{As}$ & 7.632 & 3.5 \\
${ }^{109} \mathrm{Ag}$ & 7.032 & 193 \\
${ }^{112} \mathrm{Cd}$ & 6.013 & 39 \\
${ }^{139} \mathrm{La}$ & 7.632 & 20 \\
${ }^{141} \mathrm{Pr}$ & 7.646 & 574 \\
${ }^{205} \mathrm{Tl}$ & 7.279 & 5560 \\
${ }^{208} \mathrm{~Pb}$ &
\end{tabular}


A. S. Litvinenko, N.G. Shevchenko, A. Yu. Buk1, P. L. Rondrat'ev, G.A. Sav1tsk11, A.A. Khomich, V. M. Khvastunov, I. I. Chkalov

Ukr. Fiz. Zhur. 17, 1197 (1972)

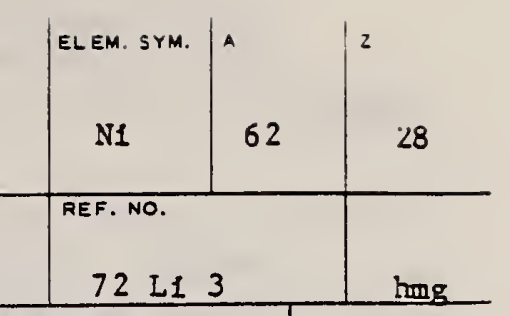

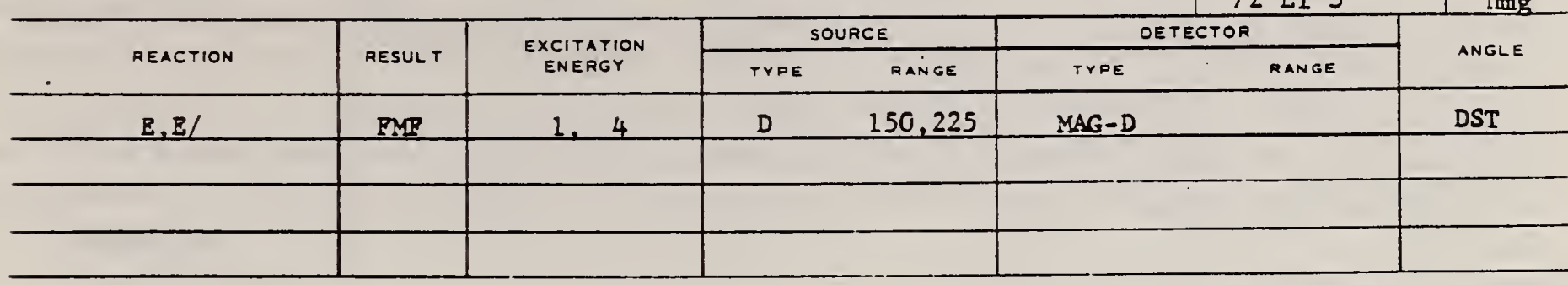

$B(B L) \quad L$ EV $1.17,3.75$

T а 6. жиц а ।

Параметры фермневского растределения плотности зарлда

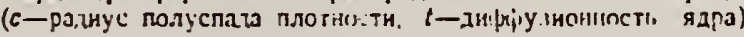

\begin{tabular}{|c|c|c|}
\hline 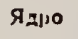 & c. $\phi$ & 1. $d$ \\
\hline $1 \because \cdots 4$ & $1.012 \pm 0.007$ & $2.311+i \pm 0.011$ \\
\hline 1:an. & $: 3,178 \mid 11,111: i$ & $2,145+0.020$ \\
\hline$\left[\because x^{2}\right.$ & $1.1027 \div-0.01019$ & $2,5.60) 0,0.31$ \\
\hline $\mathrm{Nin?}$ & $1,1111=0.011$ & $2.5012 \pm 0.011 ;$ \\
\hline
\end{tabular}

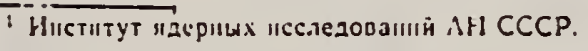

T $6 . ?$ iा 11 a 2

\begin{tabular}{|c|c|c|c|c|c|c|}
\hline & & & $\begin{array}{l}\text { Данные васто- } \\
\text { ящей рәботы }\end{array}$ & & בаннце других работ & \\
\hline & $\Delta 130$ & & $\begin{array}{c}B(E \lambda) \uparrow \\
e^{\lambda}+i^{2} \lambda\end{array}$ & $\begin{array}{c}E(E \lambda) \uparrow \\
e^{\lambda(3) 2 \lambda}\end{array}$ & 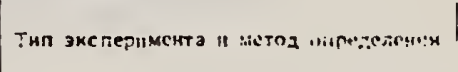 & '? \\
\hline Fest & $\begin{array}{l}1.4 \\
4.85\end{array}$ & $\frac{2^{+}}{3^{-}}$ & $\begin{array}{l}531.9 \pm 32,4 \\
45133 \pm 410\end{array}$ & $\begin{array}{r}533 \\
4390\end{array}$ & (cé). борновское прнб.7::incs:t: & $\mid 6 !$ \\
\hline$\Gamma \mathrm{e}^{50}$ & 0.85 & $2^{+}$ & $678.1 \pm 47.5$ & $\begin{array}{l}7 \simeq 0 \\
1250 \pm 270 \\
1 \geq 40 \\
x 0 \pm \pm 10 n\end{array}$ & 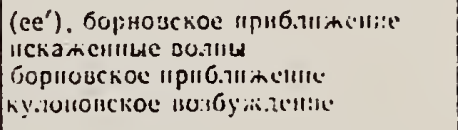 & 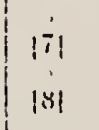 \\
\hline $\mathrm{Fe}^{\mathrm{sin}}$ & $\begin{array}{l}0.81 \\
3.86\end{array}$ & $\frac{2^{+}}{3-}$ & $\begin{array}{l}943.2 \pm 79 \\
138 \mathrm{sin} \pm 1260\end{array}$ & & & \\
\hline $\mathrm{Ni}^{62}$ & $\begin{array}{l}1.17 \\
3.75\end{array}$ & $\frac{2 \div}{3-}$ & $\begin{array}{l}618.6 \pm 42.1 \\
14359 \pm 962\end{array}$ & $\begin{array}{r}87 i=11 \\
20100 \pm 540\end{array}$ & (ее'), нскажен!:ıе волнш & [?] \\
\hline
\end{tabular}


K. Shoda, M. Sugawara, T. Saito, H. Miyase, A. Suzuki, S. Oikawa, and $\mathrm{J}$. Uegaki

PICNS-72, 321 Sendai

NS-72, 321 Sendai

\begin{tabular}{c|c|c}
\hline REACTION & RESULT & $\begin{array}{c}\text { EXCITATION } \\
\text { ENERGY }\end{array}$ \\
\hline G,P & ABX & $16-27$ \\
\hline & & \\
\hline & & \\
\hline
\end{tabular}

\section{A STATES}

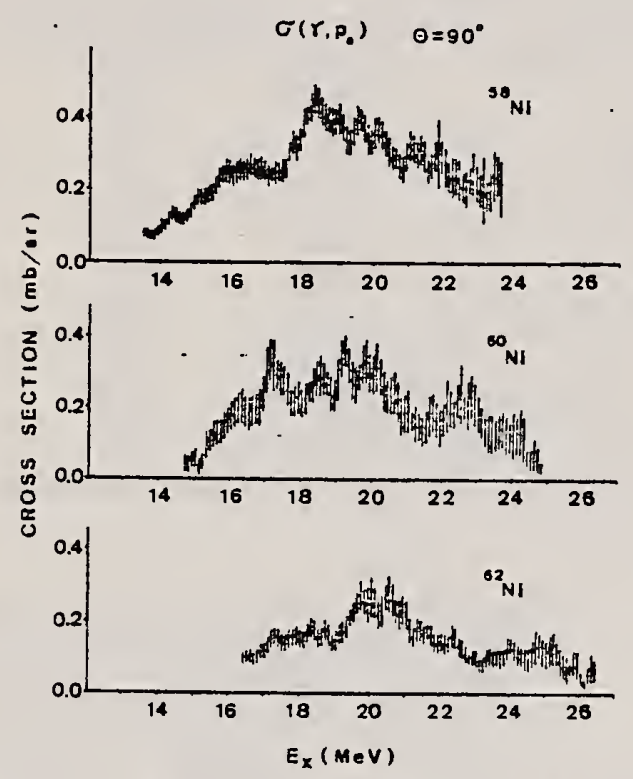

Fig. 10 The $\left(\gamma, \mathrm{P}_{0}\right)$ cross sections of $\mathrm{Ni}$ 1sotopes obtained from proton spectra by the (e,e'p) reaction. 
रEF. H. Myase, S. O1kawa, A. Suzuki, J. Uegak1, T. Salto,

$M$ Sugawara, and $R$. Shoda

PICNS-73, Vol. I, p. 553 Asilomar

\begin{tabular}{|c|c|c|c|c|c|c|c|}
\hline METHOD & & & & & & $\begin{array}{l}\text { REF.NO. } \\
73 \text { MI } 7\end{array}$ & himg \\
\hline \multirow{2}{*}{ REACTION } & \multirow{2}{*}{ RESULT } & \multirow{2}{*}{$\begin{array}{l}\text { EXCITATION } \\
\text { ENERGY }\end{array}$} & \multicolumn{2}{|c|}{ SOURCE } & \multicolumn{2}{|c|}{ DETECTOR } & \multirow{2}{*}{ ANGLE } \\
\hline & & & TYPE & RANGE & TYPE & RANGE & \\
\hline $\mathbf{B}, \mathbf{P}$ & $A B X$ & $16-29$ & & $0-29$ & MAG-D & & DST \\
\hline & & & & & & 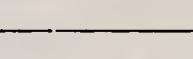 & \\
\hline & & & & & & & \\
\hline & & & & & & & 72 \\
\hline
\end{tabular}

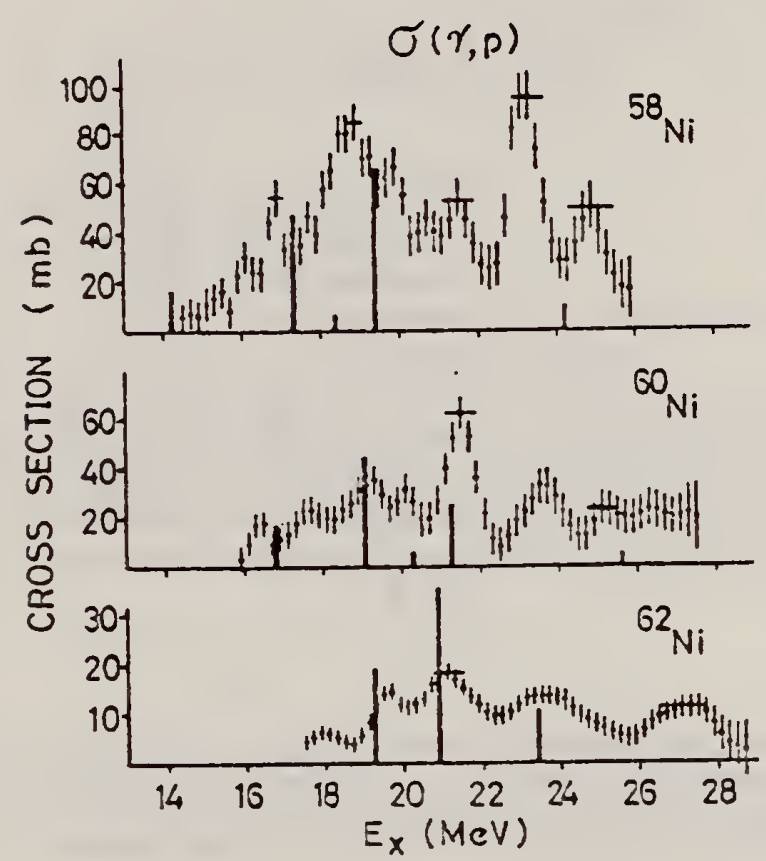

Fig. 1
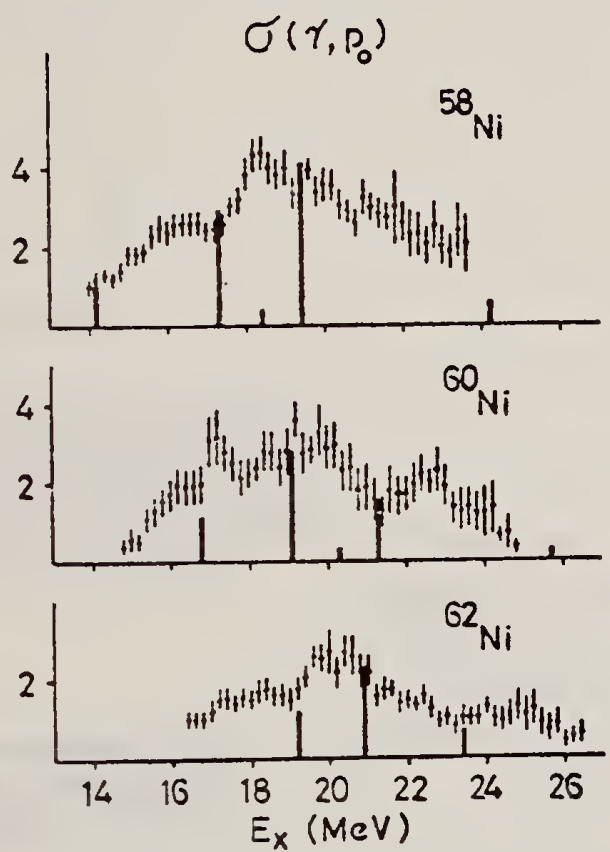

Fig. 2

Table 1 Experimental and theoretical results

\begin{tabular}{|c|c|c|c|c|c|c|}
\hline Nucleus & $T_{0}$ & $\int_{(m b-M e V)} \sigma_{n}^{3)}$ & $\int_{(n b-M e V)} \sigma_{p}$ & $\int_{(m b-1 ! e v)} \sigma_{n}+\int \sigma_{p}$ & $\frac{\int \sigma_{p}}{\int \sigma_{n}+\int \sigma_{p}}$ & $\frac{\left|c_{>}\right|^{2}}{\left|c_{<}\right|^{2}+\left|c_{>}\right|^{2}}$ \\
\hline${ }^{58} \mathrm{NI}$ & 1 & $310 \pm 30$ & $480 \pm 100$ & $790 \pm 130$ & 0.61 & 0.45 \\
\hline $60_{\text {Ni }}:$ & 2 & $620 \pm 50$ & $210 \pm 80$ & $830 \pm 130$ & 0.25 & 0.27 \\
\hline${ }^{62} \mathrm{N1}$ & 3 & & $110 \pm 25$ & & & 0.17 \\
\hline
\end{tabular}


REF.

R. Moreh, A. Wolf, I. Jacob, and A. Nof Nucl. Phys. A224, 86 (1974)

$-$

\begin{tabular}{l|c|c|}
\hline METHOD \\
\hline REACTION & RESULT & $\begin{array}{c}\text { EXCITATION } \\
\text { ENERGY }\end{array}$ \\
\hline$G, G$ & LFT & 7 \\
\hline$\cdot$ & & \\
\hline & & \\
\hline
\end{tabular}

$\Gamma_{Y}=0.48 \pm 0.05 \mathrm{eV}$

$\underline{7=7.646 \mathrm{MEV}}$

$\Gamma_{0} / \Gamma_{\gamma}=0.64$
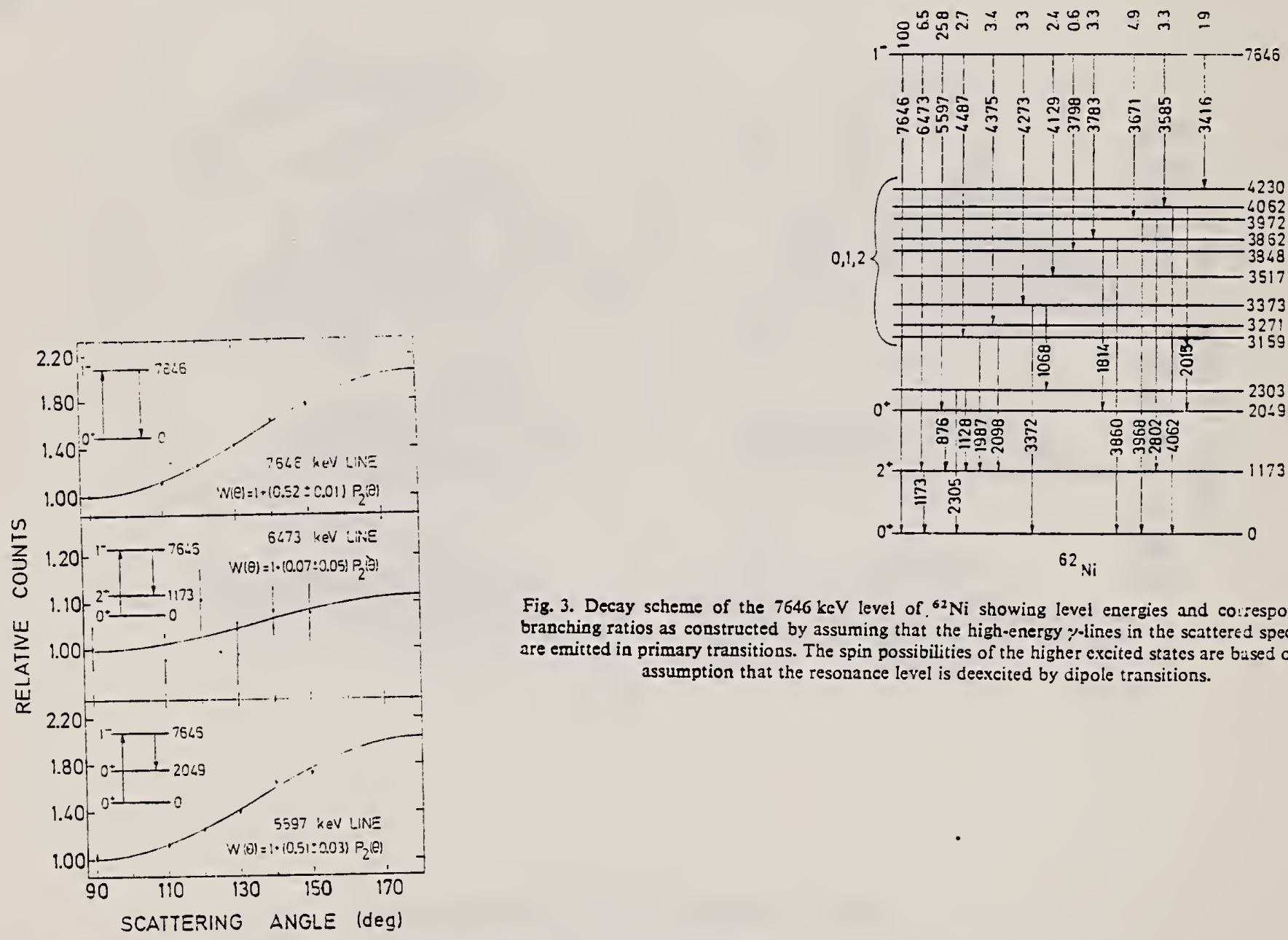

Fig. 3. Decay scheme of the $7646 \mathrm{keV}$ level of ${ }^{62} \mathrm{Ni}$ showing level energies and co:respond.ak branching ratios as constructed by assuming that the high-energy \%-lines in the seattered spectran are emitted in primary transitions. The spin possibilities of the higher excited states are bused on his assumption that the resonance level is deexcited by dipole transitions.

Fig. 4. Angular distribution of the elastic and some inelastic lines in ${ }^{62} \mathrm{Ni}$ as measured using + $30 \mathrm{~cm}^{3} \mathrm{Ge}(\mathrm{Li})$ detector. The solid lines have the form $W(\theta)=1+A P_{2}(\cos \theta)$ and are least squiri fits to the experimental distributions. In each case the corresponding $\% \cdots$ cascade is indie::ied. 
R. Moreh, O. Shahal, and I. Jacob
Nucl. Phys. A228, 77 (1974) -

REF.

Nucl. Phys. A228, 77 (1974)

(1)

(1)

\begin{tabular}{|c|c|c|c} 
ELEM. SYM. & A & 2 \\
Ni & 62 & 28 \\
\hline $\begin{array}{c}\text { REF. NO. } \\
74 \text { MO } 7\end{array}$ & egf \\
\hline
\end{tabular}

\begin{tabular}{|c|c|c|c|c|c|c|c|}
\hline \multirow{2}{*}{ REACTION } & \multirow{2}{*}{ RESULT } & \multirow{2}{*}{$\begin{array}{l}\text { EXCITATION } \\
\text { ENEAGY }\end{array}$} & \multicolumn{2}{|c|}{ SOUACE } & \multicolumn{2}{|c|}{ DETECTOR } & \multirow{2}{*}{ ANGLE } \\
\hline & & & TYPE & manoc & Trpe & RANGE & \\
\hline$C, G$ & XمبN & 7 & D & 7 & $N A T=D$ & & 135 \\
\hline & & & & & & & \\
\hline & & & & & & & \\
\hline
\end{tabular}

$7=7.646$ FUNC TEMP

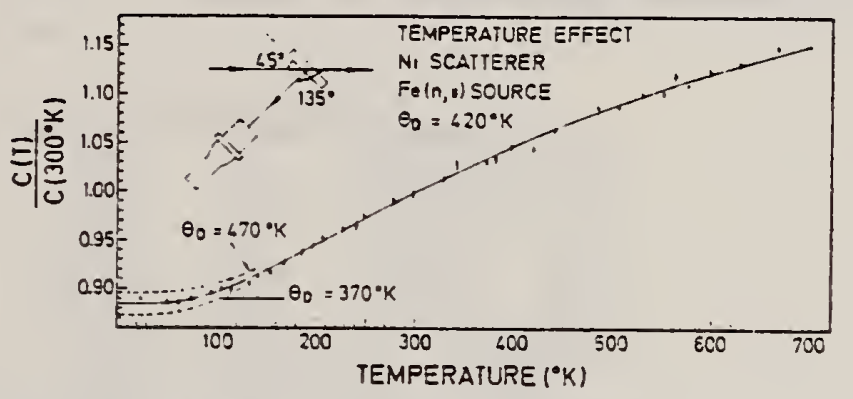

Fig. 4. Relative scattering yield from a $\mathrm{Ni}$ scatterer as a function of temperature. The scatterer thickness is $0.9 \mathrm{~cm}$ and the geometry is indicated in the figure. The seattering yield is normalised to $T=$ $300^{\circ} \mathrm{K}$. The solid curve is the theoretical result obtained using eq. (1) with $\theta_{0}=420^{\circ} \mathrm{K}, \delta=14.35 \mathrm{eV}$, $\Gamma=0.48 \mathrm{eV}, \Gamma_{0}, T=0.68$, while the dotted curves correspond to theoretical results inaving the same parame!e:s but with $\theta_{v}=470^{\circ} \mathrm{K}$ and $\theta_{D}=370^{\circ} \mathrm{K}$. The dotted curves approach the solid curve and nearly coincide with is at higher temperatures; for clurity, this is not shown in the figure. 


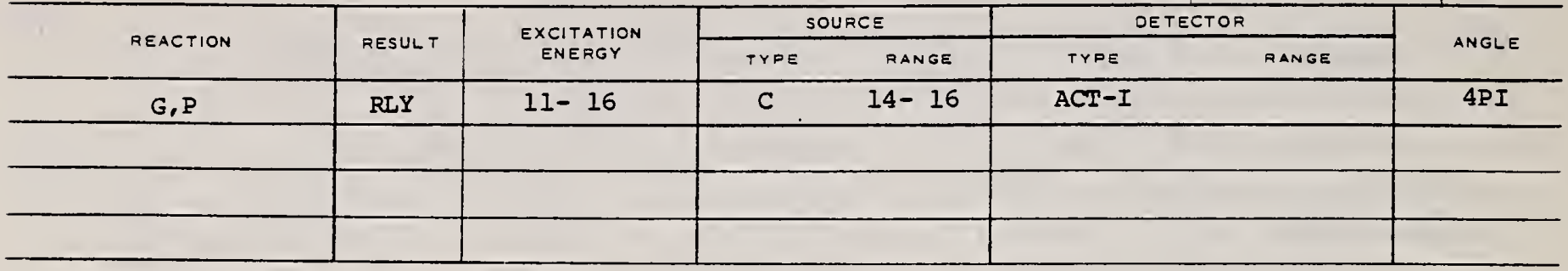

The yields of $(y, p)$ reactions on ${ }^{62} \mathrm{Ni},{ }^{4} \mathrm{Ni}$, and ${ }^{33} \mathrm{Cr}$ are studied $i z$ ranges of $E_{\text {ran }}$ rear the respective thresholds. Considerable differences are found between the curve shapes, yields, and observed thresholds for the $\mathrm{Ni}$ isotopes and ${ }^{93} \mathrm{Cr}$.

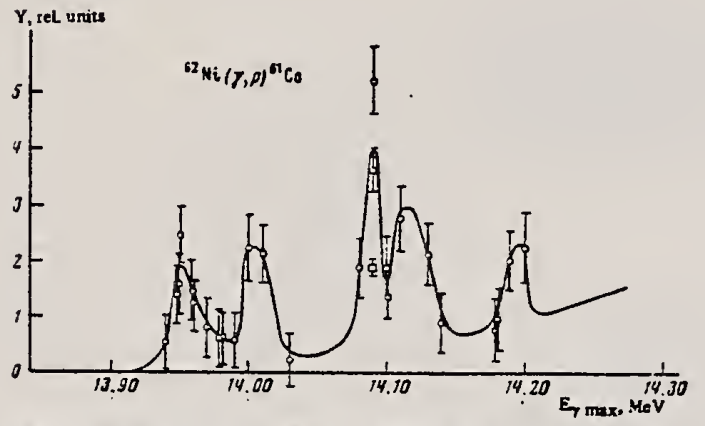

FIG. 4. Measured yields of ${ }^{62} \mathrm{Ni}(\gamma, p)^{61} \mathrm{Co}$ in the region of $E_{\gamma} \max$ $=13.94-14.20 \mathrm{MeV}$. Statistical errors are indicated; the point with the symbol $a$ is the rms error.

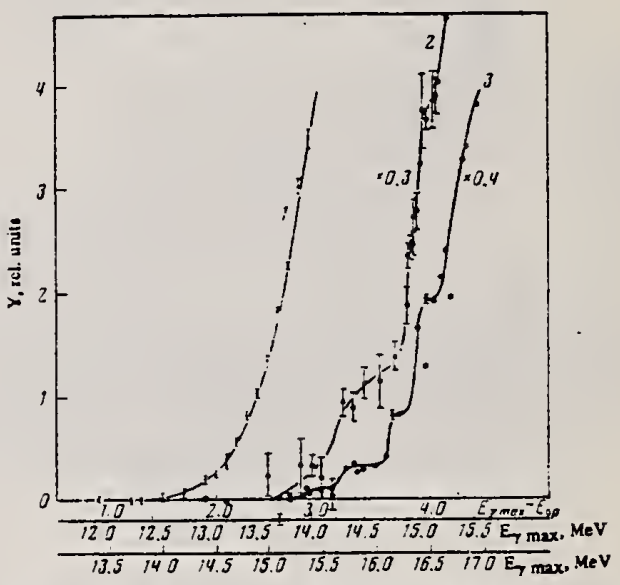

FIG. 3. Yields of the reactions ${ }^{53} \mathrm{Cr}(\gamma, \mathrm{p})^{52} \mathrm{~V}$ (curve 1$),{ }^{64} \mathrm{Ni}(\gamma, \mathrm{p})^{63} \mathrm{Co}$ (curve 2), and ${ }^{62} \mathrm{Ni}(\gamma, p)^{61} \mathrm{Co}$ (curve 3 ) as functions of $\mathrm{E}_{\gamma}$ max. Lowest scale for ${ }^{64} \mathrm{Ni}(\gamma, \mathrm{p})$; middle scale for ${ }^{62} \mathrm{Ni}(\gamma, \mathrm{p})$ and ${ }^{53} \mathrm{Cr}(\gamma, \mathrm{p})$. 
aer. E. Wolynec, W.R. Dodge, E. Hayward

Phys. Rev. Lett. 42,27 (1979)

.

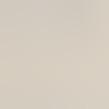

\begin{tabular}{|c|c|c|c|} 
ELEM. SYM. & Ni & 62 & 28 \\
\hline $\begin{aligned} \text { AEF. NO. } \\
79 \text { WO 3 }\end{aligned}$ & $\mathrm{hg}$ \\
\hline
\end{tabular}

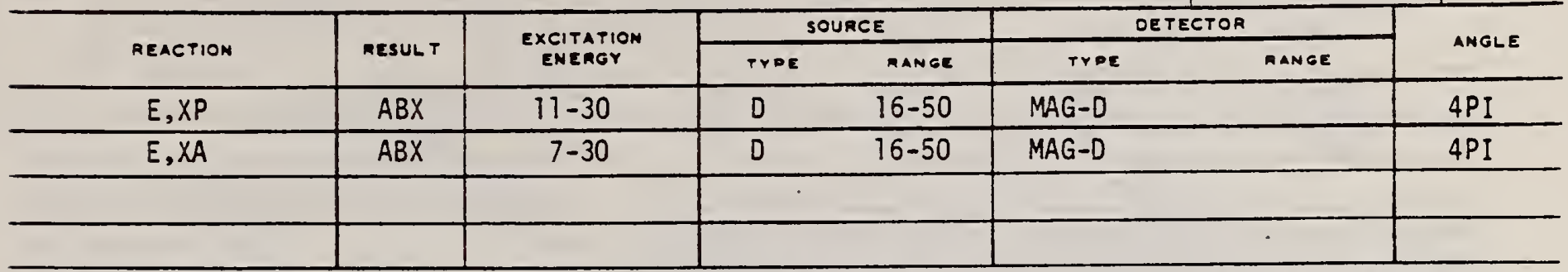

The $(f, p)$ and $(e, a)$ cross sections for targets of ${ }^{59} \mathrm{Ni},{ }^{50} \mathrm{Ni}$, and ${ }^{\mathrm{i}} \mathrm{Ni}$ have been measured to the electron energy range $16-50 \mathrm{MeV}$. They have been analyzed using the distorted-wave Bora-approximation $E 1$ and $E 2$ virtual-photon spectra. Protons are emitted primarily following $E l$ absorption but a emission results from a combination of $E 1$ and $E 2$ absorption. The $E 2$ isoscalar giant resonance decays predominantly by a emission

(E,XP) VIRTUAL PHOTON G,XP (E,XA) VIRTUAL PHOTON $G, X A$ for these auclel.

TABLE I. Resonance parameters for $\sigma_{y, p}$

\begin{tabular}{lcccc}
\hline \hline Nucleus & $\begin{array}{c}E_{x} \\
(\mathrm{MeV})\end{array}$ & $\begin{array}{c}\Gamma \\
(\mathrm{MeV})^{3}\end{array}$ & $\begin{array}{c}\int_{0}^{30} \mathrm{OdE} \\
(\mathrm{MeV} \mathrm{mb})\end{array}$ & $\begin{array}{c}\mathrm{SR}^{h} \\
(5)\end{array}$ \\
\hline${ }^{58} \mathrm{Ni}$ & $19.2 \pm 0.5$ & $6.5=1.3$ & $739 \pm 40$ & $85 \pm 5$ \\
${ }^{50} \mathrm{Ni}$ & $18.5 \pm 0.5$ & $9.2 \pm 1.3$ & $304 \pm 20$ & $34 \pm 2$ \\
${ }^{62} \mathrm{Ni}$ & $21.0 \pm 0.5$ & $5.8 \pm 1.0$ & $140 \pm 10$ & $15 \pm 1$ \\
\hline
\end{tabular}

${ }^{2} \Gamma$ is the full width at balf maximum.

bSR stands for sum rule; the $E 1$ SR equais $60 \mathrm{NZ} / \mathrm{A}$ MeV mb.

TABLE II. El compoesets in the $(y, \alpha)$ reaction.

\begin{tabular}{|c|c|c|c|c|}
\hline Nucleus & $\begin{array}{c}E_{3} \\
(\mathrm{MeV})\end{array}$ & $\begin{array}{c}\Gamma \\
(\mathrm{MeV})^{2}\end{array}$ & $\int_{(\mathrm{MeV} \mathrm{mb})}^{5 \tilde{J} E}$ & $\begin{array}{l}\mathrm{SR}^{b} \\
(\mathrm{PC})\end{array}$ \\
\hline${ }^{58} \mathrm{Ni}$ & $13.3 \pm 0.5$ & $6 \pm 1$ & $15.3=1.3$ & $1.3=0.2$ \\
\hline${ }^{50} \mathrm{Nit}$ & $21.5 \pm 1.0$ & $6 \pm 1$ & $13.5=1.4$ & $2.1=0.2$ \\
\hline${ }^{62} \mathrm{Ni}$ & $18.3=1.0$ & $5 \pm 1$ & $4.3=0.6$ & $0.5 \pm 0.1$ \\
\hline
\end{tabular}

'I Is the full width at balf maximum.

${ }^{3} E \mathrm{I} \mathrm{SR}$ equals $60 \mathrm{NZ} / \mathrm{A} \mathrm{MeV} \mathrm{mb.}$

TABLE IU. E2 components in the $(\%, \alpha)$ reaction.

\begin{tabular}{lccrc}
\hline \hline & $\begin{array}{c}E_{\mathrm{x}} \\
(\mathrm{MeV})\end{array}$ & $\begin{array}{c}\Gamma \\
(\mathrm{MeV})^{2}\end{array}$ & $\begin{array}{c}\int \sigma d E \\
(\mathrm{MeV} \mathrm{mb})\end{array}$ & \multicolumn{1}{c}{$\begin{array}{c}\mathrm{SR}^{b} \\
(\mathrm{fl})\end{array}$} \\
\hline${ }^{58} \mathrm{Ni}$ & $16.5 \pm 0.5$ & $4.2 \pm 1.0$ & $10.4=0.7$ & $56 \pm 4$ \\
${ }^{50} \mathrm{Ni}$ & $16.0 \pm 0.5$ & $3.7 \pm 0.3$ & $6.9=0.4$ & $52=3$ \\
${ }^{52} \mathrm{Ni}$ & $16.8 \pm 0.5$ & $4.5 \pm 1.0$ & $5.1 \pm 0.4$ & $28 \pm 2$ \\
\hline
\end{tabular}

I I the full ridth at half maximum.

${ }^{b} E 2$ SR equals $0.22 Z^{2} / A^{1 / A} \mu \mathrm{b} / \mathrm{MeV}$. 
ReF. E. Wolynec, W.R. Dodge, R.G. Leicht, E. Hayward

Phys. Rev. C22, 1012 (1980)

$\mid$\begin{tabular}{c|c|} 
ELEM. SYM. & $\wedge$ \\
NI & 62
\end{tabular}

80 Wo 1 hg

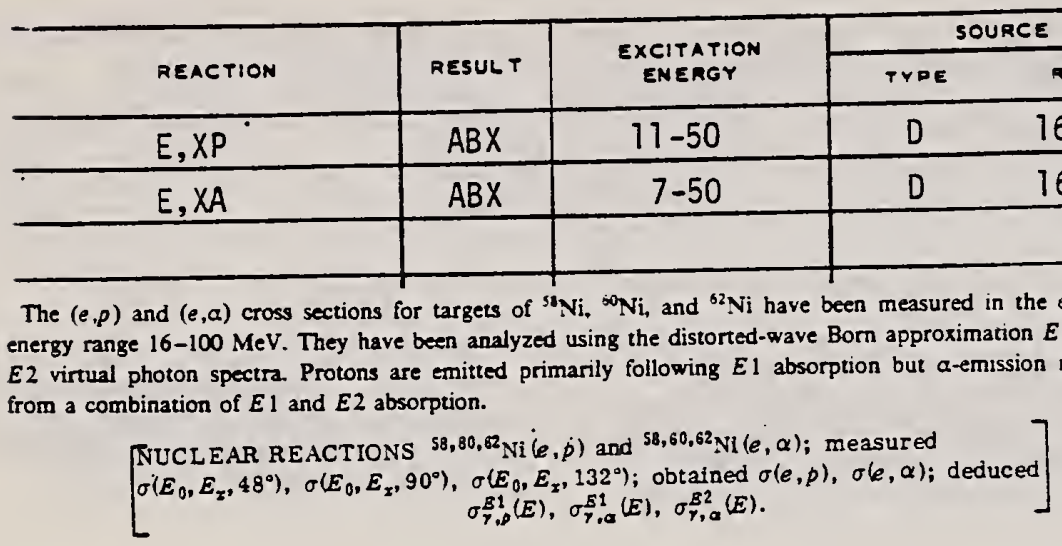

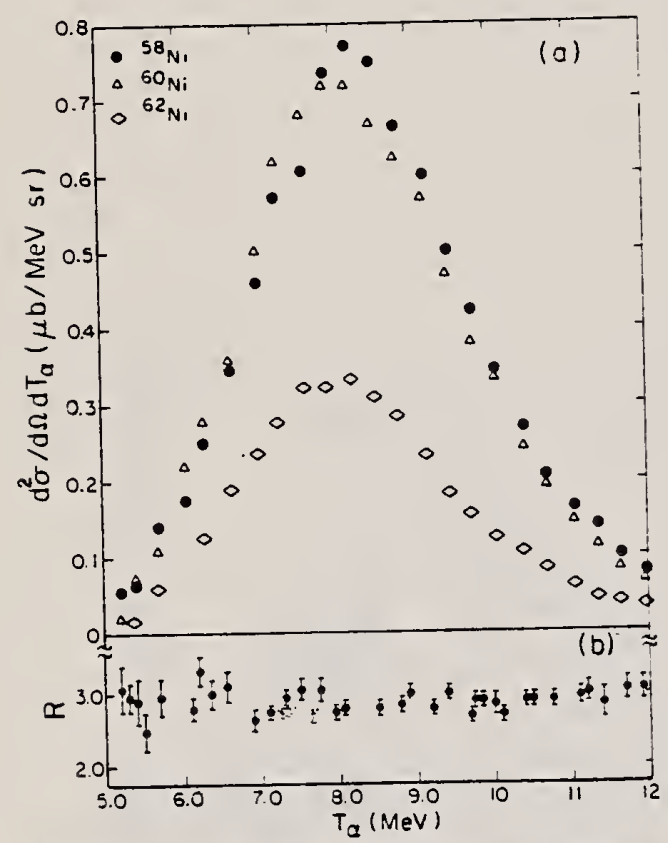

FIG. 2. (a) The $\alpha$ spectra $d^{2} \sigma / d T_{a} d \Omega$ measured at $90^{\circ}$ when $50 \mathrm{MeV}$ electrons are incidenc on targets of ${ }^{58} \mathrm{Ni}$, when and ${ }^{2} \mathrm{Ni}$. (b) The ratio of the number of $\alpha$ particles produced by electro plus photodisintegration in ${ }^{58} \mathrm{Nl}$ to the number produced by electrodisintegration alone. This ratio was obtained by piacing a $0.217 \mathrm{~g} / \mathrm{cm}^{2} \mathrm{Ta}$ radiator in the beam ahead of the ${ }^{58} \mathrm{Ni}$ target.
(E,XP) VIRTUAL PHOTON $G, X P$

(E,XA) VIRTUAL PHOTON $G, X A$

1. Measurement also made at $100 \mathrm{MeV}$

2. Assumptions:

For photons: $\frac{d \sigma}{d r}(\theta)=$ constant

For alphas:

$\frac{d \sigma}{d r}(\theta)=\sigma\left(90^{\circ}\right)\left[A\left(E_{0}\right)+B\left(E_{0}\right) \sin ^{2} \theta\right]$ $A\left(E_{0}\right), B\left(E_{0}\right)$ determined empirically

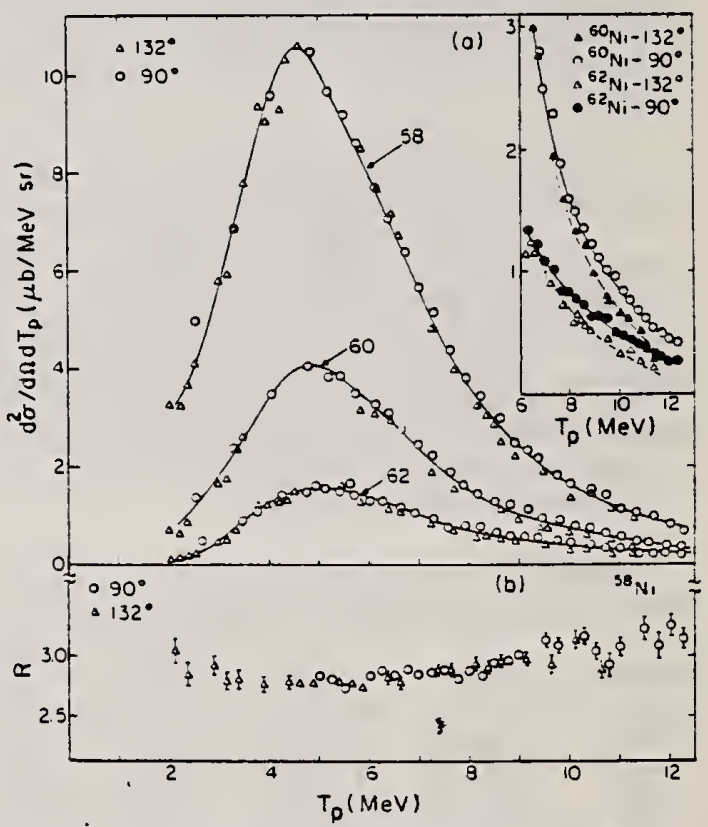

FIG. 3. (a) The proton spectra $d^{2} \sigma / d T$, $d Q$ measured at $90^{\circ}$ and $132^{\circ}$ when $50 \mathrm{MeV}$ electrons are incident on targets of ${ }^{58} \mathrm{Ni},{ }^{80} \mathrm{Ni}$, and ${ }^{2} \mathrm{Ni}$. The insert shows the tails of the energy spectra for ${ }^{80} \mathrm{Nl}$ and ${ }^{2} \mathrm{Ni}$ where the protons are slightly forward peaked. (b) The ratto of the number of protons produced by electro plus photodisintegration in ${ }^{58} \mathrm{Ni}$ to the number produced by electrodisintegration alone. This ratio was determined by placing a $0.217 \mathrm{~g} / \mathrm{cm}^{2} \mathrm{~T}$ a radiator in the beam $7.6 \mathrm{~cm}$ ahead of the ${ }^{58} \mathrm{Nl}$ target.

(over) 


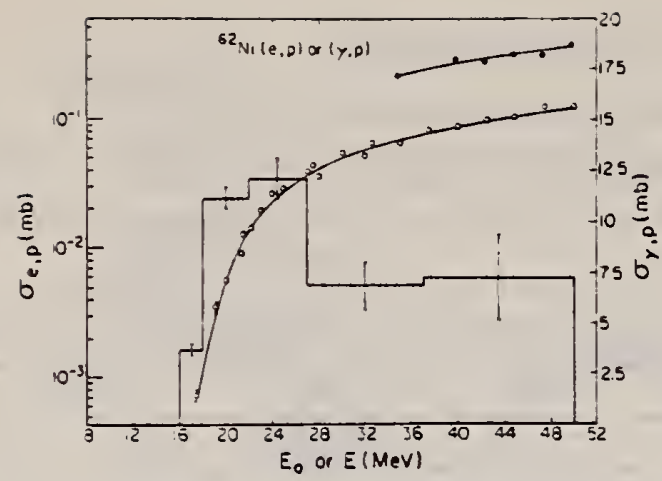

FIG. 3. The $\sigma_{0, p}\left(E_{0}\right)$ and $Y_{a, p}\left(E_{0}\right)$ for ${ }^{\Sigma_{2}}$ :I neft-hand scale) obtained by using the $E 1$ virtual photon spectrum in Eq. (1) and the Davies-Bethe-Madmon bremsstrahlung cross section in Eq. (2).

TABLE IV. Percentage of the $E 1$ and $E 2$ sums in the $\alpha$ channel. E1 sum: $60 \mathrm{N2} / \mathrm{A} \mathrm{MeV} \mathrm{mb.} \Sigma 2$ sum: $0.22 Z^{2} A^{-1 / 3} \mu \mathrm{b} / \mathrm{MeV}$. $E 2$ bin: $14-20 \mathrm{MeV}$. Upper llmits of the integrals $=50 \mathrm{MeV}$.

\begin{tabular}{ccccc}
\hline \hline & & \multicolumn{2}{c}{$E 2$} \\
Nucleus & Schlff & D-B-M & Schiff & D-B-M \\
\hline${ }^{58} \mathrm{Ni}$ & $4.8 \pm 0.5$ & $6.0 \pm 0.6$ & $24 \pm 3$ & $15 \pm 3$ \\
${ }^{\infty} \mathrm{NI}$ & $4.4 \pm 0.7$ & $5.4 \pm 0.7$ & $24 \pm 4$ & $15 \pm 4$ \\
${ }^{2} \mathrm{NI}$ & $2.4 \pm 0.3$ & $2.9 \pm 0.3$ & $10 \pm 2$ & $6 \pm 2$ \\
\hline
\end{tabular}

TABLE V. $\sigma_{a, p}$ at $100 \mathrm{MeV}$.

\begin{tabular}{|c|c|c|c|}
\hline Nucleus & $\begin{array}{c}\sigma_{e s}(\text { meas }) \\
(m b)\end{array}$ & $\begin{array}{c}\sigma_{\text {eo }} \text { (calc) } \\
\text { (mb) }\end{array}$ & $\begin{array}{l}\sigma_{\text {e., }}(\text { corrs }) \\
(\mathrm{mb})\end{array}$ \\
\hline${ }^{58} \mathrm{NI}$ & $1.15 \pm 0.02$ & 1.10 & 0.98 \\
\hline${ }^{\infty} \mathrm{NI}$ & $0.50 \pm 0.01$ & 0.47 & 0.42 \\
\hline${ }^{2} \mathrm{Ni}$ & $0.24 \pm 0.01$ & 0.22 & 0.19 \\
\hline
\end{tabular}

TABLE VI. $\sigma_{e . \alpha}$ at $100 \mathrm{MeV}$.

\begin{tabular}{|c|c|c|c|}
\hline Nucleus & $\begin{array}{c}\sigma_{\text {e. } \alpha \text { (meas) }}(\mathrm{mb}) \\
\end{array}$ & $\begin{array}{c}\sigma_{a . \alpha}(\mathrm{calc}) \\
(\mathrm{mb})\end{array}$ & $\sigma_{\text {e. }}(\operatorname{cor} x)$ \\
\hline${ }^{58} \mathrm{Ni}$ & $0.069 \pm 0.002$ & 0.084 & 0.063 \\
\hline${ }^{\circ} \mathrm{Ni}$ & $0.063=0.002$ & 0.081 & 0.060 \\
\hline $2_{\mathrm{NI}}$ & $0.033 \neq 0.001$ & 0.036 & 0.027 \\
\hline
\end{tabular}

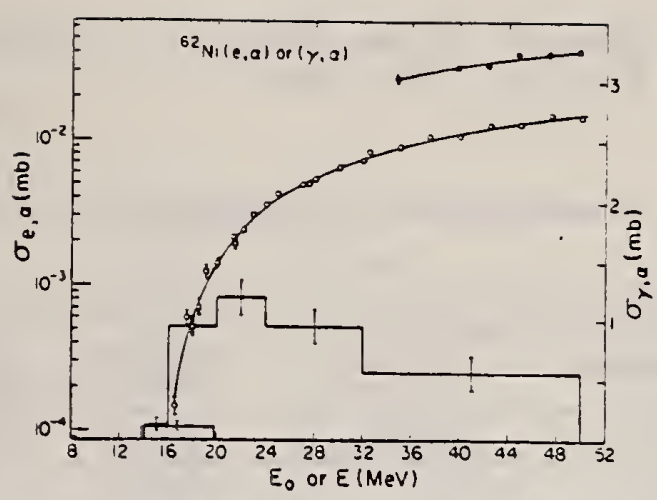

FIG. 13. The measured $\sigma(e, \alpha)$ for ${ }^{62} \mathrm{NI}$ (open circles) as a function of total incident electron energy $E_{0}$ (lefthand scale). The full circles are electro plus photodisIntegration yieids obtained when the $0.217 \mathrm{~g} / \mathrm{cm}^{2}$ tantalum foll was interposed in the incident electron beam.

The smooth curves through the points result from combining the histograms, representing the $E 1$ and $E 2$

$(\gamma, \alpha)$ cross sectlons (right-hand scale), in Eqs. (1) and (2) with the $E 1$ and $E 2$ virtual photon spectra and making use of the Davies-Bethe-Maximon cross section. 
Y. Cauchois, H. Ben Abdelaziz, R. Khérouf, C. Schloesing-Möller

REF. J. Phys. G7, 1539 (1981)

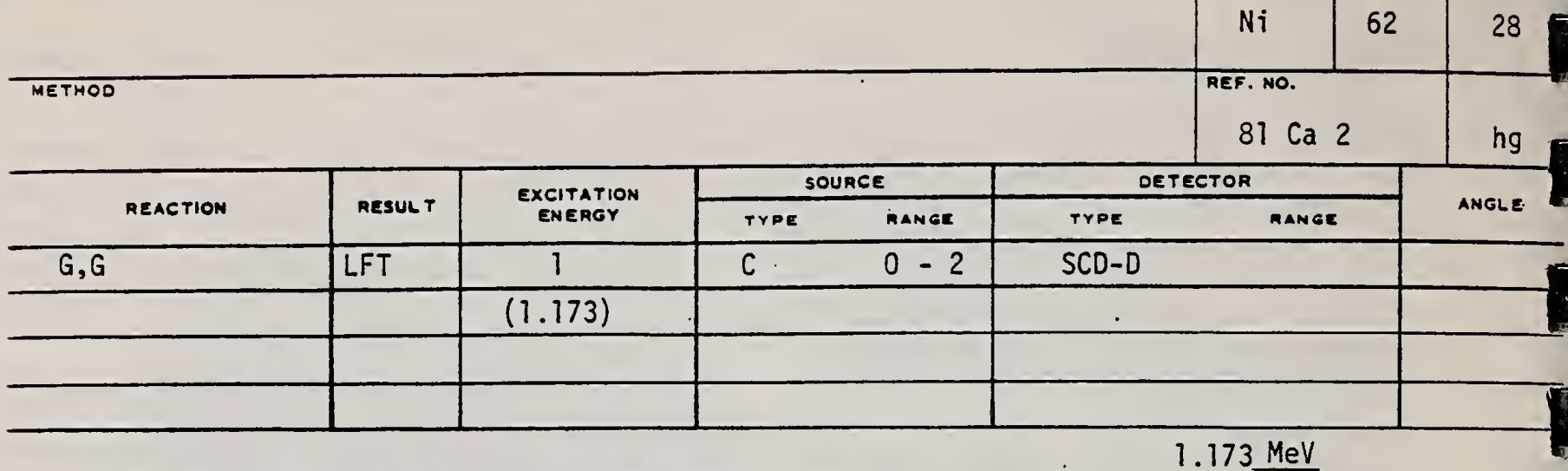

Abetract. Lifetimes of 49 excited states below $1.65 \mathrm{MeV}$ have been measured in ${ }^{24} \mathrm{Mg}$. ${ }^{27} \mathrm{Al}$.

$\underline{1.173 \mathrm{MeV}}$

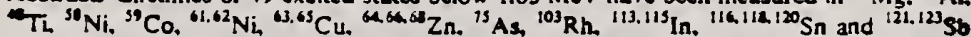
by means of nuclear resonance fiworescence experiments. The levels are excited by bremsstrahiung $x$-ray photons. The self-absorption technique applied to suitable cases provides nuclear absorption cross sections, widths and lifetimes from which the $x$-ray spectral distributions are also obtained. Scattering experiments are performed for all other cases in order to obtain widths and lifetimes from these $x$-ray photon curves. The Compton effect in the sample is taken into account. Self-absorption provides $g \Gamma_{0}$ from which $\Gamma$ is deduced using adopted $J^{*}$ and $\Gamma_{0} / \Gamma$ values; scattering provides $u=g\left(\Gamma_{0}^{2} / \Gamma\right) W(\theta)$ from which $\Gamma$ is also deduced with $J, \Gamma_{0} / \Gamma$ and mixing ratios taken from the literature. Thanks to simultaneous determination of the $x$-ray spectra all the lifetimes as given by our programs with their statistical errors form an unusually coherent set of values.

NUCLEAR REACTIONS $(\gamma, \gamma)$, bremsstrahiung excitation: natural isotopes: ${ }^{24} \mathrm{ME}$

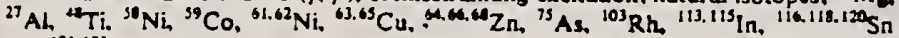
and ${ }^{121.123} \mathrm{Sb} ; E \simeq 0.5-1.65 \mathrm{MeV}$; measured $g \Gamma_{0}$ or $g\left(\Gamma_{2}^{2} / \Gamma\right) m(\theta)$; deduced $T_{1 / 2}$. 
Tableaw 3. Resultats des mesures des niveaux etudies par diffusion.

Tate 3. Results obtained using the diffusion method.

\begin{tabular}{|c|c|c|c|c|c|c|c|c|c|}
\hline Isorope & Energie (keV) & $J^{\pi}$ & $J_{0}^{*}$ & $\Gamma_{0} / \Gamma$ & $\delta$ & $\begin{array}{l}u=g\left(\Gamma_{0}^{2} / \Gamma\right) W(\theta) \\
(\mathrm{meV})\end{array}$ & $\begin{array}{l}\text { e(ps) } \\
\text { ce travail }\end{array}$ & $\tau_{\text {ref }}(p s)$ & Réfërencest \\
\hline${ }^{24} \mathrm{Ms}$ & $1368.59(4)$ & $2^{*}$ & $0^{-}$ & 1 & E2 & $1.08(13)$ & $1,76(21)$ & $1.98(4)$ & $\begin{array}{l}\text { Endt et van Jer Leun } \\
\qquad(1978)\end{array}$ \\
\hline${ }^{27} \mathrm{Al}$ & $1014,45(3)$ & $\dot{+}$ & i- & 0.971 & $+0,351(12)$ & $0,186(13)$ & $2,20(16)$ & $2,12(8)$ & $\begin{array}{l}\text { Endt et van der Leun } \\
\quad(1978)\end{array}$ \\
\hline 4 & $983,512(3)$ & $2^{\circ}$ & $0^{*}$ & 1 & E2 & $0.282(23)$ & $6,74(55)$ & $6.1(13)$ & Been (1978) \\
\hline${ }^{3} \mathrm{Ni}$ & $1454,45(15)$ & 2 & $0^{\circ}$ & 1 & E2 & $2.11(26)$ & $0.90(11)$ & $0.92(3)$ & $\begin{array}{l}\text { Kocher el Auble } \\
\text { (1976) }\end{array}$ \\
\hline${ }^{*} \mathrm{Co}$ & $1099,224(25)$ & - & $\vdots-$ & 1 & $(\mathrm{E} 2)$ & $0.069(8)$ & $4,79(55)$ & $3.17(58)$ & $\operatorname{Kim}(1976)$ \\
\hline${ }^{9} \mathrm{Co}$ & $1458.8(3)$ & & $i$ & 0.91 & $(E 2)$ & $0,68(8)$ & $1,17(14)$ & $1.52(16)$ & $\operatorname{Kim}(1976)$ \\
\hline${ }^{39} \mathrm{Co}$ & $1+30.9(3)$ & & & 0.8 & $<0.35^{\circ}$ & $1,23(15)$ & $0,254(31)$ & $0.31(3)$ & $\operatorname{Kim}(1976)$ \\
\hline${ }^{1} \mathrm{Ni}$ & $1185,7(6)$ & ?- & i- & $0.77(8)^{4}$ & $|0,14|$ & $1,88(49)$ & $0.21(5)$ & $0.16(3)$ & Andreev et al (1974) \\
\hline${ }^{62} \mathrm{Ni}$ & $1172.91(9)$ & $2^{\circ}$ & $0^{*}$ & 1 & E2 & $0.88(17)$ & $2.15(42)$ & $2.09(3)$ & Halbert (1979a) \\
\hline${ }^{4} \mathrm{Cu}$ & $1327.00(7)$ & & $1-$ & 0,84 & (E2) & $1.04(14)$ & $0,84(11)$ & $0.88(4)$ & Auble (1979b) \\
\hline${ }^{43} \mathrm{Cu}$ & $1412.05(4)$ & & ?- & 0.72 & $+0.61(-9)$ & $0.260(38)$ & $1.90(28)$ & $1.61(3)$ & Auble (19796) \\
\hline${ }^{m} Z_{n}$ & $991.5+(7)$ & $2^{\circ}$ & $0^{\circ}$ & 1 & E2 & $0.640(54)$ & $2,97(25)$ & $2,60(13)$ & Halbert (1979b) \\
\hline${ }^{\prime \prime} \mathrm{Cu}$ & $1481,83(5)$ & $:-$ & !- & 0,85 & $(E 2)$ & $1.13(19)$ & $0.79(13)$ & $0.49(5)$ & Auble (1975a) \\
\hline${ }^{*} \mathrm{Zn}_{\mathrm{n}}$ & $1039.37(6)$ & $2^{-}$ & $0^{*}$ & 1 & E2 & $0,70(6)$ & $2.71(23)$ & $2.25(15)$ & Auble (19756) \\
\hline${ }^{\omega} \mathrm{Zn}$ & $1077,38(5)$ & $2^{\circ}$ & $0^{*}$ & 1 & E2 & $0.70(6)$ & $2,71(23)$ & $2,34(23)$ & Lowis (1975) \\
\hline${ }^{73}$ As & $572.5(10)$ & $\xi-$ & ?- & $1^{d}$ & $0.39^{b}$ & $0.236(26)$ & $4.14(46)$ & $3.5(9)$ & Horen et Lewis (1975) \\
\hline is As & $823,0(10)$ & & & $0.86^{d}$ & $(E 2)$ & $0.214(22)$ & $4.27(43)$ & $3.5(3)$ & Robinson et al (1967) \\
\hline${ }^{99}$ As & $865.5(10)$ & ;- & - & $0,83^{d}$ & -5 & $0,78(6)$ & $0.863(68)$ & $0,60(12)$ & Ceiliers ef al ( 1977) \\
\hline${ }_{79} \mathrm{As}$ & $1076.0(10)$ & & & $0.94^{d}$ & $0,38^{4}$ & $1,97(13)$ & $0.287(19)$ & $0.32(7)$ & Celliers el al ( 1977) \\
\hline${ }^{79}$ As & $1123.5(10)$ & 2 & $\mathfrak{j}^{-}$ & 1 & $\mathrm{El}{ }^{\star}$ & $0,224(24)$ & $1,47(16)$ & 一 & \\
\hline${ }^{79}$ As & $(349, \alpha 10)$ & $1-$ & i- & $0.67^{4}$ & $0.20^{4}$ & $1.61(29)$ & $0,180(32)$ & $0.12(3)$ & Wiison (1970) \\
\hline${ }^{19}$ As & $1370,0(10)$ & j- & $j$ & $0.47^{d}$ & $0.47^{4}$ & $0.64(13)$ & $0,218(44)$ & - & \\
\hline${ }^{103} \mathrm{Rh}$ & $803.1(2)$ & $t^{-}$ & $1-$ & 0.70 & $M I$ & $1.85(16)$ & $0.17+(15)$ & - & Harmatz (1979) \\
\hline${ }^{103} \mathrm{Rh}$ & $1277,0(2)$ & $!-$ & $t^{-}$ & 0.75 & $-0.62(30)^{c}$ & $0.81(y)$ & $0.87(10)$ & $1.3(9)$ & Harmal< (1979) \\
\hline $111 \mathrm{ln}$ & $1177(1)$ & y. & ?* & 1 & $+0.5(2)$ & $9.1(8)$ & $0.086(8)$ & $0,10(6)$ & Tuttle et al (1976) \\
\hline $111 \mathrm{ln}$ & $1510(1)$ & $?$ & $\xi^{*}$ & 0.935 & $-0.5\left\{\begin{array}{l}-1 \\
-2\end{array}\right\}$ & $6,4(9)$ & $0,071(10)$ & $0.11\}-3\}$ & Tuttle et al (1976) \\
\hline${ }^{113} \mathrm{In}$ & $1077,7(10)$ & $i$ & $\xi^{*}$ & $0.81^{\prime}$ & $(E 2)$ & $0.159(24)$ & $1,61(24)$ & $1.23(7)$ & Tuttle et al (1976) \\
\hline${ }^{113} \mathrm{In}$ & $1240.59(3)$ & $4 \cdot$ & ?० & $0.98^{3}$ & (E2) & $1.31(11)$ & $0.66(6)$ & $0.55(4)$ & Tuttle el al (1976) \\
\hline $11: \ln$ & $1+48.78(3)$ & ?ै. & $i^{\circ}$ & 0.86 & $-8^{\prime}$ & $0.90(11)$ & $0.50(6)$ & $0.52(20)$ & Tuttle ct $u /(\mid 976)$ \\
\hline $113 \mathrm{In}$ & $1+86.1(i)$ & $?-$ & $?^{*}$ & 0.787 & $-0.8^{\prime}$ & $0.63(9)$ & $0.63(9)$ & $0.4(3)$ & Tuttle et al (1976) \\
\hline${ }^{113} \ln$ & $1497.2(4)$ & $\left(2^{*}\right)$ & $?$ & $<1$ & (E2) & $1.33(16)$ & $<0.30(4)$ & - & \\
\hline $119 \ln$ & $1607.8(15)$ & $\left(\vdots^{*}\right)$ & $! \cdot$ & $\leqslant !$ & $(E 2)$ & $1.54(24)$ & $\leqslant 0.26(4)$ & - & \\
\hline $114 \mathrm{Sn}$ & $1293.54(2)$ & $2^{\circ}$ & $0^{\circ}$ & 1 & E2 & $3.58(37)$ & $0.53(6)$ & $0.522(14)$ & Curlsun el al (1975) \\
\hline${ }^{118} \mathrm{Sn}$ & $1229,64(4)$ & $2^{\circ}$ & $0^{\circ}$ & 1 & E2 & $2.75(28)$ & $0.69(7)$ & $0.67(2)$ & Curlson el al (1976) \\
\hline${ }^{120} \mathrm{Sn}$ & $1171.6(2)$ & $2^{\circ}$ & $0^{-}$ & 1 & E2 & $1.83(16)$ & $1,04(9)$ & $0.91(2)$ & Kocher $(1976)$ \\
\hline${ }^{121} \mathrm{Sb}$ & $1023.5(10)$ & $?^{*}$ & $\vdots$ & 1 & $|0.57|^{\bullet}$ & $3,69(34)$ & $0.228(21)$ & $0.20(7)^{n}$ & Tamura et al (1979) \\
\hline${ }^{121} \mathrm{Sb}$ & $1105.5(10)$ & $?^{\circ}$ & $\because$ & 0.4 & - & $0.47(4)$ & $0.42(4)$ & - & \\
\hline${ }^{121} \mathrm{Sb}$ & $11+2.5(10)$ & :- & i* & 0.6 & $(E 2)$ & $0.85(8)$ & $0.449(40)$ & $0.41(8)^{h}$ & Booth et al (1973) \\
\hline${ }^{121} \mathrm{Sb}$ & $1384.0(10)$ & 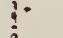 & $\vdots$ & 1 & $|0,45|^{\prime}$ & $4.7(5)$ & $0.092(10)$ & $0.088(14)^{n}$ & Booth et al( 1973$)$ \\
\hline${ }^{12]} \mathrm{Sb}$ & $1029.5(10)$ & ?* & $\vdots$ & 1 & 0.57 & $2.96(27)$ & $0,272(25)$ & $0.26(4)^{2}$ & Bouth et al (1973) \\
\hline${ }^{12]} \mathrm{Sb}$ & $1086.5(10)$ & ?* & $\vdots$ & 1 & $\mid 01>1.25^{\prime}$ & $1.00(9)$ & $0.67(0)$ & $0.72(15)^{n}$ & Bisuth et uf $(1473)$ \\
\hline
\end{tabular}

+ References pour les colonnes 3, 4, \$. 6 et 9 de shaque ligne, sauf indication appe!ee au bas de ce tableau. Pour les autres dunnces se reporter au texie.

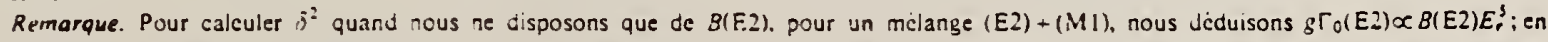
admetant $\|(\theta)=1$ et connaissunt $\Gamma_{j} i \Gamma$. notre determination de $u$ donne une premicre approxımation Je $g \Gamma_{0} d^{\prime} v \dot{u}$ une valeur de

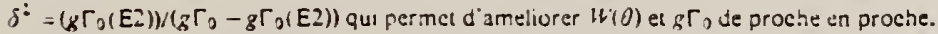

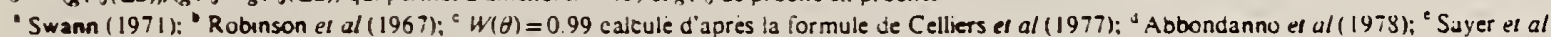
(1472): 'Tuttle et al (1976): "d'apres B1E2) de Barnes el al (196h): " calcule d'apres Booth el ai (1973): 'Williams et al (1975): j Dietrich et al (1970). 
204 
$A=64$

iVI

$A=64$ 
aEF. V. D. Afanas'ev, N. G. Afanas'ev, I. S. Gul'karov, G. A. Savitskii,

V. M. Khvastunov, N. G. Shevchenko and A. A. Khomich

Yad. Fiz. 10, 33 (1969)

Sov. J. Nucl. Phys. 10, 18 (1970)

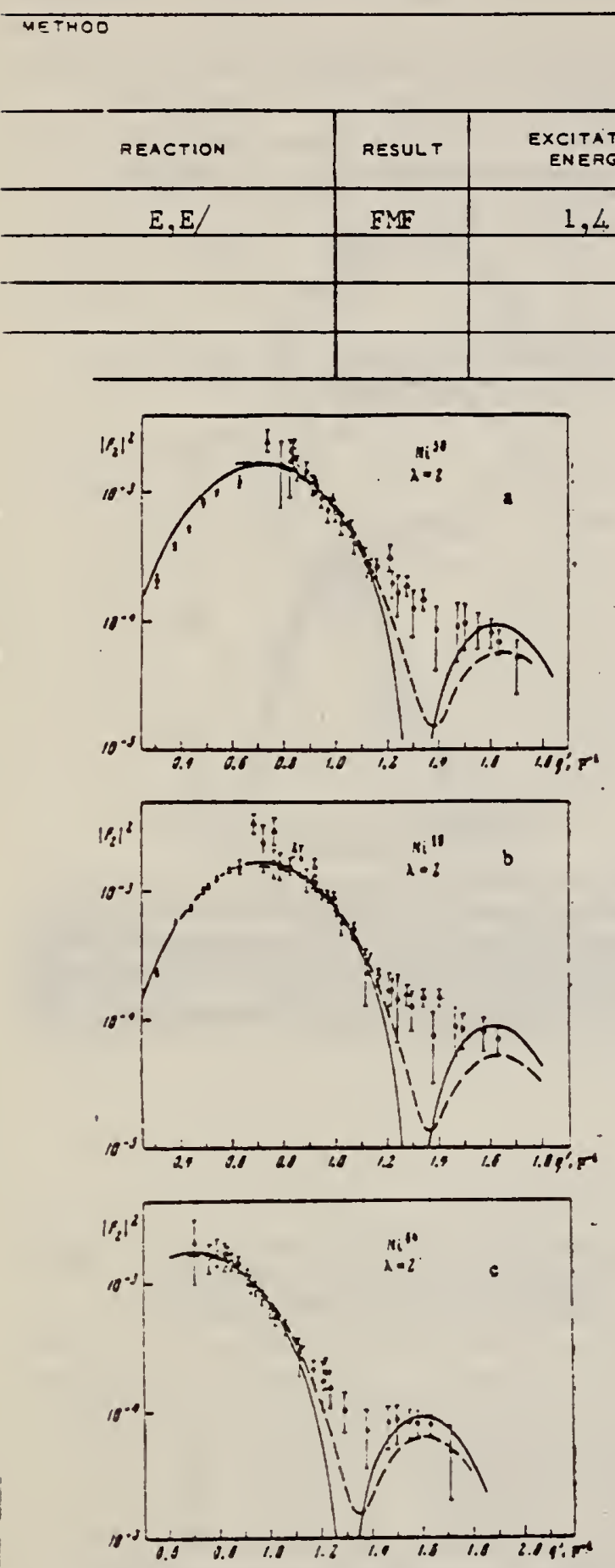

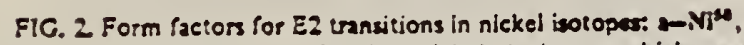

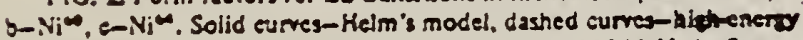
approximation. Points: O. -our dala for 150 and $225 \mathrm{MeV}, L_{\text {Stan }}$ ford data /",$x-Y a j e$ dacie $(10 \%$.

[over]

FiC. 3. RA as a function of $q^{\prime 2}$ for E2 transitions Stright !ines: 1$-\mathrm{Ni}^{38}$ (the points and straight line are raised by 0.5 ), $2-\mathrm{Ni}^{\infty}, 3-\mathrm{Nim}$ (the points and straight line are lowered by 1.0). Points: $0-150 . M \mathrm{cV}$, $-225 \mathrm{MeY}$.

Table II. Reduced probabilities of quadrupole transitions in the lsotopes $\mathrm{Nu}^{\mathrm{BO}, \infty 0, \infty 4}$

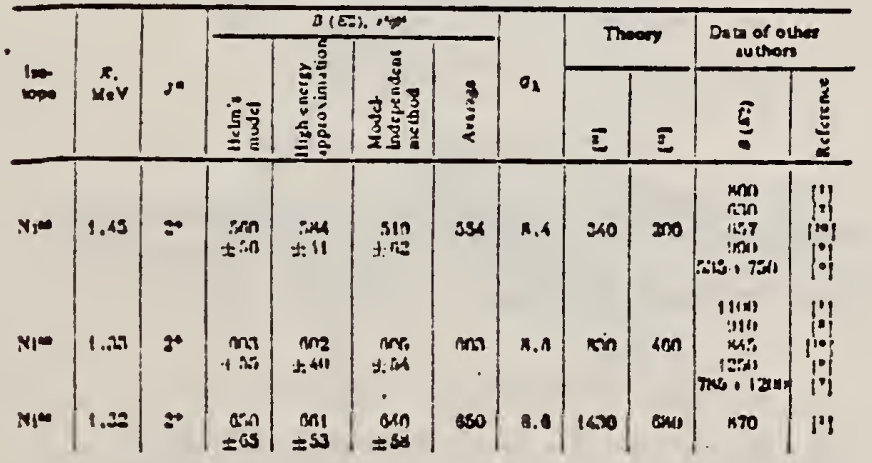


Table Ut. Reduced probabtlities of octupole transitions in the isotopes $\mathrm{Ni}^{38,60,44}$

\begin{tabular}{|c|c|c|c|c|c|c|c|c|}
\hline \multirow[b]{2}{*}{ Isotope } & \multirow{2}{*}{$\underline{s} \boldsymbol{s}$} & \multirow{2}{*}{ J" } & \multicolumn{3}{|c|}{$B(E), e^{2} F^{4}$} & \multirow[b]{2}{*}{$a_{\mathbf{1}}$} & \multicolumn{2}{|c|}{$\begin{array}{l}\text { Dats of other } \\
\text { suthors }\end{array}$} \\
\hline & & & $\begin{array}{l}\text { Holm's } \\
\text { model }\end{array}$ & $\begin{array}{c}\text { Model } \\
\text { independent } \\
\text { method }\end{array}$ & Averast & & $\Delta(E J)$ & Rofurence \\
\hline $\mathrm{Ni}^{*}$ & 4.43 & 30 & $\begin{array}{r}18800 \\
\pm 1450\end{array}$ & $\begin{array}{r}13020 \\
. \pm 780\end{array}$ & 13100 & 10 & $\begin{array}{l}19800 \\
27000 \\
14800\end{array}$ & $\begin{array}{l}\text { lol } \\
\text { (10) }\end{array}$ \\
\hline$N+\infty$ & 4.04 & 5 & $\begin{array}{r}133 m \\
\pm 1800\end{array}$ & $\begin{array}{l}13910 \\
\pm 830\end{array}$ & 13600 & 9 & $\begin{array}{l}23100 \\
35 \mathrm{~mm} \\
19100\end{array}$ & $\underset{l n j}{100}$ \\
\hline Njw & 3.55 & 5 & $\begin{array}{r}16000 \\
\pm 1800\end{array}$ & $\begin{array}{r}17000 \\
=1400\end{array}$ & 18500 & 9.4 & & \\
\hline
\end{tabular}

Table IV. Transition radii and parameters of the vibrational model of the nucleus for E2 and E3 transitions in $\mathrm{Ni}^{30,60,00}$

\begin{tabular}{|c|c|c|c|c|c|c|c|}
\hline \multirow[b]{2}{*}{ Intope } & \multirow{2}{*}{$t_{1}-I_{1}$} & \multicolumn{2}{|c|}{$R_{\text {trans }}$} & \multirow[b]{2}{*}{$\alpha_{\lambda}$ MoV } & \multirow{2}{*}{$\begin{array}{c}B \lambda, \\
M \in Y-\sec \\
\end{array}$} & \multirow{2}{*}{$\frac{B_{\lambda}}{\left(B_{\lambda h . d .}\right.}$} & \multirow[b]{2}{*}{$R_{2}^{1}$} \\
\hline & & $\begin{array}{l}\text { Our } \\
\text { result }\end{array}$ & ["] & & & & \\
\hline \multirow{2}{*}{ Nin } & $0 \rightarrow 2$ & $\begin{array}{r}4.85 \\
\pm 0.21\end{array}$ & 3.51 & $\begin{array}{r}177 \\
\pm 19\end{array}$ & $\begin{array}{r}82 \\
=9\end{array}$ & $\begin{array}{r}20.0 \\
\pm 2.2\end{array}$ & $\begin{array}{r}n .115 \\
\pm 0 . a x\end{array}$ \\
\hline & $0 \rightarrow 3$ & $\begin{array}{r}5.13 \\
\pm 0.11\end{array}$ & 6.05 & $\begin{array}{r}1.520 \\
=130\end{array}$ & $\begin{array}{r}77 \\
\pm 8\end{array}$ & $\begin{array}{r}17 \\
\pm 2\end{array}$ & $\begin{array}{r}0.101 \\
\pm 0.006\end{array}$ \\
\hline \multirow{2}{*}{ 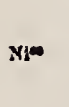 } & $0 \rightarrow 2$ & $\begin{array}{r}4.92 \\
\pm 0.15\end{array}$ & 5.55 & $\begin{array}{r}153 \\
\pm 17\end{array}$ & $\begin{array}{r}86 \\
=0\end{array}$ & $\begin{array}{c}20 \\
\pm 2.2\end{array}$ & $\begin{aligned} & 0.148 \\
= & 0.0 .8\end{aligned}$ \\
\hline & $0 \rightarrow 3$ & $\begin{array}{r}5.21 \\
\pm 0.10\end{array}$ & 6.09 & $\begin{array}{r}1500 \\
\pm 130\end{array}$ & $\begin{array}{r}92 \\
\pm 8\end{array}$ & $\begin{array}{l}18.5 \\
\pm 1.6\end{array}$ & $\begin{array}{r}0.097 \\
=0.005\end{array}$ \\
\hline \multirow{2}{*}{$N_{1} *$} & $a \rightarrow 2$ & $\begin{array}{r}4.99 \\
=0.15\end{array}$ & - & $\begin{array}{r}145 \\
\pm 10\end{array}$ & $\begin{array}{r}83 \\
=9\end{array}$ & $\begin{array}{r}17.8 \\
\pm 1.3\end{array}$ & $\begin{array}{r}0,15 n \\
\pm 0.1 \times n n\end{array}$ \\
\hline & $a-3$ & $\begin{array}{r}5.31 \\
\pm 0.11\end{array}$ & - & $\begin{array}{r}1160 \\
+130\end{array}$ & $\begin{array}{r}92 \\
\pm 12\end{array}$ & $\begin{array}{r}17.1 \\
\pm 2.2\end{array}$ & $\begin{array}{r}0.1133 \\
\pm 0.0 \times 6\end{array}$ \\
\hline
\end{tabular}

(BNh.d. is the oseillation parameter of the nucleus, obtained with a hydrody. namical model.

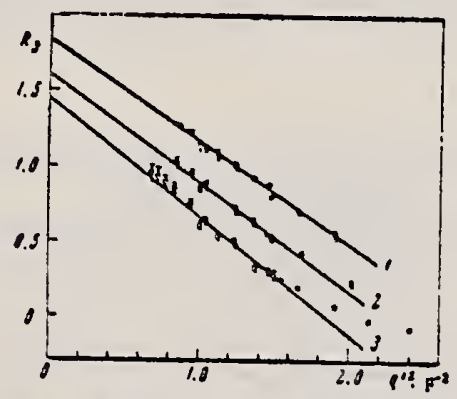

FIG. S. Analysis of $\mathbf{\mathrm { E } 3}$ transitions by the model-independent method. Straight lines: $1-\mathrm{Ni}^{32}$ (the data and straight line have been mised by 0.5 ) $2-\mathrm{Ni}^{\infty}, 3-\mathrm{Ni}^{\infty}$ (the data and straight line have been lowered by 0.5 ). Points: $0-150 \mathrm{MeV}, 0-225 \mathrm{MeV}$. 
I. S. Gul'karov, N. G. Afaras'ev, V. M. Khvastunov, N. G. Shevchenko,

V. D. Afanas'ev, G. A. Savitski, A. A. Khomich

Yad. Fiz. 2, 478 (1969)

Sov. J. Nucl. Phvs, 9,274, (1969)

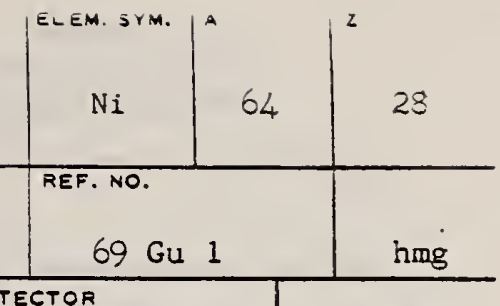

\begin{tabular}{|c|c|c|c|c|c|c|c|}
\hline \multirow{2}{*}{ REACTION } & \multirow{2}{*}{ RESULT } & \multirow{2}{*}{$\begin{array}{l}\text { EXCITATION } \\
\text { ENERGY }\end{array}$} & \multicolumn{2}{|c|}{ SOURCE } & \multicolumn{2}{|c|}{ DETECTOR } & \multirow{2}{*}{ ANGLE } \\
\hline & & & TYPE & RANGE & TYPE & RANGE & \\
\hline \multirow[t]{2}{*}{ E.E/ } & $A B X$ & $10-30$ & $D$ & 150 & MAG-D & & 55 \\
\hline & & & & $(149.7)$ & . & & \\
\hline & & & & & & & \\
\hline & & & & & & & \\
\hline
\end{tabular}

See paper for summary of other data.

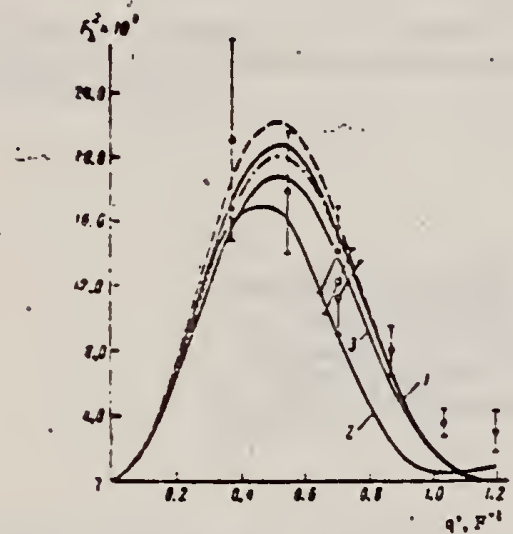

FIC. 2. Giantresonance form factor as a function of momentum transfer. Points: O-data for $\mathrm{Ni}^{\infty}, x$-for $\mathrm{Ni}^{\omega *}, \square-$ for $\mathrm{Ni}^{\text {st }}$. The dashed eurre, curve 1, and the dot-dash curve were caleutated from formula (2) for the nuclei $. \mathrm{Ni}^{3 \mathrm{~s}}+\mathrm{s}$, respectively, with $x=19 \mathrm{MeV}$. Curve 3 was alculated from the same formula for $\mathrm{Ni}^{\text {क }}$ with $\mathrm{k}=2 \mathrm{l} \mathrm{MeV}$. Curve 2 is a alculation according to the Coldhaber. Telle: collective model.

Tablo I. Absolute differential cross sections for inelastic scattering of electrons with excitation of the giant resonance in nickel isoropes

\begin{tabular}{|c|c|c|c|c|c|c|}
\hline Nectros & $0 . \operatorname{sen}$ & $\varepsilon_{0 .} x_{0} v_{!}^{\prime}$ & Q. $F^{-1}$ & $a: F^{-1}$ & sqd $\Omega, \sigma^{2} / x$ & $r^{2}(x+\infty)$ \\
\hline & $\left\{\begin{array}{l}n \\
\vdots \\
\vdots \\
\vdots \\
\vdots \\
\vdots 1\end{array}\right.$ & 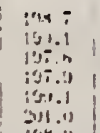 & 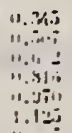 & 列 & 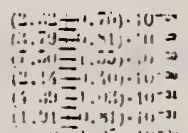 & 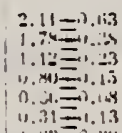 \\
\hline$\therefore$ & in & 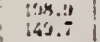 & (1"id & 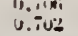 & $(\because, 14 \equiv \equiv)$ & $\mid \begin{array}{l}1.20 \\
1.43 .2010\end{array}$ \\
\hline
\end{tabular}

Vioce. The timurs of integracion of the spectra are fros 10 to $30 \mathrm{MeV}$.
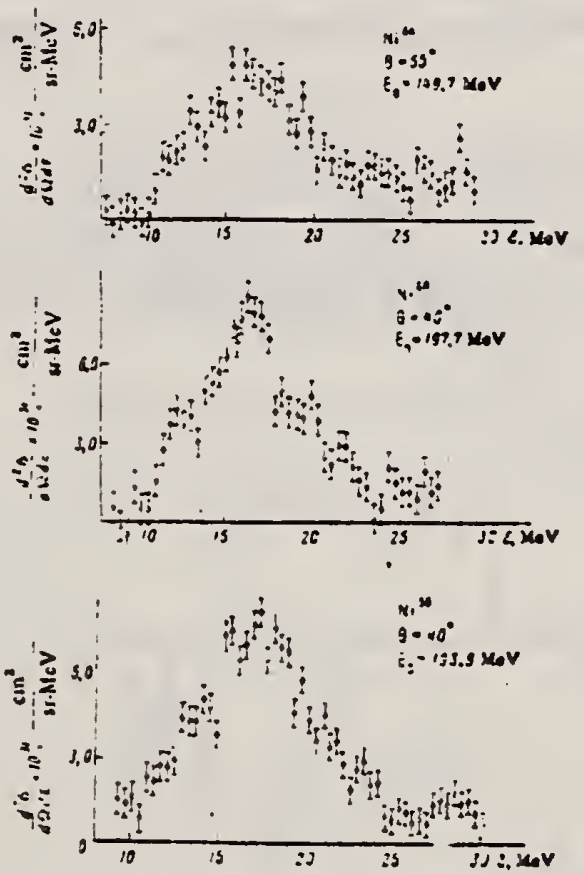

FIC. 3. Enepgy spectin of electrons inthasticlly seattered by the isotopes $\mathrm{Nim}, \infty, 54$. All three spectre were masured at the sume ralue of momentum t.:anster. 
B. S. Ratner

ZhETF P1s. Red. 13, 628 (1971)

JETP Letters $13, \frac{13}{447}$ (1971)

\begin{tabular}{|c|c|c|c|c|c|c|c|}
\hline METHOD & & $\cdot$ & & & • & $\begin{array}{l}\text { REF. NO. } \\
71 \mathrm{Ra} 1\end{array}$ & hmg \\
\hline \multirow[b]{2}{*}{ REACTION } & \multirow{2}{*}{ RESUL T } & \multirow{2}{*}{$\begin{array}{c}\text { EXCITATION } \\
\text { ENERGY }\end{array}$} & \multicolumn{2}{|c|}{ SOURCE } & \multicolumn{2}{|c|}{ DETECTOR } & \multirow{2}{*}{ ANGLE } \\
\hline & & & TYPE & RANGE & TYPE & RANGE & \\
\hline \multirow[t]{2}{*}{$G, P$} & RLY & $12-17$ & $\mathrm{C}$ & $12-17$ & $A C T-I$ & & $4 \mathrm{PI}$ \\
\hline & & & & & \multicolumn{2}{|c|}{ · } & \\
\hline & & & & & & & \\
\hline & & & & & & & \\
\hline
\end{tabular}

$\sigma=1 \times 10^{-29} \mathrm{~cm}^{2}$ at $16.2 \mathrm{MeV}$.
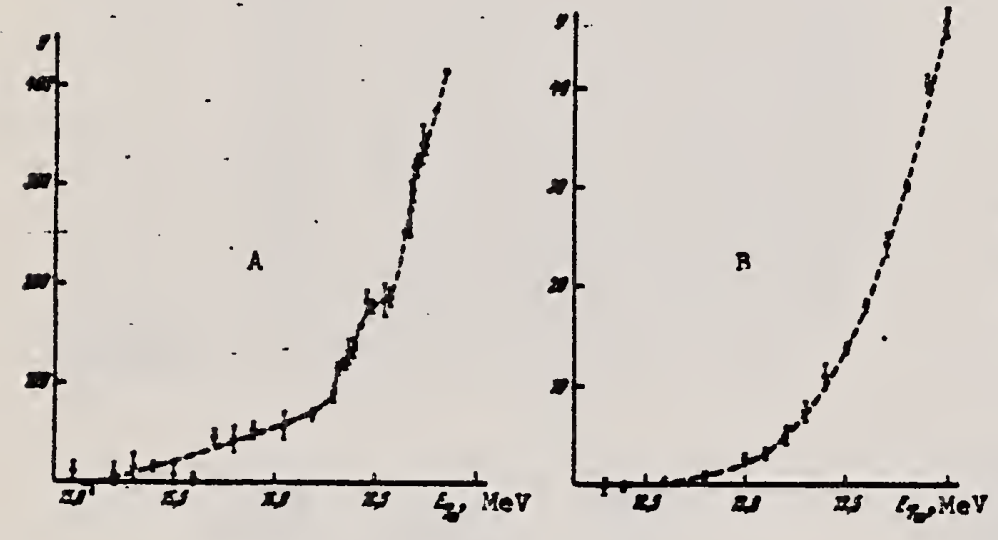

118. 1. Yleld of reacticos

$\mathrm{di}^{64}(Y, P) \mathrm{Co}^{63}(A)$ and

$C^{53}(Y, p) U^{52}(B)$ veas the

threshold, aversged ove? 3

in the laterral $10-100 \mathrm{~kJ}$
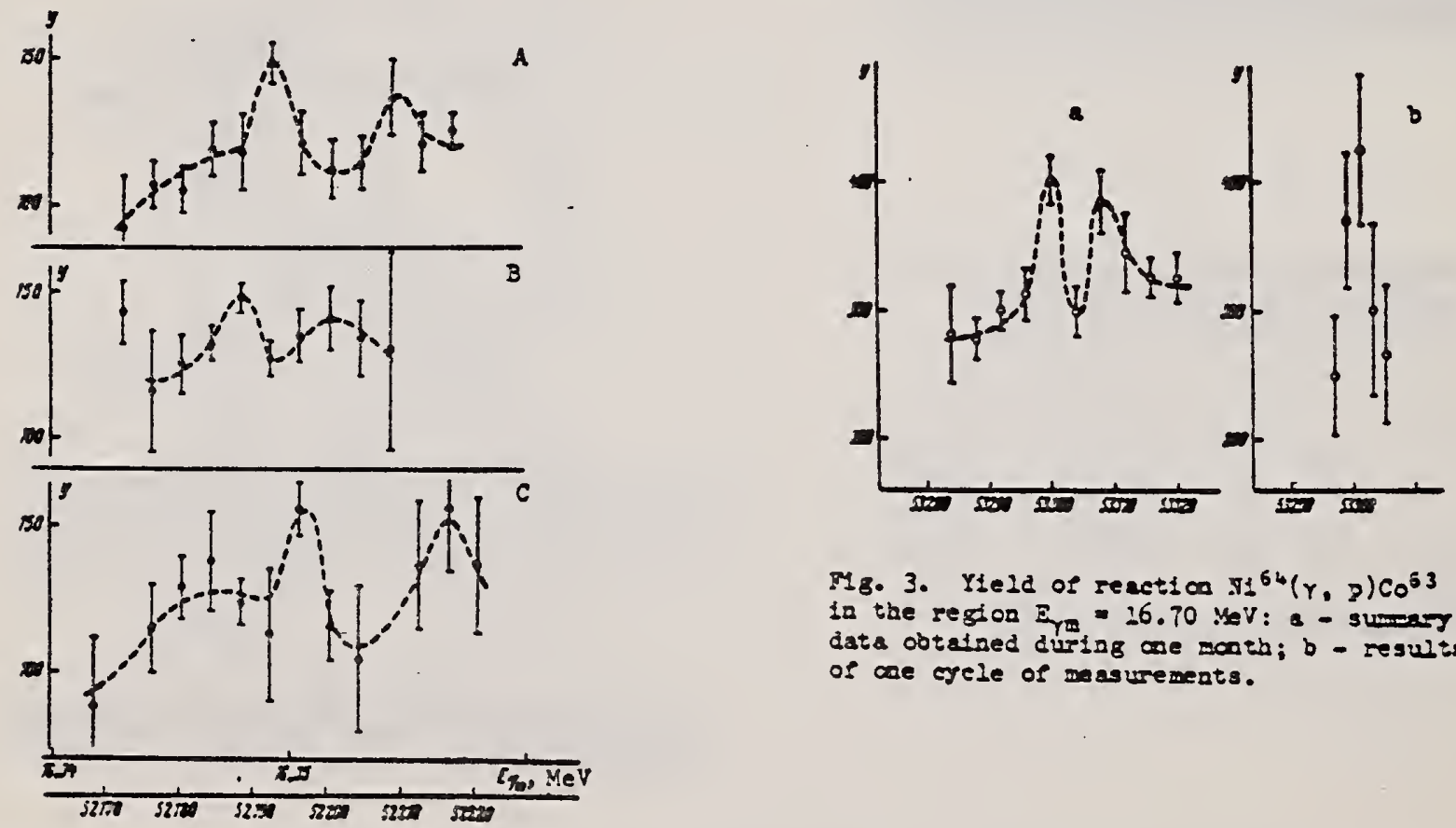

Mg. 3. Yield of reactico $\mathrm{II}^{64}(\mathrm{Y}, 3) \mathrm{CO}^{63}$

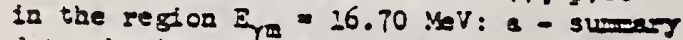
data obtaloed duriag ase nontb; b - results of cae cyele of masuremeats.

818. 2. Yield of reect10n $18^{64}(\mathrm{Y}, \mathrm{P}) \mathrm{CO}^{53}$. in the region $\mathrm{E}_{\text {YIR }}=16.35 \mathrm{NeV}$. 


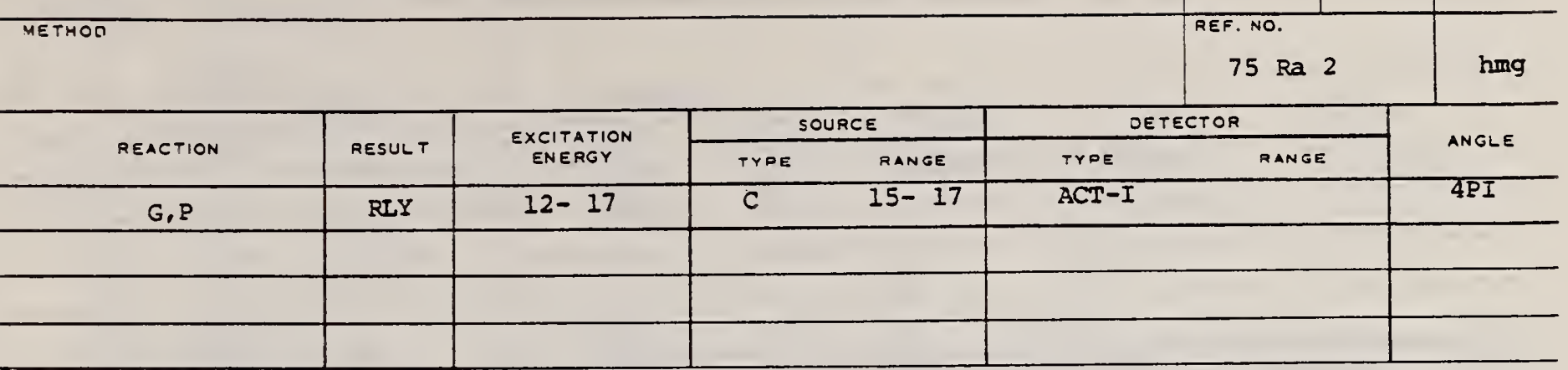

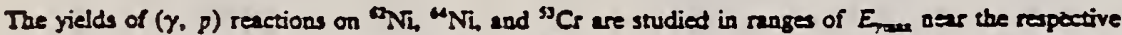
thresbolds Considerable differences are found between the curve shapes, yields, and observed threstiolds for the $\mathrm{Ni}$ isotopes and ${ }^{3} \mathrm{Cr}$.
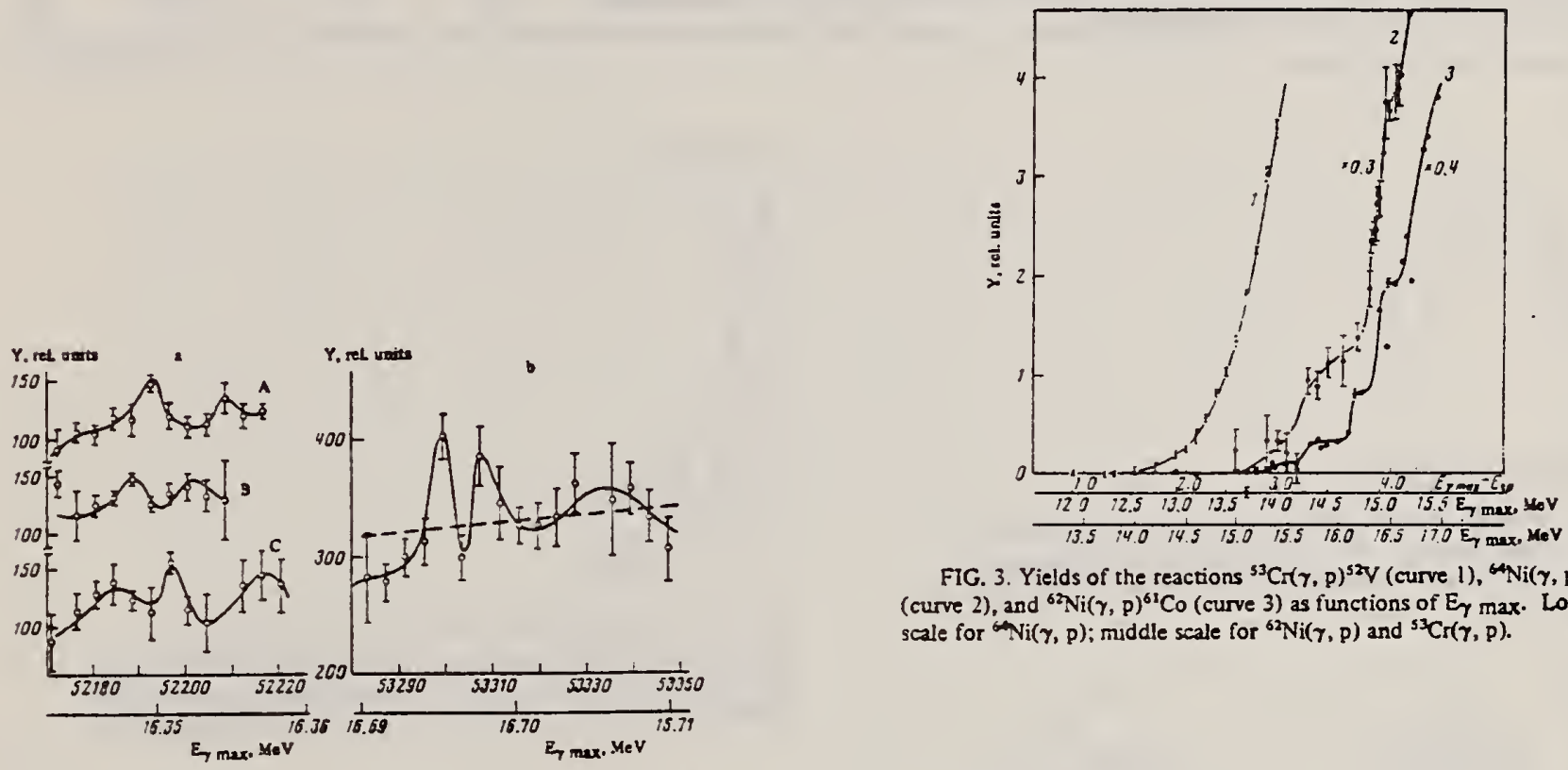

FIG. 3. Yields of the reactions $\left.{ }^{53} \mathrm{C} \cdot(\gamma, p)\right)^{52} \mathrm{~V}$ (curve 1), $\mathrm{Ni}(\gamma, \mathrm{p})^{63} \mathrm{Co}$ (curve 2), and ${ }^{62} \mathrm{Ni}(\gamma, \mathrm{p})^{63} \mathrm{Co}$ (curve 3 ) as functions of $\mathrm{E}_{\gamma}$ max. Lowest scale for ${ }^{\mathrm{Ni}}(\gamma, \mathrm{p})$; muddle scale for ${ }^{62} \mathrm{Ni}(\gamma, \mathrm{p})$ and ${ }^{53} \mathrm{Cr}(\gamma, \mathrm{p})$.

FIG. S. Yield of $\mathrm{Ni}(\gamma, p)^{63} \mathrm{Co}$ in the region of $\varepsilon_{\gamma} \max =16.35 \mathrm{MgeV}$ (a): yield of ${ }^{\infty} \mathrm{Ni}(\gamma, p)^{63} \mathrm{Co}$ in the region of $E_{\gamma} \max =16.70 \mathrm{MeV}(\mathrm{b})$. 
REF. G.V. Arustamyan, G.A. Vartapetyan,

A.S. Danagulyan, A.G. Khudaverdyan

Yad. Fiz. 32, 1165 (1980)

METHOO

Yad. Fiz. $\underline{32}, 1165$ (1980)

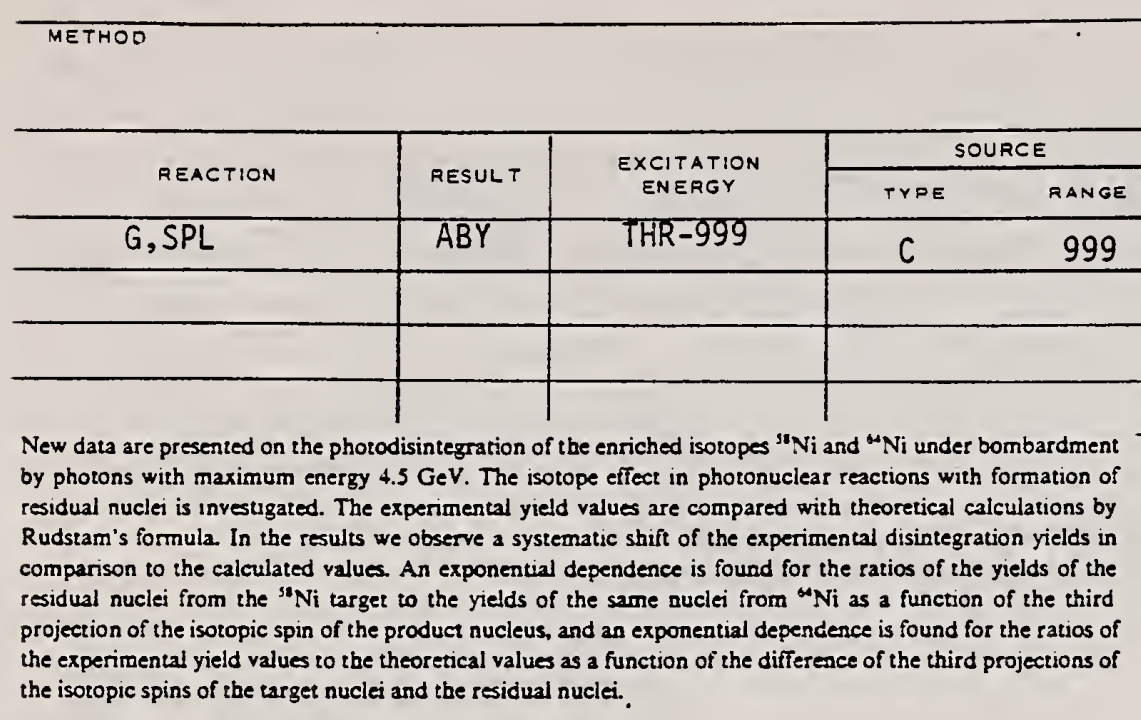

PACS numbers: 25.20 . $+y, 27.50$. $+e$

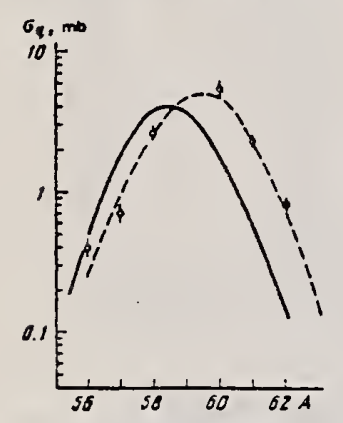

FIG. i. Distributions of independent yields of Co residual nuclei in mass number. The solid curve is a calculation with Eq. (1). and the dashed curve has been drawn from the experimental points.

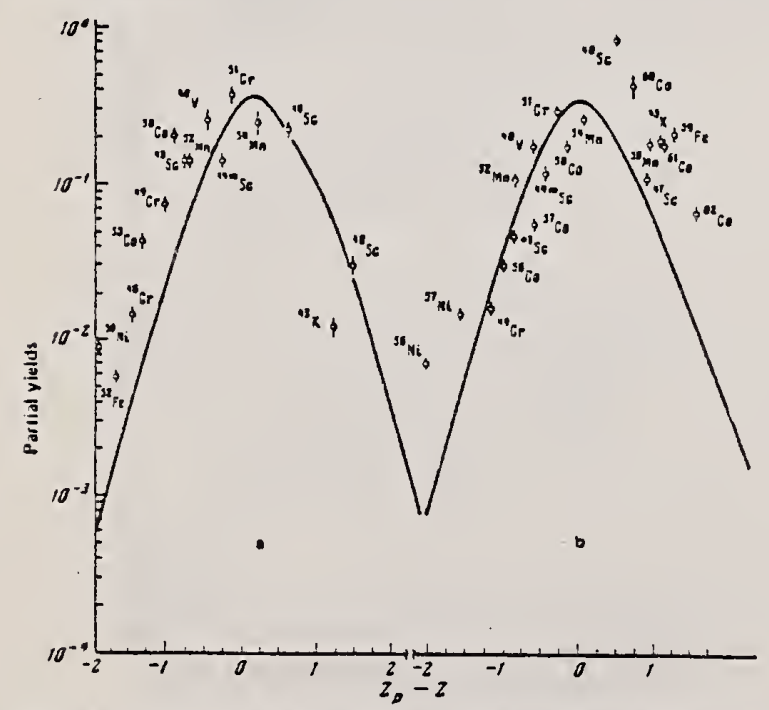

FIG. 2. Charge-dispersion curves of residual nuclei from tar- gets of ${ }^{58} \mathrm{Ni}(\mathrm{a})$ and ${ }^{54} \mathrm{Ni}(\mathrm{b})$. iREV. $7-14-64)$ USCOMM-NBS-DC

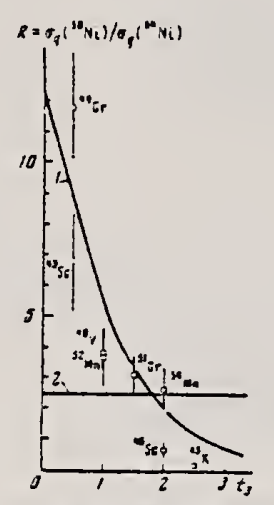

FIG. 3. Ratio of yields of identical residual nuclei from two isotopes of the target nuclei as a function of the third projection of the isotopic spins of the residual nuclei. Curve 1 is the function 15 exp $\left(-t_{3}\right)$, and curve 2 is calculated with Eq. (1). 
TABLE II.

\begin{tabular}{|c|c|c|c|c|c|c|c|c|}
\hline \multirow[b]{2}{*}{$\begin{array}{l}\text { Reovend } \\
\text { nisters }\end{array}$} & \multicolumn{3}{|c|}{ Nil (ufgel } & \multicolumn{3}{|c|}{ Doni t inget } & \multirow[b]{2}{*}{$\begin{array}{l}\text { Type } \\
\text { of yreld }\end{array}$} & \multirow[b]{2}{*}{ e. } \\
\hline & $\mathscr{0}_{\text {ur:D. }}$ & Outhere. IIIb & $\frac{\text { ogerp }}{\text { ogthou }^{\prime}}$ & ospesp. mb & "ather mb & $\frac{\text { ogenp }}{\text { opthes }^{\prime}}$ & & \\
\hline 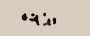 & 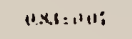 & $11.1 .1 \%$ & $\therefore i d i$ & & & & 1 & 4 \\
\hline 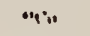 & 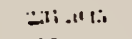 & $11 . x+1=$ & 6.16 & & & & $c$ & 3.5 \\
\hline Nis & $i x=1$ & 1.tinziz & :LN & & & & 1 & 3 \\
\hline טنxs & $=\mid i-10,0\}$ & 1.:17 & $0.15 i$ & $12.140 \pm 0.02$ & & & 1 & 2 \\
\hline $2=1: 11$ & $1.11=0.1$ & l.6it: & U.tioi & $i 6.5 \pm 1$ & 1966 & 9.35 & $c$ & 12 \\
\hline mis & U.5:11=4.ui & 11. Xंस̈:i & 198 & $R / \pm 11\}$ & 12085 & 0.255 & $c$ & 1 \\
\hline es. & - & 0.1004 & - & $1.7 \pm 0.1$ & 0.2697 & 6.81 & $c$ & as \\
\hline$* \mathrm{Yi}$ & $0.231=0.17$ & 0.0071 & -387 & $172 \pm 1$ & 0.251 & 88.1 & $I$ & 1 \\
\hline${ }^{1}$ & 11. $1 . i=0.03$ & thotis: & 9.816 & $0.5 \pm 0.03$ & 0.0058 & 13.97 & 1 & 0 \\
\hline "fee & $|x \pm 1|=$ & 11.20 & as: & - & - & - & $I$ & is \\
\hline$\therefore=18$ & - & 0.111日is & - & $0.135 \pm 0.01$ & 0.0783 & 352 & 1 & $\overline{0}$ \\
\hline Nn & $1 \pm 015$ & 0.2075 & 2353 & - & - & - & $c$ & 3 \\
\hline Min & $1.6=0=2$ & 1.596 & 0.89 & $3.8 \pm 0.4$ & 523 & 0.7267 & $t$ & 2 \\
\hline $4: 411$ & Q $2: i \pm 0,1 i$ & & & $1-36=a_{1}$ & 1042 & 212 & $c$ & 1 \\
\hline $\begin{array}{l}: M-M_{n} \\
. c_{8}\end{array}$ & $\begin{array}{l}0.9=1\} .0 \mathrm{x} \mid \\
1.1=\mathbf{2} .1\end{array}$ & $\begin{array}{l}0.3910 \\
11.942\end{array}$ & 1.71 & $\begin{array}{l}0.85 \div 0.07 \\
\cdot 3<5 \pm 0.3\end{array}$ & 25977 & 1.33 & c & is \\
\hline${ }^{4}$ & $\begin{aligned} 1.1 & =12.1 \\
0.003 & =1.106\end{aligned}$ & $\begin{array}{l}11.942 \\
11.587\end{array}$ & $\begin{array}{l}1.1677 \\
0.721\end{array}$ & & 0211 & 3.175 & $c$ & as \\
\hline$C_{8}$ & $\begin{array}{c}0.013=1.1066 \\
-\end{array}$ & $0.018 \pi$ & - & $0.13 \pm 0.01$ & 0.097 & 3.513 & $c$ & 0 \\
\hline$\omega y$ & $10.5 \pm 0.04$ & $0=0=3$ & 1.526 & $1.7 \pm 0.15$ & 0.7516 & 228 & $c$ & 1 \\
\hline use & - & 0.0233 & - & $0.07 \pm 0.02$ & 00524 & 1336 & $I$ & 3 \\
\hline "rse & $0.44 \div 0.03$ & 0.078987 & $1 . \pi 2$ & - & Q 187 & - & $c$ & 25 \\
\hline$n 5 x$ & נט.ט. & 02004 & 4.51 & $0.53 \pm 0.05$ & 0493 & 1.075 & $l$ & 2 \\
\hline كته & $0.13 \times 0.02$ & 020003 & - & $0.32 \pm 0.03$ & Q.180 & - & $i$ & 1 \\
\hline wise & $0.825]=0.0425$ & 0.0631 & 0.8390 & $4.32 \pm 0.05$ & 0.143 & 224 & $c$ & as \\
\hline $\boldsymbol{\omega}_{\mathrm{K}}$ & $0.09 \pm 0.00 y$ & 0.0200 & 4306 & 0011 & 0015 & a2t & $t$ & 23 \\
\hline
\end{tabular}

Note. $\sigma_{\text {exp }}$ and $\sigma_{\text {eineo }}$ are respectively the expertmental and theoretloal yield values; $t_{3}$ is the third projection of the isospios. 


\section{COPPER}

$Z=29$

Copper was probably discovered about 8000 B.C. by Neolithic man during the late stone age. Crude hammers, knives, and other utensils were created from this malleable metal. The early age of copper had its greatest development in Egypt where records show that mining, extracting, and refining of copper ws done on the Sina $i$ peninsula. Copper was produced extensively about 3000 B.C. on the island of Cyprus and supplied most of the Roman needs for the metal. The ore was known as aes cyprium (ore of cyprus), this was shortened to cyprium and later corrupted to cuprum. From this comes the English name copper. 
Method Synchrotron; neutron spectrum, angular distribution; nuclear emulsion; scintillator; ion chamber

Ref. No.

$55 \mathrm{Di} 1$

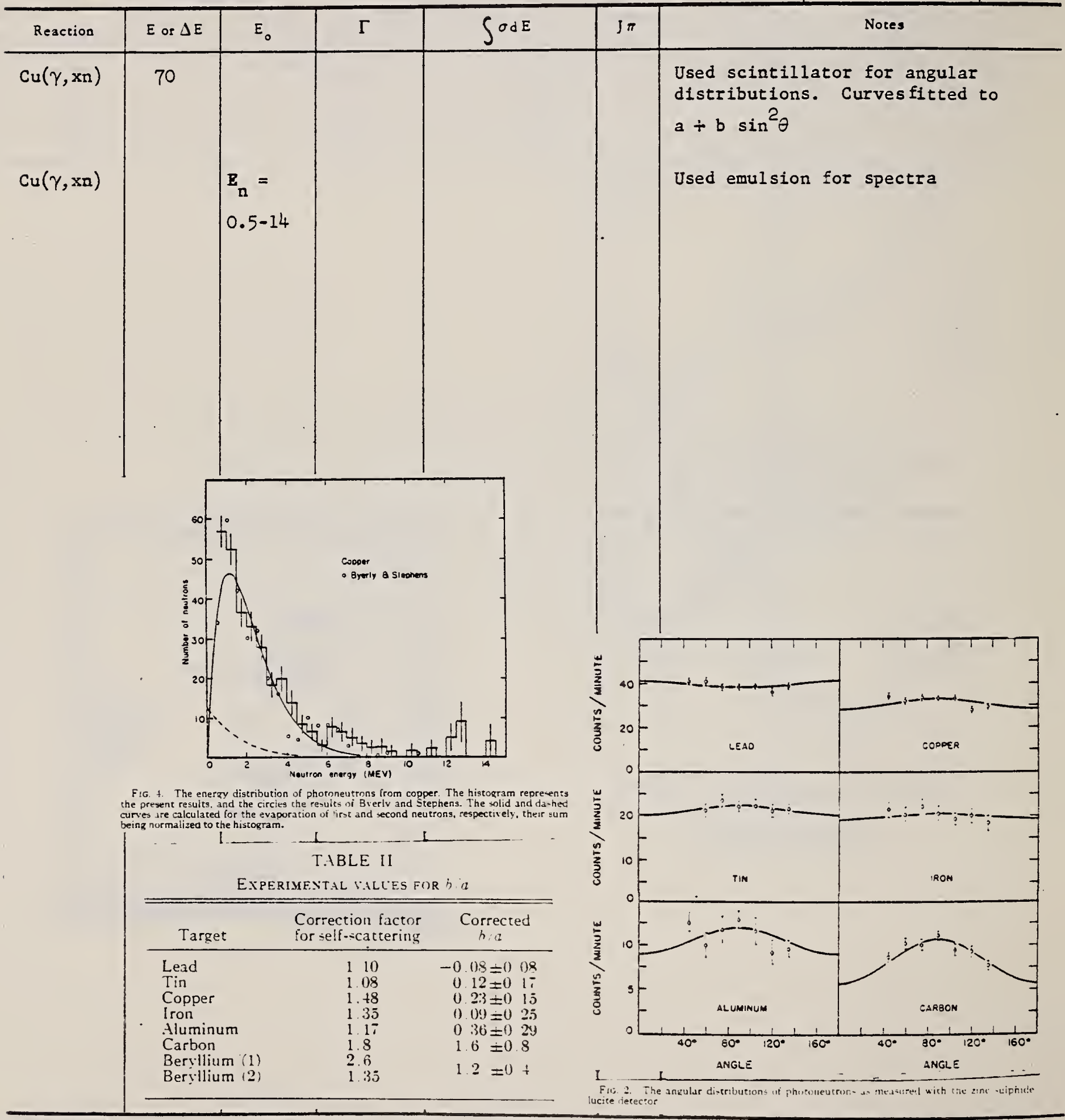


Rei. Z. Dłouhý, V. Petržílka, M. Rozkoš

Crech. J. Phys. 5, 193 (19,55)

\begin{tabular}{|r|l|l} 
Elem. Sym. & A & Z \\
Cu & & 29 \\
\hline $\begin{array}{rll}\text { Ref. No. } & \text { D } 1 & \text { EGF }\end{array}$
\end{tabular}

\begin{tabular}{|c|c|c|c|c|c|c|}
\hline Reacrion & $E$ or $\Delta E$ & $E_{0}$ & $\Gamma$ & $\int \sigma d E$ & $\mathrm{~J} \pi$ & Notes \\
\hline$C_{u}(\gamma, p)$ & 17.5 & & & • & & 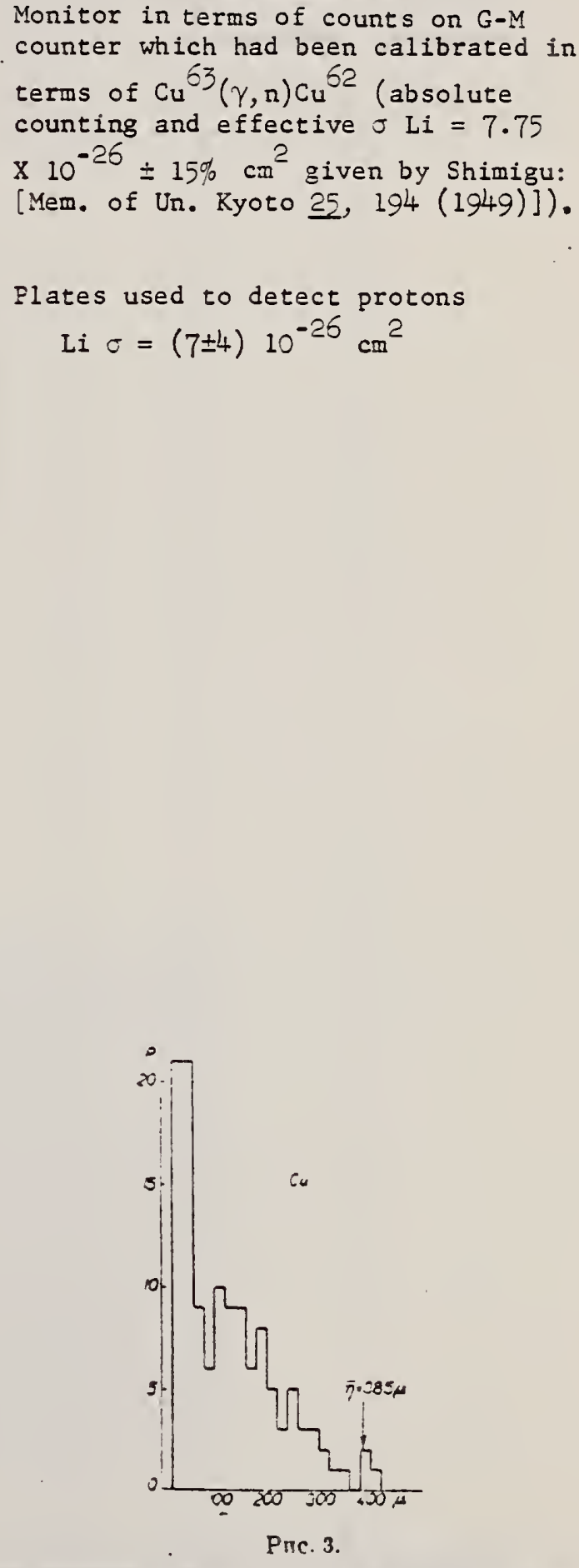 \\
\hline
\end{tabular}


Ret. D.L. Livesey

Can. J. Phys. 33, 391 (1955)

Synchrotron; neutron spectrum; nuclear emulsion Ref. No

55 Li 1

\begin{tabular}{c|c|c|c|c|c|c}
\hline Reaction & $E$ or $\Delta E$ & $E_{0}$ & $\Gamma$ & $\int \sigma d E$ & $J \pi$ & Notes \\
\hline $\mathrm{Cu}(\gamma, \mathrm{xn})$ & $\begin{array}{c}\text { Bremss. } \\
70\end{array}$ & & & & & Temperature = $1.2 \mathrm{MeV}$ \\
\end{tabular}

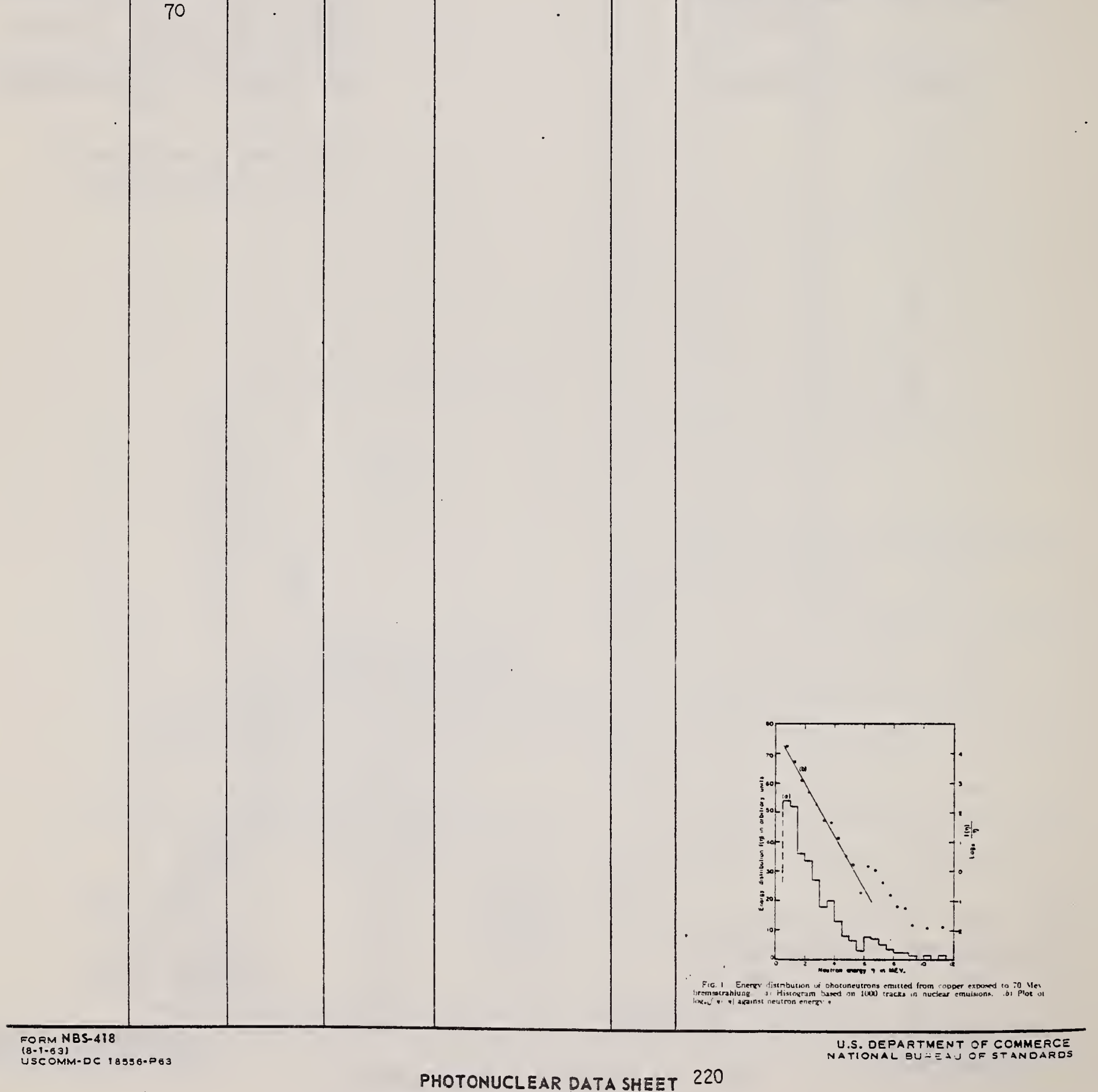


REF.

K. G. MCNeill

Phil. Mag. Ló, 321 (1955)

ELEM. SYM. A

METHOO

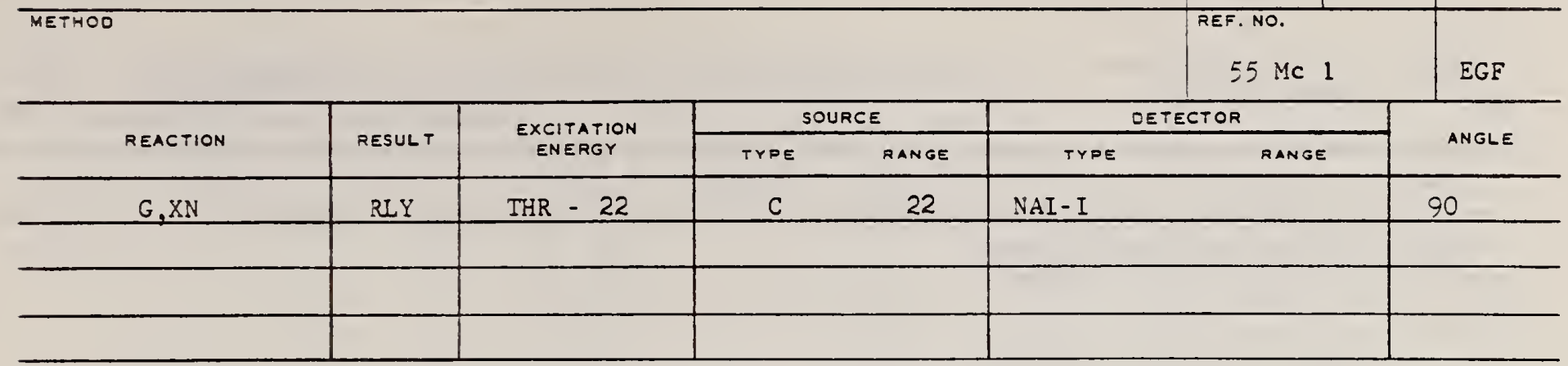

\begin{tabular}{|c|c|c|c|}
\hline $\begin{array}{l}\text { Target } \\
\text { clemont }\end{array}$ & $\begin{array}{l}\text { County in } 30 \text { minutes } \\
\text { per } 1000 \text { monitor connt. }\end{array}$ & $\begin{array}{l}2.2 \text { Mev yield molir } \\
\text { relntive to cnpler }\end{array}$ & $\underset{\times 10^{-6}}{\text { Yicld inol } / r}$ \\
\hline $\mathrm{Cn}$ & $288 \pm 15$ & $1 \cdot n$ & $3 \cdot 2$ \\
\hline $\mathrm{Cd}$ & $647 \pm 28$ & $4 \cdot 1 \pm 0 \cdot 3$ & 13 \\
\hline $\mathrm{Hg}_{\mathrm{g}}$ & $661 \pm 26$ & $0 \cdot 5=0 \cdot 9$ & 30 \\
\hline $\mathrm{Pb}$ & $470 \div 17$ & $8 \cdot 4=0 \cdot 5$ & 27 \\
\hline
\end{tabular}


Ref. R. Chastel

Compt. Rend. 242, 1440 (1956); Compt. Rend. 242, 2337 (1956);

J. Phys. Rad. 17, 518 (1956)

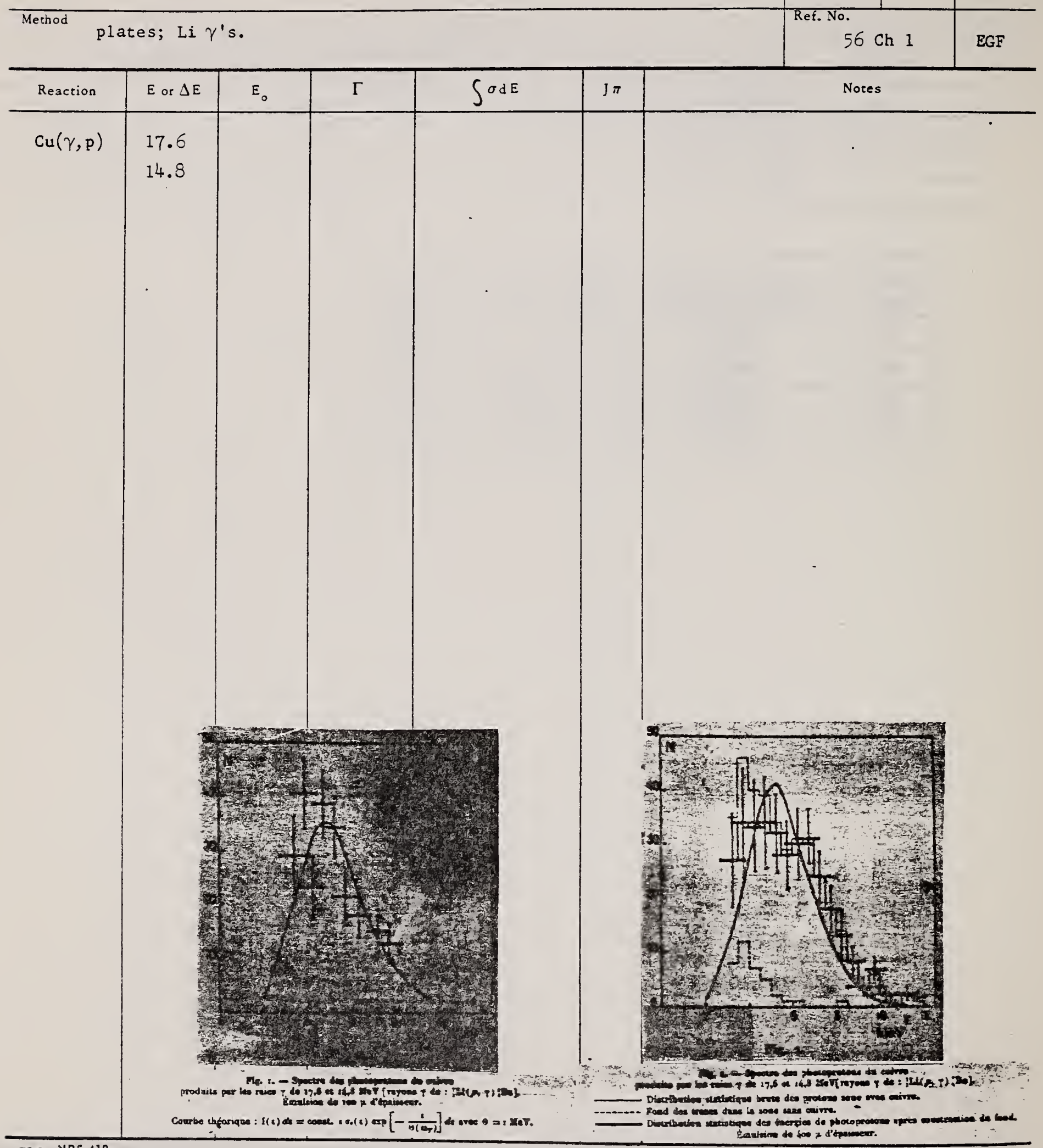


Rer. W.K. Dawson

Can. J. Phys. $24,1480(1956)$

Method Synchrotron; proton yield, spectrum; angular distribution; nuclear emulsion; ion chamber

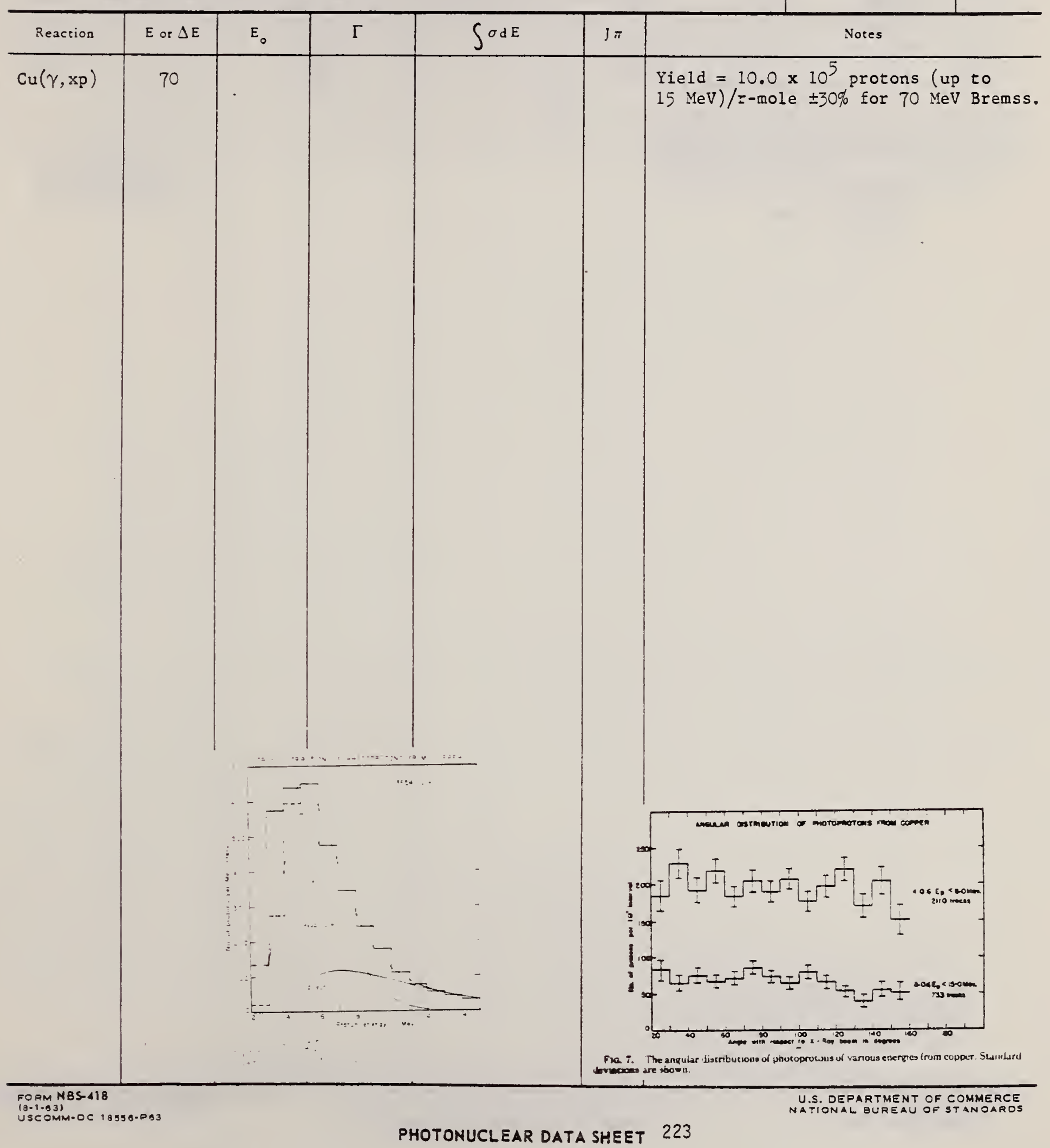


REF.

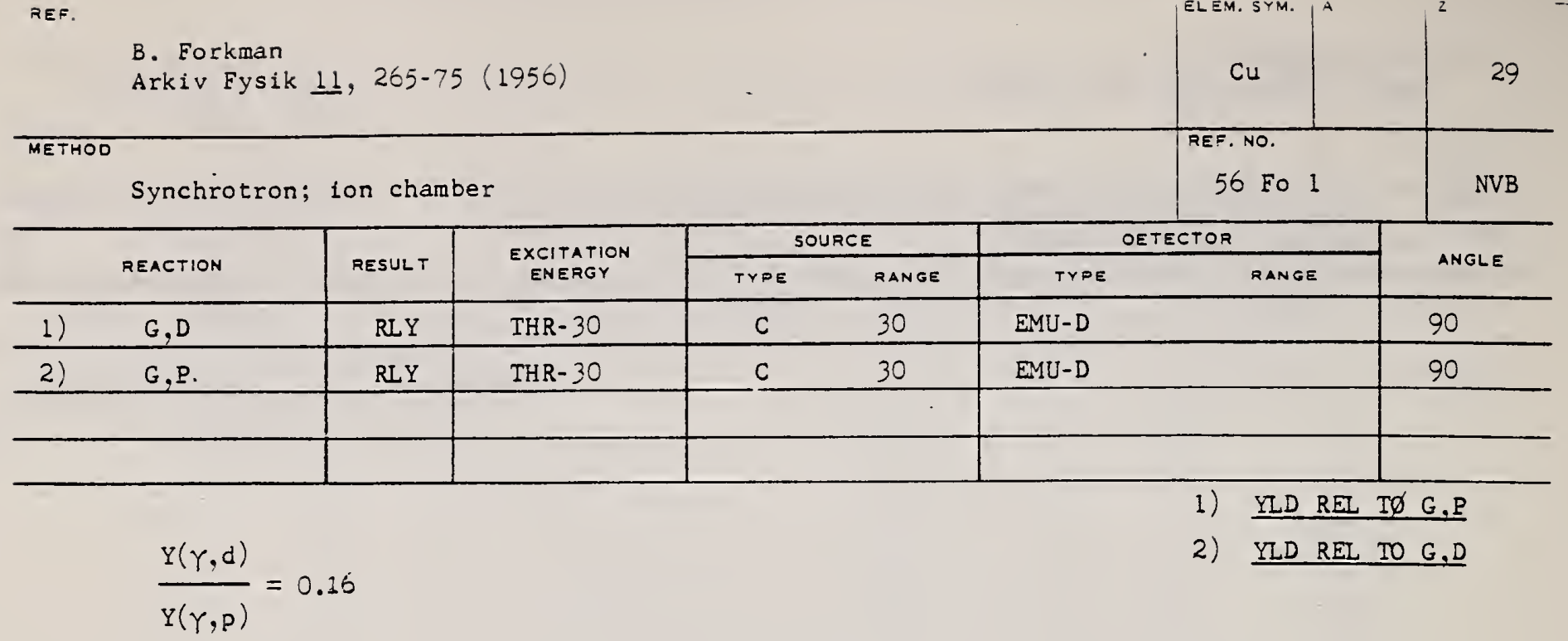


Rer. E.G. Fuller, E. Hayward

Phys. Rev. 101, 69? (1956)

Method

Betatron; photon scattering; NaI spectrometer

\begin{tabular}{c|l|l} 
Elem. Sym. & $A$ & $z$ \\
$\mathrm{Cu}$ & & 29 \\
\hline $\begin{array}{c}\text { Ref. No. } \\
\text { Fu } 1\end{array}$ & NVB
\end{tabular}

\begin{tabular}{|c|c|c|c|c|c|c|}
\hline Reaction & $E$ or $\Delta E$ & $E_{0}$ & $\Gamma$ & $\int \sigma d \mathrm{E}$ & $\int \pi$ & Notes \\
\hline $\mathrm{cu}(\gamma, \gamma)$ & $\begin{array}{c}\text { Bremss. } \\
4-40\end{array}$ & & & & & $\begin{array}{l}\text { Detector at } 120^{\circ} \text {. } \\
\text { Cross sections given here are } 13 \% \text { too } \\
\text { high due to erroneous cos } 3 \text { factor in } \\
\text { denominator of Eq. } 5 \text {. [See footnote } \\
8 \text { in Phys. Rev. } 106,993 \text { (1957)]. }\end{array}$ \\
\hline
\end{tabular}

8 in Phys. Rev. 106, 993 (1957)]. 
1 B. I. Gavrilov, L.E. Lazareva

Zhur. Eksp. i Teoret. Fiz. 30,855 (1956);

Soviet Phys. JETP 2, 871 (1957)

Mcthod $\gamma$-Bremsstrahlung; synchrotron; $\mathrm{BF}_{3}$ counter

Ref. No.

$56 \mathrm{Ga} 1$

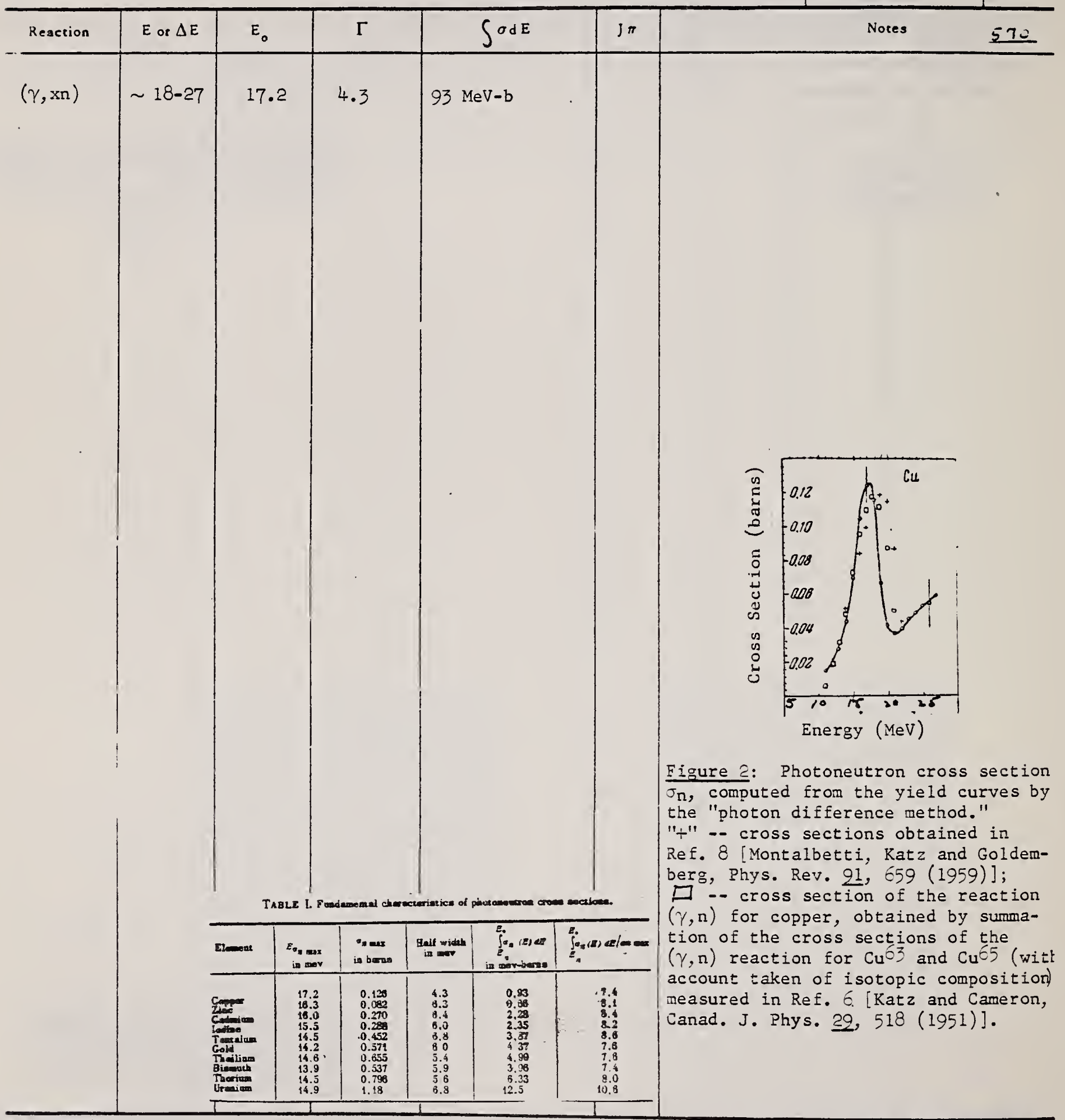


кcr. …H. Hart.ey, W.E. Stephens, E.J. Wirhold

Phys. Rev. 104, 178 (1956)

Method

Li $(p, \gamma)$ source, 480 kev protons.

Elem. Sym.

Ref. No.

56 Ha 1

$E G \vec{F}$

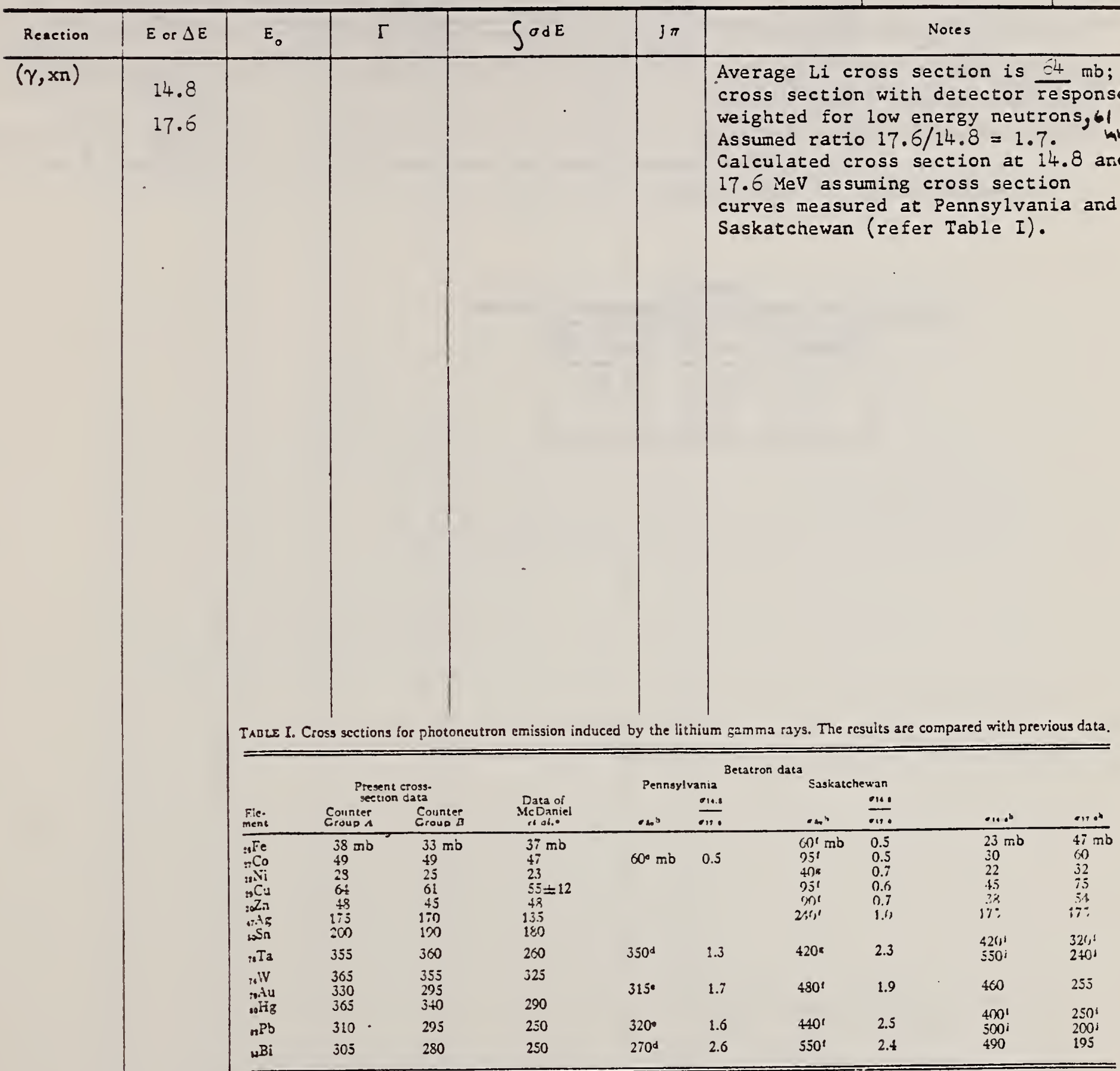

- See reterence 3.

- Averaze of 14.8- and 17.6-Mev cross sections weighted with relative intensities of the lithlum gamma-ray lines.

: R. Vathans. Ph.D. thesis. University of Pennsylvania, 1954 (unpublished).

- R. Halnetr (privace communication).

is. Halnern (nrivace reierence 23 .

- See reierence 32

Senarace cross sectiong at 14.8 and 17.6 Mev as obtained imm Grnus $A$ data and 14.8/17.6 betatron cross-section ratios.

Oolained using $14.8 / 17.5$ cross-section ratso itom Pcnnayitania betatron data. 
$R E F$.

F. Heinrich and $H$. Waffler

Helv. Phys. Acta 29, 232 (1956)

ELEM. SYM. A

$56 \mathrm{He} 1$

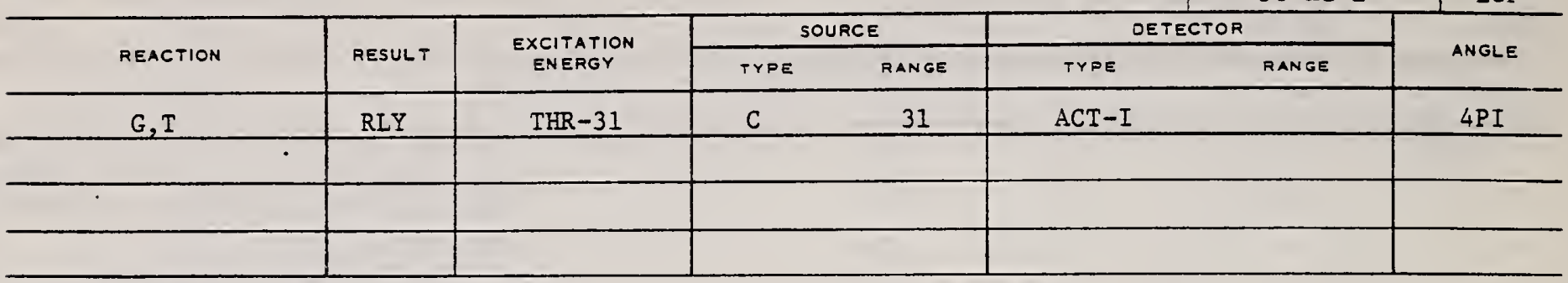

Yields relative to $(G, N)$ yields.

Tahelle 1.

Experimentelle und theoretische nuklenre Ausbeuto der $(\gamma, T)$-Prozesse.

\begin{tabular}{|c|r|r|}
\hline Element & $\eta_{\text {oxp }} \times 10^{\mathrm{s}}$ & $\eta_{\text {theor }} \times 10^{\mathrm{s}}$ \\
\hline $\mathrm{Al}$ & $240 \pm 14$ & 200 \\
$\mathrm{Co}$ & $6 \pm 1,7$ & 4 \\
$\mathrm{Cu}$ & $4,5 \pm 1,5$ & 3 \\
\hline
\end{tabular}


Rer. E. Lejkin, R. Osokina, B. Ratner

Il Nuovo Cimento 2 Suppl. 1, 105 (1956)

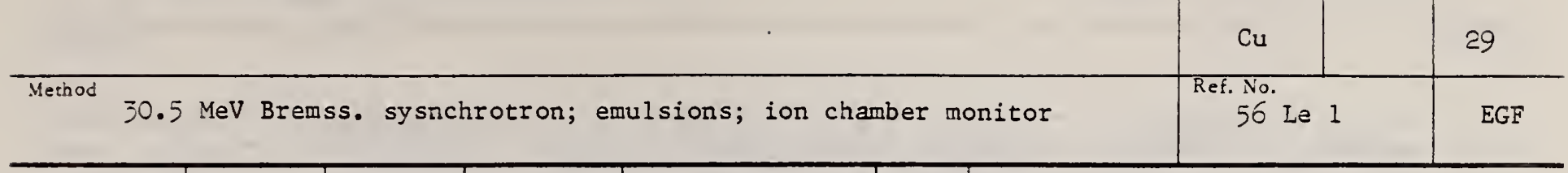

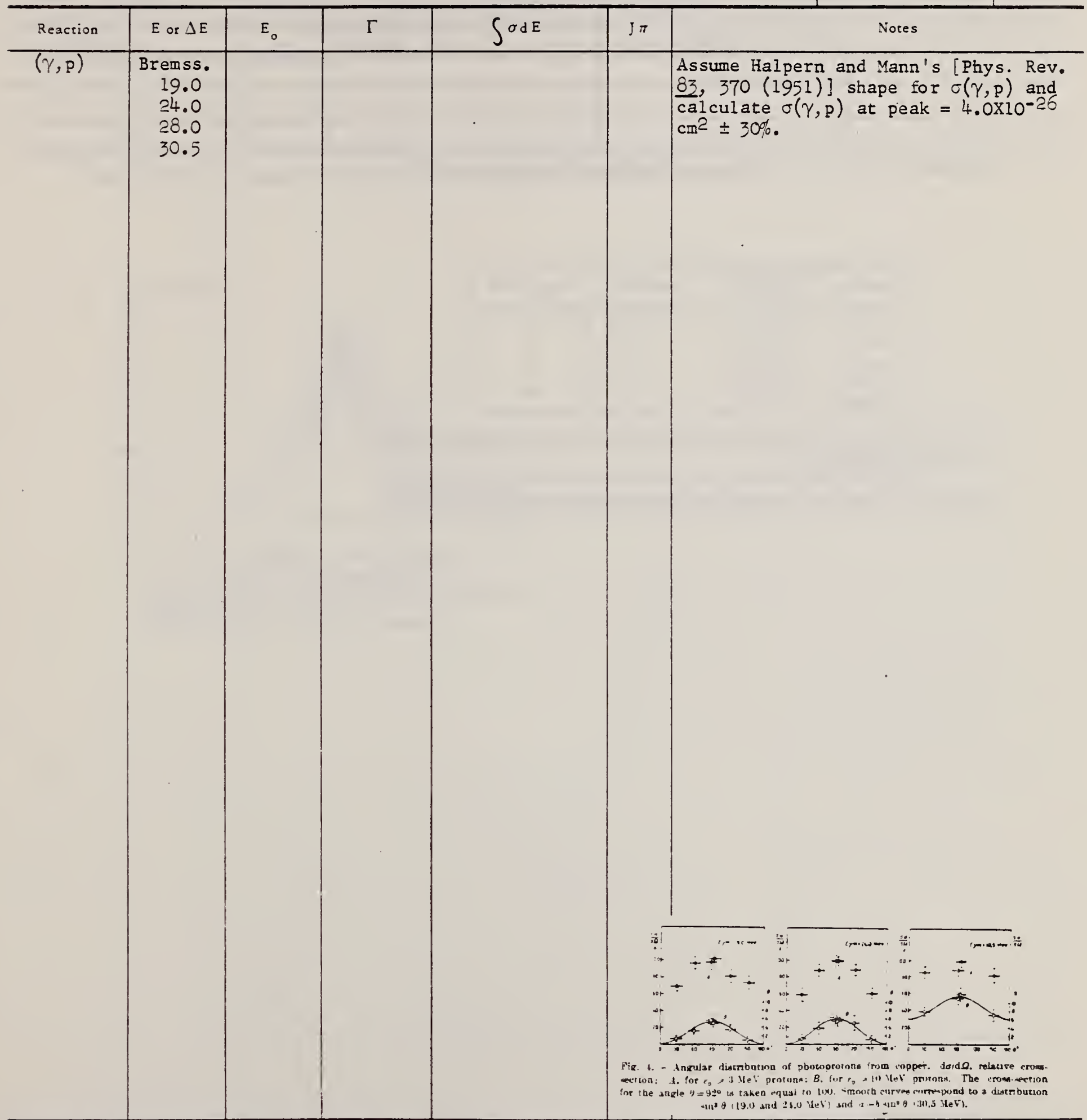




\begin{tabular}{|c|c|c|c|c|c|c|c|}
\hline METHOO & & & & & ${ }^{\circ}$ & $\begin{array}{l}\text { REF. NO. } \\
56 \text { Wa } 1\end{array}$ & $E G F$ \\
\hline \multirow[b]{2}{*}{ REACTION } & \multirow{2}{*}{ RESULT } & \multirow{2}{*}{$\begin{array}{c}\text { EXCITATION } \\
\text { ENERGY }\end{array}$} & \multicolumn{2}{|c|}{ SOURCE } & \multicolumn{2}{|c|}{ DETECTOR } & \multirow{2}{*}{ ANGLE } \\
\hline & & & TYPE & RANGE & TYPE & RANGE & \\
\hline$G, T$ & RLY & THR - 31 & $\mathrm{C}$ & 31 & $\mathrm{ACT}-\mathrm{I}$ & & $4 P I$ \\
\hline & & & & & & & \\
\hline & & & & & & & \\
\hline & & & & & & & \\
\hline
\end{tabular}

Detected activity of tritium. Yields are relative to ${ }^{63} \mathrm{Cu}(\gamma, n)$.

\begin{tabular}{|c|c|c|c|}
\hline Reaction & $\begin{array}{c}\text { Threshold energy } \\
\text { MeV }\end{array}$ & $\eta_{\text {oxp }} \times 105$ & $\eta_{\text {ruoor }} \times 10^{\text {s }}$ \\
\hline $\mathrm{AJ}$ & $18.2 \pm 0.2$ & $34 \pm 2$ & 31 \\
$\mathrm{CO}_{0}$ & $16.5 \pm 0.3$ & $7 \pm 2$ & 5 \\
${ }^{3} \mathrm{Cu}$ & $16.2 \pm 0.3$ \\
${ }^{65} \mathrm{Cu}$ & $15.1 \pm 0.3$ & $6 \pm 2$ & 4 \\
${ }^{107} \mathrm{Ag}$ & $13.9 \pm 0.6$ \\
${ }^{109} \mathrm{Ag}$ & $13.1 \pm 0.6$ & $6.5 \pm 1$ & 0.4 \\
\hline
\end{tabular}

The table shows the calculated yield ratios (according to statistical theory) as well as the measured rclative yield

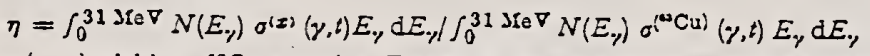

taking the $(\gamma, n)$ yield on ${ }^{63} \mathrm{Cu}$ as unity. The good agreement between the experimental 


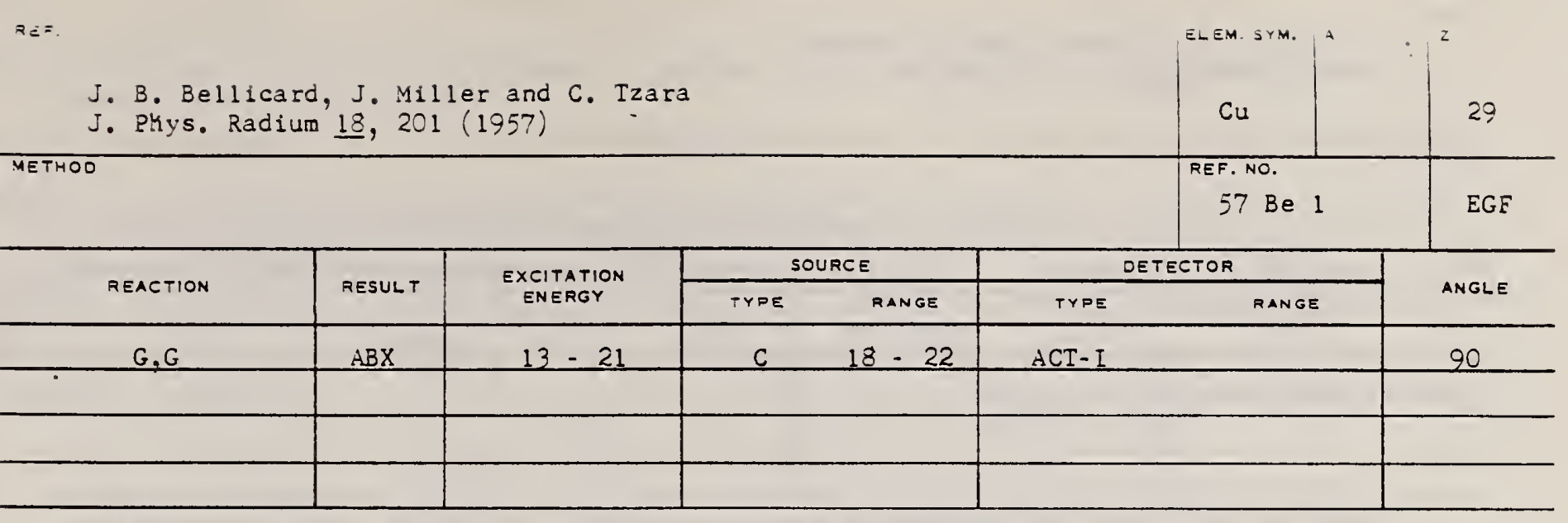

Used activity induced in $\mathrm{Cu}$ to detect photons scattered by $\mathrm{Cu}$.

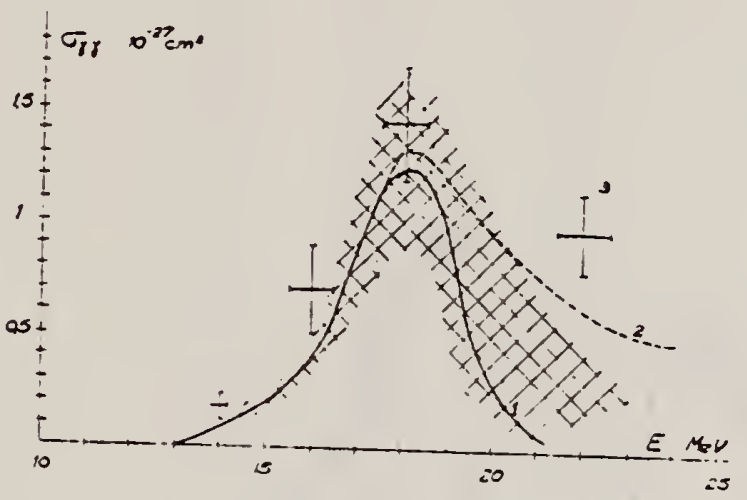

Fic. 3. - Courbe 1 : section efficace.

En grisé : zone d'imprécision.

Courbe $2:$ section enticace deduite de la relation do dispersion.

Points 3 : résultats de? Fuller et Hayvarcl. 
F. Bobard, G. Boulegue, and P. Chanson

Compt. Rend. 24h, 1761 (1957)

ELEM. SYM. A

\begin{tabular}{|c|c|c|c|c|c|c|c|}
\hline METHOD & & & & & & $\begin{array}{l}\text { REF. NO. } \\
57 \text { BO } 1\end{array}$ & EGF \\
\hline \multirow{2}{*}{ REACTION } & \multirow[b]{2}{*}{ RESULT } & \multirow{2}{*}{$\begin{array}{l}\text { EXCITATION } \\
\text { ENERGY }\end{array}$} & \multicolumn{2}{|c|}{ SOURCE } & \multicolumn{2}{|c|}{ DETECTOR } & \multirow{2}{*}{ ANGLE } \\
\hline & & & TYPE & RANGE & TYPE & RANGE & \\
\hline$G, A$ & SPC & $T H R-30$ & $\mathrm{C}$ & 31 & EMU-D & $5-15$ & DST \\
\hline & & & & & & & \\
\hline & & & & & & & \\
\hline
\end{tabular}

Yield per milligram per roentgen $\mathrm{Cu} 0.86$, Ni 0.99 , Al 1.15 for 30.5 MeVं bremsstrahlung.

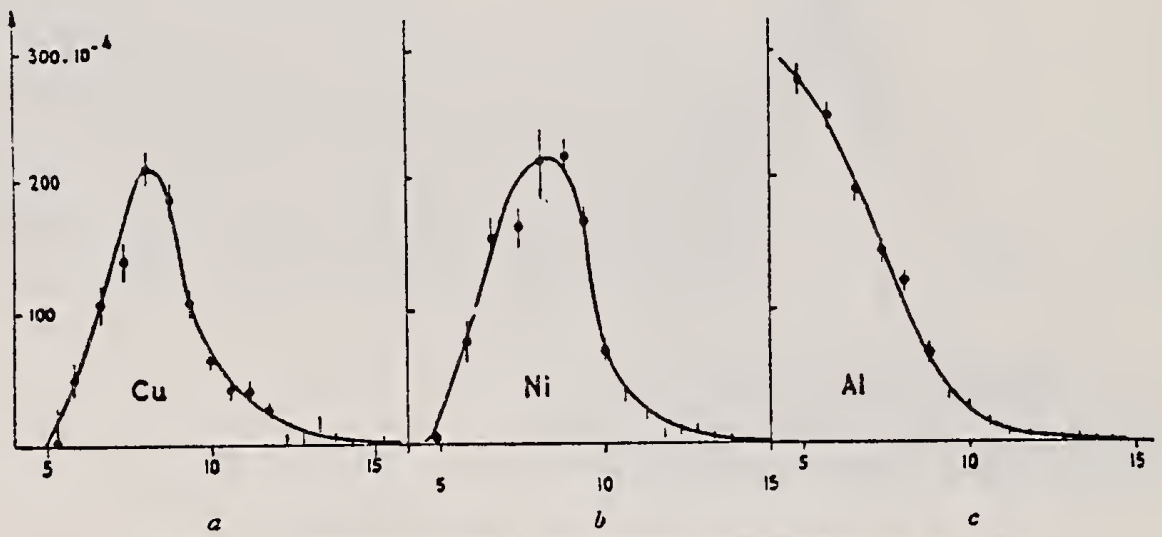

Fig. 2. - Nombre de particulcs $z /$ ing/stéladıan/Röntğen/iatervalle de : MeY. 
Ref. F. Ferrero, L. Gonel1a, R. Malvano, C. Tribuno, A.0. Hanson Nuovo Cimento 5,242 (1957)

\begin{tabular}{l|r|l}
\hline Method $31 \mathrm{MeV}$ betatron; neutron yield; angular distribution; threshold & Ref. No. & \\
detector, $\mathrm{Si}^{28}(\mathrm{n}, \mathrm{p}) \mathrm{Al}^{27}$ reaction. & $57 \mathrm{Fe} 1$ & EGF \\
\hline
\end{tabular}

\begin{tabular}{c|c|c|c|c|c|c}
\hline Reaction & $E$ or $\Delta E$ & $E_{0}$ & $\Gamma$ & $\int \sigma d E$ & $J \pi$ & Notes \\
\hline $\mathrm{Cu}(\gamma, \mathrm{n} !)$ & Bremss. & & & & & $\begin{array}{l}\text { Data not clear but probably normal- } \\
\text { i }\end{array}$
\end{tabular}

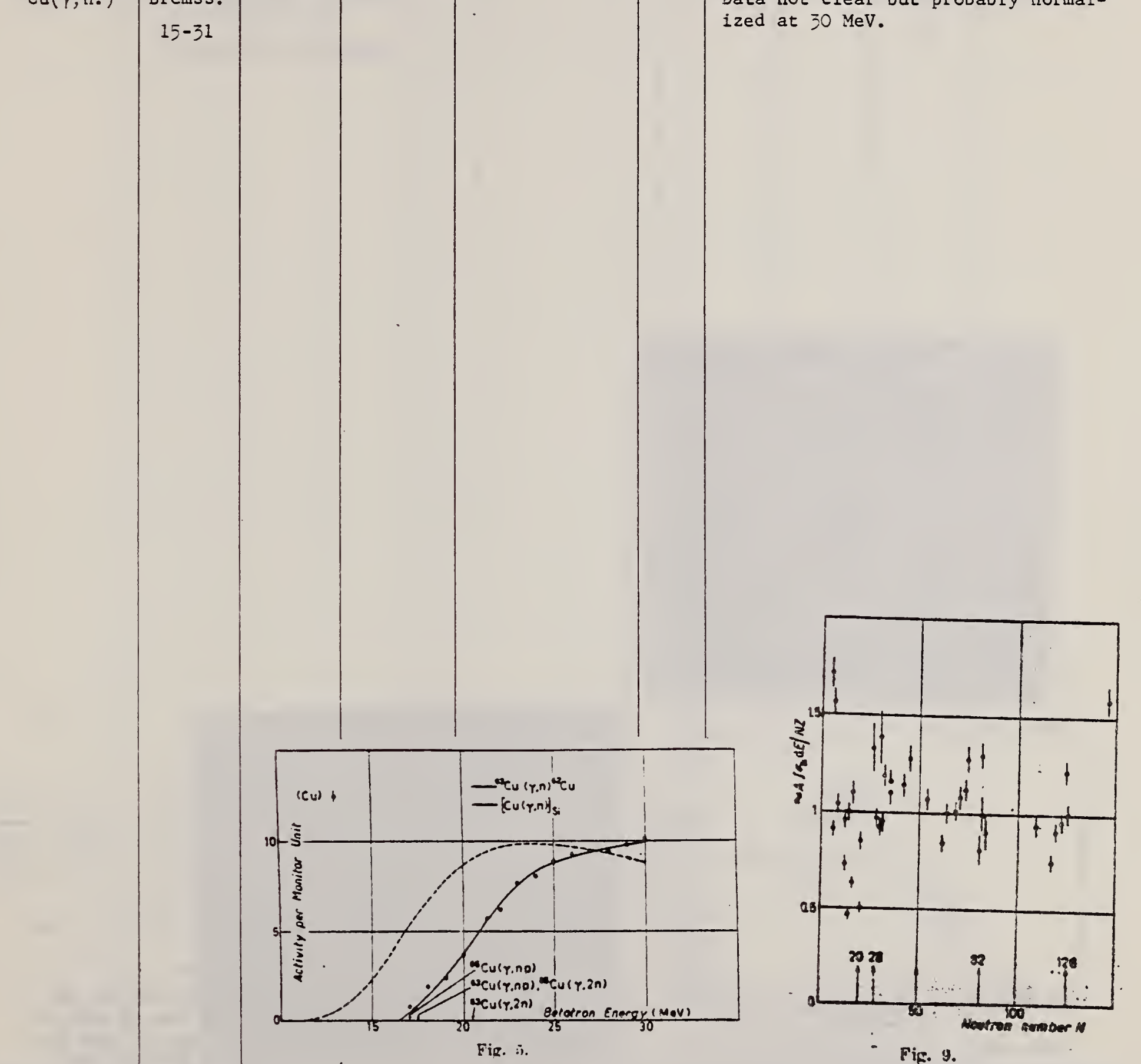

Fif. 9. 


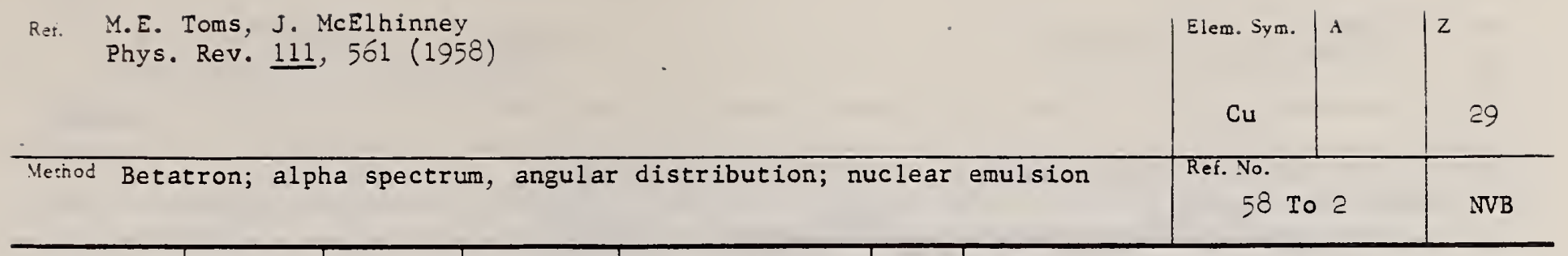

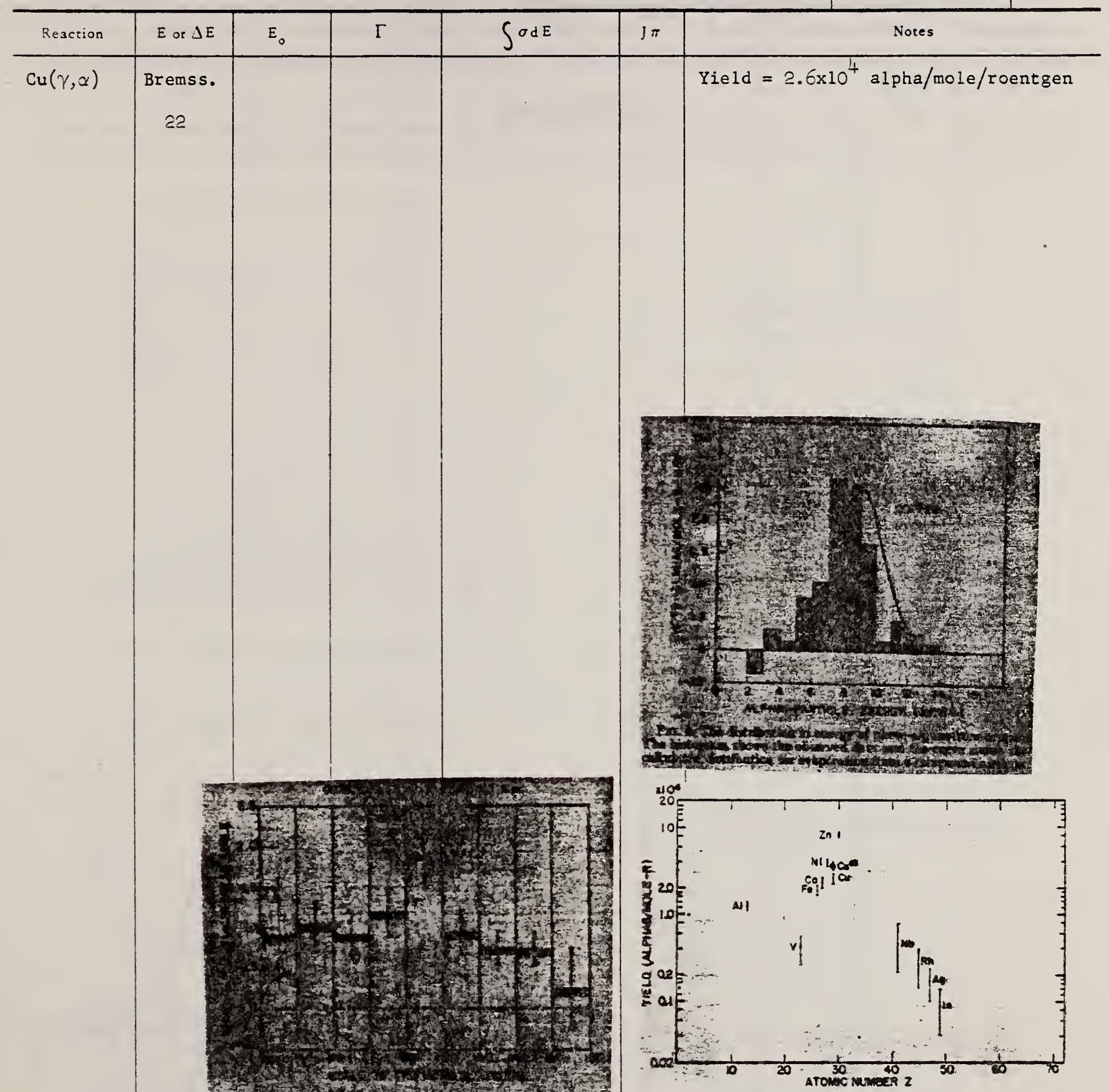

Fio. 8. Photo-alpha yields plotted against atomic aumiers for the exposeres of the survey. 
Ref. B.Ziegler

2. Physik 152, 566 (1958)

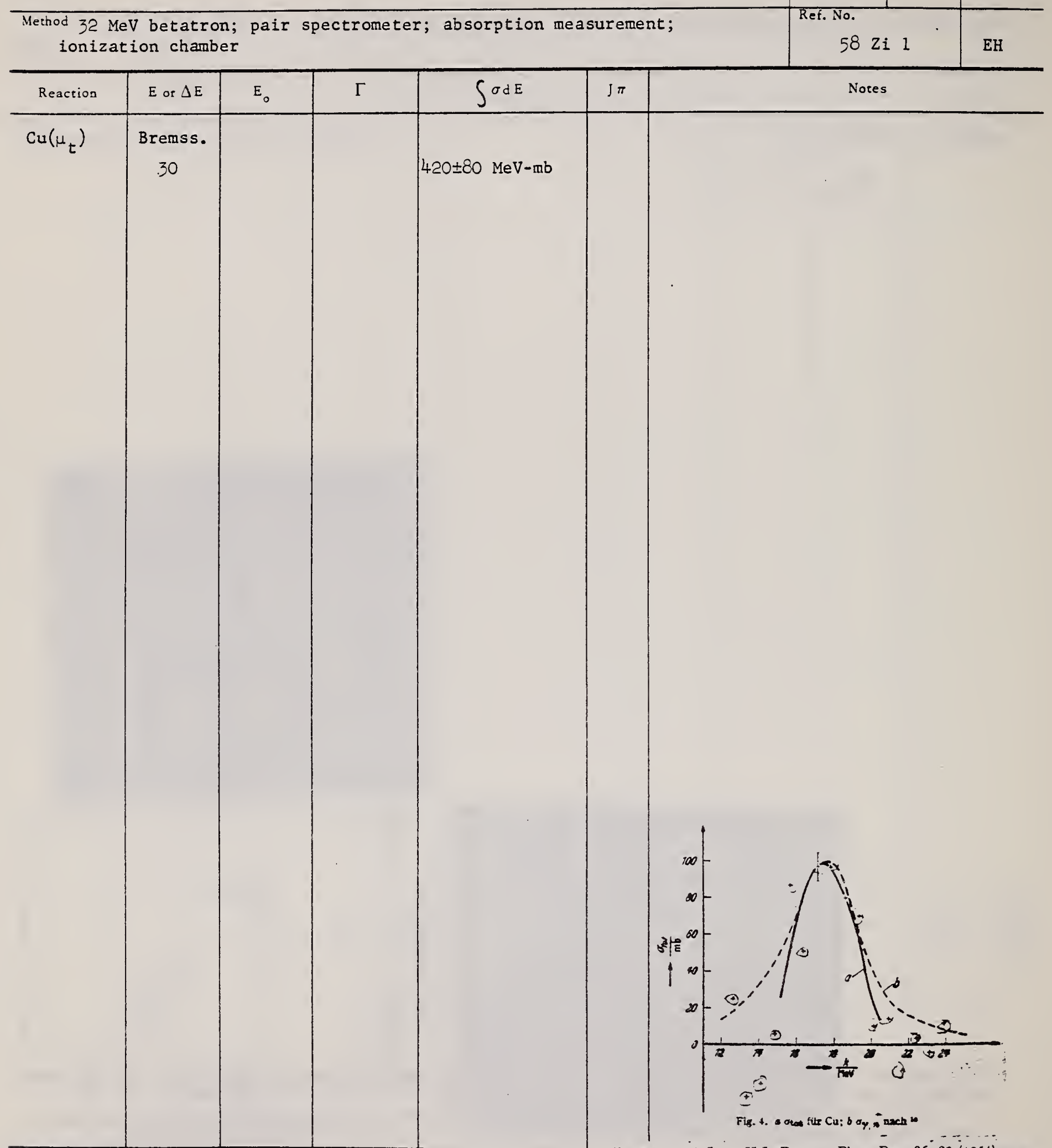


W. C. Barber and W. D. George

Phys. $R_{e}^{v} \cdot 116,1551$ (1959)

\begin{tabular}{|c|c|c|c|c|c|c|c|}
\hline \multirow{2}{*}{ REACTION } & \multirow{2}{*}{ RESULT } & \multirow{2}{*}{$\begin{array}{l}\text { EXCITATION } \\
\text { ENERGY }\end{array}$} & \multicolumn{2}{|c|}{ SOURCE } & \multicolumn{2}{|c|}{ DETECTOR } & \multirow{2}{*}{ ANGLE } \\
\hline & & & TYPE & RANGE & TYPE & RANGE & \\
\hline$E, N$ & $A B Y$ & THR - 36 & $D$ & $10-36$ & $B E 3-I$ & & $\angle P I$ \\
\hline & & & & & & & \\
\hline & & & & & & & \\
\hline
\end{tabular}

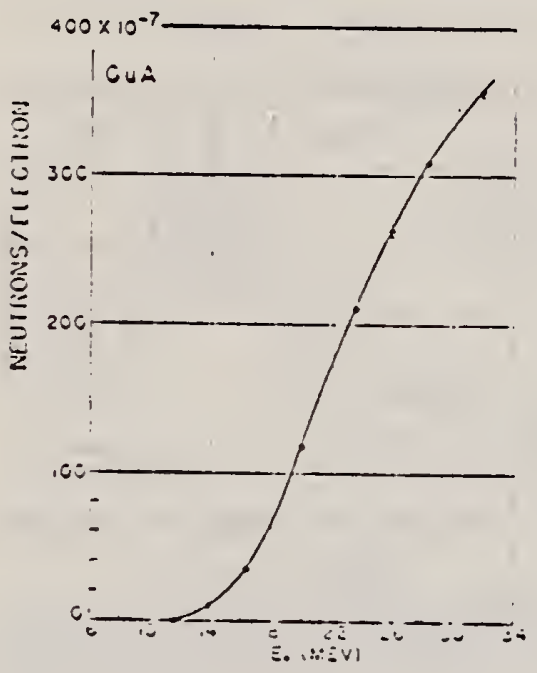

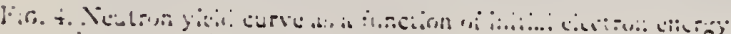

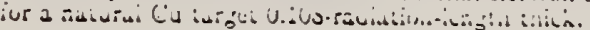
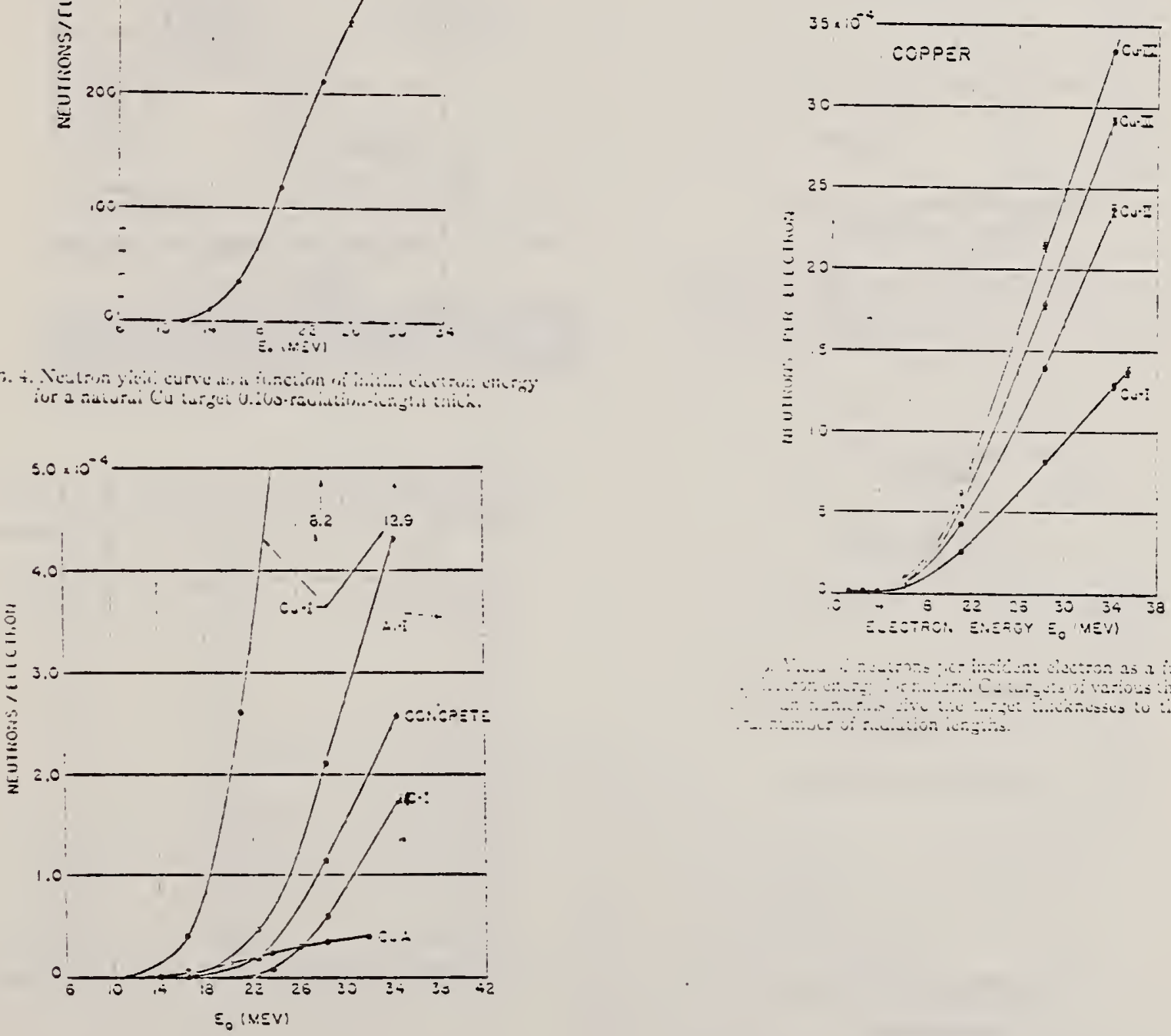

it 5 lin v a

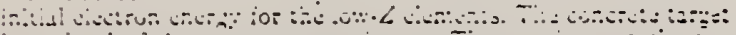

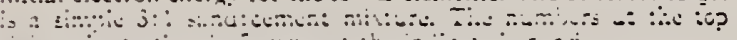

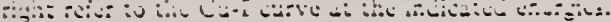




\begin{tabular}{|c|c|c|c|c|c|c|c|}
\hline \multirow{2}{*}{ REACTION } & \multirow{2}{*}{ RESULT } & \multirow{2}{*}{$\begin{array}{c}\text { EXCITATION } \\
\text { ENERGY }\end{array}$} & \multicolumn{2}{|c|}{ SOURCE } & \multicolumn{2}{|c|}{ DETECTOR } & \multirow{2}{*}{ ANGLE } \\
\hline & & & TYPE & FANGE & TYPE & RANGE & \\
\hline & & & & & & & \\
\hline & & & & & & & \\
\hline & & & & & & & \\
\hline & & & & & & & \\
\hline
\end{tabular}

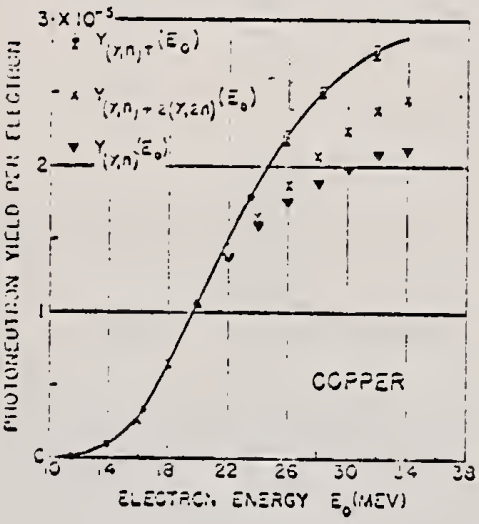

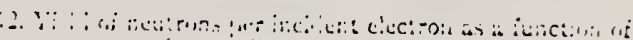

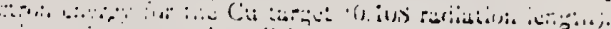

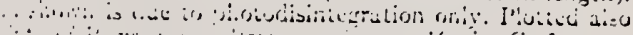

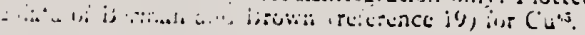

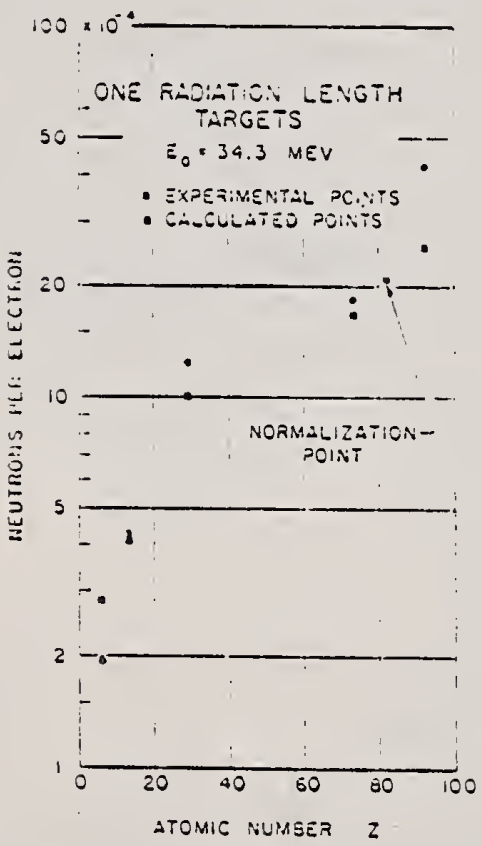

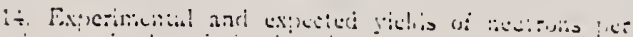

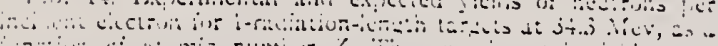

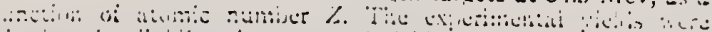

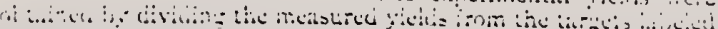

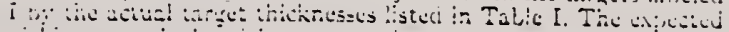

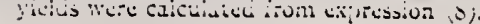

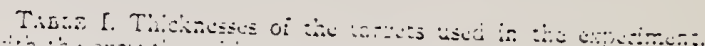

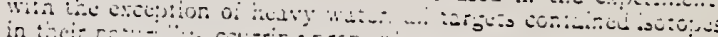

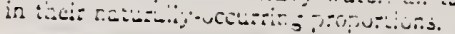
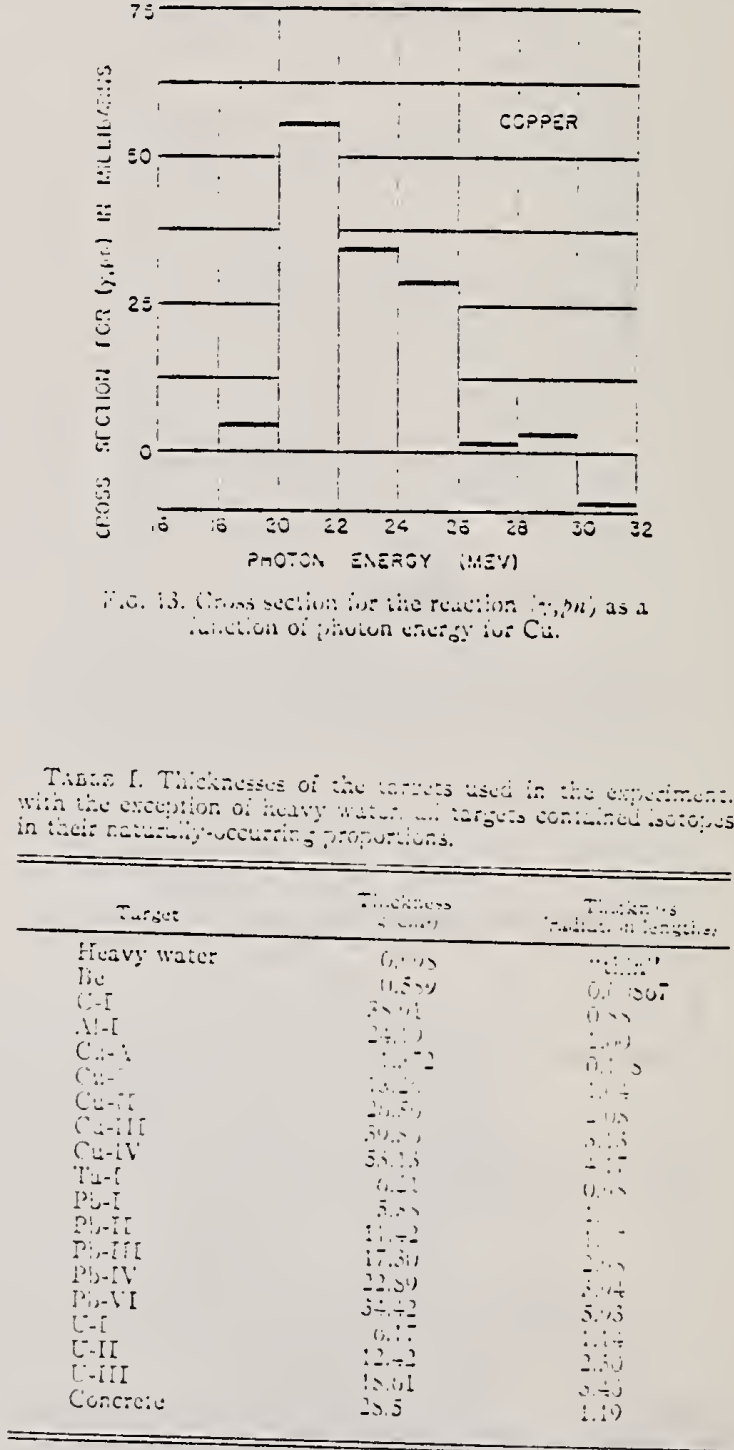

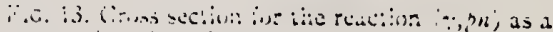

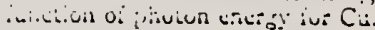


A. S. Penfold and E. L. Garwin

Phys. Rev. 116, 120 (1959)

\begin{tabular}{|c|c|c|c|c|c|c|c|}
\hline METHOD & . & & & & & $\begin{array}{l}\text { REF. NO. } \\
59 \text { Pe } 5\end{array}$ & JOC \\
\hline \multirow{2}{*}{ REACTION } & \multirow{2}{*}{ RESULT } & \multirow{2}{*}{$\begin{array}{l}\text { EXCITATION } \\
\text { ENERGY }\end{array}$} & & RCE & \multicolumn{2}{|c|}{ DETECTOR } & \multirow{2}{*}{ - ANGLE } \\
\hline & & & TYPE & RANGE & TYPE & RANGE & \\
\hline$G, G$ & $A B X$ & $19-61$ & $C$ & $19-61$ & $\mathrm{NAI}-\mathrm{D}$ & & 135 \\
\hline & & & . & & & & \\
\hline & & & & & & & \\
\hline
\end{tabular}

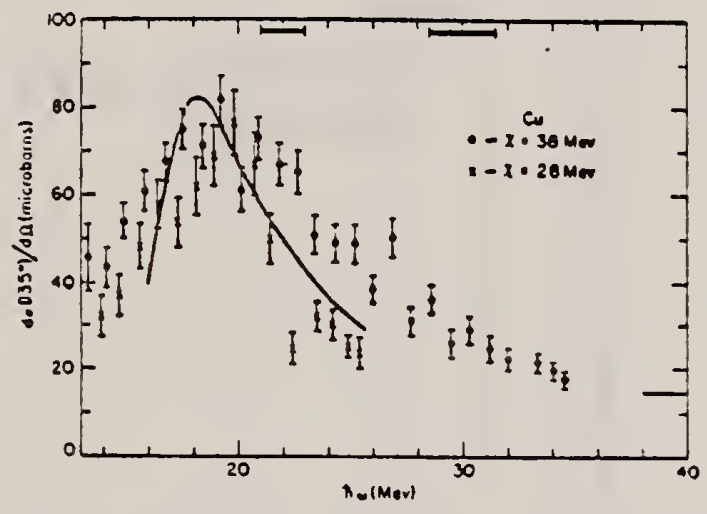

FIC. 4. The seattering cross section for $\mathrm{Cu}$ at $135^{\circ}$. The data is for irradiations at bremsstrablung energies of 28 and $38 \mathrm{Mev}$. The cross sections are for mixed elastic and inelastic scat.ering as defined by Eq. (15) in the text. The solid curve is a predicted cross section (see text for details). 
Ret. V.P. Chtznov

Zhur. Eksp. i Teoret. Fiz. 38, 809 (1960)

Soviet Phys. JETP 11, 587 (1960)

Ref. No.

Mechod $90 \mathrm{MeV}$ Bremsstrahlung; scintillator counter telescope.

$$
60 \mathrm{Ch} 1
$$

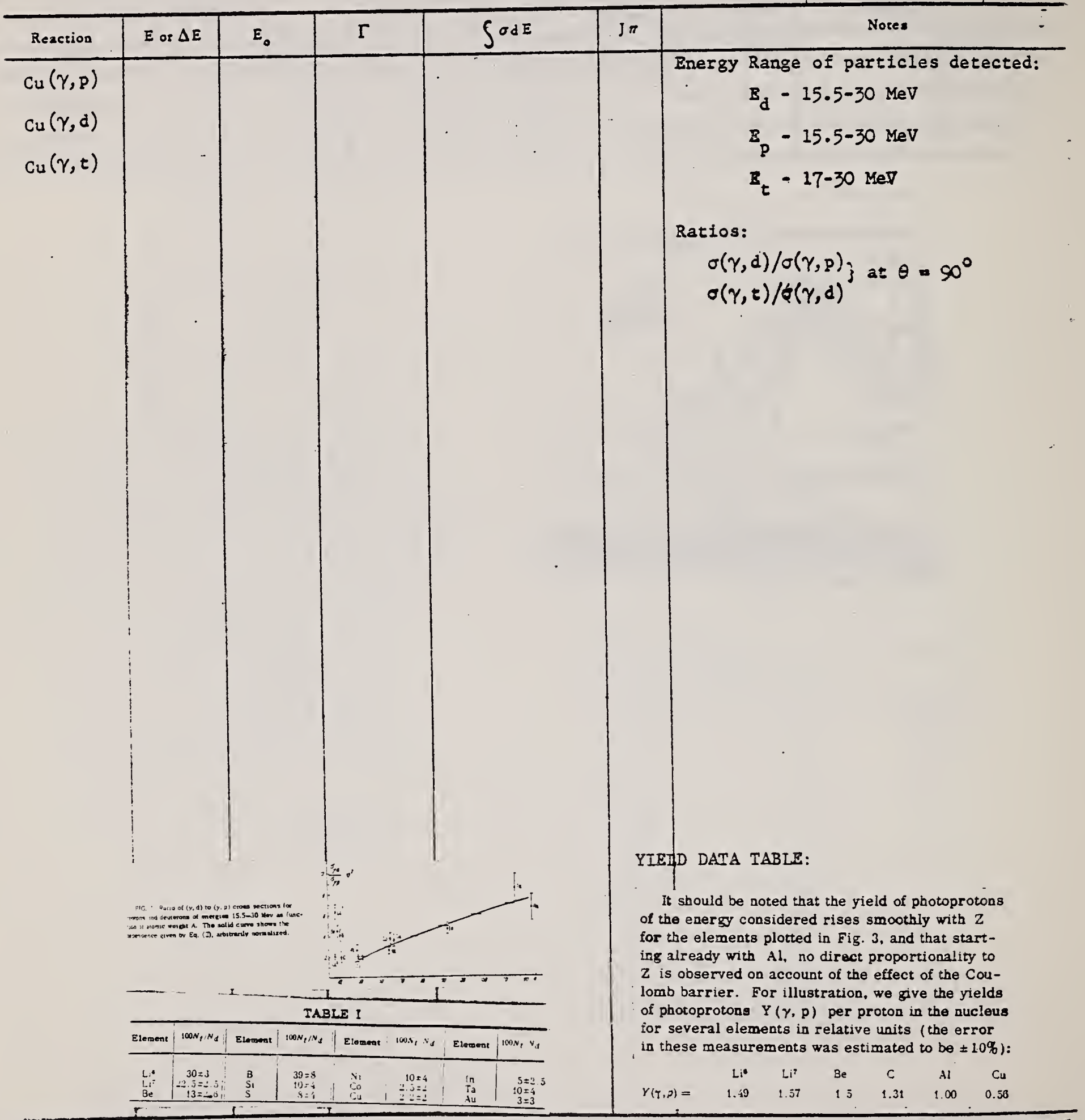


Method Betatron; photon difference; beam passes through one target surrounded by proton (proportional) counters, continues to second target surrounded by

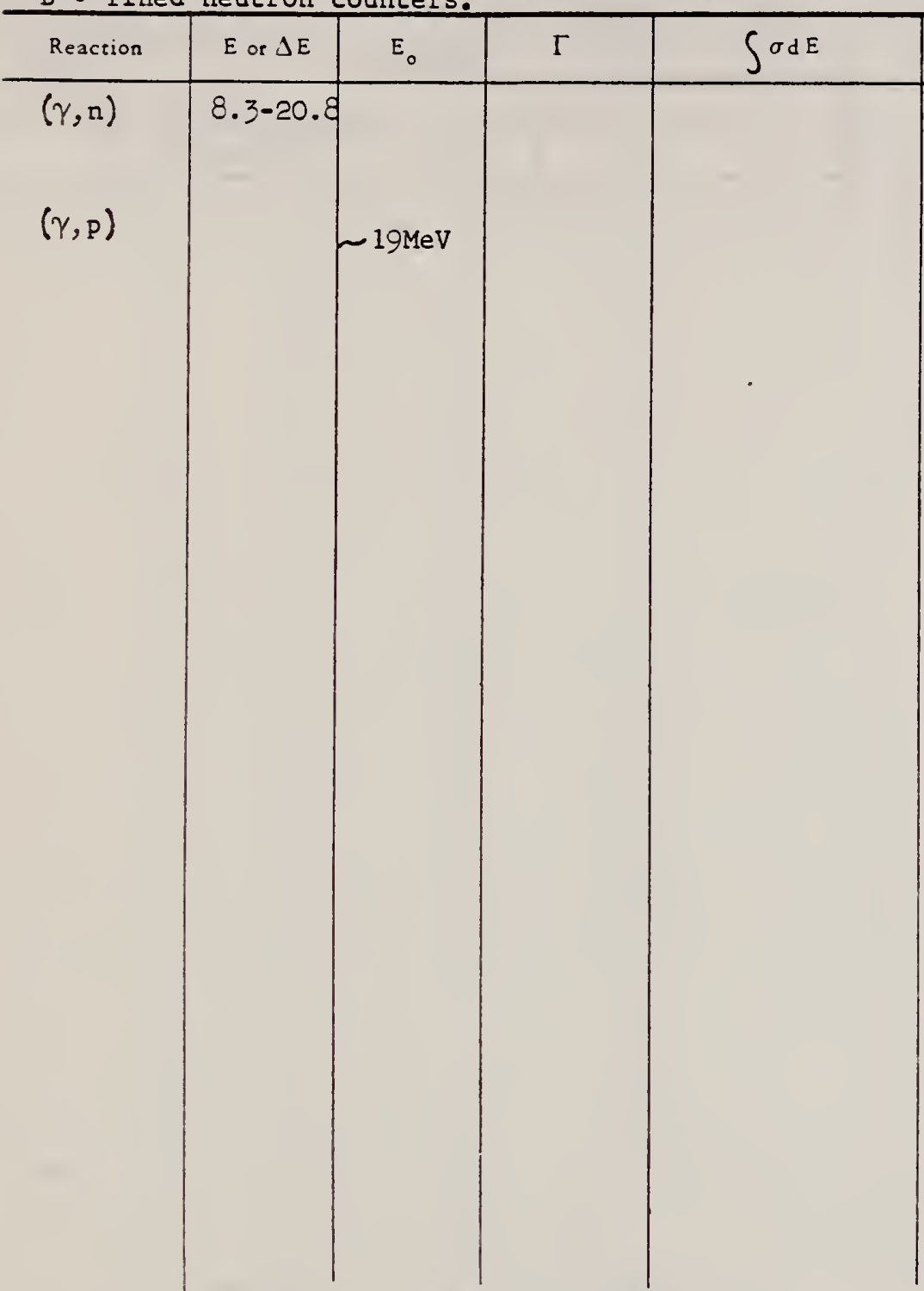

TAale II. Calculated ratios of photoproton to photoneutron cross sections.

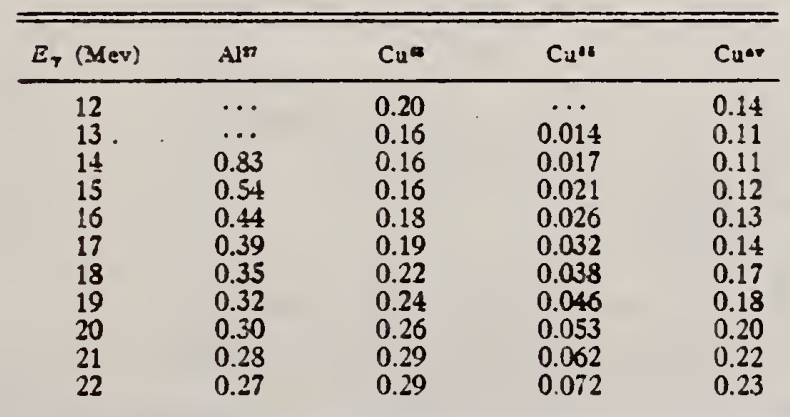

$$
\sigma_{\max }=23 \operatorname{mi}
$$

Order-of-magnitude agreement between measuring $\sigma(\gamma, \mathrm{p}) / \sigma(\gamma, \mathrm{n})$ [reciprocal of data in Figure 8$]$ and compound nucleus calculation $\left[\mathrm{Cu}_{\text {av }}\right.$ column in Table II].

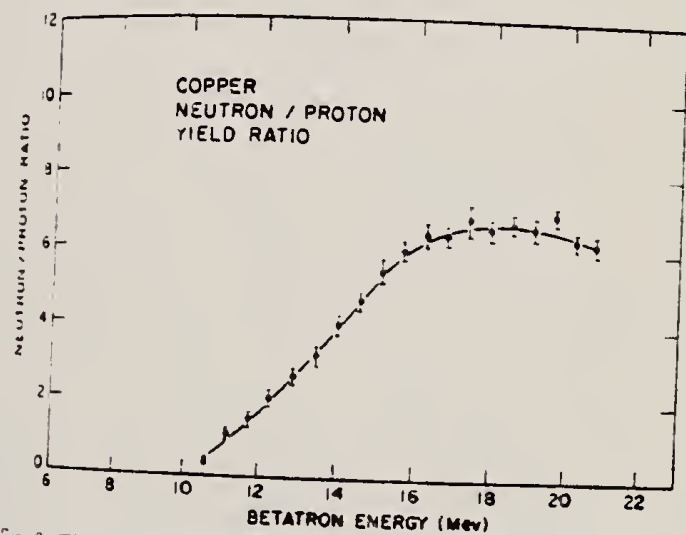

GG 8. The photoneutron to photoproton (Mev) as a finction of betatron energy.

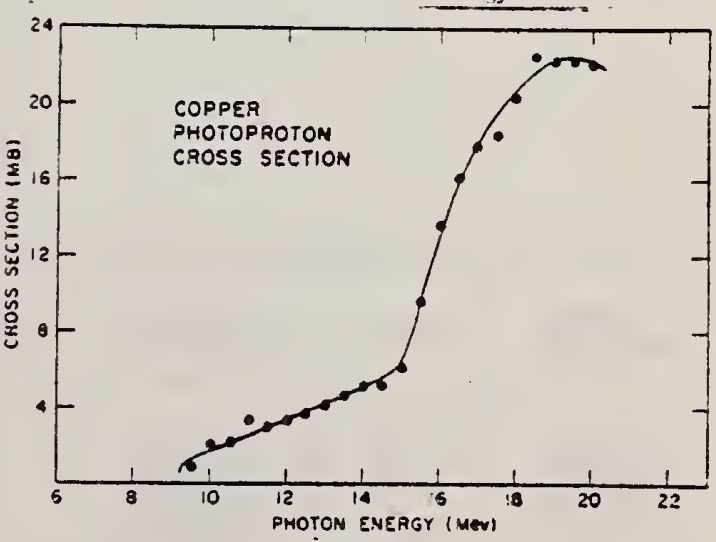

Fic. 10. The photoproton cross section for copper as a function of photon energy. 
A.P. Romar, E.D. Makhnovskii, V.P. Poddubnov

Dokl. Akad. Nauk SSSR 133, 797 (1960); Soviet Phys. Doklady 5, $824(1961)$

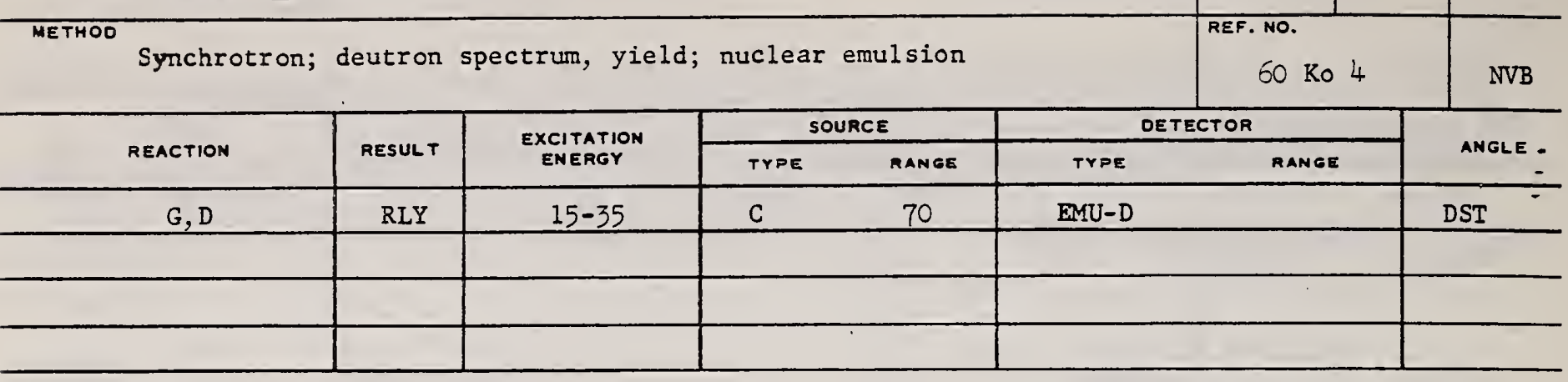

Relative yields:

$4<E_{d}<10 \mathrm{MeV}, \frac{Y(\gamma, d)}{Y(\gamma, p)}=0.07 \pm 0.04$
$3<E_{d}<10 \mathrm{MeV}, \frac{Y(\gamma, d)}{Y(\gamma, p)} \geq 0.08 \pm 0.04$

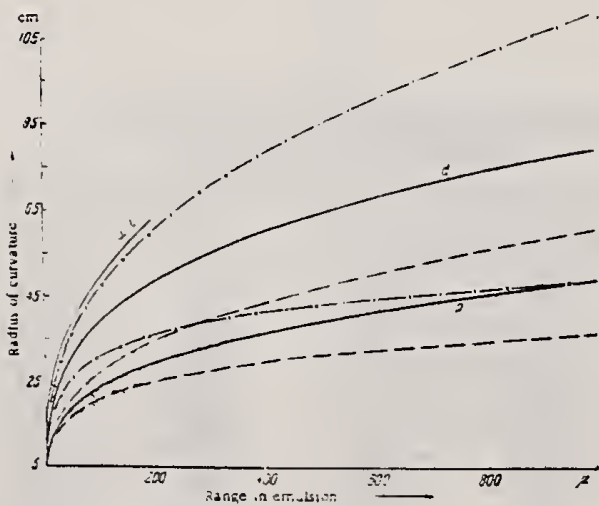

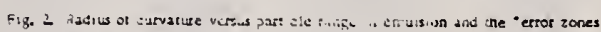

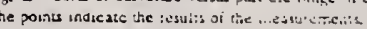

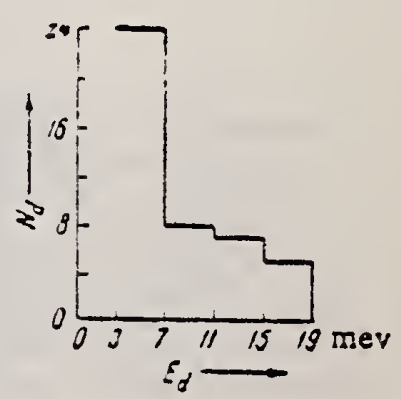

Fig. 3. Photodcuteron energy distributior. 
Ref. L.A. Kul'chitskii, V. Presperin

Zhur. Eksp. i Teoret. Fiz. 39, 1001 (1960)

Soviet Bhys. JETP 12, 696 (1961)

\begin{tabular}{l|l} 
Elem. Sym. & A \\
Cu &
\end{tabular}

Method
$90 \mathrm{MeV}$ Synchr.; proton recoil counter telescropes

$60 \mathrm{Ku} 2$

\begin{tabular}{c|c|c|c|c|c|c}
\hline Reaction & $E$ or $\Delta E$ & $E_{0}$ & $\Gamma$ & $S \sigma d E$ & $J \pi$ & Notes \\
\hline$(\gamma, n)$ & $\begin{array}{l}\text { Bremss.; } \\
\text { B =9omeV }\end{array}$ & & & $\begin{array}{l}\text { Relative yields in table are per } \\
\text { nuclear neutron. }\end{array}$
\end{tabular}
$E_{\text {max }}=90 \mathrm{MeV}$ nuclear neutron.

\begin{tabular}{l|l|l|l}
\hline Element & $\begin{array}{c}\text { Relative } \\
\text { neutron yield }\end{array}$ & Element & $\begin{array}{c}\text { Relative } \\
\text { neutron yield }\end{array}$ \\
\hline $\mathrm{Li}$ & $1.00 \pm 0.05$ & $\mathrm{Cu}$ & $0.37=0.02$ \\
$\mathrm{Be}$ & $1.22 \pm 0.09$ & $\mathrm{Cd}$ & $0.35=0.02$ \\
$\mathrm{O}$ & $0.74=0.05$ & $\mathrm{I}$ & $0.39=0.02$ \\
$\mathrm{Al}$ & $0.49 \pm 0.03$ & $\mathrm{Bi}$ & $0.41=0.03$ \\
$\mathrm{Ca}$ & $0.33 \pm 0.02$ & & \\
\hline
\end{tabular}


Rei.

B. Retbel, A.I. Mem

Phye. Rev. 118, 701 (1960)

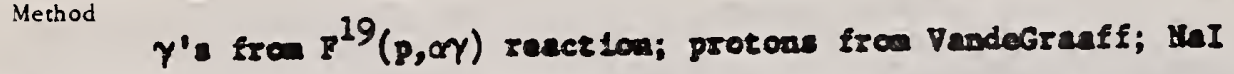

Ref. No.

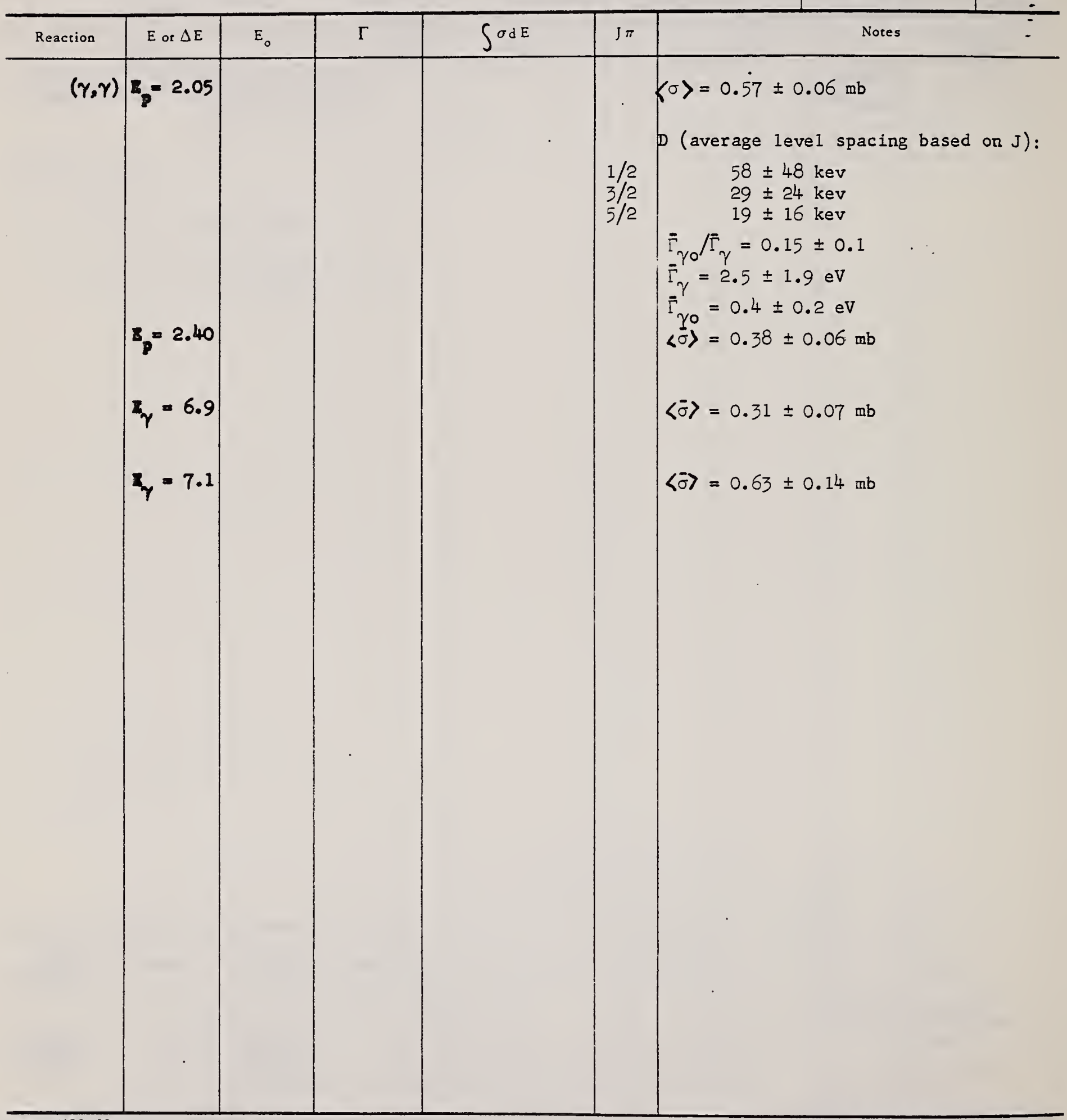


Rei. 8.C. Stein, A.C. Odian, A. Wattenberg, R. Ẅeinstein

Pthys. Rev. 119, 348 (1960)

\begin{tabular}{ll|l}
\hline Mechod $320 \mathrm{MeV}$ synchrotron; proton telescope; neutron counter & Re
\end{tabular}

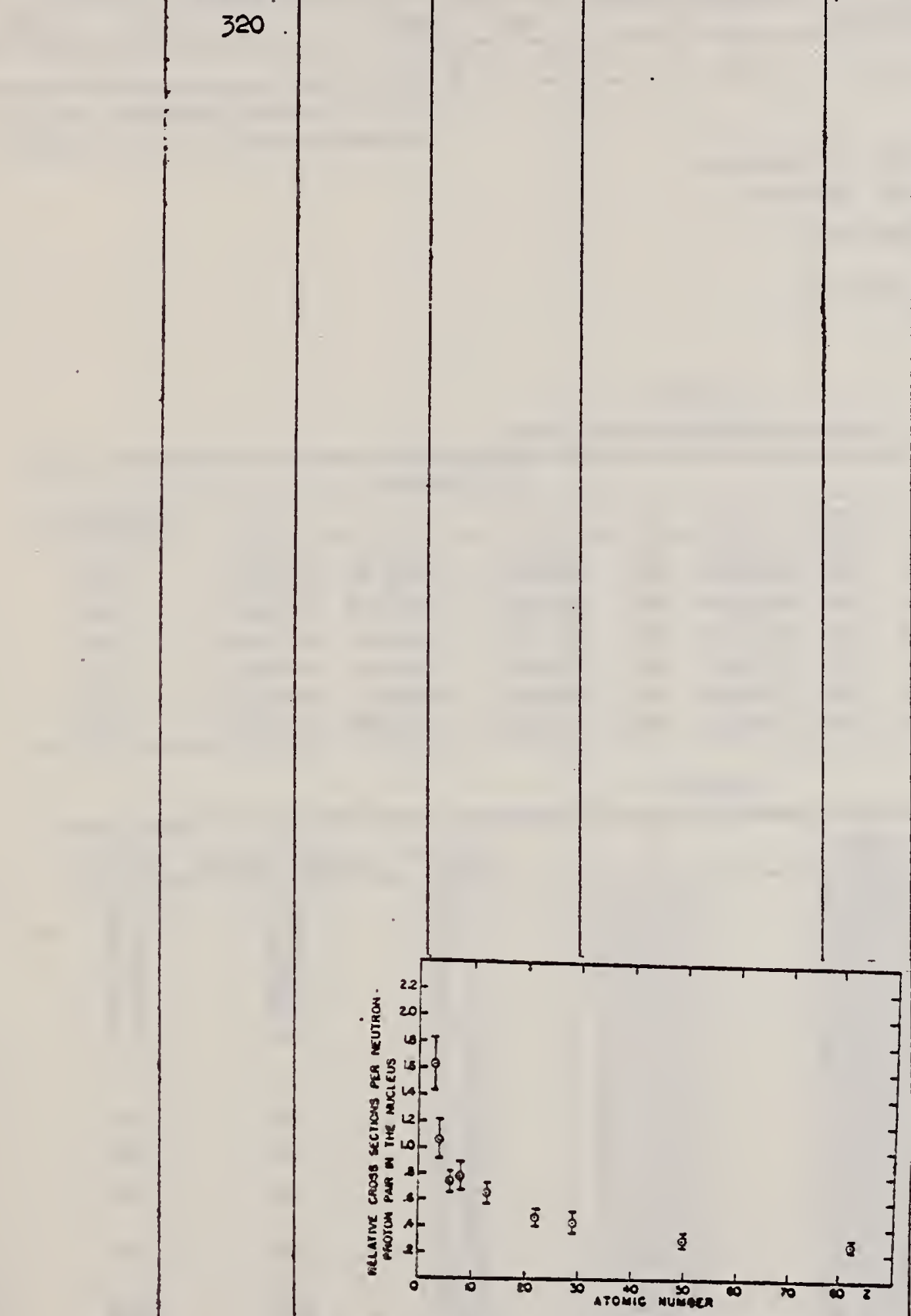

Fic. 2. Relative cross sections per neutron-proton pair in the nucleus versus atomic number. The crosson-proton pair in the of interest is divided by the cross section for deuterium and by the iactor $N Z / A$.

$$
\left.\sigma_{\mathrm{H}^{2}}=63 \mu \mathrm{b}\right]
$$

Mean photon energy - $262 \mathrm{MeV}$

Proton counter at $76^{\circ}$

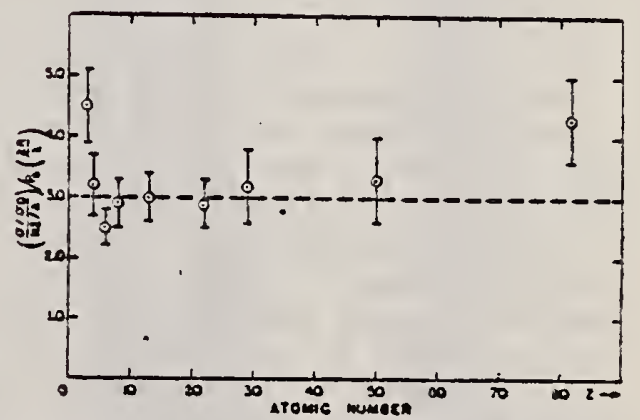

Fic. 3. The relative cross sections per neutron-proton pair corrected for the probability of excape is plotted against atomic number. The probability of escape facior is calculated using $r_{0}=1.30 \times 10^{-14} \mathrm{~cm}$ and $\lambda=3.6 \times 10^{-12} \mathrm{~cm}$. Tire pmissisitity of escape fictor is given in emression (1). The data shown are those of Fig. 2 divided by $P(2 R / \lambda)$. 
$\therefore \quad$ S.Ka: $=$, K.G. McNeil1

ㄱ․ : ?nys. 32, $1158(1961)$

$4=74=$ jesatron; iast neutron yield; angular distribution; $A l$ and $S i$ threshold detectors; ion chamber

$61 \mathrm{Ba} 2$

\begin{tabular}{|c|c|c|c|c|c|c|c|}
\hline \multirow{2}{*}{ REACTION } & \multirow{2}{*}{ RESUL T } & \multirow{2}{*}{$\begin{array}{l}\text { EXCITATION } \\
\text { EMEROY }\end{array}$} & \multicolumn{2}{|c|}{ SOURCE } & \multicolumn{2}{|c|}{ DETECTOR } & \multirow{2}{*}{ AMGCE } \\
\hline & & & Tree & RANGE & TrPe & RANGE* * & \\
\hline$G, X N$ & $A B Y$ & THR-22 & C & 22 & THR-I & $3-\div$ & DST \\
\hline$G, X \mathrm{XV}$ & $A B Y$ & THR-22 & C & 22 & THR - I & $5-+$ & DST \\
\hline
\end{tabular}

In Tables 2 and 4:

$$
\begin{aligned}
& \bar{\sigma}=\begin{array}{l}
\text { average cross section of detector } \\
\text { weighted with neutron spectrum }
\end{array} \\
& \Phi=\text { neutrons/100 roentgen/mole } \\
& W(\theta)=a_{0} \sum_{n=1}^{\infty}\left[1+A_{n} P_{n}(\cos \theta)\right]
\end{aligned}
$$

\begin{tabular}{|c|c|c|c|c|c|c|c|c|c|c|c|}
\hline \multirow[b]{2}{*}{ Element } & \multicolumn{4}{|c|}{$\operatorname{Al}(x, y)$ reaction } & \multicolumn{7}{|c|}{ Al $(n, p)$ reactions } \\
\hline & $30^{\circ}$ & $90^{\circ}$ & $150^{\circ}$ & $a_{0}$ & $30^{\circ}$ & $60^{\circ}$ & $90^{\circ}$ & $\theta_{0}$ & $e_{1}$ & $c_{2}$ & $(\bar{\sigma} \phi)^{*} \times 0^{\circ}$ \\
\hline Bismuth & $\begin{array}{l}399 \\
478\end{array}$ & $\begin{array}{l}567 \pm 130 \\
423 \pm 130\end{array}$ & $\begin{array}{l}620 \\
611\end{array}$ & $\begin{array}{l}541 \pm 85 \\
4 S t \pm 85\end{array}$ & $\begin{array}{l}3632 \\
2562\end{array}$ & $\begin{array}{l}5139 \pm 290 \\
5353 \pm 290\end{array}$ & $\begin{array}{l}3168 \\
2955\end{array}$ & $\begin{array}{l}4360=185 \\
4144 \pm 185\end{array}$ & $\begin{array}{r}0.06 \pm 0.06 \\
-0.05 \pm 0.06\end{array}$ & $\begin{array}{l}-0.35 \pm 0.1 \\
-0.53 \pm 0.1\end{array}$ & $\begin{array}{l}17.76 \\
16.87\end{array}$ \\
\hline Lead & 426 & $312 \pm 120$ & 725 & $42 y \pm 77$ & 3123 & $5754 \pm 260$ & 3154 & $4591 \pm 166$ & $-0.004 \pm 0.05$ & $-0.51 \pm 0.07$ & 18.68 \\
\hline Tantalum & 378 & $367 \pm 100$ & coss & $441 \pm 122$ & 2757 & $3024 \pm 425$ & 2088 & $2757 \pm 275$ & $0.14 \pm 0.14$ & $-0.19 \pm 0.17$ & 11.22 \\
\hline Lanthanums & 208 & $222 \pm 110$ & 330 & $243=70$ & 2139 & $3371 \pm 250$ & 1891 & $2768 \pm 160$ & $0.05 \pm 0.07$ & $-0.43 \pm 0.10$ & 11.27 \\
\hline Arsenic & 77 & $300 \pm 50$ & 108 & $97 \pm 32$ & 788 & $937 \pm 115$ & 764 & $865 \pm 74$ & $0.02 \pm 0.11$ & $-0.16 \pm 0.14$ & 3.52 \\
\hline Copper & 13 & $65 \pm 30$ & 70 & $55 \pm 20$ & 710 & $748 \pm 70$ & 569 & $700 \pm 45$ & $0.11=0.08$ & $-0.14 \neq 0.11$ & 2.85 \\
\hline
\end{tabular}

TABLE II

Normalized yields for aluminum detectors

\begin{tabular}{|c|c|c|c|c|c|c|}
\hline $\begin{array}{l}! \\
\text { Eiement }\end{array}$ & $\begin{array}{l}11 \\
a_{0}\end{array}$ & $\begin{array}{l}I 11 \\
a_{1}\end{array}$ & $\begin{array}{l}\text { IV } \\
a_{2}\end{array}$ & $\begin{array}{c}\mathrm{V} \\
(\bar{\sigma} \phi) \times 10^{\circ}\end{array}$ & $\begin{array}{c}\text { VI } \\
A_{\text {min }}(22 \mathrm{Mev}) \times 10^{\circ}\end{array}$ & 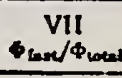 \\
\hline $\begin{array}{l}\text { Vanadium } \\
\text { Chronium } \\
\text { Manganese } \\
\text { Iron } \\
\text { Cobalt } \\
\text { Nickel } \\
\text { Copoer } \\
\text { Arsenic } \\
\text { Rubidium } \\
\text { Strontium } \\
\text { Yttrium } \\
\text { Silver } \\
\text { Cadmium } \\
\text { lodine } \\
\text { Barium } \\
\text { Lanthanum } \\
\text { Cerium } \\
\text { Dysprosium } \\
\text { Tantalum } \\
\text { Tungsten } \\
\text { Mercury. } \\
\text { Lead } \\
\text { Bismuth } \\
\text { Thoriun } \\
\text { Uranium }\end{array}$ & 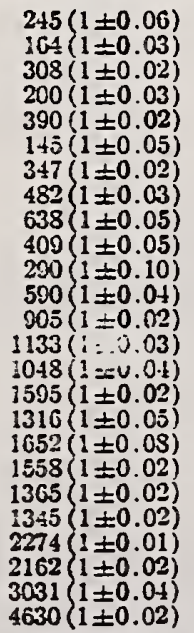 & $\begin{array}{r}0.01 \pm 0.08 \\
0.04 \pm 0.04 \\
0.07 \pm 0.03 \\
0.05 \pm 0.04 \\
0.08 \pm 0.03 \\
0.07 \pm 0.07 \\
0.05 \pm 0.03 \\
0.11 \pm 0.04 \\
0.13 \pm 0.06 \\
0.10 \pm 0.06 \\
0.08 \pm 0.12 \\
0.10 \pm 0.06 \\
0.02 \pm 0.02 \\
0.04 \pm 0.04 \\
0.10 \pm 0.06 \\
0.02 \pm 0.03 \\
0.05 \pm 0.06 \\
0.04 \pm 0.10 \\
0.04 \pm 0.03 \\
-0.07 \pm 0.03 \\
0.04 \pm 0.03 \\
0.02 \pm 0.02 \\
0.05 \pm 0.03 \\
0.06 \pm 0.05 \\
0.05 \pm 0.03\end{array}$ & $\begin{array}{l}-0.00 \pm 0.10 \\
-0.05 \pm 0.05 \\
-0.09 \pm 0.04 \\
-0.17 \pm 0.03 \\
-0.22 \pm 0.04 \\
-0.23 \pm 0.09 \\
-0.29 \pm 0.04 \\
-0.24 \pm 0.05 \\
-0.14 \pm 0.08 \\
-0.17 \pm 0.08 \\
-0.12 \pm 0.15 \\
-0.22 \pm 0.08 \\
-0.26 \pm 0.03 \\
-0.29 \pm 0.05 \\
-0.38 \pm 0.08 \\
-0.42 \pm 0.04 \\
-0.39 \pm 0.08 \\
-0.34 \pm 0.13 \\
-0.22 \pm 0.04 \\
-0.24=0.04 \\
-0.31=0.04 \\
-0.42 \pm 0.03 \\
-0.45 \pm 0.04 \\
-0.32 \pm 0.07 \\
-0.17 \pm 0.04\end{array}$ & $\begin{array}{r}6.05 \\
4.05 \\
7.61 \\
4.94 \\
9.63 \\
3.58 \\
8.57 \\
11.91 \\
15.76 \\
10.10 \\
7.16 \\
14.57 \\
22.35 \\
27.99 \\
25.89 \\
39.40 \\
32.50 \\
40.80 \\
38.48 \\
33.71 \\
33.22 \\
56.17 \\
53.40 \\
74.87 \\
114.36\end{array}$ & $\begin{array}{l}0.21 \\
0.17 \\
0.25 \\
0.18 \\
0.26 \\
0.12 \\
0.30 \\
0.33 \\
\\
0.87 \\
1.42 \\
1.04 \\
\\
2.30 \\
2.78 \\
3.36\end{array}$ & $\begin{array}{l}0.12 \\
0.10 \\
0.12 \\
0.11 \\
0.15 \\
0.12 \\
0.12 \\
0.15 \\
\\
0.07 \\
0.08 \\
0.15 \\
0.08 \\
0.08 \\
0.00\end{array}$ \\
\hline
\end{tabular}

(is) $=4.07 \times 10 \%$ mulibarn-neutron.

TABLE IV

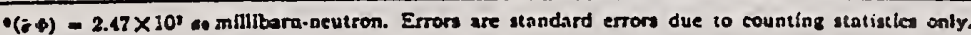


Ref. B. Forkman

Nuclear Phys. 23, 269 (1961)

Method $30 \mathrm{MeV}$ electron synchrotron; emulsions; magnetic analysis

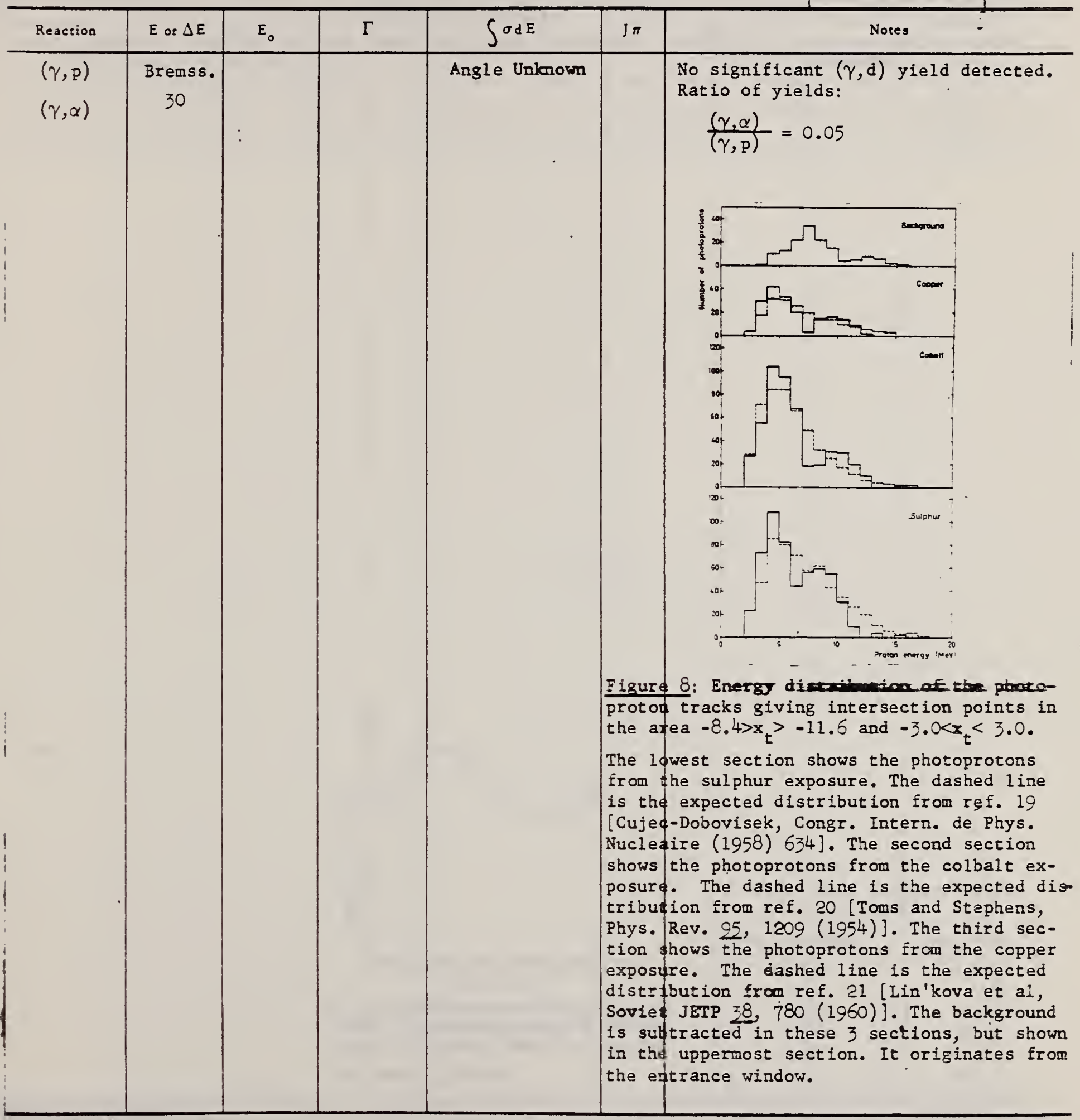


Ref. G.P. Ho, E.L. Iloff

Nuclear Phys. 27, 234 (1961)

\begin{tabular}{c|c} 
Elem. Sym. & A \\
Cu &
\end{tabular}

Ref. No.

61 Ho 1

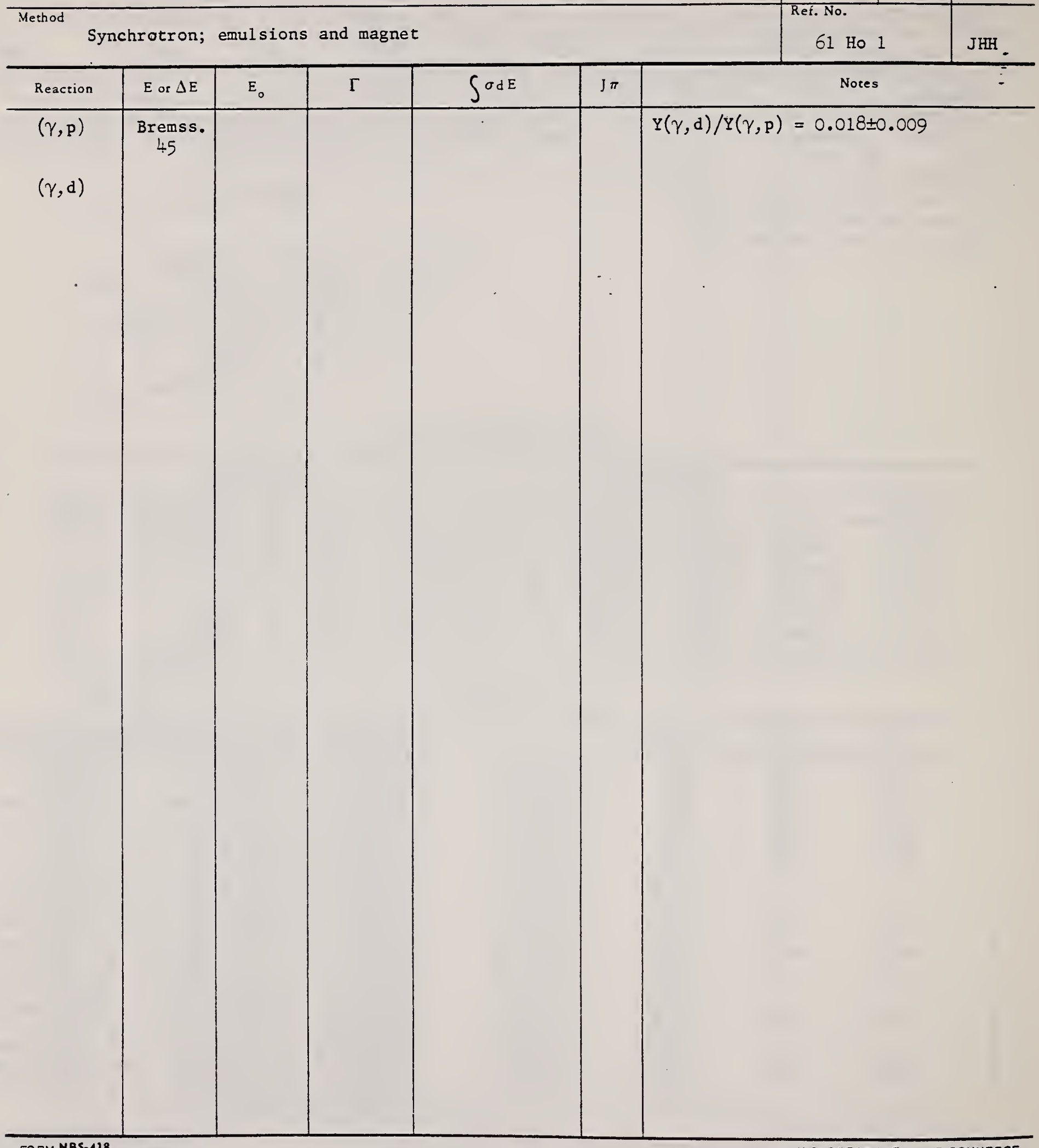


MEF.

M. Masuda

J. Phys. Soc. 16, 1801 (1961)

Betatron; proton angular distribution; ZnS scintillator

REF. NO. SOURCE

$61 \mathrm{Ma} 2$

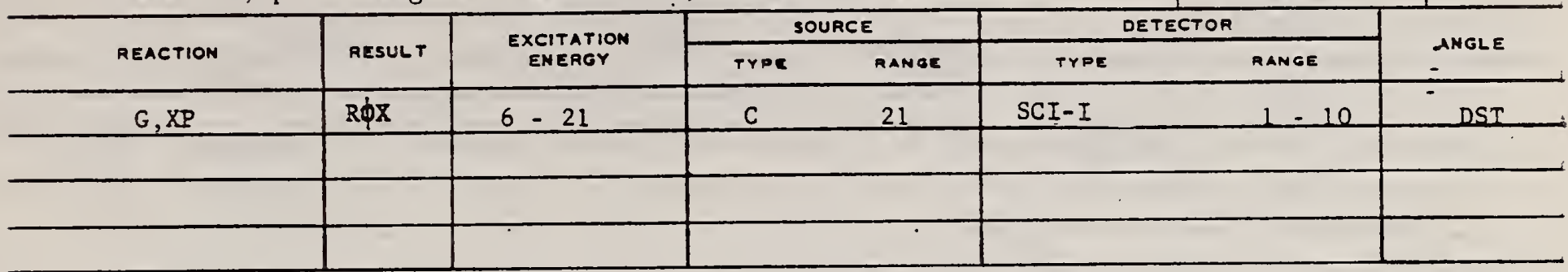

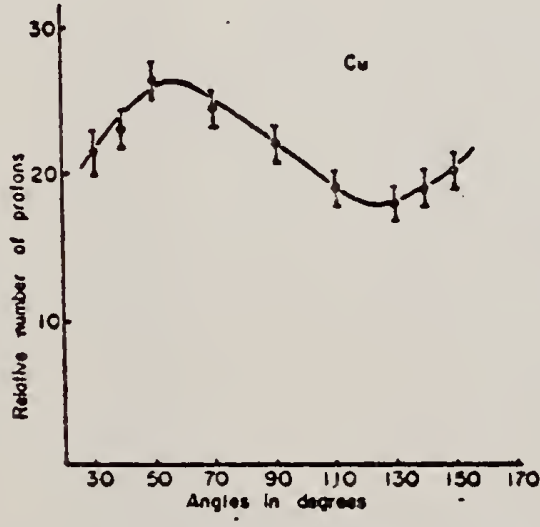

Fig. 8. Angular distribution of photo-protons from copper. The coefficients oblained by the least square fit are listed in Table III, asuming that the form is $\sum_{i=0}^{+} C_{l} P_{l}(\cos \theta)$.
Table III. Angular dist-ibution coefficients for copper.

\begin{tabular}{l|c|c|c}
\hline \multicolumn{2}{c}{ Legendre polynomials } & \multicolumn{1}{c}{ Power series } \\
\hline$C_{0}$ & 21.0494 & $a_{0}$ & 21.112 \\
$C_{1}$ & 3.0044 & $a_{3}$ & 5.8524 \\
$C_{2}$ & -1.6930 & $a_{4}$ & 8.2572 \\
$C_{3}$ & -6.0504 & $a_{3}$ & 28.449 \\
$C_{3}$ & -1.0342 & $a_{4}$ & -16.445 \\
& & $a_{5}$ & -55.612 \\
\hline
\end{tabular}


J. Miller, C. Schuh 1, C. Tzara

J. Phys. Radium 22, 529 (1961)

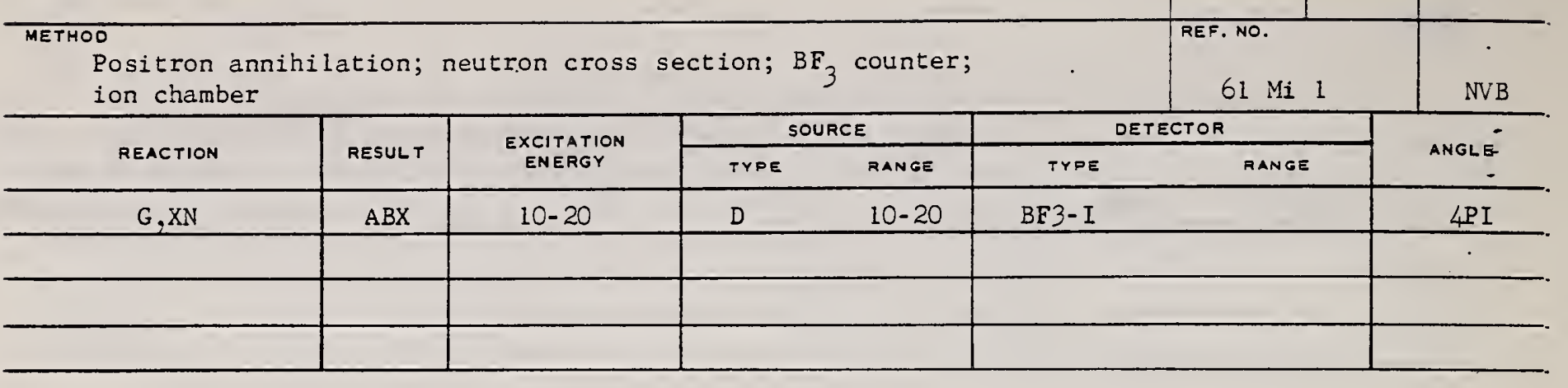

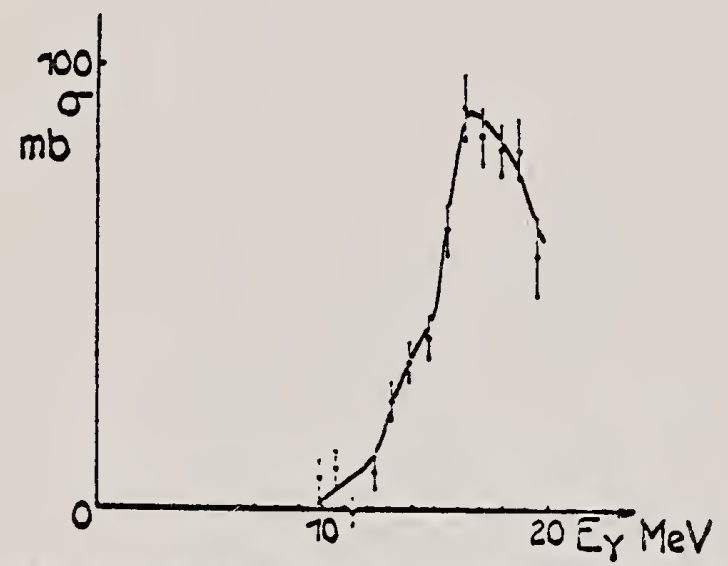

Fic, 5, - Cuivro, $\sigma(\gamma, n) \div \sigma(\gamma, n p)+2 \sigma(\gamma, 2 n)+\ldots$ 
Ri:. F. Tagliabue, J. Goldemberg

Nuclear Phys. 23,144 (1961)

Wethol $22 \mathrm{MeV}$ betatrcn; $\mathrm{Si}^{28}(\mathrm{n}, \mathrm{p}) \mathrm{Al}^{28}$ threshold detector.

$61 \mathrm{Ta} 1$

JHH

\begin{tabular}{|c|c|c|c|c|c|c|}
\hline Reaction & $E$ or $\Delta E$ & $E_{0}$ & $\Gamma$ & $\int \sigma d E$ & $J \pi$ & Notes \\
\hline$(\gamma, n)$ & $\begin{array}{c}\text { Bremss. } \\
22\end{array}$ & & & & & $\begin{array}{l}E_{n}>6 \mathrm{MeV} . \\
\begin{aligned} w\left(\theta_{n}\right)=A+B \sin ^{2} \theta \text { where } B / A= \\
0.13 \pm 0.31\end{aligned}\end{array}$ \\
\hline
\end{tabular}

Figure 4: Angular distributions of fast photoneutrons as observed with the $\mathrm{Si}^{28}(\mathrm{n}, \mathrm{p}) \mathrm{Al}{ }^{28}$ detector. Data normalized at $90^{\circ}$ in each case. 
Ref. T. Tohei, M. Sugawara, S. Mori, M. Kimura

J. Phys. Soc. Japan 16, 1657 (1961)

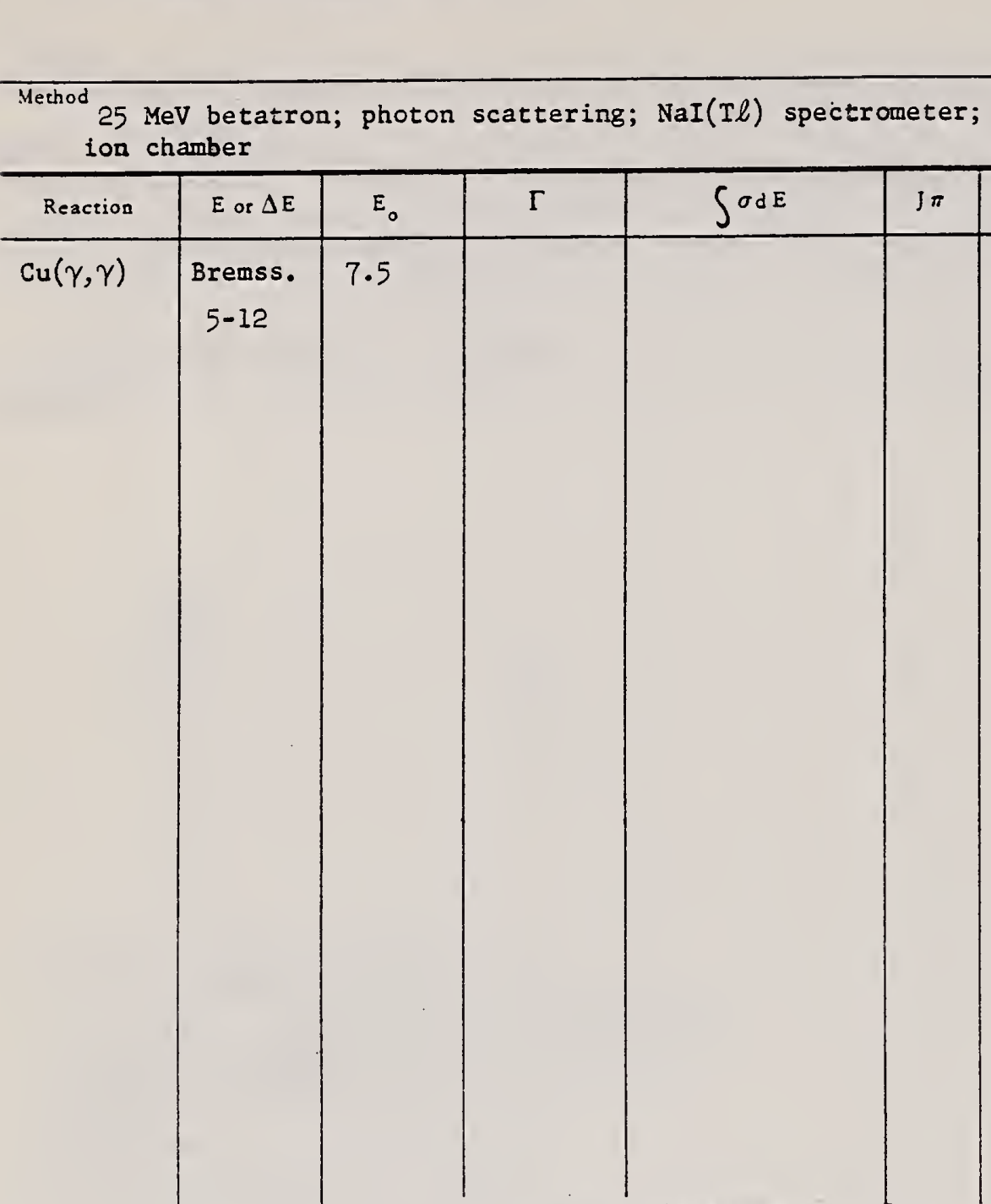

\section{References}

1) E. G. Fuller and E. Hayward: Phys. Rev. 101 (1956) 692.

2) see E. Segre: Experimental Nuclear Physics, vol. 1, p. 346.

3) J. S. Levin and D. J. Hughes: Phys. Rev. 101 (1956) 1328.

4) K. Reibel and A. K. Mann: Phys. Rev. 118 (1960) 701.

Table II The errevion of the t...'

Enery: in Ref. I should be read

4.11. . .

i, i)

3.3 . Her

3.0

5.5

10.0

7.7

12.11

9.9

1:.11 1

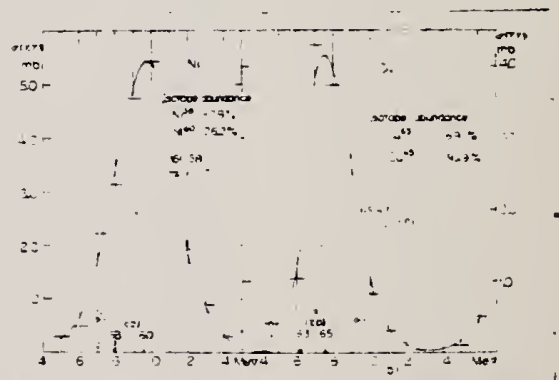

Fig. i. The elattic scattering cross sections of photons. .. .. : data from Fuller and Hay. ward ${ }^{1}$. - : data frum the experiment using the monochromatic $;$ rays

a) $v ;, ;$, by $\mathrm{Ni}$. The arrows indicate the positions of the $(\tau, p)$ and $\{, n$, threshold energies of $\mathrm{Ni}^{s 8}$ and $\mathrm{Ni}^{\text {so }}$.

b: vi $;$; by $\mathrm{Cu}$. The arrows indicate the positions of $i, p$ and $i, n$ threshold energies of $\mathrm{Cu}^{\text {is }}$ and $\mathrm{Cu}^{\text {s.s. }}$.

Table II taken from J. Phys. Soc. Japan 18, 17-22 (1963) 
Ref. G.Ben-David (Davis); B. Huebschmann

Phys.Letters 2, 87 (1962)

Elem. Sym.

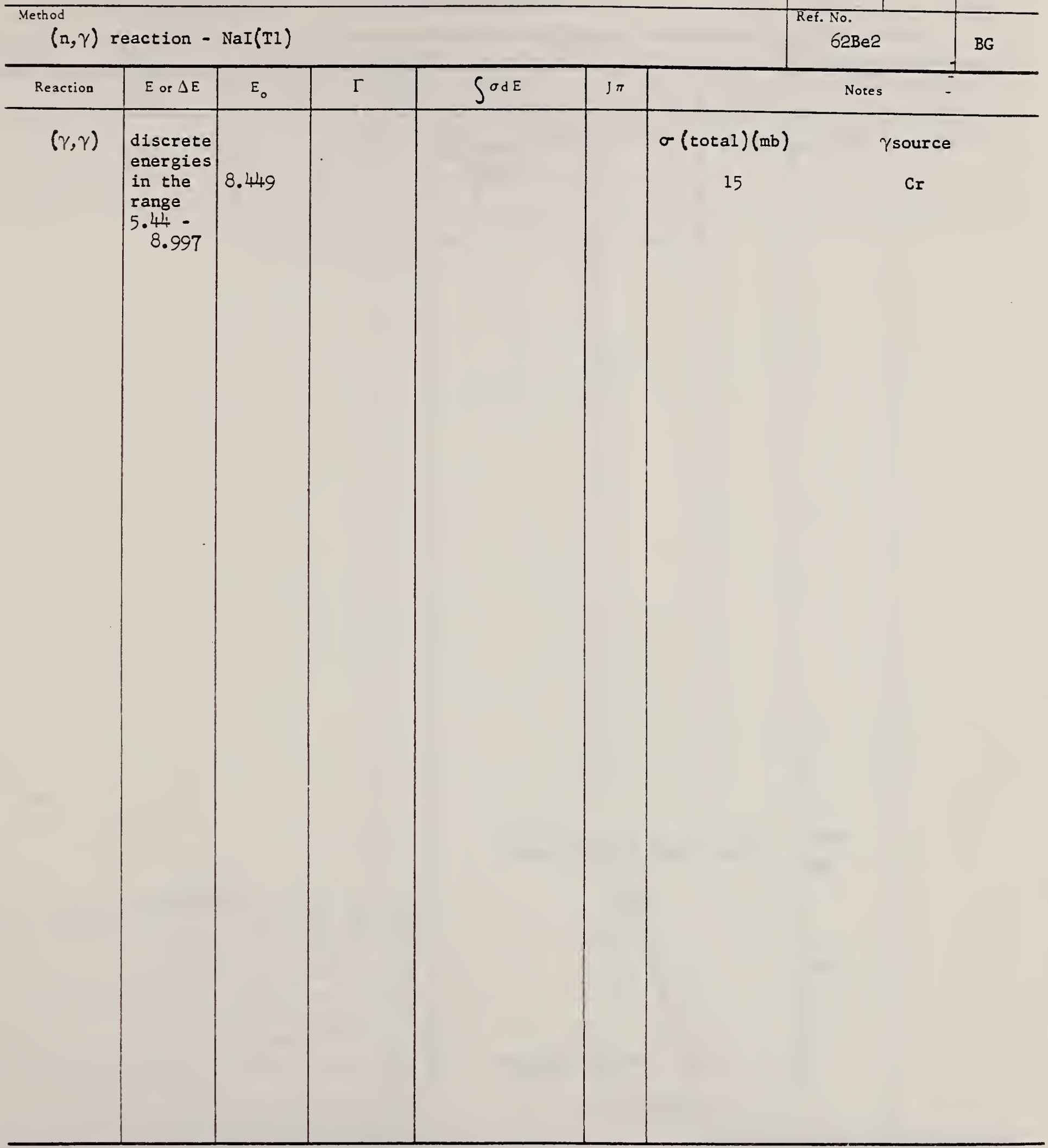


Ref. J. Miller, C. Schuhl, C. Tzara

Nuclear Phys. 32, 236 (1962)

Method Linac; monoergic photons by $\mathrm{e}^{+}$annihilation in flight; NaI

cu

Ref. No.

62 Mi 3

JHH

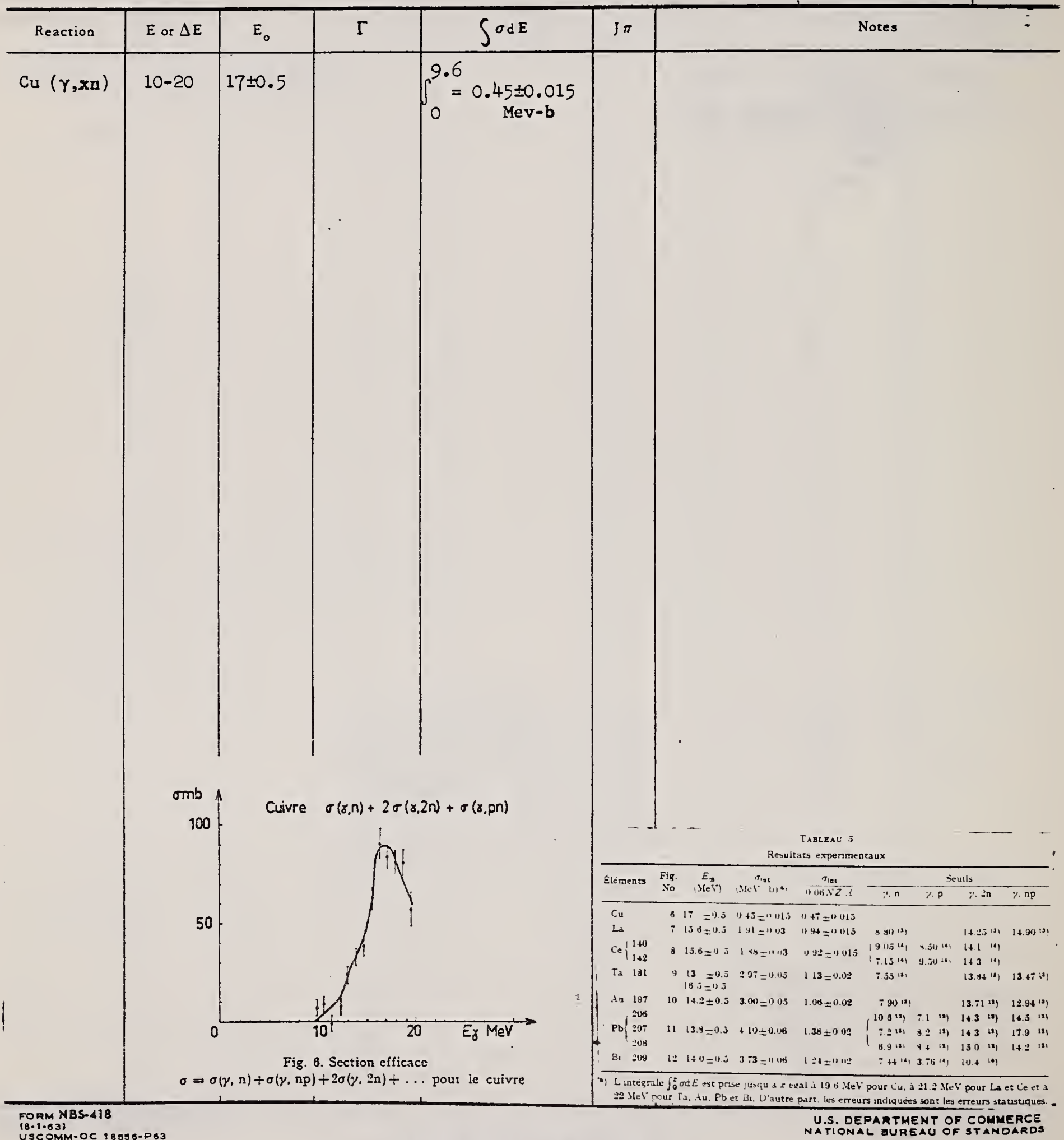

PHOTONUCLEAR DATA SHEET 254 
W. Sebaoun

J. Phys. Radium 23; 989 (196́2)

ELEM. SYM.

METHOO

Proton cross section; CSI; $\mathrm{Cu}^{63}(\gamma, \mathrm{n})$ reaction

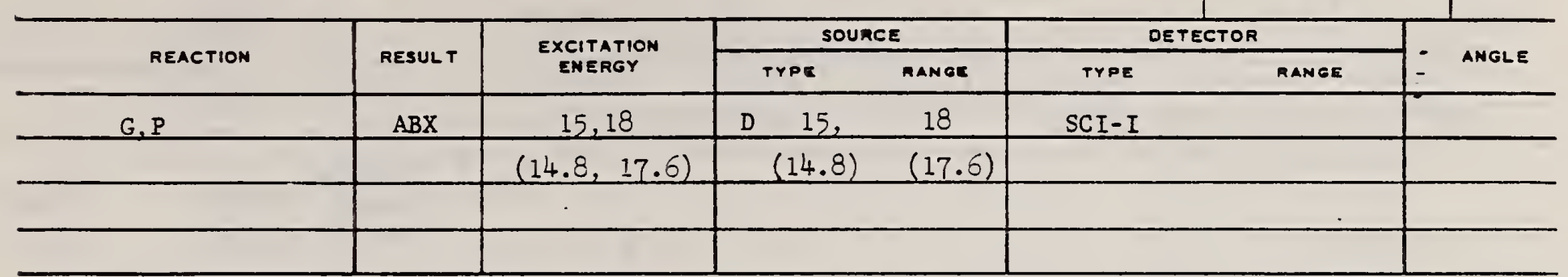

$\sigma=9.8 \pm 1.4 \mathrm{mb}$, assuming $\sigma\left[\mathrm{Cu}^{63}(\gamma, \mathrm{n})\right]=82 \pm 8 \mathrm{mb}$. 
Ref. Yu.M.Volkov, L.A.Kul'chitskif

Zhur.Ekspt1. I Teoret.Fiz. 42, 108 (1962);

Soviet Phys.JETP 15, 77 (1962)

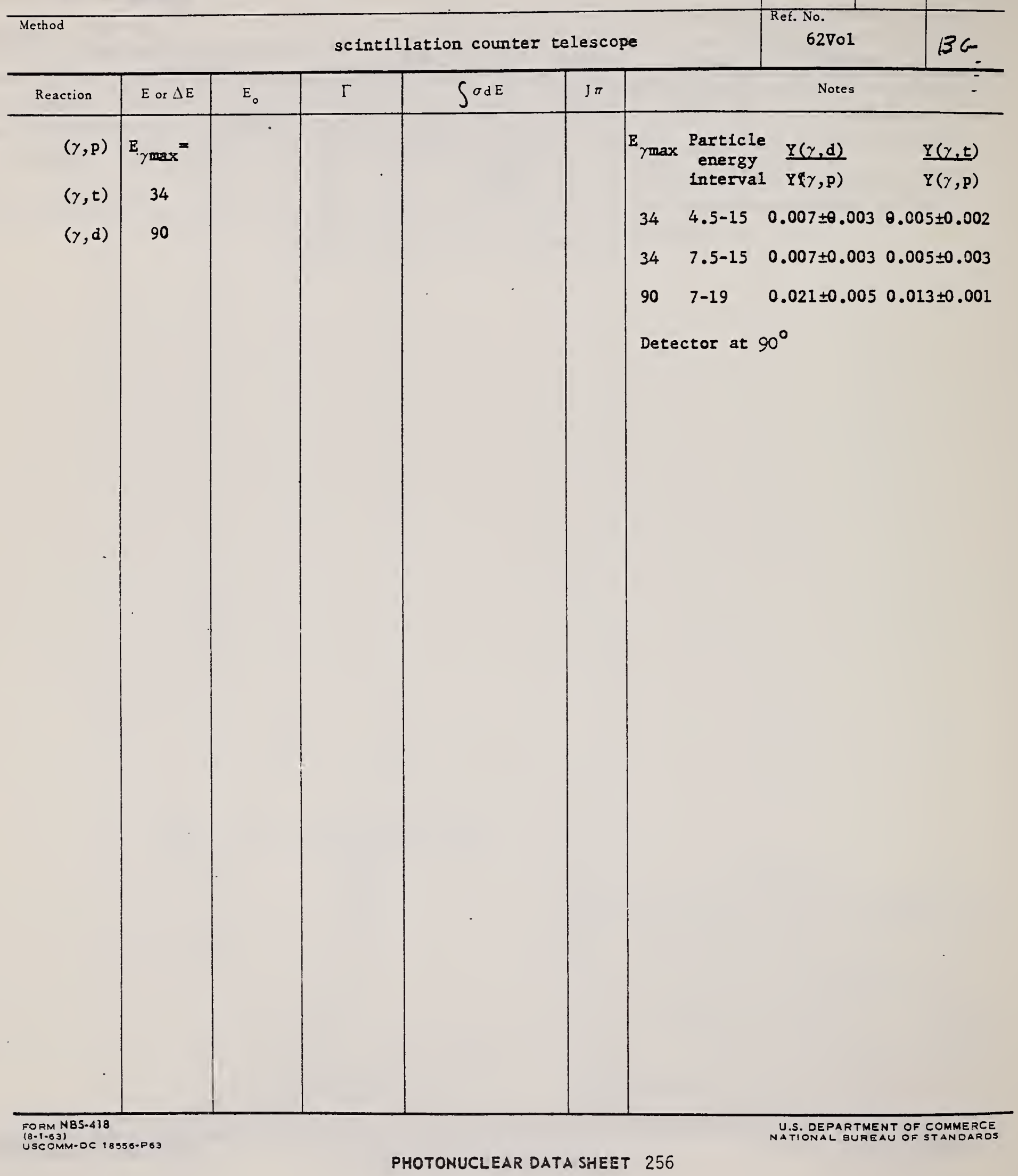


D.R. Kaipov, Yu. K. Shubnyi, Yu. G. Kosyak, R.B. Begzhanov

Zhur. Eksp. i Teoret. Fiz. 45, 443 (1963); Soviet Phys. JETP 18, 305 (1964)

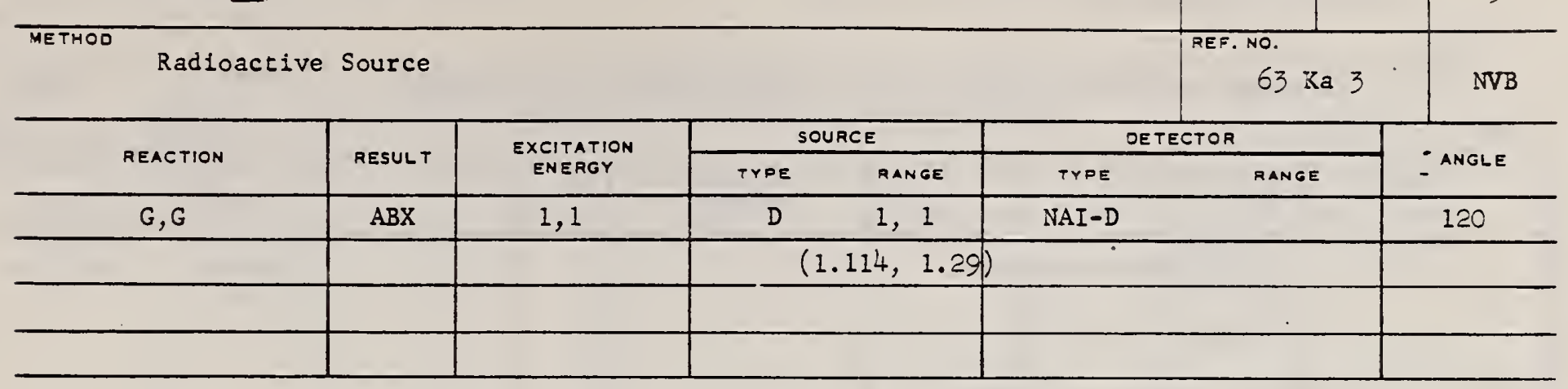

Average cross section for resonance scattering by $\mathrm{Sn}^{116}$ and $\mathrm{Cu}^{65}$ and attenuation of the resonance effect

\begin{tabular}{|c|c|c|c|c|c|c|}
\hline \multirow[b]{2}{*}{ Transition } & \multicolumn{3}{|c|}{ Liquid source } & \multicolumn{3}{|c|}{ Solid source } \\
\hline & $\overline{0}, 10-\mathrm{cm}^{2}$ & $\begin{array}{l}P l(E) . \\
i D \rightarrow e v-t\end{array}$ & $A$ & o. 10-0 $\mathrm{cm}^{2}$ & $\begin{array}{l}P .=(E) \\
10 \rightarrow \mathrm{c} V-1\end{array}$ & $\boldsymbol{A}$ \\
\hline $\begin{array}{l}\mathrm{In}^{110} \rightarrow \mathrm{Sn}^{110} \\
\mathrm{~N} l^{\circ} \rightarrow \mathrm{Cu}^{\circ}\end{array}$ & $\begin{array}{c}8.2 \pm 1.6 \\
1.58 \pm 0.26\end{array}$ & $\begin{array}{c}7.0 \pm 2.0 \\
3.36 \pm 0.26\end{array}$ & $\begin{array}{l}0.055 \\
0.010\end{array}$ & $\begin{array}{c}7.4 \pm 1.2 \\
0.97 \pm 0.18\end{array}$ & $\begin{array}{c}6.3 \pm 1.7 \\
2.05 \pm 0.60\end{array}$ & $\begin{array}{l}0.050 \\
0.021\end{array}$ \\
\hline
\end{tabular}


Ref. M. Rregar, B. Povh

Nuclear Phys. 43, 170 (1963)

Erratum in Nuclear Phys. 47, 528 (1963)

Method Betatron; $\alpha$ yields; spectra; solid state detectors; NBS chamber monitor

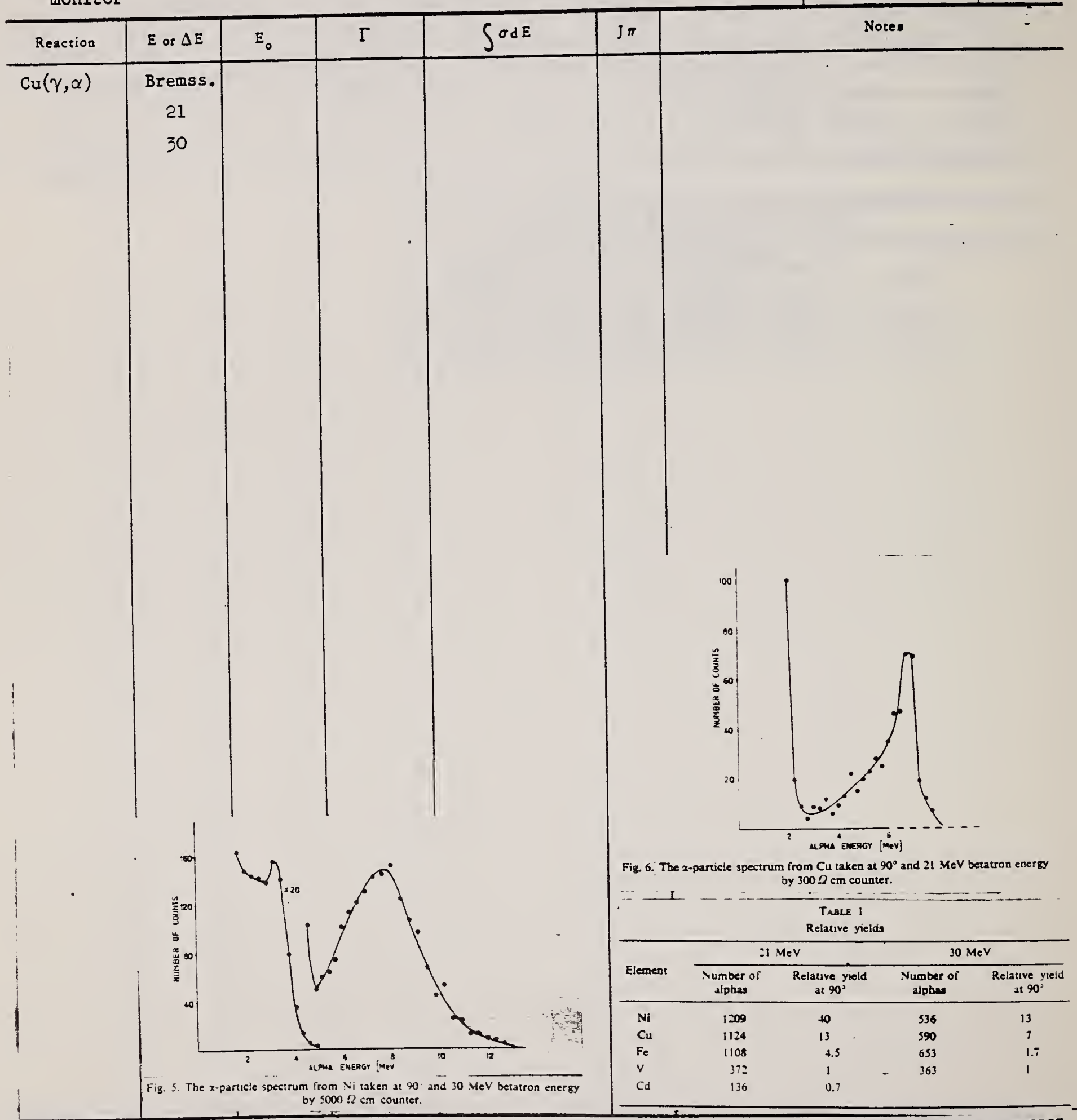


Ref. O.M.M. Mitchel1, R.G. McNeil1

Can. J. Phys. 41, 871 (1963)

\begin{tabular}{ll|l} 
& & \\
\hline Method Betatron; proton yield; angular distribution; scintillator; & Ret.
\end{tabular}
ion chamber.

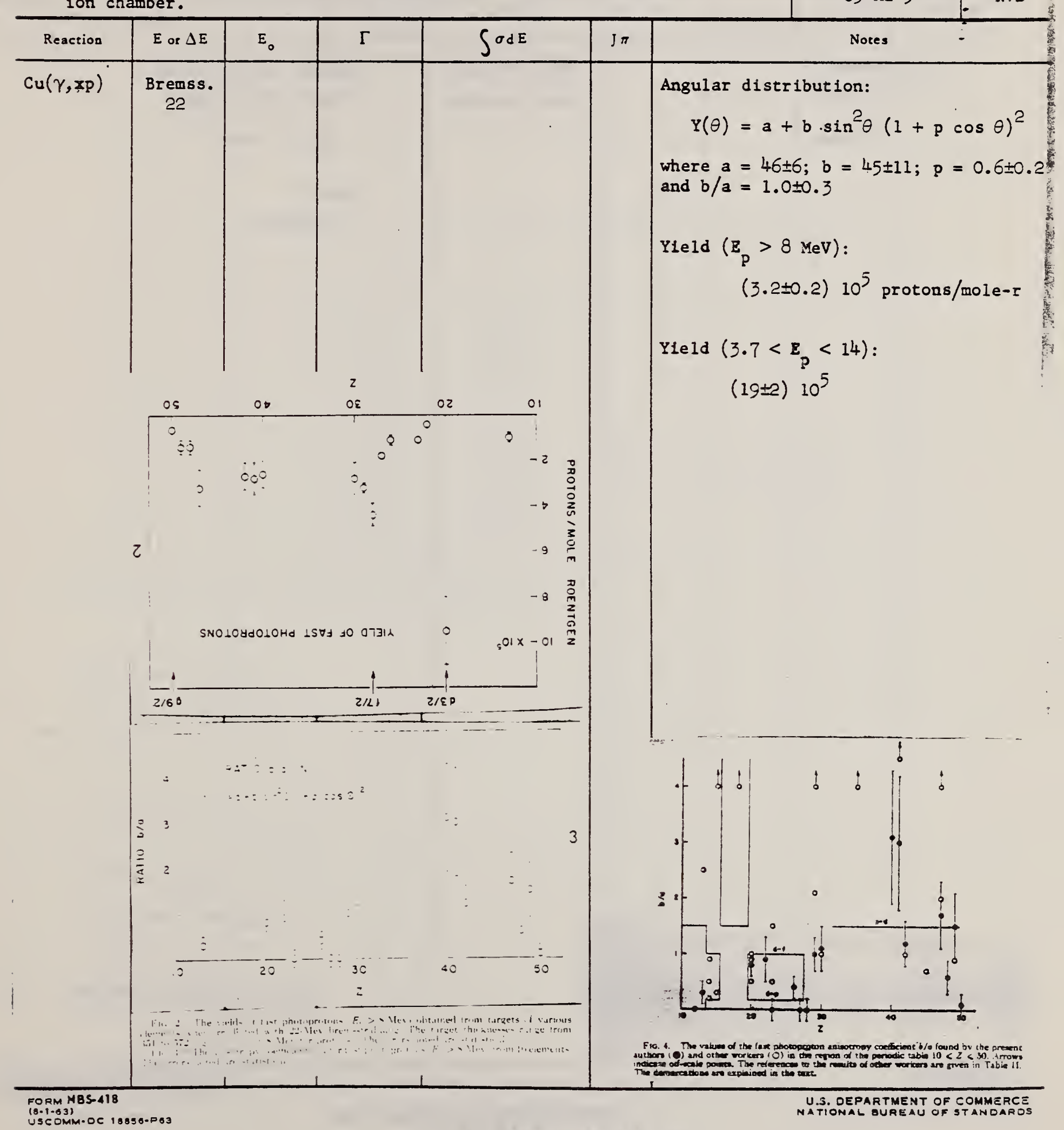

PHOTONUCLEAR DATA SHEET 259 
M.Odera, M.Yamamuro

J.Phys.soc.Japan 18, 325 (1963)

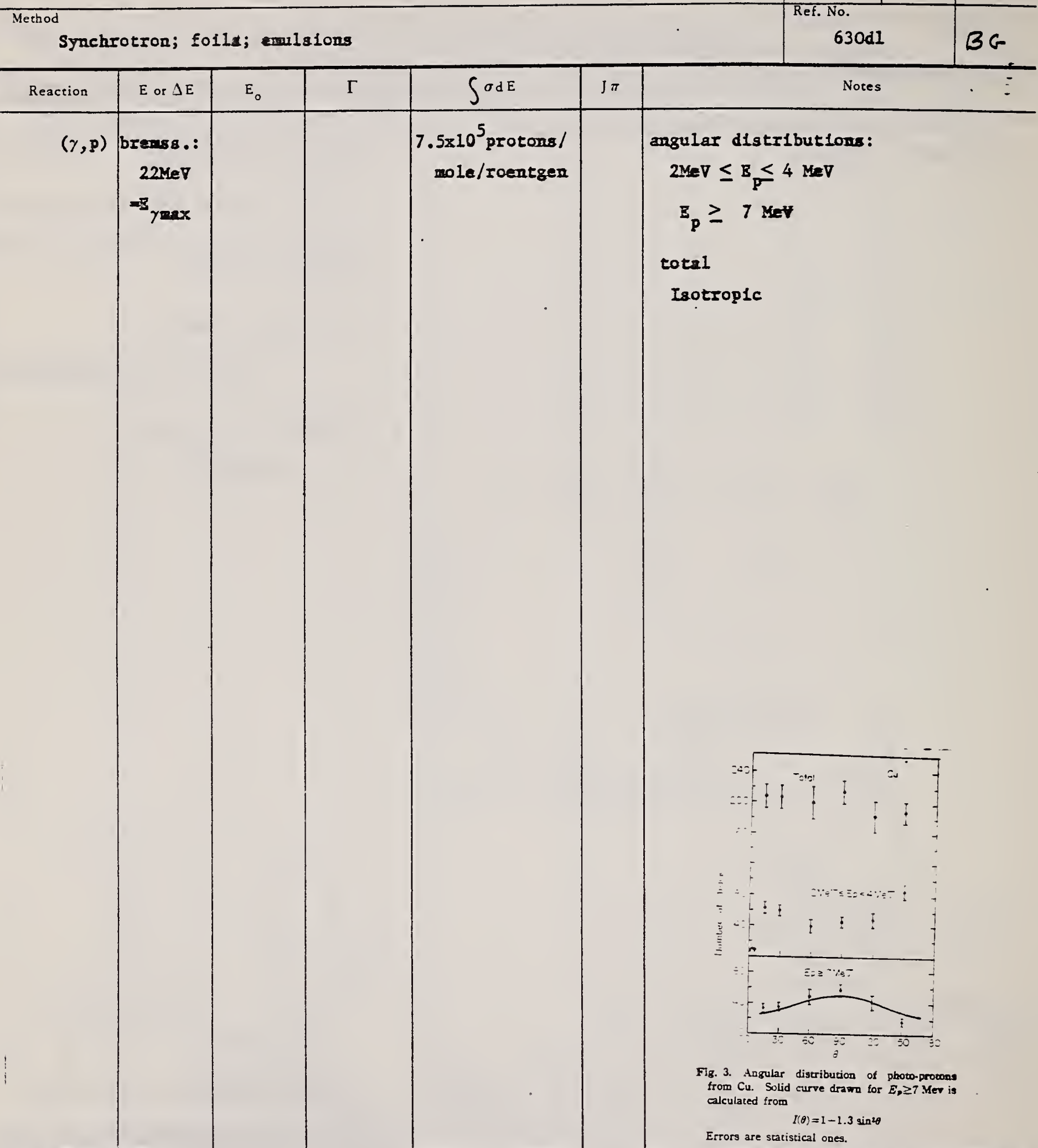


Ref. M. Yamanouchi

J. Phys. Soc. Japan 18, 638 (1963)

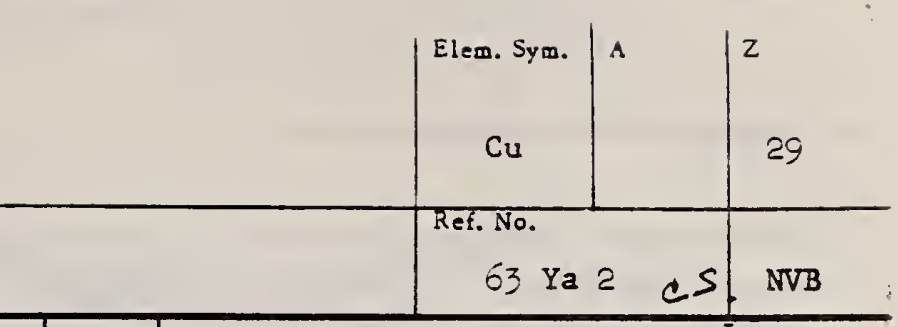

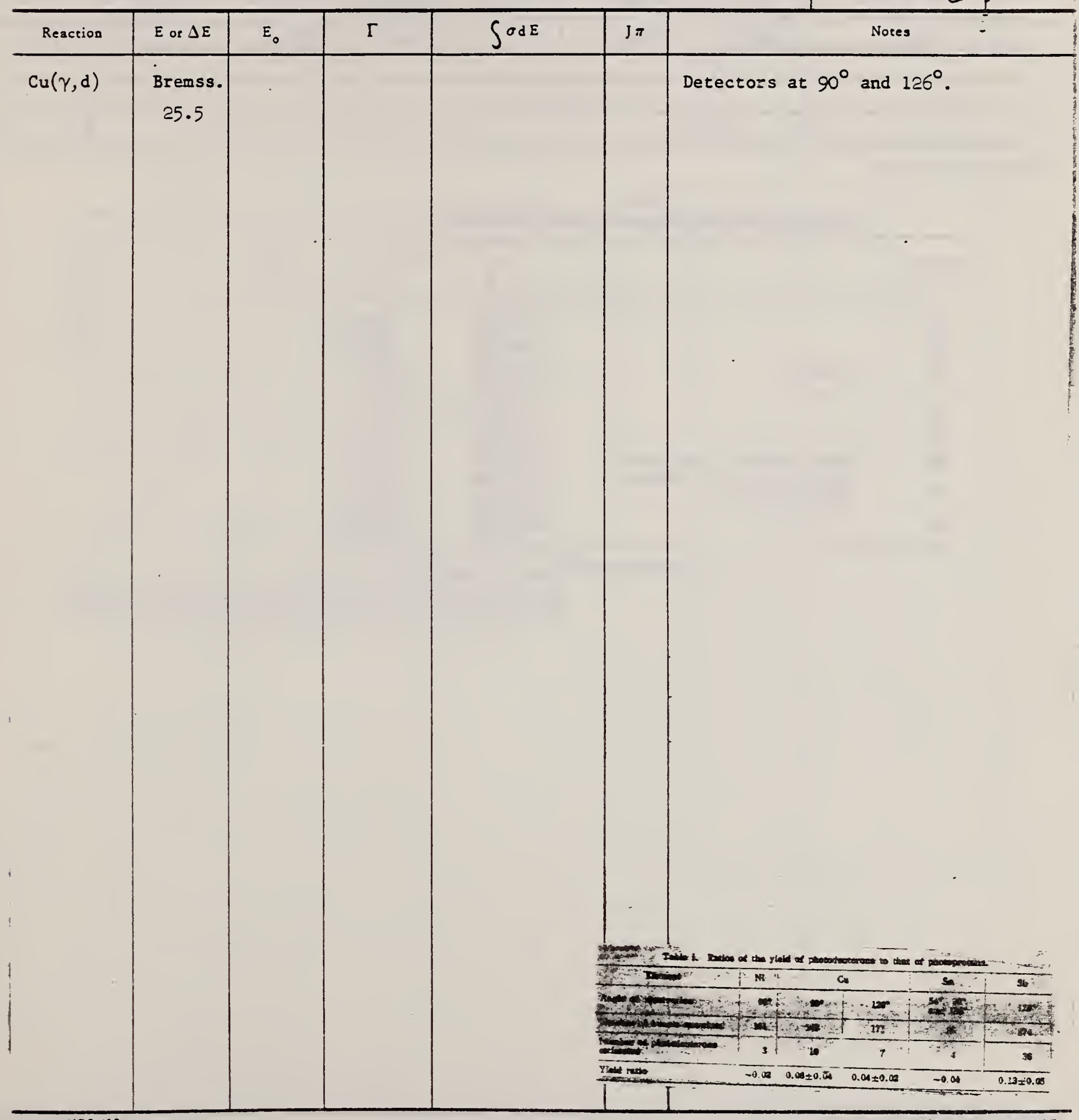


REF.

F.R. Allum, T.W. Quirk, and B.M. Spicer

Nucl. Phys. 53, 545 (1964)

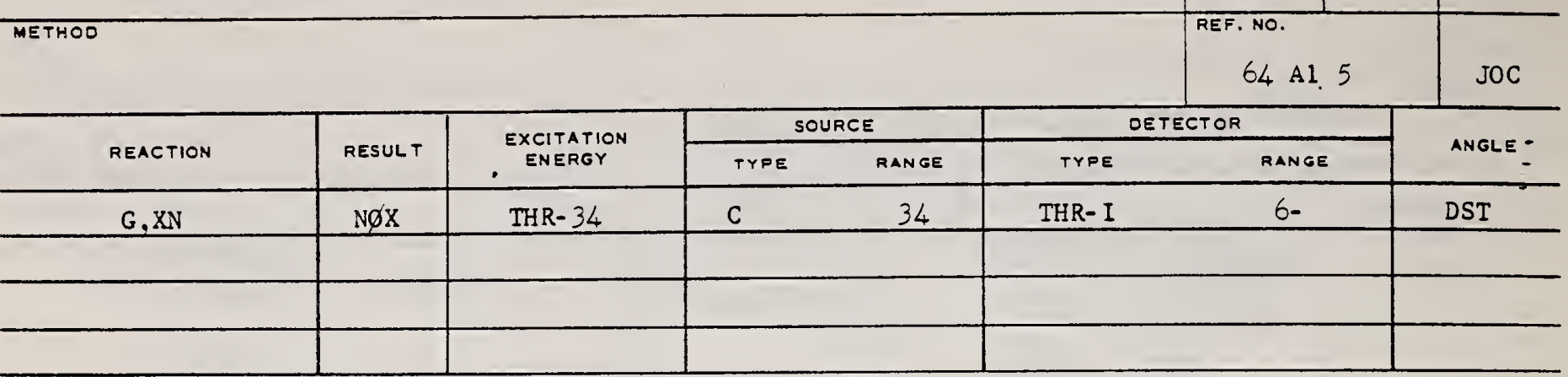

TABLE 1

Summary of present experimental data at $34 \mathrm{MeV}$ bremsstrahlung

\begin{tabular}{|c|c|c|c|}
\hline Element & & $-\frac{a_{1}}{a_{0}}$ & $\frac{a_{1}}{a_{0}}$ \\
\hline هe & \multirow{6}{*}{$\begin{array}{l}34 \mathrm{MeV} \\
22 \mathrm{MeV}\end{array}$} & $0.43 \pm 0.02$ & $0.05 \pm 0.01$ \\
\hline . $\mathrm{C}$ & & $0.61 \pm 0.04$ & $0.09 \doteq 0.0:$ \\
\hline 1,Al & & $0.39 \pm 0.03$ & $0.05 \pm 0.01$ \\
\hline ,Ti & & $0.34 \pm 0.02$ & $0.06=0.01$ \\
\hline \multirow[t]{2}{*}{${ }_{14} \mathrm{Cr}$} & & $0.33 \pm 0.02$ & $0.02=0.0:$ \\
\hline & & $0.13 \pm 0.07$ & $-0.02 \doteq 0.0$ \\
\hline "Cus & \multirow{3}{*}{$22 \mathrm{MeV}$} & $0.36 \pm 0.02$ & $0.10=0.0$ \\
\hline${ }_{10} \mathrm{Sn}$ & & $0.38 \pm 0.02$ & $0.11=0.0 \mathrm{i}$ \\
\hline$\triangle \mathrm{Ba}$ & & $0.39 \pm 0.03$ & $0.11=0.0:$ \\
\hline \multirow[t]{2}{*}{ „3Ta } & Before installation of iron shielding & $0.26 \pm 0.04$ & $0.13 \pm 0.0:$ \\
\hline & After installation of iron shielding & $0.27 \pm 0.02$ & $0.12 \pm 0.01$ \\
\hline \multirow[t]{2}{*}{${ }_{n} \mathrm{~Pb}$} & target diameter $3.0 \mathrm{~cm}$ & $0.39 \pm 0.03$ & $0.15=0.0:$ \\
\hline & target dianteter $1.5 \mathrm{~cm}$ & $0.40 \pm 0.03$ & $0.19=0.02$ \\
\hline os $\mathrm{Bi}$ & & $0.42 \pm 0.03$ & $0.17 \pm 0.02$ \\
\hline
\end{tabular}

$u_{1}+a_{1} \cos \theta+a_{1} \cos ^{2} \theta$ 
G. Baciu, A. Bonazzola, B. Minetti, C. Molino, L. Pasqualini and G. Piragino

Rev. Roum. Phys. 2, 977 (1964)

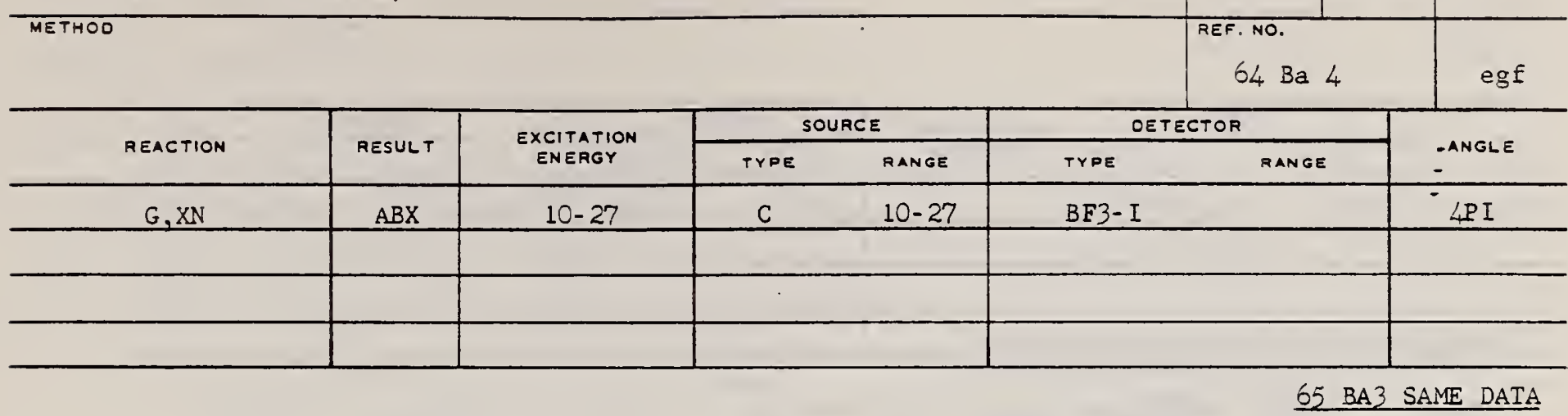

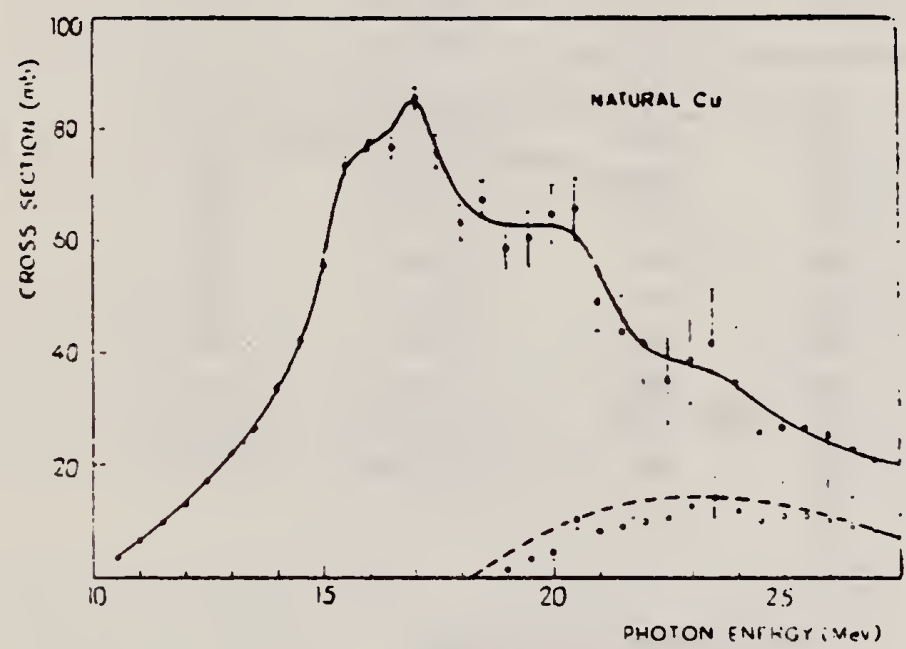

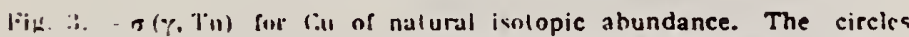
represent the value for $\sigma(y, 2 n)$ calculated (for $a=1 i .5$. VeV -1 ) in the upproxunntion that o $\left(\gamma\right.$. Tin) for nalural $C_{11}$ lias lise same averazed

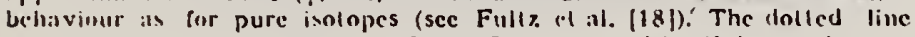
represents the behaviour of $\sigma(y, 2 n)$ measured by finliz of al. 
K.W. Chen, J.R. Dunning,Jr., J.R. Rees, W. Shlaer, J.K. Walḳer and $R$. Wilson

Phys. Rev. 135, 4B B1030 (1964)

\begin{tabular}{|c|c|c|c|}
\hline \multicolumn{4}{|l|}{ METHOD } \\
\hline \multicolumn{2}{|c|}{ REACTION } & RESULT & $\begin{array}{l}\text { EXCITATI } \\
\text { ENERGY }\end{array}$ \\
\hline \multicolumn{2}{|c|}{$E, P$} & $A B X$ & \\
\hline \multicolumn{4}{|c|}{ Tasle I. Cross sections for production of protons by electic } \\
\hline $\begin{array}{c}\text { Electron } \\
\text { target }\end{array}$ & $\begin{array}{l}\text { Energy } \\
\text { angle } \\
\text { (deg) }\end{array}$ & $\begin{array}{c}4 \mathrm{BeV} \\
\text { proton energy } \\
(\mathrm{MeV})\end{array}$ & ${ }_{10}^{-a^{2} \sigma} \mathrm{cm}^{2} / \mathrm{sr} d \mathrm{di}$ \\
\hline $\begin{array}{l}\mathrm{H} \\
\mathrm{Li}, \\
\mathrm{Li}, \\
\mathrm{Li}_{0} \\
\mathrm{C} \\
\mathrm{Al}\end{array}$ & $\begin{array}{l}59.8 \\
59.8 \\
59.8 \\
59.8 \\
59.8 \\
59.8\end{array}$ & $\begin{array}{l}374 \\
448 \\
368 \\
332 \\
374 \\
374\end{array}$ & $\begin{array}{l}3.8 . \\
0.082 \\
0.175 \\
0.280 \\
0.425 \\
1.19\end{array}$ \\
\hline $\begin{array}{l}\mathrm{H} \\
\mathrm{Li}_{4} \\
\mathrm{Li}_{4} \\
\mathrm{Li} \\
\mathrm{C} \\
\mathrm{Al}\end{array}$ & $\begin{array}{l}63.1 \\
63.1 \\
63.1 \\
63.1 \\
63.1 \\
63.1\end{array}$ & $\begin{array}{l}291 \\
355 \\
319 \\
290 \\
291 \\
291\end{array}$ & $\begin{array}{l}7.5 \circ \\
0.146 \\
0.204 \\
0.313 \\
1.01 \\
2.42\end{array}$ \\
\hline $\begin{array}{l}\mathrm{H} \\
\mathrm{Li}, \\
\mathrm{Li}_{4} \\
\mathrm{C} \\
\mathrm{Al}\end{array}$ & $\begin{array}{l}67.1 \\
67.1 \\
67.1 \\
67.1 \\
67.1\end{array}$ & $\begin{array}{l}208 \\
226 \\
206 \\
209 \\
209\end{array}$ & $\begin{array}{l}16 * \\
0.6 \\
0.92 \\
2.37 \\
6.4\end{array}$ \\
\hline $\begin{array}{l}\mathrm{H} \\
\mathrm{Li}, \\
\mathrm{Li}_{4} \\
\mathrm{Li}_{4} \\
\mathrm{Li}_{4} \\
\mathrm{Li}_{4} \\
\mathrm{C} \\
\mathrm{Al} \\
\mathrm{Cu}\end{array}$ & $\begin{array}{l}72.1 \\
72.1 \\
72.1 \\
72.1 \\
72.1 \\
72.1 \\
72.1 \\
72.1 \\
72.1\end{array}$ & $\begin{array}{l}124 \\
166 \\
144 \\
124 \\
119 \\
109 \\
123 \\
124 \\
124\end{array}$ & $\begin{array}{c}46 . \\
1.20 \\
1.53 \\
2.46 \\
2.80 \\
2.90 \\
6.6 \\
16.9 \\
42.3\end{array}$ \\
\hline $\begin{array}{l}\mathrm{H} \\
\mathrm{Li}^{8} \\
\mathrm{I}^{\circ} \\
\mathrm{C} \\
\mathrm{Al}\end{array}$ & $\begin{array}{l}44.8 \\
44.8 \\
44.8 \\
44.8 \\
44.8\end{array}$ & $\begin{array}{l}291 \\
337 \\
293 \\
291 \\
291\end{array}$ & $\begin{array}{l}2.9 \bullet \\
0.16 \\
0.29 \\
0.76 \\
1.58\end{array}$ \\
\hline $\begin{array}{l}\mathrm{H} \\
\mathrm{Li} \\
\mathrm{C} \\
\mathrm{Al}\end{array}$ & $\begin{array}{l}52.3 \\
52.3 \\
52.3 \\
52.3\end{array}$ & $\begin{array}{l}208 \\
200 \\
208 \\
208\end{array}$ & $\begin{array}{l}8.5 \\
0.91 \\
2.13 \\
4.95\end{array}$ \\
\hline $\begin{array}{l}\mathrm{H} \\
\mathrm{C} \\
\mathrm{C} \\
\mathrm{C} \\
\mathrm{Al} \\
\mathrm{Al}\end{array}$ & $\begin{array}{l}61.1 \\
61.1 \\
61.1 \\
61.1 \\
61.1 \\
61.1\end{array}$ & $\begin{array}{l}124 \\
145 \\
124 \\
115 \\
145 \\
124\end{array}$ & $\begin{array}{l}25 . \\
3.95 \\
5.75 \\
6.43 \\
10.7 \\
16.0\end{array}$ \\
\hline
\end{tabular}

- $d \sigma / d \Omega$ is, mb/ar; inside a $5.5 \%$ momentum incerval.

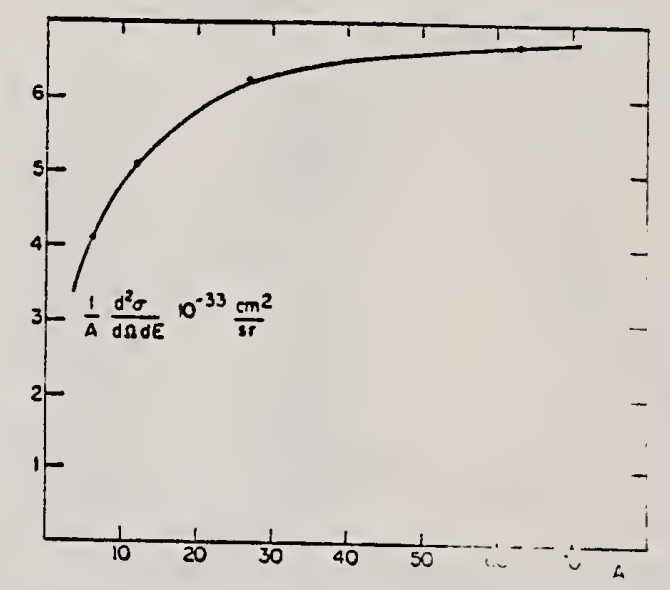

Fio. 4. Cross section, divided by $A$, as a fuukitin uf .i, iur jurorlucing protons of $124 \mathrm{MeV}$ from $4-\mathrm{BeV}$ electruns al $7 \mathrm{M.}:$ '. 
¿o=-A. E. Eerroni, S. Ferroni and C. $\because 01150$ lnys. Letzers $11,324(1964)$

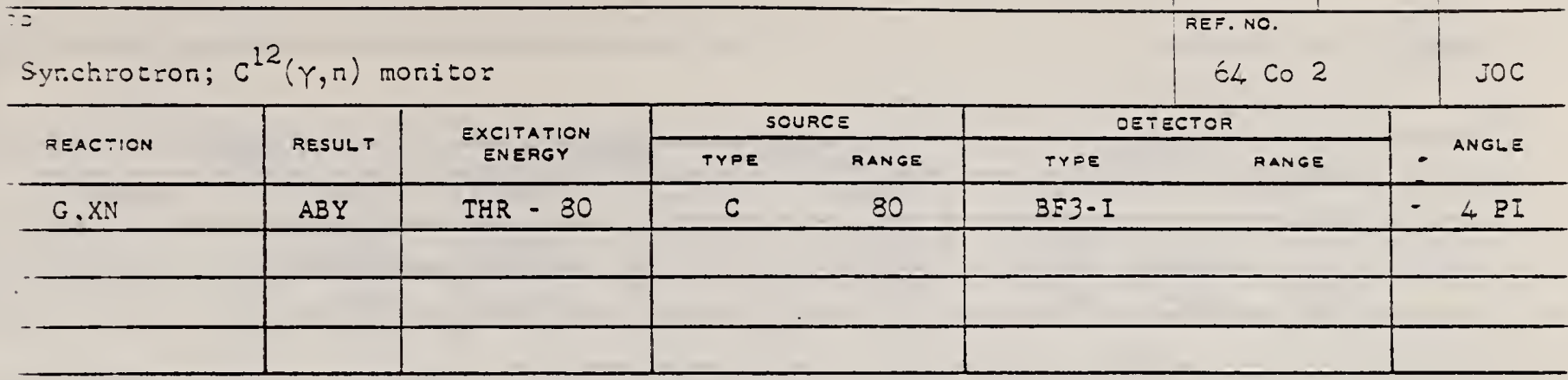

Table 1

\begin{tabular}{|c|c|c|c|c|c|c|c|}
\hline Element & $\begin{array}{l}\text { Yield }(36) \\
\text { ov } \mathrm{cm}^{2} \\
\text { mol } \mathrm{MeV}\end{array}$ & $\begin{array}{l}60 \mathrm{NZ} / \mathrm{A} \\
(\mathrm{mb} \mathrm{MeV})\end{array}$ & $\begin{array}{l}30 \\
\sum_{0}^{30}\end{array}$ & $\begin{array}{l}80 \\
\sum\end{array}$ & $\begin{array}{ll}30 & 80 \\
\Sigma_{0} / \Sigma_{0} \\
. \quad\end{array}$ & $\begin{array}{c}E_{\mathrm{m}} \\
\mathrm{MoV})\end{array}$ & $e_{m b}$ \\
\hline${ }_{24} \mathrm{Cr}$ & $23 \times 10^{-5}$ & 777 & 1.21 & 2.2 & 0.58 & 18.5 & 97 \\
\hline $25^{\mathrm{Mn}}$ & $108 \times 10^{-5}$ & 818 & 1.52 & 2.33 & 0.65 & 18.5 & 114 \\
\hline $26^{\mathrm{Fe}}$ & $68 \times 10^{-5}$ & 832 & 0.38 & 1.86 & 0.60 & 17.5 & 75 \\
\hline${ }_{27} \mathrm{Co}$ & $89 \times 10^{-5}$ & 378 & 1.08 & 1.82 & 0.59 & 17.5 & $\$ 2$ \\
\hline $28^{\mathrm{Ni}}$ & $44 \times 10^{-5}$ & 879 & 0.55 & 3.07 & 0.51 & 18.5 & 56 \\
\hline${ }_{29} \mathrm{Cus}$ & $95 \times 10^{-5}$ & 947 & 1.06 & 1.99 & 0.53 & 17.5 & 98 \\
\hline $30^{2}=$ & $88 \times 10^{-5}$ & 975 & 0.94 & 1.68 & 0.56 & 17.5 & 86 \\
\hline $3 I_{G a}$ & $130 \times 10^{-\overline{5}}$ & 1034 & 1.29 & 2.13 & $0 . \equiv 9$ & $: 3.5$ & 151 \\
\hline${ }_{32} \mathrm{Go}$ & $139 \times 10^{-5}$ & 1064 & 1.25 & 2.29 & 0.59 & 17.5 & 158 \\
\hline $33^{\mathrm{Ads}}$ & $137 \times 10^{-5}$ & 1109 & 1.22 & 2.13 & 0.56 & 17.5 & 127 \\
\hline
\end{tabular}

30

$$
\sum_{0}^{30}=\frac{\int_{0} \sigma\left(Y, X r_{1}\right) d E}{60 \mathrm{NZ} / \mathrm{A}}
$$

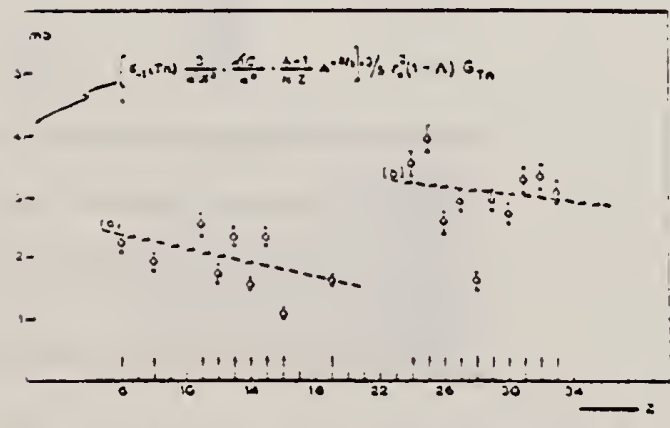

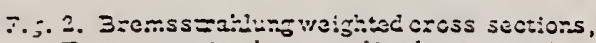

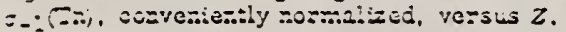

\begin{tabular}{|c|c|c|c|}
\hline E:cmeat & $\begin{array}{c}\text { mimis } \\
\text { y:cid } \\
\left(x: v^{-5}\right)\end{array}$ & $\sigma_{-i}(-\pi)$ & 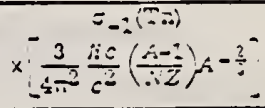 \\
\hline${ }_{0}^{-C}$ & $\div . C$ & $3 . \pm 4$ & $2 . \therefore \Sigma$ \\
\hline $3^{0}$ & 5.2 & 4.35 & $: .52$ \\
\hline$\because \because \mathrm{Na}^{2}$ & 22.6 & 1:.6ง & $2 . \cong 9$ \\
\hline $22 \times 5$ & $: 0.0$ & 8.81 & $\therefore .73$ \\
\hline$: 24.1$ & 15.9 & 23.92 & 2.20 \\
\hline$:{ }_{4} \mathrm{Si}$ & $: 1.0$ & 5.96 & 1.55 \\
\hline$\therefore: z^{2}$ & $: 9.3$ & 27.50 & 2.22 \\
\hline$: i^{5}$ & 3.5 & 3.55 & 2.57 \\
\hline$: j::$ & :อ.0 & $=7.30$ & $\therefore .8:$ \\
\hline 200 & $\llbracket 2.1$ & $: \therefore .63$ & $\therefore .02$ \\
\hline $2 \div=$ & 30 & $6: .6$ & 3.56 \\
\hline $20 \cdots$ & 125 & $? 0.2$ & 3.90 \\
\hline $20^{\circ} 0$ & $7 \%$ & $\equiv 0 . \Sigma$ & 2.55 \\
\hline 2700 & 04 & 62.5 & 2.04 \\
\hline 25.10 & 40 & $3 \div .2$ & 2.59 \\
\hline${ }_{20} \mathrm{Cu}$ & $: 02$ & $: 2.3$ & 2.96 \\
\hline $302=$ & 93 & 05.7 & 2.68 \\
\hline $3: 05$ & $\div \div 0$ & 93.0 & $2.3:$ \\
\hline${ }_{22} \mathrm{Ge}$ & 250 & 101.5 & 3.36 \\
\hline$\therefore$ Ss & $\pm \Xi:$ & SS.8 & .3 .22 \\
\hline
\end{tabular}


REF. S. C. Fultz, R. L. Bramblett, J. T. Caldwell, R. R. Harvey Phys. Rev. 133 , B1149 (1964)

Positron Annihilation; ion chamber

\begin{tabular}{|c|c|c|c|c|c|c|c|c|}
\hline \multirow{2}{*}{ REACTION } & & \multirow{2}{*}{ RESULT } & \multirow{2}{*}{$\begin{array}{l}\text { EXCITATION } \\
\text { ENERGY }\end{array}$} & \multicolumn{2}{|c|}{ SOURCE } & \multicolumn{2}{|c|}{ DETECTOR } & \multirow{2}{*}{ ANGLE:- } \\
\hline & & & & TYPE & RANGE & TYPE & RANGE & \\
\hline $\mathrm{G}, \mathrm{N}$ & $532+$ & $A B X$ & $9-28$ & $\mathrm{D}$ & $9-28$ & $B F 3-I$ & & $4 \mathrm{PI}$ \\
\hline $\mathrm{G}, 2 \mathrm{~N}$ & $534 T$ & $\mathrm{ABX}$ & $18-28$ & $\mathrm{D}$ & $18-28$ & BE3-I & & $4 \mathrm{PI}$ \\
\hline
\end{tabular}

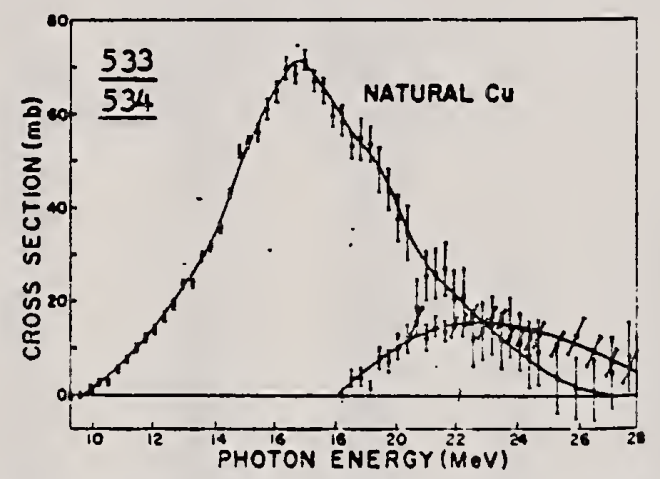

Jic. 2. Mrensuced crous sections for $(\gamma, n)$ aurl $(\gamma, 2 n)$ reactions on

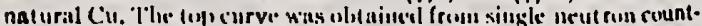

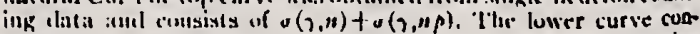

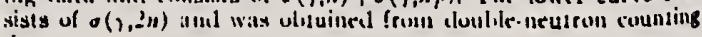
datia.

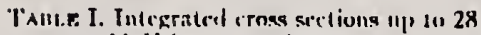
MeV fur colper isollenses.

\begin{tabular}{|c|c|c|c|c|}
\hline 1:1emene & Kencitions & 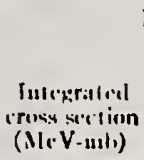 & 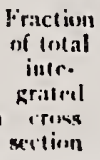 & $\begin{array}{c}\text { Tivtal } \\
\text { (McV-nil) }\end{array}$ \\
\hline Natural Cu & $\begin{array}{l}(\gamma, n)+(\gamma, n p) \\
(\gamma, 2 n) \\
(\gamma, p)^{\bullet}\end{array}$ & $\begin{array}{l}52.5 \pm 52 \\
110 \pm 11 \\
152 \pm 50\end{array}$ & $\begin{array}{l}0.67 \\
0.14 \\
0.19\end{array}$ & $787 \pm 113$ \\
\hline $\mathrm{Cu}^{*}$ & $\begin{array}{l}(\gamma, n)+(\gamma, n p) \\
\quad+\operatorname{direct} \\
(\gamma, 2 n) \\
(\gamma, n p)^{\bullet} \\
(\gamma, p)^{\star} \\
(\gamma, n) \\
\text { direct }^{\star b}\end{array}$ & $\begin{aligned} & 523 \pm 52 \\
& 80 \pm 8 \\
& 115 \pm 20 \\
& 161 \pm 48 \\
& 34 \pm \pm 34 \\
& 6+ \pm 22\end{aligned}$ & $\begin{array}{l}0.89 \\
0.11 \\
0.15 \\
0.21 \\
0.45 \\
0.08\end{array}$ & $764 \pm \infty$ \\
\hline $\mathrm{Cu}^{4}$ & $\begin{array}{l}(\gamma, n)+(\gamma, n p) \\
(\gamma, 2 n) \\
(\gamma, p)^{6}\end{array}$ & $\begin{array}{l}437 \pm 43 \\
195 \pm 19 \\
134 \pm 40\end{array}$ & $\begin{array}{l}0.57 \\
0.25 \\
0.18\end{array}$ & $766 \pm 103$ \\
\hline
\end{tabular}

- Calculated from evaporation theory. - Estimated.

20 N. V. Lin Kova, R.M. Osokina, B.S. Ratner, R.Sh.Ami rov, V.V. Akindinov, Zh. Eksp. Teor. Fiz. 38, 780 (1960); JETP 11, 566 (1960).

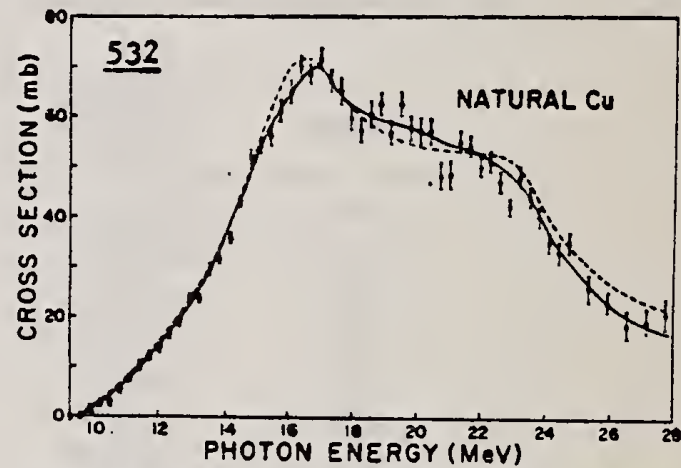

Fic. 1. Solid curve gives the average of data points of the total cross section $[\sigma(\gamma, n)+2 \sigma(\gamma, 2 n)+\sigma(\gamma, n p)]$ for natural $\mathrm{Cu}$ The dashed line represents the total cross section given by the sum of the total cross sections measured for $\mathrm{Cu}^{\omega}$ and $\mathrm{Cu}^{\omega}$ and adjusted for isotopic abundances.

T.abe II. Cross section for Li gamma rays.

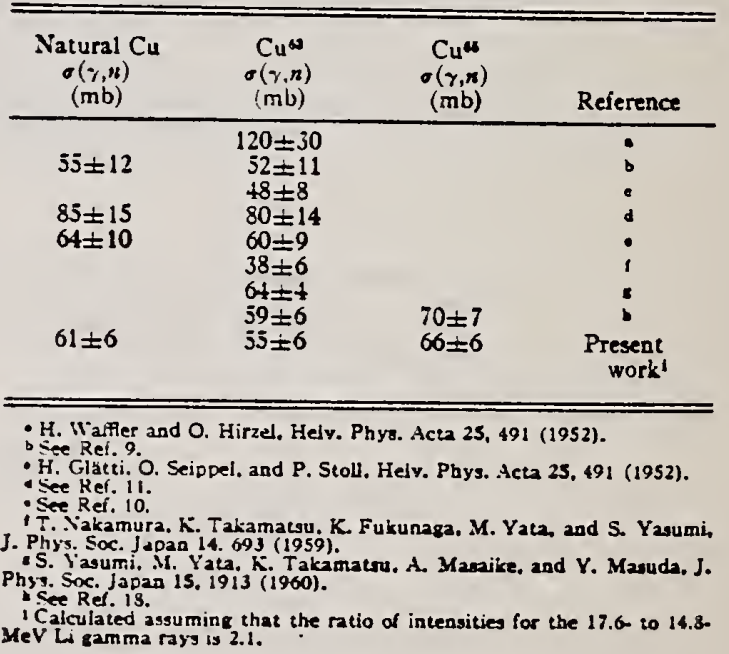

9.D. MCDaniel, R.L. Walker, and M.B. Stearns, Phys. Rev. E0, 807 (1950).

10 W.H. Hartley, W.E. Stephens, E.J. Winhold, Phys. Rev. 104, 178 (1956).

$11 \mathrm{J.H}$. Carver and E. Kondalah, Phil. Mag 45 , 988 (1954).

${ }^{18}$ G.E. Coote, W.E. Turchinetz, I.F. Wright, Nucl. Phys. 23, 468 (1961). 
REF. Akira Masaike J. Phys. Soc. Japan 19, 427 (1964)

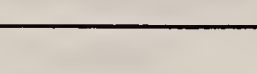

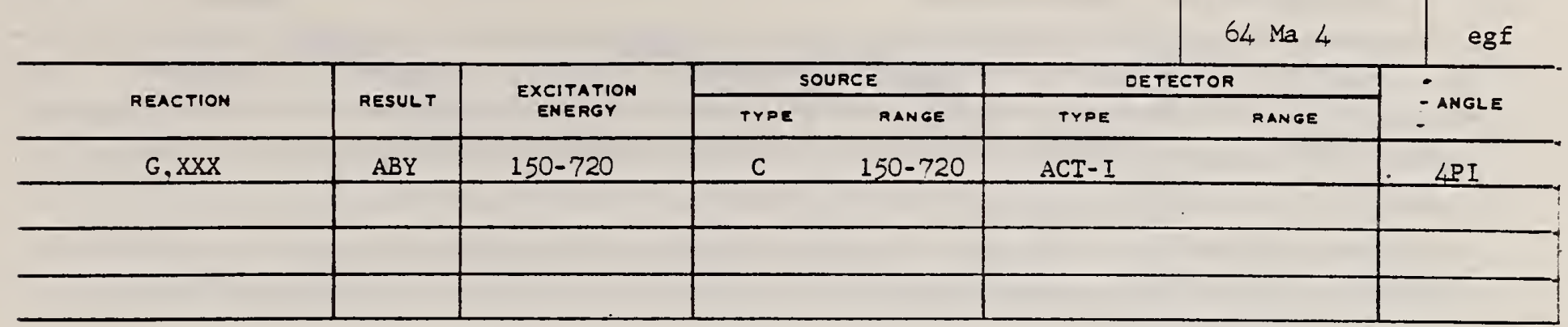

\section{$\underline{X X X}=$ CUE2 FINAL}

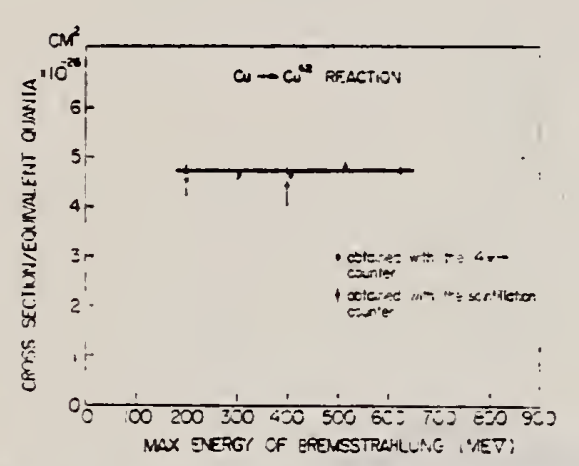

Fig. 8. The yield curve per equivalent quanta for the reaction $\mathrm{Cu} \rightarrow \mathrm{Cu}^{\mathrm{a}}$. 
Zhur. Eksp. i Teoret. Fiz. 46, $1157-1513$ (1964)

Soviet Phys. JETP 19, 783-86 (1964)

Synchrotron; ion chamber monitor

\begin{tabular}{|c|c|c|c|c|c|c|c|}
\hline \multirow[b]{2}{*}{ REACTION } & \multirow{2}{*}{ RESULT } & \multirow{2}{*}{$\begin{array}{l}\text { EXCITATION } \\
\text { ENERGY }\end{array}$} & \multicolumn{2}{|c|}{ SOURCE } & \multicolumn{2}{|c|}{ DETECTOR } & \multirow{2}{*}{ ANGLE : } \\
\hline & & & TYPE & RANGE & TYPE & RANGE & \\
\hline$G, P$ & $A B X$ & THR-27 & $\mathrm{C}$ & 30 & $S C I-I$ & $5-$ & DST \\
\hline & & & & & & & \\
\hline & & & & & & & \\
\hline & & & & & & & \\
\hline
\end{tabular}

FIG. 4. Cross section for the emission of photoprotons with energy $i p \geq 5 \mathrm{MeV}$ from copper. Dashed curve-cross section of a $\mathrm{Ni}^{* 2}(\gamma, p)$ reaction obtained in [ $\left.{ }^{10}\right]$.

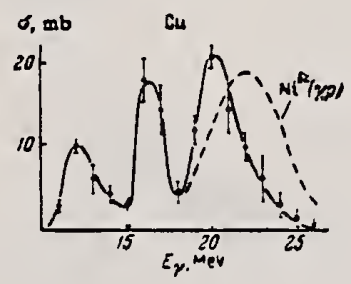


J. A. Scheer, K. Schlupmann und F. Triantafyllidis

Nucl. Phys. 5ó, 113-116 (1964)

\begin{tabular}{|c|c|c|c|c|c|c|c|}
\hline $\begin{array}{l}\text { METHOO } \\
\text { Betatron }\end{array}$ & & & & & & $\begin{array}{l}\text { REF. NO. } \\
64 \mathrm{SC} 1\end{array}$ & JOC \\
\hline \multirow{2}{*}{ REACTION } & \multirow{2}{*}{ RESULT } & \multirow{2}{*}{$\begin{array}{l}\text { EXCITATION } \\
\text { ENERGY }\end{array}$} & \multicolumn{2}{|c|}{ SOURCE } & \multicolumn{2}{|c|}{ DETECTOR } & \multirow{2}{*}{ - ANGLE } \\
\hline & & & TYPE & RANGE & TYPE & RANGE & \\
\hline $\mathrm{G}, \mathrm{A}$ & SPC & THR - 33 & $\mathrm{C}$ & 33 & SCD & $6-14$ & 90 \\
\hline & & & & . & & & \\
\hline & & & & & & & \\
\hline
\end{tabular}

ABS YIELD

Tabelle I

MeBdaten und Ergebnisse

\begin{tabular}{|c|c|c|c|c|}
\hline & $\mathbf{T i}$ & $\mathrm{Ni}$ & $\mathrm{Cu}$ & $\mathrm{Nb}$ \\
\hline Targetdicke (mg/ $\left.\mathrm{cm}^{2}\right)$ & 2.08 & 1.52 & 9.90 & 8.87 \\
\hline Bestrahlungsdauer (b) & 52.5 & 55.5 & 18.0 & 84.5 \\
\hline $\begin{array}{l}\text { Registrierte Teilchenanzahl } \\
\left(4 \leqq E_{x} \leqq 12.6 \mathrm{MeV}\right)\end{array}$ & 1861 & 2376 & 2333 & 1987 \\
\hline $\begin{array}{l}\text { Lage des Maximums } E_{\max } \text { der } \\
\text { Energieverteilung (MeV) }\end{array}$ & 6.4 & 8.2 & 8.5 & 11 \\
\hline Halbwertsbreite des Maximums (MeV) & 2.8 & 2.8 & 4.0 & 3.5 \\
\hline $\begin{array}{l}\text { Mittlerer Energieverlust } \\
\text { im Target bei } E_{x}=E_{\max }(\mathrm{MeV})\end{array}$ & 0.4 & 0.25 & 1.7 & 1.1 \\
\hline Ausbeute in $\mu \mathrm{b} / \mathrm{MeV} \bullet$ ) & $22 \pm 3.5$ & $45 \pm 7$ & $23 \pm 3.5$ & $5.5 \pm 0.8$ \\
\hline
\end{tabular}

*) Vgl. Bemerkung s) in Tabelle 2.

\section{TAaELLE 2}

Vergleich der Ergebnisse verschiedener Autoren

\begin{tabular}{|c|c|c|c|c|c|}
\hline & $E_{0}(\mathrm{MeV})$ & $\mathrm{Ti}$ & $\mathrm{Ni}$ & $\mathrm{Cu}$ & $\mathrm{vb}$ \\
\hline \multicolumn{6}{|c|}{ Ausbeure $\left(10^{2} \times N_{z} / \mathrm{Mol} . r\right)$} \\
\hline $\begin{array}{l}\text { Boulègue } \\
\text { Diese Arbeit s) } \\
\text { Toms und McElhinney }\end{array}$ & $\begin{array}{l}31 \\
32.5 \\
21.5\end{array}$ & $48 \pm 7$ & $\begin{array}{l}58.7 \\
98 \div 15 \\
39.4\end{array}$ & $\begin{array}{l}50.8 \\
50 \pm 7.5 \\
26\end{array}$ & $\begin{array}{c}12 \pm 1.8 \\
4.60)\end{array}$ \\
\hline \multicolumn{6}{|l|}{ Relative Ausbeute } \\
\hline $\begin{array}{l}\text { Boulègue } \\
\text { Kregar und Povh } \\
\text { Diese Arbeit } \\
\text { Toms und McElhinney }\end{array}$ & $\begin{array}{l}31 \\
30 \\
32.5 \\
21.5\end{array}$ & $0.49 \pm 0.08$ & $\begin{array}{l}1 \\
1 \\
1 \\
1\end{array}$ & $\begin{array}{l}0.87 \\
0.54 \\
0.51 \pm 0.08 \\
0.66\end{array}$ & $\begin{array}{l}0.12 \pm 0.02 \\
0.12^{\circ}\end{array}$ \\
\hline
\end{tabular}

-) Die Fehlerangaben beinhaitea auch die Unsicherheit in der Absoluteichung der Intensitāt des $\gamma$-Strables.

b) Dieser Wert wurde aus nur 14 beobachteten Ereignissen bestimmt.

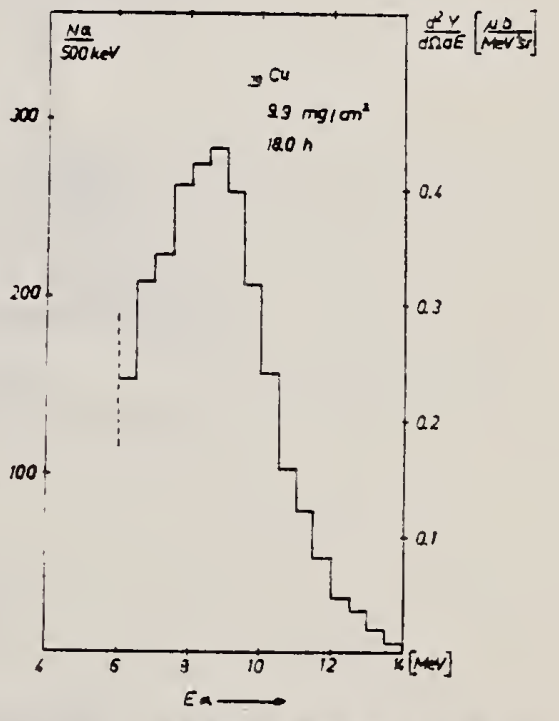

Abb. 1. Die erbaltenen Energie-Spektren der Photoalphateilchen aus $\mathrm{Ti}, \mathrm{Ni}, \mathrm{Cu}$ und $\mathrm{Nb}$. 
REF.

J. Shannon, W.E. Stephens, J.S. O'Connel1

Phys. Rev. 134, B113-17 (1964)

ELEM. SYM. A

$(1964)$.

Linac

$64 \mathrm{Sh} 3$

NVB

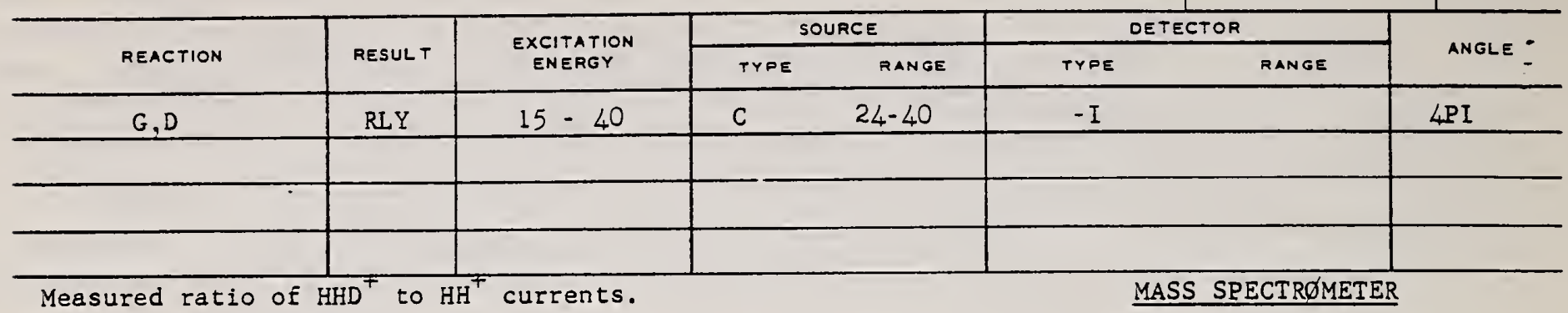

TABlE III. Observed deuteron to proton ratios for various exposures.

\begin{tabular}{|c|c|c|}
\hline Run & $\begin{array}{c}\text { Max. brem. } \\
\text { energy }\end{array}$ & Observed $Y(\gamma, D) / Y(\gamma, p)$ \\
\hline$\underset{\text { IV }}{\text { II }}$ & $\begin{array}{l}24 \\
30 \\
30 \\
40\end{array}$ & $\begin{array}{l}<0.0016 \text {, no } \mathrm{HHD}^{+} \text {observed } \\
<0.0003 \text {, no } \mathrm{HHD}^{+} \text {observed } \\
<0.00014 \text {, no } \mathrm{HHD}^{+} \text {observed } \\
\simeq 0.0009\end{array}$ \\
\hline
\end{tabular}


G. Baciu, G. C. Bonazzola, B. Minetti, C. Molino, L. Basqualini and $G$. Piragino

Nuclear Phys. 67, $178(1965)$

NBS Monitor

[Page 1 of 2]

\begin{tabular}{|c|c|c|c|c|c|c|c|}
\hline \multirow{2}{*}{ REACTION } & \multirow{2}{*}{ RESULT } & \multirow{2}{*}{$\begin{array}{l}\text { EXCITATION } \\
\text { ENERGY }\end{array}$} & \multicolumn{2}{|c|}{ SOURCE } & \multicolumn{2}{|c|}{ DETECTOR } & \multirow{2}{*}{ - ANGLE } \\
\hline & & & TYPE & RanGe & TYPE & RANGE & \\
\hline $\mathrm{G}, \mathrm{XN}$ & $A B X$ & THR -28 & C & $10-30$ & BF3-I & & $\angle P I$ \\
\hline & & & & & & & \\
\hline & & & & & & & \\
\hline
\end{tabular}

TABLS 2

Cross sections for $\mathrm{Co}, \mathrm{Ni}, \mathrm{Cu}$ and $\mathrm{Ga}$

\begin{tabular}{|c|c|c|c|c|c|}
\hline & $\begin{aligned} E_{\mathrm{m}} \\
(\mathrm{Me}\end{aligned}$ & & $\begin{array}{l}\sigma_{m} \\
(m b)\end{array}$ & $\int_{0}^{x_{a}} \sigma(E) \mathrm{d} E(\mathrm{mb} \cdot \mathrm{MeV})$ & Ref. \\
\hline $\mathrm{CO}^{\circ}$ & $\begin{array}{l}16.9 \\
16.75 \\
17.5 \\
16.5 \\
16.5\end{array}$ & $\begin{array}{l}19 \\
19 \\
19\end{array}$ & $\begin{array}{rr}130 & \\
110 & 103 \\
68 & \\
82 & 80 \\
72 & 74\end{array}$ & $\begin{array}{l}750(24) \\
709(25) \\
725 \pm 72(28) \\
701 \pm 91(29) \\
657 \pm 89(28) \\
537 \pm 34(24) \\
445 \pm 48(24)\end{array}$ & $\begin{array}{l}\text { ") } \\
\text { ") } \\
\text { ") } \\
\text { 18) } \\
\text { this work } \\
\text { this work } \\
\text { ") }\end{array}$ \\
\hline $\mathrm{Ni}$ & $\begin{array}{l}16.5 \\
16.5\end{array}$ & & $\begin{array}{l}50 \\
46 \pm 1\end{array}$ & $\begin{array}{l}340(24) \\
313 \pm 48(28) \\
276 \pm 25(24)\end{array}$ & $\begin{array}{l}\text { 12) } \\
\text { this work } \\
\text { this work }\end{array}$ \\
\hline $\mathrm{Ni}^{\mathbf{\omega}}$ & $\begin{array}{l}18.5 \\
\\
20.5 \\
19.0\end{array}$ & & $\begin{array}{l}60 \\
30 \\
21 \\
32\end{array}$ & $\begin{array}{l}330(24) \\
180(24) \\
160(24) \\
220 \pm 30(32)\end{array}$ & $\begin{array}{r}12) \\
\text { 12) } \\
13) \\
10)\end{array}$ \\
\hline $\mathrm{Ni}^{\omega \infty}$ & 16.5 & & 85 & $440(=20 \%)(24)$ & ") \\
\hline $\mathrm{Cu}$ & $\begin{array}{l}19.5 \\
\\
17.2 \\
17 \\
16.75 \\
17.0\end{array}$ & & $\begin{array}{l}120 \\
126 \\
90 \\
71 \pm 7 \\
86 \pm 2\end{array}$ & $\begin{array}{l}870(20) \\
904(27) \\
930(27) \\
450 \pm 15(19,6) \\
745 \pm 74(28) \\
733 \pm 105(28) \\
451 \pm 18(20)\end{array}$ & $\begin{array}{l}\text { 1) } \\
\text { 18) } \\
\text { 18) } \\
\text { 19) } \\
\text { 11) } \\
\text { this work } \\
\text { this work }\end{array}$ \\
\hline $\mathrm{Ga}_{\mathbf{a}}$ & 16.5 & & $115 \pm 3$ & $947 \pm 98(28)$ & this work \\
\hline
\end{tabular}

$\sigma_{m}$ is the peak value of the cross section, $E_{m}$ is the peak energy and $\int_{0}^{\pi} \sigma(E) d E$ is the integrated cross section. The upper limit of the integration is indicated in parentheses.

) Value obtained subtracting the $(\gamma, 2 n)$ reaction contribution from the $\sigma(\gamma, T n)$.

D) Value obtained by subtracting the $\mathrm{Ni}^{4}(\gamma, \mathrm{n}) \mathrm{Ni}^{\prime \prime}$ reaction contribution from the $\sigma(\gamma, \mathrm{Tn})$ for natural nickel corrected for the $(\gamma, 2 n)$ reaction contribution.

8) R. Montalbetti, L. Katz and J. Goldenberg, Phys. Rev. 91 (1953) 659

9) P. A. Flurnoy, R. S. Ticie and W. D. Whitehead, Phys. Rev. 120 (1960) 1424

10) E. B. Bazhanov, A. P. Komar and A. V. Kulikov, JETP 46 (1964) 1497

11) J. Goldenberg and L. Katz. Can. J. Phys. 32 (1954) 49

12) L. Kaiz and A. O. W. Camoron, Can. J. Phys. 29 (1951) 518

13) J. P. Roalswing, R. N. H. Haslam and D. J. McKenzic, Can. J. Phys. 37 (1959) 607

14) J. H. Carver, and W. Tuchinetz. Proc. Phys. Soc. 73 (1959) 585

15) L. W. Jones and K. M. Terwillinger, Phys. Rev. 91 (1953) 699

16) B. I. Gavrilov and L. E. Lazareva, JETP (Sovie: Physies) 3 (1962) 871

17) J. Miller, C. Schuhl and C. Tzara. Nuciear Physics 32 (1962) 236

18) S. C. Fultz, R. L. Bramblett, J. T. Caldwetl and R. R. Harvey, Phys. Rev. 133 (1964) 81149 
REF.

G. Baciu, G. C. Bonazzola, B. Minetti, C. Molino, L. Pasqualini: and $G$. Piragino

Nuclear Phys. 67,178 (1965)

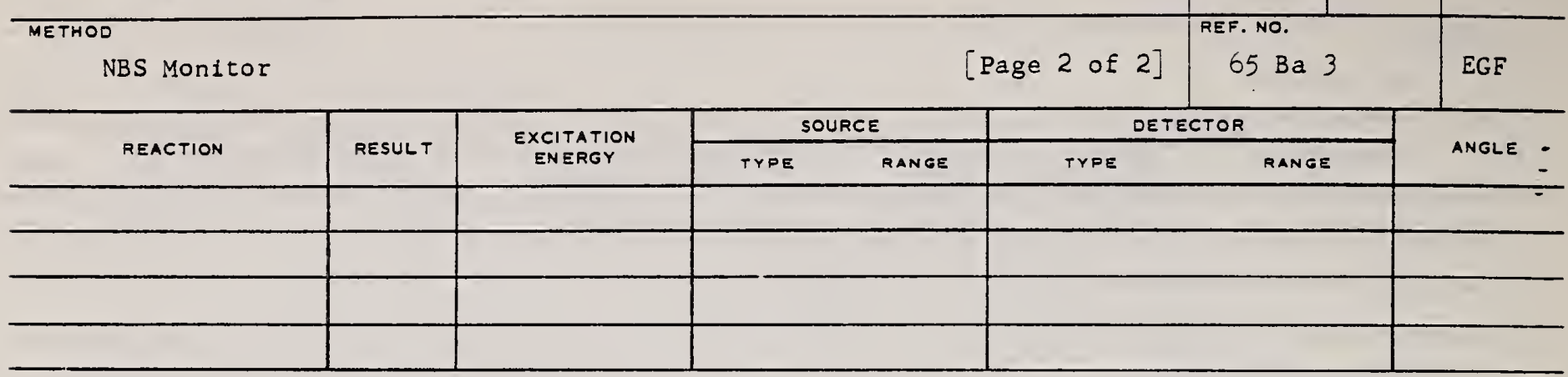

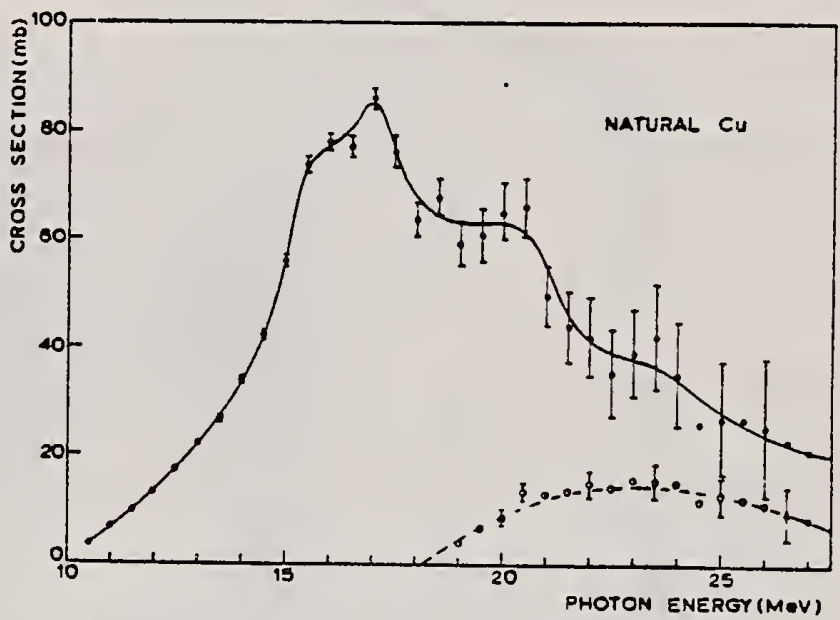

Fig. 3. The $\sigma(\gamma, \mathrm{Tn})$ for natural copper. An average curve is drawn through the experimental points. Open circles represent a calculation of the $\sigma(\gamma, 2 n)$ with $a=6.5 \mathrm{MeV} \perp$ and assuming that $\sigma(\gamma, \mathrm{Tn})$ has the same behaviour for $\mathrm{Cu}^{\circ 3}$ and $\mathrm{Cu}^{\mathrm{N}}\left(\right.$ see ref. $\left.{ }^{10}\right)$ ). The dashed line gives the $\sigma(\gamma, 2 \mathrm{n})$ as measured by Fuitz et al. "8). 


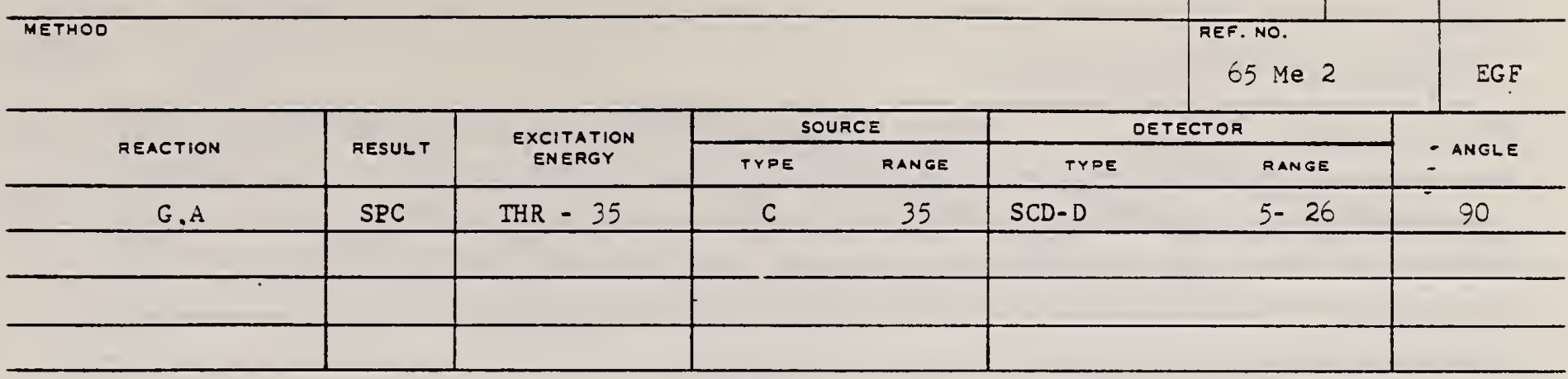
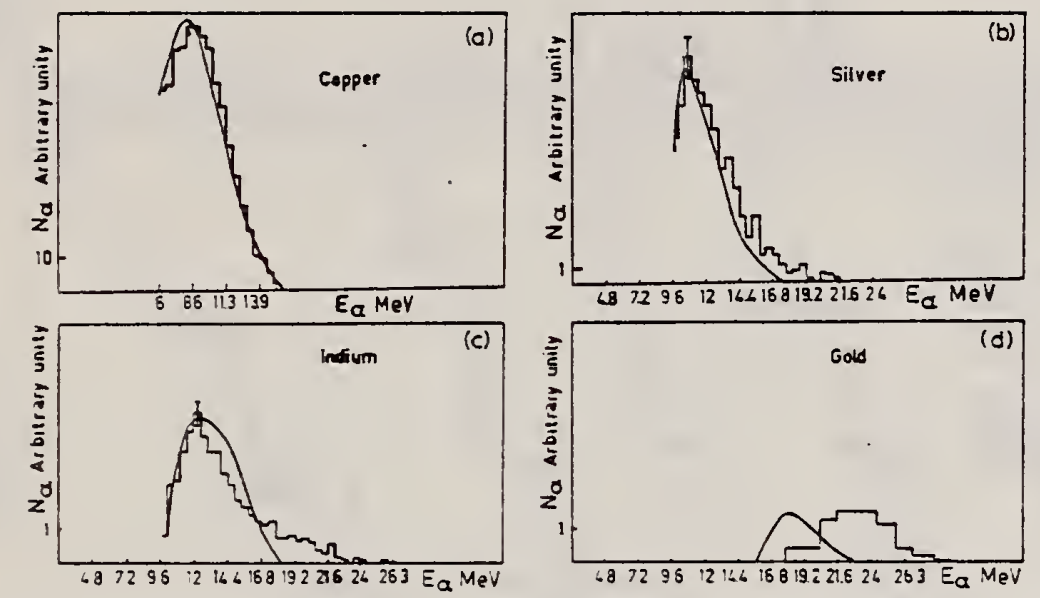

Fig. 2. The histograms show the experimental $\alpha$-spectra. The solid lines are the calculated evaporative spectra corrected for target self-absorption and normalized to the maximum of the experimental spectra.

TABLE 1

$\alpha$ yields from the $90^{\circ}$ data. Yield (per mole $R$ )

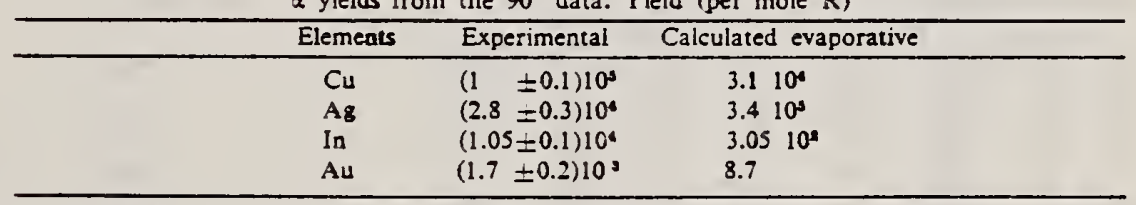

Errors in experimental yields are compounded of statistical errors and errors in the absolute calibration of the beam. 
REF.

J.M. Wyckoff, B. Ziegler, H.W. Koch, and R. Uhlig

phys. Rev. 137, B576-94 (1965)

Synchrotron; ion chamber monitor

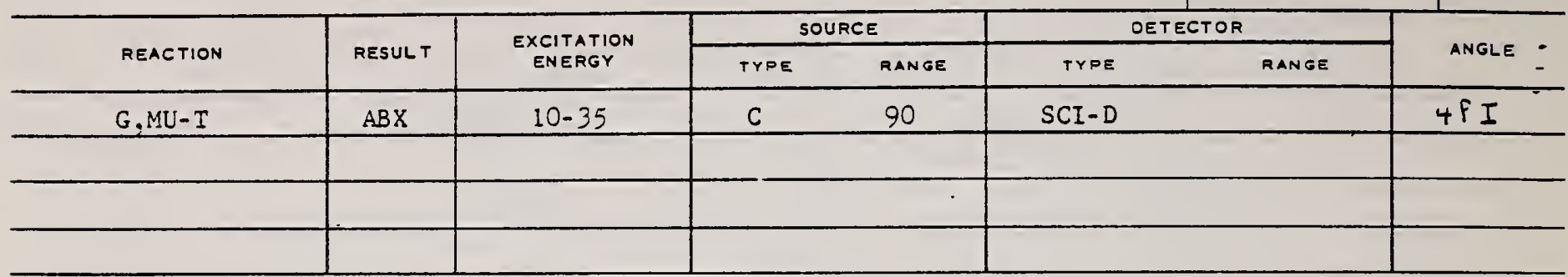

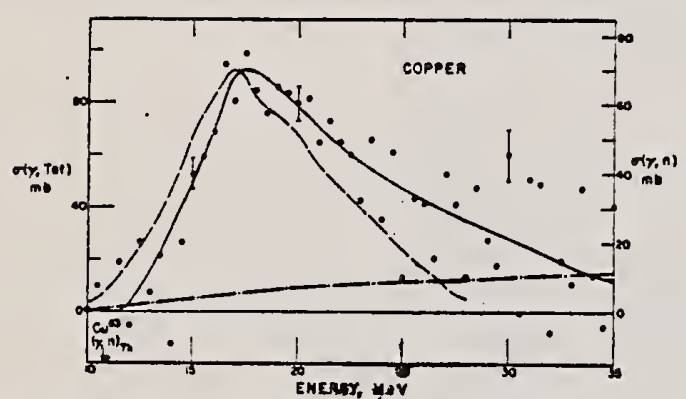

Frc. 27. Copper total photomudear crose section. The dashed ine represents the $\sigma(\gamma, \pi)$ cross section of the Livermore group (Ref. 32) used with the rigin-hand ordinate scale.

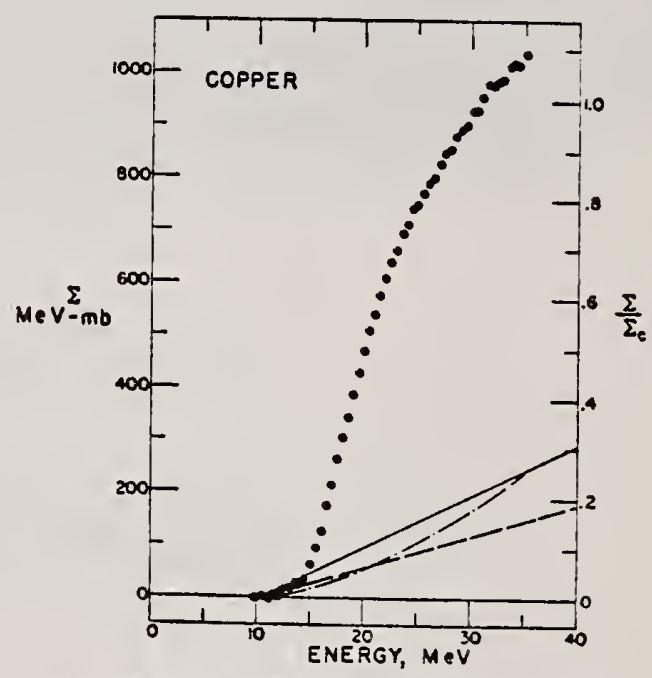

FiG. 28. Copper total photonuclear cross section integrated over energy. 
REF. G. Ben-David, B. Arad, J. Balderman, and Y. Schlesinger

Phys. Rev. 146, B852 (1966)

METHOD

Nuclear Resonance Scattering using $N, G$ reactions.

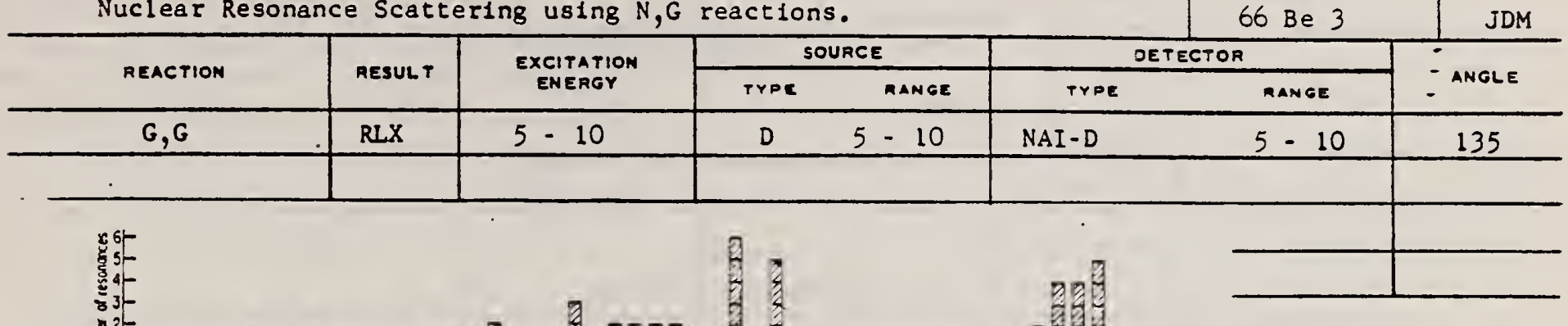

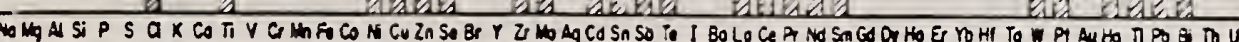

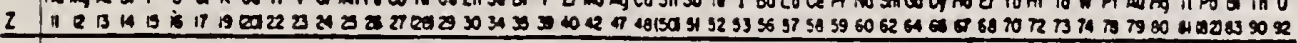

12 口

is 4

is

10

7

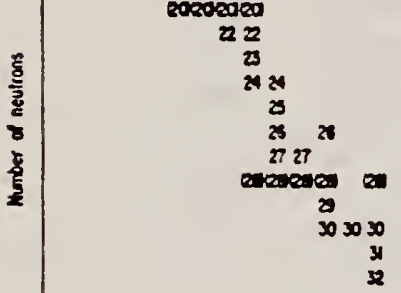

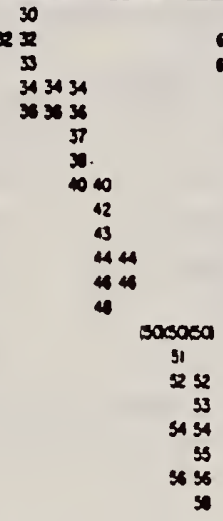

so

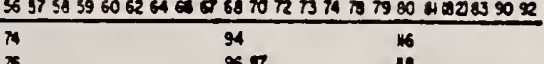

Cos

6

is 63

$\pi$

$\infty$

363 of

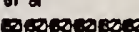

c1 67 a 44

- 7000

$2 \pi \frac{n}{2}$

14

$\begin{array}{lll}51 & 74 & \pi 74 \\ 253 & & \pi\end{array}$

$44 \quad 84$

103

86

4 80

s0 5090

929292

93

93

95
$\times 96$
97

99

$\begin{array}{ll}9 \pi & 10 \\ 99 & 10 \\ 0000 & 00\end{array}$

101000

mor never

is ese

105

of

$\cos$

$\infty$

10

12 112

14

17

19

FIG. 3. Histogram of distribution of observed resonances among the different targets. The atomic number is given directly beneath the chemical symbol followed by the neutron numbers of the naturally occurring isotopes. Magic numbers are shown in brackets.

TADLE III. List of effective cross sections.

\begin{tabular}{|c|c|c|c|c|c|c|c|}
\hline Scatterer & $\begin{array}{l}\text { Energy } \\
(\mathrm{MeV})\end{array}$ & $\begin{array}{c}\text { Gamms } \\
\text { cource }\end{array}$ & (mb) & Scatterer & $\begin{array}{l}\text { Energy } \\
\text { (MeV) }\end{array}$ & $\begin{array}{c}\text { Gammo } \\
\text { cource }\end{array}$ & $\stackrel{3}{(m b)}$ \\
\hline 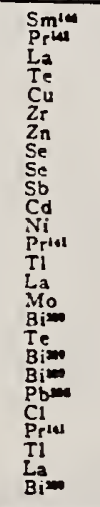 & $\begin{array}{l}8.997 \\
8.981 \\
8.532 \\
8.532 \\
8.499 \\
8.406 \\
8.119 \\
7.819 \\
7.76 \\
7.67 \\
7.64 \\
7.64 \\
7.644 \\
7.64 \\
7.634 \\
7.634 \\
7.634 \\
7.528 \\
7.416 \\
7.300 \\
7.285 \\
7.235 \\
7.185 \\
7.16 \\
7.15 \\
7.149\end{array}$ & $\begin{array}{l}\mathrm{Ni} \\
\mathrm{Cr} \\
\mathrm{Ni} \\
\mathrm{Ni} \\
\mathrm{Cr} \\
\mathrm{Se} \\
\mathrm{Ni} \\
\mathrm{Ni} \\
\mathrm{K} \\
\mathrm{V} \\
\mathrm{Fe} \\
\mathrm{Fe} \\
\mathrm{Fe} \\
\mathrm{Ge} \\
\mathrm{Cu} \\
\mathrm{Cu} \\
\mathrm{Cu} \\
\mathrm{Ni} \\
\mathrm{Se} \\
\mathrm{Ag} \\
\mathrm{Fe} \\
\mathrm{Fe} \\
\mathrm{Se} \\
\mathrm{Cu} \\
\mathrm{Ma} \\
\mathrm{Ti}\end{array}$ & $\begin{array}{r}100 \\
9 \\
6 \\
3 . \\
24 \\
3050 \\
13 \\
50 \\
90 \\
96 \\
400 \\
70 \\
120 \\
3700 \\
7 \\
11 \\
4 \\
604 \\
100 \\
800 \\
4100 \\
34 \\
80 \\
120 \\
500 \\
2000\end{array}$ & 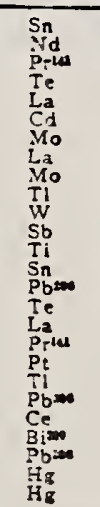 & $\begin{array}{l}7.01 \\
6.867 \\
6.867 \\
6.7 \\
6.54 \\
6.474 \\
6.44 \\
6.413 \\
6.413 \\
6.413 \\
26.3 \\
6.31 \\
6.31 \\
6.27 \\
6.15 \\
5.3 \\
6.12 \\
6.12 \\
5.19 \\
5.99 \\
5.9 \\
5.646 \\
5.646 \\
5.53 \\
5.44 \\
4.903\end{array}$ & 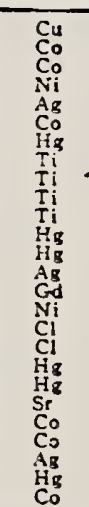 & 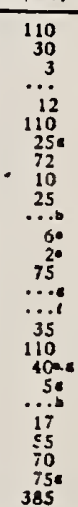 \\
\hline
\end{tabular}

- High-energy componeat of a compier specterm.

- A broad scattered opectrum with no observable peak gtructure

- There are aclually two lines of energies 7.647 and $7.633 \mathrm{MeV}$.

(a) haviag

has enerefore been corrected. although there is no possibulity at present of

ray probably an independent leveilo the comples opectirum of $\mathrm{NI} 7$

- Rough

May be inelastic componeat fom 7.328 lenel in Te

- The relative liae intendities in this case are due to Grober

co. Wnrkera.

i Noline la knowa for the wource at this eneres. 
H. Hoffmann, B. Prowe and H. Ullrich

Nuclear Phys. 85,631 (1966)

ELEM. SYM. A

\begin{tabular}{|c|c|c|c|c|c|c|c|}
\hline $\begin{array}{l}\text { METHOD } \\
\text { Betatron }\end{array}$ & & & & & & $\begin{array}{l}\text { REF. NO. } \\
66 \text { Ho } 3\end{array}$ & JDM \\
\hline \multirow{2}{*}{ REACTION } & \multirow{2}{*}{ RESULT } & \multirow{2}{*}{$\begin{array}{l}\text { EXCITATION } \\
\text { ENERGY }\end{array}$} & \multicolumn{2}{|c|}{ SOURCE } & \multicolumn{2}{|c|}{ DETECTOR } & \multirow{2}{*}{ ANGLE: } \\
\hline & & & TYPE & RANGE & TYPE & RANGE & \\
\hline$G, A$ & $A B Y$ & THR-31 & $C$ & 31 & $S C D-D$ & $3-14$ & 130 \\
\hline & & & & & & & \\
\hline & & & & & & & \\
\hline
\end{tabular}

TABLE 1

Experimental data and results

\begin{tabular}{|c|c|c|c|c|c|c|c|}
\hline Element & $\mathbf{M g}$ & Al & $\mathbf{s}$ & $\mathrm{Ni}$ & $\mathrm{Cu}$ & $\mathrm{Zn}$ & Error (\%) \\
\hline target thickness $\left(\mathrm{mg} / \mathrm{cm}^{2}\right.$ ) & 0.81 & 1.54 & 0.80 & 2.50 & 2.68 & 3.00 & 54) \\
\hline dose $(r)$ & 6190 & 25400 & 23200 & 3880 & 5840 & 4220 & 10 \\
\hline $\begin{array}{l}\text { yield absolute }\left(10^{s} / \mathrm{mole} \cdot r\right) \\
\quad \text { for } E_{\mathrm{m}}>3.16 \mathrm{MeV}\end{array}$ & 0.61 & 0.93 & 1.46 & 1.65 & 0.92 & 2.42 & $11 \bullet$ \\
\hline yield relative to $\mathrm{Ni}$ & 0.36 & 0.56 & 0.88 & 1 & 0.55 & 1.43 & 54) \\
\hline$Y_{Y, a} / Y_{y, \cot }(\%)$ & 9.6 & 11.4 & 12.4 & 7.0 & 3.2 & b) & \\
\hline Duciear temp. $\theta(\mathrm{MeV})$ & 1.43 & 1.48 & 1.46 & 1.04 & & 0.91 & 10 \\
\hline $\begin{array}{l}\text { level density parameter a } \\
\left(\mathrm{MeV}^{-1}\right)\end{array}$ & 5.1 & 4.8 & 4.9 & 8.6 & & 10.8 & 10 \\
\hline
\end{tabular}

-) For $\mathrm{S}$, the error of the target thickness has been $10 \%$ of the absolute yield $14 \%$ and of the relative yield $10 \%$.

b) For $\mathrm{Zn}_{\mathrm{n}} \sigma_{\gamma_{\mathrm{t}} \text { tot }}$ is not known.

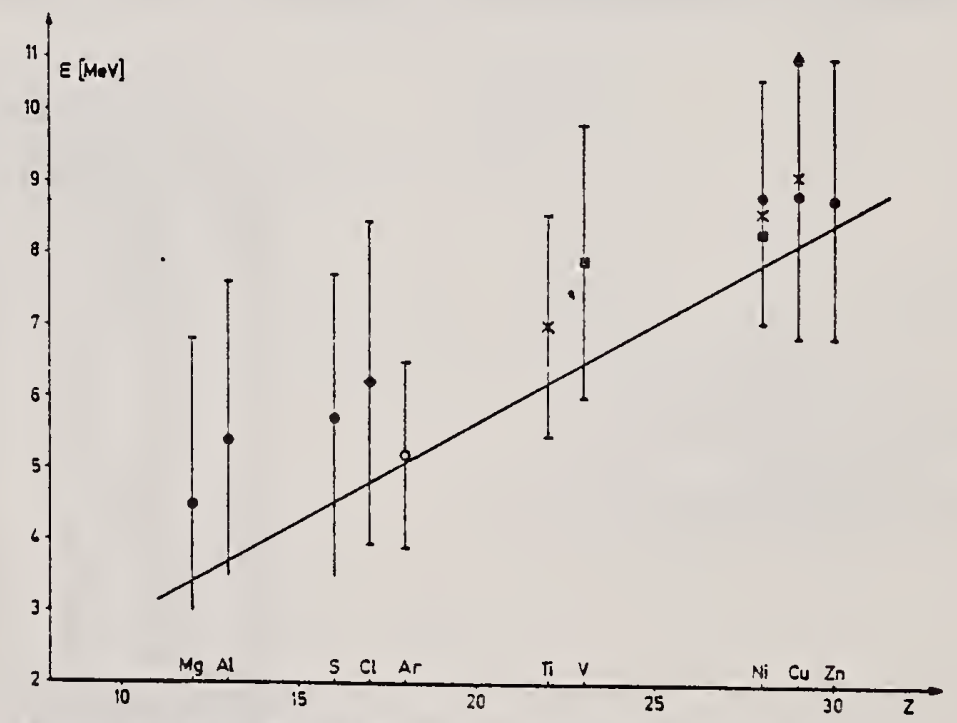

Fig. 4. Position of the peaks in different photoalpha spectra plotted against $Z$ of the target nuclei.

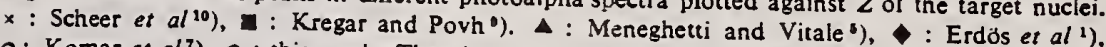

0 : Komar et $\left.a l^{7}\right),:$ : this work. The signs show the position of the maximum. the bars give the widhs at half maximum. The curve shows the height of the Coulomb barrier. 
REF

Yu. M. Volkov, A.P. Komar and.V.P. Chizhov

J. Nucl. Phys. (USSR) 3, 277 (1966)

Sov. J. Nucl. Phys. 3, 198 (1966)

\begin{tabular}{|c|c|c|c|c|c|c|c|}
\hline METHOD & & & & & & $\begin{array}{l}\text { REF. NO. } \\
66 \text { VO } 1 \\
\end{array}$ & JDM \\
\hline \multirow[b]{2}{*}{ REACTION } & \multirow[b]{2}{*}{ RESULT } & \multirow{2}{*}{$\begin{array}{c}\text { EXCITATION } \\
\text { ENERGY }\end{array}$} & \multicolumn{2}{|c|}{ SOURCE } & \multicolumn{2}{|c|}{ DETECTOR } & \multirow{2}{*}{ - ANGLE } \\
\hline & & & TYPE & RANGE & TYPE & RANGE & \\
\hline$G, D$ & RLY & THR - 52 & & $23-52$ & $T E L-D$ & $3.6-6.0$ & 90 \\
\hline$G, P$ & RIY & THR - 52 & & $23-52$ & TEL-D & $3.6-5.2$ & 90 \\
\hline & & & & & & & \\
\hline
\end{tabular}

The results of irradiation of $\mathrm{Cu}$ are listed in Table II.

Table II

\begin{tabular}{l|l|l|l}
\multicolumn{4}{c|}{ Table II } \\
\hline$E_{\text {Ym. MeVI }}$ & $N$ & $N_{p}$ & $\left(\right.$ N/N $\left.N_{p}\right) \cdot 10^{*}$ \\
\hline 23 & 8 & 606 & 1.3 \\
26.5 & 5 & 593 & 0.8 \\
28.5 & 8 & 502 & 1.6 \\
33 & 9 & 559 & 1.6 \\
52 & 2 & 175 & 1.1
\end{tabular}


$67 \mathrm{Ge} 2$

HMG

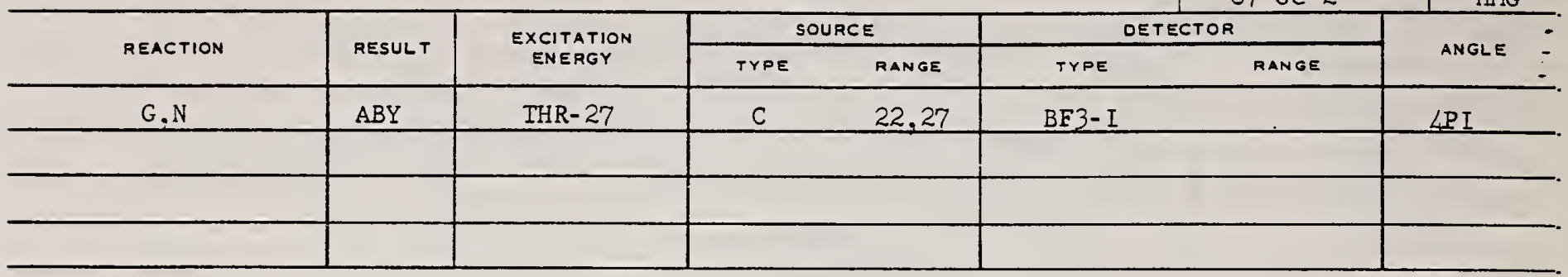

Table 7. Comparison of neutron ytelds. Yields are given in units of (neutron com MeV nueleus) $\times 10^{-}=0$ The estrated uncertainties In $Y$ and $Y_{c}$ are of the order of $6 x$ and $10 x$, reapectively.

\begin{tabular}{|c|c|c|c|c|c|c|c|c|c|c|c|}
\hline \multirow[t]{2}{*}{ Element } & \multirow[t]{2}{*}{$E_{0}$} & \multirow[t]{2}{*}{$Y\left(E_{0}\right)$} & UCRL & Saclay & va. & MBS(OId) & $\frac{\text { UCRL }}{\text { Exp }}$ & $\frac{\text { Sacley }}{\text { Exp }}$ & Ve. & $\begin{array}{l}\text { NBS(O1d) } \\
\text { Exp }\end{array}$ & \multirow[t]{2}{*}{ Ref. } \\
\hline & & & \multicolumn{4}{|c|}{$Y_{c}$} & \multicolumn{4}{|c|}{$\bar{X}^{2}$} & \\
\hline Pb & $\begin{array}{l}27 \\
22\end{array}$ & $\begin{array}{l}103 \\
111\end{array}$ & $\begin{array}{l}86 \\
92\end{array}$ & 116 & & & $\begin{array}{l}0.83 \\
0.83\end{array}$ & 1.05 & & & 26,30 \\
\hline Au & $\begin{array}{l}27 \\
22\end{array}$ & $\begin{array}{l}89 \\
92\end{array}$ & $\begin{array}{l}97 \\
98\end{array}$ & 88 & & 115 & $\begin{array}{l}1.09 \\
1.07\end{array}$ & 0.96 & & 1.25 & $\frac{24}{38}, 30$, \\
\hline Ta & $\begin{array}{l}27 \\
22\end{array}$ & $\begin{array}{l}81 \\
85\end{array}$ & $\begin{array}{l}82 \\
79\end{array}$ & $\begin{array}{l}77 \\
80\end{array}$ & & 113 & $\begin{array}{l}1.01 \\
0.93\end{array}$ & $\begin{array}{l}0.95 \\
0.94\end{array}$ & & 1.33 & $\begin{array}{l}27,30, \\
38\end{array}$ \\
\hline Ho & $\begin{array}{l}27 \\
22\end{array}$ & $\begin{array}{l}67 \\
69\end{array}$ & $\begin{array}{l}75 \\
77\end{array}$ & 82 & & 103 & $\begin{array}{l}1.12 \\
1.12\end{array}$ & 1.19 & & 1.49 & $\begin{array}{l}27,31, \\
39\end{array}$ \\
\hline$A B$ & $\begin{array}{r}27 \\
22\end{array}$ & $\begin{array}{l}36 \\
34.8\end{array}$ & & & & & & & & & \\
\hline $\mathrm{Cu}$ & $\begin{array}{l}27 \\
22\end{array}$ & $\begin{array}{l}14.4 \\
12.6\end{array}$ & $\begin{array}{l}13.2 \\
11.5\end{array}$ & 12.4 & & & $\begin{array}{l}0.92 \\
0.91\end{array}$ & 0.98 & & & 28,30 \\
\hline$C_{0}$ & $\begin{array}{l}27 \\
22\end{array}$ & $\begin{array}{l}12.7 \\
10.6\end{array}$ & $\begin{array}{r}12.1 \\
9.9\end{array}$ & & 13.5 & & $\begin{array}{l}0.95 \\
0.94\end{array}$ & & 1.27 & & 29,34 \\
\hline $\mathrm{Ca}$ & 27 & 1.69 & & 1.13 & 1.01 & & & 0.67 & 0.60 & & 32,35 \\
\hline P & 27 & 2.35 & & & 1.76 & & & & 0.75 & & 36 \\
\hline Al & 27 & 1.92 & 1.62 & & 1.38 & & 0.84 & & 0.72 & & 25,37 \\
\hline $0^{10}$ & 27 & 0.54 & 0.42 & 0.48 & 0.42 & & 0.78 & 0.89 & & & 16,32 , \\
\hline c & 27 & 0.50 & 0.35 & 0.33 & 0.46 & & 0.70 & 0.66 & & & $\begin{array}{l}37 \\
25,32, \\
33\end{array}$ \\
\hline
\end{tabular}




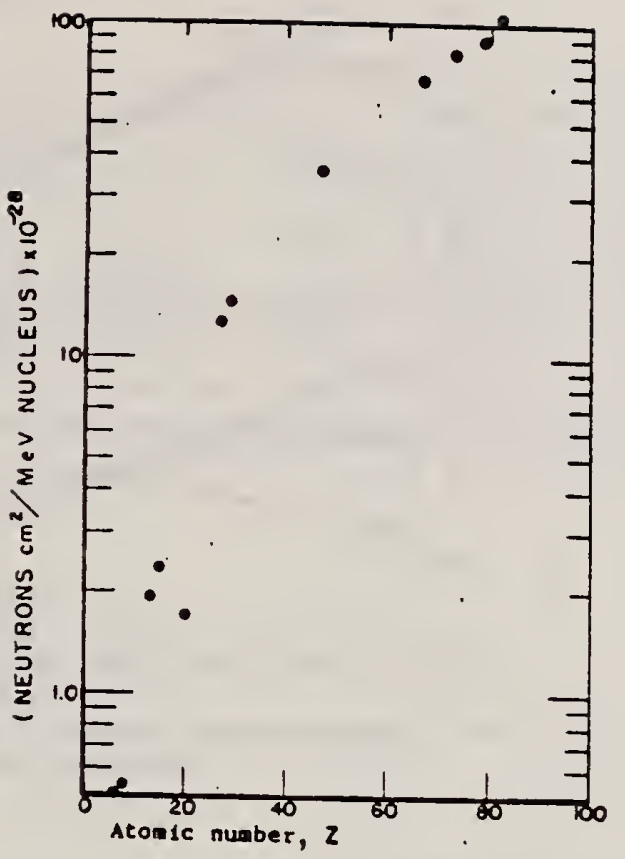

11g. 31. Absolute neutron yield as function of atomic number. The neutron yield froo calcium

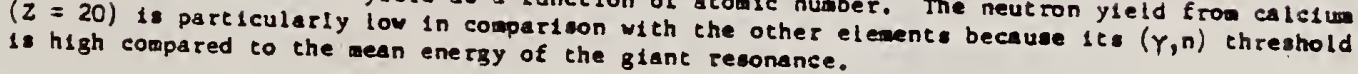


M. Giannini, P. Oliva, D. Prosperi and G. Toumbev

Nucl. Phys. Al01, 145 (1967)

Note: Varied Doppler Width

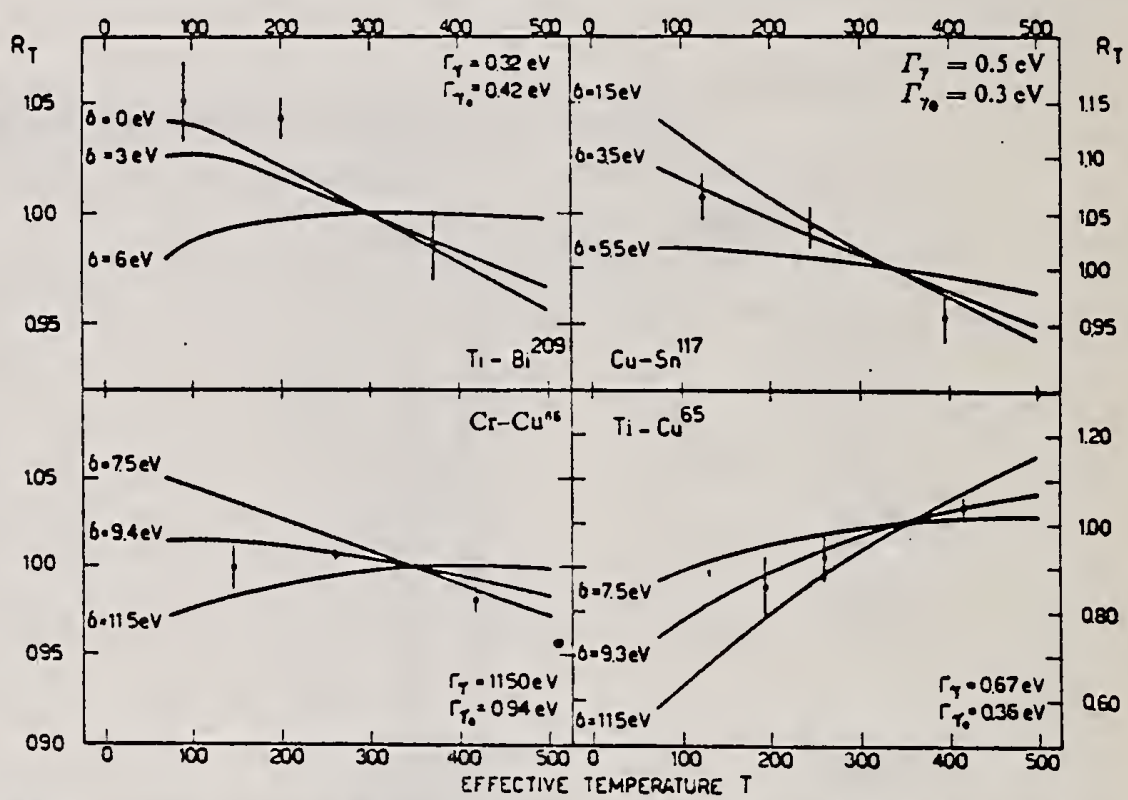

Fig. 7. Calculated variation in resonant scaltering cross section as a function of seatterer temperature for different values of $i$. Eq. (II) defines $R_{T}$.

TABLE 3

Angular distribution results

\begin{tabular}{|c|c|c|c|c|c|c|}
\hline $\begin{array}{l}\text { Resuilint } \\
\text { isotopt }\end{array}$ & $\begin{array}{l}\text { Resonant } \\
\text { level encrgy } \\
(\mathrm{MeV})\end{array}$ & $\begin{array}{l}\text { Ground } \\
\text { state spin }\end{array}$ & $\begin{array}{l}\text { Resonant } \\
\text { level spin }\end{array}$ & $\begin{array}{l}\text { Statisticul } \\
\text { factor } g\end{array}$ & $A_{2}^{e \times D}$ & $A_{1}^{\text {th }}$ \\
\hline$B i$ & 7.15 & $\stackrel{n}{2}$ & $\begin{array}{l}4 \\
\frac{11}{2} \\
\frac{3}{2} \\
\frac{7}{2} \\
2\end{array}$ & $\begin{array}{l}1.2 \\
1.0 \\
0.8\end{array}$ & $0.15 \pm 0.04$ & $\begin{array}{l}0.09 \\
0.19 \\
0.03\end{array}$ \\
\hline Sn & 7.01 & 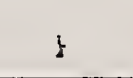 & $\frac{1}{2}$ & $\begin{array}{l}1.0 \\
2.0\end{array}$ & $0.24 \pm 0.04$ & $\begin{array}{l}0 \\
0.25\end{array}$ \\
\hline $\mathrm{Cu}$ & 8.50 & 3 & $\begin{array}{l}1 \\
3 \\
8\end{array}$ & $\begin{array}{l}0.5 \\
1.0 \\
1.5\end{array}$ & $0.00 \pm 0.05$ & $\begin{array}{l}0 \\
0.16 \\
0.14\end{array}$ \\
\hline $\mathrm{Cu}$ & 6.07 & 3 & $\begin{array}{l}\frac{1}{2} \\
\frac{1}{3} \\
\frac{3}{3} \\
\frac{1}{3}\end{array}$ & $\begin{array}{l}0.5 \\
1.0 \\
1.5\end{array}$ & $0.20 \pm 0.04$ & $\begin{array}{l}0 \\
0.16 \\
0.14\end{array}$ \\
\hline
\end{tabular}


TABLE 4

Experimintal results

\begin{tabular}{|c|c|c|c|c|c|c|c|}
\hline $\begin{array}{l}\text { Source- } \\
\text { scatterer }\end{array}$ & $\begin{array}{l}\text { Energy } \\
\text { (MeV) }\end{array}$ & $\Gamma_{\gamma}(\mathrm{eV})$ & $I_{; 0}^{\prime}(\mathrm{EV})$ & $\Gamma_{70} / \Gamma_{7}$ & $\delta(\mathrm{eV})$ & $\left\langle\sigma_{y \gamma}\right\rangle(\mathrm{b})$ & $\bar{\sigma}_{r_{t}}(b)$ \\
\hline $\mathrm{Ti}=2 \times 10 \mathrm{Bi}$ & 7.15 & $0.32 \div 0.23$ & $0.42=0.14$ & $>0.68$ & $<2$ & $2.6 \pm 0.8$ & $3.6 \pm 1.2$ \\
\hline $\mathrm{Cu} \cdot{ }^{11} \mathrm{~S} \mathrm{Sn}$ & 7.01 & $0.5 \pm 1.1$ & $0.3 \doteq 0.3$ & & $3.6 \pm 0.7$ & $1.2 \pm 0.4$ & $3.4 \pm 3.5$ \\
\hline $\mathrm{Cr}-{ }^{*} \mathrm{Cu}$ & 8.50 & $11.5 \pm 8.0$ & $0.94=0.29$ & $0.08 \div 0.04$ & $9.4=0.7$ & $(4.2 \doteqdot 1.3) \cdot 10^{-8}$ & $0.64 \pm 0.20$ \\
\hline$\left\{\mathrm{Ti}+{ }^{* 5} \mathrm{Cu}\right.$ & 6.07 & $0.67 \pm 0.35$ & $0.36 \div 0.07$ & $0.54=0.19$ & $9.3 \pm 0.8$ & $0.44 \pm 0.13$ & $2.0 \pm 0.4$ \\
\hline Tit-" $\mathrm{Cu}$ & 6.07 & $0.32 \pm 0.18$ & $0.16 \pm 0.03$ & $0.51 \div 0.18$ & $9.2 \pm 0.8$ & $0.20 \pm 0.06$ & $0.92 \div 0.19$ \\
\hline
\end{tabular}

In the last two columns, $\left\langle\sigma_{y \gamma}\right\rangle$ and $\bar{\sigma}_{r_{n}}$ are effective cross sections measured at temperature $T_{0}=300^{\circ} \mathrm{K}$. 


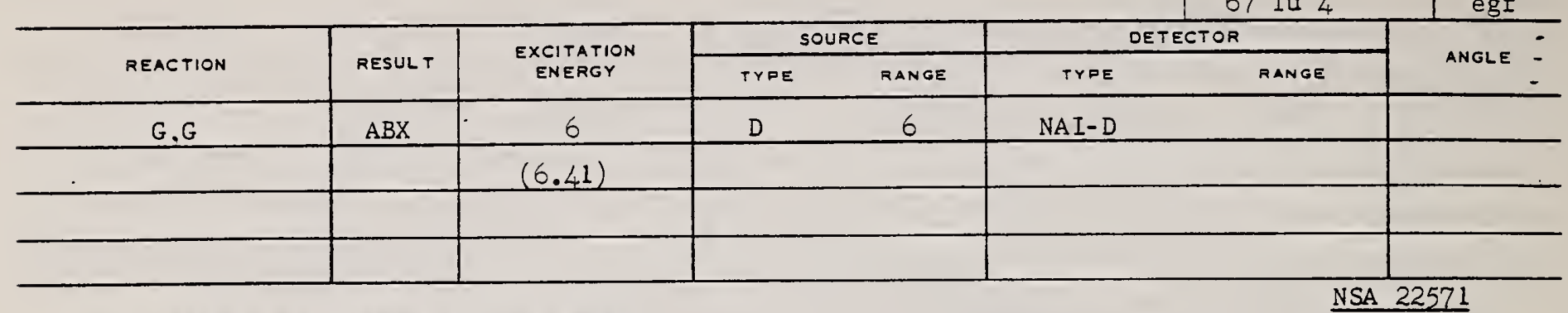

22571 RESONANCE SCATTERING OF GAMMA RAYS BY

COPPER. Tumbev, G. Khr. Compt, Rend. Acad. Bulg. Scl., 20:

541-3(1967). (In Russian).

Gamma rays from the capture of thermal neutrons can be used

to investigate regonance scattering in the region of 6 to $9 \mathrm{MeV}$.

The advantage of using monochromatic gamma rays for investi-

gating resonance scattering is obvious in this case where excita-

tion of oniy one level is to be expected. Resonance scattering by

copper was observed with the use of $\mathrm{TiO}_{2}$ having a weight of $1350 \mathrm{~g}$

as a source of gamma rays. Source and scatterer were natural

isotopic mixtures. Resonance gamma rays having an energy

$E_{\text {gamma }}=6.41 \mathrm{MeV}$ showed an increased count rate due to nuclear

resonance scattering of gamma rays from Ti on $\mathrm{Cu}$. Control ex-

periments were carried out with the source and without it. The

eross-gection for the gamma ray resonance scattering $\sigma$. Was

determined from the count rates under the 6.41 MeV pholopeaks

at different reactor power levels for a 4 in. $\times 6$ in. NaI(TI) crys-

tai. The value of $\sigma_{\gamma y}$ was found to be $16.6 \pm 3.4 \mathrm{mb}$. Since a

naturaf mixture of copper isotope was used as the seattcring

agent, it was not possible to determine whether ${ }^{32} \mathrm{Cu}$ or ${ }^{4} \mathrm{Cu}$ scat-

tered the $6.41-\mathrm{MeV}$ gamma rays by resonance. (TTT) 
REF. N. N. Kaushal, E. J. Winhold, P. F. Yergin, H. A. Medicus and R. H. Augustson

Phys. Rev. 175,1330 (1968)

\begin{tabular}{|c|c|c|}
\hline ELEM. SYM. & A & $z$ \\
\hline $\begin{array}{c}\text { REF. NO. } \\
68 \mathrm{Ka} 1\end{array}$ & HMG \\
\hline RANGE & ANGL \\
\hline 10-85 & 67 \\
\hline
\end{tabular}

NEUT ENGY SPEC

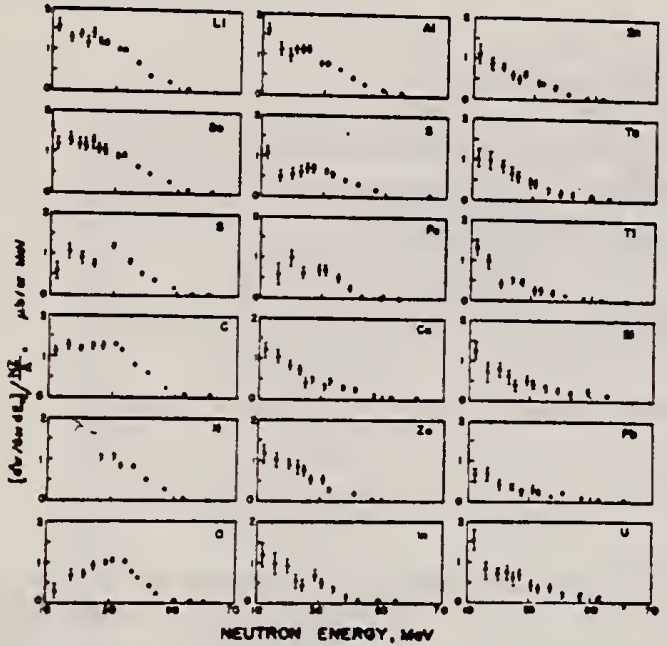

Fro. 6. Observed neutron spectra due to 55-85-MeV difference photon spectra. The effective croes sections have been divided by SZ/A.

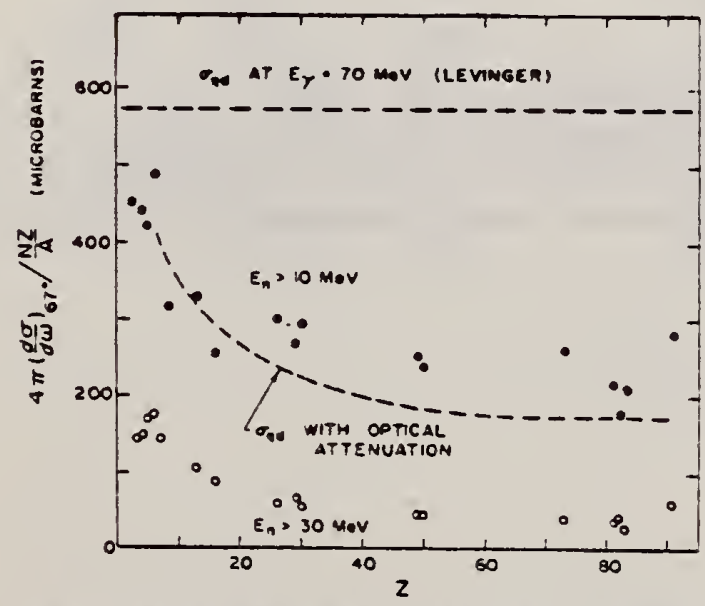

FiG. 7. Effective cross sections for production of fast neutrons with energies greater thsn $10 \mathrm{MeV}$ (solid circles) and $30 \mathrm{MeV}$ (open circles) by the 55-85-MeV photon difference spectrum. The dashed curves are modified quasideuteron mode! predictions as discussed in the text.
TABIx I. Comparison of present cross-section values in mb for production of bigh-energy photoneutrons by 55-85-MeV photons with measured cross sections $\sigma\left(\gamma_{1} T_{n}\right)$, also in mb, for total photoneutron production. The present cross-section values are uncertain by 8 to $10 \%$ because of counting statistics and normalization errors; in addition all values depend on an absolute normali2ation in terms of the deuteron photodisintegration cross section, which is known to about $10 \%$ at these energies.

\begin{tabular}{|c|c|c|c|c|}
\hline Target & $\begin{array}{c}4 r(d \sigma / d \omega)_{\sigma^{\circ}} \\
\left(E_{\mathrm{a}}>10 \mathrm{MeV}\right) \\
{[\text { Present }} \\
\text { experiment] }\end{array}$ & $\begin{array}{c}\sigma(\gamma \\
\text { Jones and } \\
\text { Terniligere }\end{array}$ & $\begin{array}{l}\left.T_{n}\right) \\
\text { Costa at ab. }\end{array}$ & $\begin{array}{l}\text { Other } \\
\text { results }\end{array}$ \\
\hline $\begin{array}{l}\mathrm{Li} \\
\mathrm{Be} \\
\mathrm{B} \\
\mathrm{C} \\
\mathrm{O} \\
\mathrm{N} \\
\mathrm{S} \\
\mathrm{Fo} \\
\mathrm{Ca} \\
\mathrm{Zn} \\
\mathrm{In} \\
\mathrm{Sn} \\
\mathrm{T} \\
\mathrm{T} \\
\mathrm{Pb} \\
\mathrm{Bi} \\
\mathrm{U}\end{array}$ & $\begin{array}{c}0.75 \\
1.0 \\
1.0 \\
1.5 \\
1.3 \\
2.8 \\
2.1 \\
4.2 \\
4.3 \\
4.4 \\
7.4 \\
7.0 \\
10.7 \\
10.7 \\
8.3 \\
13 \\
16\end{array}$ & $\begin{array}{c}2.7 \\
1.3 \\
5.5 \\
16 \\
20\end{array}$ & $\begin{array}{l}1.0 \\
2.3 \\
1.4 \\
1.4 \\
1.6 \\
4.6 \\
4.4 \\
12 \\
19 \\
15\end{array}$ & $\begin{array}{l}2.3^{d} \\
2.4^{d} \\
8^{d} \\
6.5^{d}\end{array}$ \\
\hline
\end{tabular}

enetion between 55 and $85 \mathrm{MeV}$, as read from Figs.

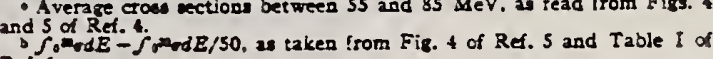
Ref.6. Corta, L. Papualinl, G. Piragino, and L. Roario. Nuovo Cimento 42. 306 (1966). Cimento 42 , 148 (1966). 
REF.

I. Tomimasu

J. Phys. Soc. Japan 25, 655

\begin{tabular}{|c|c|c|c|c|c|c|c|}
\hline \multirow[b]{2}{*}{ REACTION } & \multirow{2}{*}{ RESULT } & \multirow{2}{*}{$\begin{array}{l}\text { EXCITATION } \\
\text { ENERGY }\end{array}$} & \multicolumn{2}{|c|}{ SOURCE } & \multicolumn{2}{|c|}{ OETECTOR } & \multirow{2}{*}{ ANGLE:- } \\
\hline & & & TYPE & RANGE & TYPE & RANGE & \\
\hline $\mathrm{G}, \mathrm{XN}$ & $A B X$ & $.10-24$ & $\mathrm{C}$ & $10-24$ & BE3-I & & $4 P I$ \\
\hline & & & $\cdot$ & & & & \\
\hline & & & & & & & \\
\hline
\end{tabular}

Table II. Parameters of the photoneutron cross sections for natural $\mathrm{Cu}$ and $\mathrm{Pb}$. The contribution of the $(r, p)$ cross section for Cu was considered.

\begin{tabular}{|c|c|c|c|c|c|c|c|}
\hline & $\begin{array}{c}\boldsymbol{K}_{\mathrm{m}} \\
(\mathrm{MeV})\end{array}$ & 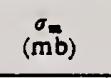 & $\begin{array}{c}\Gamma \\
\text { (MeV) }\end{array}$ & $\begin{aligned} & \sigma_{0}=\sum_{m b} \\
&(\mathrm{MeV}-\mathrm{mb})\end{aligned}$ & $\Sigma / \Sigma 0$ & $(\mathrm{mb} / \mathrm{MeV})$ & $\frac{\sigma-2}{0.00225 A^{3 / 3}}$ \\
\hline $\mathrm{Cu}$ & $17.2 \pm 0.3$ & $78 \pm 8$ & $8.0 \pm 0.5$ & $587 \pm 90$ & $0.62 \pm 0.1$ & $1.81=0.24$ & $\begin{array}{c}0.75 \pm 0.11 \\
\left(0.95=0.14^{*}\right)\end{array}$ \\
\hline $\mathrm{Pb}$ & $14.1 \pm 0.3$ & $660 \pm 60$ & $5.0 \pm 0.2$ & $3910 \pm 590$ & $1.32 \pm 0.2$ & $18.6 \pm 2.4$ & $1.13 \pm 0.17$ \\
\hline
\end{tabular}

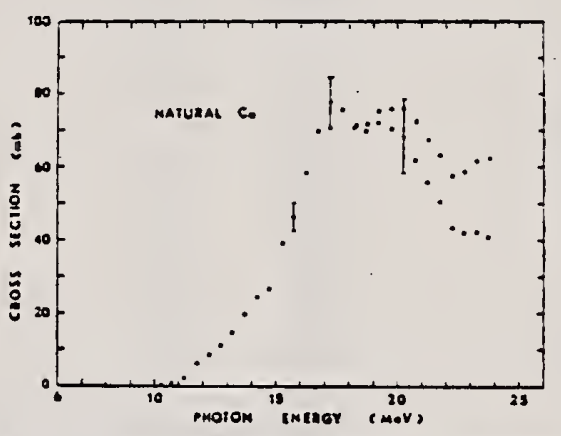

Fig. 10. The photoneutron cross section for natural $\mathrm{Cu}$ is represented by the open circles. The photoneutron yield cross section is represented by the closed circles.

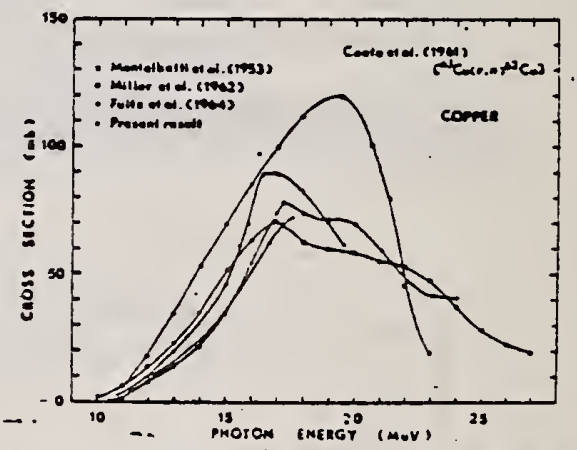

Fig. 12. Comparison of the photoneutron cross sections for natural $\mathrm{Cu}$. 


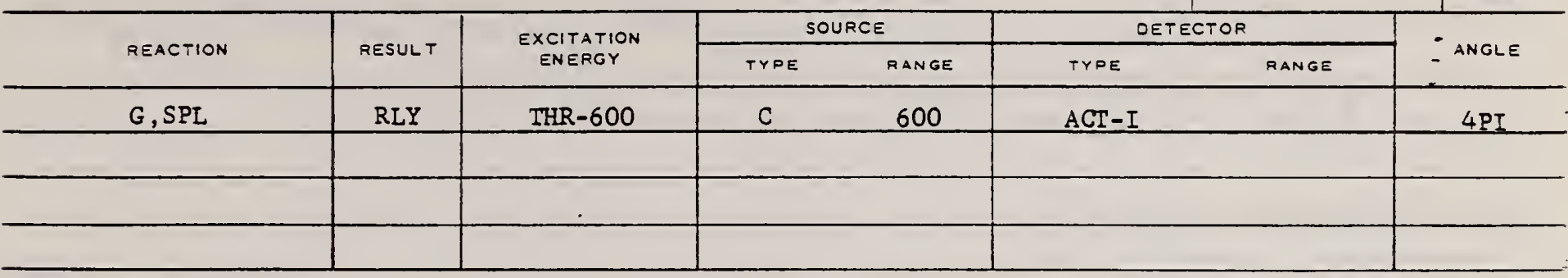

Tasxulu 1 - Rese relation dei prododli di opallazione.

\begin{tabular}{|c|c|c|}
\hline Reaxionx MixtKxzitumale (O) & Prudormu anuiostrive & 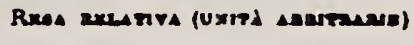 \\
\hline 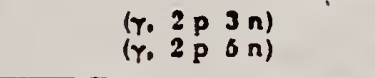 & Cow & $8 \pm 1$ \\
\hline 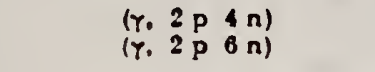 & Co"l & $B \pm 1$ \\
\hline 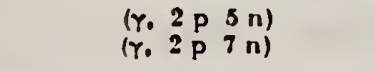 & $\operatorname{Cos}$ & $2.0 \pm 0.4$ \\
\hline 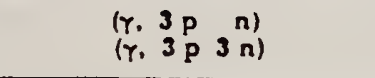 & Post & $0,20 \pm 0.04$ \\
\hline 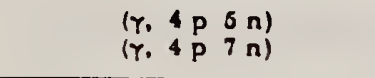 & $\mathbf{M n} \mathbf{m}$ & $0,11 \pm 0.02$ \\
\hline 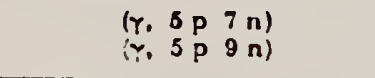 & Crs & $2,0 \pm 0,5$ \\
\hline $\begin{array}{l}(Y .8 \text { p } 90 n) \\
(y .8 \text { pII } n)\end{array}$ & Sote & $0,20 \pm 0,08$ \\
\hline \multicolumn{3}{|c|}{ 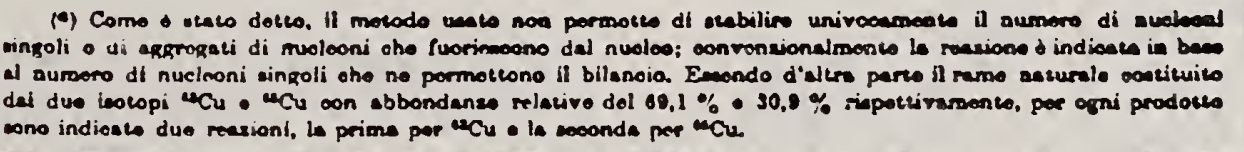 } \\
\hline
\end{tabular}


B. S. Ishkhanov, I.M. Kapitonov, E.V. Lazutin, I.M. Piskarev, V.G. Shevchenko

Ser. III Fiz. Astron. 25, 606 (1970)

70 Is 6

\begin{tabular}{|c|c|c|c|c|c|c|c|}
\hline \multirow[b]{2}{*}{ REACTION } & \multirow[b]{2}{*}{ RESULT } & \multirow{2}{*}{$\begin{array}{l}\text { EXCITATION } \\
\text { ENERGY }\end{array}$} & \multicolumn{2}{|c|}{ SOURCE } & \multicolumn{2}{|c|}{ DETECTOR } & \multirow[b]{2}{*}{ ANGLE: } \\
\hline & & & TYPE & RANGE & TYPE & RANGE & \\
\hline$G, X N$ & $A B X$ & $10-30$ & $\mathrm{C}$ & $10-30$ & BF 3-I & & 4PI \\
\hline & & & & & & & \\
\hline & & & & & & & \\
\hline & & & & & & & \\
\hline
\end{tabular}

. Таблица 2

28200 PHOTONEUTRON REACTIONS ON COPPER. ISHKGanor, B, S.; Kapilonot, I. M.: Laxutí, E. V.: P1skerer, I. M.: Shevehenko, v. G, Vestn. Mosk, Univ., Ser, III. Fiz. Astron. 11: 606-13(Nov-Dec 1970). (In Rusol in).

The structure of photoneutron differential cross section in copper was studied. The energy dependence of cross sections of pholonevtron reactions on copper at excitation from the threshold to $30 \mathrm{MeV}$ was determined. Theoretical and experimental dala were compared. (R.V.J.)

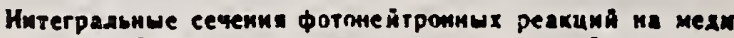

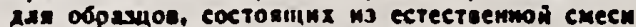
nзотопов

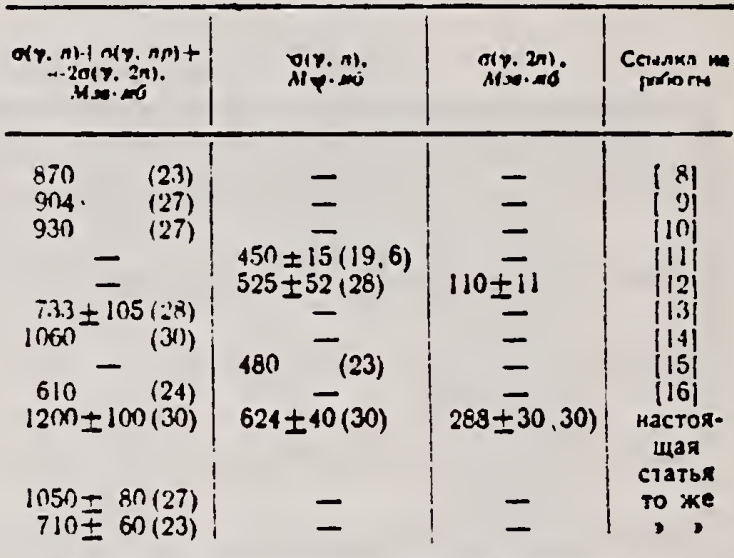

В екобках указан верхиий предет интегрнропания.

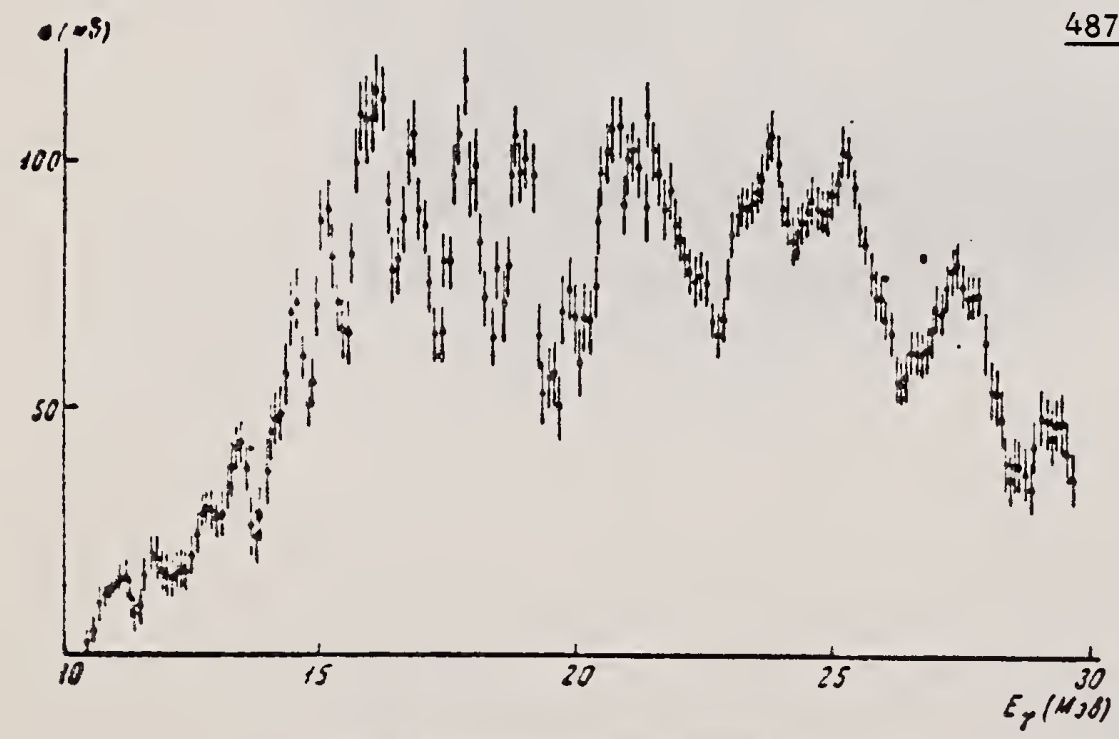

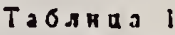

Ropory pazıмиाнх фотонеi-

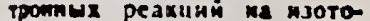
nax medx

\begin{tabular}{|c|c|c|}
\hline Hoton & T Tran & $\operatorname{linmor}_{(M)}$ \\
\hline $\mathrm{Cu}$ & {$\left[\begin{array}{l}(Y, n) \\
(\gamma, n r) \\
(\gamma .2 n)\end{array}\right.$} & $\begin{array}{l}111.81 \\
16.72 \\
13.74\end{array}$ \\
\hline con & $\begin{array}{l}(\gamma, n) \\
(\gamma, n p) \\
(\gamma, 2 n) \\
(\gamma, 3 n)\end{array}$ & $\begin{array}{r}9.91 \\
17.11 \\
17.82 \\
28,66\end{array}$ \\
\hline
\end{tabular}

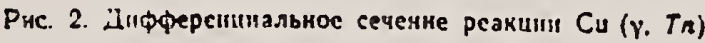


Yu. P. Antuf'ev, V. L. Agranovich, V. B. Ganenko, V. S. Kuz'menko, I. I. Miroshnichenko, and P. V. Sorokin

Yad. Fiz. 13, 473 (1971); Sov. J. Nucl. Phys. 13, 265 (1971)

\begin{tabular}{|c|c|c|c|c|c|c|c|}
\hline METHOD & & & & & & $\begin{array}{l}\text { REF. NO. } \\
71 \text { An } 1 \\
\end{array}$ & hmg \\
\hline \multirow[b]{2}{*}{ REACTION } & \multirow[b]{2}{*}{ RESULT } & \multirow{2}{*}{$\begin{array}{c}\text { EXCITATION } \\
\text { ENERGY }\end{array}$} & & $R C \varepsilon$ & \multicolumn{2}{|c|}{ DETECTOR } & \multirow[b]{2}{*}{ - ANGLE } \\
\hline & & & TYPE & RANGE & TYPE & RANGE & \\
\hline$G, P$ & SPC & $37-999$ & $\mathrm{C}$ & 700.999 & $T E L-D$ & $25-400$ & DST \\
\hline$G, D$ & SPC & $45-999$ & C & 700,999 & $T E L-D$ & $25-400$ & DST \\
\hline
\end{tabular}

Table I. Values of the parameter $T, \mathrm{MeV}$

\begin{tabular}{|c|c|c|c|c|c|c|c|c|c|c|c|c|c|c|c|c|}
\hline \multirow{3}{*}{ Terger } & \multicolumn{10}{|c|}{$E_{0}-700 \mathrm{MeV}$} & \multicolumn{6}{|c|}{$\mathrm{E}_{0}-1200 \mathrm{MeV}$} \\
\hline & \multicolumn{5}{|c|}{ Protons } & \multicolumn{5}{|c|}{ Deuterons } & \multicolumn{3}{|c|}{ Protons } & \multicolumn{3}{|c|}{ Deuterons } \\
\hline & $+\infty$ & $\infty$ & $\infty$ & $100 \%$ & 1200 & $\infty$ & $\infty$ & $\infty$ & 100 & 120 & $\infty$ & $\infty$ & 130 & $\infty$ & $\infty$ & 1200 \\
\hline $\mathrm{Li}$ & 48 & 42 & 34 & 30 & 27 & 28 & 26 & 22 & 21 & 20 & & is & 28 & & 27 & 26 \\
\hline Bo & 48 & 43 & 36 & 30 & 27. & 28 & 26 & 26 & 22 & 19 & & 45 & 28 & & 27 & 24 \\
\hline C & 50 & 4 & 38 & 30 & 26 & $\mathbf{3 4}$ & 33 & 29 & 23 & 19 & 60 & 48 & 35 & 37 & 36 & 23 \\
\hline Si & & 43 & & & 28 & & 27 & & . & 22 & & 46 & 35 & & 28 & 25 \\
\hline $\mathrm{Cu}$ & & & & & & & & & & & & 45 & 29 & & 27 & 24 \\
\hline$T$ & & & & & 28 & & & & & 21 & & 45 & 36 & & 27 & $x$ \\
\hline $\mathrm{Pb}$ & & & & & & & & & & & 51 & & 29 & 36 & & 2 \\
\hline
\end{tabular}

$999=1.2 \mathrm{GEV}, \mathrm{D} / \mathrm{P}$

Yield of protons $30-400 \mathrm{MeV}$, deuterons $30-200 \mathrm{MeV}$.

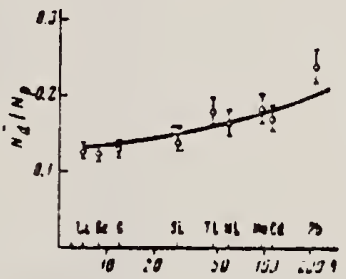

FIG. 4. The ratios $N_{d} / N_{p}$ as 2 function of target-nucleus mass number $A$ at an angle $\theta=60^{\circ}$ for $E_{0}=$ $1200 \mathrm{MeV}$. Solid curve $-\mathrm{A}^{0.13}$

The measured secondary-particle spectra for kisetic energies $\mathrm{T}>80 \mathrm{MeV}$ are well descrtbed by the expression

$$
d^{2} \sigma / d \Omega d T Q=\text { const } T \exp (-T / \tau) \text {. }
$$

which is identical to the formula for the evaporation process. (1) In Table I we have given the values of the parameter $T$ for the nuclei studied, at various angles. The accuracy in determination of $\tau$ is about $10 \%$. 
REF. I. A. Grishaev, A. N. Krinftsyn, N.I. Lapin, V.I. Nikiforov, G. D. Pugachev, and B.I. Shramenko

Yad. F1z, 14., 35 (1971)

Sov. J. Nucl. Phys. 14, 20 (1972)

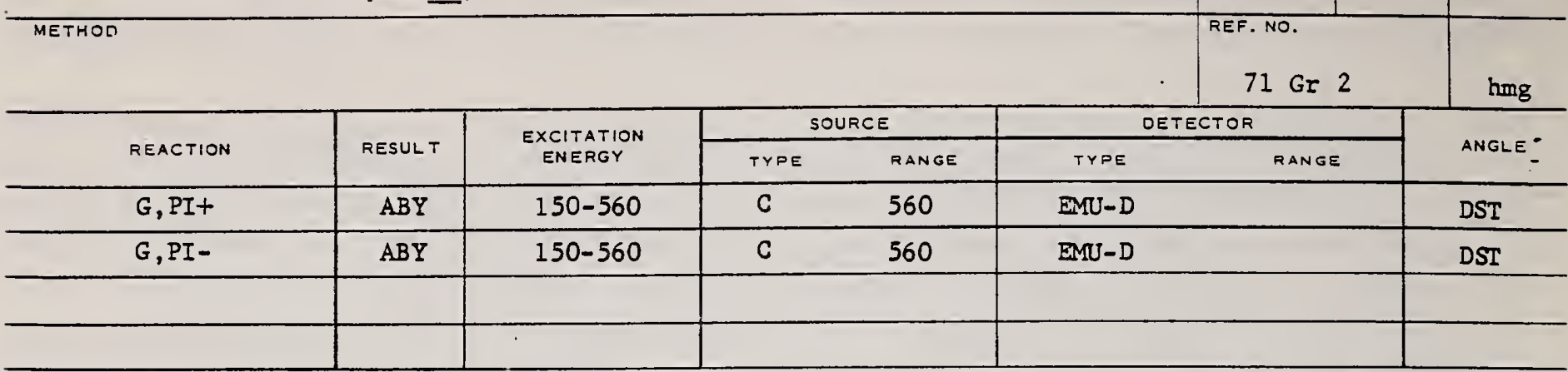

Cross section for photoproduction of $\pi^{-}$and $\pi^{*}$ mesons for $E_{0}=560 \mathrm{MeV}$

\begin{tabular}{|c|c|c|c|c|c|c|c|}
\hline \multirow{5}{*}{ Mants } & \multicolumn{7}{|c|}{$10 \mathrm{~m} \mathrm{~cm}^{2} / \mathrm{cos}$ MeV equ quent } \\
\hline & \multicolumn{3}{|c|}{$0-\infty$} & \multirow{2}{*}{\multicolumn{4}{|c|}{ 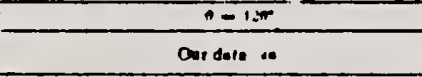 }} \\
\hline & \multirow{2}{*}{$\begin{array}{l}\text { Dere or } \\
\text { of } 1 \text { i. T. } \\
33 \mathrm{Mov}\end{array}$} & \multirow{2}{*}{\multicolumn{2}{|c|}{$\begin{array}{l}\text { Our dates. } \\
T=40 \mathrm{x} \text { iv }\end{array}$}} & & & & \\
\hline & & & & \multicolumn{2}{|c|}{$\mathrm{T}=40 \mathrm{MeV}$} & \multicolumn{2}{|c|}{$T \cdot$ Mn MeV } \\
\hline & $\rightarrow$ & $\rightarrow$ & - & $\Rightarrow$ & $\pi-$ & $\ldots$ & *- \\
\hline $\begin{array}{l}C \\
\hat{A} \\
C \\
c\end{array}$ & $\begin{array}{l}21.6 \pm 0.5 \\
42.4 \pm 1.0 \\
28.8 \pm 1.6\end{array}$ & $\begin{array}{l}20.6 \pm 1.8 \\
33.3 \pm \pm 3 \\
31.8 \pm 5.6\end{array}$ & $\begin{array}{l}202 \pm 3 \\
47.5 \pm 4 \\
66 \pm 8.6\end{array}$ & $\begin{array}{c}278 \pm 2.1 \\
37 \pm 4 \\
190 \pm 7 \\
20 \pm \\
2018\end{array}$ & $\begin{array}{l}36.8 \pm 2.8 \\
76 \pm 55 \\
152 \pm 10.8 \\
369 \pm 27\end{array}$ & 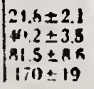 & 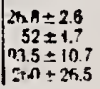 \\
\hline
\end{tabular}

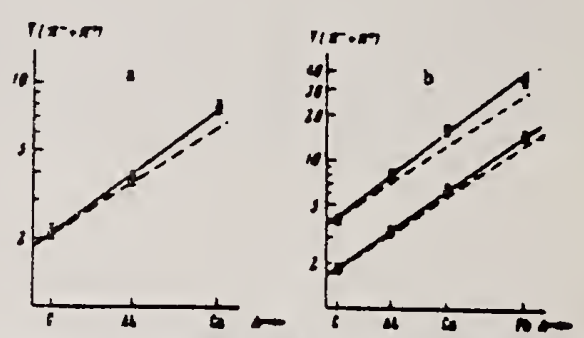

FIC. I. Total yetd of cherpod newons as a function of atomic wointe The sotid atraight line ts the experiment araght line is the $A^{2 / 3} \mathrm{law}, \mathrm{a}-0-60^{\circ}, T=40 \mathrm{MeV}: \mathrm{b}-0=120^{\circ}$. Pointa: $O-T=40 \mathrm{MeV}, \Delta-\mathrm{T}=0 S \mathrm{MeV}$.

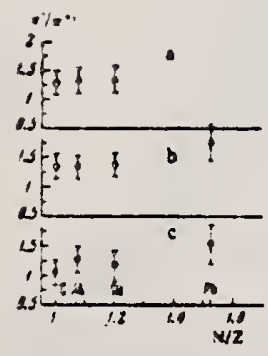

FIC. 3. $\pi / 7^{\circ}$ yield ratio as a function of $N / 2.2-\theta=60^{\circ}, T=40 \mathrm{MeV} ; b-d=120^{\circ}$, $\mathrm{T}=40 \mathrm{MeV} ; \mathrm{c}-0-120^{\circ}, \mathrm{T}=65 \mathrm{MeV}$. 


\begin{tabular}{l|l|l} 
ELEM. SYM. & A & 29 \\
$\mathrm{Cu}$ & & \\
\hline REF. NO. & egf
\end{tabular}

\begin{tabular}{|c|c|c|c|c|c|c|c|}
\hline \multirow{2}{*}{ REACTION } & \multirow{2}{*}{ RESULT } & \multirow{2}{*}{$\begin{array}{c}\text { EXCITATION } \\
\text { ENERGY }\end{array}$} & \multicolumn{2}{|c|}{ SOURCE } & \multicolumn{2}{|c|}{ DETECTOR } & \multirow{2}{*}{ - ANGLE } \\
\hline & & & TYPE & RANGE & TYPE & RANGE & \\
\hline \multirow[t]{2}{*}{$G, F$} & $A B Y$ & IHR-900 & C & $300-900$ & ERG-1 & & $4 P I$ \\
\hline & & & & & & & - \\
\hline & & & & & & & \\
\hline
\end{tabular}

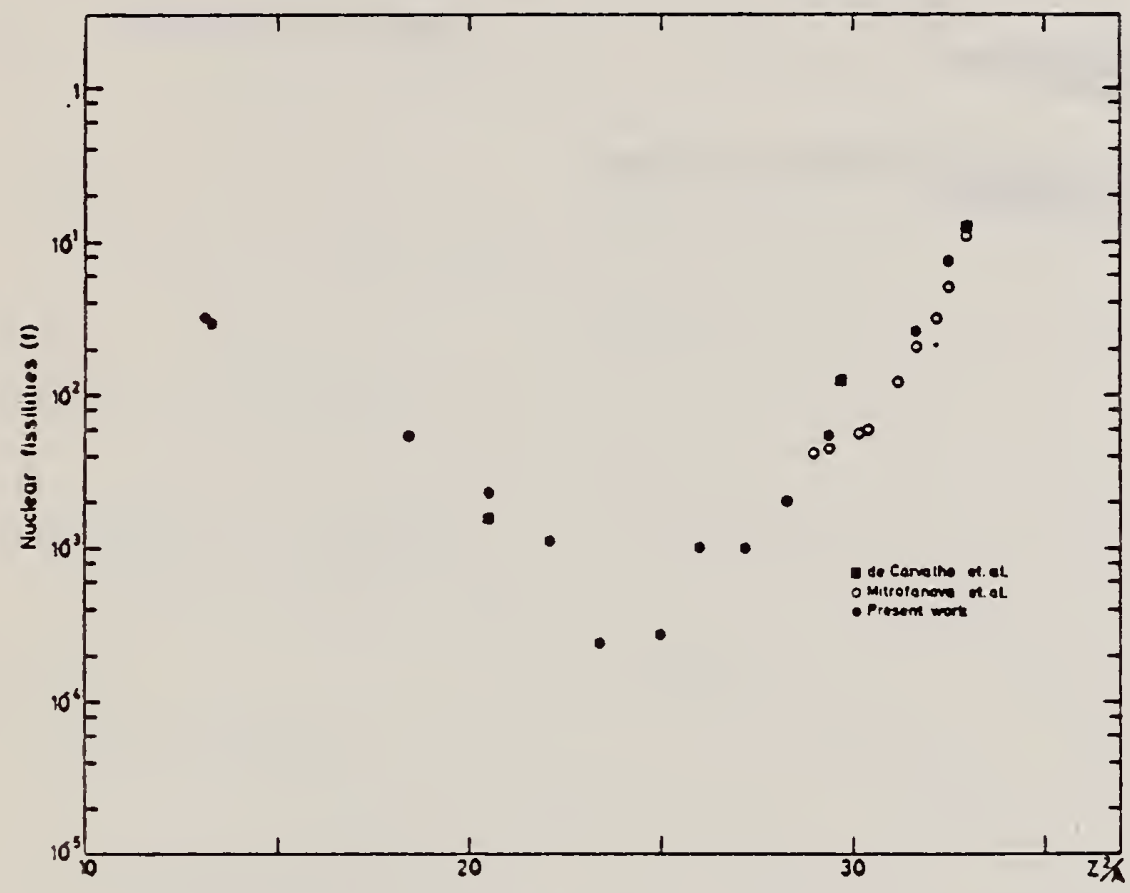

Fig. 2. Nuclear fissilitics as a function of $Z^{2} / A$.

TABLE 1

The constant fission cross sections above the threshold

\begin{tabular}{|c|c|c|c|}
\hline Element & $\sigma_{f}\left(\mathrm{~cm}^{2}\right)$ & Element & $\sigma_{\mathrm{f}}\left(\mathrm{cm}^{2}\right)$ \\
\hline $\begin{array}{l}\mathrm{Pb} \\
\mathrm{Au} \\
\mathrm{Ta} \\
\mathrm{Yb} \\
\mathrm{Ho} \\
\mathrm{Gd} \\
\mathrm{Nd}\end{array}$ & $\begin{array}{l}(5.0 \doteq 0.2) \times 10^{-37} \\
(1.7 \pm 0.1) \times 10^{-29} \\
(3.3 \pm 0.2) \times 10^{-20} \\
(1.2 \pm 0.2) \times 10^{-22} \\
(5.5 \pm 0.3) \times 10^{-39} \\
(5.3 \pm 0.8) \times 10^{-21} \\
(1.3 \pm 0.2) \times 10^{-29}\end{array}$ & $\begin{array}{l}\mathrm{La} \\
\mathrm{Sn} \\
\mathrm{Az} \\
\mathrm{Mo} \\
\mathrm{Cu} \\
\mathrm{Ni}\end{array}$ & $\begin{array}{l}(1.1 \pm 0.1) \times 10^{-30} \\
(4.3 \pm 1.1) \times 10^{-30} \\
(8.4 \pm 2.0) \times 10^{-30} \\
(1.7 \pm 0.4) \times 10^{-20} \\
(6.6 \pm 1.2) \times 10^{-20} \\
(5.8 \pm 0.1) \times 10^{-23}\end{array}$ \\
\hline
\end{tabular}




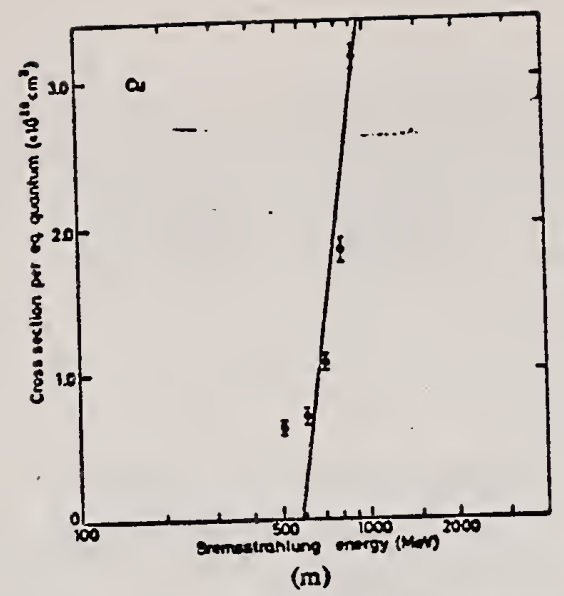

Fig 1. Cross sections per equivalent quantum $\sigma_{0}(\hat{E})$ as a function of $\log E$ of $\mathrm{Pb}, \mathrm{Ab}, \mathrm{Ta}, \mathrm{Yb}, \mathrm{Ho}$. $\mathrm{Gd}, \mathrm{Nd}, \mathrm{La}, \mathrm{Sn}, \mathrm{Ag}, \mathrm{Mo}, \mathrm{Cu}$ and $\mathrm{Ni}$.

290 
H. J. Von Eyss, H. Schier, and B. Schoch

Elba-71, Tagungsbericht Elektronen Beschleuniger Arbeits Gruppen

(Sept. 1971) Justus Liebig-Universitat Giessen.

P. 391

\begin{tabular}{|c|c|c|c|c|c|c|c|}
\hline \multirow{2}{*}{ REACTION } & \multirow{2}{*}{ RESULT } & \multirow{2}{*}{$\begin{array}{l}\text { EXCITATION } \\
\text { ENERGY }\end{array}$} & \multicolumn{2}{|c|}{ SOURCE } & \multicolumn{2}{|c|}{ DETECTOR } & \multirow{2}{*}{ - ANGLE } \\
\hline & & & TYPE & RANGE & TYPE & RANGE & \\
\hline$E, N$ & $A B X$ & THR- 266 & $\mathrm{C}$ & $150-266$ & $T O F-D$ & & 90 \\
\hline & & & & & & $\cdot$ & \\
\hline & & & & & & & \\
\hline & & & & & & & \\
\hline
\end{tabular}

See over for figure. 


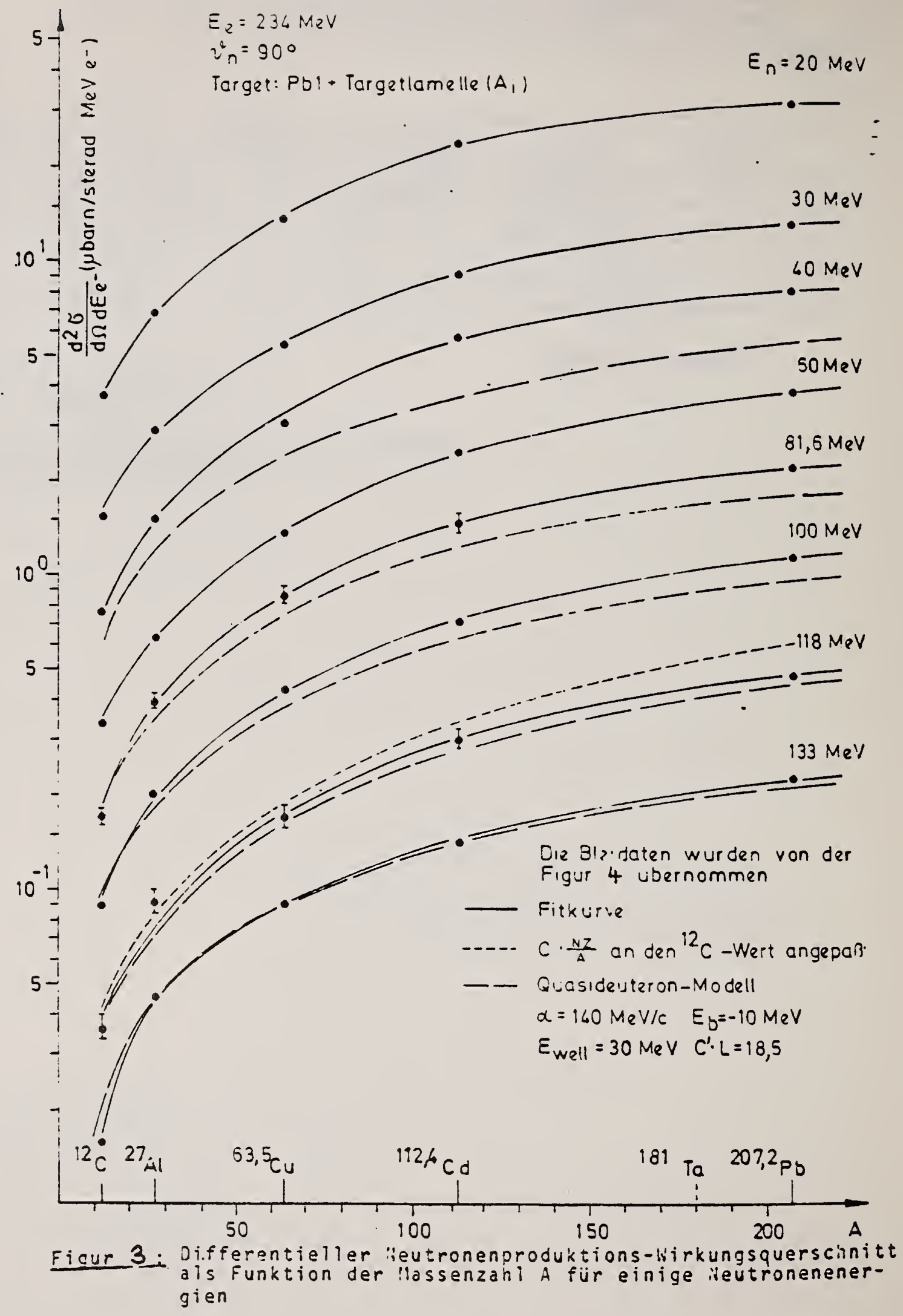




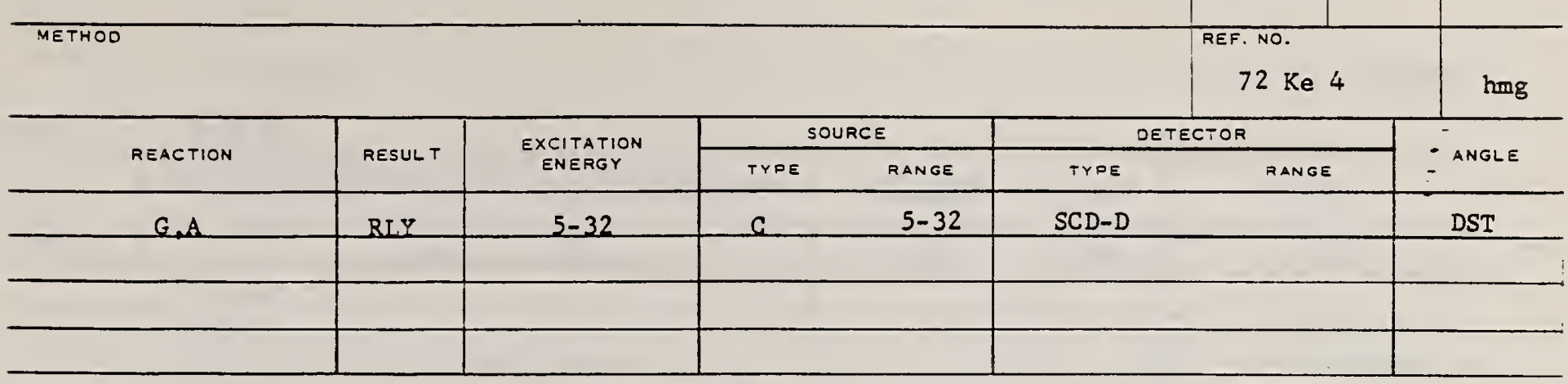
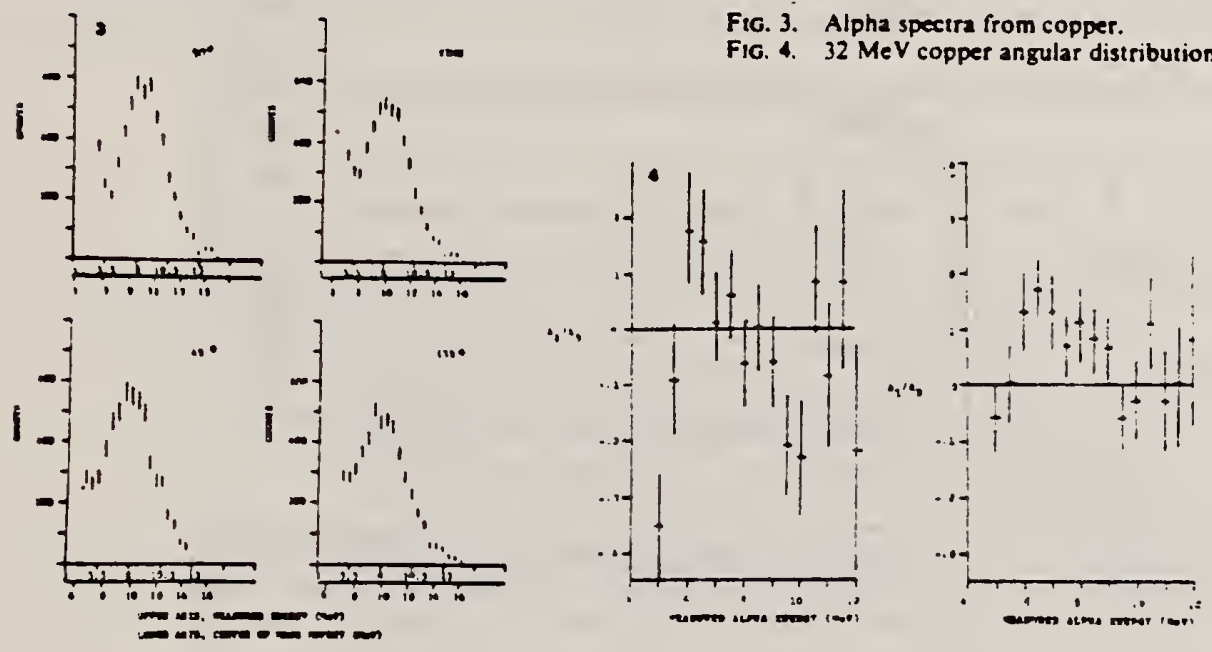

Fic. 3. Alpha spectra from copper.

Fig. 4. $32 \mathrm{MeV}$ copper angular distribution.

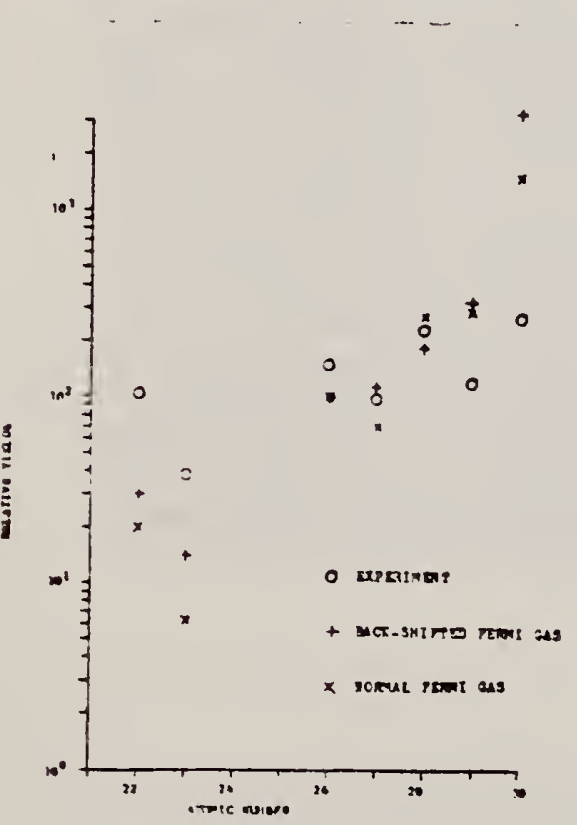

Fic. 13. Experimental and theoretical relative photo alpha yields for $32 \mathrm{MeV}$ electron beam energy.
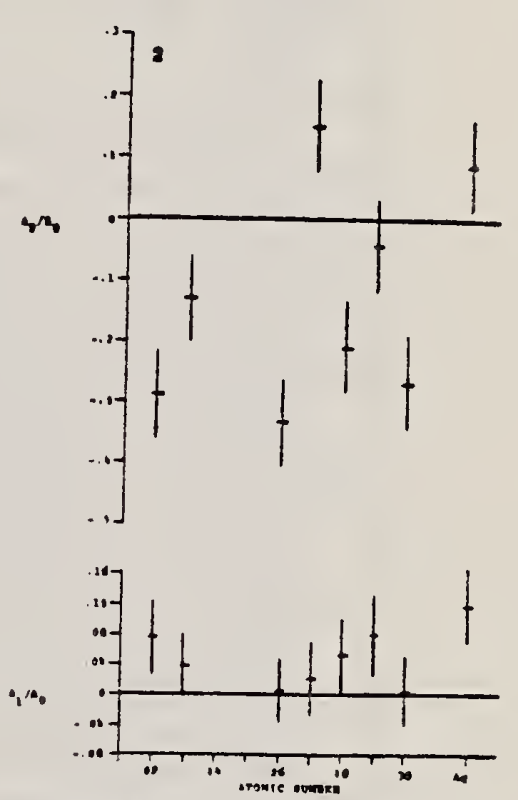

Fic. 2. Angular distributions for $32 \mathrm{MeV}$ electron energy.

Table 3. Observed angular distribution parameters for $32 \mathrm{MeV}$ electron energy

\begin{tabular}{lrcc}
\hline Element & $A_{0}$ & $A_{1} / A_{n}$ & $A_{2} A_{0}$ \\
\hline $\mathrm{Ti}$ & $7.03=0.15$ & $0.073 \pm 0.052$ & $-0.286=0.073$ \\
$V$ & $2.58 \pm 0.06$ & $0.037=0.042$ & $-0.126 \pm 0.069$ \\
$\mathrm{Fe}$ & $10.22=0.30$ & $0.006 \pm 0.043$ & $-0.333 \pm 0.072$ \\
$\mathrm{Co}$ & $6.30 \pm 0.20$ & $0.022 \pm 0.048$ & $-0.016 \pm 0.077$ \\
$\mathrm{Ni}$ & $15.95 \pm 0.49$ & $0.051 \pm 0.048$ & $-0.213 \pm 0.074$ \\
$\mathrm{Cs}$ & $8.37 \pm 0.28$ & $0.076 \pm 0.056$ & $-0.035 \pm 0.081$ \\
$\mathrm{Zn}$ & $17.87 \pm 0.61$ & $0.004 \pm 0.045$ & $-0.270 \pm 0.073$ \\
$A_{8}$ & $0.39 \pm 0.01$ & $0.115 \pm 0.049$ & $+0.093 \pm 0.074$
\end{tabular}


Ref. V.P. Kovalev, V.P. Khar 1ts, V.V. Gordeev, V. I. Isaev (USSR)

Atomnaya Energiya 32, 496 (1972)

Atomina Energ1ya 32,496 (1972)

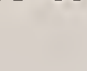

METHOO

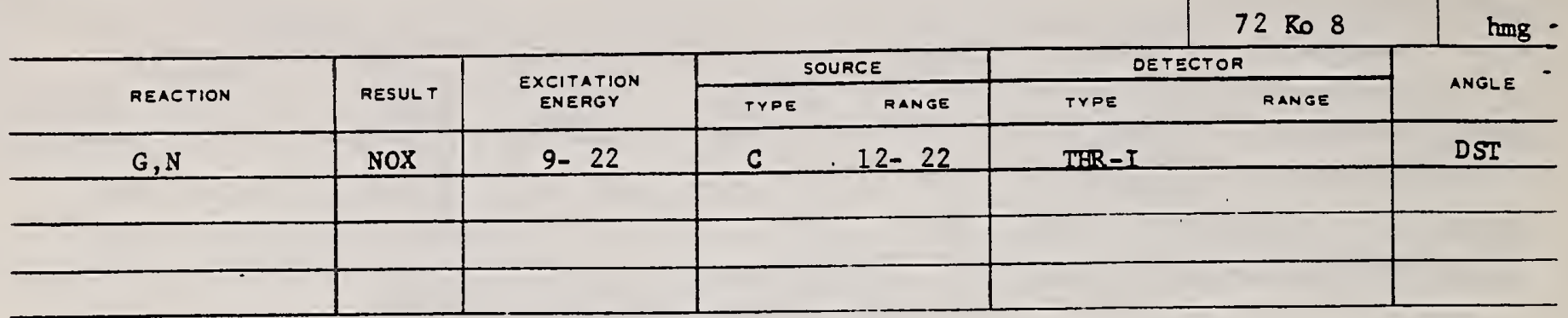

\begin{tabular}{|c|c|c|c|c|c|c|c|c|c|c|}
\hline \multirow{2}{*}{ Mins- } & \multirow{2}{*}{ 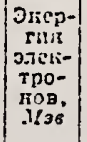 } & \multirow{2}{*}{$\begin{array}{l}\text { Дeтck- } \\
\text { тор }\end{array}$} & \multicolumn{7}{|c|}{ Yrot, араo } & \multirow{2}{*}{$B L A$} \\
\hline & & & 30 & 50 & 70 & 90 & 110 & 130 & 150 & \\
\hline \multirow{2}{*}{$\mathrm{Al}$} & $|22,5|$ & $\Gamma^{31}(n, p) \mid$ & $1,05 \doteq 0,08$ & $1,03 \pm 0,0 \mathrm{~S}$ & $0,97 \pm 0,08$ & $1,0 \pm 0,08$ & $0,08 \pm 0,0 \mathrm{~S}$ & $1,02 \pm 0,08$ & $|1,0,1 \pm 0,08|$ & $\left|\begin{array}{c}\text { IIзотpon- } \\
\text { HOO }\end{array}\right|$ \\
\hline & 22,5 & $A L^{2:}(n, p)$ & $0,90 \pm 0,15$ & $\mid 0,9.5 \pm 11,15$ & $1,112 \div \div 0,15$ & $1,01) \pm-0,11$ & $0,96 \pm 0,13$ & $|1,07 \pm 0,13|$ & $|1,01=0,: 3|$ & 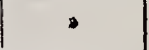 \\
\hline \multirow{2}{*}{$\mathrm{Ti}$} & $|22,5|$ & $\left|p^{31}(n, R)\right|$ & $1,0,4 \pm 0,07 \mid$ & $0,96 \pm 0,0 \bar{i}$ & $1,03 \pm 0,07$ & $1,00 \pm 0,07$ & $0,0 S \pm 0,07$ & $|1,05 \pm 0,07|$ & $|1,03=0,07|$ & 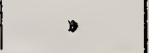 \\
\hline & $22,5 \mid$ & $|A|^{2 \pi}(n, p) \mid$ & $1,06 \div 0,13$ & $0,04 \pm 0,1.3 \mid$ & $1,04 \pm 0,12$ & $1,00 \pm 0,12$ & $0,05 \pm 0,11$ & $|0,98 \div 0,11|$ & $|1,02 \pm 0,10|$ & $\bullet$ \\
\hline \multirow{4}{*}{$\mathrm{Cu}$} & 12,5 & $\Gamma^{31}(n, p)$ & $0,07 \doteq 0,10$ & $1,04 \div 0,10 \mid$ & $1,02 \pm 0,10$ & $1,00=0,10$ & $1,01 \pm 0,10$ & $|0,90 \pm 0,10|$ & $|0,96=0,10|$ & , \\
\hline & 17.0 & $\left|\mathrm{p}^{31}(n, p)\right|$ & $1,03 \pm 0,07$ & $|0,37 \pm 0,07|$ & $1,00 \div 0,07$ & $1,00 \div 0,07$ & $1,00 \doteq 0,07$ & $0,95 \pm 0,07$ & $0,88 \pm 0,07$ & * \\
\hline & 22,5 & $\left|p^{31}(1, p)\right|$ & $0, S i \pm 0,0 \bar{j}$ & $|0,0,4 \div 0,05|$ & $0,07 \doteqdot 0,05$ & $1,00 \pm 0,05$ & $0,00=0,05$ & $|0,03 \pm 0,05|$ & $|0,91 \pm 0,05|$ & $0,15 \pm 0,0,1$ \\
\hline & 22,5 & $A \ln ^{2}(n, p)$ & $0,75 \pm 0,00)$ & $|0,36 \pm 0,07|$ & $0,05 \doteq 0,06$ & $1,00 \pm 10,05$ & $1,02 \pm 0,05$ & $0,01=0,0, x$ & $0,90=0,0$. & $10,25 \div 0,00$ \\
\hline \multirow{3}{*}{ No } & $|22.5|$ & $\left|p^{\prime 31}(n, p)\right|$ & $0,00 \div 0,05$ & $0,9.3 \pm 0,0.5 \mid$ & $0,03 \pm 0,05$ & $1,00 \pm 0,05$ & $0,93 \pm 0,05$ & $|0,92 \div 0,05|$ & $\left|0, S_{2}^{\prime}=0,0 j^{\prime}\right|$ & $0,21=0,0$. \\
\hline & $2 \leqslant, 5$ & $A 1^{22}(n . P)^{\prime}$ & $0,80 \doteq 0,0 s$ & $0,0 j \pm 0,18$ & $0,0.5=0.07$ & $1,(1)=0,00$ & $0,0 \cdot \dot{1}=0,05$ & $0, S: 3 \pm 0,04$ & $0,72=0,0.4$ & $0,44=0,0 \mathrm{~S}$ \\
\hline & 22,5 & $\Delta !^{27}(n, \pi)$ & $0,72 \doteq 0,08$ & $|0, S 4 \doteq 0,05|$ & $0,50 \doteq 0,0 \mathrm{~s}$ & $1,00=0,0 \mathrm{~S}$ & $0,05 \pm 0,05$ & $0, S 7=0,0 \mathrm{~S}$ & $0,63 \pm 0,08$ & $0, i s \div 0,1 S$ \\
\hline \multirow{2}{*}{ W } & 22,5 & $\mathrm{P}^{32}(n, \rho)$ & $0,8.5 \pm 0,0 ;$ & $0,90 \doteqdot 0,0^{\prime}$ & $0,0 S=0,0 \alpha^{\prime}$ & $1,00=0,0^{\prime}$ & $0.05 \doteq 0,01$ & $0,92 \pm 0,04$ & $0,057=0,0.4$ & $0,25=0,04$ \\
\hline & 22,5 & $\Lambda l 27(\Omega, ?)$ & $0,75 \doteq 0,00$ & $0,3: 5=0,06$ & $0,59 \pm 0,05$ & $1,00 \pm 00,0.5$ & $0,07=0,01$ & $0,50=0,0$, & $0.75=0.0 .4$ & $0,5 x=0.64$ \\
\hline \multirow{2}{*}{$\mathrm{Pb}$} & 22,5 & $P^{31}(n, p)$ & $0,70=0,0 \div x$ & $0,85=0,04$ & $0,0 i \doteq 0,04$ & $1,(0)=0,0 \%$ & $0,95=0,015$ & $0,33=0,01$ & $17, S i=0,0$ & $0,3 i=0,0 j$ \\
\hline & 22,5 & $\left|A l^{27}(n, p)\right|$ & $0,70 \doteq 0,09$ & $|0,81=0,08|$ & $0,94=0,07$ & $1, \infty=0,06$ & $0,0,=0,06$ & $0, s 0=0,05$ & $0,00=0,05$ & $10,60 \pm 0,: 2$ \\
\hline
\end{tabular}

[over] 


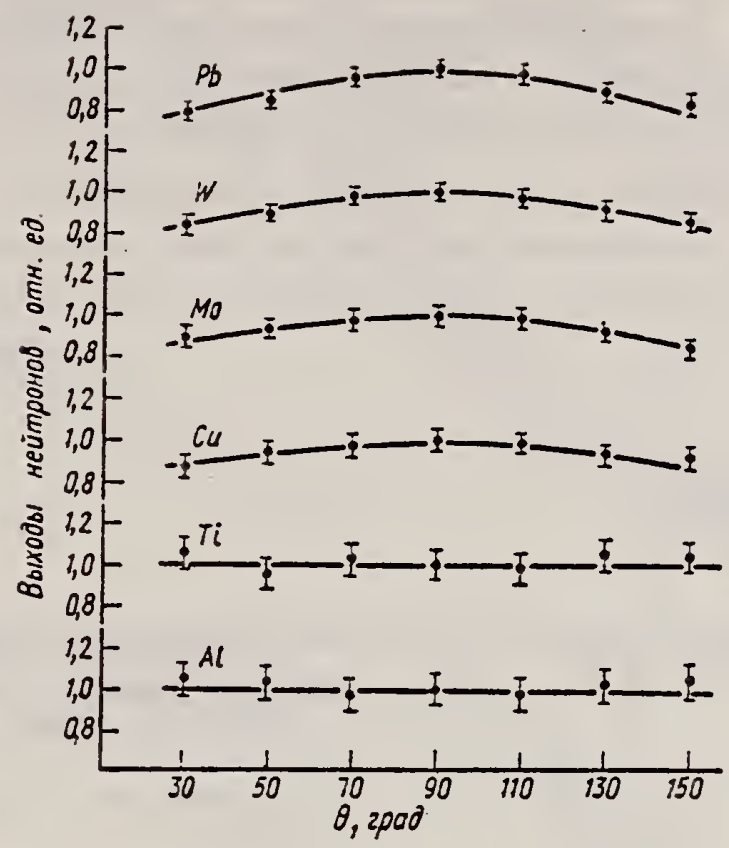

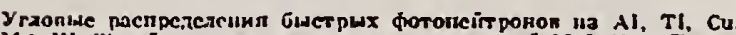

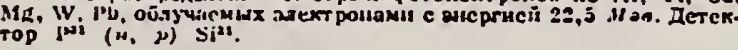


R.F. Barrett, J.R. Birkelund, B.J. Thomas, K.S. Lam, and H.H. Thies Nucl. Phys. A210, 355 (1973)

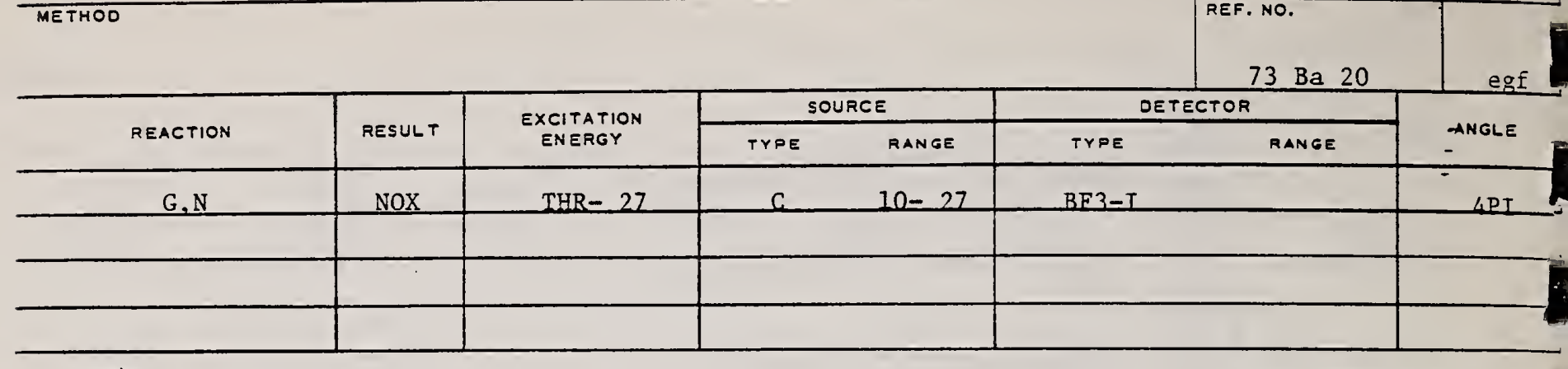

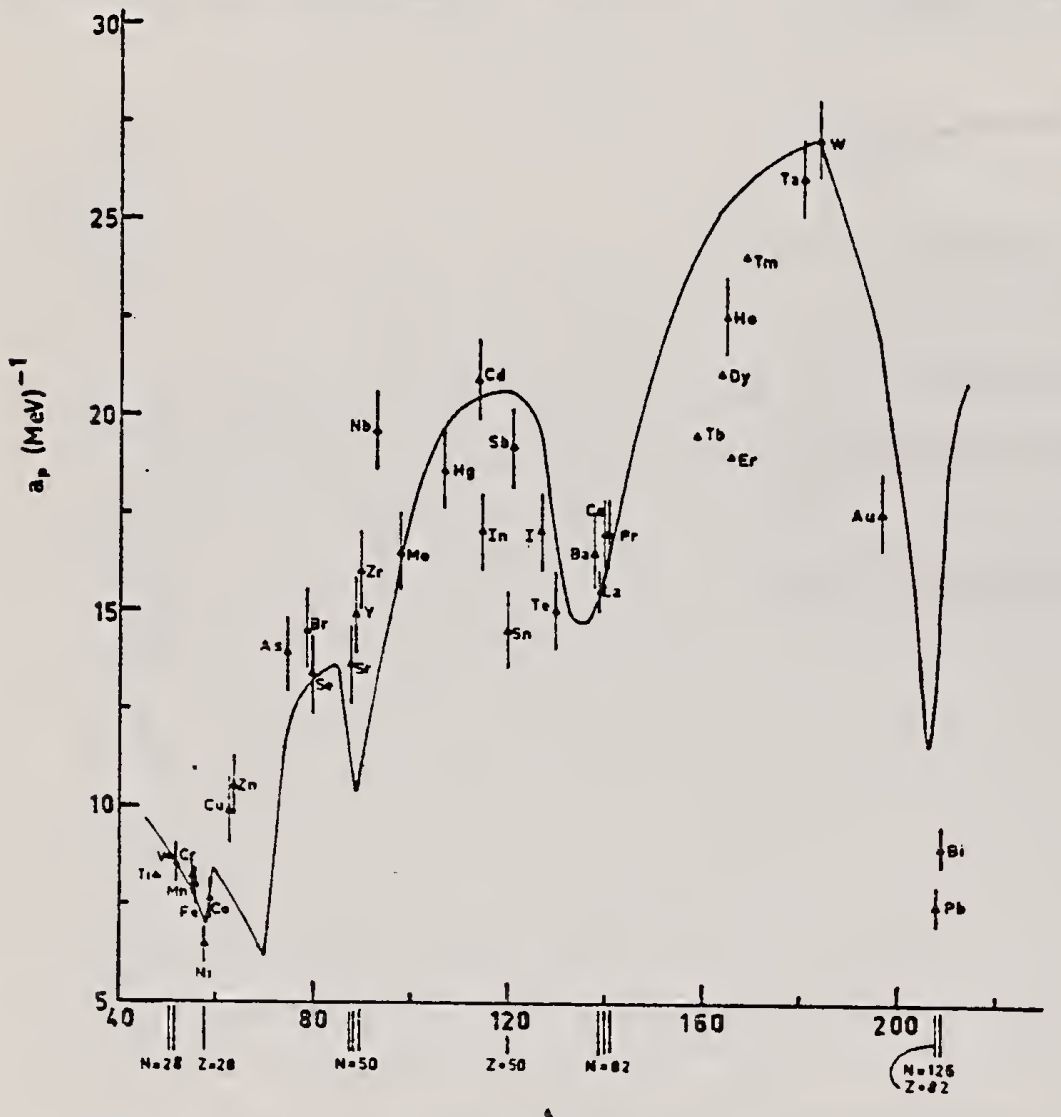

A

Fig. 12. Experimental values of the level density parameter $a_{p}$ (Fermi gas formula plus pairing correction) versus atomic number $A$. The continuous curve is a least-squares fit to the data of a theoretical calculation from Newton ${ }^{15}$ ).

MEAN NEUT ENERGY

1

H. Baba and s. Baba, Japan Atomic Energy Research Institute report JAERI-1183 (1969).

2

H. Baba, Nucl. Phys. A159, 625 (1970).

15

T.D. Newton, Can. J. Phys. 34, 804 (1956).

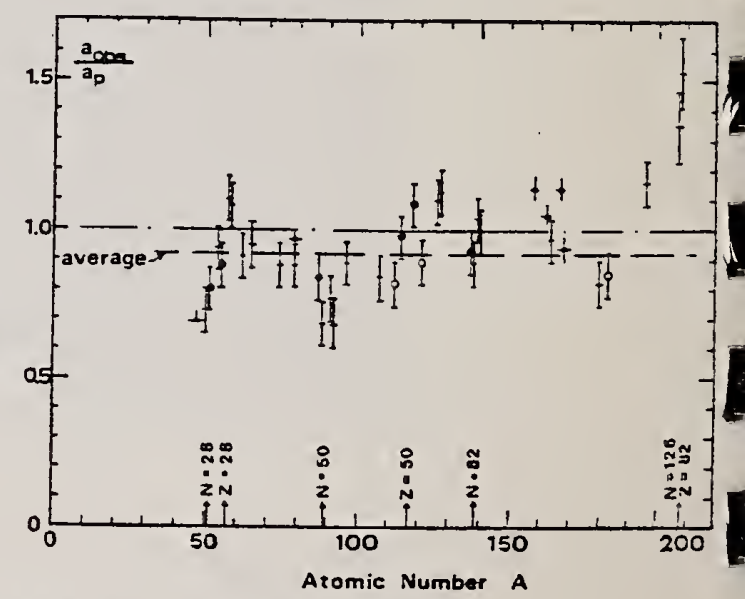

Fig. 15. Ratio $a_{o b a} / a_{0}$ versus atomic number $A$. Here $a_{o b s}$ is the level density parameter taken from the neutron resonance work of refs. ${ }^{1,2}$ ), and $a_{p}$ is the level density parameter derived from the present $(\theta, n)$ work. Filled circles represent points where nuclei in the neutron resonance and in the $(\gamma, n)$ experiment were the same. Open circles represent points where the respective nuclei were approximately matched. Triangles represent points which are based on measurement of neutron mean energies at two bremsstrahlung energies only.

(over) 
AEF. P. Dougan and $W$. Stiefler

Z. Physik 265, 1 (1973)

\begin{tabular}{|c|c|c|c|c|c|c|c|}
\hline METHOD & & & & & & $\begin{array}{l}\text { REF. NO. } \\
73 \text { DO } 9\end{array}$ & egf. \\
\hline \multirow{2}{*}{ REACTION } & \multirow{2}{*}{ RESULT } & \multirow{2}{*}{$\begin{array}{l}\text { EXCITATION } \\
\text { ENERGY }\end{array}$} & \multicolumn{2}{|c|}{ SOURCE } & \multicolumn{2}{|c|}{ DETECTOR } & \multirow{2}{*}{ ANGLE ${ }^{-}$} \\
\hline & & & TYPE & RANGE & TYPE & RANGE & \\
\hline $\mathrm{G}, \mathrm{XP}$ & $A B Y$ & $86-400$ & & 400 & \multicolumn{2}{|l|}{$T R L-D$} & DST \\
\hline & & & & & & & \\
\hline
\end{tabular}

sections in microbams/sterrad $\cdot \mathrm{MeV} \cdot \mathrm{eq}$ quantum

\begin{tabular}{|c|c|c|c|c|c|c|c|c|}
\hline \multirow[t]{2}{*}{ Energy } & \multicolumn{8}{|l|}{ Angle } \\
\hline & 30 & 40 & so & 60 & 74 & 90 & 110 & 130 \\
\hline 81.9 & $\begin{array}{r}12.3 \\
2.1\end{array}$ & & & & $\begin{array}{l}6.17 \\
2.0\end{array}$ & & & \\
\hline 87.3 & & $\begin{array}{l}8.77 \\
2.0\end{array}$ & $\begin{array}{l}7.65 \\
2.2\end{array}$ & $\begin{array}{l}6.55 \\
2.0\end{array}$ & & $\begin{array}{l}3.85 \\
2.2\end{array}$ & $\begin{array}{l}3.02 \\
2.3\end{array}$ & $\begin{array}{l}2.27 \\
2.9\end{array}$ \\
\hline 99.8 & $\begin{array}{r}10.1 \\
2.5\end{array}$ & & & & $\begin{array}{l}4.41 \\
2.5\end{array}$ & & & \\
\hline 104.8 & & $\begin{array}{l}6.91 \\
2.5\end{array}$ & $\begin{array}{l}5.72 \\
2.7\end{array}$ & $\begin{array}{l}4.95 \\
2.5\end{array}$ & & $\begin{array}{l}2.85 \\
2.7\end{array}$ & $\begin{array}{l}1.92 \\
3.2\end{array}$ & $\begin{array}{l}1.48 \\
3.8\end{array}$ \\
\hline 106.7 & $\begin{array}{l}9.17 \\
3.1\end{array}$ & $\begin{array}{l}7.27 \\
.2 .8\end{array}$ & $\begin{array}{l}5.76 \\
2.6\end{array}$ & $\begin{array}{l}4.93 \\
2.5\end{array}$ & $\begin{array}{l}3.92 \\
2.6\end{array}$ & $\begin{array}{l}2.84 \\
2.4\end{array}$ & $\begin{array}{l}2.16 \\
2.8\end{array}$ & \\
\hline 116.8 & $\begin{array}{l}7.37 \\
2.9\end{array}$ & & & & $\begin{array}{l}3.36 \\
2.9\end{array}$ & & & \\
\hline 121.3 & & $\begin{array}{l}5.23 \\
2.8\end{array}$ & $\begin{array}{l}4.17 \\
3.2\end{array}$ & $\begin{array}{l}3.39 \\
3.0\end{array}$ & & $\begin{array}{l}1.96 \\
3.3\end{array}$ & $\begin{array}{l}1.28 \\
3.8\end{array}$ & $\begin{array}{l}0.874 \\
4.9\end{array}$ \\
\hline 129.2 & $\begin{array}{l}6.39 \\
4.0\end{array}$ & $\begin{array}{l}4.82 \\
3.8\end{array}$ & $\begin{array}{l}4.02 \\
3.4\end{array}$ & $\begin{array}{l}3.32 \\
3.2\end{array}$ & $\begin{array}{l}2.62 \\
3.5\end{array}$ & $\begin{array}{l}1.88 \\
3.2\end{array}$ & $\begin{array}{l}1.20 \\
4.0\end{array}$ & \\
\hline 150.3 & $\begin{array}{l}4.08 \\
5.2\end{array}$ & $\begin{array}{l}3.37 \\
4.6\end{array}$ & $\begin{array}{l}2.45 \\
4.4\end{array}$ & $\begin{array}{l}2.14 \\
4.1\end{array}$ & $\begin{array}{l}1.54 \\
4.6\end{array}$ & $\begin{array}{l}1.06 \\
4.3\end{array}$ & $\begin{array}{l}0.710 \\
5.4\end{array}$ & \\
\hline 169.7 & & $\begin{array}{l}2.39 \\
3.9\end{array}$ & $\begin{array}{l}2.00 \\
3.3\end{array}$ & $\begin{array}{l}1.63 \\
3.3\end{array}$ & $\begin{array}{l}1.09 \\
2.4\end{array}$ & $\begin{array}{l}0.660 \\
4.0\end{array}$ & & \\
\hline 186.7 & & $\begin{array}{l}1.68 \\
4.9\end{array}$ & $\begin{array}{l}1.39 \\
4.2\end{array}$ & $\begin{array}{l}1.01 \\
4.5\end{array}$ & $\begin{array}{l}0.685 \\
3.1\end{array}$ & $\begin{array}{l}0.368 \\
5.7\end{array}$ & & \\
\hline 203.6 & & $\begin{array}{l}1.24 \\
5.7\end{array}$ & $\begin{array}{l}0.949 \\
5.0\end{array}$ & $\begin{array}{l}0.650 \\
5.5\end{array}$ & $\begin{array}{l}0.372 \\
4.2\end{array}$ & $\begin{array}{l}0.180 \\
8.1\end{array}$ & & \\
\hline
\end{tabular}

$222.3 \quad 1.01 \quad 0.344 \quad 0.578$

$225.4 \quad 0.340$

$\begin{array}{llll}238.7 & 0.676 & 0.528 & 0.388\end{array}$

5.7

$\begin{array}{llll}4.6 & 8.4 & 7.3\end{array}$

241.7

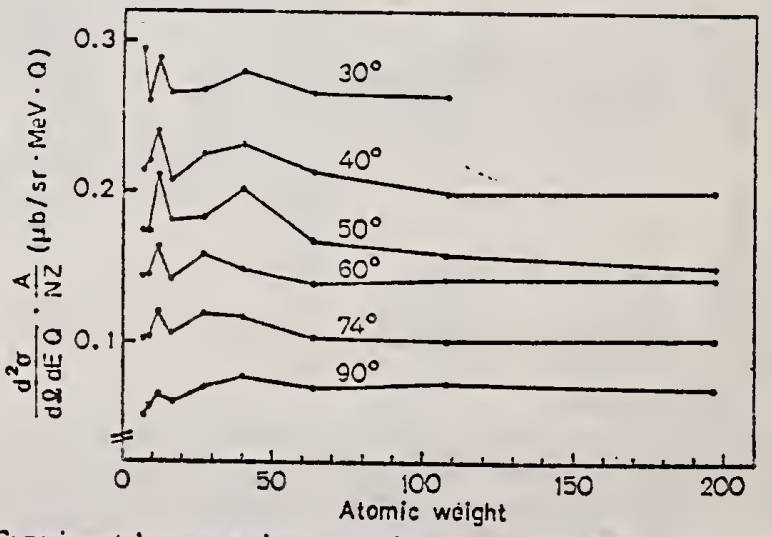

Fig. 8. Experimental cross-sections at various angles for $E_{p}=150 \mathrm{MeV}$ divided by $N Z / A$ plotted as a function of atomic weight 


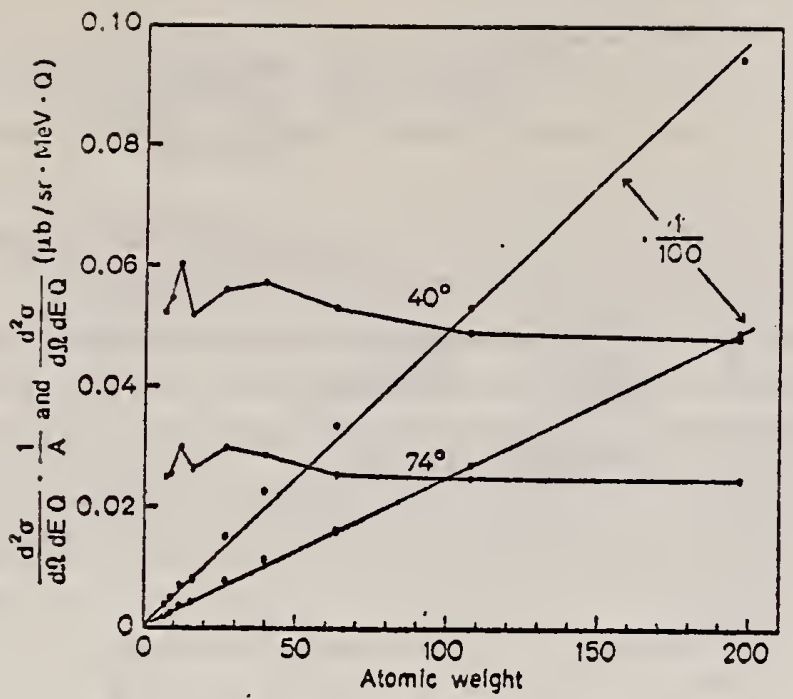

Fig. 9. In this figure, the straight lines show the experimental cross-sections at $40^{\circ}$ and $74^{\circ}$ for $E_{,}=150 \mathrm{MeV}$. The other curves are the same cross-sections divided by atomic weight

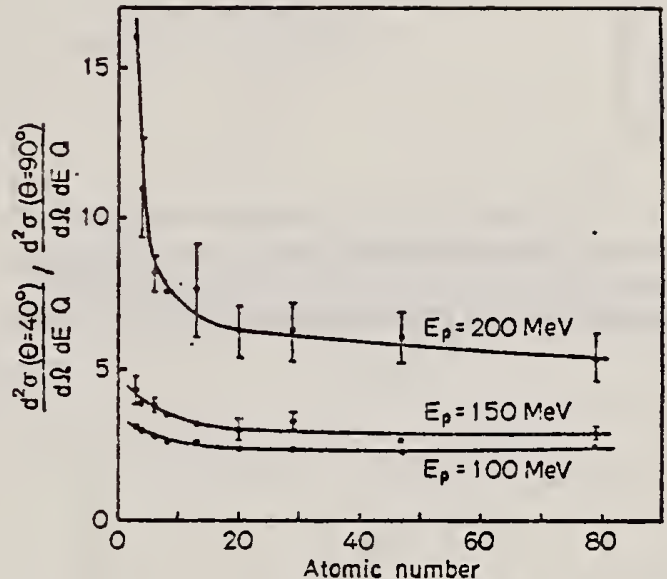

Fig. 6. The ratios of the experinental cross-sections at 40 and 90 degrees for selected proton energies as a function of atomic number 
REF.

P. Dougan, T. Kivikas, K. Lugner, V. Ramsay, and W. Stiefler Phys. Letters $\underline{46 \mathrm{~B}}, 359$ (1973)

73 Do 11. egf

\begin{tabular}{|c|c|c|c|c|c|c|c|}
\hline \multirow[b]{2}{*}{ REACTION } & \multirow[b]{2}{*}{ RESULT } & \multirow{2}{*}{$\begin{array}{l}\text { EXCITATION } \\
\text { ENERGY }\end{array}$} & \multicolumn{2}{|c|}{ SOURCE } & \multicolumn{2}{|c|}{ DETECTOR } & \multirow{2}{*}{ ANGLE: } \\
\hline & & & TYPE & RANGE & TYPE & RANGE & \\
\hline$G, X P$ & $A B Y$ & $90-400$ & $\mathrm{C}$ & 400 & TEL-D & & DST \\
\hline & & & & & & & \\
\hline & & & & & & & \\
\hline & & & & & & & \\
\hline
\end{tabular}

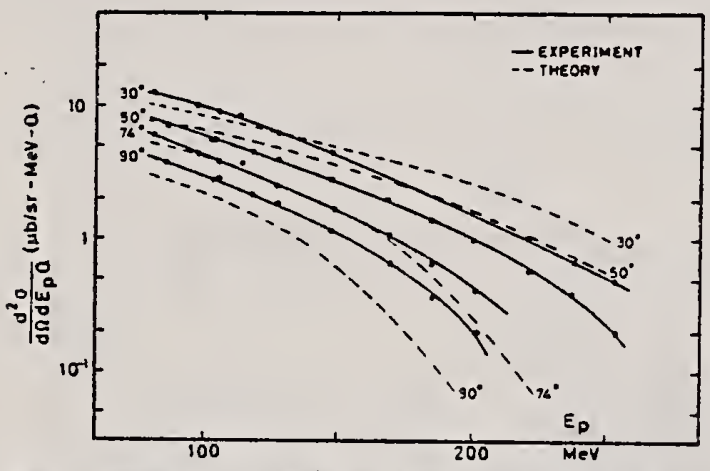

Fig. 2. Comparison of experimental and calculated cross sections for copper. The calculated results have been renormalized at a proton energy of $150 \mathrm{MeV}$ and an angle of $74^{\circ}$ by a factor of 0.78 . 
REF. J. von Byss and G. Lührs
Z. Physik 262, 393 (1973)

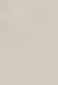

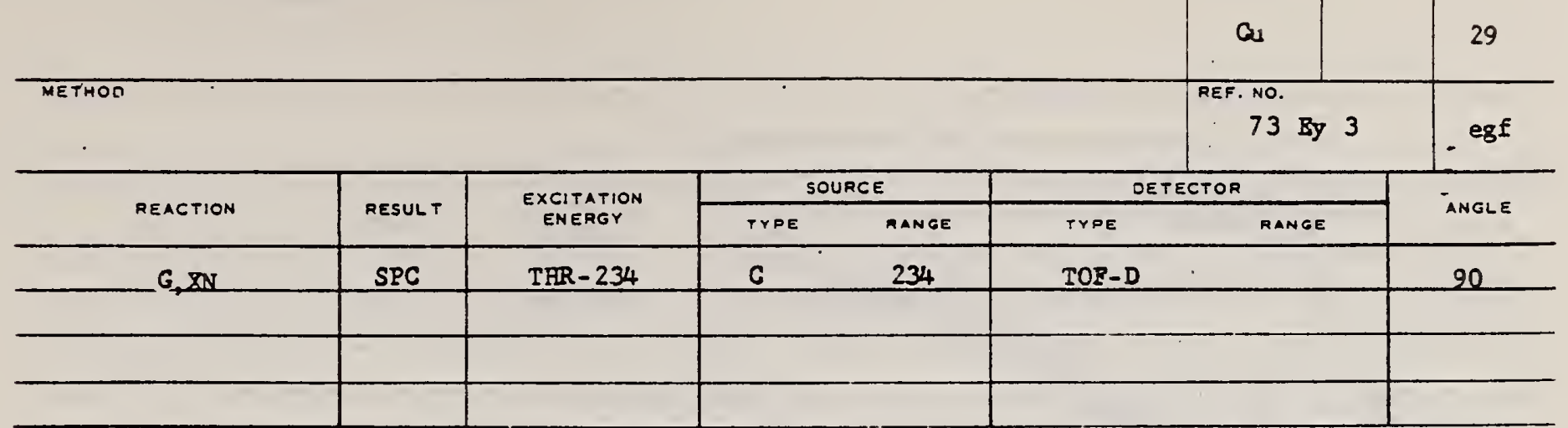

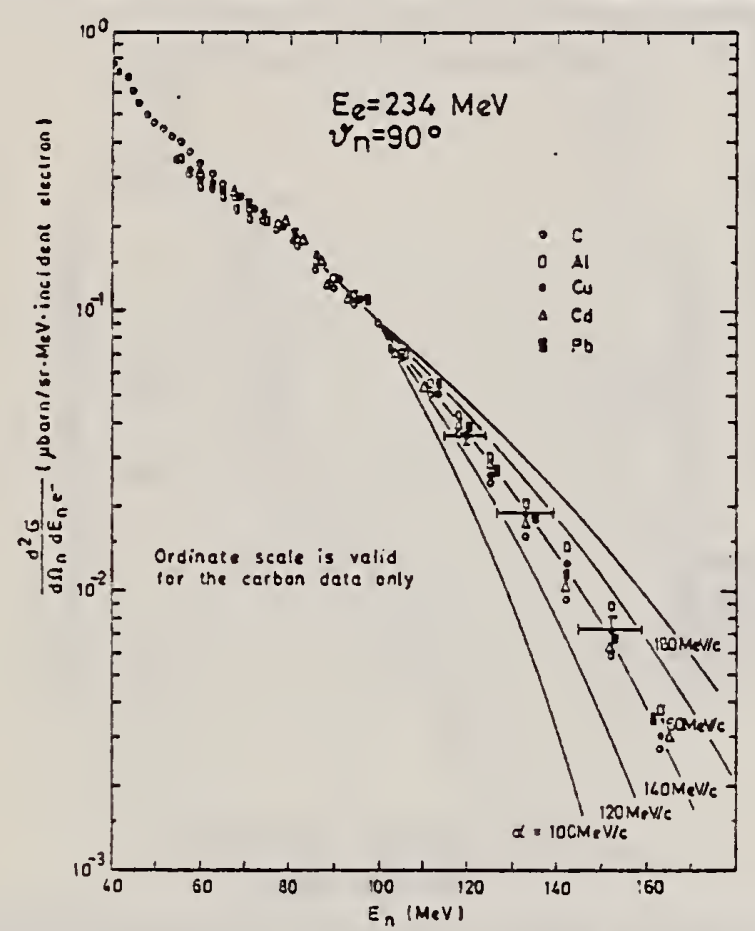

Fig. 8. Comparison of the shape of the high-energy part of the photonestron spectra from $\mathrm{C}, \mathrm{Al}, \mathrm{Cu}, \mathrm{Cd}$ and $\mathrm{Pb}$. These measurements were performed with the same \%-shower spectrum, produced in a $0.3 \mathrm{~cm}$ thick lead sheet (see Fig. 2b). All spectra were fitted to the value for carbon at $E_{n}=100 \mathrm{MeV}$. The values predicted by a quasideuteron model (solid lines), which are also firted at $E_{\mathrm{r}}=100 \mathrm{MeV}$, were calculated with the parameters (defined in the text): $E_{b}=-10 \mathrm{MeV}, E_{\text {well }}=30 \mathrm{MeV}$ and $C^{\prime} L=19.0$ for different impulse parameters $\alpha=100,120,140,160$ and $180 \mathrm{MeV} / \mathrm{c}$

Fig. 9. Dependence of the production cross section on the mass number $A$ with the neutron energy as parameter, measured at $E_{e}=234 \mathrm{MeV}$. The $\gamma$-quanta were produced in a $0.3 \mathrm{~cm}$ thick lead sheet (see Fig. $2 \mathrm{~b}$ ) in front of the target of mass number $A$. The solid lines are fit curves through the measured values. The dashed lines are values calculated using a quasi-deuteron model with the parameters (defined in the text): $E_{b}=-10 \mathrm{MeV}, E_{\text {well }}=30 \mathrm{MeV}, \alpha=140 \mathrm{MeV} / \mathrm{c}$ and $C^{\prime} L=19.0$. The dotted curve represents the dependence $N Z / A$, fitted at $A=12$. The error bars correspond to the statistical error
NBUTS B ABP $12 \mathrm{MBV}$

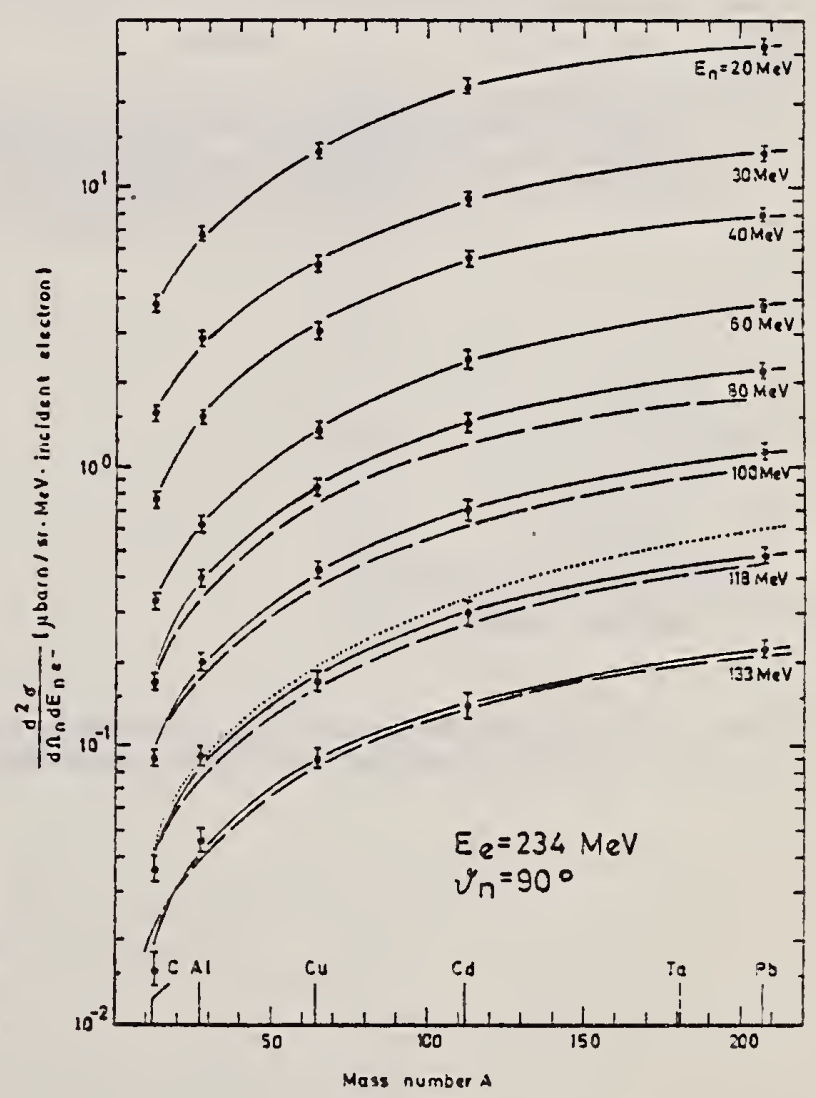

(over) 


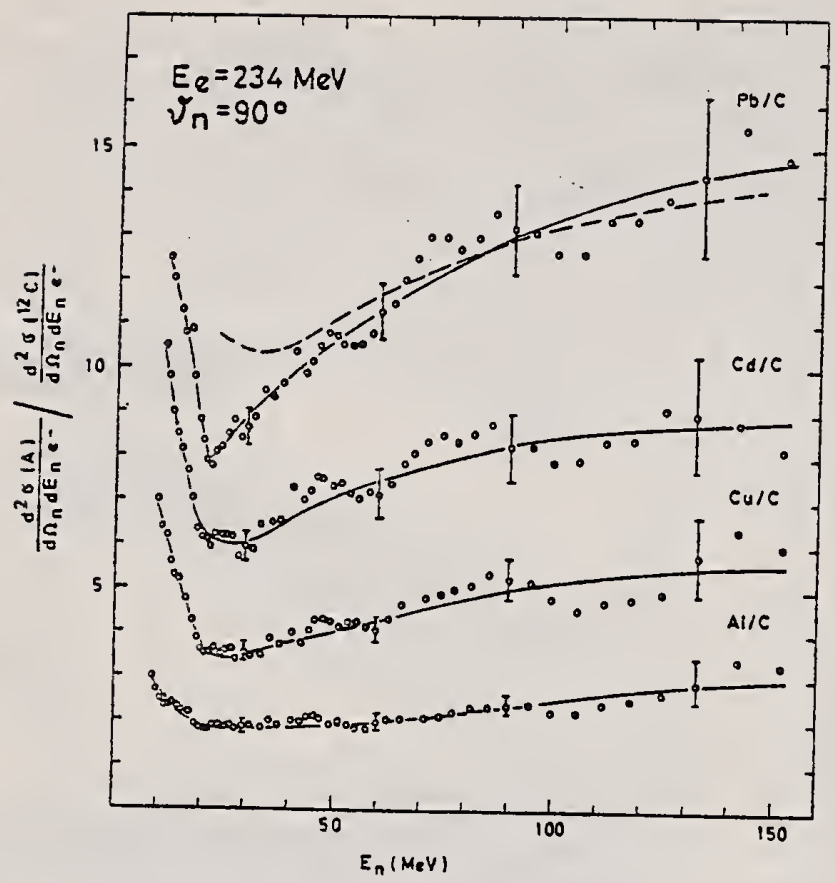

Fig. 10. Neutron yield from targets of mass number $A$ relative to carbon, measured at $E_{e}=234 \mathrm{MeV}$. The target arrangement is that of Fig. 2b. The solid lines are fit curves through the experimental values. The dashed curve shows the energy dependence of the ratio of the nuciear absorption factors $f_{a}(\mathrm{~Pb}) / f_{a}(\mathrm{C})$, taken from Fig. 6 . The error bars correspond to the statistical error 
REF. A. Järund, B. Friberg, and B. Forkman

2. Physik 262,15 (1973)

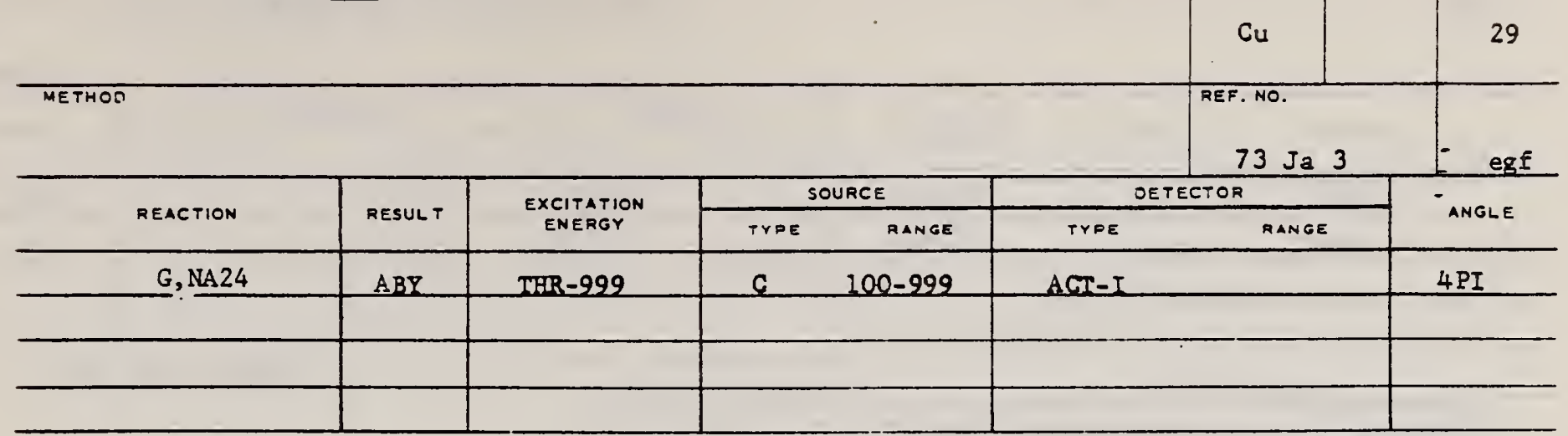

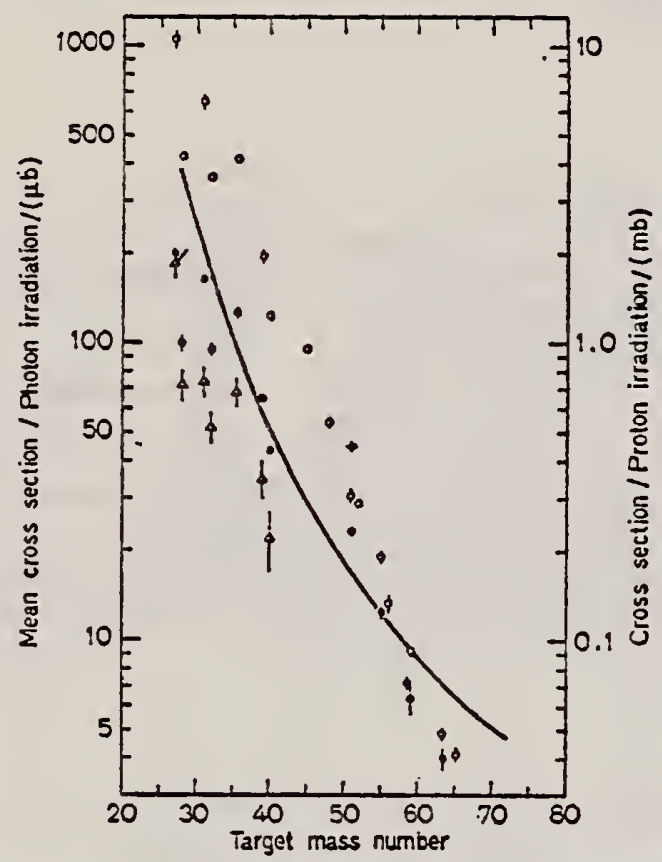

Fig. 7. Mean cross sections for ${ }^{24} \mathrm{Na}$ production as a function of target mass aumber. Present work filled circles. Noga et al. [3] open triangles, Kumbartzki et al. [13] cross and Korteling et al. [1] $400 \mathrm{MeV}$ protons open circles. The solid line gives the mean cross sections calculated by Jonsson ef al. [17]

$999=1$ GEV

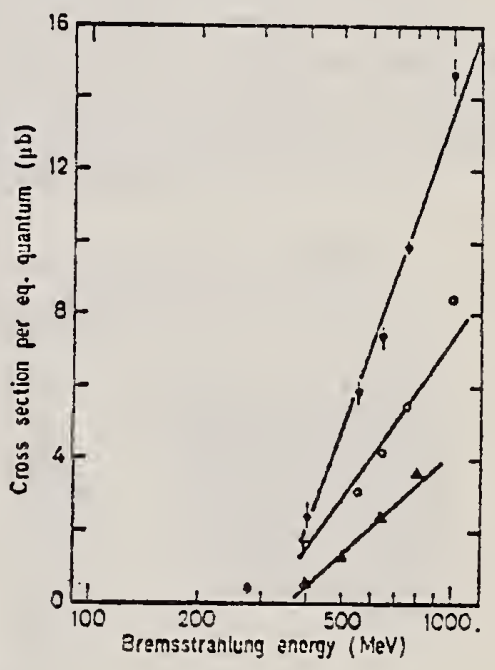

Fig. 6

Fig. 6. The determined yiclds for the reactions ${ }^{55} \mathrm{Mn} \rightarrow{ }^{24} \mathrm{Na}$ (iilled circles), ${ }^{59} \mathrm{Co} \rightarrow{ }^{24} \mathrm{Na}$ (open circles) and ${ }^{63,65} \mathrm{Cu} \rightarrow{ }^{24} \mathrm{Na}$ (nilled triangles)

' Korteling, R.G. et al. , J. Inorg.

Nucl. Chem. 29, 2863 (1967).

${ }^{3}$ Noga, V.I. et al., Sov. J. Nucl. Phys.

9, 637 (1969).

13 Kunbartzk1, G. et al. , Nucl. Phys. Al76,

23 (1971).

17

Jonsson, G.G. et al. , LiNNP7 212, Oct. 1972,

to be published in Physica Scripta. 
Yad. Fiz. 19, 945 (1974)

Sov. J. Nucl. Phys. 19, 484 (1974)

\begin{tabular}{|c|c|c|c|c|c|c|c|}
\hline \multirow{2}{*}{ REACTION } & \multirow{2}{*}{ RESULT } & \multirow{2}{*}{$\begin{array}{c}\text { EXCITATION } \\
\text { ENERGY }\end{array}$} & \multicolumn{2}{|c|}{ SOURCE } & \multicolumn{2}{|c|}{ DETECTOR } & \multirow{2}{*}{ ANGLE } \\
\hline & & & TYPE & RANGE & TYPE & RANGE & \\
\hline$G, \operatorname{Cos} 8$ & RLX & THR-999 & $\mathrm{C}$ & $300 * 999$ & $\mathrm{ACT}-\mathrm{I}$ & & $4 \mathrm{PI}$ \\
\hline$E, \operatorname{Co58}$ & $\mathrm{RLX}$ & THR-999 & $\mathrm{C}$ & $300 * 999$ & ACT-I & & $4 \mathrm{PI}$ \\
\hline & & & & & & & \\
\hline
\end{tabular}

The induced-activity method has been used to study the ratio of the cross sections for photo- and electrodisintegration of auclei for the reactions ${ }^{27} \mathrm{Al} \rightarrow{ }^{24} \mathrm{Na}$ and ${ }^{63.65} \mathrm{Cu} \rightarrow{ }^{54} \mathrm{Co}$ in the energy interval 300-1200 MeV. The results of the measurements are compared with calculations with various assumptions regarding the spectra of virtual and real photons.

FIG. 4. The ratio oO $/ \mathrm{J}_{\mathrm{e}}$ ds 3 function of $E_{0}$ for various reactions. Points: $+-i^{37} \mathrm{Al} \rightarrow$ ${ }^{24} \mathrm{Na} ;{ }^{163,65} \mathrm{Cu} \rightarrow{ }^{58} \mathrm{Co}$. These points represent the data of the present work and of ref. 3. The other designations are given in ref. 9 .

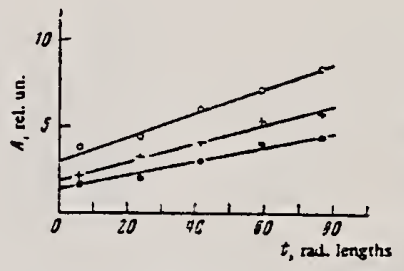

FIG. 1

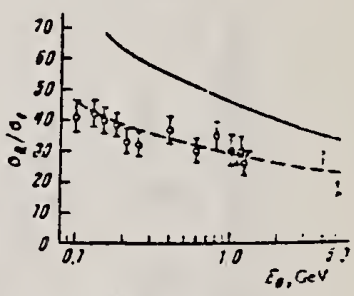

FIG. 2
FIG. I. Target activity as a function of radiator thickness. Points: $0-E_{0}=\$ 00 \mathrm{Mev},+-1170 \mathrm{MeV},--600 \mathrm{MeV}$.

FIG. 2. The ratio $\sigma \mathrm{Q} / \sigma_{\mathrm{e}}$ as a function of electron en:rgy $E_{0}$ Points: $0_{-27} \mathrm{Al} \rightarrow{ }^{3{ }_{1}} \mathrm{Na}$; $-{ }^{63.65} \mathrm{Cu} \rightarrow{ }^{58} \mathrm{Co}$. The thin verticul line show's the datu of ref. $f$. and the heavy vertical line with end bass shows the data of ref. 5. The eurves are thiooretical.

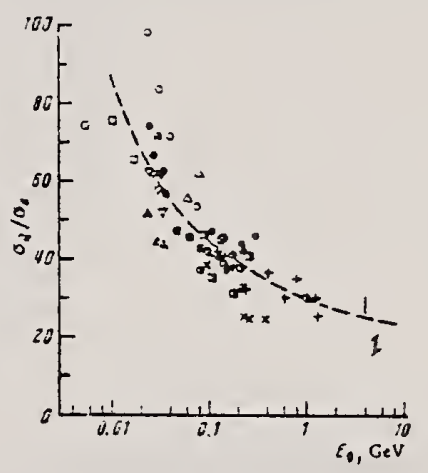

3 V.I. Noga et al., Ukr. Fiz. Zh. 13, 2003 (1968).

${ }^{4}$ F.D.S. Butement, H.M.A. Karim, U.V. Myint, and M.B. Zaman,

J. Inorg. Nucl. Chem. 33, 2791 (1971).

${ }^{5}$ C.B. Fulmer, K.S. Toth, I.R. Williams, and G.F. Dell, Phys.Rev. C4, 2123 (1971).

${ }^{9}$ G.G. Jonsson and K. Lindgren, Physica Scripta 7,49 (1973). 
Yu. I. I1tov, B.V. Stepula, N. G. Afanas'ev, R.V. Akhmerov, AEF. and N.P. Severin

Yad. F1z. 19, 479 (1974)

Sov. J. Nucl. Phys. 19,240 (1974)

\begin{tabular}{|c|c|c|c|c|c|c|c|}
\hline METHOD & & & & & & $\begin{array}{l}\text { AEF. NO. } \\
74 \text { T1 } 3 \\
\end{array}$ & - hong \\
\hline \multirow{2}{*}{ REACTION } & \multirow{2}{*}{$\begin{array}{l}\text { RESULT } \\
\end{array}$} & \multirow{2}{*}{$\begin{array}{l}\text { EXCITATION } \\
\text { ENERGY }\end{array}$} & \multicolumn{2}{|c|}{ Sounce } & \multicolumn{2}{|c|}{ DETECTOR } & \multirow{2}{*}{ ANGLE } \\
\hline & & & TrPE & ianee & TrPe & RANGE & \\
\hline$E, B /$ & $A B X$ & $0-600$ & $D$ & $* 1$ & MAG-D & & DST \\
\hline & & & & & & & \\
\hline & & & & & & & \\
\hline
\end{tabular}

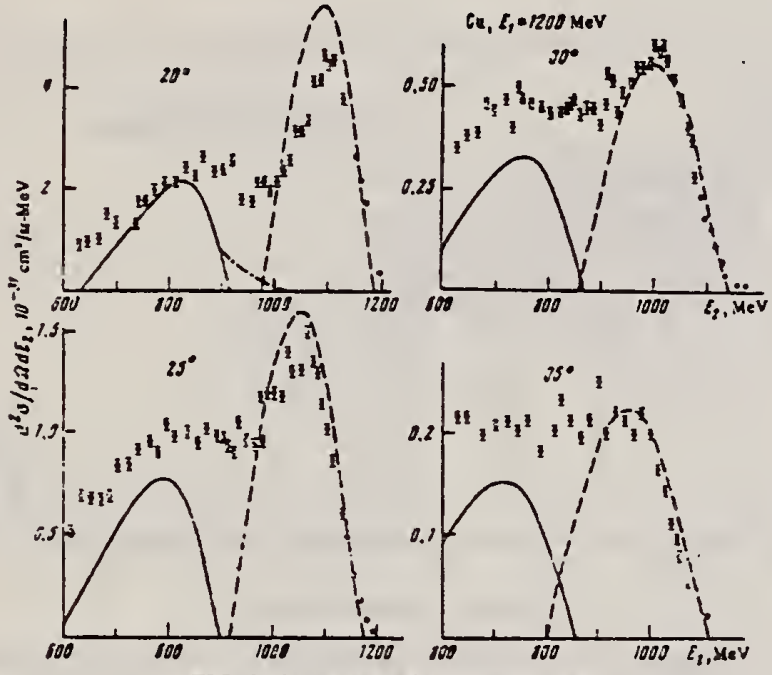

FIG. 2. The same as Fig. 1 but for $\mathrm{Cu}$.
Fig. 2. Spectra of inelastic scattering by $\mathrm{Cu}$ for $E_{1}=1.2 \mathrm{GeV}$. The dashed curve is the quasielastic-scattering cross section, the solid curve is the electroproduction cross section calculated according to ref. 7 , and the dot-dash curve is the electro-production cross section at threshold.(12) A radiation correction has been made to the experimental data.

${ }^{7}$ E.J. Moniz, Phys. Rev. 184, 1154 (1969). 12W. Czyz, and J.D. Walecka, Nucl. Phys. 51 , $312(1964)$. 
REF. N. M. Bachschi, P. David, J. Debrus, F. Lubke,

H. Mommsen, R. Schoenmackers, G. G. Jonsson, K. Lindgren Nucl. Phys. A264, 493 (1976)

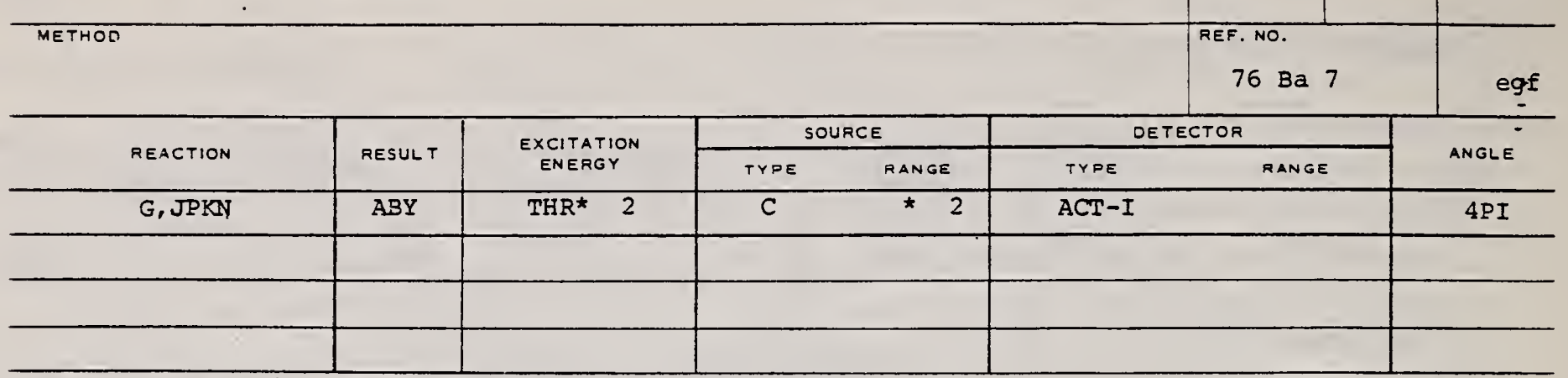

Abseract: Yields and isomeric siend ratios of nuclei produced in the irradiation of "Sc and "st $\mathrm{Cu}$ with bremssinatiung of $E^{\mathrm{max}}=2 \mathrm{GeV}$ have been measured by the activation method. The sy perimental yields are compared is predictions with a Rudstam formula modified to photoniclear reactions.

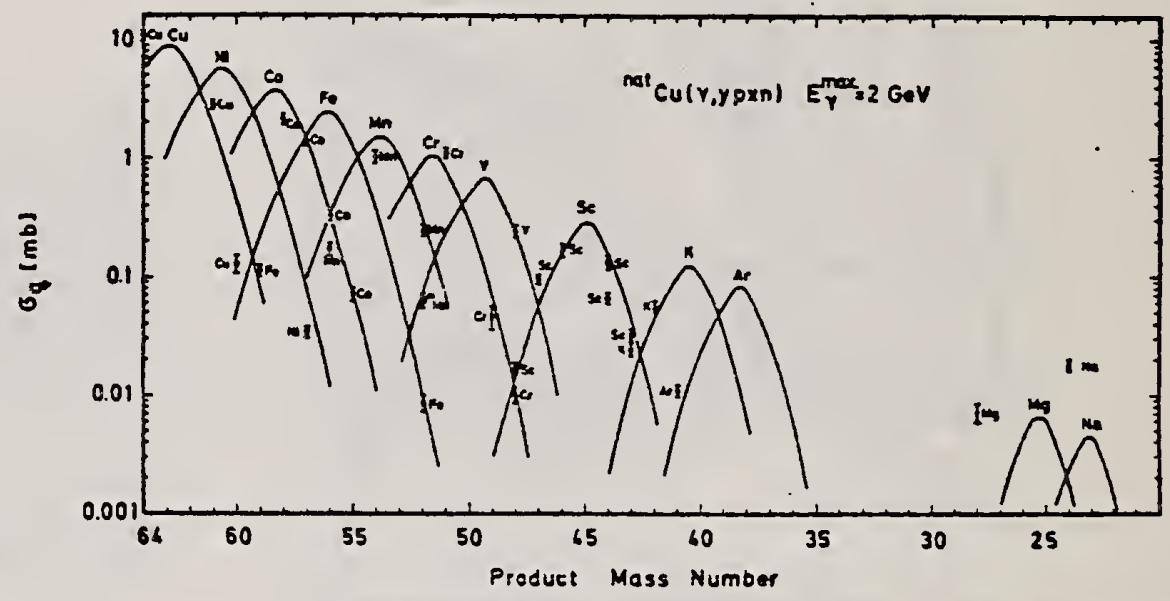

Fig. 2. Yields of nuclei produced in the irradiation of ${ }_{\mathrm{Cu}}$ with bremsstrahlung of $\mathrm{E}_{\mathrm{y}}^{\mathrm{max}}=2 \mathrm{GeV}$. The curves are calculated with eq. (1).

TABLE I

Cross section and isomeric ratios

\begin{tabular}{|c|c|c|c|}
\hline Target & $\sigma_{a}$ (ground state) & $\sigma_{q}$ (isomer) & $\frac{\sigma_{q}^{|(2)|}}{\sigma_{q}^{|(z)|}}$ \\
\hline 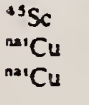 & 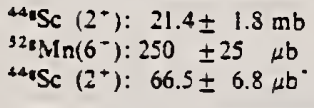 & 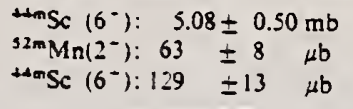 & $\begin{array}{l}0.24=0.03 \\
0.25=0.04 \\
1.9=0.3\end{array}$ \\
\hline
\end{tabular}


REF. A. S. Danagulyan, N. A. Demekhina

Yad. Fiz. 24, 681 (1976)

Sov. J. Nucl. Phys. 24, 355 (1976)

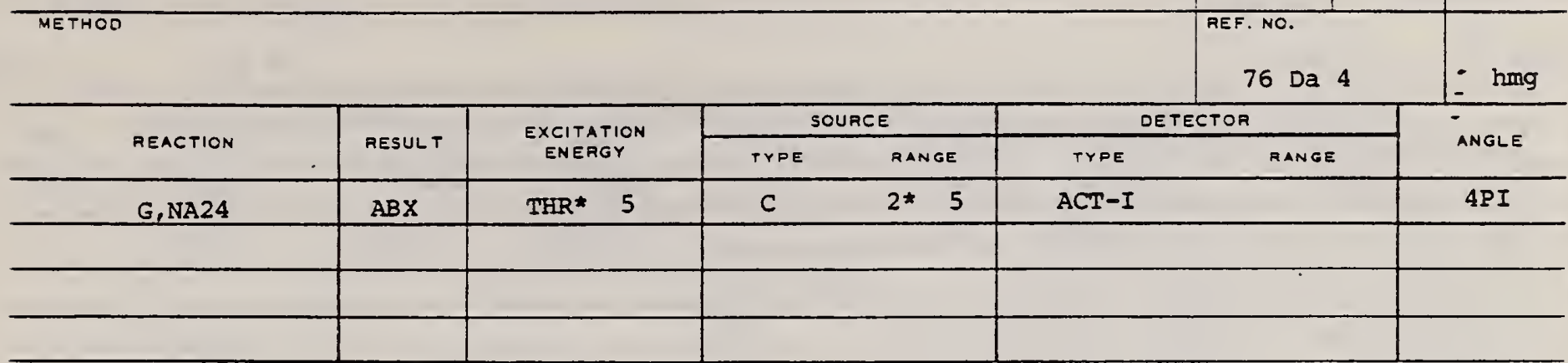

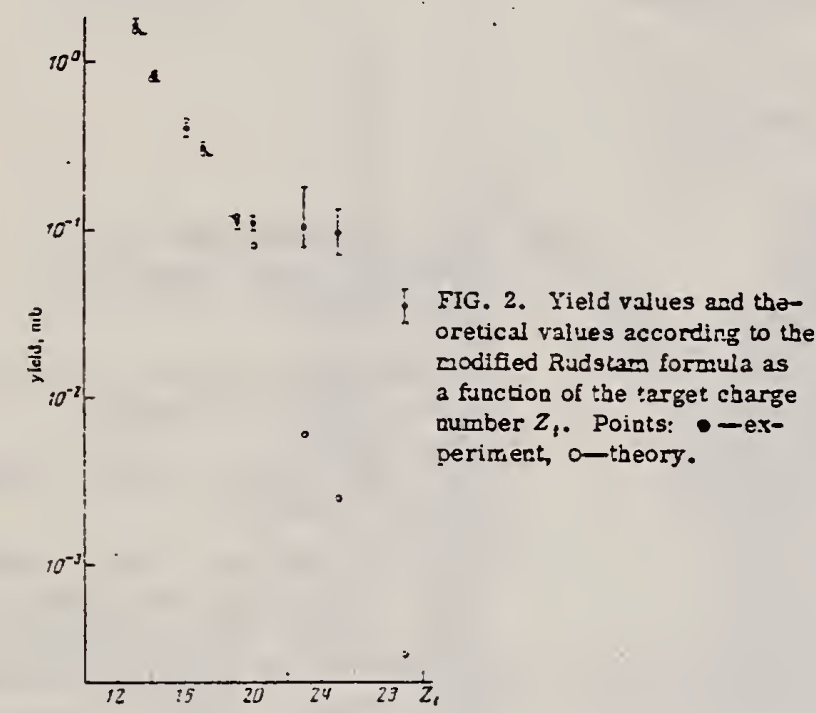

*ENERGY, GEV

TABLE I. Experimental yields and reaction cross sections obtained in the measurements at the Erevan electron accelerator.

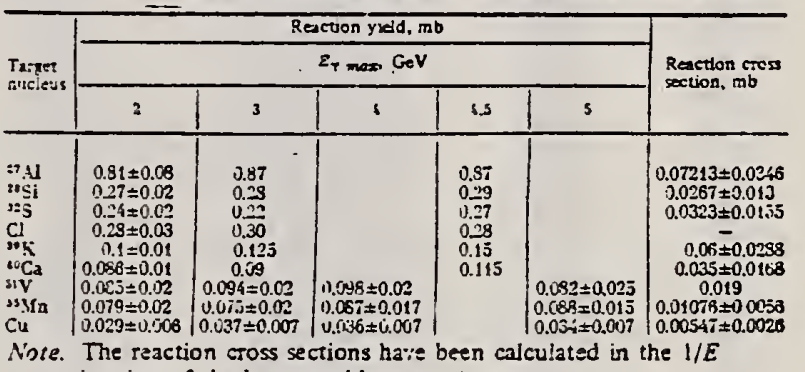

approximation of the bremsstrahlung spectrum. 
76 Em 2

egf.

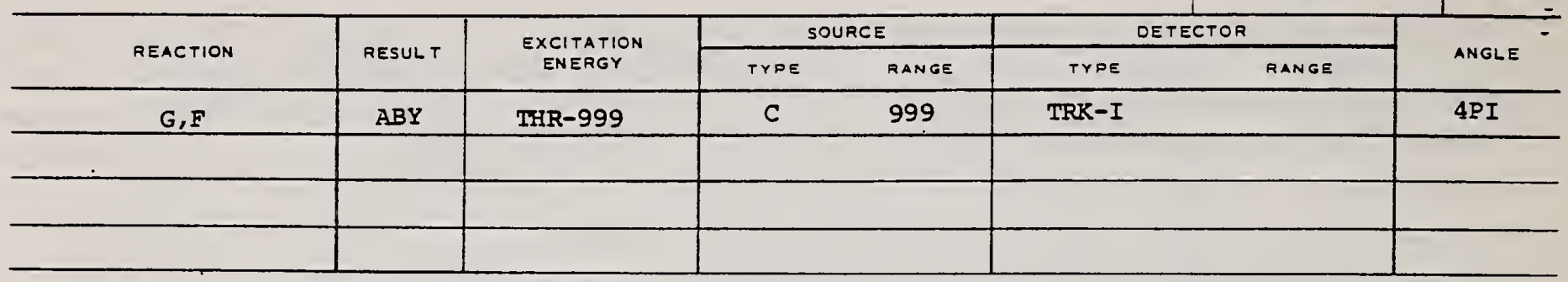

TABLE 1

Measured values of $\sigma_{\mathrm{q}}$ at $E=1000 \mathrm{MeV}$ and deduced values of $\sigma_{\mathrm{k}}$ assumed constant from $E_{0}$ to $1000 \mathrm{MeV}$
$999=1 \mathrm{GEV}$

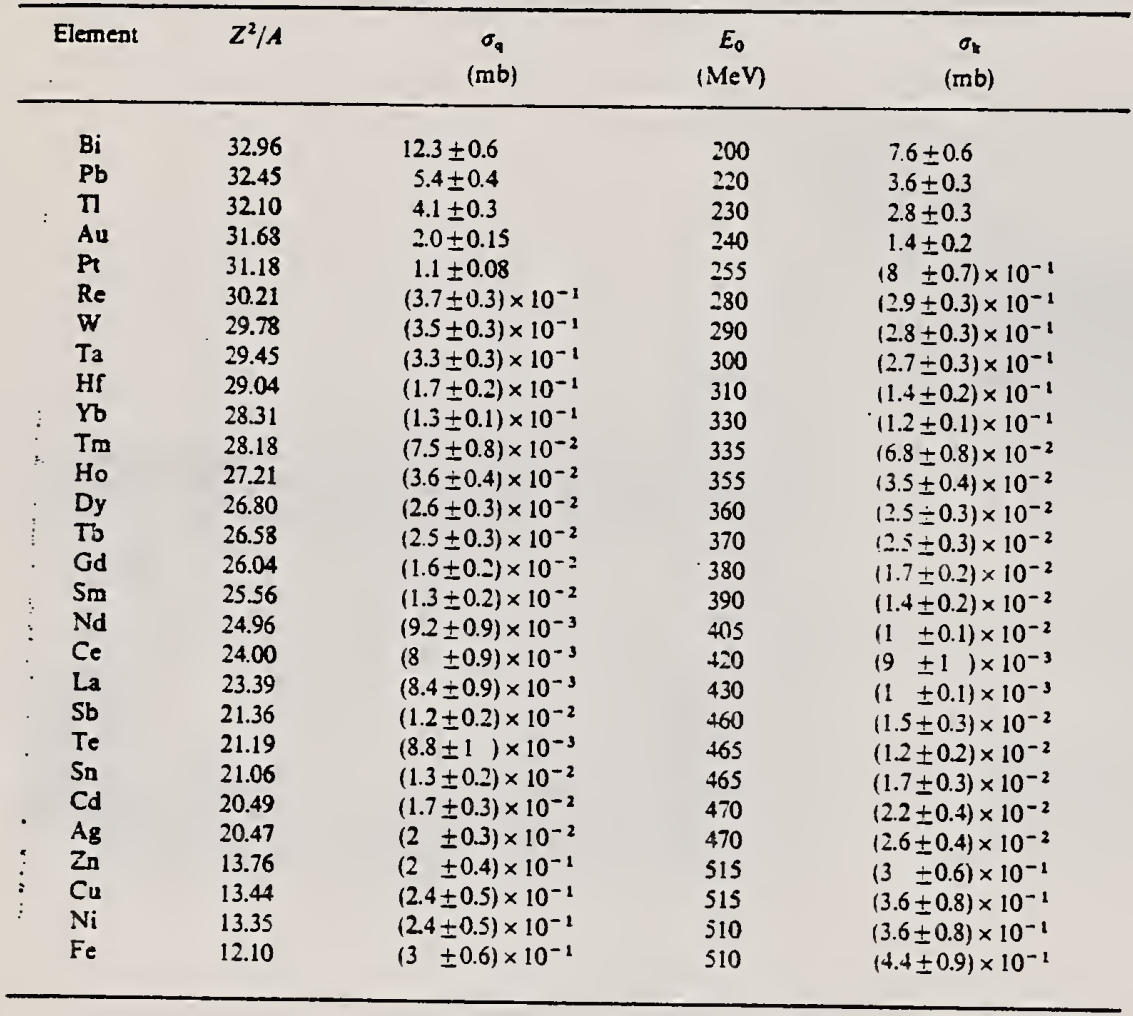

Fig. 2. Nuciear fissilities as a function of $Z^{2}$ ' $A$. Experimental points: solid circles represent our data; squares, the data from ref. ${ }^{4}$ ); open circles. the data from ref. ${ }^{7}$ ); and crosses, the data from (p. $)$ experiments $\left.{ }^{20}\right)$. The straight line is the best fit calculated from our data for $Z^{2} / A>26$. The dashed curve is the curve VI calculated by Nix and Sassi ${ }^{12}$.

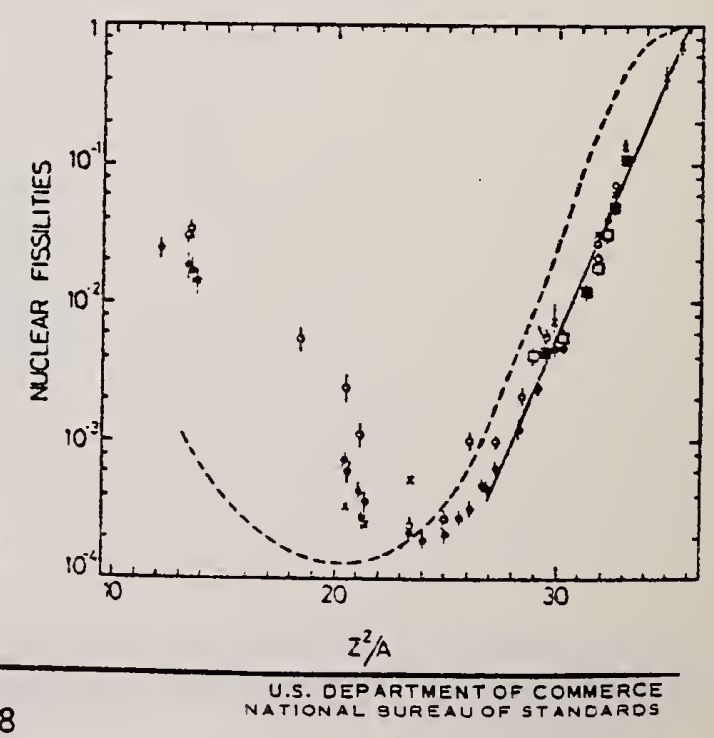

4.V. Mitrofanova et al. Sov. J. Nucl. Phys. 6 , 512 (1968).

7 T. Methasiri et al., Nucl. Phys. Al67, 97 (1971). 12 J.R. Nix et al., Nucl. Phys. 8I, 61 (1966).

20 N.A. Perifilov et al., JETP (Sov. Phys.) 14, 623 (1962); Proc. Symp. on the physics \& chemistry of fission, Salzburg 1965, vol. 2 (IAEA) Vienna, 1965, p. 283 . 
Y. Watase, S. Homma and T. Kitagaki

J. Phys. Soc. Japan 40, 1531 (1976)

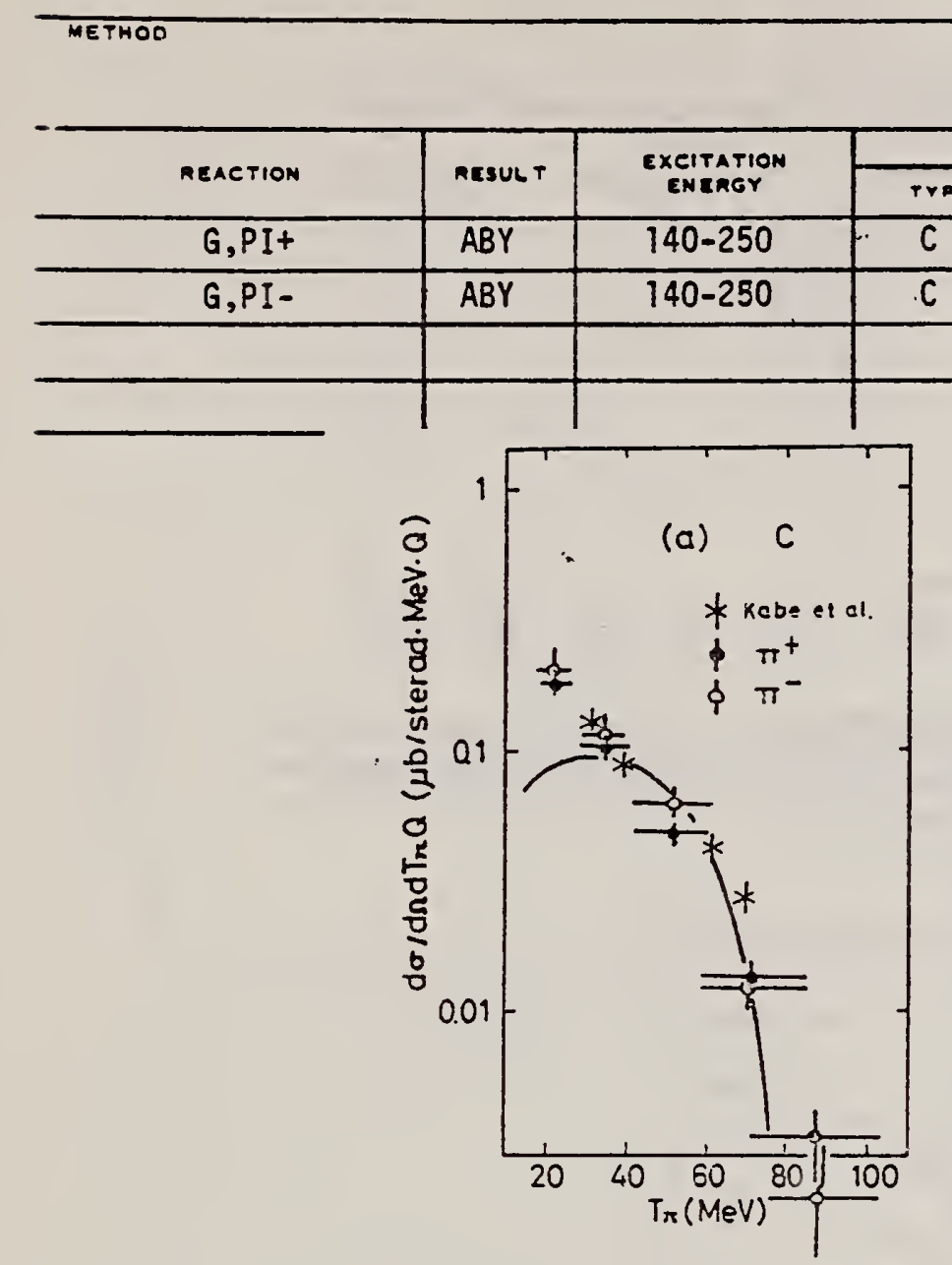

$\mathrm{Cu}$

REF. NO.

76 Wa 3

egf

\begin{tabular}{|c|c|}
\hline SOURCE & OETECTOA \\
\hline RAMGE & Troe nAMGe \\
\hline
\end{tabular}

-

ANGLE
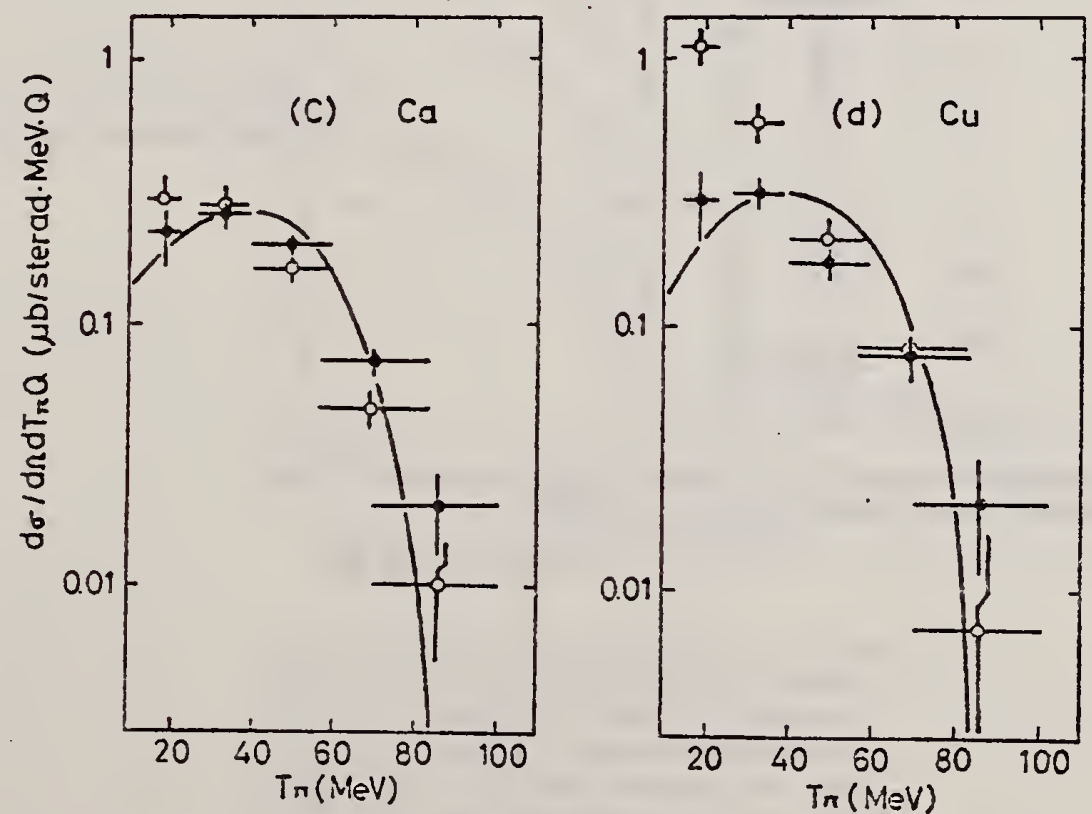

Fig. 2. The energy spectra of photoproduced $:=$ from $\mathrm{C}, \mathrm{Al}, \mathrm{Ca}$, and $\mathrm{Cu}$ at $90^{\circ}$ in the laboratory stitem by $250-\mathrm{MeV}$ bremsstrahlung. The dara of $\mathrm{Ca}$ are normalized to 0.26 ub sierad-1

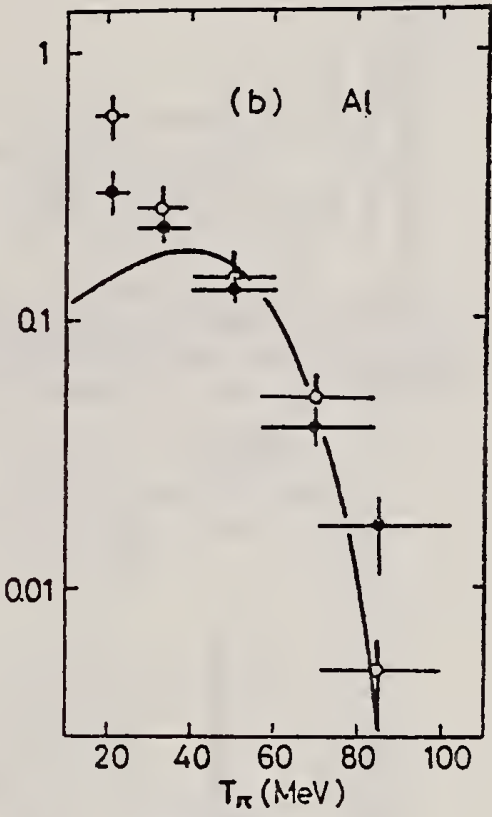

90



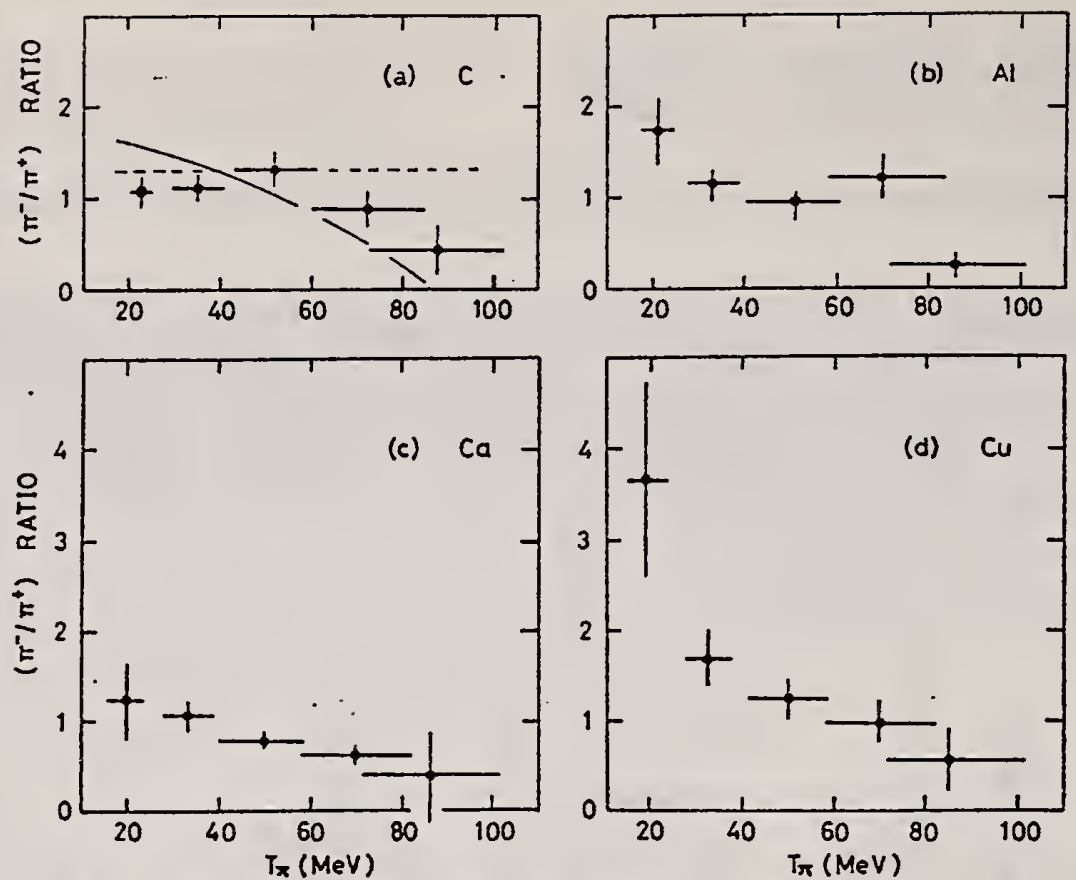

Fig. 3. The $=-/ \pi^{-}$ratio as a function of the kinetic energy of pions produced from $\mathrm{C}, \mathrm{Al}, \mathrm{Ca}$. and $\mathrm{Cu}$ by $250-\mathrm{MeV}$ bremsstrahlung. The solid curve in (a) is the calculated energy spectrum of $=-t^{+}$ratio including the Coulomb potential for $C$. The dashed curve is the ratio calcuisied neglecting the Coulomb potential.

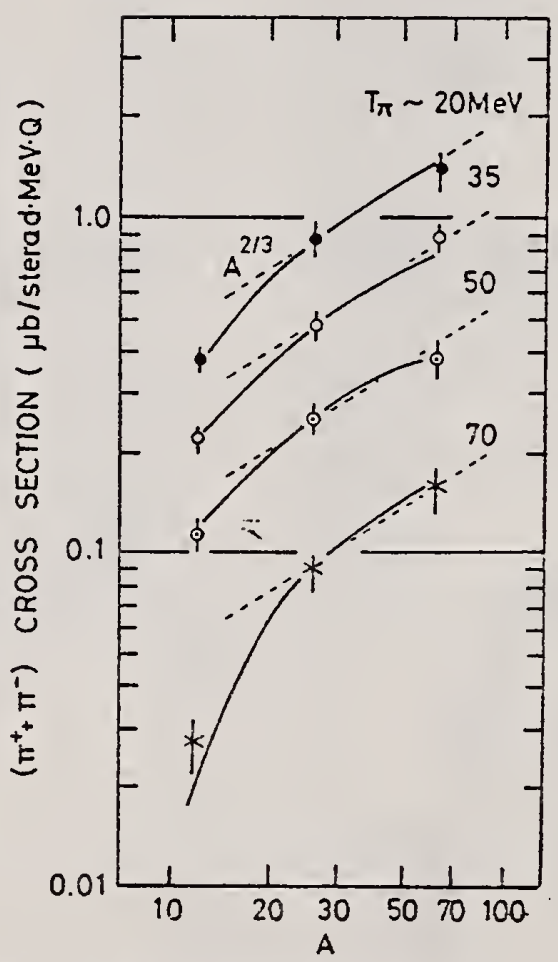

Fig. 4. The A-dependence of the $\left(\pi^{-} \div-0^{-}\right)$cross sections at the pion kinetic energies of $-20 \mathrm{MleV}$ $\sim 35 \mathrm{MeV}, \sim 50 \mathrm{MeV}$ and $\sim 70 \mathrm{MeV}$. The solid curves show the relative A-dependence obrained from the theoretical calculation. The dashed lines show $A^{2 / a}$ dependence only for guiling eyes. 
A.S. Danagulyan, N.A. Demekhina and G.A. Vartapetyan Nucl. Phys. A285, 482 (1977)

\begin{tabular}{|c|c|}
\hline $\begin{array}{c}\varepsilon t \leq v .: \cdots \\
\mathrm{Cu}\end{array}$ & 29 \\
\hline$R E=\cdot .,$. & \\
\hline $77 \mathrm{Da} 3$ & egf \\
\hline
\end{tabular}

\begin{tabular}{|c|c|c|c|c|c|c|c|}
\hline \multirow{2}{*}{$R E A=T I O N$} & \multirow{2}{*}{$R \equiv S J L T$} & \multirow{2}{*}{$\begin{array}{c}E \times C 1 T=-10 \% \\
E N \equiv=5 y\end{array}$} & \multicolumn{2}{|c|}{ SOURES } & \multicolumn{2}{|c|}{ IETECTO } & \multirow{2}{*}{ - ancle } \\
\hline & & & $r=\equiv$ & A-VEE & -ros & 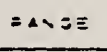 & \\
\hline$G, S P L$ & $A B Y$ & $T H R * 5$ & $C$ & $2 \star 5$ & $A C T-I$ & & $4 P I$ \\
\hline & & & & & & & \\
\hline & & & & & & & \\
\hline
\end{tabular}

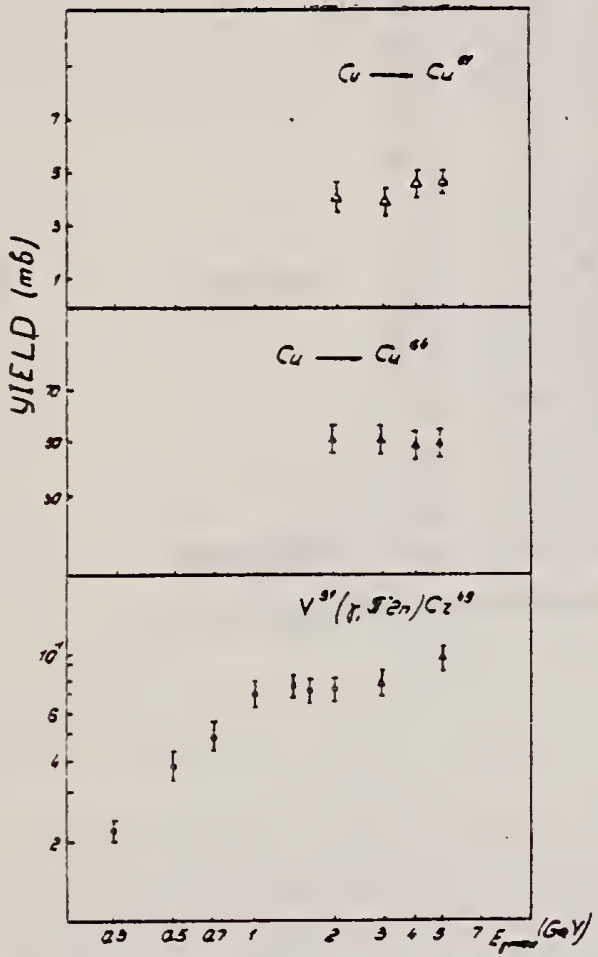

Fig 1. Characteristic curves of some simple reaction yields.

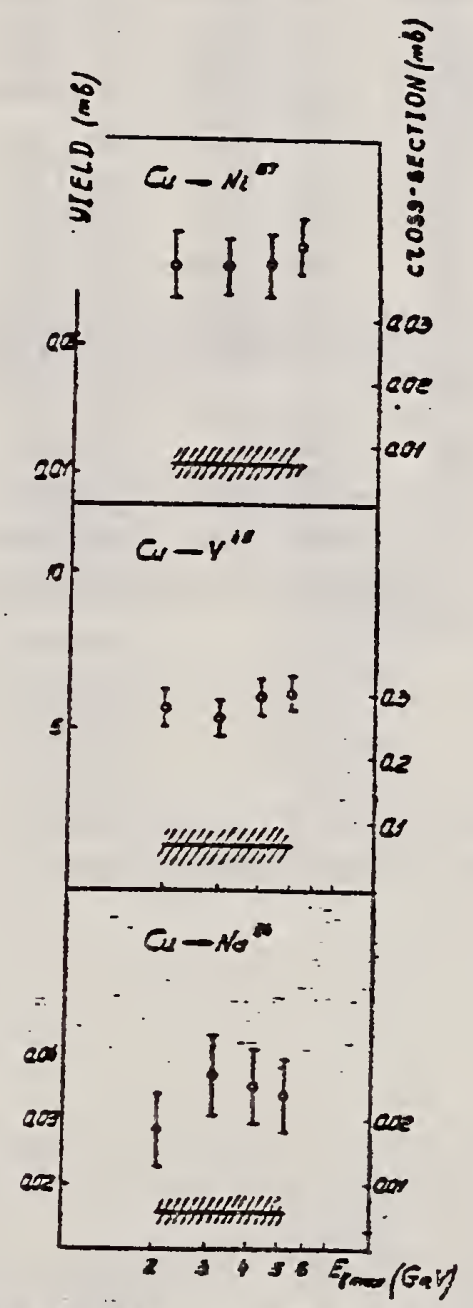

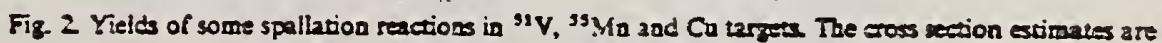
obcained in the I/E approximativa for brexosstrahluag. 
TABLE 2

Photospallation reaction yields (mb per eq. quantum)

\begin{tabular}{|c|c|c|c|c|c|c|c|}
\hline \multirow{2}{*}{$\begin{array}{c}\text { Residual } \\
\text { nuclei }\end{array}$} & \multicolumn{6}{|c|}{ Reaction yields (mb) } & \multirow{2}{*}{$\begin{array}{l}\text { Reaction } \\
\text { cross } \\
\text { sections } \\
\text { (mb) }\end{array}$} \\
\hline & $\begin{array}{r}E_{y \max }= \\
\text { (ex }\end{array}$ & $\begin{array}{l}=2 \mathrm{Ge} ! \\
\text { exp) }\end{array}$ & $\begin{array}{c}3 \mathrm{GeV} \\
\text { (exp) }\end{array}$ & $\begin{array}{c}4 \mathrm{GeV} \\
(\exp )\end{array}$ & $\begin{array}{l}5 \mathrm{GeV} \\
(\exp )\end{array}$ & $\begin{array}{c}S \text { GeV } \\
\text { (cal) }\end{array}$ & \\
\hline \multicolumn{8}{|c|}{ Cu larget } \\
\hline${ }^{62} \mathrm{Zn}$ & ${ }_{52}^{0.05}$ & $\begin{array}{l} \pm 0.015 \\
\pm 5\end{array}$ & $\begin{array}{c}0.07 \pm 0.02 \\
51 \pm 5\end{array}$ & $\begin{array}{c}0.06 \pm 0.02 \\
49 \pm 4.9\end{array}$ & $\begin{array}{l}0.05 \pm 0.015 \\
50.2 \pm 5\end{array}$ & & \\
\hline${ }^{6} \mathrm{Cu}$ & $4.24^{2}$ & \pm 0.4 & $3.98 \pm 0.4$ & $4.58 \pm 0.46$ & $4.58 \pm 0.46$ & 2.4 & \\
\hline${ }^{37} \mathrm{Ni}$ & $\begin{array}{r}0.065 \\
\leqq 0.067\end{array}$ & \pm 0.01 & $0.064 \pm 0.01$ & $0.067 \pm 0.011$ & $0.068 \pm 0.01$ & $\begin{array}{l}0.12 \\
0.02\end{array}$ & $0.0065 \pm 0.003$ \\
\hline${ }^{\circ} \mathrm{Co}$ & & & & & $0.3 \pm 0.05$ & 0.54 & \\
\hline${ }^{38} \mathrm{Co}$ & 3.67 & \pm 0.3 & $3.49 \pm 0.3$ & $3.3 \pm 0.3$ & $3.5 \pm 0.3$ & 4.76 & \\
\hline${ }^{37} \mathrm{Co}$ & 2.5 & \pm 0.25 & $2.2 \pm 0.2$ & $2.47 \pm 0.2$ & $2.2 \pm 0.2$ & 2.09 & \\
\hline${ }^{36} \mathrm{Co}$ & 0.77 & \pm 0.08 & $0.7 \pm 0.07$ & $0.75 \pm 0.07$ & $0.77 \pm 0.08$ & 0.606 & \\
\hline${ }^{33} \mathrm{Co}$ & 0.16 & \pm 0.031 & $0.14 \pm 0.025$ & $0.124 \pm 0.025$ & $0.16 \pm 0.031$ & 0.13 & \\
\hline${ }^{39} \mathrm{Fe}$ & 0.34 & \pm 0.08 & & $0.28 \pm 0.07$ & $0.32 \pm 0.05$ & 0.274 & \\
\hline${ }^{86} \mathrm{Mn}$ & 0.3 & \pm 0.03 & $0.27 \pm 0.03$ & & $0.3 \pm 0.03$ & 0.48 & \\
\hline${ }^{4} \mathrm{Mn}$ & 1.68 & \pm 0.17 & $1.66 \pm 0.16$ & $1.65 \pm 0.16$ & $1.64 \pm 0.16$ & 2.33 & \\
\hline$\$ 2 \mathrm{Mn}$ & 0.53 & \pm 0.05 & $0.47 \pm 0.05$ & $0.525 \pm 0.05$ & $0.473 \pm 0.05$ & 0.55 & \\
\hline${ }^{31} \mathrm{Cr}$ & 1.92 & \pm 0.2 & $1.92 \pm 0.2$ & $1.78 \pm 0.18$ & $1.9 \pm 0.2$ & 1.36 & \\
\hline${ }^{48} \mathrm{~V}$ & 0.56 & \pm 0.06 & $0.53 \pm 0.05$ & $0.6 \pm 0.06$ & $0.61 \pm 0.06$ & 0.46 & $0.066 \pm 0.03$ \\
\hline${ }^{48} \mathrm{Sc}$ & 0.07 & \pm 0.017 & $0.05 \pm 0.012$ & $0.062 \pm 0.015$ & $0.061 \pm 0.015$ & 0.036 & \\
\hline${ }^{47} \mathrm{Sc}$ & 0.13 & \pm 0.027 & $0.11 \pm 0.022$ & $0.1 \pm 0.02$ & $0.122 \pm 0.024$ & 0.128 & \\
\hline${ }^{6} \mathrm{Sc}$ & 0.41 & \pm 0.05 & $0.37 \pm 0.074$ & $0.36 \pm 0.07$ & $0.35 \pm 0.07$ & 0.336 & \\
\hline${ }^{4}$ Sc & & & $0.13 \pm 0.01$ & $0.15 \pm 0.015$ & $0.14 \pm 0.05$ & & \\
\hline $\operatorname{sm}_{S c}$ & 0.253 & \pm 0.025 & $0.27 \pm 0.03$ & $0.26 \pm 0.026$ & $0.24 \pm 0.025$ & 0.35 & \\
\hline${ }^{43} \mathrm{Sc}$ & 0.292 & \pm 0.03 & $0.285 \pm 0.03$ & $0.265 \pm 0.03$ & $0.25 \pm 0.02$ & 0.11 & \\
\hline${ }^{43} \mathrm{~K}$ & 0.0536 & $6 \pm 0.005$ & $0.058 \pm 0.006$ & & $0.051 \pm 0.005$ & 0.04 & \\
\hline${ }^{42} \mathrm{x}$ & 0.118 & \pm 0.01 & $0.097 \pm 0.01$ & $0.09 \pm 0.01$ & $0.1 \pm 0.01$ & 0.117 & \\
\hline${ }^{24} \mathrm{Na}$ & 0.029 & \pm 0.006 & $0.037 \pm 0.007$ & $0.036 \pm 0.007$ & $0.034 \pm 0.007$ & 0.012 & $0.0056 \pm 0.0025$ \\
\hline
\end{tabular}

Calculated values are obtained using Rudstam's formula. Cross section estimates are made in the $1 / E$ approximation. 


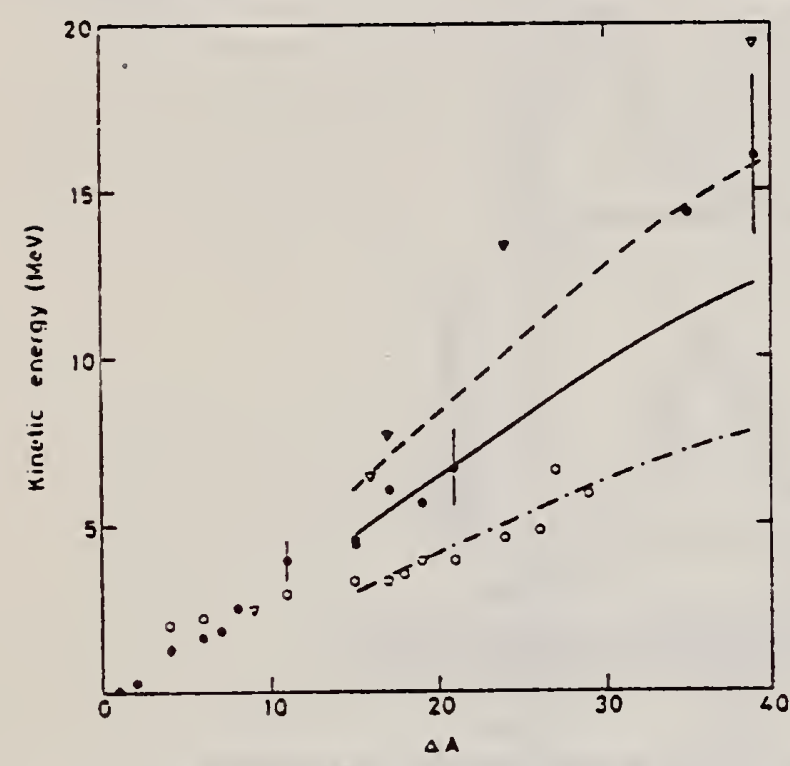

Fig. 1. The kinetic enszgias of fragments produced in $\mathrm{Cu}$ as a function of the mass number tifference $\Delta A$ between fragments and target: - denotos the messured man energies, 0 the energies valculated with Monte Carlo program [10], $\nabla$ the energies from lission calculation [11], - _- , _ and -..- are the energies calculated frotr tie sersiempirical formula of [9] multiplied by factors of $1,1.56$ and 2.02 respectively. The random error is given by bars in soms points
MEAN FRAGMENT RANGES

Table 1. Mean ranges and mean kizecic energies in thaee direecions for ${ }^{24} \mathrm{~N}_{3}$ produced in diferent tarzets

\begin{tabular}{|c|c|c|}
\hline & $\begin{array}{l}\text { Range } \\
\mathrm{mg} / \mathrm{cm}^{2}\end{array}$ & $\begin{array}{l}\text { Kineric } \\
\text { energy } \\
\text { Met" }\end{array}$ \\
\hline $\begin{array}{l}\text { Cu iorward } \\
\text { Cu backuard } \\
\text { Ci perpendie. }\end{array}$ & $\begin{array}{l}3.64 \pm 0.55 \\
2.17 \pm 0.33 \\
3.09 \pm 0.45\end{array}$ & $\begin{array}{l}21.0 \pm 3.8 \\
10.2 \div 1.8 \\
16.7 \div 3.0\end{array}$ \\
\hline $\begin{array}{l}\text { Ag formaid } \\
\text { Ag ba:kuiged } \\
\text { Ag garpendic }\end{array}$ & $\begin{array}{l}7.61 \pm 1.19 \\
6.65 \pm 1.09 \\
7.20 \pm 1.05\end{array}$ & $\begin{array}{l}37.1=6.7 \\
31.8=5.7 \\
35.0=6.3\end{array}$ \\
\hline $\begin{array}{l}\text { Au forkard } \\
\text { tu bechward } \\
\text { tu perpondic." }\end{array}$ & $\begin{array}{l}17.4 \div 2.6 \\
: 6.0 \pm 2.4 \\
12.6 \pm 5.4\end{array}$ & $\begin{array}{l}69.5 \pm 12.5 \\
62.0=11.5 \\
492=3 . .4\end{array}$ \\
\hline
\end{tabular}

- The siatisiical urcertainty in the jield was specialig large

Table 2. Means ranges in three directions, forward to backward ratios and mean kinctic energies of different fragments produced in copper

\begin{tabular}{|c|c|c|c|c|c|c|}
\hline \multirow[t]{2}{*}{ Fragment } & \multicolumn{4}{|c|}{ Range $\mathrm{mg} \mathrm{cm} \mathrm{cm}^{2}$} & \multirow{2}{*}{$\begin{array}{l}\text { Forkurd/ } \\
\text { Backward }\end{array}$} & \multirow{2}{*}{$\begin{array}{l}\text { Mean } \\
\text { kinetı } \\
\text { energy } \\
\text { MeV }\end{array}$} \\
\hline & Forward & Backward & $\begin{array}{l}\text { Perpen- } \\
\text { dicular }\end{array}$ & $\begin{array}{l}\text { Random } \\
\text { error }\end{array}$ & & \\
\hline${ }^{6+} \mathrm{Cu}$ & 0.018 & 0.009 & $0.0 \approx 1$ & $=0.002$ & 2.0 & 0.043 \\
\hline${ }^{6} \mathrm{Cu}$ & 0.10 & 0.05 & 0.05 & \pm 0.01 & 2.0 & 0.26 \\
\hline${ }^{99} \mathrm{Fe}$ & 0.43 & 0.31 & 0.28 & \pm 0.05 & 1.4 & 1.23 \\
\hline${ }^{7} \mathrm{Ni}$ & 0.63 & 0.20 & 0.41 & \pm 0.06 & 3.1 & 1.6 \\
\hline${ }^{90} \mathrm{Co}$ & 0.66 & 0.24 & 0.49 & \pm 0.07 & 27 & 1.8 \\
\hline${ }^{39} \mathrm{Co}$ & 0.87 & 0.32 & 0.61 & \pm 0.09 & 27 & 2.5 \\
\hline $3: \mathrm{Mn}$ & 1.07 & 0.42 & 1.13 & \pm 0.13 & 2.5 & 3.9 \\
\hline${ }^{43} \mathrm{Sc}$ & 1.41 & 0.66 & 1.08 & \pm 0.16 & 2.1 & 4.4 \\
\hline$+? \mathrm{~V}$ & 1.41 & $0.5 y$ & 0.97 & \pm 0.15 & 2.4 & 4.5 \\
\hline${ }^{46} \mathrm{Sc}$ & $1 \div 1$ & $0.5 i$ & 1.24 & $=0.19$ & 2.0 & 6.0 \\
\hline$\therefore+5$ & 1.61 & 0.67 & 1.23 & \pm 0.18 & 2.5 & 5.6 \\
\hline$\therefore:$ & $: \infty$ & C.:- & 1.41 & \pm 0.21 & 2.3 & 6.7 \\
\hline 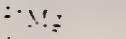 & $\because z$ & $1:$ & 3.4 & \pm 0.4 & 2.4 & 14.3 \\
\hline$\therefore \therefore$ & $:=$ & $\because z$ & 3.1 & $=0.4$ & 1.7 & 16.0 \\
\hline
\end{tabular}


77 Ja 2

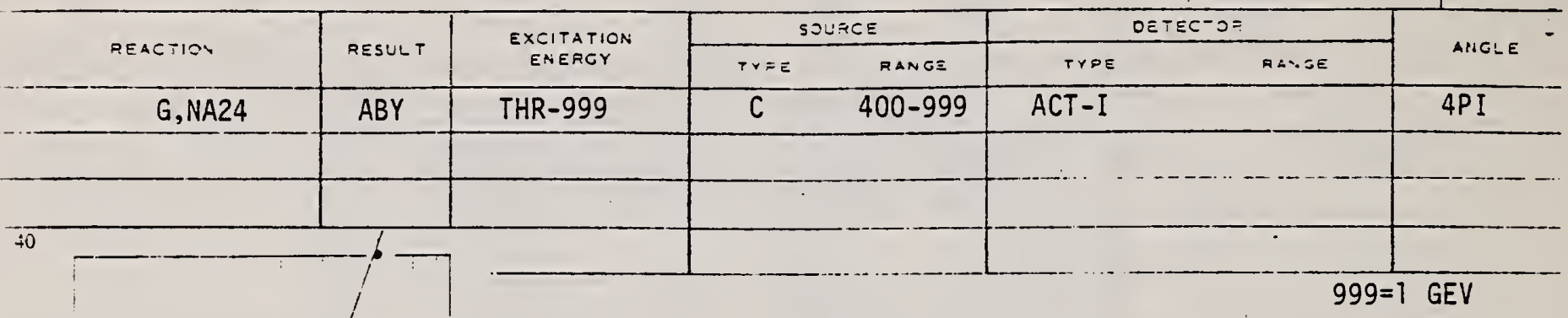

Fi... 1 a.j. The measured yield as a function of bremsstrahlung end point energy. The error bars give the statistical errors in the numbers of $j$ yi:inte detected. The solid lines are fitted to the yield points with the least-squares method. The yield from $\mathrm{Cu}$ (Fig. 1a) is misured in [1] and has neen iscalculated using the monitor curve of [S]

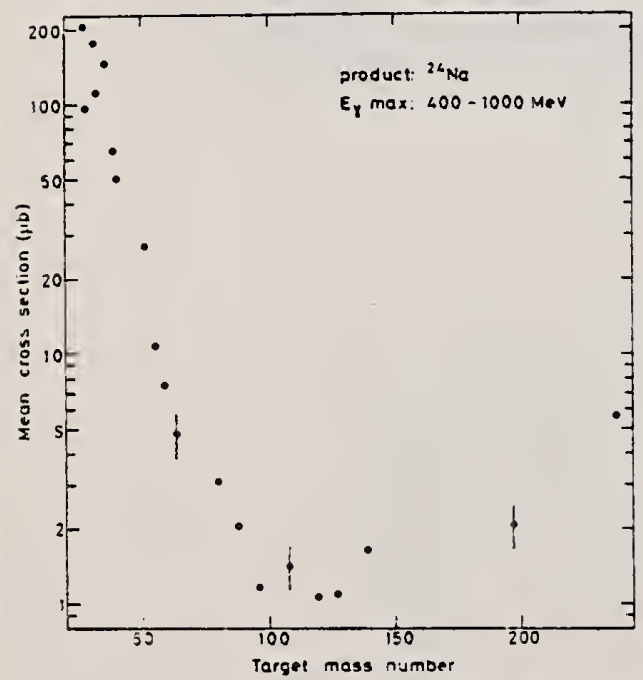

Fig. : . - - - - an cross section in the energy range 400 to $1000 \mathrm{MeV}$

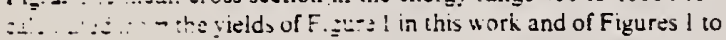

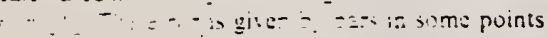

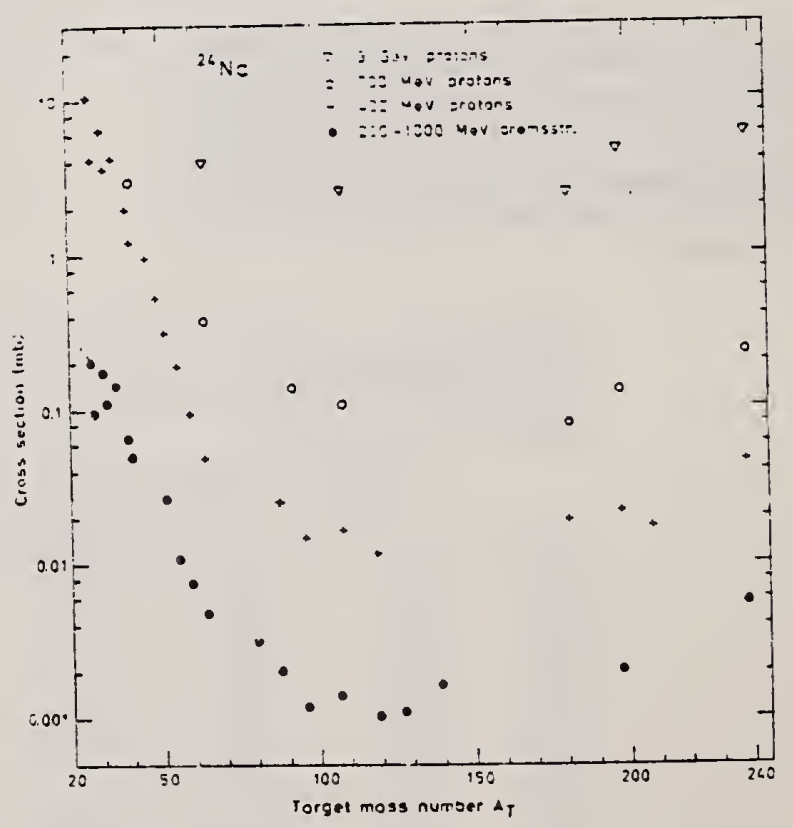

rig. A. Mcan cross sections of the present work and of [1] ( $\bullet)$ coinfared with tlis cross sections in proton irradiations: $+400 \mathrm{MeV}$ from $[4] .0700 \mathrm{NfeV}$ from [16] and an extrapolated value from [17]. $\nabla 3$ Gel fion [18] 
J.J. Murphy II, H.J. Gehrhardt and D.M. Skopik Nucl. Phys. A277, 69 (1977)

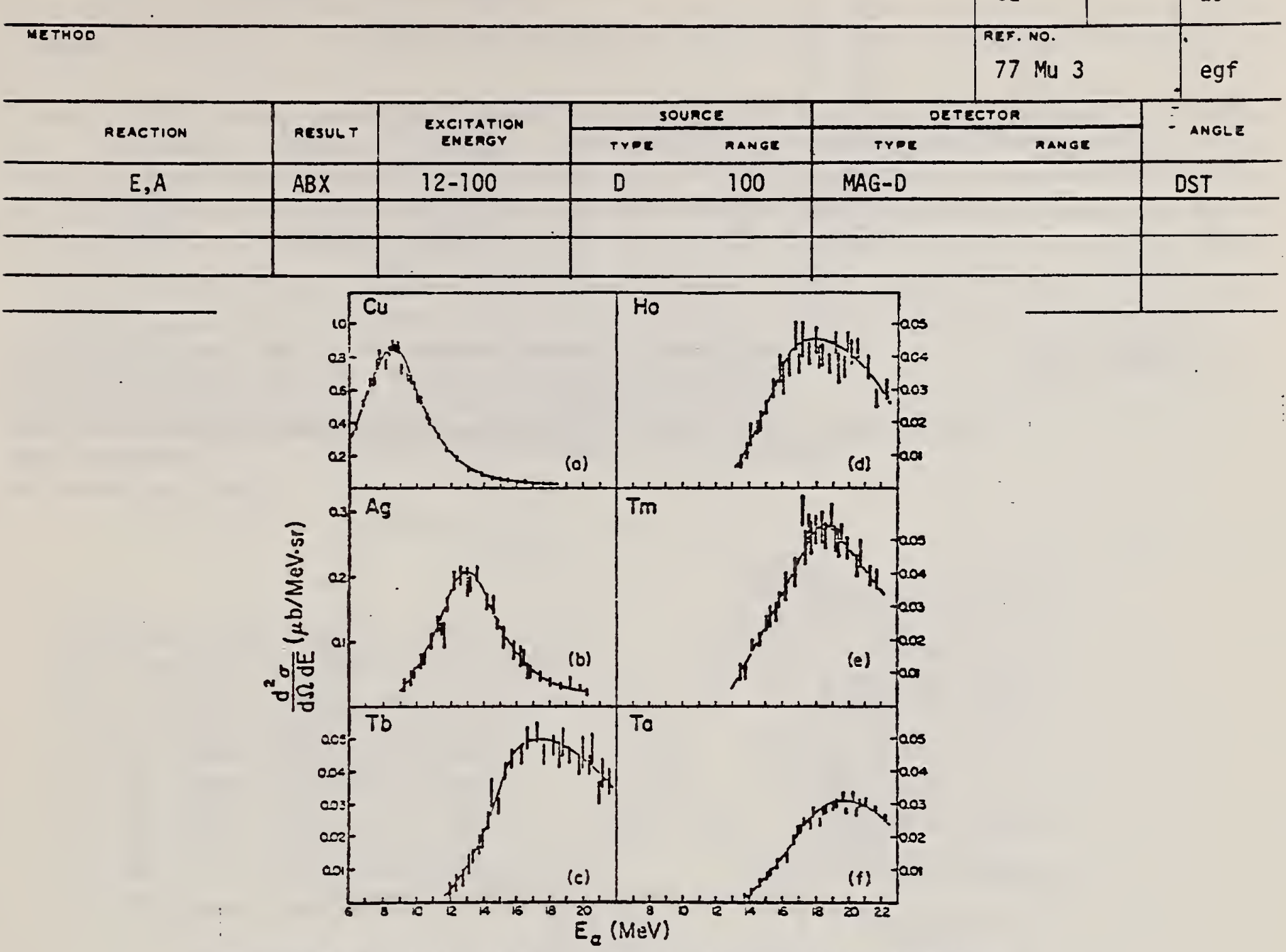

Fig. 1. The $z-$-article energy spectra at $50^{\circ}$ in the lab for the six nuclei strdied. Note that as $Z$ in-

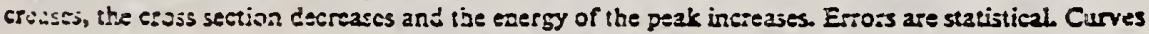
are to guide the eye.

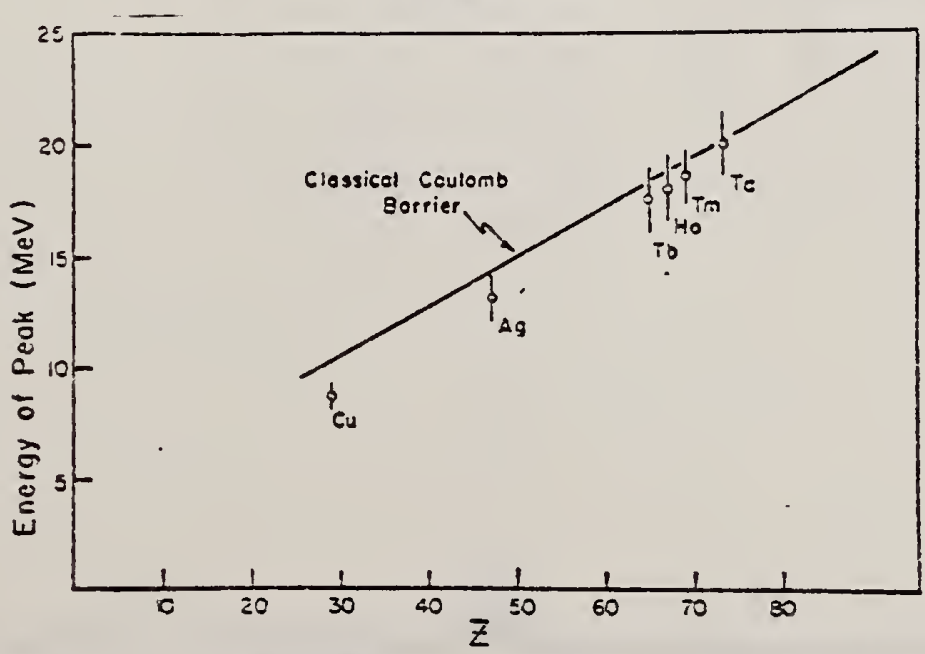

Fig. 2. Energy of $i=$ tess fection peak as a function of $Z$. The solid line is the egergy of the ciassical 


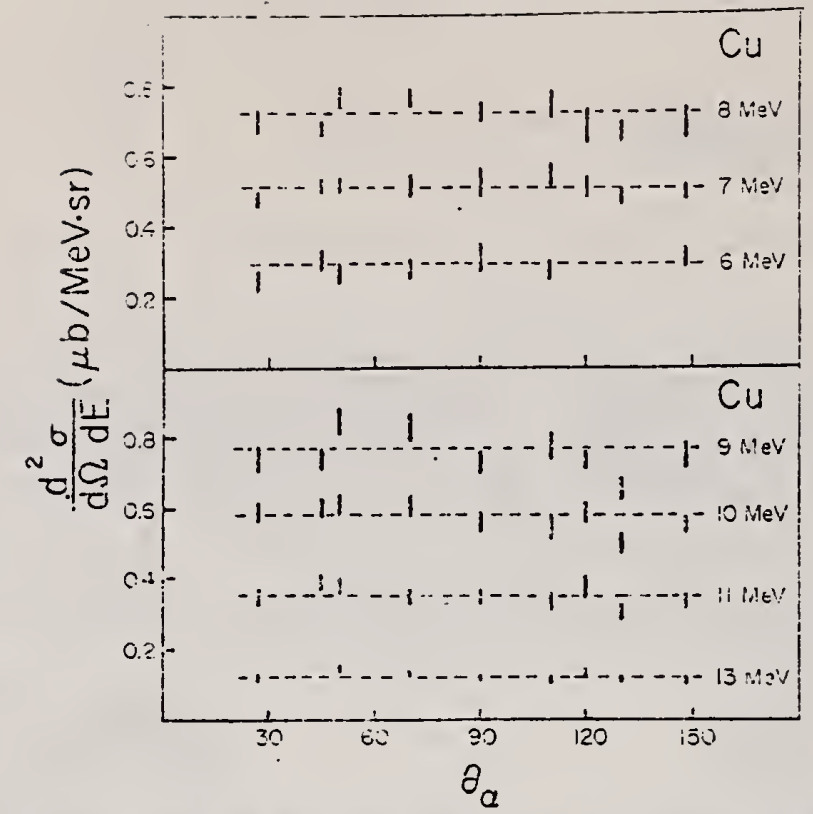

Fig. 3. Angular distributions for copper $(Z=29)$. These isotropic distributions indicate an evaporation process. Errors are statistical. Curves are to guide the cye.

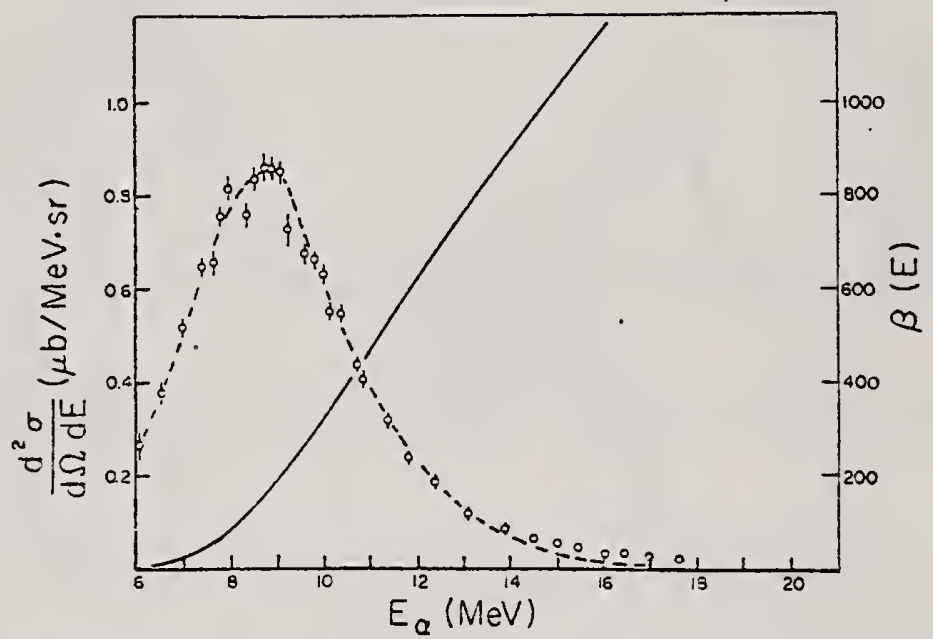

Fig. + . The $\alpha$-particle energy spectrum at $50^{\circ}$ for copper. The dash curve is the calculated evaporation model cross section. The solid curve (scale to right) gives the penetrabilities used in the calculation. 
REF. A.S. Danagulyan, N.A. Demekhina

Yad. Fiz. 27, 877 (1978)

Sov. J. NuCT. Phys. 27,466 (1978)

$78 \mathrm{Da} 13$

\begin{tabular}{|c|c|c|c|c|c|c|c|}
\hline \multirow{2}{*}{ REACTION } & \multirow{2}{*}{ RESULT } & \multirow{2}{*}{$\begin{array}{c}\text { EXCITATION } \\
\text { ENEROY }\end{array}$} & \multicolumn{2}{|c|}{ SOUACE } & \multicolumn{2}{|c|}{ DETECTOR } & \multirow{2}{*}{ ANGLLE } \\
\hline & & & TYPE & inange & Trpe & RANGE & \\
\hline G,MN52 & $A B Y$ & $T H R * 5$ & $C$ & $2 * 5$ & $A C T-D$ & & 4PI \\
\hline $\mathrm{G}, \mathrm{SC} 44$ & $A B Y$ & $T H R \star 5$ & $C$ & $2 * 5$ & $A C T-D$ & & $4 P I$ \\
\hline & & & & & & & \\
\hline
\end{tabular}

We discuss dat concernirg the ratios oi the sieids of different isomeric states in the elemernts "Se and

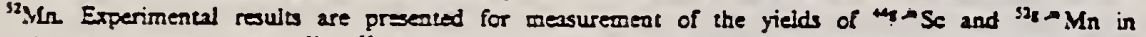
disintegration of irgets of "V, "Mn, and $\mathrm{Cu}$ by phocons with exergies from 2 to $5 \mathrm{GeV}$; theoretical values of yields for these elements were obcained by means of the five-parameter Rudstam formula. The partern of formation of high-spia siates in photodisintegration reactions is discussed in terms of the ascaderaporative model.

PACS numbers: $25.20+y .27 .40+z$

TABLE I.

\begin{tabular}{|c|c|c|c|c|c|c|}
\hline \multirow{3}{*}{$\begin{array}{l}\text { Type } \\
\text { of } \\
\text { aryzer }\end{array}$} & \multirow{3}{*}{$\begin{array}{c}\text { Lomierse } \\
\text { syates }\end{array}$} & \multicolumn{4}{|c|}{ Yeeld $\quad$ no } & \multirow{3}{*}{ Theon } \\
\hline & & \multicolumn{4}{|c|}{ Experment } & \\
\hline & & 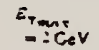 & $3 \mathrm{CeV}$ & $+\mathrm{GeV}$ & $3 \mathrm{CeV}$ & \\
\hline "V & $\begin{array}{l}\text { MSo } \\
\text { Wse }\end{array}$ & $\begin{array}{l}0.77=0.03 \\
0.35=0.06\end{array}$ & $\begin{array}{l}n .\{i=0.03 \\
0.4 .5 \pm 0.00\end{array}$ & $\begin{array}{l}0 . ; i=0.0 i \\
0.5 i=0.07\end{array}$ & $\begin{array}{l}0.76=0.0 ; \\
0.56=0.07\end{array}$ & 1.03 \\
\hline "Yo & "urse & $\begin{array}{l}0 .\{5 \pm 0.04 \\
0.72 \neq 0.04\end{array}$ & $\begin{array}{l}0.47=0.04 \\
0.7 z=0.04\end{array}$ & $\begin{array}{l}0.12=0.03 \\
0.35=0.1\end{array}$ & $\begin{array}{l}0.55=0.05 \\
0.15=0.05\end{array}$ & 1.3 \\
\hline "Mng & $\begin{array}{l}32-180 \\
220510\end{array}$ & $\begin{array}{c}0.43 \pm 0.05 \\
0.55\end{array}$ & $\begin{array}{c}0.13=0.04 \\
0.53\end{array}$ & $\begin{array}{l}0.6=0.06 \\
0.3 j\end{array}$ & $\begin{array}{c}0 .+8>0.05 \\
0.55\end{array}$ & 1.34 \\
\hline $\mathrm{Cu}$ & $\begin{array}{l}m-5 e \\
\text { urse }\end{array}$ & $0 \leq=0.03$ & $\begin{array}{l}0.27 \pm 0.03 \\
0.13 \simeq 0.01\end{array}$ & $\begin{array}{l}0.26=0.023 \\
0.1 j=0.02\end{array}$ & $\begin{array}{l}0.24 \pm 0.03 \\
0.16 \times 0.25\end{array}$ & 0.35 \\
\hline $\mathrm{Cu}$ & $\operatorname{sem} \mathrm{Ma}$ & $0.53 \pm 0.05$ & $0.47 \pm 0.05$ & $\begin{array}{l}0.123=0.01 \\
0.53=0.05\end{array}$ & $0.173 \div 0.05$ & 0.55 \\
\hline
\end{tabular}

TABLE I.

\begin{tabular}{|c|c|c|c|}
\hline $\begin{array}{l}\text { Type } \\
\text { of } \\
\text { angs: }\end{array}$ & $\begin{array}{c}\text { Proton emer- } \\
\mathrm{d}, \mathrm{YeV}\end{array}$ & $\begin{array}{l}\text { Lomeme } \\
\text { nold atio }\end{array}$ & Remiste \\
\hline & & ${ }^{m}$ Sejuse & \\
\hline MV & $\begin{array}{c}65-300 \\
100-300 \\
2000-5000\end{array}$ & $\begin{array}{c}0.75 \pm 0.03 \\
0.88 \\
0.87 \neq 0.06\end{array}$ & Present work \\
\hline น.seF. & $=300$ & $\begin{array}{l}0.51=0.02 \\
1.03=0.05\end{array}$ & !r] \\
\hline usin & $\begin{array}{c}235 \\
300 \\
=0-300 \\
2000-3000\end{array}$ & $\begin{array}{c}0.72 \\
0.64 \\
1.09=0.05 \\
1.02=0.02\end{array}$ & $\begin{array}{l}{[y]} \\
{[?]} \\
\text { Preni work }\end{array}$ \\
\hline cin & $\begin{array}{c}230-300 \\
2000-3000\end{array}$ & $\begin{array}{l}1.24=0.08 \\
184=0.16\end{array}$ & ['] \\
\hline NAs & $230-800$ & 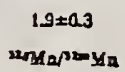 & ['] \\
\hline w & $\begin{array}{c}70 \\
100-250\end{array}$ & $\begin{array}{l}0.47 \\
0.56\end{array}$ & {$[7]$} \\
\hline${ }^{2} \mathrm{Mo}$ & $\begin{array}{c}100-300 \\
200-x \times 0\end{array}$ & $\begin{array}{c}0.88 \\
t .12=0.1\end{array}$ & {$\left[{ }^{n]}\right.$ Preseat vork } \\
\hline $\begin{array}{l}\text { "Co } \\
\mathrm{Cu}\end{array}$ & $\begin{array}{r}150 \\
\$ 000\end{array}$ & $\begin{array}{c}1.62 \\
4.1=0.4\end{array}$ & ${ }_{\text {Paseni wark }}^{[1]}$ \\
\hline
\end{tabular}


ner. K. Baba, I. Endo, M. Fujisaki, S. Kadota, Y. Sumi, H. Fujii, Y. Murata, S. Noguchi, A. Murakami Nuct. Phys. A322, 349 (1979)

\begin{tabular}{|c|c|c} 
ELEM. SYM. & & \\
CU & & 29 \\
\hline $\begin{array}{c}\text { AEF. NO. } \\
79 B a 8\end{array}$ & $h g$ \\
\hline TECTOA & ANGEE \\
\hline MANGE & OST \\
\hline & OST \\
\hline
\end{tabular}

Abstract: The photoproduction of charged pions in the sub $\mathrm{GeV}$ region has been studied for two nuclear targets, copper and lead, by using a magnetic spectrometer. The photon energies are determined in steps of $50 \mathrm{MeV}$ by a subtraction method for the bremsstrahlung spectrum. The observed pion *AVG PHOTON ENERGY momentum spectra reveal characteristic features of quasi-free production (QFP) even for such heavy nuclei as copper and lead. The data are compared with results obtained by a PWIA calculation, which give a good fit to the data. The OFP cross sections per relevant nucleon at $44.2^{\circ}$ and the average photon energy $\langle k\rangle=668 \mathrm{MeV}$ are found to be approximately proportional to $\mathrm{A}^{-1 / 3}$.
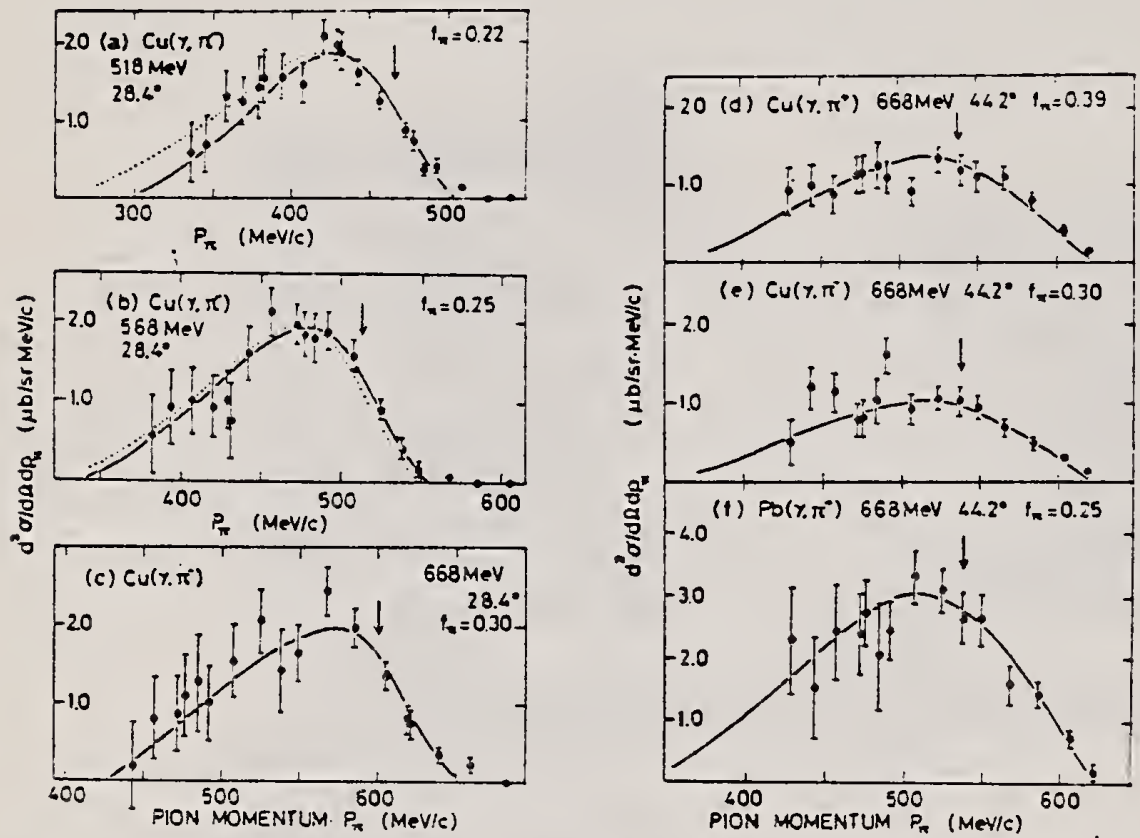

Fig. 1. Typical examples of the measured pion spectra. Errors are statistical only. The solid curies are $f_{\pi} \times$ (PWIA calculation) with parameter values $p_{F}=270 \mathrm{MeV} / c, \varepsilon=25 \mathrm{MeV}$ and $f_{\pi}$ being shown in the figure. The dotted curves in (a) and (b) correspond to the eases in which $p_{F}=300 \mathrm{MeV} / \mathrm{c}$ while $\varepsilon$ is unchanged, and $\varepsilon=35 \mathrm{MeV}$ while $\mathrm{p}_{\mathrm{F}}$ is unchanged, respectively. Arrows denote the values of the pion momentum, $p_{\text {frce, }}$ which is calculated from the assumption that the target nucleon is free and at rest. 


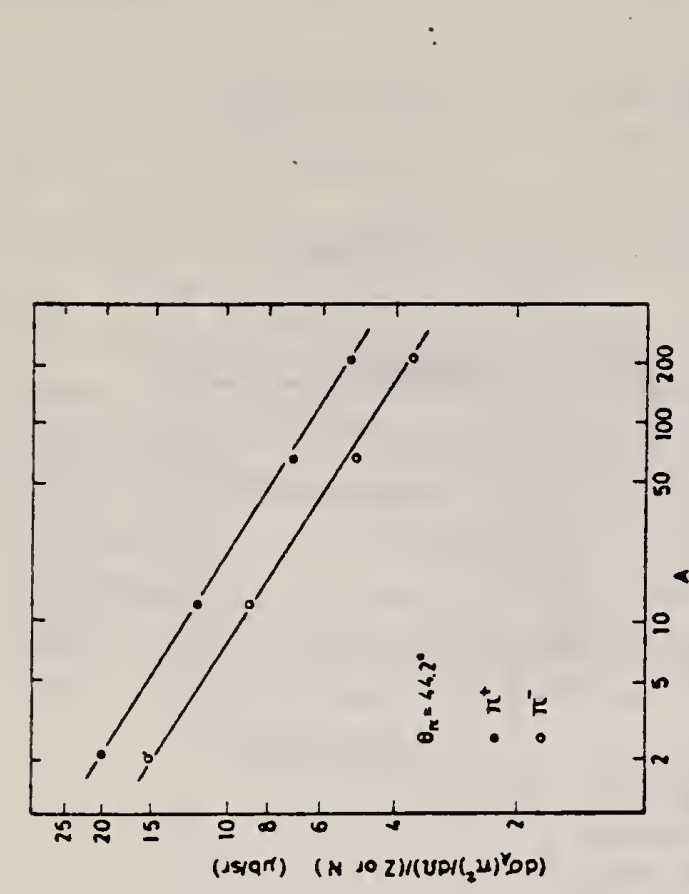

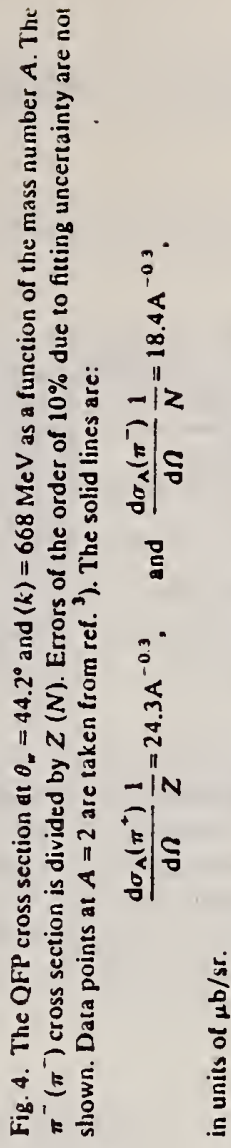
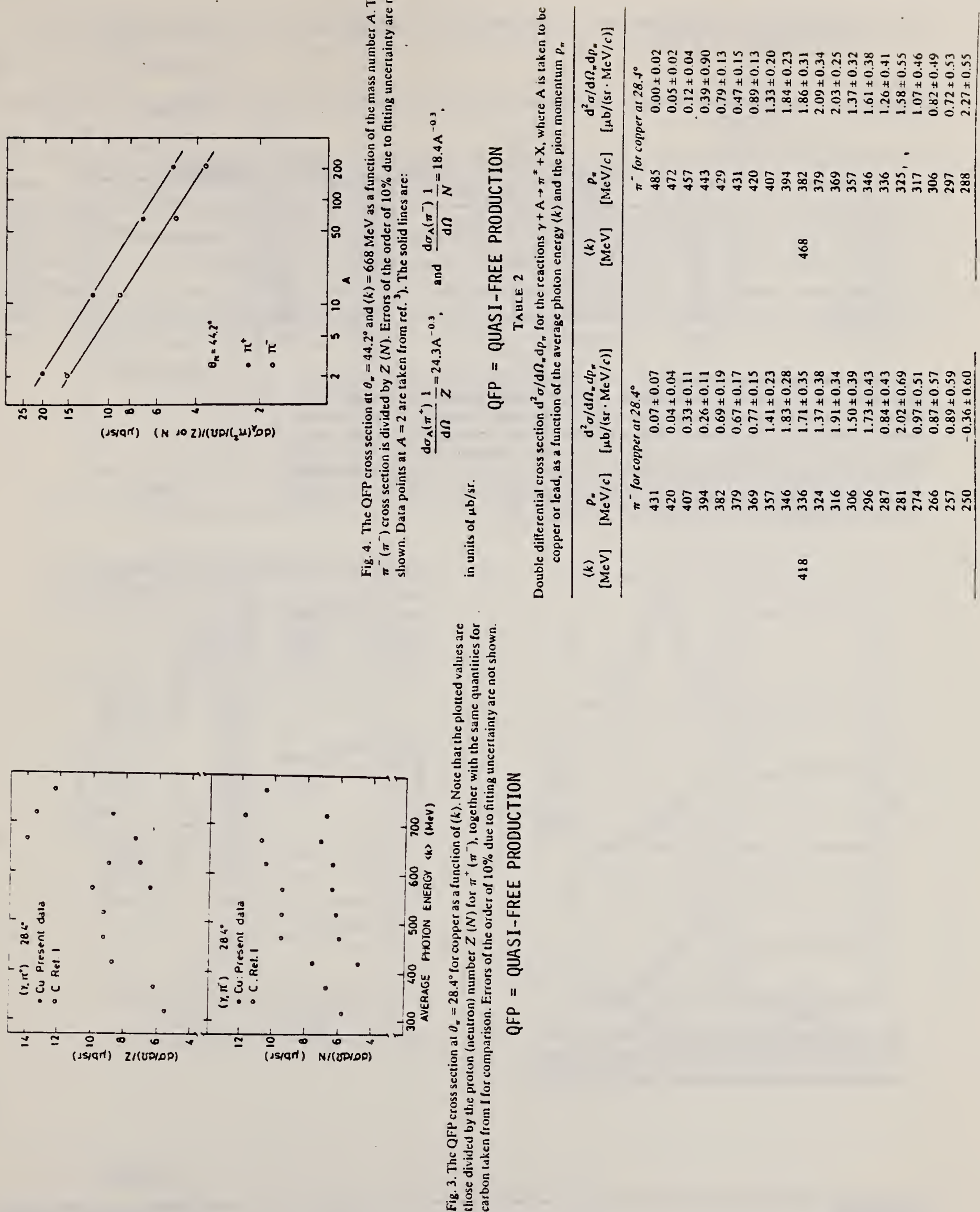
ref. J.-0. Adler, G. Andersson, H.-A. Gustafsson, K. Hansen

Z. Phys. A295, 65 (1980)

80 Ad 10

\begin{tabular}{|c|c|c|c|c|c|c|c|}
\hline \multirow{2}{*}{ REACTION } & \multirow{2}{*}{ AESULT T } & \multirow{2}{*}{$\begin{array}{l}\text { EXCITATION } \\
\text { ENERGY }\end{array}$} & \multicolumn{2}{|c|}{ Sounce } & \multicolumn{2}{|c|}{ DETECTOR } & \multirow[b]{2}{*}{ ANGLE } \\
\hline & & & Trpe & inanez & TYPE & RANGE & \\
\hline$G, P$ & $A B Y$ & THR-500 & c & 500 & TEL-D & & $\overline{D S T}$ \\
\hline$G, D$ & $A B Y$ & THR-500 & $C$ & 500 & TEL-D & & DST \\
\hline$G, T$ & ABY & THR- 500 & $C$ & 500 & TEL-D & & DST \\
\hline $\mathrm{G}, \mathrm{HE} 3$ & RLY & THR 500 & $C$ & 500 & TEL-D & & DST \\
\hline
\end{tabular}

The energy and angular distributions of $p, d, t,{ }^{3} \mathrm{He}$ and ${ }^{4} \mathrm{He}$ from the three targets $\mathrm{Cu}$, $\mathrm{Ag}$ and $\mathrm{Au}$ were measured at five different angles for bremsstrahlung with peak energy $500 \mathrm{MeV}$. The measurements were made using a telescope consisting. of four surfacebarrier detectors. The experimental 'data are compared with cascade-evaporation calculations. For the ${ }^{4} \mathrm{He}$-distributions the calculations were extended to include the contribution from knock-out of surface alphas by the cascade nucleons. The comparison shows that the main contribution comes from evaporation but that there is a direct component of the order of $10 \%$.
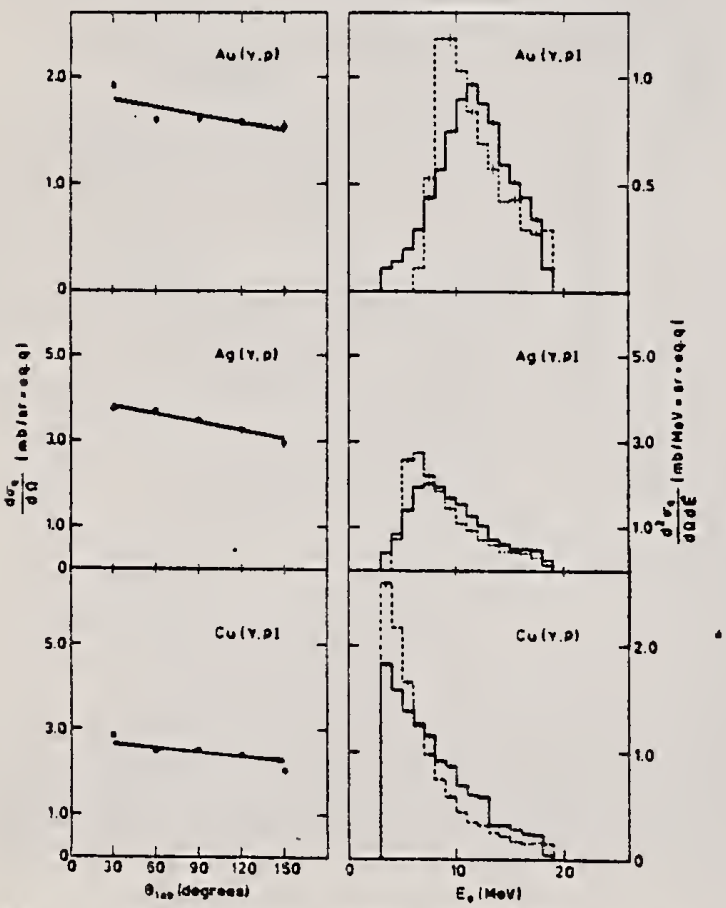

Fig. 2 Experimental proton angular (filled circles) and energy (solid histogram) distributions fiom the three targets $\mathrm{Au}$. Ag and $\mathrm{Cu}$ compared with anguiar (solid line) and energy idashed histo. gram) distributions obtained from cascade-evaporation calculations

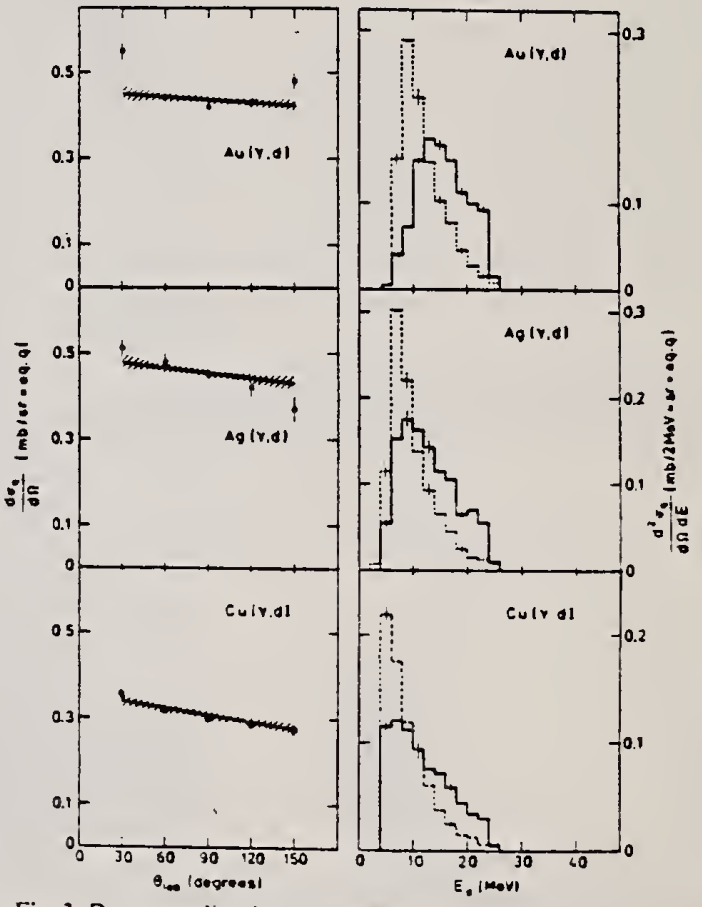

Fig. 3. Deuteron distnbutions. See csption of Fig. ? 


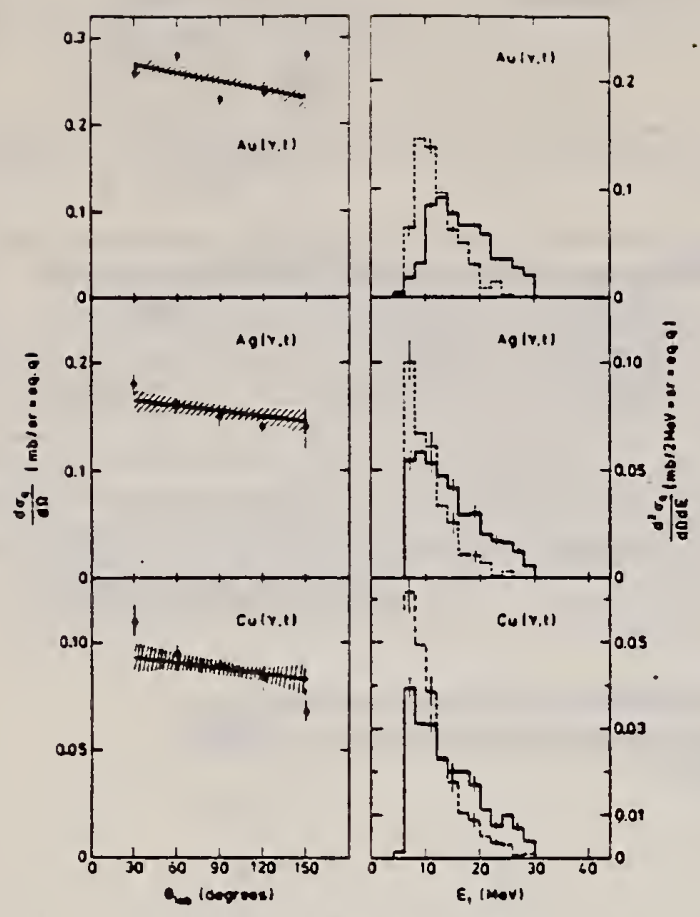

Fig. 4. Triton distributions. See caption of Fig. 2

Table 2 Integrated gelds. normalization factors and calculated direct contribution.

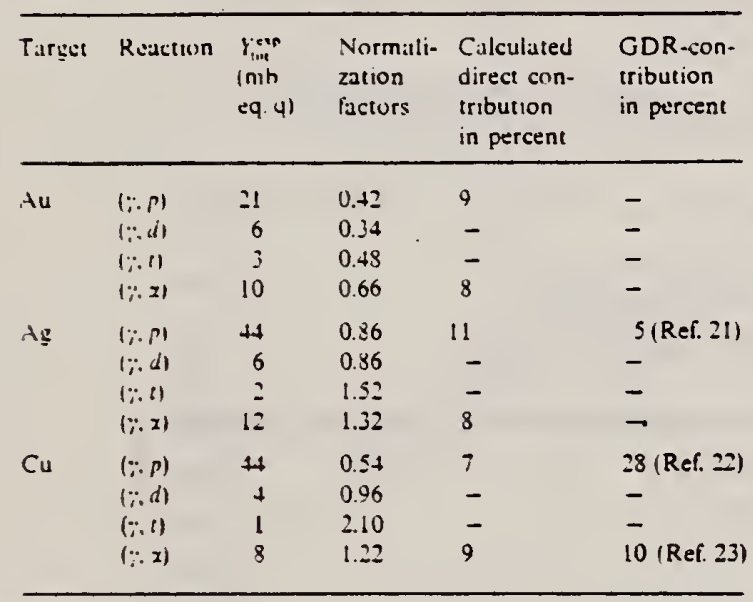

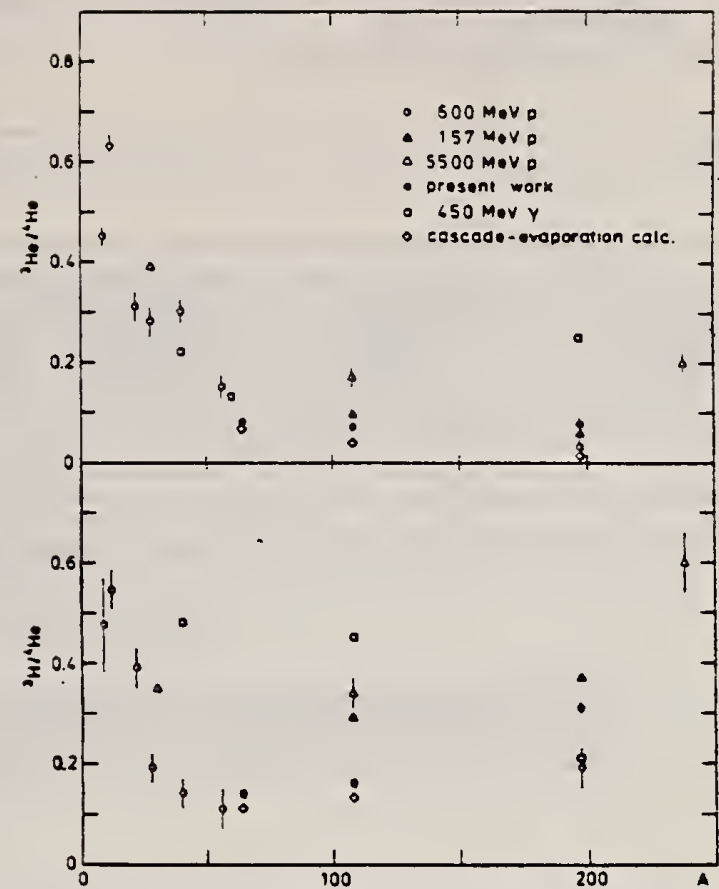

Fig. 6. Comparison between different measurements of the yield ratios ${ }^{3} \mathrm{He} /{ }^{4} \mathrm{He}$ and ${ }^{3} \mathrm{H} /{ }^{4} \mathrm{He}$ as a function of massnumber

321 
aEF. J. Arends, J. Eyink, A. Hegerath, K.G. Hilger, B. Mecking, G. Nöldeke, $H$. Rost

Phys. Lett $\underline{98 B}, 423$ (1981)

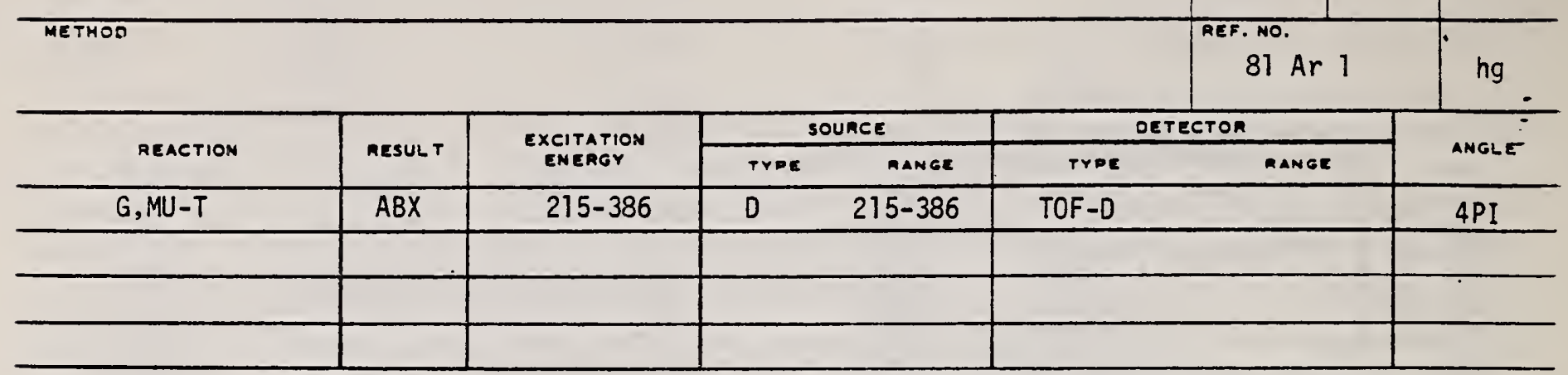

DATA ALSO IN 81 AR3

Double differential cross sections for the photo-emission sf protons and charged pion production were investigated for 1 number of target nuciei ( $\mathrm{He}, \mathrm{Be}, \mathrm{C}, \mathrm{O}, \mathrm{Al}, \mathrm{Ti}, \mathrm{Cu}, \mathrm{Sa}, \mathrm{Pb}$ ) in the photon energ range $k=(215-386) \mathrm{MeV} . \mathrm{O}$ the theib of these experimental results the total hadronic cross section was determined.

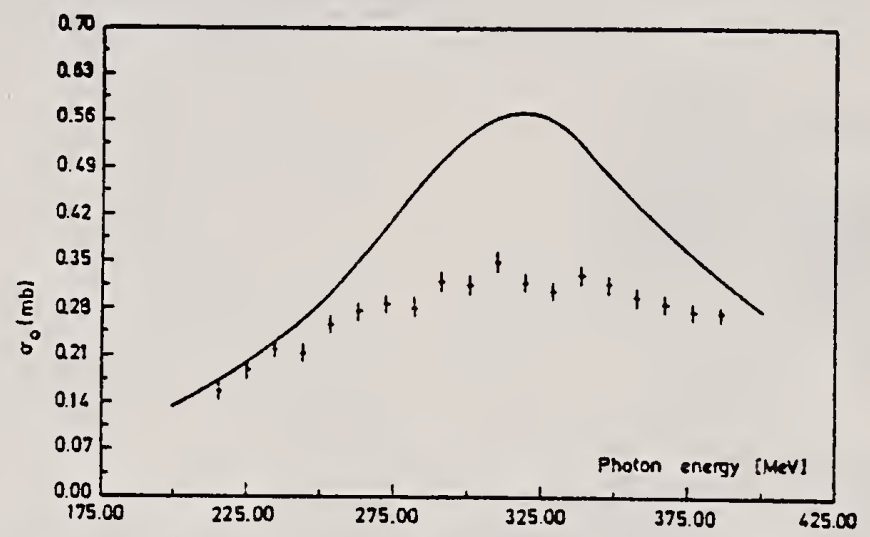

Fig. 7. Parameter $\sigma_{0}$ as a function of photon energy (data points) compared to the mean cross section for a free nucleon (sotid line).

The total hadronic cross sections for all measured elements can be parametrized in the form

$\sigma(k, A)=\sigma_{0}(k) \cdot A^{x}$,

$A$ being the atomic number, with a constant exponent $x=1.1$. The photon energy dependence of $\sigma_{0}$ is shown in fig. 7. Compared to the mean cross section for a free nucleon (the solid line in fig. 7) the excitation of the $\Delta$-resonance is suppressed. Such a suppression is expected in the $\Delta$-hole model [11]. 
neF. J. Arends, J. Eyink, A. Hegerath, K.G. Hilger, B. Mecking, G. Nöldeke, H. Rost

Nucl. Phys. A358, 367c (1981)

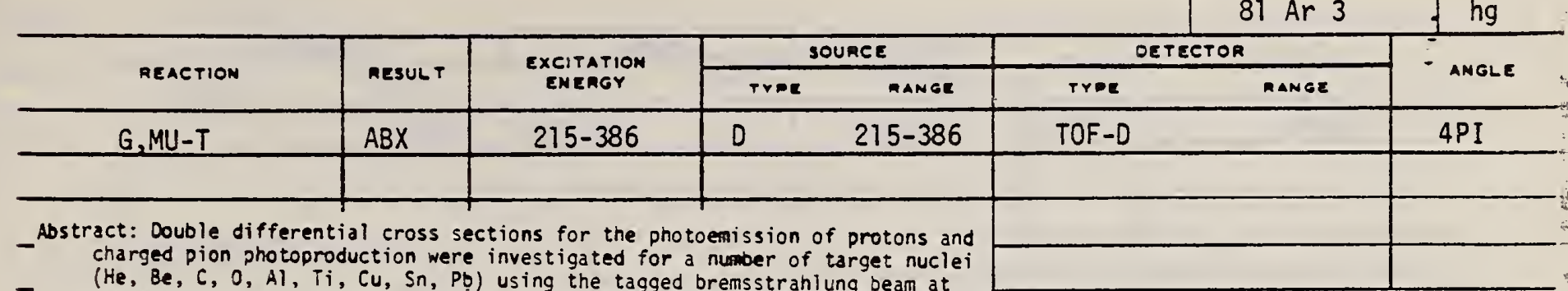

the $80 \mathrm{nn} 500 \mathrm{HeV}-$ Synchrotron in the photon range $k=(215-386) \mathrm{MeV}$. On the ba-

sis of these experimental results the total hadronic cross section was deter-

nined.

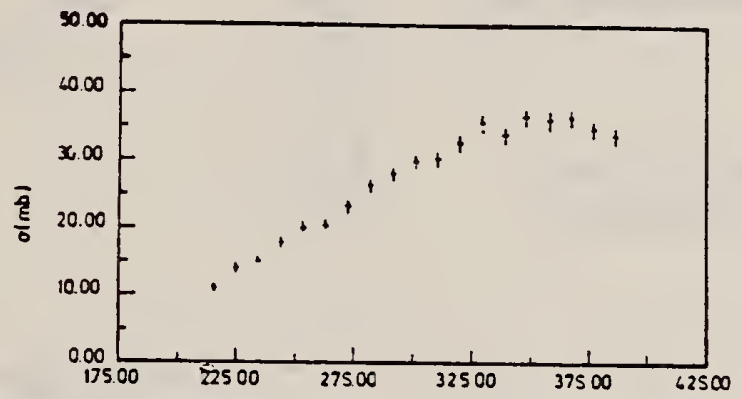

Fig: 2. Cross section for the process: $k$ (MeV

The proton threshold is $\$ 8 \mathrm{MeV}$.
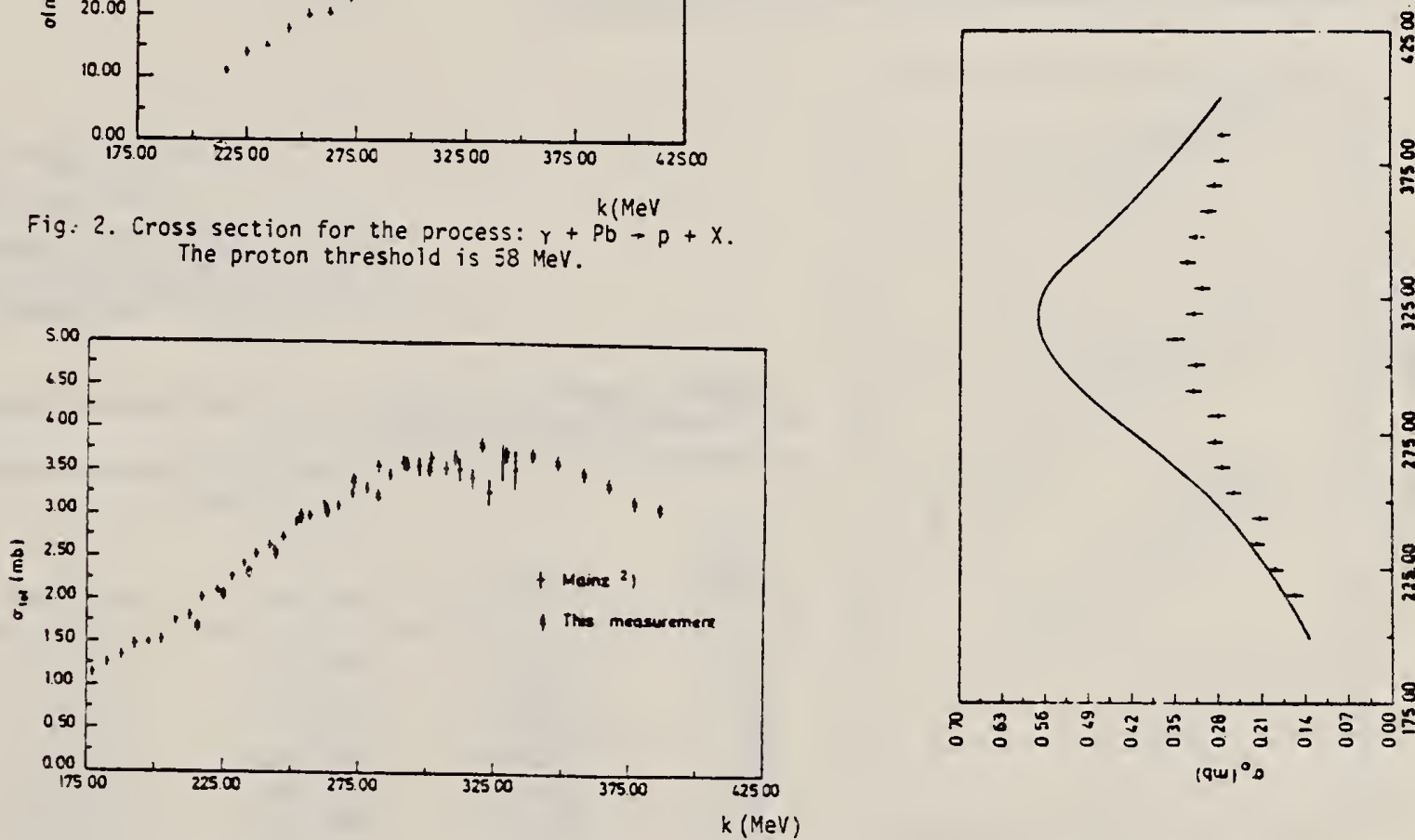

Fig. 3. Total hadronic cross section for Ee. The data are compared to the cross section taken from rer. ${ }^{2}$ ).

The photon energy dependence of the total cross sections for heavier nuclei are similar to the Be results. The complete data set can be parametrized in the
form

$$
\sigma(k, A)=\sigma_{0}(k) \cdot A^{x} \text {. }
$$

The exponent is constant $x=1.1$. The photon energy dependence of $\sigma_{0}$ is shown in fig. 4. Compared to the mean cross section for a free nucleon, the excitation of the $\Delta$-resonance is suppressed. 
REF. R.A. Schumacher, G.S. Adams, D.R. Ingham, J.L. Matthews, W.W. Sapp, felem. srm. A |a R.S. Turley, R.O. Owens, B.L. Roberts

Phys. Rev. C25, 2269 (1982)

\begin{tabular}{|c|c|c|c|c|c|c|c|}
\hline \multirow[b]{2}{*}{ REACTION } & \multirow{2}{*}{ RESULT } & \multirow{2}{*}{$\begin{array}{l}\text { EXCITATION } \\
\text { ENERGY }\end{array}$} & \multicolumn{2}{|c|}{ SOUACE } & \multicolumn{2}{|c|}{ DETECTOR } & \multirow{2}{*}{ ANGLE: } \\
\hline & & & TroE & MANOE & TYPE & RANGE & \\
\hline $\mathrm{G}, X P$ & $A B X$ & 150,300 & D. & 150,300 & MAG-D & & DST \\
\hline & & & & . & & & \\
\hline & & & & & & & \\
\hline
\end{tabular}

Inelurive photoproton crow sections for the reaction $\mathrm{Cu}(Y, p) X$ have been measured for 2 photon energy of $300 \mathrm{MeV}$ at proton angles $45^{\circ}, 90^{\circ}$, and $135^{\circ}$, and for $150 \mathrm{MeV}$ at $45^{\circ}$. The

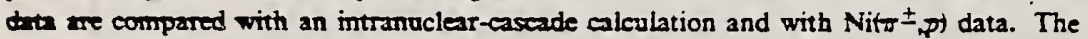
angular distribution is analyzed to obtain an estimate of the number of nucleons involved in the interaction.

$\left[\begin{array}{l}\text { NUCLEAR REACTIONS Cu( }(\gamma, p) X, E=150 \mathrm{MeV}, \theta=45^{\circ}, E=300 \\ \mathrm{MeV}, \theta=45^{\circ}, 90^{\circ}, 135^{\circ} ; \text { measured } \sigma\left(E_{p}, \theta\right) \text {; intranuclear cascade analysis. }\end{array}\right]$

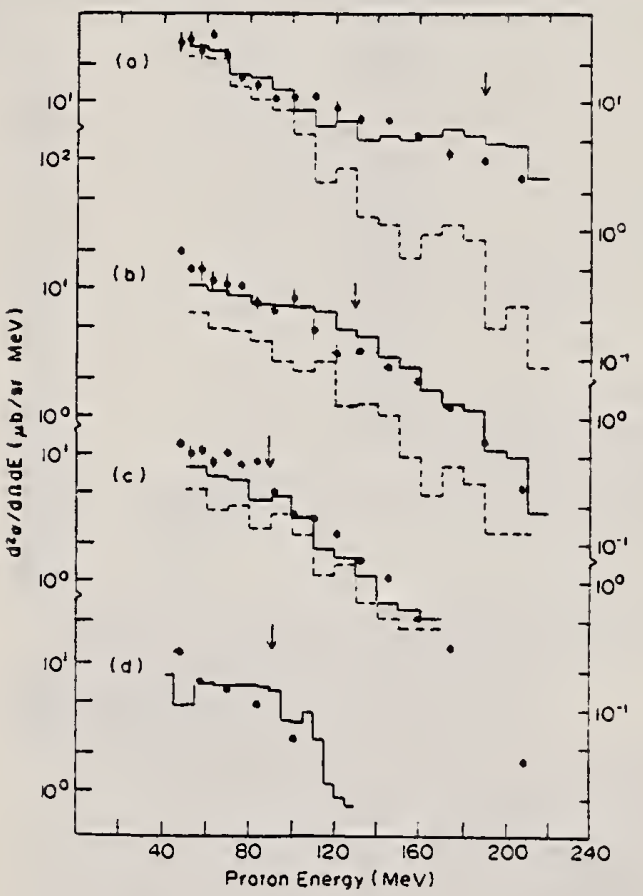

FiG. 2. $\mathrm{Cu}(\gamma, p) X$ cross sections: (a) $300 \mathrm{MeV}, 45^{\circ}$; (b) $300 \mathrm{MeV}, 90^{\circ}$; (c) $300 \mathrm{MeV}, 135^{\circ}$; (d) $150 \mathrm{MeV}, 45^{\circ}$. Only statistical errors are shown. Also plotted are the resuits of a cascade calculation where the solid lines represent the total yield, and the dashed lines the yield due to quasifree pion production only. The arrows indicate the proton energies expected for free deuteron photodisintegration kinematics.

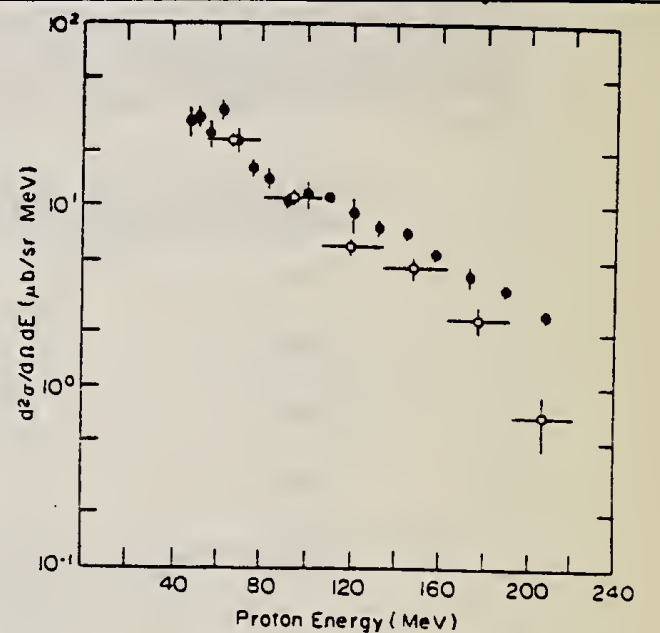

FIG. 3. Comparison of the present data at $300 \mathrm{MeV}$, $45^{\circ}$ (closed circles) with Bonn $\mathrm{Cu}(\gamma, p) X$ data (Ref. 26) for $E_{Y}=291 \mathrm{MeV}, 4^{\circ}$ (open circles).

TABLE I. Inclusive cross sections for the $\mathrm{Cu}(\gamma, p) X$ reaction. Errors given are statistical only. The overall systematic uncertainty is $\pm 7 \%$.

\begin{tabular}{|c|c|c|c|c|}
\hline$\underset{(\mathrm{MeV})}{E_{p}}$ & $\begin{array}{c}45^{\circ} \\
(\mu \mathrm{b} / \mathrm{sr} \mathrm{MeV})\end{array}$ & $\begin{array}{c}E_{r}=300 \mathrm{MeV} \\
90^{\circ} \\
(\mu \mathrm{b} / \mathrm{sr} \mathrm{MeV})\end{array}$ & $\begin{array}{c}135^{\circ} \\
(\mu \mathrm{b} / \mathrm{sr} \mathrm{MeV})\end{array}$ & $\begin{array}{c}E_{Y}=150 \mathrm{MeV} \\
45^{\circ} \\
(\mu \mathrm{b} / \mathrm{sr} \mathrm{MeV})\end{array}$ \\
\hline 47.0 & $29.0 \pm 6.0$ & $19.8 \pm 1.6$ & $11.6 \pm 0.9$ & $12.4 \pm 1.3$ \\
\hline 51.7 & $30.0 \pm 4.0$ & $14.0 \pm 1.2$ & $9.8 \pm 1.4$ & \\
\hline 56.9 & $25.0 \pm 4.0$ & $14.0 \pm 2.7$ & $10.5 \pm 1.1$ & $7.2 \pm 0.5$ \\
\hline 62.5 & $33.0 \pm 4.0$ & $11.6 \pm 1.8$ & $8.4 \pm 0.8$ & \\
\hline 68.7 & $23.0 \pm 4.0$ & $10.8 \pm 2.2$ & $9.9 \pm 1.0$ & $6.2 \pm 0.4$ \\
\hline 75.5 & $15.5 \pm 1.6$ & $10.4 \pm 0.9$ & $8.0 \pm 0.5$ & \\
\hline 82.9 & $13.7 \pm 1.8$ & $7.7 \pm 1.0$ & $8.5 \pm 0.5$ & $4.9 \pm 0.3$ \\
\hline 91.0 & $10.7 \pm 1.1$ & $6.8 \pm 0.6$ & $5.06 \pm 0.26$ & \\
\hline 99.9 & $112 \pm 1.9$ & $8.6 \pm 1.8$ & $3.31 \div 0.19$ & $2.5 \pm 0.18$ \\
\hline 109.6 & $11.0 \pm 0.6$ & $4.9 \pm 1.1$ & $3.04 \pm 0.23$ & \\
\hline 120.2 & $8.9 \pm 1.9$ & $3.1 \pm 0.8$ & $228 \pm 0.18$ & \\
\hline 131.8 & $7.4 \pm 0.9$ & $3.3 \pm 0.2$ & $1.42 \pm 0.07$ & \\
\hline 144.4 & $7.1 \pm 0.6$ & $2.4 \pm 0.2$ & $1.04 \pm 0.09$ & \\
\hline 158.1 & $5.5 \pm 0.3$ & $1.90 \pm 0.16$ & $0.51 \pm 0.03$ & \\
\hline 173.0 & $4.0 \pm 0.6$ & $1.19 \pm 0.07$ & $0.288 \pm 0.018$ & \\
\hline 189.3 & $3.4 \pm 0.3$ & $0.65 \pm 0.04$ & & \\
\hline 206.9 & $2.5 \pm 0.2$ & $0.27 \pm 0.02$ & $0.039 \pm 0.003$ & \\
\hline
\end{tabular}


$A=59$ 
REF. K. Beckert, H.W. Hersch, F. Herrmann, P. Kleinvechter,

H. Schobbert, I. Fodor, and I. Szentpetery

Izv. Akad. Nauk SSSR. Ser. Fiz. 38, 2083 (1974)

Bull. Acad. Sci. USSR Phys. Ser. 38,60 (1974)

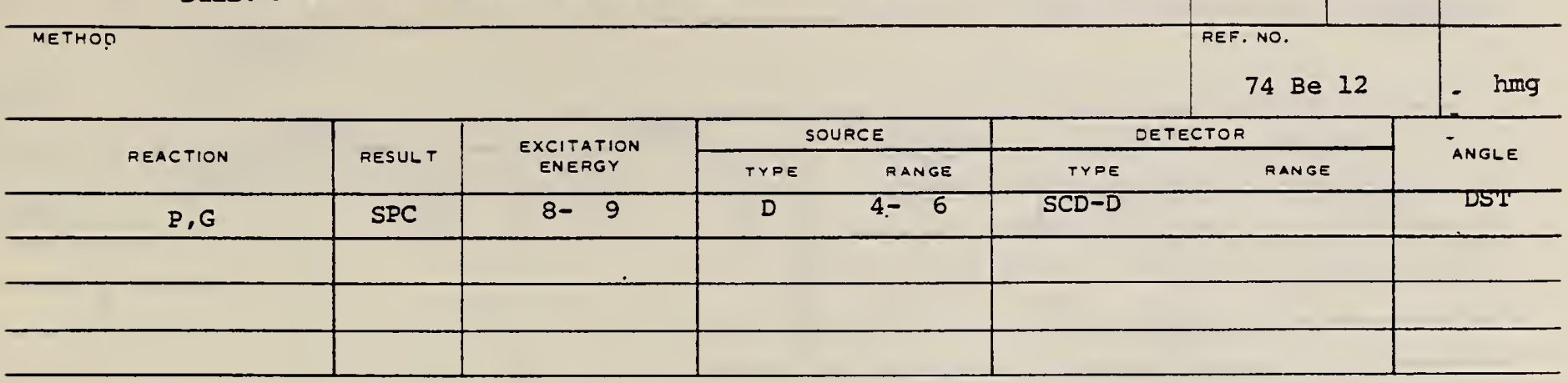

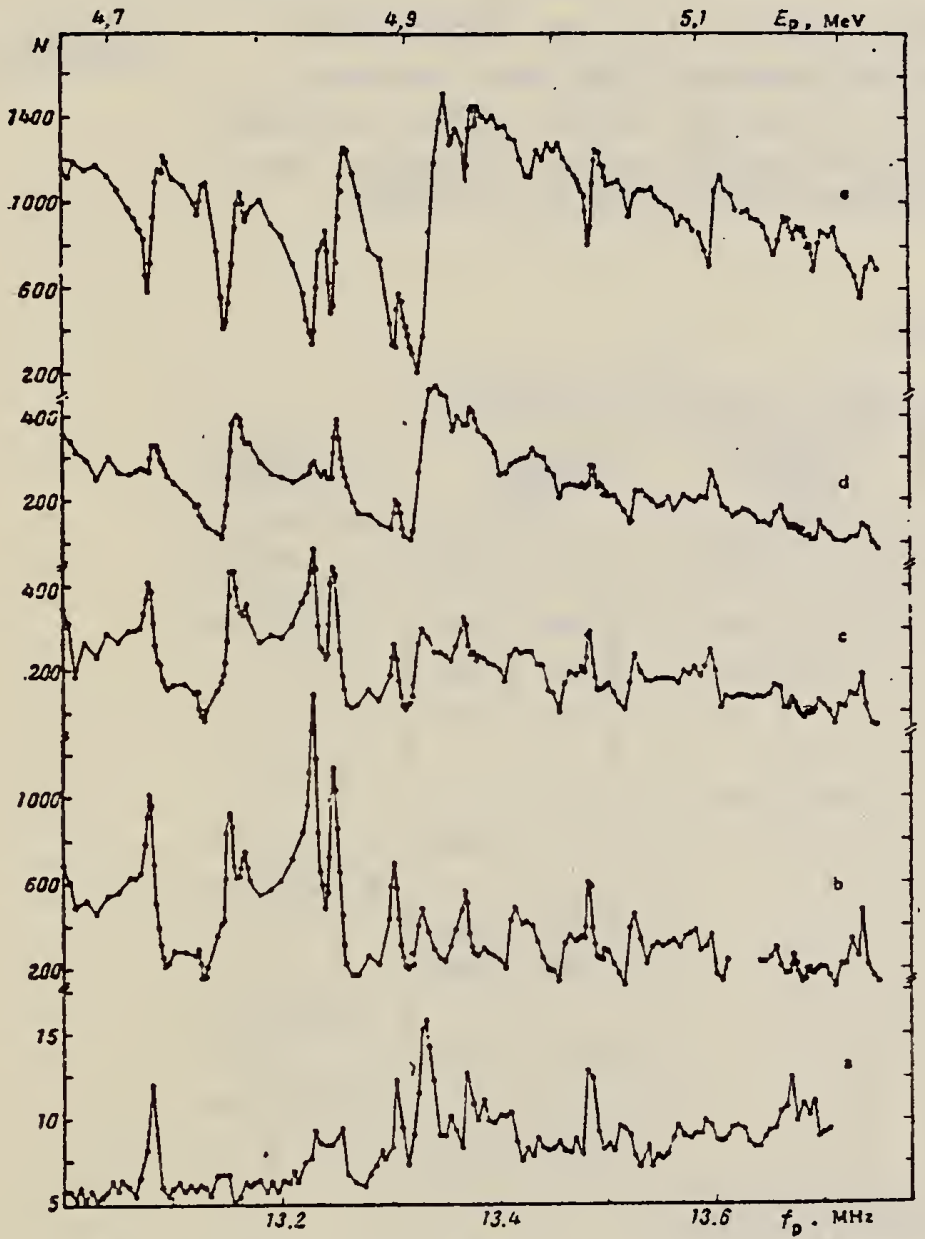

TABLE 2

\begin{tabular}{|c|c|c|}
\hline$\underset{k \in V}{z_{b}^{\text {lab }}}$ & 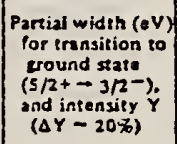 & 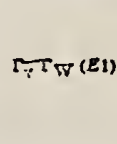 \\
\hline $\begin{array}{l}4 \pi 40 \pm 4 \\
4900 \pm 4 \\
4950=4 \\
50 \%=4\end{array}$ & $\begin{array}{l}33.2 \\
23.6 \\
31,2 \\
16,6\end{array}$ & $\begin{array}{l}3.4 \cdot 10^{-3} \\
6.7 \cdot 0^{-1} \\
8,8 \cdot 10^{-3} \\
4,7 \cdot 10^{-3}\end{array}$ \\
\hline
\end{tabular}

Fig. 1. Excitation functions for: a) ${ }^{58} \mathrm{Ni}(p, y){ }^{59} \mathrm{Cu}$ at $90^{\circ}$ for $\left.E_{Y}>6.5 \mathrm{MeV} ; b-e\right){ }^{58} \mathrm{Ni}\left(p, p_{0}\right)$ for angles of: b) $165^{\circ} ; c$ ) $145^{\circ} ;$ d) $125^{\circ}$; e) $95^{\circ}$ ( $N$ is the number of counts per $u(i)$. 
Ref. O.E. Kraft, Yu.V. Naumov, S.S. Parzhitskii, B.F. Petrov, Z. Salekh,

E.V. Sizov

Izv. Akad. Nauk SSSR 41, 82 (1977)

Buti. Acad. Sci. 41, $\overline{65}(1977)$

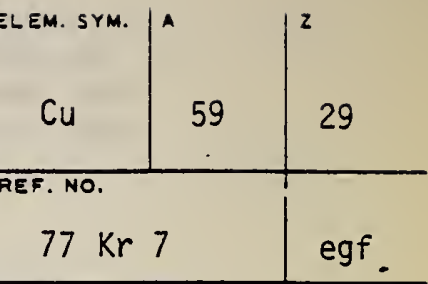

\begin{tabular}{|c|c|c|c|c|c|c|c|}
\hline \multirow{2}{*}{ REACTION } & \multirow{2}{*}{ RESULT $T$} & \multirow{2}{*}{$\begin{array}{l}\text { EXCITATION } \\
\text { ENERGY }\end{array}$} & \multicolumn{2}{|c|}{ SOURCE } & \multicolumn{2}{|c|}{ DETECTOR } & \multirow{2}{*}{ ANGLE } \\
\hline & & & TYPE & RANGE & TYPE & RANGE & \\
\hline$P, G$ & $\overline{L F T}$ & $4-5$ & $D$ & $7-2$ & $S C D-D$ & & 90 \\
\hline & & & & & & & \\
\hline & & & & & & & \\
\hline
\end{tabular}

A study is reported of the $\gamma$-decay of analog resonances in the ${ }^{58} \mathrm{N1}(\mathrm{pr}){ }^{59} \mathrm{Cu}$ re-

action. The following analogs of the exclted states of ${ }^{59} \mathrm{~N} 1$ were observed:

5 STATES, $4.35-5.31$

$0.466,0.878$, and $1303 \mathrm{keV}$. The quant1t1es $\mu_{\gamma}$ and the values of $B(M I)$ have been determined for transitions from the analogs to the ${ }^{59} \mathrm{Cu}$ levels. Analog $B$ and $\gamma-$ transitions are compared, and analog-antianalog transitions are analyzed.

Table 1

Intensities of Direct Transitions from ${ }^{59} \mathrm{Cu}$ Resonances

\begin{tabular}{|c|c|c|c|c|c|c|c|c|c|c|c|c|c|c|c|c|}
\hline \multirow{2}{*}{$F_{x \in v}$} & \multirow[t]{2}{*}{${ }^{i f}$} & \multicolumn{3}{|c|}{$\begin{array}{c}E_{\mathrm{p}}=050 \mathrm{keV} \\
E^{*}=4319 \pm 1 \mathrm{keV} \\
I^{n}=1_{1}-\end{array}$} & \multicolumn{3}{|c|}{$\begin{array}{c}E_{p p}=1426 \mathrm{keV} \\
E^{*}=4817 \pm 1 \mathrm{keV} \\
I^{n}= \pm t^{-1}-\end{array}$} & \multicolumn{3}{|c|}{$\begin{array}{c}E_{\Gamma^{2}}=1813 \mathrm{kcV} \\
\Sigma^{0}=5230 \pm 1 \mathrm{keV} \\
I^{r}=04_{2^{-}}\end{array}$} & \multicolumn{3}{|c|}{ 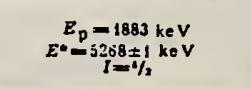 } & \multicolumn{3}{|c|}{$\begin{array}{c}E_{\nu}=1023 \mathrm{keV} \\
E \cdot=5310 \pm 1 \mathrm{keV}\end{array}$} \\
\hline & & $I_{Y}$ & $r_{Y} \in V$ & 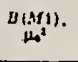 & $I_{Y}$ & $r_{y}, e v$ & 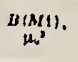 & $I_{Y}$ & $r_{r}, \mathrm{eV}$ & $v_{\substack{u \\
\mu, 2},}$ & $I_{Y}$ & $r_{Y}, e v$ & ${ }_{\mu_{1}}^{\left.B_{1}, M_{1}\right)}$ & $t_{\Upsilon}$ & $\left|r_{Y}, \mathrm{ev}\right|$ & $\Delta(3)$, \\
\hline 0 & $1 / 2-$ & 6 & 0.003 & 0,003 & 16 & 0,08 & 0,06 & 01 & 1,5 & 0,90 & 29 & 0,015 & 0,01 & 15 & 0,03 & 0,02 \\
\hline 491 & $1 / 2-$ & 17 & 0,008 & $0, n$ & 66 & 0,32 & $0,3 i$ & 5 & 0,00 & 0,09 & 18 & 0,01 & 0,08 & - & - & - \\
\hline 912 & $3 / 2-$ & - & - & - & 3 & 0.015 & 0,02 & - & - & - & 7 & 0,001 & 0,01 & - & - & - \\
\hline 1937 & $3 / 2$ & - & - & - & 0 & 0,045 & $0 ; 17$ & - & - & - & - & - & - & - & - & - \\
\hline $221: 5$ & $3 / 2$ & 17 & 0,008 & 0,08 & 4 & $a, 02$ & 0,10 & 4 & 0,07 & 0,23 & - & - & - & - & - & - \\
\hline 2318 & $1 / 2$ & 25 & 0,012 & 0.12 & - & - & - & - & - & - & 8 & 0,005 & 0,015 & - & - & - \\
\hline 2324 & $1 / 2$ & - & - & - & 2 & 0,010 & 0,08 & - & - & - & - & - & - & $B 8$ & 0,13 & 0,41 \\
\hline 2707 & $5 / 2$ & - & - & - & - & - & - & - & - & - & 12 & 0,007 & 0,035 & - & - & - \\
\hline 2927 & $3 / 2$ & - & - & - & - & - & - & - & - & - & 7 & 0,008 & 0,025 & - & - & - \\
\hline 302.5 & $(2 / 2)$ & 11 & 0.105 & 0,18 & - & - & - & - & - & - & - & - & - & 9 & 0,018 & 0,12 \\
\hline 3114 & $(5 / 2)$ & $n$ & 0,104 & 0,18 & - & - & - & - & - & - & 12 & 0,007 & 0,06 & - & - & - \\
\hline 3130 & $(3 / 2)$ & 15 & 0.507 & 0,33 & - & - & - & - & - & - & - & - & - & 7 & 0,017 & $0,1 i$ \\
\hline 3431 & $(5 / 2)$ & - & - & - & - & - & - & - & - & - & 7 & 0,004 & 0,05 & - & - & - \\
\hline
\end{tabular}

Note. For the $E_{p}=1923 \mathrm{keV}$ reson ance, the spin of which is unknown, we give values of $g$ r and $g B(\mathrm{MI})$, where 8 is a ctatistical fector equal to $\frac{2 J+1}{\left(2 j_{p}+1\right)\left(2 J_{2}+1 ;\right.} ; J$ is the spin of the reson ance, $J_{p}$ is the proton spin, and $J_{0}$ is the spin of the target nucle us. 
$\mathrm{Cu}$
$\mathrm{A}=60$

Cu

$A=60$

CU 
Ref. J.H. Carver, G.A. Jones

Nuclear Phys. 24, 607 (1961)

\begin{tabular}{|c|c|c|}
\hline & $\mathrm{Cu}$ & 29 \\
\hline Method Radioactivity & $\begin{array}{l}\text { Kei. No. } \\
\quad 61 \mathrm{Ca} 1\end{array}$ & JOC \\
\hline
\end{tabular}

\begin{tabular}{|c|c|c|c|c|c|c|c|}
\hline Reaction & $E$ or $\triangle E$ & $E_{0}$ & $\Gamma$ & $\int \sigma d E$ & $3 \pi$ & Notes & - \\
\hline $\mathrm{Ni}^{58}(\mathrm{~d}, \gamma)$ & $3 \cdot 5-4 \cdot 5$ & & & $\cdot$ & & At $E_{d}=4.5 \mathrm{MeV}, \sigma(d, \gamma)$ & $\mu b$ \\
\hline
\end{tabular}



REF. O. E. Kraft, Yu. V. Naumov, and I. V. Sizov

Yad. Fiz. 20, 1081 (1974)

Sov. J. Nucl. Phys. 20, 567 (1975)

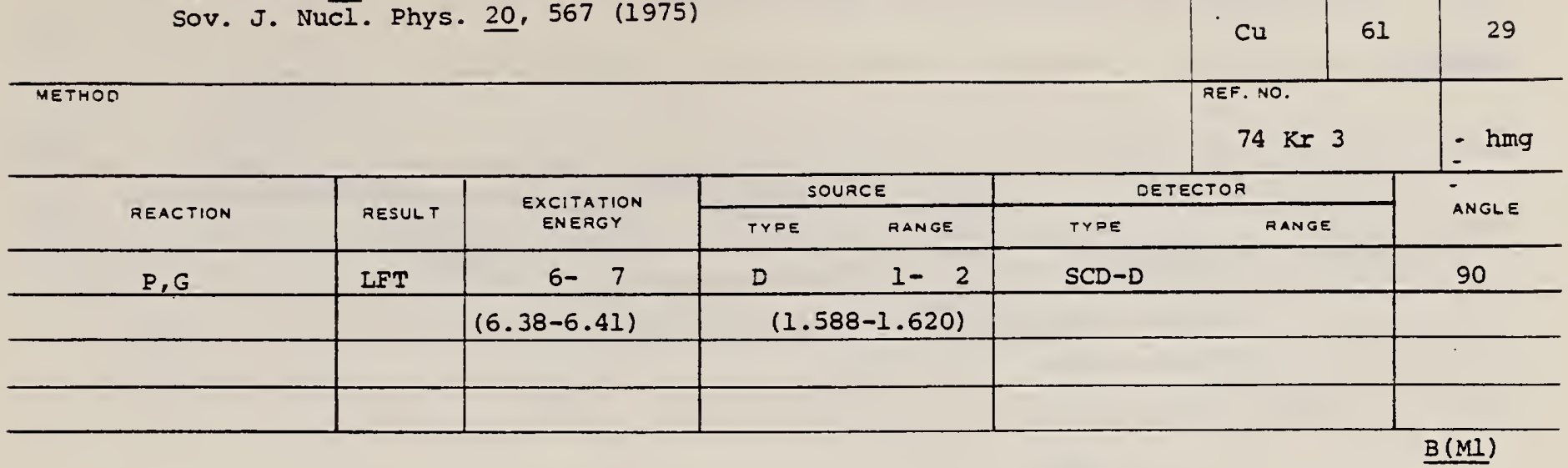

We measured the $\gamma$ spectra of the resonance decay in the reaction ${ }^{10} \mathrm{Ni}(p, \gamma)^{b 1} \mathrm{Cu}$ at proton energies $E_{p}=1588,1599,1605$, and $1620 \mathrm{keV}$. These resonances are identified as the components of the fine structure of the analog stace $\rho_{3 / 2}$. The intensities of the population of the sate of " $\mathrm{Cu}$ sith excication energy up to $3 \mathrm{MeV}$ ase oblained. The decay scheme of these slates is constructed. Comparison with beta decay points to the need for taking into account the $l$ part in the operator of the $M 1 \gamma$ transition when assessing the role of the polarization effects in the $\gamma$ decay of isobar analog resonances. The analog-antianalog transition is slowed down by an approxinate factor 10 compared with the single-particle ostimate.

\begin{tabular}{|c|c|c|c|c|c|c|c|c|c|}
\hline \multirow{2}{*}{$\varepsilon_{\text {ler keV }}$} & \multirow{2}{*}{$J=$} & \multicolumn{4}{|c|}{$P_{T} \omega_{0}, \mathrm{eV}$} & \multicolumn{4}{|c|}{$B(\mathrm{X}(\mathrm{t}), 10, \mathrm{~m}$} \\
\hline & & liess & 1500 & lous & 16.0 & 1588 & 1509 & $100 \mathrm{~s}$ & $18=0$ \\
\hline 86 & $1 / 3$ & & 168 & & & & & & \\
\hline $\begin{array}{l}676.4 \\
969.4 \\
969\end{array}$ & 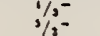 & $\begin{array}{l}0.8 \\
1.5\end{array}$ & 11.6 & 5.4 & $<12$ & 0.3 & 4.9 & $\begin{array}{l}0.0 \\
2.3\end{array}$ & $<0$ \\
\hline 1395.1 & $3 / 3-$ & 4.0 & $1+6$ & 101 & 9.8 & 2.8 & 10.0 & $\begin{array}{l}1.5 \\
7.0\end{array}$ & $\begin{array}{l}1.5 \\
6.7\end{array}$ \\
\hline 190 & $(3 / 3-1)$ & $=$ & 0.8 & $\begin{array}{l}1.5 \\
20\end{array}$ & $\begin{array}{l}0.6 \\
1.3\end{array}$ & $=$ & 0.7 & 1.2 & $\begin{array}{l}0.5 \\
1.2\end{array}$ \\
\hline $\begin{array}{l}2089 \\
2203\end{array}$ & $\begin{array}{l}1 / 3^{-} \\
\left(3 / 3^{-}\right)\end{array}$ & 1.1 & $\begin{array}{l}5.8 \\
5.0\end{array}$ & 3.9 & 6.5 & 1.1 & 6.4 & 1.2 & 7.0 \\
\hline $\begin{array}{l}2357.3 \\
2673.3\end{array}$ & $3 / 1=$ & 5 & 50 & -9 & 1.0 & 2.0 & - & $=$ & 1.3 \\
\hline $\begin{array}{l}2583 \\
2587\end{array}$ & 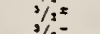 & 15 & 40 & - & $=$ & 2.9 & 6.3 & $\stackrel{2.7}{-}$ & $\overline{-}$ \\
\hline 2792 & & - & -2 & $\overline{2.3}$ & 1.9 & & 4.9 & $\overline{4.3}$ & 3.2 \\
\hline $\begin{array}{l}28599 \\
2993\end{array}$ & $=3$ & ${ }_{0.7}^{2.7}$ & 2.3 & $=$ & 5.3 & 5.5 & 4.6 & - & 10.2 \\
\hline $\begin{array}{l}302 \\
304\end{array}$ & (ii & 3.0 & 1.7 & - & 2.3 & 6.9 & 3.8 & $=$ & 5.2 \\
\hline $\begin{array}{l}3062.4 \\
3034.1\end{array}$ & $(1 / 2-1 / 2)$ & $\begin{array}{l}1.9 \\
0.8 .2\end{array}$ & 1.7 & $\bar{z}$ & 1.2 & 4.6 & 50 & $=$ & $\overline{2.9}$ \\
\hline & & & & & & & 6.9 & - & 6.0 \\
\hline
\end{tabular}


REF. O.E. Kraft, Yu. V. Naumov, and I.V. Sizov

Izv. Akad. Nauk SSSR. Ser. Fiz. 39, 70 (1975)

Bull. Acad. Sci. USSR Phys. Ser. $\underline{39}, 59$ (1975)

\begin{tabular}{|c|c|c|c|c|c|c|}
\hline METHOD & & & $\cdot$ & & $\begin{array}{l}\text { REF. NO. } \\
75 \mathrm{Kr} 15\end{array}$ & hmg - \\
\hline \multirow{2}{*}{ REACTION } & \multirow{2}{*}{ RESULT } & \multirow{2}{*}{$\begin{array}{l}\text { EXCITATION } \\
\text { ENERGY }\end{array}$} & SOURCE & \multicolumn{2}{|c|}{ DETECTOR } & \multirow{2}{*}{ AnGle } \\
\hline & & & RANGE & TYDE & RANGE & \\
\hline \multirow[t]{2}{*}{$P, G$} & LFT & $6-7$ & D $\quad I-2$ & $N A I-D$ & & 90 \\
\hline & & $(6.3-6.6)$ & $(1.6-1.9)$ & & & . \\
\hline & & & & & & \\
\hline & & & & & & \\
\hline
\end{tabular}
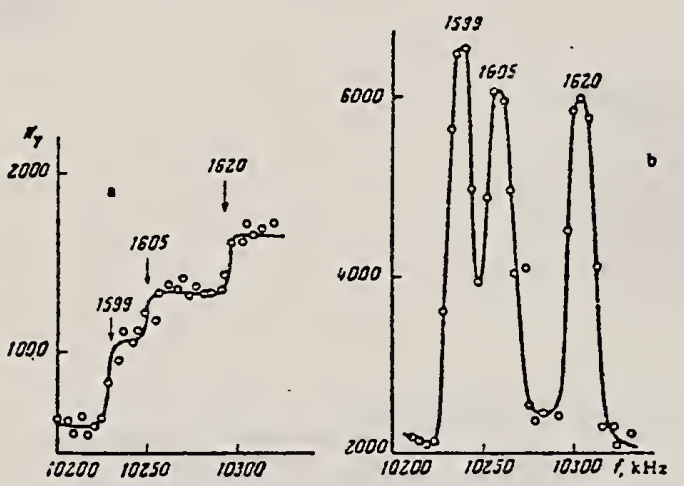

Fig. 1. Excitation function of the ${ }^{60} \mathrm{Ni}(\mathrm{py}){ }^{61} \mathrm{Cu}$

reaction in the $p_{3 / 2}$-IAR region. a) Thick tar-

get; b) thin target.

Table 1

Characteristics of the Isobar-Analog Pesonances of ${ }^{61} \mathrm{Cu}$

\begin{tabular}{|c|c|c|c|c|c|c|c|c|}
\hline \multirow{2}{*}{$\varepsilon \cdot k \in V$} & \multirow{2}{*}{$E_{p} \cdot k \in V$} & \multirow{2}{*}{$t^{*}$} & \multicolumn{3}{|c|}{$r_{\gamma_{\theta}, e V}$} & \multicolumn{3}{|c|}{$r_{r_{0}, e v}$} \\
\hline & & & $\begin{array}{l}\text { present } \\
\text { poover }\end{array}$ & [i] & 1101 & $\begin{array}{l}\text { present } \\
\text { oxpert }\end{array}$ & [7] & $\{10]$ \\
\hline $\begin{array}{l}6374 \\
62880 \\
63395 \\
6131 \\
6824 \\
64 i 41\end{array}$ & 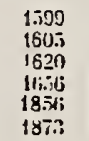 & $\begin{array}{l}1 / 2- \\
3 / 2^{-} \\
3 / 2^{-} \\
1 / 2^{-} \\
1 / 5= \\
1 / 2^{-}\end{array}$ & 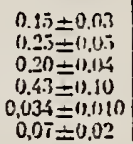 & $\begin{array}{l}0.2 \\
0.2 \\
0.3 \\
0.1 \\
=\end{array}$ & $\begin{array}{l}0.05 \\
0.14 \\
0.10 \\
0.19 \\
=\end{array}$ & $\begin{array}{l}0.72 \\
0.7 \\
0.5 n \\
0.50 \\
0.33 \\
0.25\end{array}$ & $\begin{array}{l}0.6 \\
0.5 \\
0.4 \\
0.5 \\
=\end{array}$ & $\begin{array}{l}0.21 \\
0.26 \\
0.16 \\
0.27 \\
=\end{array}$ \\
\hline
\end{tabular}

-The tolat widths are given without allowance for the angular discribution of graye 
$A=63$ 
Ref. J.G. Campbe 11

Australian J. Phys. 8,445 (1955)

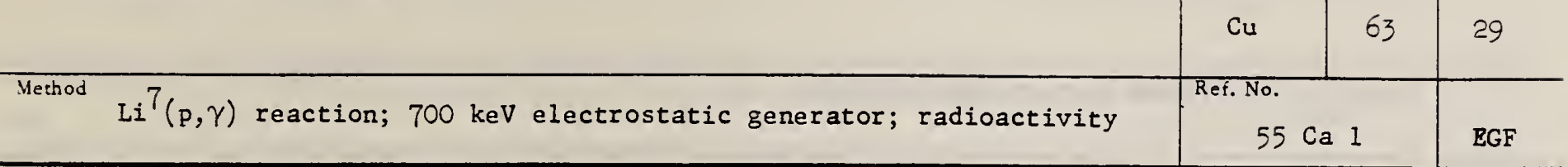

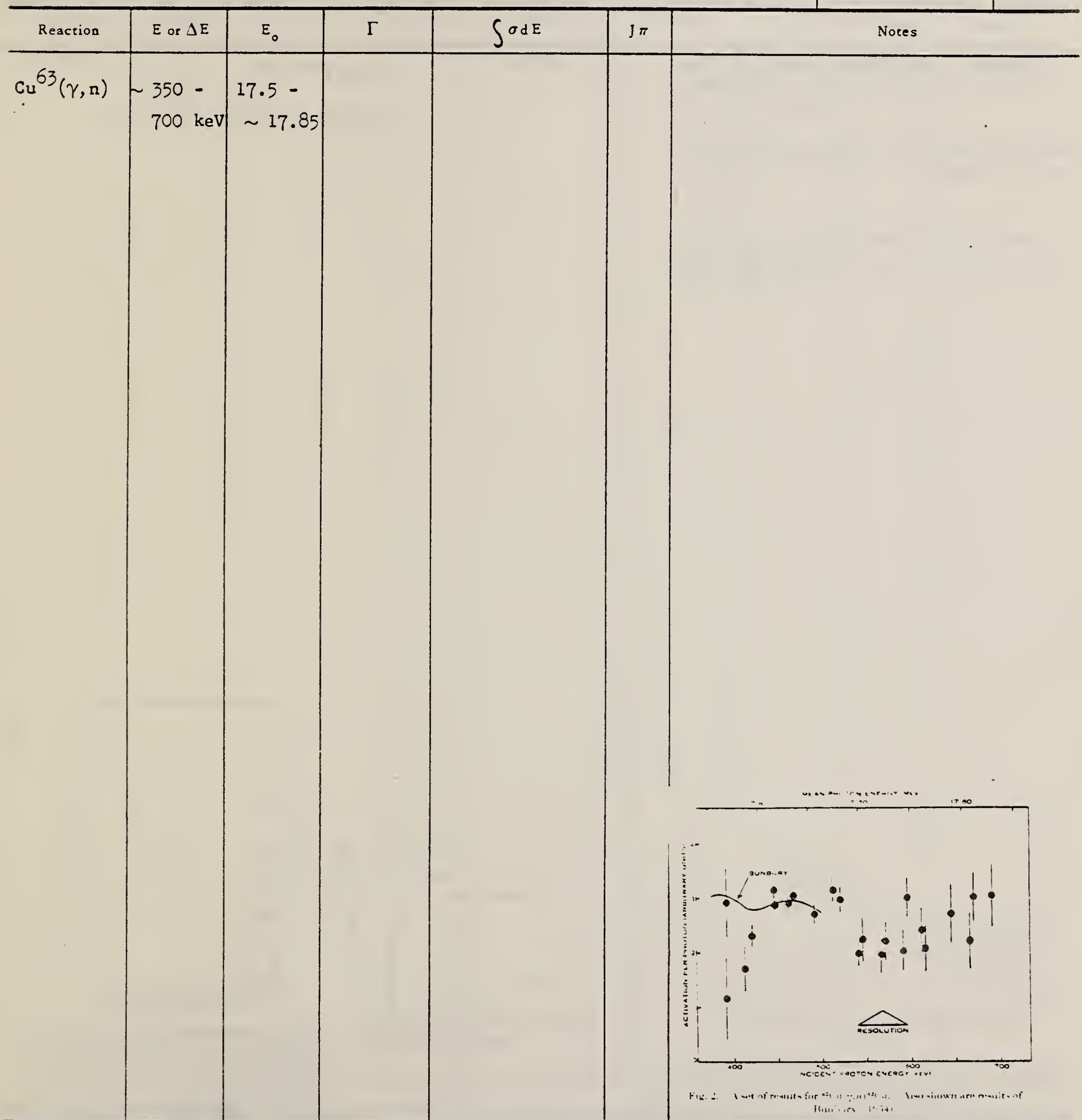


Ref. M.B. Scott, A.O. Hanson, D.W. Kerst

Phys. Rev. 100, 209 (1955)

Elem. Sym. A

Method

Monoergic electrons from $22 \mathrm{MeV}$ Betatron.

Ref. No.

$55 \mathrm{Sc} 1$

EGF

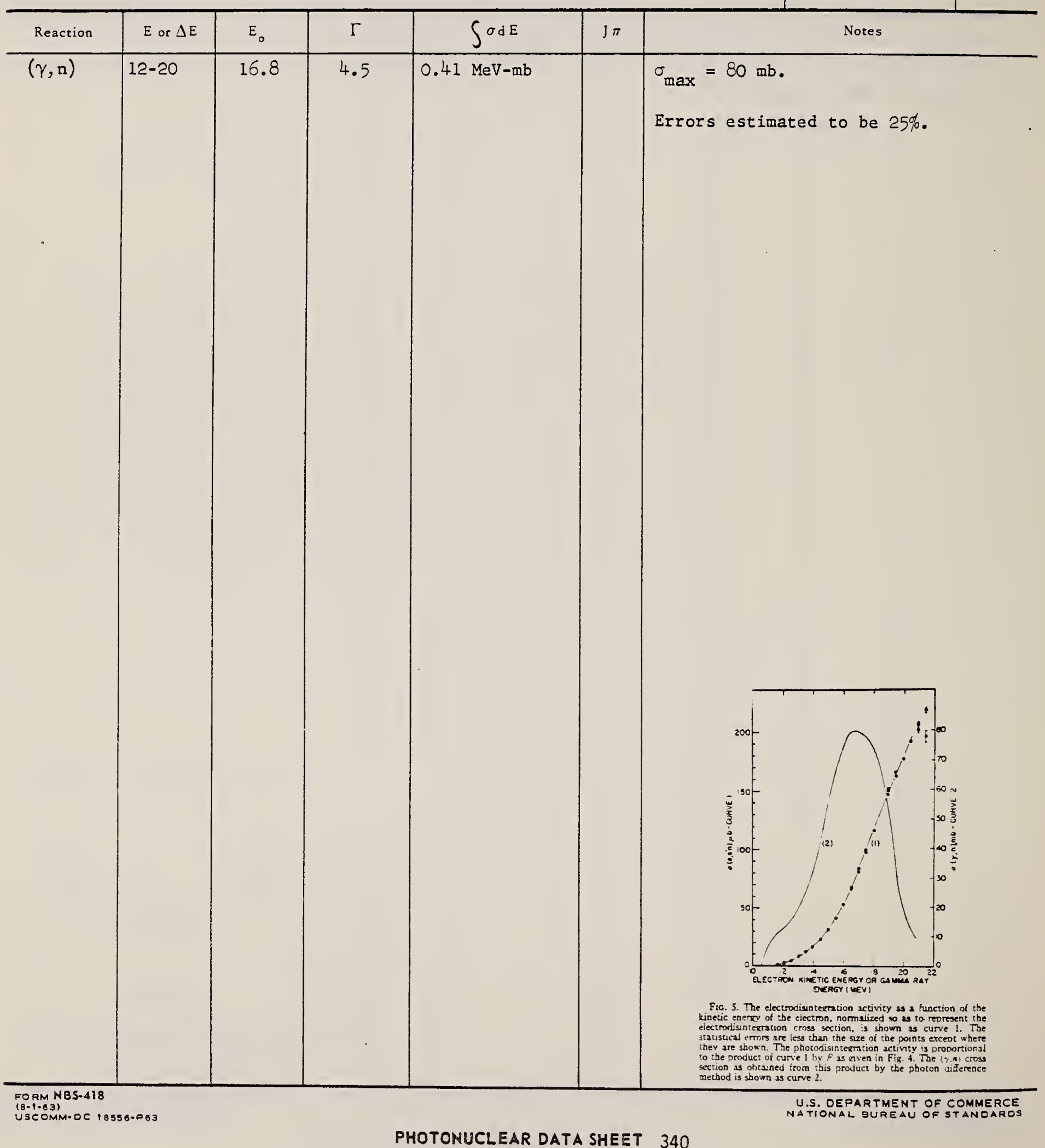


Ref. R. L. Hines

Phys. Rev. 105, 1534 (1957)

Elem. Sym. $\mid A \quad z$

$\mathrm{Cu}$

Ref. No.

Method Michigan University synchrotron; Victoreen counter; betatron 10.1 min

$57 \mathrm{Hi} 1$

\begin{tabular}{|c|c|c|c|c|c|}
\hline Reaction & $E$ or $\Delta E$ & $\mathrm{E}_{0}$ & $\Gamma$ & $\int \sigma d E$ & Notes \\
\hline$\left(e, e^{\prime} n\right)$ & $\begin{array}{l}29.5 \\
46.5 \\
63.5 \\
81.5\end{array}$ & 16. & & & $\begin{array}{l}97 \% \text { electric dipole and } 3 \% \text { electric } \\
\text { quadrupole required to fit experi- } \\
\text { mental points. } \\
\text { No corrections made for nuclear signs; } \\
\text { these would tend to increase fraction } \\
\text { of } \mathrm{E}_{2} \text {. } \\
\mathrm{Cu}^{63}(\gamma, \mathrm{n}) \mathrm{Cu}^{62} \text { cross section from } \\
\mathrm{Katz} \text { and Cameron [Can. J. Phys. } 29 \text {, } \\
518(1951)] \text {. }\end{array}$ \\
\hline
\end{tabular}

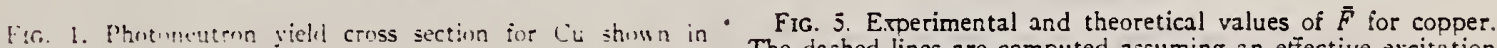

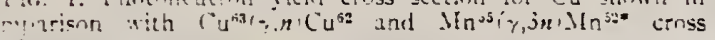
$\cdots$ ns

The dashed lines are computed assuming an effective excitation energy of $1+$ Lev for the electric quadrupole process 
Ref. W.L. Bendel, J. McElhinney, R.A. Tobin Phys. Rev. 111, 1297 (1958)

Elem. Sym

$z$

Cu

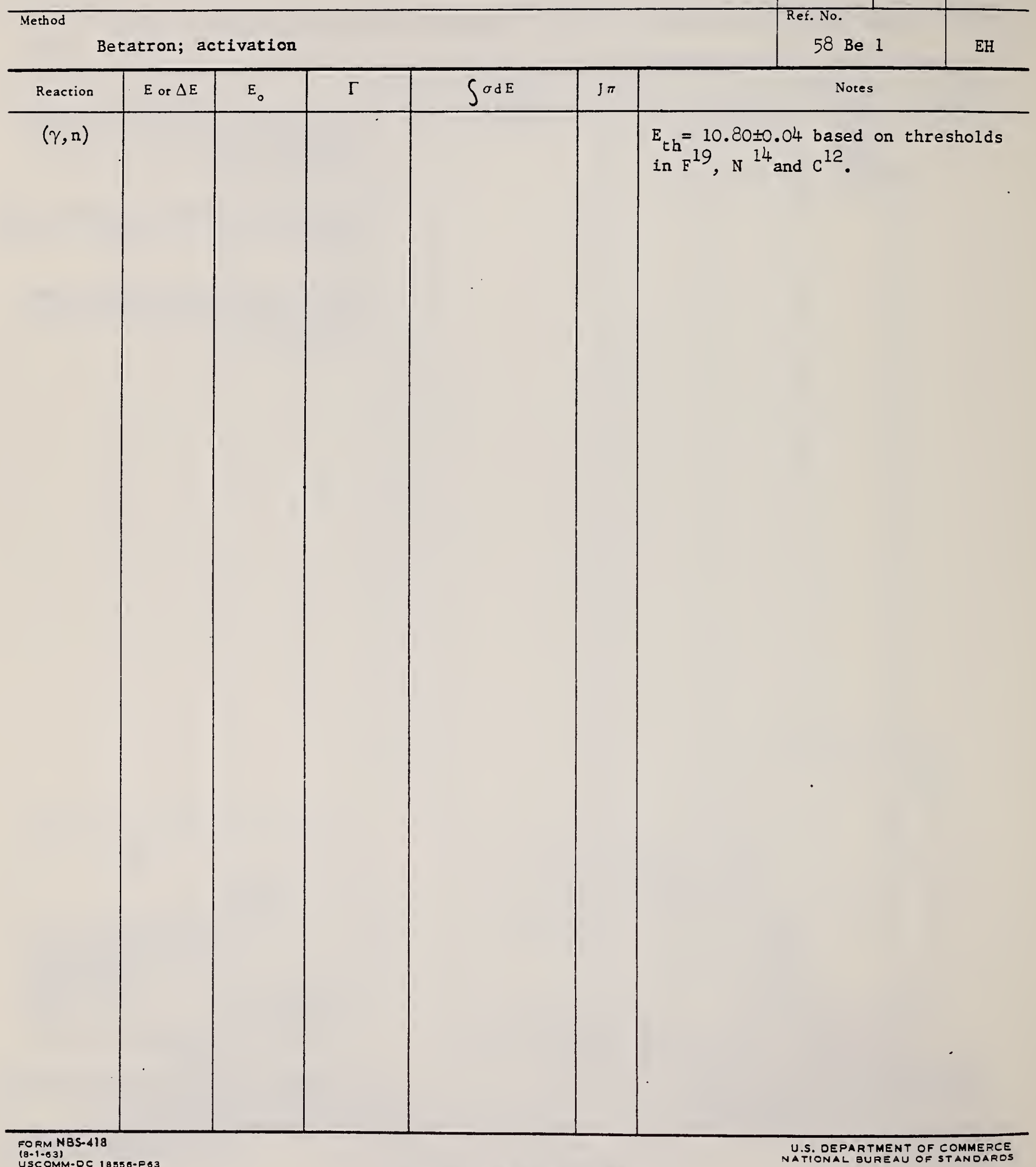


Ref. M.E. Toms, J. McElhinney

Phys. Rev. 111, 561 (1958)

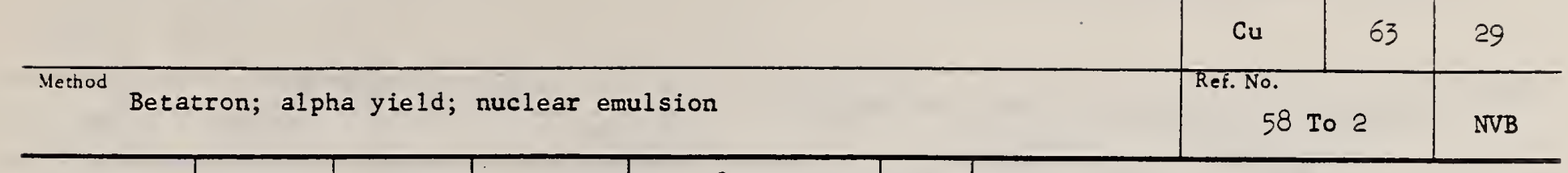

\begin{tabular}{c|c|c|c|c|c|c}
\hline Reaction & $E$ or $\Delta E$ & $E_{0}$ & $\Gamma$ & $\int \sigma d E$ & $j \pi$ & Notes \\
\hline $\mathrm{Cu}^{63}(\gamma, \alpha)$ & $\begin{array}{c}\text { Bremss. } \\
22\end{array}$ & & & & Yield $=3.6 \times 10^{4}$ al pha/mole/roentgen. \\
& & & Target enriched to $99.5 \% \mathrm{Cu} 63$.
\end{tabular}

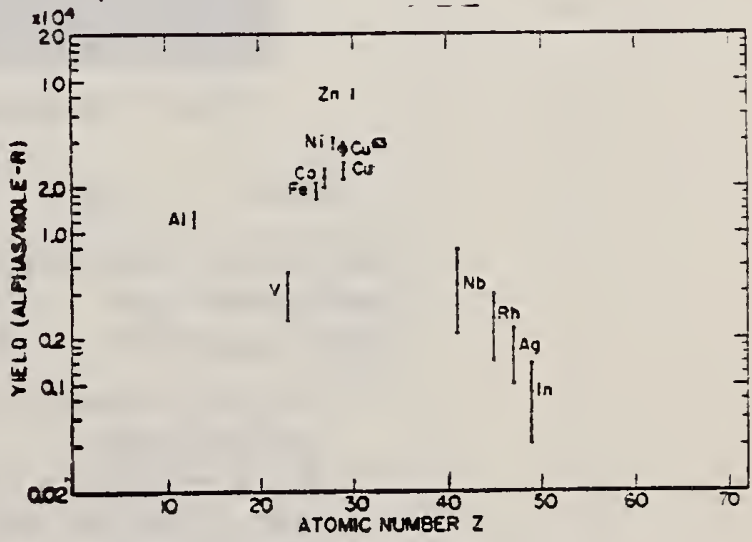

Frc. 8. Photo-alpha yields plotted against atomic numbers for the exposures of the survey. 
Ref. T. Nakamura, K. Takamatsu, K. Fukunaga, M. Yata, S. Yasumi J. Phys. Soc. Japan 14. 693 (1959)

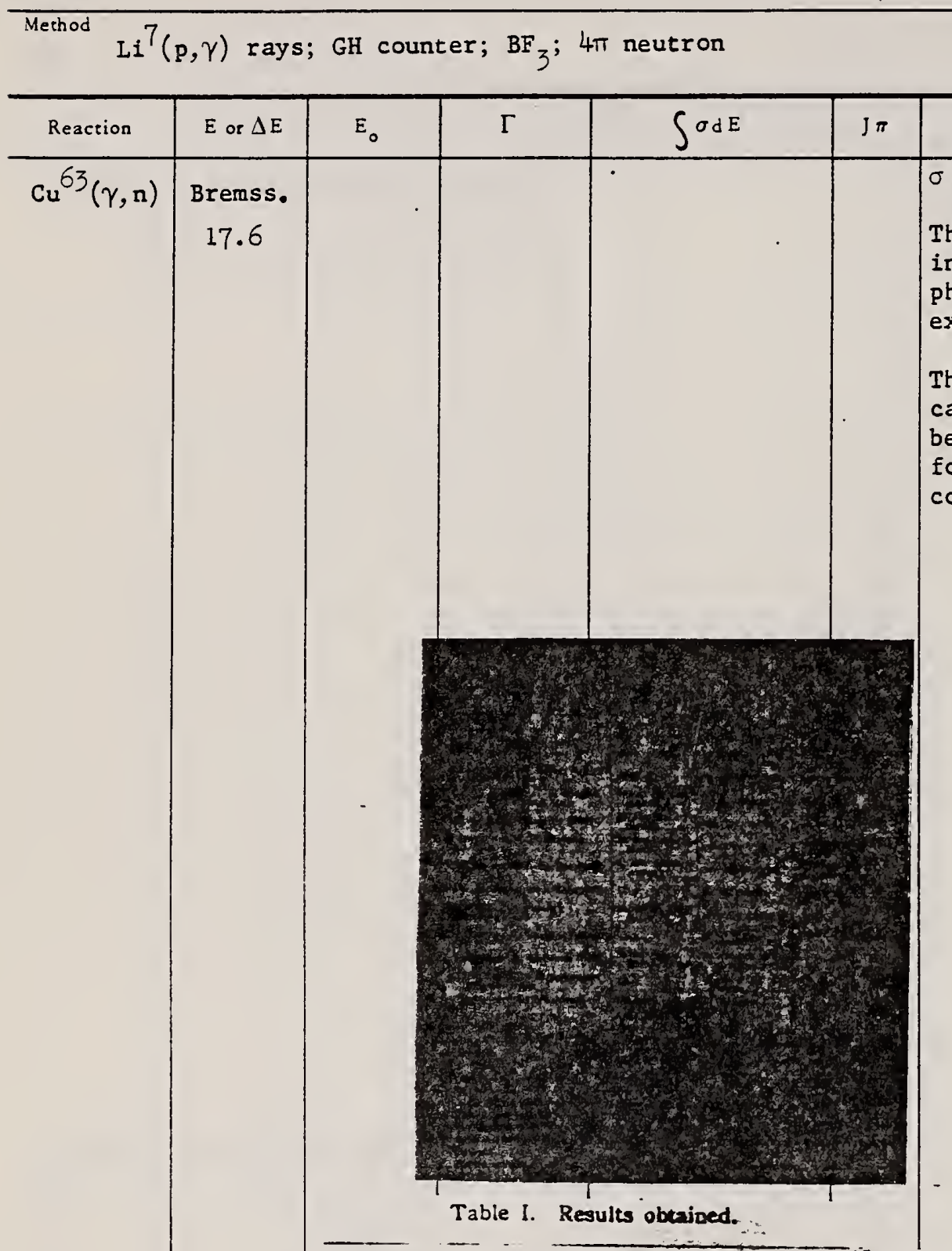

\begin{tabular}{|c|c|c|c|}
\hline Reaction & $\stackrel{\lambda}{(\min -1)}$ & $\frac{(L(m p)}{(m b)}$ & $\begin{array}{l}\text { arfo Mea } \\
\text { (mb) }\end{array}$ \\
\hline Cut $(r, x)$ & $00695^{*} \pm$ & $637.7 \pm 15 \times$ & 48.5 \\
\hline$Z^{2}{ }^{2}(T, n) Z_{n}$ & 0.018 & $20.7 \pm 18 \%$ & 23.3 \\
\hline$A^{2}{ }^{2}, n$ & 0. & $54.6 \pm 16 \%$ & 61.5 \\
\hline
\end{tabular}

- The decay constant of Cun was determinal is. our measurement.

- For the reduction to $17.6 \mathrm{Mer}$ mancinich r-ray, we used the ratio $1: 2$ as the trate ratio of $14.8 \mathrm{Mev}$ to $17.6 \mathrm{Mev} \gamma \cdot \mathrm{ray}$, and the resuits of bremsstrahlung experiments as the excitation curve for each elements.
14) T. Nakamura, K. Fukunaga, K. Takamatsu and S. Yasumi: Mem. Coll. Sci. Kyoto Univ. (to be published).

15) S. Yasumi: J. Phys. Soc. Japan 12 (1957) 443.

16) P. V. C. Hough: Phys. Rev. 80 (1950) 1069.

17) R. W. King: Rev. Mod. Phys. 26 (1954) 327.

18) Y. Uemura, M. Sonoda, Y. Saji, S. Yasumi. Y. Ishizaki and Y. Ohno: Bull. Inst. Chem. Res. Kyoto Univ. 29 (1952) 66.

19) W. A. Fowler, C. C. Lauritsen and T. Laurit. sen: Rev. Mod. Phys. 20 (1948) 235.

20) C. A. Barnes, J. H. Carver, G. H. Stafford and D. H. Wilkinson: Phys. Rev. 86 (1952) 359. 


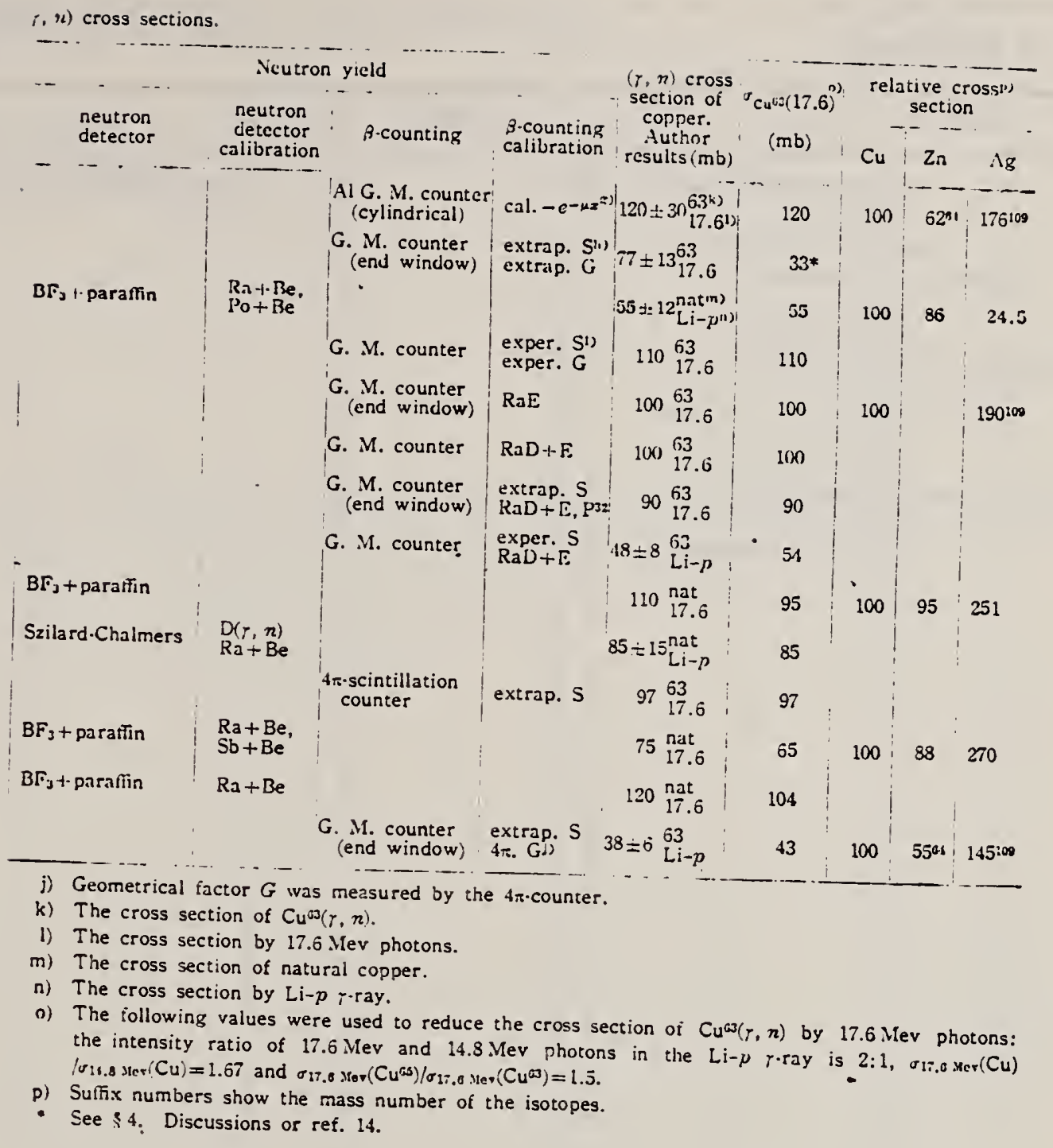


Ref. A. S. Penfold, E.L. Garwin

Phys. Rev. 115, 420 (1959)

Elem. Sym.

Method $100 \mathrm{MeV}$ Betatron

Ref. No.

\begin{tabular}{l|l|l|l|l|l|l}
\hline Reaction & $E_{\text {or }} \Delta \mathrm{E}$ & $\mathrm{E}_{0}$ & $\Gamma$ & SodE & J $\pi$ & Notes \\
\hline$(\gamma, \mathrm{n})$ & & & & & & $\mathrm{E}_{\mathrm{th}}=10.78 \pm 0.03 \mathrm{MeV}$
\end{tabular}

$E_{t h}=10.78 \pm 0.03 \mathrm{MeV}$. 
iict. E.C. Booth

Nuclear Phys. 10, $4: 26$ (1960)

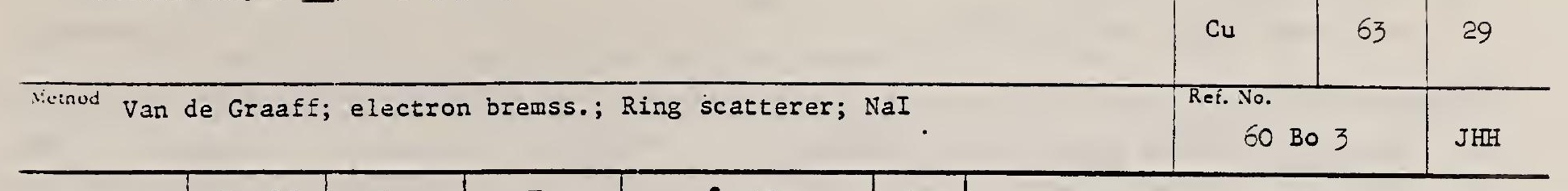

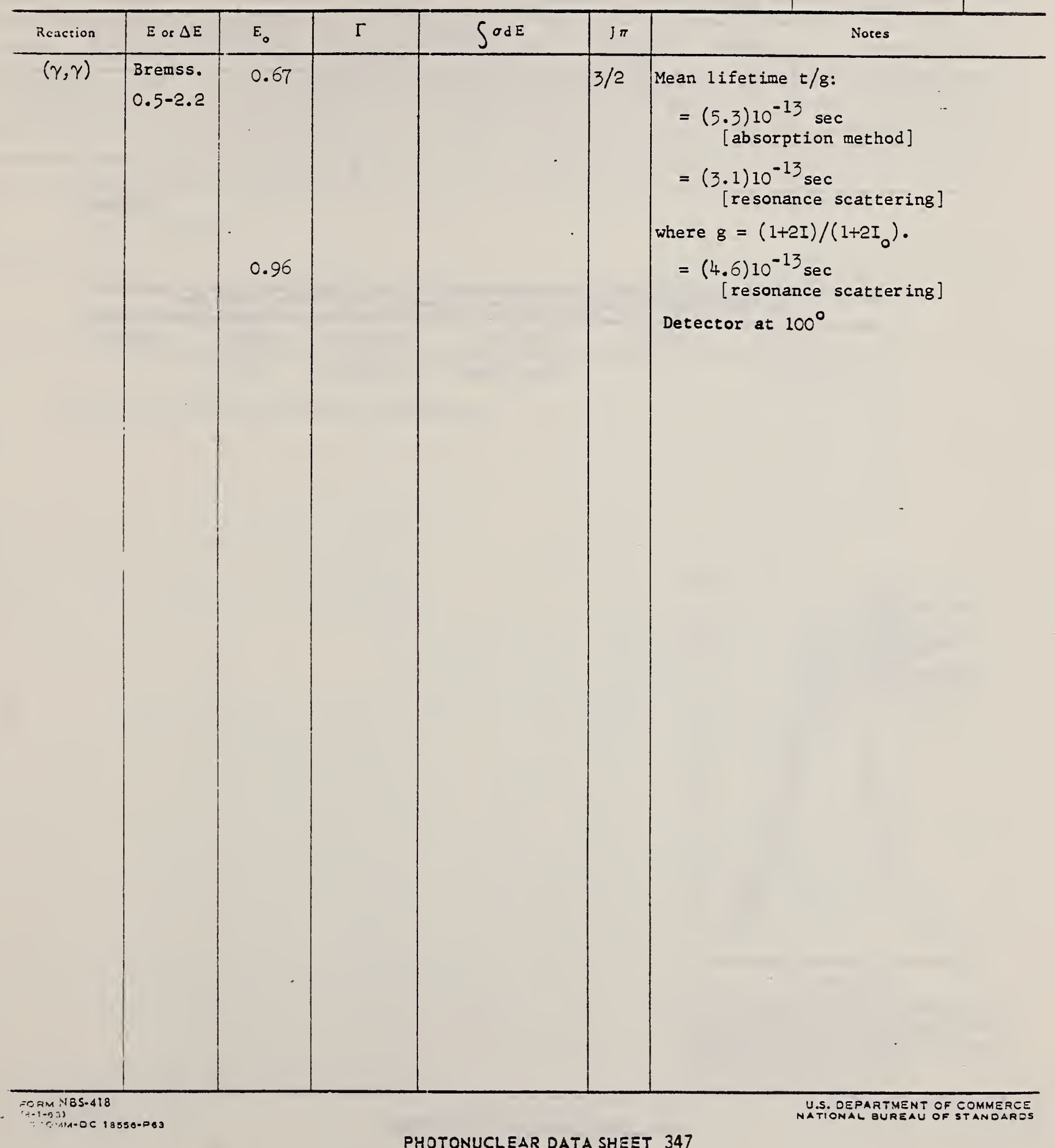


REF.

K. N. Geller, J. Halpern, and E. G. Muirhead

Phys. Rev. 118, 1302-12 (1960)

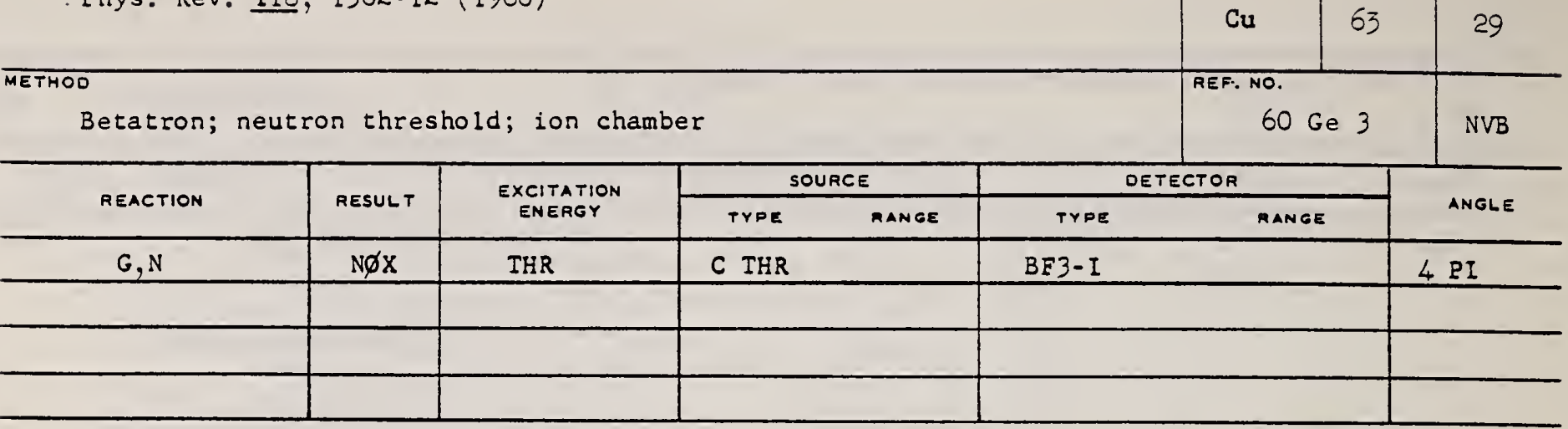

THRESH $\varnothing \mathrm{LD}$

TABLE I. Summary and comparison of neutron scparation cnesgics inierred from present threshold measurements with values predicted from mase data and reaction encrgies. All cnergies are expressed in the center-of-mass system in Mev.

\begin{tabular}{|c|c|c|c|c|c|}
\hline Rrartlem & No, runs & l'resent results & Other results & Mcthod & Refcrence \\
\hline $\mathrm{Cu}^{63}(\gamma, n) \mathrm{Cu}^{\mathrm{an}}$ & 3 & $10.833 \pm 0.017$ (calib) & $10.826 \pm 0.018$ & mass data & j \\
\hline
\end{tabular}

IK. S. Quisenberry, T. T. Scolman, and A. O. Nier, Phys. Rev. 104, 461 (1956). 
S. Yasumi, M. Yata, K. Takamatsu, A. Masaike, Y. Masuda

J. Phys. Soc. Japan 15, 1913 (1960)

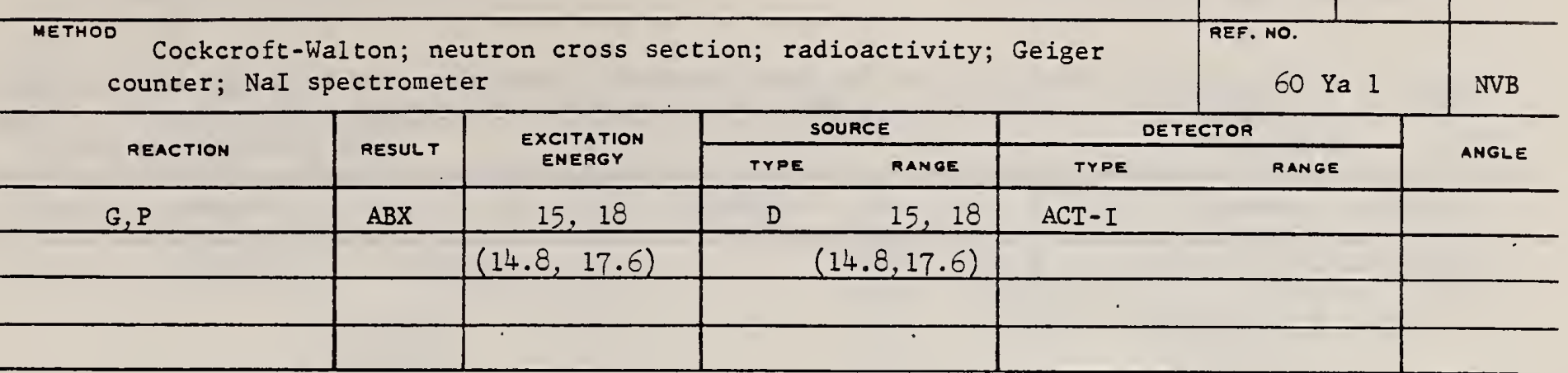

$\sigma_{L i}=62 \pm 4 \mathrm{mb}$ (both $\mathrm{Li} \gamma^{\prime} \mathrm{s}$ )

$\sigma_{17.6}=76 \pm 5 \mathrm{mb}$

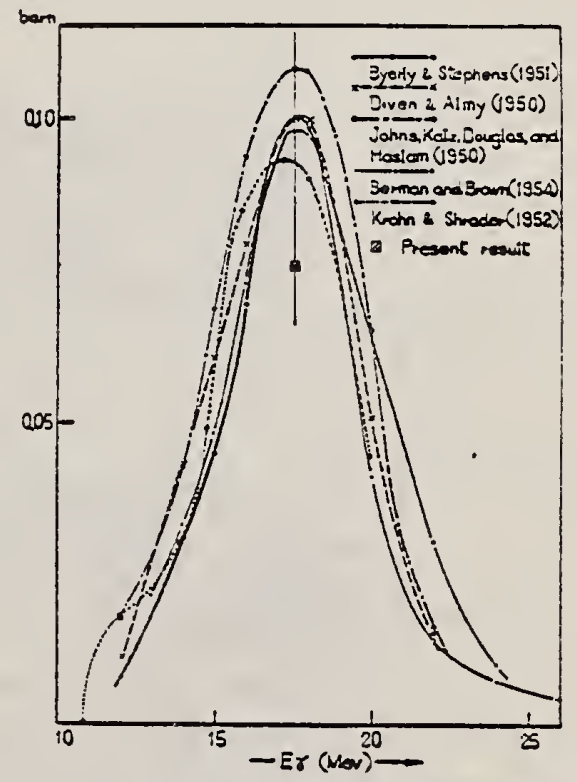

Fig. 103). Excitation curves of the reaction $\mathrm{Cu}^{\circ 3}$ $(7, n) \mathrm{C}^{62}$ obtained by various authors. A point represents the value for $17.6 \mathrm{Mev}$ y-ray determined in the present experiment. 
Ref. G.E. Coote, W.E. Turchinetz, I.F. Wright Nuclear Phys. 23, 468 (1961)

Method Monoergic $\gamma^{\prime} s$ from $\mathrm{Li}^{7}(\mathrm{p}, \gamma)$ and $\mathrm{B}^{11}(\mathrm{p}, \gamma)$ reactions; activation

Ref. No.

61 Co 2

$\mathrm{JHH}$

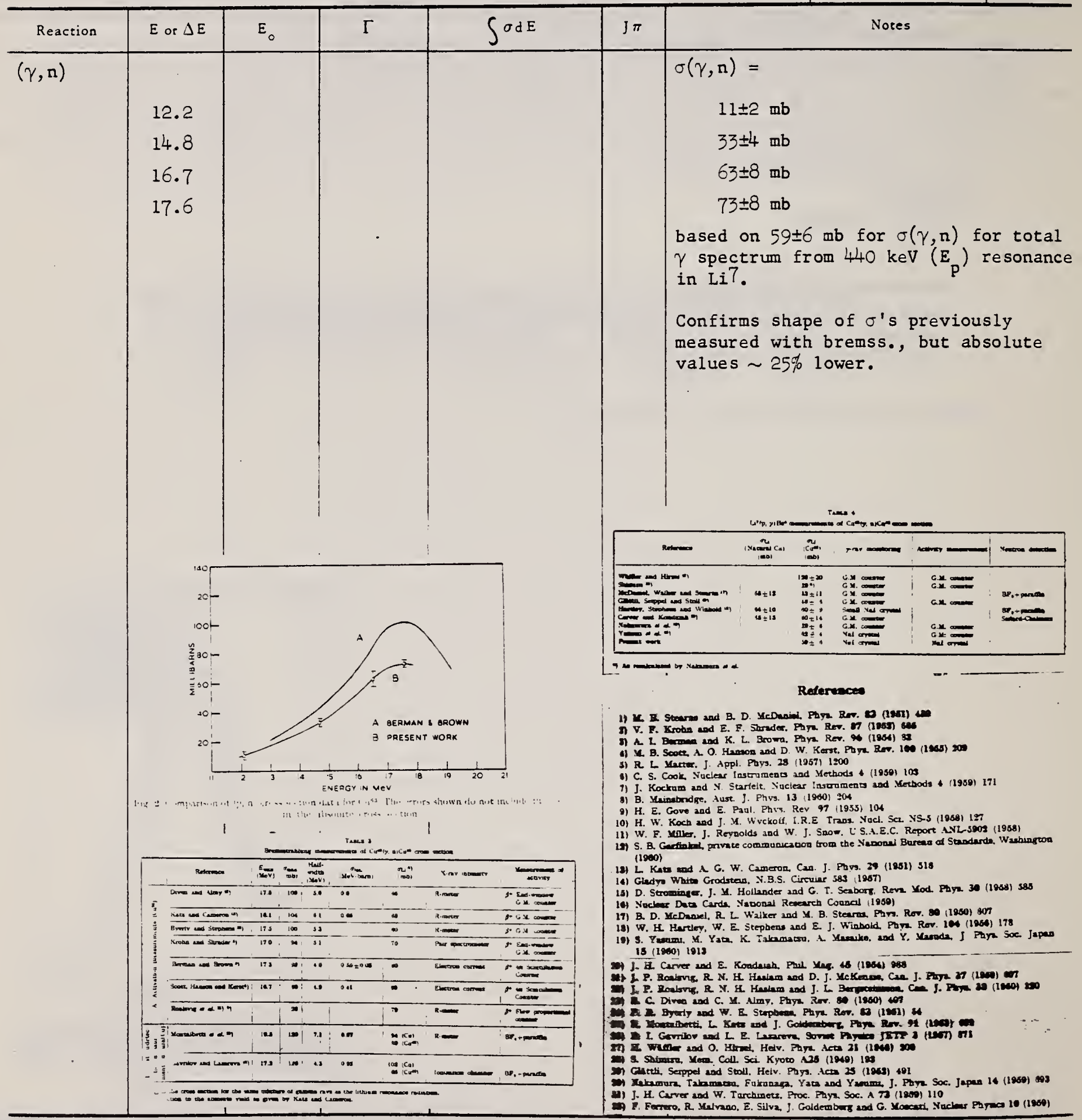


Ref. T. Rothem, F.R. Metzger, C.P. Swann Nuclear Phys. 22, 505 (1961)

\begin{tabular}{l|l|l} 
& $\mathrm{Cu}$ & 63 \\
\hline $\begin{array}{l}\text { Method Resonance scattering; absolute cross section and angular distri- } \\
\text { bution measurement; NaI. }\end{array}$ & $\begin{array}{r}\text { Ref. No. } \\
61 \text { Ro } 1\end{array}$ & $\mathrm{JHH}$ \\
\hline
\end{tabular}

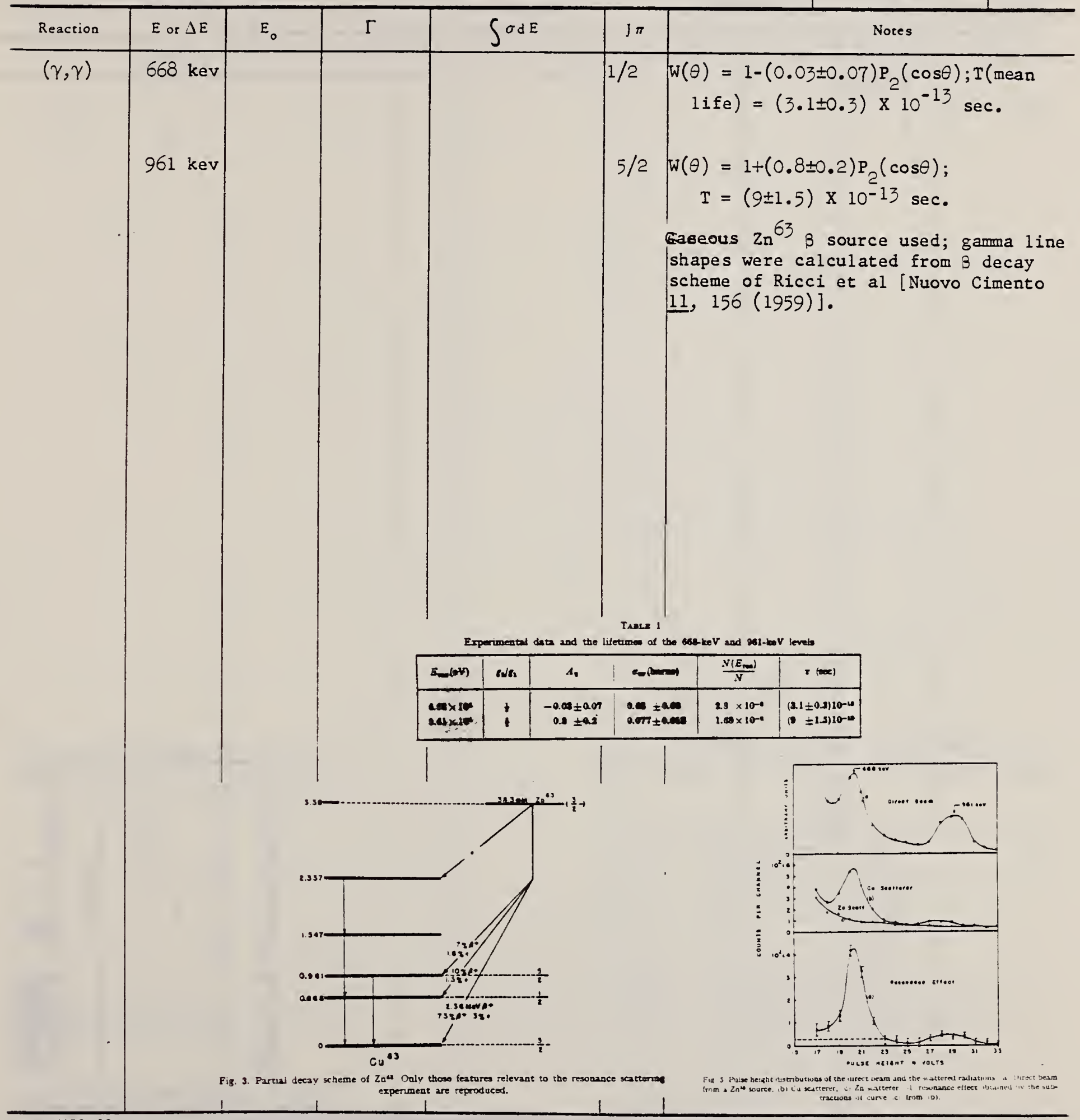


Ref. E.C. Booth, K.A. Wright

Nuclear Phys. 35, 472 (1962)

Elem. Sym.

\begin{tabular}{l|l} 
A & 2 \\
63 & 29
\end{tabular}

$\mathrm{Cu}$

Method $4 \mathrm{MeV}$ electron Van de Graaff; brems8.; nuclear resonance scattering, ring scatterer; NaI

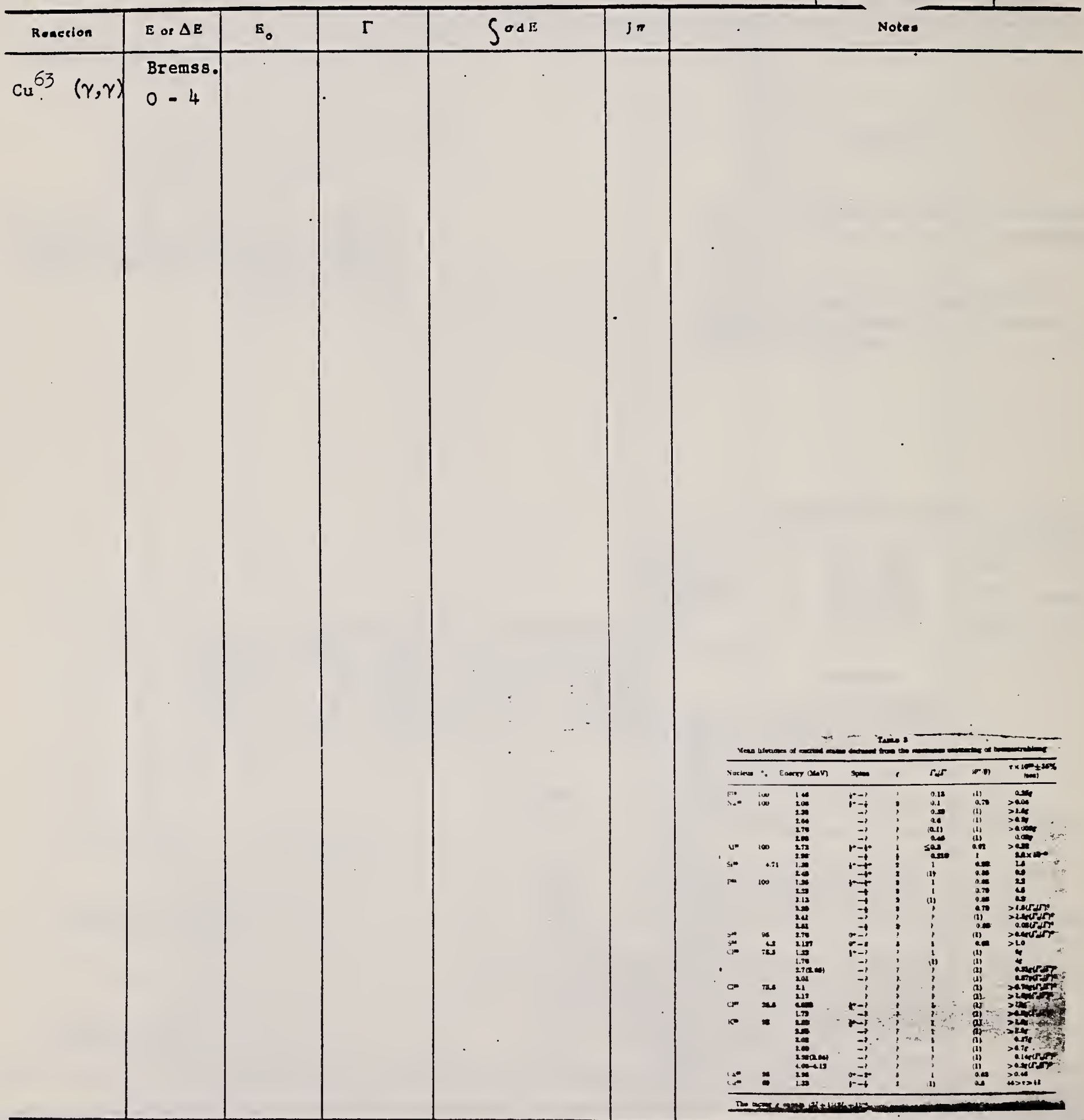


Wi. V.P. Chizhov, A.P, Komar, L.A. Kulchitsky, A.V. Kulikov, E.D. Makhnovel: y, Yu.M. Volkov

Nuclear Phys. 552 (1962)

$90 \mathrm{MeV}$ Synchrotron; magnetic spectrometer; emulsions; NaI counter telescope

Ref. No.

$62 \mathrm{Ch} 2$

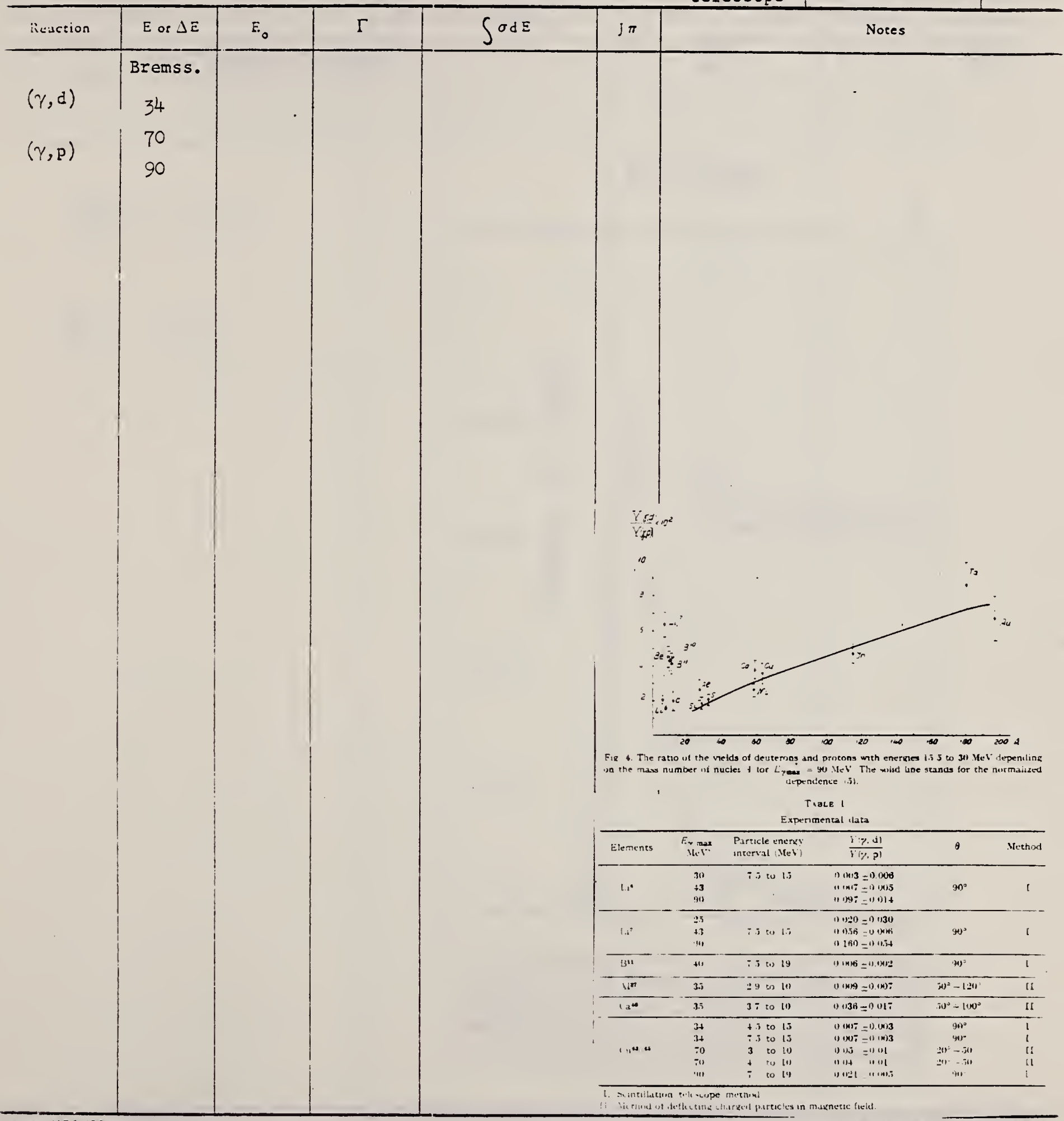


Ref. W.E. Del Bianco, W.E. Stephens

Phys. Rev. 126, 709 (1962)

Method Electrostatic generator, $\mathrm{H}^{3}(p, \gamma) \mathrm{He}^{4}$ reaction; activation of positron emitter; 2 NaI in coincidence.

\begin{tabular}{l|c|c|c|c|c|c}
\hline Rezction & $E$ or $\Delta E$ & $E_{0}$ & $\Gamma$ & $\int \sigma d E$ & $J \pi$ & Notes \\
\hline$(\gamma, \pi)$ & 20.48 & & & & & $\sigma(\gamma, \pi)=52.5 \pm 2.1$
\end{tabular}

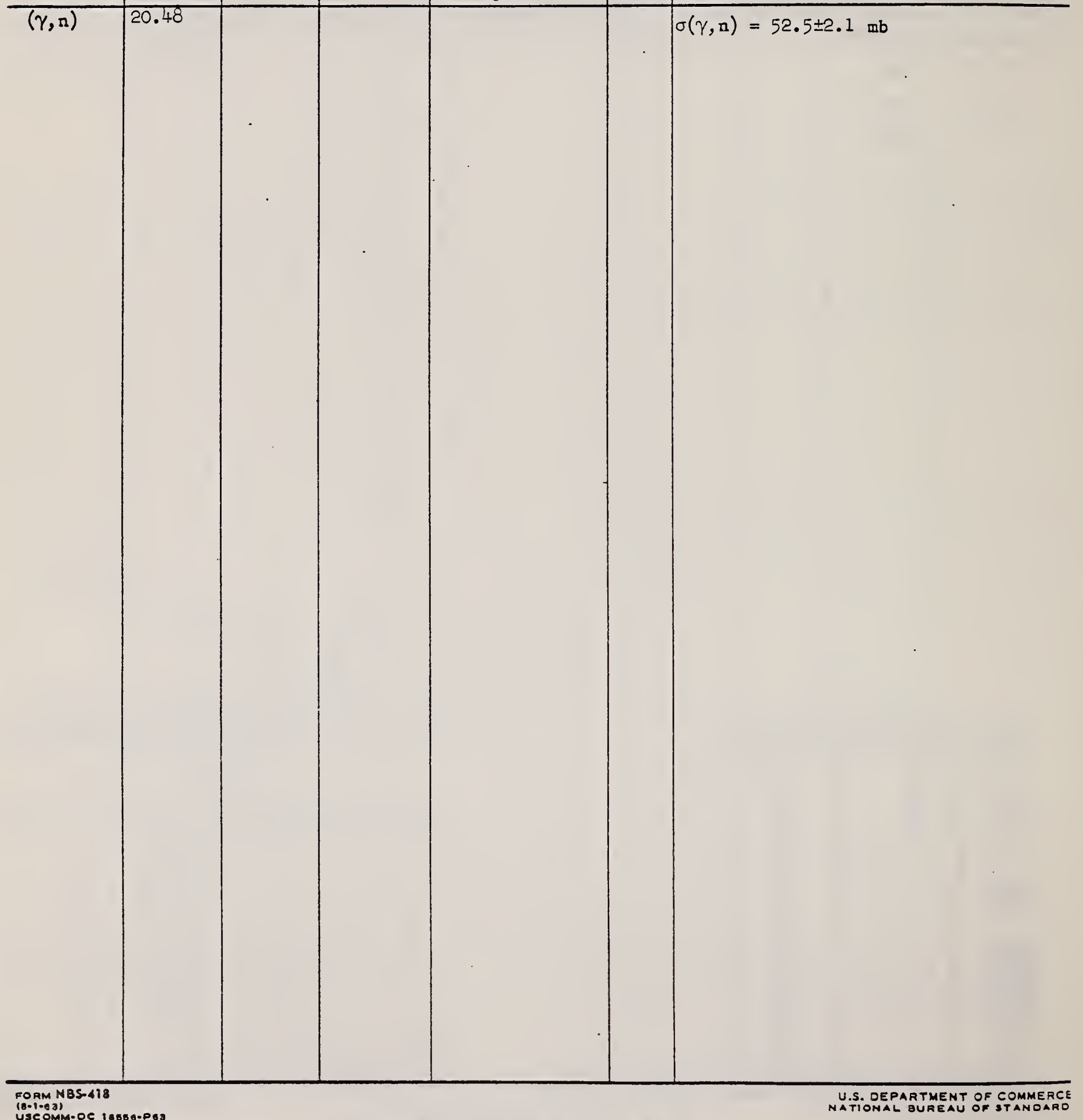


J. Goldemberg, E.W. Hamburger, A. Szily

An. Acad. Brasil. Cienc. 35, 169 (1963)

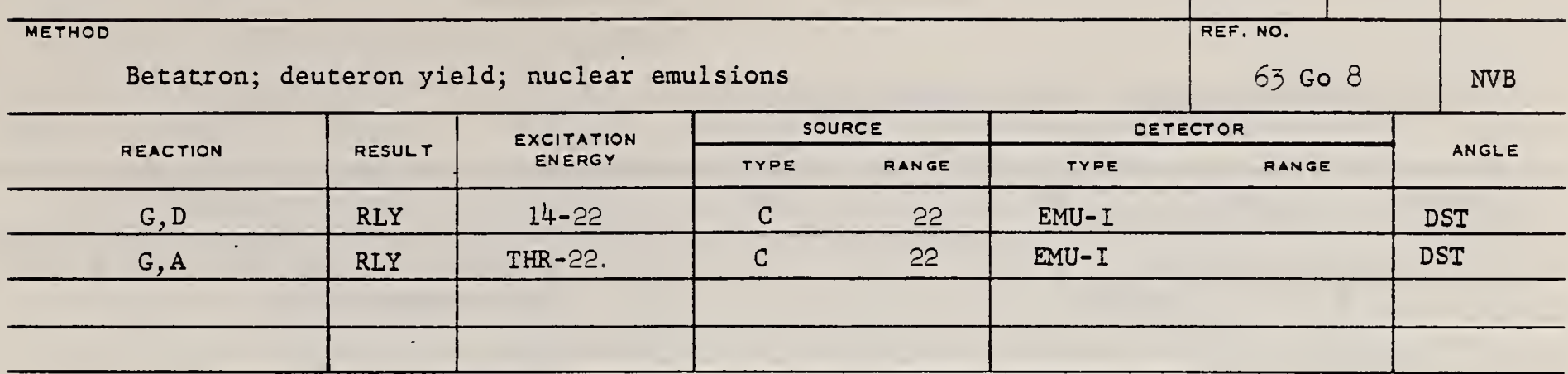

$$
\begin{aligned}
& \frac{Y_{d+H e^{j}}}{Y_{P}}=4.5 \pm 2.5 \% \\
& \frac{Y_{\alpha+t}}{Y_{P}}=4.5 \pm 2.5 \%
\end{aligned}
$$

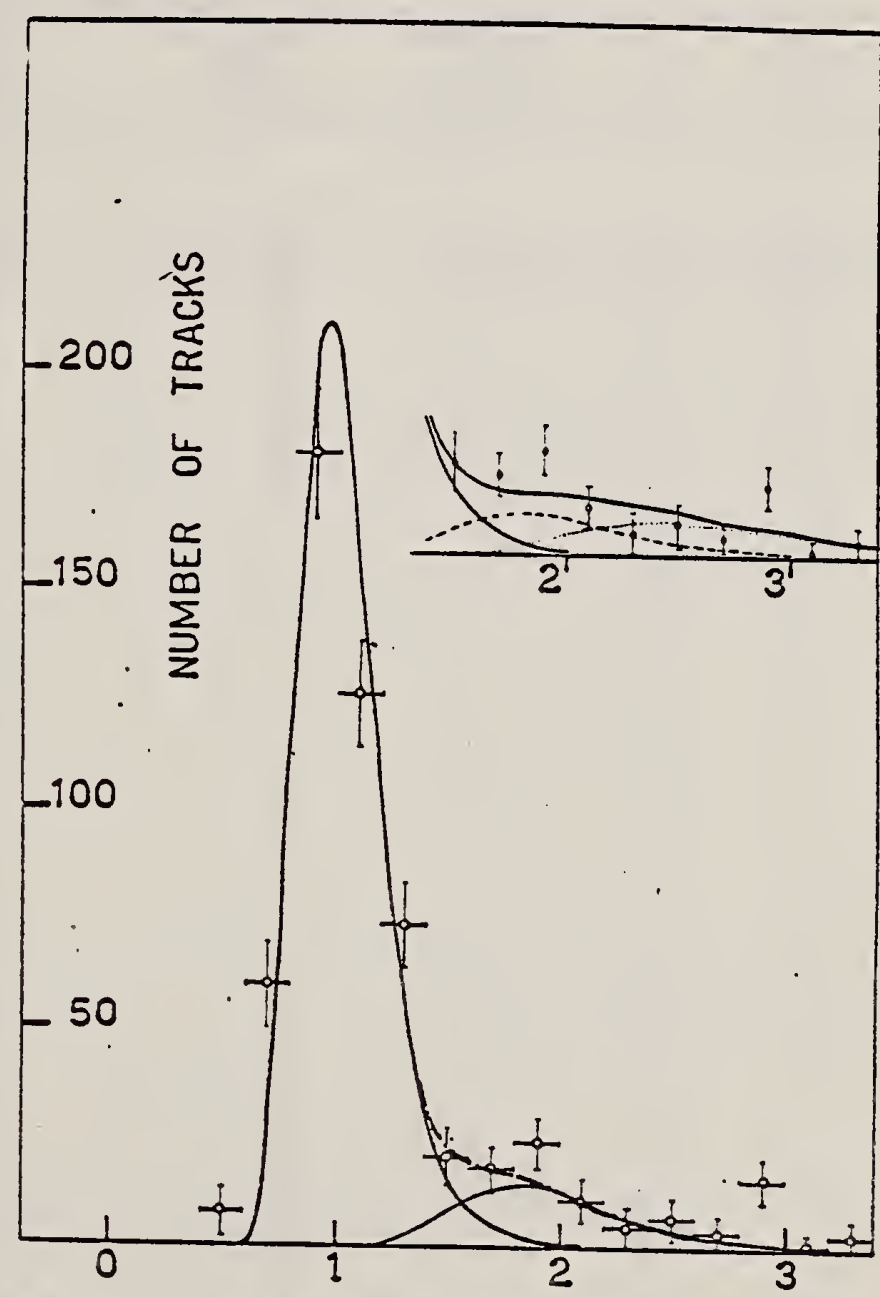

Fig. 6 - Total mass histogram in the plates exposed in positions $n^{\circ} \mathrm{z}$ $1,2,8$ and 9. The full lines give the calculated shapes of the proton and deuteron peaka, sormalized respectively to 460 and 65 tracka; the dot-dashed line is the sum of the two peaks. In the inset the same experimental data is shown, but the deuteron curve is normalized to 42 tracka, while the dotted line corresponds to 44 alpha particlea; the dot-dashed line is the sum of the three peaks. 
Ref. J.A. McIntyre, G.R. Tandon

Phys. Letters 4,117 (1963)

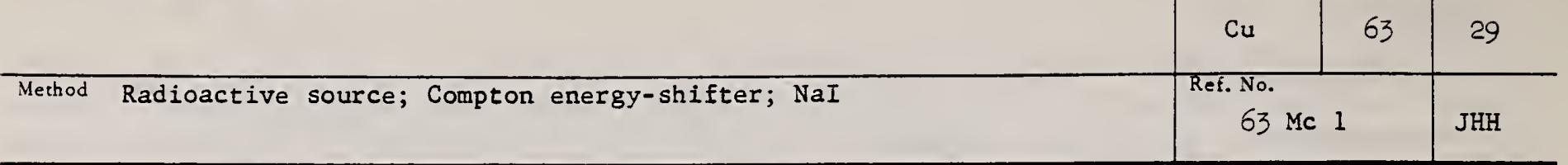

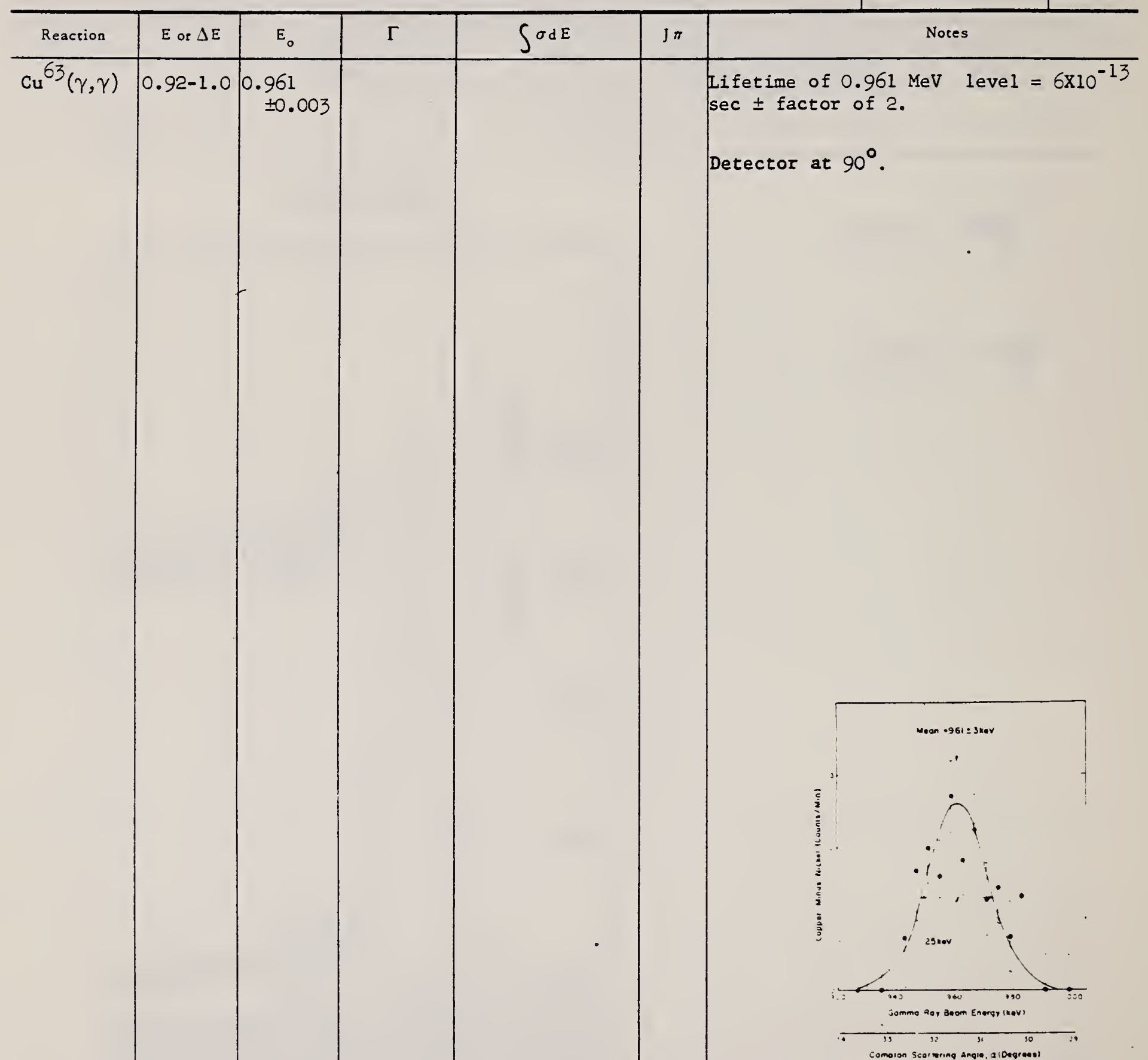

Fig. - The difference in : ounting rate of the $\mathrm{N}_{3}(\mathrm{~T})$ The difference in :ounting rate of the Nallth and counter for elistic scattering from the copper and nickel targets is ploted againat the Compton scattering angle The second sbocissil scule gives the energy of the -rais striking the tarcet correponutna to each angle kach point represents tour hours of counting with the copper target ind iour hours of counting with the aickel tarjet. 


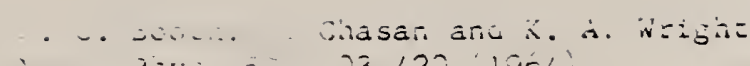

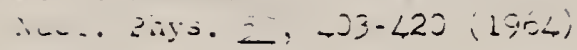

Cu

6329

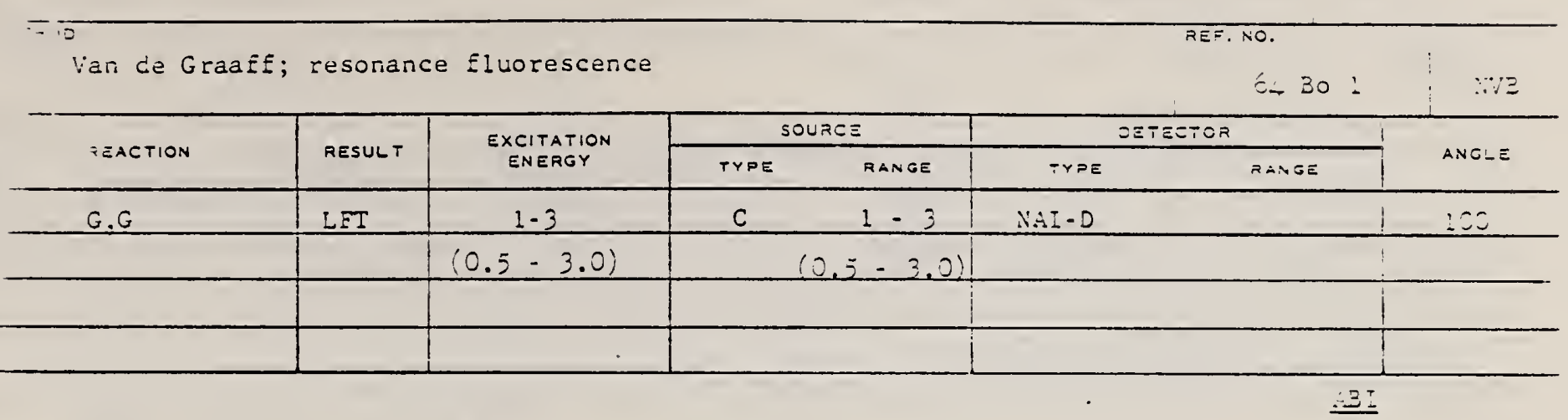

TABLE 1

Cases of obscrved pesonance fluoresenee

\begin{tabular}{|c|c|c|c|c|c|c|c|c|}
\hline $\begin{array}{l}\text { Nucleus } \\
\text { multipol. }\end{array}$ & $\begin{array}{l}\text { State } \\
\text { (MicV) }\end{array}$ & Spin & $\Gamma_{0} / \Gamma$ & $\begin{array}{c}\tau\left(g w \Gamma_{0}^{3} / \Gamma^{3}\right)^{-1} \\
(\mathrm{scc}) .\end{array}$ & $\begin{array}{c}\text { Mean lifetime } T \\
\text { BCW } \\
\text { (sec) }\end{array}$ & $\begin{array}{c}\text { Mean iffetme T } \\
\text { other } \\
\text { (sec) }\end{array}$ & Rei. & $\begin{array}{l}\Gamma_{0} / \Gamma_{W} \\
\mathrm{BCW}\end{array}$ \\
\hline$\overline{\mathrm{Cu}^{33}}$ & 0.00 & $\frac{3}{2}-$ & & & & & & \\
\hline MI & 0.67 & $\frac{1}{2}-$ & 1 & $86 \pm 30 \times 10^{-11}$ & $43 \pm 15 \times 10^{-11}$ & $31 \pm 3 \times 10^{-14}$ & 20) & 0.25 \\
\hline
\end{tabular}


S. Costa, F. Ferrero, S. Ferroni and R. Malvano

Proc. Paris Conference 1034 (1964)

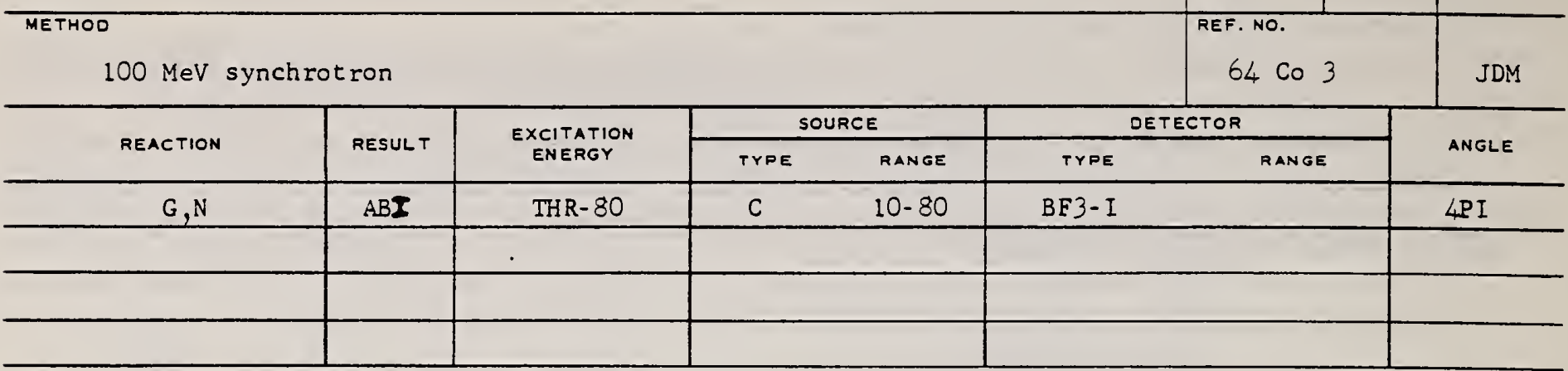

TABLB

\begin{tabular}{|c|c|c|c|c|c|}
\hline ELEMENT & $\left.\begin{array}{l}\text { Yield }(36 \mathrm{MeV}) \\
\left(\frac{\mathrm{n} \cdot \mathrm{cm}^{2}}{\mathrm{~mol} \cdot \mathrm{MeV}}\right) \\
\times 10^{8}\end{array}\right)$ & $\Sigma_{0}^{30}$ & $\Sigma_{0}^{80}$ & $\Sigma_{0}^{30} / \Sigma_{0}^{80}$ & $\begin{array}{c}\sigma_{-1} \\
(m b)\end{array}$ \\
\hline 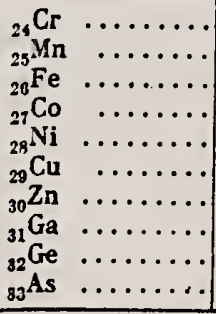 & $\begin{array}{r}83 \\
108 \\
68 \\
89 \\
44 \\
95 \\
88 \\
130 \\
139 \\
137 \\
\end{array}$ & $\begin{array}{l}1.21 \\
1.52 \\
0.88 \\
1.08 \\
0.55 \\
1.06 \\
0.94 \\
1.29 \\
1.35 \\
1.22\end{array}$ & \begin{tabular}{l|}
2.1 \\
2.33 \\
1.46 \\
1.82 \\
1.07 \\
1.99 \\
1.68 \\
2.18 \\
2.29 \\
2.18
\end{tabular} & $\begin{array}{l}0.58 \\
0.65 \\
0.60 \\
0.59 \\
0.51 \\
0.53 \\
0.56 \\
0.59 \\
0.59 \\
0.56\end{array}$ & $\begin{array}{r}62 \\
76 \\
50 \\
64 \\
34 \\
72 \\
66 \\
94 \\
101 \\
100\end{array}$ \\
\hline
\end{tabular}

$\Gamma^{b}=\frac{A}{60 \mathrm{NZ}} \int^{\mathrm{b}} \sigma(E) \mathrm{d} E$ is the integrated cross section measured in units of the classical dipole $60 \mathrm{NZ} / \mathrm{A} \mathrm{mb}$. MeV. 
REF. S.C. Fultz, R.L Bramblett, J.T. Caldwell, R.R. Harvey

Phys. Rev. 133, B1149-54 (1964)

METHOD

Positron Annihilation; ion chamber

[Page 1 of 2]

64 Fu 1

NVB

\begin{tabular}{|c|c|c|c|c|c|c|c|c|}
\hline \multirow{2}{*}{ REACTION } & & \multirow{2}{*}{ RESULT } & \multirow{2}{*}{$\begin{array}{l}\text { EXCITATION } \\
\text { ENERGY }\end{array}$} & \multicolumn{2}{|c|}{ SOURCE } & \multicolumn{2}{|c|}{ DETECTOR } & \multirow{2}{*}{ ANGLE } \\
\hline & & & & TYPE & RANGE & TYPE & RANGE & \\
\hline$G, N$ & $18+$ & $\mathrm{ABX}$ & $10-28$ & $D$ & $10-28$ & $B E 3-I$ & & $\angle P I$ \\
\hline $\mathrm{G}, 2 \mathrm{~N}$ & 19 & $A B X$ & $19-28$ & D & $10-28$ & BF3-I & & $4 P I$ \\
\hline & & & & & & & & \\
\hline & & & & & & & & \\
\hline
\end{tabular}

Sample enriched to $99.35 \% \mathrm{Cu}^{63}$.

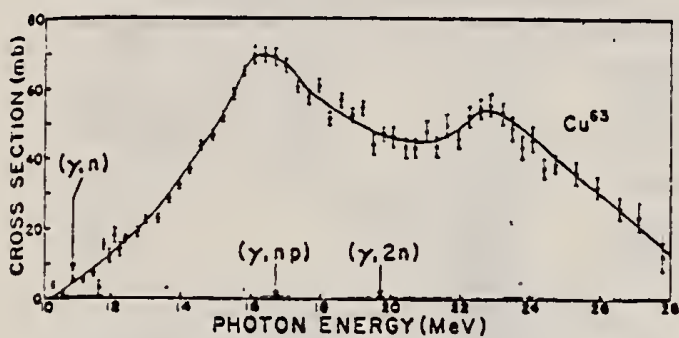

[iic. 3. Total cross section $[\sigma(\gamma, n)+2 \sigma(\gamma, 2 n)+\sigma(\gamma, n p)]$ for $\mathrm{Cu}^{4}$ obtained from single-neutron counting data.

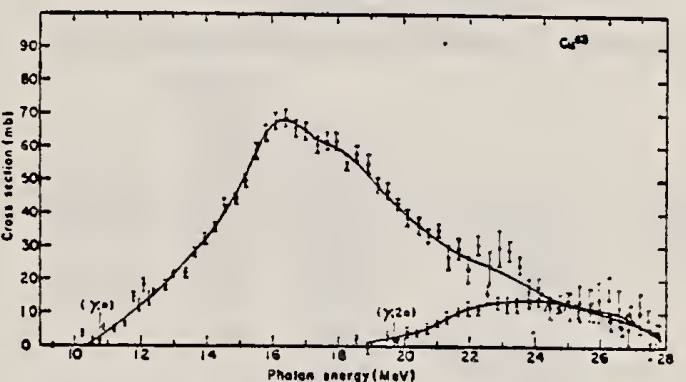

Fig. 4. Partial cross sections measured for $\mathrm{Cu}^{\infty}$. The top curve consists of $\sigma(\gamma, n)+\sigma(\gamma, n p)$ plus contributions from direct interactions and was obtained from single-neutron counting data. The lower curve consists of $\sigma(\gamma, 2 n)$ and was obtained from doubleneutron counting data.

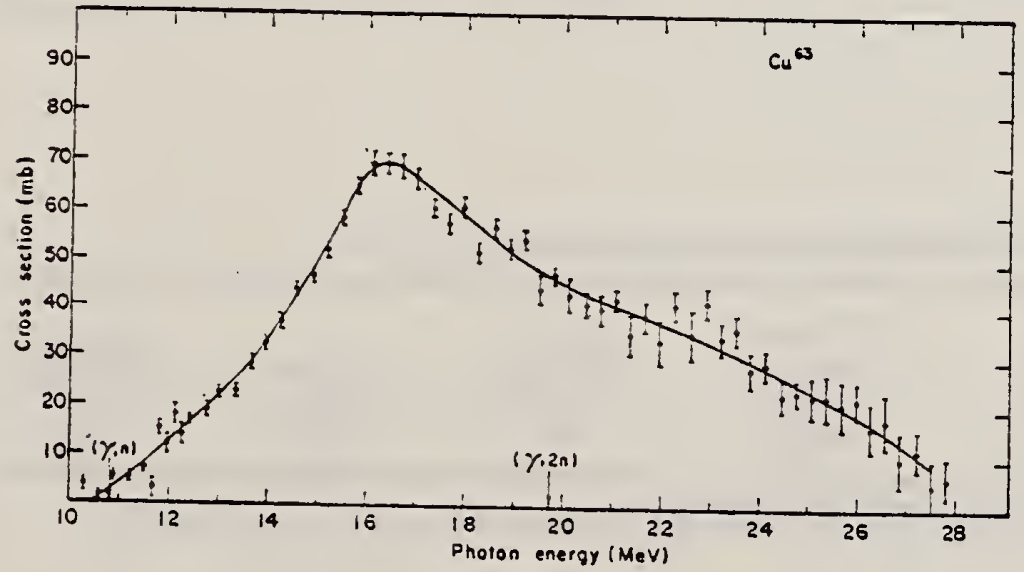

FIG. 5. The formation cross sec. tion of $\mathrm{Cu} \omega, \sigma(y, n)+\sigma(y, n p)+\sigma(y, 2 n)$ $T \sigma_{\text {direar. }}$ Contributions irom $\sigma(\gamma, p)$ are not included here. 
REF.

S.C. Fultz, R.L. Bramblett, J.T. Caldwell, R.R. Harvey Phys. Rev. 133, B 1149-54 (1964)

Positron Annihilation; ion chamber

[Page 2 of 2]

REF. NO.

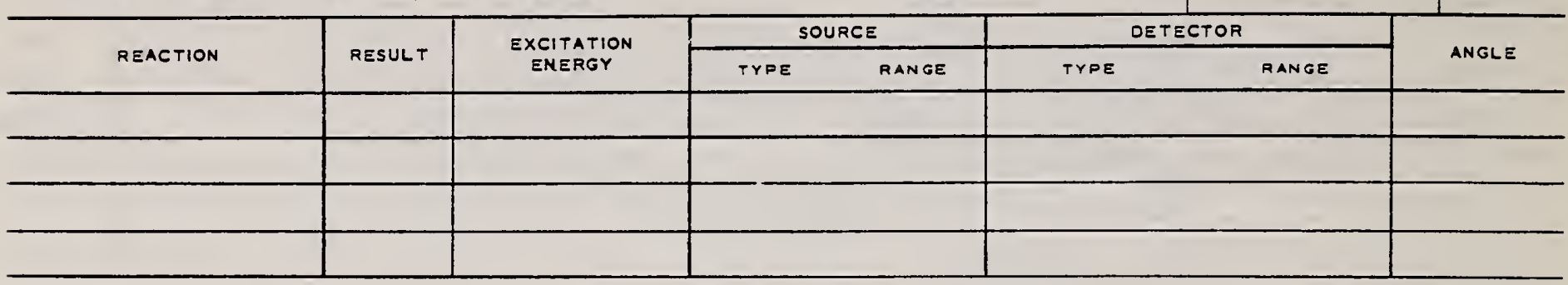

$64 \mathrm{Fu} 1$

TABLE I. Integrated cross sections up to 28 $\mathrm{MeV}$ for copper isotopes.

\begin{tabular}{|c|c|c|c|c|}
\hline Element & Reaction & $\begin{array}{l}\text { Integrated } \\
\text { cross section } \\
\text { (MeV-mb) }\end{array}$ & $\begin{array}{l}\text { Fraction } \\
\text { of total } \\
\text { inte- } \\
\text { grated } \\
\text { cross } \\
\text { section }\end{array}$ & $\begin{array}{c}\text { Total } \\
(\mathrm{MeV}-\mathrm{mb})\end{array}$ \\
\hline Natural $\mathrm{Cu}$ & $\begin{array}{l}(\gamma, n)+(\gamma, n p) \\
\gamma, 2 n) \\
(\gamma, p)\end{array}$ & $\begin{array}{l}525 \pm 52 \\
110 \pm 11 \\
152 \pm 30\end{array}$ & $\begin{array}{l}0.67 \\
0.14 \\
0.19\end{array}$ & $787 \pm 113$ \\
\hline $\mathrm{Cu}^{63}$ & $\begin{array}{l}(\gamma, n)+(\gamma, n p) \\
\quad+\text { direct } \\
(\gamma, 2 n) \\
(\gamma, n p)^{\star} \\
(\gamma, p)^{\bullet} \\
(\gamma, n) \\
\text { direct }^{b}\end{array}$ & $\begin{array}{c}523 \pm 52 \\
80 \pm 8 \\
115 \pm 20 \\
161 \pm 18 \\
344 \pm 34 \\
64 \pm 22\end{array}$ & $\begin{array}{l}0.89 \\
0.11 \\
0.15 \\
0.21 \\
0.45 \\
0.08\end{array}$ & $764=09$ \\
\hline $\mathrm{Cu}^{\mathrm{as}}$ & $\begin{array}{l}(\gamma, n)+(\gamma, n p) \\
(\gamma, 2 n) \\
(\gamma, p)^{0}\end{array}$ & $\begin{array}{l}437 \pm 43 \\
195 \pm 19 \\
134 \pm 10\end{array}$ & $\begin{array}{l}0.57 \\
0.25 \\
0.18\end{array}$ & $766 \pm 103$ \\
\hline
\end{tabular}

TABLE II. Cross section for $\mathrm{Li}$ gamma rays.

\begin{tabular}{|c|c|c|c|}
\hline $\begin{array}{c}\text { Natural Cu } \\
\sigma(\gamma, n) \\
(m b)\end{array}$ & $\begin{array}{c}C u^{63} \\
\sigma(\gamma, n) \\
(m b)\end{array}$ & $\begin{array}{c}\mathrm{Cu} \text { os } \\
\sigma(\gamma, n) \\
(\mathrm{mb})\end{array}$ & Reference \\
\hline $55 \pm 12$ & $\begin{array}{c}120 \pm 30 \\
52 \pm 11 \\
48 \pm 8\end{array}$ & & i \\
\hline $\begin{array}{l}85 \pm 15 \\
64 \pm 10\end{array}$ & $\begin{array}{l}80 \pm 14 \\
60 \pm 9 \\
38 \pm 6\end{array}$ & & i \\
\hline $6 i \pm 6$ & $\begin{array}{l}64 \pm 4 \\
59 \pm 6 \\
55 \pm 6\end{array}$ & $\begin{array}{l}70 \pm 7 \\
66 \pm 6\end{array}$ & $\begin{array}{c}\text { b } \\
\text { Present } \\
\text { work }\end{array}$ \\
\hline
\end{tabular}

TABLE III. Quadrupole moments and Lorentz line parameters.

\begin{tabular}{|c|c|c|c|c|c|c|c|c|}
\hline $\begin{array}{l}\text { Nuciear } \\
\text { shape }\end{array}$ & Isotope & (Mev) & $\begin{array}{c}\sigma_{0} \\
(m b)\end{array}$ & (Mev) & $\begin{array}{c}E_{b} \\
(\mathrm{MeV})\end{array}$ & $\left(\begin{array}{c}a b \\
m b\end{array}\right)$ & (Mev) & (b) \\
\hline $\begin{array}{l}\text { Prolate } \\
\text { Spheroid }\end{array}$ & $\begin{array}{l}\text { Cuns } \\
\text { Cuss }\end{array}$ & $\begin{array}{l}16.00 \\
16.00\end{array}$ & $\begin{array}{l}48.5 \\
54.7\end{array}$ & $\begin{array}{l}3.5 \\
4.2\end{array}$ & $\begin{array}{l}19.0 \\
19.25\end{array}$ & $\begin{array}{l}+4.5 \\
62.0\end{array}$ & $\begin{array}{l}7.5 \\
7.5\end{array}$ & $\begin{array}{l}1.1=0.4 \\
1.2 \pm 0.4\end{array}$ \\
\hline $\begin{array}{l}\text { Oblate } \\
\text { Splueroid }\end{array}$ & $\underset{\mathrm{Cuw}}{\mathrm{Cuw}}$ & $\begin{array}{l}16.50 \\
16.75\end{array}$ & $\begin{array}{l}62.5 \\
37.5\end{array}$ & $\begin{array}{l}5.0 \\
5.0\end{array}$ & $\begin{array}{l}21.25 \\
20.5\end{array}$ & $\begin{array}{l}22.0 \\
36.4\end{array}$ & $\begin{array}{l}7.1 \\
6.0\end{array}$ & $\begin{array}{l}-1.4=0.4 \\
-1.1 \pm 0.4\end{array}$ \\
\hline
\end{tabular}

TABLE IV. Integrated nuciear formation cross sections and $\sigma_{-2}$ values.

\begin{tabular}{ccccc}
\hline & $\int_{0}^{2 \mathrm{~s}} \sigma d E$ & $\int_{0}^{2 \mathrm{~s}} \sigma d E+W$ & $0.06 \mathrm{VZ} / A$ & $0.00225 A^{6 / 3}$ \\
$(\mathrm{MeV}-\mathrm{mb})$ & $(\mathrm{MeV}-\mathrm{mb})^{\mathrm{b}}$ & 939 & $\begin{array}{c}\sigma-2 \\
(\mathrm{mb} / \mathrm{MeV})\end{array}$ \\
\hline $\mathrm{Cu}^{63}$ & $764 \pm 109$ & $913 \pm 121$ & $2.1 \pm 0.3$ & 2.4 \\
$\mathrm{Cu}^{65}$ & $766 \pm 103$ & $960 \pm 124$ & 964 & $2.6 \pm 0.3$ \\
\hline
\end{tabular}

The integrated cross sections include estimated contributions from $(y . p)$ reactions.

"The correction " $W$ " is the sum of the high- and lowenergy wing corrections to the area under the resonance curves for the obiate cace. 
M. Masuda, M. Kondo, S. Takeda, M. Okumura, and J. Ookuma

J. Phys. Soc. Japan 19, 2339 (1964)

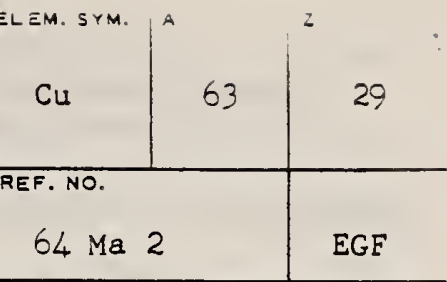

\begin{tabular}{|c|c|c|c|c|c|c|c|}
\hline \multirow{2}{*}{ REACTION } & \multirow{2}{*}{ RESULT } & \multirow{2}{*}{$\begin{array}{l}\text { EXCITATION } \\
\text { ENERGY }\end{array}$} & \multicolumn{2}{|c|}{ SOURCE } & \multicolumn{2}{|c|}{ DETECTOR } & \multirow{2}{*}{ ANGLE } \\
\hline & & & TYPE & RANGE & TYPE & RANGE & \\
\hline $\mathrm{G}, \mathrm{XP}$ & SPC & THR - 17 & $\mathrm{C}$ & 17 & $S C D-D$ & $3-9$ & \\
\hline & & & & & & & \\
\hline & & & & & & & \\
\hline
\end{tabular}

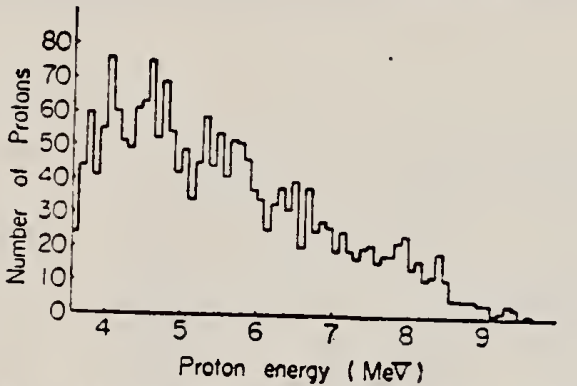

Flg. 3. Energy spectrum of emitted protons from copper foil irradiated by $17 \mathrm{MeV}$ bremsstrahlung. 
REF. I.A. Grishaev, D.I. Sikora, V.A. Shkoda-Ul'yanov, B.I. Shramenko Atomnaya Energiya 18,28 (1965)

Soviet Atomic Energy 18, 29 (1965)

ELEM. SYM. A

\begin{tabular}{|c|c|c|c|c|c|c|c|}
\hline \multirow{2}{*}{ REACTION } & \multirow{2}{*}{ RESULT } & \multirow{2}{*}{$\begin{array}{l}\text { EXCITATION } \\
\text { ENERGY }\end{array}$} & \multicolumn{2}{|c|}{ SOURCE } & \multicolumn{2}{|c|}{ DETECTOR } & \multirow{2}{*}{ ANGLE } \\
\hline & & & TYPE & RANGE & TYPE & RANGE & \\
\hline$G, N$ & $A B X$ & THR- 44 & & $10-66$ & $A C T-I$ & & $\angle P I$ \\
\hline & & . & & & & & \\
\hline & & & & & & & \\
\hline
\end{tabular}

Measure yields from electrons bombarding thick targets. Cross section derived from shower theory. $\sigma$, mbarns

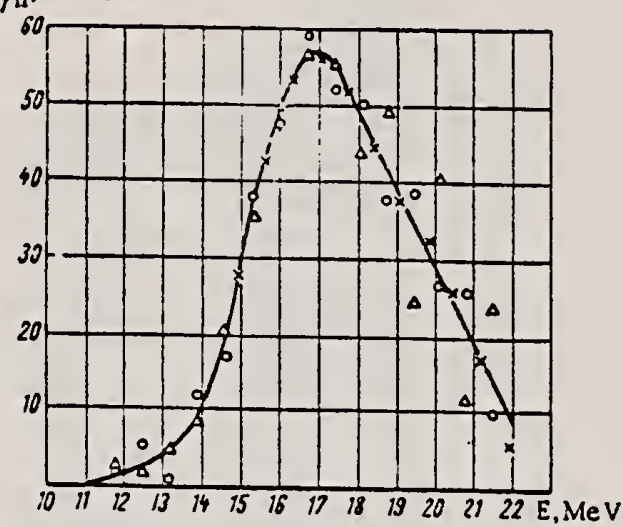

Fig. 8. Excitation function of the $(\gamma, n)$ reaction in $\mathrm{Cu}^{\text {w }}$. calculated by means of the Belen'kii Tamm equilibrium photon spectrum and the experimental yieids of the present study: $x$ ) Method using first and second derivatives $[1,15] ; 0) a b$ breviated photon difference method for thick specimens, proposed by D. I. Sikora; $\Delta$ ) photon-difference method for thick specimens. 
D. F. Herring, I. C. Nascimento, R. B. Walton, and R. E. Sund Phys. Rev. 139, B562 (1965)

\begin{tabular}{l|l|l} 
ELEM. SYM. & A & $z$ \\
Cu & 63 & 29 \\
REF. NO. \\
65 He 1 & EGF \\
\hline
\end{tabular}

\begin{tabular}{|c|c|c|c|c|c|c|c|}
\hline \multirow{2}{*}{ REACTION } & \multirow{2}{*}{ RESUL T } & \multirow{2}{*}{$\begin{array}{c}\text { EXCITATION } \\
\text { ENERGY }\end{array}$} & \multicolumn{2}{|c|}{ SOURCE } & \multicolumn{2}{|c|}{ OETECTOR } & \multirow{2}{*}{ ANGLE } \\
\hline & & & TYPE & RANGE & TYPE & RANGE & \\
\hline$E, N$ & RLY & THR- 32 & $\mathrm{D}$ & $14-32$ & $\mathrm{ACT}-\mathrm{I}$ & & $\angle P I$ \\
\hline$E+, N$ & RLY & THR- 32 & $\mathrm{D}$ & $14-32$ & ACT - I & & $\angle \mathrm{PI}$ \\
\hline & & & & & & & \\
\hline
\end{tabular}

Ratio- of positron to electron induced activity determined.

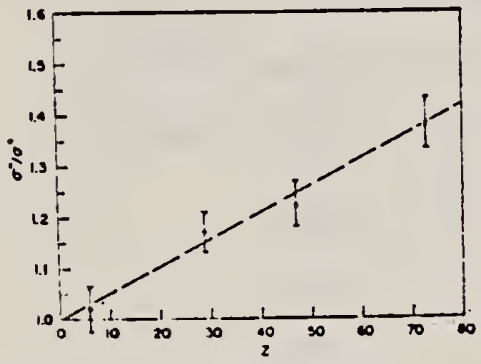

Fic. 4. The ratio $\sigma-1 \sigma^{+}$as a function of atomic number at $27-\mathrm{MeV}$ (total) bombarding energy. The straight line is for comparison purposes. 
REF.

K. Abe, N. Kawamura, H. Nihei, H. Tsubota and N. Mutsuro

J. Phys. Soc. Japan 25, 1723 (1968)

\begin{tabular}{|l|l|l} 
ELEM. SYM. & A & 2 \\
Cu & 63 & 29 \\
\hline $\begin{array}{c}\text { REF. NO. } \\
68 \mathrm{Ab} \mathrm{2}\end{array}$ & egf
\end{tabular}

\begin{tabular}{|c|c|c|c|c|c|c|c|}
\hline \multirow[b]{2}{*}{ REACTION } & \multirow{2}{*}{ RESULT } & \multirow{2}{*}{$\begin{array}{c}\text { EXCITATION } \\
\text { ENERGY }\end{array}$} & \multicolumn{2}{|c|}{ SOURCE } & \multicolumn{2}{|c|}{ DETECTOR } & \multirow{2}{*}{ ANGLE } \\
\hline & & & TYPE & RANGE & TYPE & RANGE & \\
\hline \multirow[t]{2}{*}{$G, X P$} & SPC & THR- 27 & C & 27 & $S C D-D$ & $2-16$ & 90 \\
\hline & & $(26.6)$ & & & & & . \\
\hline & & & & & & & \\
\hline & & & & & & & \\
\hline
\end{tabular}

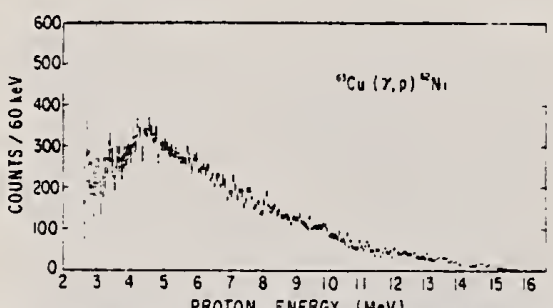

Fig. 1. Energy spectrum of photoprotons from ${ }^{3} \mathrm{Cu}$ at $90^{\circ}$, with bremsstrahlung end-point energy $26.6 \mathrm{MeV}$. 
REF. W. J. Alston III, H. H. Wilson and E. C. Booth

Nucl. Phys. Al16́, 281 (1968)

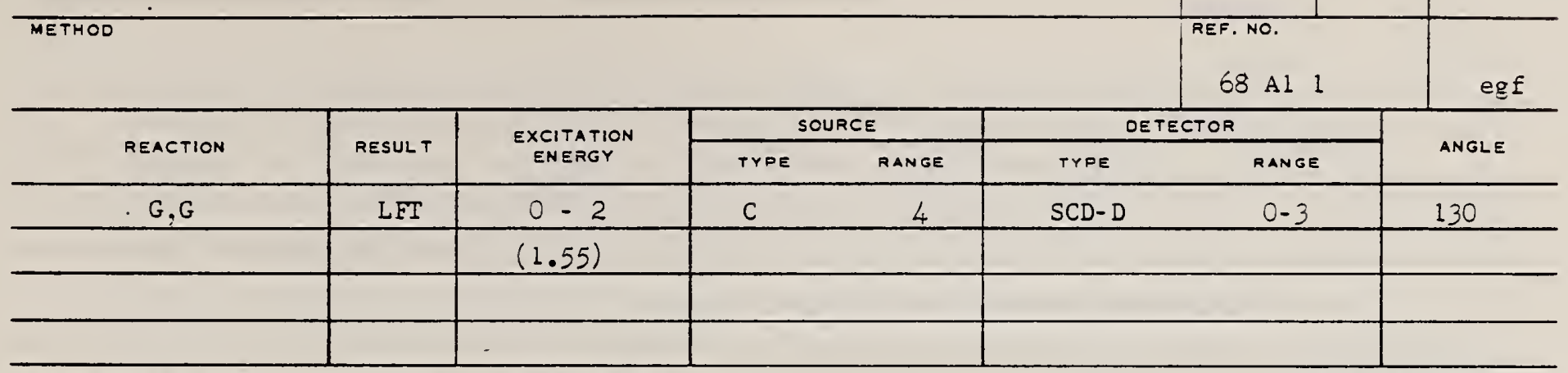

Angle greater than $90^{\circ}$ for all measurements.

SELF-ABSORPTION

TABLE 1

Direct and absorption measurements of resonance fluorescence

\begin{tabular}{|c|c|c|c|c|c|c|c|}
\hline Nucleus & $\begin{array}{c}E_{\mathrm{r}} \\
(\mathrm{MeV})\end{array}$ & $J_{r}$ & $\Gamma \cdot I \Gamma$ & $\begin{array}{c}g W \Gamma_{0} \Gamma_{\mathrm{o}} / \Gamma \\
(\mathrm{meV})\end{array}$ & $\begin{array}{l}\text { Error } \\
(\%)\end{array}$ & $\begin{array}{l}\text { This work } \Gamma_{0} \\
(\mathrm{meV})\end{array}$ & $\begin{array}{c}\text { Other work } \\
\Gamma_{0}\end{array}$ \\
\hline \multirow[t]{13}{*}{${ }^{*} \mathrm{Mn}$} & 0.000 & $\frac{5}{2}-$ & & & & & \\
\hline & 1.527 & $\left(\frac{7}{2}\right)$ & 0.9 & 5.2 & 25 & $8-12$ & \\
\hline & & & & abs a) & 40 & 8.0 & \\
\hline & 1.884 & $?$ & $\left.0.82^{\circ}\right)$ & 41 & 25 & $50 / \mathrm{gW}$ & \\
\hline & & & & abs a) & 10 & $55 / g$ & \\
\hline & 2.197 & $?$ & $\left.(0.8)^{\circ}\right)$ & 17 & 25 & $21 / \mathrm{gW}$ & \\
\hline & & & & abs & 20 & $17 / g$ & \\
\hline & 2.252 & $?$ & $\left.(0.9)^{c}\right)$ & 17 & 25 & $19 / \mathrm{gW}$ & \\
\hline & & & & abs & 20 & $13 / g$ & \\
\hline & 2.365 & $?$ & $?$ & 3.5 & 36 & $(2-6) \Gamma / \Gamma_{0}$ & . \\
\hline & 2.564 & $?$ & $(1.0)$ & 50 & 25 & $50 / g W$ & \\
\hline & & & & abs a) & 20 & $61 / 9$ & \\
\hline & 2.751 & ? & ? & 6.7 & 42 & $6.7\left(\Gamma / \Gamma_{0}\right) / \mathrm{gW}$ & \\
\hline \multirow[t]{5}{*}{${ }^{30} \mathrm{Co}$} & 0.000 & $i^{-}$ & & & & & \\
\hline & 1.187 & $\left(\frac{7}{2}-\right)$ & $(1.0)$ & 6.8 & 25 & 7.5 & $\left.0.33(E 2)^{d}\right)$ \\
\hline & & & & abs & 25a) & 12 & \\
\hline & & $\left(2^{-}\right)$ & $(1.0)$ & 6.8 & $=5$ & $(5.4-6.5)$ & $0.27(E 2)$ \\
\hline & & & & abs & 254) & 9.6 & \\
\hline \multirow[t]{3}{*}{${ }^{93} \mathrm{Cu}$} & 0.000 & $3^{-}$ & & & & & \\
\hline & 1.414 & $2^{-}$ & $?$ & 1.6 & 30 & $(1.1-1.7) \Gamma / \Gamma_{0}$ & \\
\hline & 1.551 & $3-$ & $?$ & 1.7 & 37 & $(1.7-2.5) \Gamma / \Gamma_{0}$ & $\left.0.1(E 2)^{e}\right)$ \\
\hline \multirow[t]{3}{*}{${ }^{\prime \prime G a}$} & 0.000 & $3^{-}$ & & & & & \\
\hline & 0.872 & $\left(3^{-}\right)$ & 0.95 & 1.1 & 35 & $0.8 / W$ & \\
\hline & 1.107 & $(?-)$ & 0.95 & 8.0 & 20 & $8.4 / W$ & \\
\hline \multirow[t]{4}{*}{ "3As } & 0.000 & $i^{-}$ & & & & & \\
\hline & 0.86 & $?$ & $?$ & 1.7 & 20 & $1.7 \Gamma / g W \Gamma_{0}$ & \\
\hline & 1.07 & $?$ & ? & 2.6 & 30 & $2.6 \Gamma / g W \Gamma_{0}$ & \\
\hline & 1.35 & $?$ & $?$ & 3.6 & 20 & $3.6 \Gamma / g W \Gamma_{0}$ & \\
\hline \multirow[t]{3}{*}{ "Y } & 0.000 & $\div-$ & & & & & \\
\hline & 1.51 & $2^{-}$ & $(1.0)$ & $522)$ & 30 & 28 & $\left.0.37\left(E_{2}\right)^{t}\right)$ \\
\hline & & & & abs •) & 15 & 22 & \\
\hline
\end{tabular}

a) Measured with Nal.

o) Ref. $\left.{ }^{2}\right)$.

c) Measured with a $\mathrm{Ge}(\mathrm{Li})$ detector to $\pm 10 \%$.

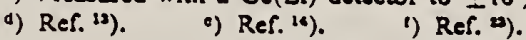

${ }^{13}$ D.G. Alkhazov, K.I. Erokhina and I.K. Lemberg, Izv.Akad.Nauk.SSSR

(ser.fiz.) 28 (1964) 1667.

${ }^{23}$ G.A. Peterson and J. Alster, Phys. Rev. 166 (1968) 136.

${ }^{24}$ N. Nath, M.A. Rothman, D.M. Van Patter and C.E. Mandeville,

Nucl. Phys. 13 (1959) 74 . 
TABLE 3

Information on the $1.414,1.551$ and $1.862 \mathrm{MeV}$ states in " $\mathrm{Cu}$

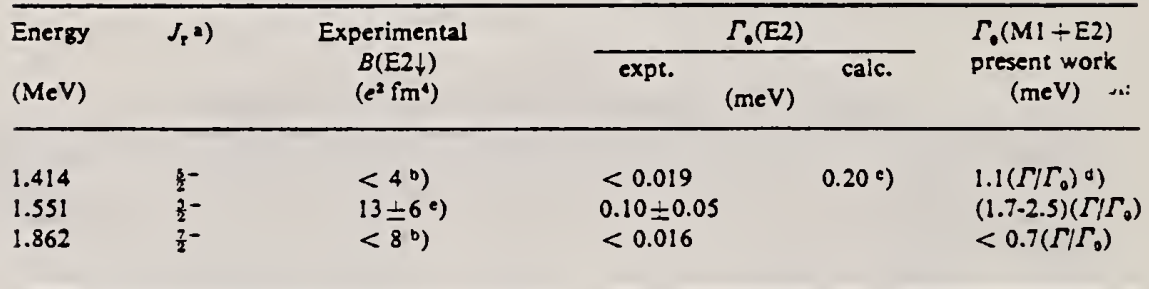

2) Ref. ${ }^{20}$ ).

b) Ref. ${ }^{17}$ ); the upper limits quoced here were not published later by Gove.

c) Based upon the value $B(E 2 !)(1.17)$ for ${ }^{3} \mathrm{Ni}$ of $1.7 \times 10^{-60} \mathrm{e}^{2} \mathrm{~cm}^{4}$; sec ref. $\left.{ }^{10}\right)$.

d) A pure M1 transition is assumed; see discussion in text.

') Ref. ").

14.B.G. Harvey, J.R. Meriwether and A. Bussiere, Nuc1. Phys. 70 (1965) 305.

17 H.E. Gove, Nuc1. Instr. 28 (1964) 180.

${ }^{19}$ Nuclear Data Al (1966) no. $1 ;$ Bl (196́) no.6́.

${ }^{25} \mathrm{D}$. Bachner et al., Nucl. Phys. A99 (1967) 487. 


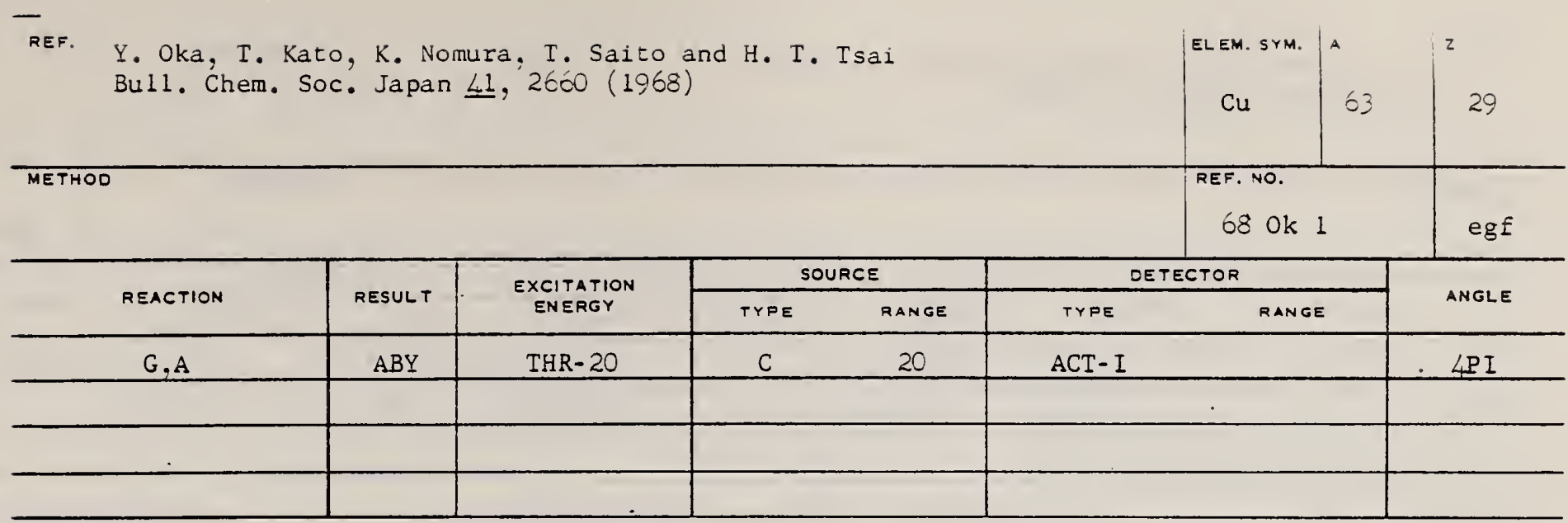

TABLZ 1. SUMMARY OE D̈̈TA ON $(r, a)$ RZACTIONS WTTH $20 \mathrm{MeV}$ BREXSSTRAHLITO

\begin{tabular}{|c|c|c|c|c|c|c|c|}
\hline \multicolumn{2}{|c|}{ Nuclide } & \multirow[b]{2}{*}{$\left(-Q^{E_{(n)}} \mathrm{MeV}\right)$} & \multicolumn{3}{|c|}{ Observed gamma-ray } & \multicolumn{2}{|c|}{ Results obtained } \\
\hline $\begin{array}{c}\text { Parent } \\
\text { (Nitural } \\
\text { abundance, \%) }\end{array}$ & $\begin{array}{l}\text { l'roduct } \\
\text { (Hlalf-life) }\end{array}$ & & $\begin{array}{l}\text { Energy } \\
\text { (MeV) }\end{array}$ & $\begin{array}{l}\text { Branching } \\
\text { ratio }(\%)\end{array}$ & $\begin{array}{l}\text { Type of } \\
\text { multipole } \\
\text { transition }\end{array}$ & $\mu\left(\mathrm{Ci} / \mathrm{mg}^{n}\right)$ & $\begin{array}{c}\text { Yirlil } \\
\left(\mathrm{mol}^{-1} \cdot k-1\right)\end{array}$ \\
\hline siv $(99.75)$ & ${ }^{47} \mathrm{Sc}(3.4 d)$ & 10.27 & 0.160 & 100 & $M H+E 2$ & $1.99 \times 10^{-3}$ & $2.8 \times 10^{3}$ \\
\hline${ }^{\circ} \mathrm{Cu}(30.9)$ & ${ }^{1} \mathrm{Co}(99 \mathrm{~min})$ & 6.75 & 0.068 & 39 & $M I+E 2$ & $7.23 \times 10^{-3}$ & $9.7 \times 10^{3}$ \\
\hline${ }^{n G a(39.6)}$ & ${ }^{67} \mathrm{Cu}(6 \mathrm{ihr})$ & 3.15 & 0.184 & 41 & $M I$ & $2.70 \times 10^{-3}$ & $9.6 \times 10^{3}$ \\
\hline${ }^{n} \mathrm{Ge}(7.67)$ & $\cos \mathrm{Zn}(1+\mathrm{hr})$ & 5.89 & 0.435 & 100 & $M 4$ & $1.11 \times 10^{-2}$ & $3.0 \times 10^{3}$ \\
\hline$" B r(49.48)$ & $" \lambda s(39 \mathrm{hr})$ & 6.46 & 0.246 & 2.81 & $M I+E 2$ & $1.97 \times 10^{-0}$ & $4.3 \times 102$ \\
\hline $100 A_{g}(48.65)$ & ${ }^{100} \mathrm{Rh}(36 \mathrm{hr})$ & 3.28 & $0.319+0.306$ & 24.8 & $M 1+E 2$ & $8.29 \times 10^{-4}$ & $3.7 \times 10^{1}$ \\
\hline $113 \ln (95.77)$ & $" 1 \mathrm{Ag}(7.6 \mathrm{~d})$ & 3.78 & 0.340 & 6 & $M 1+E 2$ & $5.70 \times 10^{-5}$ & $4.3 \times 10^{1}$ \\
\hline
\end{tabular}

a) The value corrected at the end of $: \mathrm{hr}$ irradiation $\left(9.4 \times 10^{3} \mathrm{R} / \mathrm{min}\right)$.

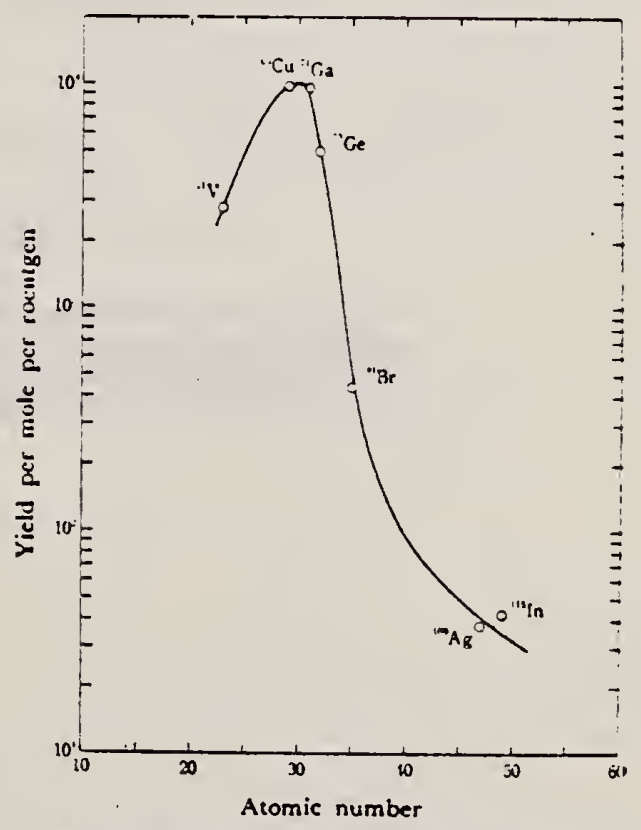

Fig. 1. The yieid curve for $(r, a)$ reaction with $20 \mathrm{MeV}$ bremsstrahiung. 


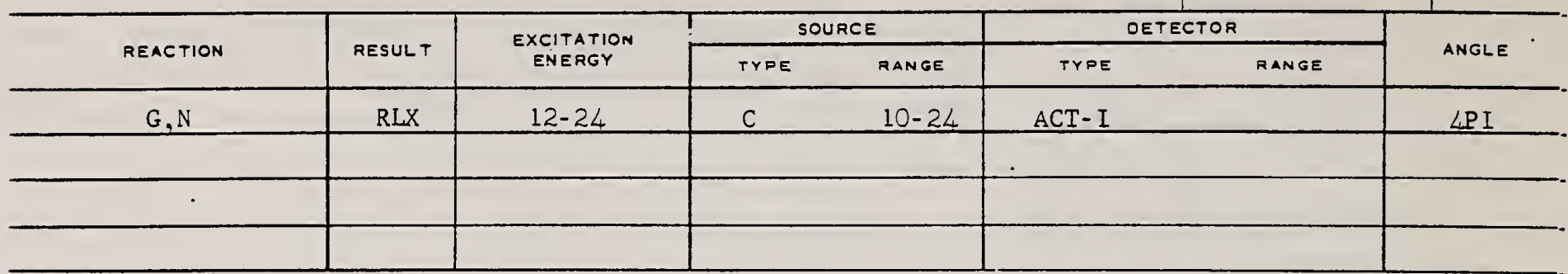

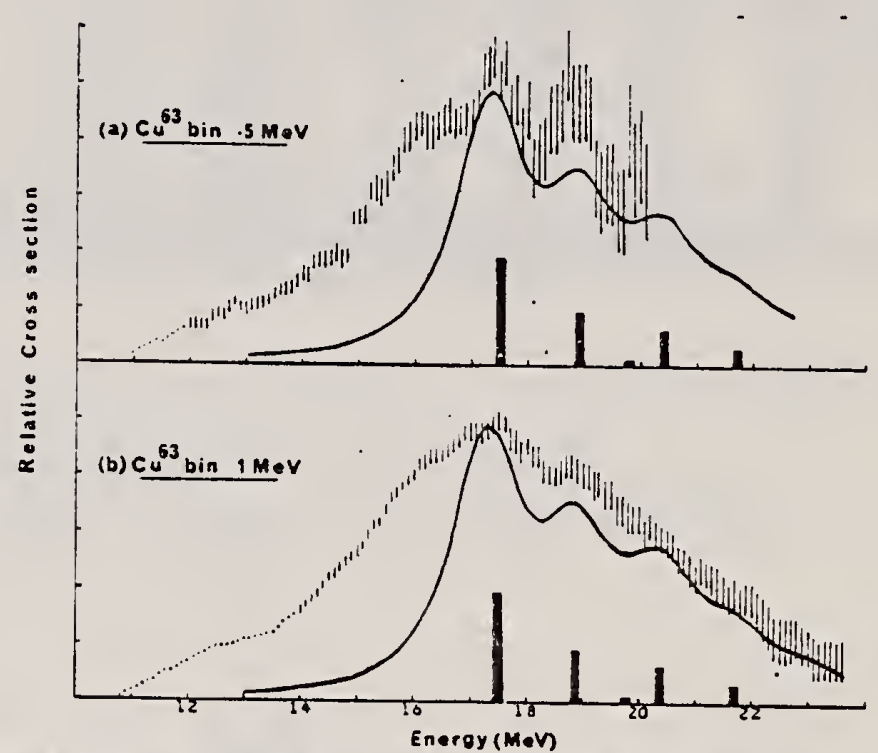

Fig. 2. The ${ }^{\circ 3} \mathrm{Cu}(\gamma, n){ }^{02} \mathrm{Cu}$ cross section analysed in (a) 0.5 and (b) $1 \mathrm{MeV}$ bins. The errors shown represent the total experimental uncertainty for each point. The continuous curve is the shape of the "Ni photo-absorption cross section predicted by Huber ") using the parameters in table I displaced by $1.5 \mathrm{MeV}$ to a lower energy. The vertical bars represent the relative strengths of the individual shifted theoretical levels. 
J. C. Ritter, R. E. Larson and J. I. Hoover

Nuc1. Phys. A110, 463 (1968)

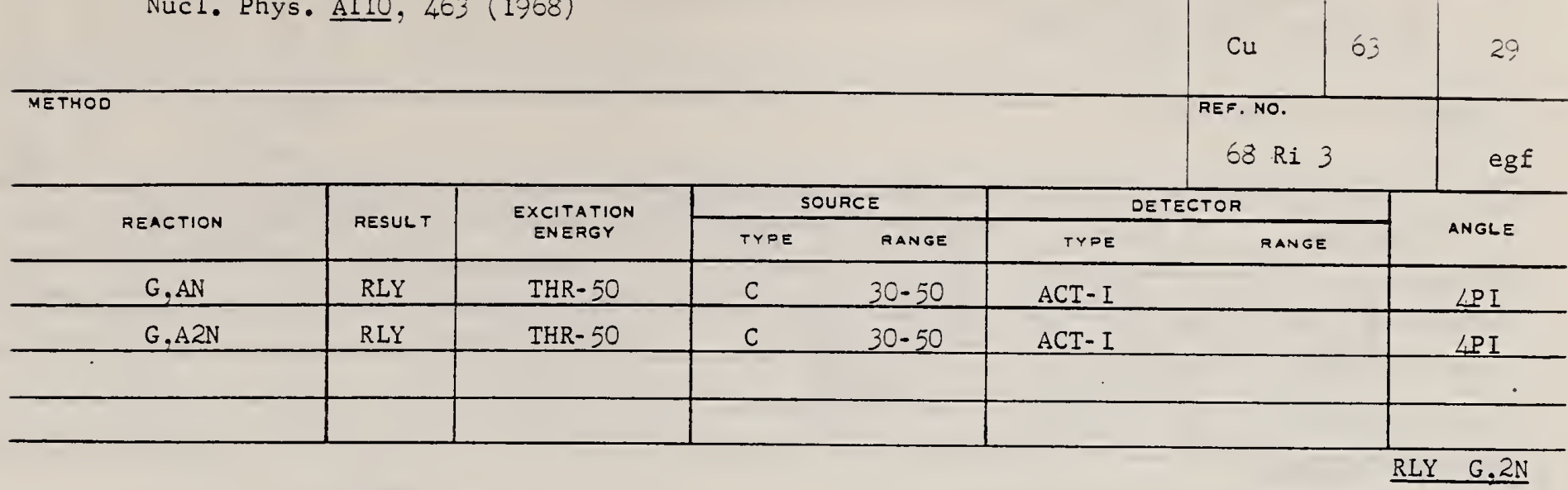

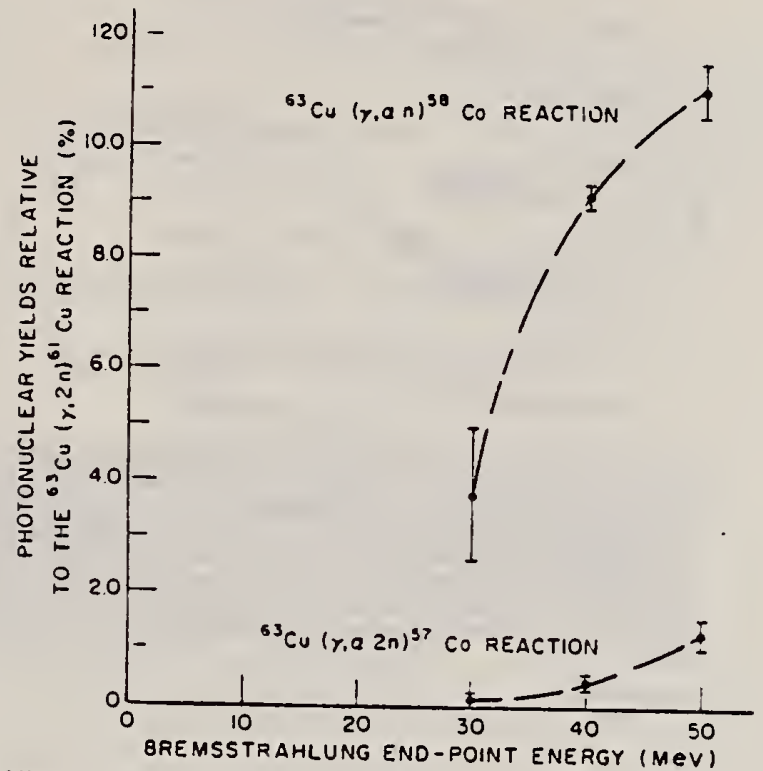

Fig. 1. Yiclds of the $(\gamma, \alpha n)$ and $(\gamma, \alpha 2 n)$ reactions relative to the $(\gamma, 2 n)$ reaction on ${ }^{3} \mathrm{Cu}$ 


\begin{tabular}{|c|c|c|c|c|c|c|c|c|}
\hline \multirow{2}{*}{\multicolumn{2}{|c|}{ REACTION }} & \multirow{2}{*}{ RESULT } & \multirow{2}{*}{$\begin{array}{l}\text { EXCITATION } \\
\text { ENERGY }\end{array}$} & \multicolumn{2}{|c|}{ SOURCE } & \multicolumn{2}{|c|}{ DETECTOR } & \multirow{2}{*}{ ANGLE } \\
\hline & & & & TYPE & RANGE & TYPE & RANGE & \\
\hline$G, N$ & 420 & $A B X$ & THR-25 & $D$ & $10-25$ & $\mathrm{ACT}-\mathrm{I}$ & & $\angle P I$ \\
\hline \multirow[t]{3}{*}{ G.2N } & $421+$ & $A B X$ & THR-26 & $D$ & $10-26$ & $\mathrm{ACT}-\mathrm{I}$ & & $\angle P I$ \\
\hline & & & $(25.7)$ & & & & & \\
\hline & & & & & & & & \\
\hline
\end{tabular}

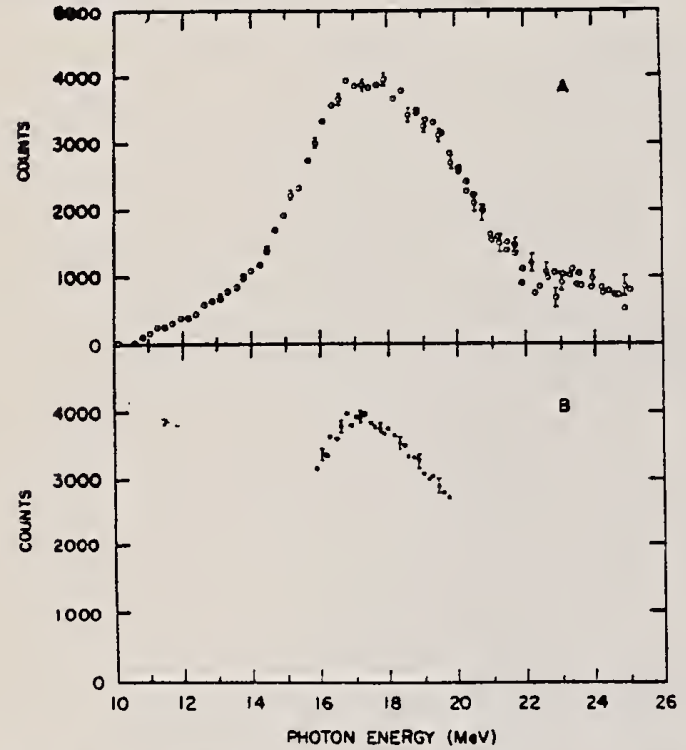

FrG. 8. (A) The ${ }^{a} \mathrm{Cu}(\gamma, n)$ yield versus annihilation $\gamma$-ray energy for $2 \% \gamma$-ray resolution. This yield is the difference between the positron and electron data shown in Fig. 7 . (B) The ${ }^{*} \mathrm{Cu}(\gamma, n)$ yield versus annihilation $\gamma$-ray energy for $1.5 \% \gamma$-ray resolution. These data were approximately normalized to the data in Fig. 8(A).

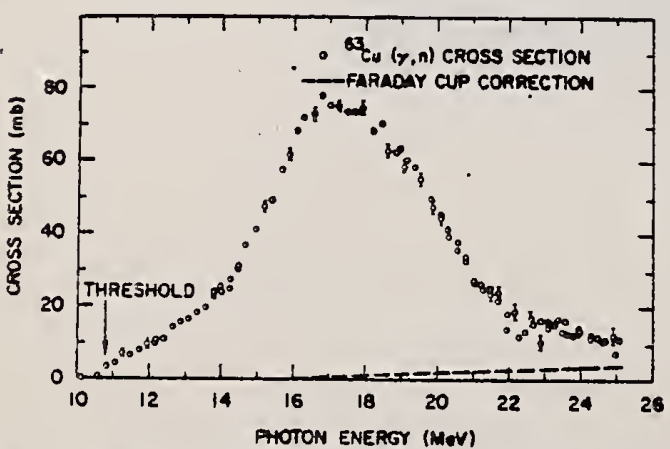

Fig. 9. The " $\mathrm{Cu}(\gamma, n)$ cross section versus photon energy for $2 \%$-ray resolution. The data shown were corrected for the emission of secondary electrons from the Faraday cup, and the magnitude of this correction is also shown. See text for discussion of errors.

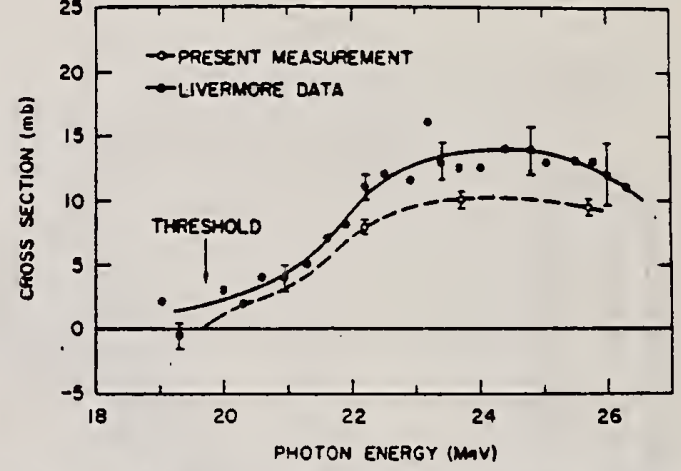

Fig. 12. The " $\mathrm{Cu}(\gamma, 2 n)$ cross section from the present measurement and from the measurement by Fultz $a$ al. at Livermore (Ref. 5). The latter data were shifted upward in energy by $2.7 \%$ as explained in the caption of Fig. 11. The error bars include only the statistical uncertainties in the yield measurements. See text for a discussion of the errors. The dashed curve through the present data was used in the integration and is drawn on the basis of the datz points, the threshold energy, and the shape of the Livermore idate.

Table I. $=\dot{C u}(\gamma, 2 n)$ cross sections. See text for a discussion of errors.

\begin{tabular}{cc}
\hline \hline$\gamma$-ray energy (MeV) & Cross section (mb) \\
\hline 22.2 & $8.0 \pm 0.5$ \\
23.7 & $10.0 \pm 0.5$ \\
25.7 & $9.3 \pm 0.5$ \\
\hline
\end{tabular}

TABLE II. Integrated photoreaction cross sections of ${ }^{a} \mathrm{Cu}$ up to $25 \mathrm{MeV}$.

\begin{tabular}{lccc}
\hline \hline Experiment & Reaction & $\begin{array}{c}\text { Integrated cross } \\
\text { section }(\mathrm{MeV} \mathrm{mb})\end{array}$ & $\begin{array}{c}\text { Total } \\
(\mathrm{MeV} \text { mb) }\end{array}$ \\
\hline Present & $(\gamma, n)$ & $490 \pm 40$ & \\
& $(\gamma, 2 n)$ & $36 \pm 12^{\circ}$ & \\
Fults et ab. & $(\gamma, n)+(\gamma, p n)$ & $60 \pm 15^{\circ}$ & $586 \pm 67$ \\
& $(\gamma, 2 n)$ & $515 \pm 52^{\circ}$ & $560 \pm 57$ \\
\hline \hline
\end{tabular}

- Based on the dached curve in Fls. 12.

- Derived from $(\gamma, n)$ dacs of present work and $[(y, n)+(y, p, x)]$ data $o f$ Fultzet al. (Ref. S). inear data (Ret. S) anifted by the factor $\mathbf{1 . 0 2 7}$. Without

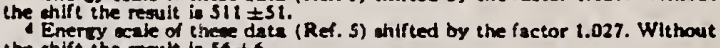
the thift the rewit in $56 \pm 6$. 


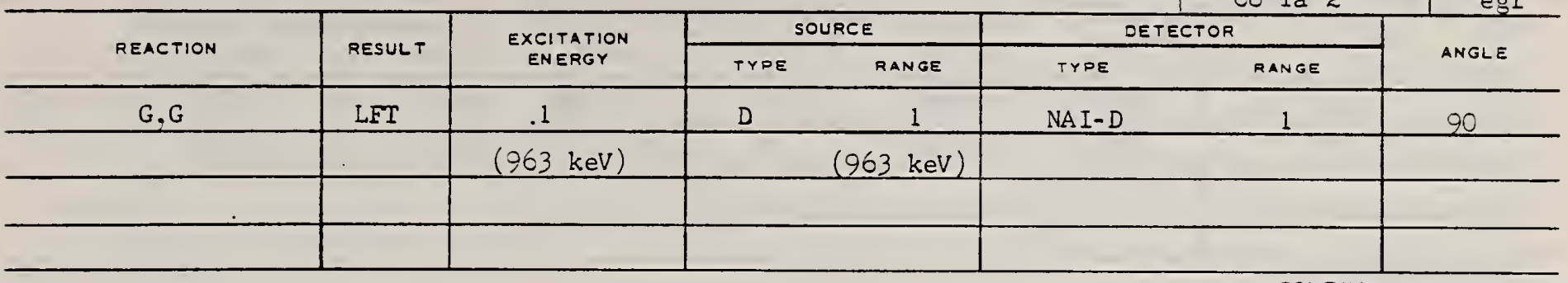

TABLE 1

Lifetime measurements.

\begin{tabular}{ccc}
\hline Line & Mean life $\left(10^{-14} \mathrm{sec}\right)$ & \multicolumn{1}{c}{ Investigator } \\
\hline & $963-\mathrm{keV}$ level in ${ }^{83} \mathrm{Cu}$ & Avg. of ref. 18--30) \\
2 & $91 \pm 6$ & This measurement \\
& $110 \pm 16$ & Avg. of ref. ${ }^{23.24)}$ \\
3 & $963-\mathrm{keV}$ level in ${ }^{25: S m}$ \\
4 & $4.3 \pm 0.3$ & This measurement \\
5 & $7.1 \pm 2.1$ & From I and 3 \\
5 & $21 \pm 2$ & This measurement \\
6 & $16 \pm 5$ & \\
\hline
\end{tabular}

18) J. B. Cumming, A. Schwarzschild, A. W. Sunyar and X: Porile, Phys. Rev. 120 (1960) 2128.

19) T. Rothem, F. R. Metzger and C. P. Swann, Nucl. Physi: (1961) 505 .

20) M. A. Eswaran, H. E. Gove, A. E. Litherland and C. Browis Phys. Letters 8 (1964) 52.

21) 1. Marklund, Nucl. Physics 9 (1958) 83.

22) L. Grodzins, Phys. Rev. 109 (1958) 1014.

23) G. G. Shute and B. S. Sood, Proc. Roy. Soc. (London) A:r (i960) 52.

21) F. R. Metzger, Phys. Rev. 137 (1965) B1415.
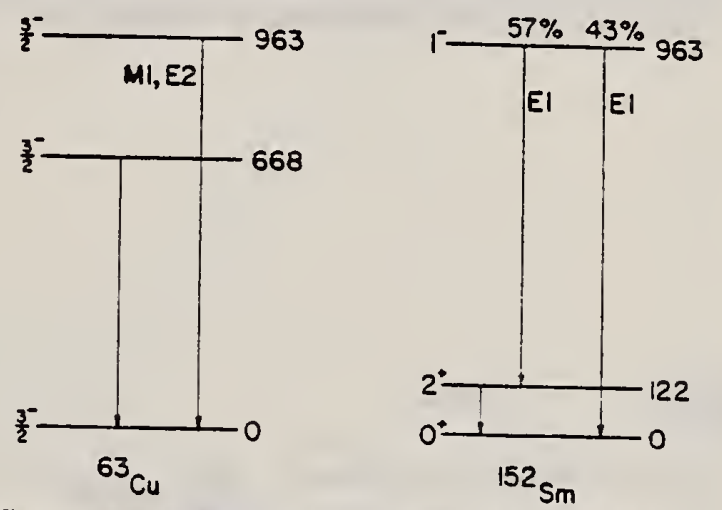

Fig. 11. Level schemes of ${ }^{13} \mathrm{Cu}$ and ${ }^{152} \mathrm{Sm}$ below $1000 \mathrm{keV}$. All crergies are in $\mathrm{keV}$. 
Yu. P. Antuf'ev, V. L. Agranovich. V. B. Ganenko, V. S. Kuzmenko, I. I. Miroshnichenko, and P. V. Sorokin

Ukr. Fiz. Zh. 14, 248 (1969)

Sum mary

The cross-sections of the $(\gamma, \mathrm{p})(\gamma, d)$ reactions were investigated. $\mathrm{Li}^{7}, \mathrm{Be}^{0}, \mathrm{Cl}^{12}, \mathrm{Si}^{2 *}$. $\mathrm{Cu}^{\circ}$. Mos and $\mathrm{Ta}^{1 \mathrm{sis}}$ targets were irradiated with the bremsstrahlung of 700 and $1200 \mathrm{MeV}$ maximum energy from the Kharkov PhTI Ac. Sci. UkrSSR linear accelerator. The photopsotons and deuterons were detected by the scintillation telescope at $30^{\circ}, 60^{\circ}$, and $120^{\circ}$ with the beam. Possible mechanisms of the proton and deuteron photoproduction are dis. cussed. The qualitative agreement of $A$ dependence of the cross-sections is observed with a suggestion on the meson mechanism for these reactions.
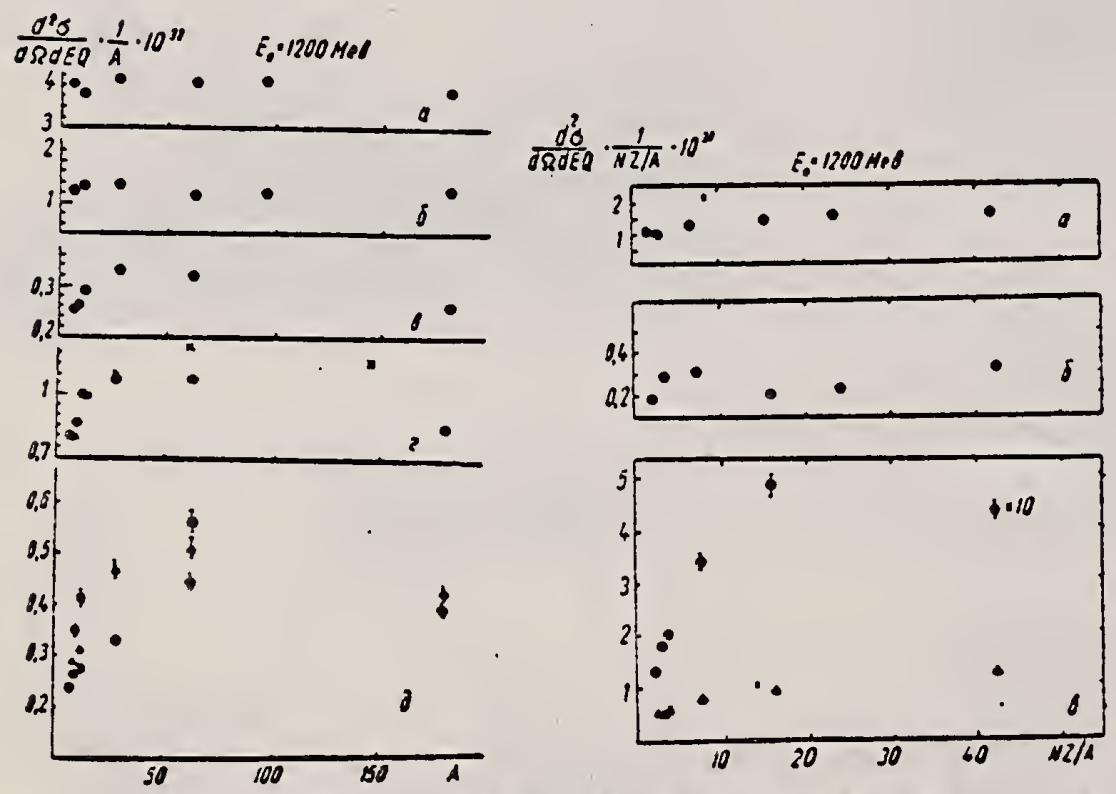

Рис. 1. Залежність перерізу ( $\gamma, p)$-реакuі від $A: a-\theta-30^{\circ}, \varepsilon_{p}=97$ Mea; $6-E_{p}=$ -205 Mes; $\theta-\theta=60^{\circ}, E,=230$ Meo; $z-E,-157$ Meө $\left(X-\right.$ дані [3]); $\partial-\theta=120^{\circ}$. $0-E_{p}=120$ Мes, $\Delta-E,=157$ Меo, $-E_{p}=230$ Мев. Абсолютне значення перерізу наведено прн енергї лротонів $E_{z}=120$ Меo. Інші дані нормовані до перерізу для $\mathrm{Li}^{7}$ прн $\varepsilon_{p}=120$ Мев.

Рнс. 2. Залежність перерізу ( $\gamma, d$ )-реакціi від $N Z / A: a-\theta=30^{\circ}, E_{d}=97$ Мев; $6-\theta=$ $=30^{\circ}, E_{d}=205$ Мes; $\theta: \Delta-\theta_{0}=60^{\circ}, E_{d}=97$ Мев, $O-\theta=120^{\circ}, E_{d}=97$ Мев (перерізи

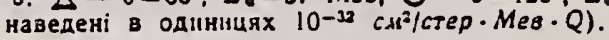


Rer. R. B. Begzhanov and S. M. ikhrarov

ZhETF Pis. Red. 10, 39 (1969)

JETP Letters 10, 26 (1909)

\begin{tabular}{|c|c|c|c|c|c|c|c|}
\hline METHOD & & & & & & $\begin{array}{l}\text { REF. NO. } \\
69 \mathrm{Be} 7\end{array}$ & hmg \\
\hline \multirow{2}{*}{ REACTION } & \multirow{2}{*}{ RESUL T } & \multirow{2}{*}{$\begin{array}{l}\text { EXCITATION } \\
\text { ENERGY }\end{array}$} & \multicolumn{2}{|c|}{ SOURCE } & \multicolumn{2}{|c|}{ OETECTOR } & \multirow{2}{*}{ ANGLE } \\
\hline & & & TYPE & RANGE & TYPE & RANGE & \\
\hline \multirow[t]{2}{*}{$G, G$} & LFT & 6,8 & $\mathrm{D}$ & 6,8 & D & & DST \\
\hline & & & & & & & $(90,135)$ \\
\hline & & & & & - & & \\
\hline & & & & & & & \\
\hline
\end{tabular}

Self-Absorption.

Results of determination of the resonance-level parameters

\begin{tabular}{|c|c|c|c|c|c|c|}
\hline & $\begin{array}{l}\text { Source- } \\
\text { otterer }\end{array}$ & ${ }_{\text {KeV }}^{E_{1}}$ & $\begin{array}{c}<\sigma_{p p}>\text {. } \\
m b\end{array}$ & $\begin{array}{l}\Gamma_{y_{0}} \\
\mathrm{ev}^{\prime}\end{array}$ & $\begin{array}{l}D, \\
\mathrm{keV}\end{array}$ & Reference \\
\hline Pb & - $20^{64}$ & 7.38 & $33 \pm 4.5$ & $0.59 \div 0.12$ & $53.70 \pm 0.13$ & This work \\
\hline$\pi$ & - 11096 & 5.413 & $11.2 \pm 1.4$ & $0.11=0.02$ & $8.58 \pm 1.57$ & $"$ \\
\hline $\mathrm{Ti}$ & - La 139 & 5.413 & $1504 \pm 2.10$ & $0.29 \pm 0.05$ & $8.93 \pm 1.42$ & 11 \\
\hline & - Bi 209 & 7.15 & $1200 \pm 230$ & $0.32 \pm 0.07$ & $1.84=0,40$ & $"$ \\
\hline & & 5.996 & 1550 & - & - & [1] \\
\hline & & 7.15 & $2600 \pm 800$ & $0.42 \pm 0.14$ & - & [.3] \\
\hline & $-\mathrm{Cu}_{3}^{65}$ & 6.07 & $423 \pm 103$ & $0.34 \pm 0.06$ & $99.1 \pm 17.4$ & This work \\
\hline & & 5.07 & $440 \pm 130$ & $0.35 \pm 0.07$ & & [5] \\
\hline & $-\mathrm{Cu}_{4}^{63}$ & 6.07 & $21.5 \pm 71$ & $0.13 \pm 0.04$ & $57.14 \pm 12.7 \pi$ & This work \\
\hline & & 6.07 & $200 \pm 50$ & $0.15 \pm 0.03$ & - & [f] \\
\hline & & 8.50 & $22 \pm 7$ & $0.25 \pm 0.08$ & $13 n \pm 40$ & This work \\
\hline \multirow[t]{2}{*}{$\mathrm{C}$} & $-\mathrm{Cu}^{63}$ & 8.439 & 35 & 75 & - & [1] \\
\hline & & 1.50 & $19 \pm 6$ & $0.23 \pm 0.09$ & - & $\lfloor 5\rfloor$ \\
\hline & $-\mathrm{Ca}^{65}$ & $\begin{array}{l}8.50 \\
8.499\end{array}$ & $\begin{array}{c}36 \pm 9 \\
80\end{array}$ & $\begin{array}{c}0.47 \pm 0.10 \\
10.5\end{array}$ & $\begin{array}{c}21.36 \pm 4.54 \\
-\end{array}$ & $\begin{array}{c}\text { This work } \\
\text { (1) }\end{array}$ \\
\hline & & 8.50 & $42=13$ & $0.94 \pm 0.29$ & - & [द] \\
\hline & & 7.01 & $1150=240$ & $0.1 \dot{15} \pm 0.04$ & $0.44 \pm 0.12$ & This work \\
\hline \multirow[t]{2}{*}{$\mathrm{Cu}$} & $-S_{D} 1$ & 7.01 & 1000 & - & - & (1) \\
\hline & & 7.01 & $1200 \pm 460$ & $0.3 \pm 0.3$ & - & [.] \\
\hline$H_{g}$ & $-\mathrm{Mo}_{0} 96$ & 6.\$4 & $201 \pm 37$ & $0.12 \pm 0.04$ & $|023 \pm 3.07|$ & This work \\
\hline
\end{tabular}


$72 \mathrm{Dr} 2$

\begin{tabular}{|c|c|c|c|c|c|c|c|}
\hline \multirow{2}{*}{ REACTION } & \multirow{2}{*}{ RESULT } & \multirow{2}{*}{$\begin{array}{l}\text { EXCITATION } \\
\text { ENERGY }\end{array}$} & \multicolumn{2}{|c|}{ SOURCE } & \multicolumn{2}{|c|}{ DETECTOR } & \multirow{2}{*}{ ANGLE } \\
\hline & & & TYPE & RANGE & TYPE & RANGE & \\
\hline $\mathrm{G}, \mathrm{N}$ & $\mathrm{ABX}$ & $11-26$ & $\mathrm{C}$ & $11-26$ & $\mathrm{ACT}-1$ & & $4 \mathrm{PI}$ \\
\hline & . & & & & & & \\
\hline & & & &. & & & \\
\hline
\end{tabular}
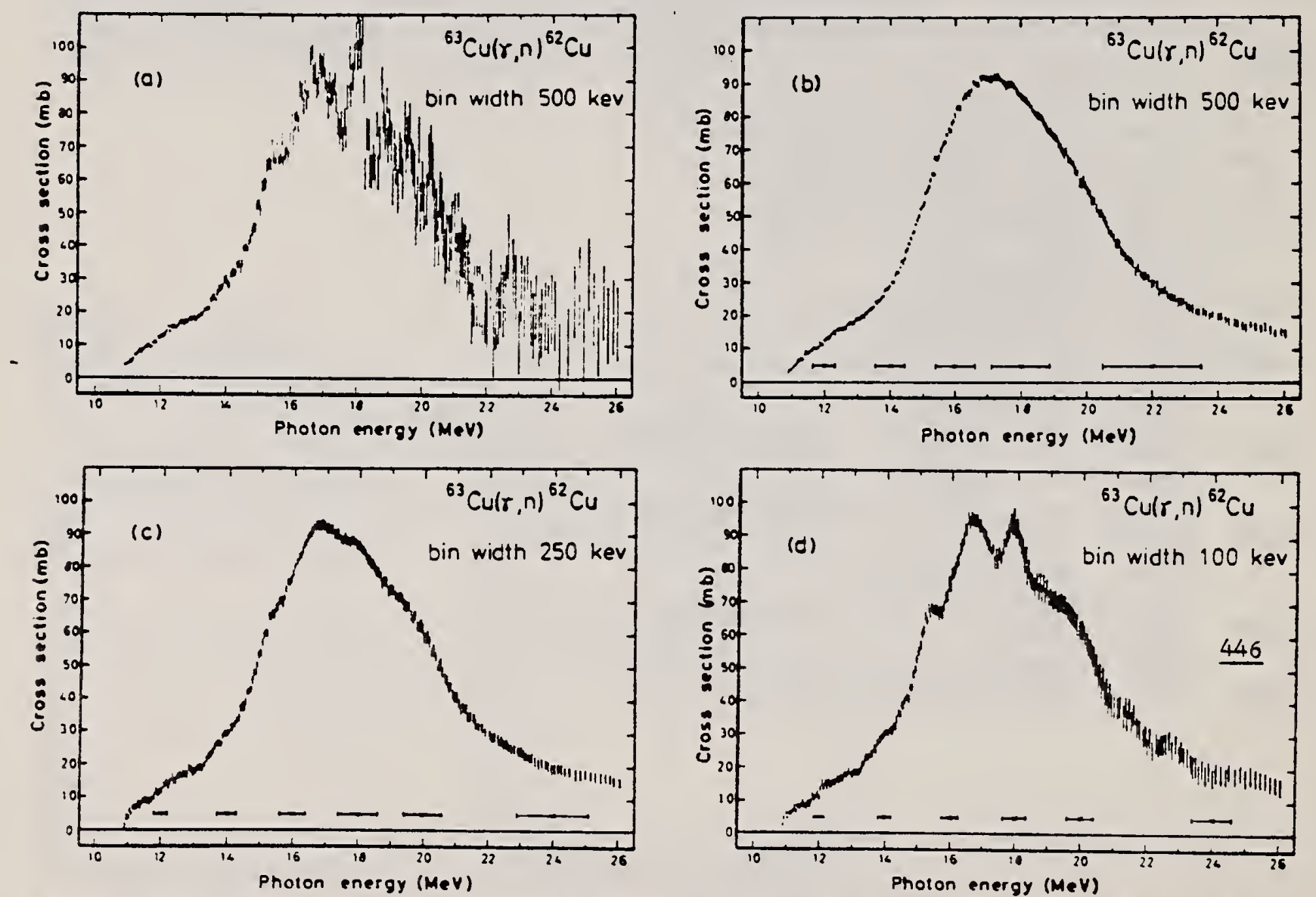

Fig. 2. Cross section for ${ }^{\circ 3} \mathrm{Cu}(\because, n)^{\circ 2} \mathrm{Cu}$ from threshold energy $1026 \mathrm{MeV}$. (a) shows the cross-section curve obtained with an analysis bin width of $0.5 \mathrm{MeV}$ using the LP method. (b), (c) and (d) show the same cross sectinn calculated from yield data with the analysis bin widths of $500 \mathrm{keV}$, $250 \mathrm{keV}$ and $100 \mathrm{keV}$ using the CLS method. The horizontal bars represent the FWHM of experimental resolution and not the uncertainty in energy. 
Ref. A.A.C. Klaasse, P.F.A. Goudsmit, P.K.A. de Witt Huberts PICNS-72, 425 (1972) Sendai

\begin{tabular}{|c|c|c|}
\hline ELEM. SYM. & $A$ & $z$ \\
\hline $\mathrm{Cu}$ & 63 & 29 \\
\hline \multicolumn{3}{|l|}{ REF. NO. } \\
\hline $72 \mathrm{KI}$ & 7 & hum \\
\hline
\end{tabular}

\begin{tabular}{|c|c|c|c|c|c|c|c|}
\hline \multirow{2}{*}{ REACTION } & \multirow{2}{*}{ RESUL T } & \multirow{2}{*}{$\begin{array}{l}\text { EXCITATION } \\
\text { ENERGY }\end{array}$} & \multicolumn{2}{|c|}{ SOURCE } & \multicolumn{2}{|c|}{ DETECTOR } & \multirow{2}{*}{ ANGLE } \\
\hline & & & TYPE & RANGE & TYPE & RANGE & \\
\hline$E, E /$ & FME & 1 & $D$ & $25-85$ & $M A G-D$ & & DST \\
\hline & & & & & & & \\
\hline & & & & & & & \\
\hline
\end{tabular}

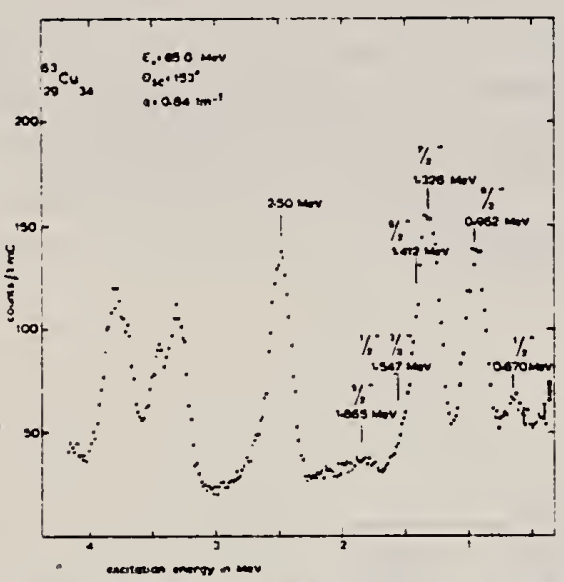

Eig. 12. Spectrum of electrons inelastically scattered by ${ }^{3} \mathrm{Cu}$.

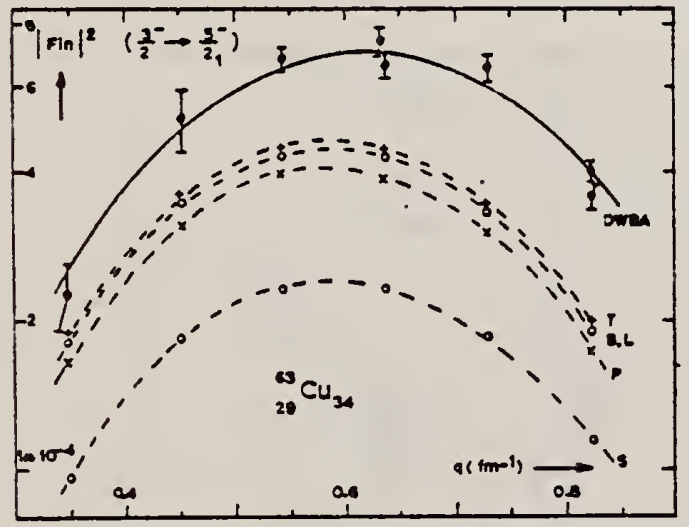

Fig. 13. Experimental and theoretical form factors of the $0.96 \mathrm{MeV}$ excitation in $63 \mathrm{Cu}$. 


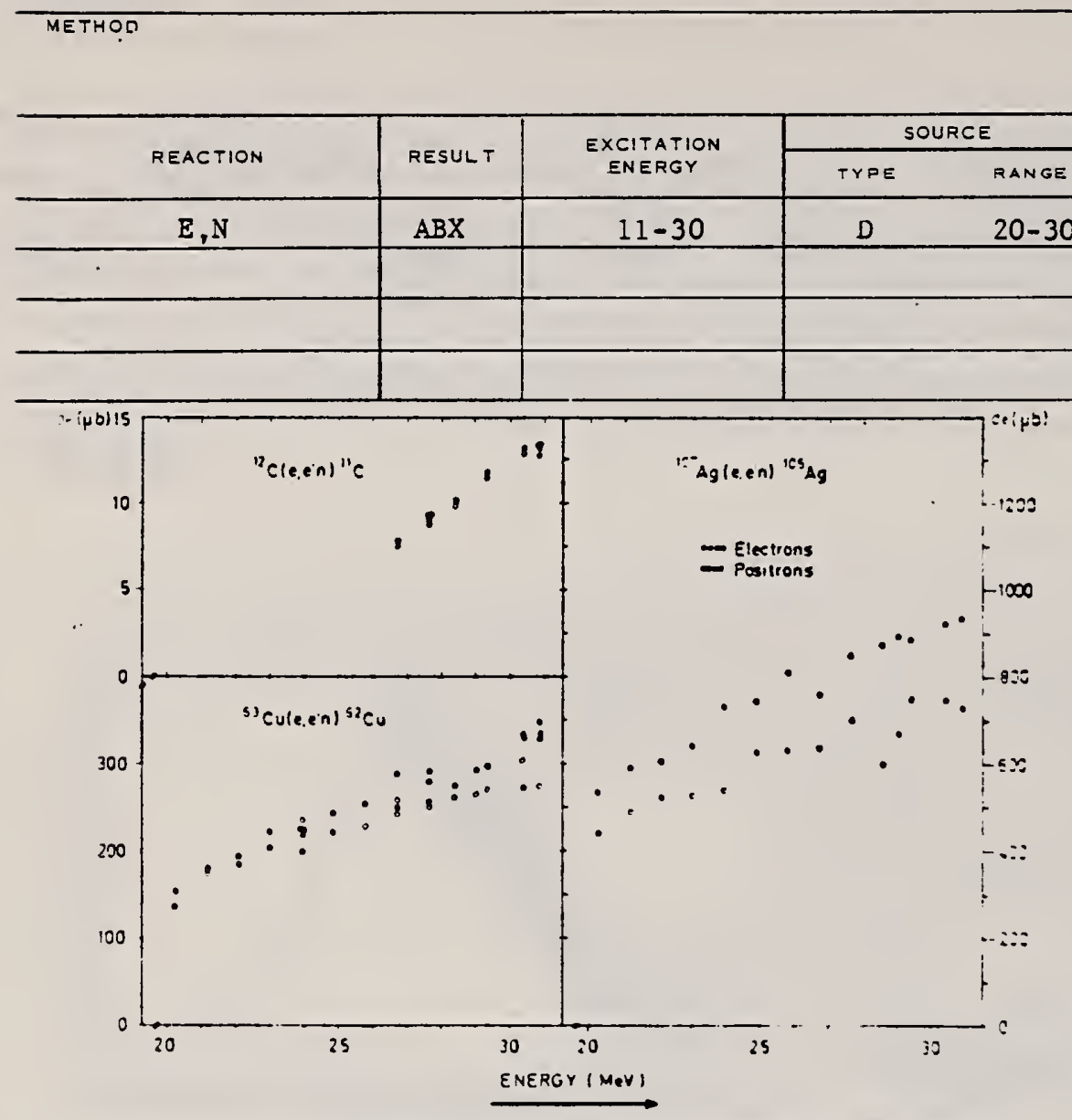

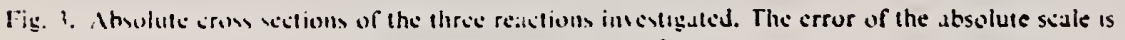
siminilid to the : $88^{\circ}$.

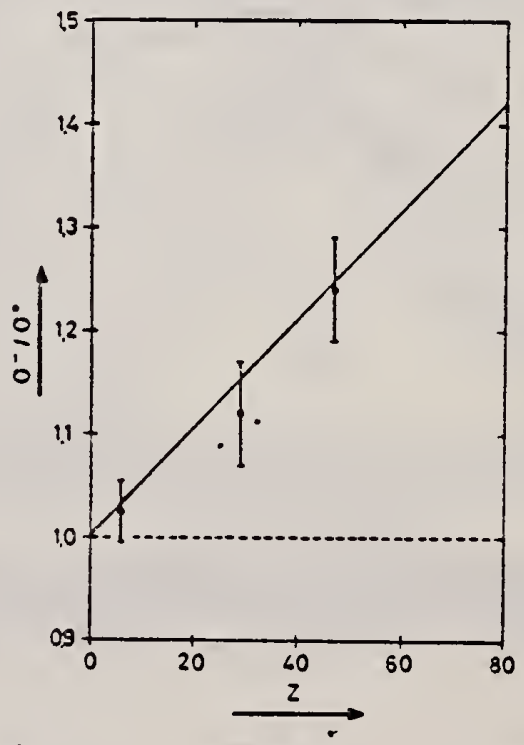

Fig. 4. The measured ratios of $\sigma^{-1} \sigma^{+}$at an energy of $27 \mathrm{MeV}^{2}$ compared with the. straight line given by Herring ef al. ${ }^{\circ}$ ).

FORM N3S-418

[REV. $7-14-64$

USCOMM-DC 26010.264
${ }^{6}$ D. F. Herring, I. C. Nascimento, R.B. Walton and R.E. Sund, 376 PH Phys. Rev. 139 (1965) 562 


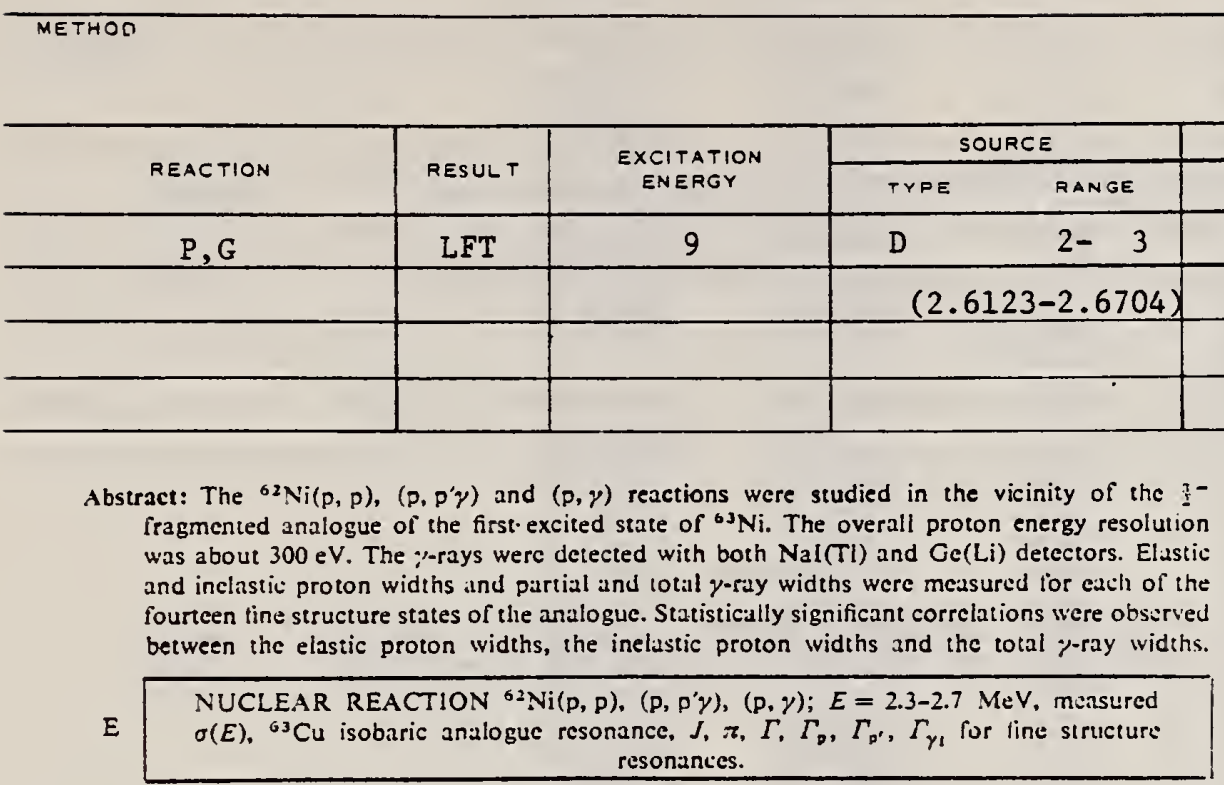

fragmented analogue of the first excited state of ${ }^{6} \mathrm{Ni}$. The overall proton energy resolution the $y$-rays were detected with both $\mathrm{NaI}(\mathrm{Tl})$ and $\mathrm{Ce}(\mathrm{Li})$ detectors. Elustio fourteen tine structure states of the analogue. Statistically significant correlations were observed between the elastic proton widths, the inelastic proton widths and the total j-ray widths. resoninices.

TABLE 3

Partial $y$-ray widths for the 1- analogue state in ${ }^{63} \mathrm{Cu}$

\begin{tabular}{|c|c|c|c|c|c|}
\hline $\begin{array}{c}E_{9} \\
(\mathrm{MeV})\end{array}$ & $\begin{array}{l}\left.\Gamma_{0}{ }^{b}\right) \\
(\mathrm{eV})\end{array}$ & $\begin{array}{c}E_{\mathrm{p}} \\
(\mathrm{k}=\mathrm{V})\end{array}$ & $\begin{array}{c}\left.\Gamma_{,}{ }^{\mathrm{c}}\right) \\
(\mathrm{meV})\end{array}$ & $\begin{array}{l}\text { M1 }{ }^{\text {む) }} \\
\text { (W.u.) }\end{array}$ & $\begin{array}{c}\left.\text { E2 }{ }^{\circ}\right) \\
\text { (w.u.) }\end{array}$ \\
\hline \multirow[t]{3}{*}{2.6123} & 20 & 0 & 83.0 & $0.609 E-02$ & $0.142 E-00$ \\
\hline & & 670 & 15.3 & $0.1+3 E-02$ & $0.393 E-01$ \\
\hline & & 2011 & 30.4 & $0.491 E-02$ & $0.194 E-00$ \\
\hline \multirow[t]{3}{*}{2.6193} & 15 & 0 & 17.3 & $0.127 E-02$ & $0.295 E-01$ \\
\hline & & 670 & 13.9 & $0.130 E-02$ & $0.357 E-0 !$ \\
\hline & & 1411 & 6.9 & $0.859 E-03$ & $0.286 E-01$ \\
\hline \multirow[t]{2}{*}{2.6376} & 10 & 0 & 172.3 & $0.126 E-01$ & $0.291 E-00$ \\
\hline & & 962 & 13.4 & $0.138 E-02$ & $0.405 E-01$ \\
\hline \multirow[t]{2}{*}{2.6335} & $\leq$ & 0 & 11.2 & $0.814 E-03$ & $0.189 E-01$ \\
\hline & & 962 & 15.0 & $0.155 E-02$ & $0.455 E-01$ \\
\hline \multirow[t]{6}{*}{2.6390} & 5 & 0 & 18.1 & $0.132 E-02$ & $0.306 E-01$ \\
\hline & & 962 & 17.1 & $0.183 E-02$ & $0.537 E-01$ \\
\hline & & $15+7$ & 26.2 & $0.343 E-02$ & $0.118 E-00$ \\
\hline & & 1863 & 20.1 & & $0.113 E-00$ \\
\hline & & 2081 & 12.1 & & \\
\hline & & 2092 & 31.7 & & \\
\hline \multirow[t]{5}{*}{$2 .\left(6 \div 66^{2}\right)$} & 15 & 0 & 156.4 & $0.114 E-01$ & $0.263 E-00$ \\
\hline & & 670 & 43.5 & $0.401 E-02$ & $0.109 E-00$ \\
\hline & & 1411 & 19.2 & $0.237 E-02$ & $0.782 E-01$ \\
\hline & & 2062 & 15.6 & & \\
\hline & & 2081 & 26.1 & & \\
\hline
\end{tabular}


TABLE 3 (continued)

\begin{tabular}{|c|c|c|c|c|c|}
\hline $\begin{array}{c}E_{\mathrm{p}} \\
(\mathrm{MeV})\end{array}$ & $\begin{array}{l}\left.\Gamma_{\mathrm{p}} \mathrm{b}\right) \\
(\mathrm{cV})\end{array}$ & $\begin{array}{c}E_{\mathrm{f}} \\
(\mathrm{keV})\end{array}$ & $\begin{array}{c}\left.\Gamma_{y}{ }^{\mathrm{C}}\right) \\
(\mathrm{meV})\end{array}$ & $\begin{array}{l}\left.\text { M1 }{ }^{\circ}\right) \\
\text { (W.u.) }\end{array}$ & $\begin{array}{c}\left.E 2^{d}{ }^{d}\right) \\
\text { (W.u.) }\end{array}$ \\
\hline \multirow[t]{3}{*}{2.6508} & 10 & 0 & 8.6 & $0.522 E-03$ & $0.144 E-01$ \\
\hline & & 962 & 105.5 & $0.109 E-01$ & $0.317 E-00$ \\
\hline & & 1411 & 33.1 & $0.408 \Sigma-02$ & $0.134 E-00$ \\
\hline \multirow[t]{4}{*}{$\left.2.6536^{\circ}\right)$} & 5 & 0 & 23.4 & $0.1 \div 0 E-02$ & $0.392 E-0.1$ \\
\hline & & 670 & 14.3 & $0.132 E-02$ & $0.357 E-01$ \\
\hline & & 962 & 62.5 & $0.643 \vec{E}-02$ & $0.188 E-00$ \\
\hline & & 1547 & 56.3 & $0.73 ! E-02$ & $0.250 E-00$ \\
\hline \multirow[t]{5}{*}{2.6584} & 10 & 0 & 12.4 & $0.89 \Xi E-03$ & $0.207 E-01$ \\
\hline & & 670 & 12.1 & $0.112 E-02$ & $0.303 E-01$ \\
\hline & & 962 & 31.8 & $0.326 E-02$ & $0.951 E-01$ \\
\hline & & 2011 & 16.9 & $0.25: E-G 2$ & $0.104 E-00$ \\
\hline & & 2062 & 19.8 & & \\
\hline \multirow[t]{4}{*}{2.6617} & 40 & 0 & 132.1 & $0.9 \leqslant 4 E-0 ?$ & $0.220 E-00$ \\
\hline & & 962 & 72.1 & $0.739 E-02$ & $0.215 E-00$ \\
\hline & & 1411 & 101.9 & $0.1 \leq \Sigma E-01$ & $0.410 E-00$ \\
\hline & & 1547 & 30.5 & $0.395 E-02$ & $0.13 \leq E-00$ \\
\hline \multirow[t]{5}{*}{2.6631} & 125 & 0 & 97.1 & $0.702 E-02$ & $0.162 E-00$ \\
\hline & & 670 & 62.8 & $0.576 E-02$ & $0.156 E-00$ \\
\hline & & 962 & 120.0 & $0.123 E-01$ & $0.359 E-00$ \\
\hline & & 1411 & 42.2 & $0.517 E-02$ & $0.169 E-00$ \\
\hline & & 1547 & 53.8 & $0.697 E-02$ & $0.238 E-00$ \\
\hline \multirow[t]{3}{*}{2.6664} & 5 & 0 & 11.3 & $0.819 E-03$ & $0.189 E-01$ \\
\hline & & 670 & 10.6 & $0.973 E-03$ & $0.263 E-01$ \\
\hline & & 962 & 17.8 & $0.182 E-02^{\circ}$ & $0.531 E-01$ \\
\hline \multirow[t]{3}{*}{2.6675} & 20 & 0 & 13.3 & $0.961 E-03$ & $0.222 E-01$ \\
\hline & & 670 & 21.2 & $0.195 E-02$ & $0.5 \geq 3 E-01$ \\
\hline & & 962 & 51.3 & $0.525 E-02$ & $0.153 E-\infty 0$ \\
\hline \multirow[t]{4}{*}{2.6704} & 5 & 0 & 77.2 & $0.557 E-02$ & $0.12 S E-\infty$ \\
\hline & & 670 & 9.3 & $0.848 E-03$ & $0.229 E-01$ \\
\hline & & 962 & 7.9 & $0.811 E-03$ & $0.236 E-01$ \\
\hline & & 1547 & 19.7 & $0.254 E-02$ & $0.864 E-01$ \\
\hline
\end{tabular}

2) Resonant energy for resonances which are very close to another resonance observed in the capture excitation function.

b) The j-yalue assignment is tentative for resonances with elastic widths $\leqq 10 \mathrm{eV}$.

c) The estimated uncertainty in the \%-ray widths is $30 \%$ for widths grester than $50 \mathrm{meV}, 50 \%$ for widths between 10 and $50 \mathrm{meV}$, and $100 \%$ for widths less than $10 \mathrm{meV}$. The limit of observ. ability for the $\%$-ray widths is about $5 \mathrm{meV}$.

4) These strengths are calculated assuming that the transition is either pure M1 or E2. If the spin and parity of the final state is unknown, then no entry is shown. 
REF. M. Boivin, Y. Cauchois, Y. Heno, C. Schloesing-Moller, V. Zecevic

C.R. Acad. Sc. Paris 2813, 201 (1975)

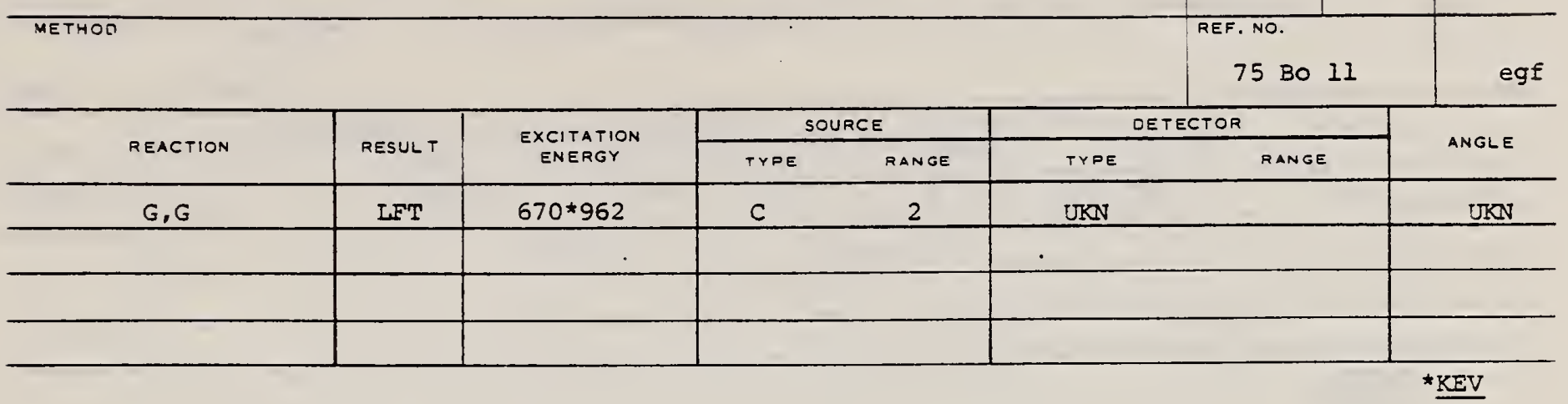

\section{ThaLenu}

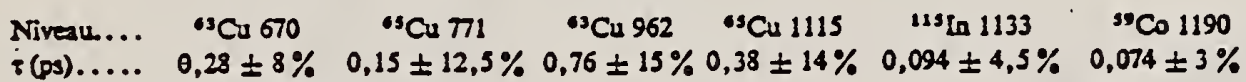


O.E. Kraft, Yu.V. Naumov, S.S. Parzhitskii, I.V. Sizov

Izv. Akad. Nauk SSSR Ser. Fiz. 39, 1268 (1975)

Bull. Acad. Sci. USSR Phys. Ser. 39, 150 (1975)
$\mathrm{Cu}$

$75 \mathrm{Kr} 14$

hmg

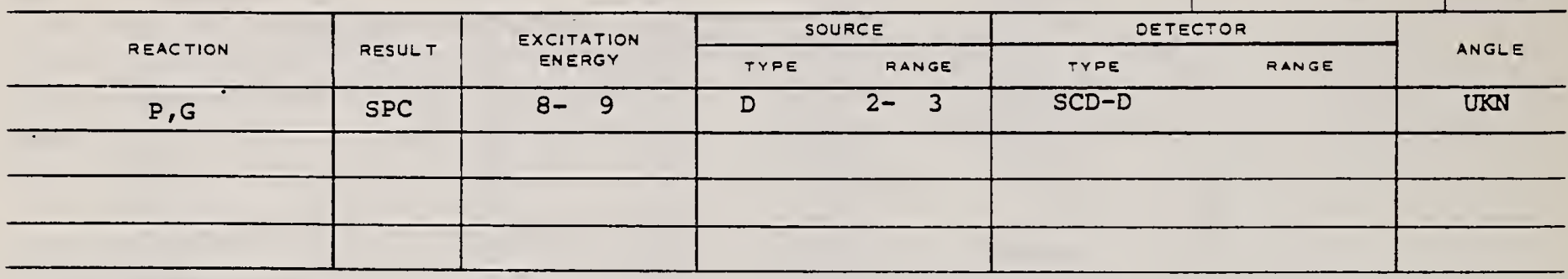

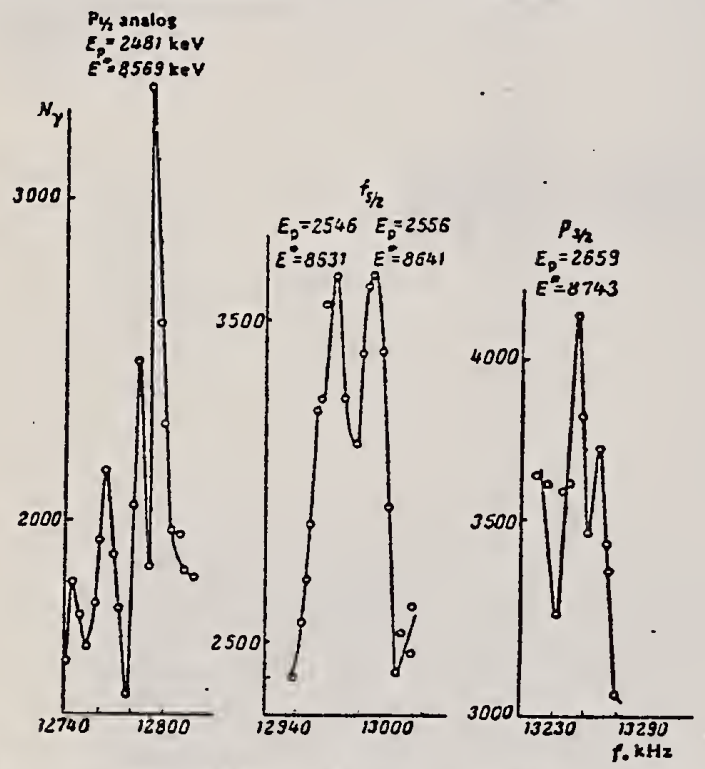

Fig. 1. Excitation function near the $p_{1 / 2}$ $f_{5 / 2}$, and $p_{3 / 2}$ analog states in ${ }^{63} \mathrm{cu}$.
Table 1

\begin{tabular}{|c|c|c|c|c|c|c|c|c|c|}
\hline \multirow{3}{*}{$E_{10}$} & \multirow{3}{*}{$1=$} & \multirow{2}{*}{\multicolumn{2}{|c|}{ 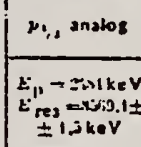 }} & \multicolumn{4}{|c|}{10, , 202103 } & \multirow{2}{*}{\multicolumn{2}{|c|}{$\frac{p_{y_{1}} \text {, } 2 \text { slog }}{E_{p}=3559 \mathrm{keV} .}$}} \\
\hline & & & & \multicolumn{2}{|c|}{ 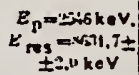 } & \multicolumn{2}{|c|}{ 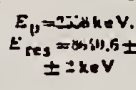 } & & \\
\hline & & $\left|r_{t^{\prime} \cdot 10 .}\right|$ & 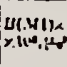 & 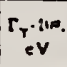 & 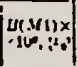 & 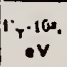 & 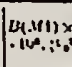 & 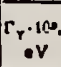 & 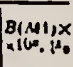 \\
\hline & & 22 & & & & & & & \\
\hline 668,3 & & 11 & $\begin{array}{l}3.0 \\
1.9\end{array}$ & 0.25 & $\mid \begin{array}{ll}0.42 \\
B 2\end{array}$ & 1.6 & 0.01 & $\begin{array}{l}6.0 \\
5.0\end{array}$ & 0,87 \\
\hline 361,6 & $3 \%-$ & 2.6 & $\because 2$ & 2.0 & 0.39 & 2.8 & 0.56 & 7.9 & 1,45 \\
\hline $\begin{array}{l}1410.4 \\
141\end{array}$ & & $5 \overline{5}$ & $\vec{E}: 2$ & 1.1 & $\left|\begin{array}{l}0.24 \\
0.25\end{array}\right|$ & 2.9 & $\begin{array}{l}0.31 \\
0,66\end{array}$ & 4.1 & $\begin{array}{l}7.2 \\
1.0\end{array}$ \\
\hline & - & & 4.3 & 2.3 & 0.55 & 2.6 & 0.63 & 1.8 & 0.41 \\
\hline 201 & $2 y_{3}-1(1 / 2)-$ & 3.7 & $1 . \overline{1}$ & 1.0 & $\left|\begin{array}{l}0.28 \\
0.41\end{array}\right|$ & $0 . \overline{8}$ & $0, \overline{24}$ & $1 . \overline{6}$ & $0 . \overline{45}$ \\
\hline 208 & $\begin{array}{l}1 / 2-(3 /=-) \\
1 / 2-(1 / 7-)\end{array}$ & 7.7 & 2.4 & $=$ & $=$ & 1.1 & $E 2$ & 0.8 & 0.23 \\
\hline 2433 & $1 / 2=-1 / 2-(1 / 1,-)$ & $\overline{1}$ & $=$ & $\overline{-}$ & $=$ & 0.87 & 0.30 & 1.6 & 0.52 \\
\hline 2405 & $\pi$ & $10^{1.9}$ & 0.69 & $=$ & $\bar{z}$ & 15 & $\overline{5.56}$ & $0-5$ & $0-73$ \\
\hline 2233.7 & $3 / 2-(1 / 2-)$ & 0.7 & 0.27 & $=$ & $=$ & 2.2 & $\begin{array}{l}.30 \\
0.83\end{array}$ & 0.9 & 0.32 \\
\hline 2677.5 & $1 / 2-3 / 2-3 / 2-$ & 9.9 & 4.2 & z & - & 0.3 & 0.32 & 1.7 & 0.66 \\
\hline $\begin{array}{l}26 ! \\
27\end{array}$ & $1 / 2=, 3 / 2-,(1 / 2)$ & 3.1 & 2,2 & $\overline{0}$ & $\bar{z}$ & 1.2 & $0 . \overline{51}$ & $\overline{-}$ & 二 \\
\hline 28 & $1 / 2-\overrightarrow{y / n}=: 1-$ & $\overline{-}$ & $=$ & 1.0 & 0.39 & $=$ & $=$ & $2 \overline{4}$ & $\overline{0}$ \\
\hline $\begin{array}{l}28 \\
28\end{array}$ & 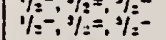 & 3.3 & $1, \overline{6}$ & - & $=$ & 0.7 & $0 . \overline{32}$ & 0,8 & 0.30 \\
\hline $2 ! n$ & & 3.3 & 1.6 & $\overline{-}$ & $=$ & $=$ & $=$ & 1.19 & $\begin{array}{l}0.49 \\
0.40\end{array}$ \\
\hline $3642=3$ & $1 / 2 \div, 1 / 2=3 / 2=$ & $\because 5$ & 10.0 & - & $\overline{-}$ & - & -7 & $\div$ & 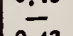 \\
\hline $31(x)=3$ & $i_{1}=3 / 2=3 / 2=$ & 0.21 & 1.8 & & - & 4.0 & 0.10 & 0.1 & 0,3 \\
\hline 34: & - & 4,4 & 2.3 & - & - & 0.9 & 0.46 & $\overline{-}$ & $=$ \\
\hline 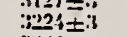 & $\overline{-}$ & 4.8 & $2 \overline{7}$ & & - & 0.9 & 0.49 & 1.6 & 0.82 \\
\hline $\begin{array}{l}324=3 \\
3 \% 2=4\end{array}$ & - & 1.6 & $\begin{array}{l}0.90 \\
3.0\end{array}$ & $\overline{-}$ & $\overline{-}$ & 1,3 & $\begin{array}{l}0.72 \\
0.62\end{array}$ & - & 3 \\
\hline 32 & & 3.5 & 4.5 & 0.7 & 0.40 & 2,5 & 1.42 & 3.8 & 2.0 \\
\hline & & $\begin{array}{l}3.5 \\
4.8\end{array}$ & $\begin{array}{l}2.2 \\
3.0\end{array}$ & $\begin{array}{l}= \\
=\end{array}$ & $\bar{z}$ & $=$ & $=$ & $=$ & $\bar{z}$ \\
\hline & & 3.7 & 2.4 & $=$ & - & $\bar{z}$ & -. & $4 \overline{2}$ & 2.4 \\
\hline & & & & & & 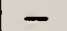 & - & & \\
\hline & & & & $=$ & -- & - & - & 1.6 & 0,78 \\
\hline $\begin{array}{l}36 \\
37\end{array}$ & & $\begin{array}{l}4.4 \\
2.6\end{array}$ & 3.2 & $=$ & $\ddot{z}$ & $\bar{z}$ & --- & $=$ & $\bar{z}$ \\
\hline & & & $\because$ & $=$ & - & - & - & 2.0 & 1.5 \\
\hline & & - & - & $=$ & -- & - & - & $\because$ & $\because \cdots$ \\
\hline 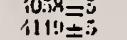 & & & $\bar{z}$ & $\overline{-}$ & $\overline{-}$ & $\because$ & $=$ & $\begin{array}{l}2,2 \\
4.6\end{array}$ & $\begin{array}{l}1.8 \\
4.0\end{array}$ \\
\hline
\end{tabular}

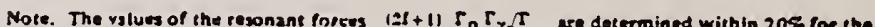
case of a $90^{\circ}$ ingle between the directions of the $r$ mys and the incident beam. The $F_{r}$ values given do not incorporate the anjular distribution. 


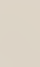

\begin{tabular}{|c|c|c|} 
ELEM. SYM. & A & 2 \\
Cu & 63 & 29 \\
\hline REF. NO. & Kr 15 & hmg \\
\hline
\end{tabular}

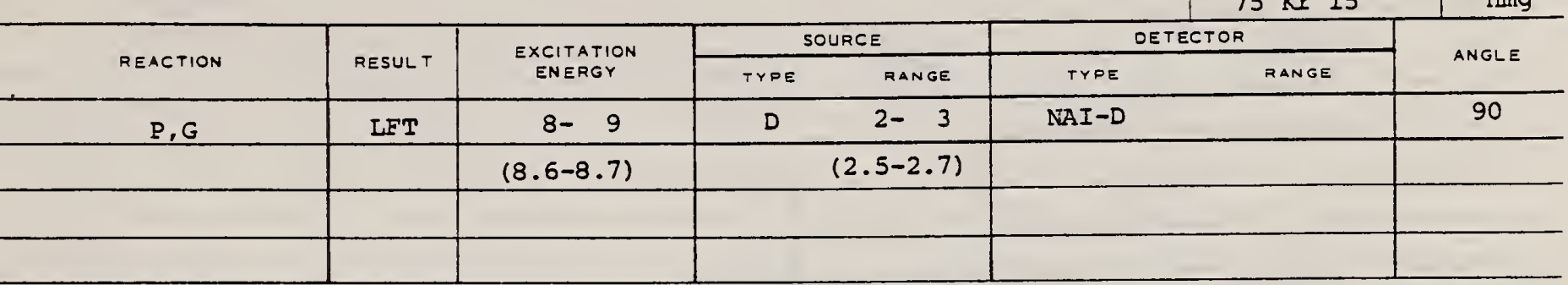

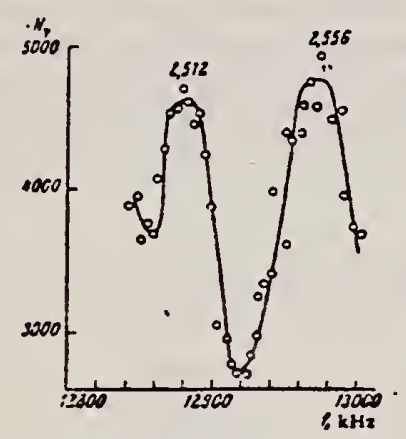

Fig. 2. Excitation function of the ${ }^{82} \mathrm{Ni}(\mathrm{pr})^{63} \mathrm{Cu}$ reaction. The target "thickness" was $15 \mathrm{keV}$ for $E_{p}=2.5 \mathrm{MeV}$.

Table 2

\begin{tabular}{|c|c|c|c|}
\hline$E \cdot$. kev & $\underset{k e v}{t_{1}, \cdot}$ & $1^{-}$ & 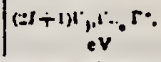 \\
\hline $\begin{array}{l}8567 \\
8597 \\
86.31 \\
8671 \\
85 i 3\end{array}$ & 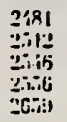 & $\begin{array}{l}1 / 2- \\
(3 / 2-) \\
(1 / 2-) \\
3 /:^{-}\end{array}$ & $\begin{array}{l}0.4 i=0.04 \\
0.30=13.111 \\
0.11=01,113 \\
0.20=11.11 \\
11.2 i=0.10\end{array}$ \\
\hline
\end{tabular}

-The values of the forees are given wishout ailow. -The values of the forees are given without allow.
ance for the angular distribution of the grays. 
C. O. Wene

Z. Phys. A272, 77 (1975)

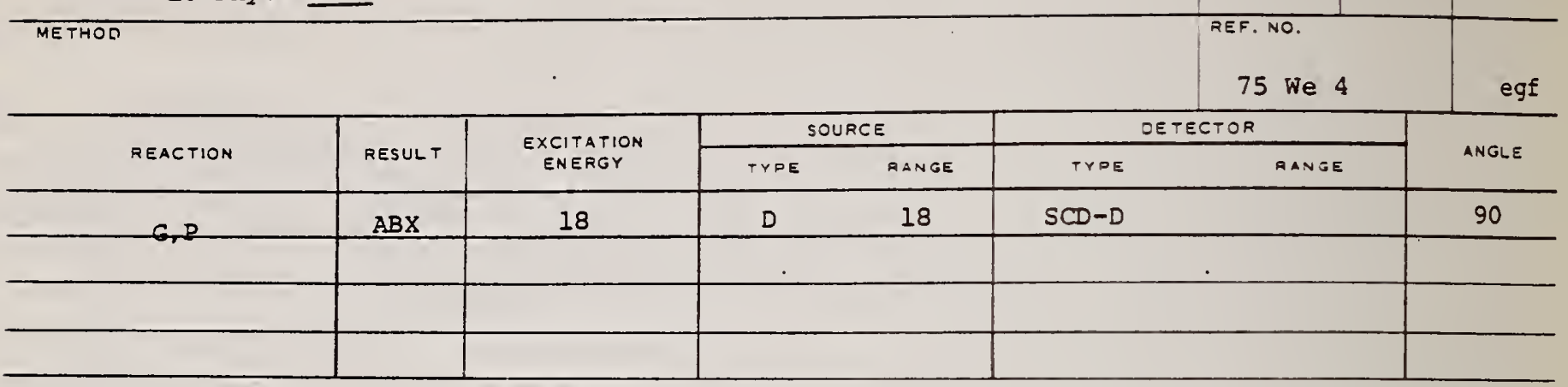

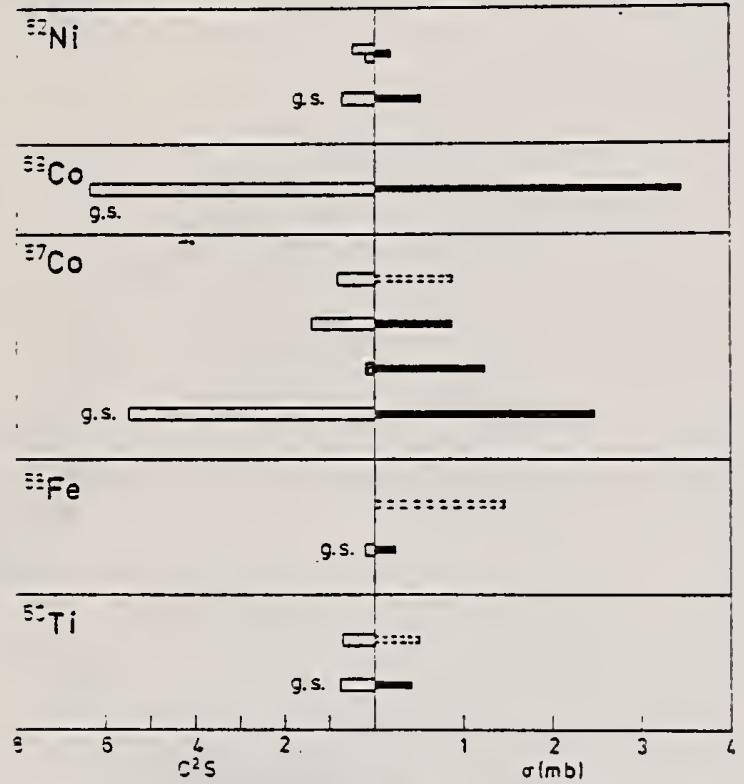

Fis. 5. Correlation between the spectroscopic factors and the crosssections meastired in this work. Open staples indicate $/,=3$ pick-up and cross hatched staples $t_{0}=1$ pick-up. Dashed staples indicate that the cross section is uncertain due to the subtraction of a large baci-ground

\begin{tabular}{|c|c|c|c|}
\hline \multirow{2}{*}{$\begin{array}{l}\text { Daughter } \\
\text { sucleus }\end{array}$} & \multicolumn{2}{|l|}{ Lerel } & \multirow{2}{*}{$\begin{array}{l}\sigma^{2} \\
(m b)\end{array}$} \\
\hline & $(. \mathrm{SeV})$ & $j=$ & \\
\hline${ }^{-} \mathrm{C}_{3}$ & $\begin{array}{l}0 \\
1.16\end{array}$ & $\begin{array}{l}0^{\circ} \\
?^{\circ}\end{array}$ & $\begin{array}{l}\leqq 0.2^{\circ} \\
\leqq 0.5^{\circ}\end{array}$ \\
\hline${ }^{9} \mathrm{Ti}$ & $\begin{array}{l}0 \\
2.68\end{array}$ & $\begin{array}{l}0^{\circ} \\
4^{\circ}\end{array}$ & $\begin{array}{l}0.11=0.05 \\
(0.5)^{5}\end{array}$ \\
\hline$\therefore \mathrm{Fe}$ & $\begin{array}{l}0 \\
3.24^{n}\end{array}$ & $\begin{array}{l}0^{-} \\
0^{-?}\end{array}$ & $\begin{array}{l}0.23 \\
(1.5)^{6}\end{array}$ \\
\hline$\because{ }^{\circ} \mathrm{Co}$ & $\begin{array}{l}0 \\
1.76 \\
190 \\
2.31\end{array}$ & $\begin{array}{l}7=- \\
3:- \\
7:- \\
72^{-}\end{array}$ & $\begin{aligned} & 2.5=0.2^{\circ} \\
& 1.2=0.3 \\
& 0.9=0.2 \\
&10.9)^{\mathrm{e}}\end{aligned}$ \\
\hline${ }^{\circ} \mathrm{Co}$ & 0 & $7 \geq-$ & $35=0.8$ \\
\hline$\therefore \mathrm{Ni}$ & $\begin{array}{l}0 \\
1.18\end{array}$ & $0^{\circ}$ & $\begin{array}{l}0.51=0.09 \\
0.2 \pm 0.1\end{array}$ \\
\hline
\end{tabular}

- The quoted errors are only those due to counting statistics.

: Connidence level $99^{\circ}$.

Lincertaun because of large backgesund.

$=\sigma=: .+\mathrm{mb}$ from $[+3]$.

43. Miyase, H, Cikawa, S, Suzuki, A, Uegaki, J, Saico, T. Sugaw2ra, M. Shoda K. The photoprolon reactions of $\mathrm{Ni}$-isolopes In: Proc. Iat. Corf. Photonuclear Reactions and Applications. Vol. I, p. 553. Livermore, USA 1973 (see ReL. 13)
FOAM NBS. 418

FOAM NBS. 418

(REV. $7 \cdot 14-64$ )
USCOMM-NBS-OC
PHOTONUCLEAR DATA SHEET 382
U.S. OEPARTMENT OF COMMERCE U.S. OEPARTMENT OF COMMERCE
NATIONAL GUAEAU OF STANDAROS 


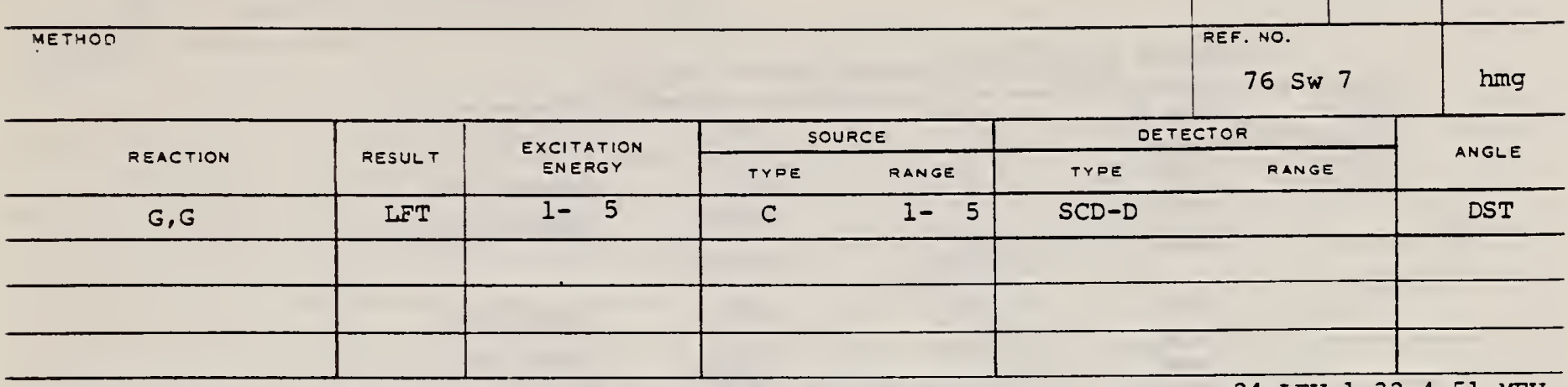

The properties of levels in ${ }^{13} \mathrm{O}$ and ${ }^{\circ} \mathrm{Ca}$ bave been investigated using the resonance fluorescence technique

with bremstrahlung serving as the source of exciting radiation. The energies and scattering cross sections for

24 levels in ${ }^{33} \mathrm{Cu}$ and 30 levels in " $\mathrm{Cu}$ up to about $4.5 \mathrm{MeV}$ were measured. A few levels known to exist in the

region of $2 \mathrm{MeV}$ for both nuclei were not observed. For a number of the lower lying levels, spin and parity

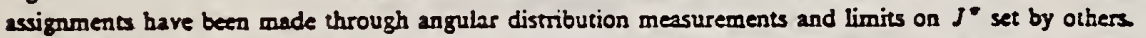

Mixing ratios for $\mathrm{few}$ of these are also given. Where $J^{*}$ and the ground state branching ratios are known the

partial widths for decays to the ground state are presented. Comparisons are made with the predictions of the

latest theoretical calculations.

TABLE L. Properties of levels in ${ }^{63} \mathrm{Cu}$.

\begin{tabular}{|c|c|c|c|c|}
\hline $\begin{array}{c}E_{\gamma}{ }^{2} \\
(\mathrm{keV})\end{array}$ & $J^{\pi^{\mathrm{b}}}$ & $\begin{array}{l}g \Gamma_{0}^{2} / \Gamma \\
(\mathrm{meV})\end{array}$ & $\Gamma_{0} / \Gamma^{c}$ & $\underset{(\mathrm{meV})}{\Gamma_{0}}$ \\
\hline $1327.0(5)$ & $\frac{7}{2}^{-}$ & $1.28(13)$ & 0.84 & $0.76(8)$ \\
\hline $1412.0(10)$ & $\frac{5}{2}^{-}$ & $0.31(6)$ & 0.72 & $0.22(6)$ \\
\hline $15 \div \overline{7} .0(5)$ & $\frac{3}{2}^{-T}$ & $2.53(25)$ & 0.80 & $3.16(32)$ \\
\hline $1861.0(10)$ & $\frac{7}{2}^{-}\left(\frac{5}{2}^{-}\right)$ & $0.42(3)$ & 0.57 & $0.37(7)$ (for $\frac{7}{2}^{-}$) \\
\hline $2011.1(5)$ & $\frac{3}{2}^{-t}$ & $2.30(28)$ & 0.56 & $5.0(5)$ \\
\hline $2062.2(3)^{*}$ & $\frac{1}{2}^{-}\left(\frac{3}{2}^{-}\right)$ & $<0.16$ & 0.20 & $<1.6\left(\right.$ for $\left.\frac{1}{2}^{-}\right)$ \\
\hline $2082 . \div(10)$ & $\frac{5}{2}^{-t}$ & $0.76(17)$ & 0.39 & $1.3(3)$ \\
\hline $2092.7(5)^{*}$ & $\frac{7}{2}^{-}\left(\frac{5}{2}^{-}\right)$ & $<0.17$ & 0.10 & $<0.3\left(\right.$ for $\left.\frac{7}{2}^{-}\right)$ \\
\hline $2337.0(10)$ & $\frac{5}{2}^{-}$ & $0.23(5)$ & 0.60 & $0.26(6)$ \\
\hline $2497.5(10)$ & $\frac{3}{2}^{-}$ & $3.0(6)$ & 0.83 & $3.6(4)$ \\
\hline $2513.2(10)$ & $5^{-}$ & $2.3(3)$ & 1.00 & \\
\hline $2536.0(10)$ & $5^{\frac{\pi}{2}}$ & $0.5(1)$ & 0.28 & $1.2(6)$ \\
\hline $2697.0(10)$ & $\frac{1}{2}=\frac{3}{2}, \frac{5}{2}$ & $0.71(35)$ & 0.34 & \\
\hline $2780.1(10)$ & $\frac{1}{2}^{ \pm} \cdot \frac{3}{2}^{ \pm} \cdot \frac{5}{2}^{-}$ & $4.5(5)$ & 0.58 & \\
\hline $2858.5(10)$ & $\frac{1}{2}^{ \pm}, \frac{3}{2}^{ \pm}, \frac{5}{2}^{-}$ & $3.7(6)$ & 0.36 & \\
\hline $2977.3(10)$ & $\left(\frac{1}{2}^{ \pm}, \frac{1}{2}^{ \pm}, \frac{5}{2}^{-}\right)^{\dagger}$ & $18(2)$ & $\leq 0.78$ & \\
\hline $\begin{array}{l}3045 . \frac{1}{2}(10) \\
3100.9(10)\end{array}$ & & $2.5(4)$ & $\begin{array}{l}1.00 \\
0.55\end{array}$ & \\
\hline $\begin{array}{l}3100.9(10) \\
3405.1(10)\end{array}$ & & $\begin{array}{l}0.5(3) \\
32(4)\end{array}$ & & \\
\hline $3430.7(10)$ & & $14(2)$ & & \\
\hline $3458.6(10)$ & & $12(2)$ & & \\
\hline $4038(2)$ & & $22(4)$ & & \\
\hline $4117(2)$ & & $18(5)$ & & \\
\hline $\begin{array}{l}4294(2) \\
4358(2)\end{array}$ & & $+4(6)$ & & \\
\hline $\begin{array}{l}4358(2) \\
4513(2)\end{array}$ & & $\begin{array}{l}66(7) \\
97(10)\end{array}$ & & \\
\hline
\end{tabular}

The energies indicated with an asterisk were taken from Ref. 3.

$b$ The Refs. 8 and 13 .

$c$ The values for $\Gamma_{0} / \Gamma$ were taken from Ref. 10 except for the limit given for $2977 \mathrm{keV}$

level. The observed branch is to the $670 \mathrm{keV} \frac{1}{2}^{-}$level. 
TABLE III. Experimental $A_{2}$ values and resultant mixing ratios.

\begin{tabular}{|c|c|c|c|c|}
\hline Nuclei & $E_{\gamma}$ (keV) & $J^{2}$ & $A_{2}$ & 8 \\
\hline \multirow[t]{3}{*}{${ }^{63} \mathrm{Cu}$} & 1547 & $\frac{3}{2}^{-}$ & $0.58(9)$ & $0.27(5),(1.7(2))$ \\
\hline & 2011 & $\frac{3}{2}^{-}$ & $0.75(16)$ & $0.41(14), 1.4(3)$ \\
\hline & 2977 & $\frac{1}{2}^{-}, \frac{3}{2}^{-}, \frac{5}{2}$ & $-0.04(18)$ & \\
\hline \multirow[t]{6}{*}{${ }^{65} \mathrm{Cu}$} & 1725 & $\frac{3}{2}^{-}$ & 0.3917 & $0.15(5), 1.8(8)$ \\
\hline & 2329 & $\frac{3}{2}^{-}$ & $0.38(8)$ & $0.15(6), 1.9(5)$ \\
\hline & 2862 & & $0.09(28)$ & \\
\hline & 2875 & & $0.43(24)$ & \\
\hline & 3166 & & $-0.18(16)$ & \\
\hline & 3326 & $\frac{3}{2}, \frac{5}{2}$ & $0.89(17)$ & $0.9(5)$ if $\frac{3}{2}$ \\
\hline
\end{tabular}

8 R.L. Auble, Nucl. Data Sheets 14,119 (1975).

10 . Hartas et al., private communication.

13. Verheul, Nucl. Data B2 (\#3), 31 (1967). 
ref. K.V. Alanakyan, M.Dzh. Amaryan, R.A. Demirchyan, K.Sh. Egiyan,

i.S. Ogandzhanyan, \& Yu.G. Sharabyan

Yad. Fiz. 25, 545 (March 1977)

Sov. J. Nuc]. Phys. 25, 292 (March 1977).

REF. NO.

\begin{tabular}{|c|c|c|c|c|c|c|c|}
\hline & & & & & & $77 \mathrm{Al}$ & hmg \\
\hline \multirow[b]{2}{*}{ REACTION } & \multirow[b]{2}{*}{ RESULT } & \multirow{2}{*}{$\begin{array}{l}\text { EXCITATION } \\
\text { ENERGY }\end{array}$} & \multicolumn{2}{|c|}{ SOURCE } & \multicolumn{2}{|c|}{ DETECTOR } & \multirow{2}{*}{ ANGLE } \\
\hline & & & TYPE & RANGE & TYPE & RANGE & \\
\hline \multirow[t]{2}{*}{$G, P$} & $A B X$ & $70-999$ & $C$ & $2 * 5$ & TEL-D & --- & DST \\
\hline & & & & $(4-5)$ & & & \\
\hline & & & & & & & \\
\hline & & & & & & & \\
\hline
\end{tabular}

COHMEITS: $f \sim \exp \left(-B p^{2}\right)$

$B=E$

$$
P^{4}\left(d^{2} \sigma / d \Omega d p Q\right)
$$

$\star E, G E V, 999=4.5 \mathrm{GEV}$

The $A^{n}$-dependence and momentum spectse of photoprotons in the nuclei ${ }^{12} \mathrm{C},{ }^{27} \mathrm{AL},{ }^{43} \mathrm{Cu},{ }^{114} \mathrm{Sa}$, and ${ }^{203} \mathrm{~Pb}$

have ben studied experimentally for maximum bremstrablung energies of $20,3.0$, and $4.5 \mathrm{GeV}$. The $A$ -

dependence shows that the proton photopraduction mechnism for $E_{Y}>400 \mathrm{MeV}$ is identical for the entire kineric-enersy region $65-280 \mathrm{MeV}$ and the angle region 45-150 for the secondary protons studied.

The dependence of the exposent $n$ on the trassverse momentum $p_{1}$ is in good sgreement with the same dependence for protons produced in nuclei by primary protons. In the momentum spectra of the invariant crosesection $f=\left(E / p^{2}\right)\left(d^{2} \sigma / d \Omega d p Q\right) \sim \exp \left(-B p^{2}\right)$ it is observed that the parnmeter $B$ does not depend on the incident-photon eneray and on the target nucleas, but depends on the proton-detection angle.

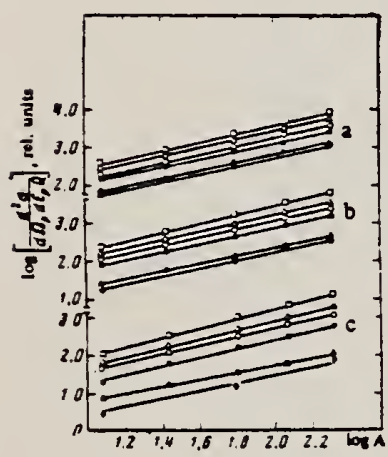

FIG. 1. Differential cross section for proton photoproduction as a function of atomic number $A$ of the nucleus at $E_{0}$ $=2 \mathrm{GeV}$. The lines a correspond to $s_{1}=60^{\circ}$, b to 90 : and c to $150^{\circ}$. Points: $\square-E_{,}=64$. $\triangle-80,0-101,=-137,-$ 209, and $-280 \mathrm{MeV}$.

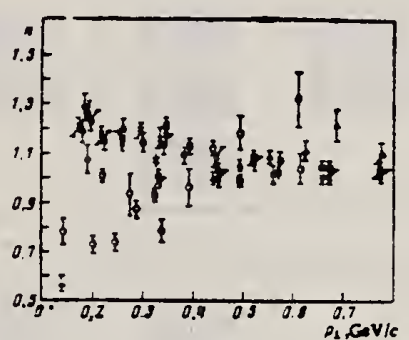

FIG. 3. The oame as Fig. 2. Experimental points: $\triangle-E_{0}=0.13,0-0.25, \triangle-$ $0.4,0-1.2,0-2.0, x-$ 3. 0 , and $-4.5 \mathrm{GeV}$.

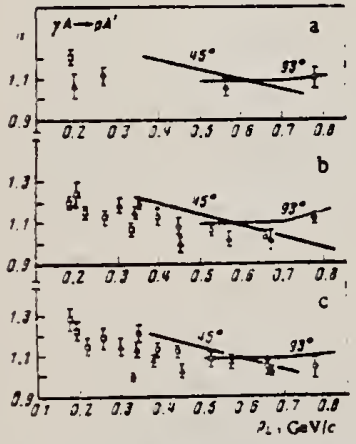

FIG. 2. Dependence of the exponent $n$ in the $A^{n}$ dependence of the cross section for the reaction $y A-p A$ as a function of proton transverse momentum: $a-E_{0}=2.0 \mathrm{GeV}, b-E_{0}=3.0$ $\mathrm{GeV}, c-E_{0}=4.5 \mathrm{GeV}$. The points for $\mathrm{a}$ and $\mathrm{b}: \Delta-s_{,}=60^{\circ}$, $\circ-90^{\circ}, c-150^{\circ}$; for $\mathrm{c}: \mathrm{s}-\vartheta_{,}=46^{\circ}, 0-86^{\circ}, a-136^{\circ}$. The curves show the dependence of $n$ on $p_{1}$ for the reaction $A\left(p, p^{\prime}\right) A^{\prime}$ taken from Ref. 9.

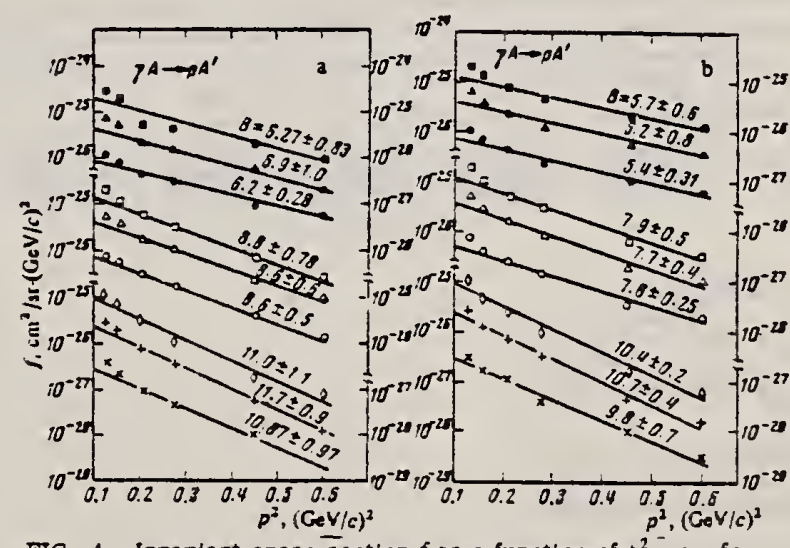

FIG. 4. Invariant cross section $f$ as a function of $p^{2}$. $a-f o r$ $E_{0}=2.0 \mathrm{GeV}, b-$ tor $E_{0}=3.0 \mathrm{GeV}$. Experimental points:

$\triangle$ - lor $\vartheta_{p}=60^{\circ}$ for the respective nuclei ${ }^{12} \mathrm{C},{ }^{63} \mathrm{Cu}$, and ${ }^{200} \mathrm{~Pb}$;

$\circ, \Delta, 0$ - the same for $\xi_{,}=90^{\circ} ; x,+$. $\circ$-the same for $\psi_{,}=15 \sigma$. 
TABLE I. Differential cross section $d^{2} \sigma / d \Omega d T Q$ of the reaction $\gamma A-p A^{\prime}$ in $\mu b / \mathrm{MeV}-\mathrm{sr}$.

\begin{tabular}{|c|c|c|c|c|c|c|c|c|}
\hline \multirow{2}{*}{$A$} & \multirow{2}{*}{$\begin{array}{l}E_{Y \cdot} \\
G_{V}\end{array}$} & \multirow{2}{*}{ des. } & \multicolumn{6}{|c|}{$\varepsilon_{p}, M \in V$} \\
\hline & & & Bi & 80 & 101 & 137 & 209 & $2: 9$ \\
\hline \multirow[t]{3}{*}{$\therefore C$} & 2 & $\begin{array}{r}60 \\
90 \\
130\end{array}$ & $\begin{array}{l}3.720 \pm 0.056 \\
2774=0.045 \\
1.132=0.032\end{array}$ & $\begin{array}{l}2.630 \pm 0.052 \\
1.387 \pm 0.047 \\
0.690 \pm 0.017\end{array}$ & $\begin{array}{l}1.907 \pm 0.057 \\
1.130=0.039 \\
0.505=0.026\end{array}$ & $\begin{array}{l}1.25 \pm 0.038 \\
0.763 \pm 0.022 \\
0.218 \pm 0.007\end{array}$ & $\begin{array}{l}0.725 \pm 0.220 \\
0.256 \pm 0.008 \\
0.071 \pm 0.005\end{array}$ & $\begin{array}{l}0.429 \pm 0.018 \\
0.117 \pm 0.007 \\
0.021=0.002\end{array}$ \\
\hline & 3 & $\begin{array}{r}80 \\
90 \\
150\end{array}$ & $\begin{array}{l}4.240=0.1 \mathrm{~m} \\
2.140=0.0 .56 \\
1.360 \pm 0.042\end{array}$ & $\begin{array}{l}3.424 \pm 0.063 \\
2.031 \pm 0.040 \\
0.877 \pm 0.029\end{array}$ & $\begin{array}{l}1.960=0.043 \\
1.145=0.029 \\
0.438 \pm 0.018\end{array}$ & $\begin{array}{l}1.829 \pm 0.048 \\
0.807 \pm 0.028 \\
0.300 \pm 0.010\end{array}$ & $\begin{array}{l}0.653 \pm 0.025 \\
0.243 \pm 0.009 \\
0.057 \pm 0.003\end{array}$ & $\begin{array}{c}0.452 \pm 0.019 \\
0.088 \pm 0.005 \\
-\end{array}$ \\
\hline & 2 & $\begin{array}{r}80 \\
90 \\
.150\end{array}$ & $\begin{array}{l}8.460 \pm 0.177 \\
5.920 \pm 0.107 \\
3.127=0.078\end{array}$ & $\begin{array}{l}8.014 \pm 0.120 \\
3.750 \pm 0.086 \\
1.797 \pm 0.035\end{array}$ & $\begin{array}{l}4.083=0.109 \\
2.502 \pm 0.084 \\
1.189=0.060\end{array}$ & $\begin{array}{l}3.253 \pm 0.097 \\
1.718=0.052 \\
0.844 \pm 0.019\end{array}$ & $\begin{array}{l}1.513 \pm 0.048 \\
0.803 \pm 0.018 \\
0.164 \pm 0.011\end{array}$ & $\bar{z}$ \\
\hline \multirow[t]{2}{*}{$n_{\mathbf{A}}$} & 3 & $\begin{array}{r}60 \\
90 \\
130\end{array}$ & $\begin{array}{c}9.960 \pm 0.239 \\
6.090=0.130 \\
3.750=0.103\end{array}$ & $\begin{array}{l}7.492 \pm 0.131 \\
4.845 \pm 0.107 \\
2.943 \pm 0.081\end{array}$ & $\begin{array}{r}4.160 \pm 0.092 \\
2.688 \pm 0.078 \\
1.34 \pm 0.042\end{array}$ & $\begin{array}{l}3.577 \pm 0.100 \\
1.995=0.065 \\
0.747=0.025\end{array}$ & $\begin{array}{l}1.538 \pm 0.058 \\
0.596 \pm 0.021 \\
0.136 \pm 0.006\end{array}$ & $\begin{aligned} 0.925 & =0.037 \\
0.239 & =0.013 \\
& -\end{aligned}$ \\
\hline & 4,5 & $\begin{array}{r}48 \\
86 \\
136\end{array}$ & $=$ & $\begin{array}{l}9.510=0.250 \\
8.200 \pm 0.095 \\
3.380=0.050\end{array}$ & $\bar{z}$ & $\bar{z}$ & $=$ & $\begin{array}{c}1.320 \pm 0.720 \\
0.248 \pm 0.020 \\
-\end{array}$ \\
\hline \multirow[t]{3}{*}{${ }^{a}{ }^{3} \mathrm{Cu}$} & 2 & $\begin{array}{r}60 \\
90 \\
150\end{array}$ & $\begin{array}{l}23.500=0.329 \\
16.721=0.268 \\
10.392 \pm 0.312\end{array}$ & $\begin{array}{r}15.170 \pm 0.299 \\
9.757 \pm 0.231 \\
3.217 \pm 0.103\end{array}$ & $\begin{array}{r}10.931=0.269 \\
6.856 \pm 0.082 \\
3.362=0.16 .3\end{array}$ & $\begin{array}{l}8.163=0.240 \\
6.111=0.134 \\
1.507 \pm 0.050\end{array}$ & $\begin{array}{l}3.939 \pm 0.140 \\
1.424=0.042 \\
0342=0.021\end{array}$ & $\begin{array}{l}2.115=0.084 \\
0.743 \pm 0.037 \\
0.115 \pm 0.011\end{array}$ \\
\hline & 3 & $\begin{array}{r}60 \\
90 \\
151)\end{array}$ & $\begin{array}{l}26.180=0.790 \\
17.800=0.320 \\
11.640 \pm 0.271\end{array}$ & $\begin{array}{r}20.580 \pm 0.340 \\
13.601=01.260 \\
7.834=0.205\end{array}$ & $\begin{array}{r}10.200 \pm 0.191 \\
7.318=0.1 ! n 1 \\
3388 \pm 0.107\end{array}$ & $\begin{array}{l}3.594 \pm 0.246 \\
5.245 \pm 0.17 \frac{2}{2} \\
2237 \pm 0.075\end{array}$ & $\begin{array}{l}3.869=0.140 \\
1.403=0.048 \\
0.368=0.017\end{array}$ & $\begin{array}{l}1.661 \pm 0.084 \\
0676 \pm 0.032 \\
0.097 \pm 0.008\end{array}$ \\
\hline & 4,5 & $\begin{array}{r}46 \\
88 \\
138\end{array}$ & $=$ & $\begin{array}{r}27.000=0.750 \\
17.401 \pm 0.250 \\
9.750 \pm 0.150\end{array}$ & $\bar{z}$ & $=$ & $\bar{z}$ & $\begin{array}{c}3550=0.180 \\
0.785 \pm 0.060 \\
-\end{array}$ \\
\hline $\log n$ & 2 & $\begin{array}{r}80 \\
90 \\
150\end{array}$ & $\begin{array}{l}45.601 \pm 0.538 \\
32.530 \pm 0.533 \\
19.571 \pm 0.391\end{array}$ & $\begin{array}{l}30.050=0.593 \\
18.890 \pm 0.466 \\
10.289 \pm 0.203\end{array}$ & $\begin{array}{l}19.970 \pm 0387 \\
33.840 \pm 0.28 \\
0.548 \pm 0.321\end{array}$ & $\begin{array}{r}13.102 \pm 0.390 \\
8.297 \pm 0.320 \\
3.032 \pm 0.090\end{array}$ & $\begin{array}{l}7.137 \pm 0.210 \\
2588 \pm 0.078 \\
0.585 \pm 0.011\end{array}$ & $\bar{z}$ \\
\hline \multirow{2}{*}{$A$} & \multirow{2}{*}{$\begin{array}{l}\varepsilon_{r v} \\
G_{e V}\end{array}$} & \multirow{2}{*}{ des } & \multicolumn{6}{|c|}{$E_{p .} M e V$} \\
\hline & & & 86 & 80 & 101 & $13 i$ & 219 & $2 \pi 3$ \\
\hline \multirow[t]{2}{*}{$114 \mathrm{So}$} & 3 & $\begin{array}{r}60 \\
90 \\
150\end{array}$ & $\begin{array}{l}55.070 \pm 1.770 \\
36.600 \pm 0.720 \\
22.500 \pm 0.560\end{array}$ & $\begin{array}{l}39.920=0.680 \\
28.260 \pm 0.530 \\
14.590 \pm 0.350\end{array}$ & $\begin{array}{r}17.800=0.430 \\
14.370=0.400 \\
8.251 \pm 0=10\end{array}$ & $\begin{array}{r}18.5500=0.490 \\
9.54 \pm \pm 0.328 \\
4.103 \pm 0.130\end{array}$ & $\begin{array}{l}7.028=0.036 \\
2.684=0.099 \\
0.664=0.033\end{array}$ & $\begin{array}{c}3.873=0.160 \\
1.137 \pm 0.055 \\
-\end{array}$ \\
\hline & 45 & $\begin{array}{r}46 \\
86 \\
138\end{array}$ & $\bar{z}$ & $\begin{array}{l}53.900 \pm 1.400 \\
32.200 \pm 0.51 \\
18.250=0.290\end{array}$ & $\bar{z}$ & $\bar{z}$ & $\bar{z}$ & $\begin{array}{l}5.640 \pm 0.320 \\
1.420 \pm 0.114 \\
0.230=0.038\end{array}$ \\
\hline \multirow[t]{4}{*}{$x p b$} & 2 & $\begin{array}{r}60 \\
90 \\
150\end{array}$ & $\begin{array}{l}80.000=1.380 \\
60.990 \pm 0.970 \\
36.890 \pm 0.730\end{array}$ & $\begin{array}{l}56.850 \pm 1120 \\
34.080=0.800 \\
18.480 \pm 0.370\end{array}$ & $\begin{array}{l}35.200=1.030 \\
23.690 \pm 0.720 \\
10.638 \pm 05.0\end{array}$ & $\begin{array}{l}23930=0.7211 \\
14.2: 0=17.800 \\
5.794=0.168\end{array}$ & $\begin{aligned} & 13 .\{10=0.200 \\
& 4 . j=01.135 \\
& 1.1112=1.057\end{aligned}$ & $\begin{array}{l}7.745=0.310 \\
2.453 \pm 0.120 \\
0.531=0.035\end{array}$ \\
\hline & 3 & $\begin{array}{r}60 \\
90 \\
150\end{array}$ & $\begin{array}{r}100.740 \pm 2.130 \\
71.350 \pm 1.270 \\
42.090 \pm 0.970\end{array}$ & $\begin{array}{l}76.030 \times 1.300 \\
48.320 \pm 0.900 \\
77.240 \times 0.680\end{array}$ & $\begin{array}{l}28 .(x)=0.4713 \\
24.7(31400650 \\
13.150=0.62\end{array}$ & $\begin{array}{r}28.000 \pm 0.8 \div 0 \\
18.420 \pm 0.3201 \\
7.294=11 \pm=11\end{array}$ & $\begin{aligned} 1: .810=0.150 \\
.780=0.170 \\
1.20=0.104\end{aligned}$ & $\begin{array}{l}7.092=0.250 \\
3 y=0.120 \\
0.589=0.034\end{array}$ \\
\hline & 4.5 & $\begin{array}{r}43 \\
88 \\
136\end{array}$ & $=$ & $\begin{array}{l}85.000 \pm 0.350 \\
58.780 \pm 0.9 \pm 11 \\
29.600 \pm 0.430\end{array}$ & $\bar{z}$ & $\bar{z}$ & $\bar{z}$ & $\begin{array}{r}11.600 \pm 0.340 \\
3.060=0.14 \\
0.165=0.084\end{array}$ \\
\hline & & & & 80 & 119 & 166 & 231 & 291 \\
\hline $\mathbb{C}$ & 4.5 & $\begin{array}{r}48 \\
38 \\
136\end{array}$ & & $\begin{array}{l}5.210 \pm 0.260 \\
2.440 \pm 0.080 \\
1.330 \pm 0.029\end{array}$ & $\begin{array}{l}3.670 \pm 0.088 \\
1.250 \pm 0.652 \\
0.427 \pm 0.020\end{array}$ & 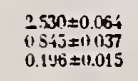 & $\begin{array}{l}1.1919 \pm 0.046 \\
0.363=0.1119 \\
0.045 \pm 0.145\end{array}$ & $\begin{array}{l}0.785=0.042 \\
0.105=0.107 \\
18.018 \pm 0 \text { ov2 }\end{array}$ \\
\hline
\end{tabular}

TABLE II. Values of the parameter $B$ in $(\mathrm{GeV} / c)^{-2}$ in the relation $E_{p} / p_{p}^{2}\left(d^{2} \sigma / d \Omega, d p_{p} Q\right)=f \sim \exp \left(-B p^{2}\right)$.

\begin{tabular}{|c|c|c|c|c|c|c|c|c|c|}
\hline \multirow[b]{2}{*}{ Taget } & \multicolumn{3}{|c|}{$E_{1}=2.0 \mathrm{GeV}$} & \multicolumn{3}{|c|}{$3.0 \mathrm{GoV}$} & \multicolumn{3}{|c|}{$\omega \mathrm{COV} V$} \\
\hline & $a,-600$ & $90^{\circ}$ & $150^{\circ}$ & 600 & $90^{\circ}$ & $150^{\circ}$ & $66^{\circ}$ & $86^{\circ}$ & $130^{\circ}$ \\
\hline 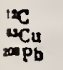 & $\begin{array}{l}4.874 \pm 0.512 \\
5.300 \pm 0.627 \\
5.204 \pm 0.753\end{array}$ & $\begin{array}{l}7.78 \pm 0.482 \\
7.337=0.627 \\
7.805 \pm 0.721\end{array}$ & $\begin{aligned} 9.481 & =0.303 \\
10.47 & \pm 0.609 \\
10.088 & =0.96\end{aligned}$ & $\begin{array}{l}6.288 \pm 0.805 \\
8.972=0.939 \\
8.870 \pm 1.514\end{array}$ & $\begin{array}{l}8.823 \pm 0.197 \\
3.359 \pm 0.6 \pm 2 \\
3.858 \pm 0.783\end{array}$ & $\begin{array}{l}10.373 \pm 0.977 \\
11.697 \pm 094 \\
: 0.983 \pm 1.188\end{array}$ & $\begin{array}{c}6.08 \mathrm{i} \pm 0.173 \\
\\
-\end{array}$ & $\begin{array}{c}8.066 \pm 0.49 \\
=\end{array}$ & $\begin{array}{c}11.262=0.481 \\
\vdots\end{array}$ \\
\hline
\end{tabular}

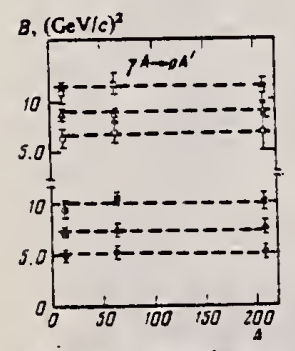

FIG. 6. Dependence of the parameter $B$ from the relation

$f \sim \exp \left(-B p^{2}\right)$ on the atomic number of the target nucleus. The

solid points refer to $E_{0}=2.0 \mathrm{GeV}$, and the bollow points to $E_{0}$

$=3.0 \mathrm{GeV}$ : the points $\bullet$ and 0 are for $\psi_{,}=60^{\circ}, \Delta$ and $\Delta$ are for

$90^{\circ}$, and and 0 are for $150^{\circ}$. 
aEF. U. Kneiss1, G. Kuhl, and K.H. Leister

Z. Physik A281, 35 (1977)

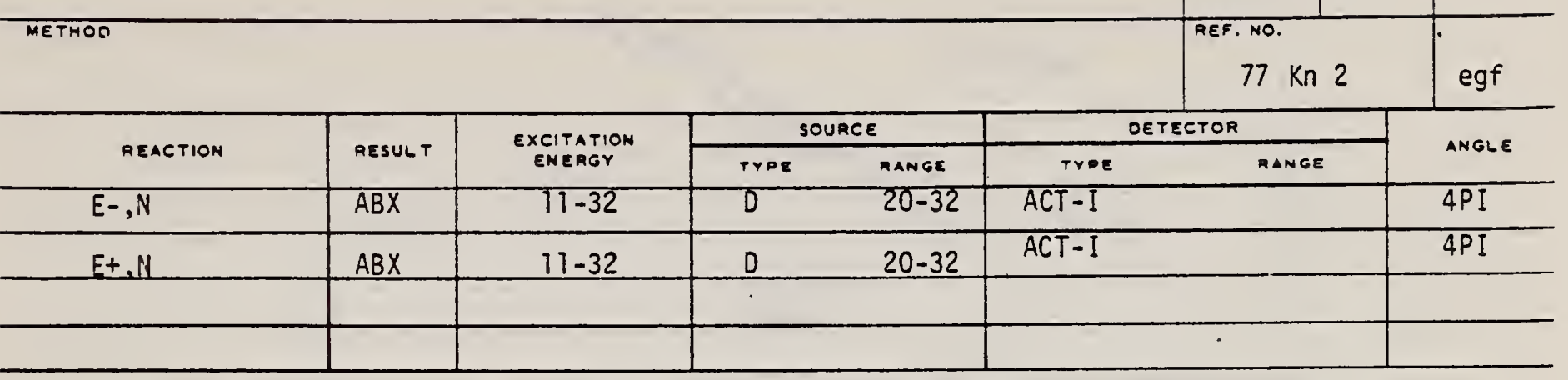

See figure on ather side 

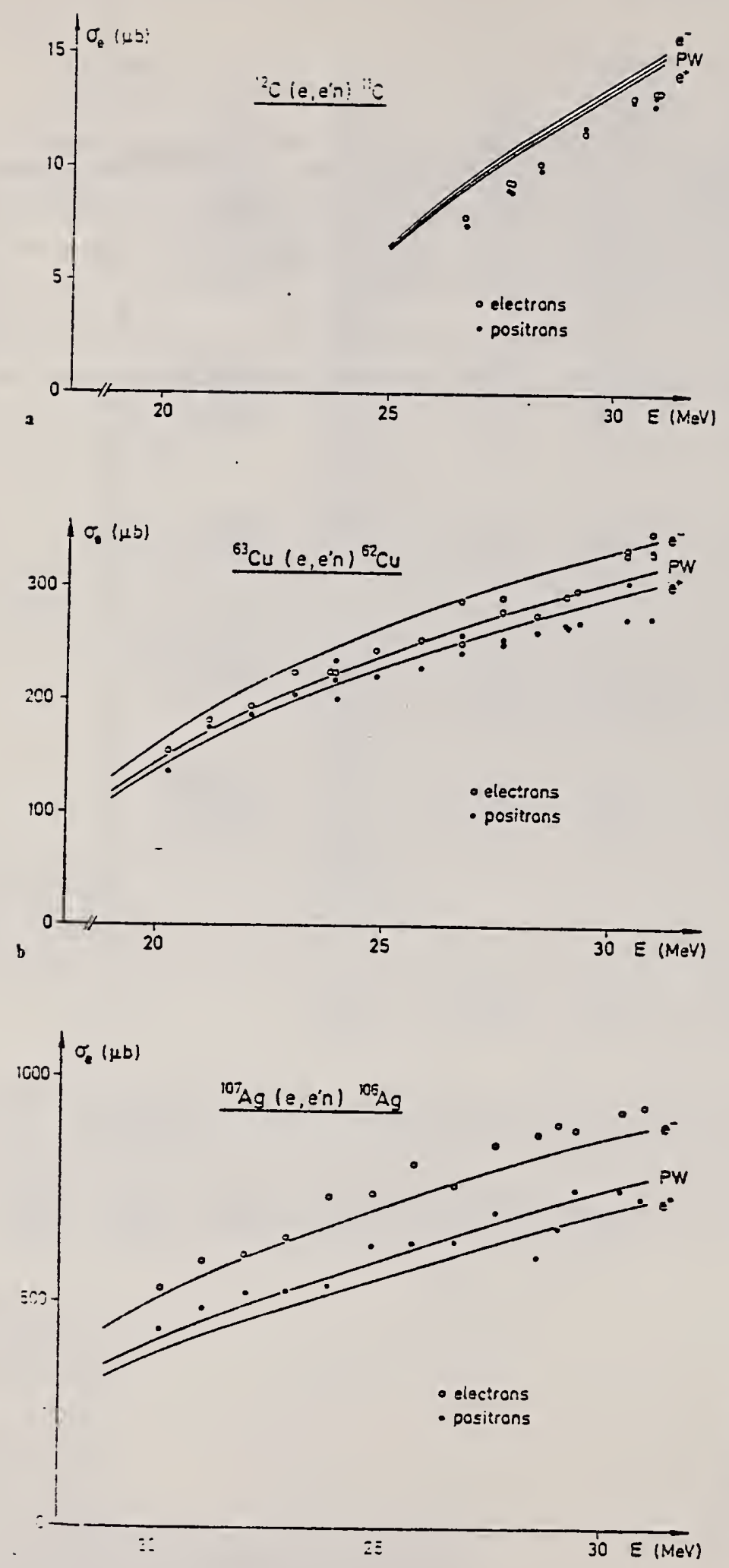

Fig. 1. a Experimental absolute $\left(e, e^{\prime} n\right)$ cross section for ${ }^{22} \mathrm{C}$ logether with the results of DWBAt and PIV calculations. b Experimental absolute $\left(e, e^{\prime} n\right)$ c:oss section for ${ }^{6}{ }^{3} \mathrm{Cu}$ together with the results of DWBAt and PIV calculations. e Experimental absolute (e,e' $n$ ) cross section for ${ }^{10}$ 'Ag together with the results of DW'BA and PW calculations 
aef. O.E. Kraft, Yu.V. Naumov, S.S. Parzhitskii, Z. Salekh, I.V. Sizov Izv. Akad. Nauk SSSR 41, 44 (1977)

But1. Acad. Sci. 41, $\overline{35}$ (1977)

$\mid$\begin{tabular}{c|c} 
EL EM. SYM. & \\
$\mathrm{CU}$ & 63
\end{tabular}

29

\begin{tabular}{|c|c|c|c|c|c|c|c|}
\hline METMOD & & & & & . & $\begin{array}{l}\text { REF. NO. } \\
77 \mathrm{Kr} 6\end{array}$ & egf \\
\hline \multirow{2}{*}{ REACTION } & \multirow{2}{*}{ RESULT T } & \multirow{2}{*}{$\begin{array}{l}\text { EXCITATION } \\
\text { ENERGY }\end{array}$} & \multicolumn{2}{|c|}{ SOURCE } & \multicolumn{2}{|c|}{ DETECTOR } & \multirow{2}{*}{ ANGLE } \\
\hline & & & TYPE & FANGE & TYPE & AANGE & \\
\hline$\overline{P, G}$ & NOX & $8-9$ & & $2-3$ & $5 C D-D$ & & DST \\
\hline & & & & & & & \\
\hline & & & & & & & \\
\hline & & & & & & & \\
\hline
\end{tabular}

Measurements are reported of the angular distrfbutions of $\gamma$-rays due to trans1t1ons from the analog resonances corresponding to the ground and the flrst and

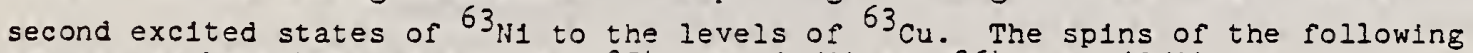
$8.57,8.74$ resonances have been determined: $8743 \mathrm{keV}(3 / 2)$ and $8640 \mathrm{keV}(5 / 2)$.

\section{$8.64 \mathrm{MEV}$}

\begin{tabular}{|c|c|c|c|c|}
\hline 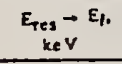 & $a_{1}$ & $a_{d}$ & a & 0 \\
\hline 1 & 2 & 3 & 1 & 3 \\
\hline $8505 \rightarrow 0,0$ & $-0,01=0,09$ & $-0,07 \pm 0,11$ & $-0,05 \pm 0,06$ & - \\
\hline $\begin{array}{l}8603=678 \\
8563-362\end{array}$ & $\begin{array}{l}-0,2.3 \pm 0.22 \\
+0,11=0,05\end{array}$ & $\begin{array}{l}-0,42 \pm \pm 1,2,2, \\
-0,13 \pm 0,44 i\end{array}$ & $\begin{array}{l}-0,4 J=0,02 \\
+0,05 \pm 0,07\end{array}$ & $\overline{-}$ \\
\hline $8563 \rightarrow 1326$ & $-0,21=0,25$ & $+0,15 \pm 0,45$ & $-0,14=0,2 i$ & \\
\hline $8 \mathrm{sin} \rightarrow 1 / 10$ & & $-0,21 \pm 0,03$ & $-0,06 \pm 0,11$ & - \\
\hline $8.5,9 \rightarrow 1547$ & $=0,16=0.13$ & $+0,06 \pm 0,16$ & $-0,11 \pm 0,08$ & - \\
\hline $8.369-2060$ & $-0,30=0,25$ & $-0,0 \overline{0} \pm 0,31$ & $-0,23=0,15$ & - \\
\hline $8=63$ - 20890 & $+0,3=0,07$ & $-0.09 \pm 0,03$ & $+0,72=0,07$ & - \\
\hline $\begin{array}{l}3503=2497 \\
3=60=2712\end{array}$ & $\begin{array}{c}-0.13=0,13 \\
+13=0.8\end{array}$ & $\begin{array}{l}+0,4 i=0,17 \\
+0,3\end{array}$ & $\begin{array}{r}+0,04 \pm 0,21 \\
+\end{array}$ & $\overline{-}$ \\
\hline $\left.8 j \varepsilon^{\prime}\right)-3 j^{\prime} j 3^{\prime}$ & $+0,07=0,2 !$ & $-0.12=0.26$ & $\begin{array}{r}r \\
+0,02=0,0,15\end{array}$ & $\overline{-}$ \\
\hline $850=2673$ & $-0,11=0,22$ & $\begin{array}{l}-0,18=0,25 \\
+0,01-014\end{array}$ & $-0,19=0,16$ & - \\
\hline 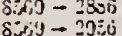 & $\begin{array}{l}+0,04=0,1 ! \\
-0,50 \pm 0.15\end{array}$ & $\begin{array}{l}+0,19=0.14 \\
+0,16 \pm 0,13\end{array}$ & $\begin{array}{l}+0,0 i \pm 0,07 \\
-0,42=0,11\end{array}$ & $\overline{-}$ \\
\hline $8.00-35-8$ & $-0,7 i=0,2 i$ & $+0,49 \pm 0, \therefore 7$ & $-0,50 \pm 0,23$ & 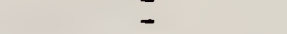 \\
\hline $813-3160$ & $-0.111)=0.12$ & $-0,36 \pm 0,49$ & $-0,05 \pm 0,32$ & - \\
\hline 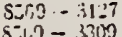 & $-0.27=0.17$ & $+5,03 \pm 0,-1$ & $-0,25=0,10$ & - \\
\hline 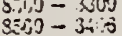 & $\begin{array}{l}-1), 2=4=0,12 \\
-0, \div 3=0,33\end{array}$ & $\begin{array}{l}+0,23 \simeq 0,16 \\
+0,10 \pm 0,48\end{array}$ & $\begin{array}{l}-0,14 \pm 0,13 \\
-0,4 j \pm 0,21\end{array}$ & $\overline{-}$ \\
\hline 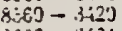 & $-0, j 2=0,10$ & $+0,77 \pm 0,14$ & $-0,18 \pm 0,32$ & - \\
\hline $5 \%-31$ & $-2.11=0.15$ & $-0,39=0,18$ & $-0,05 \pm 0,22$ & \\
\hline $\begin{array}{l}37.3-0.0 \\
8743=58\end{array}$ & $\begin{array}{l}-0,0 !=1,0,00 \\
-0,1 i=0,0\end{array}$ & $\begin{array}{l}-0,0 j \pm 0,07 \\
-0,10=0,05\end{array}$ & $\begin{array}{l}+0,03 \pm 0,04 \\
-0,22 \pm 0,06\end{array}$ & $\begin{array}{l}+0,23 \pm 0,02 \text { or } 40<8<-(n) \\
-0,15+0,09 \text { or }+2,8 \pm 0,5\end{array}$ \\
\hline$\xi: i 3 \rightarrow \xi ;\}$ & $-0,09=0,02$ & $-0,03 \pm 0,03$ & $\div 0,07 \pm 0,02$ & $+0,14 \underbrace{+0,12}_{-0,07}$ or $+2,8 \pm 0,3$ \\
\hline $5: 13-: 40$ & $-10.10=0,41$ & $-0,03=0,01$ & $-0,11 \pm 0,02$ & $-0,02 \pm 0,05$ or $4,8+1,3$ \\
\hline 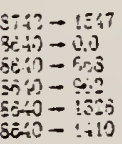 & 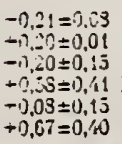 & $\begin{array}{l}-0,07=0,10 \\
-0,070 \pm 0,01 \\
+0,02 \pm 0,02 \\
+0,33 \pm 0,30 \\
-0,26=0,18 \\
+0,12 \pm 0,46\end{array}$ & $\begin{array}{l}+0.18 \pm 0,06 \\
+0,16 \pm 0,0.5 \\
+0.21 \pm 0,10 \\
+0,68 \pm 0.33 \\
-0,03 \pm 0.16 \\
+0,70 \pm 0,28\end{array}$ & $\begin{array}{l}+0,15=0,10 \text { or } \\
-0,20 \pm 0,01 \\
-0,3<\delta<-0,1 \\
-6,09=0,11 \\
-0,3 \cdot=8<-0,1\end{array}$ \\
\hline $8010-i=15 i$ & $+0,21=0,08$ & $+0,23 \pm 0,10$ & $+0,32 \pm 0,13$ & $-1,38 \div 0,09$ \\
\hline
\end{tabular}

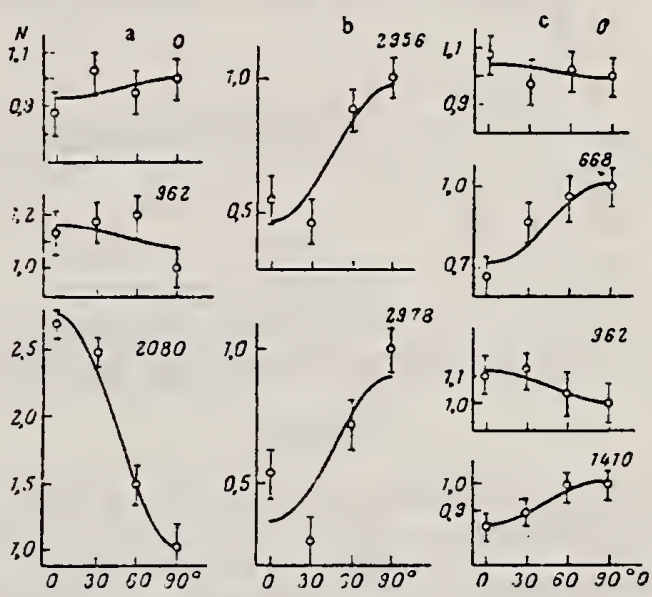

F1g. 1. Angular distributions of Y-rays due to transitions from the analog resonances at 8569 ( $a, b)$ and 8743 (c) keV to the levels of ${ }^{63} \mathrm{Cu}$. llumbers indicared against curves are the energies of these levels in $\mathrm{keV}$. 
S.G. Knyazyan, A.T. Margaryan, S.S. Stepanyan, P.K. Kir'yanov, V.A. Maisheev \& A.M. Frolov

Phys. Lett. 79B, 143 (November 1978)

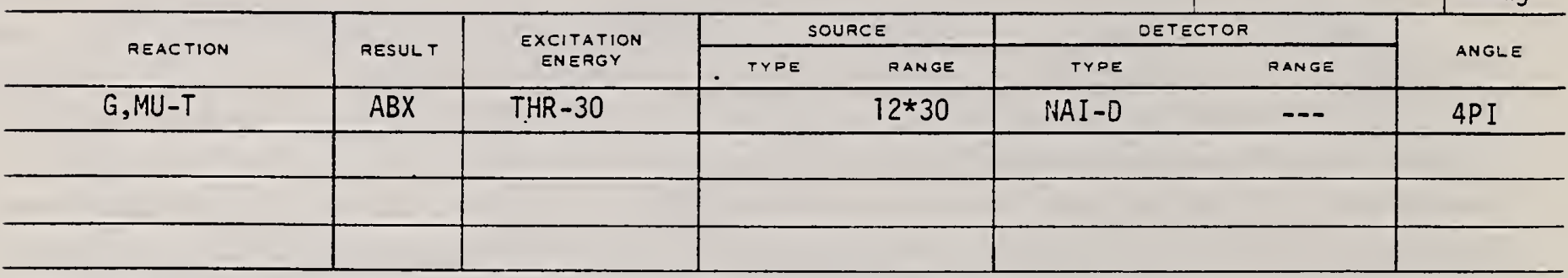

The cotal cross seetion of hadron photoproduction on $\mathrm{C}, \mathrm{Cu}$ and $\mathrm{Pb}$ nuclei is measured for six energy values in the range 12-30 GcV. The obtained eross-scetion valucs for $\mathrm{C}$ and $\mathrm{Cu}$ nuelei have a weak energy dependence at high energies (above $20 \mathrm{GeV}$ ). The cross seetion for the $\mathrm{Pb}$ nucleus is soneuhat higher in comparison with that expected, and energy dependence is not observed. The $A$-dependence of the effective number of hadrons agrecs with VDM predictions.

\section{$c$}

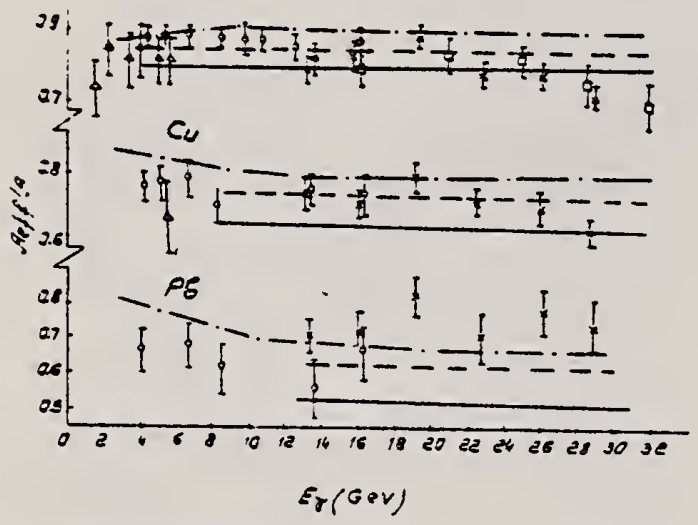

Fig. 3. Energy dependence of $A_{\mathrm{eff}} / \mathrm{A}$ for $\mathrm{C}, \mathrm{Cu}, \mathrm{Pb}$ nuelei. For comparison the data of DESY and SLAC-UCSB, and also the the oretical curves, corresponding to VDil and to the case when the photon is $\sim 20 \%$ of the time in a "pure" state, without shadowing. $\triangle$, DESY; $\odot, S L A C-U C S B ; x$, Serpukhov; J, Serpukhov [4]; - VD.H; - - 0.8 VD.1 +0.2 pofntlike interaction; - - general VDII.

Table 1

Hadron phoroproduction cross sections (in $\mu \mathrm{b}$ ) for $\mathrm{C}, \mathrm{Cu}, \mathrm{Pb}$ nuclei for different energies of rquanta. Only statistieal errors are given.

\begin{tabular}{llll}
\hline $\begin{array}{c}\gamma \text {-quanta energy } \\
\text { (GeV })\end{array}$ & ${ }^{12} \mathrm{C}$ & ${ }^{64} \mathrm{Cu}$ & ${ }^{207} \mathrm{~Pb}$ \\
\hline $12.6-15.0$ & $1084 \pm 48$ & $5600 \pm 240$ & $17140=1170$ \\
$15.0-17.7$ & $1100 \pm 43$ & $5200 \pm 310$ & $17480=1140$ \\
$17.7-21.0$ & $11-5=34$ & $5740 \pm 340$ & $19680 \pm 1720$ \\
$21.0-24.6$ & $1058 \pm 53$ & $5220=460$ & $16400 \pm 1720$ \\
$24.6-27.9$ & $1047 \pm 55$ & $4870 \pm 350$ & $17920=1920$ \\
$27.9-30.0$ & $930 \pm 66$ & $4730 \pm 510$ & $16840 \pm 2810$ \\
\hline
\end{tabular}

Table 2

$\checkmark a l u e$ of $A$ eff for nuelei $C, C u, P b$ for different energies of $r$ quanta. Only statistical errors are given.

\begin{tabular}{|c|c|c|c|}
\hline $\begin{array}{l}\text { r-quanta energy } \\
(\mathrm{GeV})\end{array}$ & ${ }^{12} \mathrm{C}$ & ${ }^{64} \mathrm{Cu}$ & ${ }^{207} \mathrm{~Pb}$ \\
\hline $12.6-15.0$ & $0.79 \pm 0.04$ & $0.77: 0.04$ & $0.73: 0.05$ \\
\hline $15.0-17.7$ & $0.81=0.04$ & $0.72 \pm 0.05$ & $0.75=0.06$ \\
\hline $17.7-21.0$ & $0.87 \pm 0.4$ & $0.80=0.05$ & $0.85 \pm 0.7$ \\
\hline $21.0-24.6$ & $0.80=0.05$ & $0.74 \pm 0.07$ & $0.72=0.08$ \\
\hline $24.6-27.9$ & $0.79 \pm 0.05$ & $0.69=0.05$ & $0.79=0.09$ \\
\hline $27.9-30.0$ & $0.71 \div 0.05$ & $0.68=0.07$ & $0.75 \pm 0.13$ \\
\hline
\end{tabular}

$$
\frac{A_{\mathrm{eff}}}{A}=\frac{\sigma_{\mathrm{t}}(\gamma, A)}{Z \sigma_{\mathrm{t}}(\gamma, \mathrm{p})+(A-Z) \sigma_{\mathrm{t}}(\gamma, \mathrm{n})},
$$

where

$$
\begin{aligned}
& \sigma_{t}(\gamma, p)=(98.7 \pm 3.6)+(65 \pm 10) E^{-1 / 2} \mu \mathrm{b}, \\
& \sigma_{t}(\gamma, n)=\sigma_{t}(\gamma, p)-(18.3 \pm 6.1) E^{-1 / 2} \mu \mathrm{b} .
\end{aligned}
$$


REF. K. Masumoto, T. Kato, N. Suzuki

Nucl. Inst. Meth. 157, 567 (1978)

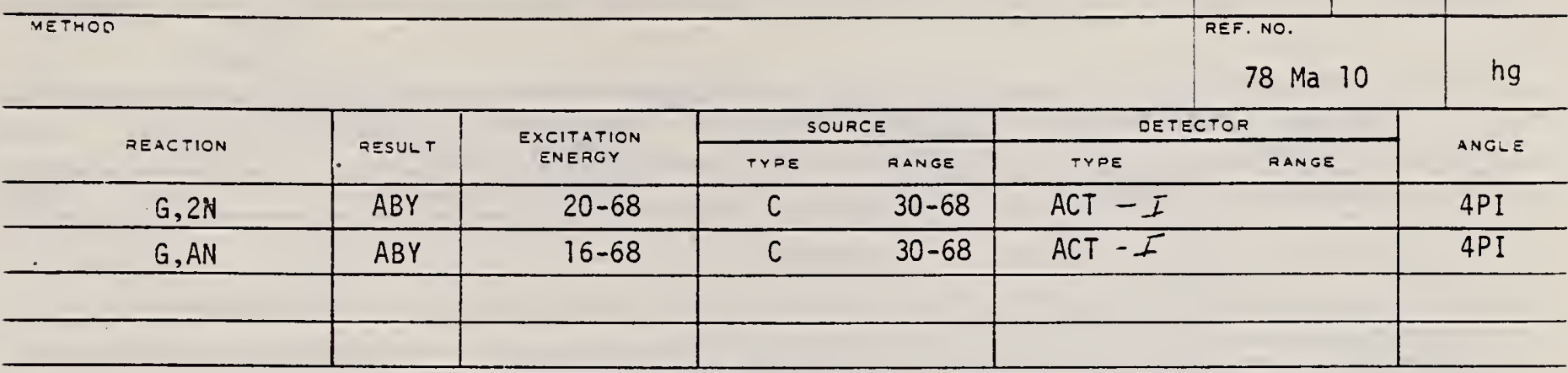

\section{Analysis is made of reactions interfering with} photon activation analysis procedures.

The activation yield curves have been presented for a number of photonuclear reactions in the energy range from 30 to $68 \mathrm{MeV}$, in order to evaluate quantutatively the interferences due to competing reactions in multielement photon activation analysis. The general features of the yields as functions of both target mass number and excitation energy were elucidated from the data obtained. discussion being given on the results in terms of the reaction mechanism.

Simultaneous neutron activation due to appreciable neutron production from the converter and surrounding materials has also been studied, and. finally, the magnitudes of interferences in real multielement analysis were given in the form of their energy dependences.

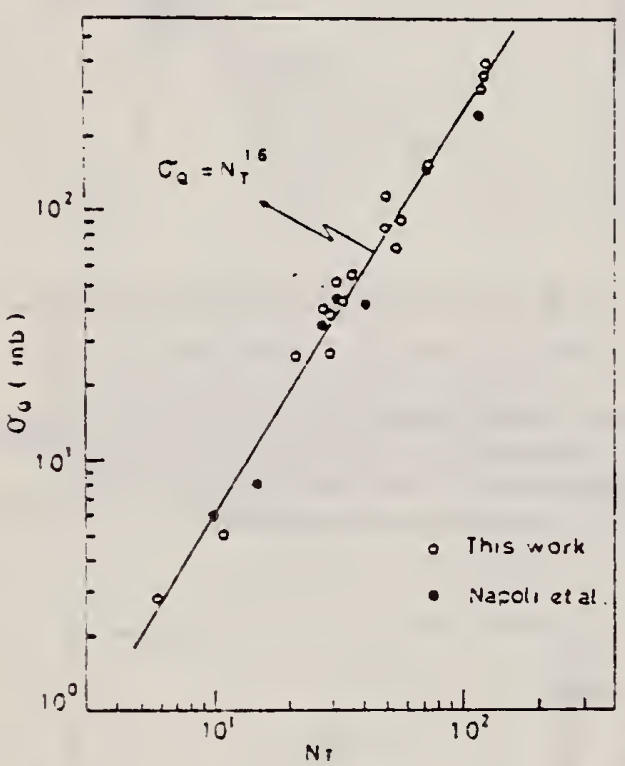

Fig. 2. Yield per equsalent quanta versus target ncutron number.

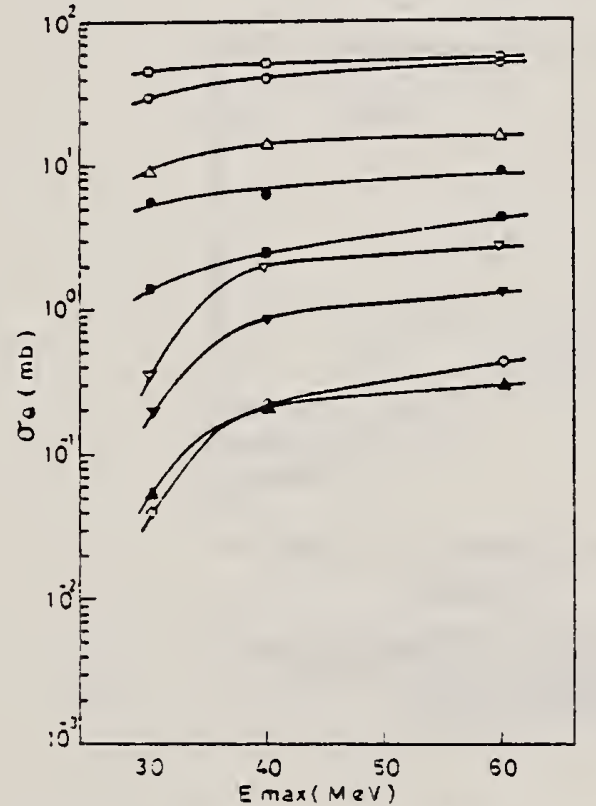

Fig. 6. Analuation yiaid curves for the reactions on $\mathrm{Co} . \mathrm{Ni}$ and

$\left.\partial^{54} \mathrm{Cor} \%, \mathrm{n}\right)^{69} \mathrm{Co}$. ${ }^{50} \mathrm{Co}(\%, 2 \mathrm{n})^{57} \mathrm{CO} . \dot{\mathrm{Cu}}{ }^{58} \mathrm{Ni}(\%, \mathrm{n})^{57} \mathrm{Ni}$.

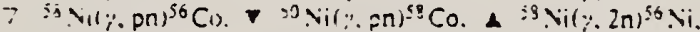

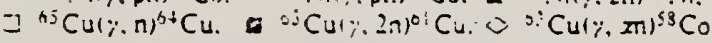


78 Mu 9

\begin{tabular}{|c|c|c|c|c|c|c|c|}
\hline \multirow{2}{*}{ REACTION } & \multirow{2}{*}{ RESULT } & \multirow{2}{*}{$\begin{array}{l}\text { EXCITATION } \\
\text { ENERGY }\end{array}$} & \multicolumn{2}{|c|}{ SOURCE } & \multicolumn{2}{|c|}{ DETECTOR } & \multirow{2}{*}{ ANGLE } \\
\hline & & & TYPE & FANGE & TYPE & RANGE & \\
\hline E.A & $A B X$ & $5-100$ & $D$ & 100 & $M A G-D$ & & DST \\
\hline & & & & & & & \\
\hline & & & & & & & \\
\hline & & & & & & & \\
\hline
\end{tabular}

a particies from the electrodisintegration of seven nucle with $Z$ between 29 and 79 have been observed. Energy spectra at $50^{\circ}$ in the laboratory for six nuclei and angular distribtions for five nuclei are reported. The cross sections exhibit a broad peak whose magnitude decreases with increasing $Z$; the energy of the peak increases as $Z$ increases. Angular distributions at the bighest energies measured become increasiogly

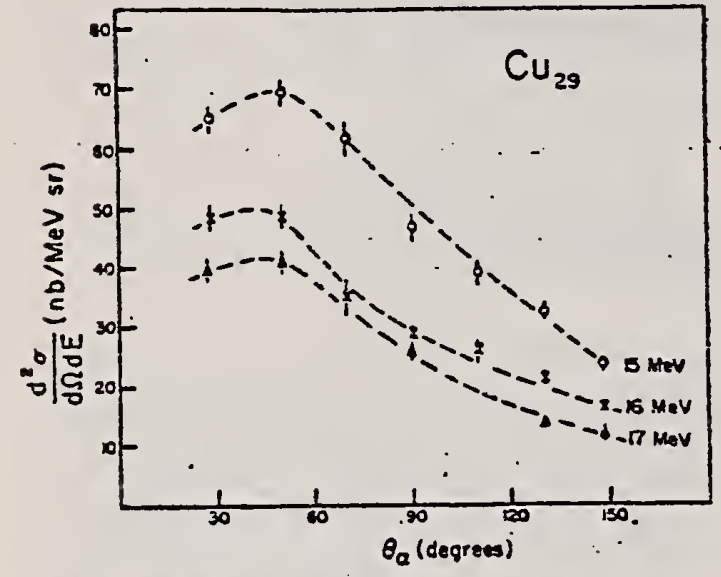

FIG. 1. High energy angular distributions for copper $(z=29)$. The expected forward peaking due to the importance of the direct process is seen.

1.J. Murphy, II, H.J. Gehrhardt, and O.M. Skopik, Nucl. Phys. A277, 69 (1977).

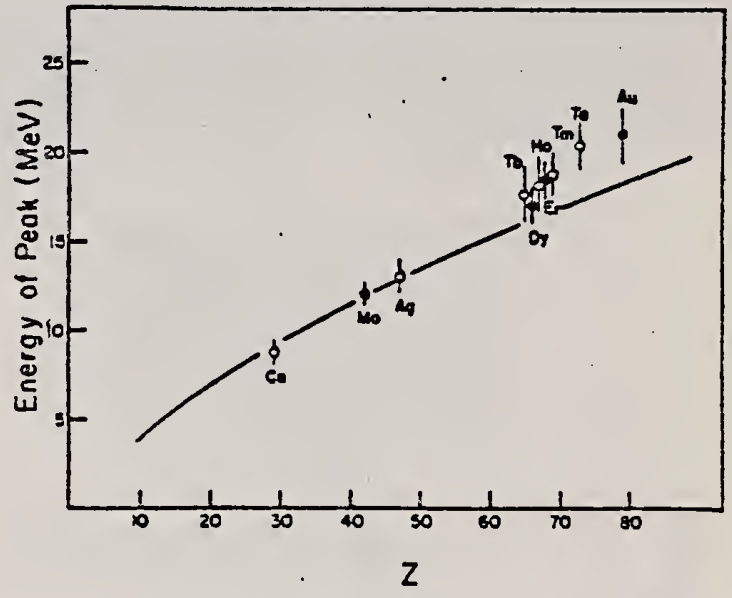

FIG. 3. Energy of the cross section peak as a function of $Z$. The solid line is the energy of the classical Coulorab barzier. The closed circles are the current work; the open circles are from Rel. 1.

$\therefore$

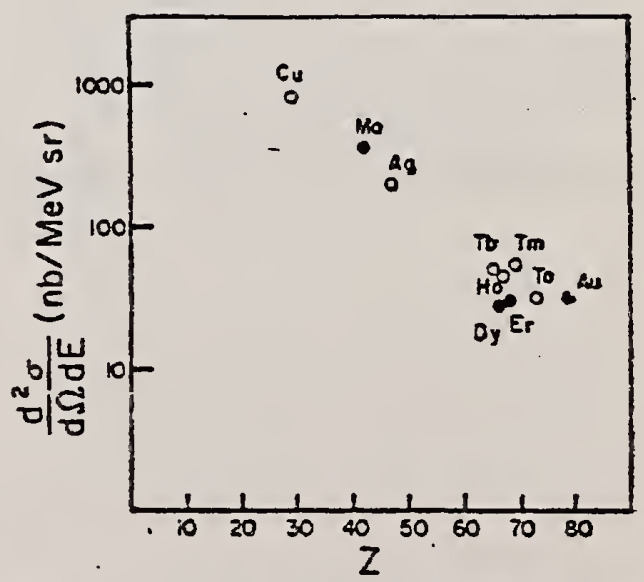

FTG. 4. Magnitude of cross section peak as a function of 2 . The closed circles a re the current work; the open circles are from Ref. 1. 
REF.

L.Z. Dzhilavyan, N.P. Kucher

Yad. Fiz. 30,294 (1979)

Sov. J. Nuct. Phys. 30,151 (1979)

\begin{tabular}{|c|c|c|c|c|c|c|c|}
\hline \multirow{2}{*}{ REACTION } & \multirow[b]{2}{*}{ RESULT } & \multirow{2}{*}{$\begin{array}{l}\text { EXCITATION } \\
\text { ENERGY }\end{array}$} & \multicolumn{2}{|c|}{ SOURCE } & \multicolumn{2}{|c|}{ DETECTOR } & \multirow{2}{*}{ ANGLE } \\
\hline & & & TYPE & RANGE & TYPE & RANGE & \\
\hline$G, N$ & $A B X$ & $12-25$ & D & $12-25$ & $\overline{A C T-D}$ & & $4 P I$ \\
\hline & & & & & & & \\
\hline & & & & & & & \\
\hline & & & & $=$ & & & \\
\hline
\end{tabular}

A beam of quasımonochromatic photons at energy 12-25 MeV has been utilized to measure the cross section for the " $\mathrm{Cu}(\gamma, n)$ reaction by detecting the induced beta activity with a two-crystal scintillation gamma spectrometer. The results are in good agreement with Ref. 12 and differ appreciably from other data obtanned in bremsstrahlung beams.

PACS numbers: 25.20. $+y$

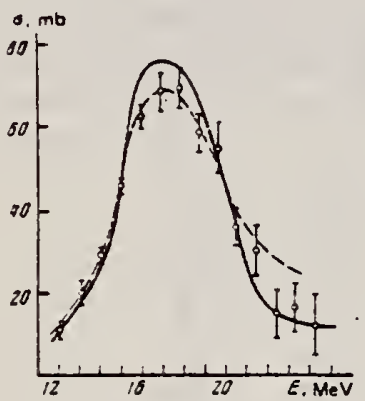

FIG. 5. Cross section for the reaction ${ }^{63} \mathrm{Cu}(\gamma, \pi)$. Solid curve-data of Ref. 12, dashed curve-data of Ref. 11, points-our data (the errors are statistical). 


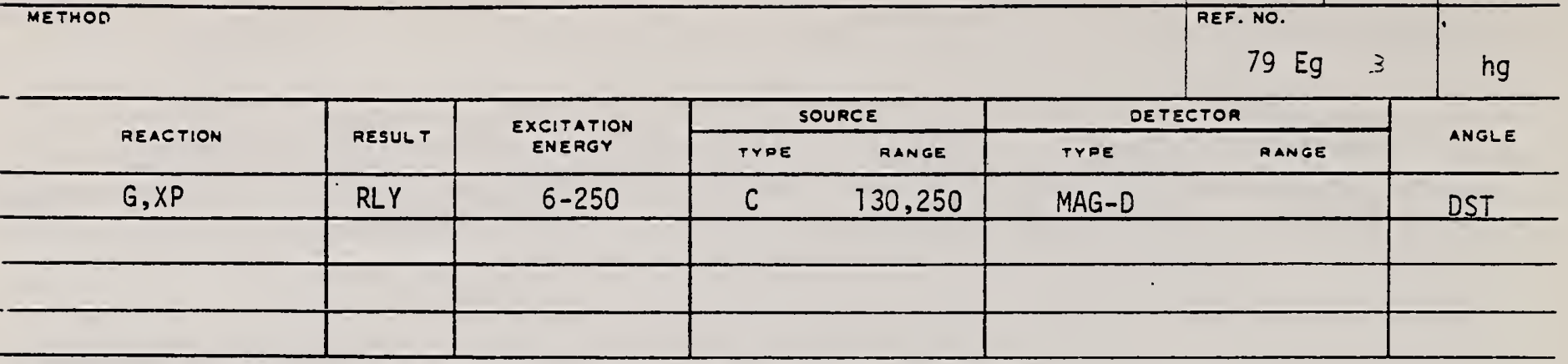

Experimental dala are presented on the inclusive photoproduction of protons in the nuclei ${ }^{12} \mathrm{C},{ }^{24} \mathrm{Mg}$.

${ }^{63} \mathrm{Cu}$, ${ }^{118} \mathrm{Sn}$, and ${ }^{203} \mathrm{~Pb}$ irradiated by bremsstrahlung with maximum energies 0.13 and $0.25 \mathrm{GeV}$. The regions of angles $30-90^{\circ}$ and of photoproton momenta $0.24-0.48 \mathrm{GeV} / c$ were studied.

PACS numbers: $25.20 .+y$

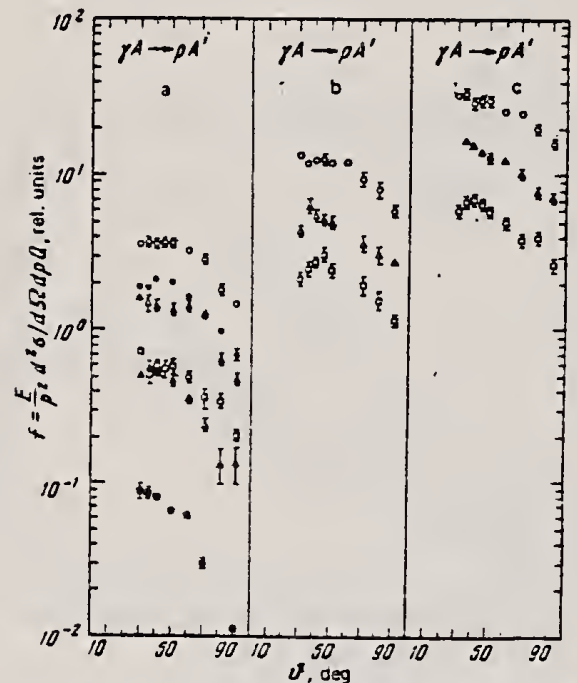

FIC. 2. Relative yields of photoprotons as a function of emission angle; experimental points: $0,-$ for $p_{p}=0.29 \mathrm{GeV} / c$; $\Delta, \Delta-0.34 \mathrm{GeV} / c ; 0, \square-0.40 \mathrm{GeV} / c$. The bollow points are for $E_{y_{\text {and }}}=0.25 \mathrm{GeV}$ and the solid points for $E_{y_{\text {max }}}=0.13 \mathrm{GeV}$ : $\mathrm{a}-\mathrm{for}^{\mathrm{t}} \mathrm{C}, \mathrm{b}-\mathrm{for}{ }^{\varnothing \mathrm{Cu}, \mathrm{c}-\mathrm{for}}{ }^{208} \mathrm{pb}$.

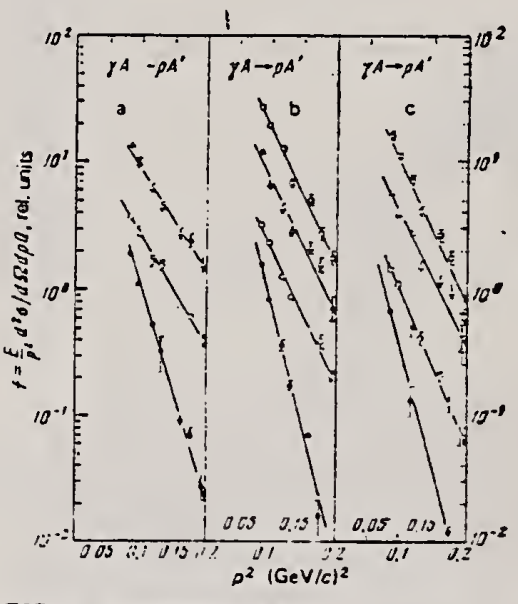

FIG. 3. Momentum spectra of protons. The experimental points are as follows: $O$ and - for ${ }^{12} \mathrm{C}, \Delta-$ for ${ }^{\circledR} \mathrm{Cu}, \square-$ for ${ }^{200} \mathrm{~Pb}$. The hollow points are for $E_{7 \mathrm{rs}}=0.25 \mathrm{GeV}$ and the solid points are for $E_{\max }=0.13 \mathrm{GeV} ; a$ - for $\vartheta_{,}=30^{\circ}, b-$ for $\vartheta_{3}=60^{\circ}$, $c-$ for $9_{0}=90^{\circ}$. The lines have been drawn through the experimental points by the method of least squares.

TABLE II. Values of the exponent $n$ in the $A^{n}$ dependence of the proton yield in reactions (2) and (3).

\begin{tabular}{|c|c|c|c|c|c|}
\hline \multirow{3}{*}{ deg. } & \multicolumn{3}{|c|}{$E_{7}=0.25 \mathrm{GoV}$} & \multicolumn{2}{|c|}{$\varepsilon_{q}=0.13 \mathrm{GeV}$} \\
\hline & \multicolumn{3}{|c|}{$p_{p}, \mathrm{CeV} / \mathrm{c}$} & \multicolumn{2}{|c|}{$p_{p} \cdot G e V / c$} \\
\hline & 0.39 & 0.36 & 0.60 & 0.39 & 0.34 \\
\hline $\begin{array}{l}30 \\
60 \\
00\end{array}$ & $\begin{array}{l}1.15 \pm+1.04 \\
1.02 \pm 0.03\end{array}$ & $\begin{array}{l}1.17=0.04 \\
111 \pm 0.02 \\
1.11=0.03\end{array}$ & $\begin{array}{l}1.20=01,1.3 \\
1.22=0.03 \\
1.24 \pm 0.05\end{array}$ & $\begin{array}{c}0.59 \pm 0.18 \\
=\end{array}$ & $\begin{aligned} 0.62=0.06 & = \\
& =\end{aligned}$ \\
\hline
\end{tabular}




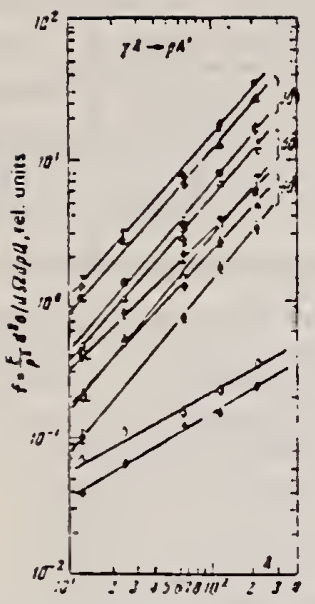

FIG. 5. A -dependence of the photoproton yield in reactions (2) and (3). Experimental points for $E_{\text {max }}=0.25 \mathrm{GeV}$ : circles$p_{p}=0.29 \mathrm{GeV} / c$; triangles $-p_{p}=0.34 \mathrm{GeV} / c$, squares $-p_{p}=0.40$ $\mathrm{GeV} / c$; balf-open symbols - for $3_{0}=30^{\circ}$, open symbols $-\vartheta_{2}=$ $=60^{\circ}$, solid symbols $-3_{,}=90^{\circ}$. for $E_{\max }=0.13 \mathrm{GeV}: Q_{-}$ $=0.29 \mathrm{GeV} / c, \vartheta_{3}=30^{\circ} ;-p_{0}=0.3+\mathrm{GeV} / c, \vartheta_{0}=30^{\circ}$. $[: ?$ lines have been drawn through the experimental points by the method of least squares.

395 
A.V. Gann, V.I. Noga, Yu.N. Ranyuk, Yu.N. Telegin, G.G. Jonsson

Sov. J. Nucl. Phys. 32, 599 (1980)

Yad. Fiz. 32,1161 (1980)

$80 \mathrm{Ga} 8$

\begin{tabular}{|c|c|c|c|c|c|c|c|}
\hline \multirow{2}{*}{ REACTION } & \multirow{2}{*}{ RESULT } & \multirow{2}{*}{$\begin{array}{l}\text { EXCITATION } \\
\text { ENERGY }\end{array}$} & \multicolumn{2}{|c|}{ SOURCE } & \multicolumn{2}{|c|}{ DETECTOR } & \multirow{2}{*}{ ANGLE } \\
\hline & & & TYPE & RANGE & TYPE & RANGE & \\
\hline$E, N$ & $A B Y$ & $10-999$ & $D$ & $320-999$ & ACT-I & & $4 P I$ \\
\hline $\mathrm{G}, \mathrm{N}$ & $A B Y$ & $10-999$ & 0 & $320-999$ & ACT - I & & $4 \mathrm{PI}$ \\
\hline
\end{tabular}

The reactions ${ }^{12} \mathrm{C} \rightarrow$ " $\mathrm{C}$ and ${ }^{~} \mathrm{Cu} \rightarrow{ }^{12} \mathrm{Cu}$ have been studied by the induced-activity method at clectron and photen energies from 0.32 to $1.2 \mathrm{GeV}$. Activation of the targets was carried out directly by an electron beam. The use of tarigets in the form of stacks permitted cross sections to be obtained for photodisintegration and electrolisintegration of the nuclei. Comparison of the experiment with theoretical calculations in the planewave approximation indicates a dominant role of $E$ l transitions of photons in these reactions.

PACS numbers: $25.20 .+y, 25.30 . C_{z}, 27.20 .+n, 27.50 .+e$

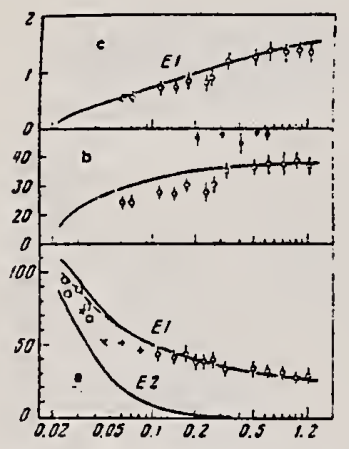

FIG. 2. The same as Fig. 1 but for the reactions $\left.{ }^{63} \mathrm{C}^{7} \cdot{ }^{7}\right)^{62} \mathrm{C}$. Points: - Results of the present work and Rel. 3, - Ref. 7, o-Ref. 9, $\times$-Ref. 10, +-Ref. 5. 
ReF. K.V. Alanakyan, M.Dzh. Amaryan, R.A. Demirchyan, K.Sh. Egijan, M.S. Ogandzhanyan, YU.G. Sharabyan

NuCl. Phys. A367, 429 (1981)

\begin{tabular}{|c|c|c|c|c|c|c|c|}
\hline METHOO & & & & & & $\begin{array}{l}\text { REF. NO. } \\
81 \text { AI } 8\end{array}$ & $\bar{\square}$ \\
\hline \multirow{2}{*}{ REACTION } & \multirow{2}{*}{ RESULT } & \multirow{2}{*}{$\begin{array}{l}\text { EXCITATION } \\
\text { ENERGY }\end{array}$} & \multicolumn{2}{|c|}{ SOURCE } & \multicolumn{2}{|c|}{ OETECTOR } & \multirow{2}{*}{ ANGLE } \\
\hline & & & TYPE & RANGE & TYDE & Range & \\
\hline$G, P$ & $A B Y$ & $6-999$ & $C$ & 999 & TEL-D & & DST \\
\hline & & & & & . & & \\
\hline & & & & & & & \\
\hline
\end{tabular}

ibstract: The angular dependences of proton photoproduction from the nuclei ${ }^{12} \mathrm{C},{ }^{63} \mathrm{Cu}$ and ${ }^{208} \mathrm{~Pb}$ irradiated by bremsstrahlung $\gamma$-quanta with maximum energy $4.5 \mathrm{GeV}$, both in the cumulative region (i.e. in the kinematical region in which the production of protons in the collision of $\gamma$-quanta of the given energy with the quasi-free nuclear nucleon is forbidden) and in the non-cumulative region, are investigated. The experimental data obtained are compared with the results of theoretical calculations of cumulative proton photoproduction according to the following models: the "quasi-two-body" scaling model, the low-nucleon correlation model, the fluctuon model and the cluster model.

NUCLEAR REACTIONS ${ }^{12} \mathrm{C},{ }^{63} \mathrm{Cu},{ }^{208} \mathrm{~Pb}(\boldsymbol{y}, \mathrm{p}), E=4.5 \mathrm{GeV}$ bremsstrahlung: measured $\sigma\left(E_{n,} \theta_{p}\right):$ dcduccd reaction mechanism. Natural target.

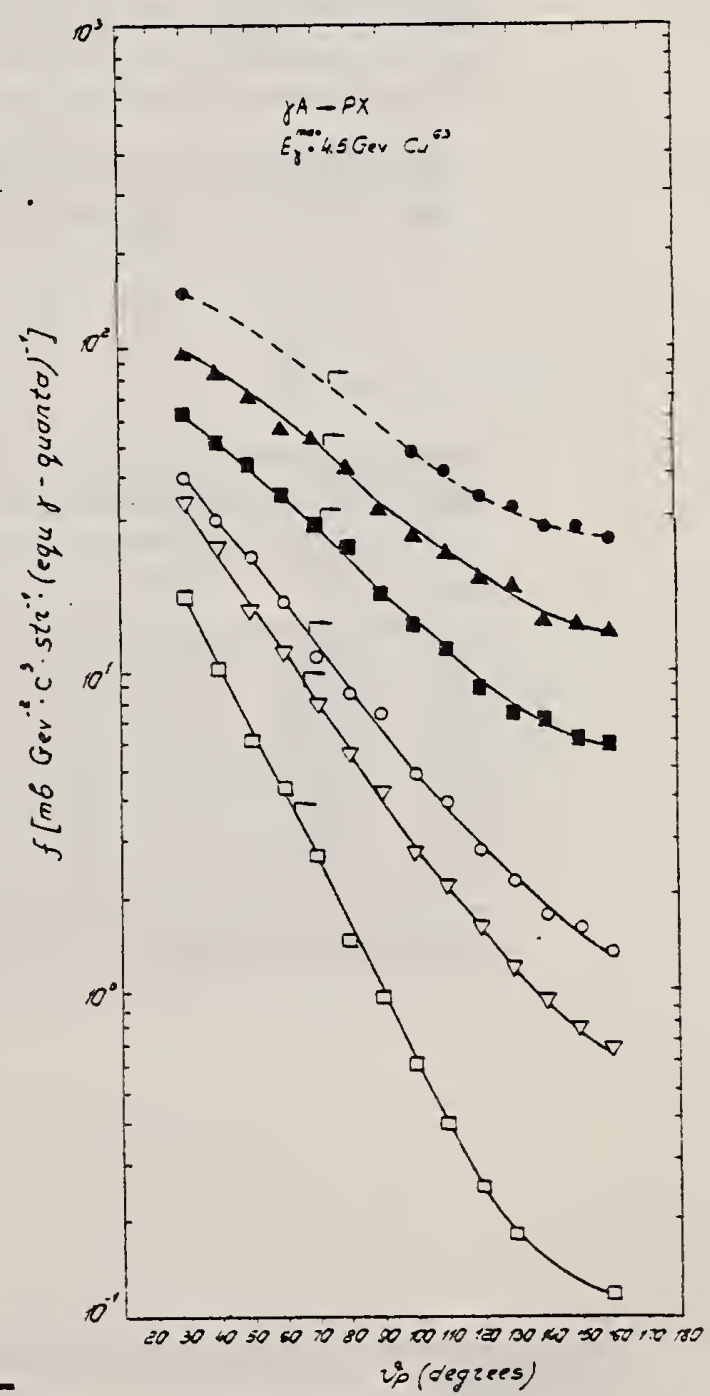

Fig. 4. The same as in fig. 3 for ${ }^{63} \mathrm{Cu}$. 
Y. Cauchois, H. Ben ABdelaziz, R. Khérouf; C. Schloesing-Möller REF. Phys. G7, 1539 (1981)

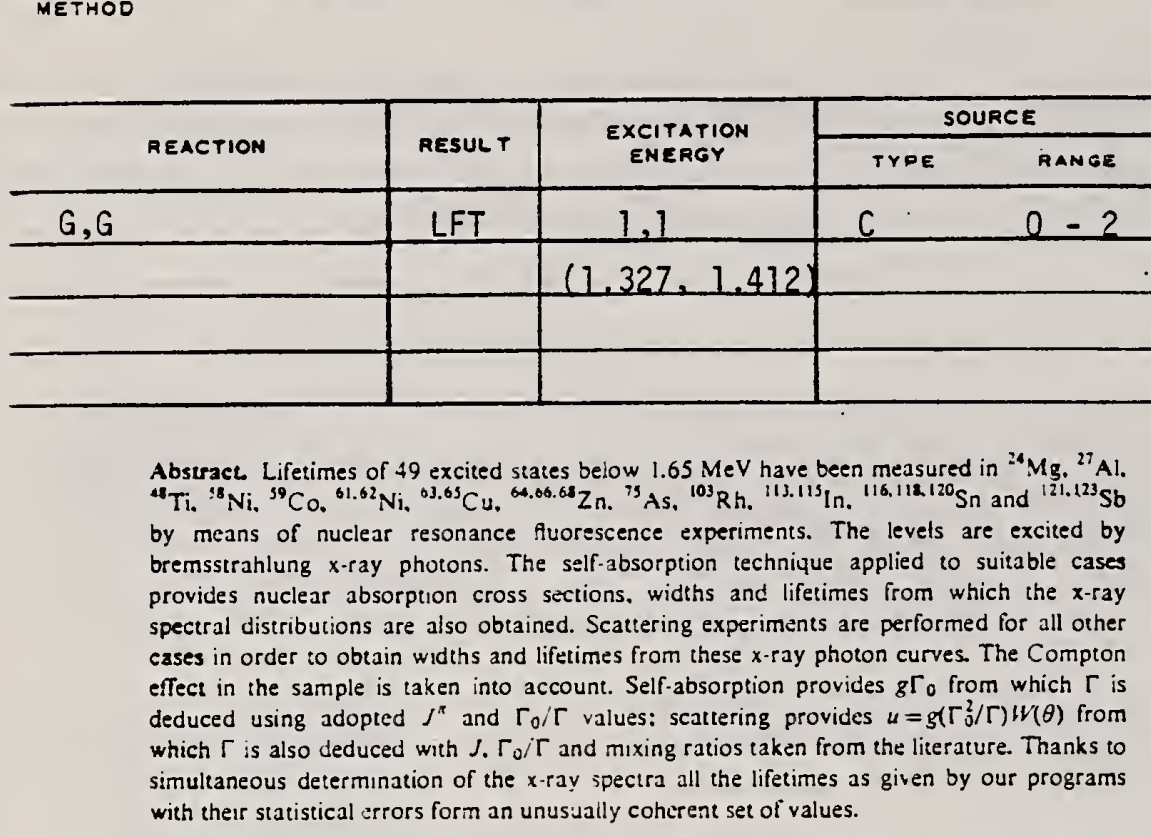

$81 \mathrm{Ca} 2$

with their statistical errors form an unusially coherent set of values.

NUCLEAR REACTIONS $(\% \%)$ bremsstrahlung excitation: natural isotopes: ${ }^{24} \mathrm{Mg}$.

${ }^{27} \mathrm{Al} .{ }^{48} \mathrm{Ti},{ }^{88} \mathrm{Ni},{ }^{59} \mathrm{Co},{ }^{61.62} \mathrm{Ni} .{ }^{63.65} \mathrm{Cu},{ }^{64.66 .08} \mathrm{Zn},{ }^{79} \mathrm{As},{ }^{103} \mathrm{Rh},{ }^{113.115} \mathrm{n},{ }^{16.118,120} \mathrm{Sn}$

and ${ }^{121.123} \mathrm{Sb}: E \simeq 0.5-1.65 \mathrm{MeV}$; measured $g \Gamma_{0}$ or $g\left(\Gamma_{\alpha}^{2} / \Gamma\right) W(\theta)$; deduced $T_{1 / 2}$.

Tableau 2. Resultats des inesures Jes niveaux etudies par self-absorption.

Table 2 Results obtained using the self-absurption incthod.

\begin{tabular}{|c|c|c|c|c|c|c|c|c|}
\hline Isotope & $\begin{array}{l}\text { Energie } \\
(\mathrm{keV})\end{array}$ & $J^{\prime \prime}$ & $J_{0}^{\pi}$ & $\Gamma_{0} / \Gamma$ & $\begin{array}{l}g \Gamma_{0}(\mathrm{meV}) \\
\text { ce travail }\end{array}$ & $\begin{array}{l}\text { ( }(p s) \\
\text { ce travail }\end{array}$ & iref (psi) & Réfërences ${ }^{\dagger}$ \\
\hline${ }^{59} \mathrm{Co}$ & $1190.0(3)$ & $2^{-}$ & $i^{-}$ & 1 & $11.3(5)$ & $0.0729(32)$ & $0.0804 \$ 1)$ & $\operatorname{kim}(1976)$ \\
\hline${ }^{03} \mathrm{Cu}$ & $669.62(5)$ & i- & - & 1 & $1.19(4)$ & $0.277(10)$ & $0.297(9)$ & Auble $(19796)$ \\
\hline${ }^{03} \mathrm{Cu}$ & $962.06(-)$ & $\vdots-$ & i- & 1 & $1.25(6)$ & $0.79:(38)$ & $0.851(43)$ & Auble (1979b) \\
\hline${ }^{03} \mathrm{Cu}$ & $1547.02(6)$ & $i-$ & $i$ & 0.803 & $2.6(1.7)$ & $0.20(13)$ & $0.1 f(0)(6)$ & Auble (1979b) \\
\hline${ }^{9} \mathrm{Cu}$ & $770.6(2)$ & ?- & - & 1 & $2.18(13)$ & $0.1 \leq 1(y)$ & $0.13(4)$ & Aubie (1975a) \\
\hline${ }^{09} \mathrm{Cu}$ & $1115.54(4)$ & $\vdots-$ & $i-$ & 1 & $2.47(28)$ & $0.400(45)$ & $0.38(2)$ & Auble (1975 1$)$ \\
\hline 113 ln & $1132.57(3)$ & $y^{*}$ & 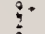 & 1 & $8.59(48)$ & $0.0920(51)$ & $0.092(5)$ & Cauchois et al (1977) \\
\hline $113 \mathrm{In}$ & $1463.5(12)$ & $\vdots$ & $?$ & 0.942 & $5,22(66)$ & $0.095(12)$ & $0.095(12)$ & Cauchois et al (1979) \\
\hline
\end{tabular}

$\uparrow$ Réfërences pour les colonnes 3.4 .5 et 8 de ce tableau. 
Tableau 3. Resultats des mesures des niveaux etudies par ditTusion.

Table 3. Results obtained using the diffusion method.

\begin{tabular}{|c|c|c|c|c|c|c|c|c|c|}
\hline Isotope & Energie (keV) & $J^{*}$ & $J_{0}^{*}$ & $\Gamma_{0} / \Gamma$ & $\dot{\delta}$ & $\begin{array}{l}u=g\left(\Gamma_{0}^{2} / \Gamma\right) W(\theta) \\
(\mathrm{meV})\end{array}$ & $\begin{array}{l}\tau(p s) \\
\text { ce travail }\end{array}$ & $T_{r e r}(p s)$ & Reiërencest \\
\hline${ }^{i 4} \mathrm{Mg}$ & $1368.59(4)$ & $2^{+}$ & $0^{*}$ & 1 & $\varepsilon 2$ & $1,08(13)$ & $1,76(21)$ & $1.98(4)$ & $\begin{array}{l}\text { Endt et van der Leun } \\
\qquad(1978)\end{array}$ \\
\hline${ }^{27} \mathrm{Al}$ & $1014.45(3)$ & $3^{+}$ & $i$ & 0.971 & $+0,351(12)$ & $0,186(13)$ & $2.20(16)$ & $2,12(8)$ & $\begin{array}{l}\text { Endt ct van der Leun } \\
\qquad(1978)\end{array}$ \\
\hline "Ti & $983.512(3)$ & $2^{\circ}$ & $0^{*}$ & 1 & $E 2$ & $0.282(23)$ & $6.74(55)$ & $6.1(13)$ & Been (1978) \\
\hline${ }^{30} \mathrm{Ni}$ & $1454.45(15)$ & $2^{\circ}$ & $0^{*}$ & 1 & E2 & $2,11(26)$ & $0.90(11)$ & $0,92(3)$ & $\begin{array}{l}\text { Kocher et Auble } \\
\text { (1976) }\end{array}$ \\
\hline${ }^{59} \mathrm{Co}$ & $1099.224(25)$ & $2^{-}$ & $\frac{1-}{2}$ & 1 & $(E 2)$ & $0.069(8)$ & $4,79(55)$ & $3.17(58)$ & $\operatorname{Kim}(1976)$ \\
\hline${ }^{59} \mathrm{Co}$ & $1+58.8(3)$ & $y^{4-}$ & 5 & 0,91 & $(E 2)$ & $0.68(8)$ & $1,17(14)$ & $1.52(16)$ & $\operatorname{Kim}(1976)$ \\
\hline${ }^{39} \mathrm{Co}$ & $1480.9(3)$ & i- & $i$ & 0.8 & $<0.35^{\circ}$ & $1,23(15)$ & $0.254(31)$ & $0.31(3)$ & $\operatorname{Kim}(1976)$ \\
\hline${ }^{61} \mathrm{Ni}$ & $1185.7(6)$ & $1-$ & ;- & $0.77(8)^{\prime}$ & $|0.14|$ & $1,88(49)$ & $0,21(5)$ & $0,16(3)$ & Andreevet al (1974) \\
\hline${ }^{62} \mathrm{Ni}$ & $1172,91(9)$ & $2^{\circ}$ & $0^{\circ}$ & 1 & E2 & $0.88(17)$ & $2,15(42)$ & $2,09(3)$ & Haibert (1979a) \\
\hline${ }^{63} \mathrm{Cu}$ & $1327,00(7)$ & & $3-$ & 0.84 & (E2) & $1.04(14)$ & $0,84(11)$ & $0,88(4)$ & Auble $(1979 b)$ \\
\hline${ }^{63} \mathrm{Cu}$ & $1+12,05(4)$ & ?- & !- & 0.72 & $+0.61\{=8\}$ & $0,260(38)$ & $1,90(28)^{\circ}$ & $1.61(3)$ & Auble (1979b) \\
\hline $\mathrm{Zn}_{n}$ & $991.5+(7)$ & $2^{\circ}$ & $0^{*}$ & 1 & E2 & $0.640(54)$ & $2,97(25)$ & $2,60(13)$ & Halbert (1979b) \\
\hline${ }^{\circ} \mathrm{Cu}$ & $1431.83(5)$ & $i^{-}$ & ?- & 0.85 & $(E 2)$ & $1,13(19)$ & $0.79(13)$ & $0,49(5)$ & Auble (1975a) \\
\hline${ }^{\infty} \mathrm{Zn}_{\mathrm{n}}$ & $1039,37(6)$ & $2^{*}$ & $0^{*}$ & 1 & $E 2$ & $0,70(6)$ & $2,71(23)$ & $2.25(15)$ & Auble (1975b) \\
\hline${ }^{*} Z_{n}$ & $1077.38(5)$ & $2^{*}$ & $0^{*}$ & 1 & $\varepsilon 2$ & $0,70(6)$ & $2,71(23)$ & $2.34(23)$ & Lewis (1975) \\
\hline${ }^{79}$ As & $572.5(10)$ & ;- & i- & $1^{d}$ & $0.39^{\circ}$ & $0,236(26)$ & $4,14(46)$ & $3.5(9)$ & Horen et Lewis (1975) \\
\hline${ }^{79}$ As & $823.0(10)$ & ?- & i- & $0.86^{d}$ & $(E 2)$ & $0.214(22)$ & $4,27(43)$ & $3,5(3)$ & Rubinson et al (1967) \\
\hline${ }^{19}$ As & $865.5(10)$ & i. & - & $0.83^{d}$ & $-\varepsilon$ & $0,78(6)$ & $0,863(68)$ & $0,60(12)$ & Celliers el al (1977) \\
\hline "As & $1076,0(10)$ & & $3-$ & $0,94^{d}$ & $0,38^{d}$ & $1,97(13)$ & $0,287(19)$ & $0.32(7)$ & Celliers el al (1977) \\
\hline is As & $1123,5(10)$ & $t^{\circ}$ & $i^{-}$ & 1 & $E I^{\triangleleft}$ & $0,224(24)$ & $1,47(16)$ & - & \\
\hline As & $13+4.0(10)$ & ?- & ?- & $0.67^{d}$ & $0.20^{d}$ & $1.61(29)$ & $0.180(32)$ & $0.12(3)$ & W'ilsun (1970) \\
\hline is & $1370 .(\times 10)$ & 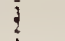 & i- & $0.47^{d}$ & $0.47^{d}$ & $0.64(13)$ & $0.218(44)$ & - & \\
\hline${ }^{103} \mathrm{Rh}$ & $803.1(2)$ & $\vdots-$ & $\vdots$ & 0.70 & $M 1$ & $1.85(16)$ & $0.174(15)$ & - & Harmatz (1979) \\
\hline${ }^{103} \mathrm{Kh}$ & 1277.0121 & $i$ & $\vdots$ & 0.75 & $-0,6 \geq(30)^{\circ}$ & $0.81(y)$ & $0.37(10)$ & $1.3(9)$ & 11:urma:14. $(1979)$ \\
\hline${ }^{113} \mathrm{ln}$ & $1177(1)$ & $1 \cdot$ & ?. & 1 & $+0.5(2)$ & $9.1(S)$ & $0.086(8)$ & $0.10(6)$ & Tut!le et $a /(1976)$ \\
\hline${ }^{113} \ln$ & $1510(1)$ & $\vdots$ & 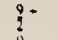 & 0,935 & $-0.5\{=11$ & $6,4(y)$ & $0.071(10)$ & $0.11 !+1\}$ & Tuttle et al $(1976)$ \\
\hline $113 \ln$ & $1077.7(: 0)$ & $\vdots$ & $\underline{3}$ & $0.81^{\prime}$ & $\left(E_{2}\right)$ & $0.159(24)$ & $1.61(24)$ & $1.23(7)$ & Tuttle et al (1976) \\
\hline $119 \ln$ & $1290.59(3)$ & 3 & 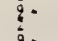 & $0.98^{\prime}$ & $\left(E_{2}\right)$ & $1.31(11)$ & $0.66(6)$ & $0.55(4)$ & Tutte et al $(1970)$ \\
\hline${ }^{115} \ln$ & $14+3.78(3)$ & 3. & ?. & 0.86 & $-8^{i}$ & $0.90(11)$ & $0.50(6)$ & $0.52(20)$ & Tuitle d" $a /(1476)$ \\
\hline $113 \mathrm{ln}$ & $14 s 6.1(1)$ & : & ?. & $0 .-87$ & $-0.8^{r}$ & $0.63(4)$ & $0.6:(9)$ & $0.4(3)$ & Tutule ct : :1(1976) \\
\hline${ }^{11 s} \ln$ & $1147.2(+1)$ & $(\vdots)$ & $\vdots$ & $<1$ & $(E 2)$ & $1.33(16)$ & $<0.30(4)$ & - & \\
\hline${ }^{115} \ln$ & $1609.8(15)$ & $(\vdots-)$ & ?- & $\leqslant !$ & $(E: 2)$ & $1.54(24)$ & $\leqslant 0,26(+1)$ & - & \\
\hline${ }^{110} \mathrm{Sn}$ & $124.3 .54(2)$ & 2 & $n^{*}$ & 1 & $E \geq$ & $3.58(37)$ & $0.53(6)$ & $0.522(1+)$ & Carlsun et a/ $(1975)$ \\
\hline${ }^{118} \mathrm{Sn}$ & $1224.64(1)$ & $2^{\circ}$ & $0^{\circ}$ & 1 & E2 & $2,75(28)$ & $0.69(7)$ & $0.67(2)$ & Caslsum el al(197h) \\
\hline${ }^{120} \mathrm{Sn}$ & $1171.6(2)$ & $2^{\circ}$ & $0^{*}$ & 1 & E2 & $1.83(16)$ & $1,04(9)$ & $0.91(2)$ & Kochur $(1976)$ \\
\hline${ }^{121} \mathrm{Sb}$ & $1023.5(10)$ & $i^{3}$ & $\vdots^{*}$ & 1 & $|0.57|^{8}$ & $3.69(34)$ & $0.228(21)$ & $0.20(7)^{h}$ & T.unura $2 t$ al $(1974)$ \\
\hline${ }^{121} \mathrm{Sb}$ & $1105,5(10)$ & ?. & $?^{7}$ & 0.4 & - & $0,47(4)$ & $0.42(4)$ & - & \\
\hline${ }^{121} \mathrm{Sb}$ & $11+2.5(10)$ & $\dot{q}$ & 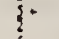 & 0.6 & $(E 2)$ & $0.85(8)$ & $0.449(40)$ & $0.41(8)^{n}$ & Booth et al $(1973)$ \\
\hline${ }^{121} \mathrm{Sb}$ & $1.784 .0(10)$ & 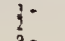 & $\vdots$ & 1 & $0.45 i^{3}$ & $4,7(5)$ & $0.092(10)$ & $0.088(14)^{h}$ & Bouthet al $(1973)$ \\
\hline${ }^{123} \mathrm{Sb}$ & $1029.5(10)$ & 2 & $\stackrel{i}{\vdots}$ & 1 & 0.57 & $2,96(27)$ & $0,272(25)$ & $0.26(4)^{\mathrm{k}}$ & Booth et al $(1973)$ \\
\hline${ }^{123} \mathrm{Sb}$ & $1086.5(10)$ & 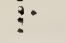 & $\vdots$ & 1 & $|\dot{\delta}|>1.26^{\prime}$ & $1.06(9)$ & $0.67(6)$ & $0.72(15)^{n}$ & Booth ef al $(1473)$ \\
\hline
\end{tabular}

+ Refererices pour les colonnes 3, 4, 5. 6 et 9 de shaque ligne, sauf indication appelec au bas de cee tableilu. l'nur les autres dounices se reportir au texte.

Rexte.
Rerque. Pout calculer $\delta^{-2}$ quand nous ne disposons que de $B(E 2)$. pour un méiange $(E 2)+(M 1)$. nous deduisons $g \Gamma 0(E 2) \times B(E 2) E_{\text {; }}^{3}:$ en

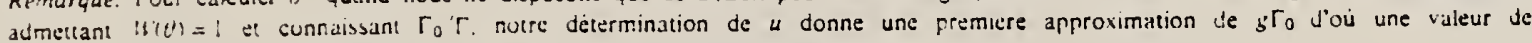

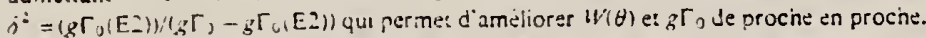

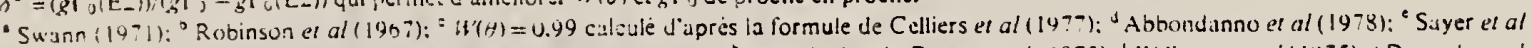
(1972): "Tuttle ef al $(1976)$ : "dapres B(E2) de Barnes et al (1966): "calcule d"apres Booth et al (1973): "Willtams et al (1975): I Dietrich el al 114701 . 
REF. M.N. Martins, E. Wolynec, M.C.A. Campos

Phys. Rev. C26, 1936 (1982)

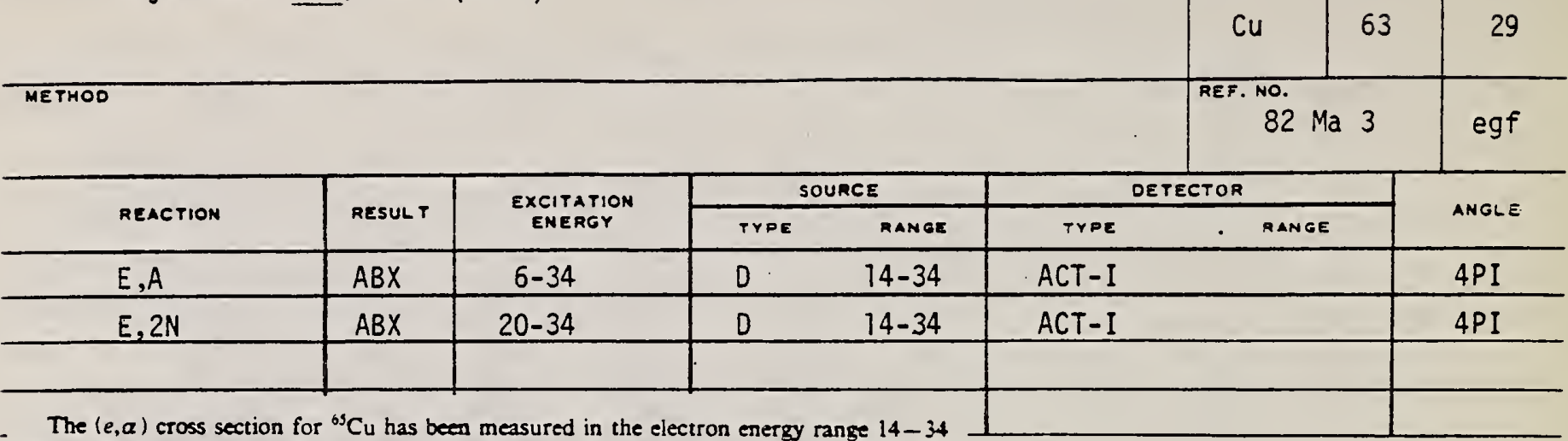

$\mathrm{MeV}$. The results have been analyzed using the distorted-wave Bom approximation $E 1$ and $E 2$ virtual photon spectra and the $E l$ and $E 2$ components of the corresponding $(\gamma, a)$ cross section were obtained. To assess the accuracy of the virual photon analysis, the $(e, 2 n)$ cross section for ${ }^{63} \mathrm{Cu}$ was also measured and the obtained $(\gamma, 2 n)$ cross section is compared with direct messurement of this cross section performed with annihilation gamma rays.

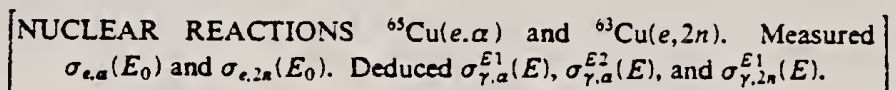

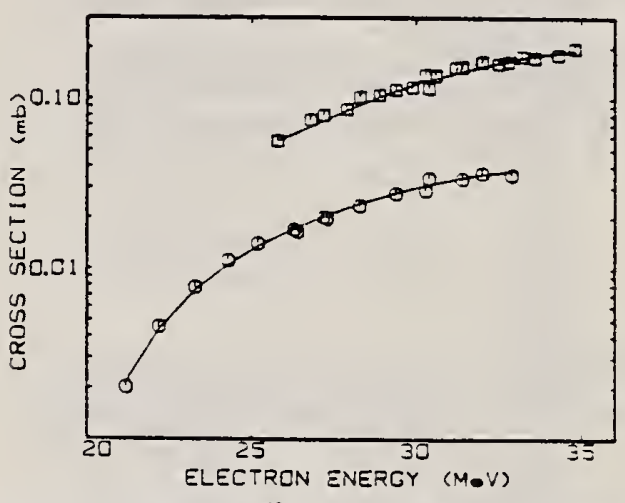

FIG. 3. $\sigma_{e, 2 n}\left(E_{0}\right)$ for ${ }^{63} \mathrm{Cu}$ (circles) and the yield of electrodisintegration plus photodisintegration (squares). The smonth curves are the best fit to the data and were obrained by combining the histogram shown in Fig. 5 with the $E I$ virtual photon spectrum and the Davies. Bethe-Maximom (DBM) bremsstrahlung cross section ia Eqs. (1) and (2).

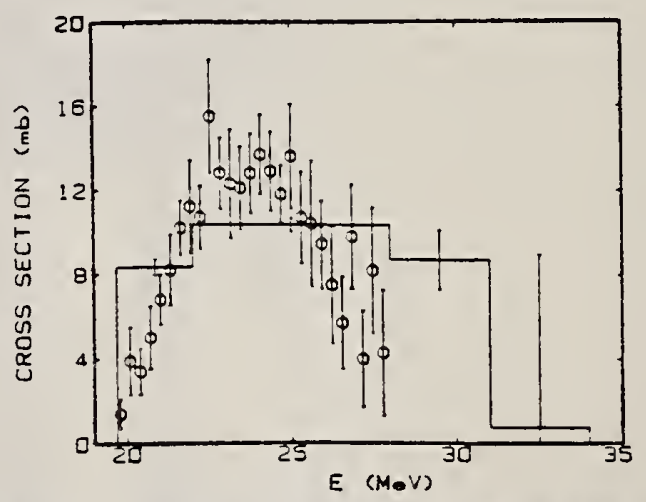

FIG. 5. ${ }^{63} \mathrm{Cu}(\gamma, 2 n)$ cross section. The histogram is the result derived from this work and the points show the measurement of Fultz et al.'

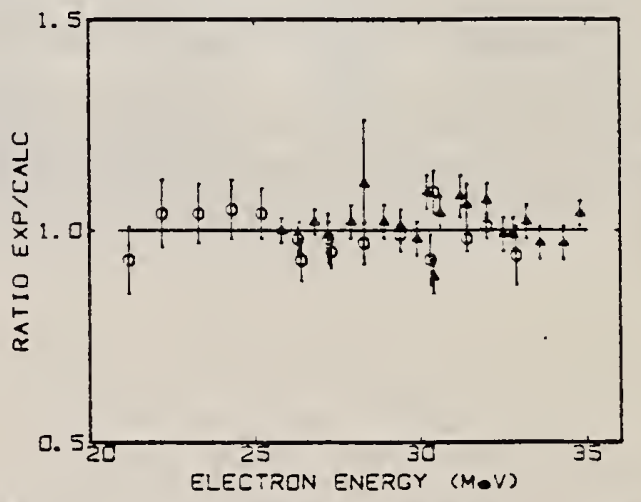

FIG. 6. Ratio of measured to calculated $(e, 2 n)$ cross section (circles) and measured to calculated yield of electrodisintegration plus photodisintegration (triangles). 
$A=65$ 
Ref. P. Erdos, P. Scherrer, P. Stoll

Helva. Phys. Acta 20, 639 (1957)

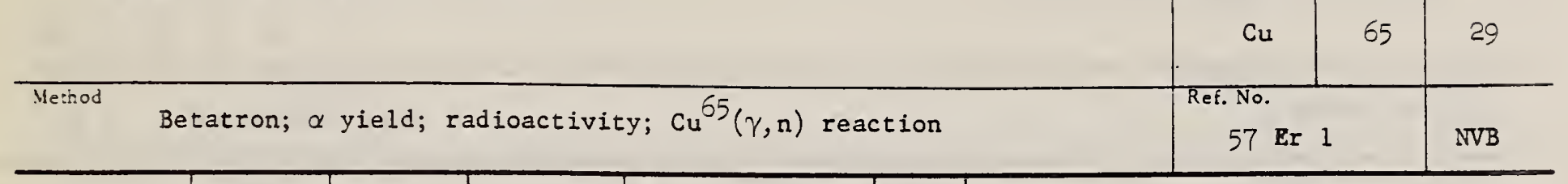

\begin{tabular}{c|c|c|c|c|c|c}
\hline Reaction & $E_{\text {or }} \mathrm{E}$ & $\mathrm{E}_{\mathrm{o}}$ & $\Gamma$ & $\int \sigma \mathrm{dE}$ & $J \pi$ & Notes \\
\hline $\mathrm{Cu}{ }^{65}(\gamma, \alpha)$ & Bremss. & & & $10 \pm 2 \mathrm{MeV}-\mathrm{mb}$ & & Based on yield measurement.
\end{tabular}

32 
Ref. W.L. Bende1, J. McElhinney, R.A. Tobin Phys. Rev. 111, 1297 (1958)

Method Ref. No.

Activation 58 Be 1

\begin{tabular}{l|l|l|l|l|l|l}
\hline Reaction & $E$ or $\Delta E$ & $E_{0}$ & $\Gamma$ & $\int \sigma d E$ & $J \pi$ & Notes \\
\hline$(\gamma, n)$ & & & & & & $\begin{array}{l}E_{t h}=9.89 \pm 0.11 \text { based on }(\gamma, n) \text { thres- } \\
\text { holds in } \mathrm{F}^{19}, \mathrm{~N}^{14} \text { and } \mathrm{C}^{12}\end{array}$
\end{tabular}


Rei. M.J. Aitken, N. Middlemas

Phys. Rev. 117, 1111 (1960)

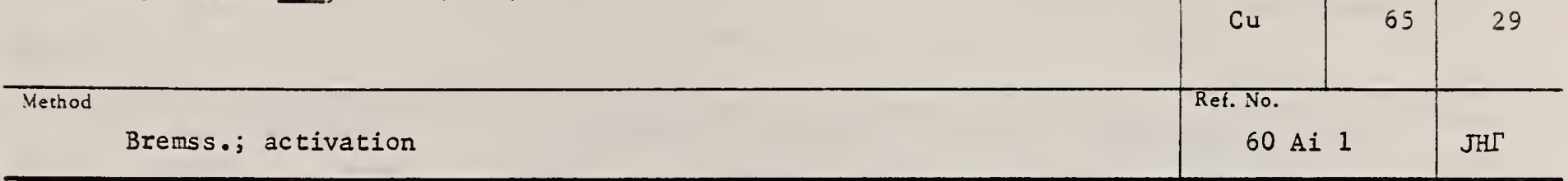

\begin{tabular}{|c|c|c|c|c|c|c|}
\hline Reaction & $E$ or $\Delta E$ & $E_{0}$ & $\Gamma$ & $\int \sigma d E$ & $\mathrm{~J} \pi$ & Notes \\
\hline$(\gamma, 3 n)$ & $E_{\text {max }}^{\text {Bremss }}=28$ & .8-110 & & $0.037 \pm .004 \int_{0}^{110} \mathrm{Mev}$ & -barn & $\begin{array}{l}\text { Determined ratio of } \mathrm{Cu}^{6} \text { produced by } \\
\mathrm{Cu}^{63}(\gamma, n) \text { and } \mathrm{Cu}^{65}(\gamma, 3 n) \text { in normal } \\
\text { copper as function of bremsstrahlung } \\
\text { energy. See Table II. }\end{array}$ \\
\hline
\end{tabular}

Frc. 1. $\mathrm{Cu} 4(\gamma, 3, \mathrm{Cu}$ yield eurve: $R$ is the ratho of $\mathrm{Cu}$ activity induced in equal weights of $\mathrm{Cras}^{\circ}$ and $\mathrm{Ca}_{0}$.

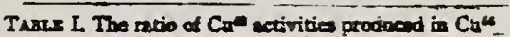
and $\mathrm{Cn}$ - by bremarnhims beans

\begin{tabular}{cc}
\hline $\begin{array}{c}\text { Bremsstrablung } \\
\text { energy } \\
\text { Yev }\end{array}$ & $\begin{array}{c}\text { Ratio of activity in } \\
\text { coppe and Cust } \\
\mathrm{Cu} / \mathrm{Ca}\end{array}$ \\
\hline 110 & $0.0414 \pm 0.0007$ \\
70 & $0.0411=0.0007$ \\
60 & $0.0356 \pm 0.0017$ \\
50 & $0.0350 \pm 0.0010$ \\
38.2 & $0.0025 \pm 0.0017$ \\
35 & $0.0205 \pm 0.0014$ \\
33.8 & $0.0070 \pm 0.0028$ \\
28.8 & $0.0017 \pm 0.0021$ \\
\hline
\end{tabular}

TABLx II. Entor introducad into absolute intensity cilibration

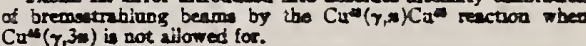

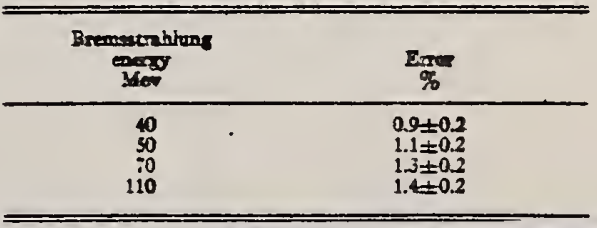


: ivi. E.C. Booth

Juclear Phys. 19,426 (1960)

Elem. Sym. |

65

z

$\mathrm{Cu}$

29

M.iind Van de Graaff; electron bremss.; Ring scatterer; NaI Rei. No.

60 Bo 3

JHH

\begin{tabular}{c|c|c|c|c|c|c}
\hline Ruaction & $E$ or $\Delta E$ & $E_{0}$ & $\Gamma$ & $\int \sigma d E$ & $J \pi$ & Notes \\
\hline$(\gamma, \gamma)$ & $\begin{array}{c}\text { Bremss. } \\
0.5-2.2\end{array}$ & 0.77 & & & $3 / 2$ & Mean lifetime $t / g:$ \\
& & & & & &
\end{tabular}

[resonance scattering]

where $g=(1+2 I) /\left(1+2 I_{0}\right)$.

Detector at $100^{\circ}$. 
-... velier, J. Halpern, ard:E. G. Muirhead

2r. =- Rev. $118,1302-12(1960)$

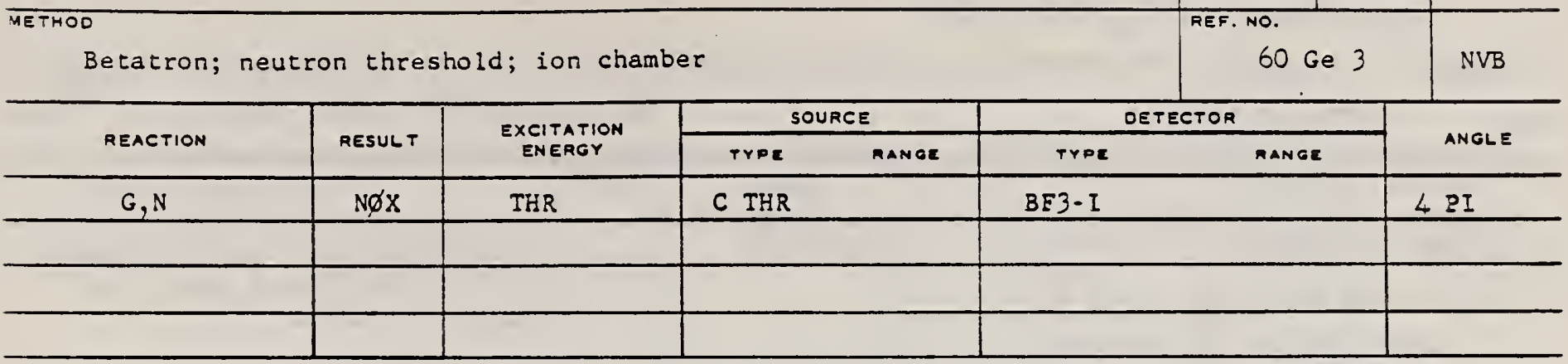

THRESH $\varnothing L D$

TABLz I. Summary and comperison of neutron scparation energies inferred from present threshold measurements with values predicted from mass data and reaction energies. All encrgies are expressed in the center-of-mess system in Mer.

\begin{tabular}{|c|c|c|c|c|c|}
\hline Rrnetlin & No. rums & l'rexent resulta & Other results & Method & Refcrence \\
\hline $\mathrm{Cu}^{*}(\gamma, n) \mathrm{Cu}^{\mu}$ & 2 & $9.896 \pm 0.028$ & $\begin{array}{l}9.913 \pm 0.006 \\
9.89 \pm 0.11\end{array}$ & $\begin{array}{l}\text { mass data } \\
\text { threshold }\end{array}$ & j \\
\hline
\end{tabular}

I K. S. Quisenberry. T. T. Scolman, and A. O. Nler, Phyn Rer, 104, 461 (19956). i See reference 2. 
Ref. N.V. Lin'kova, R.M. Osokina, B.S. Ratner, R.Sh. Amirov V.V. Akindinov

Zhur. Eksp. i Teoret. Fiz. 38, 780 (1960)

Soviet Phys. JETP 11,566 (1960)

Bremss.; emulsions

60 Ii 1

\begin{tabular}{l|l|r|r|}
\hline Method & Ref. No. & & 60 Ii 1 \\
\hline
\end{tabular}

\begin{tabular}{l|c|c|c|c|c|c}
\hline Reaction & $E$ or $\Delta E$ & $E_{0}$ & $\Gamma$ & $\int \sigma d E$ & $J \pi$ & Notes \\
\hline$(\gamma, p)$ & $12-28$ & & & $190 \mathrm{MeV}-\mathrm{mb}$ & & $\begin{array}{c}\text { Intéfgrated cross section based on } \\
(\gamma, \mathrm{p}) \text { of } 27 \mathrm{mb} \text { at peak (See }\end{array}$
\end{tabular}

Figures 4 and 5 ).

Angular distribution fitted to $I(\theta)=a+b \sin ^{2} \theta+c \sin ^{2} \theta \cos \theta$.

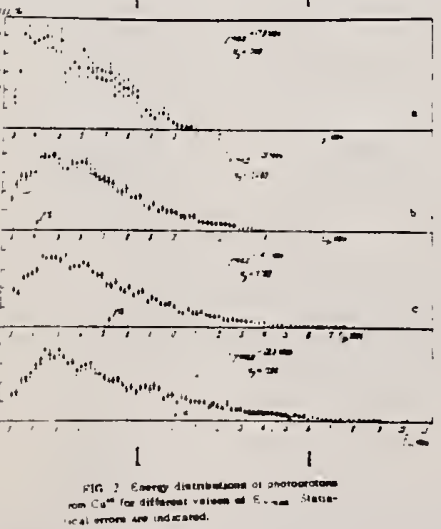

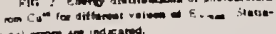

$190 \mathrm{MeV}-\mathrm{mb}$
Figures 4 and 5$).$
Angular distribution fitted to
$I(\theta)=a+b \sin ^{2} \theta+c \sin ^{2} \theta \cos \theta$.

FIG. 4. Cữ photoproton yield as a function of Eyma. Different symbols represent different sets of date. The broiken lines wor calculated from the stativical model: curve 1 for $=16$ Her ${ }^{-1}, 26$ curve 2 for $a=8$ iberat.
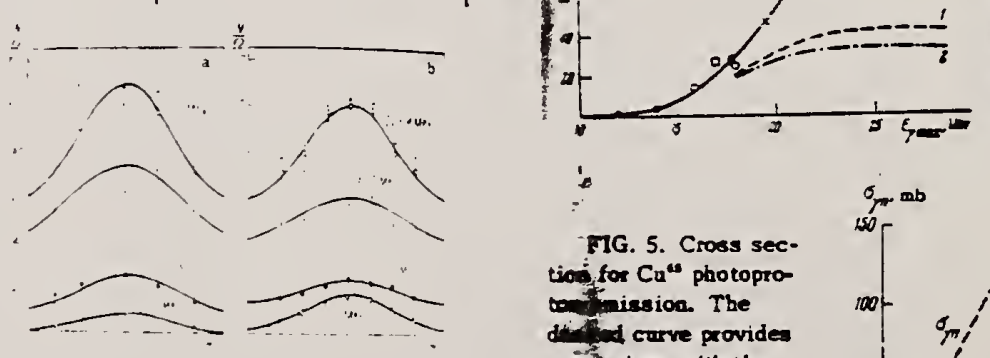

HG. 5. Cross section for Ca" photoprothission. The dind curve providea cuifurion with the creps saction for $\operatorname{cosinax} \cos ^{4} .19$
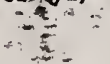

1.

Parameterg in the Angular Distribution of Protons.

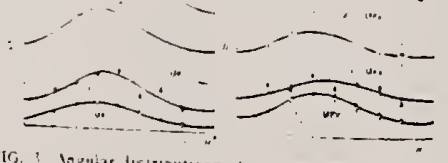

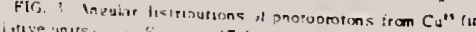

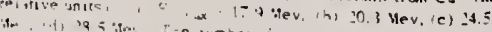

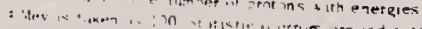

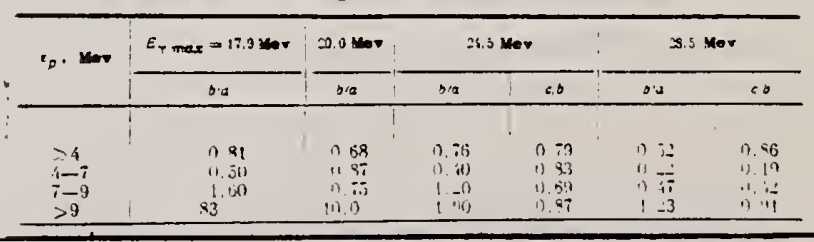
U.S. DEPARTMENT OF COMMERCE NATIONAL GUREAU OF STANDARDS 
Ref. G.E. Coote, W.E. Turchinetz, I.F. Wright Núclear Phys. 23, 468 (1961)

\begin{tabular}{l|l|c|c} 
& \multicolumn{1}{c|}{$\mathrm{Cu}$} & 65 & 29 \\
\hline Method $\mathrm{Li}^{7}(p, \gamma)$ source; activation; NaI & $\begin{array}{r}\text { Ref. No. } \\
61 \text { Co } 2\end{array}$ & $\mathrm{JHH}$ \\
\hline
\end{tabular}

\begin{tabular}{|c|c|c|c|c|c|c|}
\hline Reaction & $E$ or $\Delta E$ & $E_{0}$ & $\Gamma$ & $\int \sigma d \mathrm{E}$ & $J \pi$ & Notes \\
\hline$(\gamma, \mathrm{n})$ & & & & & & $\begin{array}{l}\sigma=70 \pm 7 \text { mb relative to } 59 \pm 6 \text { mb for } \\
\mathrm{Cu}^{63}(\gamma, \mathrm{n}) \text {, measured for } 440 \mathrm{kev}\left(\mathrm{E}_{\mathrm{p}}\right. \\
\text { resonance radiation from } \mathrm{Li}^{7} \text {. }\end{array}$ \\
\hline
\end{tabular}


Ret. V.P. Chizhov, i.?, Komar, L.A. Kuichitsky, A.V. Kulikov, E.D. Maknnovsly, Yu.M. Volkov

Nuclear Phys.

Elem. Sym.

A

$90 \mathrm{MeV}$ Synchrctron; magnetic spectrometer; emulsions; NeI counter Ref. No telescope

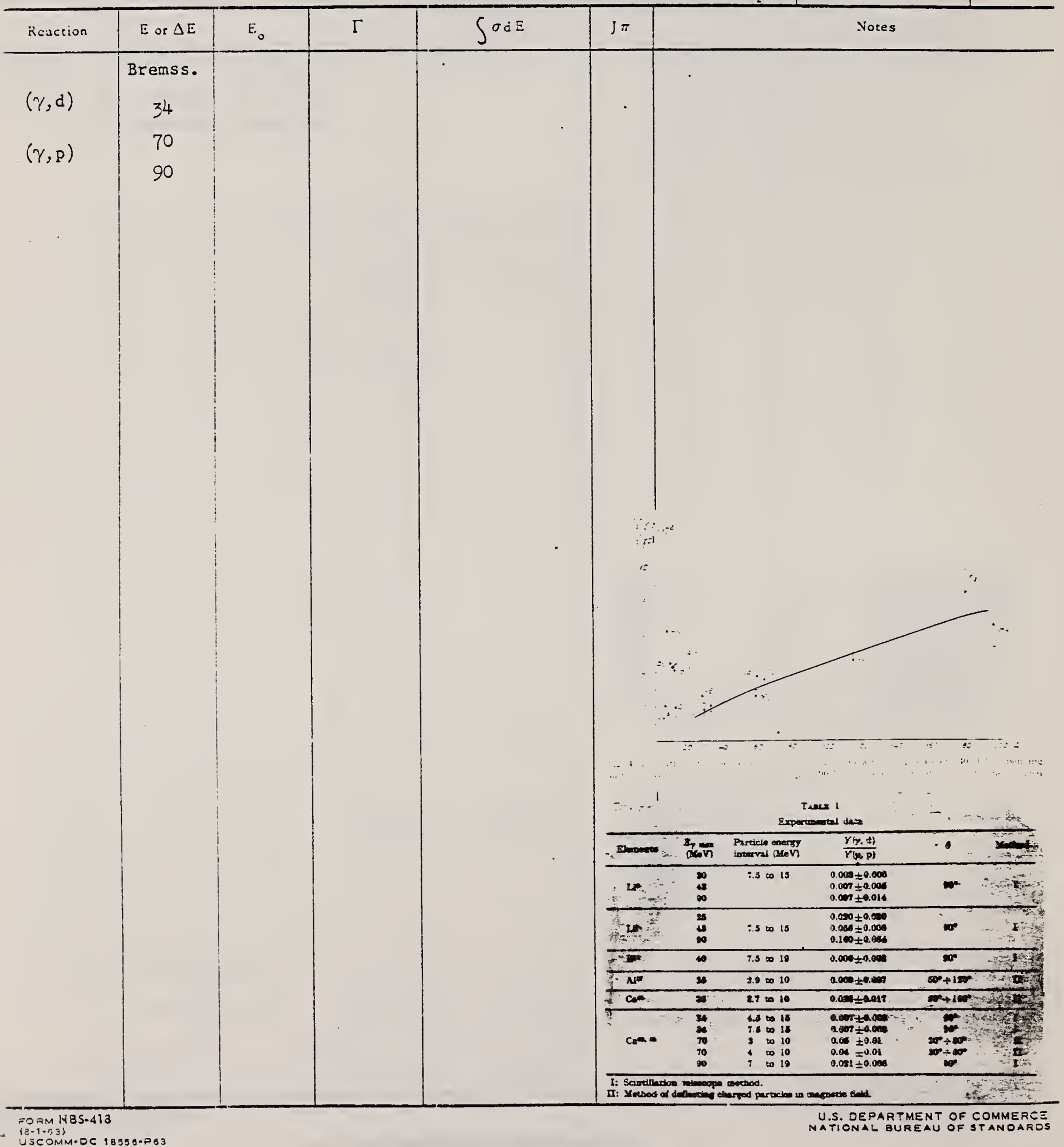


Ret. D.K. Kaipov, R.B. Begzhanov, A.V. Kuz'minov, Yu.K. Shubnyi Zhur. Eksp. i Teoret. Fiz. 44,1811 (1963)

Soviet Phys, JETP 17, 1217 (1963)

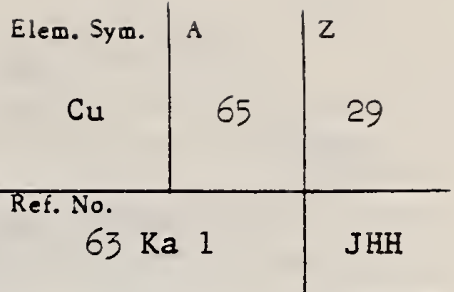

\begin{tabular}{|c|c|c|c|c|c|c|}
\hline Reaction & $E$ or $\Delta E$ & $E_{0}$ & $\Gamma$ & $\int \sigma d E$ & $\mathrm{~J} \pi$ & Notes \\
\hline $\mathrm{Cu}^{65}(\gamma, \gamma)$ & 1.114 & 1.114 & $\begin{array}{l}\Gamma_{\gamma}= \\
1.01 \times 10^{-3} \\
\mathrm{eV}\end{array}$ & & $\left(\frac{5}{2}\right)^{-}$ & $\begin{array}{l}\text { Mean resonance scattering cross } \\
\text { section: } \\
\quad \bar{\sigma}(1.114 \mathrm{MeV})=(1.42 \pm 0.14) 10^{-26} \mathrm{~cm}^{2} \\
\text { The measured } \Gamma_{\gamma} \text { infers a lifetime: } \\
T_{\gamma}=(6.5 \pm 1.6) 10^{-13} \mathrm{sec} \text { : }\end{array}$ \\
\hline
\end{tabular}

for $1.114 \mathrm{MeV}$ state.

Detector at $\sim 108^{\circ}$

Gaseous radioactive source; resonance scattering; NaI 
REF.

G.B. Beard

Phys. Rev. 135, B577-80 (1964)

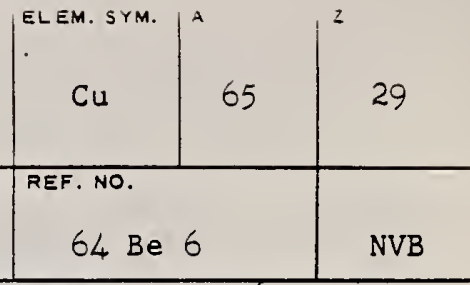

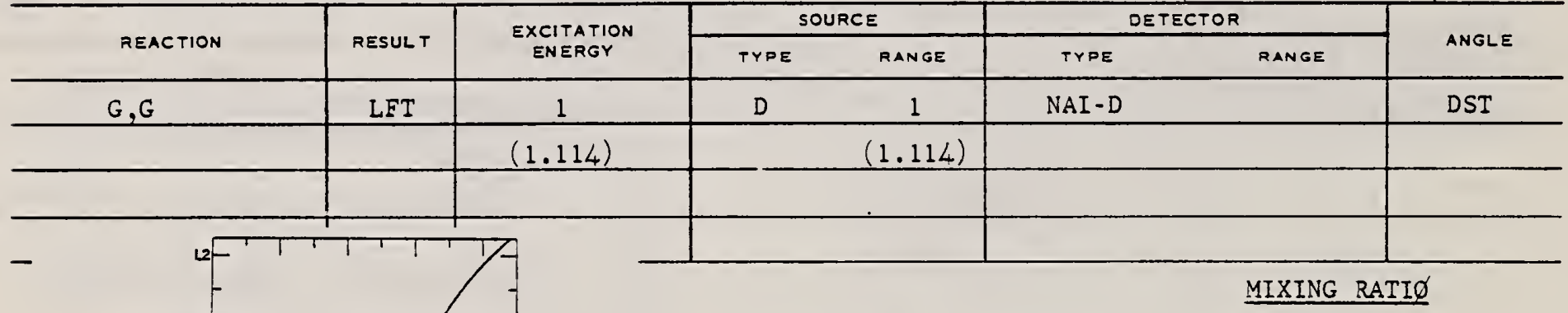

Fic. 2. Angular-correlation data. The solic curve represents the fit of the data for $A_{2}=1.02$ and $A_{4}=0.07$. The dashed curve show's the theoretical angular distribution, corrected for the finite angular resolution, for the assumption of pure $E 2$ transitions for a spin sequence of $\frac{3}{2}-\frac{7}{2}-\frac{3}{2}$. The two curves are normalized at $120^{\circ}$.

$$
\begin{aligned}
W(\cos \theta)=1 & +A_{2}^{2} P_{2}(\operatorname{Cos} \theta) \\
& +A_{4}^{2} P_{4}(\cos \theta)
\end{aligned}
$$

TABLE III. Summary of properites of the $1.114 \mathrm{MeV}$ state Rows 7 and 8 give the ration of the observed transition probabilities to the Weisshopi estimate inr the $E 2$ and $U 1$ transitions,

\begin{tabular}{|c|}
\hline 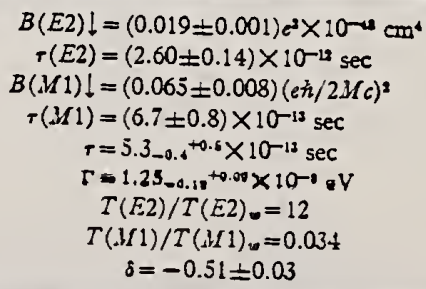 \\
\hline
\end{tabular}
spectively. $\left(R=1.2 A^{1 / 3} \times 10^{-13} \mathrm{~cm}.\right)$ D. H. Wilkinson in . Vuclear Spectroscopy, edited by F. Ajzenberk-
Selove (Academic Press inc., New York, 1960), p. 858 . 


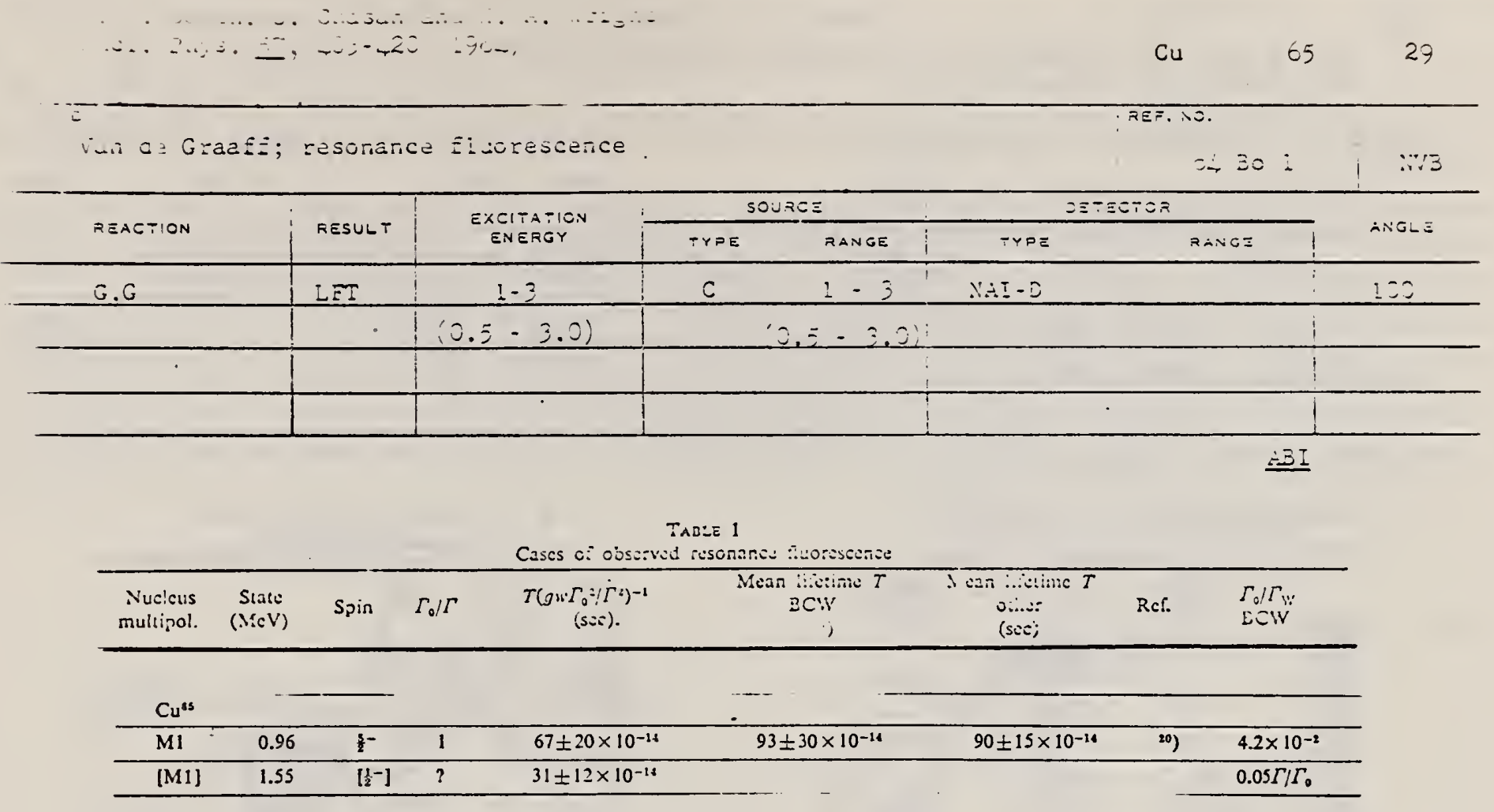


REF.

S.C. Fultz, R.L. Bramblett, J.T. Caldwell, R.R. Harvey

Phys. Rev. 133, B1149-54 (1964)

\begin{tabular}{l|l|l} 
CU & & \\
$\begin{array}{r}\text { REF. NO. } \\
64 \text { EU } 1\end{array}$ & NVB \\
\hline RANGE & ANGLE \\
\hline & LPI \\
\hline & LPI \\
\hline
\end{tabular}

Sample enriched to $99.7 \% \mathrm{Cu}^{65}$.

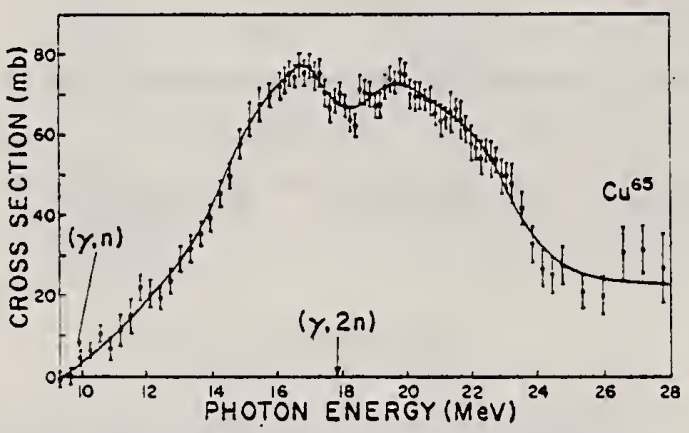

Fic. 6 . Total cross section $[\sigma(\gamma, n)+2 \sigma(\gamma, 2 n)+\sigma(\gamma, n p)]$ for $\mathrm{Cu}^{65}$ obtained from single-neutron counting dat 3 .

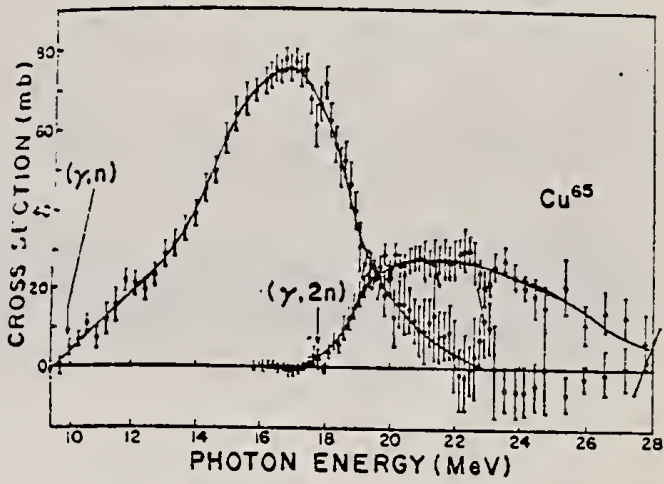

16. 7. Partial cross sections for $\mathrm{Cu}^{65}$. The top curve consists $\therefore \gamma(i, n)-\sigma(\gamma, n p)$. The lower curve consists of $\sigma(\gamma, 2 n)$ and was Whined from double-neutron counting data.

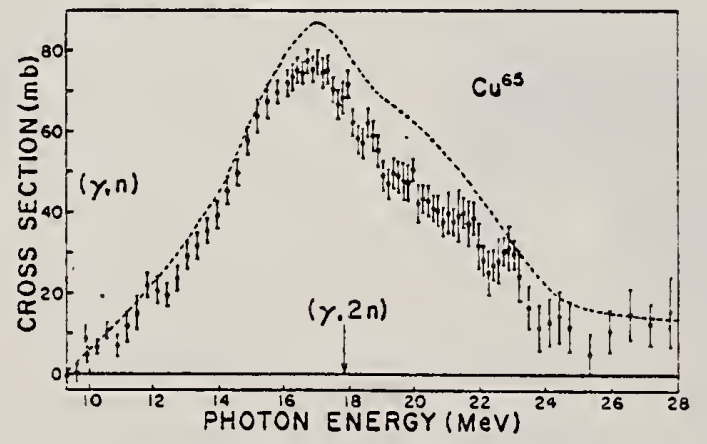

FiG. 8. The data points represent the sum $\sigma(\gamma, n)+\sigma(\gamma, n p)$ $+\sigma(\gamma, 2 n)$. The dashed line represents the nuclear formation cross section $\sigma(\gamma, n)+\sigma(\gamma, 2 n)+\sigma(\gamma, n p)+\sigma(\gamma, p)$ for which the $\sigma(\gamma, p)$ data was obtained from Ref. 20. 
RะF.

S.C. Fultz, R.L. Bramblett, J.T. Caldwell, R.R. Harvey

Phys. Rev. 133, B1149-54 (1965)

ELEM. SYM.

$\mathrm{Cu}$

REF. NO.

$64 \mathrm{Fu} 1$

NVB

Positron Annihilation; ion chamber [Page 2 of 2$]$

64 Fu 1

ANGLE

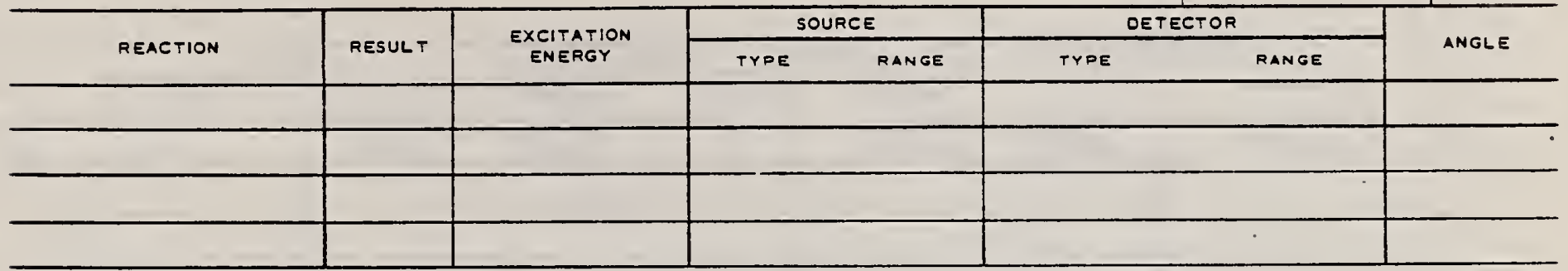

TABLE I. Integrated cross sections up to 28 . $\mathrm{MeV}$ for copper isotopes.

\begin{tabular}{|c|c|c|c|c|}
\hline Element & Reaction & $\begin{array}{l}\text { Integrated } \\
\text { cross section } \\
(\mathrm{MeV}-\mathrm{mb})\end{array}$ & $\begin{array}{l}\text { Fraction } \\
\text { of total } \\
\text { inte- } \\
\text { grated } \\
\text { cross } \\
\text { section }\end{array}$ & $\begin{array}{c}\text { Total } \\
(\mathrm{MeV}-\mathrm{mb})\end{array}$ \\
\hline Natural $\mathrm{Cu}$ & $\begin{array}{l}\left\{\begin{array}{l}\gamma, n)+(\gamma, n p) \\
\gamma, 2 \pi) \\
(\gamma, p)\end{array}\right. \\
-\end{array}$ & $\begin{array}{l}525=32 \\
110=11 \\
152 \pm 50\end{array}$ & $\begin{array}{l}0.67 \\
0.14 \\
0.19\end{array}$ & $787 \pm 113$ \\
\hline $\mathrm{Cu}^{\circ}$ & $\begin{array}{l}(\gamma, n)+(\gamma, n p) \\
+ \text { direct } \\
(\gamma, 2 \pi) \\
(\gamma, n p) \\
(\gamma, p) \\
(\gamma, n) \\
\text { direct }\end{array}$ & $\begin{array}{c}523 \pm 52 \\
80 \pm 8 \\
115 \pm 20 \\
161 \pm 48 \\
344 \pm 34 \\
64 \pm 22\end{array}$ & $\begin{array}{l}0.89 \\
0.11 \\
0.15 \\
0.21 \\
0.45 \\
0.08\end{array}$ & $764 \pm \infty$ \\
\hline $\mathrm{Cu}$ & $\begin{array}{l}(\gamma, n)+(\gamma, n p) \\
(\gamma, 2 n) \\
(\gamma, p)^{c}\end{array}$ & $\begin{array}{l}437 \pm 13 \\
195 \pm 19 \\
134 \pm 40\end{array}$ & $\begin{array}{l}0.57 \\
0.25 \\
0.18\end{array}$ & $766 \pm 103$ \\
\hline
\end{tabular}

TABLE II. Cross section for Li gamma rays.

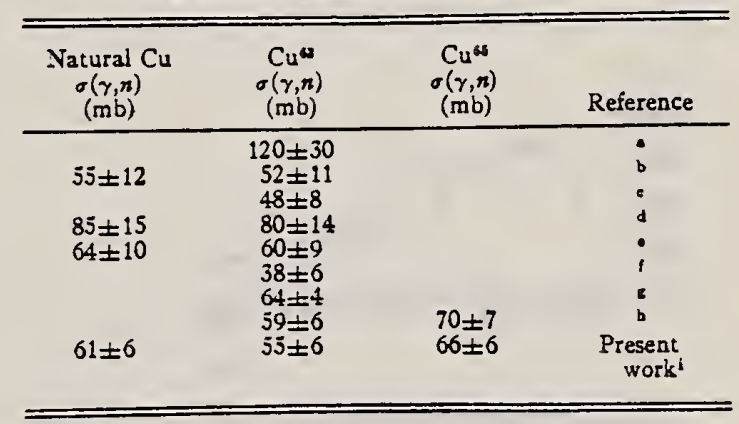

TABLE III. Quadrupole moments and Lorentz line parameters.

\begin{tabular}{|c|c|c|c|c|c|c|c|c|}
\hline $\begin{array}{l}\text { Nuclear } \\
\text { shape }\end{array}$ & Isotope & $\underset{(\mathrm{MeV})}{E_{\mathrm{e}}}$ & (mb) & $(\mathrm{MeV})$ & $\left(\begin{array}{c}E_{b} \\
\text { ev }\end{array}\right)$ & $\left(\begin{array}{c}\sigma b \\
m b\end{array}\right)$ & $(\mathrm{MeV})$ & $\begin{array}{l}O_{0} \\
\text { (b) }\end{array}$ \\
\hline $\begin{array}{l}\text { Prolate } \\
\text { Spliveroid }\end{array}$ & $\begin{array}{l}\mathrm{Cu}^{63} \\
\mathrm{Cu}\end{array}$ & $\begin{array}{l}16.00 \\
16.00\end{array}$ & $\begin{array}{l}48.5 \\
54.7\end{array}$ & $\begin{array}{l}3.5 \\
4.2\end{array}$ & $\begin{array}{l}19.0 \\
19.25\end{array}$ & $\begin{array}{l}+4.5 \\
62.0\end{array}$ & $\begin{array}{l}7.5 \\
7.5\end{array}$ & $\begin{array}{l}1.1=0.4 \\
1.2=0.4\end{array}$ \\
\hline $\begin{array}{l}\text { Oblate } \\
\text { Splieroid }\end{array}$ & $\begin{array}{l}\mathrm{Cu}_{u} u \\
\mathrm{Cu}\end{array}$ & $\begin{array}{l}16.50 \\
16.75\end{array}$ & $\begin{array}{l}62.5 \\
87.5\end{array}$ & $\begin{array}{l}5.0 \\
5.0\end{array}$ & $\begin{array}{l}21.25 \\
20.5\end{array}$ & $\begin{array}{l}22.0 \\
36.4\end{array}$ & $\begin{array}{l}7.1 \\
6.0\end{array}$ & $\begin{array}{l}-1.4=0.4 \\
-1.1=0.4\end{array}$ \\
\hline
\end{tabular}

TABLE TV. Integrated nuclear formation cross sections and $\sigma_{-2}$ values.

\begin{tabular}{|c|c|c|c|c|c|}
\hline Isotope & $\int_{(\mathrm{MeV}-\mathrm{mb})}^{2 \mathrm{~s}} \sigma d E$ & $\int_{(\mathrm{MeV}-\mathrm{mb})^{\mathrm{b}}}^{2 \mathrm{a}} \sigma d E+W$ & $\begin{array}{l}0.06 \mathrm{~V} Z / \mathrm{A} \\
(\mathrm{MeV}-\mathrm{mb})\end{array}$ & $\left(\mathrm{mb} / \mathrm{MeV}^{\sigma}\right)$ & $\begin{array}{c}0.00225 \mathrm{~A}^{\mathrm{s} / \mathrm{s}} \\
(\mathrm{mb} / \mathrm{MeV})\end{array}$ \\
\hline $\begin{array}{l}\mathrm{Cu}^{63} \\
\mathrm{Cu}^{6}\end{array}$ & $\begin{array}{l}764 \pm 109 \\
766 \pm 103\end{array}$ & $\begin{array}{l}913 \pm 121 \\
960 \pm 124\end{array}$ & $\begin{array}{l}939 \\
964\end{array}$ & $\begin{array}{l}2.1 \pm 0.3 \\
2.6 \pm 0.3\end{array}$ & $\begin{array}{l}2.4 \\
2.4\end{array}$ \\
\hline
\end{tabular}

The incegrated cross sections include estimated contributions from $(y, p)$ reactions. 


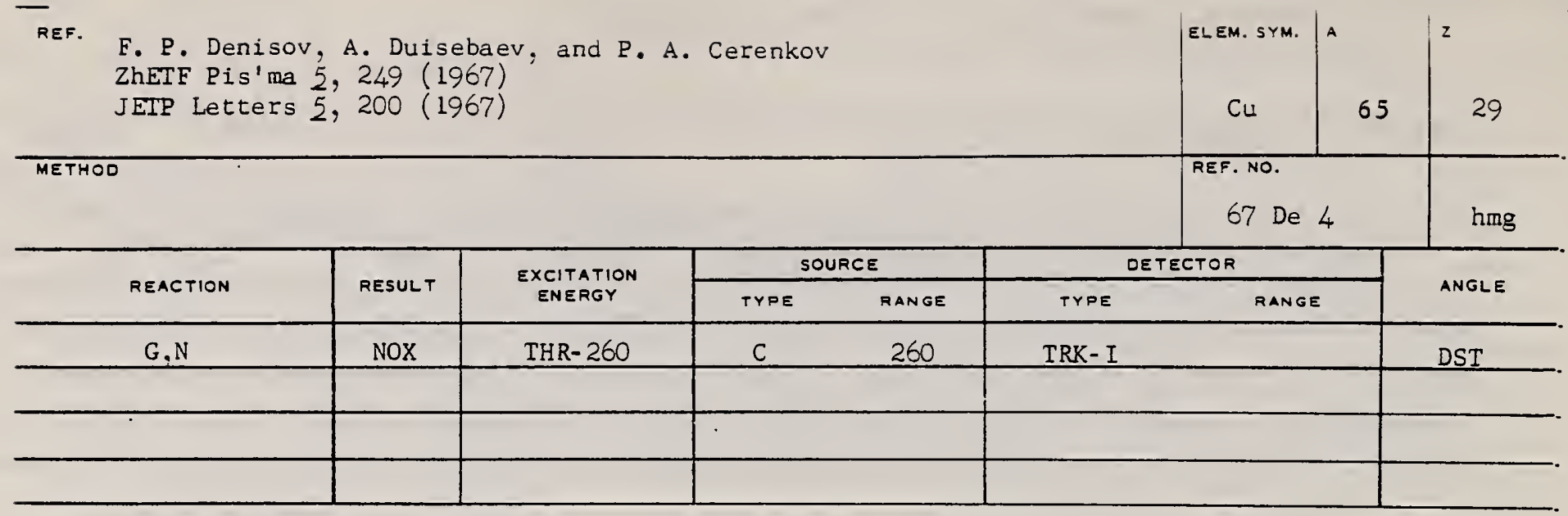

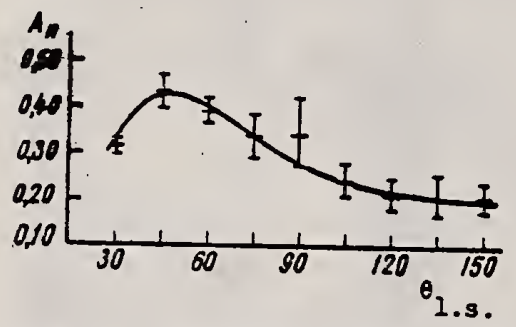

Angular distributions of $\mathrm{Cu}^{\text {at }} \mathrm{re}$ coll nuclel in the reaction $\mathrm{Cu}^{\circ 5}(r, n) \mathrm{Cu}^{\mathrm{OS}}$ 
K. Abe, N. Kawamura, H. Nihei, H. Tsubota and N. Mutsuro

J. Phys. Soc. Japan 25, 1723 (1968)

\begin{tabular}{|c|c|c|c|c|c|c|c|}
\hline METHOD & & & & & & $\begin{array}{l}\text { REF. NO. } \\
68 \text { Ab } 2\end{array}$ & egf \\
\hline \multirow{2}{*}{ REACTION } & \multirow{2}{*}{ RESULT } & \multirow{2}{*}{$\begin{array}{l}\text { EXCITATION } \\
\text { ENERGY }\end{array}$} & \multicolumn{2}{|c|}{ SOURCE } & \multicolumn{2}{|c|}{ DETECTOR } & \multirow{2}{*}{ ANGLE } \\
\hline & & & TYPE & RANGE & TYPE & RANGE & \\
\hline \multirow[t]{2}{*}{$G, X P$} & SPC & THR- 27 & C & 27 & $S C D-D$ & $2-16$ & 90 \\
\hline & & $(26.6)$ & & & & & \\
\hline & & & & & & & \\
\hline & & & & & & & \\
\hline
\end{tabular}

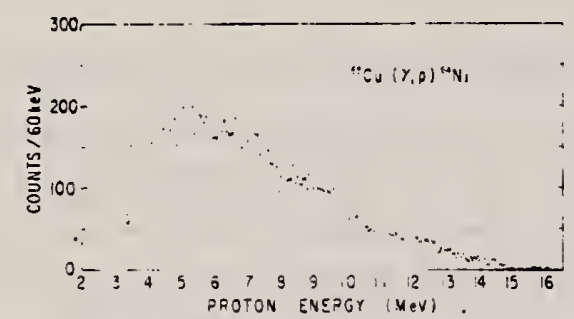

Fig. 2. Encrgy spectrum of photoprotons from os Cu at 90", with bremsstrahlung end-point encrgy $26.6 \mathrm{M} \in \mathrm{V}$. 
F. R. Metzger

Phys. Rev. 171, 1257 (1968)

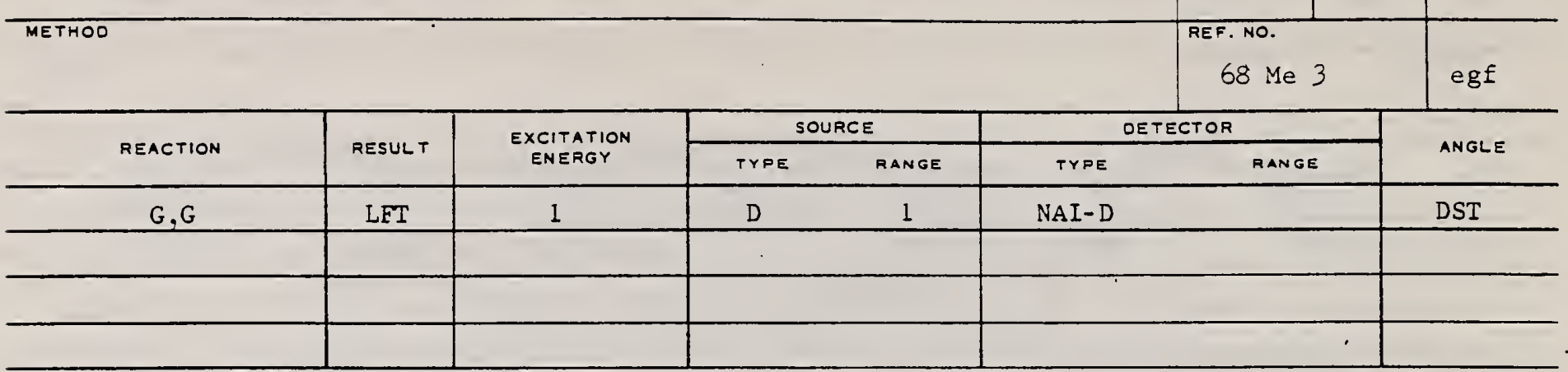

Angular distribution gives E2/MI

$\delta=-0.437 \pm 0.015$

TABLE II. Results of the self-absorption experiment.

\begin{tabular}{ccc}
\hline $\begin{array}{c}\text { Path iength } \\
\text { in Cu absorber } \\
(\mathrm{cm})\end{array}$ & $\begin{array}{c}\text { Resonant } \\
\text { attenuation }\end{array}$ & $\begin{array}{c}\text { Rarliative width } \mathrm{I} \\
(\mathrm{cV})\end{array}$ \\
\hline 1.26 & $0.913 \pm 0.006$ & $(1.62 \pm 0.13) \times 10^{-}$ \\
2.56 & $0.809 \pm 0.014$ & $(1.89 \pm 0.15) \times 10^{--}$ \\
\hline
\end{tabular}




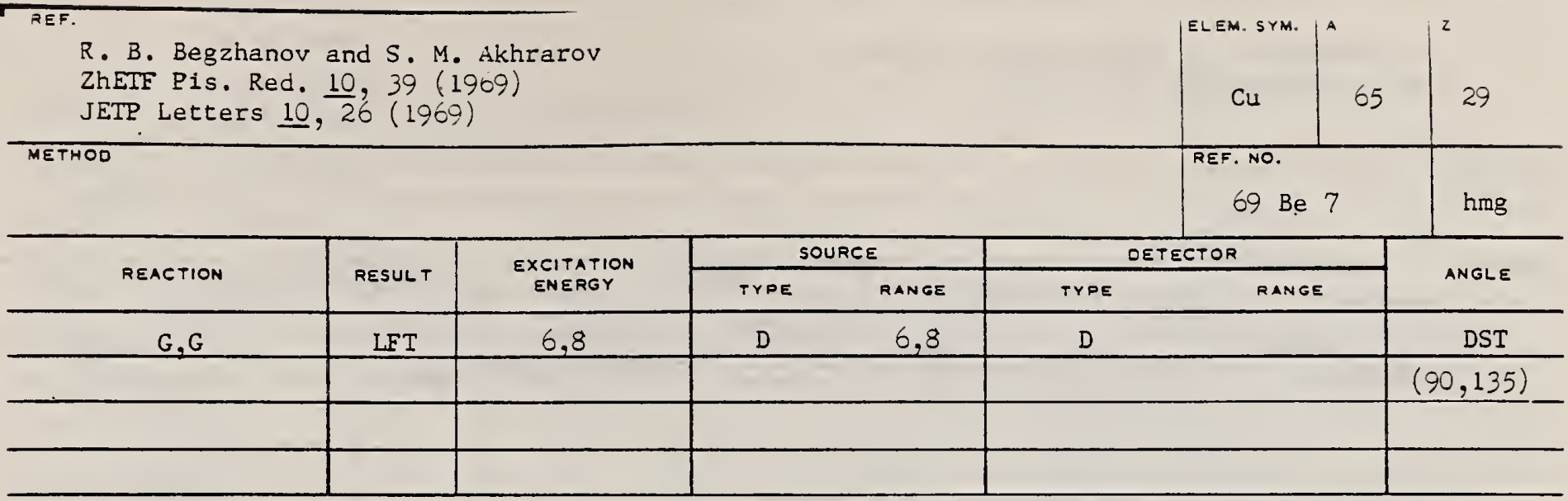

Self-Absorption.

$\underline{6.07,8.50 \mathrm{MEV}}$

Results of determination of the resonance-level parameters

\begin{tabular}{|c|c|c|c|c|c|c|}
\hline & $\begin{array}{l}\text { Source- } \\
\text { stterer }\end{array}$ & $\mathrm{HeV}^{E^{\prime}}$ & $\begin{array}{c}\left\langle\sigma_{p p}\right\rangle \\
m b\end{array}$ & $\begin{array}{l}r_{Y_{0^{\prime}}} \\
\mathrm{eV}\end{array}$ & ké & Reference \\
\hline $\mathrm{Pb}$ & - $Z_{0} 64$ & 7,38 & $33 \pm 4.5$ & $0.59 \pm 0.12$ & $53.70 \pm 10.13$ & This work \\
\hline $\mathrm{Ti}$ & -11096 & 5.413 & $11.2 \pm 1.4$ & $0.11 \neq 0.02$ & $8.58 \pm 1.57$ & $"$ \\
\hline $\mathrm{Ti}$ & - La 139 & 9,413 & $1504 \pm 2.10$ & $0.29 \pm 0.05$ & $8.9 .3 \pm 1.42$ & $"$ \\
\hline \multirow[t]{3}{*}{$\mathrm{Ti}$} & $-8 i^{209}$ & 7.15 & $1200 \pm 230$ & $0.32 \pm 0.07$ & $1.84 \leq 0.40$ & $"$ \\
\hline & & 5.996 & 1550 & - & - & [1] \\
\hline & & 7.15 & $2600 \pm 800$ & $0.42 \pm 0.14$ & - & [\$] \\
\hline \multirow[t]{2}{*}{$\overline{\mathbf{I}}$} & $-\mathrm{C}_{4} 65$ & 5.07 & $423 \pm 108$ & $0.34 \pm 0.06$ & $99.1 \pm 17.4$ & This rork \\
\hline & & 5.07 & $440 \pm 130$ & $0.36 \pm 0.07$ & & [5] \\
\hline & - $\mathrm{Cu}^{63}$ & 6.67 & $215 \pm 71$ & $0.18 \pm 0.24$ & $57.14 \pm 12.7 \pi$ & This work \\
\hline & & 5.07 & $200 \pm 50$ & $0.15 \pm 0.03$ & - & [ $\quad[6]$ \\
\hline & & 3.50 & $22 \pm 7$ & $0.25 \pm 0.08$ & $130 \pm 40$ & This work \\
\hline \multirow[t]{3}{*}{ C } & $-\mathrm{C}_{0}{ }^{63}$ & 8.499 & 35 & 75 & - & [1] \\
\hline & & 9.50 & $19 \pm 6$ & $0.28 \pm 0.09$ & - & [5] \\
\hline & & 8.50 & $36 \pm 9$ & $0.47 \pm 0.10$ & $21.36 \pm 4.54$ & This work \\
\hline & $-\mathrm{Co}^{65}$ & 8.499 & 80 & 10.5 & - & [1] \\
\hline & & 8.50 & $42 \pm 13$ & $0.94 \pm 0.29$ & - & [ 6$]$ \\
\hline & & 7.01 & $1150 \pm 240$ & $0.1 \dot{5} \pm 0.04$ & $0.44 \div 0.12$ & This work \\
\hline & $\rightarrow \mathrm{Sa}^{117}$ & $\left\{\begin{array}{l}7.01 \\
.01\end{array}\right.$ & 1000 & - & - & [1] \\
\hline & & 7.01 & $1200 \pm 4 C O$ & $0.3 \pm 0.3$ & - & [5] \\
\hline $\mathrm{Hg}_{\mathrm{g}}$ & - Mo 96 & 6.44 & $201=37$ & $0.12 \pm 0.04$ & $|0.23 \pm 3.07|$ & This work \\
\hline
\end{tabular}


$\begin{array}{llll}71 & B 1 & 1\end{array}$

egf

\begin{tabular}{|c|c|c|c|c|c|c|c|}
\hline \multirow{2}{*}{ REACTION } & \multirow{2}{*}{ RESULT } & \multirow{2}{*}{$\begin{array}{l}\text { EXCITATION } \\
\text { ENERGY }\end{array}$} & \multicolumn{2}{|c|}{ SOURCE } & \multicolumn{2}{|c|}{ DETECTOR } & \multirow{2}{*}{ ANGLE } \\
\hline & & & TYPE & RANGE & TYPE & FANGE & \\
\hline$G$, PIt & $A B Y$ & $150-700$ & C & $150-700$ & $\mathrm{ACT}-\mathrm{I}$ & & $4 P I$ \\
\hline & & & & & & & \\
\hline & & & & & & & \\
\hline
\end{tabular}

SEE $68 \mathrm{NY} 1$

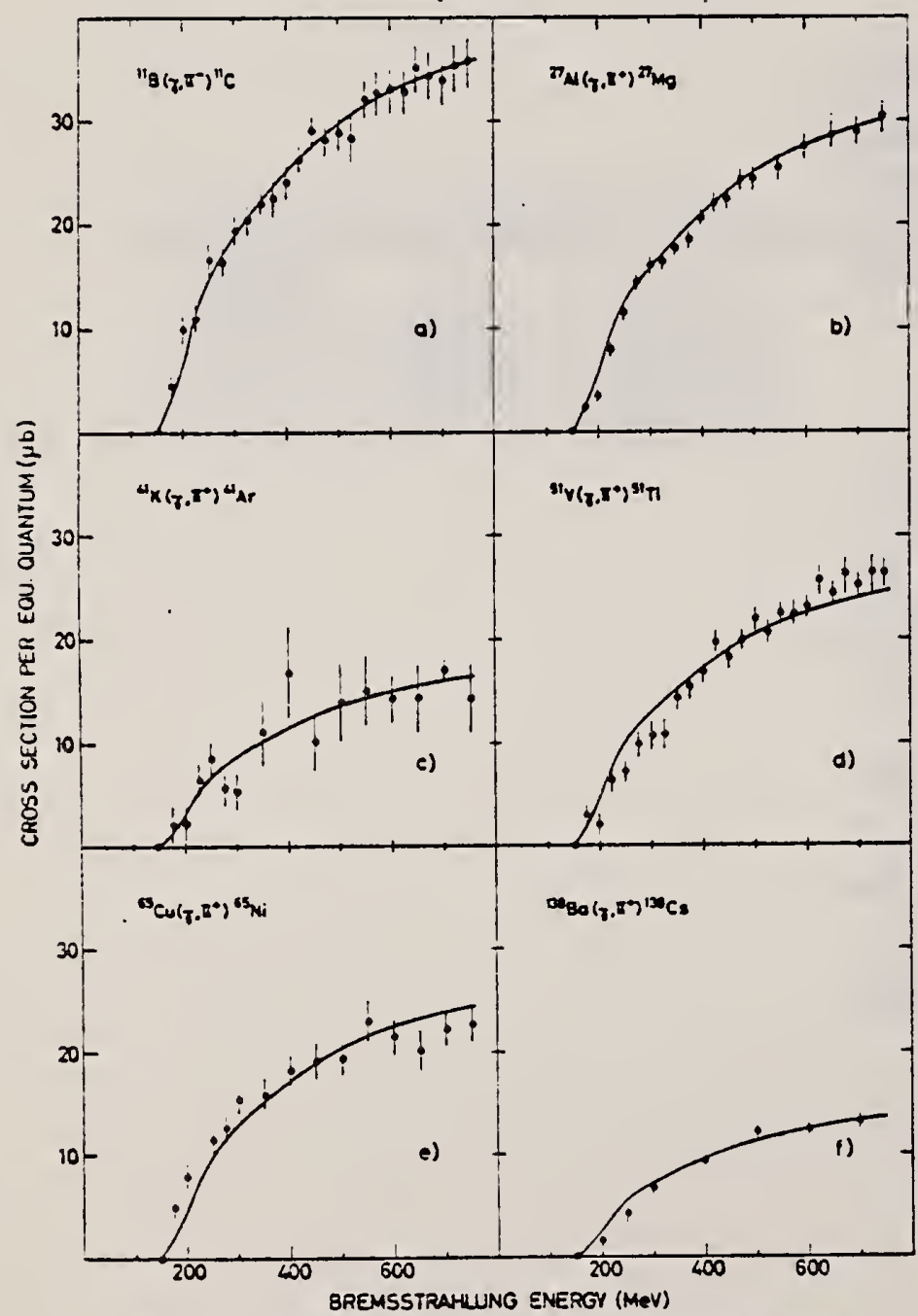

Fir. 2 Absolute yields for all but one of the measured reactions. 


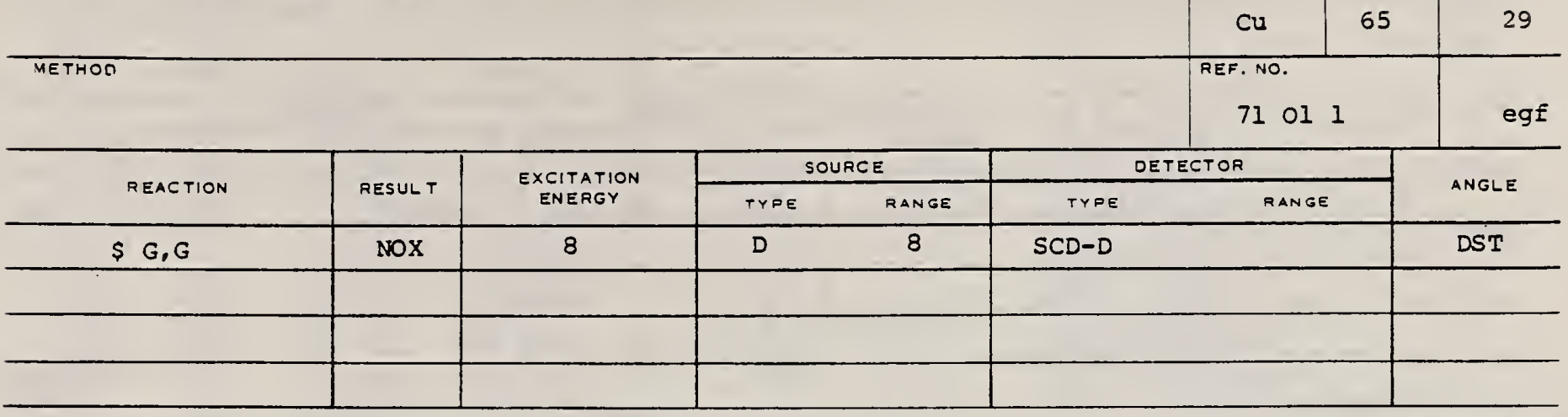

The results of the angular distribution measurement of the

elastically scattered radiation in the ${ }^{65} \mathrm{Cu}(\gamma, \gamma)$ reaction $\left(E_{\gamma}=8484 \mathrm{keV}\right)$ are shown in Fig. 2. A parametric plot of

$A_{2} \gamma$ and $A_{4} 4$ vs. $\delta^{\prime}=\delta /(1+|\delta|)$ is also reported. Two values for $\delta$ are consistent with these measurements. They are $\delta=-0.14 \pm 0.02$ and $\delta=0.61 \pm 0.01$. The experimental asymetry ratio is $\mathrm{K}=1.10 \pm 0.02$, which is only consistent with the value $K=1.07$ calculated for $\delta=0.61$ and for the resonant level spin value $j^{\pi}=5 / 2^{-}$. Thus, the decay from this level to the $3 / 2^{-}$ground state is an Ml-E2 mixture, with mixing ratio $\delta^{2}=0.37 \pm 0.01$.
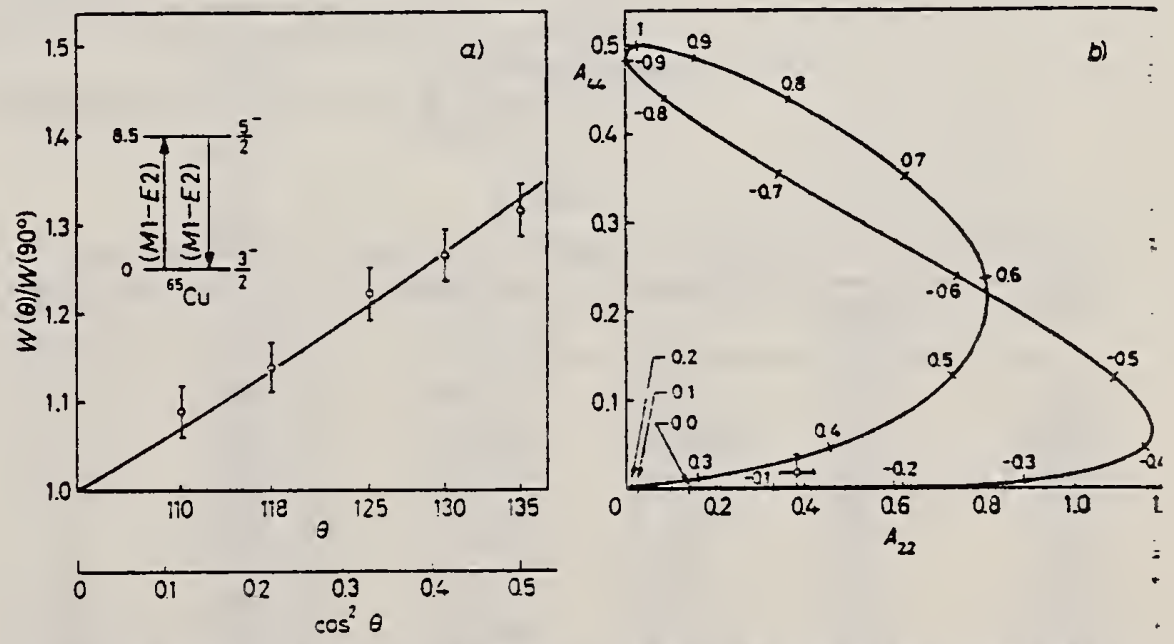

Fig. 2. - a) Angular distribution of resonantls scattered photons in ${ }^{2} \mathrm{Ca}$. The solid line is the leastsquare et through the data points. $x=0.37>0.01, I^{*}(\theta)=1-a \cos ^{2} \theta \div b \cos ^{5} \theta, a=0.56 \pm 0.04$, $b<0.21$. b) Parametric plot of $t_{2:}$ and $f_{t} \mathrm{rs} . d^{\prime}=d_{i}\left(1+f_{i}\right)$. The experimental valace $s_{t 3}=0.33=$ $=0.0+$ and $f_{4 t}<0.01$ are aiso shoma. 
74 Wh 2

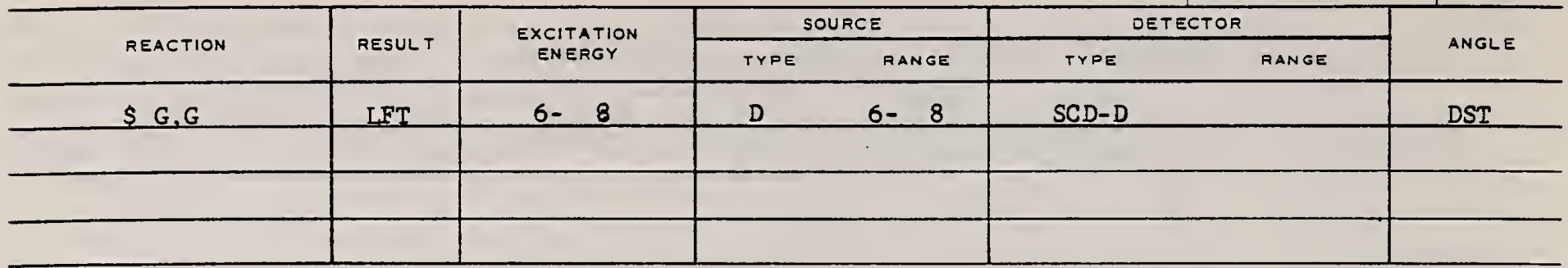

TABLE 4

Upper limit of $I_{0} / I$, the temperature variation rattio $R_{T}$, and the self-absorption ratio $R$

\begin{tabular}{|c|c|c|c|c|}
\hline $\begin{array}{l}\text { Scatterer } \\
\text { (y-source) }\end{array}$ & $\begin{array}{c}E_{0} \\
(M \circ v)\end{array}$ & $\begin{array}{c}I_{0} / I^{\prime} \\
( \pm 15 \%)\end{array}$ & $\left.R_{T}{ }^{2}\right)$ & $\left.R(\%)^{\circ}\right)$ \\
\hline${ }^{63} \mathrm{Cu}(\mathrm{Ti})$ & 6.556 & 0.80 & $0.94 \pm 0.02$ & $1.1 \neq 0.5$ \\
\hline${ }^{69} \mathrm{C} .:(\mathrm{Cu})$ & 7.306 & 0.52 & $1.035 \doteq 0.004$ & $3.5 \pm 0.5$ \\
\hline $100 \mathrm{Mo}(\mathrm{Cu})$ & 7.637 & 0.28 & $1.043 \div 0.007$ & $0.8 \pm 0.3$ \\
\hline${ }^{100} \mathrm{Mo}(\mathrm{Ti})$ & 0.418 & .0 .85 & $1.032 \div 0.003$ & $0.6 \doteq 0.3$ \\
\hline${ }^{118} \mathrm{Sn}(\mathrm{Cu})$ & 6.988 & 0.84 & $1.020 \pm 0.009$ & $5.7 \pm 0.2$ \\
\hline${ }_{126} \mathrm{Tc}(\mathrm{Cu})$ & 7.915 & $0.4 \pm 0.1$ & $0.95=0.05$ & $6 \doteq 5$ \\
\hline${ }^{30} \mathrm{Te}(\mathrm{Cu})$ & 7.637 & $0.45 \div 0.10$ & $0.84 \doteqdot 0.05$ & $0.9 \pm 1.5$ \\
\hline${ }^{139} \mathrm{La}(\mathrm{Cu})$ & 7.637 & 0.55 & $0.95 \pm 0.01$ & $2.2 \doteq 0.3$ \\
\hline${ }^{139} \mathrm{La}(\mathrm{Ti})$ & 6.418 & 0.78 & $0.968 \pm 0.008$ & $6.4 \pm 0.8$ \\
\hline${ }^{14} \operatorname{Pr}(\mathrm{Cu})$ & 7.915 & 0.25 & $1.02 \div 0.01$ & $0.9 \div 0.9$ \\
\hline $1+1 \operatorname{Pr}(\mathrm{Cu})$ & 7.252 & 0.51 & $1.005 \div 0.003$ & $5.9 \pm 0.4$ \\
\hline${ }^{1+4} \mathrm{Nd}(\mathrm{Cu})$ & 7.915 & 0.27 & $0.89=0.05$ & $<0.5$ \\
\hline $180 \mathrm{~W}(\mathrm{Ti})$ & 0.418 & 0.31 & $1.030 \doteq 0.004$ & $<0.5$ \\
\hline${ }^{203} \mathrm{Tl}(\mathrm{Ti})$ & 6.418 & 0.28 & $1.03=0.01$ & $1.6 \pm 0.3$ \\
\hline $205 \mathrm{TI}(\mathrm{Cu})$ & 7.252 & 0.58 & $1.02 \doteq 0.01$ & $1.6 \pm 0.7$ \\
\hline${ }^{209} \mathrm{Bi}(\mathrm{Cu})$ & 7.637 & 1.00 & $1.00=0.02$ & $2 \pm 1$ \\
\hline${ }^{209} \mathrm{Bi}(\mathrm{Ti})$ & 7.168 & 1.00 & $0.971 \doteq 0.005$ & $28.0 \pm 0.6$ \\
\hline
\end{tabular}

a) The values of $R_{T}$ are given for $10 \mathrm{~g} / \mathrm{cm}^{2}$ thick seatterers placed at an angle of $60^{\circ}$ and a detector angle of $135^{\circ}$.

b) The values of $R$ are given for the same seatterer-detector gcometry as that of $R_{r}$ and a $20 \mathrm{gicm}^{2}$ thick absorber.

TABLE 7

Summary of $\Gamma, \Gamma_{0}$ and $\delta$ of resonance levels measured in the present work and in earlicr works ${ }^{3.16 .27}$ )

\begin{tabular}{|c|c|c|c|c|c|}
\hline Isotope & $\begin{array}{l}\text { Enerzy } \\
(\mathrm{MeV})\end{array}$ & $\begin{array}{c}\Gamma \\
(\mathrm{meV})\end{array}$ & $\begin{array}{c}\Gamma_{0} \\
(\mathrm{meV})\end{array}$ & $\begin{array}{c}\delta \\
(e V)\end{array}$ & $\begin{array}{l}\text { Ground state } \\
\text { transitionl }\end{array}$ \\
\hline${ }^{65} \mathrm{Cu}$ & 6.556 & $70 \pm 20$ & $2 S+2 s$ & $11.2 \doteq 0.8$ & \\
\hline$\left.{ }^{69} \mathrm{Ga}{ }^{a}\right)$ & 7.306 & $105 \div 40$ & $48 \pm 7$ & $6.2 \doteq 0.5$ & E.1 \\
\hline $\left.100 \mathrm{MO}^{\circ}\right)$ & 7.637 & $140 \pm 40$ & $40 \doteq 5$ & $4.5=0.5$ & Ei \\
\hline$\left.{ }^{100} \mathrm{MO}^{\circ}\right)$ & 6.418 & $50 \pm 35$ & $25 \pm 8$ & $4.25 \pm 0.25$ & EI \\
\hline${ }^{118} \mathrm{Sn}$ & 6.988 & $152 \pm 5$ & $128 \div 3$ & $5.5 \doteq 0.5$ & El \\
\hline${ }^{126} \mathrm{Te}$ & 7.915 & $12 \doteq 6$ & $5 \pm 2$ & $11 \pm 2$ & $M 1$ \\
\hline${ }^{130} \mathrm{Te}$ & 7.637 & $60 \doteq 30$ & $30=10$ & $15=2$ & E1 \\
\hline$\left.{ }^{139} \mathrm{La}^{\circ}\right)$ & 7.637 & $170 \pm 40$ & $47 \doteq 6$ & $10.5 \pm 0.5$ & El \\
\hline${ }^{139}\left(\mathrm{La}^{8}\right)$ & 6.418 & $85 \pm 13$ & $67 \doteq 8$ & $9.5=0.5$ & E1 \\
\hline$\left.{ }^{141} \mathrm{Pr}^{5}\right)$ & 7.915 & $7 \pm 3$ & $2 \doteqdot 1$ & $6.6 \div 1.0$ & $M 1$ \\
\hline$\left.{ }^{1+1} \mathrm{Pr}^{0}\right)$ & 7.252 & $290=30$ & $110 \doteq 10$ & $6.4=0.5$ & El \\
\hline$\left.{ }^{244} \mathrm{Nd}^{b}\right)$ & 7.915 & $30 \pm 10$ & $8 \pm 3$ & $14.0=0.5$ & $\mathrm{MI}$ \\
\hline${ }^{186} \mathrm{~W}$ & 6.418 & $46 \pm 35$ & $6 \pm 3$ & $1 \pm 1$ & E1 \\
\hline$\left.{ }^{203} \mathrm{Tl}{ }^{\circ}\right)$ & 6.418 & $350 \pm 60$ & $82 \pm 15$ & $0.5 \doteq 0.5$ & \\
\hline $\left.205 \pi 1^{\circ}\right)$ & 7.252 & $50 \pm 30$ & $25 \pm 6$ & $5.2 \pm 1.5$ & $M 1$ \\
\hline${ }^{209} \mathrm{Bi}$ & 7.637 & $>500$ & $>30$ & & \\
\hline$\left.{ }^{209} \mathrm{Bi}{ }^{\circ}\right)$ & 7.168 & $820 \div 40$ & $820=40$ & $5.8 \pm 0.8$ & El \\
\hline
\end{tabular}

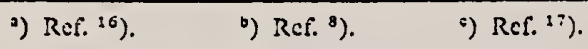


TABLE 6

Values of $A_{2}, N_{\|} / N_{\perp}$, spins, and mixing amplitudes $x$

\begin{tabular}{|c|c|c|c|c|c|c|c|}
\hline $\begin{array}{l}\text { Scatterer } \\
\text { (\%-source) }\end{array}$ & $\begin{array}{c}E_{0} \\
(\mathrm{McV})\end{array}$ & $A_{2}$ & $N_{i 1} / N_{\perp}$ & $S_{0} \pi$ & $J^{\pi}$ & $S_{i}^{\pi}$ & $x$ \\
\hline${ }^{65} \mathrm{Cu}(\mathrm{Ti})$ & 6.556 & 0 & & $\mathrm{t}^{-}$ & 1 & 3 & 0 \\
\hline${ }^{69} \mathrm{Gu}(\mathrm{Cu})$ & 7.306 & $0.14 \doteq 0.01$ & $1.046 \pm 0.022$ & $3-$ & $i^{+}$ & $i^{-}$ & 0 \\
\hline $100 \mathrm{MO}(\mathrm{Cu})$ & 7.637 & $0.49=0.05$ & $1.17 \div 0.05$ & $0^{r}$ & $1^{-}$ & $0^{+}$ & 0 \\
\hline $100 \mathrm{MO}(\mathrm{Cu})$ & $\left.7.102^{3}\right)$ & $0.013 \doteq 0.016$ & & $0^{+}$ & $1^{-}$ & $2^{+}$ & $-0.06=0.02$ \\
\hline${ }^{100} \mathrm{Mo}(\mathrm{Ti})$ & 6.418 & $0.52 \doteqdot 0.02$ & $1.15 \pm 0.03$ & $0^{+}$ & $1^{-}$ & $0^{+}$ & 0 \\
\hline${ }^{100} \mathrm{Mo}(\mathrm{Ti})$ & $\left.5.355^{\circ}\right)$ & $0.19=0.08$ & & $0^{+}$ & $1^{-}$ & $2^{+}$ & $0.21 \div 0.12^{3}$, \\
\hline${ }^{118} \mathrm{Sin}(\mathrm{Cu})$ & 6.988 & $0.48 \pm 0.02$ & $1.12 \pm 0.05$ & $0^{+}$ & $1-$ & $0^{+}$ & 0 \\
\hline${ }^{126} \mathrm{Te}(\mathrm{Cu})$ & 7.915 & $0.46 \pm 0.11$ & $0.86 \div 0.10$ & $0^{-*}$ & $1^{+}$ & $0^{+}$ & 0 \\
\hline${ }^{130} \mathrm{Te}(\mathrm{Cu})$ & 7.637 & $0.48 \pm 0.04$ & $1.12 \pm 0.04$ & $0^{+}$ & $1^{-}$ & $0^{+}$ & 0 \\
\hline${ }^{139} \mathrm{La}(\mathrm{Cu})$ & 7.637 & $0.16 \pm 0.02$ & $1.024 \doteq 0.015$ & $\Sigma^{+}$ & $\frac{7}{2}-$ & $\frac{7}{3} \div$ & 0 \\
\hline${ }^{139} \mathrm{La}(\mathrm{Ti})$ & 6.418 & $0.093 \pm 0.004$ & $1.018 \pm 0.006$ & $i^{+}$ & $y-$ & $z^{+}$ & 0 \\
\hline $1+1 \operatorname{Pr}(\mathrm{Cu})$ & 7.915 & $0.41 \div 0.06$ & $0.94 \pm 0.03$ & + & $3^{+}$ & $i^{+}$ & $0.26 \pm 0.13$ \\
\hline${ }^{141} \operatorname{Pr}(\mathrm{Cu})$ & 7.252 & $0.23 \pm 0.06$ & $1.03=0.02$ & $3^{+}$ & - & 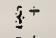 & 0 \\
\hline${ }^{14+4} \mathrm{Nd}(\mathrm{Cu})$ & 7.915 & $0.50 \pm 0.03$ & $0.92 \doteqdot 0.09$ & $0^{+}$ & $1^{+}$ & $0^{+}$ & 0 \\
\hline${ }^{186} \mathrm{~W}(\mathrm{Ti})$ & 6.418 & $0.49 \pm 0.05$ & $1.15 \pm 0.06$ & $0^{+}$ & $1-$ & $0^{+}$ & 0 \\
\hline${ }^{186} \mathrm{~W}(\mathrm{Ti})$ & $\left.6.296^{3}\right)$ & $-0.011 \div 0.014$ & & $0^{+}$ & $1^{-}$ & $2^{+}$ & $-0.10 \pm 0.0: \because$ \\
\hline${ }^{203} \mathrm{~T}(\mathrm{Ti})$ & 6.418 & 0 & $1.01 \doteqdot 0.01$ & $t^{+}$ & $\frac{3}{2}$ & $\frac{1}{3}^{-}$ & $\overline{0}$ \\
\hline${ }^{205} \mathrm{~T} l(\mathrm{Cu})$ & 7.252 & $0.71 \doteq 0.08$ & $0.90 \doteq 0.02$ & \pm & $\frac{3}{2}+$ & $2^{+}$ & $-0.25 \pm 0.05$ \\
\hline $205 \mathrm{~T} 1(\mathrm{Cu})$ & $\left.7.047^{\circ}\right)$ & $-0.69 \pm 0.03$ & & $t^{+}$ & $3^{4}$ & $2^{+}$ & $0.33 \div 0.04$ \\
\hline${ }^{209} \mathrm{Bi}(\mathrm{Cu})$ & 7.637 & $0.24 \pm 0.04$ & & $i^{-}$ & $\left(\begin{array}{l}7 \\
0 \\
2\end{array}\right)$ & $3^{-}$ & \\
\hline${ }^{209} \mathrm{Bi}(\mathrm{Ti})$ & 7.168 & $0.20 \pm 0.02$ & $1.040 \doteq 0.015$ & $z^{-}$ & $3^{+}$ & 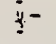 & \\
\hline
\end{tabular}

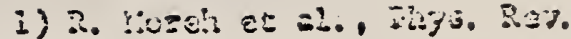

C2 (1970) $114 \%$

3) A. Vibif, et ai., Eyy.Rs.

C5 (1972) 2276

15) R. butch et 21. Ekyz. Lett. 338 (1971) 71

16) R. jusa et a1., ringu. Rev.

C7 (1973) 1235

17) R. Hore? er 21. , Nuel. Thys. A217 (1973) 477

29) B. Hordh et al., Pigs. Hev. C4 (1971) 2265

30) R. ilorgl et al. , Ptwys. Rev. 173 (1959) 1961

Errors refer to one standard deviation.

") Inelastic transitions.

b) Ref. ${ }^{17}$ ).

TABLE 8

?) Ref. 15).

Values of $\Gamma_{6}, D, k_{E 1}$ and $k_{M 1}$

\begin{tabular}{|c|c|c|c|c|c|c|c|c|c|}
\hline \multicolumn{5}{|c|}{ El transitions } & \multicolumn{5}{|c|}{ Ml transitions } \\
\hline $\begin{array}{l}\text { scaltersr } \\
\text { ( } \gamma \text {-source) }\end{array}$ & $\begin{array}{c}E_{0} \rightarrow E_{f} \\
(\mathrm{MeV})\end{array}$ & $\begin{array}{c}\Gamma_{i} \\
(\mathrm{mcV})\end{array}$ & $\begin{array}{c}D \\
(\mathrm{eV})\end{array}$ & $\begin{array}{c}k_{E 2} \\
\left(10^{-9} \mathrm{MeV}^{-3}\right)\end{array}$ & $\begin{array}{c}\text { scatterer } \\
(\gamma \text {-source })\end{array}$ & $\begin{array}{l}E_{0} \rightarrow E_{t} \\
(\mathrm{MeV})\end{array}$ & $\begin{array}{c}\Gamma_{!} \\
(\mathrm{meV})\end{array}$ & $\begin{array}{c}D \\
(\mathrm{eV})\left(10^{-6}\right.\end{array}$ & 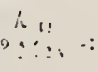 \\
\hline$\left.{ }^{62} \mathrm{Ni}(\mathrm{Fe})^{2}\right)$ & $\begin{array}{r}7.646 \\
\rightarrow 1.172\end{array}$ & 24 & 12300 & 0.5 & ${ }^{126} \mathrm{Te}(\mathrm{Cu})$ & $\begin{array}{r}7.915 \\
\rightarrow 0.666 \\
\rightarrow 1.421\end{array}$ & $\begin{array}{l}2.3 \\
1.7\end{array}$ & 260 & $\therefore$ \\
\hline${ }^{69} \mathrm{Ga}(\mathrm{Cu})$ & $\begin{array}{r}7.306 \\
\rightarrow 0.572 \\
\rightarrow 0.872\end{array}$ & $\begin{array}{l}3.2 \\
2.7\end{array}$ & 660 & $\begin{array}{l}1.0 \\
0.9\end{array}$ & ${ }^{1+1} \operatorname{Pr}(\mathrm{Cu})$ & $\begin{array}{r}7.915 \\
\rightarrow 1.298\end{array}$ & 1.3 & 90 & $\because$ \\
\hline${ }^{100} \mathrm{Mo}(\mathrm{Cu})$ & $\begin{array}{r}7.637 \\
-0.535 \\
\rightarrow 1.063\end{array}$ & $\begin{array}{l}40 \\
5.7\end{array}$ & 670 & $\begin{array}{l}7.7 \\
1.4\end{array}$ & & $\begin{array}{l}\rightarrow 1.437 \\
\rightarrow 1.550 \\
\rightarrow 1.655\end{array}$ & $\begin{array}{l}0.5 \\
1.4 \\
1.0\end{array}$ & & $\begin{array}{c}\ddots \\
\vdots \\
i\end{array}$ \\
\hline & $\rightarrow\lfloor .46\rfloor$ & 1.4 & & 0.4 & $1+1 \operatorname{Pr}(F c) \Rightarrow$ & $\begin{array}{r}7.632 \\
\rightarrow 0.1+5\end{array}$ & & 170 & \\
\hline$\left.: 12 \mathrm{Cd}(\mathrm{Fe})^{b}\right)$ & $\begin{array}{r}7.632 \\
\rightarrow 0.617 \\
\rightarrow \quad 1.223\end{array}$ & $\begin{array}{c}11 \\
7.3\end{array}$ & 350 & $\begin{array}{l}4 \\
3.4\end{array}$ & & $\begin{array}{l}\rightarrow 0.1+5 \\
\rightarrow 1.130 \\
\rightarrow 1.293\end{array}$ & $\begin{array}{l}5.6 \\
6.4 \\
0.4\end{array}$ & & li \\
\hline$\cdot$ & $\begin{array}{l}\rightarrow 1.223 \\
\rightarrow 1.429 \\
\rightarrow 1.468\end{array}$ & $\begin{array}{l}7.3 \\
2 \\
1.7\end{array}$ & & $\begin{array}{l}3.4 \\
1 \\
0.9\end{array}$ & & $\begin{array}{l}\rightarrow 1.437 \\
\rightarrow 1.451 \\
\rightarrow 1.582\end{array}$ & $\begin{array}{l}5.6 \\
6.5 \\
1.1\end{array}$ & & $\begin{array}{l}\vdots i \\
i j \\
i j \\
2 j\end{array}$ \\
\hline${ }^{130} \mathrm{Te}(\mathrm{Cu})$ & $\begin{array}{r}7.637 \\
\rightarrow 0.337 \\
\rightarrow 1.589\end{array}$ & $\begin{array}{l}16 \\
18\end{array}$ & 360 & $\begin{array}{l}5.5 \\
8.3\end{array}$ & ${ }^{144} \mathrm{Nd}\left(\mathrm{C}_{4}\right)$ & $\begin{array}{r}7.915 \\
-0.697 \\
-1.041\end{array}$ & $\begin{array}{l}13 \\
2.7\end{array}$ & 380 & $\therefore$ \\
\hline${ }^{139} \mathrm{La}(\mathrm{Cu})$ & $\begin{array}{r}7.637 \\
\rightarrow 1.384\end{array}$ & 3 & 190 & 2.5 & & & 6.2 & & $\therefore$ \\
\hline & $\rightarrow 1.533$ & 3 & & 2.7 & $205 \mathrm{Tl}(\mathrm{Cu})$ & $\begin{array}{r}7.252 \\
\rightarrow 0.205\end{array}$ & 4 & 1.00 & j \\
\hline${ }^{141} \operatorname{Pr}(\mathrm{Cu})$ & $\begin{array}{r}7.252 \\
\rightarrow 0.146 \\
\rightarrow 1.120\end{array}$ & $\begin{array}{l}82 \\
8.6\end{array}$ & 220 & $\begin{array}{l}38 \\
6.5\end{array}$ & & & & & \\
\hline${ }^{186} \mathrm{~W}(\mathrm{Cu})$ & $\begin{array}{r}6.418 \\
\rightarrow 0.122\end{array}$ & 12 & 110 & 14 & & & & & \\
\hline
\end{tabular}

The values of $D$ refer to an excitation encrgy $E_{0}$.
s) Ref. ${ }^{2}$ ).
v) Ref. ${ }^{29}$ ).
c) $\operatorname{Ref} .{ }^{30}$ ). 
REF. M. Boivin, Y. Cauchois, Y. Heno, C. Schloesing-Moller, V. Zecevic

C.R. Acad. Sc. Paris 281B, 201 (1975)

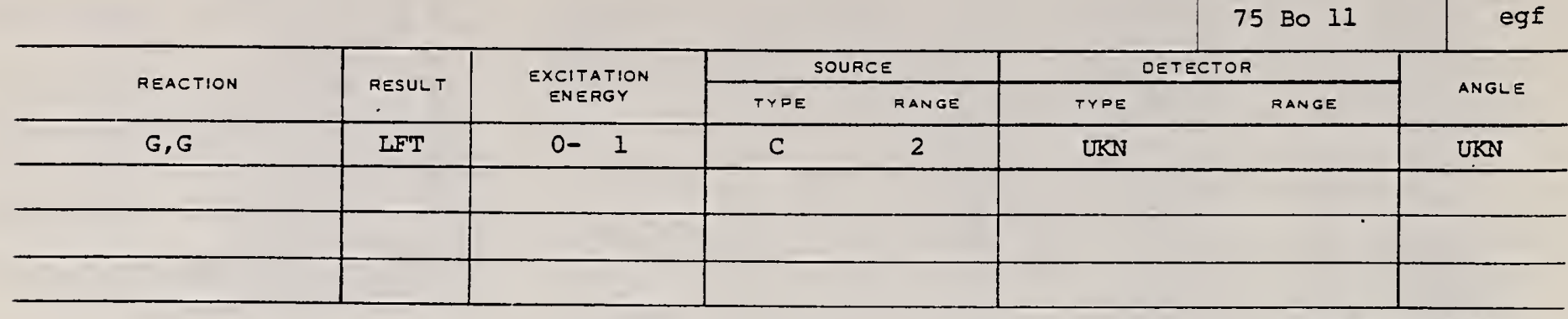

771 and $1115 \mathrm{KEV}$

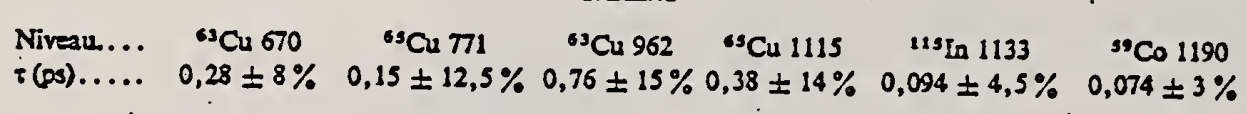


Ref. E. Wolynec, G. Moscati, J. R. Moreira, O. D. Goncalves, M. N. Martins

Phys. Rev. C11, 1083 (1975)

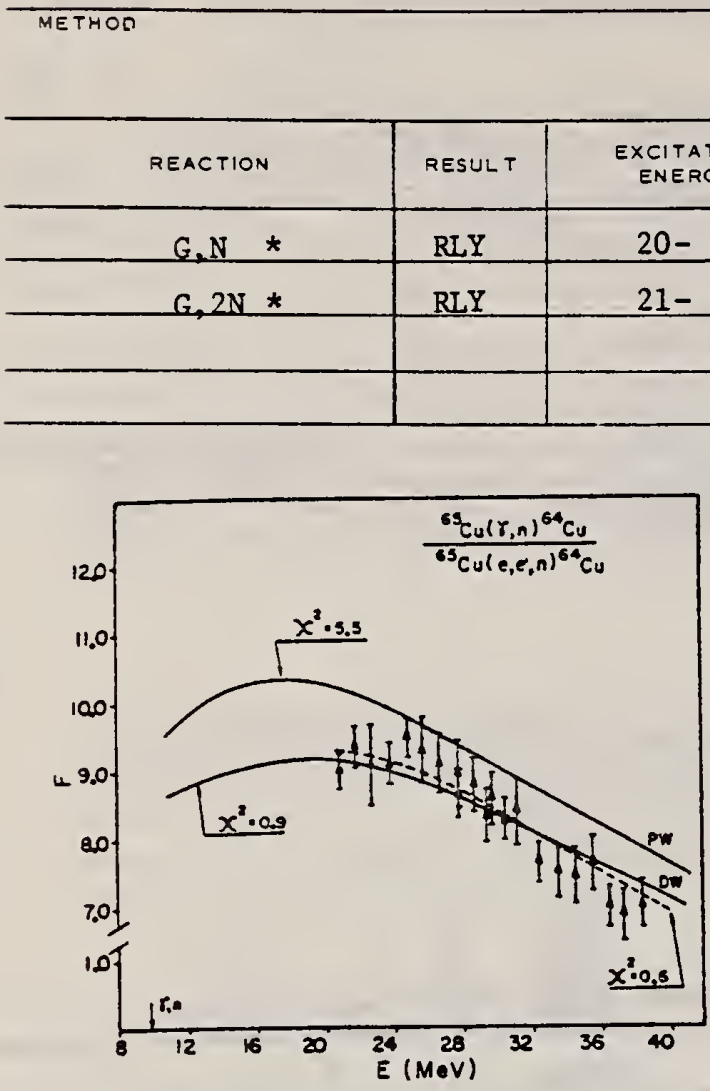

FIG. 4. Measured $F$ for ${ }^{55} \mathrm{Cu}(\gamma, \pi)$. Dashed curre is a polynomial fit to the points. Full curves are $F_{P W}$ and $F_{D W}$ predictions.

$$
\begin{aligned}
& F_{\mathrm{PW}}^{(Z V)}=\left(N_{p} / Z_{p}{ }^{2} r_{p}{ }^{2} N_{r}\right) \\
& \times \frac{\int_{0}^{Z_{1}-m_{\varphi}} \sigma_{\gamma}(\omega) \phi\left(E_{1}, \omega, Z_{\gamma}\right)(d \omega / \omega)}{\int_{0}^{s_{1}-m_{\varphi}} \sigma_{\gamma}(\omega) N_{\mathrm{PW}}^{B_{1}}\left(E_{1}, \omega\right)(d \omega / \omega)}, \\
& F_{\text {DW }}^{(B)}=\left(N_{r} / Z_{r}^{2} r_{*}^{2} N_{r}\right) \\
& \times \frac{\int_{0}^{\varepsilon_{1}-m_{q}} \sigma_{\gamma}(\omega) \phi\left(E_{1}, \omega, Z_{,}\right)(d \omega / \omega)}{\int_{0}^{z_{1}-m_{\gamma}} \sigma_{\gamma}(\omega) N_{D W}^{Z_{1}^{1}}\left(E_{1}, \omega, Z_{\xi}\right)(d \omega / \omega)},
\end{aligned}
$$

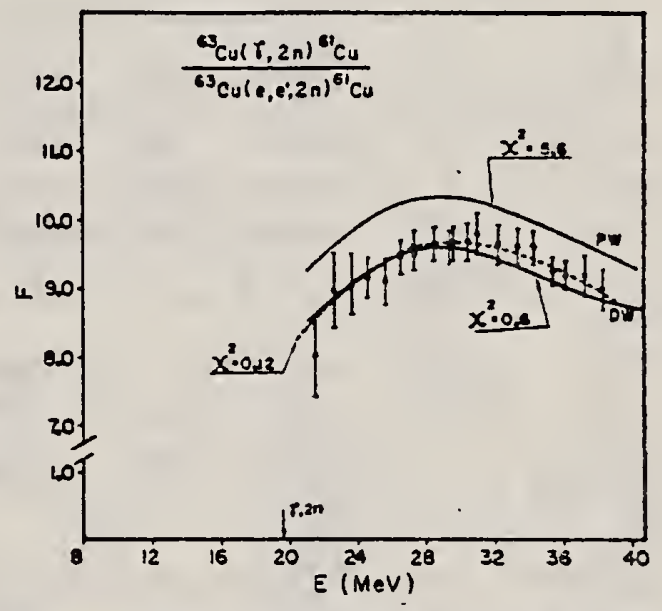

FTG. 5. Measured $F$ for ${ }^{\infty} \mathrm{Cu}(\gamma, 2 n)$. Dashed curve is a polynomial fit to the polnts. Full curves are $F_{\text {pw }}$ and $F_{D W}$ predictions. 


\begin{tabular}{|c|c|c|c|}
\hline & $\mid \begin{array}{c}\text { EL EM. SYM. } \\
\mathrm{Cu}\end{array}$ & A 65 & 29 \\
\hline & \multicolumn{2}{|l|}{$\begin{array}{l}\text { REF. NO. } \\
76 \text { SW } 7\end{array}$} & $\mathrm{hmg}$ \\
\hline \multicolumn{3}{|c|}{ DETECTOR } & \multirow{2}{*}{ ANGLE } \\
\hline TYPE & \multicolumn{2}{|l|}{ RANGE } & \\
\hline$S \subseteq D-D$ & & & DST \\
\hline & & & \\
\hline & & & \\
\hline
\end{tabular}

The properties of levels in ${ }^{3} \mathrm{Cu}$ and ${ }^{3} \mathrm{Cu}$ bave been invertignted using the resonance fluoressence technique with bremsstrahlung serving as the source of exeiting radintion. The energies and scattering cross sections for 24 levels in ${ }^{63} \mathrm{Cu}$ and 30 levels in ${ }^{65} \mathrm{Cu}$ up to about $4.5 \mathrm{MeV}$ were measured. A few leveis krown to exist in the region of $2 \mathrm{MeV}$ for both nuelei were not observed. For a number of the lower lying levels, spin and parity assignments have been made through angular distribution measurements and limits on $\mathrm{J}^{\mathbf{2}}$ set by ochers. Mixing ratios for a few of these are also given. Where $J$ and the ground state branching ratios are known the partial widths for decays to the ground state are presented Comparisons are made with the predictions of the latest theoretical calsulations.

TABLE II. Properties of levels in ${ }^{65} \mathrm{Cu}$.

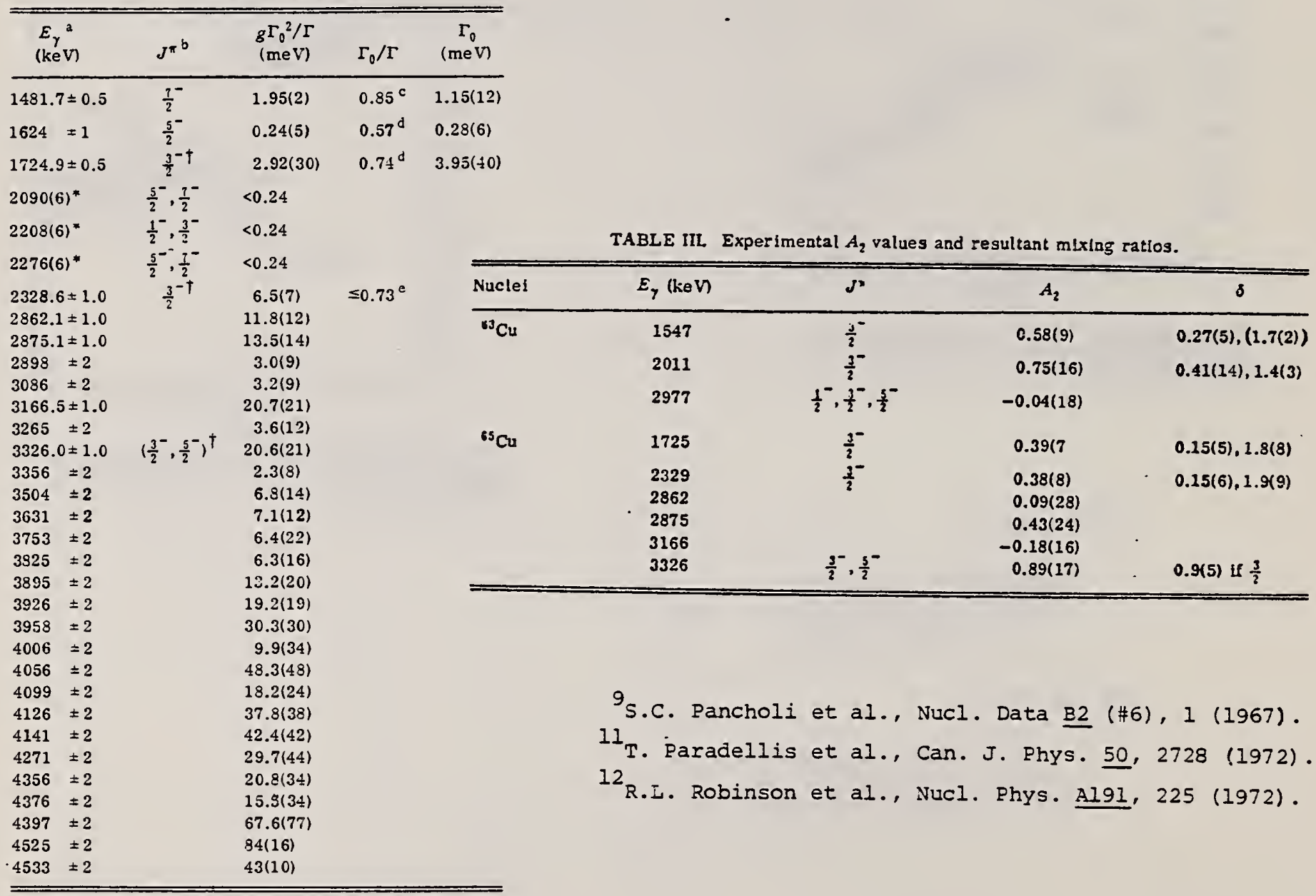

The energies indicated with an asterisk were taken from Ref. 9.

${ }^{b}$ The values for $J$ indicated with a dagger are from this study; the others were taken from Ref. 9.

c This value for $\Gamma_{0} / \Gamma$ was taken from Ref. 12 .

These values for $\Gamma_{0} / \Gamma$ were taken from Ref. 11 .

e This limit was obtained in this study where a branch is observed to the $771 \mathrm{keV} \frac{1}{2}^{-}$level. 
ref. V.N. Polishchuk, N.G. Shevchenko, N.G. Afanas'ev, A.A. Khomich,

I.I. Chkalov, \& A.S. Litvinenko

Yad. Fiz. 26, 20 (July 1977)

Sov. J. Nucl?. Phys. 26, 9 (July 1977)

\begin{tabular}{|c|c|c} 
ELEM. SYM. & A & 2 \\
\hline RU & 65 & 29 \\
\hline $\begin{array}{c}\text { REF. NO. PO } 3 \\
\text { PII/18/80 }\end{array}$ \\
\hline
\end{tabular}

\begin{tabular}{|c|c|c|c|c|c|c|c|}
\hline \multirow{2}{*}{ REACTION } & \multirow{2}{*}{ RESULT } & \multirow{2}{*}{$\begin{array}{l}\text { EXCITATION } \\
\text { ENERGY }\end{array}$} & \multicolumn{2}{|c|}{ SOURCE } & \multicolumn{2}{|c|}{ DETECTOR } & \multirow{2}{*}{ ANGLE } \\
\hline & & & TYPE & RANGE & TYPE & FANGE & \\
\hline$E, E /$ & FMF & $0-5$ & $D$ & 120 & MAG-D & $--\cdot$ & DST \\
\hline & & $(0.77-4.26)$ & & & & & \\
\hline & & & & & & & \\
\hline & & & & & & & \\
\hline
\end{tabular}

We report the results of an experimental study of low-lying states in ${ }^{63} \mathrm{Cu}$ by the method of inelastic

scattering of electrons with energy $E_{0}=120 \mathrm{MeV}$ in the region of momentum transfer to the nucleus

$q^{\prime}=0.78-1.15 F^{-1}$. Values are obtained for the reduced transition probability $B(E \lambda) \uparrow$ from the

ground state of the nucless to excited states with $\omega=0.77,1.11,1.48,2.62,3.16,3.523 .85$, and 4.26
$\mathrm{MeV}$.

TABLE I. Value of reduced probability $B(E \lambda)$ for transition of the nucleus from the ground state to an excited state.

\begin{tabular}{|c|c|c|c|c|c|c|}
\hline \multirow[b]{2}{*}{ Nucteus } & \multirow[b]{2}{*}{$\varepsilon, \mathrm{MeV}$} & \multirow[b]{2}{*}{$\lambda$} & \multirow[b]{2}{*}{ I* } & \multicolumn{3}{|c|}{$B(E \lambda)+\mu^{\mu} \cdot F^{\prime \lambda}$} \\
\hline & & & & $\begin{array}{l}\text { Our data } \\
\text { (nbrational modn) }\end{array}$ & $\begin{array}{l}\text { Dets of } \\
\text { Rof. } 2\end{array}$ & $\begin{array}{l}\text { Data of } \\
\text { Ref. } 4\end{array}$ \\
\hline${ }^{\circ} \mathrm{Cu}$ & $\begin{array}{l}0.77 \\
1.11 \\
1.48 \\
2.62 \\
3.16 \\
3.52 \\
3.85 \\
i .26\end{array}$ & $\begin{array}{l}2 \\
2 \\
2 \\
\frac{2}{3} \\
3 \\
3 \\
3 \\
3 \\
3\end{array}$ & $\begin{array}{l}1 / 2= \\
1 / 2= \\
1 / 2= \\
(1 / 2+) \\
(1 / 2+) \\
(1 / 2+1, \\
(1 / 2+) \\
(1 / 2+) \\
\left(3 / 2^{+}+12\right.\end{array}$ & $\begin{array}{c}115 \pm 15 \\
210 \pm 25 \\
218 \pm 25 \\
7482 \pm 226 \\
4211 \pm 463 \\
4846=533 \\
3665 \pm 454 \\
2760 \pm 310\end{array}$ & $\begin{array}{r}117 \\
351 \\
364 \\
1815 \\
891 \\
1320 \\
594 \\
792\end{array}$ & $\begin{array}{l}100 \\
230 \\
340\end{array}$ \\
\hline$\cdots \mathrm{Ni}$ & 3.32 & $\frac{2}{3}$ & $\frac{3+}{3-}$ & $\begin{aligned} & 661 \pm 58(10) \\
& 16800 \pm 1200(10)\end{aligned}$ & & \\
\hline \multicolumn{4}{|c|}{$\begin{array}{l}\text { Sum of } B_{,}\left(E_{2}\right) ! \\
J=1 /:-, 3 / 2,7 / 2-\end{array}$} & $543 \pm 37$ & 832 & 730 \\
\hline \multicolumn{4}{|c|}{$\underset{J=(1 / 2+),(2 / 2+)_{1},(1 / 2+),\left({ }^{2} / 2^{+}+\right)}{\operatorname{Sum} \text { of } B_{S}(E 3) \dagger}$} & $20200 \pm 1110$ & 4620 & \\
\hline \multicolumn{4}{|c|}{$\begin{array}{c}\operatorname{Sum} \text { of } B_{3}(E 3) \dagger \\
\left.J=\left(1 / 2^{+}\right),\left(1 / 2^{+}\right)\right)_{2},\left(1 / 2^{+}\right),\left(1 / 2^{+}\right)\end{array}$} & $18420 \pm 1000$ & 4521 & \\
\hline
\end{tabular}

Note. The values of $B(E \lambda)$ f from Ref. 2 were recalculated from the relation
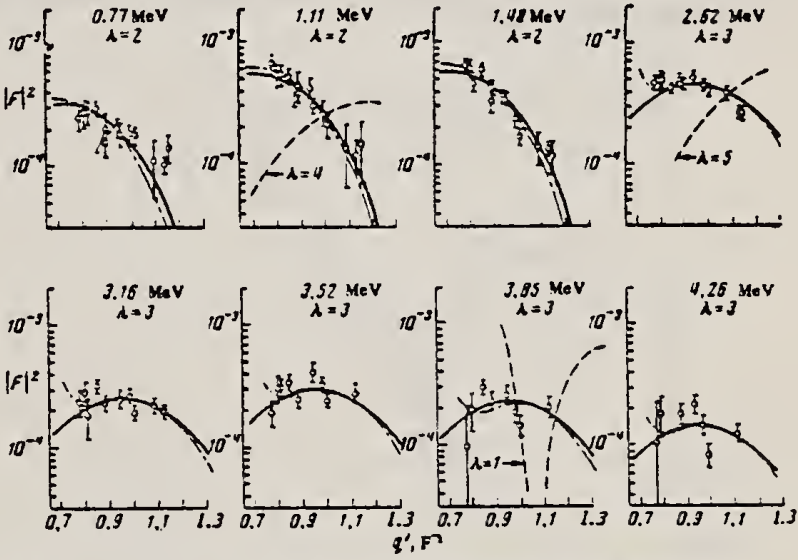

FIG. 2. Inelastic form factors as functions of the momentum transfer to the nucleus. 
ref. K. Masumoto, T. Kato, N. Suzuki

Nucl. Inst. Meth. 157, 567 (1978)

年

\begin{tabular}{|c|c|c|c|} 
ELEM. SYM. & $A$ & 2 \\
CU & 65 & \\
& &
\end{tabular}

(1)

\begin{tabular}{|l|l|}
\hline REF. NO. \\
\hline
\end{tabular}

$78 \mathrm{Ma} 10$

hg

\begin{tabular}{|c|c|c|c|c|c|c|c|}
\hline \multirow{2}{*}{ REACTION } & \multirow{2}{*}{ RESULT } & \multirow{2}{*}{$\begin{array}{l}\text { EXCITATION } \\
\text { ENERGY }\end{array}$} & \multicolumn{2}{|c|}{ SOURCE } & \multicolumn{2}{|c|}{ OETECTOR } & \multirow{2}{*}{ ANGLE } \\
\hline & & & TYPE & RANGE & TYPE & RANGE & \\
\hline$G, N$ & $A B Y$ & $10-68$ & $C$ & $30-68$ & $A C T-I$ & & $4 P I$ \\
\hline & & & & & & & \\
\hline & & & & & & & \\
\hline & & & & & & & \\
\hline
\end{tabular}

Analysis is made of reactions interfering with

photon activation analysis procedures.

The activation yield curves have been presented for a number of photonuclear reactions in the energy range from 30 to $68 \mathrm{MeV}$, in order to evaluate quantitatively the interferences due to competing reactions in multielement photon activation analysis. The general features of the yields as functions of both target mass number and excitation energy were elucidated from the data obtained, discussion being given on the results in terms of the reaction mechanism.

Simultaneous neutron activation due to appreciable neutron production from the converter and surrounding materials has also been studied, and, finally, the magnitudes of interferences in real multielement analysis were given in the form of their energy dependences.

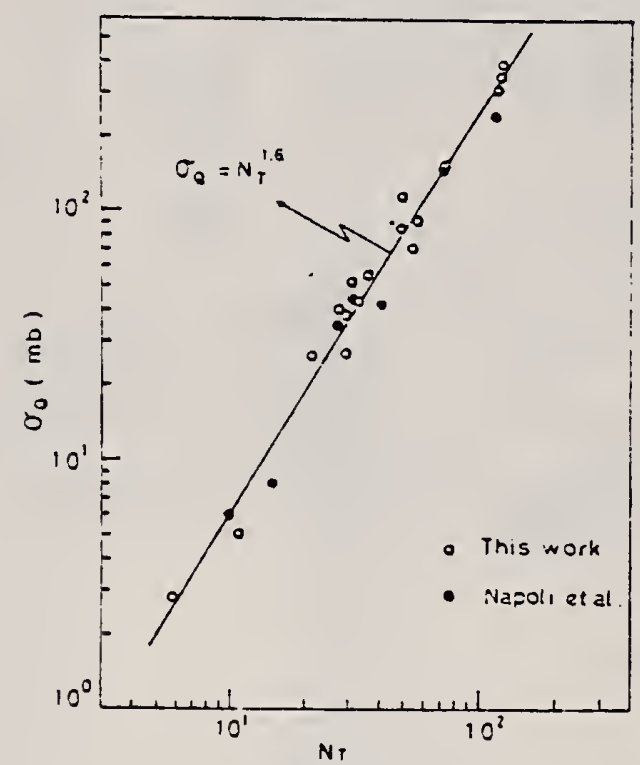

Fig. 2. Yield per equivalent quanta versus targat ncutron num. ber.

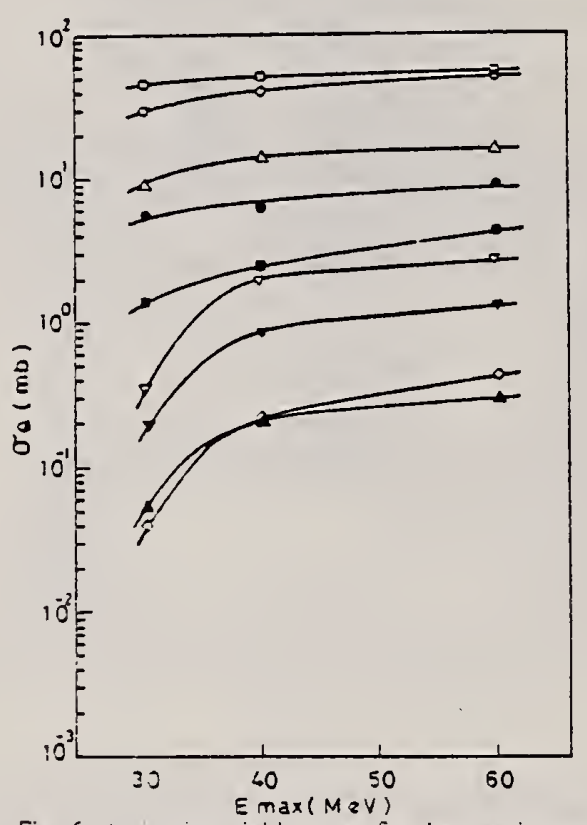

Fig. 6. A::isation yie!d curves for the reactions on $\mathrm{Co}, \mathrm{Ni}$ and $\mathrm{Cu}$

${ }^{59} \mathrm{Co}(\%, \mathrm{n})^{58} \mathrm{Co} .0{ }^{59} \mathrm{Co}(\%, 2 n)^{57} \mathrm{Co},{ }^{58} \mathrm{Ni}(\%, n)^{57} \mathrm{Ni}$.

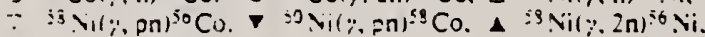

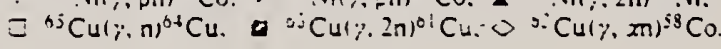




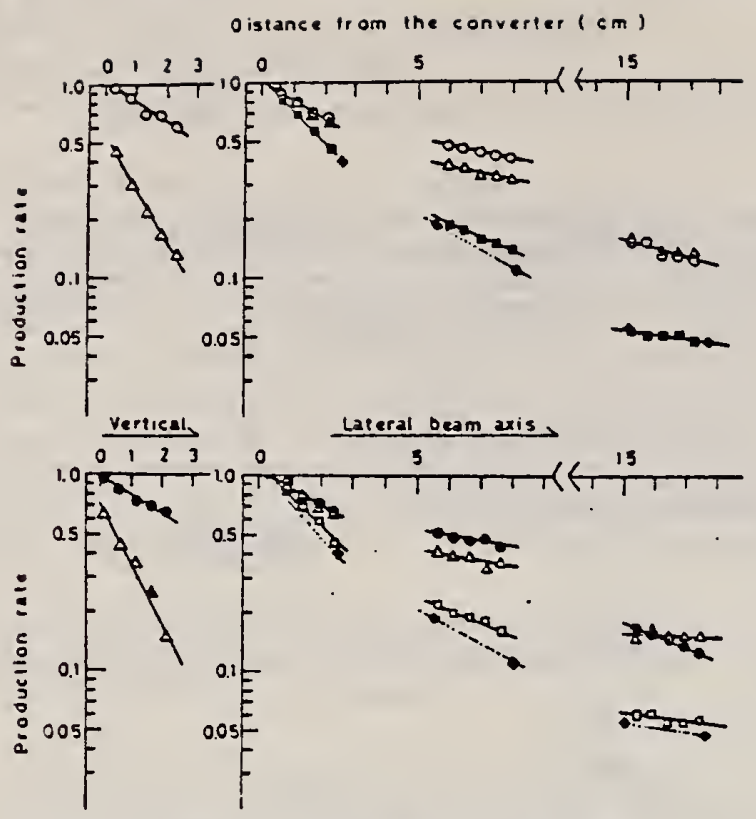

Fig. 13. Prodliction rutes of the neutron reactions and the photonuclear resctions is a funct:on of distunce from the converter in vertical and latera! diractions

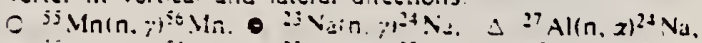

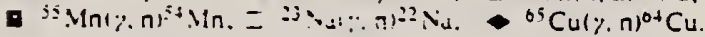


R.0. Avakyan, A.É. Avetisyan, N.Z. Akopov, S.S. Danagulyan,

I.Kh. Kosakov, A.A. Oganesyan, Zh.V. Petrosyan, S.P. Taroyan,

REF. G.M. Élbakyan

Sov. J. Nucl. Phys. 33, 192 (1981)

Yad. Fiz. 33,362 (1981)

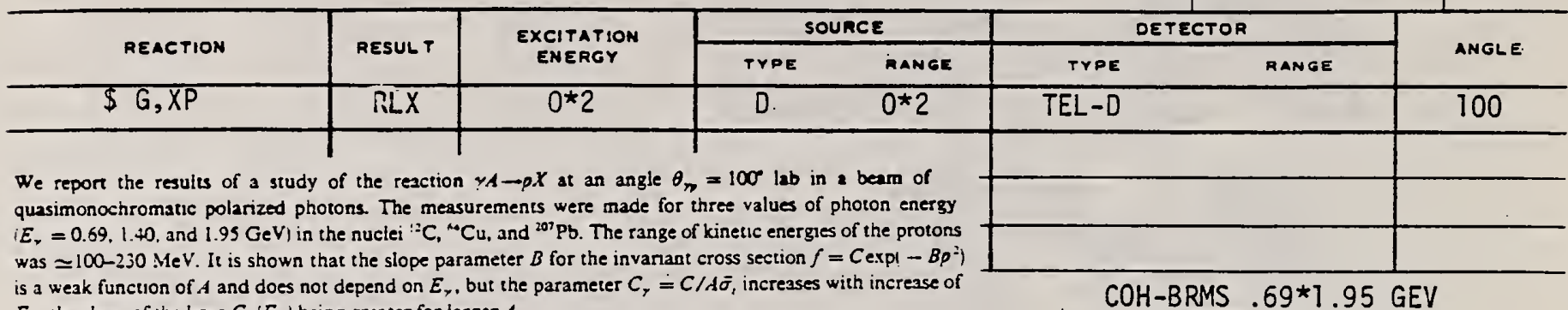

d $E_{\gamma}$ but the parameter $C_{\gamma} \doteq C / A \bar{\sigma}_{l}$ increases with increase $E_{y}$, the slope of the lines $C_{y}\left(E_{y}\right)$ being greater for larger $A$.

PACS numbers: $25.20 .+\mathrm{y}, 13.60 . \mathrm{Rj}$

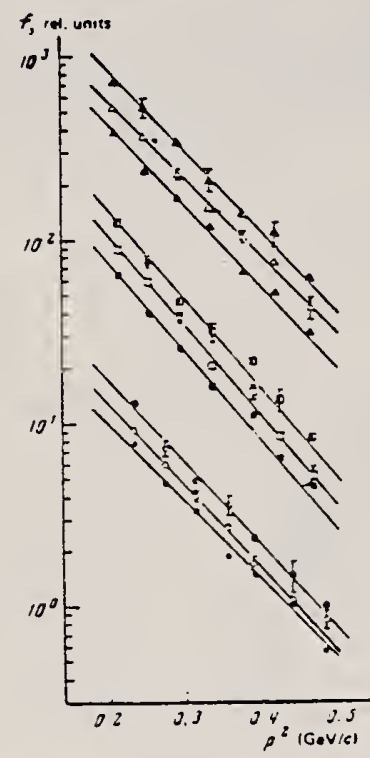

FiG. 2. Invariant cross scctions/ for photoproduction of cumulative protons as a function of their momentum squared

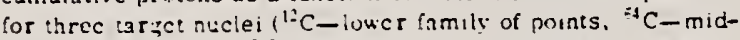
dle family of points. : hollow, and combined points correspond respectwely ts the values $t_{1}-0.019 .1$ i 0 and $1.95 \mathrm{Le} l^{\circ}$. The curves are described in the :ext.

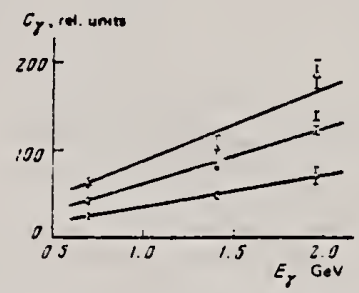

Fil. 2. The dependence of the paramcter $C_{7}$ on $E_{7}$. Points: $=-{ }^{i} \mathrm{C},=-{ }^{i 4} \mathrm{Cu}, \Delta-{ }^{207} \mathrm{ph}$.

T.ABL.L: it.

\begin{tabular}{|c|c|c|c|c|}
\hline \multirow{2}{*}{$E_{7,}, \mathrm{Giv}$} & \multirow{2}{*}{ Parameter } & \multicolumn{3}{|c|}{ Nucleus } \\
\hline & & 'c & $m a$ & $=\mathrm{Pb}$ \\
\hline 0.53 & $\begin{array}{l}B \\
C\end{array}$ & $\begin{array}{l}0.50=0.51 \\
71.9=1.39 \\
=11.7\end{array}$ & $\begin{array}{c}11.01=0.32 \\
663 \pm+i 1 \\
-53\end{array}$ & $\begin{aligned} & 10.19=0.36 \\
& 3252=302\end{aligned}$ \\
\hline 1.20 & $\begin{array}{l}8 \\
6\end{array}$ & $\begin{aligned} 10 . \tilde{R}=0.31 \\
105.4=93\end{aligned}$ & $\begin{aligned} 11.21 & =0.22 \\
973 & =5 ! \\
& =56\end{aligned}$ & 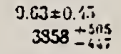 \\
\hline 1.25 & $\begin{array}{l}B \\
C\end{array}$ & $\begin{aligned} 10.36 & =0.49 \\
136.0 & \pm 20.5\end{aligned}$ & $\begin{array}{l}11.14=0.37 \\
1317=160\end{array}$ & $\begin{array}{r}10.07=0.31 \\
6201+5 i 2\end{array}$ \\
\hline
\end{tabular}

Note. The parameter $B$ is given in units of $(\mathrm{GeV} / c)^{-2}$, while $C$ is given in relatuve units.

BLE L. Lnvariant cross section (in relative units)

\begin{tabular}{|c|c|c|c|c|c|c|c|c|}
\hline \multirow{2}{*}{ Vucleus } & \multirow{2}{*}{ E.' } & \multicolumn{7}{|c|}{ TD. McV } \\
\hline & & 110 & 1:5 & 153 & 377 & iju & 210 & המג \\
\hline \multirow[t]{3}{*}{$\because=C$} & $\begin{array}{l}0 \text { cy } \\
1 .+1 \\
1.13\end{array}$ & $\begin{array}{r}7.8=0.13 \\
y .15=19.3 i \\
13.1=1 . v 0\end{array}$ & $\begin{array}{l}i S 0=0.1 u \\
6 . U A=U . j u \\
i . Z=0.71\end{array}$ & $\begin{array}{l}3.40=0 u s \\
f .4=0.2 \\
4.91=0 . j 3\end{array}$ & $\begin{array}{l}1.34=0.05 \\
3.6,1 \pm 1) 1.1 \\
j .62 \pm 0.41 .\end{array}$ & $\begin{array}{l}1.55=010 j \\
1.6^{2}=016 \\
-3 i=0 . i 5\end{array}$ & $\begin{array}{l}1.95=0.0 i \\
1.0 T=0.1 \% \\
1 . n=t\end{array}$ & 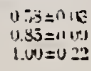 \\
\hline & & \multicolumn{7}{|c|}{$\tau_{p}$, MeV } \\
\hline & & ivi: & $1: 6$ & $1: 5$ & $16:$ & {$[5]$} & 30.3 & 291 \\
\hline \multirow[t]{3}{*}{ "Cu } & $\begin{array}{l}0.69 \\
1.11 \\
1 . j 5\end{array}$ & 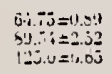 & 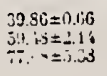 & $\begin{array}{l}36.10=0.35 \\
j 7.31=1.73 \\
46.32=6.11\end{array}$ & $\begin{array}{l}19.97=0.43 \\
21.1, i=1 . i 1 \\
31.61=3 . w\end{array}$ & $\begin{array}{l}11 . j i \neq 1) .33 \\
11 . j s=1.05 \\
21.52=2.61\end{array}$ & $\begin{array}{r}6.49=0.27 \\
5.5 i=0 \text { ou } \\
13.42=1.57\end{array}$ & $\begin{array}{l}4.59=0.20 \\
3.21=0.61 \\
3.37=1.42\end{array}$ \\
\hline & & \multicolumn{7}{|c|}{$I_{p}$, MeV } \\
\hline & & tos & 133 & 16 & 163 & 182 & $\therefore 41$ & 292 \\
\hline "arpb & $\begin{array}{l}0.69 \\
1.411 \\
1 . j 5\end{array}$ & 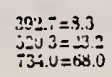 & 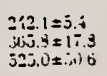 & $\begin{array}{l}172.5 \pm 4.6 \\
27.2=13.2 \\
335.6=36.7\end{array}$ & $\begin{array}{l}119.2=3.7 \\
147.2 \pm 2.4 \\
213.4 x \geq 4.3\end{array}$ & $\begin{array}{c}66.8 \pm 2.6 \\
108.2=3.7 \\
137.4 \pm 21.1\end{array}$ & $\begin{array}{r}51.4=2.2 \\
76.8 \pm 7.0 \\
108.5=16.9\end{array}$ & $\begin{array}{l}31.2 \pm 1.2 \\
\{2.8=5.3 \\
62.4 \pm 12.5\end{array}$ \\
\hline
\end{tabular}


aef. R.0. Avakyan, A.E. Avetisyan, N:Z. Akopov, S.S. Danaguiyan,

I.Kh. Kosakov, A.A. Oganesyan, Zh.V. Petrosyan, S.P. Taroyan,

G.M. Elbakyan

Sov. J. Nucl. Phys. 33, 448 (1981)

METHOO

\begin{tabular}{|c|c|c|c|c|c|c|c|}
\hline \multirow{2}{*}{ REACTION } & \multirow{2}{*}{ RESULT } & \multirow{2}{*}{$\begin{array}{l}\text { EXCITATION } \\
\text { ENERGY }\end{array}$} & \multicolumn{2}{|c|}{ SOURCE } & \multicolumn{2}{|c|}{ DETECTOR } & \multirow{2}{*}{ ANGLE } \\
\hline & & & TrPe & RANGE & TYPE & mange & \\
\hline$\$ G, X P$ & ASM & $0 \star 2$ & $C$ & $0 * 2$ & UKN & & 100 \\
\hline & & & & & & & \\
\hline & & & & & & & \\
\hline
\end{tabular}

COH-BRMS . $69 * 7.95 \mathrm{GEV}$

At the present time it is rather well established that the experimental values of the invariant cross section $f=\left(E / p^{2}\right)\left(d^{2} \sigma / d \Omega d p\right)$ of the reaction

$$
a A-b X
$$

in the cumulative region ${ }^{1.2}$ are described by an exponential dependence of the form $f=C \exp \left(-B p^{2}\right)$. Most of the experiments in which reaction (1) induced by various particles $(\pi, p, \gamma, \ldots)$, has been studied were designed to study the energy, angular, and $A$ dependence of the parameters $B$ and $C .^{3-9} A s$ a result of the investigations it is has been established that the parameter $B$ does not depend on the mass number $A$ of the target nucleus, on the type of incident particle, or on its energy, beginning with $E_{a} \simeq 1 \mathrm{GeV}$, while the parameter $C_{0}=C / \sigma_{\text {tot }}\left(\sigma_{\text {tut }}\right.$ is the total cross section for the $a \mathrm{~A}$ interaction) does not depend on the type of particle $a$. In addition to the established properties of the quantities $B$ and $C$ it would be interesting to check the dependence of the parameters $B$ and $C$ on the direction of polarization of the initial particle. For this purpose it is necessary to measure the asymmetry $\Sigma$ of the cross section for reaction (1) as a function of the direction of the initial-particle polarization vector.

In the present work we report the results of a study of the photoproduction of cumulative protons at an angle $\theta_{y}=100^{\circ}$ in the laboratory system in the nuclei ${ }^{12} \mathrm{C}$, ${ }^{64} \mathrm{Cu}$, and ${ }^{207} \mathrm{~Pb}$ for three photon energy values $\left(E_{y}=0.69,1.40\right.$, and $\left.1.95 \mathrm{GeV}\right)$. The possibility of measurement at a definite photon energy was based on the use of the method of subtraction of the coherent peak $\mathrm{k}^{10.11}$ in the spectrum of quasimonochromatic polarized photons emitted by electrons in passing through 2 diamond crystal. ${ }^{\text {2 }}$ The existence of a significant degree of polarization of the photons in the coherent

TABLE I.

\begin{tabular}{|c|c|c|c|c|c|c|}
\hline \multirow{3}{*}{$x_{1} \cdot \operatorname{cov}$} & \multicolumn{6}{|c|}{ Nucleus } \\
\hline & \multicolumn{2}{|c|}{ Ix } & \multicolumn{2}{|c|}{ cu } & \multicolumn{2}{|c|}{$-p D$} \\
\hline & I & $0(2)$ & $z$ & $\theta(z)$ & $=$ & (12) \\
\hline $\begin{array}{l}1.69 \\
1.40 \\
1.95\end{array}$ & $\begin{array}{r}-0.0784 \\
0.0642 \\
0.05300\end{array}$ & $\begin{aligned} & =0.0233 \\
& =0.0336 \\
& =0.09336\end{aligned}$ & $\begin{array}{r}-0.1539 \\
0.0831 \\
0.1808\end{array}$ & & $\begin{array}{r}-0.1192 \\
-0.04096 \\
11.9931\end{array}$ & \\
\hline
\end{tabular}

peak has enabled us to measure the value of the crosssection asymmetry $\Sigma$ of the reaction $\gamma A-p X$. The asymmetry was calculated from the relation

$$
\Sigma=\frac{1}{\bar{P}_{1}} \frac{y^{\prime}-y^{-}}{y^{2}+y^{-}-2 y^{-1}}
$$

where $y^{\prime}, y^{-}$are the reaction yields in the case of perpendicular and parallel orientation of the photon polarization vector with respect to the reaction plane in the coherent bremsstrahlung spectrum; $y *$ is the reaction yield for an ordinary bremsstrahlung spect rum; $\bar{P}_{y}$ is the average value of photon polarization in the subtracted coherent peak.

Measurements of $\Sigma$ were made in the nuclei ${ }^{12} \mathrm{C},{ }^{64} \mathrm{Cu}$, and ${ }^{207} \mathrm{~Pb}$ for protons with kinetic energy respectively $\tau_{p}=173,164$, and $163 \mathrm{MeV}$. The energy bin was $\Delta \Gamma$ $==60 \mathrm{MeV}$.

The experimental apparatus and measurement technique have been described in detail elsewhere. ${ }^{13}$

Numerical values of $\Sigma$ with their standard deviations $\sigma(\Sigma)$ are given in the table.

The values of $\sigma(\Sigma)$ contain both the statistical error and the error in determination of the quantity $\bar{P}_{y}{ }^{13}$

From the figure, where we have shown $\Sigma$ as a function of $E_{y}$ for the three nuclei it can be seen that the absolute values of the asymmetry in the region investigated are insignificant and depend weakly on $E_{y}$. We note that $\Sigma$ for carbon is close to zero for all $E_{\gamma}$, and the maximum value $0.29=0.16$ is achieved in the case of lead for $E_{y}=1.95 \mathrm{GeV}$. The data show that within experimental error the asymmetry is almost indepen-

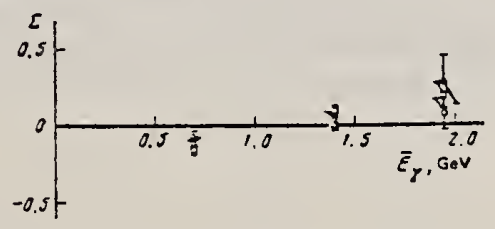

FIG. 1. Asymmetry I of the cross section for photoproduction of cummulative protons as a function of the photon energy $\varepsilon_{7}$

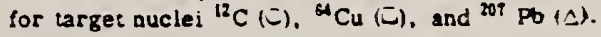


Y. Cauchois, H. Ben Abdelaziz, R. Khérouf, C. Schloesing-Möller

REF. J. Phys. G7, 1539 (1981)

\begin{tabular}{|c|c|c|c|c|c|c|c|}
\hline METHOD & & & & & & $\begin{array}{l}\text { REF. NO. } \\
81 \mathrm{Ca} 2\end{array}$ & hg \\
\hline \multirow[b]{2}{*}{ REACTION } & \multirow{2}{*}{ RESULT } & \multirow{2}{*}{$\begin{array}{l}\text { EXCITATION } \\
\text { ENERGY }\end{array}$} & & & \multicolumn{2}{|c|}{ DETECTOR } & \multirow{2}{*}{ AMGLE } \\
\hline & & & TYPE & RANGE & TYPE & RANGE & \\
\hline \multirow[t]{2}{*}{$\overline{G, G}$} & LFT & 1 & & $0-2$ & SCD-D & & \\
\hline & & $1.482)$ & & & & & \\
\hline & & & & & & & \\
\hline & & & & & & & \\
\hline
\end{tabular}

Abstract. Lifetimes of 49 excited states below $1.65 \mathrm{MeV}$ have been measured in ${ }^{24} \mathrm{Mg} .{ }^{27} \mathrm{Al}$,

$1.482 \mathrm{MeV}$

${ }^{48} \mathrm{Ti} .{ }^{18} \mathrm{Ni},{ }^{99} \mathrm{Co},{ }^{61.62} \mathrm{Ni},{ }^{63.65} \mathrm{Cu},{ }^{64.66 .66} \mathrm{Zn} .{ }^{79} \mathrm{As},{ }^{103} \mathrm{Rh}, 113.115 \mathrm{ln} .{ }^{116,118.120} \mathrm{Sn}$ and ${ }^{121.123} \mathrm{Sb}$ by means of nuclear resonance fuorescence experiments. The levels are excited by bremsstrahlung $x$-ray photons. The self-absorption technique applied to suitable cases provides nuclear absorption cross sections, widths and lifetimes from which the $x$-ray spectral distributions are also obtained. Scattering experiments are performed for all other cases in order to obtain widths and lifetimes from these $x$-ray photon curves. The Compton effect in the sample is taken into account. Self-absorption provides $g \Gamma_{0}$ from which $\Gamma$ is deduced using adopted $J^{x}$ and $\Gamma_{0} / \Gamma$ values: scattering provides $u=g\left(\Gamma_{0}^{2} / \Gamma\right) W(\theta)$ from which $\Gamma$ is also deduced with $J, \Gamma$ o $/ \Gamma$ and mixing ratios taken from the literature. Thanks to simultaneous determination of the $x$-ray spectra all the lifetimes as given by our programs with their statistical errors form an unusually coherent set of values.

NUCLEAR REACTIONS $(\gamma, \gamma)$, bremsstrahlung excitation: natural isotopes: ${ }^{3} \mathrm{Mg}$. ${ }^{27} \mathrm{Al} .{ }^{48} \mathrm{Ti} .{ }^{88} \mathrm{Ni} .{ }^{59} \mathrm{Co}{ }^{51.62} \mathrm{Ni} .{ }^{63.69} \mathrm{Cu} .{ }^{66.66 .68} \mathrm{Zn},{ }^{79} \mathrm{As} .{ }^{103} \mathrm{Rh},{ }^{113.113} \mathrm{In}, 116.118 .120 \mathrm{Sn}$ and ${ }^{121.1: 3} \mathrm{Sb} ; E=0.5-1.65 \mathrm{MeV}$; measured $g \Gamma_{0}$ or $g\left(\Gamma_{0}^{2} / \Gamma\right) W(\theta)$; deduced $T_{1 / 2}$.

1

Tableau 2. Resultats des mesures des niveaux etudies par self-absorption.

Table 2 Results obtanned using the self-absorption methou.

\begin{tabular}{|c|c|c|c|c|c|c|c|c|}
\hline Isotope & $\begin{array}{l}\text { Energie } \\
\text { (keV) }\end{array}$ & $j^{*}$ & $J_{0}^{\pi}$ & $\Gamma_{0} / \Gamma$ & $\begin{array}{l}g \Gamma_{0} \text { (meV) } \\
\text { ce travall }\end{array}$ & $\begin{array}{l}\text { : (ps) } \\
\text { ce travail }\end{array}$ & $\tau_{\text {ref }}(p s)$ & Réfërences ${ }^{\dagger}$ \\
\hline${ }^{59} \mathrm{Co}$ & 1190.0131 & $?^{-}$ & $?-$ & 1 & $11.3(5)$ & $0.0729(32)$ & $0.080(4)$ & $\operatorname{Kim}(1976)$ \\
\hline${ }^{63} \mathrm{Cu}$ & $669.62(5)$ & $\vdots-$ & $i-$ & 1 & $1.19(4)$ & $0.277(10)$ & $0.297(9)$ & Aubie $(1979 b)$ \\
\hline${ }^{63} \mathrm{Cu}$ & $462.06(4)$ & i- & - & 1 & $1.25(6)$ & $0.792(38)$ & $0.851(43)$ & Auble (1979b) \\
\hline${ }^{63} \mathrm{Cu}$ & $15+7,0 \geq(6)$ & i- & i- & 0.803 & $2.6(1.7)$ & $0.20(13)$ & $0.160(16)$ & Aubie $(1979 b)$ \\
\hline${ }^{69} \mathrm{Cu}$ & $770.6(2)$ & :- & j- & 1 & $2,18(13)$ & $0,151(y)$ & $0.13(4)$ & Auble (1975a) \\
\hline${ }^{63} \mathrm{Cu}$ & $1115.54(4)$ & 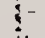 & $\vdots-$ & 1 & $2.77(28)$ & $0,400(+5)$ & $0.38(2)$ & Auble $(1975 a)$ \\
\hline 119 In & $1132.57(3)$ & $2+$ & $\dot{2}$ & 1 & $8.59(48)$ & $0.0920 \times 51)$ & $0.092(5)$ & Cauchois et a/ $(1977)$ \\
\hline${ }^{119} \ln$ & 1463.51121 & $i$ & !ै & 0.942 & $5,22(60)$ & $0.095(12)$ & $0.095(12)$ & Cauchols et al( (1979) \\
\hline
\end{tabular}

† Refirences pour les colonnes 3.4. 5 et 8 de ce tableau. 
Tableau 3. Resultats des mesures des niveaux etudies par dillusion.

Table 3. Results obrained using the diftusion method.

\begin{tabular}{|c|c|c|c|c|c|c|c|c|c|}
\hline I solope & Energie (kel') & $J^{x}$ & $J_{0}^{\pi}$ & $\Gamma_{0} / \Gamma$ & $\dot{\delta}$ & $\begin{array}{l}u=g\left(\Gamma_{0}^{2} / \Gamma\right) L^{\prime}(\theta) \\
(\mathrm{meV})\end{array}$ & $\begin{array}{l}\tau(p s) \\
\text { ce travail }\end{array}$ & $\tau_{\text {ref }}(p s)$ & Réfërencest \\
\hline${ }^{24} \mathrm{Mg}$ & $1368.54(4)$ & $2^{+}$ & $0^{\circ}$ & 1 & E2 & $1,08(13)$ & $1,76(21)$ & $1,98(4)$ & $\begin{array}{l}\text { Endil et van der Leun } \\
\qquad(1978)\end{array}$ \\
\hline${ }^{27} \mathrm{Al}$ & $1014,45(3)$ & 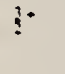 & $\vdots$ & 0.971 & $+0.351(12)$ & $0,186(13)$ & $2,20(16)$ & $2.12(8)$ & $\begin{array}{l}\text { Endl ct van der Leun } \\
\qquad(1978)\end{array}$ \\
\hline${ }^{48} \mathrm{Ti}$ & $983.512(3)$ & $2^{*}$ & $0^{*}$ & 1 & E2 & $0.282(23)$ & $6,74(55)$ & $6,1(13)$ & Been $(1978)$ \\
\hline${ }^{s} \mathrm{Ni}$ & $1454,45(15)$ & $2^{*}$ & $0^{*}$ & 1 & E2 & $2,11(26)$ & $0,90111)$ & $0,92(3)$ & $\begin{array}{l}\text { Kocher el Auble } \\
\quad(1976)\end{array}$ \\
\hline${ }^{99} \mathrm{Co}$ & $1099.224(25)$ & i- & ?- & 1 & $(E 2)$ & $0,069(8)$ & $4.79(55)$ & $3.17(58)$ & $\operatorname{Kim}(1976)$ \\
\hline${ }^{59} \mathrm{Co}$ & $1+58.8(3)$ & & i- & $0,9 i$ & $(E 2)$ & $0,68(8)$ & $1,17(14)$ & $1.52(16)$ & $\operatorname{Kim}(1976)$ \\
\hline${ }^{59} \mathrm{Co}$ & $1+80.9(3)$ & & $i^{-}$ & 0.8 & $<0.35^{\circ}$ & $1,23(15)$ & $0.254(31)$ & $0.3 \llbracket(3)$ & $\operatorname{Kim}(1976)$ \\
\hline${ }^{1} \mathrm{Ni}$ & $1185.7(6)$ & !- & $2^{3}$ & $0,77(8)^{\prime}$ & $10,14 i$ & $1,88(49)$ & $0,21(5)$ & $0,16(3)$ & Andrcev et al (1974) \\
\hline${ }^{02} \mathrm{Ni}$ & $1172,91(9)$ & $2^{-}$ & $0^{*}$ & 1 & E2 & $0.88(17)$ & $2,15(42)$ & $2,09(3)$ & Halbert (1979a) \\
\hline${ }^{61} \mathrm{Cu}$ & $1327.00(7)$ & & $i^{3-}$ & 0.84 & $(E 2)$ & $1.04(14)$ & $0,84(i 1)$ & $0.88(4)$ & Auble (1979b) \\
\hline${ }^{63} \mathrm{Cu}$ & $1+12.05(4)$ & ? & $2^{3-}$ & 0,72 & $+0,61\{-9\}$ & $0.260(38)$ & $1.90(28)$ & $1,6 i(3)$ & Auble (1979b) \\
\hline${ }^{\infty} n$ & $991.5+(7)$ & 2 & $0^{*}$ & 1 & E2 & $0.640(54)$ & $2,97(25)$ & $2,60(13)$ & Halbert (1979b) \\
\hline${ }^{09} \mathrm{Cu}$ & $1481.83(5)$ & $?^{-}$ & $i^{-}$ & 0,85 & (E2) & $1,13(19)$ & $0,79(13)$ & $0,49(5)$ & Auble (1975a) \\
\hline${ }^{66} \mathrm{Zn}$ & $1039,37(6)$ & $2^{+}$ & $0^{-}$ & 1 & E2 & $0,70(6)$ & $2.71(23)$ & $2.25(15)$ & Auble (1975b) \\
\hline $\mathrm{Zn}$ & $1077.38(5)$ & $2^{\circ}$ & $0^{*}$ & 1 & E2 & $0.70(6)$ & $2,71(23)$ & $2,34(23)$ & Lewis (1975) \\
\hline As & $572.5(10)$ & :- & $1-$ & $1^{d}$ & $0,39^{\circ}$ & $0.236(26)$ & $4,14(46)$ & $3.5(9)$ & Horen et Lewis (1975) \\
\hline${ }^{9} \mathrm{As}$ & $823,0(10)$ & 8 & ? & $0.86^{d}$ & $(E 2)$ & $0,214(22)$ & $4,27(43)$ & $3,5(3)$ & Robinson et al (1967) \\
\hline${ }_{79}^{19} \mathrm{As}$ & $865.5(10)$ & 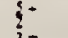 & i- & $0.83^{d}$ & - $^{2}$ & $0,78(6)$ & $0.863(68)$ & $0.60(12)$ & Cellicrs et al (1977) \\
\hline As & $1076.0(10)$ & & & $0,94^{d}$ & $0,38^{d}$ & $1,97(13)$ & $0.287(19)$ & $0,32(i)$ & Celliers et al (1977) \\
\hline${ }^{13} \mathrm{As}$ & $1128,5(10)$ & $I^{*}$ & $2^{-}$ & 1 & $E I^{\sigma}$ & $0.224(24)$ & $1,47(16)$ & - & \\
\hline & $13+9 .(\times 10)$ & t- & ?- & $0.67^{\mathrm{d}}$ & $0.20^{d}$ & $1,61(29)$ & $0.180(32)$ & $0.12(3)$ & Wilson (1970) \\
\hline As & $1370.0 \times 101$ & 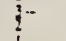 & !- & $0.47^{d}$ & $0,47^{\mathrm{J}}$ & $0.64(13)$ & $0,218(44)$ & - & \\
\hline${ }^{03} \mathrm{Rh}$ & $803.1(2)$ & 1 & $!$ & 0,70 & $M 1$ & $1.55(16)$ & $0, ! 74(15)$ & - & Harmatz $(1979)$ \\
\hline${ }^{103} \mathrm{Kh}$ & $1277 .(x 21$ & $?$ & $1-$ & 0.75 & $-0.122(30)^{e}$ & $0,81(9)$ & $0.87(10)$ & $1.3(9)$ & Harm:1l< (1979) \\
\hline 11111 & $1177(1)$ & $!$ & $\because$ & 1 & $+0.5(2)$ & $9.1(8)$ & $0.086(8)$ & $0.10(6)$ & Tuttle ct al(1976) \\
\hline${ }^{113} \mathrm{ln}$ & $1510(1)$ & $\vdots$ & $\begin{array}{l}y- \\
\vdots \\
\vdots\end{array}$ & 0.935 & $-0.5\{\div 3\}$ & $6.7(9)$ & $0.071(10)$ & $0.11_{1}^{1+21}$ & Tutic et $4 /(1976)$ \\
\hline $115 \ln$ & $1077.7(10)$ & $i$ & ?. & $0.81^{\prime}$ & $(E 2)$ & $0.159(24)$ & $1.61(24)$ & $1.23(7)$ & Tuttle ct al( $(1976)$ \\
\hline $119 \ln$ & $1290 . \vdots 9(3)$ & 3. & ?. & $0.98^{J}$ & $(\mathrm{~F}: 2)$ & $1.31(11)$ & $0,66(6)$ & $0.55(4)$ & Tultle et a/(19:6) \\
\hline $119 \ln$ & $1448.73(3)$ & $\xi^{*}$ & $? \cdot$ & $0.3 \mathrm{~h}$ & $-8^{r}$ & $0.40(11)$ & $0.50(6)$ & $0.52(20)$ & Tuttle $d t a /(1476)$ \\
\hline $119 \mathrm{ln}$ & 1486.1111 & $\xi$ & ?. & 0.787 & $-0.8^{\prime}$ & $0.6 .3(9)$ & $0.63(9)$ & $0.4(3)$ & Tuttle $2 u(1) y i n)$ \\
\hline${ }^{119} \operatorname{In}$ & $1+47.2(4)$ & $1 \vdots 1$ & $u^{\circ}$ & -1 & (E2) & $1.33(16)$ & $<0,30(4)$ & - & \\
\hline $131 \mathrm{n}$ & I $607.8(! 5)$ & $\left(!^{\circ}\right)$ & $\xi \cdot$ & $\leqslant !$ & (E:2) & $1.54(24)$ & $\leqslant 0.26(4)$ & - & \\
\hline${ }^{110} \mathrm{Sn}$ & $1243.54(2)$ & 2 & $0)^{-}$ & 1 & E? & $3.58(37)$ & $0.5 .3(6)$ & $0.522(1+)$ & Carlsun el a/(1975) \\
\hline${ }^{118} \mathrm{Sn}$ & $1224.6 \div 1 \div 1$ & $z^{\circ}$ & $0^{-}$ & 1 & E? & $2,75(28)$ & $0.69(7)$ & $0.67(2)$ & Carlsuncti al(1976) \\
\hline${ }^{2}=\mathrm{Sn}$ & $11 \div 1.6(2)$ & $2^{\circ}$ & $0^{*}$ & 1 & EZ & $1.83(16)$ & $1.0+(4)$ & $0.91 ! 2)$ & Kexler $(1476)$ \\
\hline${ }^{121} \mathrm{Sh}$ & 1023.51101 & 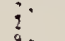 & $\vdots$ & 1 & $0.57_{1}$ & $3.69(34)$ & $0.228(21)$ & $0.20(7)^{h}$ & Tamura el $a(11979)$ \\
\hline${ }^{121} \mathrm{Sb}$ & $1105.5(10)$ & ?- & 3 & 0.4 & - & $0.47(4)$ & $0 . \div-1(4)$ & - & \\
\hline${ }^{121} \mathrm{Sb}$ & $11+2.5(10)$ & $\vdots$ & $\vdots$ & 0.6 & $(E: 2)$ & $0.85(8)$ & $0.449(40)$ & $0,41(8)^{h}$ & Booth ef sil (1973) \\
\hline${ }^{21} \mathrm{Sb}$ & 1384.01101 & 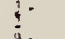 & $\vdots$ & 1 & $0.451^{8}$ & $4.7(5)$ & $0.39 \geq 1101$ & $0.085(1+)^{h}$ & Boulh el ul( $\left.1 y^{-3} 3\right)$ \\
\hline${ }^{123} \mathrm{Sb}$ & $1024.5(10)$ & $\vdots$ & $\vdots$ & 1 & $0.371^{\circ}$ & $2.46(27)$ & 0.2721251 & $0.2+(4)^{4}$ & Boxth of al $\left(19^{-3} 3\right)$ \\
\hline${ }^{133} \mathrm{Sb}$ & IUSis: : : 101 & $\vdots^{*}$ & 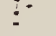 & 1 & $i>1.26^{3}$ & $1.06(y)$ & $0.67(6)$ & $0.2(15)^{17}$ & Booth ef : $1(1473)$ \\
\hline
\end{tabular}

+ References pour !es colonnes ?, 4.5 .5 et y de chaque ligne, sauf indication appe!ce au has de ce iahleau. Pour les autre: donnces se repurter au texte.

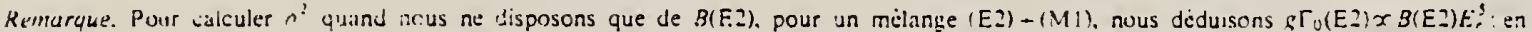
admettant $U(H)=1$ et sornatssant $\Gamma, \Gamma$. notse determination de $u$ donne une premiere approximation de $g \Gamma_{0} J^{\circ}$ $\dot{0}^{*}=\left(g \Gamma_{0}(E 2){ }_{1} \Gamma_{0}-g \Gamma_{0}(E 2)\right)$ qui permet d anelwurer $\|(\theta)$ et $g \Gamma_{0}$ Je proche sll proche.

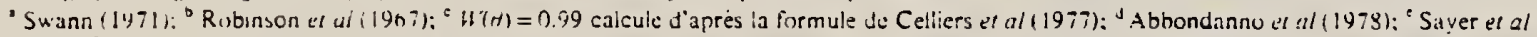

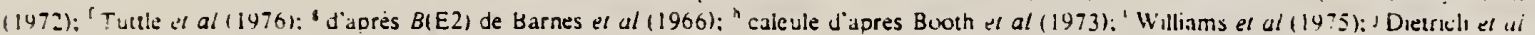
(1970). 
REF. M.N. Martins, E. Wolynec, M.C.A. Campos

Phys. Rev. C26, 1936 (1982)

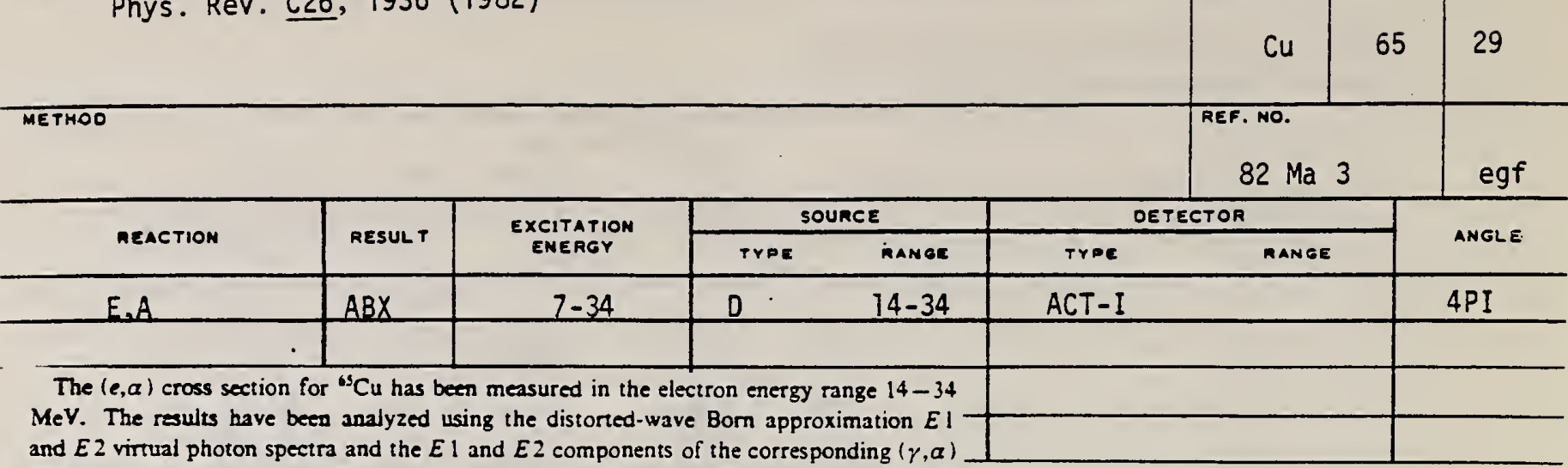

crass section were oblained. To assess the accuracy of the vir

$(e, 2 n)$ cross section for ${ }^{63} \mathrm{Cu}$ was also measured and the obtained $(\gamma, 2 n)$ cross section is compared with direct mieasurement of this cross section performed with annihilation gamma rays.

[NUCLEAR REACTIONS ${ }^{65} \mathrm{Cu}(e, \alpha)$ and ${ }^{63} \mathrm{Cu}(e, 2 n)$. Measured

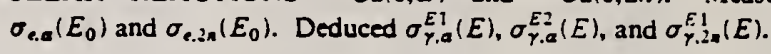

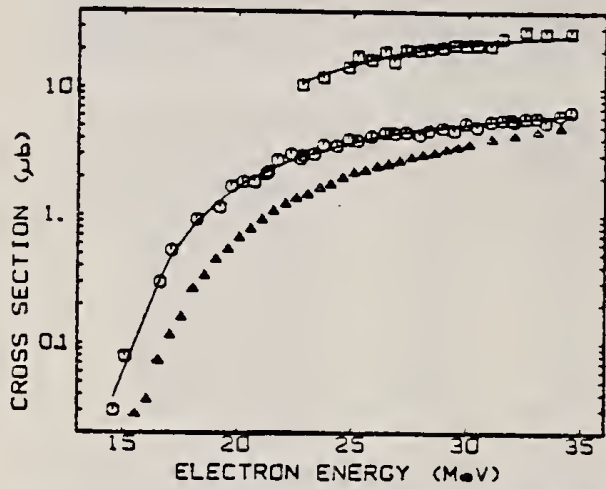

FIG. 4. $\sigma_{e, a}\left(E_{0}\right)$ for ${ }^{65} \mathrm{Cu}$ (eircles) and the yield of electrodisintegration plus photodisintegration (squares). The smooth curves are the best fit to the data and were obtained by combining the $E 1$ and $E 2$ histograms of Fig. 7 with the virtol photan spectra and the DBM bremsstrablung cross section in Eqs. (1) and (2). The triangles show the $(e, a)$ cross section from Ref. 6 .

TABLE III. $(\gamma, \alpha)$ strength for nuclet in the $A=60$ region. $E$ I sum: $60 . \mathrm{VZ} / \mathrm{A} . \mathrm{MeV}$ mb: $E 2$ sum: $0.2 Z Z$ : $A^{-1 / 3} \mu \mathrm{b} / \mathrm{MeV}$.

\begin{tabular}{ccccc}
\hline Nucleus & $\begin{array}{c}\int_{0}^{30} \sigma_{r . a}(E) d E \\
(\mathrm{MeV} \mathrm{mb})\end{array}$ & $\begin{array}{c}\text { Fraction } \\
\text { of } E \text { I sum }\end{array}$ & $\begin{array}{c}\text { Fraction } \\
\text { of }\end{array}$ E sum & Ref. \\
\hline${ }^{56} \mathrm{Fe}$ & $21 \pm 3$ & $2.1 \pm 0.3$ & $7 \pm 1$ & 2 \\
${ }^{88} \mathrm{Ni}$ & $43 \pm 4$ & $3.9 \pm 0.4$ & $21 \pm 3$ & 1 \\
${ }^{50} \mathrm{Co}$ & $17 \pm 2$ & $1.7 \pm 0.2$ & $5 \pm 1$ & 2 \\
${ }^{60} \mathrm{Ni}$ & $41 \pm 4$ & $3.5 \pm 0.4$ & $21 \pm 5$ & 1 \\
${ }^{62} \mathrm{Ni}$ & $17 \pm 2$ & $1.5 \pm 0.2$ & $8 \pm 2$ & 1 \\
${ }^{\circ} \mathrm{Zn}$ & $78 \pm 16$ & $6.9 \pm 1.5$ & $25 \pm 3$ & 2 \\
${ }^{65} \mathrm{Cu}$ & $10 \pm 1$ & $1.0 \pm 0.1$ & $3 \pm 1$ & This \\
& & & & Hork \\
\hline
\end{tabular}

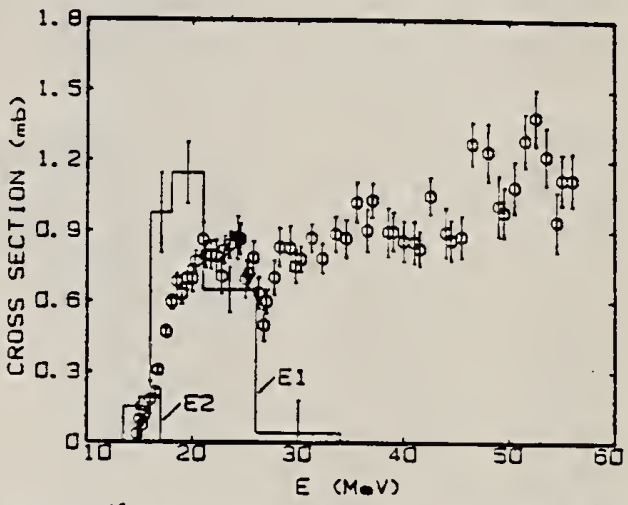

FIG. 7. ${ }^{63} \mathrm{Cu}(\gamma, \alpha)$ cross sections. The $E 1$ and $E 2$ histograms are the results from this work. The points show the $(\gamma, a)$ cross section from Ref. 6 . 


\section{ZIIC \\ $\tau=30$}

Zinc, in combination with copper, was known in Roman times as the alloy brass; the individual metal was not isolated until much later. The first smelting and extraction of the impure metal was carried out in China and India about 1000 A.D. Paracels is (1490-1541) refers to zinc as a bastard form of copper. This is the earliest authenticated use of the word "zinc" to describe the metal. 
Ref. 2. Dlouhý; v. Petržílka, M. Rozkos̆

Czech. J. Phys. 5, 193 (1955)

Mechod $\mathrm{Li}(\mathrm{p}, \gamma)$ source; nuclear emulsions; $G-M$ coun ters; $\mathrm{Cu}^{63}(\gamma, \mathrm{n})$ reaction;

flux calibration.

\begin{tabular}{|c|c|c|c|c|c|c|}
\hline Reaction & $E$ or $\Delta E$ & $E_{0}$ & $\Gamma$ & $\int \sigma d E$ & $\mathrm{~J} \pi$ & Notes \\
\hline $\mathrm{z} n(\gamma, \mathrm{p})$ & 17.6 & & & & & $\begin{array}{l}\sigma=(4 \pm 2) 10^{-26} \mathrm{~cm}^{2} \\
\text { Monitor in terms of counts on G-M } \\
\text { counter which had been calibrated in } \\
\text { terms of } \mathrm{Cu}^{63}(\gamma, \mathrm{n}) \mathrm{Cu}^{62} \text { (absolute } \\
\text { counting and effective } \sigma \text { Li }=7.75 \\
\text { x } 10^{-26} \pm 15 \% \mathrm{~cm}^{2} \text { given by Shimigu: } \\
\text { [Mem. of Un. Kyoto } 25 \text {, } 194 \text { (1949] }\end{array}$ \\
\hline
\end{tabular}


Ke. J.i G ivrilov, L.E. Lazareva

Zhu.r. riksp. i Teoret. Fiz. 30, 855 (1956);

Scviet Phys. JETP 2, 871 (1957)
Elem. Sym.

A

$\mathrm{Zn}$

30

$\bar{M}_{1}$ (nod $\gamma$-Bremsstrahlung; synchrotron; $\mathrm{BF}_{3}$ counter

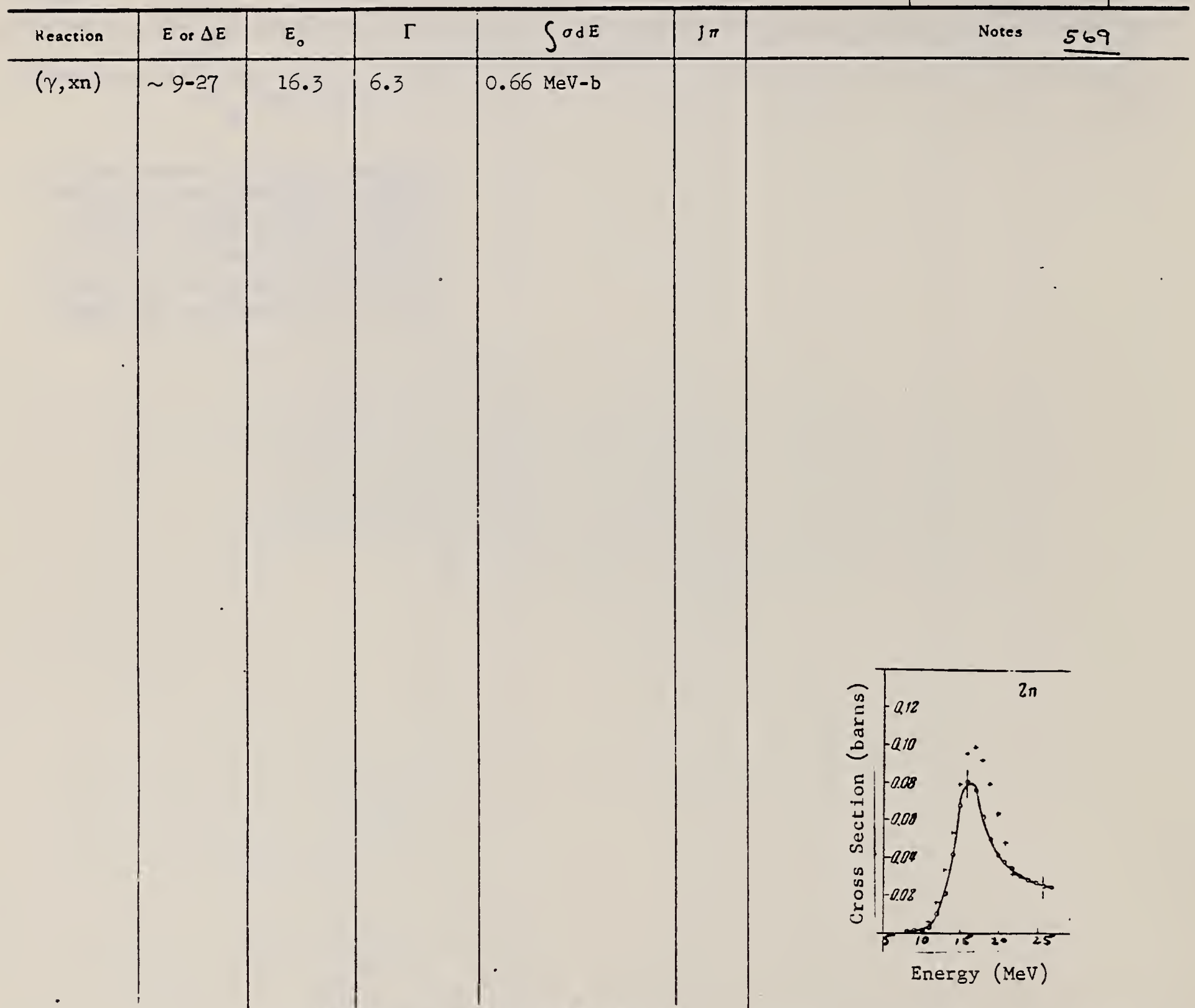

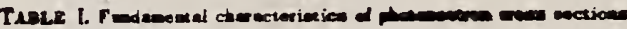

\begin{tabular}{|c|c|c|c|c|c|}
\hline Elemen & 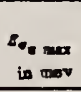 & $\begin{array}{l}\text { "n max } \\
\text { in barss }\end{array}$ & $\begin{array}{l}\text { Galf widet } \\
\text { in merer }\end{array}$ & 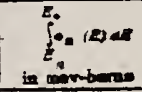 & $\int_{0}^{8 .}$ \\
\hline 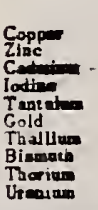 & $\begin{array}{l}17.2 \\
16.3 \\
16.0 \\
15.5 \\
14.5 \\
14.2 \\
14.6 \\
13.9 \\
14.5 \\
14.9\end{array}$ & $\begin{array}{l}0.128 \\
0.082 \\
0.270 \\
0.288 \\
0.452 \\
0.571 \\
0.655 \\
0.537 \\
0.736 \\
1.18\end{array}$ & $\begin{array}{l}4.3 \\
6.3 \\
6.4 \\
6.0 \\
6.8 \\
6.0 \\
5.4 \\
5.9 \\
5.6 \\
6.8\end{array}$ & $\begin{array}{r}0.33 \\
-\quad 0.88 \\
\therefore \quad 2.38 \\
2.35 \\
3.37 \\
4.37 \\
4.80 \\
3.98 \\
1.33 \\
12.5\end{array}$ & 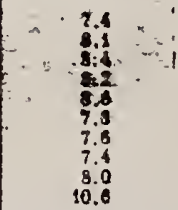 \\
\hline
\end{tabular}

Figure 2: Photoneutron cross section $\sigma_{n}$, computed from the yield curves by the "photon difference method." "+" -- cross sections obtained in Ref. 8 [Montalbetti, Katz, and Goldemberg, Phys. Rev. 21, 659 (1959)]. 
W. H. Ha:tley, W.E. Stephens, E.J. Winhold

Phy s. Rev. 104, 178 (1956)

M. thod $\mathrm{Li}(\mathrm{p}, \gamma)$ source, $480 \mathrm{kev}$ protons; $\mathrm{BF}_{3}$ counters.

Rei. No.

$56 \mathrm{Ha} \mathrm{l}$

$E G F$

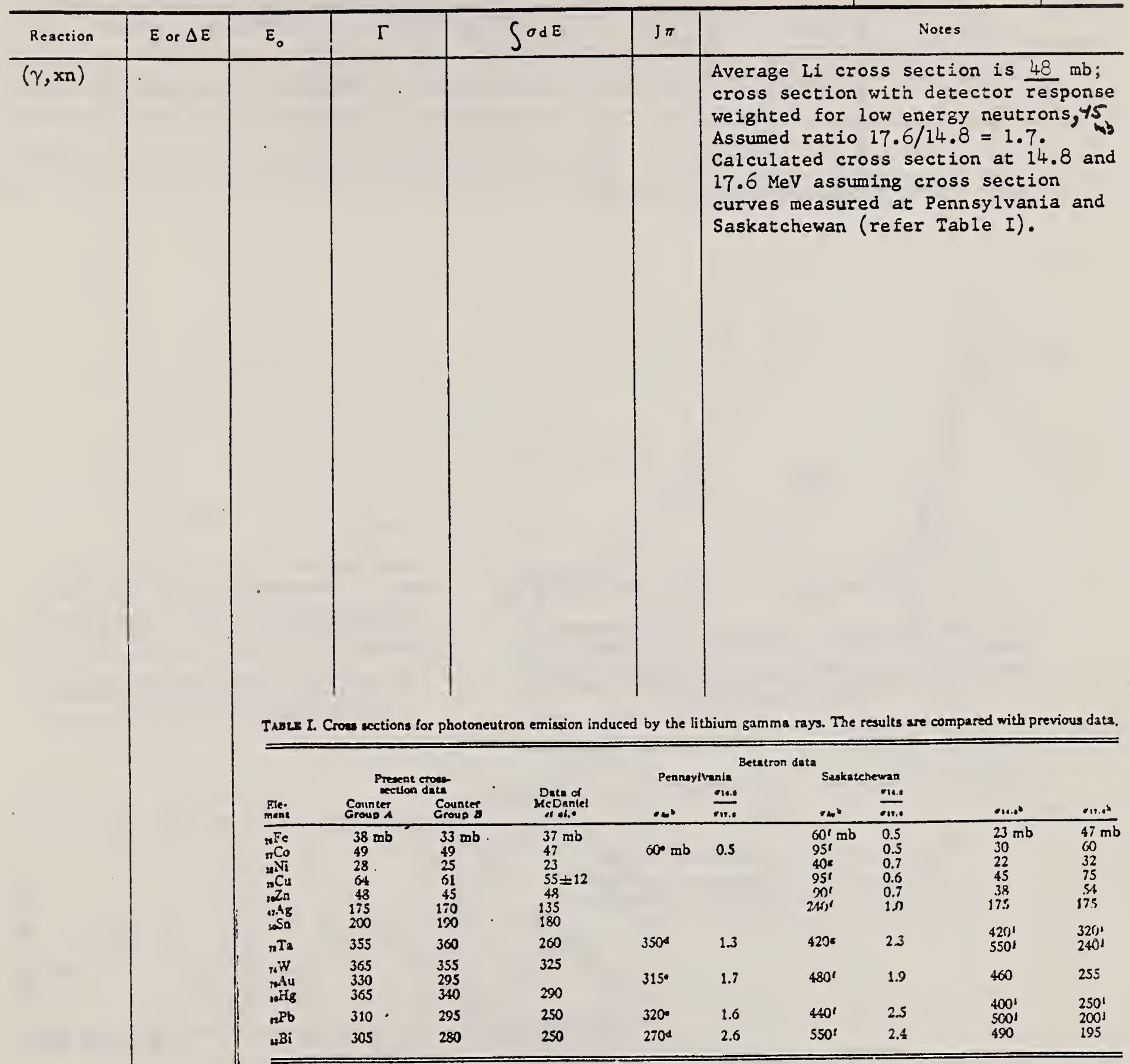

- See reference 3r

- Average of 14.8- and 17.6-Mer crom ectione weighted with relative intendites of the lleblum gamma-ray linea.

i See reference 24. Nathans. Ph.D. thesie. Univenity of Peasoglvania, 1954 (unpubliahed).

I. Helpers (private communication).

isee reference 23 .

See reference 32 .

'Obealned usiag $14.8 / 17.6$ cross-cection mato from Pennsylvania betatron data.

i Obtained using $14.8 / 17.5$ croe-wection ratio from Saskatchewan becatron data. 
R. M. Osokina and B. S. Ratner

Zhur. Eksp. i Teoret. Fiz. 32, 20 (1957)

Soviet Phys. JETP 5, 1 (1957)

[Page 1 of 2]

\begin{tabular}{|c|c|c|c|c|c|c|c|}
\hline \multirow{2}{*}{ REACTION } & \multirow{2}{*}{ RESULT T } & \multirow{2}{*}{$\begin{array}{l}\text { EXCITATION } \\
\text { ENERGY }\end{array}$} & \multicolumn{2}{|c|}{ SOURCE } & \multicolumn{2}{|c|}{ DETECTOR } & \multirow{2}{*}{ ANGLE } \\
\hline & & & TYPE & RANGE & TYPE & RANGE & \\
\hline$G, P$ & $\mathrm{ABX}$ & THR -31 & $C$ & $20-31$ & EMU-D & $4-18$ & DST \\
\hline & & & & & & & \\
\hline & & & & & & & \\
\hline
\end{tabular}

Note: Fast photoproton mean $\mathrm{E}_{\mathrm{p}} \geq 9 \mathrm{MeV}$.
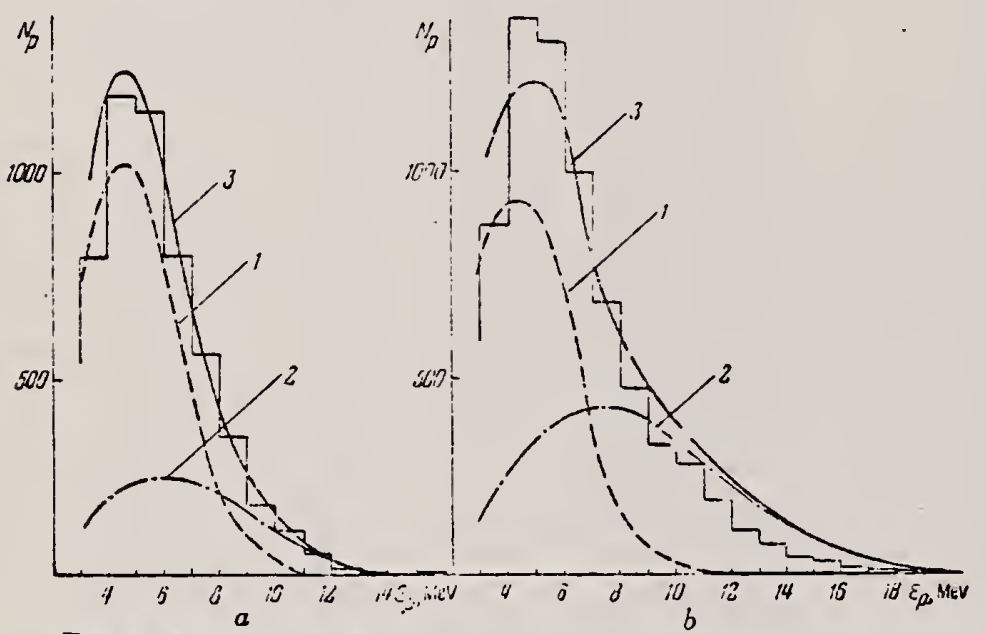

FIG. 2. Energy distributions of photoprotons from zinc obtained at energies $E \gamma_{m}: a-20.8 \mathrm{mev}$ and $b=28.6 \mathrm{mev} . l-$ spectra calculated according to evaporation the ory; 2 - spectra calculated according to the direct photoeffect model lit taking shells into account; 3 the sum of curves $I$ and 2 .

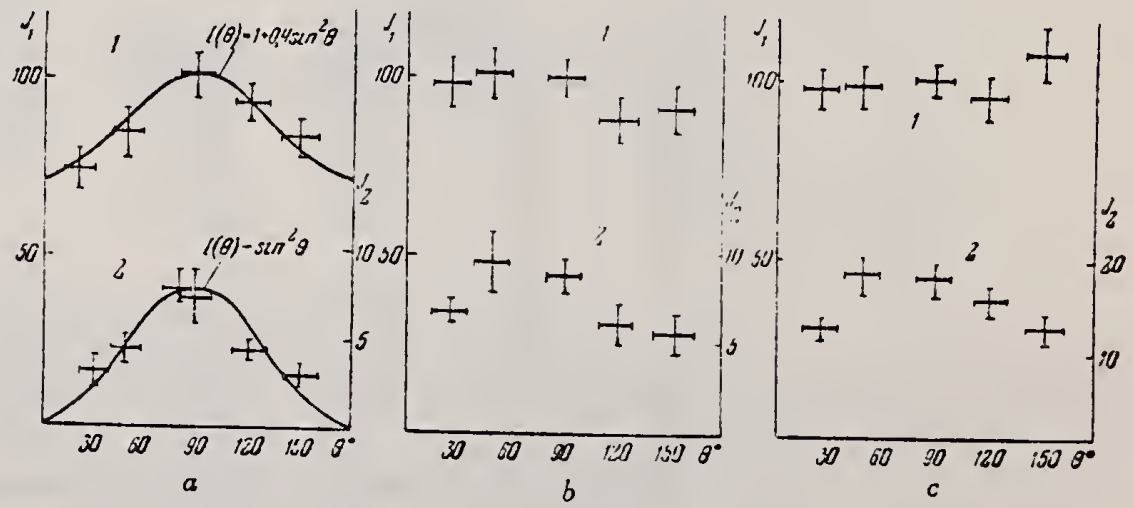

FIG. 4. Angular distributions of p.1st r $r=x \cdot n$ f from $z$ inc obtained at energy values $E_{\gamma_{m}}: a-20.8, b-2 \ldots . .3$ and $=-28.6 \mathrm{mev} . I_{1}$ and $I_{2}$ are the relative numbers of protons prr unit snild angle for protons: $l$ - with energies $\epsilon_{p} \geq 3$ mev, 2 - with energies $\epsilon_{p} \geq 9$ mev. 


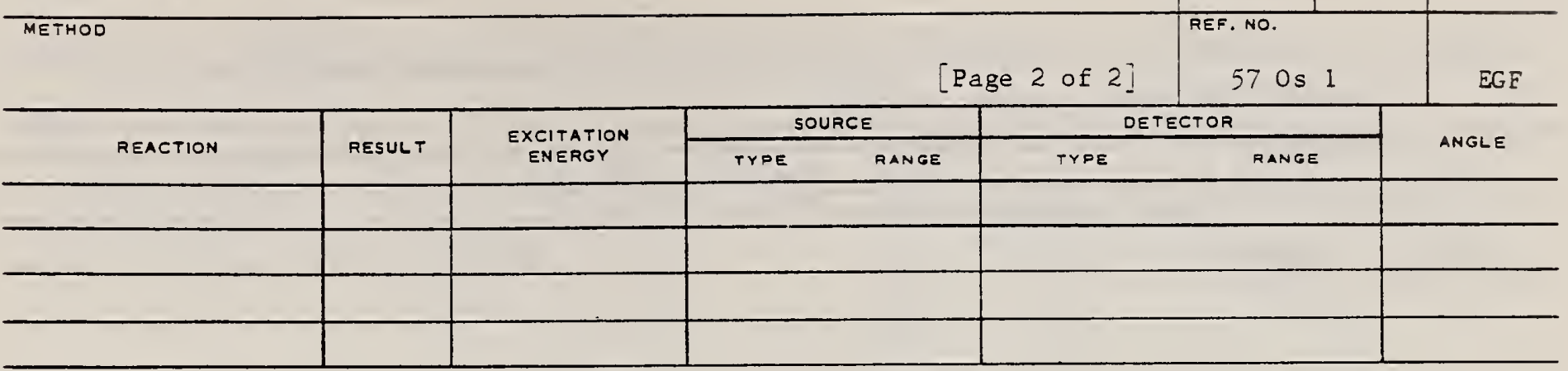

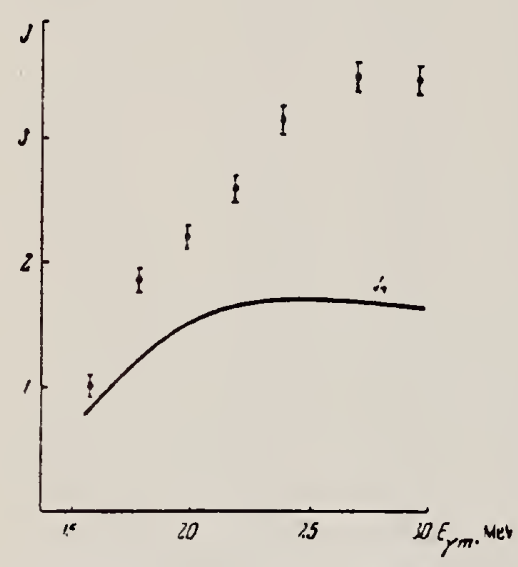

FIG.5. Dependence on $\varepsilon_{\gamma}$ of the yield of photoprotons with energies $\epsilon_{p} \geq 3 \mathrm{mev}$ from zinc. $l_{T}$ is the curve calculated according to evaporation the $\alpha y$ and normalized according to the data on angular distribution on the assumption that at $\varepsilon_{\gamma m}=\mathbf{2 0 . 8}$ mev the isotropic part of the yield $(75 \%)$ is determined by evaporation. is the yie ld in relative units reduced to the same ionization in a thick-walled ionization chamber.

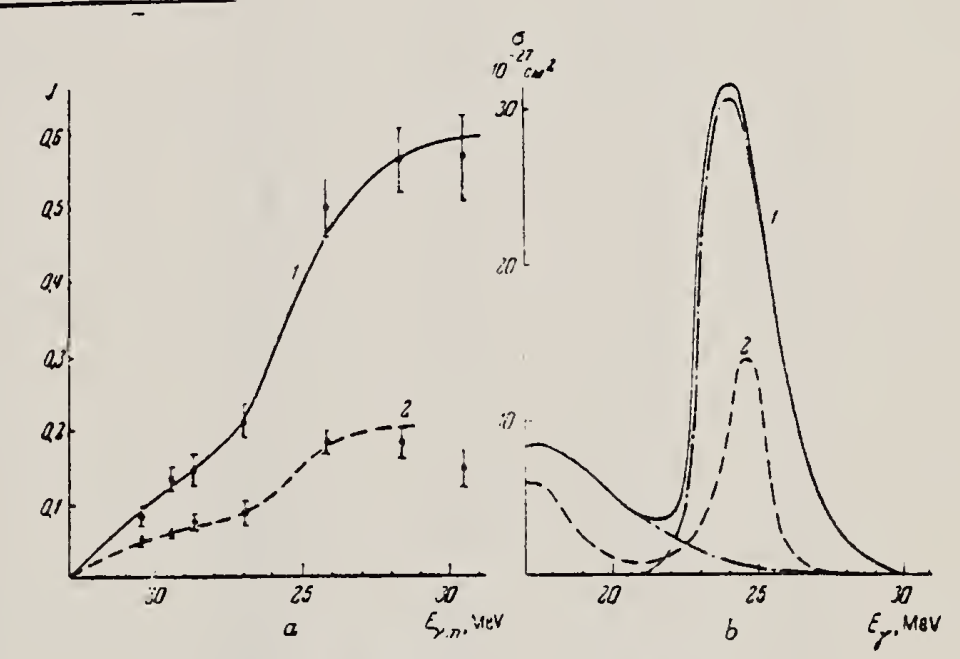

FIG. 6. $a$-dependence on $E_{\gamma m}$ of the yield of tast photoprotons from zinc; $b$ - cross-section for the emission of fast protons from zinc. $1-\epsilon_{p} \geq 9,2-$

$$
-8 \leqslant \varepsilon_{p} \leqslant \leqslant 11 \mathrm{mex}
$$


Ref. M.E. Toms, J. McElhinney

Phys. Rev. 111, 561 (1958)

\begin{tabular}{l|l|l|l} 
& 30 & $2 n$ & \\
\hline Method & & Ref. No.. \\
Betatron; alpha yield; nuclear emulsion & 58 To 2 & NVB \\
\hline
\end{tabular}

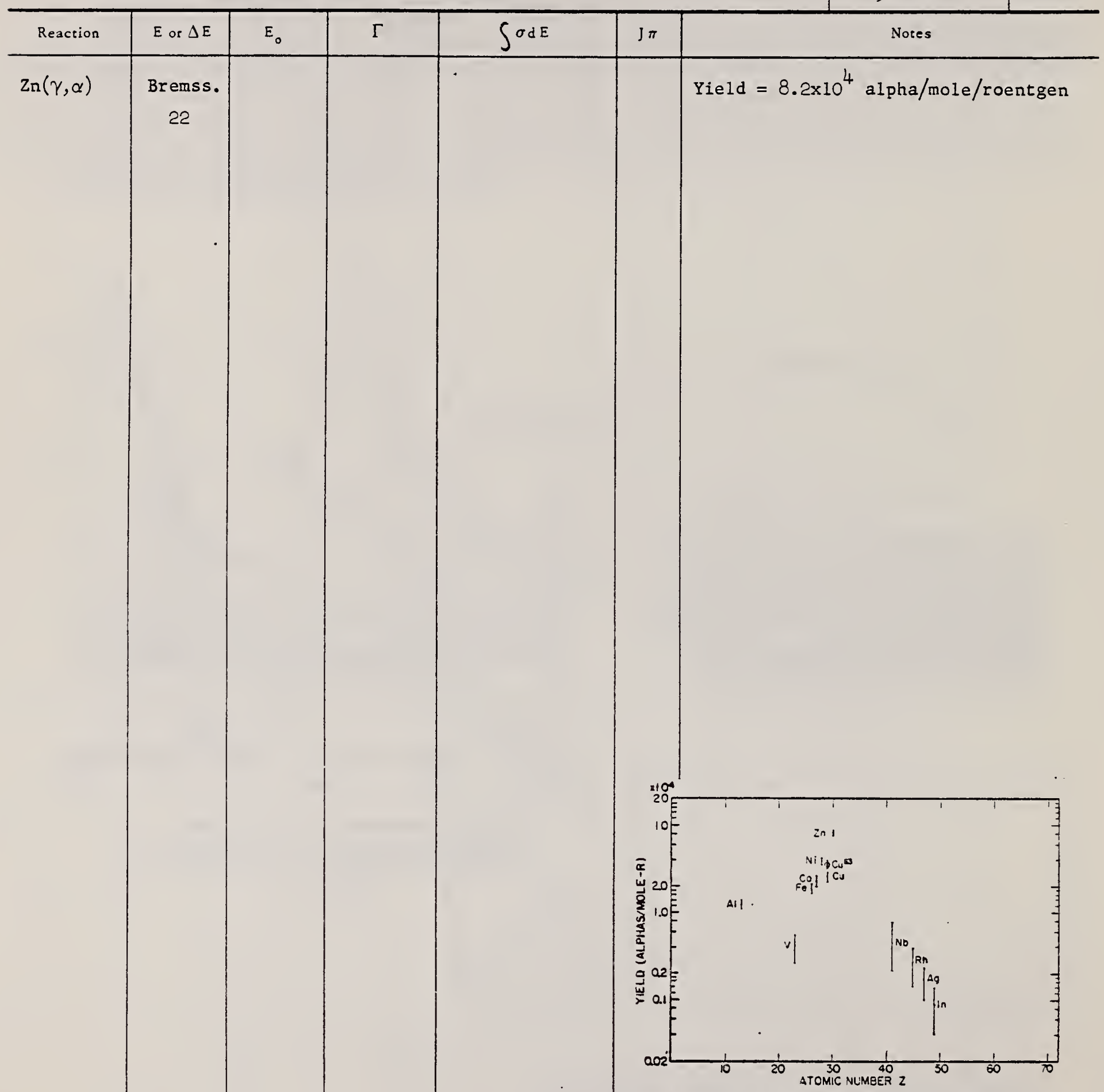

FIc. 8. Photo-alpha yields plotted against atomic numbers for the exposures of the survey. 
ii.t. K. Reibel, A.K. Mann

Phys. Rev. 118, 701 (1960)

\begin{tabular}{c|c|c} 
Elem. Sym. & A & $z$ \\
$\mathrm{Zn}$ & & 30 \\
\hline $\begin{array}{l}\text { Ref. No. } \\
60 \mathrm{Re} \mathrm{1}\end{array}$ & $\mathrm{JHH}$
\end{tabular}

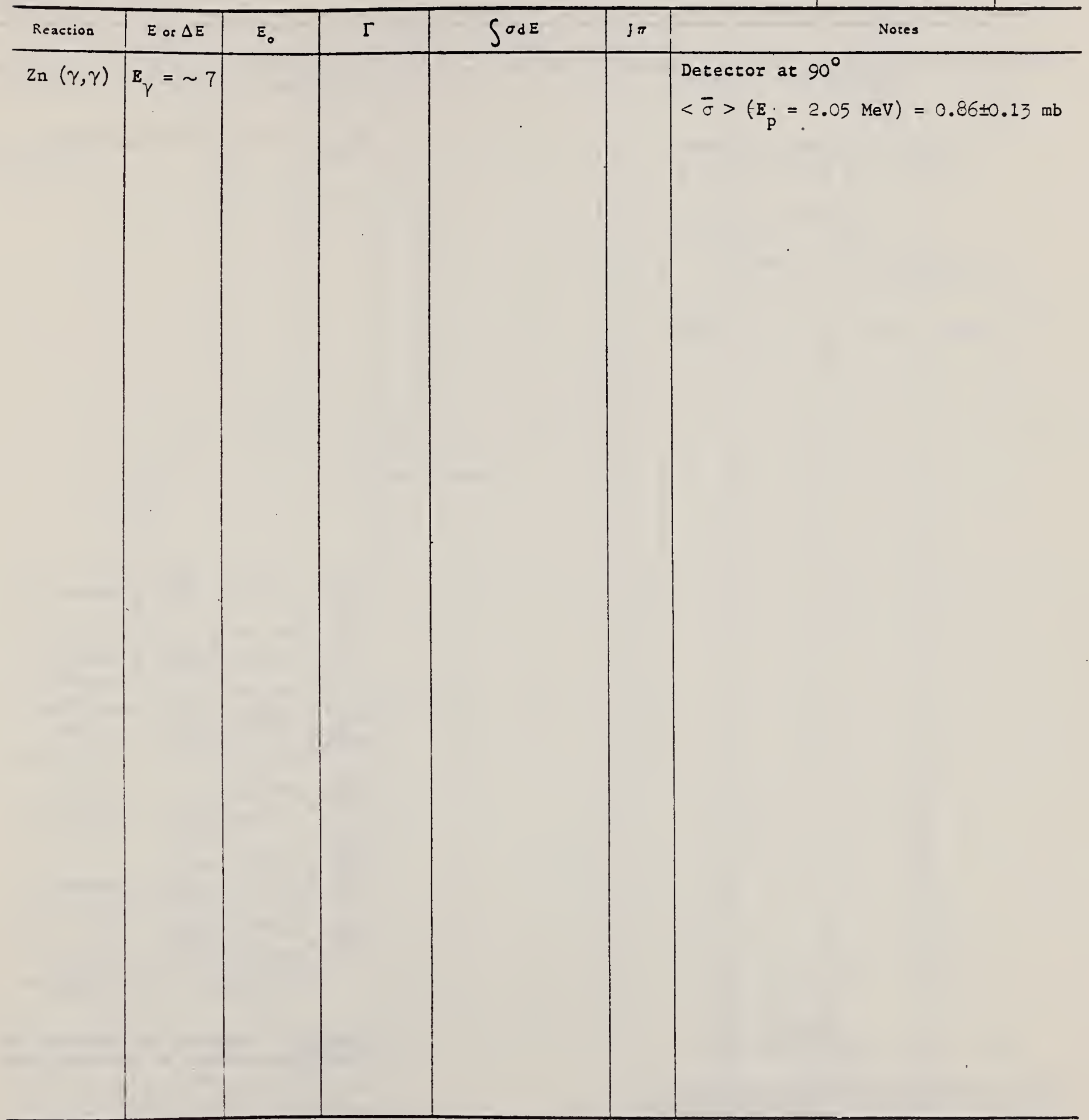


Rer. F. Tagliabue, J. Coldemberg

Nuclear Phys. $1+4$ (1961)

Sictivi $22 \mathrm{MeV}$ betaticn; $\mathrm{Si}^{28}(\mathrm{n}, \mathrm{p}) \mathrm{Al}^{28}$ threshold detector.

\begin{tabular}{|c|c|c|c|c|c|c|}
\hline Ricateion & $E$ or $\Delta E$ & $E_{0}$ & $\Gamma$ & $\int \sigma d E$ & $j \pi$ & Notes \\
\hline$(\gamma, n)$ & $\begin{array}{c}\text { Bremss. } \\
22\end{array}$ & & & & & 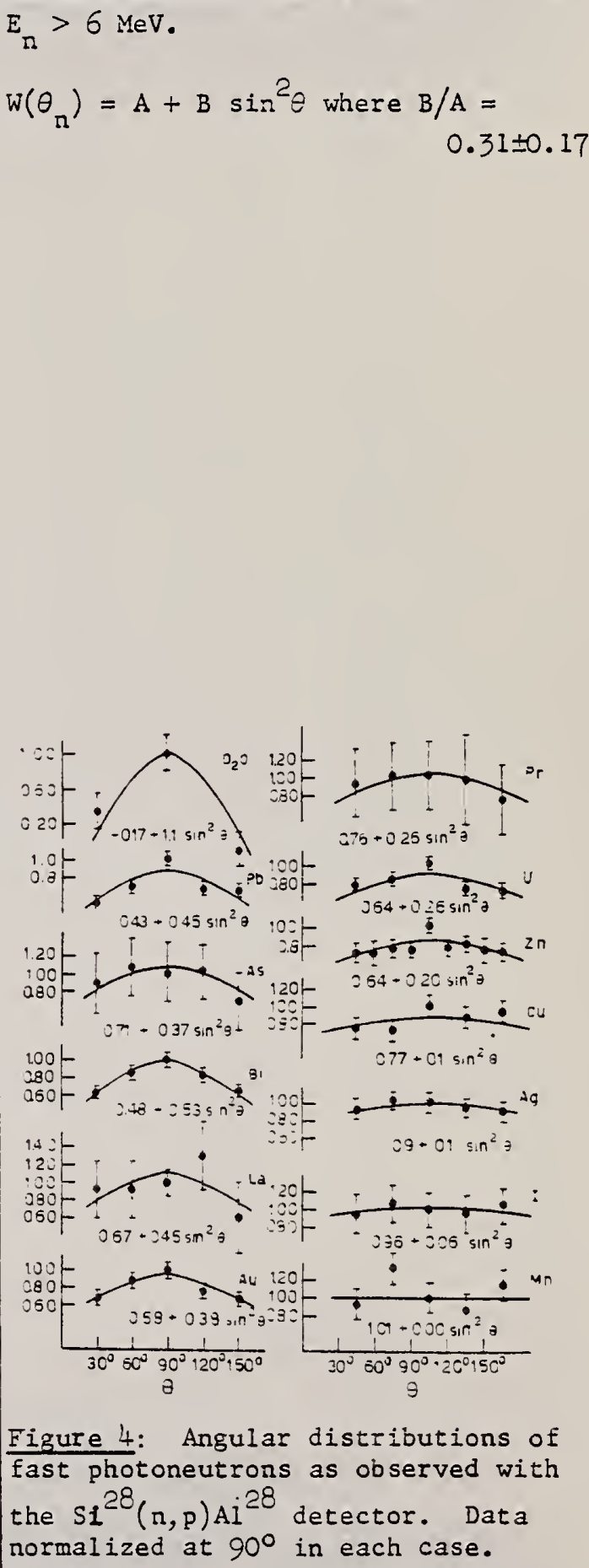 \\
\hline
\end{tabular}


Ref. O.M.M. Mitche11, K.G. McNeill

Can. J. Phys. $\underline{41}, 871$ (1963)

Method Betatron; proton yield; angular distribution; scintillator; ion chamber.

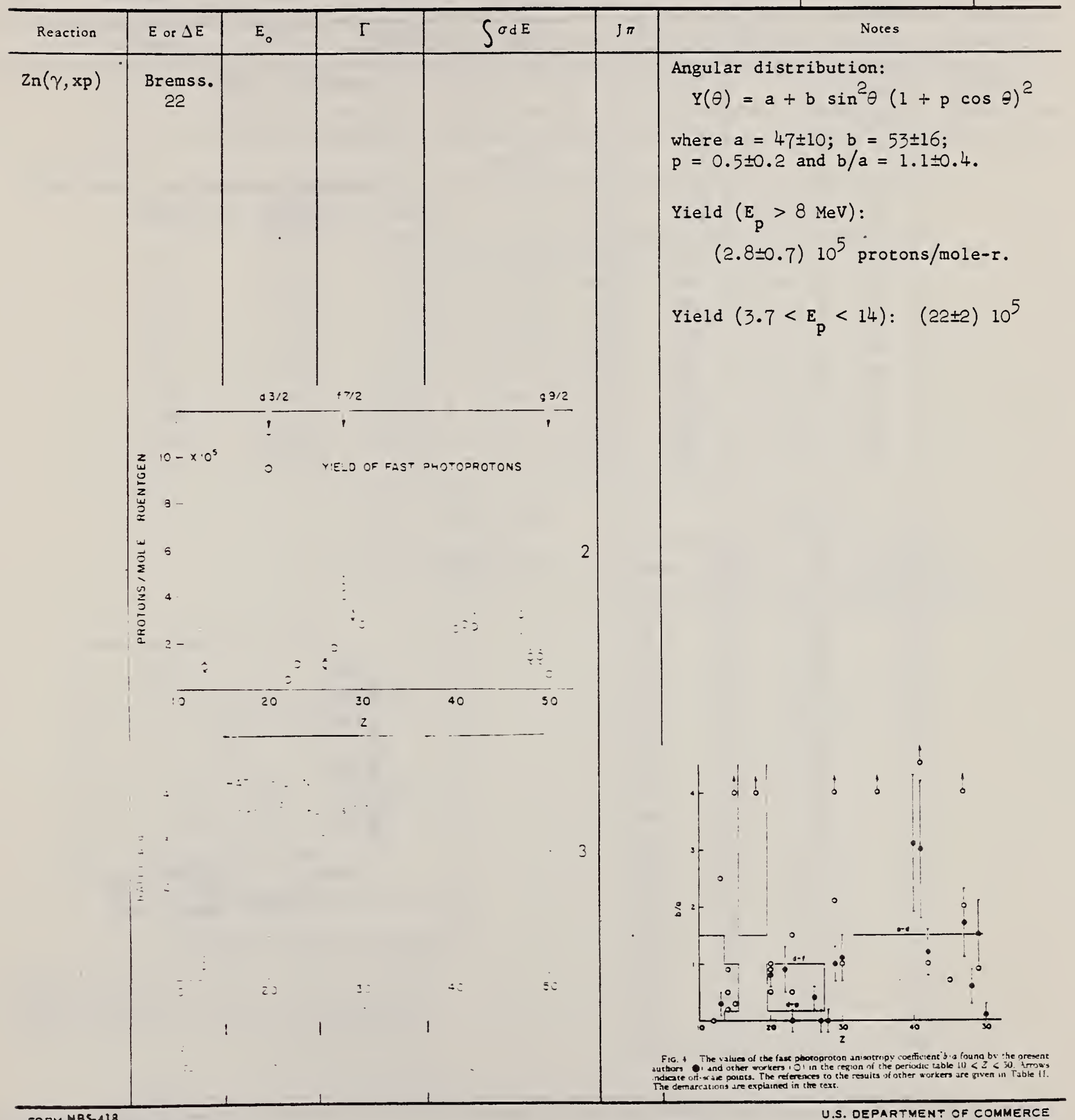


Ref. M. Sugawara, S. Mori, A. Ono, A. Hotta, M. Kimura

J. Phys. Soc. Japan 18, 17 (1963)

Method $25 \mathrm{MeV}$ betatron; photon scattering; NaI spectrometer; NBS chamber Ref. No.

$63 \mathrm{Su} 1$ 30

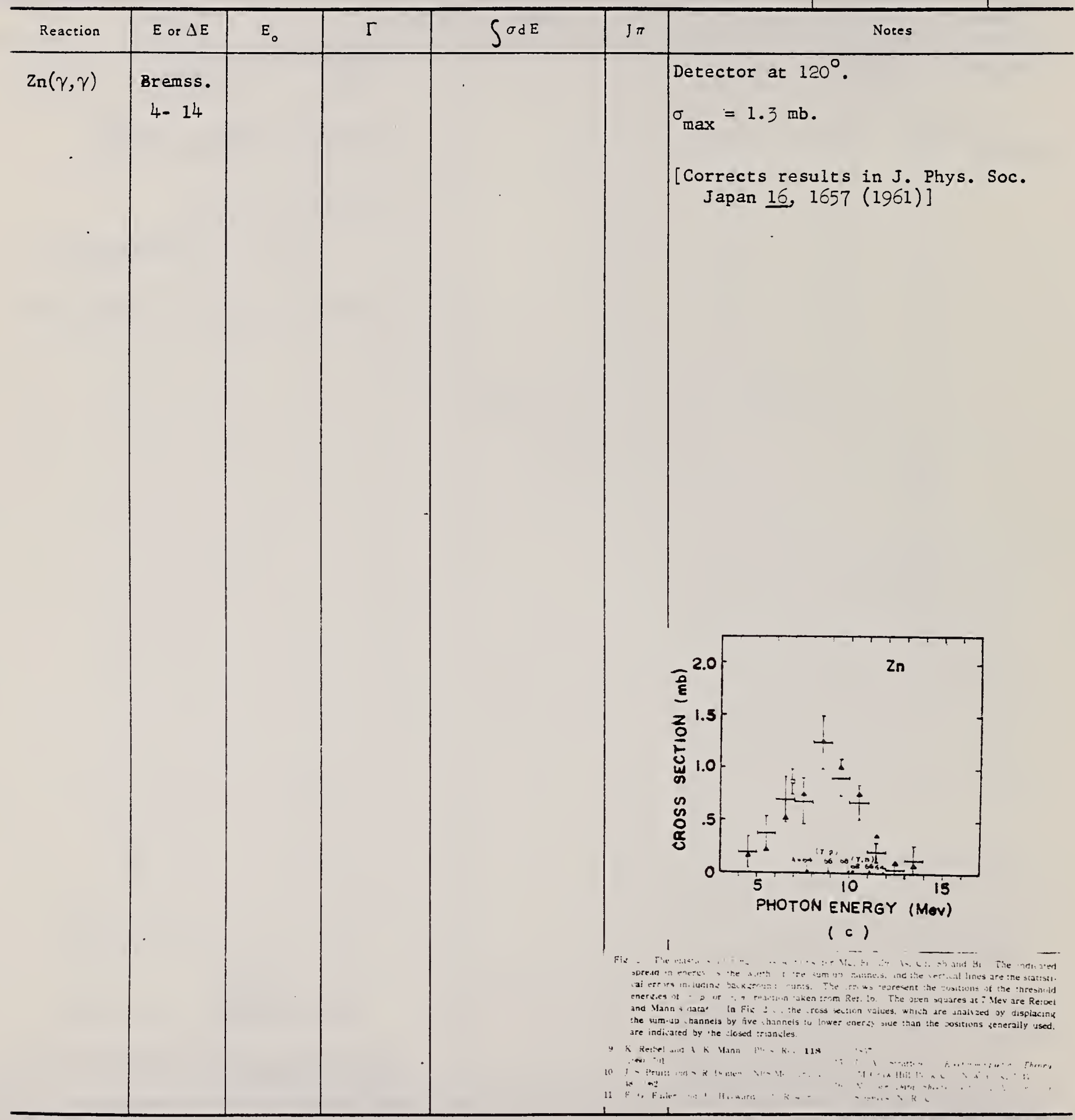




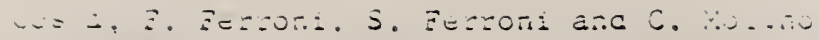

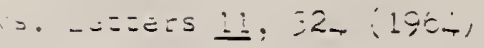

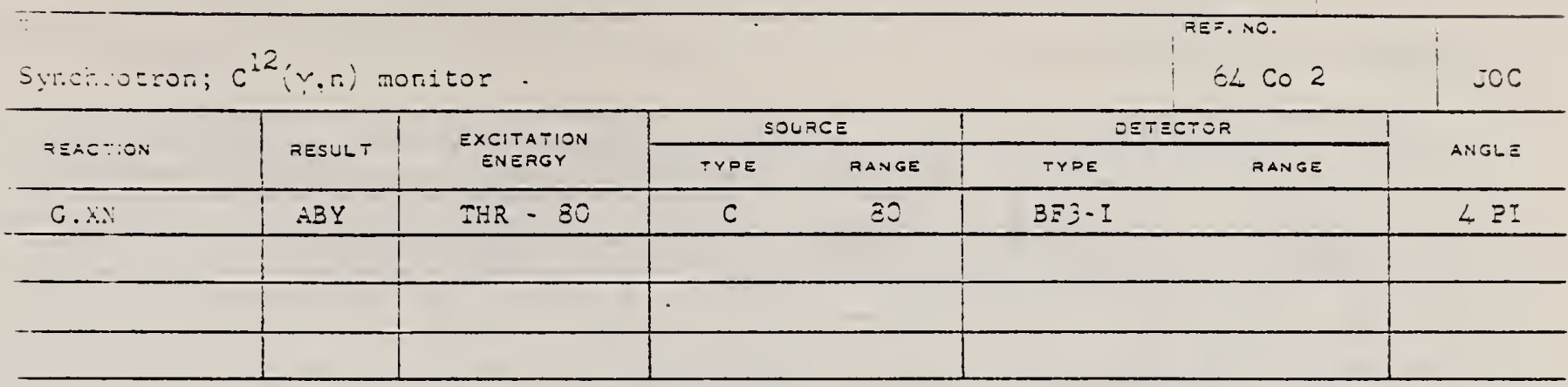

Table 1

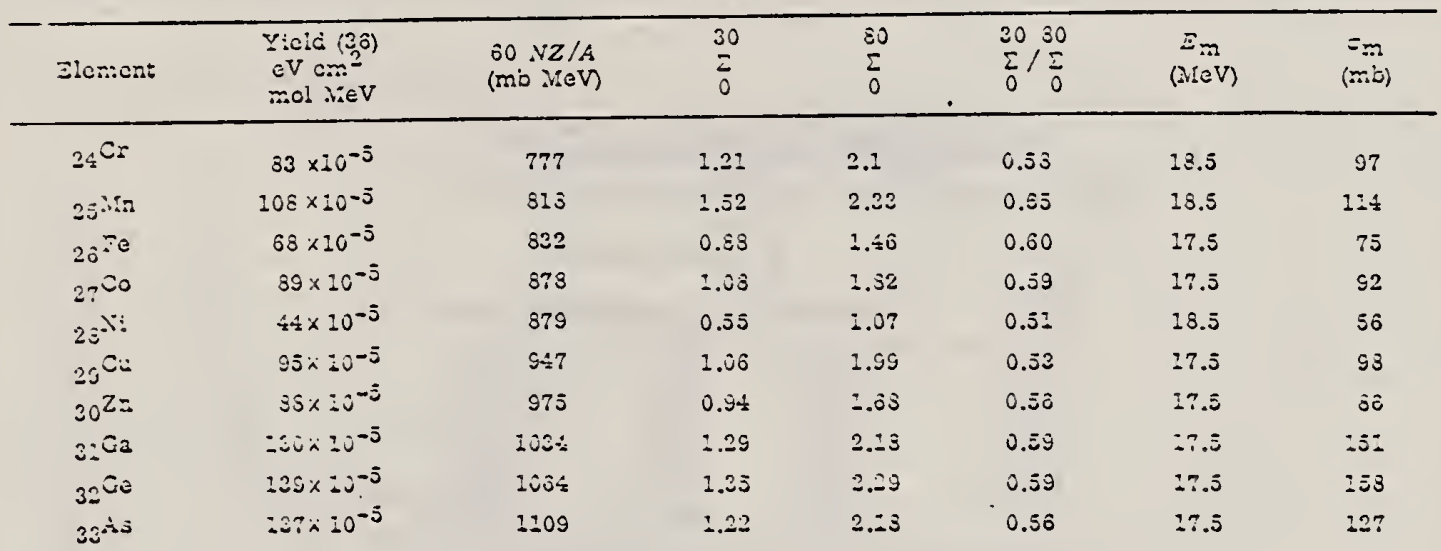

$$
\begin{aligned}
& \text { j0 } \\
& \sum_{0}^{30}=\frac{j \sigma(Y, x \pi) d E}{60.1 / A}
\end{aligned}
$$

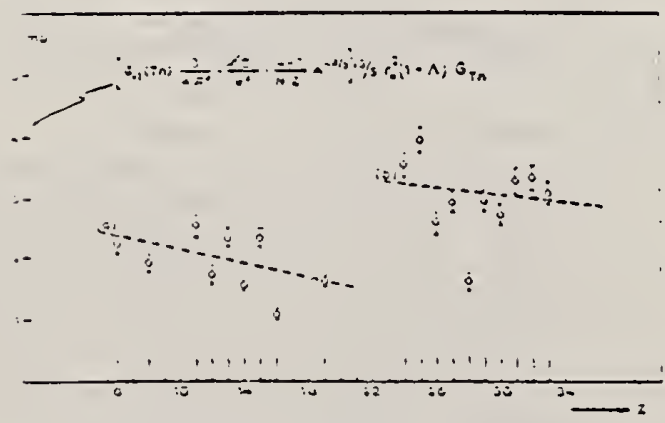

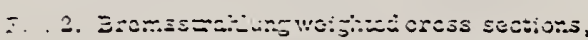

\begin{tabular}{|c|c|c|c|}
\hline E:sme: & 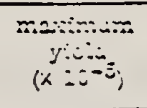 & $\sigma_{-2}(r)$ & 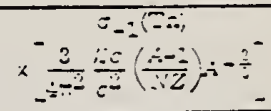 \\
\hline$\approx$ & $\therefore .0$ & $3 . \pm=1$ & 2.25 \\
\hline 30 & 5.2 & $\therefore .05$ & $\therefore .52$ \\
\hline$\because \because \mathrm{a}$ & $=0.0$ & $: \therefore .00$ & 2.45 \\
\hline 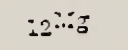 & $=0 . \hat{6}$ & $3.3=$ & $\therefore=3$ \\
\hline $22 \therefore i$ & : $\Xi .5$ & 22.52 & $2.3 \hat{v}$ \\
\hline$\because \because 3 i$ & $\because \bar{Q} \hat{\varepsilon}$ & 5.50 & :.55 \\
\hline$: \equiv ?$ & $: 9.3$ & $: 7 . \equiv 0$ & $2 . \therefore 2$ \\
\hline$: 0^{5}$ & $9 . \Sigma$ & $\Xi . \equiv \bar{\Sigma}$ & $\therefore . \therefore$ \\
\hline : & $\therefore 2.8$ & $: 2.00$ & $=\hat{*}$ \\
\hline $20^{02}$ & $\because 2.2$ & $: 2.03$ & $\therefore .02$ \\
\hline $2 \div C=$ & Eิ & $0: .0$ & $\Xi . \Xi \tilde{~}$ \\
\hline $2 z^{2}$ & $:: 5$ & $\because 0 .:$ & 2.50 \\
\hline $20^{50}$ & $\because:$ & $\Xi \bar{E}$ & Z.. \\
\hline$=700$ & $\therefore$ & $\dot{a}=\bar{E}$ & $2.5 \div$ \\
\hline $2 s$ & $=\hat{0}$ & $3 \div .2$ & J污 \\
\hline $2 j^{C i}$ & $=02$ & $: 2.3$ & 2.00 \\
\hline 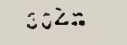 & 53 & oz.7 & 2.05 \\
\hline $2: \overline{0}$ & $\therefore 0$ & 53.5 & Z.: \\
\hline 2000 & $: \equiv 0$ & 105.5 & 3.30 \\
\hline 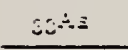 & $: \Sigma:$ & $s . \hat{\varepsilon}$ & $3.2=$ \\
\hline
\end{tabular}

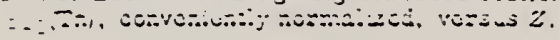


REF.

J. R. Van Hise, R. A. Meyer, and J. P. Hummel

Phys. Rev. 139, B554 (1965)

Betatron; NBS chamber monitor REF. NO.

65 Va 3

NVB

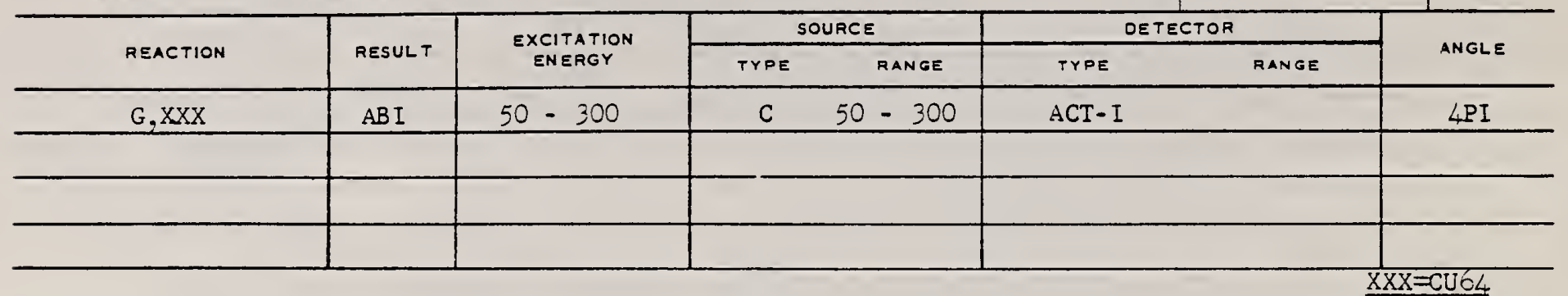

TABLE 1. Integrated cross sections for the $S^{22}(\gamma, n p) P^{\infty}$,

$\mathrm{Ca}^{*}(\gamma, n p) \mathrm{K}^{24}$, and $\mathrm{Zn}^{\omega}(\gamma, n p) \mathrm{Cu}^{n+1}$ reactions.

\begin{tabular}{|c|c|c|c|}
\hline \multirow{2}{*}{$\frac{\begin{array}{c}E_{\max } \\
(\mathrm{MeV})\end{array}}{\text { so }}$} & \multicolumn{3}{|c|}{$\begin{array}{l}\int_{0}^{B} \sigma d E(\mathrm{MeV} m b) \\
\mathrm{Ca}^{+0}(\gamma, n p) \mathrm{K}^{4 \times} \mathrm{Za}^{n 6}(\gamma, n p) \mathrm{Cu}^{64}\end{array}$} \\
\hline & $64 \pm 2$ & $31=1$ & $12 x=3$ \\
\hline 100 & $79 \pm 5$ & $35 \pm 5$ & $160 \pm 7$ \\
\hline 140 & $81 \pm 6$ & $35 \pm 7$ & $160 \pm 20$ \\
\hline 200 & $107 \pm 8$ & $43 \pm 9$ & $270 \pm 30$ \\
\hline 250 & $150 \pm 10$ & $72 \pm 11$ & $370 \pm 45$ \\
\hline 300 & $190 \pm 12$ & $88 \pm 14$ & $400 \pm 60$ \\
\hline
\end{tabular}


rer.

J. C. Acquadro, R. O. Cesar, J. Goldemberg and E. W. Hamburger

An. Acad. Brasil Cienc. 38,257 (1966)

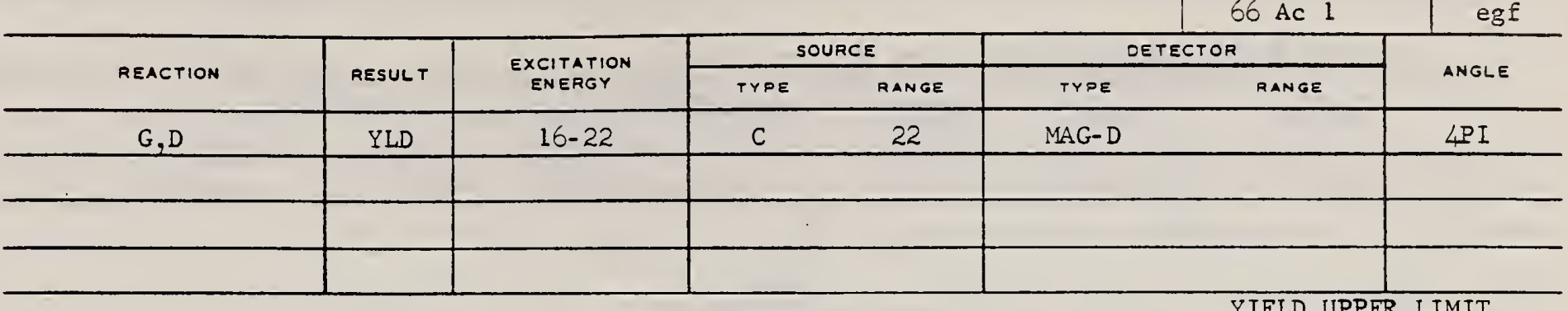

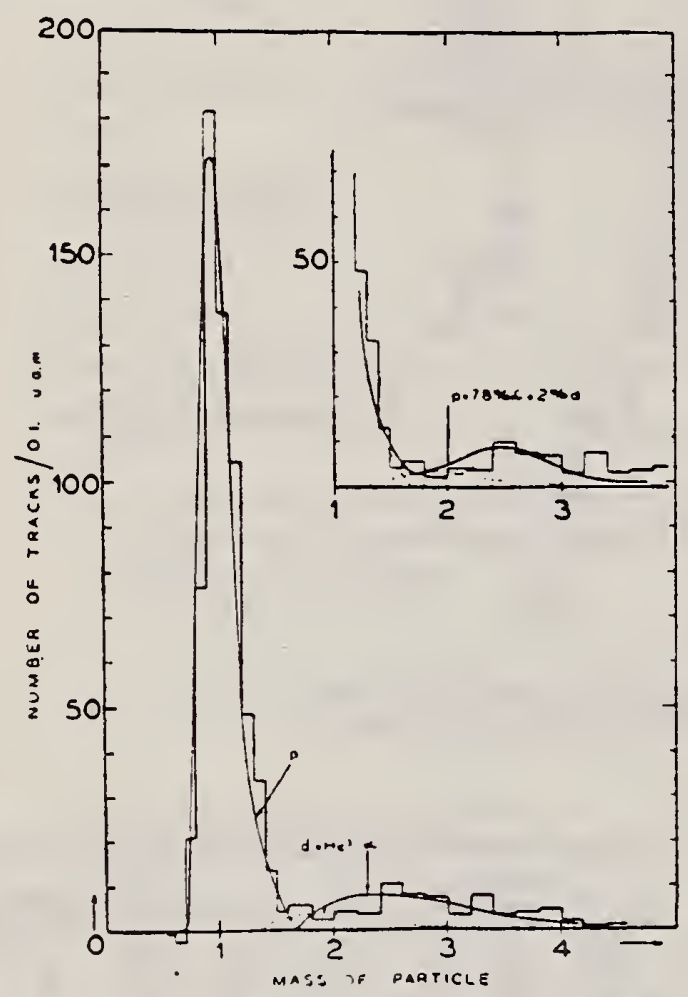

Fig. 2' "Mass" histogram for the 1!117 trachs measured

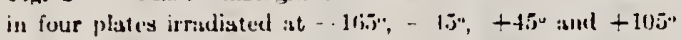
to the incident beant, renpectively (pmestions $n^{v} 1, j, 5$ e 10 ).

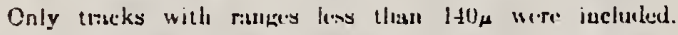

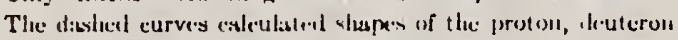

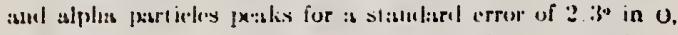

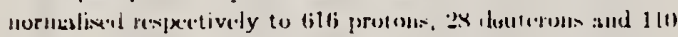
inlphia particles. In the low.r part, the full rurve gives the

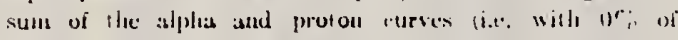
deuteroms). In the uperer part the full curse represents the

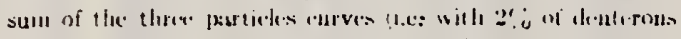
and $7.3^{\prime \prime}{ }_{c}$ of al allia patriclews. 
REF. G. Ben-David, B. Arad, J. Balderman, and Y. Schlesinger Phys. Rev. 146, B852 (1966)

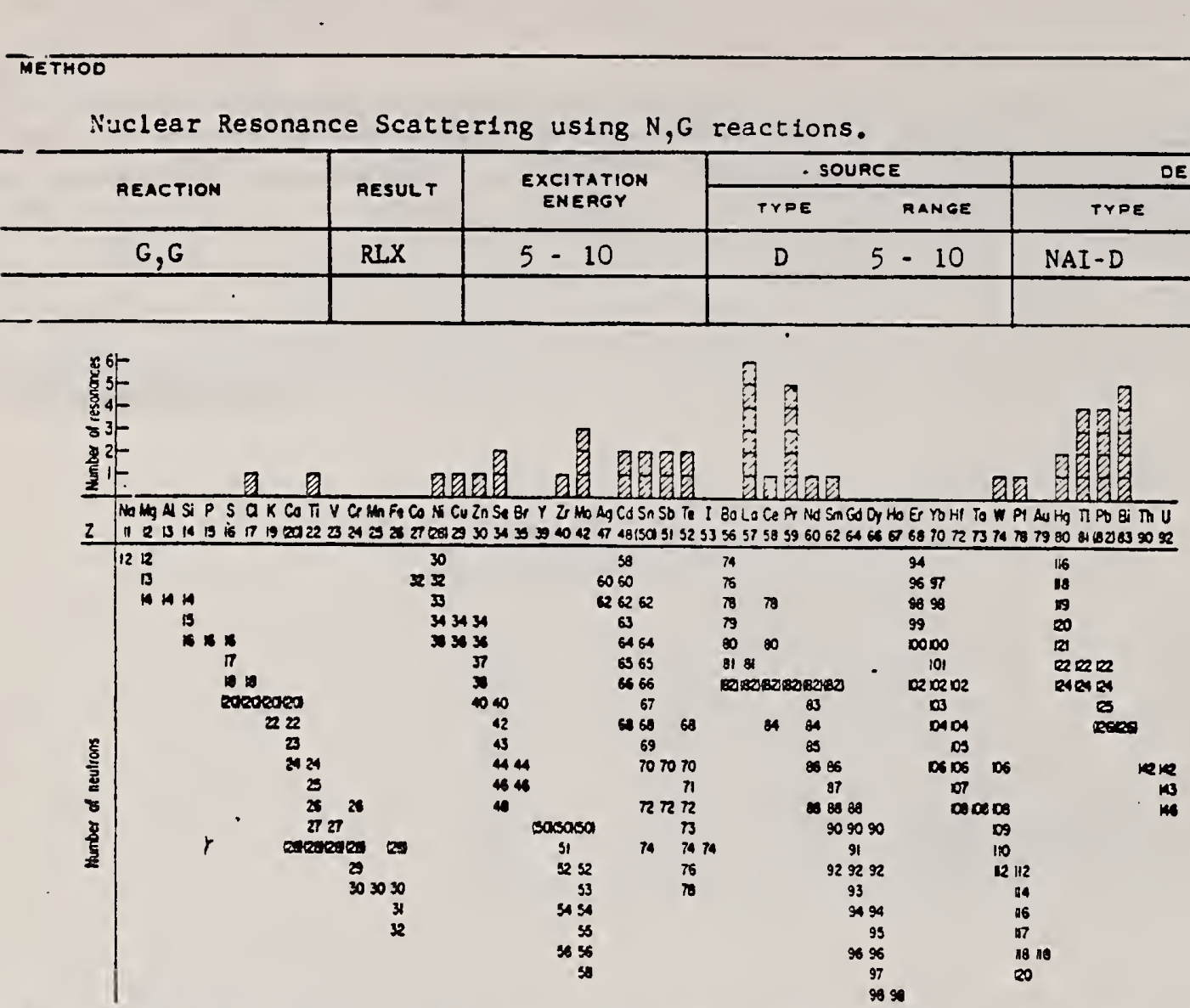

Fic. 3. Histogram of distribution of observed resonances among the diferent targets. The atomic number is given directly beneath the chemical symbol followed by the neutron numbers of the naturally occurring isotopes. Magic numbers are shown in brackets.

PกNM Nes-418

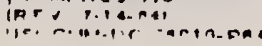

TABLE III. List of effective cross sections.

\begin{tabular}{|c|c|c|c|c|c|c|c|}
\hline Scatterer & $\begin{array}{l}\text { Energy } \\
(\mathrm{MeV})\end{array}$ & $\begin{array}{l}\text { Gamme } \\
\text { cource }\end{array}$ & $\stackrel{8}{m b})$ & Scatterer & $\begin{array}{l}\text { Energy } \\
\text { (MeV) }\end{array}$ & $\begin{array}{l}\text { Gamme } \\
\text { cource }\end{array}$ & $\stackrel{8}{(m b)}$ \\
\hline 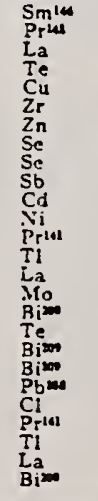 & $\begin{array}{l}8.997 \\
8.881 \\
8.532 \\
8.532 \\
8.499 \\
8.496 \\
8.110 \\
7.817 \\
7.76 \\
7.67 \\
7.64 \\
7.64 \\
7.64 \\
7.64 \\
7.634 \\
7.634 \\
7.6 .34 \\
7.528 \\
7.416 \\
7.300 \\
7.285 \\
7.285 \\
7.185 \\
7.66 \\
7.15 \\
7.149\end{array}$ & $\begin{array}{l}\mathrm{Ni} \\
\mathrm{Cr} \\
\mathrm{Ni} \\
\mathrm{Ni} \\
\mathrm{Cr} \\
\mathrm{Se} \\
\mathrm{Ni} \\
\mathrm{Ni} \\
\mathrm{K} \\
\mathrm{V} \\
\mathrm{Fe} \\
\mathrm{Fe} \\
\mathrm{Fe} \\
\mathrm{Fe} \\
\mathrm{Cu} \\
\mathrm{Cu} \\
\mathrm{Cu} \\
\mathrm{Ni} \\
\mathrm{Se} \\
\mathrm{As} \\
\mathrm{Fe} \\
\mathrm{Fe} \\
\mathrm{Se} \\
\mathrm{Cu} \\
\mathrm{Mn} \\
\mathrm{Ti}\end{array}$ & $\begin{array}{r}100 \\
9 \\
6 \\
3 n \\
24 \\
3050 \\
13 \\
50 \\
90 \\
\cdots \\
400 \\
7 \\
120 \\
3700 \\
7 \\
11 \\
4 \\
664 \\
100 \\
800 \\
4100 \\
34 \\
80 \\
120 \\
50 \\
2000\end{array}$ & 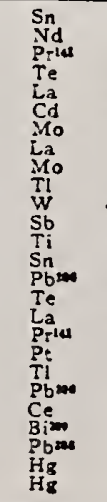 & $\begin{array}{l}7.01 \\
6.867 \\
6.867 \\
6.7 \\
6.54 \\
6.474 \\
6.44 \\
6.413 \\
6.413 \\
6.413 \\
0.3 \\
6.31 \\
6.31 \\
6.27 \\
6.15 \\
5.8 \\
6.12 \\
6.12 \\
5.99 \\
5.99 \\
5.9 \\
5.646 \\
5.646 \\
5.53 \\
5.44 \\
4.903\end{array}$ & $\begin{array}{l}\mathrm{Cu} \\
\mathrm{Co} \\
\mathrm{Co} \\
\mathrm{Ni} \\
\mathrm{Ag} \\
\mathrm{Co} \\
\mathrm{Hg} \\
\mathrm{Ti} \\
\mathrm{Ti} \\
\mathrm{Ti} \\
\mathrm{Ti} \\
\mathrm{Hi} \\
\mathrm{Hg} \\
\mathrm{Hg} \\
\mathrm{Ag} \\
\mathrm{Gd} \\
\mathrm{Ni} \\
\mathrm{Ci} \\
\mathrm{Cl} \\
\mathrm{Hg} \\
\mathrm{Hg} \\
\mathrm{Sr} \\
\mathrm{Co} \\
\mathrm{Co} \\
\mathrm{Ag} \\
\mathrm{Hg} \\
\mathrm{Co}\end{array}$ & $\begin{array}{c}110 \\
30 \\
3 \\
\ldots \\
12 \\
110 \\
250 \\
72 \\
10 \\
25 \\
\ldots . \\
60 \\
20 \\
75 \\
\ldots 8 \\
\ldots 35 \\
110 \\
400 \\
50 \\
\ldots 1 \\
17 \\
55 \\
70 \\
758 \\
385\end{array}$ \\
\hline
\end{tabular}

High-enerzy component of a complex spectrum.

There seactered spectrum with no ooservable peak structure

qual intengities in the iron has therefore been corrected, although there is no pom. The croso bection

deciding which line is responsible for each resonance.

rays on Te.

Roush estimate.

May be inelatic component from 7.323 lemel in $T$

co. The relative line iatendtes in this cane on due to Gromber and Noline to

Difecult to resoive anows the many nourse lines present at this enerw.

PHOTONUCLEAR DATA SHL 


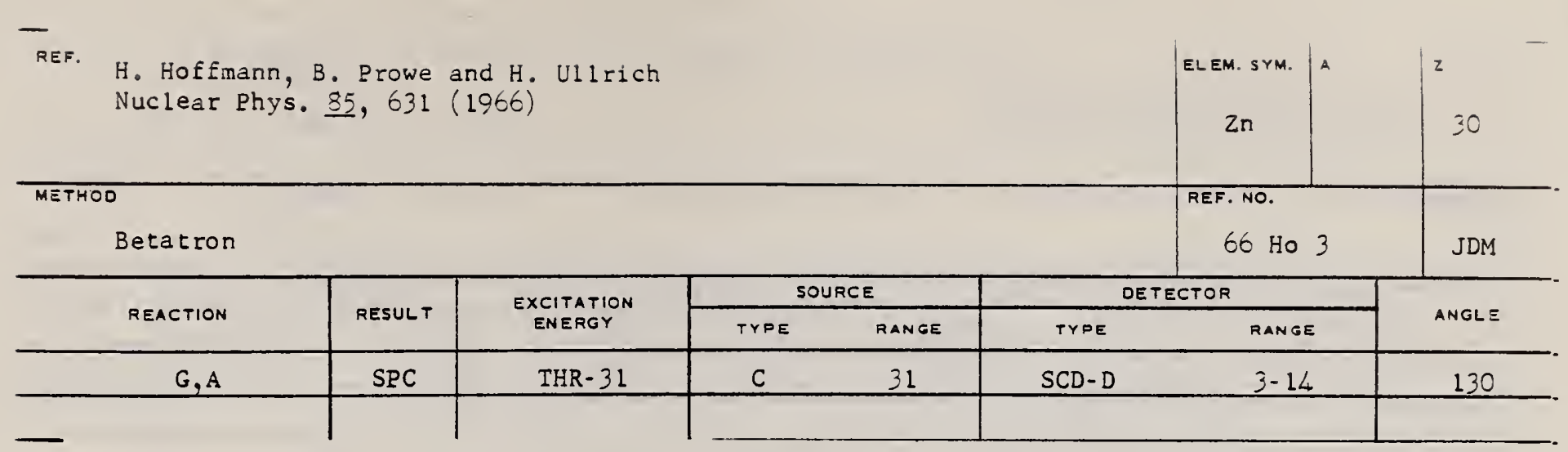

TABLE 1

Experimental data and results

\begin{tabular}{|c|c|c|c|c|c|c|c|}
\hline Element & Mg & Al & $\mathbf{s}$ & $\mathrm{Ni}$ & $\mathrm{Cu}$ & $Z_{n}$ & Error $(\%)$ \\
\hline target thickness $\left(\mathrm{mg} / \mathrm{cm}^{2}\right)$ & 0.81 & 1.54 & 0.80 & 2.50 & 2.68 & 3.00 & $.53)$ \\
\hline dose $(r)$ & 6190 & 25400 & 23200 & 3880 & 5840 & 4220 & 10 \\
\hline $\begin{array}{l}\text { yield absolute }\left(10^{s} / \mathrm{mole} \cdot \mathrm{r}\right) \\
\text { for } E_{\mathrm{m}}>3.16 \mathrm{MeV}\end{array}$ & 0.61 & 0.93 & 1.46 & 1.65 & 0.92 & 2.42 & $11 *)$ \\
\hline yield relative to $\mathrm{Ni}$ & 0.36 & 0.56 & 0.88 & 1 & 0.55 & 1.43 & 5*) \\
\hline$Y_{Y, a} / Y_{Y, 100}(\%)$ & 9.6 & 11.4 & 12.4 & 7.0 & 3.2 & b) & \\
\hline nuclear temp. $\theta(\mathrm{MeV})$ & 1.43 & 1.48 & 1.46 & 1.04 & & 0.91 & 10 \\
\hline $\begin{array}{l}\text { level density parameter a } \\
\left(\mathrm{MeV}^{-1}\right)\end{array}$ & 5.1 & 4.8 & 4.9 & 8.6 & & 10.8 & 10 \\
\hline
\end{tabular}

-) For $\mathrm{S}$, the error of the target thickness has been $10 \%$ of the absolute yield $14 \%$ and of the reiative yield $10 \%$.

D) For $\mathrm{Zn} \sigma_{\mathrm{y}, \text { lot }}$ is not known.
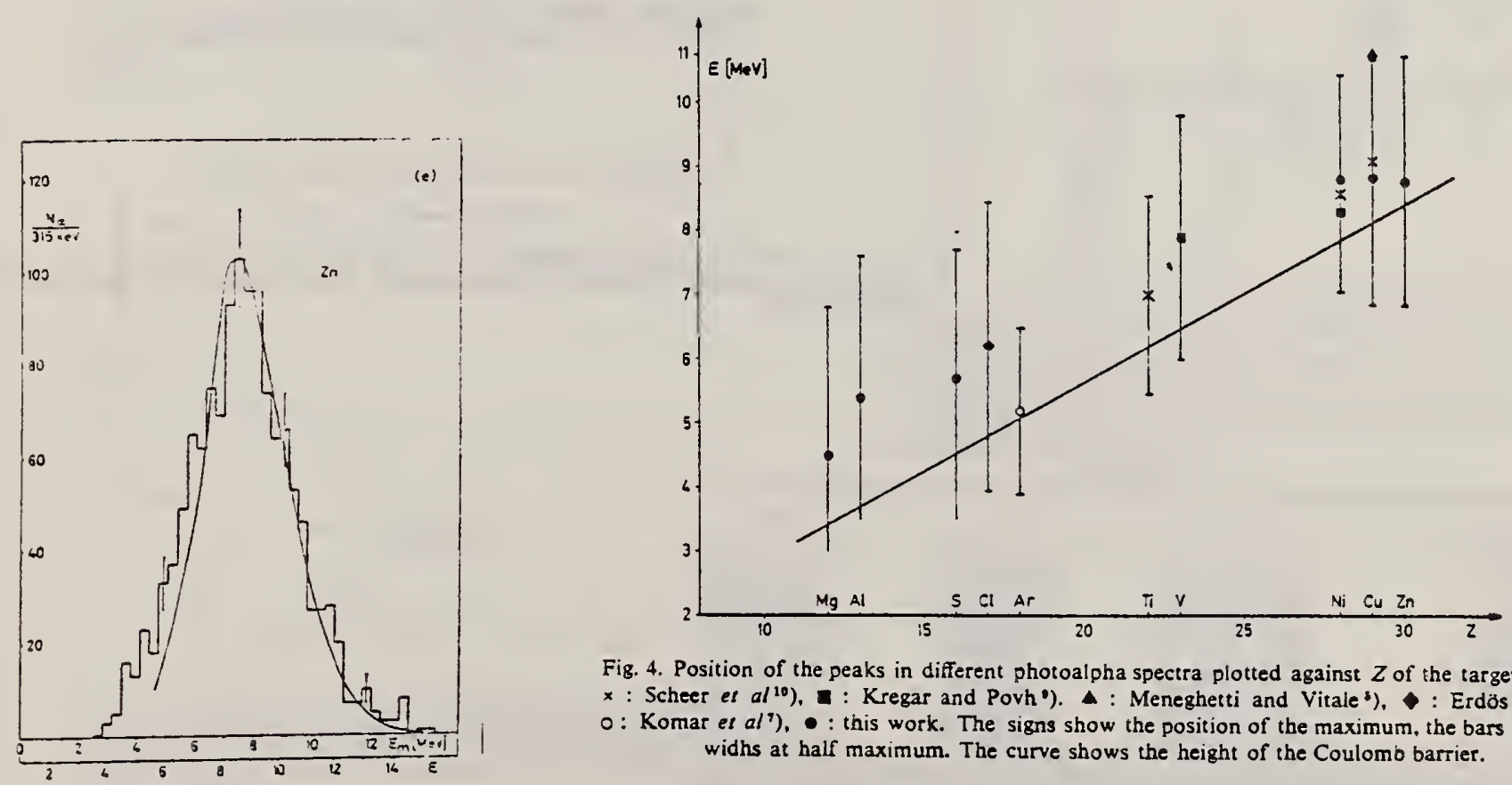

Fig. 4. Position of the peaks in different photoalpha spectra plotted against $Z$ of the target nuclei. $x$ : Scheer $\left.e t a l^{10}\right)$, : Kregar and Povh"). 4 : Meneghetti and Vitaie $\left.{ }^{2}\right), \bullet:$ Erdös et al ${ }^{2}$ ), $0:$ Komar et al'), : this work. The signs show the position of the maximum, the bars give the widhs at half maximum. The curve shows the height of the Coulomo barrier.

Fig. 3d-e. Photozlpha spectru of $\mathrm{Ni}$ and $\mathrm{Zn}$. Notations as in fig. 3a-c.

Fig. 3f. Statistical plot of the measured speetra. The straighe lines are drawn to give the best fit. 
$67 \mathrm{Hu} 2$

\begin{tabular}{|c|c|c|c|c|c|c|c|}
\hline \multirow{2}{*}{ REACTION } & \multirow{2}{*}{ RESUL T } & \multirow{2}{*}{$\begin{array}{l}\text { EXCITATION } \\
\text { ENERGY }\end{array}$} & \multicolumn{2}{|c|}{ SOURCE } & \multicolumn{2}{|c|}{ DETECTOR } & \multirow{2}{*}{ ANGLE } \\
\hline & & & TYPE & RANGE & TYPE & RANGE & \\
\hline$G, N$ & $A B Y$ & THR-22 & C & 22 & THR & $4-$ & DST \\
\hline
\end{tabular}

YIELD AT EO $=22 \mathrm{M} \bullet V$

${ }^{20}$ si $(n, p)$ ACTIVATION BY PHOTONEUTRONS
FIG. 3. The yields of fast photoneutrons from various elements as measured in the présent work and by Baker. The present results have been normalized to Baker's measurements for lead.
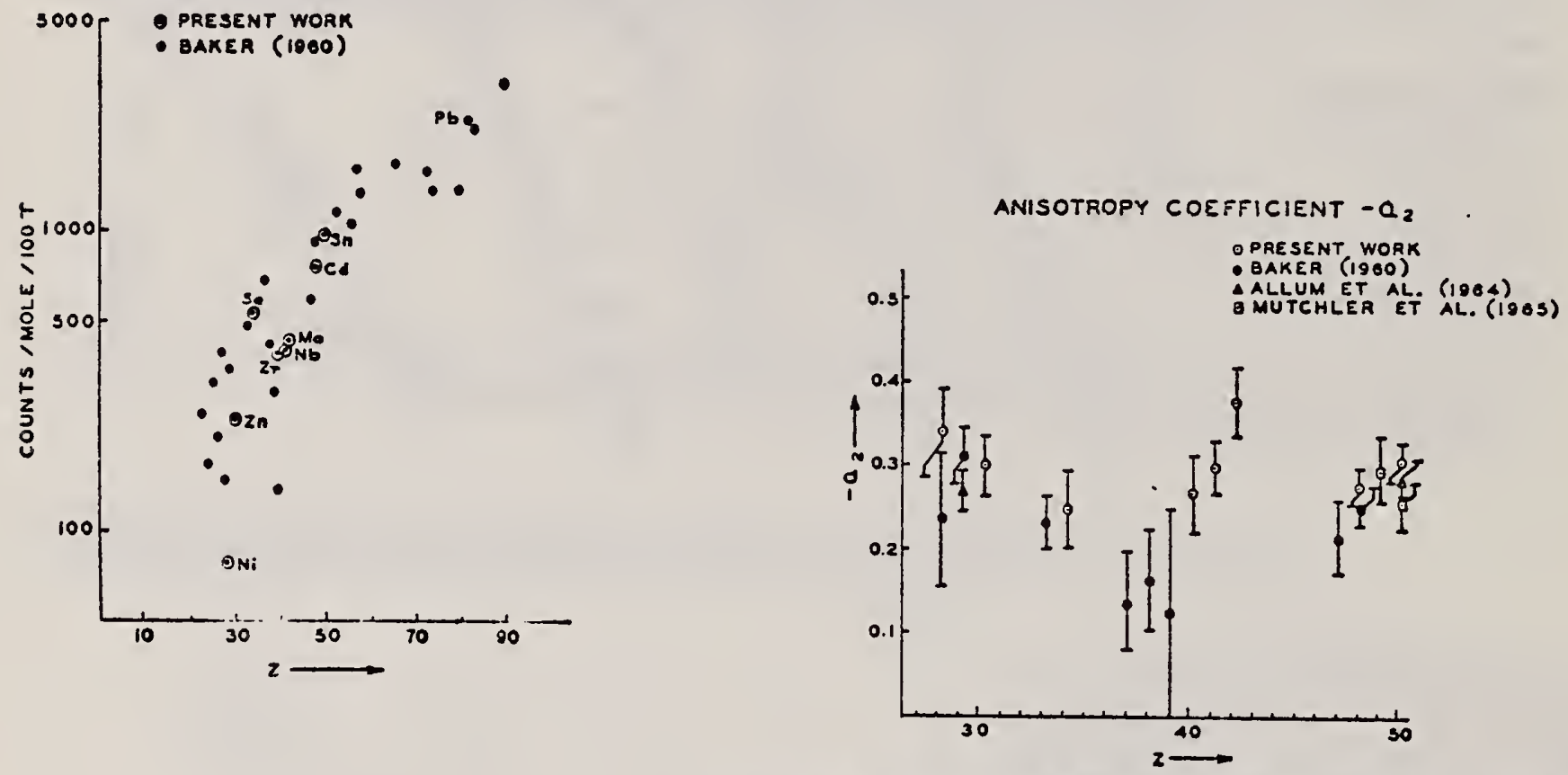

Fic. 2. The anisotropy coefficients $a_{2}$ in the formula $W(\theta)=c_{0}\left(1+a_{1} P_{1}+a_{2} P_{2}\right)$ obtained in the present work, and those obtained by other workers in the same part of the Periodic Table.

TABLE I

\begin{tabular}{|c|c|c|c|}
\hline Elcment & $a_{0}^{\circ}$ & $a_{1}$ & $a_{2}$ \\
\hline $\begin{array}{l}\text { Nickel } \\
\text { Zinc } \\
\text { Sclenium } \\
\text { Zirconium } \\
\text { Niobium } \\
\text { Molybdenum } \\
\text { Cadmium } \\
\text { Tin } \\
\text { Lead }\end{array}$ & $\begin{array}{r}77(1.0 \pm 0.05) \\
236(1.0 \pm 0.04) \\
525(1.0 \pm 0.05) \\
380(1.0 \pm 0.05) \\
392(1.0 \pm 0.03) \\
410(1.0 \pm 0.03) \\
755(1.0 \pm 0.02) \\
325(1.0 \pm 0.02) \\
2274(1.0 \pm 0.02)\end{array}$ & $\begin{array}{l}0.14 \pm 0.04 \\
0.06 \pm 0.03 \\
0.10 \pm 0.04 \\
0.03 \pm 0.04 \\
0.01 \pm 0.02 \\
0.05 \pm 0.03 \\
0.05 \pm 0.01 \\
0.08 \pm 0.02 \\
0.06 \pm 0.02\end{array}$ & $\begin{array}{l}-0.34 \pm 0.06 \\
-0.30 \pm 0.04 \\
-0.25 \pm 0.05 \\
-0.27 \pm 0.05 \\
-0.30 \pm 0.03 \\
-0.41 \neq 0.04 \\
-0.28 \pm 0.02 \\
-0.30 \pm 0.02 \\
-0.48 \pm 0.02\end{array}$ \\
\hline
\end{tabular}


ReF. N. N. Kaushal, E. J. Winhold, P. F. Yergin, H. A. Medicus and

R. H. Augustson

Phys. Rev. 175,1330 (19,68)

\begin{tabular}{|c|c|c|c|c|c|c|c|}
\hline \multirow{2}{*}{ REACTION } & \multirow{2}{*}{ RESULT } & \multirow{2}{*}{$\begin{array}{l}\text { EXCITATION } \\
\text { ENERGY }\end{array}$} & \multicolumn{2}{|c|}{ SOURCE } & \multicolumn{2}{|c|}{ DETECTOR } & \multirow{2}{*}{ ANGLE } \\
\hline & & & TYPE & RANGE & TYPE & RANGE & \\
\hline \multirow[t]{2}{*}{$\mathrm{G}, \mathrm{N}$} & $A B X$ & $50-85$ & $\mathrm{C}$ & 55,85 & TOF - D & $10-85$ & 67 \\
\hline & & & & & & & $(67.5)$ \\
\hline$\cdot$ & 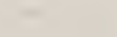 & & & & . & & . \\
\hline & & & & & & & \\
\hline
\end{tabular}

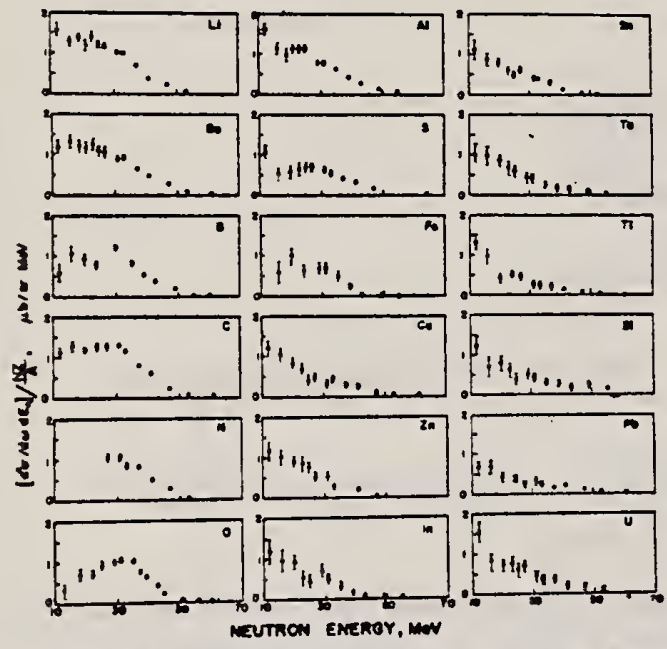

Fro. 6. Observed neutron spectra due to 55-85-MeV difference Ho. 6. Observed neutros spectra due to Ss-as have been divided by $N Z / A$.

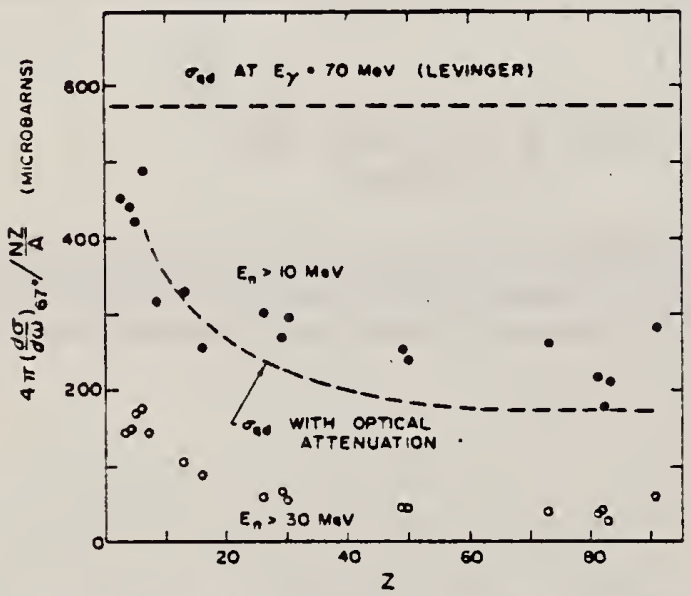

FIG. 7. Effective cross sections for production of fast neutrons with energies greater than $10 \mathrm{MeV}$ (solid circles) and $30 \mathrm{MeV}$ (open circles) by the 55-85-MeV photon difference spectrum. The dashed curves are modified quasideuteron model predictions as discussed in the text.
ThaII I. Comparizon of present cross-section values in mb for production of high-energy photoneutrons by $55-85-\mathrm{MeV}$ photons with measured cross sections $\sigma(\gamma, T n)$, also in $m b$, for total photoneutron production. The present cross-section values are uncertain by 8 to $10 \%$ because of counting statistics and normalization errors; in addition all values depend on an absolute normalization in terms of the deuteron photodisintegration cross section, which is known to about $10 \%$ at these energies.

\begin{tabular}{|c|c|c|c|c|}
\hline Target & $\begin{array}{c}4 \pi(d \sigma / d \omega) a^{*} \\
\left(E_{.}>10 \mathrm{MeV}\right) \\
\text { [Present } \\
\text { experiment] }\end{array}$ & $\begin{array}{c}\sigma(\gamma \\
\text { Jones and } \\
\text { Terwilliger }\end{array}$ & $\begin{array}{l}T n) \\
\text { Costa ef al. }\end{array}$ & $\begin{array}{l}\text { Other } \\
\text { results }\end{array}$ \\
\hline$\overline{L i}$ & 0.75 & & 1.0 & \\
\hline$\overline{B e}$ & 1.0 & 2.7 & 2.3 & $2.3^{\circ}$ \\
\hline B & 1.0 & & 1.4 & \\
\hline C & 1.5 & 1.3 & 1.4 & $2.4^{\mathrm{d}}$ \\
\hline 0 & 1.3 & & 1.6 & \\
\hline Al & 2.8 & 5.5 & 4.6 & $8 d$ \\
\hline$s$ & 2.1 & & 4.4 & $6.5 \mathrm{~d}$ \\
\hline $\mathrm{Fe}$ & 4.2 & 16 & 12 & \\
\hline $\mathrm{Cu}$ & 4.3 & 20 & 19 & \\
\hline $\mathrm{Zn}_{0}$ & 4.4 & & 15 & \\
\hline Io & 7.4 & & & \\
\hline $\overrightarrow{S_{n}}$ & 7.0 & & & \\
\hline$T_{2}$ & 10.7 & 95 & & \\
\hline $\mathrm{Tl}$ & 10.7 & & & \\
\hline $\mathrm{Pb}$ & 8.3 & 100 & & \\
\hline $\mathrm{Bi}$ & 13 & & & \\
\hline $\bar{U}$ & 16 & 65 & & \\
\hline
\end{tabular}

Average cosese sections between $\$ 5$ and $85 \mathrm{MeV}$, as read from Figs. 4

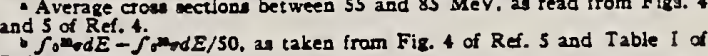

- $S$. Corta I Panualing, G. Pirseino, and L. Rosaio. Nuovo Clmento 12. 306 (1966)

GG. Bintop S Coata. S. Ferroni, R. Malvano, and G. Ricco. Nuovo Cimento 2. 142 (1966). 
REF. L. A. Currie and R. H. Rodriguez-Pasques Nuc1. Phys. A157, 49 (1970)

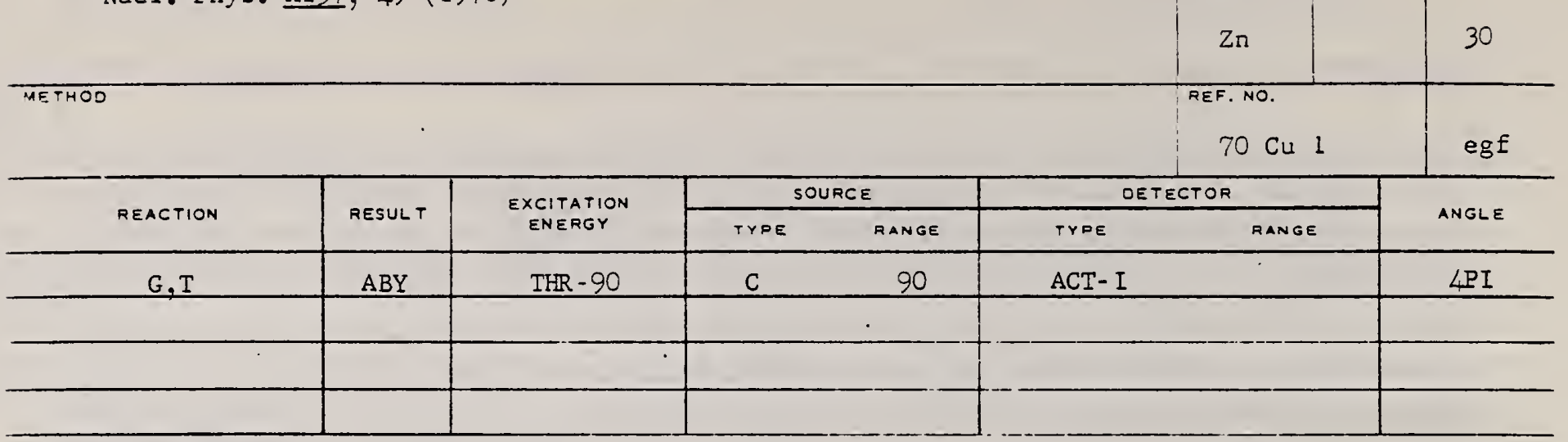

TABL: 4

-

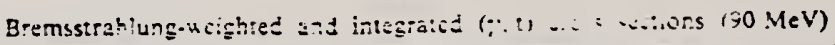

\begin{tabular}{|c|c|c|c|c|}
\hline & $2: A]$ & $\mathrm{Zn}$ & Sa & ${ }^{209} \mathrm{Bi}$ \\
\hline$\sigma_{-1}(\mathrm{mb})$ & 0.072 & $0.007_{4}$ & 0065 & $0.007_{2}$ \\
\hline$\sigma_{0}(\mathrm{McV} \cdot \mathrm{mb}:$ & 4.0 & $0.4_{2}$ & 3.8 & $0.4_{1}$ \\
\hline
\end{tabular}

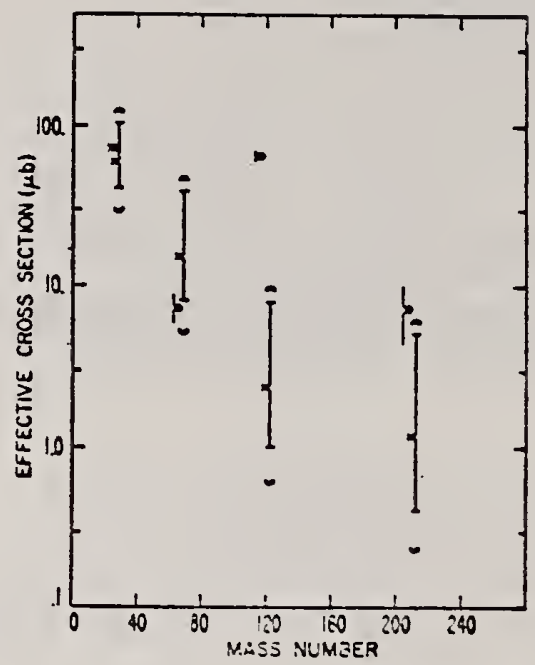

Fig. 3. Experimental (0) and stutistical medel (x) ahsolute photetriton yiclds ( $\$ 0$ MeV). Yiclds expressed in terms of "effective cross scctions" (wib), are fletted virsus mass number. Limits for the uxperimental yiclds represent \pm one standard deriation: those for : "s sulculated jicl's correspond to limiting values for the level density parameter $(-)$ and for the $r^{2}$, is atsorption sross scition ( 
S. Costa, L. Ferrero, L. Pasqualini, and E. Mancini

Lettere al Nuovo Cimento $\underline{2}, 665$ (1971)

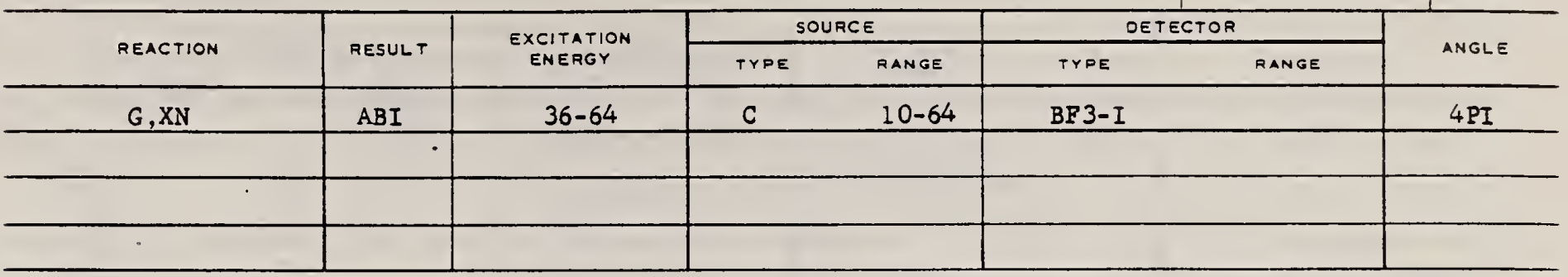

FAST N YIELD
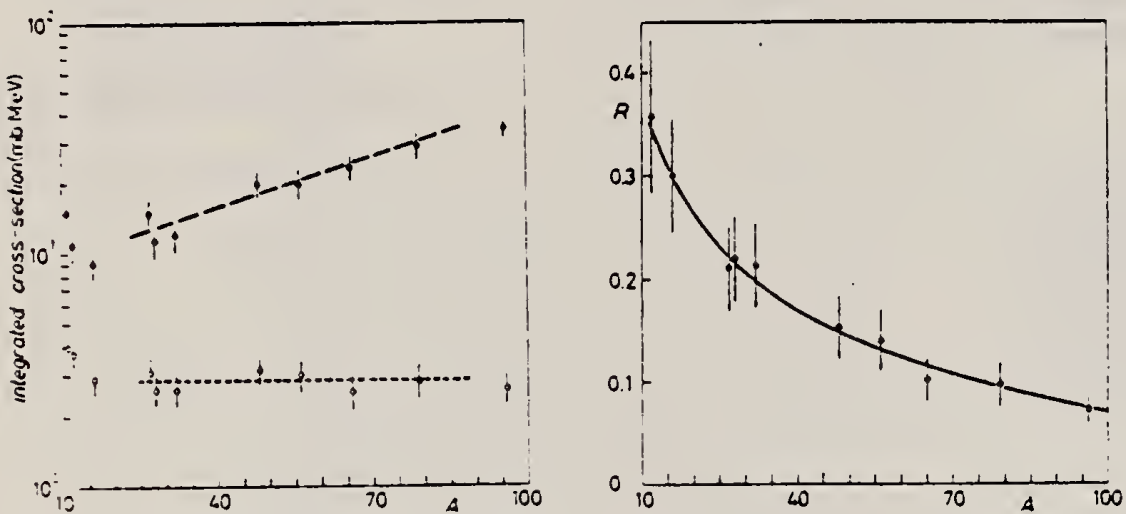

Fig. :-

rig. :3.

Hig :. - Experimeutul photoneutron cross-eectinis integrated over photon encrgy between 36 and

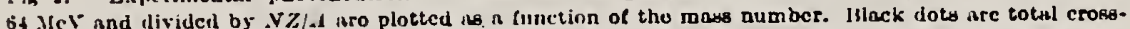
sections not corrected for neutron multiplicity; open circles represent fast neutron cross sections (sec test). Tho dashed lines aro drawn only to guide the eje.

Fis. 3. - The ratlo betrecn - fast s and total photoncutron integrated croes-sections a function of the mass number A. The solid line represents a ft of the ratios calculated for somo nuclei by taking into account the theoretical neutron enersy apectra given by GABRIEL and SLAMilLer (") and the cttl. cleacies of our detector (seo Fig. 1). 
Can. J. Phys. 50, 1554 (1972)

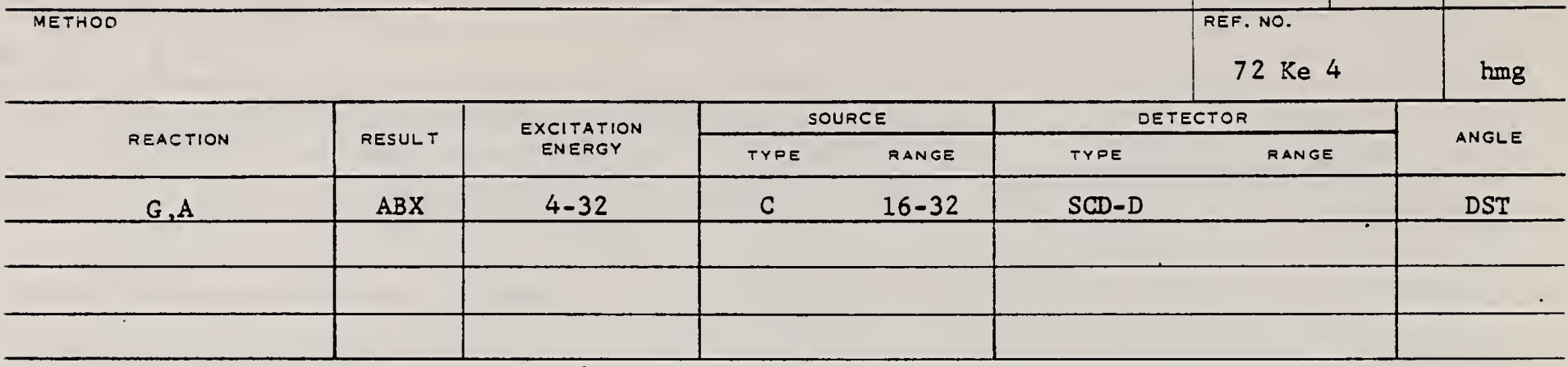

FABlt 3 Observed angular distribution parameters for

\begin{tabular}{|c|c|c|c|}
\hline$=-$ & $\ldots==$ & $=-$ & $===-\ldots$ \\
\hline isment & $A_{1}$ & $A_{1} / A_{i}$ & $A_{2} 4$. \\
\hline$T_{1}$ & $7.03 \pm 0.15$ & $0.073 \pm 0.052$ & $-0.2 \times 6=0,1173$ \\
\hline$V$ & $2.5 x \pm 0.06$ & $0.037=0.042$ & $-0.126=01 x, y$ \\
\hline $\mathrm{Fe}$ & $10.22=0.30$ & $0.006=0.04 ?$ & $-0.333 \div 010=$ \\
\hline Co & $6 \times 0=0.20$ & $0.022=0.04 x$ & $-0.016=0117$ \\
\hline$v_{i}$ & $15.95=0.49$ & $0.051=0.04 x$ & $-0.213-010-2$ \\
\hline Cu & $6.37=0.2 x$ & $0076=0.056$ & $-00.35-0$ ilx: \\
\hline$\angle n$ & $17 x 7=0.0 i$ & $0.10 n 4=0.045$ & $-0.2 \gamma_{1}=0,73$ \\
\hline$A g$ & $0: 9=0.01$ & $0.115=0.049$ & $-1)(\mathrm{N}) ;-0117.4$ \\
\hline
\end{tabular}

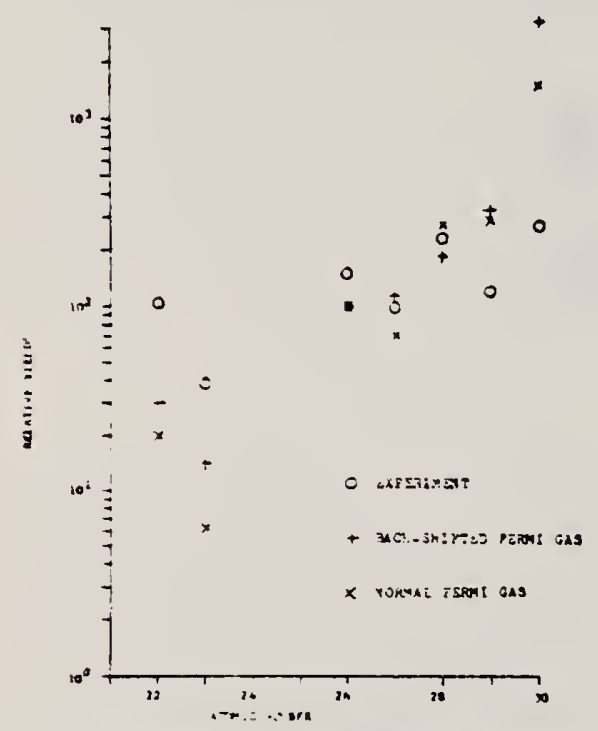

Fic. 13 Expenmentai and theoretical relative photo a!pria yieids for $32 \mathrm{Met}$ electron beam energy.
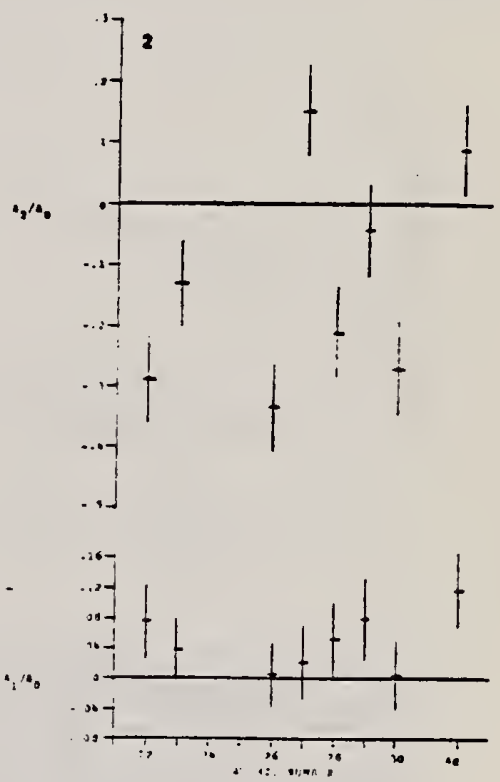

Fic. : Angular distributions for $32 \mathrm{MeV}$ electron energy.

TABLE 4. Zinc end poincs

\begin{tabular}{lccc}
\hline $\begin{array}{l}\text { Eleition } \\
\text { energy } \\
\text { (MeV) }\end{array}$ & $\begin{array}{c}\text { Efiecuve } \\
\text { end point } \\
\text { (MeV) }\end{array}$ & $A_{1}: A_{0}$ & $. A_{2} / A_{0}$ \\
\hline 16 & 14.4 & $-0.010=0.050$ & $-0.747 \pm 0.096$ \\
18 & 16.9 & $-0.078=0.044$ & $-0.562 \pm 0.075$ \\
20 & 19.0 & $-0.020=0.038$ & $-0.463 \pm 0.064$ \\
22 & 21.2 & $-0.012=0.033$ & $-0.430 \pm 0.060$ \\
24 & 23.5 & $-0.003 \pm 0.033$ & $-0.200=0.061$ \\
26 & 25.5 & $-0.028 \pm 0.035$ & $-0.361 \pm 0.060$ \\
28 & 27.6 & $-0.007 \pm 0.037$ & $-0.313 \pm 0.063$ \\
30 & 29.5 & $-0.002 \pm 0.035$ & $-0.313 \pm 0.062$ \\
\hline
\end{tabular}




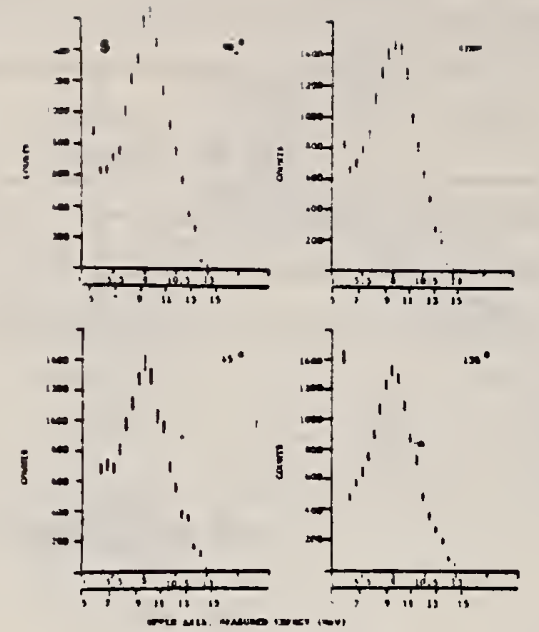

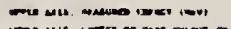

FiG. 5. Alpha spectra from unc.

Fic. 6. $32 \mathrm{MeV}$ zinc anguiar distribution.

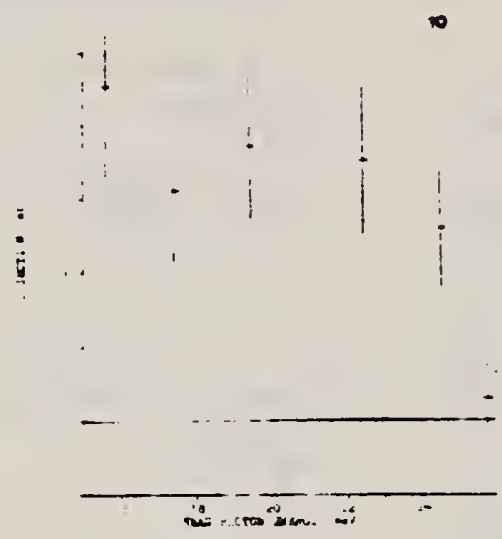

FIC: 50 Zinc photoaipha cross secin:!:
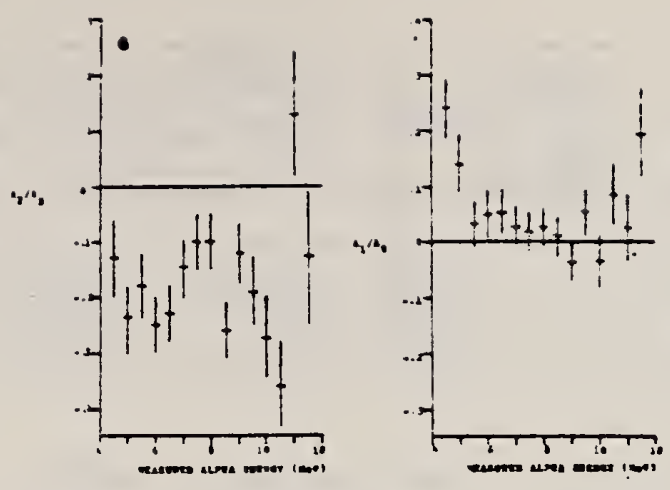
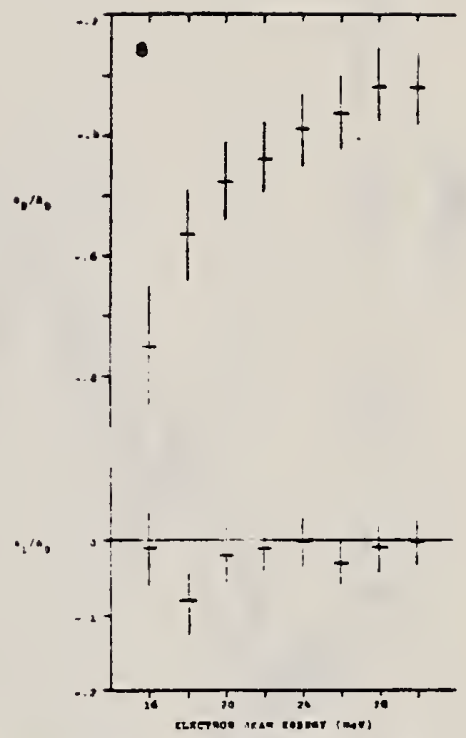

Fic. 8. Zine angular distributions for electron energes from $16-30 \mathrm{MeV}$ 
REF.

R.F. Barrett, J.R. Birkelund, B.J. Thomas, K.S. Lam, and H.H.. Thies

Nucl. Phys. A210, 355 (1973)

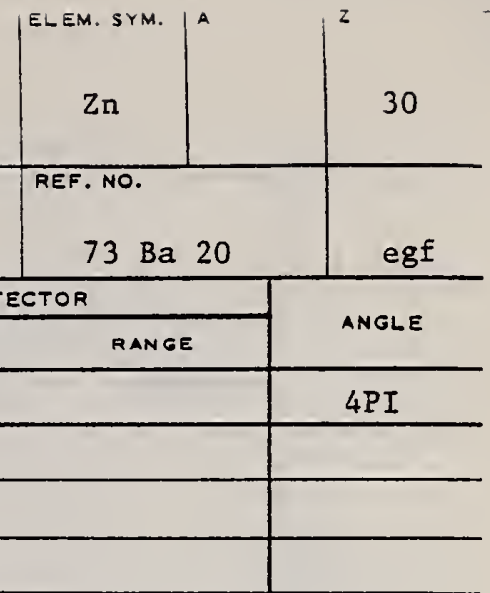

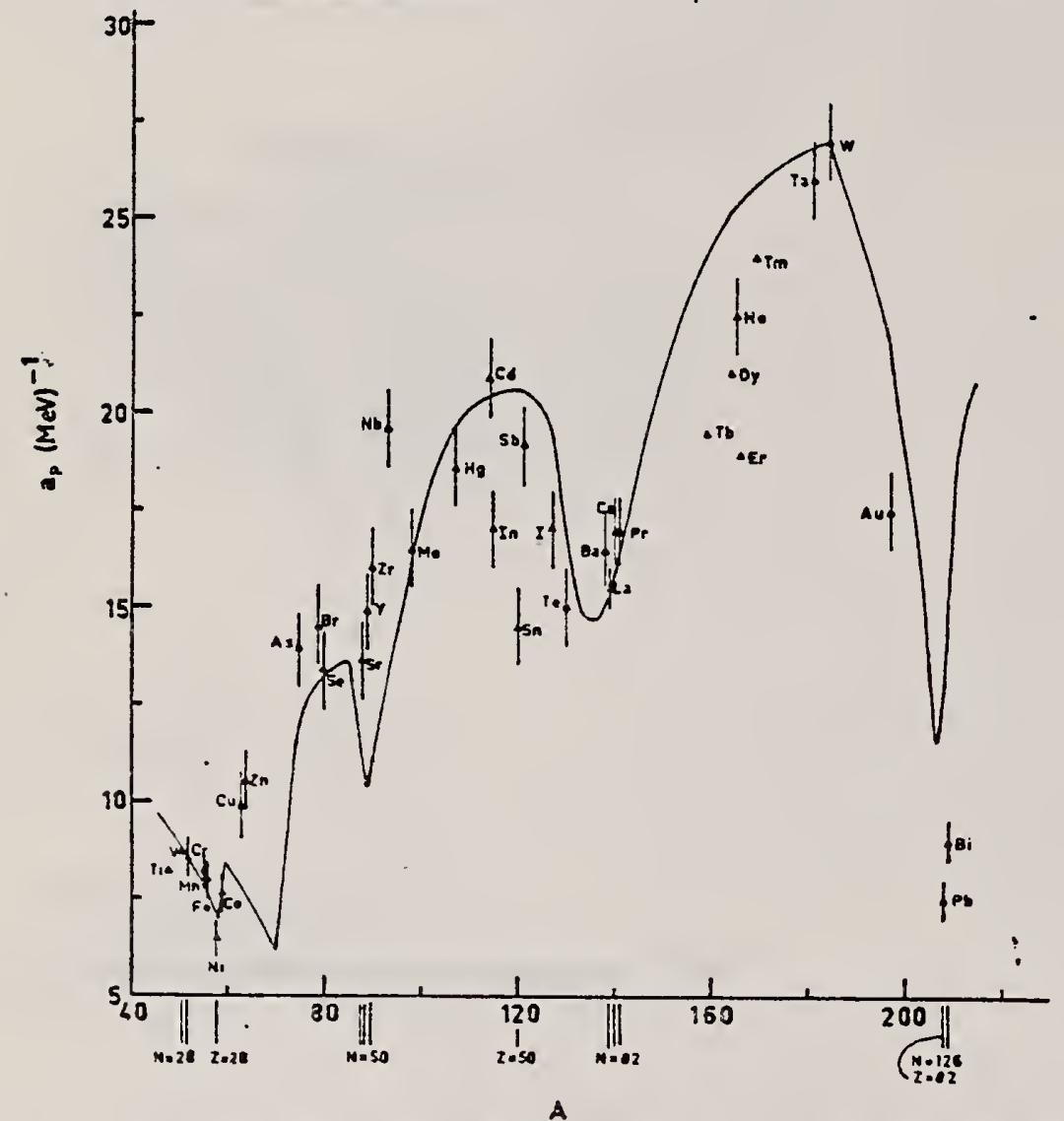

Fig. 12. Experimental values of the level density parameter $a_{0}$ (Fermi gas formula plus pairing correction) versus atomic number $A$. The continuous curve is a least-squares fit to the data of a theoretical calculation from Newton ${ }^{13}$ ).

MEAN NEUT ENERGY

1

H. Baba and 3. Baba, Japan Atomic Energy Research Institute report JAERI-1183 (1969).

2

H. Baba, Nucl. Phys. A159, 625 (1970). 15

T.D. Newton, Can. J. Phys. 34, 804 (1956).

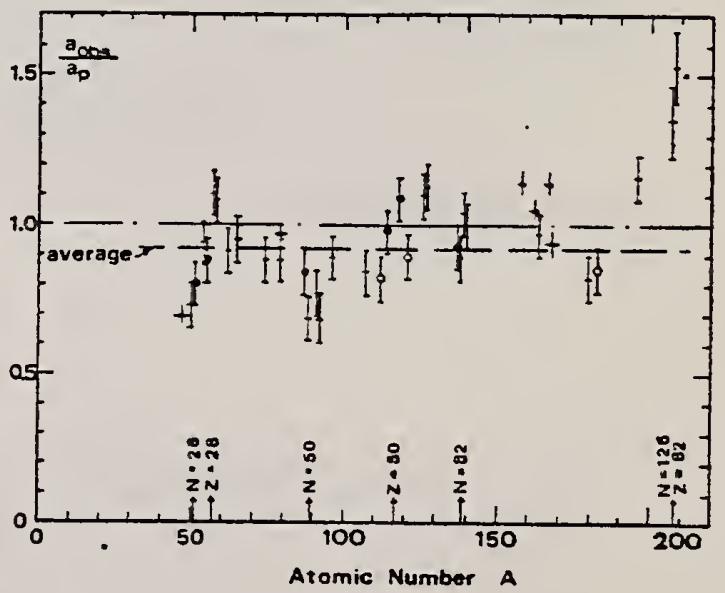

Fig. 15. Ratio $a_{000} a_{0}$ versus atomic number $A$. Here $a_{00 s}$ is the level density parameter taken from the neutron resonance work of refs. 1.2 ), and $a_{s}$ is the level density parameter derived from the present $(\%, n)$ work. Filled circles represent points where nuclei in the neutron resonance and in the $(\gamma, n)$ experiment were the same. Open circles represent points where the respective nuclei were approximately matched. Triangles represent points which are based on measurement of deutron mean energies at two bremsstrahlung energies only. 
TABLE 3

Comparison of experimental and theoretical data on nuclear level densities with Fermi gas formulae, and comparison of nuclear level density parameters from $(\%, n)$ and $n$-resonance absorption experiments

\begin{tabular}{|c|c|c|c|c|c|c|c|c|c|}
\hline \multirow{3}{*}{$\begin{array}{l}\text { Target } \\
\left.\text { Ti }^{3}\right)\end{array}$} & \multirow{2}{*}{\multicolumn{2}{|c|}{$\begin{array}{c}N \\
\text { (residual } \\
\text { nucleus) }\end{array}$}} & \multicolumn{2}{|c|}{$\begin{array}{c}\text { Goodness } \\
\left.\text { of fit }{ }^{\circ}\right)\end{array}$} & \multirow[t]{2}{*}{$\begin{array}{c}\hat{E}_{0}(24) \\
\left.(\mathrm{MeV})^{\circ}\right)\end{array}$} & \multirow[t]{2}{*}{$\begin{array}{c}T \\
\left.(\mathrm{MeV})^{\triangleleft}\right)\end{array}$} & \multirow[t]{2}{*}{$\frac{a_{p}}{\left.\left(\mathrm{MeV}^{-1}\right)^{c}\right)}$} & \multirow[t]{2}{*}{$\begin{array}{c}a_{0 \infty \infty} \\
\left.\left(\mathrm{MeV}^{-1}\right)^{\prime}\right)\end{array}$} & \multirow[t]{2}{*}{$a_{060 /} / a_{0}$} \\
\hline & & & $\begin{array}{l}\text { no } \\
\text { p.e. }\end{array}$ & $\begin{array}{l}\text { with } \\
\text { p.c. }\end{array}$ & & & & & \\
\hline & $\begin{array}{l}23 \\
24 \\
25 \\
26 \\
27\end{array}$ & $\begin{array}{r}8 \% \\
8 \% \\
73 \% \\
5 \% \\
5 \%\end{array}$ & & & 1.93 & & $8.1-{ }^{47} \mathrm{Ti}$ & $6.41-^{47} \mathrm{Ti}$ & 0.79 \\
\hline$V *$ & 27 & $100 \%$ & & & 1.96 & & $8.7-30 \mathrm{~V}$ & $6.35-{ }^{51} \mathrm{~V}$ & 0.73 \\
\hline $\mathrm{Cr}$ & $\begin{array}{l}25 \\
27 \\
28 \\
\frac{28}{29}\end{array}$ & $\begin{array}{r}4 \% \\
84 \% \\
10 \% \\
2 \%\end{array}$ & $\mathbf{P}$ & G & 1.89 & & $8.6-{ }^{31} \mathrm{Cr}$ & $6.9-{ }^{31} \mathrm{Cr}$ & $\underline{0.80}$ \\
\hline $\mathrm{Mn}$ & 29 & $100 \%$ & V.P. & G & 2.1 & & $8.2-^{34} \mathrm{Mn}$ & $7.82-{ }^{36} \mathrm{Mn}$ & 0.94 \\
\hline $\mathrm{Fe}$ & $\begin{array}{l}27 \\
29 \\
30\end{array}$ & $\begin{array}{r}6 \% \\
92 \% \\
2 \%\end{array}$ & F & G & 1.96 & & $8.0-{ }^{35} \mathrm{Fe}$ & $7.06-5{ }^{5} \mathrm{Fe}$ & 0.88 \\
\hline$C_{0}$ & 31 & $100 \%$ & $\mathbf{P}$ & F & 2.12 & & $7.7-58 \mathrm{Co}$ & $8.35-{ }^{60} \mathrm{Co}$ & 1.08 \\
\hline$\stackrel{\mathrm{Ni}}{(Z=28)}$ & $\begin{array}{l}29 \\
31 \\
32 \\
33 \\
35\end{array}$ & $\begin{array}{r}68 \% \\
26 \% \\
1 \% \\
4 \% \\
1 \%\end{array}$ & V.P. & $\mathbf{P}$ & 2.04 & 1.4 & $6.5-{ }^{57.7} \mathrm{Ni}$ & $7.19-59 \mathrm{Ni}-$ & 1.10 \\
\hline $\mathrm{Cu}$ & $\begin{array}{l}33 \\
35\end{array}$ & $\begin{array}{l}69 \% \\
31 \%\end{array}$ & V.P. & $\mathbf{P}$ & 1.78 & 1.0 & $9.8-^{62} \mathrm{Cu}$ & $8.90-{ }^{6+} \mathrm{Cu}$ & 0.91 \\
\hline$z_{n}$ & $\begin{array}{l}33 \\
35 \\
36 \\
37\end{array}$ & $\begin{array}{r}49 \% \\
28 \% \\
4 \% \\
19 \%\end{array}$ & $F$ & $\mathbf{F}$ & 1.61 & & $10.5-^{64.4} \mathrm{Zn}$ & $10.0-63 \mathrm{Zn}$ & 0.95 \\
\hline As & 41 & $100 \%$ & V.P. & $F$ & 1.44 & & $14.5-^{74}$ As & $12.81-{ }^{76}$ As & 0.88 \\
\hline Se") & $\begin{array}{l}41 \\
42 \\
43 \\
45 \\
47\end{array}$ & $\begin{array}{r}9 \% \\
8 \% \\
24 \% \\
50 \% \\
9 \%\end{array}$ & & & 1.39 & & $13.3-{ }^{78} \mathrm{Se}$ & $12.8-{ }^{78} \mathrm{Se}$ & 0.97 \\
\hline $\mathrm{Br}$ & $\begin{array}{l}43 \\
45\end{array}$ & $\begin{array}{l}45 \% \\
49 \%\end{array}$ & V.P. & V.P. & 1.41 & & $14.5-^{79} \mathrm{Br}$ & $12.69-{ }^{\circ} \mathrm{Br}$ & 0.88 \\
\hline Sr & $\begin{array}{l}47 \\
48 \\
49\end{array}$ & $\begin{array}{r}10 \% \\
7 \% \\
83 \%\end{array}$ & $\mathbf{F}$ & G & 1.31 & & $13.6-^{-97} \mathrm{Sr}$ & $11.4-{ }^{87} \mathrm{Sr}$ & $\underline{0.84}$ \\
\hline
\end{tabular}

2) Neutron numbers and abundances of respective residual nuclei in $(i, n)$ experiments.

b) These give an assessment of the goodness of fit of a calculated $E_{n}$ versus $E_{0}$ curve to the observed data, using the Fermi gas level density formula both without and with pairing corrections.

c) Bremsstrahlung photoneutron mean energies $E_{\mathrm{a}}$ for peak bremsstrahlung energy $E_{0}=24 \mathrm{MeV}$.

d) Nuclear temperature from fit with constant-temperature formula.

-) Level density parameter $a_{0}$ derived from the present $(\gamma, n)$ experiment, using a Fermi gas formula plus pairing correction, and corresponding residual nucleus (the atomic weight shown is the weighted average of atomic weights of the respective isotopes present).

1) As coiumn 7, but using dara on n-resonance absorption from refs. 1. 2).

8) Measurements of $\bar{E}_{\mathrm{a}}\left(E_{\mathrm{u}}\right)$ for these nuclei were made only for $E_{0}=21,23$ and $24 \mathrm{MeV}$. 
REF.

V. Emma, S. Lo Nigro, C. Milone

Nuc1. Phys. A257, 438 (1976)

$76 \operatorname{Ein} 2$

egf

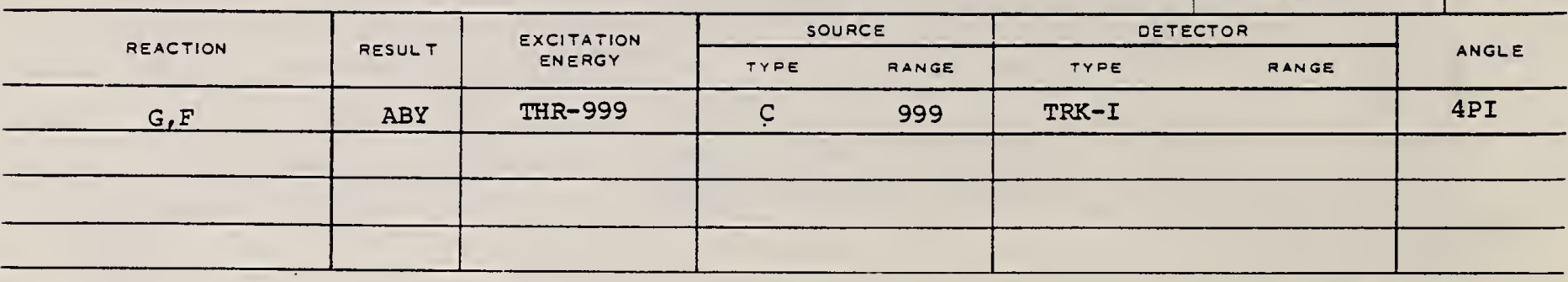

TABte 1

Measured values of $\sigma_{q}$ at $E=1000 \mathrm{MeV}$ and deduced values of $\sigma_{\mathrm{z}}$ assumed constant from $E_{0}$ to $1000 \mathrm{MeV}$

\begin{tabular}{|c|c|c|c|c|}
\hline Element & $Z^{2} / A$ & $\begin{array}{c}\sigma_{\mathrm{q}} \\
(\mathrm{mb})\end{array}$ & $\begin{array}{c}E_{0} \\
(\mathrm{MeV})\end{array}$ & $\begin{array}{c}\sigma_{k} \\
(m b)\end{array}$ \\
\hline $\begin{array}{l}\mathrm{Bi} \\
\mathrm{Pb} \\
\mathrm{T} \\
\mathrm{Au} \\
\mathrm{Pt} \\
\mathrm{Re} \\
\mathrm{W} \\
\mathrm{Ta} \\
\mathrm{Hf} \\
\mathrm{Yb} \\
\mathrm{Tr} \\
\mathrm{Ho} \\
\mathrm{Dy} \\
\mathrm{Tb} \\
\mathrm{Gd} \\
\mathrm{Sm} \\
\mathrm{Nd} \\
\mathrm{Ce} \\
\mathrm{La} \\
\mathrm{Sb} \\
\mathrm{Te} \\
\mathrm{Sa} \\
\mathrm{Cd} \\
\mathrm{Ag} \\
\mathrm{Zn} \\
\mathrm{Cu} \\
\mathrm{Ni} \\
\mathrm{Fe}\end{array}$ & $\begin{array}{l}32.96 \\
32.45 \\
32.10 \\
31.68 \\
31.18 \\
30.21 \\
29.78 \\
29.45 \\
29.04 \\
28.31 \\
28.18 \\
27.21 \\
26.80 \\
26.58 \\
26.04 \\
25.56 \\
24.96 \\
24.00 \\
23.39 \\
21.36 \\
21.19 \\
21.06 \\
20.49 \\
20.47 \\
13.76 \\
13.44 \\
13.35 \\
12.10\end{array}$ & $\begin{array}{l}12.3 \pm 0.6 \\
5.4 \pm 0.4 \\
4.1 \pm 0.3 \\
2.0 \pm 0.15 \\
1.1 \pm 0.08 \\
(3.7 \pm 0.3) \times 10^{-1} \\
(3.5 \pm 0.3) \times 10^{-1} \\
(3.3 \pm 0.3) \times 10^{-1} \\
(1.7 \pm 0.2) \times 10^{-1} \\
(1.3 \pm 0.1) \times 10^{-1} \\
(7.5 \pm 0.8) \times 10^{-2} \\
(3.6 \pm 0.4) \times 10^{-2} \\
(2.6 \pm 0.3) \times 10^{-2} \\
(2.5 \pm 0.3) \times 10^{-2} \\
(1.6 \pm 0.2) \times 10^{-2} \\
(1.3 \pm 0.2) \times 10^{-2} \\
(9.2 \pm 0.9) \times 10^{-3} \\
(8 \pm 0.9) \times 10^{-3} \\
(8.4 \pm 0.9) \times 10^{-3} \\
(1.2 \pm 0.2) \times 10^{-2} \\
(8.8 \pm 1) \times 10^{-3} \\
(1.3 \pm 02) \times 10^{-2} \\
(1.7 \pm 0.3) \times 10^{-2} \\
(2 \pm 0.3) \times 10^{-2} \\
(2 \pm 0.4) \times 10^{-1} \\
(2.4 \pm 0.5) \times 10^{-1} \\
(2.4 \pm 0.5) \times 10^{-1} \\
(3 \pm 0.6) \times 10^{-1}\end{array}$ & $\begin{array}{l}200 \\
220 \\
230 \\
240 \\
255 \\
280 \\
290 \\
300 \\
310 \\
330 \\
335 \\
355 \\
360 \\
370 \\
380 \\
390 \\
405 \\
420 \\
430 \\
460 \\
465 \\
465 \\
470 \\
470 \\
515 \\
515 \\
510 \\
510\end{array}$ & $\begin{array}{l}7.6 \pm 0.6 \\
3.6 \pm 0.3 \\
2.8 \pm 0.3 \\
1.4 \pm 0.2 \\
(8 \pm 0.7) \times 10^{-1} \\
(2.9 \pm 0.3) \times 10^{-1} \\
(2.8 \pm 0.3) \times 10^{-1} \\
(2.7 \pm 0.3) \times 10^{-1} \\
(1.4 \pm 0.2) \times 10^{-1} \\
(1.2 \pm 0.1) \times 10^{-1} \\
(6.8 \pm 0.8) \times 10^{-2} \\
(3.5 \pm 0.4) \times 10^{-2} \\
(2.5 \pm 0.3) \times 10^{-2} \\
(2.5 \pm 0.3) \times 10^{-2} \\
(1.7 \pm 0.2) \times 10^{-2} \\
(1.4 \pm 0.2) \times 10^{-2} \\
(1 \pm 0.1) \times 10^{-2} \\
(9 \pm 1) \times 10^{-3} \\
(1 \pm 0.1) \times 10^{-3} \\
(1.5 \pm 0.3) \times 10^{-2} \\
(1.2 \pm 0.2) \times 10^{-2} \\
(1.7 \pm 0.3) \times 10^{-2} \\
(2.2 \pm 0.4) \times 10^{-2} \\
(2.6 \pm 0.4) \times 10^{-2} \\
(3 \pm 0.6) \times 10^{-1} \\
(3.6 \pm 0.8) \times 10^{-1} \\
(3.6 \pm 0.8) \times 10^{-1} \\
(4.4 \pm 0.9) \times 10^{-1}\end{array}$ \\
\hline
\end{tabular}

Fig. 2. Nuclear fissilities as a function of $Z^{2}$,A. Experimental points. solid circles represent our data; squares, the data from ref. $\left.{ }^{4}\right)$ : open ercles. the data from (el. $\left.{ }^{\top}\right)$; and crosses. the data from (p) experiments ${ }^{20}$ ). The straight line is the best tit calculated from our data for $Z^{2}, A>26$. The dashed curve is the curve VI calculated by Nix and Sassi ${ }^{12}$ L.
$999=1 \mathrm{GEV}$

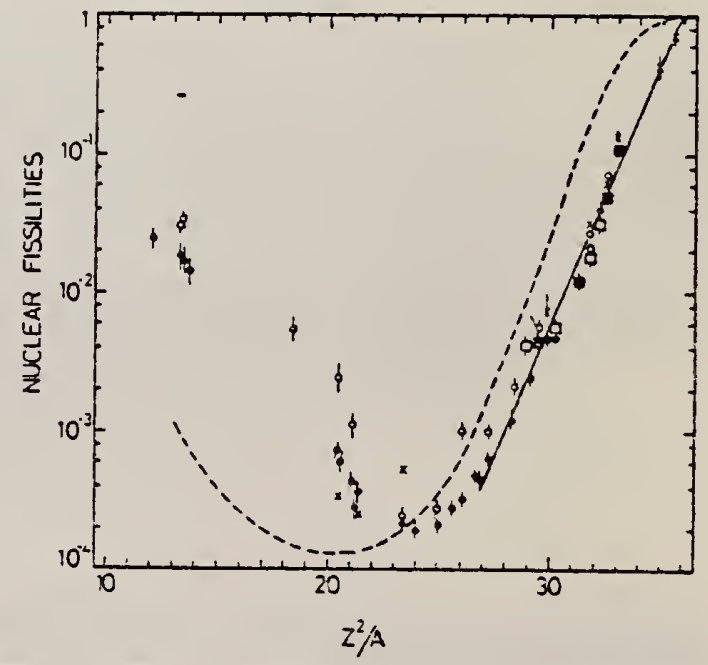

${ }^{4}$ A.V. Mitrofanova et al. Sov. J. Nucl. Phys. 6 , 512 (1968).

7 T. Methasiri et al.. Nucl. Phys. Al67, 97 (1971).

12 J.R. Nix et al., Nucl. Phys. 81, 61 (1966).

20 Perifilov et al., JETP (Sov. Phys.) 14, 623 (1962); Proc. Symp. on the physics \& chemistry of fission, Salzburg 1965, vol. 2 (IAEA) Vienna, 1965, p.283. 
M.D. DeSouz Santos, J. Goldemberg, R.R. Pieroni, E. Silva, O.A. Boŕllo, S.S. Villaca, J.L. Lopes

Int. Conf. Peaceful Uses of Atomic Energy II (UN, NY), 169 (1955)

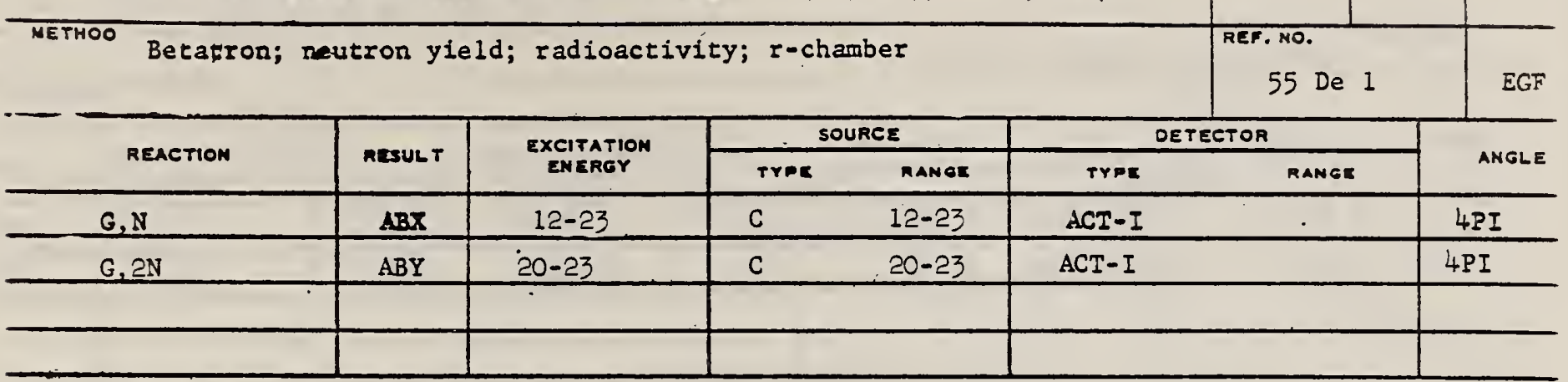

threshold $(\gamma, 2 n)=20.35 \pm 0.35 \mathrm{MeV}$

THRESHOLD $\underline{\text { NN }}$

aro.

$\left.2 n^{\alpha n}(t) 2 n\right)$

CROSS-SECTION

$\operatorname{acs}$
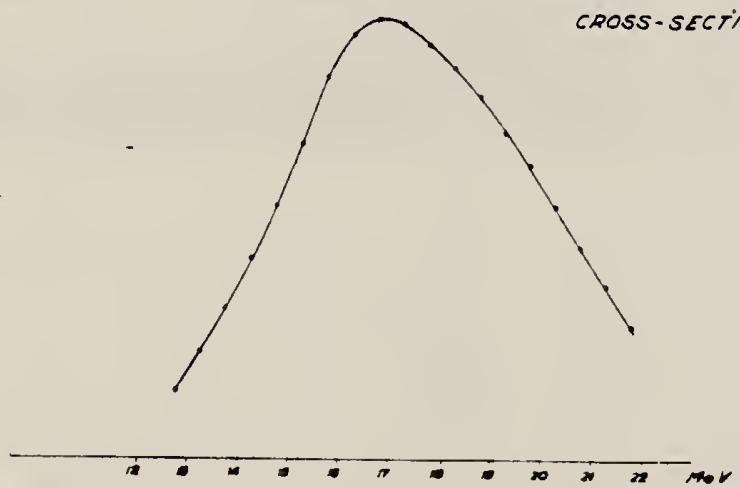

0.0

Excitarion Function

$2 n^{64}(6.2 n) 2 n^{62}$

3.

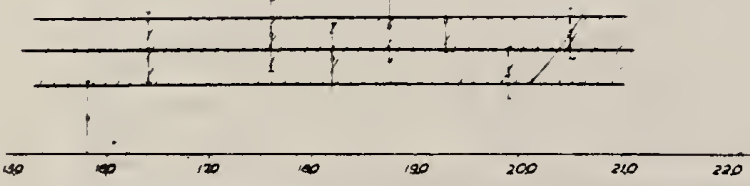

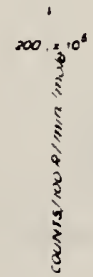

$\infty$ :

201

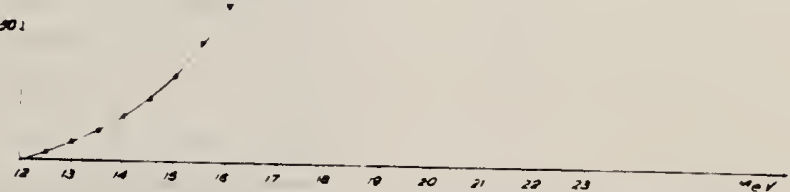


REF.

S.S. Villaca, J. Goldemberg

An. Acad. Brasil. Cienc. 27, 427 (1955)

METHOD Betatron; ion chamber monitor

\begin{tabular}{|c|c|c|} 
EL EM. SYM. & & \\
$\mathrm{Zn}$ & 64 & 30 \\
\hline $\begin{aligned} \text { REF. NO. Vi i } & \text { NVB }\end{aligned}$
\end{tabular}

\begin{tabular}{|c|c|c|c|c|c|c|c|}
\hline \multirow{2}{*}{ REACTION } & \multirow{2}{*}{ RESULT } & \multirow{2}{*}{$\begin{array}{l}\text { EXCITATION } \\
\text { ENERGY }\end{array}$} & \multicolumn{2}{|c|}{ SOURCE } & \multicolumn{2}{|c|}{ DETECTOR } & \multirow{2}{*}{ ANGLE } \\
\hline & & & TyPE & RANGE & TYPE & RANGE & \\
\hline $\mathrm{G}, \mathrm{N}$ & $A B X$ & $12-22$ & $\mathrm{C}$ & $12-22$ & $\mathrm{ACT}-\mathrm{I}$ & & $4 P I$ \\
\hline$G, 2 \mathrm{~N}$ & $A B Y$ & $15-22$ & C & $12-22$ & ACT-I & & 4PI \\
\hline & & & & & & & \\
\hline
\end{tabular}
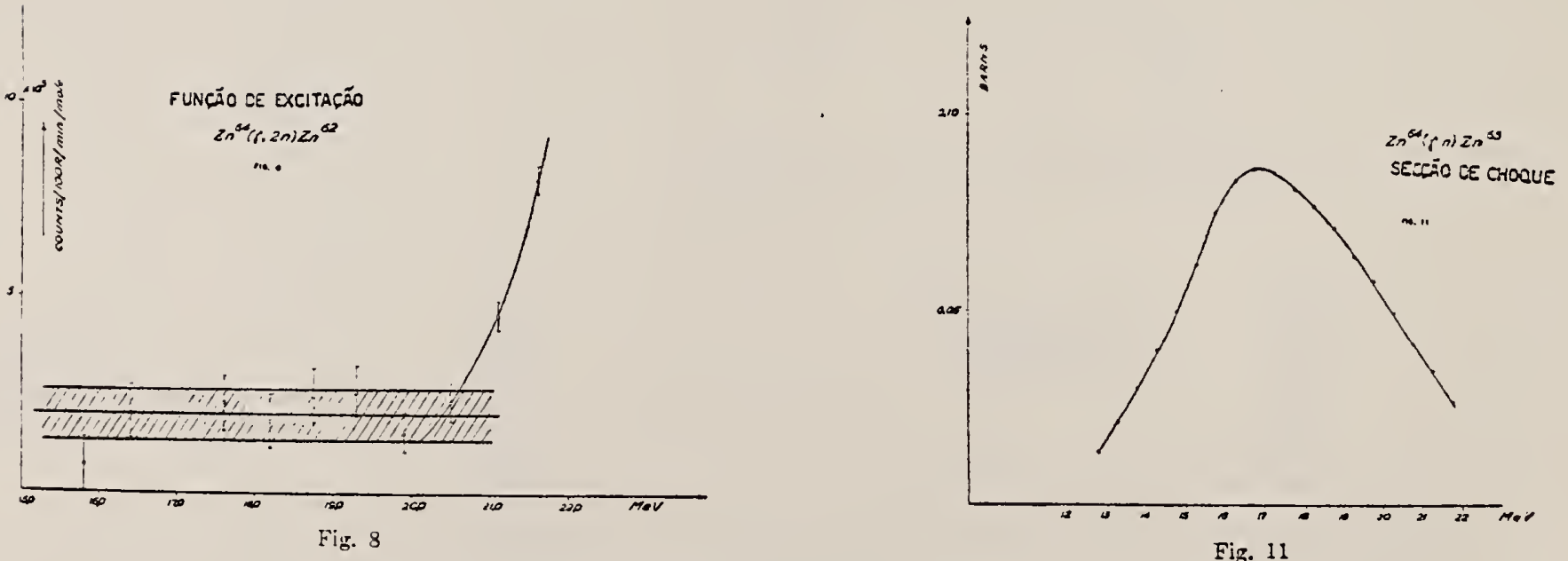

Fig. 11

\begin{tabular}{|c|c|c|c|c|c|c|}
\hline Elemento & I.imial & $E_{\max }$ & $\sigma_{\text {max. }}$ & $\Delta$ & $\Gamma$ (bitg.: & $\int_{\sigma . d i t}$ \\
\hline & 11,62 & 17 & 0,087 & 2,9 & 6,2 & 2,03 \\
\hline$z n^{3+}(\gamma$. & Mev. & Mev. & barns & Me: & II cuv. & Iev $\times$ bars \\
\hline
\end{tabular}


REF.

A. BI Slouf1, P. BIdos, and P. Stoll

Melv. Phys. Acta 30, 265 (1957)

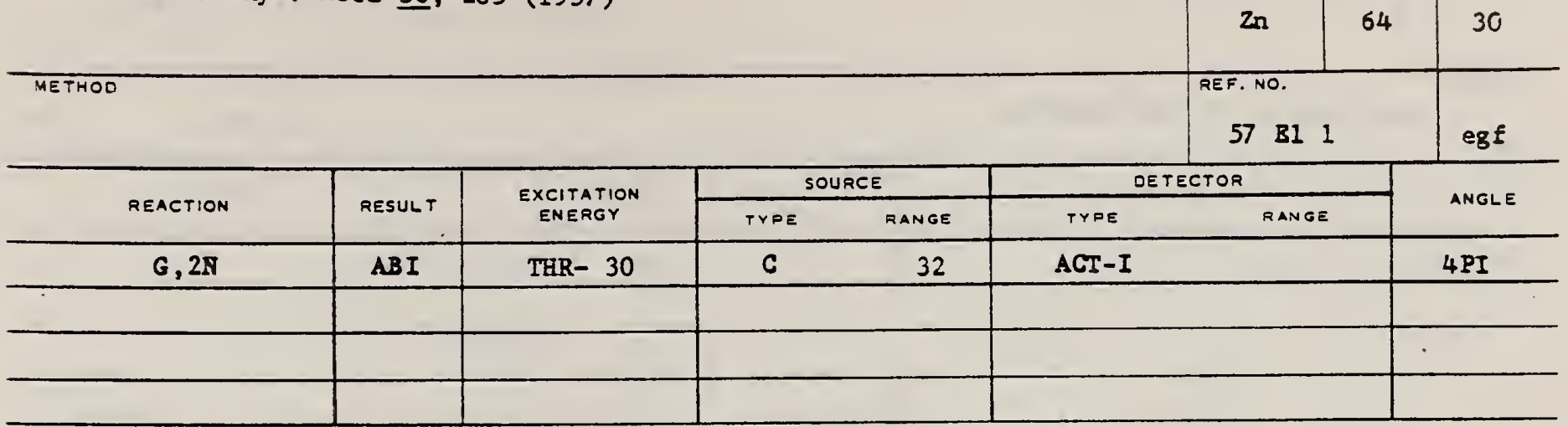

Tabclle 1.

Zusammenstellung der gem. W. Q.

\begin{tabular}{|c|c|c|c|}
\hline Renktion & $\begin{array}{l}Q-1 V e r t \\
\text { MeV }\end{array}$ & $\mathrm{MeV}$ ham & Verlialtnis der Querscinnitte \\
\hline $\left.\mathrm{Zn}^{* 4}(\gamma, \mathrm{np}) \mathrm{Cu}^{* 4 *}\right)$ & 18,65 & 0,02 & $\sigma_{7 n^{68}}(\gamma, p)$ \\
\hline $\left.\mathrm{Zn}^{68}(\gamma, p)\left(u^{67 * *}\right)^{6}\right)$ & 10,01 & 0,08 & $\sigma_{\mathrm{Zn}}{ }^{6 q}(;, n p)$ \\
\hline $7 n^{44}(\gamma, 2 n) Z n^{13}$ & 20,82 & 0,08 & $\sigma_{\%, n^{68}(\gamma, n p)}$ \\
\hline$M 0^{22}(\gamma, n p) \times b^{10}$ & $19, \overline{3}$ & 0,02 & $\overline{\sigma_{Z n+1}(\gamma, 2 n)}$ \\
\hline \multirow[t]{2}{*}{$30^{98}(\gamma, p) \mathrm{Nb}^{37}$} & & \multirow[t]{2}{*}{0,09} & $=4,5$ \\
\hline & & & $\overline{\sigma_{\mathrm{Al} 0} \cdot 2(\gamma, \mathrm{np})}= \pm, \mathrm{v}$ \\
\hline $\begin{array}{l}\sigma_{\max }: 5,3 \\
\sigma_{\max }: 11,5\end{array}$ & bei $E$ & $=27 \pm 0$ & $\begin{array}{ll}\text { MeV } & \Gamma=3,7 \mathrm{MeV} \\
\text { MeV } & \Gamma=6.4 \mathrm{MeV} .\end{array}$ \\
\hline
\end{tabular}


Ref. J. Goldemberg, L. Marquez Nuclear Phys. I, 202 (1958)

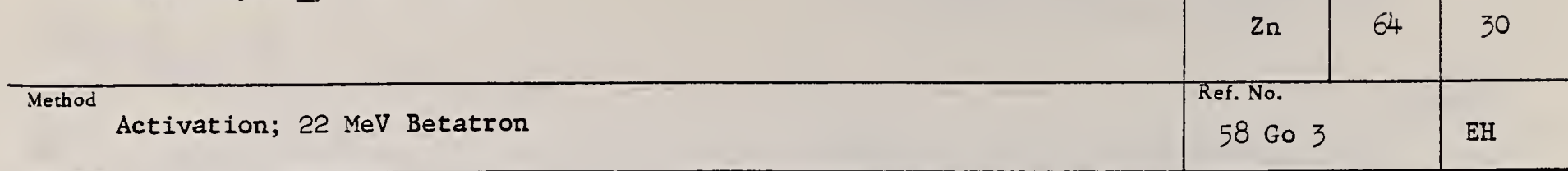

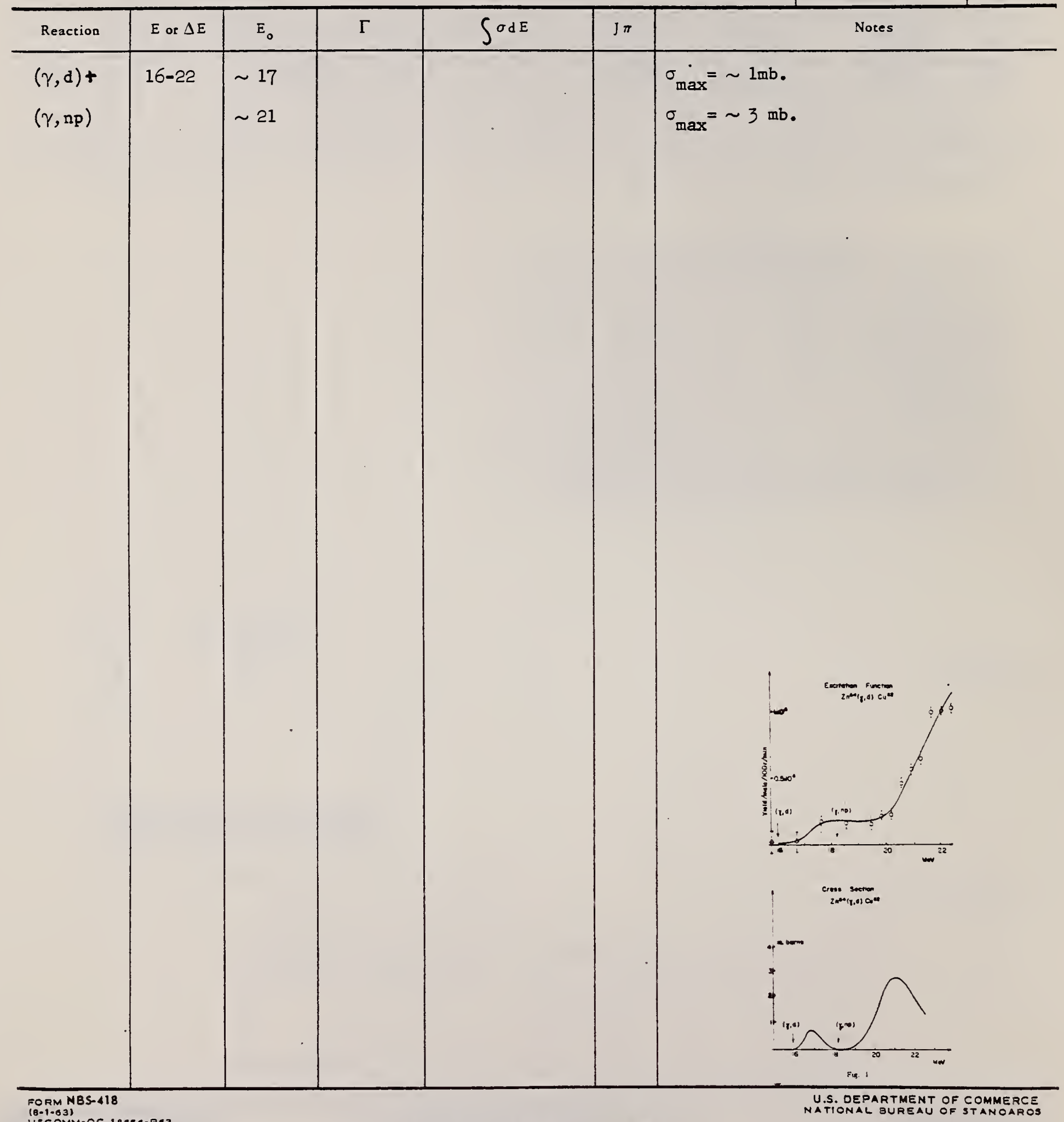


REF.

A. Hofmann, P. Stoll

Belv. Phys. Acta 31, 591 (1958)

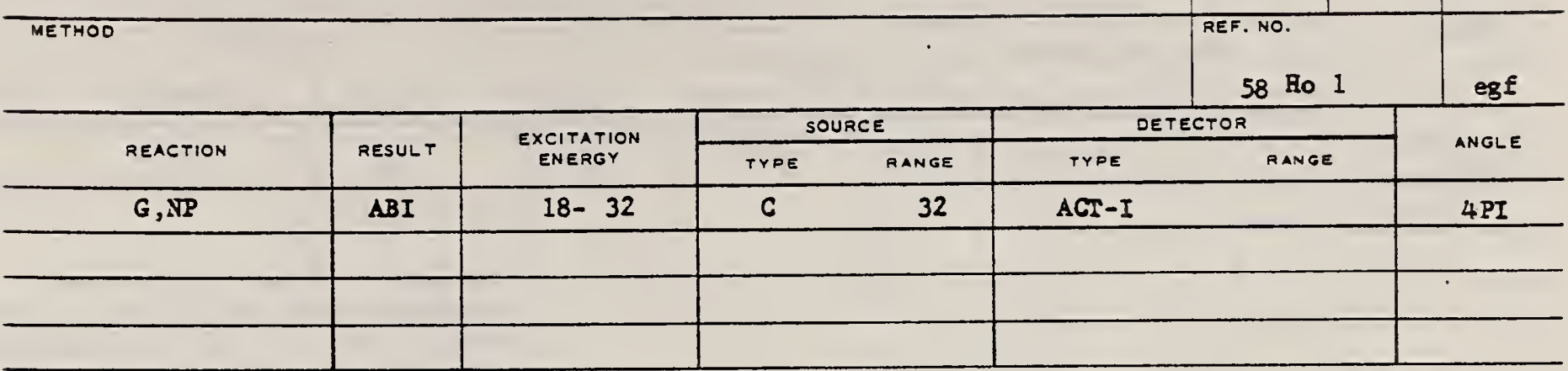

$(\gamma, n p)$ ylelds inclade $(y, d)$.

Tabelle I

\begin{tabular}{|c|c|c|c|c|c|}
\hline Reaktion & $\begin{array}{l}\text { Q-Wert } \\
\text { MeV }\end{array}$ & $\begin{array}{l}\text { I.W.Q. } \\
\text { MuY barn }\end{array}$ & $\underset{\mathrm{nnb}}{\sigma_{\max }}$ & $\begin{array}{c}E_{\operatorname{mnx}} \\
M c V\end{array}$ & $\underset{\mathrm{McV}}{\Gamma}$ \\
\hline $\mathrm{Ca}^{40}(y, p n) \mathrm{K}^{-38}$ & -24.3 & 0,005 & 2.4 & $30 \pm 1$ & 2,1 \\
\hline $\mathrm{Zn}^{04}(\gamma, p n) \mathrm{Cu}^{43}$ & $-18,35$ & 0.03 & & & \\
\hline $\mathrm{Zn}^{88}(\gamma, p m) \mathrm{Cu}^{84}$ & -18.65 & 0,1031 & 7,2 & $28 \pm 1$ & 4 \\
\hline$Z_{n^{68}}(\gamma, p) C u^{67}$ & $-10,01$ & 0.19 & 11,4 & $22,7 \pm 1$ & 6 \\
\hline$S c^{30}(\gamma, p n) A s^{78}$ & $-20,43$ & 0.12 & & & \\
\hline$Z n^{64}(y, 2 n) Z n^{82}$ & -20.82 & 0.018 & & & \\
\hline$M n^{12}(\%, p n) \times b^{00}$ & -19.5 & 0,02 & & & \\
\hline $\mathrm{Sb}^{123}(\gamma, p n) \mathrm{Sn}^{131}$ & -18.2 & $0,0000 \mathrm{i}$ & & & \\
\hline
\end{tabular}


Ref. T. Nakamura, K. Takamatsu, K. Fukunaga, N. Yata, S. Yasuni

J. Phys. Soc. Japan 14, 693 (1959)

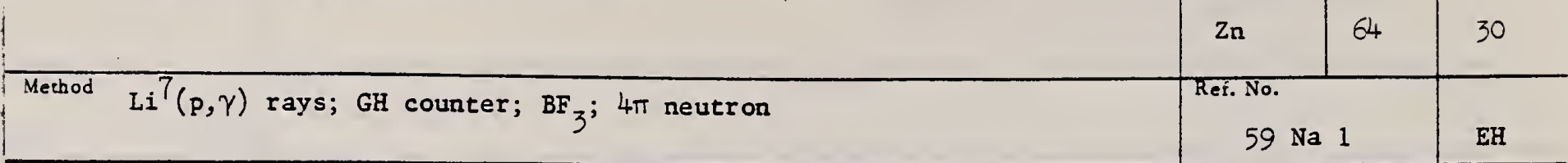

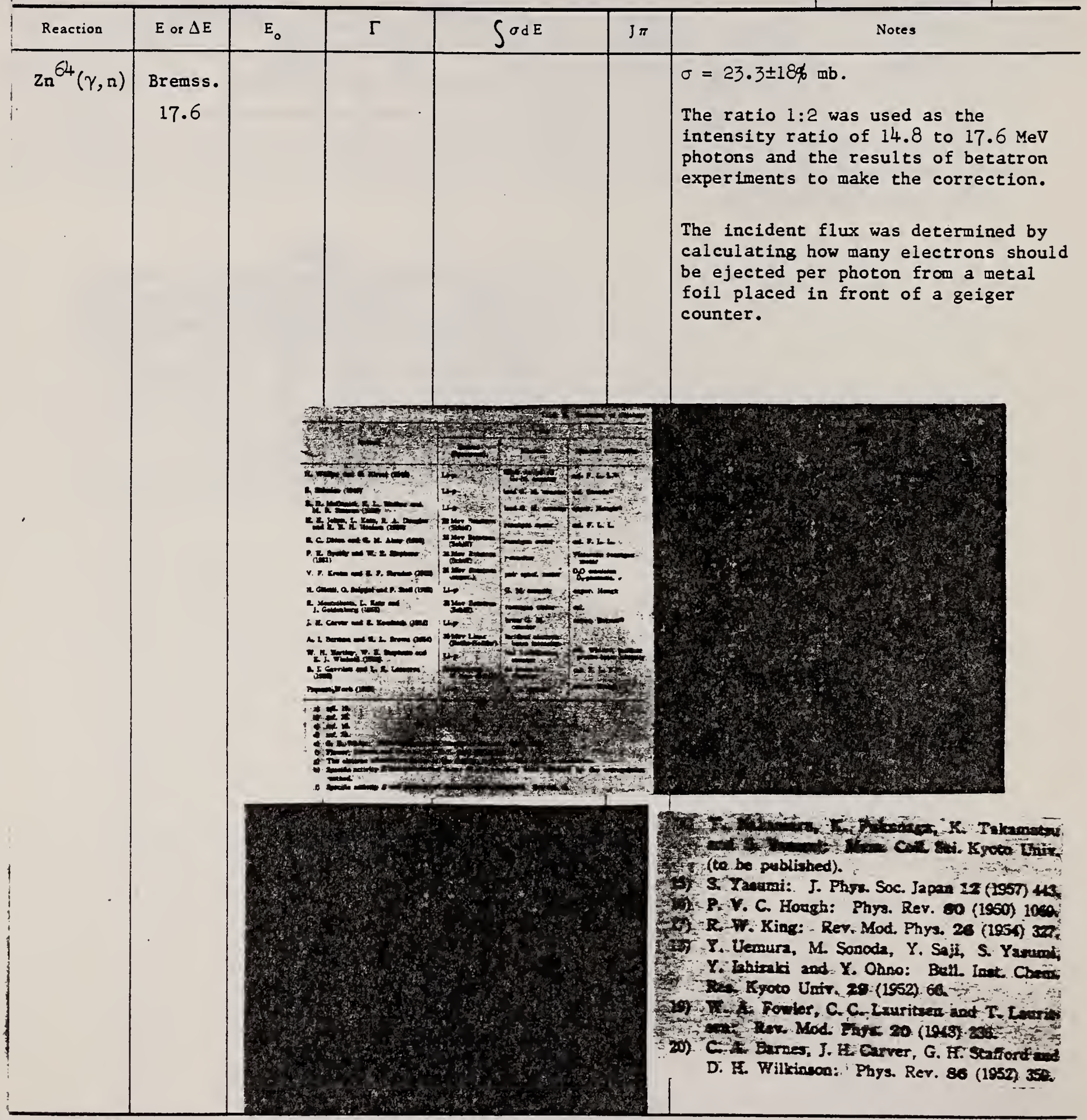


REF.

J.P. Roalsvig, R.N.H. Haslam, J.L. Bergsteinsson

Can. J. Phys. 38,320 (1960)

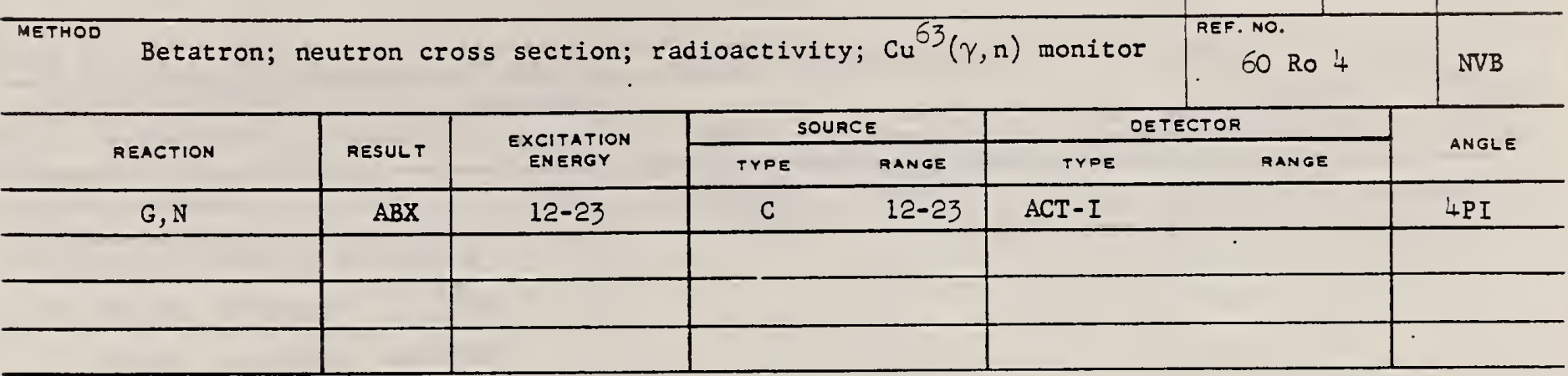

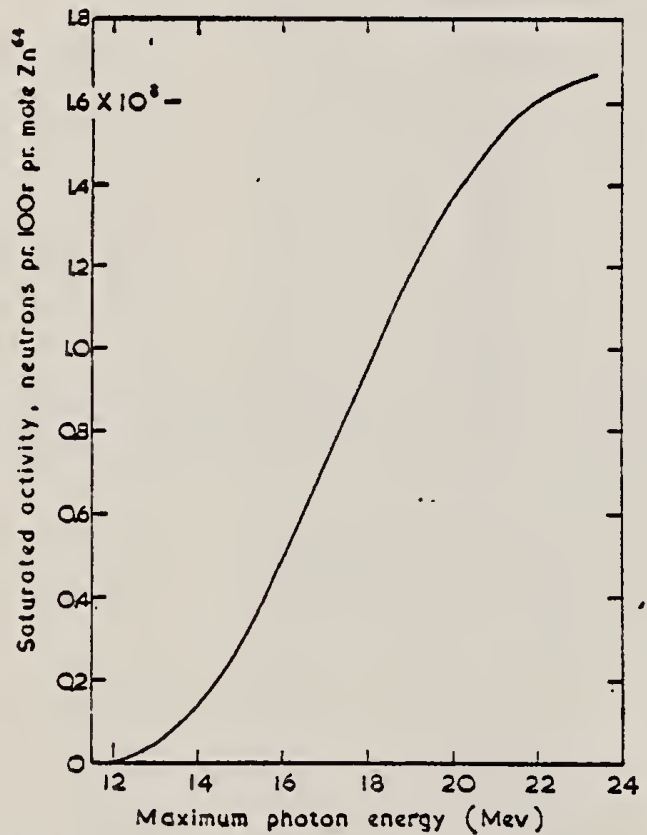

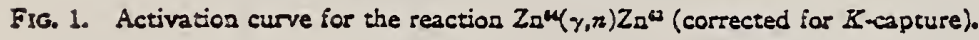

TABLE I

\begin{tabular}{|c|c|c|c|c|c|c|c|}
\hline References & Yield, n/molc $100 \mathrm{r}$ & $\sigma_{\operatorname{mib}}^{\sigma_{\max }}$ & $\begin{array}{l}E_{\max } \\
\text { Mev }\end{array}$ & $\begin{array}{l}\Gamma_{1 / 21} \\
\text { Mev }\end{array}$ & $\int_{\text {Mev-barn }}^{s_{1}} \sigma(\gamma, n) d E$, & $\left(E_{2}\right.$, Mev $)$ & $\left\{\begin{array}{c}\text { Ratio } \\
\left\{\sigma \text { for } \mathrm{Cu}^{* 0}(\gamma, n)\right\} / \\
\left.\sigma \text { for } \mathrm{Zn}^{\omega}(\gamma, n)\right\} \text { at } \\
17.6 \mathrm{Mev}\end{array}\right.$ \\
\hline $\begin{array}{l}\text { Price and licrst (1950) } \\
\text { Katz. et al. (1951) } \\
\text { Katz and Canicron (1951)* } \\
\text { Strauch (1951) } \\
\text { Marshall (1951) } \\
\text { Sagane (1052) } \\
\text { Montalbetti et al. (1953) } \\
\text { Bunbury (1954) } \\
\text { Gavrilov and Lazareva (1950) } \\
\text { Present work }\end{array}$ & 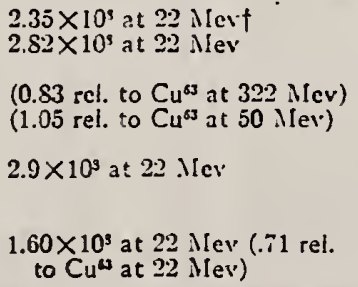 & $\begin{array}{l}120 \\
124\end{array}$ & $\begin{array}{l}18.5 \\
18.7\end{array}$ & $\begin{array}{l}7.1 \\
7.9\end{array}$ & $\begin{array}{c}0.83 \\
0.99 \\
(\sim .50) \\
(\sim .77 \\
(\sim .50)\end{array}$ & $\begin{array}{l}(24) \\
(2 \ddagger) \\
(322) \ddagger \\
(50) \\
(67) \ddagger\end{array}$ & $\begin{array}{l}1.3 \\
1.9\end{array}$ \\
\hline
\end{tabular}

-Recalculation of values of Katz es al. (195i) using photon difference method.

tFor natural element.

iThese values are calculated from a relative integrated cross section of 0.89 compared to the reaction $\mathrm{Cu} \uplus(\gamma, n) \mathrm{Cu}^{\text {ta }}$, assuming the cross section to be small above the giant dipole resonance. 
Ref. G.E. Coote, W.E. Turchinetz, I.F. Wright Nuclear Phys. 23, 468 (1961)

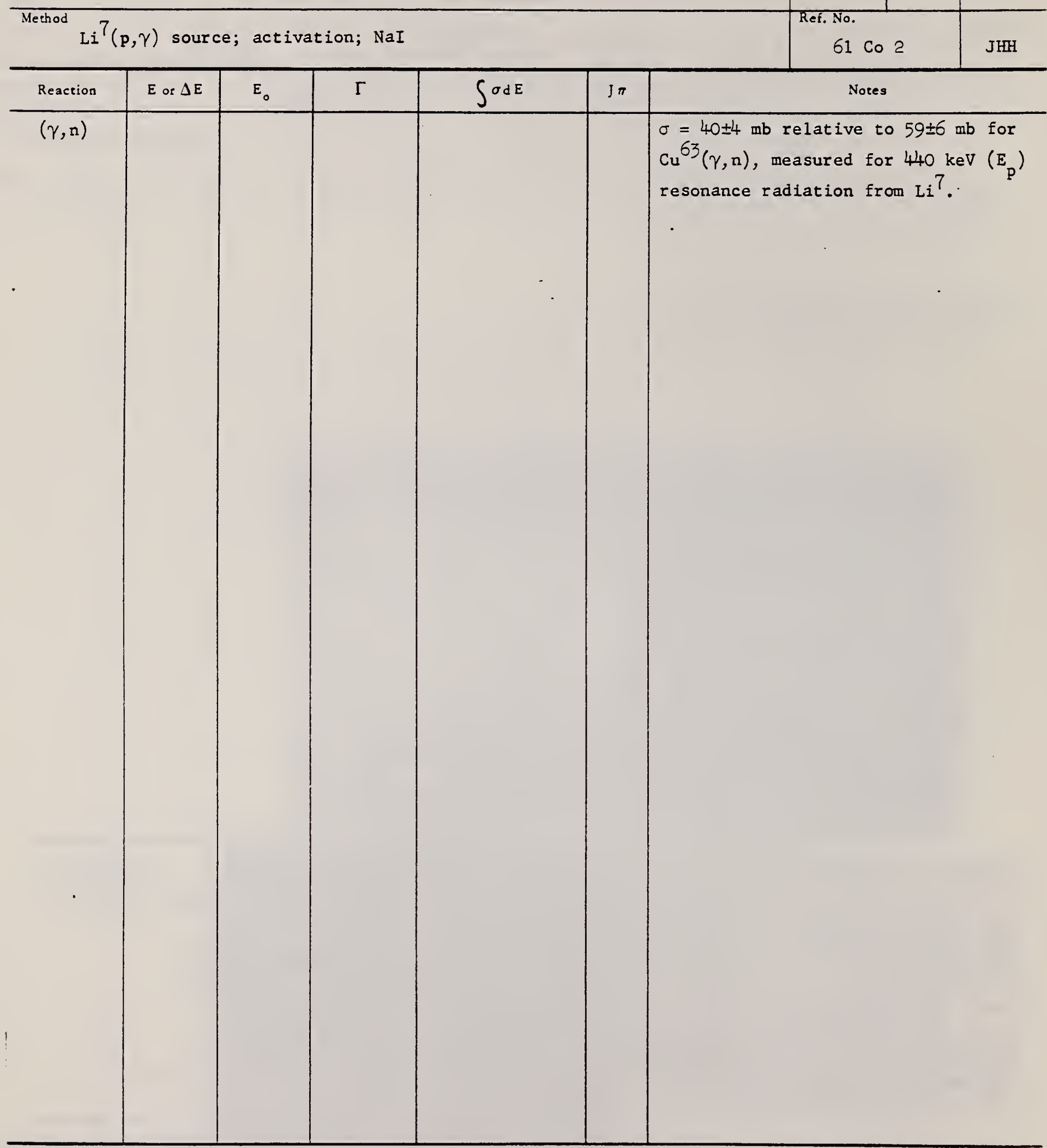


Ref. W.E. Del Bianco, W.E. Stephens Phys. Rev. 126, 709 (1962)

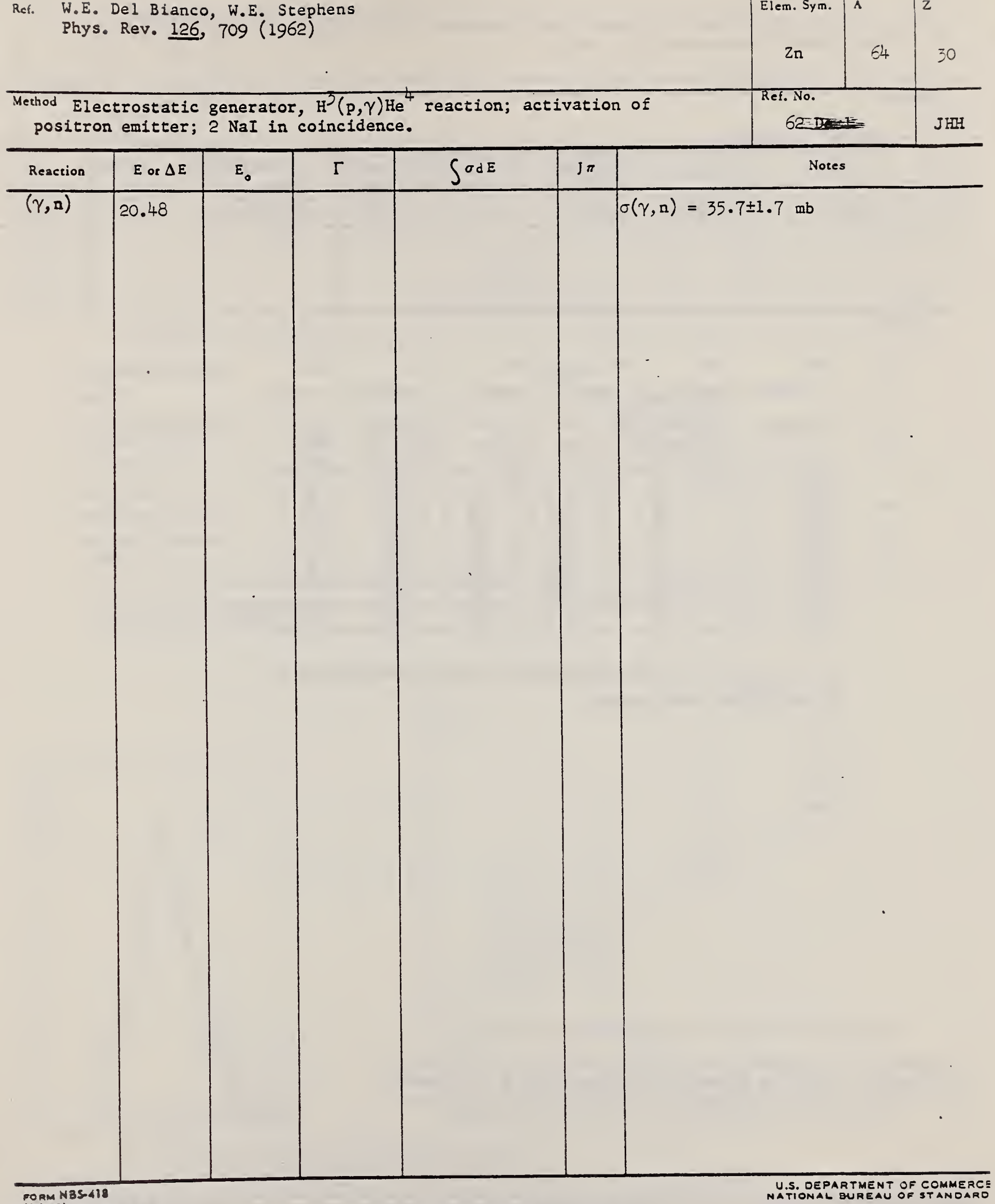

FORM N
(B-I-Ga)
USCOMM

PHOTONUCLEAR DATA SHEET 471 
S. Costa, F. Ferrero, S. Ferroni and R. Malvano

Proc. Paris Conference 1034 (1964)

$100 \mathrm{MeV}$ synchrotron

\begin{tabular}{|c|c|c|c|c|c|c|c|}
\hline \multirow{2}{*}{ REACTION } & \multirow{2}{*}{ RESULT } & \multirow{2}{*}{$\begin{array}{c}\text { EXCITATION } \\
\text { ENERGY }\end{array}$} & \multicolumn{2}{|c|}{ SOURCE } & \multicolumn{2}{|c|}{ DETECTOF } & \multirow{2}{*}{ ANGLE } \\
\hline & & & TYPE & RANGE & TYPE & RANGE & \\
\hline$G, N$ & $A B$ & THR- 80 & C & $10-80$ & BE3-I & & $\angle P I$ \\
\hline & & & & & & & \\
\hline & & & & & & & \\
\hline
\end{tabular}

TABLB

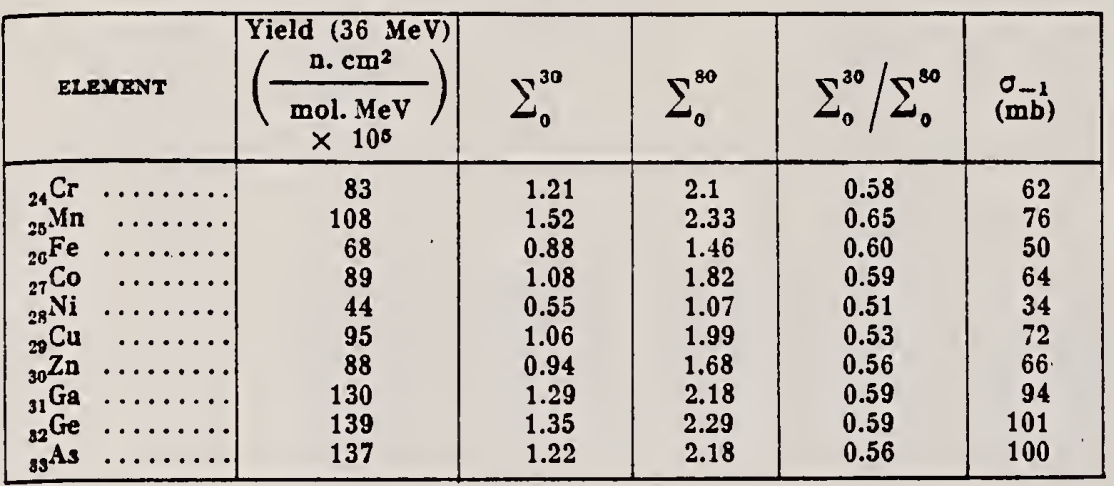

$\Gamma^{b}=\frac{A}{60 \mathrm{NZ}} \int{ }^{b} \sigma(E) \mathrm{d} E$ is the integrated cross section measured in units of the classical dipole $60 \mathrm{NZ} / \mathrm{A} \mathrm{mb}$. $\mathrm{MeV}$. 


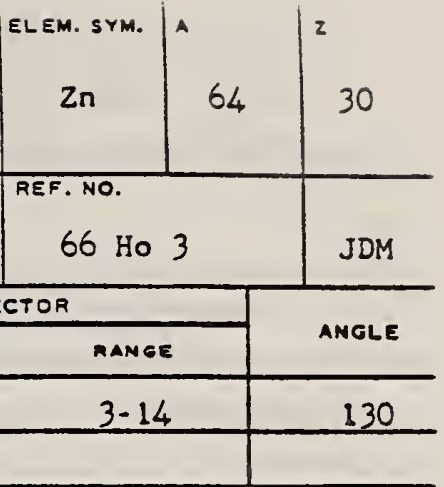

TAale 1

Experimental data and results

\begin{tabular}{|c|c|c|c|c|c|c|c|}
\hline Element & M8 & $\mathbf{A}$ & $\mathbf{s}$ & $\mathrm{Ni}$ & $\mathrm{Cu}$ & $\mathrm{Zn}$ & Error $\%)$ \\
\hline target thickness $\left(\mathrm{mg} / \mathrm{cm}^{2}\right)$ & 0.31 & 1.54 & 0.80 & 2.50 & 2.68 & $3 . \infty$ & sa) \\
\hline dose $(r)$ & 6190 & 25400 & 23200 & 3880 & 5840 & 4220 & 10 \\
\hline $\begin{array}{l}\text { yield absolute }\left(10 \% / \mathrm{mole}^{\circ} \mathrm{r}\right) \\
\text { for } \varepsilon_{\mathrm{m}}>3.16 \mathrm{MeV}\end{array}$ & 0.61 & 0.93 & 1.46 & 1.65 & 0.92 & . $\quad 242$ & $11 \%$ \\
\hline yield relative to $\mathrm{Ni}$ & 0.36 & 0.56 & 0.88 & 1 & 0.55 & 1.43 & S4) \\
\hline$Y_{Y, \alpha} / Y_{Y, \cot }(\%)$ & 9.6 & 11.4 & 124 & 7.0 & 3.2 & ) & \\
\hline nuclear temp. $\theta(\mathrm{MeV})$ & 1.43 & 1.48 & 1.46 & 1.04 & & 0.91 & 10 \\
\hline $\begin{array}{l}\text { lovel density parameter a } \\
\left(\mathrm{MeV}^{-1}\right)\end{array}$ & 5.1 & 4.8 & 4.9 & 8.6 & & 10.8 & - 10 \\
\hline
\end{tabular}

-) For $S$, the error of the target thickness has been $10 \%$ of the absolute yield $14 \%$ and of the relative yield $10 \%$.

v) For $\mathrm{Zn} \sigma_{7, \text { tar }}$ is not known.
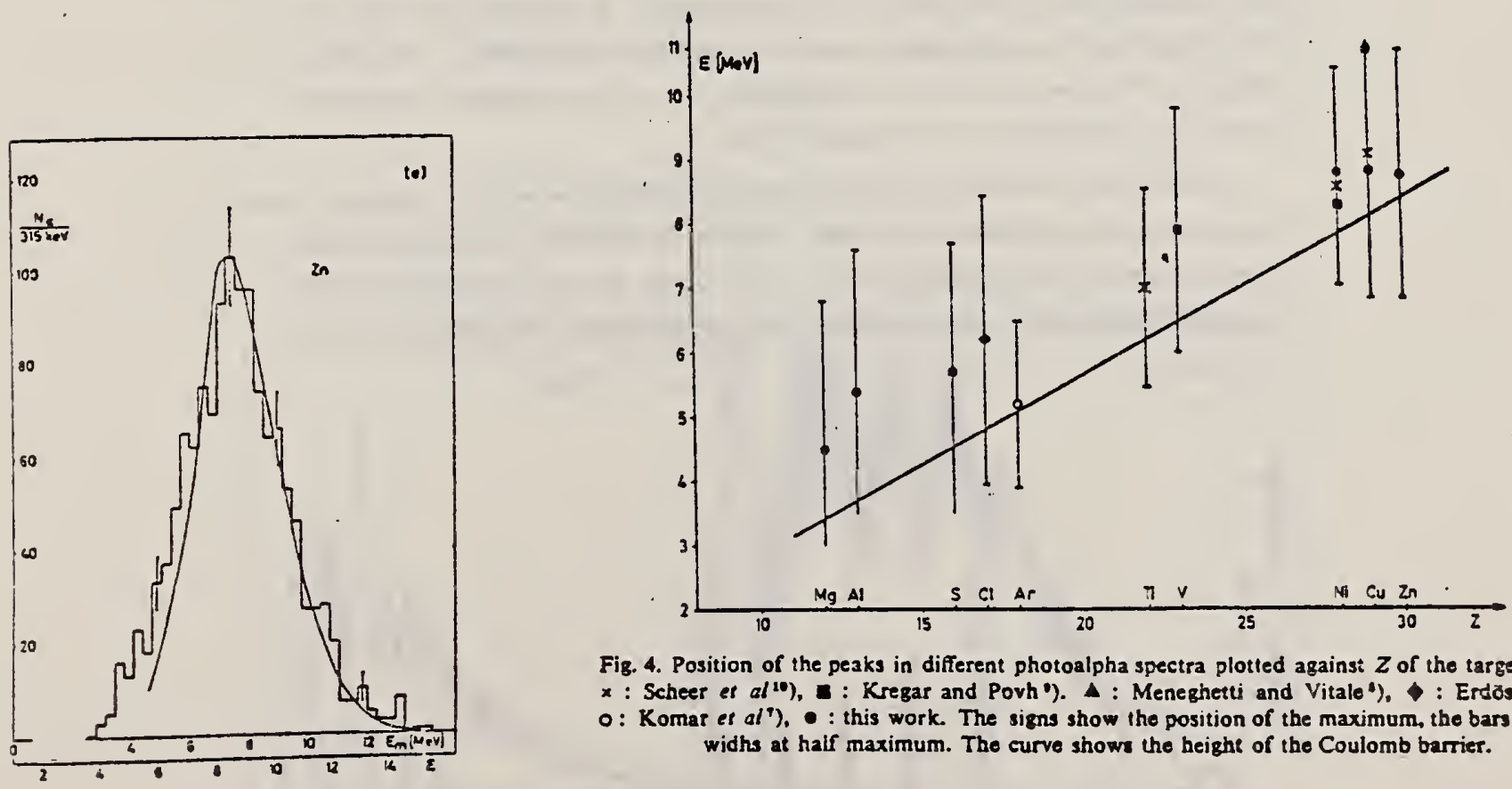

Fig. 4. Position of the peaks in different photoalpha spectra plotted against $Z$ of the target nuciei. $x$ : Scheer et al $\left.{ }^{10}\right)$, : : Kregar and Povh \%. $\Delta$ : Meneghetti and Vitale $\%$. : Erdos ef al ${ }^{1}$ ), 0 : Komar ef $\left.a l^{7}\right)$, - : this work. The signs show the position of the maximum, the bars give the widhs at half maximum. The curve shows the height of the Coulomb barrier.

Fig. 3d-e. Photoalpha spectra of $\mathrm{Ni}$ and $\mathrm{Zn}$. Notations as in fig. 3a-c.

Fig. 3r. Statistical plot of the measured spectra. The straight tines are drawn to give the best fit. 


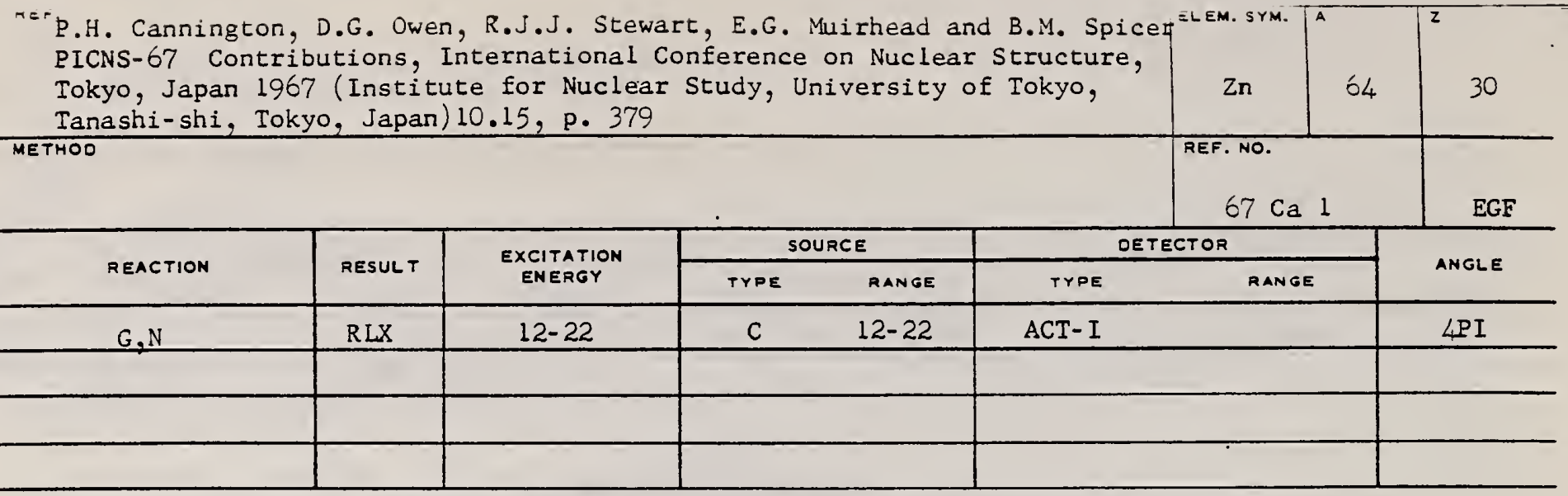

Experimental Measurentents of Vibretional Splittise of the Giant Dipole Reconence*

P. H. Canninpton, D. G. Awen, R.J.J. Stenart, E. G. Muistead and B. M. Spicar

Univeraity of Melboume, Australia

The yield eurve for the reaction $2 n^{64}(y, n)$ has been masured in 0.1 Mel stepe from threshold to $23 \mathrm{HeV}$, and that for Prith $(Y, \Omega)$ has been measured in 0.05 Mel stepe from threahold to $17.5 \mathrm{KeV}$. In both cases, the positron activity of the residual nucleus was datected by conting andhilation radiation. The cross sections were obtained from the yield curve by the Leise-Penfold method.

The cross section for the $2 n^{64}(Y, n)$ reaction is shown in Fig. 1. Also show are the predictions of Greiner ${ }^{1)}$, whose model considers the Goldhaber-Teller type dipole vibration, the low energy surface vibrations of spherical nuclei, and the coupling of these two vibrations. The predictions show only the enerpy, and inteprated absorption eross section for the severel triensitions.

The Prini $(r, n)$ cooss section is show in Fiz. 2, and the calculations of Huber ${ }^{2)}$ are shown in blocked form; their de'tail is the same as above. In this case, the surface vibration phanen enerzy was not so easily fixed as in the case of even-A $\mathrm{Zn}^{64}$. Mhere ware, in the case of $\mathrm{Fr}^{1 \mathrm{hl}}$, tho possible choices indicated by the low enersy spectre of neighbouring muclei. The mone suitable one is indicated in Fis. 2.

In both cases, the anount of strueture found experinentally exceds that predicted by the dipole-eurface vibration-interference mocil. However, by woreening the experinental resolvtion, the apreernent on be readily inproved. The surplus structure in both crose sections is aregumably due to single particle effects which are neglected in the nodel.

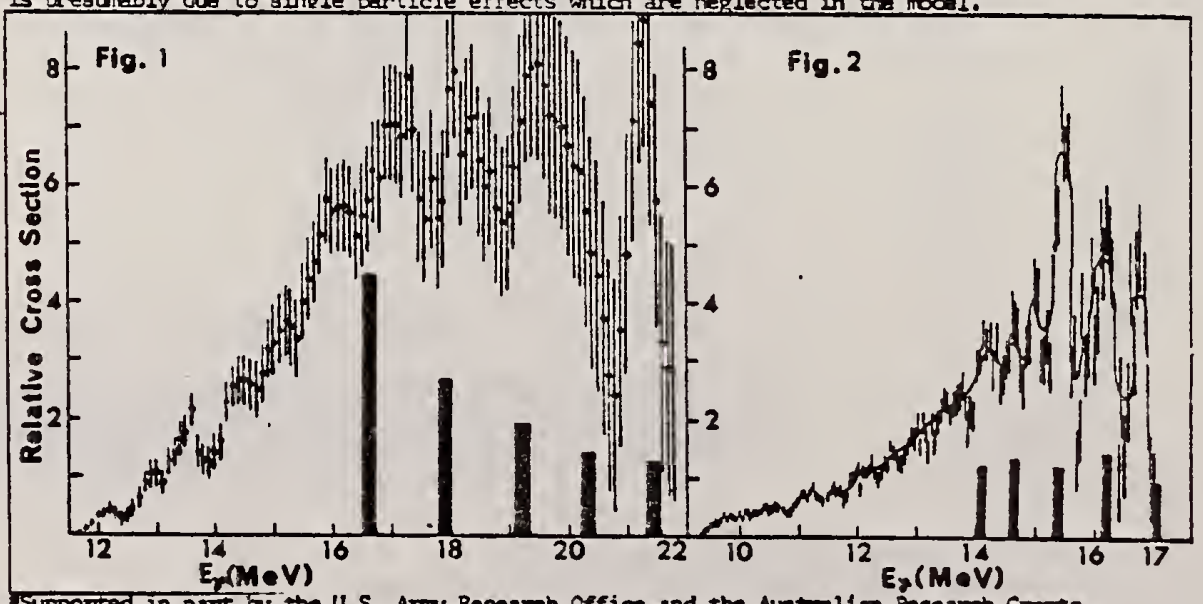

Supported in part by the U.S. Anmy Research Cffice and the Austrelfen Reseanch Gernts Conndtree.

Raferences: 1) W. Greiner, private commnication (1965).

2) M. Huber, private communication (1965). 
S. Costa, F. Ferrero, C. Manfredotti, L. Pasqualini and G. Piragino and $H$. Arenhovel

Nuovo Cimento $48 \mathrm{~B}, 461$ (1967)

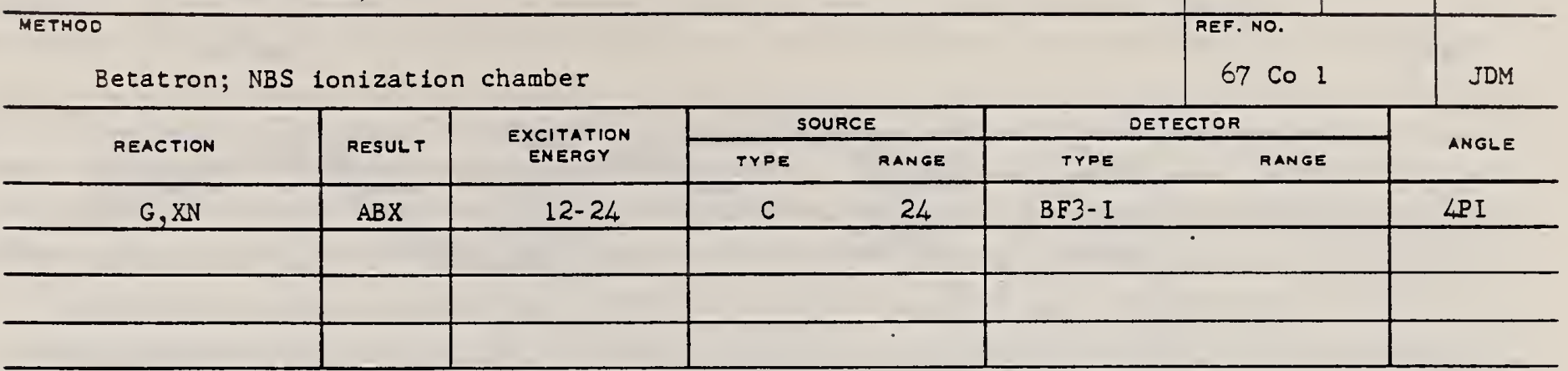

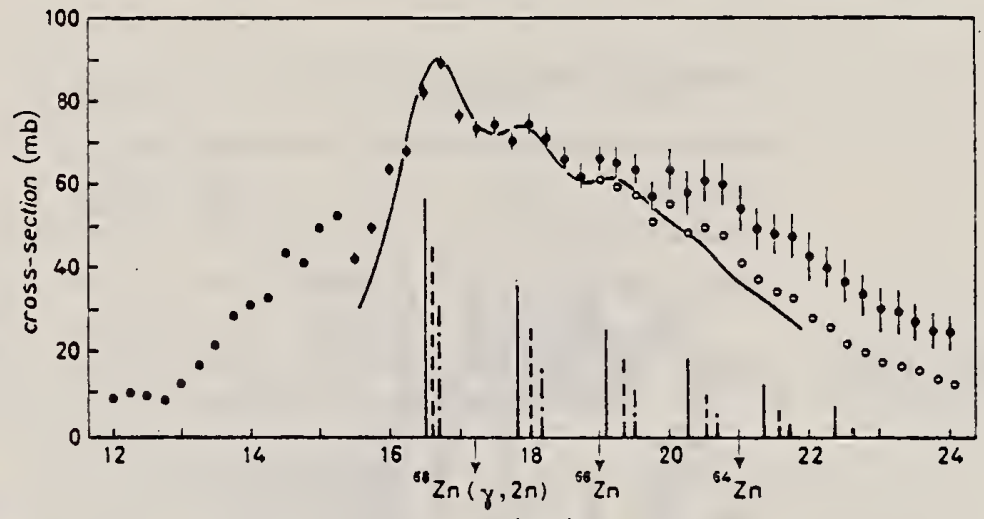

$\varepsilon_{1}$ (MeV)

Fis. 2. - $(\gamma, \mathrm{Tn})$ crose-geotion for, Zn. The vertical bars represent the dipole atrengths calculated for "Zo (-), "Zo (- - ) and "Zn (-,,--$)$. Open circles? give the $(\gamma, T n)$ crose-gection corrected for neutron multiplicity. The level deneity parameter used bas been taken trom ret. ("). 
REF. D. G. Owen, E. G. Muirhead and B. M. Spicer

Nucl. Phys. Al22, 177 (1968)

(177 (1968)

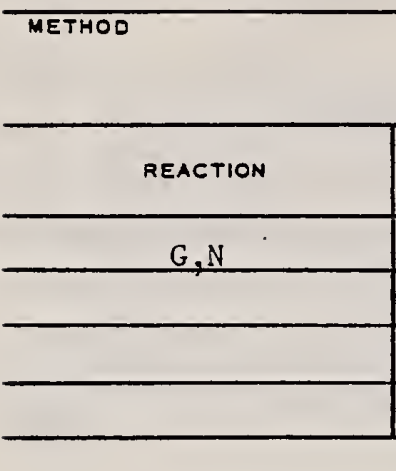

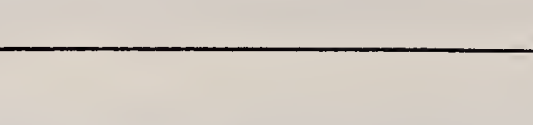

\begin{tabular}{c|c} 
RESULT & $\begin{array}{c}\text { EXCITATION } \\
\text { ENERGY }\end{array}$ \\
\hline RLX & $12-24$ \\
\hline & \\
\hline & \\
\hline
\end{tabular}

\begin{tabular}{|c|c|}
\hline \multicolumn{2}{|c|}{ SOURCE } \\
\hline TYPE & RANGE \\
\hline $\mathrm{C}$ & $10-24$ \\
\hline & \\
\hline & \\
\hline & \\
\hline
\end{tabular}

68 Ow 1

egf

\begin{tabular}{|c|c} 
ANGLE \\
\hline \\
\hline
\end{tabular}

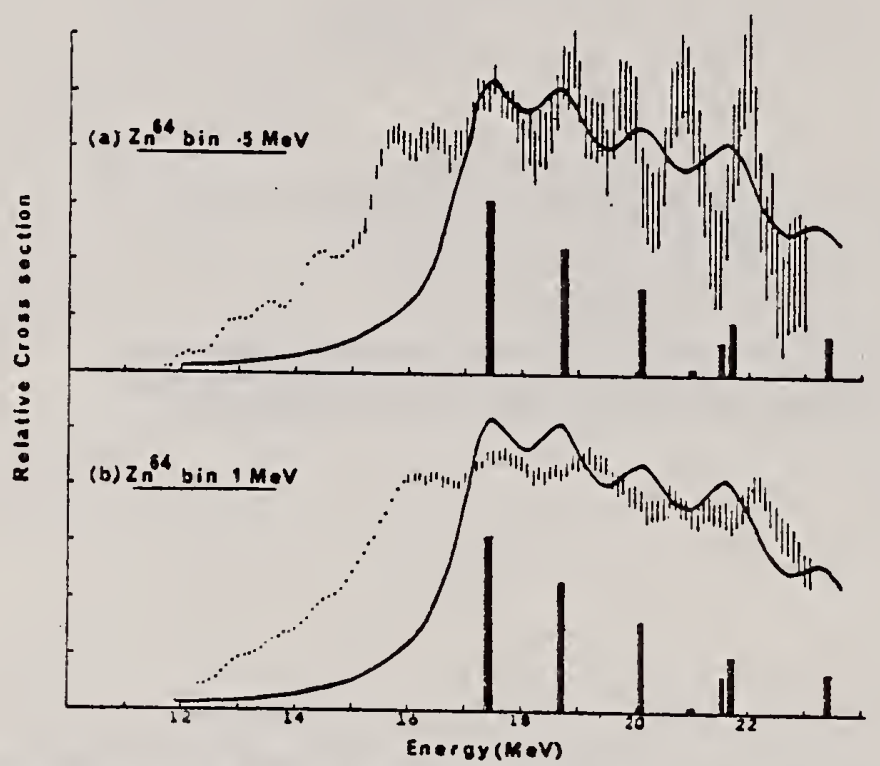

Fig. 1. The " $\mathrm{Zn}(\gamma, n)^{\omega 2} \mathrm{Zn}$ cross section analysed in (a) 0.5 and (b) $\perp \mathrm{MeV}$ bins. The errors shown represent the total experimental uncerainty in each point. The continuous curve is the shape of the "Zn photo-absorption cross section predicted by Huber 4 ) using the parameters in table 1 . The vertical bars represent the relative strengths of the individual theoretical levels. 
R. B. Begzhanov and S. M. Akhrarov

ZhETF Pis. Red. 10, 39 (1969)

JETP Letters 10,26 (1969)

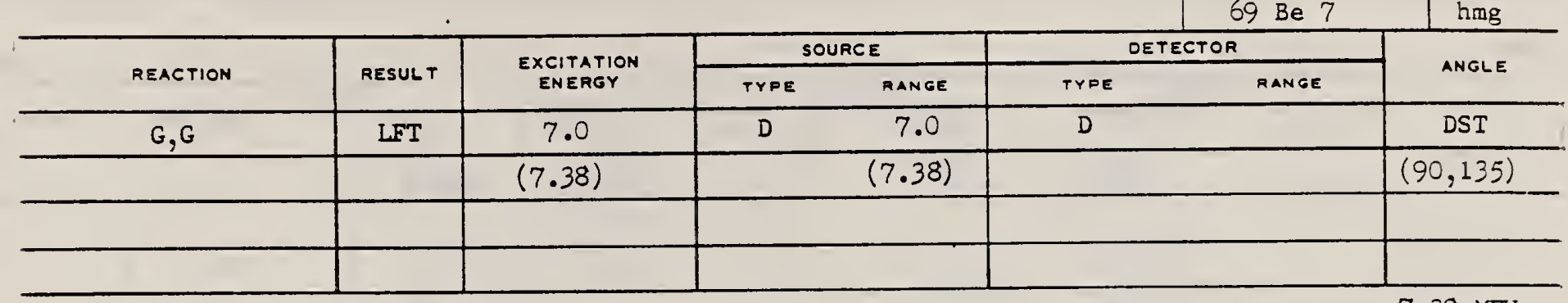

Self-Absorption.

Results of deterinination of the resonance-level peraneters

\begin{tabular}{|c|c|c|c|c|c|c|}
\hline & $\begin{array}{l}\text { Source- } \\
\text { atterer }\end{array}$ & ${ }_{\mathrm{MeV}}{ }^{\prime}$ & $\begin{array}{l}\left\langle a_{p p}\right\rangle \\
m b\end{array}$ & $\begin{array}{l}\Gamma_{y_{0}} \\
e^{\prime}\end{array}$ & $\begin{array}{c}D \\
k \in V\end{array}$ & Reference \\
\hline $\mathrm{Pb}$ & $-2 a^{64}$ & 7.38 & $3.3 \pm 4.5$ & $0.59 \div 0.12$ & $53.70 \pm 0.13$ & This work \\
\hline$\pi$ & - Mo96 & 6.513 & $11.2 \pm 1.4$ & $0.11=0.02$ & $8.58 \pm 1.57$ & $"$ \\
\hline$T i$ & - Le 139 & 5.41 .3 & $1504 \pm 2.10$ & $0.23 \pm 0.05$ & $8.9 .3 \pm 1.42$ & $"$ \\
\hline & $-8 i^{209}$ & 7.15 & $1200 \pm 230$ & $0.32 \pm 0.07$ & $1.34 \pm 0,40$ & $"$ \\
\hline & & 5.996 & 1550 & - & - & [1] \\
\hline & & 7.15 & $2600 \pm 800$ & $0.42 \pm 0.14$ & - & [3] \\
\hline & $-C_{u} 65$ & 6.07 & $423 \pm 108$ & $0.34 \pm 0.06$ & $99.1 \pm 17.4$ & Mals vork \\
\hline & & 5.07 & $440 \pm 130$ & $0.35 \pm 0.97$ & & \\
\hline & $-\mathrm{C}_{\mathrm{e}} 63$ & 6.07 & $215 \pm 71$ & $0.18 \pm 0.94$ & $57.14 \pm 12.7 \pi$ & This work \\
\hline & & 6.07 & $200 \pm 50$ & $0.15 \pm 0.9 .3$ & - & [6] \\
\hline & $\mathrm{Cr}_{0} \mathrm{~s}$ & 3.50 & $22 \pm 7$ & $0.25 \pm 0.08$ & $130 \pm 40$ & This vork \\
\hline & $C^{-}$ & $\begin{array}{l}8.499 \\
8.50\end{array}$ & $19 \pm 6$ & $0.28 \pm 0.09$ & - & $\cdot \begin{array}{l}{[1]} \\
{[5]}\end{array}$ \\
\hline & & 8.50 & $38 \pm 9$ & $0.47 \pm 0.10$ & $21.36 \pm 4.54$ & Ths work \\
\hline \multirow[t]{3}{*}{ c. } & $-\mathrm{Cs}^{65}$ & 8.499 & 80 & 10.5 & - & [1] \\
\hline & & 8.50 & $42 \pm 13$ & $0.94 \pm 0.29$ & - & [ค] \\
\hline & & 7.01 & $1150 \pm 240$ & $0.1 \dot{5} \pm 0.04$ & $0.44 \pm 0.12$ & This vork \\
\hline & & $\begin{array}{l}7.01 \\
7.01\end{array}$ & $\begin{array}{c}1000 \\
1200 \pm 400\end{array}$ & $0.3 \pm 0.3$ & - & [5] \\
\hline Hg & $\rightarrow M_{0} 96$ & 6.44 & $201 \pm 3 ?$ & $0.12 \pm 0.04$ & $|0.23 \pm 3.08|$ & This vork \\
\hline
\end{tabular}


Ref. V.D. Afanas'ev, N.G. Afanas'ev, A. Yu. Buki, G.A. Savitskii,

V.M. Khvastunov, N.G. Shevchenko

Yad. Fiz. 12, 885 (1970)

Sov. J. Nucl. Phys. 12, 480 (1971)

70 Af 1

\begin{tabular}{|c|c|c|} 
ELEM. SYM. & A & \\
Zn & 64 & 30 \\
REF. NO. & \\
70 Af 1 & $\mathrm{hmg}$ \\
\hline
\end{tabular}

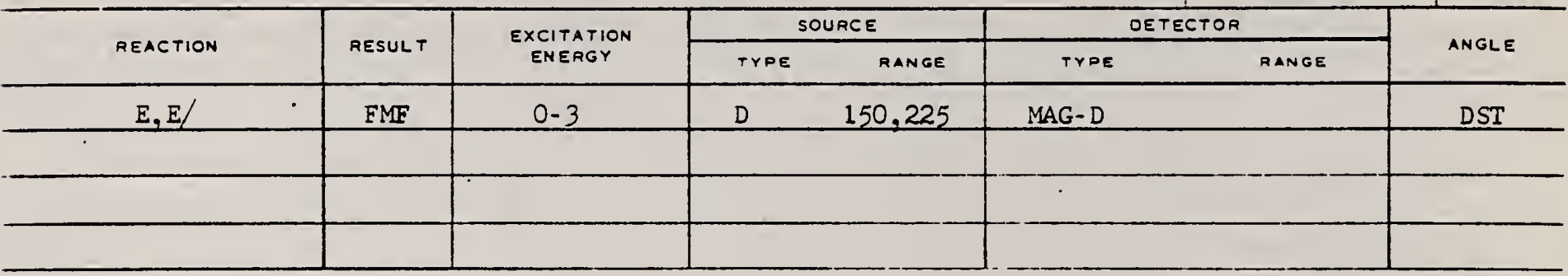
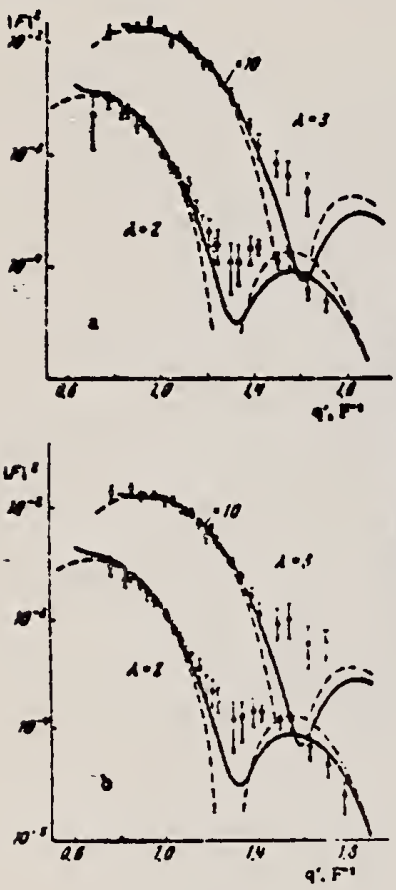

FIC. 2. Form factors of $E_{2}$ and $E_{3}$ transitions in $\mathrm{Zn}^{\circ+}(a)$ and $\mathrm{Zn}^{\text {ob }}$ (b). The solid curves pertain to the vibrational model with cat culations in the high-energy approximation; the dashed curves pertain to Heim's model with cat. culations in the Born approxima tion. The experimental values and curves for E3 transitions are en larged 10-rold. Point: $O-E_{0}$. $150 \mathrm{MeV}, 0-\mathrm{E}_{0}-225 \mathrm{MeV}$.
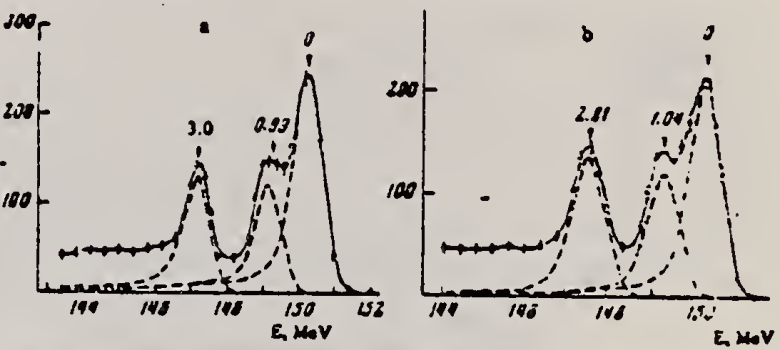

FIC. I. Spectra of clectrons scastesed by (a) $\mathrm{Zn}^{\infty}$ and (b) $\mathrm{Zn}^{\omega \infty}$ at $75^{\circ}\left(Z_{0}\right.$ - $\left.150 \mathrm{MoV}\right)$. Ordinates aro given in arbitrary units.

Table I. Reduced probabilities and fitting parameters $\mathrm{N}_{\lambda}$ and $\mathrm{B}_{\lambda}$ of $\mathrm{E2}$ and $\mathrm{E} 3$ transitions in $\mathrm{Zn}$ isotopes

\begin{tabular}{|c|c|c|c|c|c|c|c|c|}
\hline \multirow{2}{*}{$\frac{8}{\xi}$} & \multirow[b]{2}{*}{$\vec{z}$} & \multirow{2}{*}{10} & \multicolumn{2}{|c|}{ Vibretioned moded } & \multicolumn{2}{|c|}{ Hedre' a moded } & \multicolumn{2}{|c|}{ Oderer remils } \\
\hline & & & $x_{2} \cdot n$ & " (nx)! & $A_{2} \cdot 10$ & $"(x \leq) \mid$ & \begin{tabular}{|c|} 
O(F,R) \\
(expertimenou)
\end{tabular} & 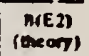 \\
\hline & $\{1.04$ & $2+5$ & & $1720+140$ & $0.546 \pm 0.01 \mathrm{n}$ & $1100 \pm x$ & $1000+160$ & $\operatorname{limple!~}_{1 \rightarrow 0 j}$ \\
\hline & |3.3 & $2 \cdot$ & $\begin{array}{l}0.070+0.003 \\
0.114+0.000 \\
0.070+0.000\end{array}$ & $\begin{array}{l}32300+2300 \\
1 \times 00 \pm 150 \\
23000+2400\end{array}$ & $\begin{array}{l}0.400+0.011 \\
0.557=0.017 \\
0.0 .013\end{array}$ & $\left\{\begin{array}{l}1000+150 \\
1530+74 \\
20300+150\end{array}\right.$ & $\begin{array}{r}1100 \\
1150\end{array}$ & 2000 1"1 \\
\hline
\end{tabular}

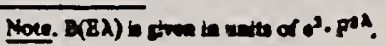

Table II. Parameters of the charge distribution in $\mathrm{Zn}$ lsotopes for the Fermi model and the Gaussian uniform model

\begin{tabular}{|c|c|c|c|c|}
\hline \multirow{2}{*}{ leoropen } & \multicolumn{2}{|c|}{ Fenend nodel } & \multicolumn{2}{|c|}{ Gessen uniform moded } \\
\hline & $a r$ & 48 & $x, p$ & ef \\
\hline $\begin{array}{l}2 n: 4 \\
2 n^{n}\end{array}$ & $\begin{array}{l}1.265+0.016 \\
1.291+0.022\end{array}$ & $\begin{array}{l}2.755+0.017 \\
2.803 \div 0.027\end{array}$ & $\begin{array}{l}4.500 \div 0.017 \\
1.509 \div 0.029\end{array}$ & $\begin{array}{l}0.211=0.015 \\
0.8 n=0.011\end{array}$ \\
\hline
\end{tabular}


REF. B.C. Cook, R.C. Morrison, and F.H. Schamber

Phys. Rev. Letters 25, 685 (1970)

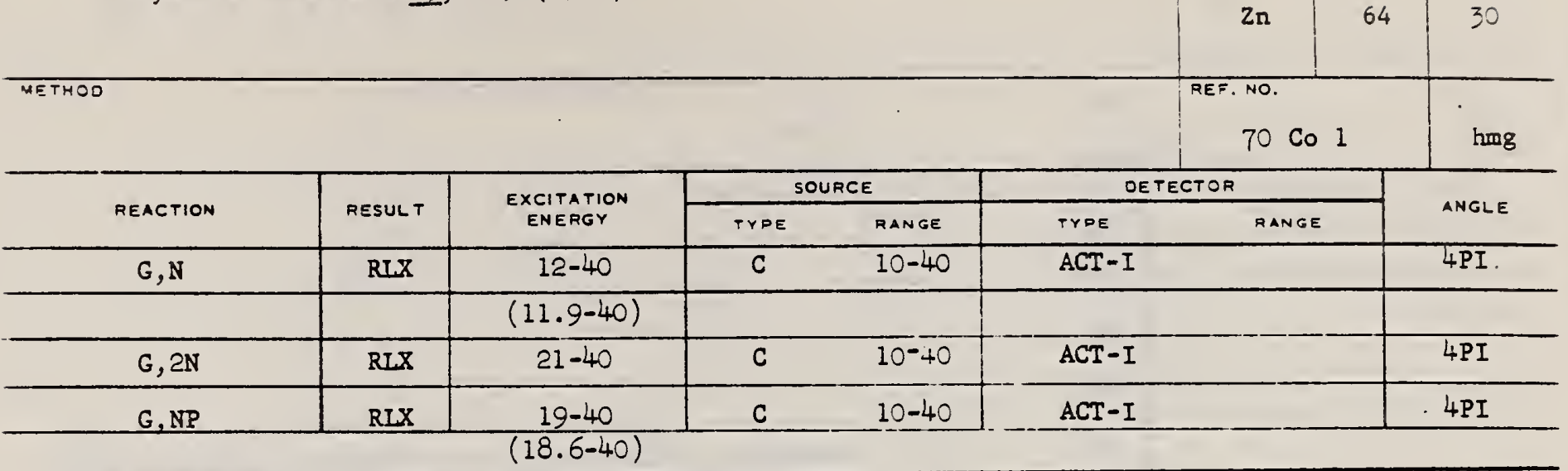

Abstract: The $(\gamma, n p)$ reaction is discussed as a probable channel for observation of the $\mathrm{T}=\mathrm{T}_{0}+1$ component of the giant dipole resonance, and experimental evidence is presented in support of this conjecture in the case of ${ }^{34} \mathrm{Zn}$.

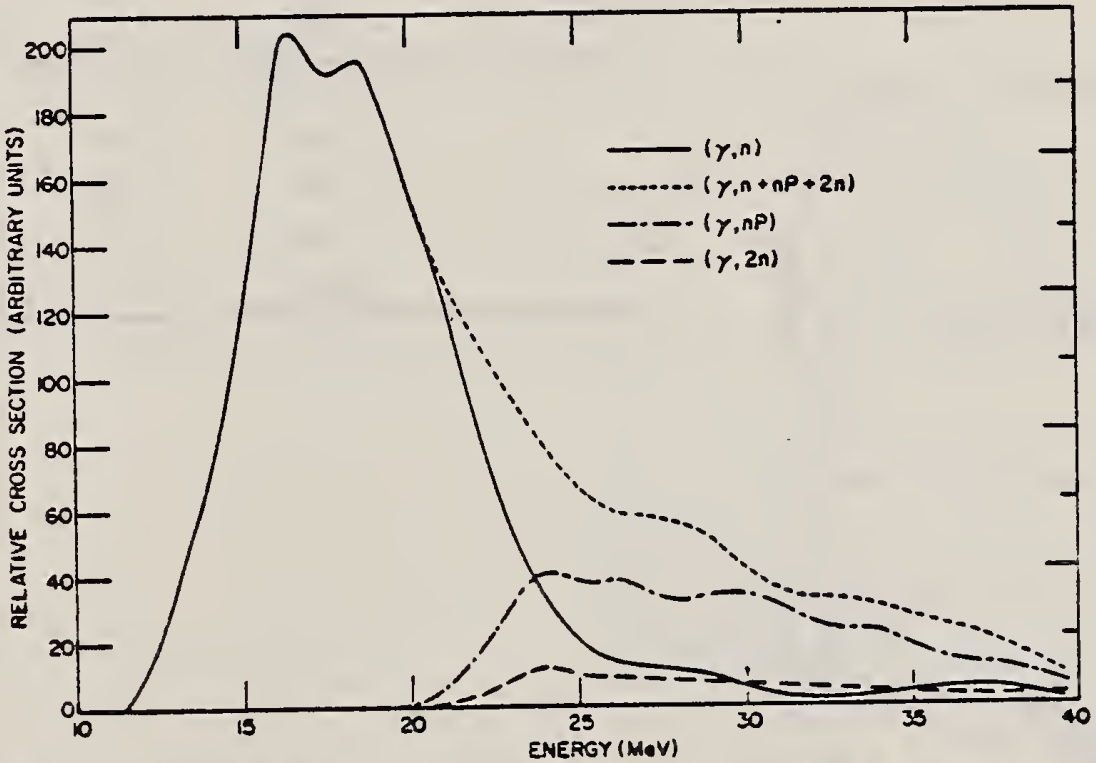

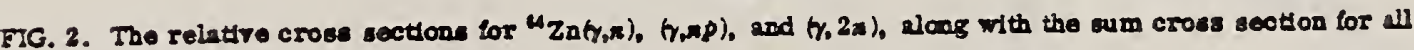
three reactlon. 


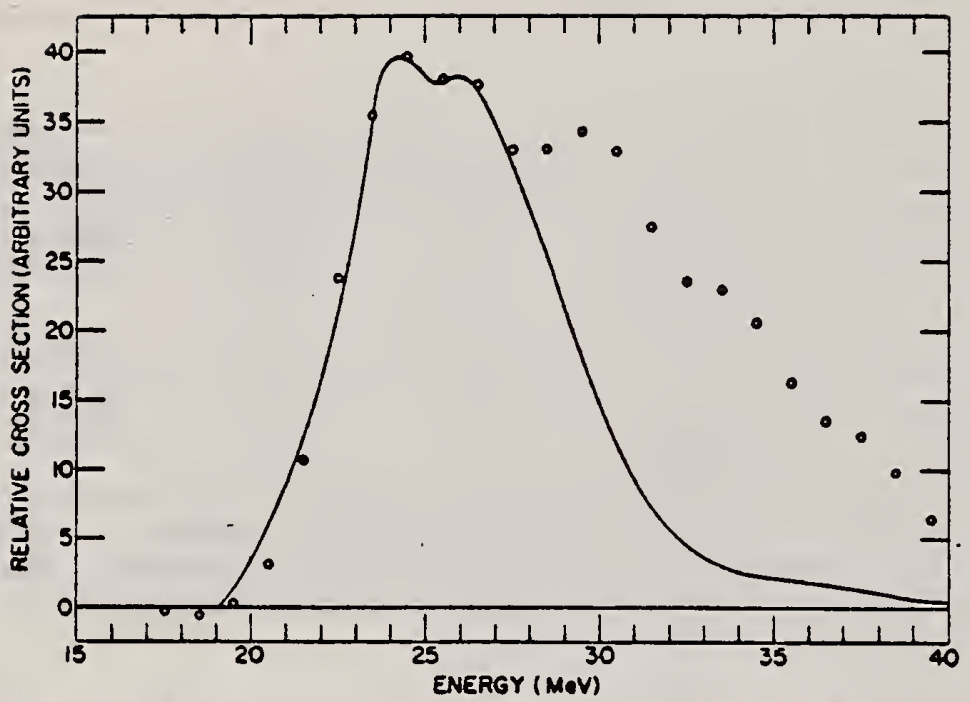

FIG. 3. The measured cross section for ${ }^{64} \mathrm{Zn}(\gamma, n p)^{62} \mathrm{Cu}$ (polnts). The solid curve is the measured $(\gamma, n)$ cross section shifted up in energy by $7.7 \mathrm{MeV}$ and multiplied by 0.196 . 


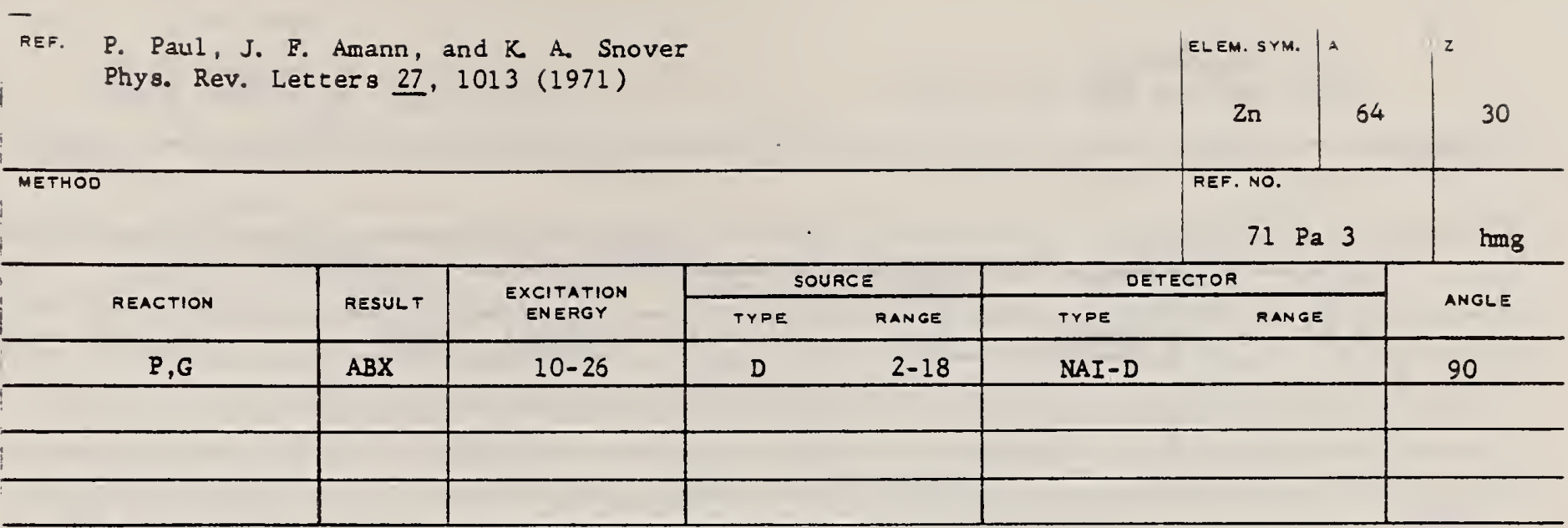

TABLE I. Separation energles $\triangle E=E>-E_{<}$of the $T+1$ and $T$ components of the GDR observed from proton capture into various nuclel with ground-state isospin $T$. P1s obtained from Eq. (2) in the text.

\begin{tabular}{|c|c|c|c|c|}
\hline Sucleus & $\Delta E(\mathrm{MeV})$ & $I$ & $V(\mathrm{MeV})$ & Rer. \\
\hline${ }^{42} \mathrm{Cs}$ & $3.0 \pm 0.2$ & 1 & $63: 4$ & 13 \\
\hline${ }^{49} \mathrm{se}$ & $4.8 \pm 0.2$ & $7 / 2$ & $52: 2$ & Present \\
\hline${ }^{60} 111$ & $3.0=0.2$ & 2 & $60 \pm 4$ & 5 \\
\hline${ }^{64} 20$ & $3.2 \pm 0.3$ & 2 & $68 \pm 6$ & Bresent \\
\hline $6420^{\circ}$ & $2.9=0.3$ & 2 & $62 \approx 6$ & Present \\
\hline${ }^{80} \mathrm{Sr}$ & $3.7 \pm 0.5$ & 6 & $47 \pm 6$ & $I$ \\
\hline $89 y$ & $3.9 \pm 0.5$ & $27 / 2$ & $54 \pm 7$ & 2 \\
\hline $89 y=$ & $3.8 \pm 0.4$ & $2 / 2$ & $52: 6$ & 2 \\
\hline${ }^{90} \mathrm{zr}$ & $.3 .9=0.5$ & 5 & $58: 7$ & 1 \\
\hline 91370 & $3.6 \pm 0.7$ & $9 / 2$ & $59 \pm 10$ & 2 \\
\hline
\end{tabular}

First excited stato.

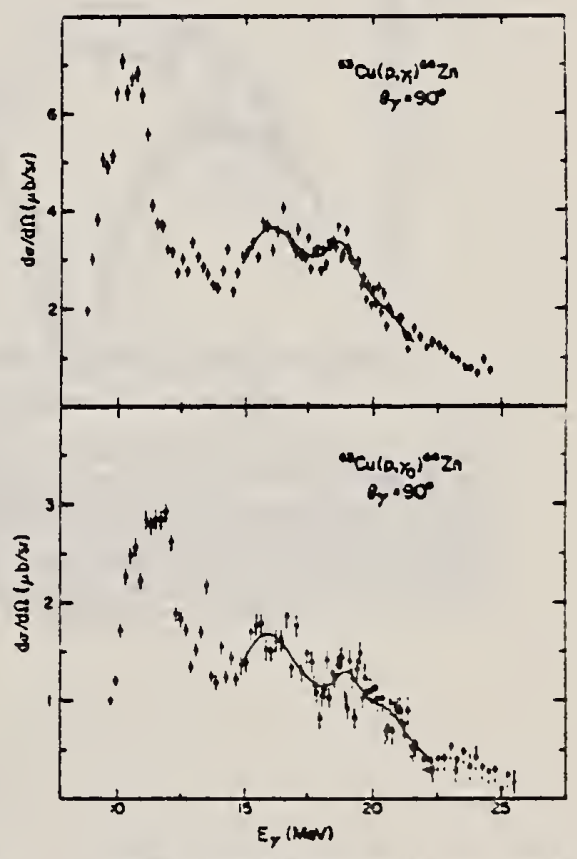

FIG. 2. Proton-capture Field curres for the groundstate $(\gamma d)$ and first-excited-stato $(\gamma)$ transitions in $\mathrm{H}_{\mathrm{Z}}$ plotted as a function of $\gamma$ ray soarzo. 
J. W. Lightbody Jr.

Phys. Letters 38B, 475 (1972)

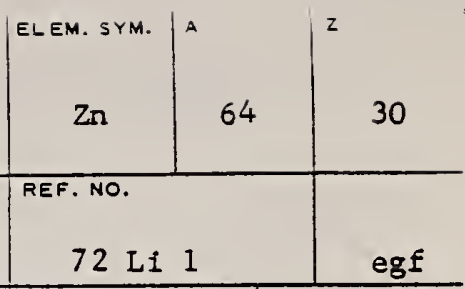

\section{.}

$72 \mathrm{Lil} \quad$ egf

\begin{tabular}{|c|c|c|c|c|c|c|c|}
\hline \multirow{2}{*}{ REACTION } & \multirow{2}{*}{ RESULT } & \multirow{2}{*}{$\begin{array}{l}\text { EXCITATION } \\
\text { ENERGY }\end{array}$} & \multicolumn{2}{|c|}{ SOURCE } & \multicolumn{2}{|c|}{ DETECTOR } & \multirow{2}{*}{ ANGLE } \\
\hline & & & TYFE & RANGE & TYFE & RANGE & \\
\hline $\mathrm{E}, \mathrm{E} /$ & FMF & $0-2$ & $\mathrm{D}$ & $60-120$ & $M A G-D$ & & DST \\
\hline & & & & & . & & \\
\hline
\end{tabular}

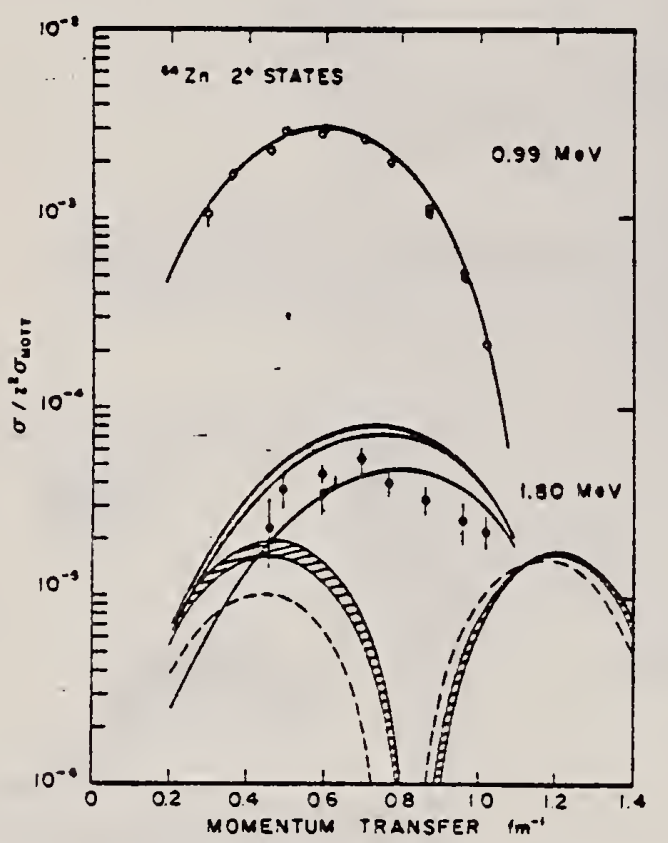

Fig. 3. Electron scattering form factors for the lowest two $2^{+}$states in ${ }^{64} \mathrm{Zn}$. Solld lines were calculated using $a$ best flt admixture and phase. The dashed line represents the harmonic two-phonon form factor. The shaded and cross-hatched reglons were determined by using admixtures which flt the measured $B R$ for $\Phi=$

$$
\pi \text { and } 0 \text {, respectively. }
$$


F. R. Metzger

Nuc1. Phys. A189, 409 (1972)

TABLE I

Properties of the $\mathrm{Zn}$ levels observed in the bremsstrahiung experiments

\begin{tabular}{|c|c|c|c|c|c|c|}
\hline Tuergy & lisotupe & Spin & Parity & $I_{\mathrm{o}} / I$ & $\Gamma_{0}(\mathrm{meV})$ & $\Gamma_{0} \cdot 0 .(\mathrm{meV})$ \\
\hline 3346 & $(68)$ & 1 & & $\left.(0.70)^{\circ}\right)$ & $42 \pm 7$ & $\left\{\begin{array}{l}19.4 \quad 10^{-4}(E 1) \\
0.061^{0.01)} \text { (MI) }\end{array}\right.$ \\
\hline $3: 66$ & 64 & 10 & $+\infty$ & $\left.0.54^{\mathrm{c}}\right)$ & $8.2=1.3$ & 0.012 \\
\hline 3 & 66 & 1 & $(+, \infty)$ & $0.69 \circ$ & $16=3$ & 0.022 \\
\hline$: 39$ & ind & $1 \%$ & 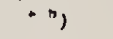 & $\left.0.72^{\circ}\right)$ & $6.9=1.6$ & 0.109 \\
\hline$\therefore: 3$ & $(66)$ & (1) (.) & $(-, \cdot)$ & $0.51^{\bullet}$ & $8 \div 3$ & $1.7 \quad 10^{-4}$ \\
\hline $2-144$ & at & 1 & 101 & $\left.(1.0)^{\prime}\right)$ & $18=3$ & $3=10^{-4}$ \\
\hline$:-1 ;$ & $(68)$ & (1) & & $\left.(1.0)^{\prime}\right)$ & $8.5 \pm 2.2$ & $\begin{cases}1.5,10^{--4}(\mathrm{El}) \\
0.009 \text { (MI) }\end{cases}$ \\
\hline$\$ 734$ & 66 & 1 & $(-)$ & $\left.(1.0)^{\prime}\right)$ & $24=3$ & $4.1,10^{-4}$ \\
\hline$+1 \leqslant 9$ & 64 & 1 & $(-)$ & $(0.54)$ & $32=9$ & $4.0 \cdot 10^{-4}$ \\
\hline+295 & 66 & 10 & $(*)$ & $\left.0.60^{\circ}\right)$ & $67=20$ & 0.046 \\
\hline+139 & (68) & (1) & & $\left.(1.0)^{\prime}\right)$ & $38=10$ & $\begin{array}{l}14.21^{10^{-4}}(\mathrm{EI}) \\
10.025^{\prime} \text { (MI) }\end{array}$ \\
\hline$\$ 426$ & 66 & 1 & $(-)$ & (1.0)') & $65=10$ & $6.8 \cdot 10^{-2}$ \\
\hline+455 & 64 & $1 " 1$ & -0 & $(1.0)^{(n, n)}$ & $51 \quad \therefore 9$ & 0.031 \\
\hline Hh: & 66 & $1 \bullet$ & $\left.(+)^{-0.1}\right)$ & $\left.0.29^{\circ}\right)$ & $28=21$ & i). 017 \\
\hline $146 n$ & $(68)$ & 1 & & (1.0)') & $65 \pm 19$ & $\begin{array}{l}6.510^{--}, 1,1 \\
0.040 \quad(\mathrm{Wi})\end{array}$ \\
\hline+503 & (68) & (1) & & $\left.(1.0)^{\prime}\right)$ & $38=-13$ & $\begin{array}{l}13.6 \cdot 10^{-4}(21) \\
10.023 \text { (ख1) }\end{array}$ \\
\hline 4609 & (66) & (1) & & $\left.(1.0)^{\prime}\right)$ & $54=15$ & $\begin{array}{l}15.0 \times 10^{-4} \text { (12) } \\
10.030 \text { (ख) }\end{array}$ \\
\hline 4664 & (64) & (1) & & (1.0)' & $11=4$ & $\left\{\begin{array}{l}1.0,10^{-4}(E 1) \\
0.006 \quad(\mathrm{N1})\end{array}\right.$ \\
\hline 4685 & (66) & (1) & & $\left.(1.0)^{\prime}\right)$ & $64=16$ & $\begin{cases}5.6 \times 10^{-\triangleleft} & (E 1) \\
0.034 & (. M 1)\end{cases}$ \\
\hline 4806 & (66) & (•) & $\tau^{-1)}$ & $\left.0.81^{\bullet}\right)$ & $100=25$ & 0.049 \\
\hline
\end{tabular}

-, Based on ref. "), see text.

-, Rci.',

$\rightarrow$ Re: ${ }^{12}$ ).

अ, Ret. ').

e) Ref. ${ }^{10}$ \%

1) Assumed in the aosence of evidence for branching.

1) Assuming that the branch to the $2_{1}^{*}$ state, seen in the bremsstrahiung experiment, is the oniy orar.ch to an excited state.

-) Refs. 11,12 ) contradict each other with respect to this branching.

1) Ref. ${ }^{10}$ ) favors a (-) assignment. See text. 
i) H. Veihcul, Nucl. Data B2-3 (196i) 65

a) M. :. Martin and M. X. Ran, Nuei. Datd B2-n,iytmi ij

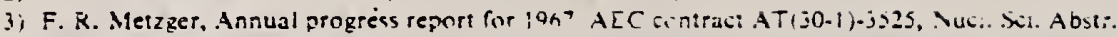
$\therefore-7661,1968$

t) F. R. Metzger, Annual progress report for 1968, AEC contract AT(30-1)-3525, Nucl. Sci. Abstr. $23.15411,1969$

5) F. R. Metzger, Phys. Rev. Lett. 18 (1967) 434: Phys. Rev. 171 (1968) 1257;

II. Berman and G. B. Beard, Phys. Rev. C2 (1970) ISO6:

W. Schumacher, J. Weiss and H. Langhotf, Phys. Lett 318 (1969) 61 :

H. Langhoff, Phys. Rev. A3 (1971) I

6) F. R. Metzger. Phys. Rev. 187 11969) 1680, 1700: Vucl. Phys. A182 (1972) 213

7) F. R. Metzger, Nucl. Phys. A158 (1970) 8.8

3) R. P. Singh and M. L. Rustgi. Phys. Rev. C3 $(1971): 1172$

9) H. Ottmar, N. M. Ahmed, U. Fanger, D. Hech, W. Mictedelis and H. Schmidt, Nuil. Phys. Al6t (:9?:) 69

0) D. C. Camp and G. L. Meredith, Nucl. Phys. Al66:197i, j49

ii) J. Konijn, R. van Lieshout, J. P. Deutsch dnd L. Grerises, Nucl. Phys. A91 (1967) 459

12) L. G. Mann. K. G. Tirsell and S. D. Bloum, Nuci. Phys. 197 (1967) 425 
HEF. G.E Clark, R. C. Morrison, J.E.E. Baglin, B. C. Cook Nucl. Phys. A213, 358 (1973)

\begin{tabular}{|c|c|c|c|c|c|c|c|}
\hline METHOO & & & & & & $\begin{array}{l}\text { REF. NO. } \\
73 \mathrm{Cl} 6\end{array}$ & egf \\
\hline \multirow{2}{*}{ REACTION } & \multirow{2}{*}{ RESUL T } & \multirow{2}{*}{$\begin{array}{l}\text { EXCITATION } \\
\text { ENERGY }\end{array}$} & \multicolumn{2}{|c|}{ SOURCE } & \multicolumn{2}{|c|}{ DETECTOR } & \multirow{2}{*}{ ANGLE } \\
\hline & & & TYPE & RANGE & TYPE & RANGE & \\
\hline$G, X P$ & $A B X$ & $8-26$ & & $15-26$ & SCD-D & & DST \\
\hline & & & & & & - & \\
\hline & & & & & & & \\
\hline
\end{tabular}

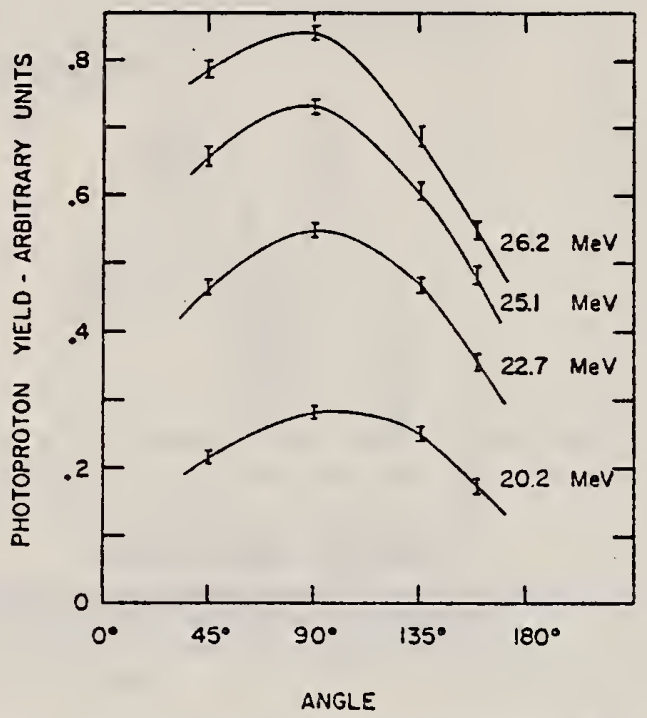

Fig. 3. Angular distributions of protons with energies greater than $8 \mathrm{MeV}$, for several bremsitrahlung end-point energies.

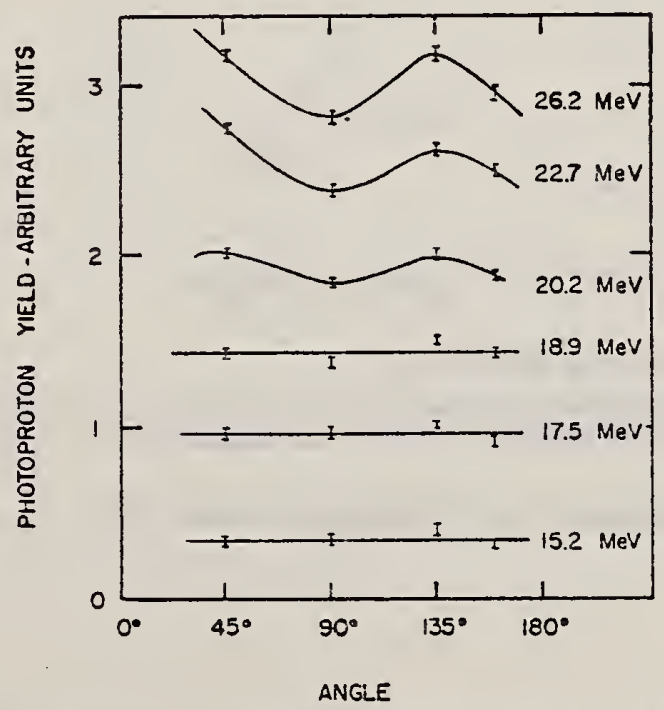

Fig. 4. Angular distributions of protons with energies between 4 and $8 \mathrm{MeV}$, for several bremsstrahlung end-point energies. 


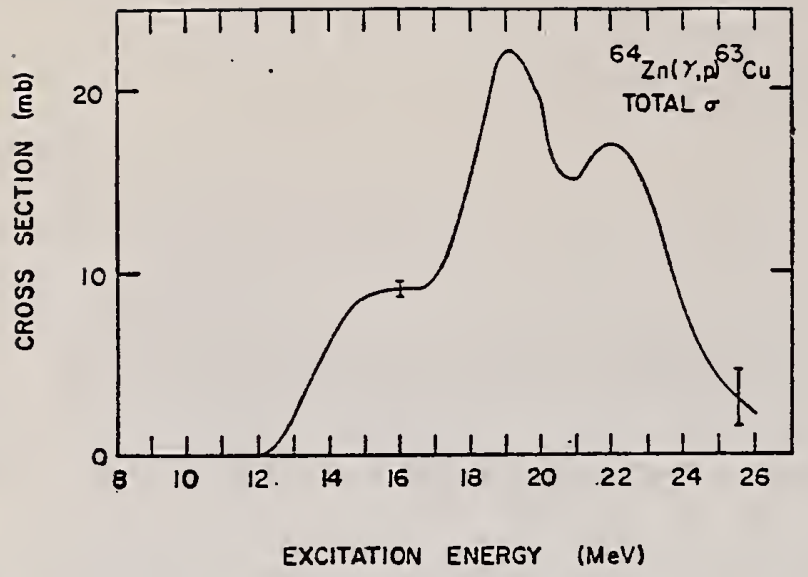

Fig. 6. Total cross section for production of photoprotons with energies above $4 \mathrm{MeV}$.

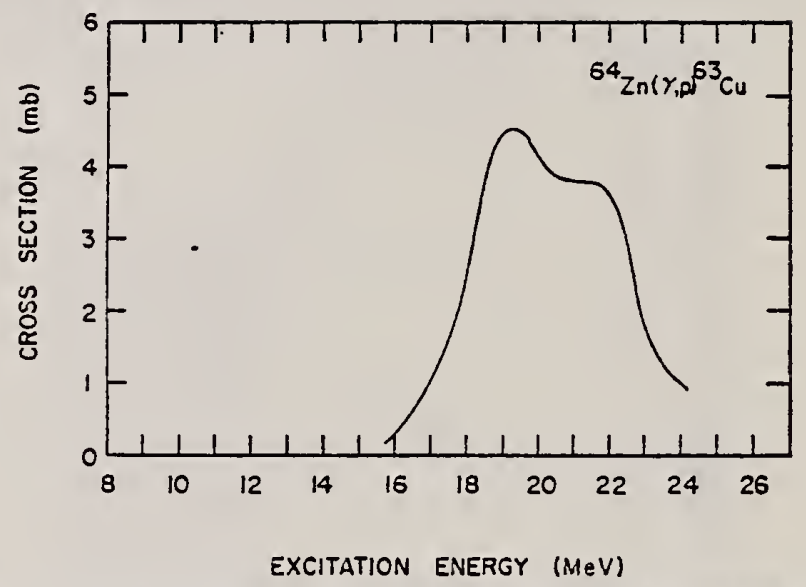

Fig. 7. Total cross section for production of photoprotons with energies above $8 \mathrm{MeV}$.

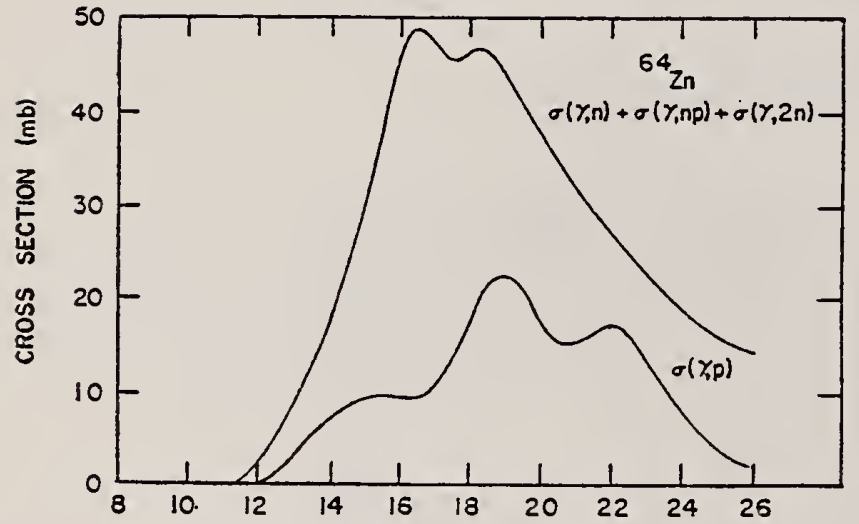

EXCITATION ENERGY (MeV)

Fig. \&. The ${ }^{6+} \mathrm{Zn}$ photoproton cross section of this work, and the sum of the $(\gamma, \pi),(\gamma, p),(\gamma, 2 \pi)$ and $(\gamma, \mathrm{np})$ cross sections obtained by Schamber and co-workers $\left.{ }^{8 .}{ }^{9}\right)$.

9 B. C. Cook, R. C. Morr1son, F.H. Schamber, Phys. Rev. Lett. 25, 085 (1970). 


\begin{tabular}{|c|c|c|c|c|c|c|c|}
\hline METHOO & & & & & & $\begin{array}{l}\text { REF. NO. } \\
73 \text { De } 3\end{array}$ & hmg \\
\hline \multirow[b]{2}{*}{ REACTION } & \multirow[b]{2}{*}{ RESULT } & \multirow{2}{*}{$\begin{array}{l}\text { EXCITATION } \\
\text { ENERGY }\end{array}$} & & & \multicolumn{2}{|c|}{ DETECTOR } & \multirow{2}{*}{ ANGLE } \\
\hline & & & TYPE & $\overline{\text { RANGE }}$ & TYPE & RANGE & \\
\hline \multirow[t]{2}{*}{$G, N$} & RLX & $20-22$ & D & $20-22$ & $A C T-I$ & & 90 \\
\hline & & $(20.43-21.94)$ & & & & & \\
\hline & & & & & & & \\
\hline & & & & & & & \\
\hline
\end{tabular}

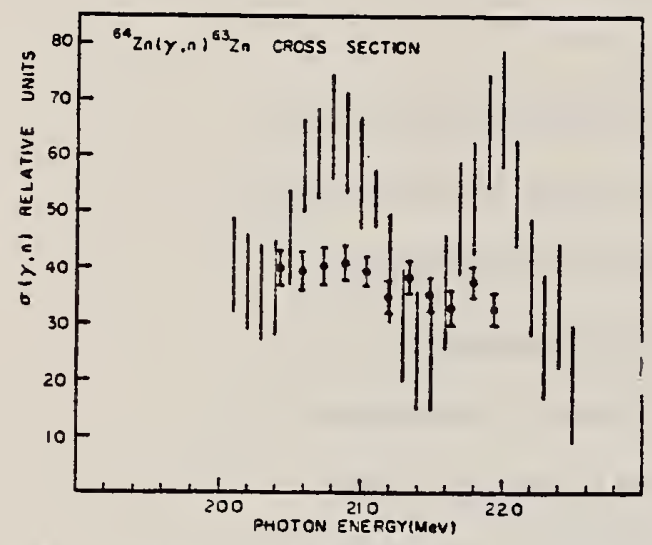

Fig. 1. Relative cross section of the ${ }^{64} \mathrm{Zn}(\gamma, n)^{63} \mathrm{Zn}$ reaction. The dots represent the results of this experiment and the vertical lines the results of Owen et al. (1968) analyzed in $0.5 \mathrm{MeV}$ bins.

Owen et a1. Nucl. Phys. A122, 177 (1908). 
REF. W. Del Blanco, S. Kundu, and P. Boucher

PICNS-73, Vol.I, p. 537 As1lomar

METHOO

an

REF. NO

73 De 8

\begin{tabular}{|c|c|c|c|c|c|c|c|}
\hline \multirow{2}{*}{ REACTION } & \multirow{2}{*}{ RESULT } & \multirow{2}{*}{$\begin{array}{c}\text { EXCITATION } \\
\text { ENERGY }\end{array}$} & \multicolumn{2}{|c|}{ SOURCE } & \multicolumn{2}{|c|}{ DETECTOR } & \multirow{2}{*}{ ANGLE } \\
\hline & & & TYPE & RANGE & TYPE & RANGE & \\
\hline $\mathbf{G}, \mathbf{N}$ & $A B X$ & $20-22$ & & $20-22$ & ACT-I & & $4 \mathrm{PI}$ \\
\hline$\cdot$ & & & . & & & & \\
\hline & & & & & & & \\
\hline & & & & & & & \\
\hline
\end{tabular}

The measurement of $(\gamma, \pi)$ cross sections in spherical medium weight nuclei is of great interest for determining the coupling of low energy surface vibrations and high energy dipole oscillations. The coupling has been theoretically investigated by Huber et al. ${ }^{1)}$ and found to result in a considerable splitting of the photonuclear resonance. Experimentally bremsstrahlung measurements have indicated a pronounced structure in $(\gamma, n)$ cross sections 2,3$)$ which is not present in measurements with $y$-rays from positron annihilation in light 4,5$)$. In this experiment a photoactivation method and monochromatic $\gamma$-rays from the ${ }^{3} H(p, \gamma)^{4}$ He reaction were employed to measure the $(\gamma, n)$ cross section for ${ }^{50} \mathrm{Cr}$ and ${ }^{64} \mathrm{Zn}$. The $\gamma-\mathrm{rays}$ were monitored by a $\mathrm{NaI}(\mathrm{T} l)$ crystal enclosed in a lead and paraffin shield to reduce background radiation. The positron activity was determined by a coincidence detector consisting of two NaI(T $)$ crystals set on the annihilation radiation photopeaks. The $\gamma$-ray energy was varied in steps of $150 \mathrm{keV}$ from 20.43 to $\approx 22.2 \mathrm{MeV}$ and the energy resolution was less than $110 \mathrm{keV}$ over the entire energy range. The experimental cross sections of the two reactions were found to vary smoothly as a function of energy. The results for the ${ }^{64} \mathrm{Zn}(\gamma, n)$ process do not agree with those of Owen et al. ${ }^{2)}$, who observed two resonances $\approx 0.5$ to $1 \mathrm{MeV}$ wide in the same energy range. The shape of the ${ }^{50} \mathrm{Cr}$ $(\gamma, n)$ cross section is in fair agreement with the calculation of Huber et al. ${ }^{1)}$ for widths of the dipole states of the order of $3 \mathrm{MeV}$.

(over) 
1) M.G. Huber, M. Danos, H. Weber and W. Greiner, Phys. Rev. 155, 1073(1967).

2) D.G. Owen, E.G. Muirhead and B.M. Spicer, Nucl. Phys. A122, $177(1968)$.

3) P.H. Cannington, R:J. Stewart and B.M. Spicer, Nucl. Phýs. Al00, 385(1968).

4) R.L. Bramblett, J.T. Caldwell, B.L. Berman, R.R. Harvey and S.C. Fultz, Phys. Rev. 148, 1198 (1966).

5) R.E. Sund, V.V. Verbinki, H. Weber and L.A. Kull, Phys. Rev. C2, 1129 (1970). 
.

$\mid$\begin{tabular}{r|r} 
EL EM. SYM. \\
$2 \pi$
\end{tabular}

$\mathrm{n}$

$73 \mathrm{Ne} 4$

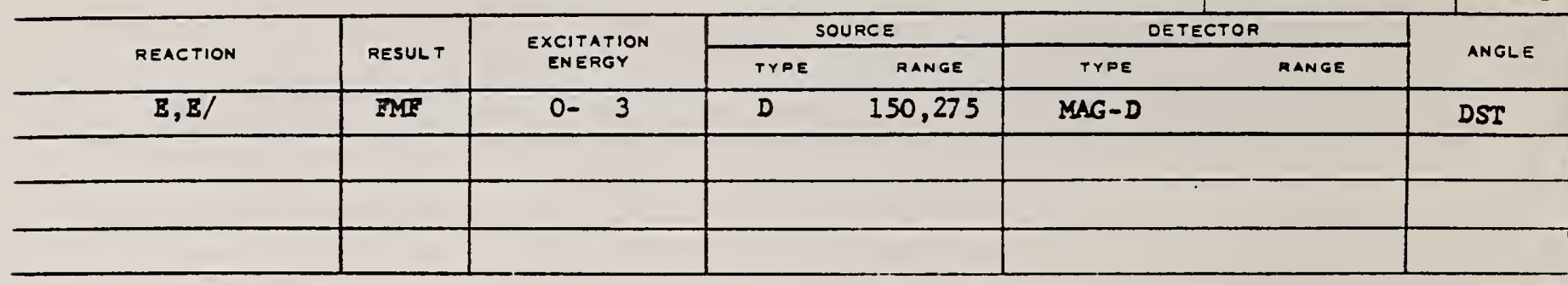

$\int \frac{d \sigma / d \Omega}{(d \sigma / d \Omega)_{\text {Mott }}}$

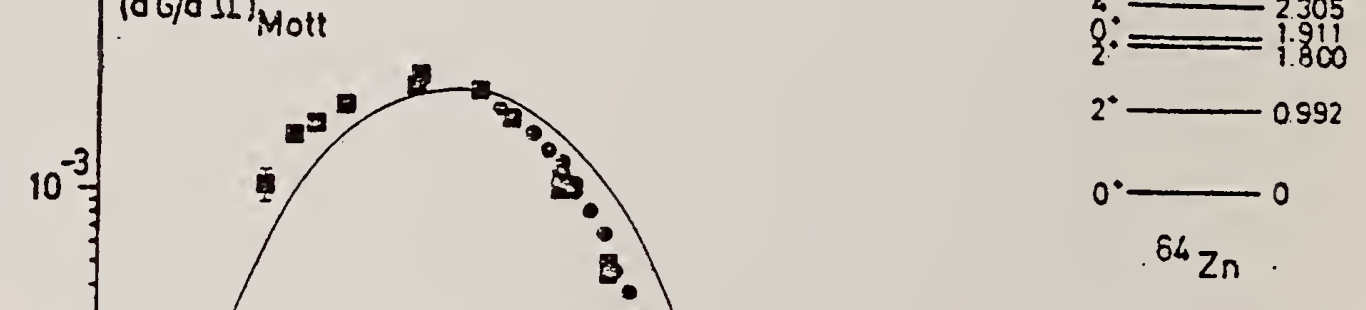

$4^{\circ}=2.305$

$C_{2}\left(2_{i}^{+}\right)$

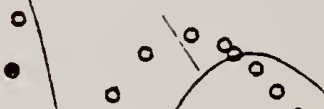

:

$C 2(2+)$

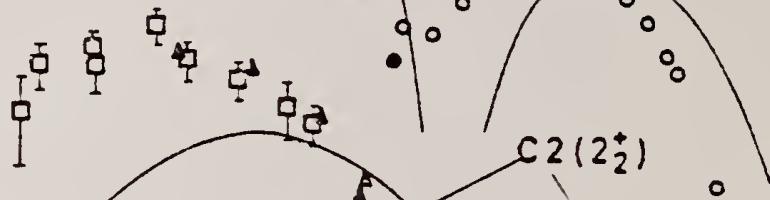

10
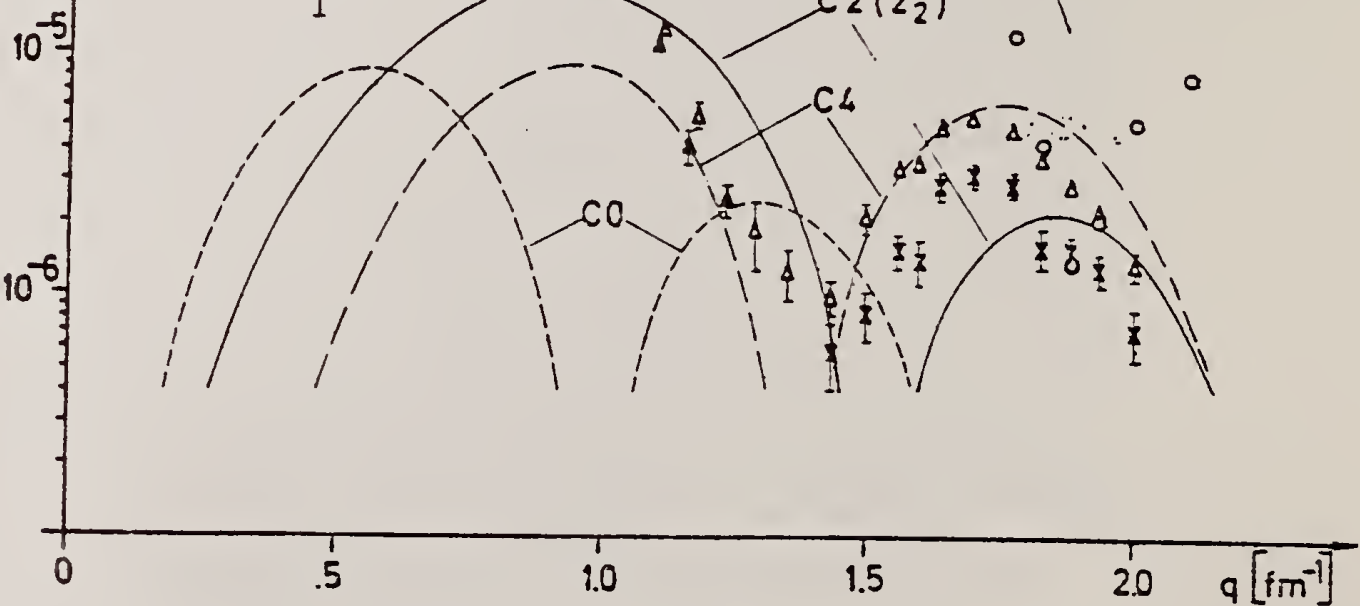

Fig. 1: Form factors for the transitions to the $2_{1}^{+}, 2_{2}^{+}$and $4_{2}^{+}$states in ${ }^{64} \mathrm{Zn}$.

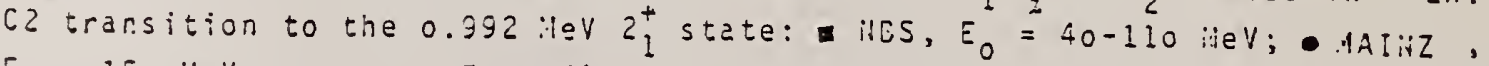
$E_{0}=150 \mathrm{ieV} ; 0 \mathrm{i} A I: I z, E_{0}=275 \mathrm{ieV}$. C2 transition to the 1.300 ieV $2_{2}^{+}$state: (over) 
References:

1) H. Ehrenberg, et. al.; Nucl. Instr. and Meth. 105 (1972) 253

2) R. Ueunausen, S.P. Fivozinsky, J. W. Lightbody, Jr. and S. Penner; Bul]. Am. Phys. Soc. 15 (1970) 501

3) S. Penner, et. al.; Froc. of the Int. Conf. on ilucl. Structure; Sendai 1972

4) H. Herminghaus and $H$. Kaiser; to be publisher

5) E. Borie, D. Drechsel, and K. Lezuo; Contribution to the Int. Conf. on Photonuclear Reactions anc Applications; Asilomar; 1973 


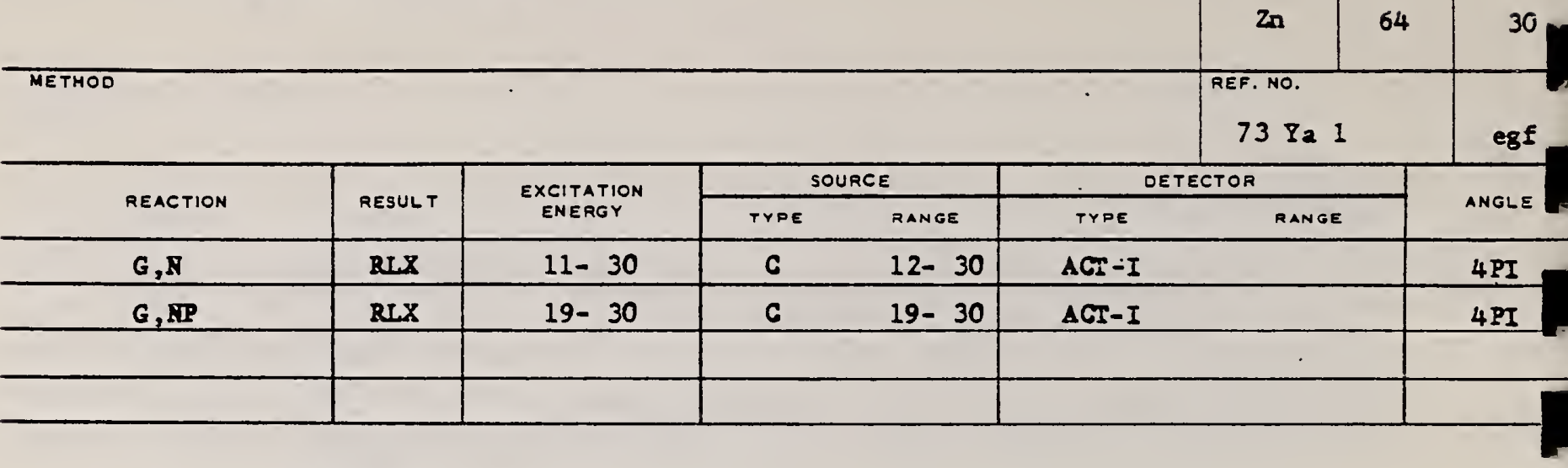

Rat10 $\frac{\sigma_{0}(30)(\gamma, n p)}{\sigma_{0}(30)(\gamma, n)}=0: 23$

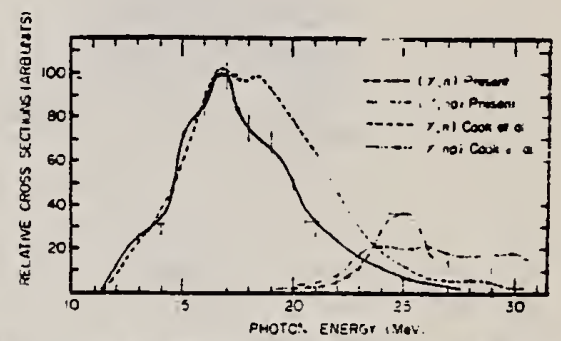

Fig. 2. The relative cross section curves for th. u $Z n(r, n)$ and $(r, n p)$ along with the corresponding results of ref. 17

17 B.C. Cook et al., Phys. Rev. Letters 25, 685 (1970). 
REF. A.M. Goryachev, G.N. Zalesnyi, and B.A. Tulupov Izv. Akad. Nauk SSSR. Ser. Fiz. 39, 134 (1975)

Bull. Acad. Sci. USSR Phys. Ser. 39, 116 (1975)

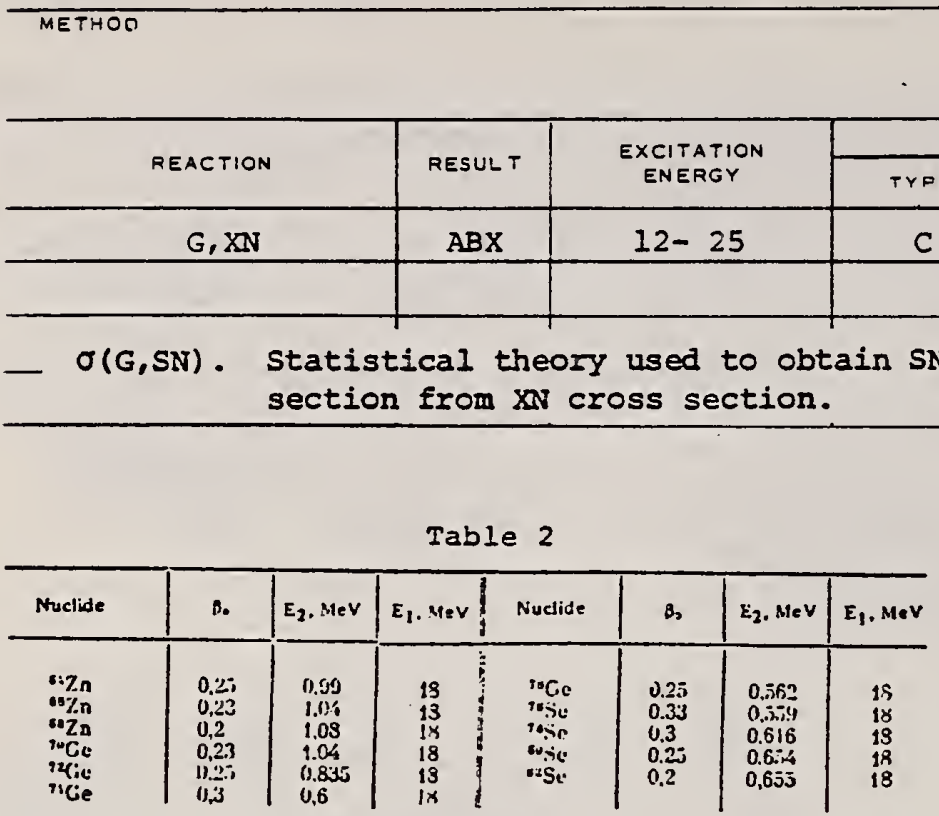

Table 3

\begin{tabular}{|c|c|c|c|c|c|}
\hline Nuclide & $0, \mathrm{mb}$ & Nuclide & $0, \mathrm{mb}$ & Nuclide & $a, \mathrm{mb}$ \\
\hline $\begin{array}{l}: \mathrm{Zn}_{n} \\
: \mathrm{Zn}_{n} \\
: \mathrm{Zn}_{n} \\
{ }^{\prime} \mathrm{Ce}\end{array}$ & 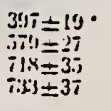 & 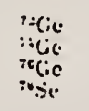 & $\begin{array}{l}i c 0 \pm 3 i \\
8 i 2 \pm 41 \\
1 ! 1 \pm 13 \\
930 \pm \overline{0}\end{array}$ & 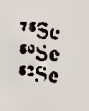 & $\begin{array}{l}1021 \pm=02 \\
1020=50 \\
1667 \pm 53\end{array}$ \\
\hline
\end{tabular}

- Slean - square ersors

$$
\text { -....... }
$$

Values given are for $\sigma_{0}(24.2 \mathrm{MeV})$.

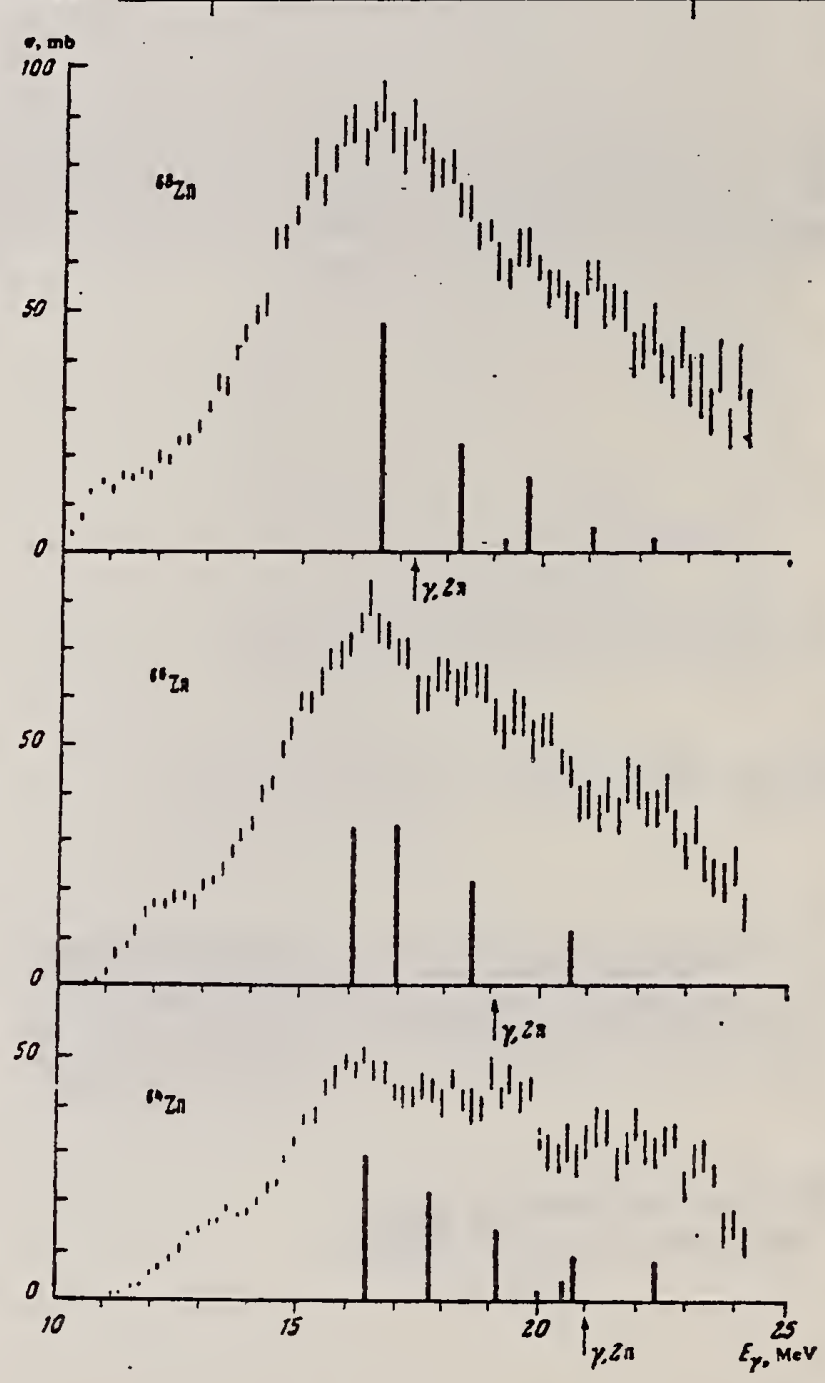

Fig. 1. Cross sections of photoneutzon reactions on $64,66,68 \mathrm{zn}$. The dipole photoabsorption forces are taken from $[6,7]$ (the solid black columns).

6.G. Huber et al., Phys. Rev. 155, 1073 (1967 ${ }^{7}$ M.G. Huber et al., Z. Phys. 192, 223 (1966). 
REF. P. Carlos, H. Beil, R. Bergere, J. Fagot, A. Lepretre, A. Veyssiere, G. V. Solodukhov

Nucl. Phys. A258, 365 (1976)

\begin{tabular}{|c|c|c|c|c|c|c|c|}
\hline METHOD & & - & & & & $\begin{array}{l}\text { REF. NO. } \\
76 \mathrm{Ca} 1\end{array}$ & egf \\
\hline \multirow{2}{*}{ REACTION } & \multirow{2}{*}{ RESUL T } & \multirow{2}{*}{$\begin{array}{l}\text { EXCITATION } \\
\text { ENERGY }\end{array}$} & \multicolumn{2}{|c|}{ SOURCE } & \multicolumn{2}{|c|}{ DETECTOR } & \multirow{2}{*}{ ANGLE } \\
\hline & & & TYPE & RANGE & TYPE & RANGE & \\
\hline$G, N$ & $\mathrm{ABX}$ & $12-30$ & & $12-30$ & MOD-I & & $4 P I$ \\
\hline $\mathrm{G}, 2 \mathrm{~N}$ & $A B X$ & $15-30$ & & $12-30$ & MOD-I & & $4 \mathrm{PI}$ \\
\hline & & & & & & 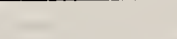 & \\
\hline
\end{tabular}

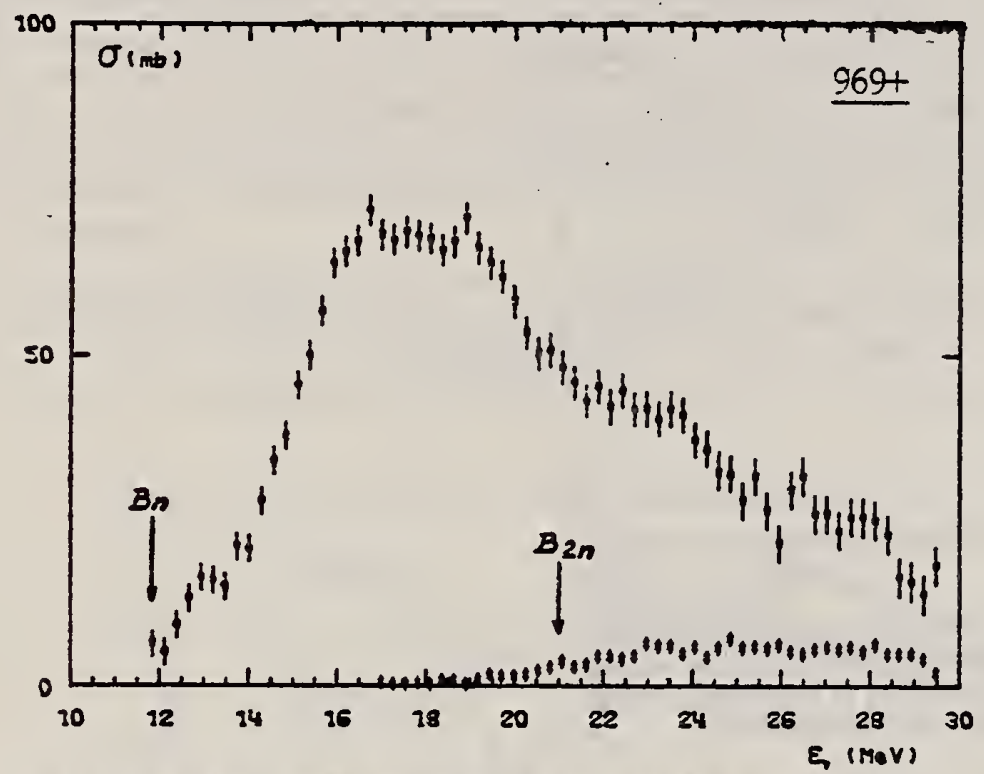

Fig 1. Partial photoneutron croses section $[\sigma(\gamma, n)+\sigma(\gamma, p a)]$ and $\sigma(\gamma, 2 n)$ for ${ }^{\circ} \mathrm{Zn}$. Arrows $B_{0}$ and $B_{2 n}$ indicate theoretical threahold values for $(y, n)$ and $(y, 2 n)$ reactions respectively. Data wero corrected for oxysen but not for impuritica.

There 3

Integrated photoneutron crose sections and comparizon with sum rules

\begin{tabular}{|c|c|c|c|c|c|c|c|c|c|c|c|}
\hline Nucleus, & $\cdots \mathrm{Zn}$ & $\left\{\begin{array}{l}69 \mathrm{Ga} \\
{ }^{11} \mathrm{Ga}\end{array}\right.$ & ${ }^{10} \mathrm{Ge}$ & ${ }^{12} \mathrm{Ge}$ & ${ }^{94} \mathrm{Ge}$ & ${ }^{16} \mathrm{Ge}$ & هA 9 & reso & $14 \mathrm{se}$ & iose & "se \\
\hline$E_{\mathrm{N}}(\mathrm{MeV})$ & 29 & 26.5 & 26.5 & 26.5 & 26.5 & 26.5 & 26.5 & 26.5 & 26.5 & 26.5 & 26.5 \\
\hline$\sigma_{\infty}(\mathrm{MeV} \cdot \mathrm{b})$ & 0.75 & 0.91 & 0.78 & 0.94 & 1.02 & 3.12 & 1.09 & 1.01 & 1.06 & 1.11 & 1.13 \\
\hline$\frac{\sigma_{00 \mathrm{~d}}}{0.06 \mathrm{NZ}}$ & 0.78 & 0.87 & 0.75 & 0.38 & 0.94 & 1 & 0.98 & 0.90 & 0.92 & 0.94 & 0.95 \\
\hline$B_{0}-B_{0}(\mathrm{MeV})$ & 4.2 & $\left\{\begin{array}{l}3.7 \\
1.4\end{array}\right.$ & 3 & 1 & -0.8 & -2.6 & 3.3 & 1.7 & 0.1 & -1.5 & -3 \\
\hline$\sigma_{-10}(m b)$ & 38 & 52 & 44 & $\$ 4$ & 39 & 64 & 63 & 58 & 62 & 65 & 67 \\
\hline$\sigma_{-i \mathrm{~d}} \mathrm{~d}^{-1}(\mathrm{mb})$ & 0.15 & 0.18 & 0.15 & 0.18 & 0.19 & 0.20 & 0.20 & 0.18 & 0.19 & 0.19 & 0.19 \\
\hline$\sigma_{-2 m}\left(m b \cdot \mathrm{MoV}^{-1}\right)$ & 2.0 & 3.1 & 25 & 3.2 & 3.6 & 3.9 & 3.7 & 3.4 & 3.8 & 3.9 & 4.2 \\
\hline$\sigma=\sigma_{a d}-1(\mu \mathrm{b} \cdot \mathrm{MeV}-1)$ & 1.9 & 2.6 & 2.1 & 26 & 2.8 & $2.9^{\circ}$ & 2.8 & 2.5 & 2.7 & 2.6 & 2.7 \\
\hline
\end{tabular}


REF. R. Neuhausen, J. W. Lightbody, Jr., S. P. Fivozinsky, and $S$. Penner

Nucl. Phys. A263, 249 (1976)

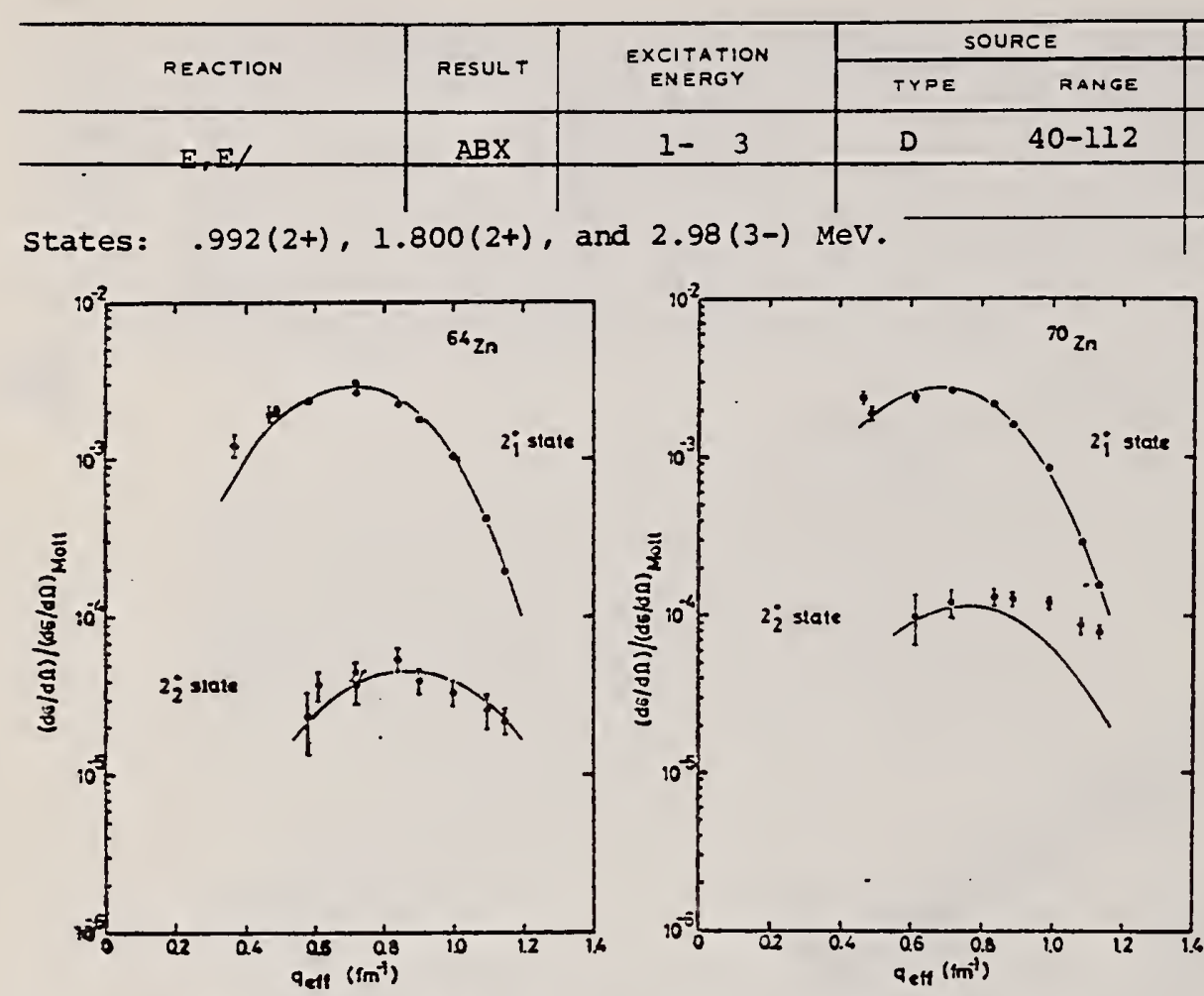

egf

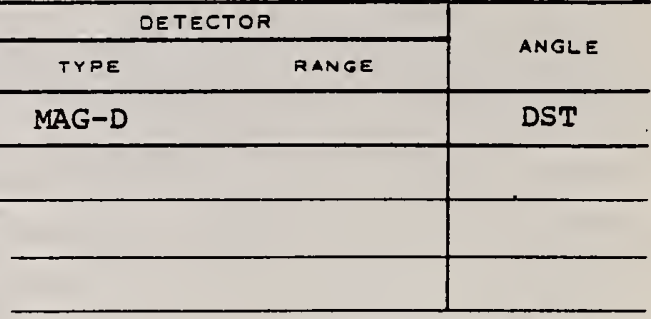

$2+, 2+, 3-$ STATES

Fig. 2 Cross sections divided by the Mott cross section for the excitation of the first and second $2^{+}$ Frate in ${ }^{\circ} \mathrm{Zn}$ and ${ }^{\circ} \mathrm{Zn}$, respectively, versus the effective momentum transfer. The cross sections measuned at different values of the incident energy $E$ were transformed to the common energy $E_{0}=120 \mathrm{MeV}$. The curves are the best fit of the anharmonic vibrator model.

TABLE 6

Reduced transition probabilities in single particle units, deformation parameters and deformation lengths $(R=1.2 \mathrm{fm} \times A f)$

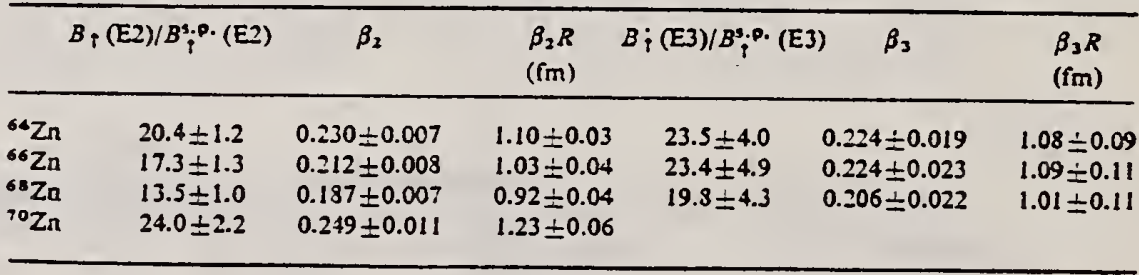

TABLE 7

The $2_{1}^{+}$and $2_{3}^{+}$state $\mathrm{AVM}$ fitting parameters for ${ }^{64} \mathrm{Zn}$ and ${ }^{70} \mathrm{Zn}$

\begin{tabular}{|c|c|c|c|c|c|c|c|c|}
\hline & $(\tilde{n} / 2 \sqrt{B C})^{f}$ & $\begin{array}{c}c_{\mathrm{lr}} \\
(\mathrm{fm})\end{array}$ & $\begin{array}{c}z_{\text {ti }} \\
(\mathrm{fm})\end{array}$ & $a$ & $\begin{array}{c}Q\left(2_{1}^{+}\right)(A V M) \\
\text { (b) }\end{array}$ & BR(AVM) & BR(othe) & $B\left(E 2 ; 0_{1}^{+} \rightarrow 22_{2}^{+}\right)$ \\
\hline${ }^{6} \mathrm{Zn}_{\mathrm{n}}$ & $0.109 \pm 0.004$ & $4.47 \pm 0.08$ & $0.53 \pm 0.06$ & $0.165 \pm 0.005$ & $-0.124=0.012$ & $456 \pm 70$ & $159 \pm 12$ & $8 \pm 2$ \\
\hline${ }^{\circ} \mathrm{Zn}$ & $0.122 \pm 0.006$ & $4.29 \pm 0.08$ & $0.71 \pm 0.05$ & $0.25 \pm 0.02$ & $-0.233 \pm 0.022$ & $72( \pm 26)$ & & $50 \pm 13$ \\
\hline
\end{tabular}

Derived $2+$ state static quadrupole moments, $2_{3}^{+}$state branching ratios, and $B\left(E 2 ; 0_{1}^{+} \rightarrow 22_{2}^{+}\right)$are given. ) Ref. $\left.{ }^{19}\right)$. 


)

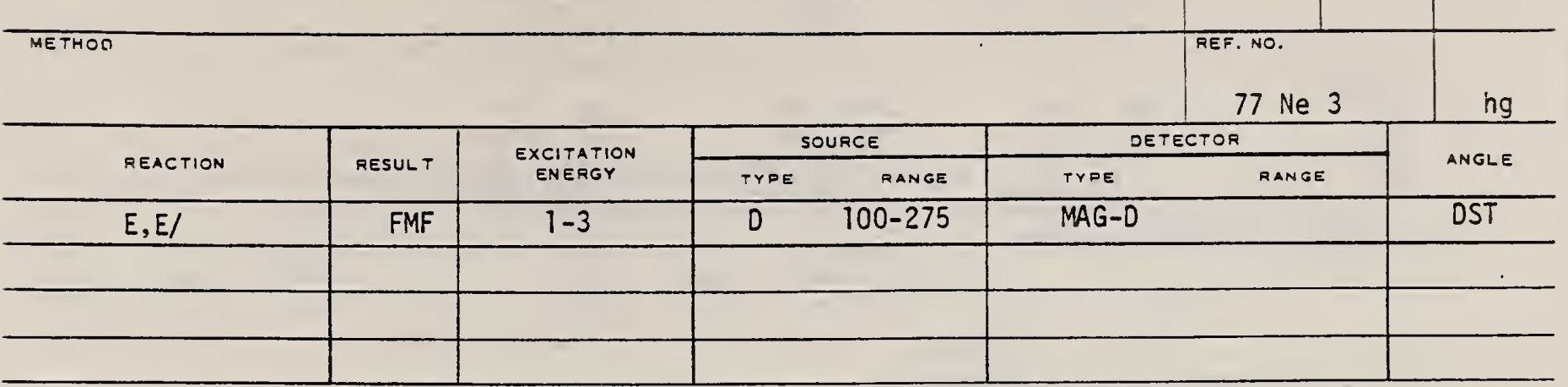

Abstract: The inelastic electron scattering cross sections for the quadrupole transitions to the $2_{i}^{+}$and 2 ; states in the even $\mathrm{Zn}$ isotopes ${ }^{64} \mathrm{Zn}$. ${ }^{60} \mathrm{Zn}$ and ${ }^{68} \mathrm{Zn}$ and for the hexadecapole transition to the $4{ }_{1}^{+}$ state in ${ }^{\circ} \mathrm{Zn}$ have been measured in a momentum transfer range up to $q=2.2 \mathrm{fm}^{-1}$. In the frame. work of the vibrational model these states are considered as one- and two-quadrupole-phonon states. The measurements are characterized by high statistical accuracy and by an overall resolution of $\delta E_{i} E_{0}=10^{-3}$ which permitted separation of aimost all members of the two-phonon triplet. The measured cross sections are analyzed with phenomenological models as well as with a FourierBessel expansion of the transition charge density. The latter analysis yields realistic crror bands for the transition charge densities and model-independent values for the reduced transition probabilities and transition radii.

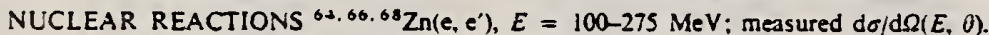
${ }^{64.66 .68} \mathrm{Zn}$ levels deduced transition charge density, $B_{i}(\mathrm{E} i)$ and transition charge radii $R_{t r}$ Enriched targets.

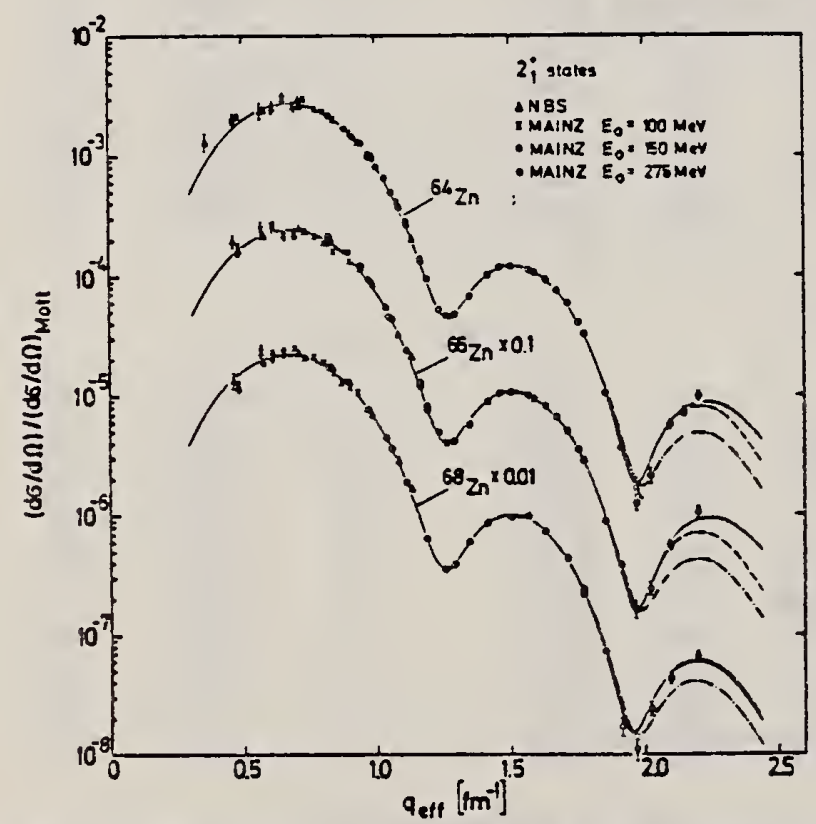

Fig. 3. Cross sections divided by the Mott cross section for the allowed transitions to the $2_{i}^{+}$state in ${ }^{6} \mathrm{Zn}$. ${ }^{\circ} \mathrm{Zn}$ and ${ }^{\circ 8} \mathrm{Zn}$ versus the effective momentum transfer. The measured cross sections are transformed to a common incident energy $E_{0}=275 \mathrm{MeV}$. The curves represent best fit DWBA calculations with the Fourier-Dessel expansion of the transtion charge density (solid line), the modified Tassie model (dashed line) and the Gaussian model (dashed-dotted line).
LEV. $.992,1.800,2.305$

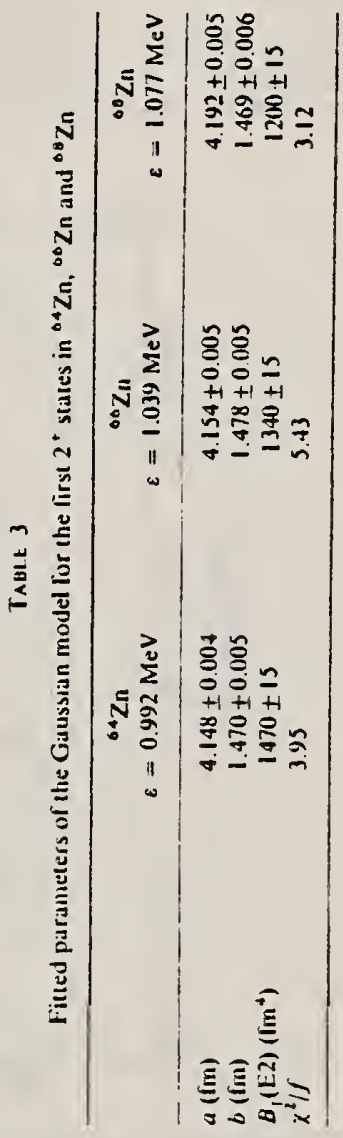


TABLE 5

Reduced transition probabilities $B_{,}(\mathrm{E} 2)$ and transition radii $R_{\mathrm{tr}}$ for the $2_{\mathrm{i}}^{+}$states in ${ }^{64} \mathrm{Zn},{ }^{60} \mathrm{Zn}$ and ${ }^{68} \mathrm{Zn}$

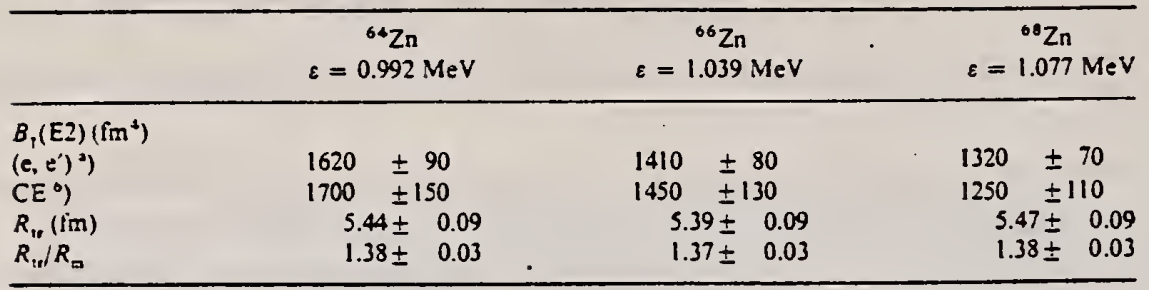

) Model independent analysis, this work.

b) Ref. ${ }^{1 \epsilon}$ ).

TAHLE 8

Recluced iransition probabilities $B_{1}(E)$ and transition radii $R_{1 f}$ for the forbidden transition to the $2 z_{z}^{*}$

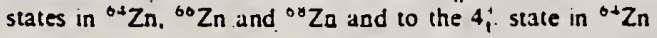

\begin{tabular}{|c|c|c|c|c|}
\hline$\cdot$ & $\varepsilon=\begin{aligned}{ }^{64} \mathrm{Zn} \\
i=2 \\
i=2\end{aligned}$ & $\varepsilon=\begin{array}{l}{ }^{\circ 6} \mathrm{Zn} \\
i=273 \mathrm{MeV} \\
i=2\end{array}$ & $\begin{array}{c}{ }^{\circ} \mathrm{Zn} . \\
=1.883 \mathrm{MeV} \\
i=2\end{array}$ & $\begin{array}{c}\varepsilon=2.305 \mathrm{MeV} \\
i=4\end{array}$ \\
\hline $\begin{array}{l}B .(E ;)\left(\mathrm{fm}^{2 \mathrm{~d}}\right) \\
R_{1,(\mathrm{fm})} \\
R_{\mathrm{t}} R_{\mathrm{m}} \\
R_{1,}^{2}\left(2_{2}^{+}\right) / R_{\mathrm{tr}}^{2}\left(2_{1}^{*}\right)\end{array}$ & $\begin{array}{c}17.0 \pm 1.2 \\
4.6 \pm 0.1 \\
1.17 \pm 0.03 \\
0.71 \pm 0.03\end{array}$ & $\begin{array}{l}4.5 \pm 0.7 \\
4.5 \pm 0.1 \\
1.14 \pm 0.03 \\
0.69 \pm 0.04\end{array}$ & $\begin{array}{l}46 \pm 7 \\
5.9 \pm 0.1 \\
1.49 \pm 0.03 \\
1.17 \pm 0.06\end{array}$ & $\begin{array}{l}(3.4 \pm 1.0) \times 10^{4} \\
6.7 \pm 0.3 \\
1.70 \pm 0.08\end{array}$ \\
\hline
\end{tabular}

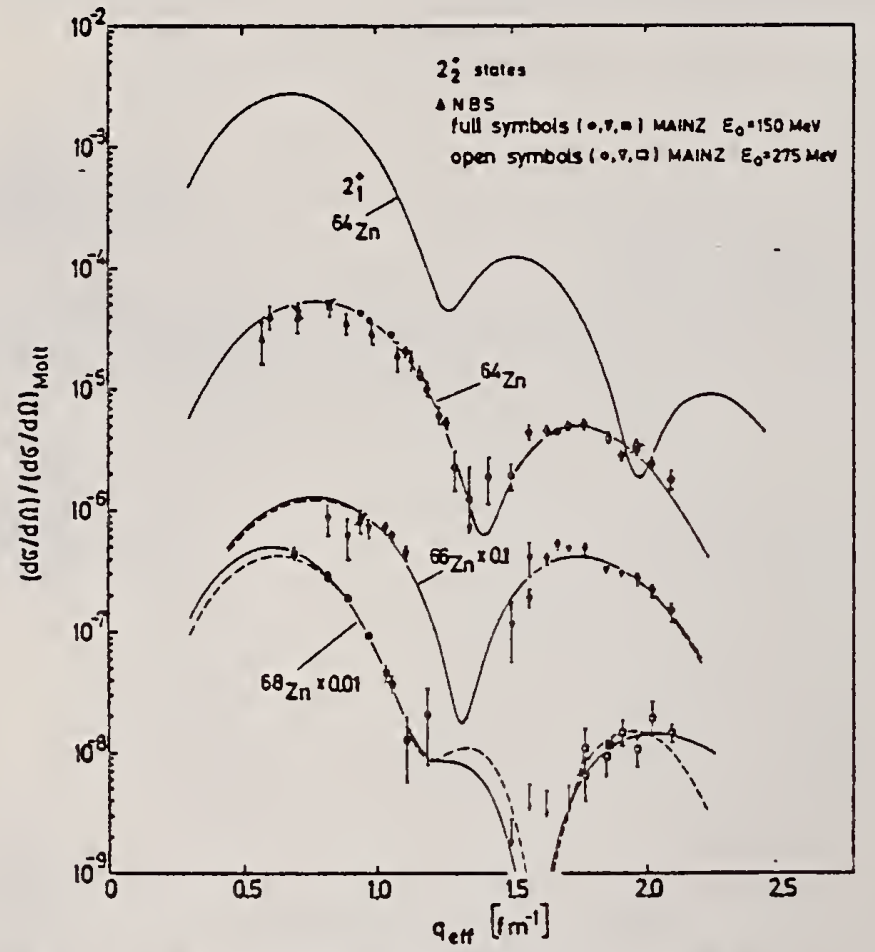

Fig. 8. Same as fig. 3, but for the forbidden transitions to the $2:$ states in ${ }^{\circ 4} \mathrm{Zn}$. ${ }^{\circ 0} \mathrm{Zn}$ and ${ }^{\circ} \mathrm{Zn}$. respectively. The curves represent hest-fit DWBA calculations with the Fourier-Bessel expansion of the transition charge density (solid line) and the phenornenolisical model given in ey. (2?) (dushed line). Fur exmparison. ihe shape of the cress settion for the allowed transition to the $z_{i}^{*}$ state in ${ }^{\circ+} Z n$ is shown (uppermost curve). 
REF. Reiner Neuhausen

Nucl. Phys. A282, 125 (1977)

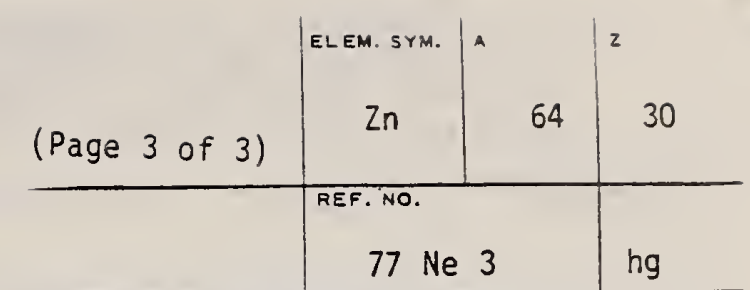

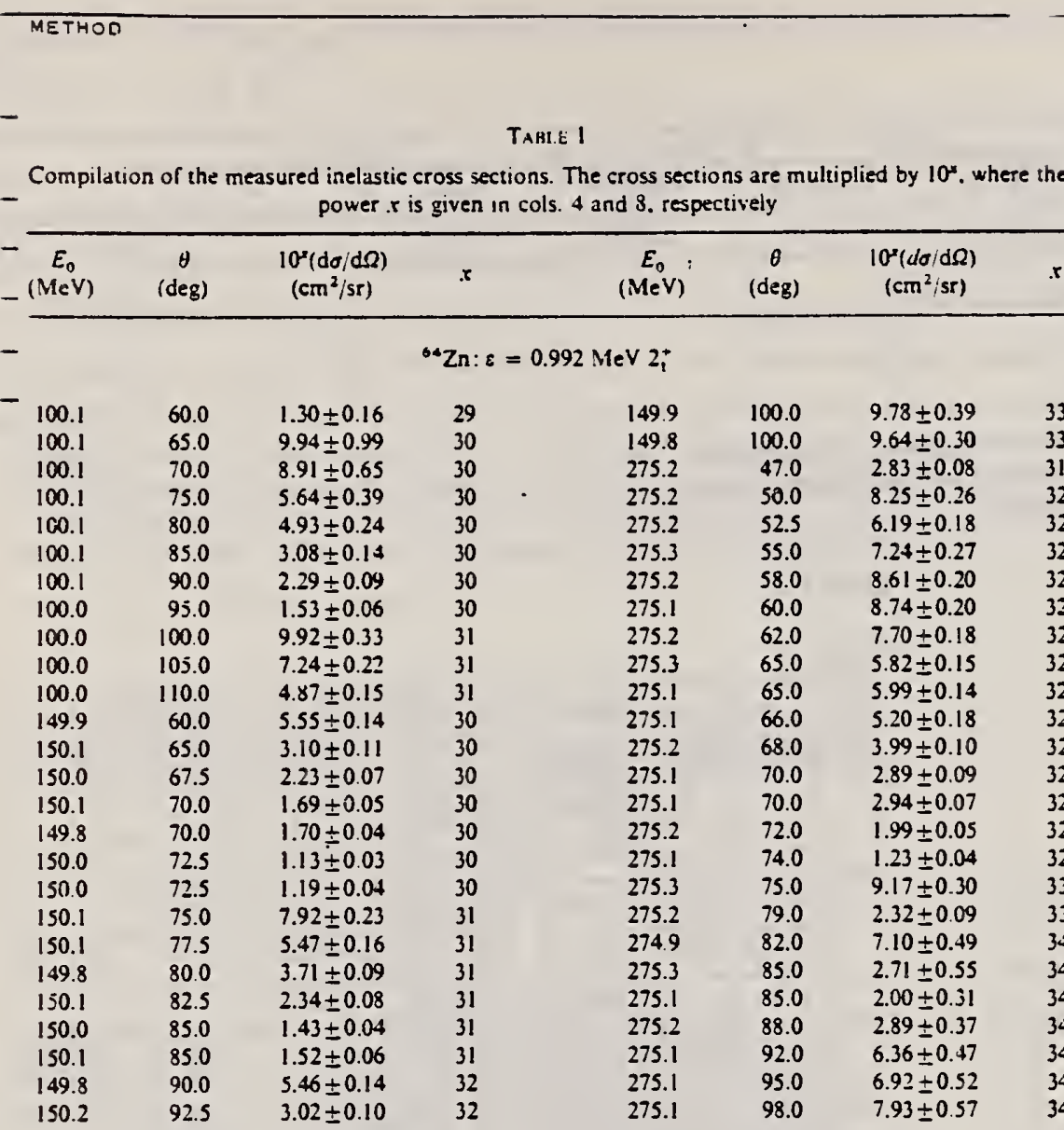

${ }^{64} \mathrm{Zn}: \varepsilon=1.800 \mathrm{MeV} \mathrm{2} ;$

$\begin{array}{llllllll}149.9 & 60.0 & 1.30 \pm 0.05 & 31 & 275.2 & 58.0 & 1.6 \pm 0.7 & 33 \\ 149.3 & 70.0 & 5.57 \pm 0.16 & 32 & 275.2 & 62.0 & 1.25 \pm 0.29 & 33 \\ 150.0 & 72.5 & 4.15 \pm 0.17 & 32 & 275.1 & 65.0 & 2.35 \pm 0.29 & 33 \\ 149.8 & 80.0 & 2.03 \pm 0.06 & 32 & 275.2 & 68.0 & 1.99 \pm 0.16 & 33 \\ 150.0 & 85.0 & 1.16 \pm 0.11 & 32 & 275.1 & 70.0 & 1.72 \pm 0.12 & 33 \\ 149.8 & 90.0 & 5.56 \pm 0.23 & 33 & 275.2 & 72.0 & 1.67 \pm 0.09 & 33 \\ 150.2 & 92.5 & 3.86 \pm 0.46 & 33 & 275.3 & 75.0 & 1.43 \pm 0.09 & 33 \\ 149.9 & 100.0 & 1.33 \pm 0.21 & 33 & 275.2 & 79.0 & 8.77 \pm 0.58 & 34 \\ 149.8 & 100.0 & 1.43 \pm 0.14 & 33 & 274.9 & 82.0 & 5.43 \pm 0.45 & 34 \\ 275.2 & 47.0 & 2.73 \pm 0.38 & 32 & 275.3 & 85.0 & 5.50 \pm 0.64 & 34 \\ 275.2 & 50.0 & 9.7 \pm 1.3 & 33 & 275.1 & 85.0 & 5.01 \pm 0.42 & 34 \\ 275.2 & 52.5 & 2.9 \pm 1.1 & 33 & 275.2 & 88.0 & 3.26 \pm 0.34 & 34 \\ 275.3 & 55.0 & 1.3 \pm 1.3 & 33 & 275.1 & 92.0 & 1.99 \pm 0.33 & 34\end{array}$

$\begin{array}{lrllllll}149.9 & 60.0 & 1.69 \pm 0.37 & 32 & 275.2 & 72.0 & 7.4 \pm 0.8 & 34 \\ 149.8 & 70.0 & 8.05 \pm 0.62 & 33 & 275.3 & 75.0 & 7.8 \pm 0.9 & 34 \\ 149.8 & 80.0 & 3.55 \pm 0.32 & 33 & 275.2 & 79.0 & 5.36 \pm 0.52 & 34 \\ 149.8 & 90.0 & 1.30 \pm 0.15 & 33 & 274.9 & 82.0 & 3.77 \pm 0.42 & 34 \\ 149.8 & 100.0 & 3.5 \pm 1.4 & 34 & 275.3 & 85.0 & 3.58 \pm 0.58 & 34 \\ 275.2 & 62.0 & 3.7 \pm 1.2 & 34 & 275.1 & 85.0 & 2.72 \pm 0.43 & 34 \\ 275.1 & 65.0 & 9.1 \pm 2.3 & 34 & 275.2 & 88.0 & 1.83 \pm 0.30 & 34 \\ 275.2 & 68.0 & 8.8 \pm 1.3 & 34 & 275.1 & 92.0 & 1.17 \pm 0.32 & 34 \\ 275.1 & 70.0 & 8.6 \pm 1.4 & 34 & & & & \end{array}$


ReF. A.A. Nemashkalo, N.G. Afanas'ev, Yu.V. Vladimirov, V.P. Likhachev, G.A. Savitskii, \& V.M. Khvastunov

Pisima Zh. Eksp. Teor. Fiz. 26, No. 7, 569 (1977)

JETP Lett. 26, No. 7, 422 (0) 1977)

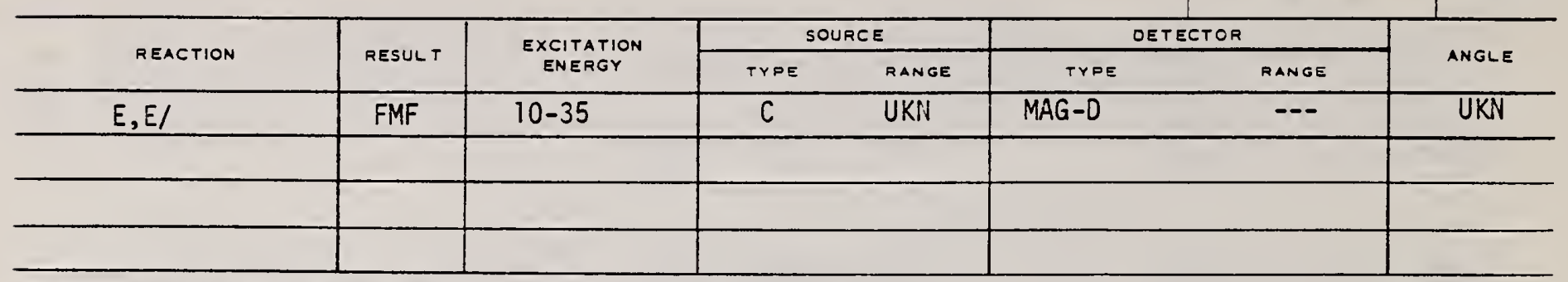

Results are presented of the investigation of giant multiple resonances in the nuclei ${ }^{4} \mathrm{Zn}$ and ${ }^{124} \mathrm{Sn}$ with the aid of inelastic scattering of electrons, performed in Khar'kov with the LUE-300 linear electron accelerator.

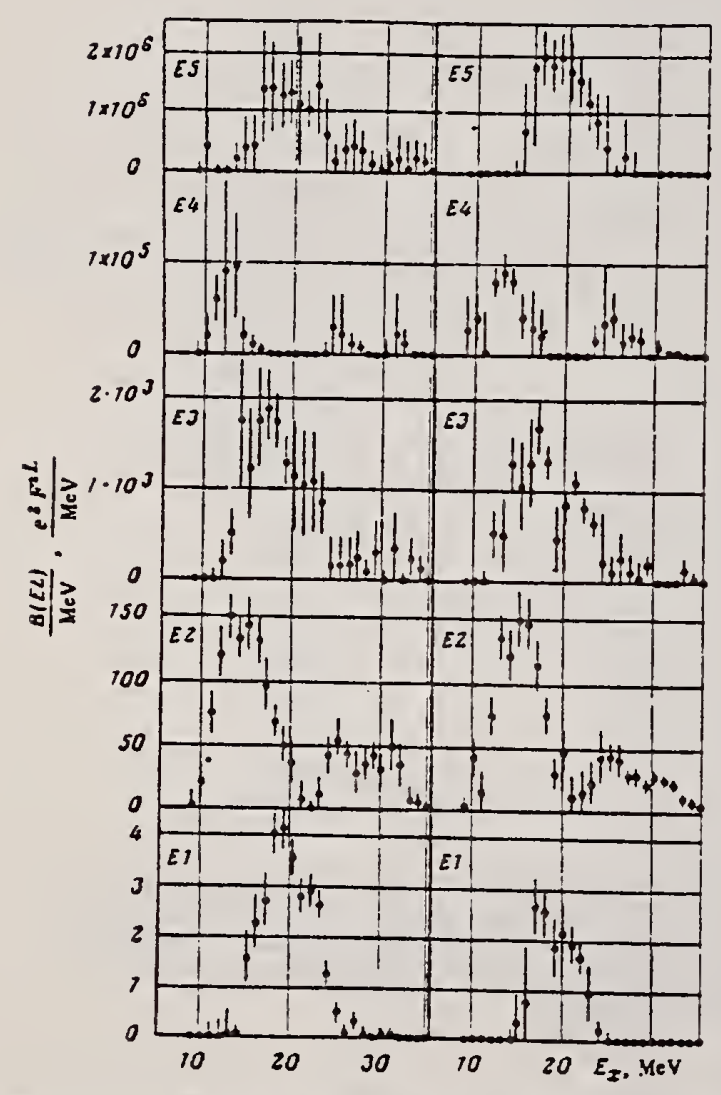

TABLE II.

\begin{tabular}{|c|c|c|c|c|c|c|c|c|}
\hline \multirow{2}{*}{11} & \multirow{2}{*}{$E_{x, M e V}$} & \multirow{2}{*}{$r_{x}, \mathrm{MeV}$} & \multirow{2}{*}{ UED,$c^{2} F^{24}$} & \multirow{2}{*}{ AT } & \multicolumn{2}{|c|}{ Lim. of EWSR. \% } & \multicolumn{2}{|c|}{$5 \mathrm{~B} \cdot \mathrm{B} / \mathrm{MeV}$} \\
\hline & & & & & rotal & $\Delta T=0.1$ & our data & athers \\
\hline 51 & $\frac{0.206}{2.1206}$ & \begin{tabular}{|l}
4.352 .8 \\
3.5208 \\
\end{tabular} & $\frac{3.552 .1}{9.5812}$ & 1 & $=$ & \begin{tabular}{|c|}
63516 \\
02811 \\
\end{tabular} & $\frac{21: 3}{86: 3}$ & $78-82$ \\
\hline \multirow{4}{*}{$\xi 2$} & $0-11$ & - & $1380: 90$ & $\frac{2}{-}$ & $\frac{-}{47: 0,5}$ & $\frac{10 \div 1}{-}$ & - & \\
\hline & $15,0 \pm 0.2$ & $6.0 \leq 0.4$ & $600 \leq 70$ & $\div$ & $23 \pm 3$ & $49: 5$ & $50 \div 1$ & $58-65$ \\
\hline & $251 \geq 03$ & $38=1.6$ & $90: 50$ & $\frac{1}{-}$ & $6=3$ & $11: 5$ & $100 \geq 4$ & \\
\hline & $304 \div 0,8$ & $5,0: 1, ?$ & $110 \div 50$ & $\frac{1}{-}$ & $9+4$ & $\frac{16=7}{-}$ & $-121: 3$ & $111-140$ \\
\hline \multirow[b]{2}{*}{ E3 } & $0-11$ & - & $44100 \pm 1200$ & 0 & $86 \pm 0,8$ & $19 \pm 2$ & - & \\
\hline & $\frac{16.6 \div 0.4}{29.4: 2.6 !}$ & $\frac{4.2: 1,4}{6,5: 3,1}$ & 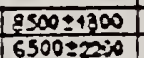 & $\overline{-}$ & $\frac{5,5: 12}{5,4 \pm 20}$ & $\div$ & $\frac{65 \div \frac{2}{86}}{160}$ & $\frac{x 0-32}{\cos -155}$ \\
\hline \multirow{4}{*}{$\frac{E 4}{E 5}$} & $0-11$ & - & $4.3 \pm 0.21 \times 05$ & E & $40 \leq 0.2$ & - & & \\
\hline & $12,930.5$ & $3,2=1.1$ & $0,3 \pm 12400^{3}$ & $=$ & $2.094,2$ & $=$ & $52 \pm 2$ & \\
\hline & $25+=0.8$ & $2.5=1.4$ & $144: 2524$ & - & $0.7 \pm 0.3$ & $=$ & $102 \pm 4$ & \\
\hline & $0-35$ & - & $(1.0 \pm 25)=2$ & - & $20 \pm 1,0$ & $=$ & & \\
\hline
\end{tabular}

FIG. 1. "Zn. Dependence of the relative probabilities of transitions with multipolarities $L=1-5$ on the excitation energies. Left-Helm's mode!. right-high-energy approximation. 
REF. S.S. Verbitskii, A.M. Lapik, B.S. Ratner, A.N. Sergievskii JETP Lett. 27,295 (1978)

\begin{tabular}{|c|c|c|c|c|c|c|c|}
\hline METHOO & & & & & & $\begin{array}{l}\text { REF. NO. } \\
78 \text { Ve } 6\end{array}$ & hg \\
\hline \multirow{2}{*}{ REACTION } & \multirow{2}{*}{ RESULT } & \multirow{2}{*}{$\begin{array}{l}\text { EXCITATION } \\
\text { ENERGY }\end{array}$} & & & \multicolumn{2}{|c|}{ DETECTOR } & \multirow{2}{*}{ ANGLE } \\
\hline & & & TYPE & RANGE & TYPE & RANGE & \\
\hline \multirow[t]{2}{*}{$G, X N$} & $A B X$ & $16-26$ & $\mathrm{C}$ & $12-27$ & SCI -0 & & $4 P I$ \\
\hline & & & \multicolumn{2}{|c|}{$(11.9-26.3)$} & & & \\
\hline & & & & & & & \\
\hline & & & & & & & \\
\hline
\end{tabular}

The cross section of the reaction ${ }^{64} \mathrm{Zn}(\gamma, n)^{63} \mathrm{Zn}$ was investigated for the highenergy component of the neutron spectrum $\left(\epsilon_{n} \geq 3.7 \mathrm{MeV}\right)$. An analysis of the results indicates that the interpretation of the structure observed in the cross section of the ${ }^{60} \mathrm{Zn}(\gamma, n)^{63} \mathrm{Zn}$ as a manifestation of isospin splitting is in error.

PACS numbers: $25.20 .+y, 24.30 . C z$

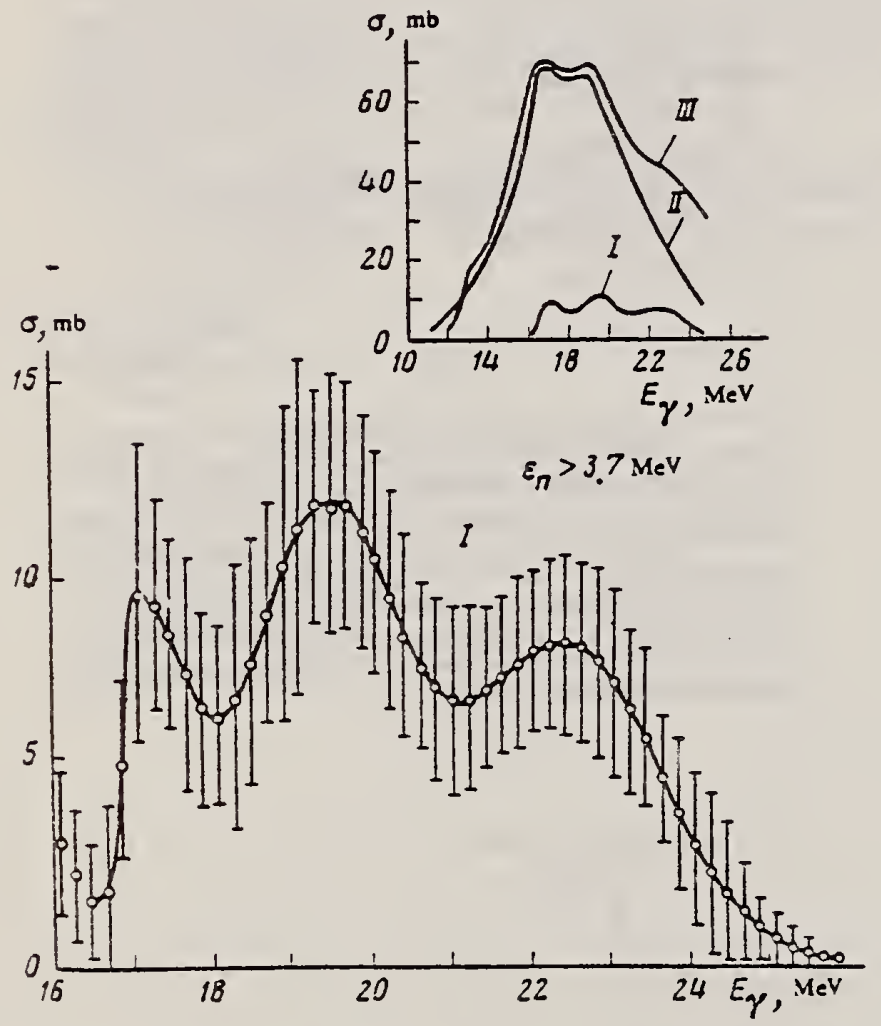

FIG. 1. Curve 1) Cross section of the reaction $" \mathrm{Zn}(\gamma \cdot n) \cdot \mathrm{Zn}$ for neutrons with energy $\epsilon_{n}>3.7 \mathrm{MeV}$, obtained in the present study. Curve II) Cross section of the resetion " $\mathrm{Zn}(\gamma, n){ }^{\circ} \mathrm{Za}$ from is!. Curve III)

Total cross section of the reactions ${ }^{*} \mathrm{Zn}(\gamma, n){ }^{*} \mathrm{Zn}$ and ${ }^{*} \mathrm{Zn}(\gamma, n p){ }^{\circ 2} \mathrm{Cu}$ from ${ }^{\circ 1}$. 
REF. S.S. Verbitskii, A.M. Lapik, B.S. Ratner, A.N. Sergievskii Sov. J. Nucl. Phys. 28, 741 (1978)

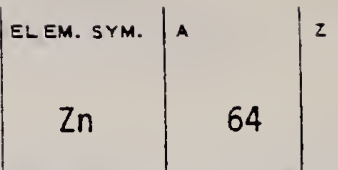

78 Ve 7

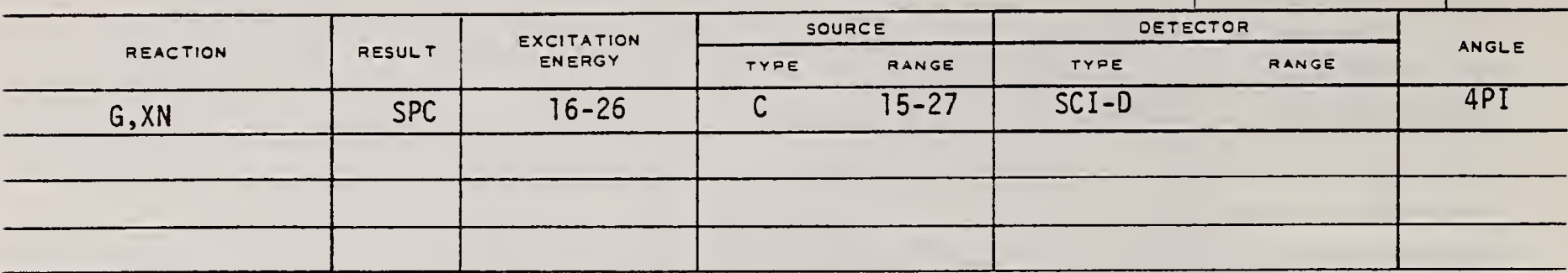

The yield curve of the reaction ${ }^{60} \mathrm{Zn}(\gamma, n)^{63} \mathrm{Zn}$ was measured for neutrons with $\epsilon_{n}>3.7 \mathrm{MeY}$; the energy spectra of the photoneutrons were also measured at various values of the bremsstrahlung maximum energy $E_{\gamma m}$. It is concluded from analysis of the obtained data and from comparison with the results of analogous studies made for iron isotopes that the probability of decay of doorway states into more complex configurations increases with increasing distance from the region of nuclei with filled shells.
NEUTS ABOVE 3 MEV

See also 78 Ve 6

PACS numbers: $25.20 .+y, 24.30 . \mathrm{Cz}, 27.50 .+e$

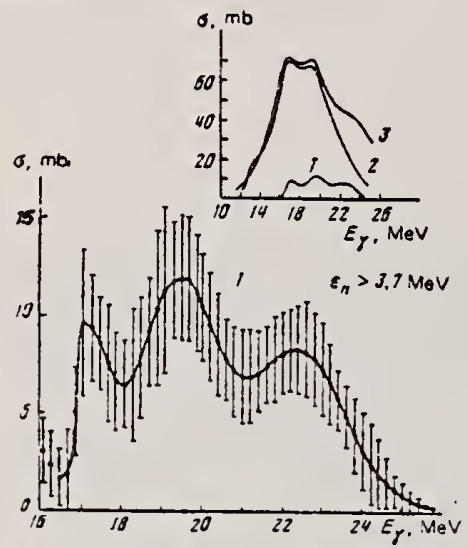

FIG. 2. Cross section of the reaction ${ }^{64} \mathrm{Zn}(\gamma, n)^{63} \mathrm{Zn}$ for $\varepsilon_{\text {. }}$ $>3.7 \mathrm{MeV}$ (curve 1). Comparison of the data for the highenergy neutrons with results obtained for neutrons of all energles in Refs. 12 (curve 2) and 14 (curve 3).
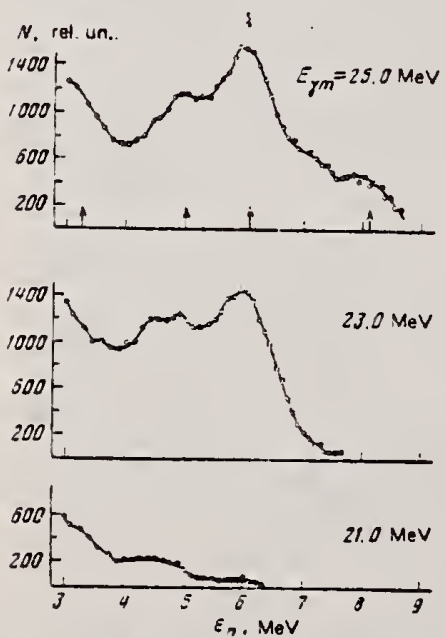

FIG. 4. Energy spectra of the neutrons from the rcaction ${ }^{16} \mathrm{O}(\gamma, \pi)^{15} \mathrm{O}$. The arrou's indicate the positions of the main peaks in the spectrum, measured by the time-of-night proCORM cedure. ${ }^{18}$

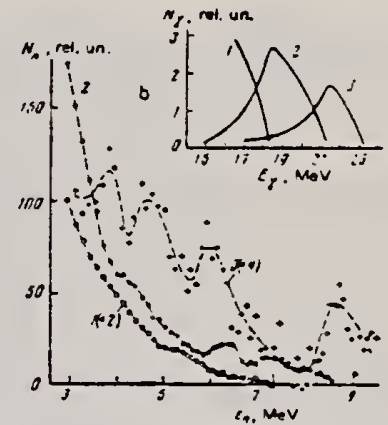

FIG. 3. a) Energy spectra of neutrons from the reaction ${ }^{6} \mathrm{Zn}(\gamma, n)^{63} \mathrm{Zn}$ obtained at different values of $E_{\gamma_{m}}$. b) Difference energy spectra of neutrons from the reaction $\mathrm{Zn}(\gamma$, $\pi)^{63} \mathrm{Zn}$ oblained by subtracting the spectrum at $E_{y m}=13.0 \mathrm{MeV}$ from the spectrum at $21.0 \mathrm{MeV}$ (curve 2) and subtracting the spectrum at $E_{7 m}=21.0 \mathrm{MeV}$ from the spectrum at $23.0 \mathrm{MeV}$ (curve 3) (the spectra are reduced to the same irradiation dose), compares with the spectrum at $E_{y m}=18.0 \mathrm{McV}$ (curve 1). The insert shows the spectra of the bremsstrahlung that produced the neutron spectra.

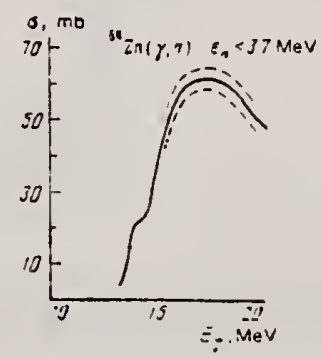

FIG. 6. Cross section of the reaction ${ }^{\alpha} \mathrm{Zn}(\gamma, \pi)^{\nabla} \mathrm{Zn}$ for neutron emission with $\varepsilon_{n}<3.7 \mathrm{MeV}$, obinined by subtracting the cross section for $\varepsilon_{n}>3.7 \mathrm{MeV}$ from the cross section for the emission $a$ neutrons of a d energies. 
Ref. Y. Cauchois, H. Ben Abdelaziz, R. Khérouf, C. Schloesing-Möller

J. Phys G7, 1539 (1981)

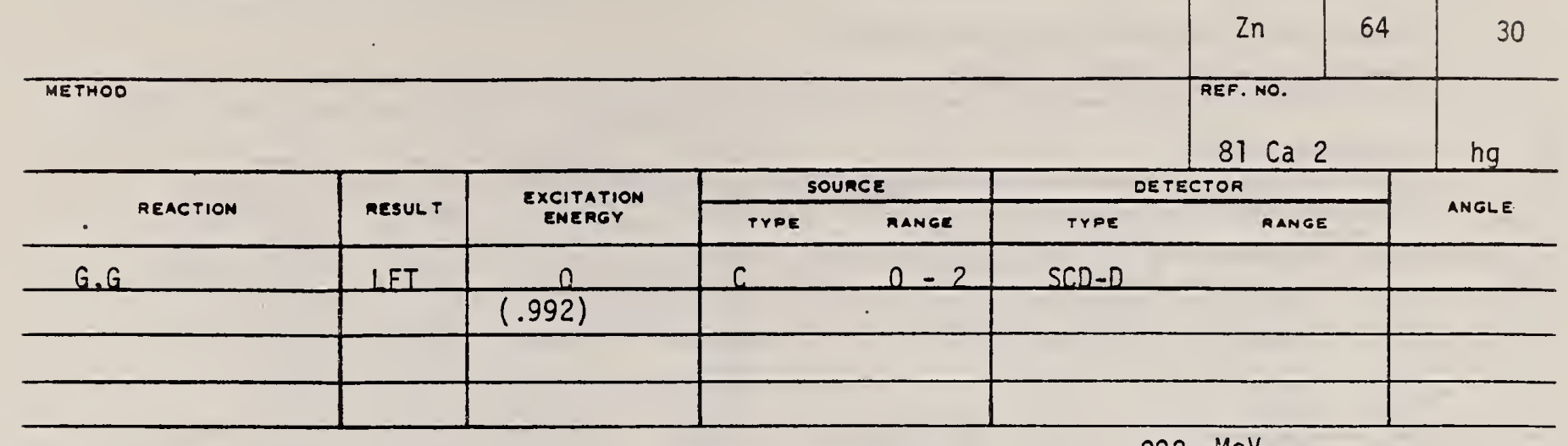

Absuract. Lifetimes of 49 excited states below $1.65 \mathrm{MeV}$ have been measured in ${ }^{24} \mathrm{Mg}$. ${ }^{27} \mathrm{Al}$.

${ }^{18} \mathrm{Ti} .{ }^{18} \mathrm{Ni},{ }^{39} \mathrm{Co},{ }^{61.62} \mathrm{Ni},{ }^{63.65} \mathrm{Cu} .{ }^{64.00 .68} \mathrm{Zn},{ }^{19} \mathrm{As},{ }^{103} \mathrm{Rh},{ }^{113.113} \mathrm{In},{ }^{116,118.120} \mathrm{Sn}$ and ${ }^{121.123} \mathrm{Sb}$

by means of nuclear resonance fiuorescence experiments. The levels are excited by bremsstrahlung $x$-ray photons. The seif-absorption technique applied to suitable cases provides nuclear absorption cross sections, widths and lifetimes from which the $x$-ray spectral distributions are also obtained. Scattering experiments are performed for all other cases in order to obtain widths and lifetimes from these x-ray photon curves. The Compton effect in the sumple is taken into account. Self-absorption provides $g \Gamma_{0}$ from which $\Gamma$ is deduced using adupted $J^{n}$ and $\Gamma_{0}, \Gamma$ values; scartering provides $u=g\left(\Gamma_{0}^{2} / \Gamma\right) W(\theta)$ from which $\Gamma$ is also deduced with $J . \Gamma_{0} / \Gamma$ and mixing ratios taken from the literature. Thanks to simultaneous determination of the $x$-ray sfectra ail the lifecimes as given by our programs with their statistical errors form an unusually cohcrent set of values.

NUCLEAR REACTIONS $(\%, \gamma)$, bremsstrahlung excitation: natural isotopes: ${ }^{24} \mathrm{Mg}$.

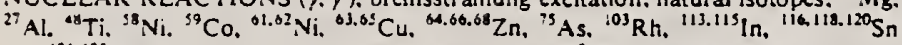
and ${ }^{121.123} \mathrm{Sb}: E=0.5-1.65 \mathrm{MeV}$; measured $g \Gamma_{0}$ or $g\left(\Gamma_{0}^{2} / \Gamma\right) W(\theta)$ : deduced $T_{1 / 2}$. 
Tableau 3. Resultats des mesures des niveaux etudies par dirfusion.

Table 3. Results obtained using the diffusion method.

\begin{tabular}{|c|c|c|c|c|c|c|c|c|c|}
\hline Isotope & Energie (keV) & $J^{\pi}$ & $J_{0}^{\Re}$ & $\Gamma_{0} / \Gamma$ & $\delta$ & $\begin{array}{l}u=g\left(\Gamma_{0}^{2} / \Gamma\right) W(\theta) \\
(\mathrm{meV})\end{array}$ & $\begin{array}{l}\tau(p s) \\
\text { ce travail }\end{array}$ & $\tau_{\text {ref }}(p s)$ & Réfërencest \\
\hline${ }^{24} \mathrm{Mg}$ & $1368,59(4)$ & $2^{+}$ & $0^{*}$ & 1 & $E 2$ & $1,08(13)$ & $1,76(21)$ & $1,98(4)$ & $\begin{array}{l}\text { Endt et van der Leun } \\
\quad(1978)\end{array}$ \\
\hline${ }^{37} \mathrm{Al}$ & $1014.45(3)$ & $\xi^{*}$ & $\vdots+$ & 0.971 & $+0.35 !(12)$ & $0,186(13)$ & $2.20(16)$ & $2,12(8)$ & $\begin{array}{l}\text { Endt et van der Leun } \\
\qquad(1978)\end{array}$ \\
\hline${ }^{42} \mathrm{Ti}$ & $983.512(3)$ & $2^{\circ}$ & $0^{*}$ & 1 & E2 & $0,282(23)$ & $6.74(55)$ & $6,1(13)$ & Been (1978) \\
\hline${ }^{\prime} \mathrm{Ni}$ & $1454.45(15)$ & $2^{*}$ & $0^{*}$ & 1 & E2 & $2,11(26)$ & $0.90(11)$ & $0.92(3)$ & $\begin{array}{l}\text { Kocher et Auble } \\
(1976)\end{array}$ \\
\hline${ }^{59} \mathrm{Co}$ & $1099.224(25)$ & $\frac{3-}{2}$ & $?$ & 1 & $(E 2)$ & $0.069(8)$ & $4,79(55)$ & $3,17(58)$ & $\operatorname{Kim}(1976)$ \\
\hline${ }^{99} \mathrm{Co}$ & $1458,8(3)$ & & ;- & 0.91 & $(E 2)$ & $0,68(8)$ & $1,17(14)$ & $1.52(16)$ & $\operatorname{Kim}(1976)$ \\
\hline${ }^{99} \mathrm{Co}$ & $1480.9(3)$ & & $i-$ & 0.8 & $<0.35^{\circ}$ & $1.23(15)$ & $0.254(31)$ & $0.31(3)$ & $\operatorname{Kim}(1976)$ \\
\hline${ }^{61} \mathrm{Ni}$ & $1185.7(6)$ & $i^{-}$ & $1-$ & $0,77(8)^{i}$ & $|0,14|$ & $1,88(49)$ & $0,21(5)$ & $0.16(3)$ & Andreev et al (1974) \\
\hline${ }^{62} \mathrm{Ni}$ & $1172.91(9)$ & $2^{+}$ & $0^{+}$ & 1 & E2 & $0.88(17)$ & $2.15(42)$ & $2.09(3)$ & Halbert (1979a) \\
\hline${ }^{6} \mathrm{Cu}$ & $1327,00(7)$ & & $3-$ & 0.84 & $(E 2)$ & $1.04(14)$ & $0.84(11)$ & $0.88(4)$ & Auble (1979b) \\
\hline${ }^{33} \mathrm{Cu}$ & $1412.05(4)$ & & $i-$ & 0.72 & $+0.61\{-91)$ & $0,260(38)$ & $1,90(28)$ & $1,61(3)$ & Auble (1979b) \\
\hline${ }^{n+} \mathrm{n}$ & $991.54(7)$ & $2^{*}$ & $0^{+}$ & 1 & E2 & $0.640(54)$ & $2,97(25)$ & $2.60(13)$ & Halbert (1979b) \\
\hline${ }^{\circ 9} \mathrm{Cu}$ & $1481,83(5)$ & $i^{-}$ & $i^{-}$ & 0.85 & $(E 2)$ & $1,13(19)$ & $0,79(13)$ & $\rho .49(5)$ & Auble (1975a) \\
\hline${ }^{66} \mathrm{Zn}_{\mathrm{n}}$ & $1039.37(6)$ & $2^{+}$ & $0^{*}$ & 1 & E2 & $0.70(6)$ & $2,71(23)$ & $2.25(15)$ & Auble (1975b) \\
\hline $\mathrm{Zn}$ & $1077,38(5)$ & $2^{*}$ & $0^{\circ}$ & 1 & E2 & $0.70(6)$ & $2.71(23)$ & $2,34(23)$ & Lcwis (1975) \\
\hline${ }^{79}$ As & $572.5(10)$ & ?- & ?- & $1^{6}$ & $0.39^{\circ}$ & $0.236(26)$ & $4.14(46)$ & $3,5(9)$ & Horen ct Lowis (1975) \\
\hline${ }^{79}$ As & $823,0(10)$ & & $3-$ & $0,86^{4}$ & $(E 2)$ & $0.214(22)$ & $4.27(43)$ & $3.5(3)$ & Robinson el al (1967) \\
\hline${ }^{79}$ As & $865.5(10)$ & & - & $0.83^{\mathrm{d}}$ & $-c$ & $0.78(6)$ & $0.863(68)$ & $0,60 \times 12)$ & Cellicrs et al (1977) \\
\hline 79 As & $1076.0(10)$ & & - & $0.94^{d}$ & $0.38^{4}$ & $1,97(13)$ & $0,287(19)$ & $0.32(7)$ & Celliers et al (1977) \\
\hline${ }^{79} \mathrm{As}$ & $1128,5(10)$ & !* & $\xi$ & 1 & $E I^{d}$ & $0,224(24)$ & $1,47(16)$ & - & \\
\hline${ }^{75} \mathrm{As}$ & $1349.0 \times 101$ & $1-$ & !- & $0.67^{d}$ & $0.20^{d}$ & $1.61(29)$ & $0.180(32)$ & $0.12(3)$ & Wiison (1970) \\
\hline is is & $1370.0(10)$ & $\vdots$ & $t^{-}$ & $0.47^{4}$ & $0.47^{d}$ & $0.64(13)$ & $0.218(+4)$ & - & \\
\hline${ }^{03} \mathrm{Rh}$ & $803.1(2)$ & $\vdots-$ & $!^{-}$ & 0.70 & $\$ 1$ & $1.85(16)$ & $0,174(15)$ & - & Harmatz (1979) \\
\hline${ }^{103} \mathrm{Rh}$ & $1277.0(2)$ & $3^{-}$ & $\frac{1}{2}$ & 0.75 & $-0.62(30)^{c}$ & $0.81(9)$ & $0.87(10)$ & $1.3(9)$ & H:armat $\angle(1979)$ \\
\hline $111 \ln$ & $1177(1)$ & U. & $?$ & 1 & $+0.5(2)$ & $9.1(8)$ & $0.086(8)$ & $0.10(x)$ & Tuttle at a/ (1976) \\
\hline${ }^{113}$ ln & $1510(1)$ & $?$ & !* & 0,935 & $-0.5\left\{\begin{array}{l}-1 \\
-2\end{array}\right\}$ & $6 . \div(9)$ & $0.071(10)$ & $0.11,-2\}$ & Turtle et al (1476) \\
\hline $119 \ln$ & $1077.7(10)$ & $\because$ & $?+$ & $0.81^{1}$ & (E2) & $0.159(24)$ & $1.61(24)$ & $1,23(7)$ & Tutt!c et a $(1476)$ \\
\hline $119 \ln$ & $1290.59(3)$ & 4 & 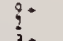 & $0.98^{1}$ & $(\mathrm{~F}, 2)$ & $1.31(11)$ & $0 . n h(0)$ & $0.55(4)$ & Tutte ef el $(1476)$ \\
\hline $119 \ln$ & $1448.78(3)$ & $y^{*}$ & 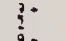 & 0.86 & $-8^{i}$ & $0.90(11)$ & $0.50(0)$ & $0.52(20)$ & Tuttc ef all:4iol \\
\hline $119 \mathrm{ln}$ & $1486.1(1)$ & $3-$ & ?ै & 0.737 & $-0.8^{f}$ & $0.63(9)$ & $0.6:(9)$ & $0.4(3)$ & Tulde et $a(11476)$ \\
\hline 115 In & $1447.2(4)$ & $\left(3^{\circ}\right)$ & ?* & $<1$ & $(E 2)$ & $1.33(16)$ & $<0.30(4)$ & - & \\
\hline $119 \ln$ & $1607.8(15)$ & $(\xi *)$ & !* & $\leqslant !$ & $(E 2)$ & $1.54(24)$ & $\leqslant 0.26(4)$ & - & \\
\hline${ }^{116} \mathrm{Sn}$ & $1293.54(2)$ & $2^{\circ}$ & $0^{\circ}$ & 1 & E2 & $3.58(37)$ & $0,53(6)$ & $0.522(14)$ & Carlson et al (19;5) \\
\hline${ }^{118} \mathrm{Sn}$ & $1229.64(4)$ & $2^{+}$ & $0^{\circ}$ & 1 & $E 2$ & $2.75(28)$ & $0.09(7)$ & $0.67(2)$ & Carlsoust al $(14: 6)$ \\
\hline${ }^{120} \mathrm{Sn}$ & $1171.6(2)$ & $?^{*}$ & $0^{\circ}$ & 1 & E2 & $1.83(16)$ & $1.04(y)$ & $0.91(2)$ & Kuslier $(1476)$ \\
\hline${ }^{121} \mathrm{Sb}$ & $1023.5(10)$ & $\vdots$ & $\vdots$ & 1 & $|0.57|^{8}$ & $3.69(34)$ & $0.228(21)$ & $0.20(i)^{h}$ & Tiımura ef al(14;9) \\
\hline${ }^{12} \mathrm{Sb}$ & $1105.5(10)$ & $\xi^{*}$ & $?$ & 0.4 & - & $0.47(4)$ & $0.42(4)$ & - & \\
\hline${ }^{121} \mathrm{Sb}$ & $1142.5(10)$ & $?^{+}$ & 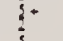 & 0.6 & $(E 2)$ & $0.85(8)$ & $0.449(40)$ & $0,41(s)^{n}$ & Bowthet al $(1973)$ \\
\hline${ }^{121} \mathrm{Sb}$ & 1384.04101 & ?- & $\vdots$ & 1 & $|0,45|^{8}$ & $4.7(5)$ & $0.092(10)$ & $0.0 x \leq(14)^{h}$ & Boothe! al $(1973)$ \\
\hline${ }^{123} \mathrm{Sb}$ & $1029.5(10)$ & $\sum_{3}^{+}$ & 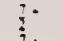 & 1 & $|0,57|^{1}$ & $2.96(27)$ & $0.272(25)$ & $0.26(4)^{3}$ & Borth et a! (1973) \\
\hline${ }^{123} \mathrm{Sb}$ & $1086.5(10)$ & $\xi^{4}$ & $\vdots+$ & 1 & $|\delta|>1.26^{3}$ & $1.06(y)$ & $0.67(6)$ & $0.72(15)^{n}$ & Bowh et al $(1473)$ \\
\hline
\end{tabular}

+ References pour les colonnes 3,4,5. 6 et 9 de chaque ligne, sauf indication appelee au has de ce tableau. Pour tes autres donne:s se reporter au texic.

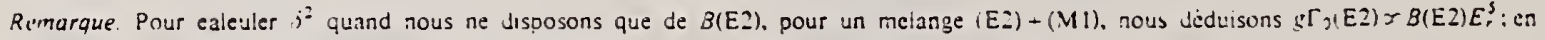

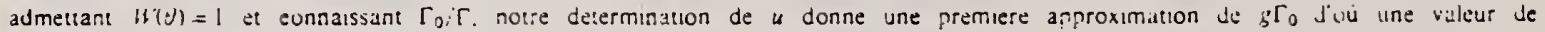
$\left.\delta^{2}=\lg \Gamma_{0}(E Z) /\left(g \Gamma_{0}\right)-g \Gamma_{0}(E 2)\right)$ qui permet d'ameliorer $W^{\prime}(\theta)$ et $g \Gamma_{0}$ de proene en proche.

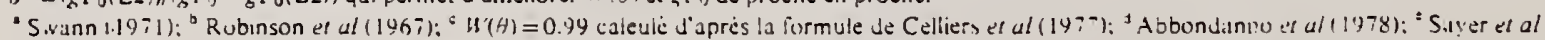
(14:2): 'Tuttle et al 11976): "d'apres B(E2) de Barnes et al (1966): " calcule diıpres Bnoth el al (1973): 'Williams et al(19:5): I Dietricli et ul (1970). 
REF. W.R. Dodge, R.G. Leicht, E. Hayward, E. Wolynec

Phys. Rev. C24, 1952 (1981)

Zn

81 Do 2

\begin{tabular}{|c|c|c|c|c|c|c|c|}
\hline \multirow{2}{*}{ REACTION } & \multirow{2}{*}{ RESULT } & \multirow{2}{*}{$\begin{array}{l}\text { EXCITATION } \\
\text { ENERGY }\end{array}$} & \multicolumn{2}{|c|}{ SOURCE } & \multicolumn{2}{|c|}{ DETECTOR } & \multirow{2}{*}{ ANGLE } \\
\hline & & & TYPE & MANGE & TPPE & . AANGE & \\
\hline$E, P$ & $A B X$ & $7-100$ & $D$ & $16-100$ & MAG-D & & DST \\
\hline$E, A$ & $A B X$ & $4-100$ & $D$ & $16-100$ & MAG-D & & DST \\
\hline & & & & & & & \\
\hline
\end{tabular}

The $(e, p)$ and $(e, \alpha)$ cross sections for ${ }^{56} \mathrm{Fe},{ }^{59} \mathrm{Co}$, and ${ }^{\circ} \mathrm{Zn}$ have been measured in the electron energy range $16-100 \mathrm{MeV}$. They have been analyzed using the distorted-wave

VIRT PHOTON ANAL Bom approximation $E 1$ and $E 2$ virtual photon spectra. The $E 1$ and $E 2$ components i: the proton and $\alpha$ channels have been obtained.

NUCLEAR REACTIONS ${ }^{56} \mathrm{Fe}(e, p),{ }^{56} \mathrm{Fe}(e, a),{ }^{59} \mathrm{Co}(e, p),{ }^{59} \mathrm{Co}(e, a)$, ${ }^{6} \mathrm{Zn}(e, p)$, and ${ }^{\mathrm{a}} \mathrm{Zn}(e, \alpha)$; measured $\sigma\left(E_{0}, E_{x}, 34^{\circ}\right), \sigma\left(E_{0}, E_{x}, 48^{\circ}\right)$, $\sigma\left(E_{0}, E_{x}, 62^{\circ}\right), \sigma\left(E_{0}, E_{x}, 90^{\circ}\right), \sigma\left(E_{0}, E_{x}, 118^{\circ}\right), \sigma\left(E_{0}, E_{x}, 132^{\circ}\right)$; obtained $\sigma(e, p), \sigma(e, a)$; deduced $\sigma_{\gamma, p}^{E 1}(E), \sigma_{\gamma, p}^{E 2}(E), \sigma_{\gamma, a}^{E !}(E), \sigma_{\gamma, a}^{E_{2}}(E)$.
${ }^{13}$ Y. .W., Lui, P. Bogucki, J. D. Bronson, U. Garg, C. M. Rozsa, and D. H. Youngblood, Phys. Lett. 93B, 31 (1980).

its. Costa, F. Ferrero, S. Ferroni, C. Molino and R. Milvano, Phys. Lett. $11,32+(1964) .64 \mathrm{CO}_{0}$

TABLE III. Percentage of the $E 2$ sum when only points up to $50 \mathrm{MeV}\left(E_{0}=50 \mathrm{MeV}\right)$ and when all measured points $\left(E_{0}=100 \mathrm{MeV}\right)$ are considered in the analysis. The bremsstrahlung cross section used is DBM. $E 2$ sum: $0.222^{2} \cdot A^{-1 / 3} \mu \mathrm{b} / \mathrm{MeV}$.

\begin{tabular}{|c|c|c|c|c|c|}
\hline \multirow[b]{2}{*}{ Nucleus } & \multirow[b]{2}{*}{ Reaction } & \multicolumn{2}{|c|}{ Without size effect } & \multicolumn{2}{|c|}{ With size effect } \\
\hline & & $E_{0}=50 \mathrm{MeV}$ & $E_{0}=100 \mathrm{MeV}$ & $E_{0}=50 \mathrm{MeV}$ & $E_{0}=100 \mathrm{MeV}$ \\
\hline${ }^{36} \mathrm{Fe}$ & $\begin{array}{l}(e, a) \\
(e, p)\end{array}$ & $\begin{array}{r}9 \pm 3 \\
47 \pm 30\end{array}$ & $\begin{array}{r}3 \pm 1 \\
8 \pm 11\end{array}$ & $\begin{array}{l}11 \div 3 \\
61 \pm 32\end{array}$ & $\begin{array}{c}7 \pm 1 \\
37 \pm 15\end{array}$ \\
\hline${ }^{39} \mathrm{Co}$ & $\begin{array}{l}(e, \alpha) \\
(e, p)\end{array}$ & $\begin{array}{r}7 \pm 2 \\
32 \pm 22\end{array}$ & $\begin{array}{r}4 \pm 1 \\
4 \pm 8\end{array}$ & $\begin{array}{r}8 \pm 2 \\
48 \pm 24\end{array}$ & $\begin{array}{r}5 \pm 1 \\
28 \pm 11\end{array}$ \\
\hline${ }^{a+} \mathrm{Zn}$ & $\begin{array}{l}(e, a) \\
(e, p)\end{array}$ & $\begin{array}{l}26 \pm 6 \\
29 \pm 43\end{array}$ & $\begin{array}{l}12 \pm 2 \\
26 \pm 15\end{array}$ & $\begin{array}{l}32 \pm 6 \\
56 \pm 46\end{array}$ & $\begin{array}{l}25 \pm 3 \\
77 \pm 2 !\end{array}$ \\
\hline
\end{tabular}

TABLE IV. Percentage of the $E !$ and $E 2$ sums in the $\alpha$ and proton channels. $E 1$ sum: $60 \mathrm{NZ} / \mathrm{A} \mathrm{MeV} \mathrm{mb}$. E2 sum: $0.22 Z^{2} A^{-1 / 3} \mu \mathrm{b} / \mathrm{MeV}$. Integrais to $100 \mathrm{MeV}$.

\begin{tabular}{|c|c|c|c|c|c|}
\hline \multirow[b]{2}{*}{ Nucleus } & \multirow[b]{2}{*}{ Reaction } & \multicolumn{2}{|c|}{$E !$} & \multicolumn{2}{|c|}{$E 2$} \\
\hline & & Schirf & DMB & Schiff & DBM \\
\hline${ }^{36} \mathrm{Fe}$ & $\begin{array}{c}(e, a) \\
(e, p) \\
(e, a)+(e, p)\end{array}$ & $\begin{array}{r}5 \pm 1 \\
67 \pm 20 \\
72 \pm 20\end{array}$ & $\begin{array}{r}6 \pm 1 \\
82 \pm 19 \\
88 \pm 19\end{array}$ & $\begin{array}{l}10 \pm 1 \\
82 \pm 14 \\
92 \pm 14\end{array}$ & $\begin{array}{l}7 \pm 1 \\
37 \pm 15 \\
4 \pm 15\end{array}$ \\
\hline${ }^{50} \mathrm{Co}$ & $\begin{array}{c}(e, \alpha) \\
(e, p) \\
(e, \alpha)+(e, p)\end{array}$ & $\begin{array}{r}5 \pm 1 \\
52 \pm 10 \\
57 \pm 10\end{array}$ & $\begin{array}{l}7 \pm 1 \\
67 \pm 12 \\
74 \pm 12\end{array}$ & $\begin{array}{r}8 \pm 1 \\
63 \pm 10 \\
71 \pm 10\end{array}$ & $\begin{array}{r}5 \pm 1 \\
28 \pm 11 \\
33 \pm 11\end{array}$ \\
\hline${ }^{\infty} \mathrm{Zn}$ & $\begin{array}{c}(e, \alpha) \\
(e, \rho) \\
(e, \alpha)+(e, p)\end{array}$ & $\begin{array}{r}16 \pm 4 \\
129 \pm 28 \\
145 \pm 28\end{array}$ & $\begin{array}{r}18 \pm 4 \\
154 \pm 30 \\
17 \pm \pm 30\end{array}$ & $\begin{array}{r}33=3 \\
137 \pm 30 \\
170=20\end{array}$ & $\begin{array}{r}25 \pm 3 \\
77 \pm 21 \\
102 \pm 21\end{array}$ \\
\hline
\end{tabular}


TABLE VI. El strength integrated up to $30 \mathrm{MleV}$.

\begin{tabular}{|c|c|c|c|c|c|}
\hline \multirow[t]{2}{*}{ Nucleus } & \multicolumn{4}{|c|}{$\int_{0}^{j 0} \sigma_{Y, x}(E) d E(\mathrm{MeV} \mathrm{mb})$} & \multirow{2}{*}{$\begin{array}{l}\text { Fraction } \\
\text { of } E ! \text { sur }\end{array}$} \\
\hline & $a$ & $p$ & $n$ & Total & \\
\hline${ }^{56} \mathrm{Fe}$ & $18 \pm 3$ & $256 \pm 26$ & $735^{2}$ & 1009 & 1.21 \\
\hline${ }^{59} \mathrm{Co}$ & $15 \pm 2$ & $211 \pm 22$ & $884^{\circ}$ & 1110 & 1.26 \\
\hline${ }^{\circ+} \mathrm{Zn}$ & $66 \pm 14$ & $545 \pm 75$ & $616^{\circ}$ & 1227 & 1.28 \\
\hline
\end{tabular}

'Reference 13.

'Reference 14.

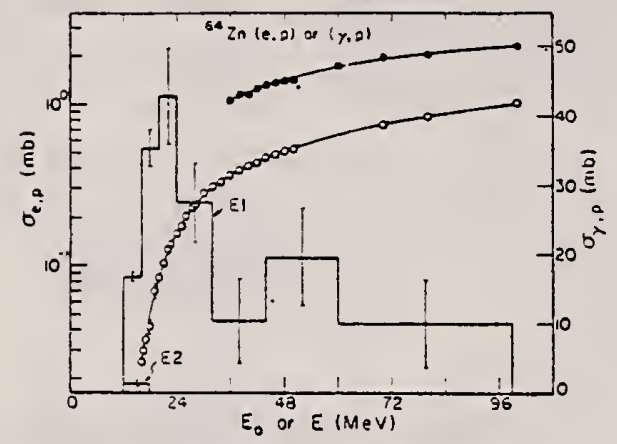

FIG. 5. The $\sigma_{e, p}\left(E_{0}\right)$ for ${ }^{a+Z n}$. See caption of Fig. 3.

FIG. 3. The measured $\sigma_{e p}\left(E_{0}\right)$ for ${ }^{56} \mathrm{Fe}$ as a function of total incident electron energy $E_{0}$ (open circles). The full circles represent the yield $Y_{\text {e.p }}\left(E_{0}\right)$ obtained when a $0.217 \mathrm{~g} / \mathrm{cm}^{2}$ tantalum foil was placed in the electron beam ahead of the target. The smooth curves are the best fits to the data and were obtained by combining the histograms representing the $E 1$ and $E 2\{\gamma, p)$ cross sections (right-hand scale) in Eqs. (1) and (2) with the $E$ l and $E 2 D W B A$ virual photon spectra and by making use of the DBM bremsstrahlung cross section. The size effect correction described in the text has been applied to the yiriual photon spectra.

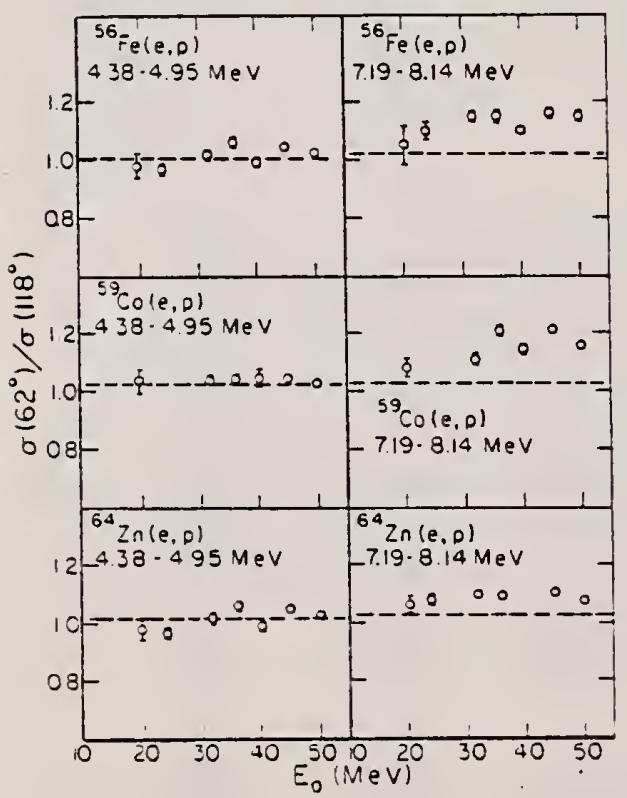

FIG. 9. The ratios of the number of protons obverved in the indicated energy bite $\Delta T$, at $62^{\circ}$ to the same number observed at $118^{\circ}, \sigma\left(62^{\circ}\right) / \sigma\left(118^{\circ}\right)$, as a function of incident clectron energy.

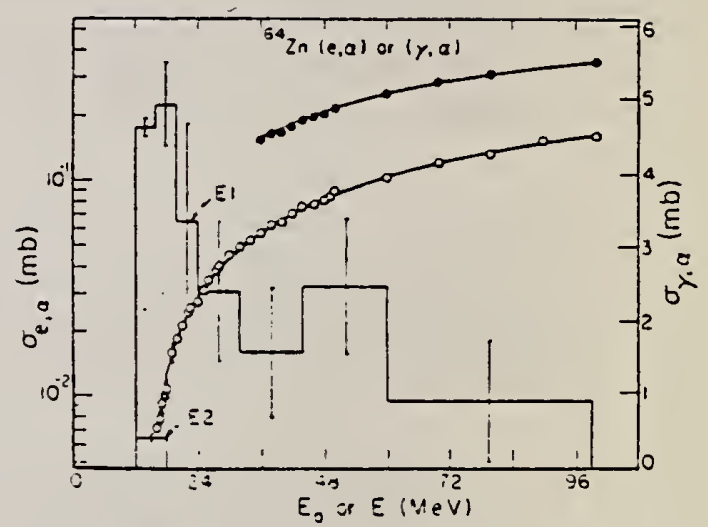

FIG. 3. The $\sigma_{\text {e. }}\left(E_{1}\right)$ for ${ }^{\circ} \mathrm{Zn}$. See caption of Fig. 3.

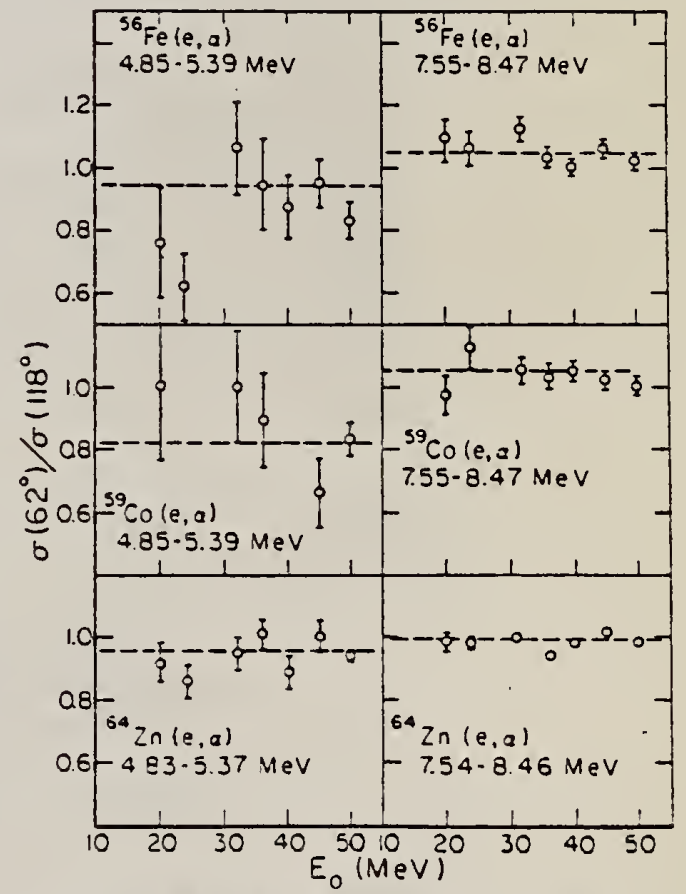

FIG. 10. The ratios of the number of a particles observed in the indicated energy bite $\lambda T_{\alpha}$ at $62^{\circ}$ to the same number observed at $118^{\circ}, \sigma\left(62^{\circ}\right) / \sigma\left(118^{\circ}\right)$, as a function of incident electron energy. 
! M.D. DeSouza Santos, J. Goldemberg, R.R. Pieroni, E. Silva, O.A. Borello, S.S. Villaca, J.L. Lopes

Int. Conf. Peaceful Uses of Atomic Energy II (UN, NY) 169 (1955)

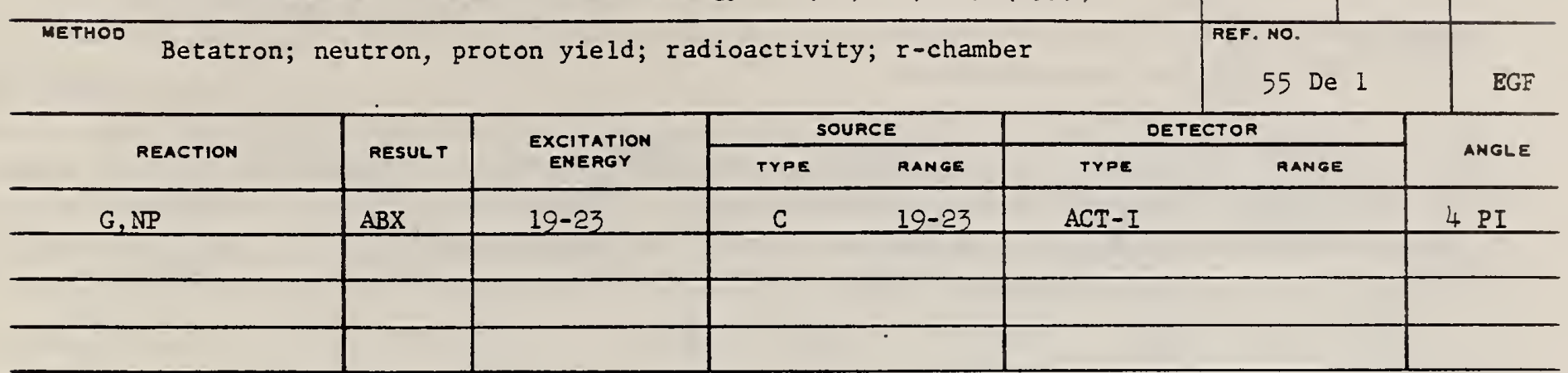

$\sigma(\gamma, \mathrm{n}) / \sigma(\gamma, \mathrm{np})=1.6$ at $21 \mathrm{MeV}$

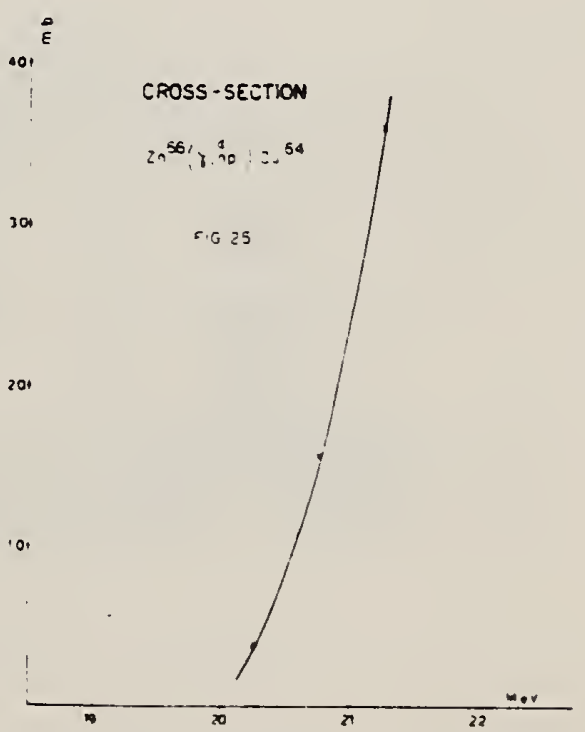


REF.

S.S. Villaca, J. Goldemberg

An. Acad. Brasil. Cienc. 27; 427 (1955)

ELEM. SYM. \&

METHOO

Betatron; ion chamber monitor

REF. NO.

$55 \mathrm{Vi} 1$

NVB

\begin{tabular}{|c|c|c|c|c|c|c|c|}
\hline \multirow{2}{*}{ REACTION } & \multirow{2}{*}{ RESUL T } & \multirow{2}{*}{$\begin{array}{l}\text { EXCITATION } \\
\text { ENERGY }\end{array}$} & \multicolumn{2}{|c|}{ SOURCE } & \multicolumn{2}{|c|}{ DETECTOR } & \multirow{2}{*}{ ANGLE } \\
\hline & & & TYPE & RANGE & TYPE & RANGE & \\
\hline$G, D$ & $A B X$ & $20-22$ & C & $20-22$ & $A C T-I$ & & 4PI \\
\hline & & & & & & & \\
\hline & & & & & & & \\
\hline
\end{tabular}

INCLUDES G.NP

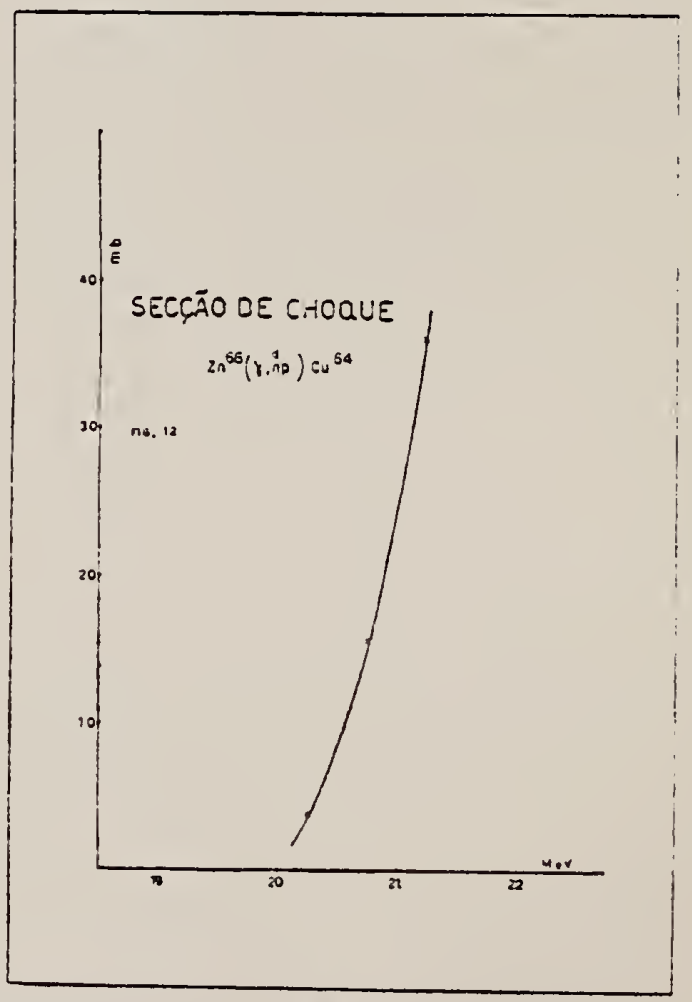

Fig. 12 
Helv. Phys. Acta 30, 265 (1957)

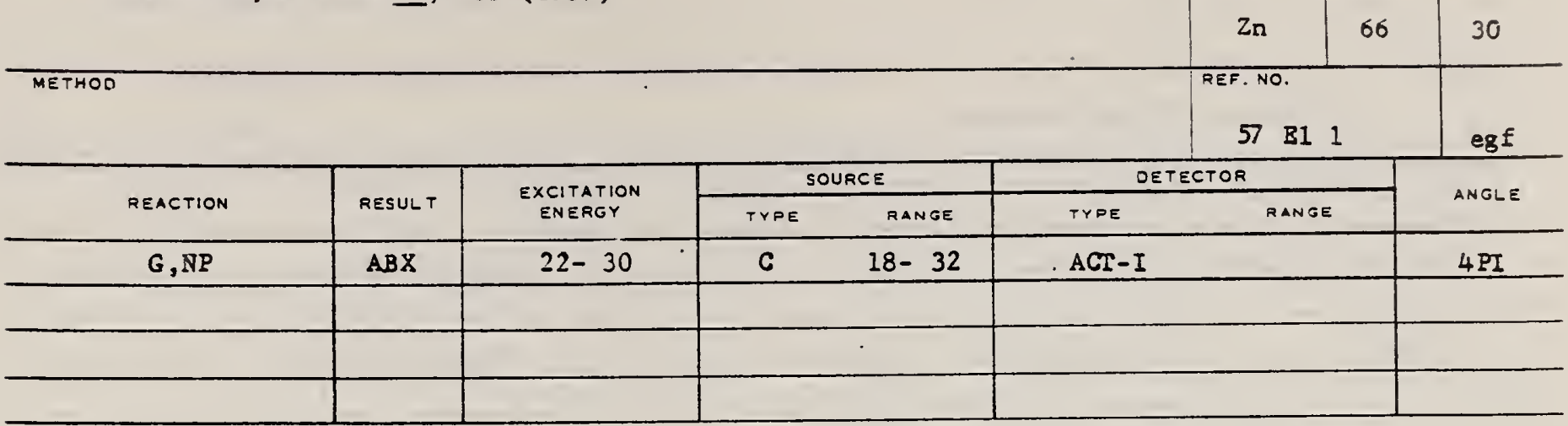

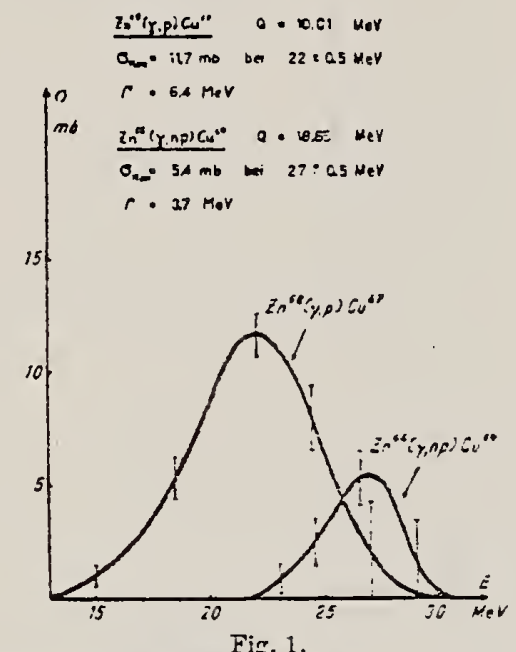

Fig. 1.

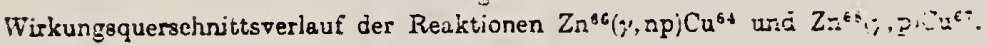

Tabelle 1.

Zusammenatcllung der tem. W. Q.

\begin{tabular}{|c|c|c|c|}
\hline lienktion & $\begin{array}{c}Q-W e r t \\
M c V\end{array}$ & $M e V$ bam & Veriniltnis der Querseinitte \\
\hline$\left.Z n^{86}(y, n p) C u^{a 4 *}\right)$ & 18,65 & 0,02 & $\sigma n^{\circ s}(\mu, p)$ \\
\hline $\left.7 n^{68}(\gamma \cdot p)\left(u^{67 * *}\right)^{8}\right)$ & 10.01 & $0,0 \mathrm{~s}$ & $\sigma_{Z n^{6 n}}(\because, n n)$ \\
\hline$Z n^{84}(\gamma, 2 n) Z n^{92}$ & 20,82 & 0,08 & $\sigma_{7 \mathrm{n}^{86}(\because, n p)}$ \\
\hline $\mathrm{M}_{0}^{02}(\because, n p) \mathrm{N}^{000}$ & 19,5 & 0,02 & $\sigma \% n^{6+}(;, 2 n)$ \\
\hline $\mathrm{Mog}(\%, p) \mathrm{Nb}^{07}$ & & 0.09 & 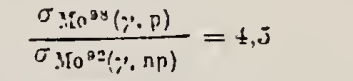 \\
\hline $\begin{array}{l}\Rightarrow \sigma_{\max }: 5,3 \\
\Rightarrow \approx\end{array}$ & (b) & $27 \pm$ & $\begin{array}{ll}\overline{\mathrm{MeV}} & \Gamma=3.7 \mathrm{MeV} \\
\mathrm{MeV} & \Gamma=6.4 \mathrm{Mcl}\end{array}$ \\
\hline
\end{tabular}


Ref. J. Goldemberg, L. Marquez

Nuclear Phys. 1, 202 (1958)

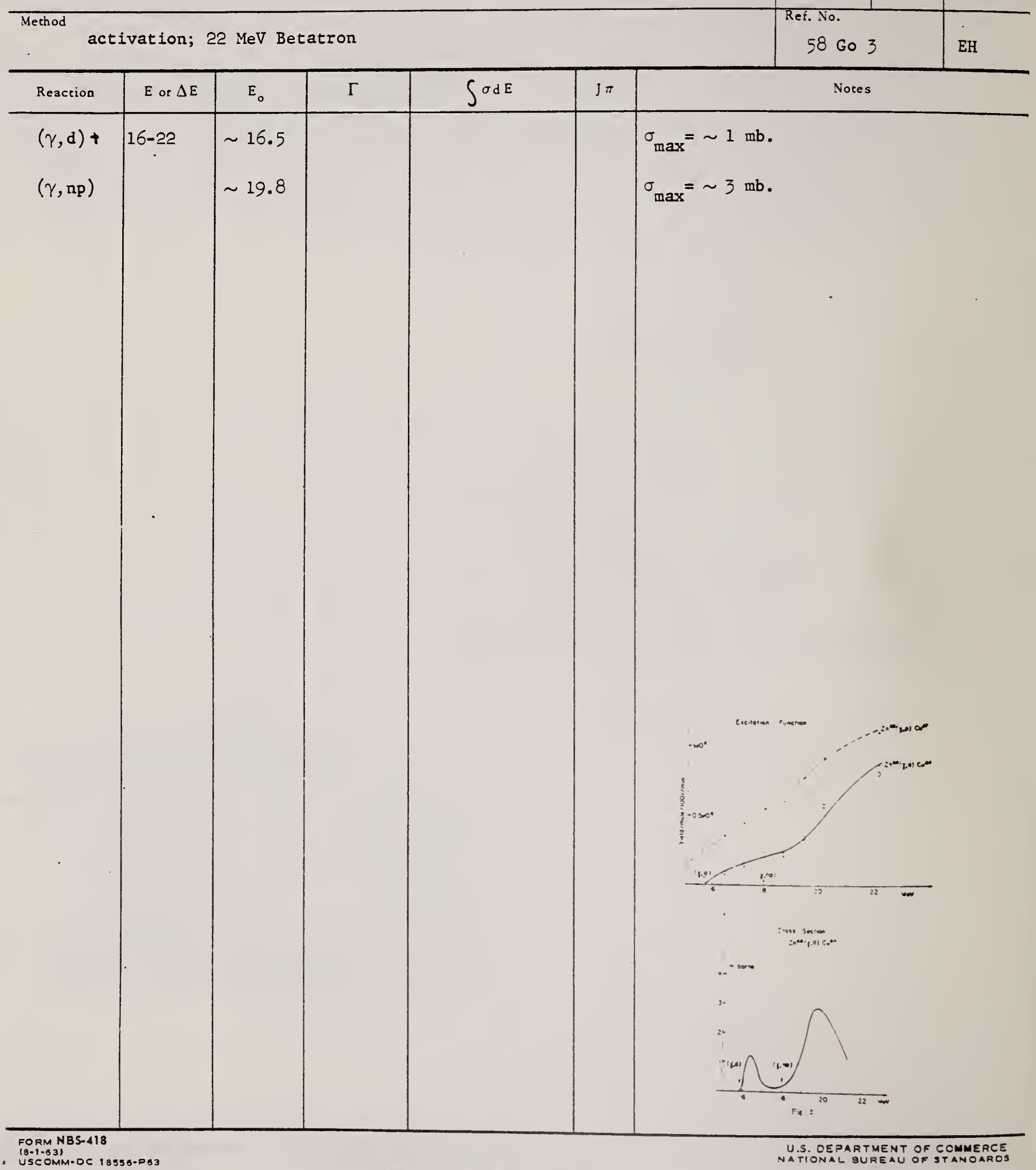


REF.

A. Hofmann, P. Stoll

Aelv. Phys. Acta 31, 591 (1958)

$(Y, n p)$ yfelds include $(Y, d)$.

Tabelic I

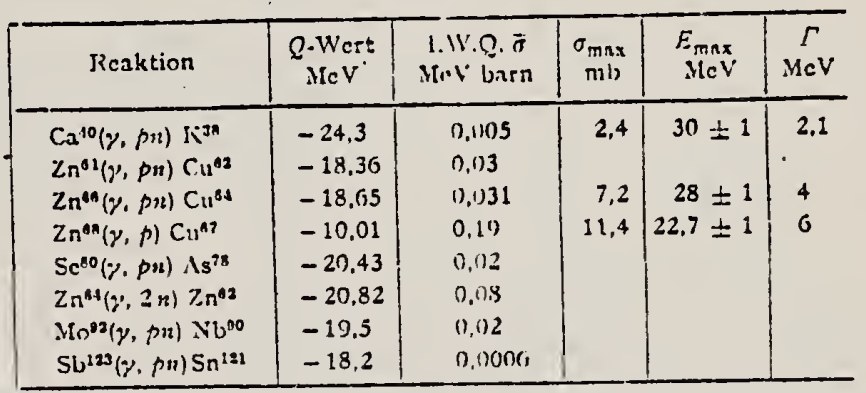

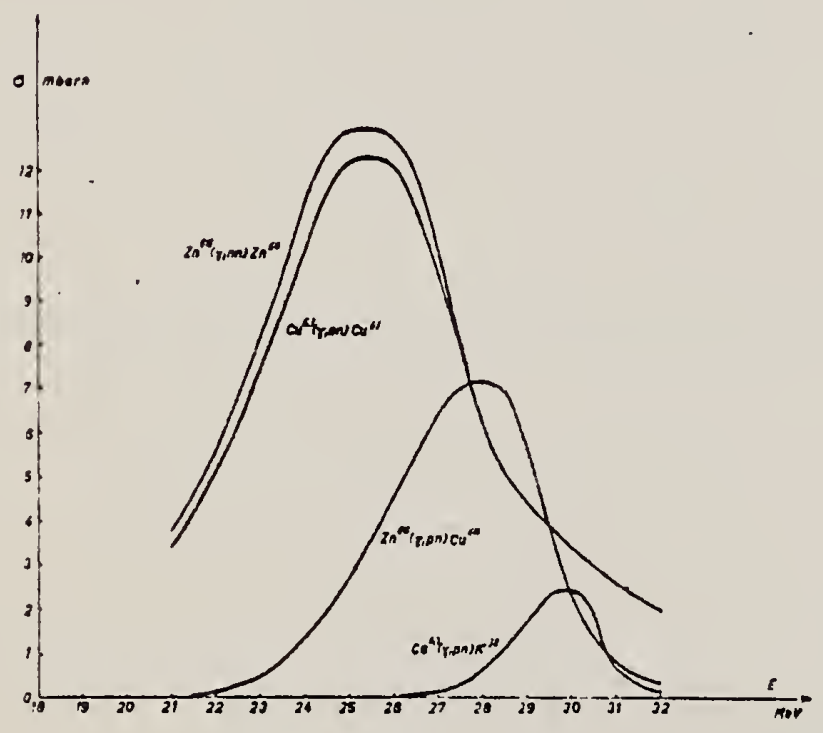

Fig. 1

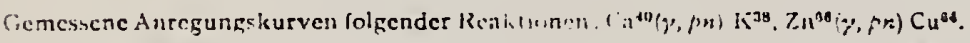

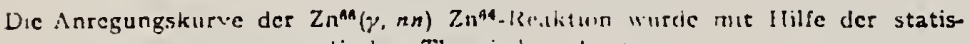
tischen Thenrie luerechnet.

Der Anteil de: $(\gamma, d)$-Reaktion ist in den rulancelicuden $(\gamma \cdot p)$-Anregungskurven cnthallin.

FORM N35. 418

IREV, $7-14-64$ :

USCOMM-NBS-OC
PHOTONUCLEAR DATA SHEET 513

U.S. OEPARTMENT OF COMMERCE 
R. B. Begzhanov and A. A. Islamov

J. Nuc1. Phys. (USSR) 5, 483 (1967)

Sov. J. Nuc1. Phys. 5, 339 (1967)

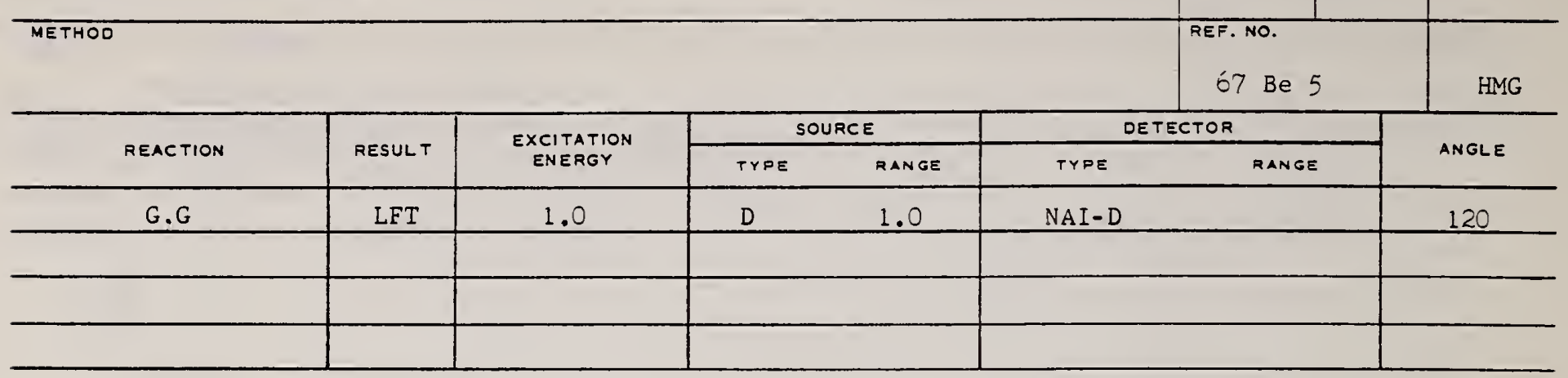

$T=(20 \pm 6) \cdot 10^{-13} \mathrm{sec} \cdot 1.064 \mathrm{MeV}$ 
Y. Oka, T. Kato, K. Nomura, T. Saito, Hui-Tuh Tsai

Bul1. Chem. Soc. Japan 41, 380 (1968)

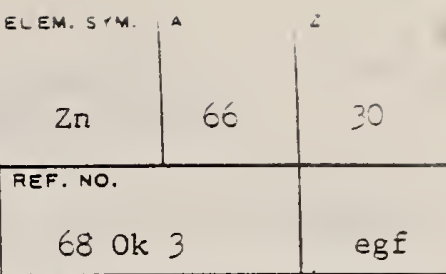

\begin{tabular}{|c|c|c|c|c|c|c|c|}
\hline \multirow{2}{*}{ REACTION } & \multirow{2}{*}{ RESULT } & \multirow{2}{*}{$\begin{array}{l}\text { EXCITATION } \\
\text { ENERGY }\end{array}$} & \multicolumn{2}{|c|}{ SOURCE } & \multicolumn{2}{|c|}{ DETECTOR } & \multirow{2}{*}{ ANGLE } \\
\hline & & & TYPE & RANGE & TYPE & RANGE & \\
\hline$G, N P$ & $A B Y$ & THR- 20 & $\mathrm{C}$ & 20 & $\mathrm{ACT}-\mathrm{I}$ & & $4 \mathrm{PI}$ \\
\hline & & & & & & & \\
\hline & & & & & & & \\
\hline
\end{tabular}

TABLE 2. THE YIELDS OP SOME (T,pn) REACtIONS WTTH $20 \mathrm{MeV}$ BREMSTTRAMLUNO

\begin{tabular}{lccc}
\hline Reaction & $\begin{array}{c}\text { Half-life } \\
\text { of } \\
\text { product }\end{array}$ & $\begin{array}{c}\text { Specific } \\
\text { activity } \\
(\mu \mathrm{Ci} / \mathrm{mg})\end{array}$ & $\begin{array}{c}\text { Yield } \\
(\mathrm{mol}-1 \cdot \mathrm{R}-1)\end{array}$ \\
\hline $\mathrm{Fe}^{\prime}(r, \mathrm{pn})^{34} \mathrm{Mn}$ & $314 \mathrm{~d}$ & $2.5 \times 10^{-4}$ & $3.6 \times 10^{2}$ \\
u $\mathrm{Zn}(r, \mathrm{pn})^{m} \mathrm{Cu}$ & $13 \mathrm{hr}$ & $7.2 \times 10^{-3}$ & $7.5 \times 10^{2}$ \\
$100 \mathrm{Pd}(r, \mathrm{pn})^{1 m \mathrm{Rh}}$ & $210 \mathrm{~d}$ & $1.1 \times 10^{-4}$ & $1.7 \times 10^{2}$ \\
\hline
\end{tabular}

a) The value corrected at the end of $1 \mathrm{hr}$ irradia. tion $(9.4 \times 10 \mathrm{R} / \mathrm{min})$. 


\begin{tabular}{|c|c|c|c|c|c|c|c|}
\hline \multirow[b]{2}{*}{ REACTION } & \multirow[b]{2}{*}{ RESUL T } & \multirow{2}{*}{$\begin{array}{l}\text { EXCITATION } \\
\text { ENERGY }\end{array}$} & \multicolumn{2}{|c|}{ SOURCE } & \multicolumn{2}{|c|}{ DETECTOR } & \multirow{2}{*}{ ANGLE } \\
\hline & & & TYPE & RANGE & TYPE & RANGE & \\
\hline \multirow[t]{2}{*}{$G, G$} & NOX & 7 & D & 7 & SCD & $1-7$ & DST \\
\hline & & $(7.368)$ & & $(7.368)$ & & & \\
\hline \multirow{2}{*}{\multicolumn{7}{|c|}{$\begin{array}{c}\text { TABLE } 2 \\
\text { Excitation energies of levels of " } \mathrm{Zn} \text { populated by the transitions from the resonant level and reduced } \\
\text { transition probabilities from the resonant level to the levels }\end{array}$}} & \\
\hline & & & & & & & $368 \mathrm{M}$ \\
\hline
\end{tabular}

\begin{tabular}{ccccc}
\hline $\begin{array}{c}\text { Excitation } \\
\text { energy } \\
(\mathrm{keV})\end{array}$ & $\begin{array}{c}\text { Spin and } \\
\text { parity }\end{array}$ & $\begin{array}{c}\text { Gamma-ray } \\
\text { energy } \\
(\mathrm{keV})\end{array}$ & $\begin{array}{c}\text { Relative } \\
\text { intensity }\end{array}$ & $\begin{array}{c}\text { Reduced } \\
\text { transition } \\
\text { probability } \\
\text { (arbitrary units) -) }\end{array}$ \\
\hline 0 & $0^{+}$ & 7368 & 100 & 25.7 \\
1039 & $2^{+}$ & 6326 & $\approx 0.3$ & $\approx 0.1$ \\
1873 & $2^{+}$ & 5495 & 14.3 & -8.6 \\
2373 & $0^{+}$ & 4995 & $\$ 0.4$ & $\$ 0.3$ \\
3106 & 0 & 4262 & 8.6 & 10.5 \\
3528 & 0 & 3840 & 1.6 & 2.8 \\
3824 & 0 & 3544 & 1.6 & 3.6 \\
\hline
\end{tabular}

2) Reduced transition probability is defined as $I_{y} / E_{y}$, where $J_{y}$ and $E_{y}$ denote the relative intensity and the gamma-ray energy, respectively.

Fig. 10. Partial decay scheme for the $7368 \mathrm{keV}$ level of " $\mathrm{Zn}$. The transitions are labelled by energy in $\mathrm{keV}$. The relative intensities are given in parentheses.

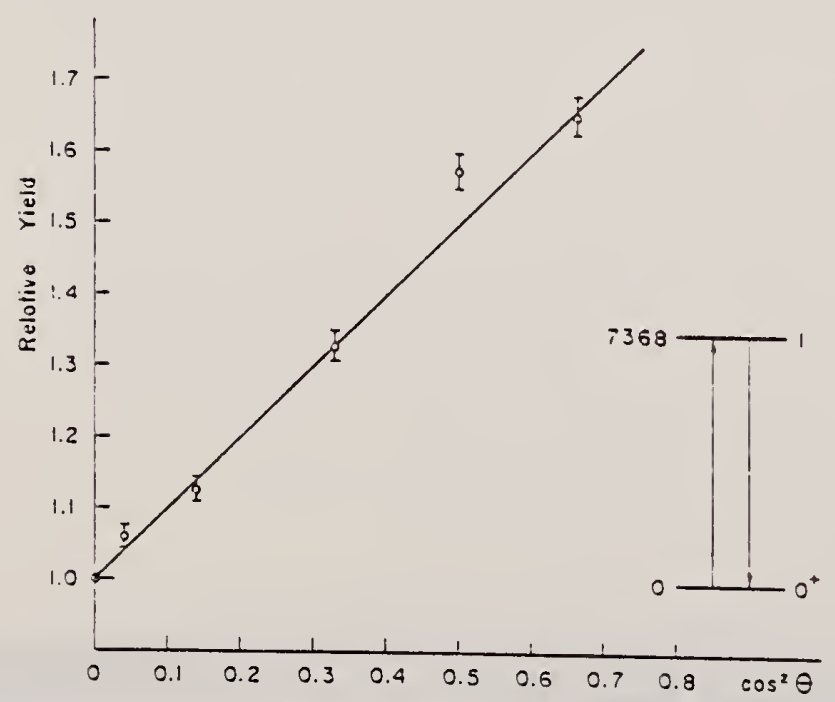




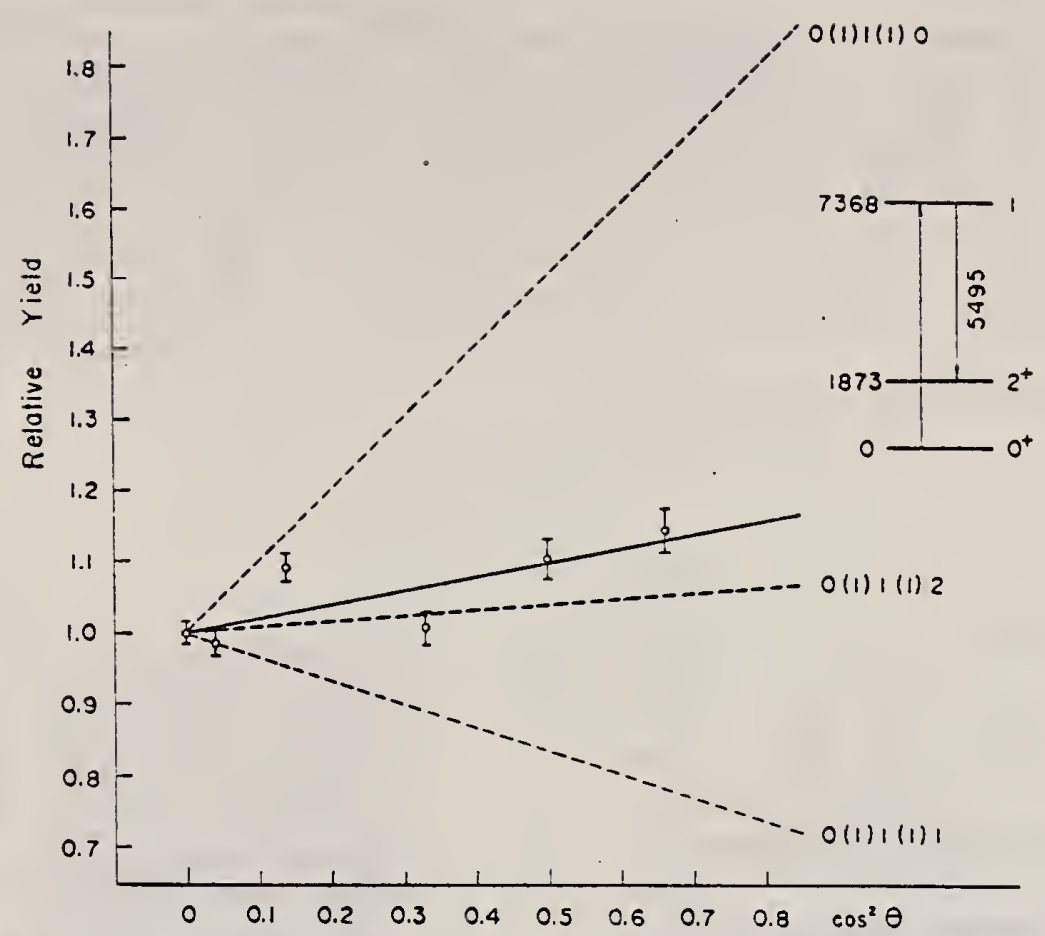

Fig. 6. Angular distribution of the inelastically scattered $5495 \mathrm{keV}$ gamma ray. The solid line is obtained by a least-squares fit to the experimental points. The dashed lines indicate the theoretical lines for $0(1) 1(1) 0,0(1) 1(1) 1$ and $0(1) 1(1) 2$ sequences.

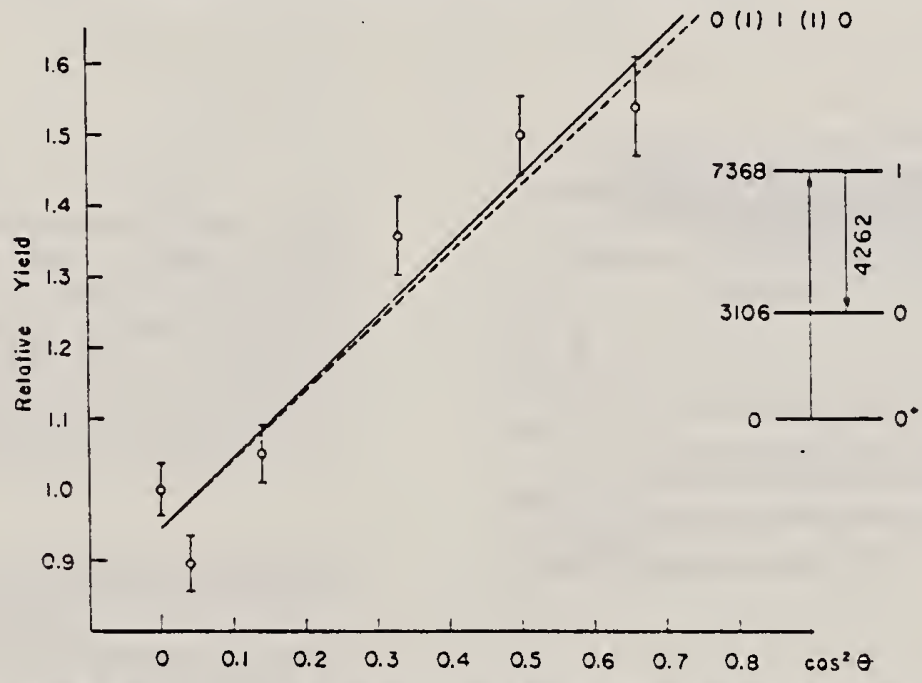

Fig. 7. Angular distribution of the inelastically scattered $4262 \mathrm{keV}$ gamma ray. The solid line is obtained by a least-squares fit to the experimental points. The dashed line indicates the theoretical line for a 0 (1) i (1)0 sequence. 
N. Shikazono and Y. Kawarasaki

J. Phys. Soc. Japan 27, 273 (1969)

$69 \mathrm{Sh} 1$

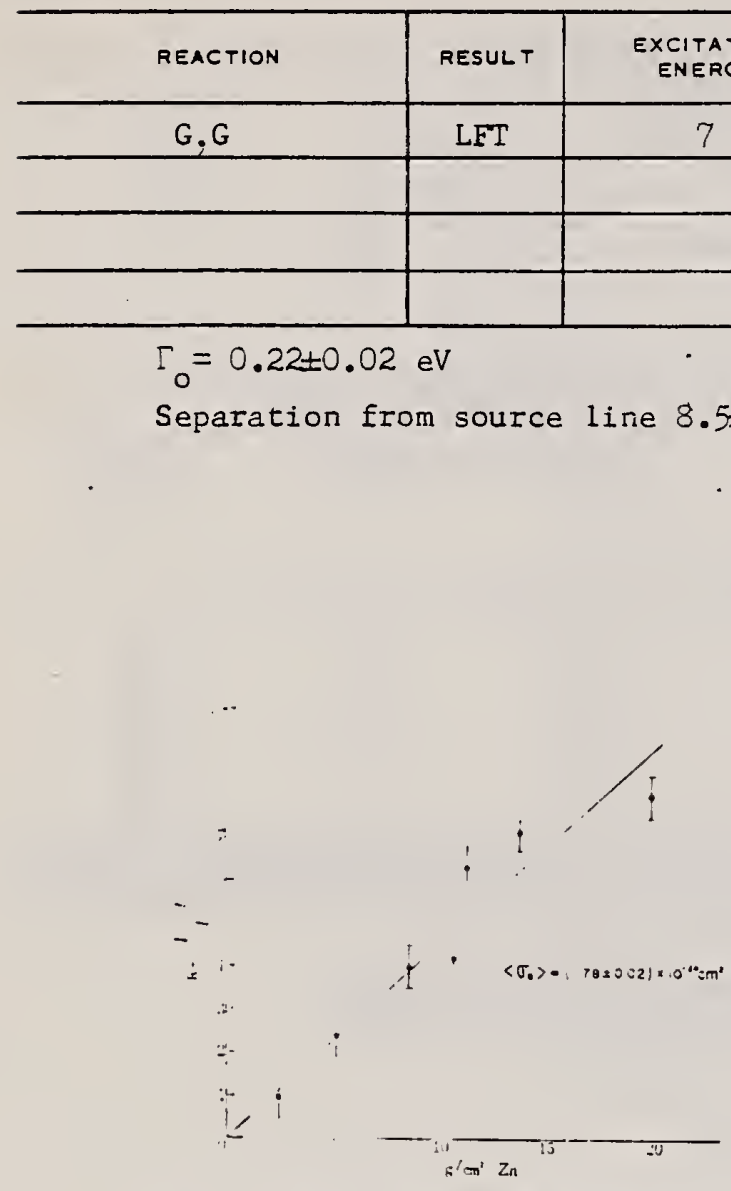

Fig. 3. Sulf-absurption ratio versus zinc absorber thickncss. The solid line indicates the least-squares fit. Lirresponding the value of the effective absorpor -ioss section to be $1.78 \pm 0.02$ barns.

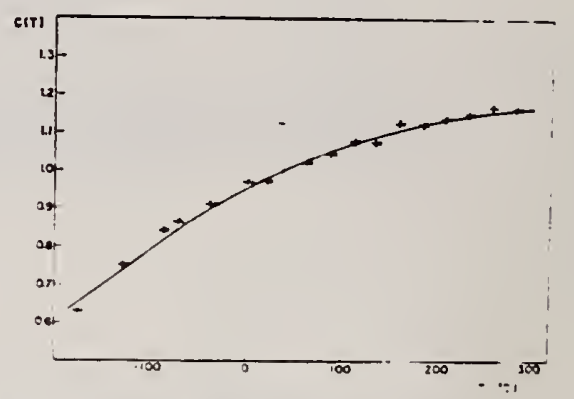

Fig. 4. Relative intensity of the sattered photons versus temperature of the scatterer. The intensity at $39^{\circ} \mathrm{C}$ is normalized to unity. The solid curve indicates a theoretical one calculared with best fit parameters: $\theta_{Z n}=350^{\circ} \mathrm{K}, j=8.5 \mathrm{eV}, \Gamma_{0}=0.22 \mathrm{eV}$, where $\theta_{Z n}$ is the Debye temperature of zinc. is the separation energy between source and target levels and $\Gamma_{0}$ the ground-state irans-ition width. 
ref. V.D. Afanas'ev, N.G. Afanas'ev, A. Yu. Buki, G.A. Savitskii,

V.M. Khvastunov, N.G. Shevchenko

Yad. Fiz. 12,885 (1970)

Sov. J. Nucl. Phys. 12,480 (1971)

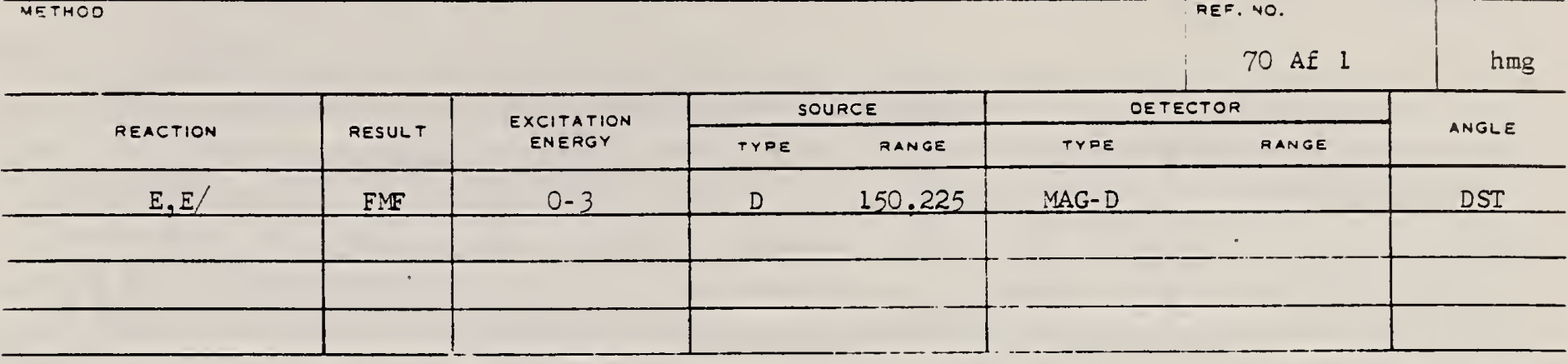

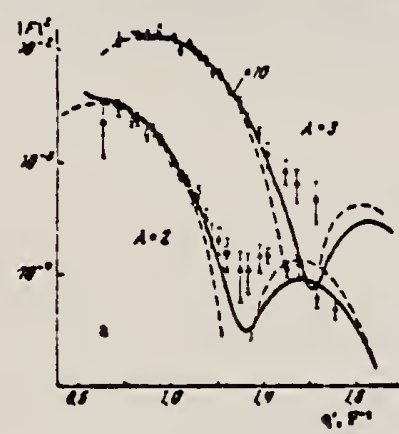

FIG. 2. Form factors of $E_{2}$ and $E_{3}$ transitions in $\mathrm{Zn}^{64}$ (a) and $\mathrm{Zn}^{66}(\mathrm{~b})$. The solid curves pertain to the vibrational model with calculations in the high-energy approximation; the dashed eurves pertain to llelm's model with cat culations in the Bom approxima tion. The experimental values and curves for $E 3$ transitions are enlarged 10-rold. Points: $O-E_{0}=$ $150 \mathrm{MeV}, 0-\mathrm{E}_{0}=225 \mathrm{MeV}$.

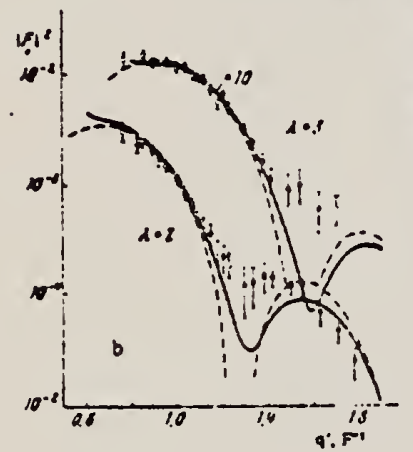

Table II. Parameters of the charge distribution in. $\mathrm{Zn}$ isotopes for the Fermi model and the Gaussian uniform model

\begin{tabular}{|c|c|c|c|c|}
\hline \multirow{2}{*}{1 sotopen } & \multicolumn{2}{|c|}{ Forml model } & \multicolumn{2}{|c|}{ Gousuen uniform model } \\
\hline & $a . F$ & $4 F$ & $R, F$ & $2 F$ \\
\hline $\begin{array}{l}2 n^{\circ} \\
2 n^{40}\end{array}$ & $\begin{array}{l}1.2655+0.015 \\
4.271+0.022\end{array}$ & $\begin{array}{l}2.751+0.017 \\
2.803+0.027\end{array}$ & $\begin{array}{l}4.500=0.017 \\
1.009-0.025\end{array}$ & $\begin{array}{l}0.21=0.015 \\
0.8 \times n=0.014\end{array}$ \\
\hline
\end{tabular}

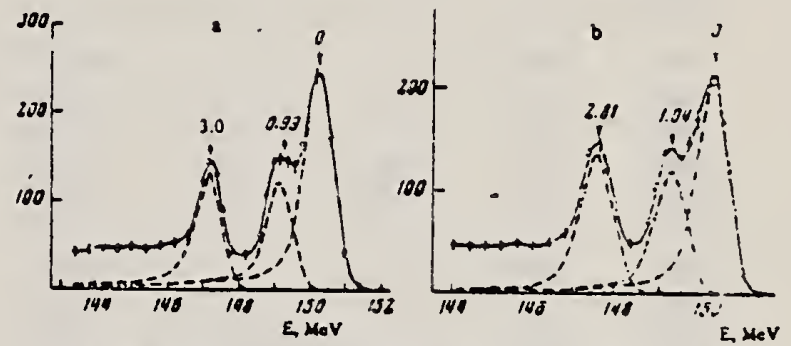

FIC. 1. Spectra of clictrons seatteres by (a) $\mathrm{Zn}^{\text {ot }}$ and (b) $Z n^{\omega}$ at $75^{\circ}\left(E_{0}=150 \mathrm{MeV}\right)$. Ordinates are given in arbitary units

Table I. Reduced probabillties and fltting parameters $N_{\lambda}$ and $B_{\lambda}$ of $E 2$ and $E 3$ transitions in $\mathrm{Zn}$ isotopes

\begin{tabular}{|c|c|c|c|c|c|c|c|c|}
\hline \multirow{2}{*}{$\begin{array}{l}\frac{2}{3} \\
\underline{3} \\
\underline{3}\end{array}$} & \multirow{2}{*}{$\begin{array}{l}\vec{z} \\
\mathbf{z} \\
\mathbf{u}\end{array}$} & \multirow{2}{*}{$11^{\circ}$} & \multicolumn{2}{|c|}{ Vibrational moded } & \multicolumn{2}{|c|}{ Hetn's model } & \multicolumn{2}{|c|}{ Outrea remills } \\
\hline & & & $N_{1} \infty$ & $\|(n<) 4$ & $A_{x} \cdot 10$ & $H(x, 1)\}$ & $\begin{array}{c}\text { Bif.n } \\
\text { (expertiment) }\end{array}$ & $\begin{array}{c}\text { RiE2) } \\
\text { (Wheory) }\end{array}$ \\
\hline & $\left\{\begin{array}{l}1.04 \\
0\end{array}\right.$ & 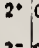 & $0.141+0.009$ & $1780+140$ & $0.516 \pm 0.01 A$ & $1, \infty+\infty$ & $11000(160)$ & 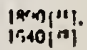 \\
\hline & $\left\{\begin{array}{l}0.93 \\
2.81\end{array}\right\}$ & $3 \cdot 6$ & $.144 \div 0.008$ & $1000+150$ & $\left\{\begin{array}{l}0.587 \pm 0.017 \\
0.48\end{array}\right.$ & $\begin{array}{c}27100+1500 \\
1530+74 \\
25000+17000\end{array}$ & 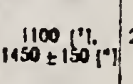 & 2000 !"l \\
\hline
\end{tabular}

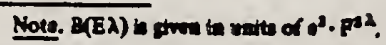




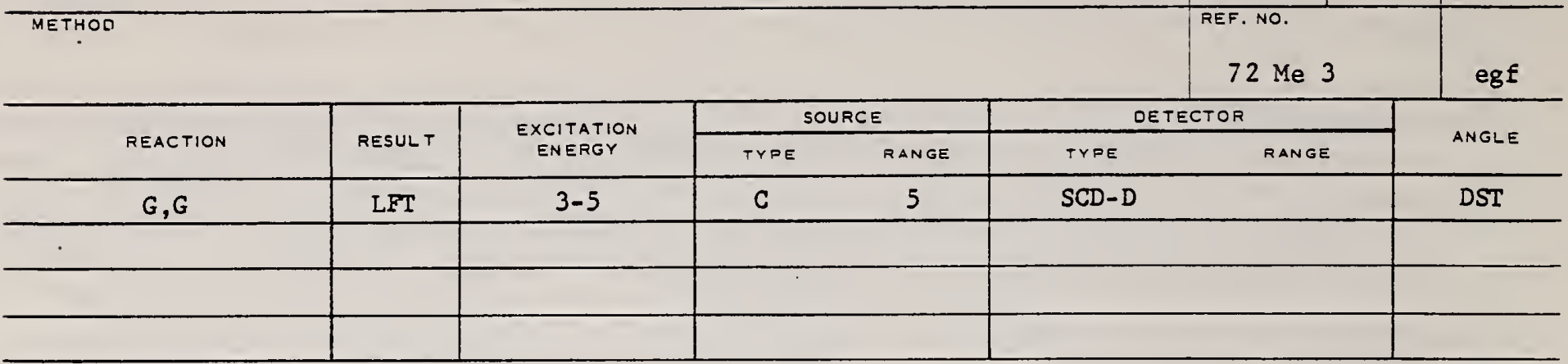

TABLE :

Propertics of the $\mathrm{Zn}$ leveis observed in the bremsstrahlung experiments

\begin{tabular}{|c|c|c|c|c|c|c|}
\hline $\begin{array}{l}\text { Encrgy } \\
\text { (kev') }\end{array}$ & Isotupe & Spin & Parity & $\Gamma_{0} / \Gamma$ & $\Gamma_{0}$ (meV) & $\Gamma_{0}$ in. (meV) \\
\hline $33+6$ & (68) & 1 & & $\left.(0.70)^{4}\right)$ & $42 \pm 7$ & $9.9<10^{-4}(E 1)$ \\
\hline 3366 & 6 & $1 \bullet$ & $+\infty$ & $\left.0.54^{\circ}\right)$ & $8.2=1.3$ & $\begin{array}{r}10.061 \\
0.012\end{array}$ \\
\hline$\vdots 381$ & 66 & 1 & $(*)$ & $0.69 \circ$ & $16=3$ & 0.022 \\
\hline $54: 5$ & 64 & $1 " 1$ & $+\infty$ & $\left.0.72^{\circ}\right)$ & $6.9 \doteq 1.6$ & 0.009 \\
\hline .433 & (66) & (1) 4.0$)$ & $\left.(-)^{\circ}\right)$ & $0.51 \cdot$ & $8=3$ & $1.7 \therefore 10^{-4}$ \\
\hline 3704 & 64 & 1 & $(-)$ & $\left.(1.0)^{\prime}\right)$ & $18=3$ & $3.2 \times 10^{-4}$ \\
\hline 3717 & (68) & (1) & & $\left.(1.0)^{\prime}\right)$ & $8.5 \pm 2.2$ & $\begin{cases}1.5 \times 10^{-4} & (\mathrm{EI}) \\
0.009 & (\mathrm{MI})\end{cases}$ \\
\hline 3739 & 66 & 1 & $(-)$ & $\left.(1.0)^{\prime}\right)$ & $24=3$ & $4.1 \times 10^{-4}$ \\
\hline$+1 \leq 9$ & $6+4$ & 1 & $(-)$ & $\left.(0.54)^{\circ}\right)$ & $32=9$ & $4.0 \cdot 10^{-6}$ \\
\hline+295 & 66 & 10 & $(*)$ & $\left.0.60^{\circ}\right)$ & $67=20$ & 0.046 \\
\hline$\$ 339$ & 1081 & (1) & & $\left.(1.0)^{\prime}\right)$ & $38=10$ & $\begin{cases}4.2 \cdot 10^{-4} & (E 1) \\
0.025 & (\mathrm{M} 1)\end{cases}$ \\
\hline$+4: 6$ & 66 & 1 & $(-)$ & $\left.(1.0)^{\prime}\right)$ & $65=10$ & $6.8 \times 10^{-4}$ \\
\hline HSS & 64 & $1 " 1$ & +0 & $(1.0)^{(.0)}$ & $51=9$ & 0.031 \\
\hline 462 & 66 & $1 \bullet$ & $(+)^{(\cdot 1)}$ & $0.29 \varphi^{\circ}$ & $28 \pm 21$ & 0.017 \\
\hline 466 & (68) & 1 & & $\left.(1.0)^{\prime}\right)$ & $65 \pm 19$ & $\begin{array}{l}16.5 \times 10^{-4}(\mathrm{E} 1) \\
10.040 \quad(\mathrm{MI})\end{array}$ \\
\hline 4503 & (68) & (1) & & $\left.(1.0)^{\prime}\right)$ & $38=13$ & $\begin{array}{ll}3.6 \times 10^{-6}(E I) \\
0.023 \quad(\mathrm{M})\end{array}$ \\
\hline 4609 & (66) & (1) & & $\left.(1.0)^{\prime}\right)$ & $54=15$ & $\begin{cases}5.0 \div 10^{-6} & (1: 1) \\
0.030 & \text { (MI) }\end{cases}$ \\
\hline 4664 & (64) & (1) & & $\left.(1.0)^{\prime}\right)$ & $11 \pm 4$ & $\mid \begin{array}{ll}11.0 \times 10^{-6} & \left(\mathrm{~L}_{1}\right) \\
0.006 & (\mathrm{M})\end{array}$ \\
\hline+685 & (66) & (1) & & $\left.(1.0)^{\prime}\right)$ & $64=16$ & $\begin{cases}5.6 \times 10^{-4}\left(E_{1}\right) \\
0.034(M 1)\end{cases}$ \\
\hline 4805 & (66) & $1 \bullet$ & $-\bullet$ & $\left.0.81^{\circ}\right)$ & $100=25$ & 0.049 \\
\hline
\end{tabular}

-) Based on ref. '), see text.

") Rer. '

') Ref. (12).

4) Ref. ${ }^{2}$.

-) Ref. ${ }^{10}$ ).

1) Assumed in the absence of evidence for branching.

1) Assuming that the branch to the $21^{*}$ state, seen in the bremsstrahlung experiment, is the only branch to an excited state.

-) Refis. 11.12 ) contradict each other with respect to this brancting.

1) Ref. ${ }^{10}$, favors a (-) assignment. See text. 
b) H. Verhcul. Nucl. Data B2-3 (1967) 65

2) M. J. Martin and M. N. Rao. Nucl. Data B2-6 (196s) t3

3) F. R. Metzger, Annual progress report for 1967, AEC contract AT(30-1)-3525, Nucl. Sci. Abstr. $2=-7661,1968$

4) F. R. Metzger, Annual progress report for 1968, AEC contract AT(30-1)-3525, Nucl. Sci. Abstr. 23-154i1. 1969

5) F. R. Metzger, Phys. Rev. Letl. 18 (1967) +34: Phys Rev. 171 (1968) 1257;

M. Eerman and G. H. Bearu. Phys. Rev. C2 11970$) 1.506$ :

M. Schumather, J. Weiss and H. Langhofr, Phys. Lcte. 31B (1969) 61:

H. Langhorf, Phys. Rev. A3 (1971) I

6) F. R. Metzger, Phys. Rev. 187 (1969) 1680, 1700: Nucl. Phys. A182 (1972) 213

7) F. R. Wetzger, Nucl. Phys. A158 $(1970) 88$

8) R. P. Singh and M. L. Rustgi, Phys. Rev. C3 (1971) 1172

$\rightarrow$ H. Ottmar, N. M. Ahmed, U. Fanger, D. Heck, W. Michaelis and H. Schmidt, Nucl. Phys. A164 (1971) 69

10) D. C. Camp and G. L. Meredith, Nucl. Phys. A166 (1971) 349

11) J. Konijn, R. van Lieshout, J. P. Deutsch and L. Grenacs, Vucl. Phys. A91 (1967) 439

12) L. G. Mann, K. G. Jirsell and S. D. Bivon, Nici. Phys. 197 (1967) +25 
H. Szichman

2. Physik 259, 217 (1973)

$73 \mathrm{Sz} 2$

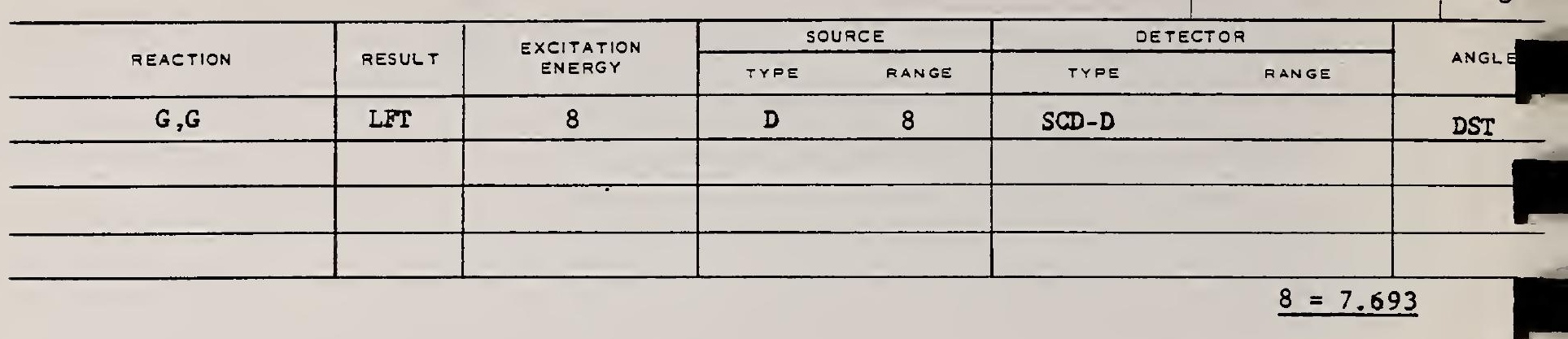

Table 1. Reduced partial radiation widths of resonance levels in ${ }^{66} \mathrm{Zn},{ }^{144} \mathrm{Sm}$ and ${ }^{120} \mathrm{Sn}$

\begin{tabular}{|c|c|c|c|c|c|c|c|}
\hline \multirow[t]{2}{*}{ Nucleus } & \multirow{2}{*}{$\begin{array}{l}\text { Energy of } \\
\text { transition } \\
(\mathrm{keV})\end{array}$} & \multirow[t]{2}{*}{$\begin{array}{l}\text { Energy of } \\
\text { final state }\end{array}$} & \multirow{2}{*}{$\begin{array}{l}\text { Relative } \\
\text { intensity } \Gamma_{J} / \Gamma_{0} \\
\text { (in percent) }\end{array}$} & \multicolumn{2}{|c|}{$\begin{array}{l}\text { Reduced widths } \\
\left(\mathrm{eV} \cdot \mathrm{meV}^{-4} \times 10^{3}\right)\end{array}$} & \multirow[t]{2}{*}{$\begin{array}{l}\text { Most likely } \\
\text { characters }\end{array}$} & \multirow{2}{*}{$\begin{array}{l}\text { Derived spin } \\
\text { and parity } \\
\text { values } \\
J_{\pi}\end{array}$} \\
\hline & & & & $K(E I)$ & $K(M 1)$ & & \\
\hline${ }^{60} \mathrm{Zn}$ & $\begin{array}{l}7693 \\
6654 \\
5819 \\
5321 \\
4930 \\
4755 \\
4587 \\
4480 \\
4452 \\
4361 \\
4263 \\
4187\end{array}$ & 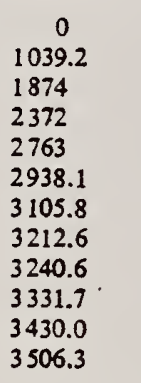 & $\begin{aligned} 100 & \pm 1 \\
42 & \pm 1 \\
<2 & \\
<3 & \\
<2 & \\
24 & \pm 2 \\
8 & \pm 1 \\
21 & \pm 2 \\
7 & \pm 2 \\
13 & \pm 2 \\
25 & \pm 3 \\
8 & \pm 2\end{aligned}$ & $\begin{array}{l}6 \pm 1 \\
4 \pm 1 \\
<0.3 \\
<0.6 \\
<0.5 \\
7 \pm 2 \\
2.4 \pm 0.6 \\
7 \pm 2 \\
2.3 \pm 0.8 \\
5 \pm 1 \\
9 \pm 2 \\
3 \pm 1\end{array}$ & $\begin{array}{l}105 \pm 21 \\
68 \pm 14 \\
<5 \\
<9 \\
<8 \\
106 \pm 23 \\
39 \pm 9 \\
111 \pm 25 \\
38 \pm 13 \\
75 \pm 19 \\
154 \pm 36 \\
52 \pm 17\end{array}$ & $\begin{array}{l}E_{1} \\
E_{1} \\
E_{1} \text { or } M 1 \\
E_{1} \text { or } . M 1 \\
E_{1} \text { or } M 1 \\
E_{1} \\
E_{1} \text { or } M 1 \\
E_{1} \\
E_{1} \text { or } M 1 \\
E_{1} \\
E_{1} \\
E_{1} \text { or } M 1\end{array}$ & $\begin{array}{l}0+ \\
2+ \\
0,1,2 \\
0,1,2 \\
0,1,2 \\
0+ \\
0,1,2 \\
0+ \\
0,1,2 \\
0,2+ \\
0,2+ \\
0,1,2\end{array}$ \\
\hline${ }^{144} \mathrm{Sm}$ & $\begin{array}{l}8995 \\
7333 \\
6828 \\
6568 \\
6514 \\
6191\end{array}$ & $\begin{array}{c}c \\
1662.0 \\
2167 \\
2426.5 \\
2480.7 \\
2804.1\end{array}$ & 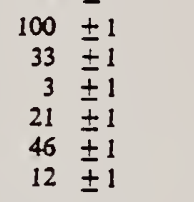 & $\begin{array}{r}15 \pm 3 \\
9 \pm 2 \\
10 \pm 4 \\
8 \pm 2 \\
18 \pm 4 \\
6 \pm 1\end{array}$ & $\begin{array}{r}412 \pm 82 \\
251 \pm 50 \\
28 \pm 11 \\
222 \pm 44 \\
499 \pm 100 \\
164 \pm 33\end{array}$ & $\begin{array}{l}E_{1} \\
E_{1} \\
E_{1} \text { or } M_{1} \\
E_{1} \\
E_{1} \\
E_{1}\end{array}$ & $\begin{array}{l}0+ \\
2+ \\
0,1,2 \\
2+ \\
0+ \\
2+\end{array}$ \\
\hline${ }^{120} \mathrm{So}$ & $\begin{array}{l}7693 \\
6522 \\
5520 \\
5337\end{array}$ & $\begin{array}{c}0 \\
1171.4 \\
2172.9 \\
2356.0\end{array}$ & $\begin{array}{r}100 \pm 1.0 \\
7.3 \pm 0.5 \\
1.4 \pm 0.3 \\
12.3 \pm 0.8\end{array}$ & $\begin{array}{l}38 \pm 11 \\
5 \pm 1 \\
1.4 \pm 0.4 \\
14 \pm 4\end{array}$ & $\begin{array}{r}932 \pm 266 \\
112 \pm 32 \\
35 \pm 10 \\
343 \pm 98\end{array}$ & $\begin{array}{l}E_{1} \\
E_{1} \\
E_{1} \text { or } H 1 \\
E_{1}\end{array}$ & $\begin{array}{l}0+ \\
2+ \\
0,1,2 \\
2+\end{array}$ \\
\hline
\end{tabular}


REF. A.M. Goryachev, G.N. Zalesnyi, and B.A. Tulupov Izv. Akad. Nauk SSSR. Ser. Fiz. 39, 134 (1975)

Bul1. Acad. Sci. USSR Phys. Ser. 39,116 (1975)

\begin{tabular}{|c|c|c|c|c|c|c|c|}
\hline METHOD & & & & & & & \\
\hline \multicolumn{3}{|c|}{ REACTION } & RESULT & \multicolumn{3}{|c|}{$\begin{array}{l}\text { EXCITATION } \\
\text { ENERGY }\end{array}$} & TrP \\
\hline \multicolumn{3}{|c|}{$G, X N$} & $\mathrm{ABX}$ & \multicolumn{3}{|c|}{$11-25$} & C \\
\hline \multirow[t]{2}{*}{$\sigma(G, S N)$} & \multicolumn{7}{|c|}{$\begin{array}{l}\text { statistical theory used to obtain SN c } \\
\text { section from XN cross section. }\end{array}$} \\
\hline & \multicolumn{6}{|c|}{ Table 2} & • \\
\hline Nuclide & B. & $E_{2}$, MeV & $\varepsilon_{1}$, Mev & Nuclide & $\beta_{2}$ & $E_{2}$, MeV & $\varepsilon_{1}$, MeV \\
\hline 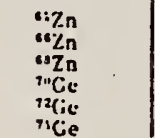 & $\begin{array}{l}0,2=1 \\
0.23 \\
0,2 \\
0,2,3 \\
1,2.1 \\
0,3\end{array}$ & $\begin{array}{l}0.99 \\
1.194 \\
1.08 \\
1.04 \\
0.830 \\
0.6\end{array}$ & 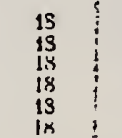 & 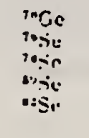 & $\begin{array}{l}0.23 \\
0.33 \\
0.3 \\
0.25 \\
0.2\end{array}$ & $\begin{array}{l}0.562 \\
0.3 .99 \\
0.616 \\
0.6: 4 \\
0,6 j 5\end{array}$ & $\begin{array}{l}18 \\
18 \\
18 \\
18 \\
18\end{array}$ \\
\hline
\end{tabular}

Table 3

\begin{tabular}{|c|c|c|c|c|c|}
\hline Nuctide & $0, \mathrm{mb}$ & Nuclide & $0, \mathrm{mb}$ & Nuclide & o. mb \\
\hline 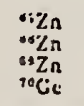 & 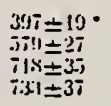 & 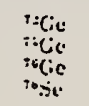 & $\begin{array}{l}i 60 \pm 37 \\
872=41 \\
911 \pm 43 \\
0: 30 \pm j 0\end{array}$ & 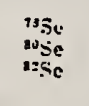 & $\begin{array}{l}1021=i 2 \\
8029=00 \\
1167=53\end{array}$ \\
\hline
\end{tabular}

:Mean - square errors

Values given are for $\sigma_{0}(24.2 \mathrm{MeV})$.

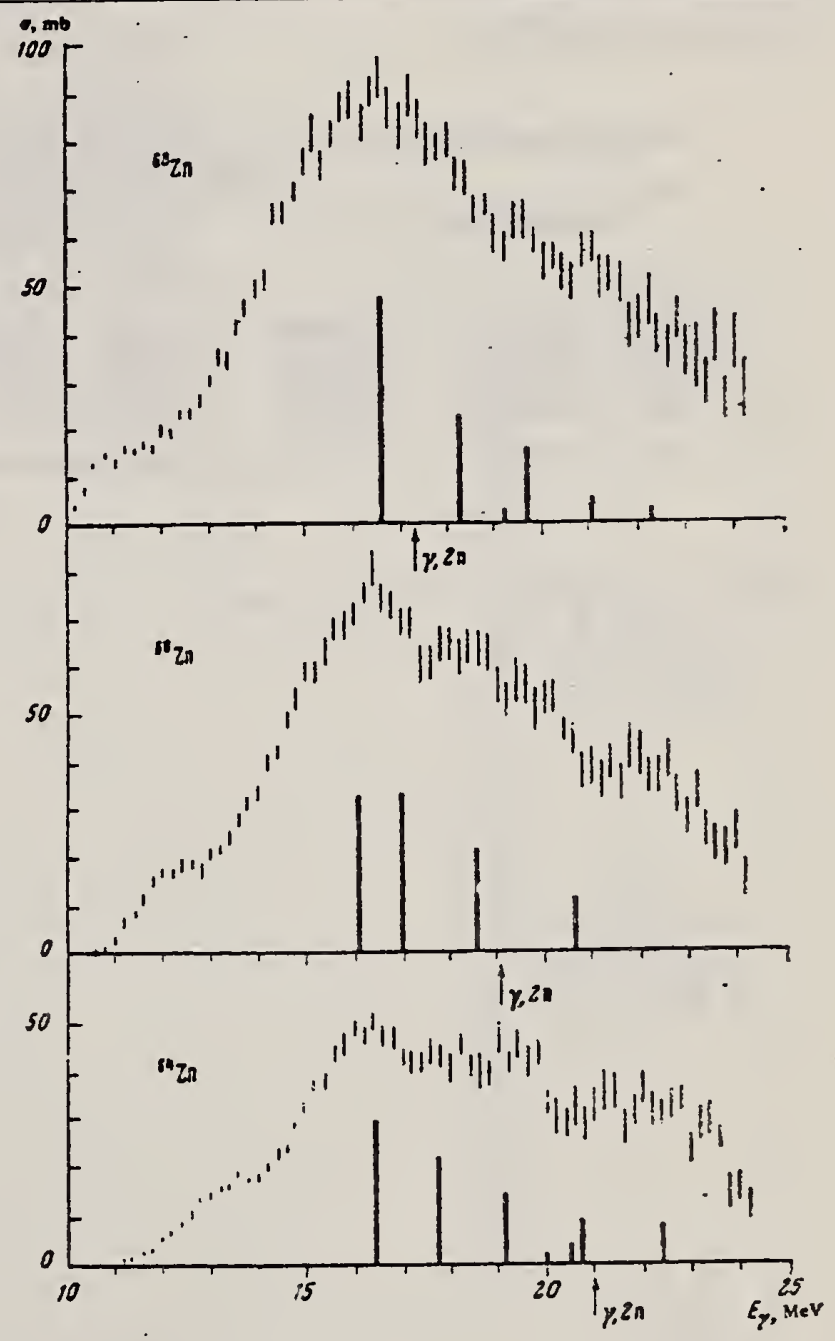

Fig. 1. Cross sections of photoneutron reactions on $64,66,68 \mathrm{zn}$. The dipole photoabsorption forces are taken from $[6,7]$ (the solid black columns).

${ }^{6}$ M.G. Huber et al., Phys. Rev. 155, 1073 (1967)

${ }^{7}$ M.G. Huber et al., Z. Phys. 192, 223 (1966). 
Ref. R. Neuhausen, J. W. Iightbody, Jr., S. P. Fivozinsky, and $S$. Penner

Nucl. Phys. A263, 249 (1976)

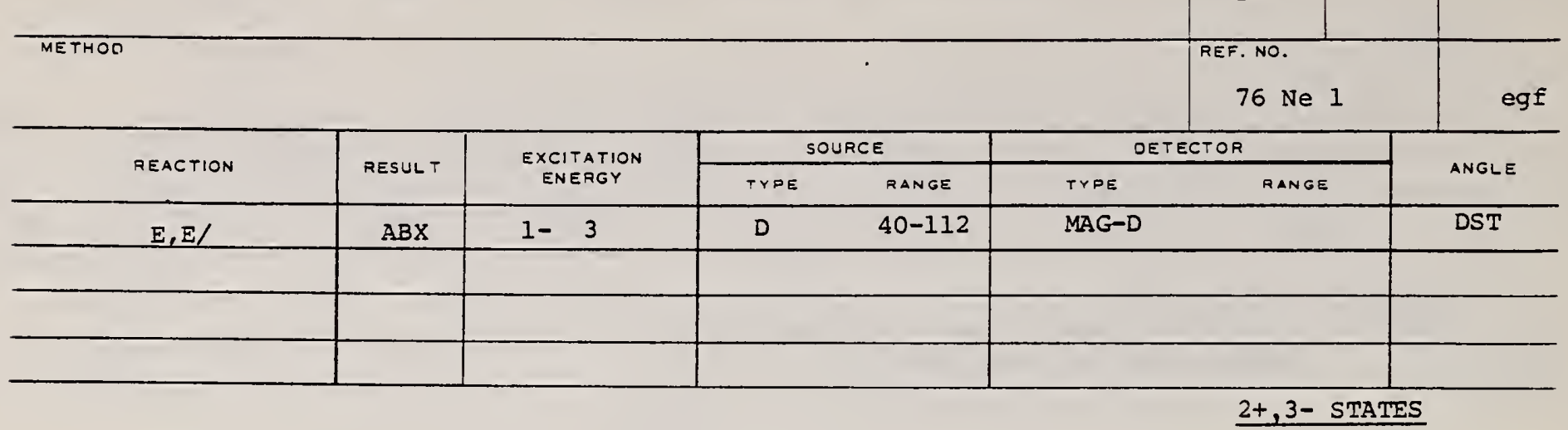

TABLE 6

Reduced transition probabilities in single particle units, deformation parameters and deformation lengths $(R=1.2 \mathrm{fm} \times A t)$

\begin{tabular}{lcccccc}
\hline$B_{i}(E 2) / B_{i}^{s . p .}(E 2)$ & $\beta_{2}$ & $\begin{array}{c}\beta_{2} R \\
(\mathrm{fm})\end{array}$ & $B_{i}(\mathrm{E3}) / B_{i}^{\text {s.p. }}(\mathrm{E} 3)$ & $\beta_{3}$ & $\begin{array}{c}\beta_{3} R \\
(\mathrm{fm})\end{array}$ \\
\hline${ }^{6<\mathrm{Zn}}$ & $20.4 \pm 1.2$ & $0.230 \pm 0.007$ & $1.10 \pm 0.03$ & $23.5 \pm 4.0$ & $0.22 \pm \pm 0.019$ & $1.08 \pm 0.09$ \\
${ }^{66} \mathrm{Zn}$ & $17.3 \pm 1.3$ & $0.212 \pm 0.008$ & $1.03 \pm 0.04$ & $23.4 \pm 4.9$ & $0.224 \pm 0.023$ & $1.09=0.11$ \\
${ }^{68} \mathrm{Zn}$ & $13.5 \pm 1.0$ & $0.187 \pm 0.007$ & $0.92 \pm 0.04$ & $19.8 \pm 4.3$ & $0.206 \pm 0.022$ & $1.01=0.11$ \\
${ }^{10} \mathrm{Zn}$ & $24.0 \pm 2.2$ & $0.249 \pm 0.011$ & $1.23 \pm 0.06$ & & & \\
\hline
\end{tabular}

States: $1.039(2+), 2.83(3-) \mathrm{MeV}$. 


\begin{tabular}{l|ll|l|l} 
(Page 1 0f 3) & $\begin{array}{c}\text { SL Em. SYM. } \\
\text { Zn }\end{array}$ & 66 & 30 \\
\hline & $\begin{array}{c}\text { REF. NO. } \\
77 \text { Ne } 3\end{array}$ & hg \\
\hline
\end{tabular}

\begin{tabular}{|c|c|c|c|c|c|c|c|}
\hline \multirow{2}{*}{ REACTION } & \multirow{2}{*}{ RESULT T } & \multirow{2}{*}{$\begin{array}{l}\text { EXCITATION } \\
\text { ENERGY }\end{array}$} & \multicolumn{2}{|c|}{ SOURCE } & \multicolumn{2}{|c|}{ OETECTOR } & \multirow{2}{*}{ ANGLE } \\
\hline & & & TYPE & RANGE & TYPE & RANGE & \\
\hline$E, E /$ & FMF & $1-3$ & $\bar{D}$ & $100-275$ & MAG-D & & DST \\
\hline & & & & & & & \\
\hline & & & & & & & \\
\hline
\end{tabular}

Abstract: The inelastic electron scattering cross sections for the quadrupole transitions to the $2 ;$ and $2 ;$ stutes in the even $\mathrm{Zn}$ isotopes ${ }^{64} \mathrm{Zn}$. ${ }^{66} \mathrm{Zn}$ and ${ }^{68} \mathrm{Zn}$ and for the hexadecapole transition to the $4_{i}^{7}$ state in ${ }^{64} \mathrm{Zn}$ have been measured in a momentum transfer range up to $q=2.2 \mathrm{fm}^{-1}$. In the framework of the vibrational model these states are considered as one- and two-quadrupole-phonon states. The measurements are characterized by high statistical accuracy and by an overall resolution of $\delta E_{i} E_{0}=10^{-3}$ which permitted separation of almost all members of the two-phonon triplet. The measured cross sections are analyzed with phenomenological models as well as with a FourierBessel expansion of the transition charge density. The latter analysis yields realistic crror bands for the transition charge densities and model-independent values for the reduced transition probabilities and transition radii.

Fig. 3. Cross sections divided by the Mott cross section for the allowed transitions to the $2_{i}^{+}$state in ${ }^{6}+\mathrm{Zn},{ }^{\circ} \mathrm{Zn}$ and ${ }^{69} \mathrm{Zn}$ versus the effective momentum transfer. The measured cross sections are transformed to a common incident energy $E_{0}=275 \mathrm{MeV}$. The curves represent best fit DWBA calculations with the Fourier-Dessel expansion of the transtion charge density (solid line),

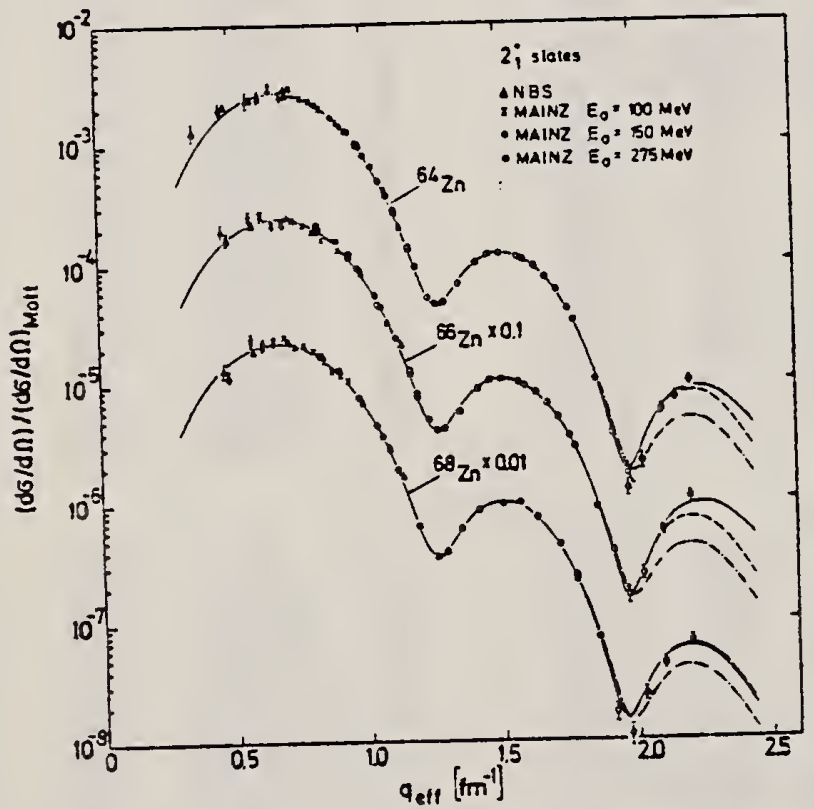

Tassie model (dashed line) and the Gaussian model (dashed-dotted line). 
Table 5

Reduced transition probabilities $B_{i}\left(E_{2}\right)$ and transition radii $R_{\mathrm{tr}}$ for the $2 ;$ states in ${ }^{60} \mathrm{Zn},{ }^{\circ 6} \mathrm{Zn}$ and ${ }^{68} \mathrm{Zn}$

\begin{tabular}{|c|c|c|c|}
\hline & $\varepsilon=0.992 \mathrm{MeV}$ & $\varepsilon=1.039 \mathrm{MeV}$ & $\varepsilon=1.077 \mathrm{MeV}$ \\
\hline \multicolumn{4}{|l|}{$B_{1}(E 2)\left(\mathrm{fm}^{2}\right)$} \\
\hline$\left.\left(e, e^{\prime}\right)^{2}\right)$ & $1620 \pm 90$ & $1410 \pm 80$ & $1320 \pm 70$ \\
\hline CE $\left.{ }^{\circ}\right)$ & $1700 \pm 150$ & $1450 \pm 130$ & $1250 \pm 110$ \\
\hline$R_{t r}(\mathrm{~lm})$ & $5.44 \pm 0.09$ & $5.39 \pm 0.09$ & $5.47 \pm 0.09$ \\
\hline$R_{t r} / R_{n}$ & $1.38 \pm 0.03$ & $1.37 \pm \quad 0.03$ & $1.38 \pm \quad 0.03$ \\
\hline
\end{tabular}

Model independent analysis, this work.

o) Ref. ${ }^{1 \epsilon}$ ).

\section{TAHLE 8}

Reduced trunsition probabilities $B_{,}\left(E_{i}\right)$ and transition radii ${ }^{\circ} R_{1}$ for the forbidden transition to the $2_{2}^{*}$ states in ${ }^{64} \mathrm{Zn},{ }^{\circ 0} \mathrm{Zn}$ and ${ }^{\circ} \mathrm{Za}$ and to the $4_{i}$, state in ${ }^{\circ 4} \mathrm{Zn}$

\begin{tabular}{|c|c|c|c|c|}
\hline . & $\begin{aligned} \varepsilon= & { }^{64} \mathrm{Zn} \\
& i .800 \mathrm{MeV} \\
& i=2\end{aligned}$ & $\begin{array}{c}\varepsilon=1.873 \mathrm{MeV} \\
i=2\end{array}$ & $\begin{array}{c}{ }^{88} \mathrm{Zn} \\
\varepsilon=1.883 \mathrm{MeV} \\
i=2\end{array}$ & $\begin{array}{c}\varepsilon=2.305 \mathrm{MeV} \\
\therefore=4 \\
\end{array}$ \\
\hline $\begin{array}{l}\text { B. }(\mathrm{Ei})\left(\mathrm{fm}^{21}\right) \\
R_{\mathrm{r}}(\mathrm{fm}) \\
R_{1 r^{\prime}} R_{\mathrm{m}} \\
R_{\mathrm{tr}}^{2}\left(2_{\vdots}^{*}\right) / R_{\mathrm{rr}}^{2}\left(2_{i}^{*}\right) \\
\end{array}$ & $\begin{aligned} & 17.0 \pm 1.2 \\
& 4.6 \pm 0.1 \\
& 1.17 \pm 0.03 \\
& 0.71 \pm 0.03\end{aligned}$ & $\begin{array}{l}4.5 \pm 0.7 \\
4.5 \pm 0.1 \\
1.14 \pm 0.03 \\
0.69 \pm 0.04\end{array}$ & $\begin{array}{ll}46 & \pm 7 \\
5.9 & \pm 0.1 \\
1.49 & \pm 0.03 \\
1.17 \pm 0.06\end{array}$ & $\begin{array}{l}(3.4 \pm 1.0) \times 10^{4} \\
6.7 \pm 0.3 \\
1.70 \pm 0.08\end{array}$ \\
\hline
\end{tabular}

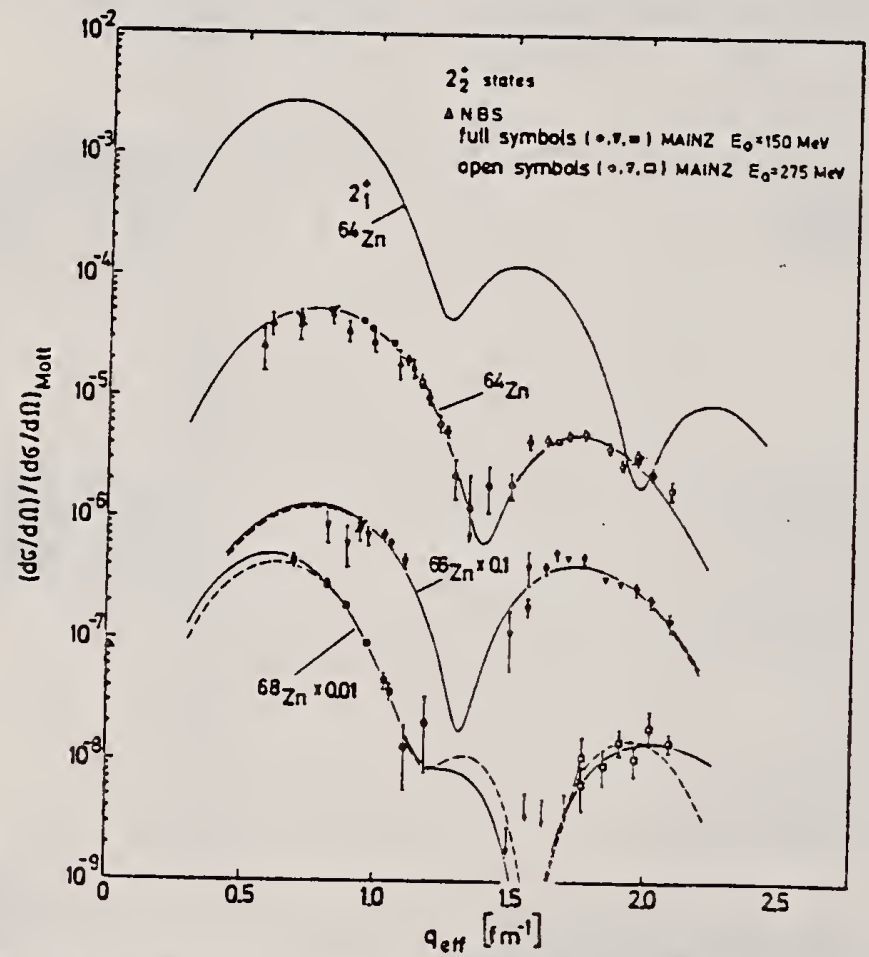

Fig. 8. Same as fig. 3. but for the forbidden transtions to the 2 ; states in ${ }^{\circ} \mathrm{Zn}$, ${ }^{\circ 6} \mathrm{Zn}$ and ${ }^{\circ}{ }^{\circ} \mathrm{Zn}$, respestively. The curves represent hest-fit DWBA calculations with the Fourier-Bessel expansion of the tr:tnsition charge density (solid line) and the phenoinenoluytcal model given in ey. (22) (dushed line). For iomparison. the shape of the cress section for the allowed iransition to the $z_{i}^{*}$ state in ${ }^{\circ+Z} Z$ is hown (uppermost curve). 
REF. Reiner Neuhausen

Nuc 1. Phys. A282, 125 (1977)

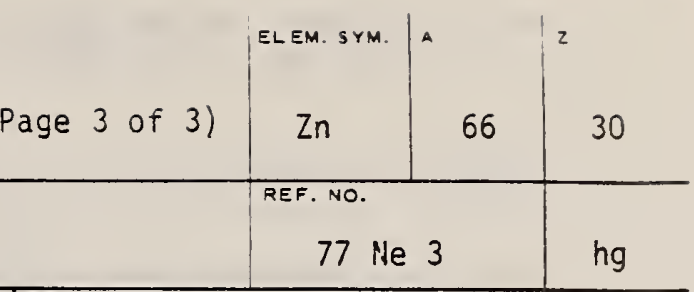

\begin{tabular}{|c|c|c|c|c|c|c|c|}
\hline \multirow{2}{*}{ REACTION } & \multirow{2}{*}{ RESULT } & \multirow{2}{*}{$\begin{array}{l}\text { EXCITATION } \\
\text { ENERGY }\end{array}$} & \multicolumn{2}{|c|}{ SOURCE } & \multicolumn{2}{|c|}{ DETECTOR } & \multirow{2}{*}{ ANGLE } \\
\hline & & & TYPE & RANGE & TYPE & RANGE & \\
\hline & & & & & & & \\
\hline & & & & & & & \\
\hline & & & & & & & \\
\hline & & 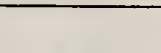 & & & & & \\
\hline
\end{tabular}

TARI : 1

Compilation of the nteasured inelastic cross sections. The cross sections are multiplied by $10^{*}$, where the power $x$ is given in cols. 4 and 3 , respectively

\begin{tabular}{|c|c|c|c|c|c|c|c|}
\hline $\begin{array}{c}E_{0} \\
(\mathrm{MeV})\end{array}$ & $\begin{array}{c}\theta \\
\text { (deg) }\end{array}$ & $\begin{array}{c}10^{x}\left(\mathrm{~d} \sigma_{i} \mathrm{~d} \Omega\right) \\
\left(\mathrm{cm}^{2} / \mathrm{sr}\right)\end{array}$ & $x$ & $\begin{array}{c}E_{0} \\
\cdot(\mathrm{MeV})\end{array}$ & $\begin{array}{c}0 \\
\text { (deg) }\end{array}$ & $\begin{array}{c}10^{x}(d \sigma / \mathrm{d} \Omega) \\
\left(\mathrm{cm}^{2} / \mathrm{sr}\right)\end{array}$ & $x$ \\
\hline \multicolumn{8}{|c|}{${ }^{66} \mathrm{Zn} ; \varepsilon=1.039 \mathrm{MeV} \mathrm{2}{ }_{i}^{*}$} \\
\hline 100.1 & 60.0 & $1.32 \pm 0.16$ & 29 & 275.1 & 42.0 & $1.47 \pm 0.05$ & 30 \\
\hline 100.1 & 65.0 & $1.02 \pm 0.11$ & 29 & 275.1 & 47.0 & $2.41 \pm 0.07$ & 31 \\
\hline 100.1 & 70.0 & $6.26 \pm 0.56$ & 30 & 275.2 & 47.0 & $2.58 \pm 0.09$ & 31 \\
\hline 100.1 & 75.0 & $4.90 \pm 0.36$ & 30 & 275.1 & 50.0 & $7.81 \pm 0.21$ & 32 \\
\hline 100.1 & 80.0 & $3.83 \pm 0.22$ & 30 & 275.1 & 52.5 & $5.35 \pm 0.18$ & 32 \\
\hline 100.1 & 85.0 & $2.70 \pm 0.14$ & 30 & 275.3 & 55.0 & $7.19 \pm 0.31$ & 32 \\
\hline 100.1 & 90.0 & $1.85 \pm 0.08$ & 30 & 275.1 & 58.0 & $7.63 \pm 0.20$ & 32 \\
\hline 100.0 & 95.0 & $1.22 \pm 0.05$ & 30 & 275.1 & 60.0 & $7.70 \pm 0.20$ & 32 \\
\hline 100.0 & 100.0 & $8.75 \pm 0.29$ & 31 & 275.1 & 62.0 & $6.76 \pm 0.17$ & 32 \\
\hline 100.0 & 1050 & $6.18 \pm 0.19$ & 31 & 275.2 & 65.0 & $5.13 \pm 0.17$ & 32 \\
\hline 100.0 & 110.0 & $4.17 \pm 0.13$ & 31 & 275.1 & 65.0 & $5.29 \pm 0.13$ & 32 \\
\hline 150.1 & 60.0 & $5.50 \pm 0.16$ & 30 & 275.1 & 66.0 & $4.54 \pm 0.14$ & 32 \\
\hline 149.9 & 60.0 & $4.84 \pm 0.12$ & 30 & 275.1 & 68.0 & $3.50 \pm 0.08$ & 32 \\
\hline 150.1 & 66.0 & $2.68 \pm 0.08$ & 30 & 275.1 & 70.0 & $2.54 \pm 0.07$ & 32 \\
\hline 149.9 & 70.0 & $1.63 \pm 0.04$ & 30 & 275.1 & 70.0 & $2.43 \pm 0.08$ & 32 \\
\hline 149.8 & 70.0 & $1.49 \pm 0.04$ & 30 & 275.1 & 72.0 & $1.66 \pm 0.05$ & 32 \\
\hline 150.2 & 72.5 & $1.06 \pm 0.03$ & 30 & 275.1 & 74.0 & $1.04 \pm 0.04$ & 32 \\
\hline 150.0 & 72.5 & $1.04 \div 0.03$ & 30 & 275.3 & 75.0 & $7.88 \pm 0.30$ & 33 \\
\hline 150.1 & 78.0 & $4.35 \pm 0.11$ & 31 & 275.1 & 79.0 & $1.97 \pm 0.07$ & 33 \\
\hline 149.8 & 80.0 & $3.18 \pm 0.08$ & 31 & $275 . i$ & 82.0 & $7.11 \pm 0.38$ & 34 \\
\hline 150.1 & 85.0 & $1.30 \pm 0.03$ & 31 & 275.1 & 85.0 & $2.52 \pm 0.33$ & 34 \\
\hline 150.0 & 85.0 & $1.31 \pm 0.04$ & 31 & 275.1 & 88.0 & $3.27 \pm 0.29$ & 34 \\
\hline 150.1 & 92.5 & $2.74 \pm 0.08$ & 32 & 275.1 & 92.0 & $6.20 \pm 0.31$ & 34 \\
\hline 150.2 & 92.5 & $2.56 \pm 0.10$ & 32 & 275.1 & 98.0 & $8.55 \pm 0.63$ & 34 \\
\hline 150.1 & 100.0 & $8.83 \pm 0.35$ & 33 & & & & \\
\hline \multicolumn{8}{|c|}{${ }^{6} \mathrm{Zn}_{\mathrm{n}} \varepsilon=1.873 \mathrm{MeV} 22_{2}^{+}$} \\
\hline 150.1 & 60.0 & $2.2 \pm 0.6$ & 32 & 275.1 & 65.0 & $1.0 \pm 0.2$ & 33 \\
\hline 150.1 & 66.0 & $1.0 \pm 0.4$ & 32 & 275.1 & 68.0 & $1.75 \pm 0.12$ & 33 \\
\hline 149.9 & 70.0 & $1.15 \pm 0.16$ & 32 & 275.1 & 70.0 & $2.03 \pm 0.14$ & 33 \\
\hline 149.8 & 70.0 & $1.03 \pm 0.19$ & 32 & 275.1 & 72.0 & $1.66 \pm 0.10$ & 33 \\
\hline 150.2 & 72.5 & $7.9 \pm 1.3$ & 33 & 275.3 & 75.0 & $1.38 \pm 0.10$ & 33 \\
\hline 150.1 & 78.0 & $5.72 \pm 0.51$ & 33 & 275.1 & 79.0 & $7.30 \pm 0.43$ & 34 \\
\hline 149.8 & 80.0 & $4.39 \pm 0.35$ & 33 & 275.1 & 82.0 & $5.74 \pm 0.36$ & 34 \\
\hline 150.1 & 85.0 & $2.38 \pm 0.35$ & 33 & 275.1 & 85.0 & $4.32 \pm 0.37$ & 34 \\
\hline 275.1 & 62.0 & $7.4 \pm 3.7$ & 34 & 275.1 & 88.0 & $2.93 \pm 0.33$ & 34 \\
\hline 275.2 & 65.0 & $2.1 \pm 0.7$ & 33 & 275.1 & 92.0 & $1.60 \pm 0.27$ & 34 \\
\hline
\end{tabular}


aEf. Y. Cauchois, H. Ben Abdelaziz, R. Khérouf, C. Schloesing-Möller J. Phys. G7, 1539 (1981)

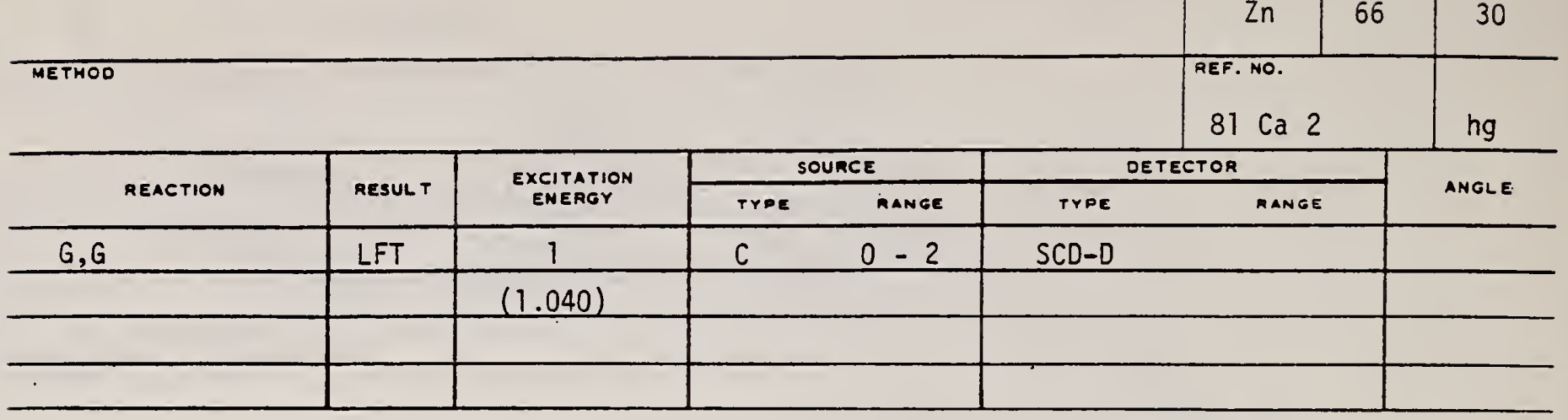

Abstracl. Lifotimes of 49 excited states belowe $1.65 \mathrm{MeV}$ have been measured in " $\mathrm{Mg}$. " Al.

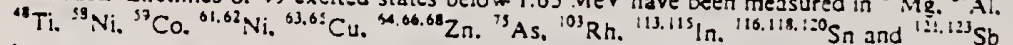
by means of nuclear resonance fluorescence experiments. The levets are excited by bremsstrahlung $x$-ray photons. The self-absorption technique applied to suitable cases provides nuclear absorption cross sections. widihs and lifetimes from which the $x$-ray spectral distributions are also obtained. Scattering experiments are performed for all other cases in order to vbtain :vidths and lifetimes from these $x$-ray photon curves. The Compton effect in the sample is taken into account. Self-absorption provides $g \Gamma_{0}$ from which $\Gamma$ is deduced using duopted $J^{*}$ and $\Gamma_{g} / \Gamma$ values: scattering provides $u=\xi\left(\Gamma \frac{1}{0} / \Gamma\right) W(r)$ from which $\Gamma$ is atso deduced with $J, \Gamma$ oir and mixing ratios taken from the literature. Thanks io simultaneous deternination of the $x$.ray spectra all the lifutumes as given by our proyrams with their statistical crrors form an unusually coherent set of values.

NUCLEAR REACTIONS $(\%, \%)$ bremsstrahlung excitation: natural isotopes: ${ }^{: 4} \mathrm{M} / \mathrm{s}$

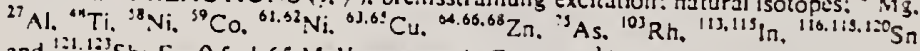
and ${ }^{2: 1.123} \mathrm{Sb}: E=0.5-1.55 \mathrm{MeV}$ : measured $g \Gamma_{0}$ or $g\left(\Gamma_{0}^{2} / \Gamma\right) w(\theta)$ : deduced $T_{1 / 2}$ 
Tableau 3. Resuitats des mesures des niveaux étudies par diffuston.

Table 3. Resuits obtaired using the diriusion mathod.

\begin{tabular}{|c|c|c|c|c|c|c|c|c|c|}
\hline Isotope & Energie (keV) & $j^{*}$ & $J_{0}^{\pi}$ & $\Gamma_{0} / \Gamma$ & $\delta$ & $\begin{array}{l}u=g\left(\Gamma_{0}^{2} / \Gamma\right) W(\theta) \\
(\mathrm{meV})\end{array}$ & $\begin{array}{l}\text { : (ps) } \\
\text { ce :ravail }\end{array}$ & $T_{\mathrm{ref}}(p s)$ & Reiërencest \\
\hline${ }^{24} \mathrm{Mg}$ & $1368.59(4)$ & 2 & $0^{+}$ & 1 & E2 & $i, 08(13)$ & $1,76(21)$ & $1,98(4)$ & $\begin{array}{l}\text { Endt et vall der Leun } \\
\qquad(1478)\end{array}$ \\
\hline$" \mathrm{Al}$ & $1014.45(3)$ & $3^{*}$ & $\vdots$ & 0.971 & $+0.351(12)$ & $0,186(13)$ & $2,20(16)$ & $2,12(8)$ & $\begin{array}{l}\text { Endt et van der Leun } \\
\quad(1978)\end{array}$ \\
\hline${ }^{48} \mathrm{Ti}$ & $983.512(3)$ & $2^{*}$ & $0^{*}$ & 1 & E2 & $0.282(23)$ & $6.74(55)$ & $6.1(13)$ & Been (1978) \\
\hline${ }^{\mathrm{Ni}}$ & $1454.45(15)$ & $2^{+}$ & $0^{+}$ & 1 & $E 2$. & $2,11(26)$ & $0,90 \times 111$ & $0.92(3)$ & $\begin{array}{l}\text { Kueher et Auble } \\
(1976)\end{array}$ \\
\hline${ }^{59} \mathrm{Co}$ & $1099,224(25)$ & $3-$ & $3^{-}$ & 1 & $(E 2)$ & $0,069(8)$ & $4,79(55)$ & $3.17(58)$ & $\operatorname{Kim}(1976)$ \\
\hline${ }^{59} \mathrm{Co}$ & $1458,8(3)$ & $4-$ & 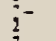 & 0,91 & $(E 2)$ & $0.68(8)$ & $1,17(14)$ & $1.52(16)$ & $\operatorname{Kim}(1976)$ \\
\hline${ }^{39} \mathrm{Co}$ & $1480,9(3)$ & & $i-$ & 0.8 & $<0.35^{4}$ & $1,23(15)$ & $0.254(31)$ & $0.31(3)$ & $\operatorname{Kim}(1976)$ \\
\hline${ }^{\circ 1} \mathrm{Ni}$ & $1185,7(6)$ & i- & i- & $0.77(8)^{1}$ & $|0,14|$ & $1.88(49)$ & $0,21(5)$ & $0.16(3)$ & Andreev el al (1974) \\
\hline${ }^{82} \mathrm{Ni}$ & $1172,91(9)$ & $2^{*}$ & $0^{*}$ & 1 & E2 & $0,88(17)$ & $2,15(42)$ & $2.09(3)$ & Halbert (1979a) \\
\hline${ }^{63} \mathrm{Cu}$ & $1327,00(7)$ & & ?- & 0.84 & (E2) & $1,04(14)$ & $0.84(11)$ & $0.88(4)$ & Auble (1979b) \\
\hline${ }^{0.3} \mathrm{Cu}$ & $1+12,05(4)$ & & $2^{-}$ & 0.72 & $+0.61(\div 9\})$ & $0,260(38)$ & $1.90(28)$ & $1,61(3)$ & Auble (1979b) \\
\hline${ }^{2 n}$ & $991,54(7)$ & $2^{*}$ & 0 & 1 & E2 & $0,640(54)$ & $2,97(25)$ & $2,60(13)$ & Halbert (1979b) \\
\hline${ }^{\circ 9} \mathrm{Cu}$ & $1481,83(5)$ & $?^{-}$ & 1- & 0,85 & $(E 2)$ & $1,13(19)$ & $0,79(13)$ & $0, \$ 9(5)$ & Auble (1975a) \\
\hline${ }^{\circ} \mathrm{n}$ & $1039.37(6)$ & $2^{+}$ & $0^{+}$ & 1 & $E 2$ & $0,70(6)$ & $2.71(23)$ & $2.25(15)$ & Auble (1975b) \\
\hline $\mathrm{Zn}$ & $1077.38(5)$ & $2^{*}$ & $0^{*}$ & 1 & $E 2$ & $0,70(6)$ & $2,71(23)$ & $2,34(23)$ & Lewis (1975) \\
\hline${ }^{19}$ As & $572,5(10)$ & $i-$ & i- & $1^{d}$ & $0,39^{6}$ & $0,236(26)$ & $4,14(46)$ & $3,5(9)$ & Horen el Lewis (1975) \\
\hline${ }^{15} \mathrm{As}$ & $823.0(10)$ & & i- & $0.86^{\circ}$ & $(E 2)$ & $0.214(22)$ & $4,27(43)$ & $3.5(3)$ & Rooinson et al (1967) \\
\hline${ }^{75}$ As & $865.5(10)$ & & - & $0.83^{d}$ & -6 & $0,78(6)$ & $0.86 \hat{3}(68)$ & $0,60(12)$ & Celliers el al (1977) \\
\hline${ }_{73}^{79}$ & $1076.0(10)$ & & 3 & $0,94^{\circ}$ & $0.38^{d}$ & $1,97(13)$ & $0.287(19)$ & $0.32(7)$ & Celliers el al (1977) \\
\hline${ }^{9} \mathrm{As}$ & $1128,5(10)$ & $\frac{1}{2}$ & $2^{-}$ & 1 & $E 1^{d}$ & $0.224(24)$ & $1,47(16)$ & - & \\
\hline "As & $1359.01010)$ & 3- & $1-$ & $0.67^{d}$ & $0.20^{d}$ & $1.61(29)$ & $0,180(32)$ & $0.12(3)$ & Wilsun (1970) \\
\hline "As & $1370.0(10)$ & - & - & $0.47^{d}$ & $0.47^{d}$ & $0.6+(13)$ & $0,218(44)$ & - & \\
\hline${ }^{103} \mathrm{Rh}$ & 803.1121 & i- & !- & 0.70 & MI & $1.85(16)$ & $0.17+(15)$ & - & Harmatz $(1979)$ \\
\hline${ }^{103} \mathrm{Rh}$ & 1277.0221 & i- & $i$ & 0,75 & $-0.62(30)^{e}$ & $0.81(4)$ & $0.87(10)$ & $1.3(9)$ & H:armale $(1979)$ \\
\hline$" 13 \ln$ & $11 ;(1)$ & is. & q. & 1 & $+0.5(2)$ & $9.1(8)$ & $0.086(8)$ & $0.10(6)$ & Tultle af $a /(1476)$ \\
\hline${ }^{113} \ln$ & $1510(1)$ & $i$ & $q^{+}$ & 0.935 & $-0.5(-2)$ & $6,4(9)$ & $0,071(10)$ & $0.11 ;-3)$ & Tuttle et al (1976) \\
\hline $113 \ln$ & $1077.7(10)$ & $i$ & ?. & $0.81^{1}$ & $(E 2)$ & $0.159(24)$ & $1,61(29)$ & $1.23(7)$ & Tulde et al $(1970)$ \\
\hline $119 \ln$ & $1290.59(3)$ & $\div$ & ?. & $0.98^{\mathrm{J}}$ & $([: 2)$ & $1.31(11)$ & $0.6 n(6)$ & $0.55(4)$ & Tuttle el al $(\mid y-h)$ \\
\hline $1131 \mathrm{ln}$ & $14 \div 9.79(3)$ & i. & ?. & 0.36 & $-8^{\prime}$ & $0.9(x 11)$ & $0.50(6)$ & $0.5 \geq(\geq 0)$ & Tuttle el al( 1476$)$ \\
\hline $115 \ln$ & $1+56.1(1)$ & $\xi^{\circ}$ & ?- & $0 .-87$ & $-0.8^{\prime}$ & $0.6 .3(9)$ & $0.63(9)$ & $0,+13)$ & Tusted al al 1476$)$ \\
\hline${ }^{11 s} \ln$ & $1+47.2(4)$ & $(\vdots)$ & 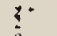 & $<1$ & (E2) & 1.331101 & $<0.30(4)$ & - & \\
\hline${ }^{119} \ln$ & $1607.8(15)$ & $(\vdots)$ & q. & $=!$ & (1::) & $1.5+(27)$ & $\leqslant 0,26(4)$ & - & \\
\hline${ }^{110} \mathrm{Sn}$ & $1243.54(2)$ & 2 & $0^{\circ}$ & 1 & $\mathrm{E} 2$ & $3.58(37)$ & $0.53(6)$ & $0.522(14)$ & 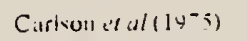 \\
\hline${ }^{118} \mathrm{Sn}$ & $1229.64(4)$ & $2^{\circ}$ & $0^{\circ}$ & 1 & E2 & $2,75(28)$ & $0.69(7)$ & $0.67(2)$ & $\left(:\right.$ :Irlsill e' $a\left(1 \mid y^{\prime} ; 6\right)$ \\
\hline${ }^{1: n} \mathrm{Sn}$ & $11: 1.6(2)$ & $2^{*}$ & $0^{*}$ & 1 & $E 2$ & $1.83(16)$ & $1.04(4)$ & $0.4(12)$ & Kovlec $(1476)$ \\
\hline${ }^{121} \mathrm{Sb}$ & $1023.5(10)$ & $3^{+}$ & $\vdots$ & 1 & $\left.0.57\right|^{6}$ & $3.69(34)$ & $0.228(21)$ & $0.2(47)^{\mathrm{h}}$ & Tamura el $a /(19: 9)$ \\
\hline${ }^{121} \mathrm{Sb}$ & $1105.5(10)$ & ?. & $\vdots$ & 0.4 & - & $0.47(4)$ & $0.42(4)$ & - & \\
\hline${ }^{121} \mathrm{Sb}$ & $1142.5(10)$ & $\vdots$ & 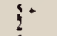 & 0.6 & $(E 2)$ & $0.85(8)$ & $0 . \$ 49(40)$ & $0.4(1,3)^{n}$ & Bouth et a/(1473) \\
\hline${ }^{121} \mathrm{Sh}$ & $138 \div .01101$ & 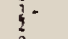 & $\vdots$ & 1 & $0.451^{3}$ & $4 . i(5)$ & $0.092(101$ & $0.0881141^{n}$ & Busth el al $(1473)$ \\
\hline${ }^{123} \mathrm{Sb}$ & $1024.5(10)$ & $\stackrel{9}{*}$ & 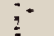 & 1 & $0.571^{4}$ & $2.96(27)$ & $0.272(25)$ & $0.2 n(-1)^{4}$ & Bowhel al $\left.10^{-3} 3\right)$ \\
\hline${ }^{123} \mathrm{Sb}$ & $1086.5(10)$ & a. & $\vdots$ & 1 & $\delta_{i}>1.26^{2}$ & $1 .() t(y)$ & $0.67(5)$ & $0.2(15)^{n}$ & $8 u x t h e$ al $(1973)$ \\
\hline
\end{tabular}

+ References pour les colonnes 3. $\rightarrow, 5.6$ et 9 de chaque ligne, sauf indication appelee au bas de ce tableau. Pour 'es autres donnees se reporter au

texte.
Remarque. Pour ealculer $i^{2}$ quand nous ne disoosons que de $B(E 2)$, pour un melange $(E Z)-(M I)$, nous Jeduisons $g \Gamma_{0}(E 2) x B(E 2) E_{r}^{3}:$ en

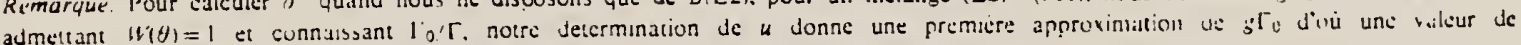
$\dot{\delta}^{2}=\left(j \Gamma_{0}(E 2)\right) /\left(g \Gamma_{0}-g \Gamma_{0}(E 2)\right)$ qu permet d'ameliore: $t h(\theta)$ et $g \Gamma_{0}$ de proche en proche.

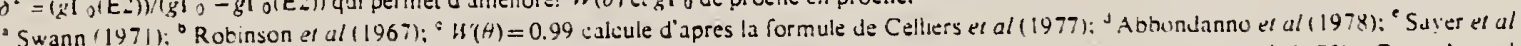

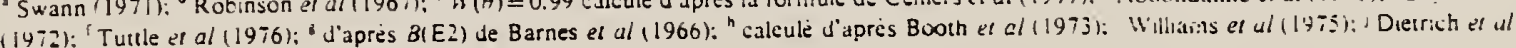
(1970). 
V.G. Ivanchenko and B.S. Ratner

ZhETF Pis'ma 3, No. 11, 452.455, 1 June 1966

JETP Letters $\frac{3}{3}$, No. 11, 296 (1966)

$30 \mathrm{MeV}$ synchrotron

66 IV 1

JDM

\begin{tabular}{|c|c|c|c|c|c|c|c|}
\hline \multirow{2}{*}{ REACTION } & \multirow{2}{*}{ RESULT } & \multirow{2}{*}{$\begin{array}{l}\text { EXCITATION } \\
\text { ENERGY }\end{array}$} & \multicolumn{2}{|c|}{ SOURCE } & \multicolumn{2}{|c|}{ OETECTOR } & \multirow{2}{*}{ ANGLE } \\
\hline & & & TYPE & RANGE & TYDE & RANGE & \\
\hline$G, P$ & $\mathrm{ABX}$ & THR - 28 & & $12-28$ & $A C T-I$ & & $\angle P I$ \\
\hline & & & & & & & \\
\hline & & & & & & & \\
\hline
\end{tabular}

$\int_{12}^{28} \sigma d E Y=118 \mathrm{MeV}-\mathrm{mb}$

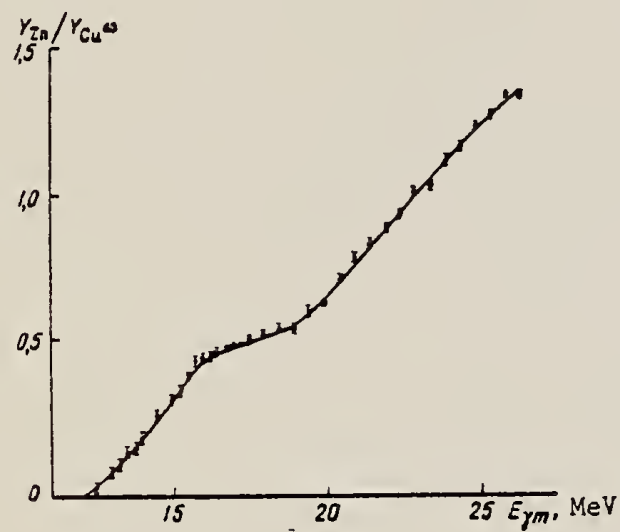

Fig. 1

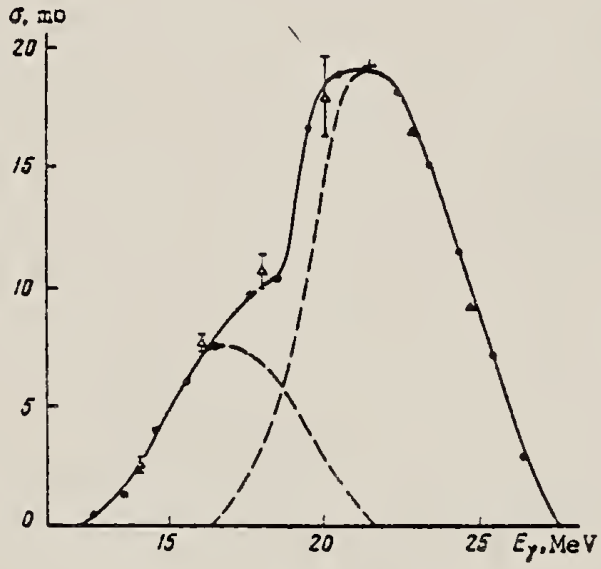

Fig. 2. Cross section of the reaction $\mathrm{Zn}^{87}(y p) \mathrm{Cu}^{80}$ vs. $\mathrm{E}_{y}$. - -- cross section calculated with $1 \mathrm{MeV}$ interval, $\Delta$-. with

- $2 \mathrm{MeV}$ interval. The dashed curves are drawn under the asisumption that the form of the cross section for proton emission from the $1 f_{7 / 2}$ shell (position of the maximum and half-width) is the same as in the case of the reaction $\mathrm{Ni}{ }^{\mathrm{ea}}(\mathrm{yp})[\sigma]$. 
REF. A. El Sioufi, P. Brdos and P. Stoll

Helv. Phys. Acta 30, 265 (1957)

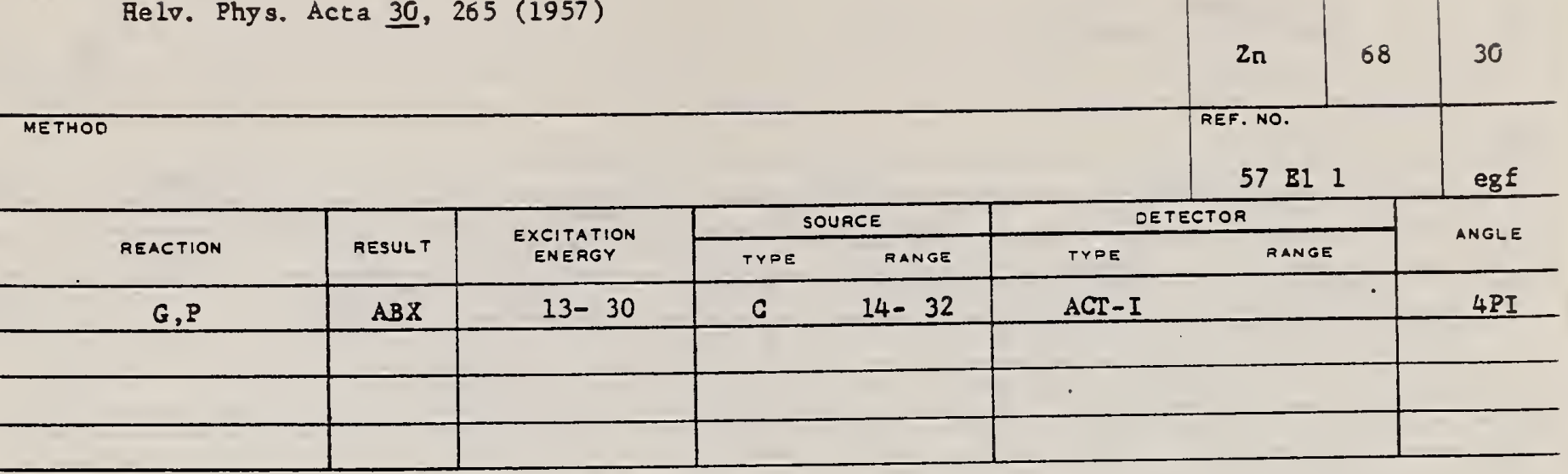

Tabello 1.

Zusammenstellung der gem. IV. Q.

\begin{tabular}{|c|c|c|c|}
\hline Rention & $\begin{array}{c}Q \cdot 1 V_{\text {crt }} \\
\mathrm{MgV}\end{array}$ & $\mathrm{MeV}$ bnrm & Veritälınis der Qucrschnitle \\
\hline$\left.Z_{n}{ }^{* *}\left(\gamma, n_{p}\right) \mathrm{Cu}^{* 4 *}\right)$ & 18,65 & 0,02 & $\sigma_{\mathrm{Zn} \mathrm{n}^{\mathrm{ng}}(y, \mathrm{p})}$ \\
\hline $\left.\left.\mathrm{Zn}{ }^{* 8}(\cdot, \mathrm{p}) \mathrm{Cu}^{4 * * *}\right)^{4}\right)$ & 10,01 & 0,08 & $\left.\bar{\sigma}_{\mathrm{Zn}}^{\mathrm{s}(y)}, \mathrm{np}\right)$ \\
\hline$Z n^{04}(y, 2 n) Z n^{12}$ & 20,82 & 0,08 & $\sigma_{Z n^{A 8}(\eta, n p)}$ \\
\hline $\mathrm{Mo}^{\circ 2}(\gamma, n p) \mathrm{Nb}$ & 19,5 & 0,02 & $\overline{\sigma_{7 n^{84}}(\gamma, 2 n)}$ \\
\hline \multirow[t]{2}{*}{$\mathrm{Mo}^{98}(\gamma, \mathrm{p}) \mathrm{Nb}^{17}$} & & 0,09 & $\sigma_{\mathrm{MIn}} \mathrm{PB}(\gamma, \mathrm{p})$ \\
\hline & & & $\left.\sigma_{M 0} *(\gamma, n j)\right)$ \\
\hline
\end{tabular}

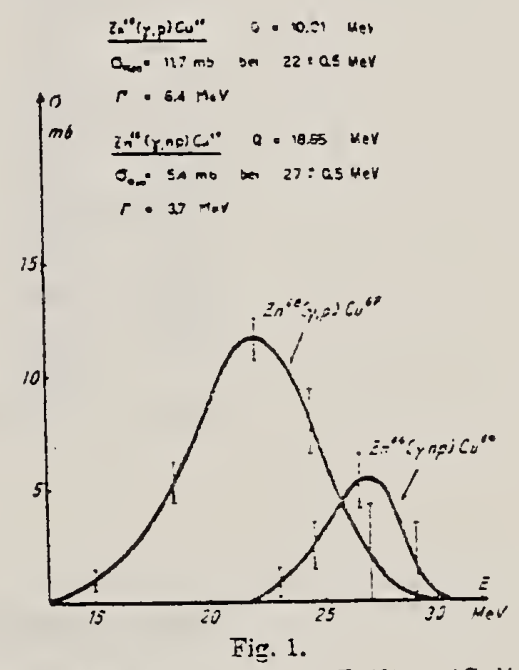

Wirkungsquerschnittsterlauf der Reaktionen $\mathrm{Zn}^{86}(\gamma \cdot \mathrm{np}) \mathrm{Cu}^{84}$ und $\mathrm{Zn}^{68}\left(\gamma \cdot \mathrm{p}_{i} \mathrm{Cu}^{67}\right.$. 
REF.

A. Hofmann, P. Stoll

He1v. Phys. Acta 31, 591 (1958)

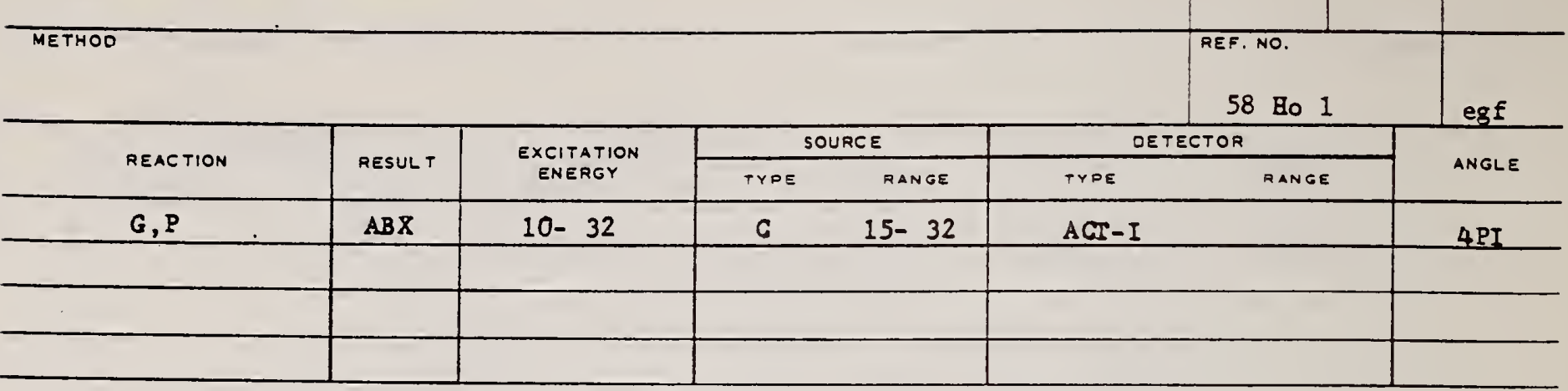

$(y, n p)$ ylelds include $(Y, d)$.

Tabelle I

\begin{tabular}{|c|c|c|c|c|c|}
\hline Reaktion & $\begin{array}{l}\text { Q.Wert } \\
\text { MeV }\end{array}$ & $\begin{array}{l}\text { 1.1V.Q. } \bar{\sigma} \\
\text { M. L barn }\end{array}$ & $\underset{m i b}{\sigma_{\operatorname{mix}}}$ & $\begin{array}{l}E_{\max } \\
\mathrm{McV}\end{array}$ & $\underset{\mathrm{McV}}{\Gamma}$ \\
\hline $\mathrm{C}_{2}{ }^{10}\left(\gamma, p_{n}\right)\left[^{3 n}\right.$ & $-24,3$ & 0,1005 & 2.4 & $30 \pm 1$ & 2.1 \\
\hline$Z n^{44}(\gamma, p n) C . u^{\wedge 3}$ & -18.36 & $0,0.3$ & & & \\
\hline$Z_{n}{ }^{s 0}(\gamma, p u) \mathrm{Cu}_{1+s}$ & -18.65 & $0,1) 31$ & 7.2 & $28 \pm 1$ & 4 \\
\hline $\mathrm{Z}_{11^{46}}(\%, p) \mathrm{Cu}^{48}$ & $-10,01$ & 0,19 & 11.4 & $22.7 \pm 1$ & 6 \\
\hline $\mathrm{Se}^{3 n}(\%, p n) \lambda s^{34}$ & $-20,43$ & 0,02 & & & \\
\hline$Z n^{64}(\gamma, 2 n) Z n^{62}$ & -20.82 & $0,0.8$ & & & \\
\hline $\mathrm{Mo}^{92}(\gamma, p u) \times \mathrm{b}^{20}$ & $-19,5$ & 11.02 & & & \\
\hline $\mathrm{Sb}^{223}(\gamma, \rho 11) S \pi^{121}$ & -18.2 & n. bonki & & & \\
\hline
\end{tabular}




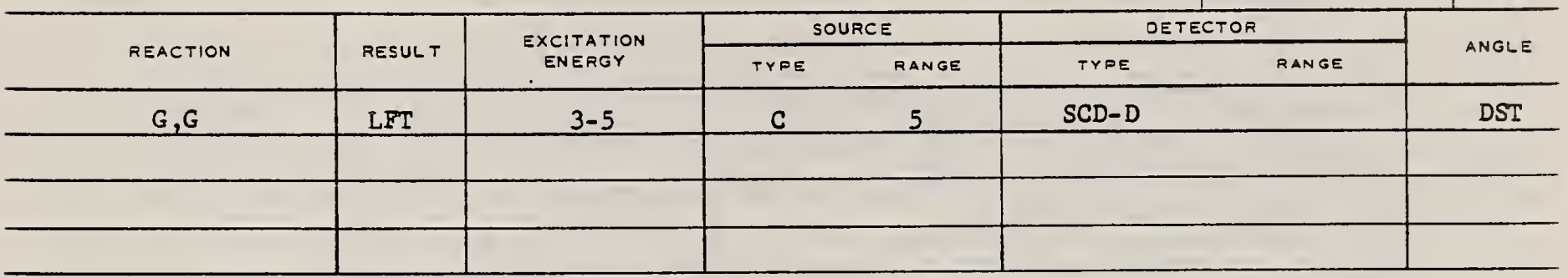

TABLE I

Properties of the $\mathrm{Zn}$ levels ohserved in the bremsstrahlung experiments

\begin{tabular}{|c|c|c|c|c|c|c|}
\hline $\begin{array}{l}\text { Energy } \\
\text { (keV) }\end{array}$ & Isotupe & Spin & Parity & $\Gamma_{0} / \Gamma$ & $\Gamma_{0}(\mathrm{meV})$ & $\Gamma_{0} \cdot{ }^{*}$ (meV) \\
\hline $33+6$ & (68) & 1 & & $\left.(0.70)^{*}\right)$ & $42=7$ & $\begin{cases}9.9 \cdot 10^{-4} & (E 1) \\
0.061 & (\mathrm{M} 1)\end{cases}$ \\
\hline 3166 & 64 & $1 \%$ & $+\bullet$ & $\left.0.54^{\circ}\right)$ & $8.2=1.3$ & 0.012 \\
\hline 381 & 66 & 1 & $(+1 *)$ & $0.69 \circ$ & $16 \pm 3$ & 0.022 \\
\hline ?4:5 & 64 & $1 \%$ & $\therefore$ & $0.72 \circ$ & $6.9=1.6$ & 0.009 \\
\hline $3+33$ & (66) & $(1)^{\infty . e)}$ & $(-)$ & $\left.0.51^{\circ}\right)$ & $8=3$ & $10^{-1} \quad 10^{-4}$ \\
\hline 3704 & 64 & 1 & $(-)$ & $\left.(1.0)^{\prime}\right)$ & $18=3$ & $3.2 \therefore 10^{-4}$ \\
\hline$: 717$ & (68) & (1) & & $(1.0,1)$ & $8.5 \pm 2.2$ & $\begin{cases}1.5 \therefore 10^{-4} & (E 1) \\
0 \cos & (\mathrm{M})\end{cases}$ \\
\hline 3739 & 66 & 1 & $(-)$ & $\left.(1.0)^{\prime}\right)$ & $24=3$ & $4.1 \cdot 10^{-6}$ \\
\hline+159 & 64 & 1 & $(-)$ & $(0.54)$ & $32=9$ & $4.0 \cdot 10^{-4}$ \\
\hline+295 & 66 & $1 \%$ & $(*)$ & $\left.0.60^{\circ}\right)$ & $67=20$ & 0.046 \\
\hline 4339 & $(68)$ & (1) & & $\left.(1.0)^{\prime}\right)$ & $38=10$ & $\begin{cases}4.2 \times 10^{-4} & \left(E_{1}\right) \\
0.025 & (\mathrm{M})\end{cases}$ \\
\hline 4426 & 66 & 1 & $(-)$ & $(1.0) \%$ & $65=10$ & $6.8 \times 10^{-4}$ \\
\hline 4455 & 64 & 10 & -1 & $\left.(1.0)^{t \cdot n}\right)$ & $51=9$ & 0.031 \\
\hline 462 & 66 & 1\% & $(+)^{(-1)}$ & $0.29 \bullet$ & $28=21$ & 0.017 \\
\hline 466 & (68) & 1 & & $\left.(1.0)^{\prime}\right)$ & $65 \doteq 19$ & $\begin{array}{ll}16.5 \times 10^{-4} & (E \mid) \\
10.040 & (.41)\end{array}$ \\
\hline+503 & (68) & (1) & & $\left.(1.0)^{\prime}\right)$ & $38=13$ & $\begin{array}{l}\left.13.6 \times 10^{-4}(E)\right) \\
10.023\end{array}$ \\
\hline 4609 & (66) & (1) & & $\left.(1.0)^{\prime}\right)$ & $54=15$ & $\begin{array}{ll}15.0 \times 10^{-4} & (\mathrm{El}) \\
10.030 & (\mathrm{MI})\end{array}$ \\
\hline 4664 & (64) & (1) & & $\left.(1.0)^{7}\right)$ & $11=4$ & $\begin{array}{ll}1.0 \times 10^{-4} & (\mathrm{E}:) \\
0.006 & (\mathrm{Mi})\end{array}$ \\
\hline 4685 & (66) & (1) & & $\left.(1.0)^{t}\right)$ & $64=16$ & $\begin{cases}5.6 \times 10^{-4} & (\mathrm{El}) \\
0.034 & (\mathrm{MI})\end{cases}$ \\
\hline 4806 & (66) & (†) & $-\bullet$ & $0.81 \%$ & $100=25$ & 0.049 \\
\hline
\end{tabular}

-) Bases on ref. '), see text.

") Ref. ").

c) Ref. ${ }^{12}$ ).

i) Ref. ${ }^{2}$ ).

-) Ref. $\left.{ }^{10}\right)$.

i) Assumed in the absence of evidence for branching.

-) Assuming that the oranch to the 2, state, seen in the bremsstrahiung experiment, is the oniy branch to an excited state.

-) Reis. 11.42 ) contradict each other with respect to this branching.

1) Ref. ${ }^{10}$ ) favors a (-) assignment. See text. 
1) H. Verhcul. Nucl. Datis B2-3 (1467) 65

2) M. J. Martin and M. N. Rao, Nuil. Data $(32-6$ (1ynd $)+3$

3) F. R. Metzger, Annual progress regnnt for 1967. Al.C contract AT(30-1)-3525, Nucl. Sit. Abstr. $2:-i 661,1968$

4) F. R. Metzger, Annual progress report for 1968, AEC contract AT(30-1)-3525, Nucl. Sisi. Abstr. $23.15431,1969$

5) F. R. Metzger, Phys. Rev. Lers. 18 (1967) 414: Phys. Rev. 171 (1968) 1257;

M. Berman and G. B. Beard, Phys. Rev. C2 (1970) ISOA;

M. Sihumacher, J. Weiss and H. Langhof, Phys. Lett. $31 B$ (1969) 61:

H. Langhof, Phys. Rev. A3 (1971) I

6) F. R. Metzger, Phys. Rev. 187 (1969) 1680, 1700; Nucl. Phys. A182 (1972) 213

i) F. R. Metzger, Nucl. Phys. A 158 (1970, 88

3) R. P. Singh and M. L. Rusigi. Phys. Rev. C3 (1971) 1172

9) H. Ortmar, N. M. Ahmed, U. Fanger, D. Heck, W. Michuelis and H. Schmidt, Nucl. Phys. Al6(1971) 69

10) D. C. Camp and G. L. Meredith, Nucl. Phys. Al66 (1971) 349

1i) J. Konijn, R. van Lieshout, J. P. Deursih and L. Grerises, Nusl. Phys. A91 (1967) 439

12) L. G. Mann, K. G. Tirsell and S. D. Bloom, Vuil. Phys. $197(1967)$ i2s 
A.S. Litolnenko, N.G. Shevchenko, N.G. Afanas'ev, V. D. Afanas'ev,

REF. A. Yu. Buk1, V. P. Likhachev, V.N. Polishchuk, G. A. Savitskil,

V.M. Thvastunov, A.A. Khomich, and I.I. Chkalov

Yad. Fiz. 18, 250 (1973)

Sov. J. Nucl. Phys. 18,128 (1974)

\begin{tabular}{|c|c|c|c|c|c|c|c|}
\hline METHOD & & & & & & $\begin{array}{r}\text { REF. NO. } \\
73 \text { LI } 5\end{array}$ & hog \\
\hline \multirow{2}{*}{ REACTION } & \multirow{2}{*}{ RESULT } & \multirow{2}{*}{$\begin{array}{l}\text { EXCITATION } \\
\text { ENERGY }\end{array}$} & & & \multicolumn{2}{|c|}{ DETECTOR } & \multirow{2}{*}{ ANGLE: } \\
\hline & & & TYPE & MANGE & TYPE & RANGE & \\
\hline \multirow[t]{2}{*}{$B, E /$} & FMF & 1,3 & $\mathrm{D}$ & 225 & MAG-D & & DST \\
\hline & & $(1.08,2.8)$ & & & & & \\
\hline & & & & & & & \\
\hline 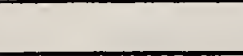 & & & & & & & \\
\hline
\end{tabular}

LEVELS: $1.08,2.8 \mathrm{MBV}$

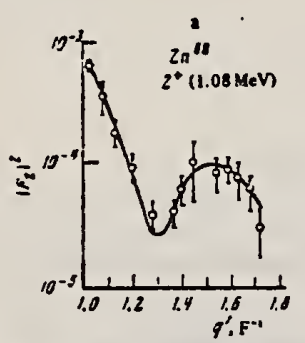

FIG. 4. Form factors of $E 2$ transitions (a) and $E 3$ transitions (b) in $\mathrm{Zn}^{\text {bs }}$. The solid curves are theoretical form-factor values fitted to the experimental points.

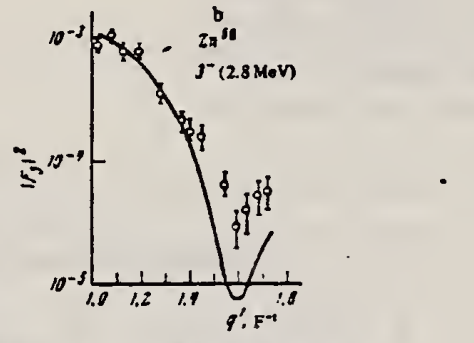
transitions $B(E \lambda) \uparrow$ for the nuclei $Z_{n}{ }^{6.6}$

\begin{tabular}{|c|c|c|c|}
\hline \multirow{2}{*}{ Nuelauss } & \multirow{2}{*}{$j \pi$} & \multicolumn{2}{|c|}{$\Delta(E \lambda) t . e^{\lambda} F^{2 \lambda}$} \\
\hline & & Our data & 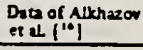 \\
\hline $2 n^{4}$ & $2^{2+}$ & $\begin{aligned} 1077 & =160 \\
23500 & =1700\end{aligned}$ & 1100 \\
\hline $2 n^{10}$ & $3^{+}-$ & $\begin{aligned} 1800 & =150 \\
33900 & =2400\end{aligned}$ & 1450 \\
\hline
\end{tabular}

Nole. For $2 n^{*}$ our data from ret. 2 áre given. 


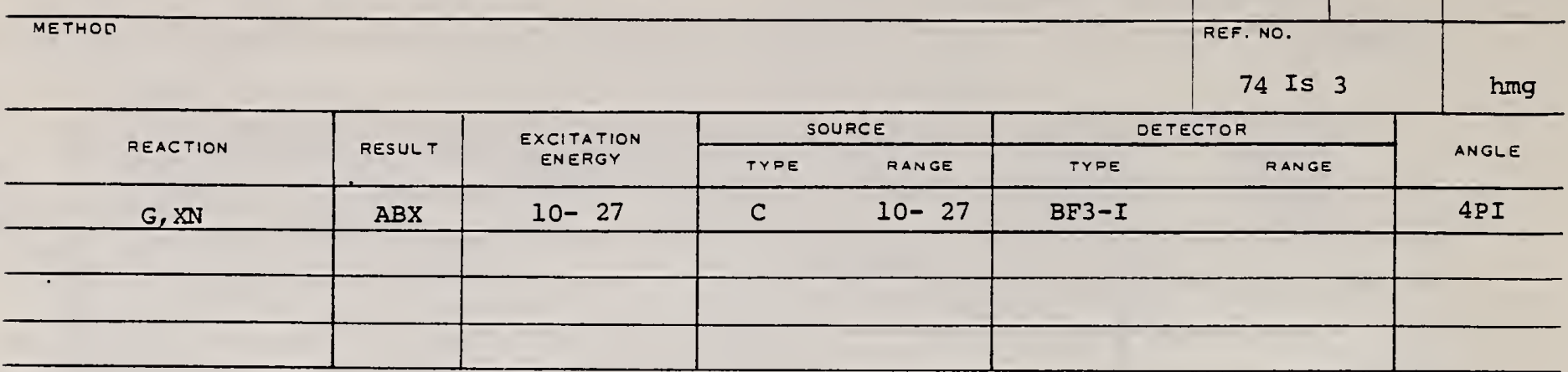

Total photoneutron cross sections have been obtained for ${ }^{\circ} \mathrm{Zn}$ and ${ }^{6 /} \mathrm{Zn}$. The measurements were carried out from threshold to $27 \mathrm{MeV}$ in 50-keV steps. A distinct structure is observed in the cross sections. The half-width of the curves is about $10 \mathrm{MeV}$. The integrated cross sections for $\mathrm{Zn}$ and ${ }^{68} \mathrm{Zn}$ without taking into account multiple processes are $800 \pm 80$ and $1630 \pm 160 \mathrm{MeV}$ mb. The expenmental data are compared with the predictions of the dynamic collective model and with the concept of isospin splitting of the giant resonance.

\begin{tabular}{|c|c|c|c|c|c|c|c|c|c|}
\hline \multirow[t]{2}{*}{ Target } & \multicolumn{5}{|c|}{ Percentuge content of ranous sotopes } & \multirow{2}{*}{$\begin{array}{l}\text { Weight of } \\
\text { targer. } 8\end{array}$} & \multicolumn{3}{|c|}{ 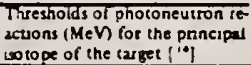 } \\
\hline & ${ }^{m} z_{n}$ & $-3 n$ & $=2$ & $=z_{n}$ & $\overline{z n}$ & & (1), n) & $|r, \mathrm{in}|$ & $T_{1} n p_{1}$ \\
\hline & 3.3 & 4.9 & 1.2 & $\begin{array}{r}1.8 \\
86.8\end{array}$ & $\begin{array}{l}0.8 \\
0.4\end{array}$ & $\begin{array}{l}78 \\
67\end{array}$ & $\begin{array}{l}11.855 \\
10.203\end{array}$ & $\begin{array}{l}21.020 \\
17.255\end{array}$ & $\begin{array}{l}\begin{array}{l}8.548 \\
19.099\end{array} \\
1.09\end{array}$ \\
\hline
\end{tabular}

14 J.H.E. Mattauch et al., Nuc1. Phys. $67, \overline{54} \overline{(1965)}$

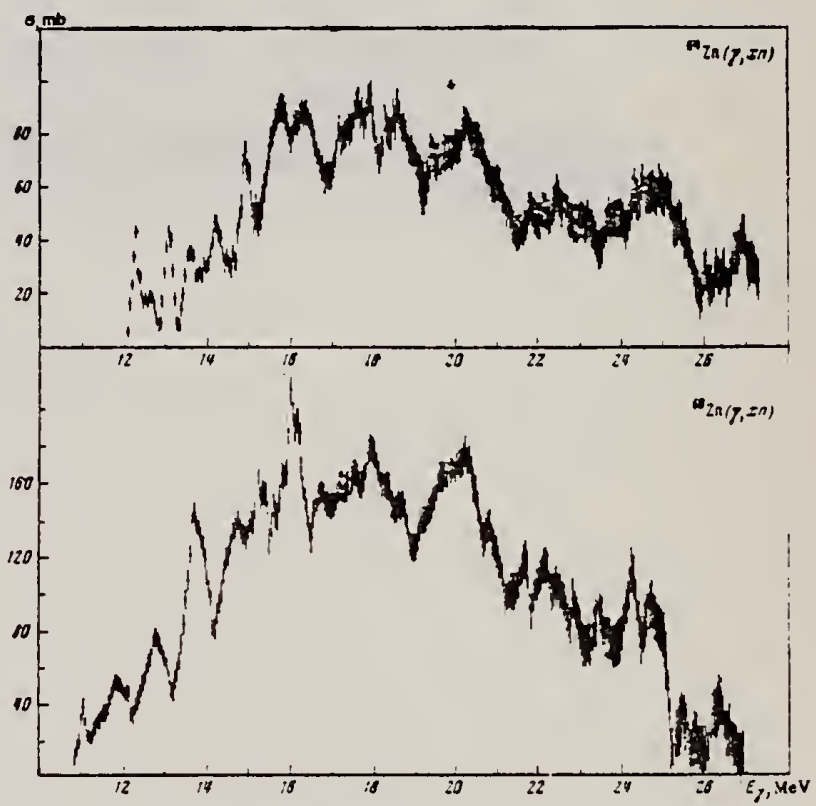

FIG. 1. Total photoneutron cross sections $\sigma(\gamma, x n)$ for $Z_{n}$ (upper figure) and ${ }^{\mathrm{Z} n}$ (lower figure). 
A.M. Goryachev, G.N. Zalesnyi, and B.A. Tulupov Izv. Akad. Nauk SSSR. Ser. Fiz. 39, 134 (1975)

Bull. Acad. Sci. USSR Phys. Ser. 39, 116 (1975)

.

\begin{tabular}{l|l} 
REF. NO. & REF
\end{tabular}

75 Go 1

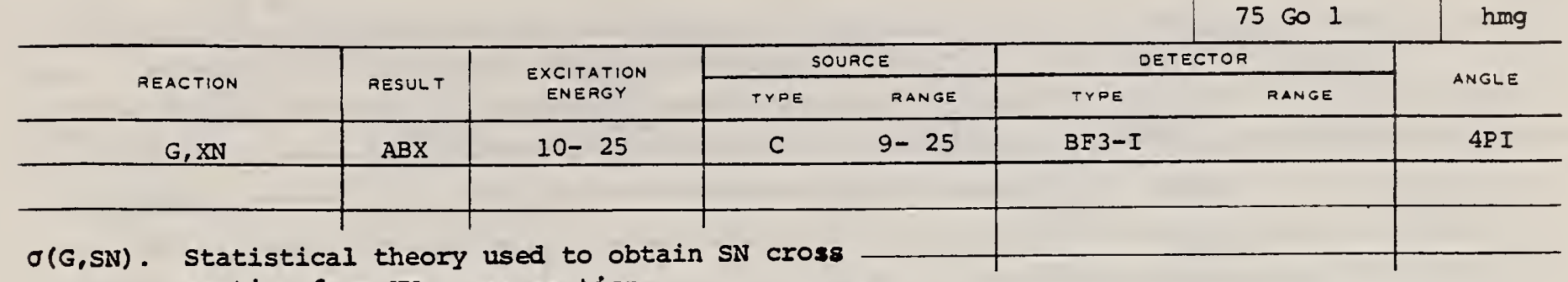
section from $\mathrm{XN}$ cross section.

Table 2

\begin{tabular}{|c|c|c|c|c|c|c|c|}
\hline Nuelide & B. & $E_{2}$, MeV & $E_{1}$, MeV & Nuclide & $B_{3}$ & $\mathrm{E}_{3}, \mathrm{MeV}$ & $E_{1}, M e V$ \\
\hline 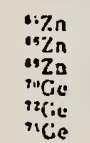 & $\begin{array}{l}0.2 i \\
0.23 \\
0.2 \\
0.23 \\
11.2-1 \\
0.3\end{array}$ & $\begin{array}{l}0.90 \\
1.119 \\
1.03 \\
1.04 \\
6.855 \\
0.6\end{array}$ & $\begin{array}{l}15 \\
13 \\
18 \\
18 \\
13 \\
16\end{array}$ & 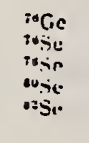 & $\begin{array}{l}0.25 \\
0.3 .3 \\
0,3 \\
0.25 \\
0,2\end{array}$ & $\begin{array}{l}0.562 \\
0.3-3.4 \\
0.616 \\
0.6=4 \\
0,655\end{array}$ & $\begin{array}{l}\text { is } \\
18 \\
19 \\
18 \\
18\end{array}$ \\
\hline
\end{tabular}

Table 3

\begin{tabular}{|c|c|c|c|c|c|}
\hline Nuctide & $o, m b$ & Nuclide & $0, \mathrm{mb}$ & Nuelide & a, mb \\
\hline 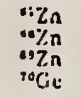 & $\begin{array}{l}3 ! 17=19 \\
37 ! 1=27 \\
714=37 \\
7.51 \pm 37\end{array}$ & 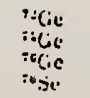 & $\begin{array}{l}700 \pm 37 \\
872 \pm 11 \\
111 \pm 43 \\
330 \pm 50\end{array}$ & $\begin{array}{l}\text { "se } \\
\text { "ose } \\
\text { "Se }\end{array}$ & $\begin{array}{l}1021=: 2 \\
1020 \pm=0 \\
1167=53\end{array}$ \\
\hline
\end{tabular}

Va?ues given are for $\sigma_{0}(24.2 \mathrm{MeV})$.

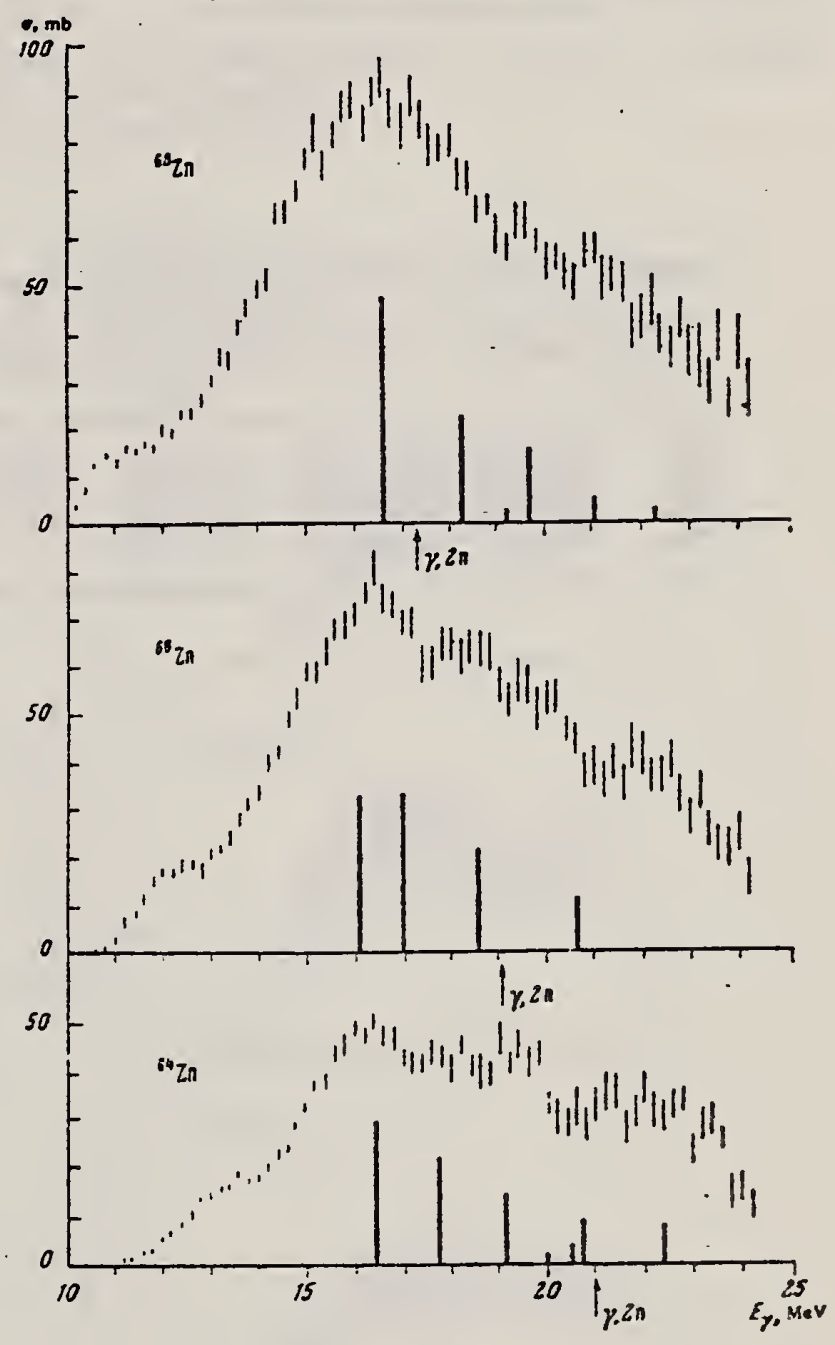

Fig. 1. Cross sections of photoneutron reactions on $64,66,68 \mathrm{z} \pi$. The dipole photoabsorption forces are taken from $[6,7]$ (the solid black columns).

G.G. Huber et al., Phys. Rev. I55, 1073 (1967).

7.G. Huber et al., Z. Fins. IE2, 223 (1966). 
R. Neuhausen, J. W. Lightbody, Jr., S. P. Fivozinsky, and $S$. Penner

Nucl. Phys. A263, 249 (1976)

\begin{tabular}{|c|c|c|} 
ELEM. SYM. & A & $z$ \\
$\mathrm{Zn}$ & 68 & 30 \\
\hline $\begin{array}{c}\text { REF. NO. } \\
76 \mathrm{Ne} 1\end{array}$ & egf \\
\hline
\end{tabular}

\begin{tabular}{|c|c|c|c|c|c|c|c|}
\hline \multirow{2}{*}{ REACTION } & \multirow{2}{*}{ RESUL T } & \multirow{2}{*}{$\begin{array}{l}\text { EXCITATION } \\
\text { ENERGY }\end{array}$} & \multicolumn{2}{|c|}{ SOURCE } & \multicolumn{2}{|c|}{ DETECTOR } & \multirow{2}{*}{ ANGLE } \\
\hline & & & TYPE & RANGE & TrPE & RANGE & \\
\hline $\mathrm{E}, \mathrm{E} /$ & $\mathrm{ABX}$ & $1-3$ & $D$ & $40-112$ & MAG-D & & DST \\
\hline & & & & & & & \\
\hline & & & & & & & \\
\hline
\end{tabular}

States: $1.077(2+), 2.75(3-) \mathrm{MeV}$.

$2+, 3-$ STATES

TABLE 6

Reduced transition probabilities in single particle units, deformation parameters and deformation lengths $(R=1.2 \mathrm{fm} \times A \dagger)$

\begin{tabular}{|c|c|c|c|c|c|c|}
\hline & 2) $/ B_{i}^{\text {s.p. }}(E 2)$ & $\beta_{2}$ & $\begin{array}{l}\beta_{2} R \\
(\mathrm{fm})\end{array}$ & $B_{i}(E 3) / B_{i}^{\text {s.p. }}(E 3)$ & $\beta_{3}$ & $\begin{array}{l}\beta_{3} R \\
\text { (fm) }\end{array}$ \\
\hline${ }^{64} \mathrm{Zn}$ & $20.4 \pm 1.2$ & $0.230 \doteq 0.007$ & $1.10 \doteqdot 0.03$ & $23.5 \pm 4.0$ & $0.224 \pm 0.019$ & $1.08 \div 0.09$ \\
\hline${ }^{6} \mathrm{Zn}$ & $17.3 \pm 1.3$ & $0.212 \div 0.008$ & $1.03 \pm 0.04$ & $23.4 \div 4.9$ & $0.224 \pm 0.023$ & $1.09 \doteq 0.11$ \\
\hline${ }^{68} \mathrm{Zn}$ & $13.5 \pm 1.0$ & $0.187 \pm 0.007$ & $0.92 \doteq 0.04$ & $19.8 \pm 4.3$ & $0.206 \pm 0.022$ & $1.01 \doteq 0.11$ \\
\hline${ }^{70} \mathrm{Zn}$ & $24.0 \pm 2.2$ & $0.249 \pm 0.011$ & $1.23 \doteqdot 0.06$ & & & \\
\hline
\end{tabular}


nef. B. Bülow, B. Johnsson and M. Nilsson

Z. Physik A282, 261 (1977)

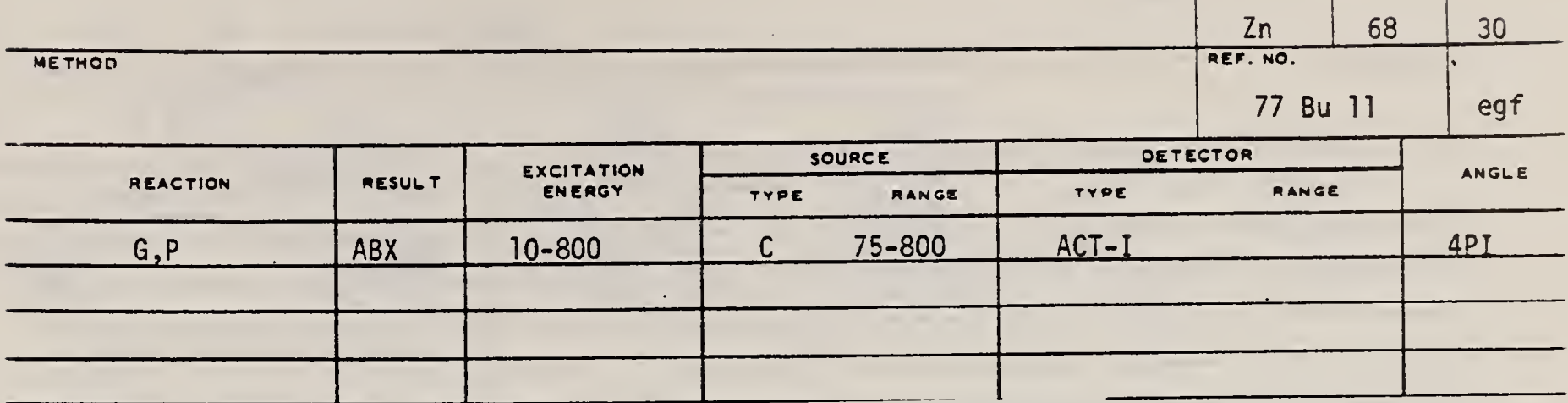

The yields of $(\gamma, p)$ reactions on ${ }^{30} \mathrm{Si}{ }^{63} \mathrm{Zn}$ and ${ }^{130} \mathrm{Te}$ bave been measured as a function of the bremsstrahlung end-point energy, $E_{7, \text { max }}$, in the energy range $75-800 \mathrm{MeV}$, using the activation method. Cross sections have been deduced and are compared to results obtained using a semi-empirical model.

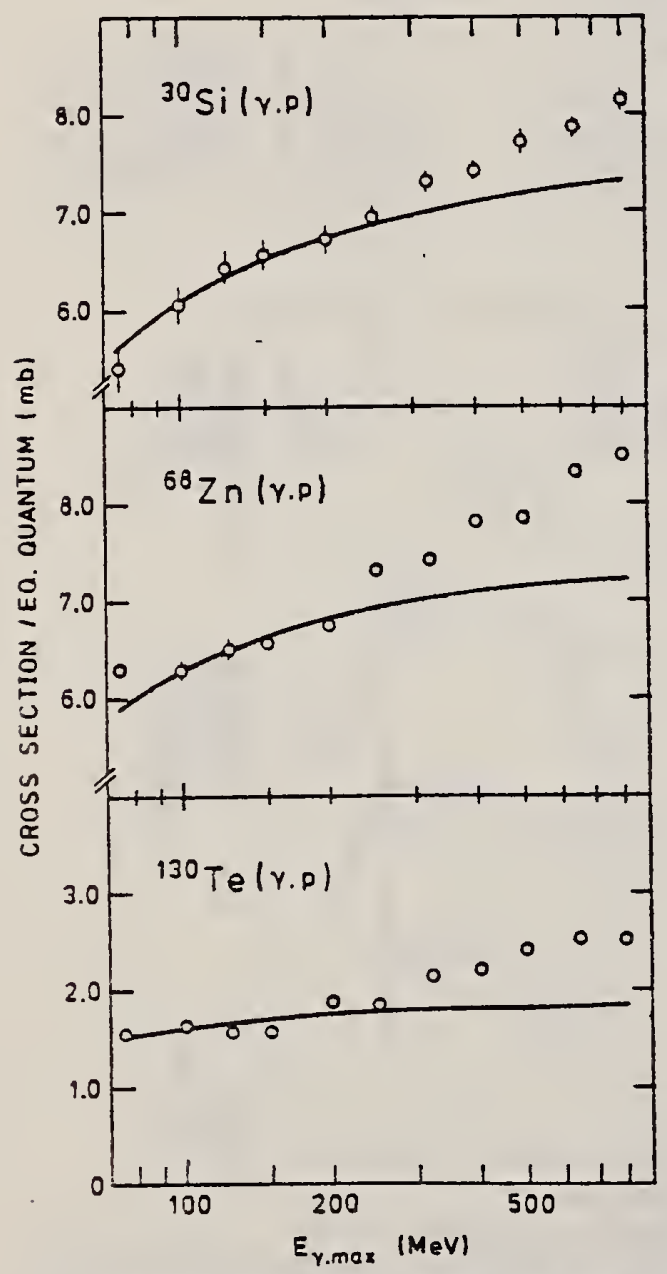

Fig. 1. Measured yields for the $(7, p)$ reactions in ${ }^{30} \mathrm{Si},{ }^{68} \mathrm{Zn}$ and ${ }_{130}^{\circ} \mathrm{Te}$. The solid lines are the fitted yields due to the giant resonance and quasideuteron cross sections

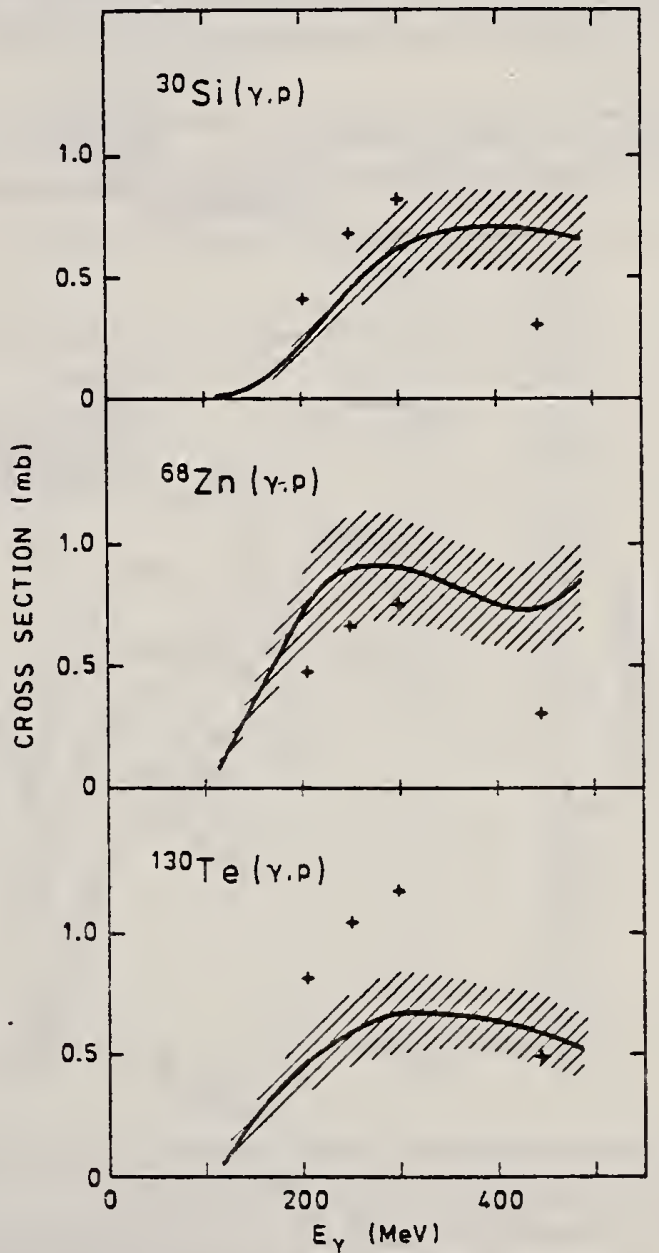

Fig. 2 The solid curves show the smoothed cross sections arising from photoproduction of mesons and the hatched areas indicate the estimated ertors. + sings are values calculated using the semiempitical formalism 


\begin{tabular}{|c|c|c|c|c|c|c|c|}
\hline \multirow{2}{*}{ REACTION } & \multirow{2}{*}{ RESULT } & \multirow{2}{*}{$\begin{array}{c}\text { EXCITATION } \\
\text { ENERGY }\end{array}$} & \multicolumn{2}{|c|}{ SOURCE } & \multicolumn{2}{|c|}{ DETECTOR } & \multirow{2}{*}{ ANGLE } \\
\hline & & & TYPE & RANGE & TYPE & RANGE & \\
\hline$E, E /$ & FMF & $1-3$ & $D$ & $100-275$ & MAG-D & & DST \\
\hline & & & & & & & \\
\hline & & & & & & & \\
\hline & & & & & & & \\
\hline
\end{tabular}

Abstract: The inelastic electron scattering cross sections for the quadrupole transitions to the $2_{i}^{+}$and $2_{3}^{+}$ states in the even $\mathrm{Zn}$ isotopes ${ }^{64} \mathrm{Zn}$, ${ }^{66} \mathrm{Zn}$ and ${ }^{68} \mathrm{Zn}$ and for the hexadecapole, transition to the $4_{i}^{7}$ state in ${ }^{64} \mathrm{Z} \Omega$ have been measured in a momentum transfer range up $10 q=2.2 \mathrm{fm}^{-1}$. In the framework of the vibrational model these states are considered as one- and two-quadrupole-phonon states. The measurements are characterized by high statistical accuracy and by an overall resolution of $\delta E ; E_{0}=10^{-3}$ which permitted separation of almost all members of the two-phonon triplet. The measured cross sections are analyzed with phenomenological models as well as with a FourierBessel expansion of the transition charge density. The latter analysis yields realistic crror bands for the transition charge densities and model-independent values for the reduced transition probabilities
and transition radii.

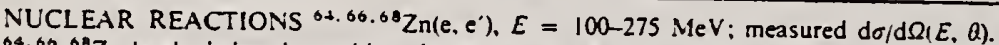

$04.60 .00 \mathrm{Zn}$ levels deduced transition charge density, $B_{i}\left(\mathrm{E}_{i}\right)$ and transition charge radii $R_{t}$. Enriched targets.

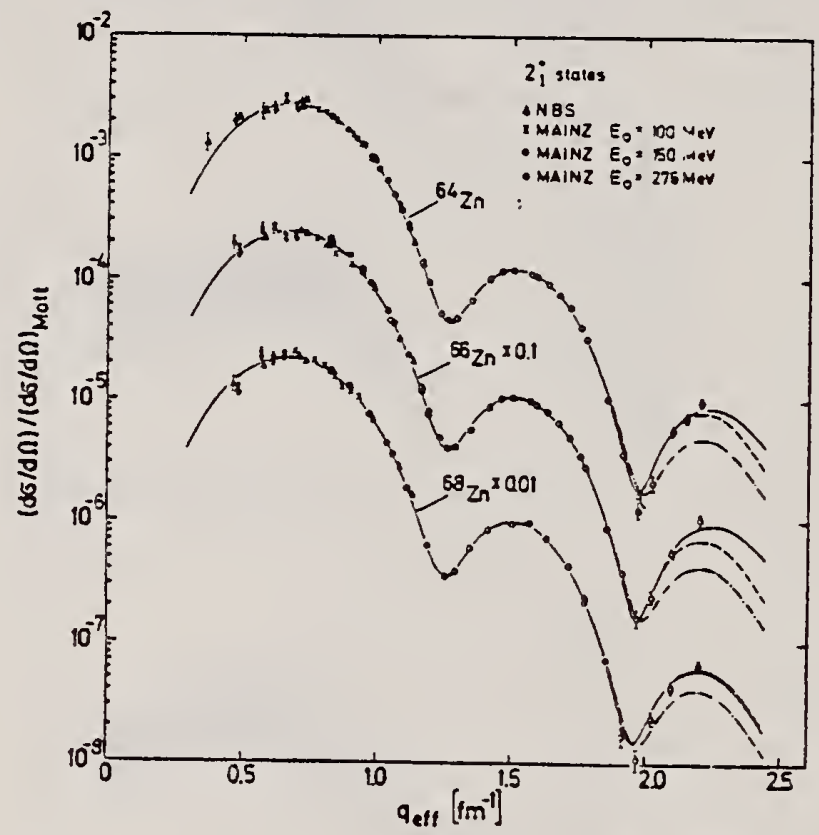

Fig. 3. Cross sections divided by the Mott cross section for the allowed transitions to the $2 ;$ state in

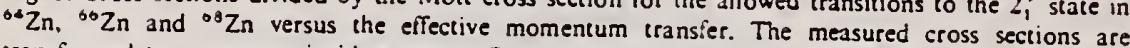
transformed to a common incident energy $E_{0}=275 \mathrm{MeV}$. The curves represent best fit DWBA cal culations with the Fourier-Bessel expansion of the transtion charge density (solid line), the modified Tassie model (dashed line) and the Gaussian model (dashed-dotted line). 
TABLE 5

Reduced transition probabilities $B_{1}(E 2)$ and transition radii $R_{\mathrm{tr}}$ for the $2_{1}^{*}$ states in ${ }^{64} \mathrm{Zn},{ }^{66} \mathrm{Zn}$ and ${ }^{69} \mathrm{Zn}$

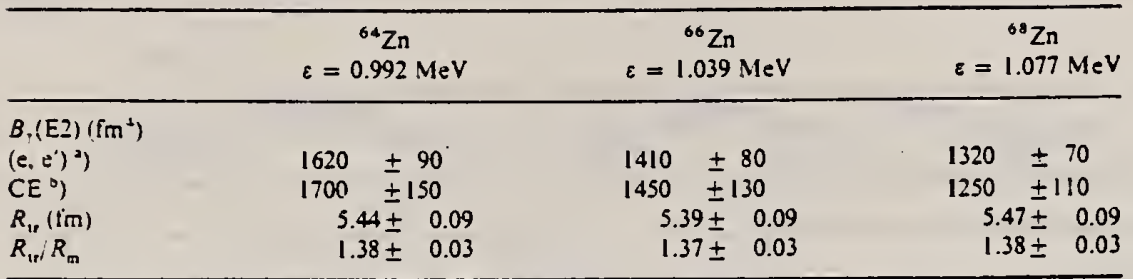

$\left.{ }^{2}\right)$ Model independent analysis, this work.

b) Ref. ${ }^{1 t}$ ).

\section{TAHLE \&}

Reduced trunsition probabilities $B_{f}(E ;)$ and trunsition radii $R_{t r}$ for the forbidden transition to the $2:$ states in ${ }^{\circ} \mathrm{Zn}$, ${ }^{\circ} \mathrm{Zn}$ and ${ }^{\circ 0} \mathrm{Za}$ and to the $4 ;$. state in ${ }^{6+} \mathrm{Zn}$

\begin{tabular}{|c|c|c|c|c|}
\hline & $\varepsilon=\begin{aligned} &{ }^{6+} \mathrm{Zn} \\
& r .800 \mathrm{MeV} \\
& i=2\end{aligned}$ & $\begin{array}{c}\varepsilon=1.873 \mathrm{MeV} \\
\quad \therefore=2\end{array}$ & 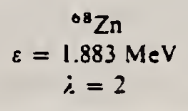 & 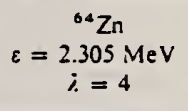 \\
\hline $\begin{array}{l}B .\left(\mathrm{Ej}_{j}\right)\left(\mathrm{fm}^{22}\right) \\
R_{\mathrm{r}}(\mathrm{fm}) \\
R_{\mathrm{tr}} R_{\mathrm{m}} \\
R_{\mathrm{rr}}^{2}(2 \vdots) / R_{\mathrm{tr}}^{2}(2 ;)\end{array}$ & $\begin{array}{c}17.0 \pm 1.2 \\
4.6 \pm 0.1 \\
1.17 \pm 0.03 \\
0.71 \pm 0.03\end{array}$ & $\begin{array}{l}4.5 \pm 0.7 \\
4.5 \pm 0.1 \\
1.14 \pm 0.03 \\
0.69 \pm 0.04\end{array}$ & $\begin{array}{l}46 \pm 7 \\
5.9 \pm 0.1 \\
1.49 \pm 0.03 \\
1.17 \pm 0.06\end{array}$ & $\begin{array}{l}(3.4 \pm 1.0) \times 10^{4} \\
6.7 \pm 0.3 \\
1.70 \pm 0.08\end{array}$ \\
\hline
\end{tabular}

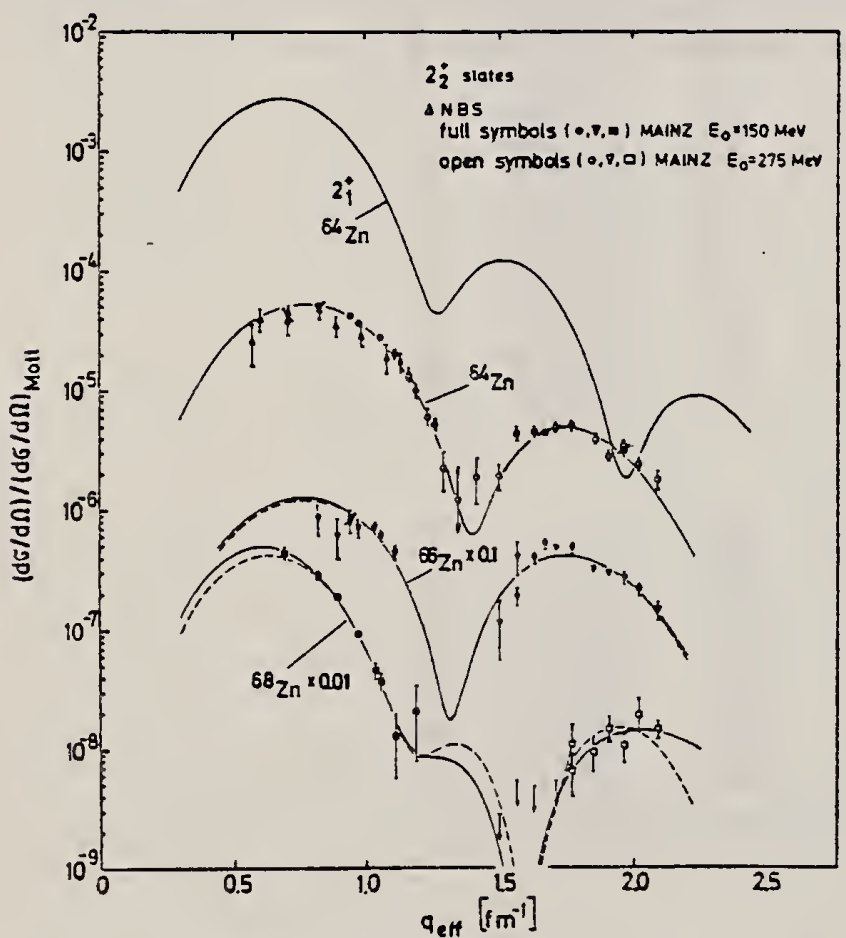

Fig. 8. Same as fig. 3. but for the forbidden transitions to the $2_{2}^{+}$states in ${ }^{6} \mathrm{Zn}$. ${ }^{\circ 0} \mathrm{Zn}$ and ${ }^{68} \mathrm{Zn}$, respectively. The surves represent hest-fit DWBA calculutions with the Fourier-Bessel expansion of the trinsition charge density folid line) and the phenornenulugital inodel given in ey. 122r (dusthed linet. Fur comparison, the shape of the cross section for the allowed iransition to the $?_{1}^{*}$ state in ${ }^{\circ+} \mathrm{Zn}$ is shown (uppermost curve). 
Reiner Neuhayseg, 125 (1977)
Nuc1. Phys. A282,

\begin{tabular}{|c|c|c|c|}
\hline Page 3 of 3 ) & $\begin{array}{c}\text { ELEM. SYM. } \\
\text { Zn }\end{array}$ & 68 & 30 \\
\hline & $\begin{array}{l}\text { REF. NO. } \\
77 \mathrm{Ne}\end{array}$ & & hg \\
\hline
\end{tabular}

\begin{tabular}{|c|c|c|c|c|c|c|c|}
\hline \multirow{2}{*}{ REACTION } & \multirow{2}{*}{ RESULT } & \multirow{2}{*}{$\begin{array}{c}\text { EXCITATION } \\
\text { ENERGY }\end{array}$} & \multicolumn{2}{|c|}{ SOURCE } & \multicolumn{2}{|c|}{ DETECTOR } & \multirow{2}{*}{ ANGLE } \\
\hline & & & TYPE & RANGE & TYPE & RANGE & \\
\hline & & & 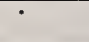 & & & & \\
\hline & & & & & & & \\
\hline & & & & & & & \\
\hline & & & & & & & \\
\hline
\end{tabular}

TARLE I

Compilation of the neasured inelastic cross sections. The cross sections are multiplied by $10^{x}$. where the power $x$ is given in cols. 4 and 3 . respectively

\begin{tabular}{|c|c|c|c|c|c|c|c|}
\hline $\begin{array}{c}E_{0} \\
(\mathrm{MeV})\end{array}$ & $\begin{array}{c}\theta \\
\text { (deg) }\end{array}$ & $\begin{array}{l}10^{x}(\mathrm{~d} \sigma / \mathrm{d} \Omega) \\
\left(\mathrm{cm}^{2} / \mathrm{sr}\right)\end{array}$ & $x$ & $\begin{array}{c}E_{0} \\
(\mathrm{MeV})\end{array}$ & $\begin{array}{c}0 \\
\text { (deg) }\end{array}$ & $\begin{array}{l}10^{2}(d \sigma / \mathrm{d} \Omega) \\
\left(\mathrm{cm}^{2} / \mathrm{sr}\right)\end{array}$ & \\
\hline \multicolumn{8}{|c|}{${ }^{68} \mathrm{Zn} ; \varepsilon=1.077 \mathrm{MeV} 2 i^{;}$} \\
\hline 100.1 & 60.0 & $1.28 \pm 0.15$ & 29 & 150.1 & 85.0 & $1.03 \pm 0.03$ & \\
\hline 100.1 & 65.0 & $8.52 \pm 1.00$ & 30 & 150.1 & 92.5 & $2.03 \pm 0.06$ & \\
\hline 100.1 & 70.0 & $6.69 \pm 0.56$ & 30 & 150.1 & 100.0 & $7.88 \pm 0.34$ & 33 \\
\hline 100.1 & 75.0 & $5.49 \pm 0.37$ & 30 & 275.1 & 52.5 & $5.00 \pm 0.17$ & 32 \\
\hline 100.1 & 80.0 & $3.36 \pm 0.20$ & 30 & 274.7 & 52.5 & $5.12 \pm 0.17$ & 32 \\
\hline 100.1 & 85.0 & $2.68=0.14$ & 30 . & 275.3 & 55.0 & $6.55 \pm 0.29$ & 32 \\
\hline $100 . i$ & 90.0 & $1.86 \pm 0.09$ & 30 & 274.7 & 55.0 & $6.24 \pm 0.18$ & 32 \\
\hline 100.1 & 95.0 & $1.18 \pm 0.06$ & 30 & 274.7 & 58.0 & $1.22 \pm 0.19$ & 32 \\
\hline 100.0 & 100.0 & $7.79 \pm 0.29$ & 31 & 274.7 & 62.0 & $6.16 \pm 0.16$ & 32 \\
\hline 100.0 & 105.0 & $5.51 \pm 0.18$ & 31 & 275.4 & 65.0 & $5.06 \pm 0.14$ & 32 \\
\hline 100.0 & 110.0 & $3.85 \pm 0.12$ & 31 & 274.7 & 68.0 & $3.22 \pm 0.09$ & 32 \\
\hline 150.1 & 50.0 & $1.26 \pm 0.04$ & 29 & 275.1 & 72.0 & $1.47 \pm 0.04$ & 32 \\
\hline 150.0 & 60.0 & $4.14 \pm 0.11$ & 30 & 275.4 & 75.0 & $6.44 \pm 0.23$ & 33 \\
\hline iso.1 & 60.0 & $4.49 \pm 0.14$ & 30 & 274.7 & 75.0 & $6.24 \pm 0.18$ & 33 \\
\hline 150.1 & 66.0 & $2.23=0.06$ & 30 & 275.1 & 79.0 & $1.59 \pm 0.07$ & 33 \\
\hline 150.0 & 72.5 & $8.71 \pm 0.23$ & 31 & 274.8 & 82.0 & $3.34 \pm 0.49$ & 34 \\
\hline 150.2 & 72.5 & $8.79 \pm 0.22$ & 31 & 275.0 & 85.0 & $1.74 \pm 0.35$ & 34 \\
\hline 150.1 & 78.0 & $3.64=0.09$ & 31 & 275.1 & 88.0 & $3.21 \pm 0.40$ & 34 \\
\hline 149.8 & 80.0 & $2.68 \pm 0.16$ & 31 & 275.0 & 92.0 & $4.75 \pm 0.40$ & 34 \\
\hline 150.0 & 85.0 & $1.01 \pm 0.06$ & 31 & 275.0 & 98.0 & $5.24 \pm 0.40$ & 34 \\
\hline \multicolumn{8}{|c|}{${ }^{68} \mathrm{Zn} ; \varepsilon=1.883 \mathrm{MeV} 2 ;$} \\
\hline 150.1 & 50.0 & $2.41 \pm 0.25$ & 31 & 275.4 & 65.0 & $<2.8$ & 34 \\
\hline 150.1 & 60.0 & $7.42 \div 0.61$ & 32 & 274.7 & 68.0 & $<2.1$ & 34 \\
\hline 150.1 & 66.0 & $3.18 \pm 0.20$ & 32 & 275.1 & 72.0 & $<1.8$ & 34 \\
\hline 150.0 & 72.5 & $1.02 \pm 0.12$ & 32 & 275.4 & 75.0 & $3.1 \pm 1.3$ & 34 \\
\hline 150.2 & 72.5 & $1.01 \mp 0.09$ & 32 & 274.7 & 75.0 & $1.9 \pm 0.8$ & 34 \\
\hline 150.1 & 78.0 & $3.45 \pm 0.52$ & 33 & 275.1 & 79.0 & $2.1 \pm 0.7$ & 34 \\
\hline 149.8 & 80.0 & $2.45 \pm 0.40$ & 33 & 274.8 & 82.0 & $2.8 \pm 0.7$ & 34 \\
\hline 150.1 & 85.0 & $5.9 \pm 3.4$ & 34 & 275.0 & 85.0 & $1.7 \pm 0.5$ & 34 \\
\hline 150.1 & 92.5 & $6.2=3.8$ & 34 & 275.1 & 88.0 & $2.6 \pm 0.8$ & 34 \\
\hline 274.7 & 62.0 & $<1.8$ & 34 & 275.0 & 92.0 & $1.6 \pm 0.3$ & 34 \\
\hline
\end{tabular}


REF. Y. Cauchois, H. Ben Abdelaziz, R. Khérouf, C. Schloesing-Möller

J. Phys. G7, 1539 (1981)

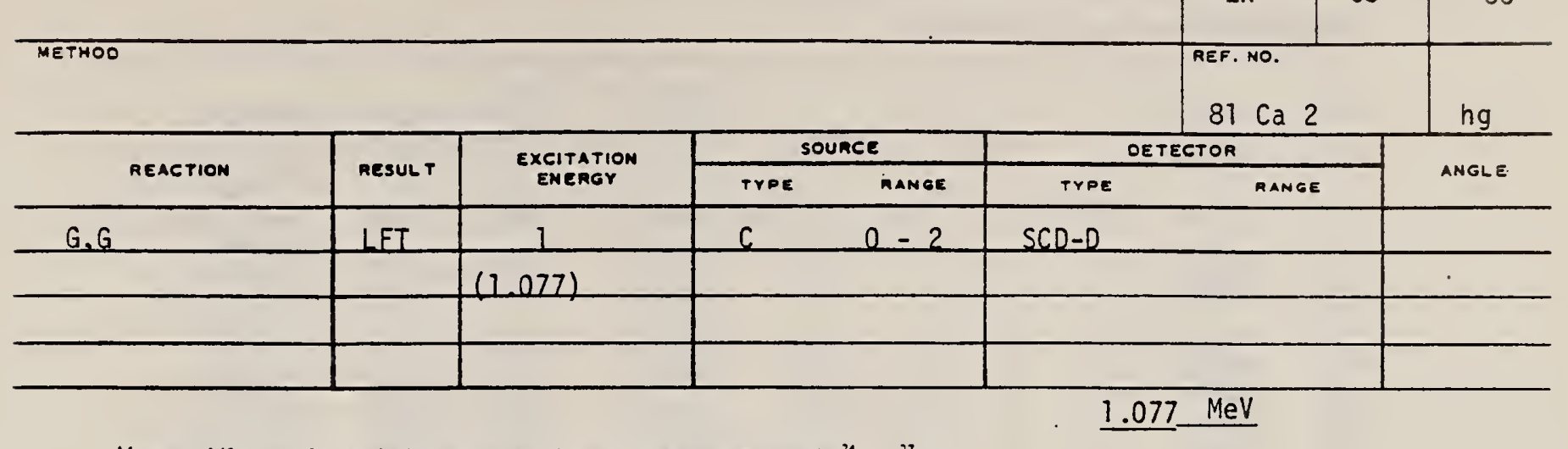

Abstrach. Lifetımes of 49 excited states below $1.65 \mathrm{MeV}$ have been measured in ${ }^{24} \mathrm{Mg}$. ${ }^{27} \mathrm{Al}$.

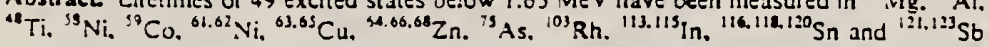
by means of nuclear resonance fuorescence experiments. The levels are excited by bremsstrahlung $x$-ray photons. The salf-absorption technique applied to suitable cases provides nuclear absorption cross sections, widihs and lifetimes from which the $x$-ray spectral distributions are also obtained. Scattering experiments are performed fo: all other cases in order to obtain tvidths and lifetirnes from these $x$-ray photon curves. The Compton effect in the sample is taken into account. Self-absorption provides $g \Gamma_{0}$ from which $\Gamma$ is deduced using adoptcu $J^{*}$ and $\Gamma$ $/ \Gamma$ valuas: scattering provides $u=g\left(\Gamma_{0}^{2} / \Gamma\right) \mid \eta(\theta)$ from which $\Gamma$ is atso deduced with $J . \Gamma_{0} / \Gamma$ and mixıng ratios taken from the literature. Thanks to simultaneous determination of the $x$-ray spectra all the lifetimes as given by our programs with their statistical errors form an unusually cohe:ent set of values.

NUCLEAR REACTIONS $(\%, \%)$ bremsstrahlung excitation; natural isotopes: ${ }^{24} \mathrm{Mg}$.

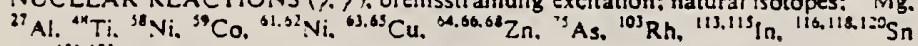
and ${ }^{121.123} \mathrm{Sb}$ : $E=0.5-1.65 \mathrm{MeV}$; measured $g \Gamma_{0}$ or $g\left(\Gamma_{0}^{2} / \Gamma\right) W(\theta)$; deduced $T_{1 / 2}$. 
Tableau 3. Resultats des mesures des niveaux etudiés par diffusion.

Table 3. Results obtained using the diffusion method.

\begin{tabular}{|c|c|c|c|c|c|c|c|c|c|}
\hline Isotope & Energie (keV) & $J^{*}$ & $J_{0}^{2}$ & $\Gamma_{0} / \Gamma$ & $\delta$ & $\begin{array}{l}u=g\left(\Gamma_{0}^{2} / \Gamma\right) w(\theta) \\
(\mathrm{meV})\end{array}$ & $\begin{array}{l}\text { ?(ps) } \\
\text { ce travail }\end{array}$ & ief (ps) & Réfërcncest \\
\hline${ }^{24} \mathrm{Mg}_{\mathrm{g}}$ & $1368.59(4)$ & $2^{*}$ & $0^{*}$ & 1 & E2 & $1,08(13)$ & $1.76(21)$ & $1,98(4)$ & $\begin{array}{l}\text { Endt et van der Lcuin } \\
\qquad(1978)\end{array}$ \\
\hline "Al & $1014,45(3)$ & $\mathfrak{d}^{*}$ & $\xi^{*}$ & 0.971 & $+0.351(12)$ & $0,186(13)$ & $2,20(16)$ & $2,12(8)$ & $\begin{array}{l}\text { Endt ct van der Leun } \\
\text { (1978) }\end{array}$ \\
\hline$" T i$ & $983.512(3)$ & $2^{+}$ & $0^{\circ}$ & 1. & E2 & $0.282(23)$ & $6.74(55)$ & $6.1(13)$ & Been (1978) \\
\hline${ }^{3} \mathrm{Ni}$ & $1454.45(15)$ & $2^{*}$ & $0^{*}$ & 1 & E2 & $2,11(26)$ & $0.90(11)$ & $0.92(3)$ & $\begin{array}{l}\text { Kocher el Auble } \\
(1976)\end{array}$ \\
\hline${ }^{99} \mathrm{Co}$ & $1099,224(25)$ & $2-$ & $3-$ & 1 & $(E 2)$ & $0,069(8)$ & $4,79(55)$ & $3,17(58)$ & $\operatorname{Kim}(1976)$ \\
\hline${ }^{99} \mathrm{Co}$ & $1458.8(3)$ & $Y-$ & ?- & 0.91 & (E2) & $0.68(8)$ & $1,17(14)$ & $1.52(16)$ & $\operatorname{Kim}(1976)$ \\
\hline "Co & $1480.9(3)$ & ?- & !- & 0.8 & $<0.35^{\circ}$ & $1.23(15)$ & $0.254(31)$ & $0.31(3)$ & $\operatorname{Kim}(1976)$ \\
\hline${ }^{6} \mathrm{Ni}$ & $1185.7(6)$ & i- & j- & $0.77(8)^{\prime}$ & $|0.14|$ & $1.88(49)$ & $0.21(5)$ & $0.16(3)$ & Andreev ef al $(197 \lambda)$ \\
\hline${ }^{52} \mathrm{Ni}$ & $1172.91(9)$ & $2^{*}$ & $0^{*}$ & 1 & $E 2$ & $0.88(17)$ & $2,15(42)$ & $2.09(3)$ & Halbert (1979a) \\
\hline${ }^{63} \mathrm{Cu}$ & $1327.00(7)$ & $3^{-}$ & $3-$ & 0.84 & (E2) & $1.04(14)$ & $0,84(11)$ & $0.88(4)$ & Auble (1979b) \\
\hline${ }^{00} \mathrm{Cu}$ & $1412,05(4)$ & ?- & $2-$ & 0.72 & $+0.61(\div-9)$ & $0.260(38)$ & $1,90(28)$ & $1,61(3)$ & Auble (1979b) \\
\hline${ }^{\infty} \mathrm{Zn}$ & $991.54(7)$ & $2^{\circ}$ & $0^{*}$ & 1 & E2 & $0,640(54)$ & $2.97(25)$ & $2.60(13)$ & Halbert (1979b) \\
\hline${ }^{45} \mathrm{Cu}$ & $1481,83(5)$ & $i^{-}$ & $3-$ & 0,85 & (E2) & $1,13(19)$ & $0.79(13)$ & $0.49(5)$ & Auble (1975a) \\
\hline${ }^{6 n}$ & $1039.37(6)$ & $2^{-}$ & $0^{\circ}$ & 1 & E2 & $0,70(6)$ & $2,71(23)$ & $2.25(15)$ & Auble (1975b) \\
\hline $\mathrm{Zn}_{\mathrm{n}}$ & $1077.38(5)$ & $2^{*}$ & $0^{*}$ & 1 & E2 & $0.70(6)$ & $2,71(23)$ & $2,34(23)$ & Lewis (1975) \\
\hline${ }^{79}$ As & $572.5(10)$ & :- & $3-$ & $1^{d}$ & $0,39^{b}$ & $0.236(26)$ & $4,14(46)$ & $3.5(9)$ & Horcil et Lcwis (1975) \\
\hline${ }^{2}$ As & $823.0(10)$ & $?^{2}$ & - & $0,86^{4}$ & (E2) & $0.214(22)$ & $4.27(43)$ & $3.5(3)$ & Robinsone al (1967) \\
\hline${ }^{99}$ As & $865.5(10)$ & i* & - & $0.83^{d}$ & $-c$ & $0.78(6)$ & $0.863(68)$ & $0.60(12)$ & Celliers ef al (1977) \\
\hline${ }_{73}^{73}$ & $1076,0(10)$ & 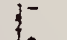 & - & $0.94^{d}$ & $0,38^{d}$ & $1,97(13)$ & $0,287(19)$ & $0.32(7)$ & Celliers et al (1977) \\
\hline${ }^{79}$ As & $1128,5(10)$ & $I^{*}$ & $\frac{1}{2}$ & 1 & $E l^{\triangleleft}$ & $0,224(24)$ & $1,47(16)$ & - & \\
\hline "As & $13+9.0(10)$ & $3-$ & t- & $0.67^{\mathrm{d}}$ & $0.20^{\mathrm{d}}$ & $1.61(29)$ & $0.180(32)$ & $0.12(3)$ & Wilsun $(1970)$ \\
\hline "As & $1370.0(10)$ & 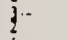 & - & $0.47^{4}$ & $0.47^{d}$ & $0.64(13)$ & $0.218(44)$ & - & \\
\hline${ }^{103} \mathrm{Rh}$ & $803.1(2)$ & - & - & 0.70 & $M !$ & $1.85(10)$ & $0.174(15)$ & - & Harmaltz $(1979)$ \\
\hline${ }^{103} \mathrm{Rh}$ & $1277.0(2)$ & - & $\frac{1}{2}$ & 0.75 & $-0.62(30)^{e}$ & $0.8 !(y)$ & $0.87(10)$ & $1.3(9)$ & I1:Irunill< $(1979)$ \\
\hline $113 \ln$ & $1177(1)$ & 4. & $?$ & 1 & $+0.5(2)$ & $9.1(8)$ & $0,086(8)$ & $0.10(6)$ & Tutle we ai $(1976)$ \\
\hline${ }^{113} \ln$ & $1510(1)$ & $i$ & $9 \cdot$ & 0.935 & $-0.5\{-1\}$ & $6.4(9)$ & $0.071(10)$ & $0.11\}: \begin{array}{l}11 \\
: 21\end{array}$ & Tuttle de cl $(1976)$ \\
\hline $1191 \pi$ & 1077.7101 & 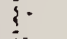 & $?$ & $0.81^{\prime}$ & (E2) & $0.159(24)$ & $1.61(24)$ & 1.23171 & Tulle de al $(1976)$ \\
\hline${ }^{115} 1 \mathrm{n}$ & $1290.59(3)$ & 3 & $i^{*}$ & $0.98^{\prime}$ & $(F, 2)$ & $1.31(11)$ & 0.66161 & $0.55(4)$ & Tutle ef of $(19: 6)$ \\
\hline $1151 \mathrm{n}$ & $1448.78(3)$ & y. & ?. & 0.86 & $-8^{\prime}$ & $0.90(11)$ & $0.50(6)$ & $0 . \leqslant 2(20)$ & Tutcle ce al $(1476)$ \\
\hline $119 \ln$ & $14 \times 6.1111$ & $\therefore$ & ?. & 0.787 & $-0.8^{\prime}$ & $0.63(9)$ & $0.63(9)$ & $0.4(3)$ & Tuttle et ul(1976) \\
\hline $1151 \pi$ & $1+47.2(4)$ & $1 \because 1$ & $\because$ & $<1$ & (E2) & $1.33(16)$ & $<0.30(4)$ & - & \\
\hline ה1" & $16(1) 7,4(15)$ & $\left(!^{\bullet}\right)$ & $\underline{0}$ & $\leqslant !$ & $(1: 2)$ & $1.5+(24)$ & $\leq 0.26(1)$ & - & \\
\hline${ }^{116} \mathrm{Sn}$ & $12 y 3.5+21$ & 2 & $0^{\circ}$ & 1 & $E 2$ & $3.58(37)$ & $0.53(6)$ & $0.522(1+1)$ & Curlsoul der al $(19 ; 5)$ \\
\hline${ }_{118}^{18} \mathrm{Sn}$ & $1229.64(4)$ & 2 & $00^{\circ}$ & 1 & E.2 & $2.75(28)$ & $0.69(7)$ & $0.6 \div(2)$ & C:urlsom en al(19:6) \\
\hline${ }^{120} \mathrm{Sn}$ & $1171.6(2)$ & $2^{\circ}$ & $0^{\circ}$ & 1 & $\mathrm{E}_{2}$ & $1.83(16)$ & $1.0 \pm(4)$ & 0.91121 & K(wixer $(1976)$ \\
\hline${ }^{12 i} \mathrm{Sb}$ & $1023.5(10)$ & $?^{\prime-}$ & $\vdots$ & 1 & $0.57 i^{\circ}$ & $3.69(34)$ & $0.228(21)$ & 0.20()$\left.^{7}\right)^{a}$ & Tanura ot ai $(19-4)$ \\
\hline${ }^{12 !} \mathrm{Sb}$ & 1105.51101 & $?^{*}$ & $i$ & 0.4 & - & $0.47(4)$ & $0.42(4)$ & - & \\
\hline${ }^{121} \mathrm{Sb}$ & $1142.5(10)$ & ?* & $\vdots$ & 0.6 & (E2) & $0.85(8)$ & $0.449(40)$ & $0,4 \|(3)^{h}$ & Bouth et al (1973) \\
\hline${ }^{121} \mathrm{Sb}$ & $1384.0(10)$ & i* & $\vdots "$ & 1 & $\left.0.45\right|^{8}$ & $4.7(5)$ & $0.092(10)$ & $0,0 \times 8(14)^{4}$ & Bouth ef of $(1473)$ \\
\hline${ }^{12 J} \mathrm{Sb}$ & $1029.5(10)$ & ". & 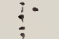 & 1 & $|0.57|^{\circ}$ & 2.961271 & $0.272(25)$ & $0.26(-4)^{3}$ & Bouth ef al $(19-3)$ \\
\hline${ }^{123} \mathrm{Sb}$ & $1086.5(10)$ & 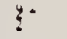 & $\vdots$ & 1 & $|\dot{d}|>1.26^{\circ}$ & $1.06(y)$ & $0.67(6)$ & $0.72(15)^{n}$ & Beweth if cil $(1973)$ \\
\hline
\end{tabular}

+ Refcrences pour les colonnes 3, 4, 5. 6 et $y$ de chaque ligne, sauf indication appelee au bas $\mathrm{dc}$ ce tableau. Puur les autrcs dunnces se rcporter au texte.

Remarque. Pour calculer $\delta^{-2}$ quand nous ne disposons que de $B(E 2)$, pour un mélange $(E 2)+(M !)$, nous deduisons $g \Gamma$ o(E2) $\propto B(E 2) E_{;}^{3} ;$ en admcttant $W(\ell)=1$ et connaissant $\Gamma_{0} / \Gamma$, notrc determination de $u$ donne une premicre approximation de g $\Gamma_{0}$ d'ou une valeur de $\delta^{2}=\left(g \Gamma_{0}\left(E_{2}\right)\right) /\left(g \Gamma_{0}-{ }_{j} \Gamma_{0}\left(E_{2}\right)\right)$ qui permet d'amétiorer $W(\theta)$ et $g \Gamma_{0}$ de proche en proche.

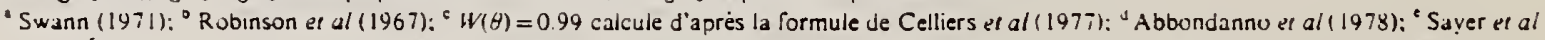
(1972): 'Tuttle ef al (1976); 'J'après B(E2) de Barnes et al (1966): " calcule d'apres Booth el al (1973); ' Williams el al (1975): I Dietrich et al (1970). 
R. Neuhausen, J. W. Lightbody, Jr., S. P. Fivozinsky, and $S$. Penner

Nucl. Phys. A263, 249 (1976)
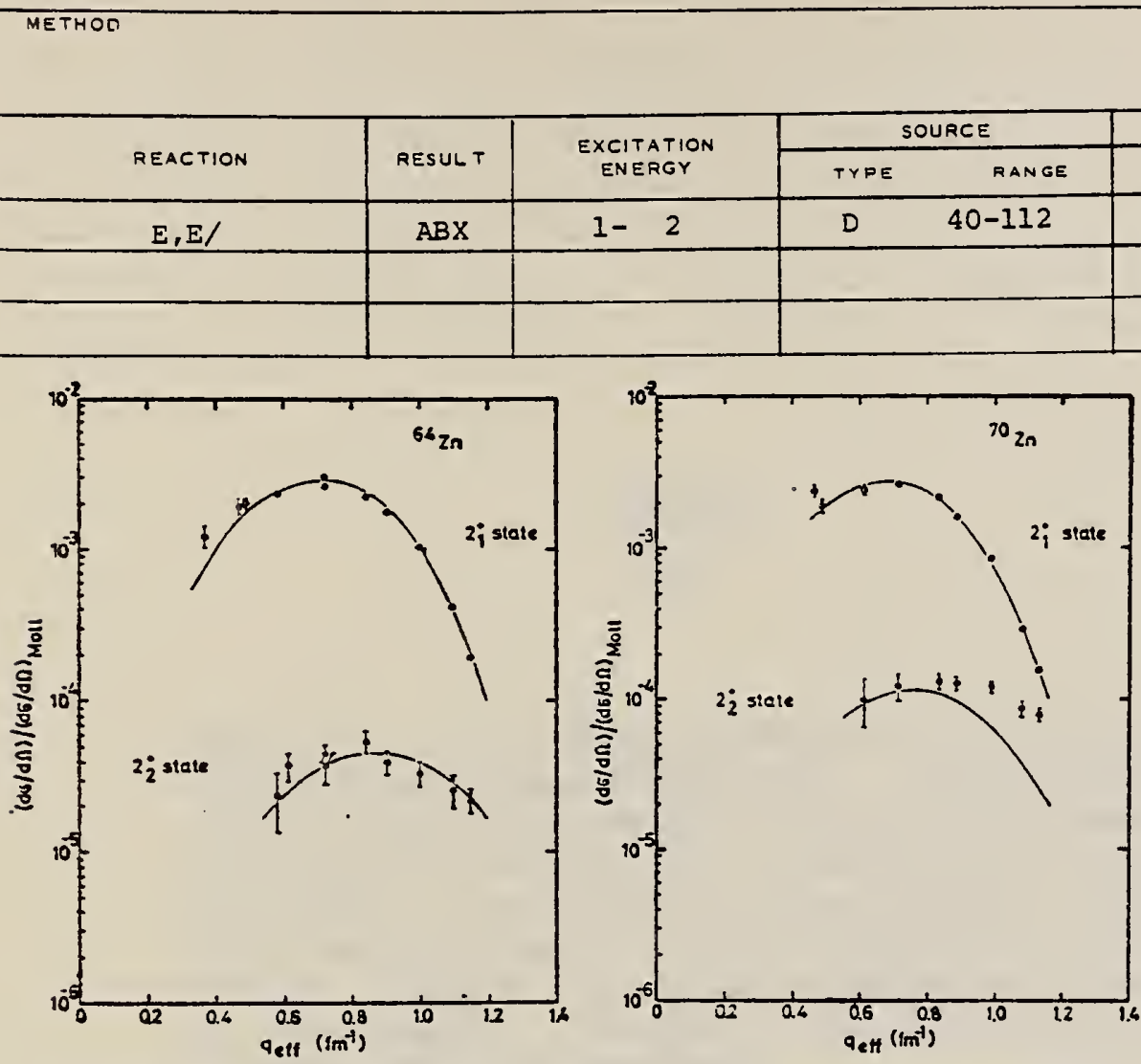

2+,2+ STATES

Fig. 2. Cross sections divided by the Mott cross section for the excitation of the first and second $2^{+}$ states in ${ }^{64} \mathrm{Zn}$ and ${ }^{70} \mathrm{Zn}$, respectively, versus the effective momentum transfer. The cross sections measured at different values of the incident energy $E$ were transformed to the common energy $E_{0}=120 \mathrm{MeV}$. The curves are the best fit of the anharmonic vibrator model.

TAale 6

Reduced transition probabilities in single particle units, deformation parameters and deformation lengths $(R=1.2 \mathrm{fm} \times A \dagger)$

\begin{tabular}{|c|c|c|c|c|c|c|}
\hline & 2)/Bs.p. (E2) & $\beta_{2}$ & $\begin{array}{l}\beta_{2} R \\
(\mathrm{fm})\end{array}$ & $B_{\uparrow}(E 3)_{i} B_{\uparrow}^{s \cdot p \cdot}(E 3)$ & $\beta_{3}$ & $\begin{array}{l}\beta_{3} R \\
(\mathrm{fm})\end{array}$ \\
\hline${ }^{64} \mathrm{Z} \Omega$ & $20.4 \pm 1.2$ & $0.230 \pm 0.007$ & $1.10 \pm 0.03$ & $23.5 \pm 4.0$ & $0.224 \pm 0.019$ & $1.08 \doteq 0.09$ \\
\hline${ }^{66} \mathrm{Zn}$ & $17.3 \pm 1.3$ & $0.212 \pm 0.008$ & $1.03 \doteq 0.04$ & $23.4 \pm 4.9$ & $0.224 \pm 0.023$ & $1.09 \doteq 0.11$ \\
\hline${ }^{68} \mathrm{Zn}$ & $13.5 \pm 1.0$ & $0.137 \pm 0.007$ & $0.92 \div 0.04$ & $19.8 \pm 4.3$ & $0.206 \doteq 0.022$ & $1.01 \pm 0.11$ \\
\hline${ }^{70} \mathrm{Zn}$ & $24.0 \pm 2.2$ & $0.249 \pm 0.011$ & $1.23 \pm 0.06$ & & & \\
\hline
\end{tabular}

19 A.K. Seǹ Guptz and D.M. Van Patter, Nucl. Phys. 50 (1964) 17.

TABLE 7

The $2_{1}^{+}$and $2+$ stats AVM fiting parameters for ${ }^{6+} \mathrm{Zn}$ and ${ }^{70} \mathrm{Zn}$

\begin{tabular}{|c|c|c|c|c|c|c|c|c|}
\hline & $(\hbar / 2 \sqrt{B C})^{\ddagger}$ & $\begin{array}{c}c_{\mathrm{qr}} \\
(\mathrm{fm})\end{array}$ & $\begin{array}{c}z_{18} \\
\text { (fm) }\end{array}$ & $a$ & $\begin{array}{c}Q\left(2_{1}^{+}\right)(\mathrm{AVM}) \\
\text { (b) }\end{array}$ & $B R(A \vee M)$ & BR(other)") & $B\left(E 2 ; 0_{1}^{+} \rightarrow 2+\right)$ \\
\hline$<Z_{n}$ & $0.109 \pm 0.004$ & $4.47 \pm 0.08$ & $0.53 \pm 0.06$ & $0.165 \pm 0.005$ & $-0.124 \pm 0.012$ & $456 \pm 70$ & $159 \pm 12$ & $8 \doteq 2$ \\
\hline${ }^{70} \mathrm{Zn}$ & $0.122 \pm 0.006$ & $4.29 \pm 0.08$ & $0.71 \neq 0.05$ & $0.25 \pm 0.02$ & $-0.233 \pm 0.022$ & $72( \pm 26)$ & & $50 \pm 13$ \\
\hline
\end{tabular}

Derived $2_{1}^{+}$state static quadrupole moments, $2_{2}^{+}$state branching ratios, and $B\left(E 2 ; 0_{1}^{+} \rightarrow 2_{2}^{+}\right)$are given. 9) Ref. ${ }^{19}$ ). 


\section{GALILII}

Gallium is a bluish-white metallic solid that becomes a liquid at near room temperature. It was discovered in 1875 by the French chemist, Lecoq de Boisbaudran, by spectroscopic examination of concentrates from a Pyrenean zinc blend. The position of the emission lines corresponded to those predicted for "eka-aluminum" a missing element between aluminum and indium in Mendeléyev's periodic scheme of the elements. He named it gallium from the Latin gallia in honor of his fatherland. 
G. Baciu, A. Bonazzola, B. Minetti, C. Molino, L. Pasqualini and G. Piragino

Rev. Roum. Phys. 2, 977 (1964)

\begin{tabular}{|c|c|c|}
\hline METHOO & $\begin{array}{l}\text { REF. NO. } \\
64 \mathrm{Ba} 4\end{array}$ & egf \\
\hline
\end{tabular}

\begin{tabular}{|c|c|c|c|c|c|c|c|}
\hline \multirow[b]{2}{*}{ REACTION } & \multirow[b]{2}{*}{ RESULT } & \multirow{2}{*}{$\begin{array}{l}\text { EXCITATION } \\
\text { ENERGY }\end{array}$} & \multicolumn{2}{|c|}{ SOURCE } & \multicolumn{2}{|c|}{ DETECTOR } & \multirow{2}{*}{ ANGLE } \\
\hline & & & TYPE & RANGE & TYPE & RANGE & \\
\hline$G, X N$ & $A B X$ & $10-27$ & $\mathrm{C}$ & $10-27$ & BF3-I & & $4 \mathrm{PI}$ \\
\hline & & & & $\cdot$ & & & \\
\hline & & & & & & & \\
\hline & & . & & & & & \\
\hline
\end{tabular}

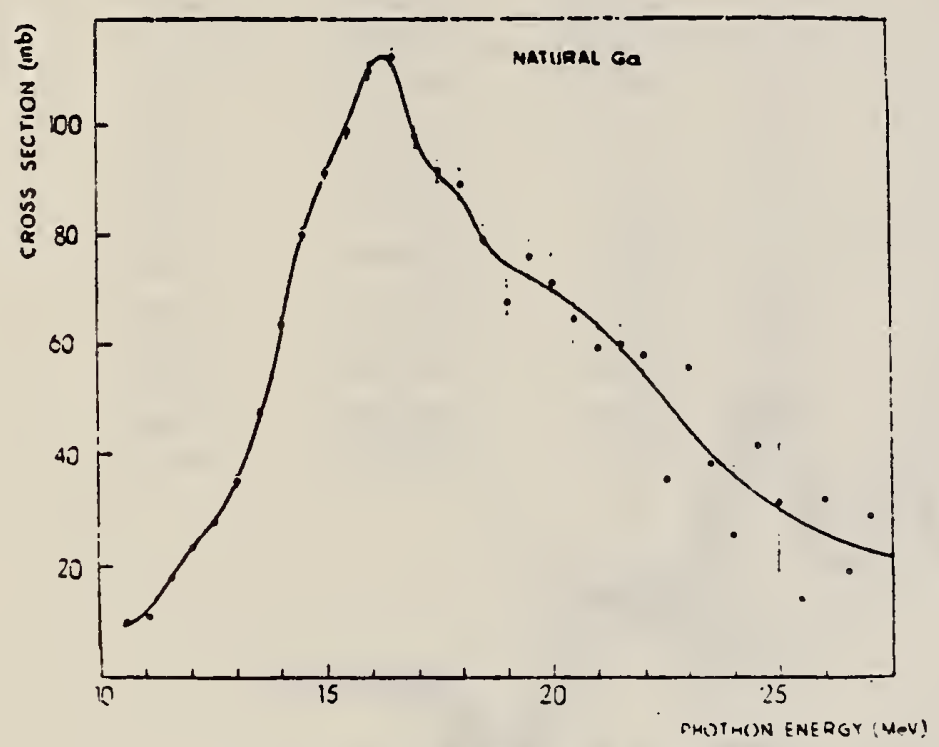

Fi... 4. $-\sigma(Y, T n)$ for ra of natural isotopic abundance. 
G. Baciu, C. Molino, B. Minetti, L. Pasqualini, G. Piragino Stud. Cercetari Fiz. 10, 903 (196́)

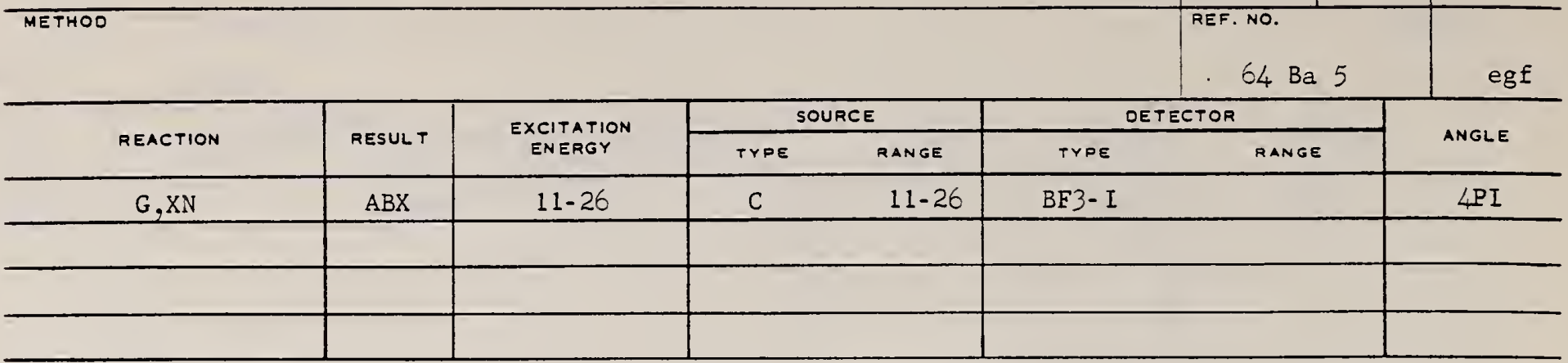

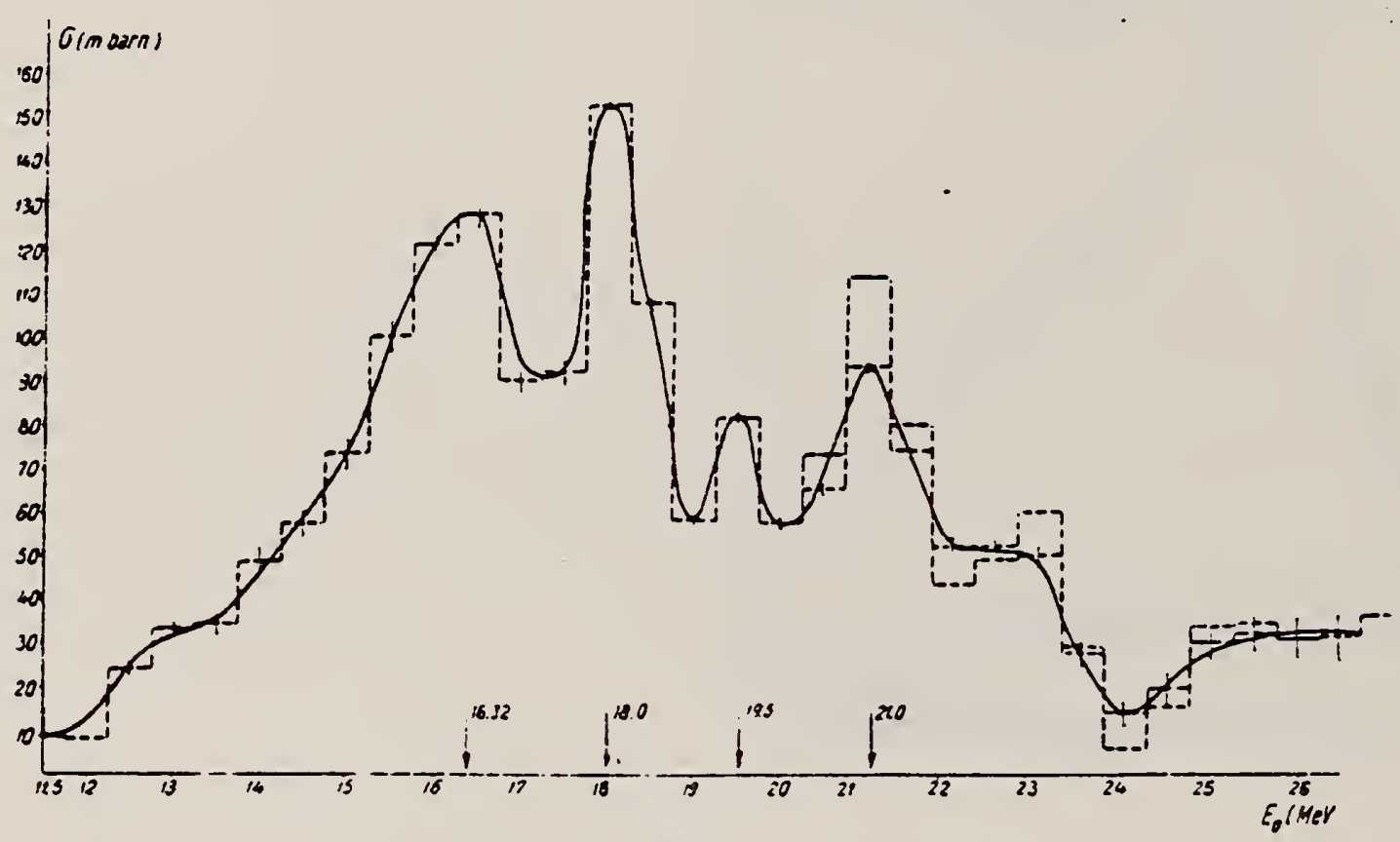

Fig. 3 


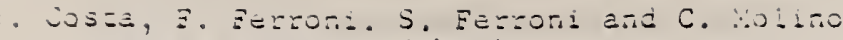

zioys. Letzers $11 ; \vdots 2<(190-)$

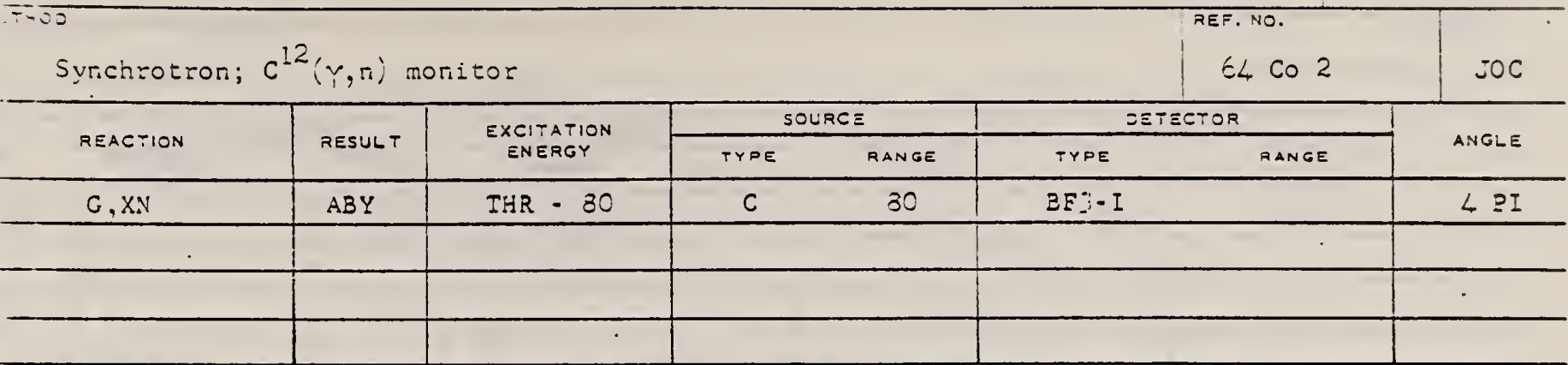

Table 1

\begin{tabular}{|c|c|c|c|c|c|c|c|}
\hline Element & $\begin{array}{l}\text { Yield (36) } \\
\mathrm{eV} \mathrm{cm} \\
\text { mol } \mathrm{MeV}\end{array}$ & $\begin{array}{l}\approx 0, \mathrm{~V} Z / A \\
(\mathrm{mb} \mathrm{NOV})\end{array}$ & $\begin{array}{l}30 \\
2 \\
0\end{array}$ & $\begin{array}{l}80 \\
\sum \\
0\end{array}$ & $\begin{array}{l}20 \\
\sum_{0} / \Sigma_{0} \\
0\end{array}$ & $\begin{array}{c}E_{m} \\
(\mathrm{MeV})\end{array}$ & $\begin{array}{l}\tau_{m} \\
(m b)\end{array}$ \\
\hline $24^{\mathrm{Cr}}$ & $83 \times 10^{-5}$ & 777 & 1.21 & 2.1 & 0.58 & 18.5 & 97 \\
\hline $25 \mathrm{Mn}$ & $10 \varepsilon \times 10^{-5}$ & 813 & 1.52 & 2.33 & 0.65 & 18.5 & 114 \\
\hline $2 \overline{0}^{\mathrm{Fe}}$ & $68 \times 10^{-5}$ & ละ2 & $0 . \varepsilon 3$ & $1.4 \varepsilon$ & 0.60 & 17.5 & 75 \\
\hline${ }_{27} \mathrm{Co}$ & $85 \times 10^{-5}$ & $\$ 78$ & 1.08 & 1.32 & 0.59 & 17.5 & 92 \\
\hline $28 \mathrm{Ni}$ & $44 \times 10^{-5}$ & 879 & $0.35^{\circ}$ & 1.07 & 0.51 & 13.5 & 56 \\
\hline${ }_{29} \mathrm{Cu}$ & $95 \times 10^{-5}$ & $9 \div 7$ & 1.06 & 1.99 & 0.53 & 17.5 & 98 \\
\hline $30^{Z=}$ & $38 \times 10^{-5}$ & 975 & 0.94 & 1.63 & $0.5 \hat{0}$ & 17.5 & ภิธิ \\
\hline $32 \mathrm{Gi}$ & $130 \times 10^{-5}$ & 2034 & 1.29 & 2.18 & 0.59 & 17.5 & 151 \\
\hline${ }_{32} \mathrm{Ge}$ & $139 \times 10^{-5}$ & 1054 & 1.35 & 2.29 & 0.59 & 17.5 & 158 \\
\hline $33 \times 5$ & $137 \times 10^{-5}$ & $: 109$ & 1.22 & 2.18 & 0.56 & 17.5 & 127 \\
\hline
\end{tabular}

;C

$\Sigma_{j}^{30}=\frac{j}{0(Y, x \pi) d E}$

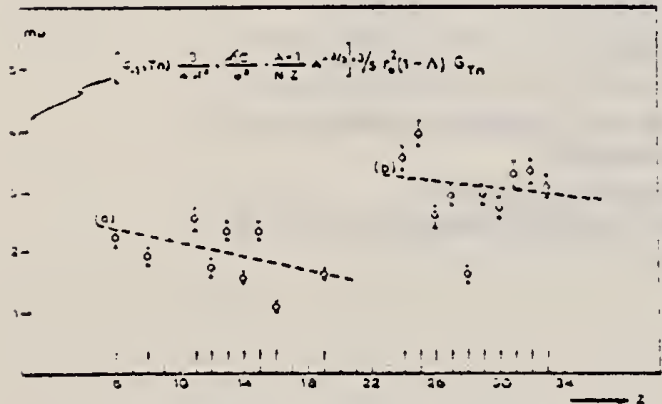

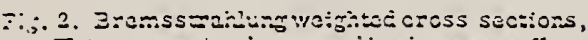

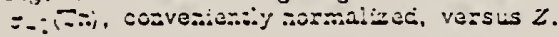

\begin{tabular}{|c|c|c|c|}
\hline$\Xi: \leq m=n t$ & 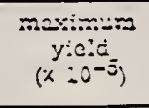 & $\sigma_{-i}(-\pi)$ & 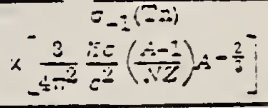 \\
\hline${ }_{0} \mathrm{C}$ & $\therefore .0$ & 3.34 & $2 .: 3$ \\
\hline $3^{\circ}$ & 5.2 & 4.95 & $: .52$ \\
\hline $21 \times 2$ & $: 3.6$ & 28.60 & $2 \therefore 9$ \\
\hline$: 2 x_{3}$ & $: 0.0$ & $3.8 I$ & ב.73 \\
\hline $23 \times 1$ & $: 5.9$ & 13.92 & 2.30 \\
\hline $14: 5$ & 12.0 & 9.90 & $\therefore . \equiv$ \\
\hline 152 & $: 0.5$ & $17 . \Xi 0$ & 2.32 \\
\hline$: \varepsilon^{5}$ & $5 . \equiv$ & $8 . \Sigma \Sigma$ & $-.3 ?$ \\
\hline$: 30$ & $=5.0$ & $\therefore 7.30$ & $\therefore .0=$ \\
\hline $20^{C=}$ & $\therefore 2.1$ & $: 2.08$ & $\therefore .02$ \\
\hline $2{ }_{2 \pi} \mathrm{Cr}$ & si, & $5: .6$ & 3.56 \\
\hline $2 E^{2}$ & $: 25$ & 75.2 & 3.90 \\
\hline${ }_{20}=0$ & 71 & $\Xi 0 . \bar{z}$ & $2.5 \overline{5}$ \\
\hline $2 \rightarrow \infty 0$ & 84 & $62 . \overline{3}$ & 2.94 \\
\hline $23 \%$ & $\div 6$ & $3 \div .2$ & $\therefore .59$ \\
\hline${ }_{20} \mathrm{Ci}$ & 202 & 72.3 & 2.50 \\
\hline $30 \angle=$ & $\$ 3$ & $6 \bar{z} .7$ & 2.63 \\
\hline $3: \leqslant 2$ & 140 & 93.5 & 3.31 \\
\hline${ }_{32} \mathrm{Ge}$ & 150 & 201.5 & 2.30 \\
\hline $33 \mathrm{As}$ & :5: & SS.ô & .3 .12 \\
\hline
\end{tabular}


G. Baciu, G. C. Bonazzola, B. Minetti, C. Molino, L. Pasqualini and $G$. Piragino

Nuclear Phys. 67, 178 (1965)

NBS Monitor

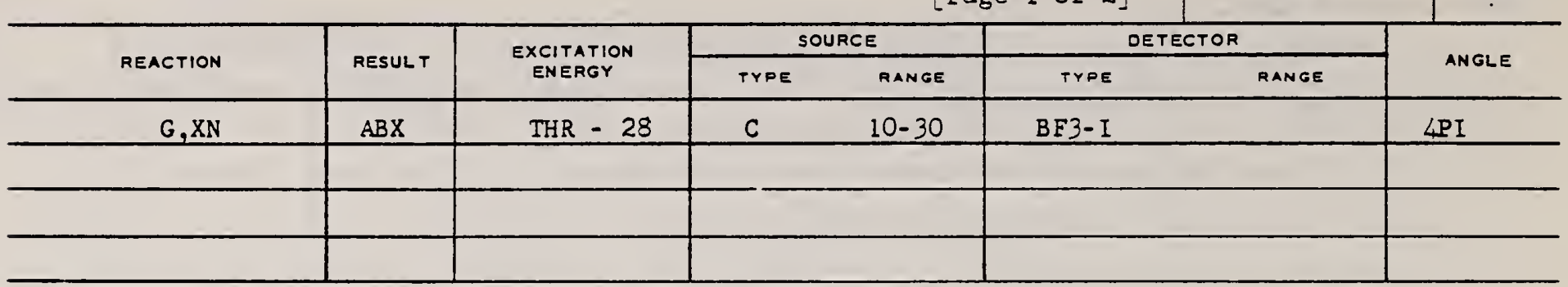

TABLE 2

Cross sections for $\mathrm{Co}, \mathrm{Ni}, \mathrm{Cu}$ and $\mathrm{Ga}$

\begin{tabular}{|c|c|c|c|c|c|}
\hline & $\begin{aligned} E_{1} \\
(\mathrm{Me}\end{aligned}$ & & $\begin{array}{l}\sigma_{m} \\
(\mathrm{mb})\end{array}$ & $\int_{0}^{x} \sigma(E) \mathrm{d} E(\mathrm{mb} \cdot \mathrm{MeV})$ & Ref. \\
\hline $\mathrm{CO}^{60}$ & $\begin{array}{l}16.9 \\
16.75 \\
17.5 \\
16.5 \\
16.5\end{array}$ & $\begin{array}{l}19 \\
19 \\
19\end{array}$ & $\begin{array}{rr}130 & \\
110 & 103 \\
68 & \\
82 & 80 \\
72 & 74\end{array}$ & $\begin{array}{l}750(24) \\
709(25) \\
725 \pm 72(28) \\
701 \pm 91(29) \\
657 \pm 89(28) \\
537 \pm 34(24) \\
445 \pm 48(24)\end{array}$ & $\begin{array}{l}\text { ") } \\
\text { ") } \\
\text { ") } \\
\text { 20) } \\
\text { this work } \\
\text { this work } \\
\text { ") }\end{array}$ \\
\hline $\mathrm{Ni}$ & $\begin{array}{l}16.5 \\
16.5\end{array}$ & & $\begin{array}{l}50 \\
46 \pm 1\end{array}$ & $\begin{array}{l}340(24) \\
313 \pm 48(28) \\
276 \pm 25(24)\end{array}$ & $\begin{array}{l}\text { 13) } \\
\text { this work } \\
\text { this work }\end{array}$ \\
\hline $\mathrm{Ni}^{4}$ & $\begin{array}{l}18.5 \\
\\
20.5 \\
19.0\end{array}$ & & $\begin{array}{l}60 \\
30 \\
21 \\
32\end{array}$ & $\begin{array}{l}330(24) \\
180(24) \\
160(24) \\
220 \pm 30(32)\end{array}$ & $\begin{array}{l}12) \\
\text { (19) } \\
\text { 12) } \\
10)\end{array}$ \\
\hline $\mathrm{Ni}{ }^{\omega}$ & 16.5 & & 85 & $440( \pm 20 \%)(24)$ & D) \\
\hline $\mathrm{Cu}$ & $\begin{array}{l}19.5 \\
17.2 \\
17 \\
16.75 \\
17.0\end{array}$ & & $\begin{array}{l}120 \\
126 \\
90 \\
71 \pm 7 \\
86 \pm 2\end{array}$ & $\begin{array}{l}870(20) \\
904(27) \\
930(27) \\
450 \pm 15(19,6) \\
745 \pm 74(28) \\
733 \pm 105(28) \\
451 \pm 18(20)\end{array}$ & $\begin{array}{l}\text { 2) } \\
\text { 18) } \\
\text { 28) } \\
\text { 17) } \\
\text { 18) } \\
\text { this work } \\
\text { this work }\end{array}$ \\
\hline $\mathrm{Ga}$ & 16.5 & & $115 \pm 3$ & $947 \pm 98(28)$ & this work \\
\hline
\end{tabular}

$\sigma_{\mathrm{m}}$ is the peak value of the cross section, $E_{\mathrm{m}}$ is the peak energy and $\int_{0}^{\sigma} \sigma(E) \mathrm{d} E$ is the integrated cross section. The upper limit of the integration is indicated in parentheses.

) Value obtained subtracting the $(\gamma, 2 n)$ reaction contribution from the $\sigma(\gamma, T n)$.

b) Value obtained by subtracting the $\mathrm{Ni}^{\omega}(\gamma, \mathrm{n}) \mathrm{Ni}^{\text {w }}$ reaction contribution from the $\sigma(\gamma, \mathrm{Tn})$ for aatural nickel corrected for the $(\gamma, 2 n)$ reaction contribution. 
REF.

G. Baciu, G. C. Bonazzola, B. Minetti, C. Molino, L. Pasqualini and $G$. Piragino

Nuclear Phys. 67, 178 (1965)

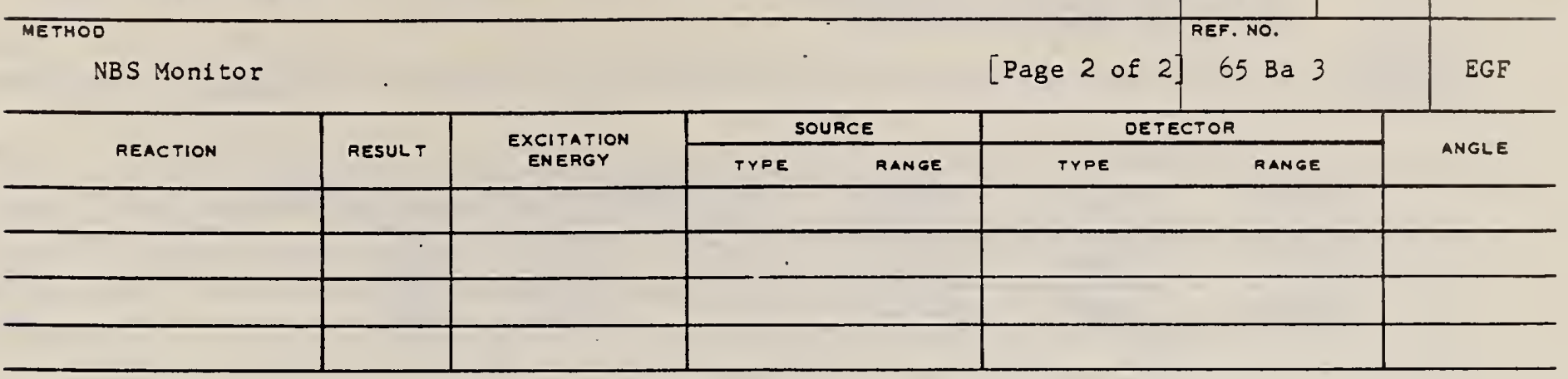

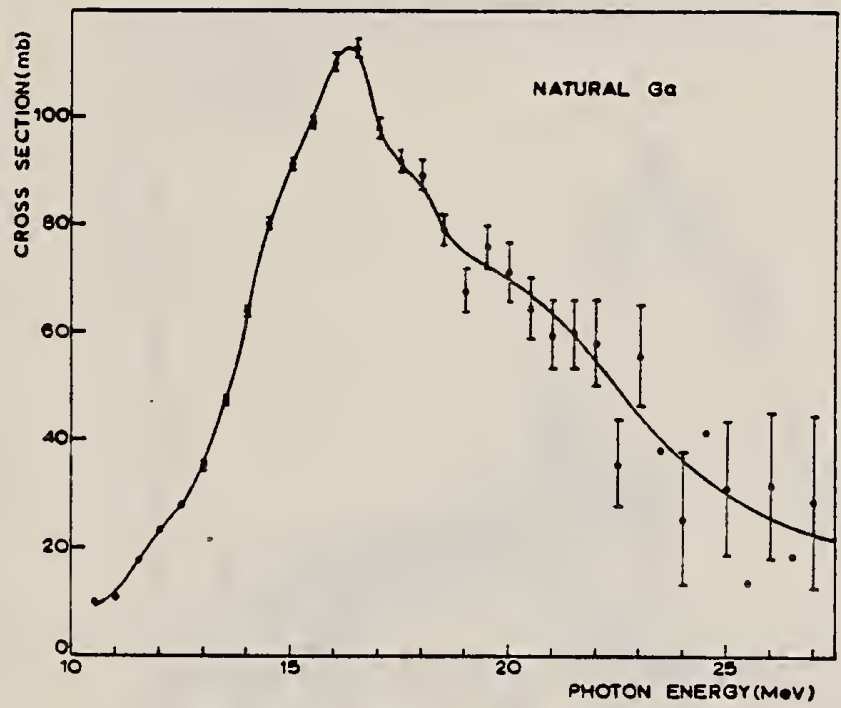

Fig. 4. The cross section $\sigma(\gamma, T n)$ for natural gallium. 
$G A$

$A=66$

$G A$

$A=66$ 
Ref. J.H. Carver, G.A. Jones

Nuclear Phys. 11, 400 (1959)

\begin{tabular}{|c|c|c|}
\hline & $\mathrm{Ga}$ & 31 \\
\hline $\begin{array}{l}\text { Method Radioactivity } \\
\text { Res }\end{array}$ & $\begin{array}{l}\text { Ref. No. } \\
59 \mathrm{Ca} 1\end{array}$ & JOC \\
\hline
\end{tabular}

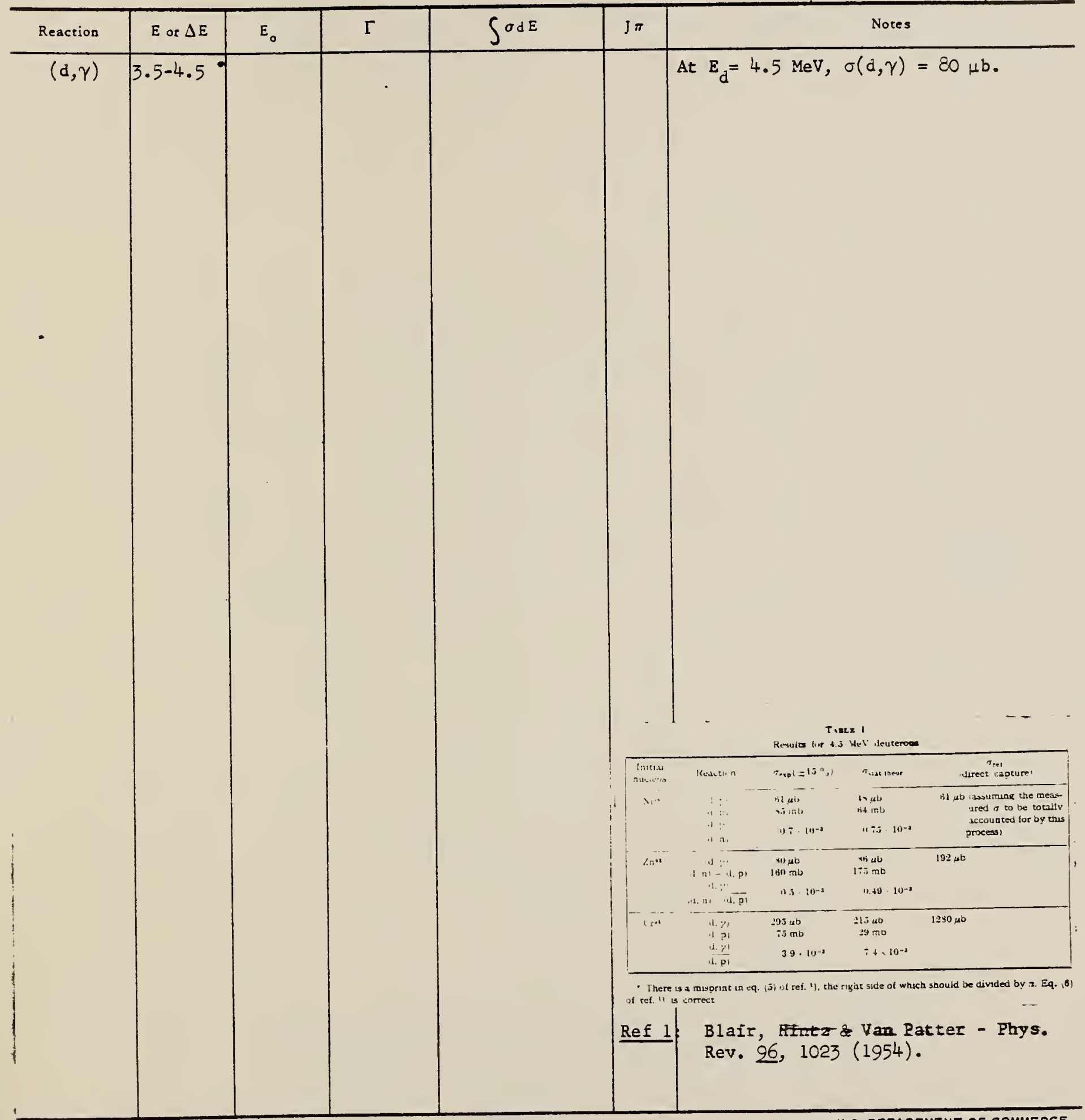


$A=69$ 
568 


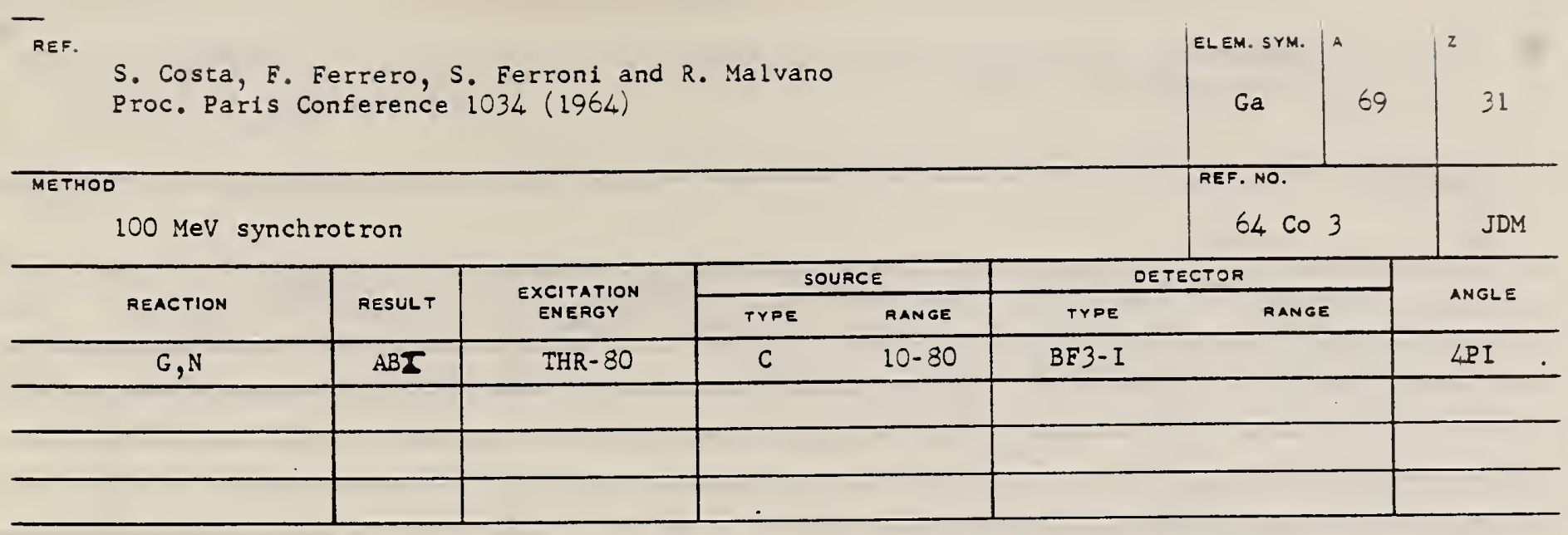

TABLB

\begin{tabular}{|c|c|c|c|c|c|}
\hline ELBMENT & $\left(\begin{array}{c}\text { Yield (36 MeV) } \\
\left(\frac{\text { n. } \mathrm{cm}^{2}}{\mathrm{~mol} . \mathrm{MeV}}\right. \\
\times 10^{5}\end{array}\right)$ & $\sum_{0}^{30}$ & $\Sigma_{0}^{80}$ & $\Sigma_{0}^{30} / \Sigma_{0}^{80}$ & $\begin{array}{c}\sigma-1 \\
(m b)\end{array}$ \\
\hline 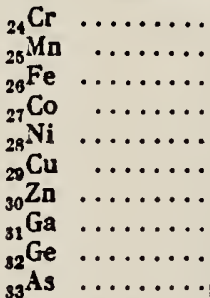 & $\begin{array}{r}83 \\
108 \\
68 \\
89 \\
44 \\
95 \\
88 \\
130 \\
139 \\
137\end{array}$ & $\begin{array}{l}1.21 \\
1.52 \\
0.88 \\
1.08 \\
0.55 \\
1.06 \\
0.94 \\
1.29 \\
1.35 \\
1.22\end{array}$ & $\begin{array}{l}2.1 \\
2.33 \\
1.46 \\
1.82 \\
1.07 \\
1.99 \\
1.68 \\
2.18 \\
2.29 \\
2.18\end{array}$ & $\begin{array}{l}0.58 \\
0.65 \\
0.60 \\
0.59 \\
0.51 \\
0.53 \\
0.56 \\
0.59 \\
0.59 \\
0.56\end{array}$ & $\begin{array}{r}62 \\
76 \\
50 \\
64 \\
34 \\
72 \\
66 \\
94 \\
101 \\
100\end{array}$ \\
\hline
\end{tabular}

$\sum^{b}=\frac{A}{60 \mathrm{NZ}} \int^{b} \sigma(E) \mathrm{d} E$ is the integrated cross section measured in units of the classical dipole $60 \mathrm{NZ} / \mathrm{A} \mathrm{mb}$. MeV. 
REF. W..J. Alston III, H. H. Wilson and E. C. Booth Nucl. Phys. Al16, 281 (1968)

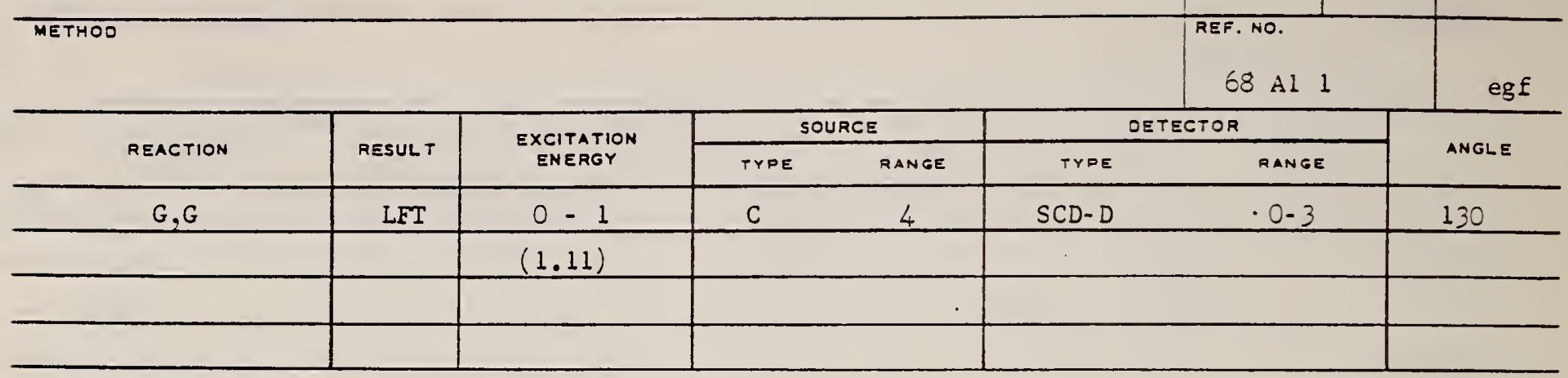

Angle greater than $90^{\circ}$ for all measurements.

TABLE 1

Direct and absorption measurements of resonance fluorescence

\begin{tabular}{|c|c|c|c|c|c|c|c|}
\hline Nucleus & $\begin{array}{c}E_{\mathrm{T}} \\
(\mathrm{MeV})\end{array}$ & $J_{t}$ & $\Gamma / \Gamma$ & $\begin{array}{c}g W \Gamma_{0} \Gamma J \Gamma \\
(\mathrm{meV})\end{array}$ & $\begin{array}{l}\text { Error } \\
(\%)\end{array}$ & $\begin{array}{c}\text { This work } \Gamma \text {. } \\
\text { (meV) }\end{array}$ & $\begin{array}{c}\text { Other work } \\
\Gamma .\end{array}$ \\
\hline \multirow[t]{13}{*}{${ }^{*} \mathrm{Mn}$} & 0.000 & $\frac{8}{2}$ & & & & & \\
\hline & 1.527 & $\left(z^{-}\right)$ & 0.9 & 5.2 & 25 & $8-12$ & \\
\hline & & & & abs a) & 40 & 8.0 & \\
\hline & 1.884 & $?$ & $\left.0.82^{\circ}\right)$ & 41 & 25 & $50 / g W$ & \\
\hline & & & & abs a) & 10 & $55 / 9$ & \\
\hline & 2.197 & $?$ & $\left.(0.8)^{c}\right)$ & 17 & 25 & $21 / g W$ & \\
\hline & & & & abs & 20 & $17 / 9$ & \\
\hline & 2.252 & $?$ & $\left.(0.9)^{\circ}\right)$ & 17 & 25 & $19 / \mathrm{g} W$ & \\
\hline & & & & abs & 20 & $13 / 9$ & \\
\hline & 2.365 & $?$ & $?$ & 3.5 & 36 & $(2-6) \Gamma i \Gamma_{0}$ & \\
\hline & 2.564 & $?$ & $(1.0)$ & so & 25 & $50 / g W$ & \\
\hline & & & & abs a) & 20 & $61 / 9$ & \\
\hline & 2.751 & $?$ & $?$ & 6.7 & 42. & $6.7\left(\Gamma / \Gamma_{0}\right) / g W$ & \\
\hline \multirow[t]{5}{*}{${ }^{*} \mathrm{Co}$} & 0.000 & $\frac{7}{2}-$ & & & & & \\
\hline & 1.187 & $\left(\frac{7}{2}-\right)$ & $(1.0)$ & 6.3 & 25 & 7.5 & $\left.0.33(E 2)^{d}\right)$ \\
\hline & & & & abs & 25 a) & 12 & \\
\hline & & $\left(a^{-}\right)$ & $(1.0)$ & 6.8 & 25 & $(5.4-6.5)$ & $0.27\left(E^{2}\right)$ \\
\hline & & & & abs & $25:)$ & 9.6 & \\
\hline \multirow{3}{*}{${ }^{2} \mathrm{Cu}$} & 0.000 & $\frac{\pi}{2}-$ & & & & & \\
\hline & 1.414 & $2=$ & $?$ & 1.6 & 30 & $(1.1-1.7) \Gamma / \Gamma_{0}$ & \\
\hline & 1.551 & $3-$ & $?$ & 1.7 & 37 & $(1.7-2.5) \Gamma / \Gamma_{0}$ & $0.1(E \geq) \bullet)$ \\
\hline \multirow[t]{3}{*}{$" \mathrm{Ga}$} & 0.000 & $3-$ & & & & & \\
\hline & 0.872 & $\left(y^{-}\right)$ & 0.95 & 1.1 & 35 & $0.8 / \mathrm{WV}$ & \\
\hline & 1.107 & $\left(3^{-}\right)$ & 0.95 & 8.0 & 20 & $8.4 / W$ & \\
\hline \multirow[t]{4}{*}{ "As } & 0.000 & $i-$ & & & & & \\
\hline & 0.86 & $?$ & $?$ & 1.7 & 20 & $1.7 \Gamma \mathrm{g} W \Gamma_{0}$ & \\
\hline & 1.07 & $?$ & $?$ & 2.6 & 30 & $2.6 \Gamma \lg W \Gamma_{0}$ & \\
\hline & 1.35 & $?$ & $?$ & 3.6 & 20 & $3.6 \Gamma / g W \Gamma_{0}$ & \\
\hline \multirow[t]{2}{*}{$* Y$} & 0.000 & $\frac{1}{2}-$ & & s2 I) & & & \\
\hline & 1.51 & 主- & $(1.0)$ & $\begin{array}{l}52 \times) \\
\operatorname{abs}=\end{array}$ & $\begin{array}{l}30 \\
15\end{array}$ & $\begin{array}{l}28 \\
22\end{array}$ & $\left.0.37(E 2)^{p}\right)$ \\
\hline
\end{tabular}

a) Measured with $\mathrm{NaL}$.

b) Ref. *).

c) Measured with a $\mathrm{Ge}(\mathrm{Li})$ detector to $\neq 10 \%$

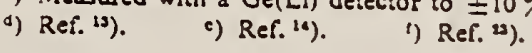

${ }^{13}$ D.G. Alkhazov, K.I. Erokhina and I.K. Lemberg, Izv.Akad.Nauk.SSSR(ser.Eiz.) $14 \frac{28}{1964)} 1667$.

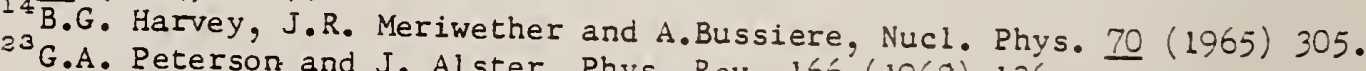

${ }^{3} \mathrm{G}$. A. Peterson and J. Alster, Phys. Rev. $1666^{\prime}(1968) 136$.

${ }^{24}$ N. Nath, M.A. Rothman, D.M. Van Patter and C.E. Mandeville, Nucl. Phys. 13 


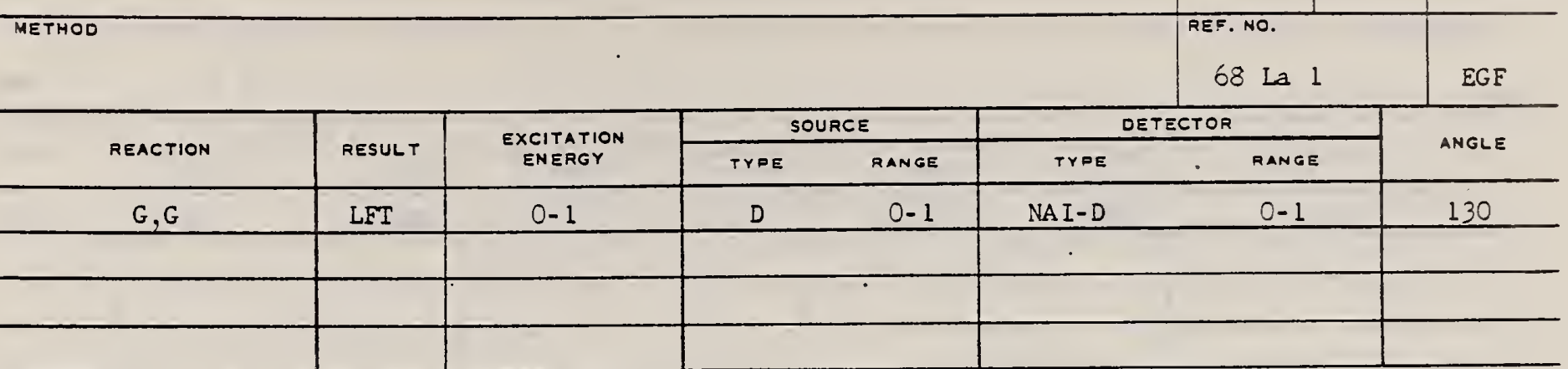

TABLe 1

Results of the resonance fluorescence investigation

\begin{tabular}{|c|c|c|c|c|c|}
\hline$E_{7}(\mathrm{keV})$ & 1337 & & 1107 & 872 & 574 \\
\hline$\sigma_{\text {scatl }}^{\left(\mathrm{GeCl}_{4}\right)}(\mathrm{mb})$ & $<10$ & 126 & \pm 6 & $218 \pm 15$ & $55 \pm 20$ \\
\hline$\frac{\sigma_{\text {scatt }}\left(\mathrm{GeBr}_{4}\right)}{\sigma_{\text {scat }}\left(\mathrm{GeCl}_{6}\right)}$ & & 0.98 & \pm 0.06 & $0.84 \pm 0.08$ & \\
\hline$\frac{\sigma_{\text {scatt }}\left(\mathrm{GeCl}_{\text {s }}\right)_{\text {solid }}}{\sigma_{\text {seatt }}\left(\mathrm{GeCl}_{\mathbf{1}}\right)_{\text {gas }}}$ & & 0.042 & \pm 0.015 & $0.17 \div 0.04$ & \\
\hline$A_{3}$ & & $<0.07$ & & $<0.12$ & \\
\hline$\varepsilon(\%)$ & & 26.8 & \pm 2.5 & $28 \pm 5$ & \\
\hline$\frac{g_{\mathrm{t}}}{g_{0}} \Gamma(\mathrm{meV})$ & & 4.1 & \pm 0.4 & $2.1 \pm 0.4$ & \\
\hline$N\left(E_{\mathrm{r}}\right)_{\exp }\left(\mathrm{eV}^{-1}\right)$ & & $(1.04$ & $\pm 0.12) \cdot 10^{-2}$ & $(2.3 \pm 0.5) \cdot 10^{-2}$ & \\
\hline$N\left(E_{\mathrm{r}}\right)_{\mathrm{Ge}}^{(e V-1)}$ & & $(1.6$ & $\pm 0.2) \cdot 10^{-1}$ & $2.7 \cdot 10^{-8}$ & $3.8 \cdot 10^{-8}$ \\
\hline$\frac{g_{0}}{g_{1}} \tau$ (psec) & & $(0.16$ & $\pm 0.02)$ & $(0.31 \div 0.06)$ & $(5 \pm 3)$ \\
\hline$\frac{\Gamma_{\text {exp }} g_{1}}{\Gamma_{\text {vibr }}(\mathrm{E} 2) g_{0}}$ & & 10 & & 16 & $8 \pm 4$ \\
\hline$\frac{T(\mathrm{M} 1)_{\text {s.p. }}}{T_{\text {exp }}} \frac{g_{0}}{g_{1}}$ & & 4.5 & & 4 & 18 \\
\hline \multicolumn{6}{|c|}{ 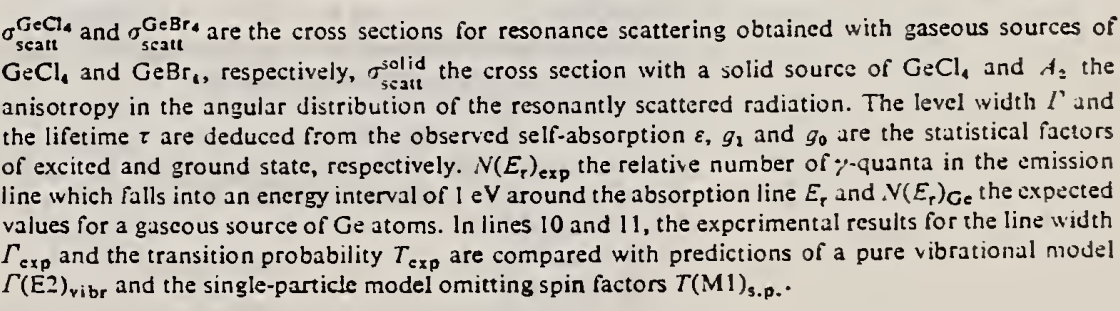 } \\
\hline
\end{tabular}




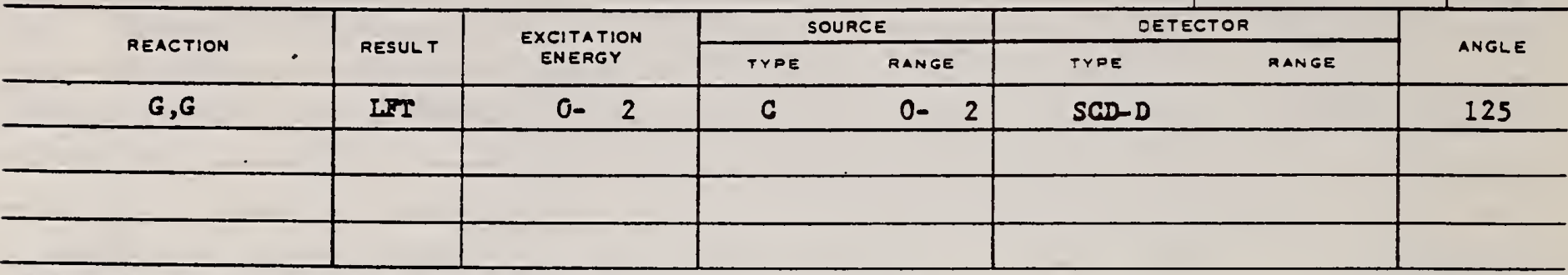

Absolute values come from normalising to know total widtha.

W is angular diatribution factor to correct for difference

in unknown and standard distribution. Assumed = 1 to get

Io values.

TABLE III. "Ge levels and results.

\begin{tabular}{|c|c|c|c|c|c|}
\hline $\begin{array}{l}\text { Level } \\
\text { energy a } \\
\text { (keV) }\end{array}$ & $J \pi$ & $\begin{array}{c}E_{y} \\
\text { This work } \\
\text { (keV) }\end{array}$ & $I_{0} / \Gamma^{*}$ & $\begin{array}{c}g \bar{W} T_{0} \Gamma_{d} / \Gamma \\
\text { Thls work } \\
\text { (meV) }\end{array}$ & $\begin{array}{c}I_{1} \\
\text { Deduced } \\
\text { (mov) }\end{array}$ \\
\hline g.s. & $\frac{3}{2}$ & & & & \\
\hline $318.4(2)$ & $\frac{1}{2}^{-b}$ & $\cdots$ & 1.0 & c & $\ldots$ \\
\hline $573.9(2)$ & $\frac{s}{2}^{-d}$ & $574(1)$ & $0.998(2)$ & $0.053(6)$ & $0.036(4)$ \\
\hline $871.7(2)$ & $\frac{1}{2}=$ & $872(1)$ & $0.948(5)$ & $1.43(15)$ & $1.51(15)$ \\
\hline $1027^{b}$ & $\left(\frac{1}{2}\right)^{-f}$ & $\cdots$ & $0.20^{\circ}$ & $\infty .06$ & $<0.5$ \\
\hline $1106.4(2)$ & $\frac{1}{2}^{-8}$ & $1106(1)$ & $0.964(2)$ & $2.7(2)$ & $2.8(2)$ \\
\hline $1336.2(2)$ & $i^{-0}$ & $1337(1)$ & $0.937(6)$ & $0.70(4)$ & $2.50(0)$ \\
\hline $1487.8(2)$ & $\left(\frac{i}{2}\right)^{+},\left(\frac{5}{2}\right)^{-1}$ & $1488(1)$ & $0.51(5)$ & $0.12(4)$ & $0.23(8) 8^{-1}$ \\
\hline $1525.7(2)$ & $\left(\frac{7}{2}, \frac{5}{2}\right)^{-8}$ & $\cdots$ & $0.33(3)$ & $<0.08$ & $\ldots$ \\
\hline $1723.5(4)^{b}$ & $\left(\frac{5}{2}\right)^{-8.1}$ & $1723(2)$ & $0.54(8)$ & $0.32(10)$ & $0.40(14)$ \\
\hline $1890.8(2)$ & $\left(\frac{3}{2}, \frac{5}{3}\right)^{-8}$ & $1892(2)$ & $0.68(5)$ & $10.3(6)$ & $15.2(15) g^{-1}$ \\
\hline $1923.0(2)$ & $\cdots$ & $\cdots$ & $0.093(9)$ & $<0.4$ & $\cdots$ \\
\hline $2022.2(2)$ & $\left(\frac{1}{2}-\frac{1}{2}\right)^{-8}$ & $2024(2)$ & $0.86(5)$ & $2.9(2)$ & $3.4(3) g^{-1}$ \\
\hline $2042.6(4)$ & $<\frac{5}{2} 8$ & $2045(2)$ & $0.67(20)$ & $2.1(2)$ & $3.2(10) g^{-1}$ \\
\hline \multicolumn{6}{|c|}{ 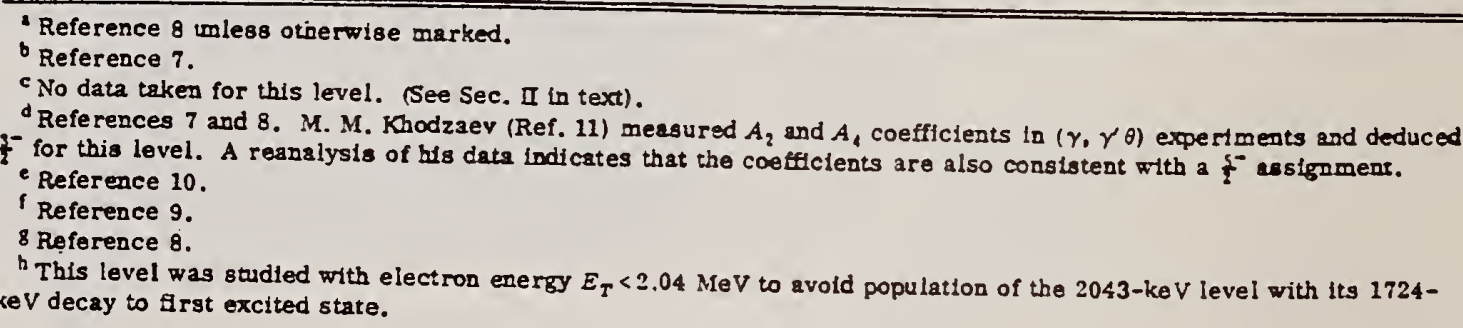 } \\
\hline
\end{tabular}

7. 2. Velkley et al., Phy 8. Rev. 179, 1090 (1969).

8. R. Zoller et 21. Nucl. Phys. A124. 15 (1969).

9.G. Couch et al. Phys. Rev. C2, 149 (1970).

$10_{S}$. Raman et al. Phys. Rev. CL, 744 (1970). 
REF. R. Moreh, O. Shahal, J. Tenenbaum, A. Wolf, and A. Nof

Phys. Rev. C7, 1885 (1973)

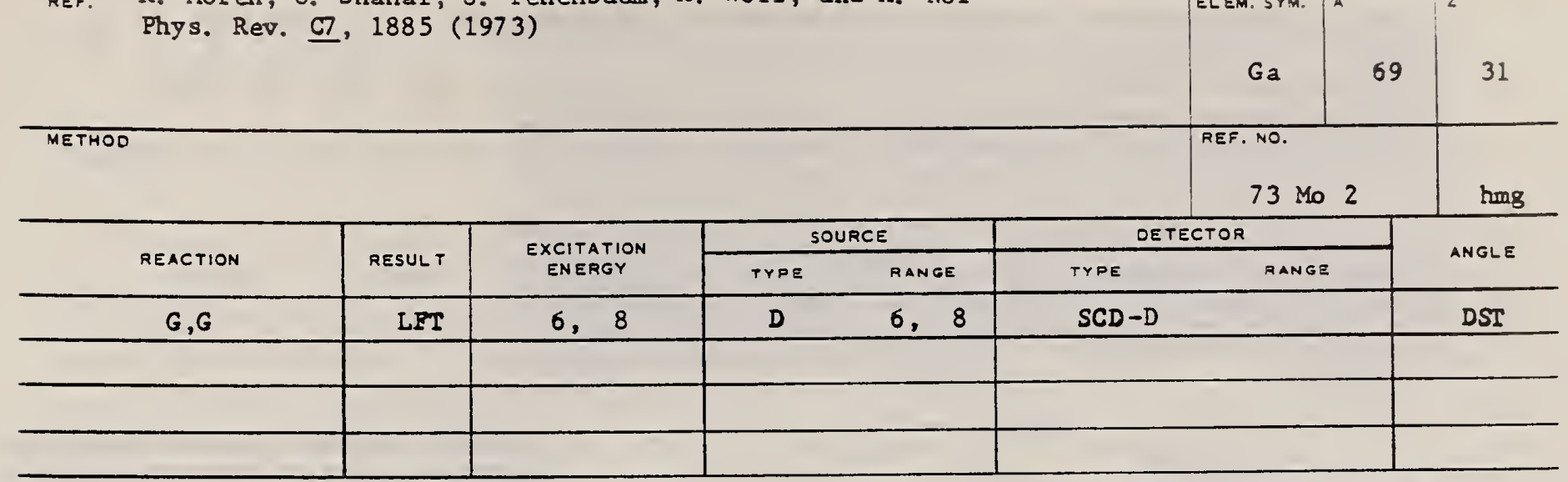

LEVBLS $7.306,6.874 \mathrm{NEV}$

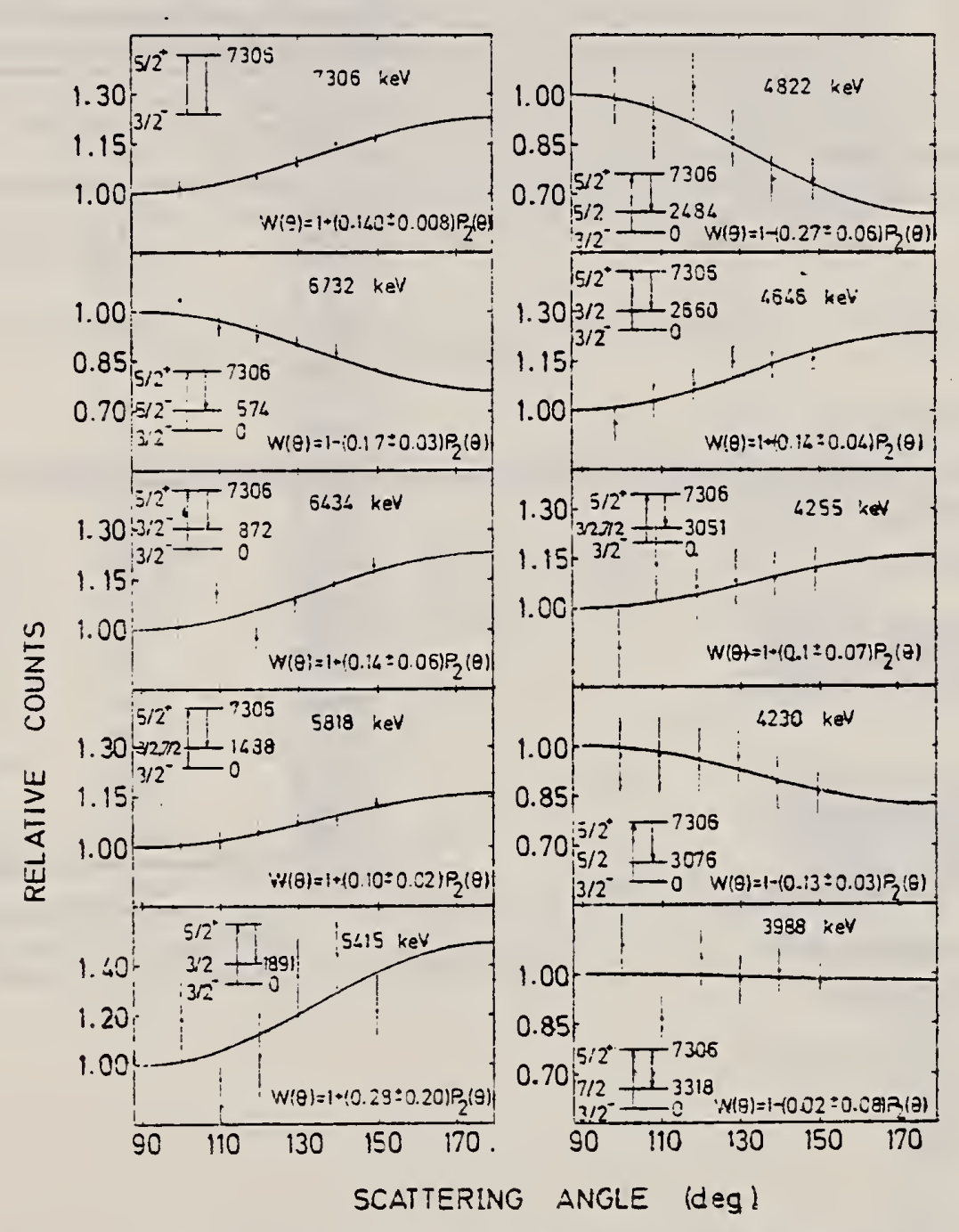

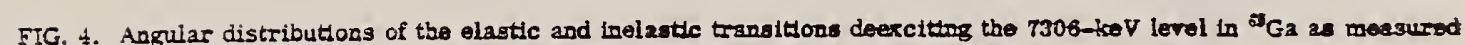
using $220-\mathrm{cm}^{3} \mathrm{Ge}(L 1)$ detector. The solid lines have the form $W(\theta)=1+A P_{2}(\cos \theta)$ and are least-square fits to the experimental distribution. In each case the corresponding $\gamma-y$ cascado is indicated.

(over) 
Elastic and inelastic scattering of monochromatic photons were used for 'stucying nuclear exergy levels in ${ }^{\circ} \mathrm{Ga}$; the photons were produced thermal neutron capture in copper and vanadium. The decay of one resonance at $7306 \mathrm{koV}$ excited by the copper $\gamma$ source and 30 low-lying level at $6874 \mathrm{keV}$ excited by the vanadium $\gamma$ source were studied in detall and $30 \mathrm{low}$-lying levels were observed from the ground stste up to $3.4 \mathrm{MeV}, 17$ oi whict are beLieved to be new levels to ${ }^{49} \mathrm{Ga}$. The anguiar distribution of some elastlic and fnelastic linea were measured and the following epth determinations were made (keV, $\left.\mathrm{J}^{\mathrm{T}}\right): 320, \frac{1}{6}{ }^{-},\left(\frac{3}{2}\right)$; $574, \frac{5}{2}^{-} ; 872, \frac{3}{2}^{-} ; 1488, \frac{3}{2}^{-}, \frac{7}{2}^{-} ; 1525\left(\frac{1}{2}, \frac{3}{2}\right) ; 1891, \frac{3}{2}^{-} ;(1978),\left(\frac{1}{2}, \frac{3}{4}\right) ; 2457, \frac{3}{2} ; 2484, \frac{5}{2} ;$ (2565), $\left(\frac{1}{2}, \frac{3}{2}\right) ; 2660, \frac{5}{2} ; 3051,\left(\frac{3}{2}, \frac{3}{2}\right) ; 3076, \frac{5}{2} ; 3318,\left(\frac{7}{2}\right) ; 6874, \frac{1}{2}\left(\frac{1}{4}\right)$ and $7306, \frac{5}{2}+$, where parentheees denote ancertain $J^{*}$ s8siguments. The parity of the $7306-\mathrm{keV}$ level was drectly determined usting a Compton polarimeter. The total radiative with of the 7306-keV level was measured and found to be $\Gamma=0.105 \pm 0.020 \mathrm{eV}$. For the $6874-\mathrm{keV}$ level, a posttve correLation coefficlent was obtained, $\rho=0.69$, between the $\left(\gamma, \gamma^{\prime}\right)$ and $(d, \pi)$ transition strengthe leading to the same final states in ${ }^{\circ} \mathrm{Ga}$. The levels of ${ }^{\circ} \mathrm{Ga}$ are compared with recent theoretical calcuiations.

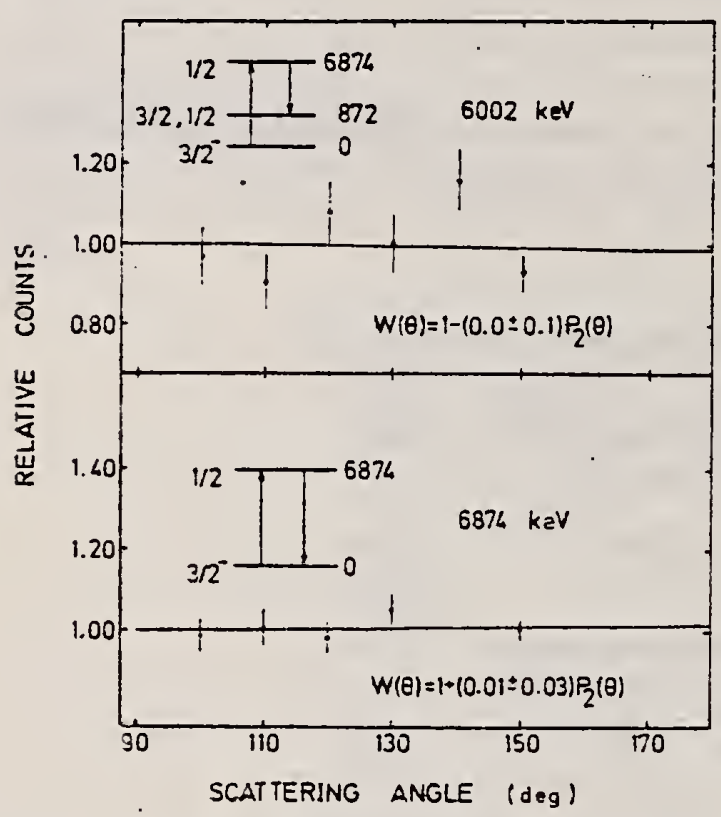

FIG. 5. Angular distribution of the elastic and one ineleatic transition deexcting the $6874-\mathrm{ke} \mathrm{V}$ level in ${ }^{\circ 9} \mathrm{Ga}$ as measured using $230-\mathrm{cm}^{3} \mathrm{Ge}$ (LI) detector. See caption to Fig. 4.

TABLE II. $y$ energies of the scattered radiation from a $\mathrm{Ga}$ target using $\mathrm{V} \gamma$ rays. Intensitles ars normalized relative to the $6874-\mathrm{keV}$ resonance line. Asterisks dercte transitions believed to correspond to a possible resonance at $7310-\mathrm{keV}$ resonance in ${ }^{74} \mathrm{Ga}$. Daggers irdicato unidencified transitions.

\begin{tabular}{cc}
\hline $\begin{array}{c}\gamma \text { line energy } \\
\text { (primaries) } \\
( \pm 4 \text { keV) }\end{array}$ & $\begin{array}{c}\text { Relative intensity } \\
( \pm 20 \%)\end{array}$ \\
\hline $7310^{*}$ & 20 \\
6874 & 100 \\
6534 & 205 \\
$6346^{*}$ & 37 \\
$6202^{*}$ & 11 \\
3002 & 80 \\
5349 & 20 \\
4980 & 10 \\
$4896^{*}$ & 25 \\
$4653 \dagger$ & 20 \\
$4619 \dagger$ & 20 \\
$4543 \dagger$ & 12 \\
4417 & 15 \\
4309 & 10 \\
421. & 15 \\
\hline
\end{tabular}

TABLE 1. $\gamma$ energie of the scattered radrtios from a Ga terget the $\gamma$ source was obrained from the $\operatorname{Cu}(x, y)$ restion. The brunching ratios of the aseumed primary tranitions sre gtven end are accurate to $=15 \%$. The $y$ ersites of the lew-energy spect rum a re linted undar seconduries. Dasgers fodicate unidentified transition.

\begin{tabular}{|c|c|c|}
\hline $\begin{array}{l}y \text { line energy } \\
\text { (primnries) } \\
\text { (kev) }\end{array}$ & $\begin{array}{c}\text { Branching ratlos } \\
(\%)\end{array}$ & $\begin{array}{l}\gamma \text { lne coners } \\
\text { (secosdarien) } \\
\text { (keV) }\end{array}$ \\
\hline $7306 \pm 2$ & 52.0 & $2484 \pm 1$ \\
\hline $6732 \pm 2$ & 3.6 & $2340=4$ \\
\hline $6434 \pm 2$ & 3.0 & $1721 \pm 3$ \\
\hline $5818 \pm 2$ & 6.0 & $1630=3 T$ \\
\hline $5415 \pm 3$ & 0.8 & $1488=2$ \\
\hline $5383 \pm 3$ & 0.1 & $1336 \pm 2$ \\
\hline $5109 \neq 3$ & 0.5 & $1105 \pm 2$ \\
\hline $4954 \pm 3$ & 1.3 & $915 \pm 2$ \\
\hline $4880=3$ & 1.0 & $872 \pm 2$ \\
\hline $4849 \pm 2$ & 1.9 & $574 \pm 2$ \\
\hline $4822=2$ & 2.0 & \\
\hline $4646=2$ & 4.2 & \\
\hline $4541=3$ & 0.6 & \\
\hline $4509=3$ & 2.0 & \\
\hline $4460 \pm 3$ & 0.4 & \\
\hline $4446 \pm 4$ & 0.3 & \\
\hline $4342 \pm 3$ & 0.4 & \\
\hline $4328 \pm 2$ & 1.2 & \\
\hline $4255 \pm 3$ & 3.6 & \\
\hline $4230=4$ & 3.4 & \\
\hline $4102=4$ & 2.2 & \\
\hline $4081 \pm 6$ & 2.2 & \\
\hline $4024 \pm 6$ & 1.0 & \\
\hline $3988=6$ & 4.1 & \\
\hline
\end{tabular}


REF. K. Ramavataram, C. Rangacharyulu, I.M. Szoghy, R. Hilko,

C. St.- Pierre

Phys. Rev. $\underline{\mathrm{C} 17}, 1583$ (1978)

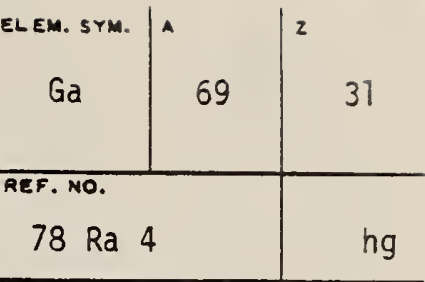

\begin{tabular}{|c|c|c|c|c|c|c|c|}
\hline \multirow{2}{*}{ REACTION } & \multirow{2}{*}{ nESUL T } & \multirow{2}{*}{$\begin{array}{l}\text { EXCITATION } \\
\text { ENERGY }\end{array}$} & \multicolumn{2}{|c|}{ SOURCE } & \multicolumn{2}{|c|}{ DETECTOR } & \multirow{2}{*}{ AMGLE } \\
\hline & & & TrPE & MANGE & TrPE & DANGE & \\
\hline \multirow[t]{2}{*}{$P, G D$} & $\overline{L F T}$ & 9 & D & 3 & $S C D-D$ & & 55 \\
\hline & & $(9.85)$ & & $3.250)$ & & & \\
\hline & & & & & & & \\
\hline & & & & & & & \\
\hline
\end{tabular}

Isobaric analog resonances in ${ }^{69} \mathrm{Ga}$ corresponding to the ground $\left(1 / 2^{-}\right)$and first excited $\left(9 / 2^{+}\right)$parent states of ${ }^{69} \mathrm{Zn}$ have been studied by the ${ }^{6 \mathrm{Zn}} \mathrm{Z}(p, \gamma)$ reaction. The $y$ decay of the ground state of ${ }^{69} \mathrm{Zn}$ is compared with the $\beta$ decay of the parent isobaric analog state. The latter is a pure Gamow-Teller transition to the ground $\left(3 / 2^{-}\right)$and third $\left(3 / 2^{-}\right)$excited states, while both Gamow-Teller and Fermi matrix elements can contribure in the decay to the second excited $\left(1 / 2^{-}\right)$state of ${ }^{69} \mathrm{Ga}$. The $M 1$ decay widths obtained from the $y$ decay of the $J^{\prime \prime}=1 / 2^{-}$isobaric analog state are in good agreement with the widths extracted from the $\log f \mathrm{f}$ values in the first two of the three $\beta$-decay branches. However, the $M 1$ decay width to the third excited state disagrees with the value deduced from the $\log f t$ value of the $\beta$ decay of the ${ }^{\circ} \mathrm{Zn}$ g.s. to this state In addition, the $M 1$ transition strength of the $9 / 2^{+}\left(T_{2}\right)$ state to the $9 / 2^{+}\left(T_{<}\right)$state in ${ }^{\circ 9} \mathrm{Ga}$ has been measured and is compared with the recently published systematic trends for the analog to antianalog. transition in other $f-p$ shell nuclei.

$$
\begin{gathered}
\text { NUCLEAR REACTIONS }{ }^{68} \mathrm{Zn}(p, \gamma), E=3.2-3.8 \mathrm{MeV} .{ }^{69} \mathrm{Ga} \text { deduced resonances, } \\
\text { measured } E_{\gamma} \text { and } \Gamma_{\gamma}, M 1 \text { strength. }
\end{gathered}
$$

TABLE I. $\gamma$-decay propertles of the LAR of the $\left(\frac{1^{-}}{2}\right)$ ground state of ${ }^{69} \mathrm{Zn}$ at $E_{q}=3.250 \mathrm{MeV}$.

\begin{tabular}{|c|c|c|c|c|c|}
\hline Transition & $\begin{array}{l}\text { Assumed } \\
\text { multipole } \\
\text { order }\end{array}$ & $\begin{array}{c}\Gamma_{\gamma} \\
(e V)\end{array}$ & $\begin{array}{l}B(M 1) \\
\left(\mu_{x^{2}}\right)^{2}\end{array}$ & $\begin{array}{c}B(E 2) \\
\left(e^{2} \mathrm{fm}^{4}\right)\end{array}$ & $\begin{array}{c}B(k n, \sigma)^{2} \\
\left(\mu_{v}\right)^{2}\end{array}$ \\
\hline $\begin{array}{l}\text { LAR }-\mathrm{g} \cdot \mathrm{S} \\
\frac{1^{-}}{2}-\frac{3}{2}^{-}\end{array}$ & $m$ & $\begin{array}{r}0.88 \\
\pm 0.20\end{array}$ & 0.080 & $\cdots$ & 0.085 \\
\hline $\begin{array}{l}\operatorname{LAR}=0.318 \\
\frac{1}{2}-\frac{1}{2}\end{array}$ & $M I$ & $<0.1$ & $<10^{-2}$ & $\cdots$ & $5 \times 10^{-6 b}$ \\
\hline $\begin{array}{l}{[A R-0.372} \\
\frac{1}{2}-\frac{1}{2}^{-}\end{array}$ & $\begin{array}{l}.11 \\
\varepsilon 2\end{array}$ & $\begin{array}{r}0.13 \\
\pm 0.11\end{array}$ & 0.09 & 14.9 & 0.01 \\
\hline $\begin{array}{l}\operatorname{LAR}-1.525 \\
\frac{1}{2}^{-}-\left(\frac{1}{2}, \frac{1}{2}\right)\end{array}$ & $\begin{array}{l}M 1 \\
E 2\end{array}$ & $\begin{array}{r}0.52 \\
=0.14\end{array}$ & 0.08 & $\begin{array}{l}\cdots \\
16.0\end{array}$ & $\cdots$ \\
\hline
\end{tabular}

${ }^{3}$ Value derluced from $\beta$ decay of ${ }^{69} 7 \mathrm{n}$.

'Value obtained assuming transition to be pure Gamow-Teller. 
$-$ 
1. Geiler, J. Halpern, and E. G. Muirhead

2t. s. Rev. $118,1302-12(1960)$

Betatron; neutron threshold; ion chamber

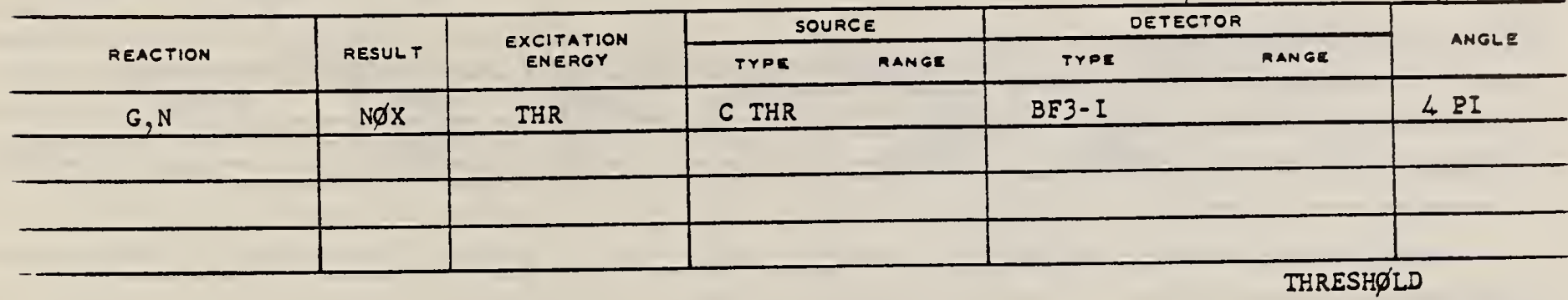

TABLS I. Summary and comparison of neutron separation energics inferred from present thresbold measurements with velues predicted from mas dara and reaction energics. All cnergies are expresed in the center-of-mass system in Mer.

\begin{tabular}{|c|c|c|c|c|c|}
\hline Rrisctiow & No, runs & l'resent results & Other results & Method & Reference \\
\hline $\mathrm{Ga}{ }^{\prime \prime}(\gamma, u) \mathrm{Ga}^{\prime \prime}$ & 1 & $9.24 \pm 0.06$ & $9.22 \pm 0.16$ & $\begin{array}{l}\text { mass data } \\
Q\left(\beta^{+}\right)\end{array}$ & $\begin{array}{l}\mathrm{m} \\
\mathrm{n}\end{array}$ \\
\hline
\end{tabular}

- Henry E. Duckworth, Mass Spectroscopy (Cambridae Univeraity Prean, New York 1958), D. 177. -L. J. Lidofisky. Revi. Modern Phyt. 29, 773 (1957). 


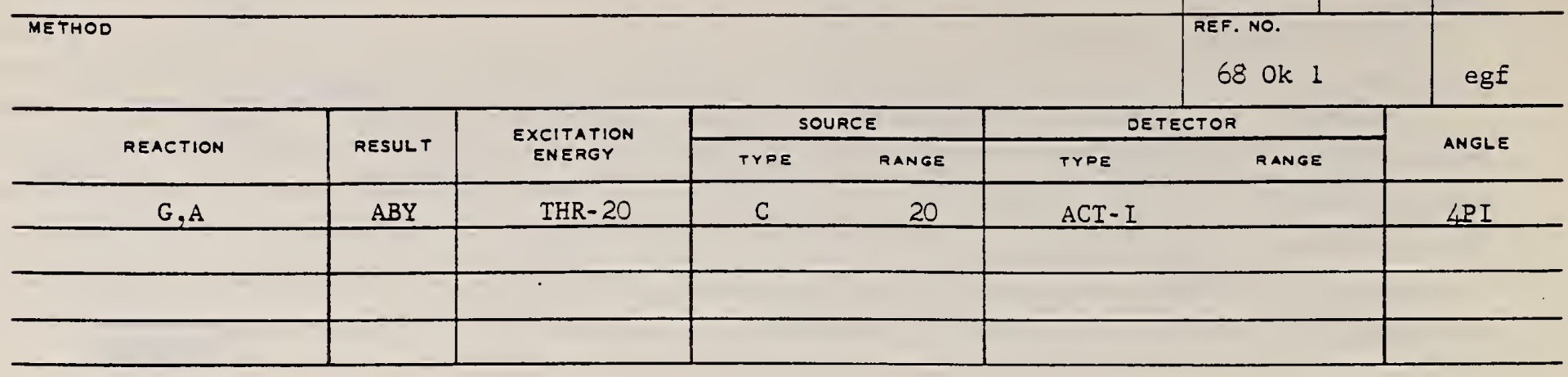

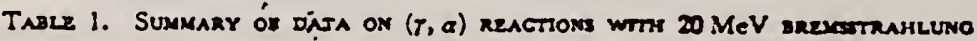

\begin{tabular}{|c|c|c|c|c|c|c|c|}
\hline \multicolumn{2}{|c|}{ Nuclide } & \multirow[b]{2}{*}{$\left(-e^{E_{(n)}}\right.$} & \multicolumn{3}{|c|}{ Observed gamma-ray } & \multicolumn{2}{|c|}{ Results obtained } \\
\hline $\begin{array}{c}\text { Parent } \\
\text { (Natural } \\
\text { 2bundance, \%) }\end{array}$ & $\begin{array}{l}\text { Product } \\
\text { (Hialf-life) }\end{array}$ & & $\begin{array}{l}\text { Energy } \\
(\mathrm{MeV})\end{array}$ & $\begin{array}{l}\text { Branching } \\
\text { ratio }(\%)\end{array}$ & $\begin{array}{l}\text { Type of } \\
\text { multipole } \\
\text { transition }\end{array}$ & $\mu\left(\mathrm{Ci} / \mathbf{m g}^{\star}\right)$ & $\begin{array}{c}\text { Yirloi } \\
(\mathrm{mol}-1 \cdot k-1)\end{array}$ \\
\hline $31 V(99.75)$ & ${ }^{\circ} \mathrm{Sc}(3.4 \mathrm{~d})$ & 10.27 & 0.160 & 100 & $M 1+E 2$ & $1.39 \times 10^{-2}$ & $2.8 \times 10^{0}$ \\
\hline${ }^{\circ 5} \mathrm{Cu}(30.9)$ & ${ }^{61} \mathrm{Co}(99 \mathrm{~min})$ & 6.75 & 0.068 & 99 & $M 1+E 2$ & $7.23 \times 10^{-2}$ & $9.7 \times 10^{3}$ \\
\hline$" \mathrm{Ga}(39.6)$ & ${ }^{67} \mathrm{Cu}(6 \mathrm{l} \mathrm{hr})$ & 5.15 & 0.184 & 41 & $M I$ & $2.70 \times 10^{-2}$ & $9.6 \times 10^{3}$ \\
\hline${ }^{3} \mathrm{Ge}(7.67)$ & $\operatorname{son} \mathrm{Zn}(1+\mathrm{hr})$ & 5.89 & 0.435 & 100 & M4 & $1.11 \times 10^{-2}$ & $5.0 \times 10^{3}$ \\
\hline $81 \mathrm{Br}(49.48)$ & "As (39 hr) & 6.46 & 0.246 & 2.81 & $M 1+E 2$ & $1.97 \times 10^{-1}$ & $4.3 \times 10=$ \\
\hline${ }^{100} \mathrm{Ag}(48.65)$ & ${ }^{105} \mathrm{Rh}(36 \mathrm{hr})$ & 3.280 & $0.319+0.306$ & 24.8 & $M 1+E 2$ & $8.29 \times 10^{-4}$ & $3.7 \times 10^{1}$ \\
\hline $113 \ln (95.77)$ & $" \mathrm{Ag}(7.6 \mathrm{~d})$ & 3.78 & 0.340 & 6 & $M 1+E 2$ & $5.70 \times 10^{-3}$ & $4.3 \times 10^{6}$ \\
\hline
\end{tabular}

a) The value corrected at the end of $1 \mathrm{hr}$ irradiation $\left(9.4 \times 10^{9} \mathrm{R} / \mathrm{min}\right)$.

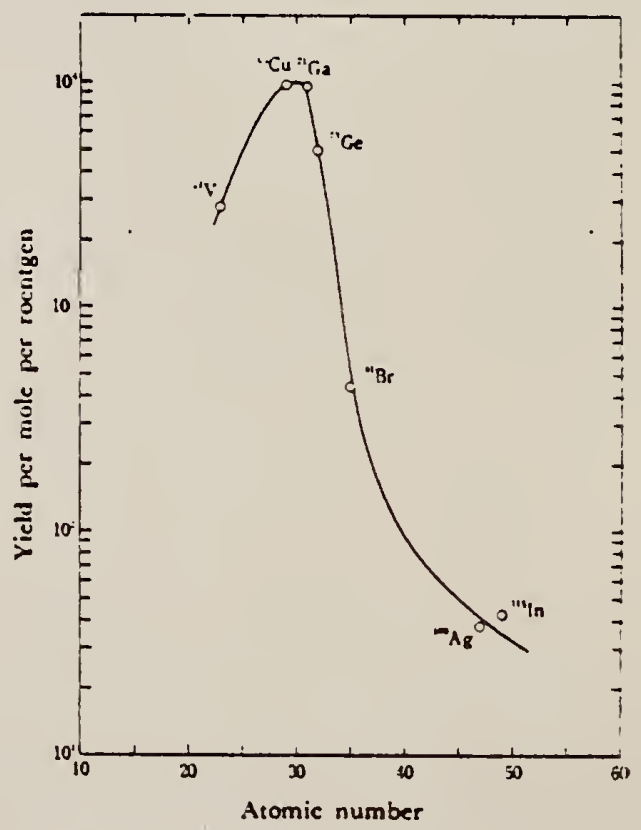

Fig. 1. The yield eurve for $(r, a)$ reaction with $20 \mathrm{MeV}$ bremsstrahlung. 


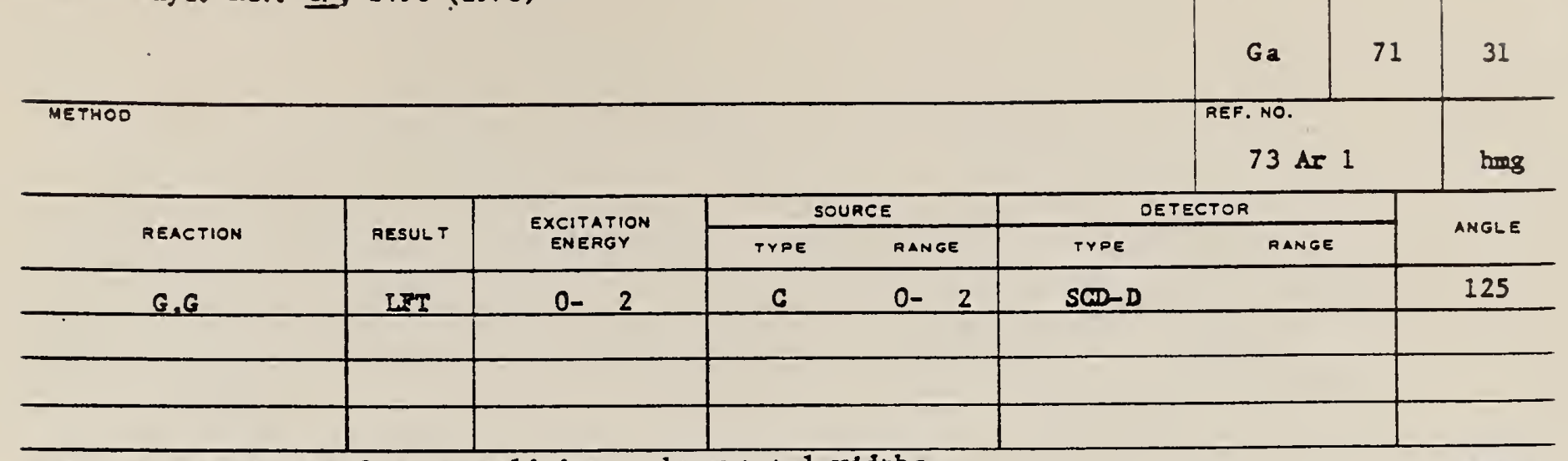

TABLE IV. ${ }^{11} \mathrm{Ga}$ levels and results.

\begin{tabular}{|c|c|c|c|c|c|}
\hline $\begin{array}{l}\text { Lovel } \\
\text { onergy } \\
\text { (kev) }\end{array}$ & $J \pi^{2}$ & $\begin{array}{c}E_{y} \\
\text { This work } \\
\text { (keV) }\end{array}$ & $\Gamma_{1} / \Gamma^{2}$ & $\begin{array}{l}g \bar{W} \Gamma_{0} \Gamma_{0} / \Gamma \\
\text { This work } \\
\text { (meV) }\end{array}$ & $\begin{array}{c}\Gamma_{0} \\
\text { Dectuced } \\
(m e V)\end{array}$ \\
\hline g.s. & $\frac{3}{2}$ & & & & \\
\hline $389.87(5)$ & $\frac{1}{2}^{-}$ & $\cdots$ & 1.0 & $<0.08$ & $\cdots$ \\
\hline $487.34(5)$ & $\frac{5}{3}$ & $\ldots$ & 1.0 & $<0.03$ & $\cdots$ \\
\hline $511.55(5)$ & $\frac{3-}{2}$ & $\cdots$ & $0.91(6)$ & $<0.08^{b}$ & $\cdots$ \\
\hline $910.3(1)$ & $\frac{5^{-}}{2},\left(\frac{t^{-}}{2}\right)$ & $910(1)$ & 1.0 & $0.57(5)$ & $0.57(5) g^{-g}$ \\
\hline $964.7(1)$ & $\frac{5}{2}$ & $965(1)$ & $0.78(3)$ & $0.28(5)$ & $0.24(4)$ \\
\hline $1107.4(2)$ & $\frac{1}{2}$ & $\cdots$ & $0.022(3)$ & $\cdots$ & $\cdots$ \\
\hline $1109.3(5)$ & $\left(\frac{1^{-}}{2}\right)$ & $1109(1)$ & 1.0 & $2.4(3)$ & $4.8(6)$ \\
\hline $1395.2(4)$ & $\left(\frac{5}{2}, \frac{7}{2}^{-}\right)$ & $1395(1)$ & 1.0 & $0.27(6)$ & $0.27(6) g^{-1}$ \\
\hline $1476.1(2)$ & $\frac{5^{-}}{2}, \frac{\frac{1}{2}^{-}}{2}$ & $\cdots$ & $0.24(2)$ & $<0.08$ & $\cdots$ \\
\hline $1493.8(4)$ & $\frac{1}{2}^{+}$ & $\cdots$ & $(0.0)$ & $<0.08$ & $\ldots$ \\
\hline $1498.7(2)$ & $\frac{5}{2}, \frac{5}{2}$ & $\cdots$ & 0.0 & $<0.08$ & $\cdots$ \\
\hline $2631.6(2)$ & $t^{-} \cdot\left(\frac{1}{2}\right)$ & $\cdots$ & $0.093(8)$ & $<0.3$ & $\cdots$ \\
\hline $1702.1(8)$ & ... & $\cdots$ & 0.0 & $<0.3$ & $\ldots$ \\
\hline $1719.7(7)$ & $\left(\frac{5^{-}}{2^{-}}, \frac{5}{2}^{-}\right)$ & $1719(1)$ & $0.43(10)$ & $0.70(18)$ & $1.6(6) g^{-1}$ \\
\hline $2084.6(2)$ & $\frac{5}{2} \cdot \frac{1}{2}$ & $2064(1)$ & $0.64(9)$ & $1.8(2)$ & $2.9(4) \mathrm{g}^{-1}$ \\
\hline
\end{tabular}

arom Rel. 12.

b amall correction was made for the background $511-k e V$ annihilation $y$ ray fron environmental radiatlon.

12W.H. 2oller, W.B. Walters, and G.E. Gordon, Nucl Phy 8. A142, 177 (1970). 


\section{DEFINITIONS OF ABBREVIATIONS AND SYMBOLS}

Note: In this list definitions are given for various photoneutron reactions in which the following symbols are used: $N, N L, n N, S N$ and $X N$. Corresponding definitions apply for reactions involving other nuclear particles where the symbols $\mathrm{N}$ (neutron) is replaced by, e.g. P, D, T, HE, A etc. Where unknown reactions result in the production of a specific radionuclide, the chemical symbol and mass number is listed as the reaction product, e.g. a G,NA22 reaction in ${ }^{59} \mathrm{Co}$.

A

ANAL

$A B I$

$A B X$

$A B Y$

ACT

ASM

AVG

BBL

$B E L$ reduced electric radiative

$B(E L)$ transition probability

BF3

BML reduced magnetic radiative

BREAKS levels located by "breaks" in the

BRKUP breakup

BRMS bremsstrahlung

BTW

C transition probability, B(ML) yield curve

$\mathrm{BF}_{3}$ neutron counter with moderator e.g., Halpern detector, long counter

between

continuous. Used to describe a photon source or a detector response function. Contrast with $D=$ discrete.

$\mathrm{CCH} \quad$ cloud chamber

CF compared with

CHRGD charged

CMPT Compton

COIN coincidence, coincide COINC

$\mathrm{COH}$ coherent

CK Cerenkov

D

deuteron or discrete. When discrete, it is used to describe a photon source or a detector response function. Contrast with $\mathrm{C}=$ continuous.

DLTE energy loss

DLTQ momentum transfer

DST distribution

DT BAL detajled balance

E

E/

electron

inelastically scattered

electron

E+ positron

EDST energy distribution or spectrum

$E / N \quad$ used only to indicate a coincidence experiment as in $(E, E / N)$. 
$N$ stands for any outgoing particle measured in coincidence with an inelastically scattered electron. Distinguish from eg., (E,N) which is used to represent an electron induced reaction when only the outgoing particle $\mathrm{N}$ is detected.

EMU emulsions (photographic plates)

EXCIT excited

$\mathrm{F}$

FMF

FM-1 inverse femtometers

FRAG fragment

G

G/

G-WIDTH

HAD

HE

He3

INT interaction, integral, intensity

INC includes

ION ionization chamber

ISOB isobaric

ISM isomer

$J$ multiplicity of particle defined by following symbol e.g. ( $G, P J N)$ with remark $\mathrm{J}=2,3,5,7$

JPI spin and parity of a nuclear J-PI state

k

second multiplicity index, e.g.
KE

L

LFT

LIM

LV,LVS level, levels

LQD liquid

MAG

MEAS

MGC

MGP

MOD

MSP

MULT

MU-T

N

$(G, J P K N)$ with both $J \& K$ posi-

tive integers greater than 1 kinetic energy

may be an integer or zero that always follows a reaction product symbol. This is used to indicate transitions to specific states in the residual nuclide. When the letter is used as in $(G, N L)$ the cross section given is that for the sum of transitions to two or more specific final states.

excited state lifetime

limit

magnetic spectrometer

measurement $(s)$

magnetic Compton spectrometer

magnetic pair spectrometer

moderated neutron detector not employing a $\mathrm{BF}_{3}$ counter, e.g. rhodium foil, Szilard-Chalmers reaction, $3 \mathrm{He}, \sigma_{L} i$ reactions, GD loaded liquid scintillator, etc.

mass spectrometer

multiple, multipole, multiplicity

used only in combination with $G$ to indicate a total photon absorption cross section measurement, i.e. (G,MU-T)

neutron (see also XN and SN). The notation $(G, N)$ is used to indicate a reaction in which only a single neutron is emitted, i.e. the reaction that can, in many cases, be measured by observing the radioactive decay of the residual nuclide. 
$n N$.

where $n$ is any integer. ( $G, n N)$ indicates the sum over all reaction cross sections in which $n$ neutrons are emitted.

NAI

$\mathrm{NaI}(T 1)$ spectrometer

SPC

NEUT neutron(s)

NOX

no cross-section data

proton (see also XP)

particle(s)

photon(s)

pion, usually written as PIt, PI-, PIO to indicate charge

POL polarized or polarization

Q-SQUAR momentum transfer squared $\left(q^{2}\right)$

$\mathrm{RCL}$

recoil

REL

RLI

$R L X$

RSP

RLY

SCTD

SCD

SCI

SEP

SEP

SIG

SPK

SPL

SYM

$\mathrm{T}$

TEL

THR

TOF

TRK

relative integrated cross-

section data

relative cross-section data

reaction spectrometer

UKN

VIB

semiconductor (solid state)

detector

scintillator detector other than

$\mathrm{NaI}$, e.g., CSI, KI, organic

Tiquid or solid), stilbene, He

separation

separated isotope used

SIGMA (cross section)
SN

sum of neutron producing reactions, $\sigma(\gamma, S N)=\sigma(\gamma, N)$

$+\sigma(\gamma, N P)+\sigma(\gamma, 2 N)+\sigma(\gamma, 3 N)$

+ etc.

photon or particle energy spectrum

spark chamber

spallation

STAT

statistical

TRNS

UNK

VIR PHOT virtual photon(s)
XN yield, $\sigma(\gamma, X N)=\sigma(\gamma, N)+2 \sigma$ $(\gamma, 2 N)+3 \sigma(\gamma, 3 N)+\sigma(\gamma, N P)+$ etc.

XP

all protons, total proton yield $\sigma(\gamma, X P)=\sigma(\gamma, P)+\sigma(\gamma, N P)+$ $2 \sigma(Y, 2 P)+$ etc.

$x X$

$X X X$

reaction products defined in REMARKS

YLD yield al1 neutrons, total neutron 
4PI a $4 \pi$ geometry was used or a method like radioactivity or a total absorption measurement

energy defined in REMARKS

* or 0

indicates the measurement

involved beams or targets

that were either polarized or aligned, or that the polarization of the reaction products was determined. The polarized particle is indicated in REMARKS.

symbols used to indicate that the units associated with the numerals on one or both sides of the symbol in a specific column are not MeV. The units are defined in REMARKS. 
BIBLIOGRAPHIC DATA

SHEET (See instructions)

1. PUBLICATION OR REPORT NO.

4. TITLE AND SUBTITLE

\section{Photonuclear Data-Abstract Sheets} 1955-1982

\section{AUTHOR(S)}

E.G. Fuller and Henry Gerstenberg

6. PERFORMING ORGANIZATION (If joint or other thon NBS. see instructions)
MATIONAL BUREAU OF STANDARDS
DEPARTMENT OF COMMERCE
WASHINGTON, D.C. 20234

9. SPONSORING ORGANIZATION NAME AND COMPLETE ADDRESS (Street, City. Stote, ZIP)

7. Contracu Grane No.

8. Type of Report \& Period Covered

10. SUPPLEMENTARY NOTES

Document describes a computer program; SF-185. FIPS Software Summary, is attached.

11. ABSTRACT (A 200 -word or less foctual summory of most significant information. If documens includes o significans
bibliogrophy or literoture survey, mention it here)

These abstract sheets cover most classes of experimental photonuclear data leading to information of the electromagnetic matrix element between the ground and excited states of a given nucleus. This fifteen volume work contains nearly 7200 abstract sheets and covers 89 chemical elements from hydrogen through americium. It represents a twentyseven year history of the study of electromagnetic interactions. The sheets are ordered by target element, target isotope, and by an assigned bibliographic reference code. Information is given on the type of measurement, excitation energies studied, source type and energies, detector type, and angular ranges covered in the measurement. For a given reference, the relevant figures and tables are mounted on a separate sheet

12. KEY WORDS (Six to iwelve entries; alphobetical order: capitalize only proper names: and seporate key words by semicolons) data-abstract sheets, elements, experimental, isotopes, nuclear physics, photonuclear 


